UNIVERSITY 


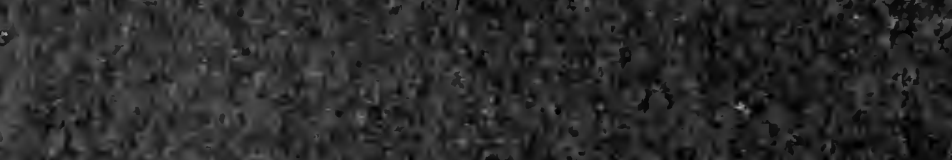

i.

s.

31

ate 

Dentidge Gremowörterbud

$$
\text { I. }
$$




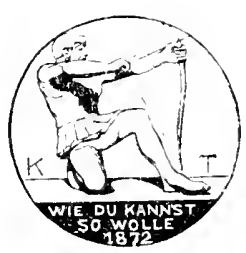




\section{haci.1). \\ S.3887d}

\section{Deutjads \\ Frembwörterbuch}

$20 n$

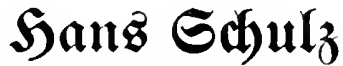

Privatbozent an ber SIniverifiät Freiburg i. $3 r$.

Eriter 3 and

$\mathfrak{A}-\mathfrak{R}$

\section{Gtra $\mathfrak{\mathfrak { B }} \mathfrak{b} \mathfrak{u r g}$}

Sirrlag von Rarl S. Sriibuter

1913 
Porom 
Germ frofelior

\title{
friedrich Kluge
}

\author{
meinem vehrer
}

in Dantbarfeit nno Trent 
. 


\section{Borwort.}

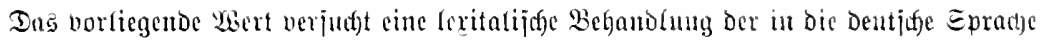

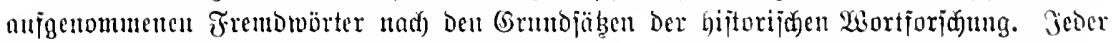
Mrtifel will Form uno Bedentumg bes behandelten Wortes angeben und bie 3eit ermit= teln, in ber is im Dentjucn Epradfgebrand) nujtritt. Bugleidy wirb ber grographijde

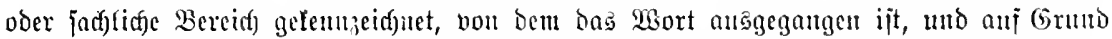

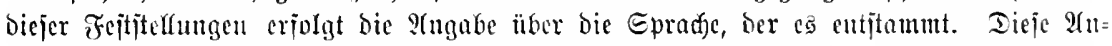

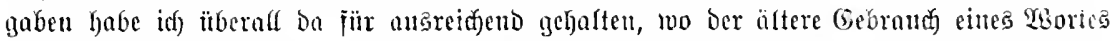

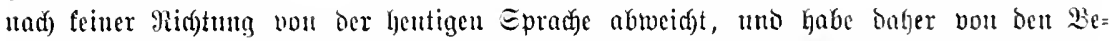

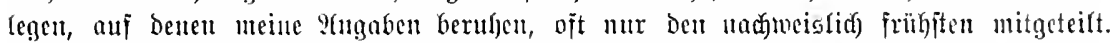

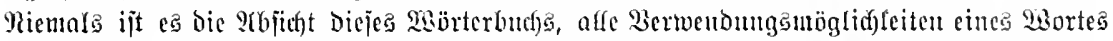

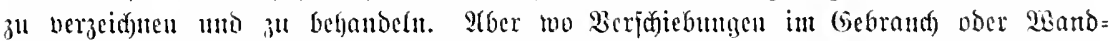

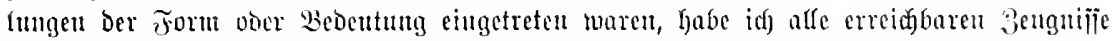
norgelegt, mitunter aud bie neucren Miundarten Gerangejogen, wem bus Fortfeben cines

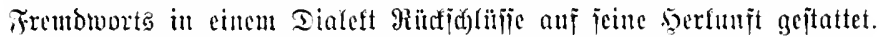

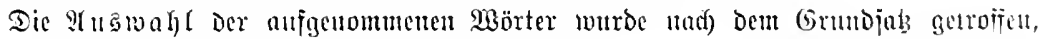

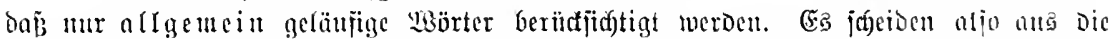

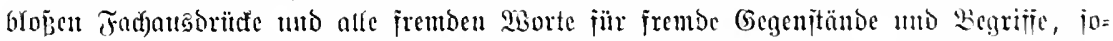

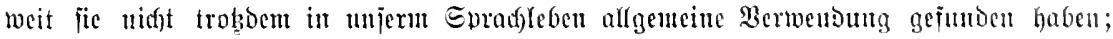

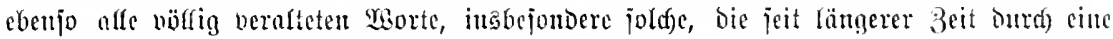

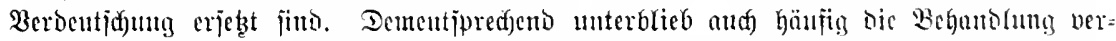

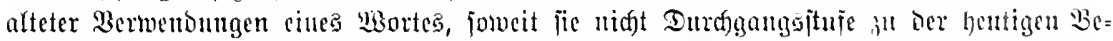

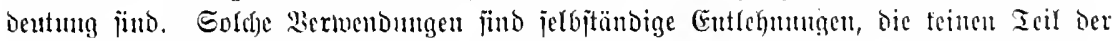
(bejd)idfte Des entipred)enden inblid) gebliebenen Wortes bildon.

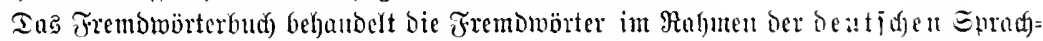

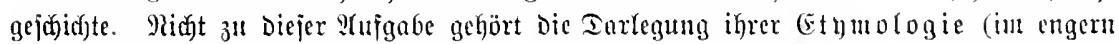

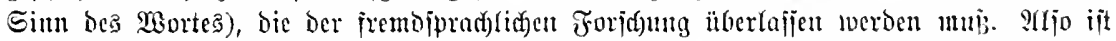

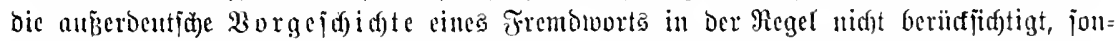

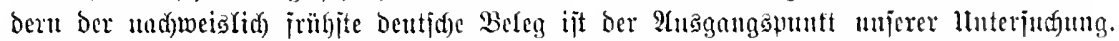

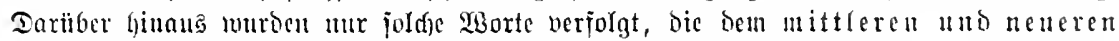

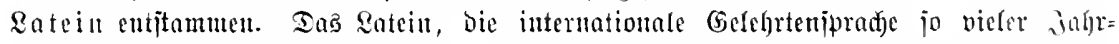

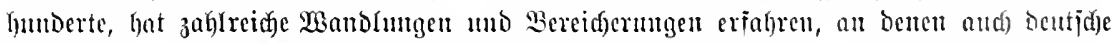

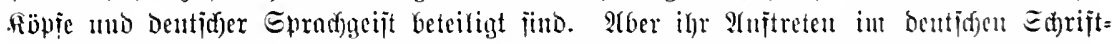

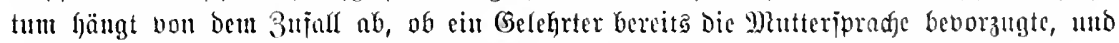

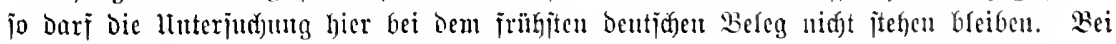

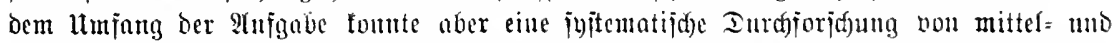

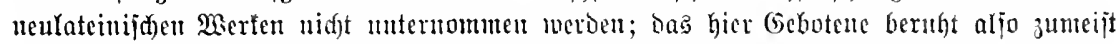

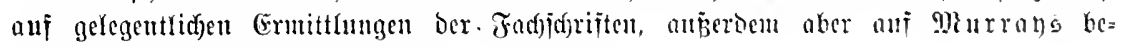

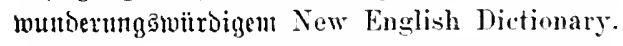




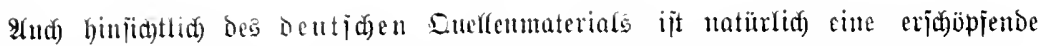

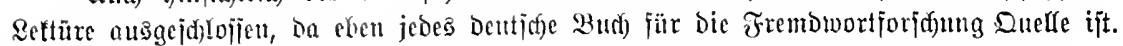

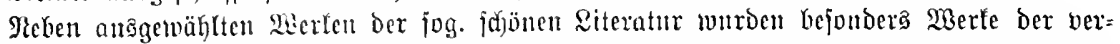

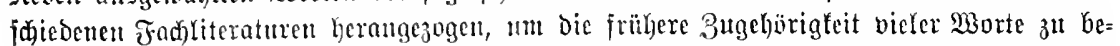

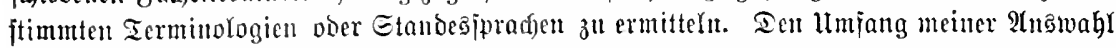

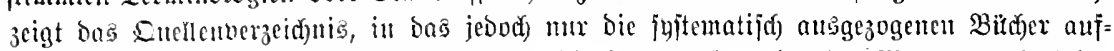
genummen worben find, nicht foldfe Merte, bie idf mur jür eitrzelme. Morte Durdigejehen und jitiert babe.

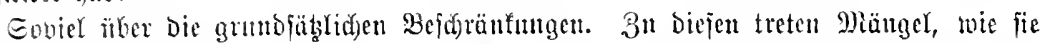
bei jeder gröferen Stbeit mit cincr fo breiten Grumblage unbermeiolid) finto. Das Jnter=

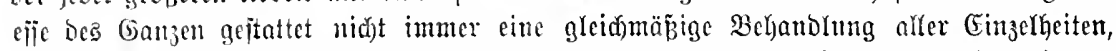

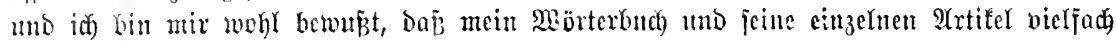

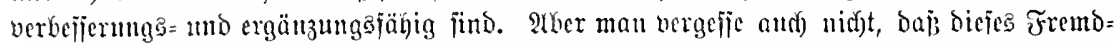

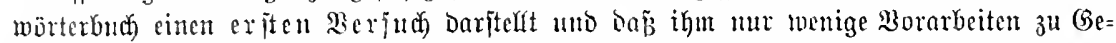
bote ftanoen. Bon Den vorhandenen Frembiörterbühern haben nur bie Werfe von

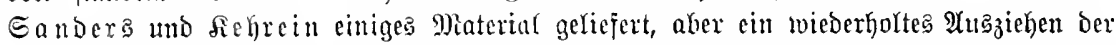

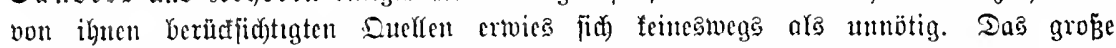

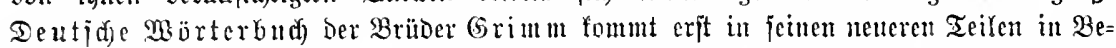

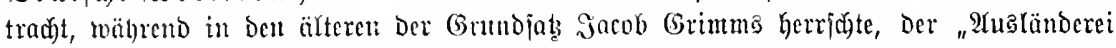

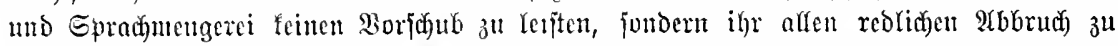

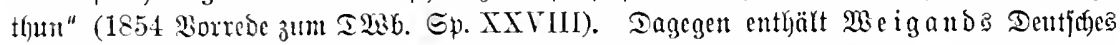

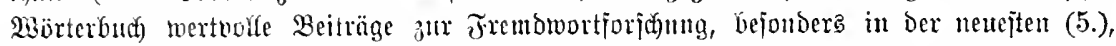
bou 5ु. Sirt $(1909,10)$ beforgten $\mathfrak{A}$ flage, Die autit) Das Material verarbeitet, das

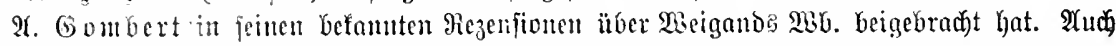

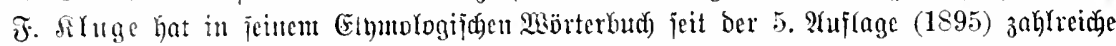

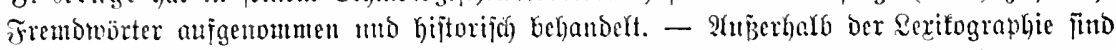

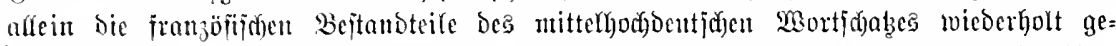

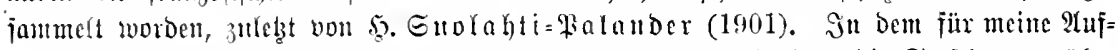

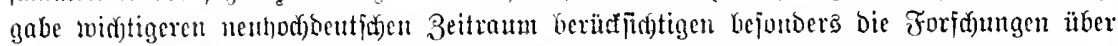

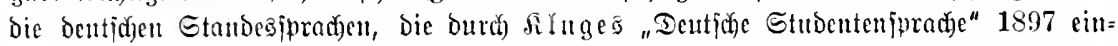

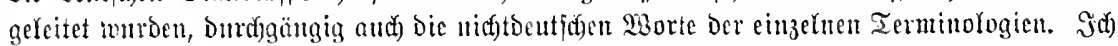

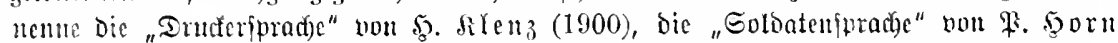

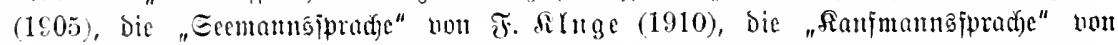

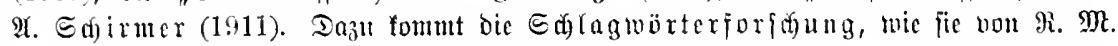

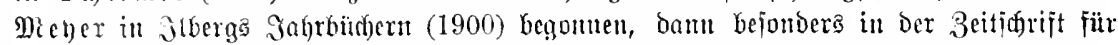

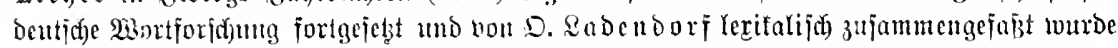

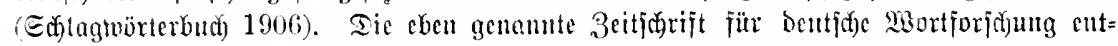

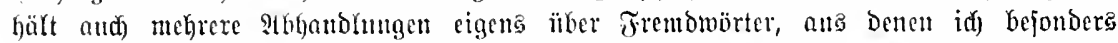

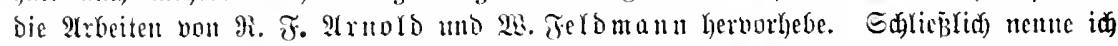
Die Freifurger Dififertationen bun $\mathfrak{I}$. T. Malgerbe, Das Fremomort im Reformations:

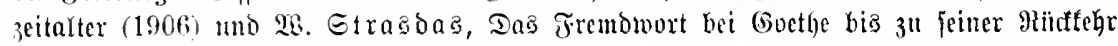

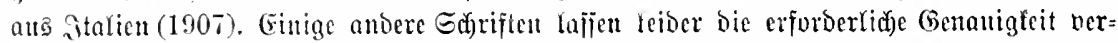

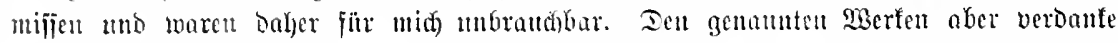

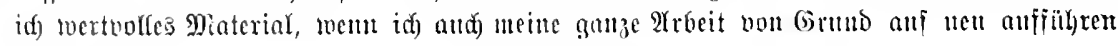
mus,te.

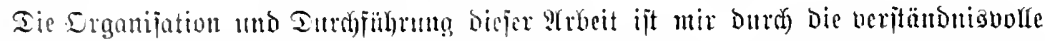

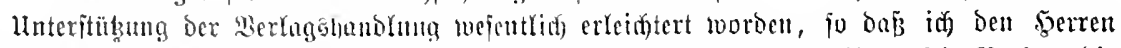

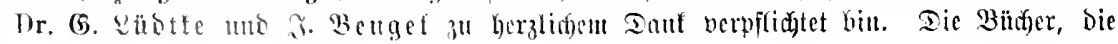




\section{IX}

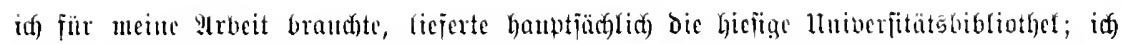

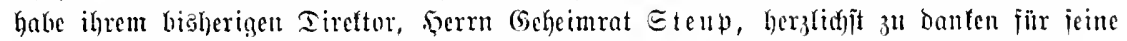

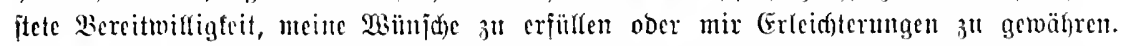

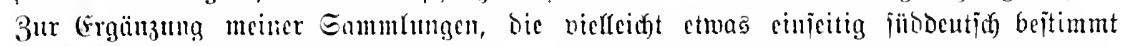

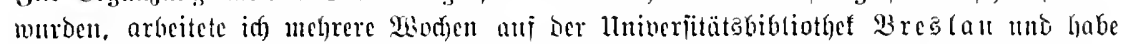

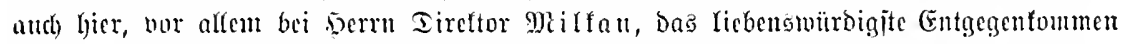

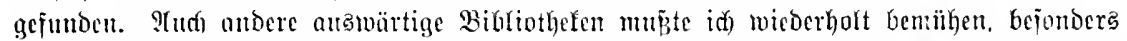

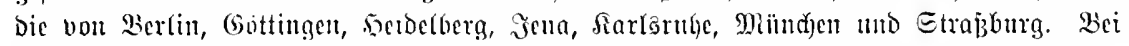

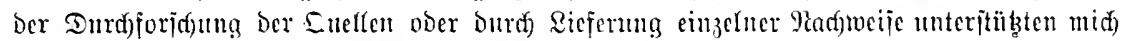

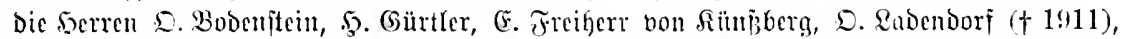

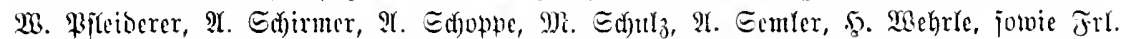

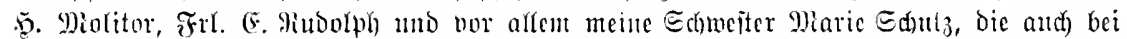

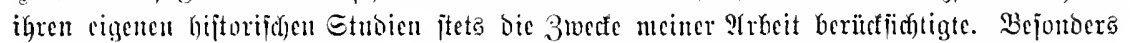

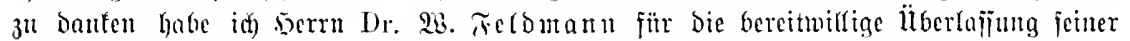

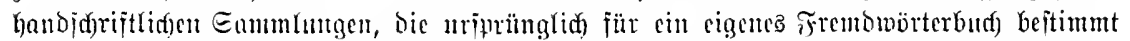

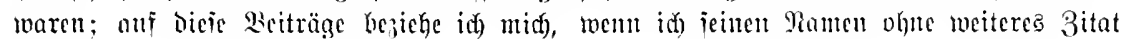
nente.

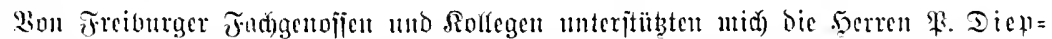

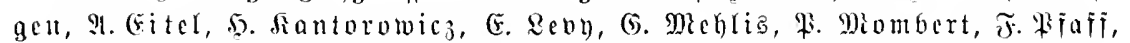

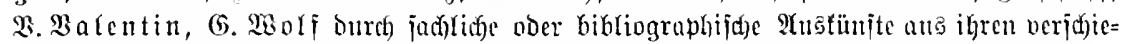
Denen Forfdungaggebiet'n mo Durdy Darreidung von Bühern. Sermann fi a ut orowicz

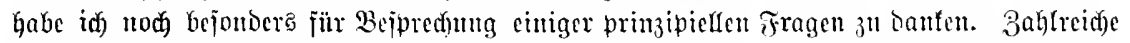

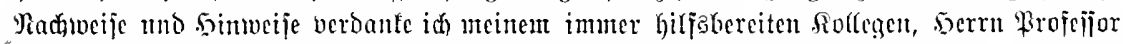

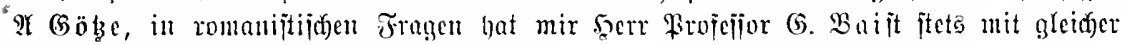
Fremtoridsfeit mertudre 2 tußfunft gegeben.

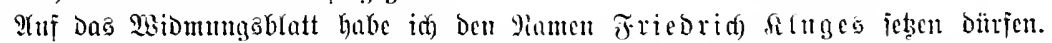

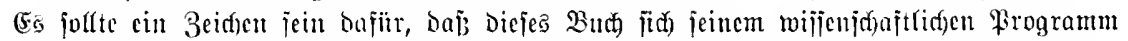

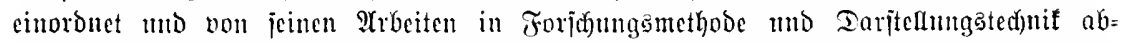

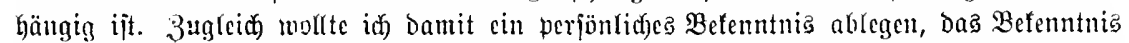

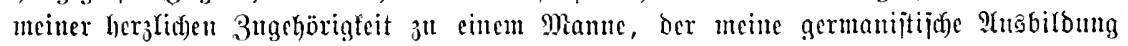

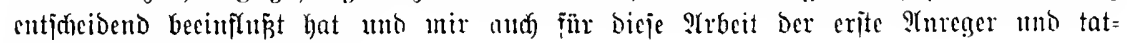
trüftigite Förocrer gemejen ijt.

Freiburg̣ i. Br., im Movember 1912. 



\section{Quellenverzeichnis:}

Qbete Dhatthias, Metamorphosis telae jurliciaria, das ijt Solbante (seriđtshündel. I II Rürnberg 1654,58, IV $167: ;$, V 1675 .

2tbrahan a Et. (clara, jubás oer Ëroidelut. Ealzburg $168<i j$.

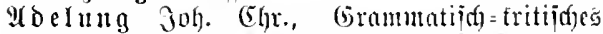
Wörterbud I-IV $17 \%+-1786$. V $131 \%$.

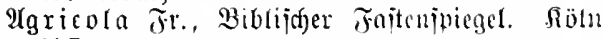
1579.

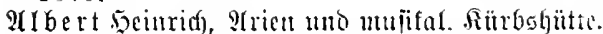
Sag. von Fifiger $=\mathrm{ND} 4 t-47$.

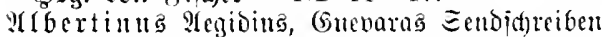

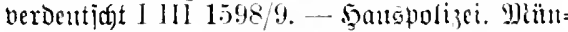

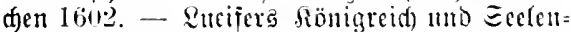
gejaiot. sogg. von Qiliencron = NL 26. - Iex

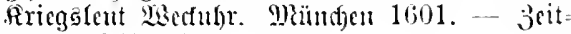
fürzer. (5bo. 1608 .

Stlemannia, hag. bon Birlityer, päter non lifafi.

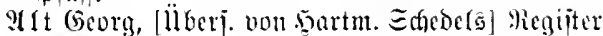

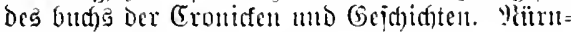
berg $149: 3$.

$\mathscr{A}$ maxanthe Franenjimmerterifon. Secipzig 1715. - Wroben Der Pocite. Franfint un Reipzig 1710.

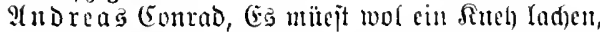

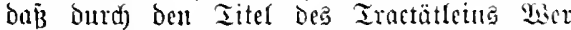
hatt Das fialb ing 2 (ng gejolagen niw. Iil= lingen 1630 .

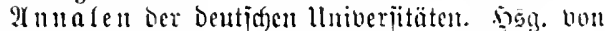

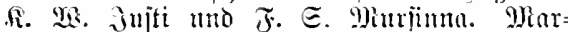
burg 1798.

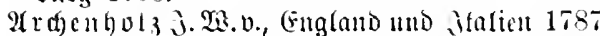
[3it. als (England I-lV, Stalien I II]. jof)idfte Des j̈ebenjührigen frieges in Tentjó)= lano bon 1751 big 1763 . Frantjurt mo Qeip. jig 1790 .

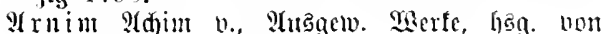
Miorris (Reipjig, siciie).
Qurnold joh. (jeorge, Brmmanell Der potit. Diber; heit. So. Dresoen 1605.

$\mathfrak{A r}_{3}$ (Eiflurt, Ehronif won Weipenburg [nad) 1471]. 5ig. von (5. 5ojmann in ben Enellen und Erörtertugen jur bayrijaen utb bentiden Gejufichte II.

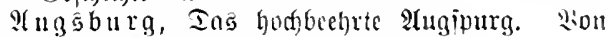

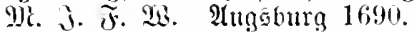

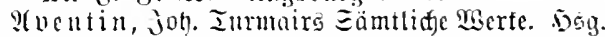
von Minter. Mänd)en $18: 1$ i⿱

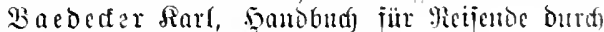
Ientigtano. (ioblen; $18+2$.

Bafrot Rarl Friebrid), (Gejd)idste jeines Rebens. I-1V. Berlin 1790. - Das Meligionzeditt von Vicolai dent jüngeren. Ihenalel $17 \times 9$. - Eeben mb Ihaten des Paitor shimbvigins. I II. 1790 .

Balbober, Enfoedter jübijajer - ob. Eadfien= (5oburgituse Acta Criminalia. Eoburg 17:37.

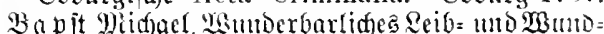
atruneybud). (Eisfebelt 1596.

Bajedow Got. Bernh., Practioge Plylojophie jür alle Etände. Ropengagen unb Qcipig 1758.

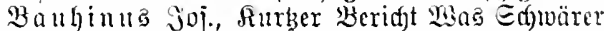
uno 9) Mübjeliger allerhano firantheiten burd)

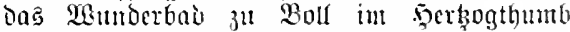
Wïtrtembery gefeilet worben. 1:i99.

Bamigfe Morib (5ujtov (lifenon. Equate). Bilder auk Der Wirfliffeit. Brestan 1834. - Iijtel=blïthen. Buber ans Dem Peben. Bres̆lau 1-34.

Bazar Der, Derliner illujtrirte Beitung 15:5. Beder joh. joad, Methodus didactica. Miünd)en 1668.

Bedf je iul Rubwig, Iie Heijetage. I 11. Mann= beim 1836 .

Bedenten von Dlamufacturen in Ientjdland. jog. bon Dem Qiebhaber gemeiner Mobliart. iena $10 ;-3$.

- Die Belege merden jitiert mit Gugabe Der Eeitenzuhl oer Eriginalorude (bei bramat.

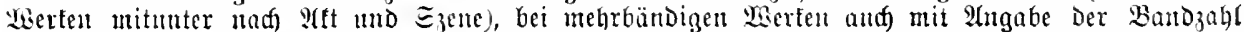

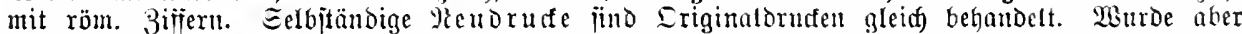

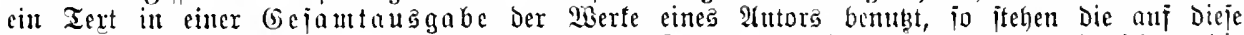
Augzgabe bezüglidjen Band= und Eeitenzahlen in flammern. Erponentzahlen bezeiduen bie Iurínge cines Therfes. 


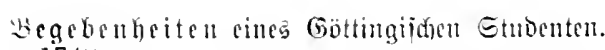
1748 .

Beicr Torian, Ganbmertaleriton. Miẗnen 1722. - Sion Ganowerg Yiecten mul (be= wohnheiten. Jena 16-6. - Non Der 3 ünfifte

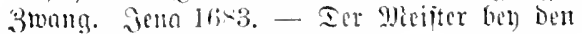
Sandoereferm. icha 1685. - Iyro, Des Qcbrituly. Senn 16-3.

Bate Bertholo v. B., Eotoatenipiegel. Frant= furt a. Me. 16015.

Beflagernug, jube fionitanzer 169s, Über= linger $163 \mathrm{~s}$.

Bcobaditer Ser. Etuttgart 1790.

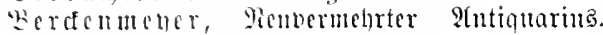
1712.

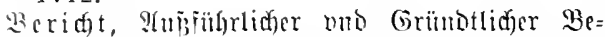
ridt) bet norgemejtu Friotlämbij(t)en no jeiner

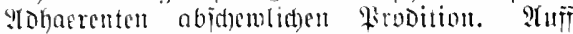

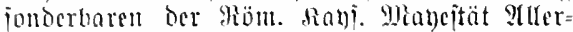

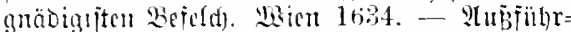

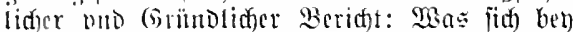
vergangmer Betäger = vno (Eroberma ber jöjten no meitberübmten Etatt Magdoburg werloffen. Getund in Jahr $16: 31$.

Berliner Der ridjtiag. 1>is.

Bertrant Goh. Freor., Ginleitung in die fo

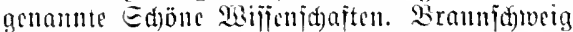
$172 ?$.

Bejefreibung Mahrhailte, Ser Eigreiden Wic= tori nunto $E(f)$ (nd)t weld)e bulangit nou $D$ ar

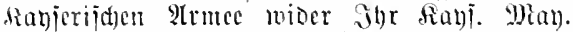
Tiebcllitales Salberitatter / Anwo 1628 Dent

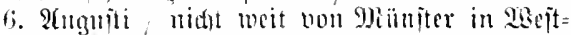
phalen bet Dem Etättlein Etattloo genamnt... crhatten morben. Mïndfon 16 ies.

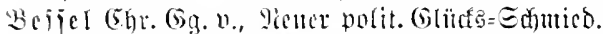
Franfint 1681. . Ed)miede des polit. (5)tünţ. sambura lifiti.

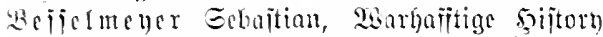

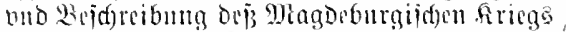

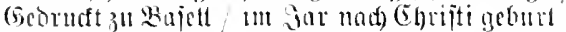
1552 .

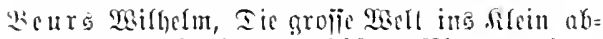

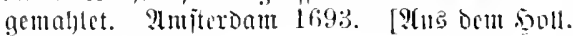
iibcrictst.]

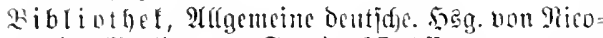
Iai. Berlin uno Etettint 17ti4 fi.

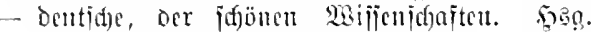
bou hilot. Solle 1767it. [aud) zitiert als "Sallij(t)e Wibtiothet"].

Wirb Fricorid), Yotizen ang Bent (Bebicte ber pindfithen sociltumbe. Berlin 1-35.

birten Eig. v., Sod) püritlider Brandenbura. altijes. Wartenth $166 ; 9$.

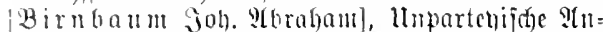
mertungen itbor cinte bebeneficte Etelfe in dem

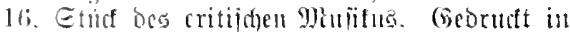
dicjem iath [17:34] - Encite, Erit. Y) $17.15, e .861$.

Bignard, Bricie an ieine Brant mo biattin.

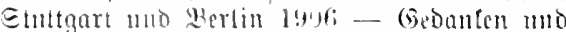

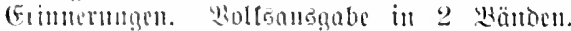
Etuttaurt mo Burlun 190i.

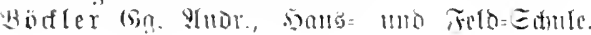

yiirnbera 16:3. - Schola militaris moderna. Teur diricgs=Edule. Frantiunt 1665 .

B̈̈̋flin non Bödtinsan F. F. E. A., Bebträge 3ur (Seidfidte Der Majul. Freiburg i. B. 1790.

B vo mer joh. jat., firtif(t) Betractungen über Dic poetilitict (Gomäloc Der Didhter. Bürich

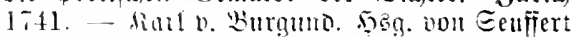
= DL 9. - Irr Yoab. 3irid) 1752 .

[Bold Fr.,] Das Intucritätsmcien in Briefent I o. E. 1782.

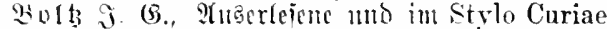
nortommestide Teutjac :hedensarten. Franfjurt mino reipjig 1731.

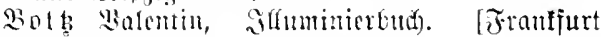
ก. ํ.] $155 \%$.

Borne sums (sa. v. Bem, Consultatio politicatheologica ïber bie Mart Brandenburg. Frant= futt a. S. 1641 .

B̈̈rme Qubu., Grinumelte diluar. (2alpzig, ijejie)

Brant Eebajtian, Yarreniffifi. \$̧ॄg. vou Barndte. Źcinziy 1854.

Bred tol Frans Joad)in, B̈̈d)jenmciñterei. Nürn= berg 15 b1.

Brentano (5l., (5ujtan Maja. Sog. non Minor $=D 1,15$.

Brodbang' dionmeriationalerifon [veridedene Inflauca murben bemïbt].

Brat Friederits, Eptjoden ans Reifen Dura

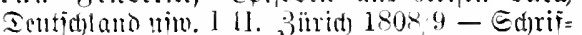
ten 17999 if.

Bit d) manu Georg, Gejlitgelte Morte. 23. 2tuff. hag. non (5o. Sppel. Derlin 1907.

Büt ner Georg, Eämtidide Mertc. Sog. non R. (F. Franzos, Frantiurt 1870 .

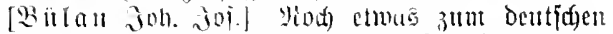
Yationalgeift. Franfunt mo Seinzig 1767.

\&ürger s. Qll., Eämtlide Werte. Sogg. bon

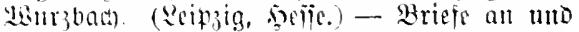
non Büraer, hou. pon Erodtmann I-IV.

Bütuct Sisolia., Dialectica Dentid), Das ift Eimutictunit. o. E. 1574.

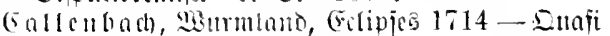
1715 - Enaji bero 1715.

(5 a mpe Joad). Sheinr., Siörterbud) zur Erflärung

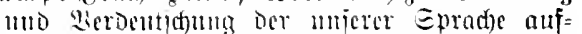
georumgenen fremoen wiorter. Bramidameta 1801.2 .21191 .1813$.

Garion Gobann, Ehrunica. Mittmberg [1532].

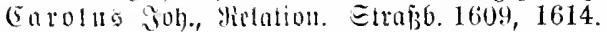

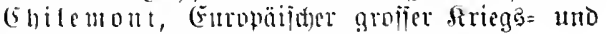
Etuato=Path. 1-I11 17027 .

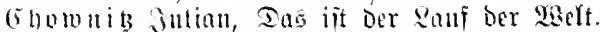
Eittengemä!be ans ùe Gegembart. 1 11. Minnn= heim 1-45.

Chronica, barinnen nuĩ das fïrbeit merben

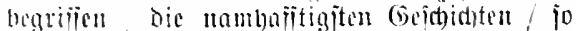
iid) rnoer nllen liablern bou ber geburt Ehriti bip auf bas M.D. XXXlill. Jur ver=

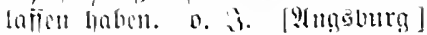

Ggron it Bimmeriide. Sog. non Baract. 2. Saft. Freibura 1 mo Tithingen $1+81 / 2$.

(5) hträ 1 G Viathon, Jo. Casa Galateus, dab ift

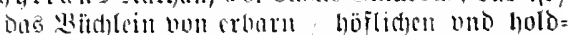
ieligen Eitten. Frantiumt a. Whe. 15!7. 
(Elaudius Whatth., Werte. Sgy. von Befr= mann. (Écipzig, seije.)

Dalgover Darcellian, Areola oder Garten= Wethlein. 111 . Diündyen 1687.

Danthatter joh). Sont., Satedfismus̆mild. Eträburg 1642 if.

Darm ï äbter Smouvig, Şanobuch zur (Gejofidte

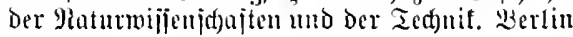
1908.

Deder Fanl, F̈̈rjtlider $\mathfrak{B a m m e i i t e r . ~} \mathfrak{A} u g ̧=$ burg 1711.

Denis $\mathscr{M}$, Einleitung in die Büdgerfunde. 1 II. YBien 1777/ .

Debrient (Edurd, Dranatija) und oramatur= gijoge Ectrifter.

Ditbaum Eammel, Berid)t mo furlse (5rzeblung ber herrtiden Taten, wetd)e Бorr Eigism. Batori, Fïrjt in Siebenbitrgen, bewieien hat. D. D. 1596. - Januarius Des 1597. Jahres. bijtorijac Biclation ujw. Morjanad) a. Boben= jee 1597. - Februarius 1597. - Martius 1597.

Dilid) Thilgetm, sijtor. Bejdereibung o. fürjtl.

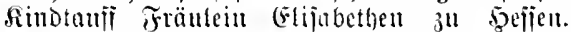
(Sajfel 159x. - Rriegjbund) / Darin bie alte mo mene Militia eigentlidf bej(f)riebent. Sajpel 1608.

Discurs, Discurs über Sisura, das ijt Buel midermertige Bedencfen. Ias (E) vom Yad)= Ia $\dot{B}$, Das luber von Buhlung Der Binjen.

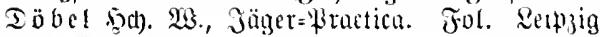
1746.

Dréblex (5. Ehr., Theaterjadule jür Tentjue. (5) rum. und Eajjel 1777.

Dunger sermann, Mörterbud) von Berbent= j(t)ngen entbel)rlider Frembmötter. Zeipjig 1882.

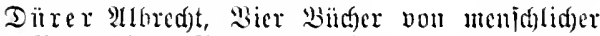
Broportion. Tainnbera 1528 . - Tagebud von

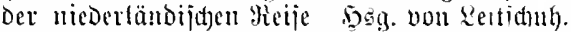
Reipzig 1884. - Interweijung Der Meijung. 1527. - Interridgt 3ur Bejejtiguny 1527.

Dürer bicronyuns, Raü Der 2 selt mo Epiet

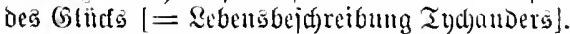
Şamburg 1668 .

Sürtuger $\mathfrak{S h}$. J. und Barthels 5 ., Iheater= Rexifun. Rrizpig 1841.

Duj(d) $3 .$, Briefe jur Bildung bes Gejamute un einen jungeu berra von Elande. 111. 17645 .

(Ebextiu joh. von Gümzburg, Eümtl. Edgriten.

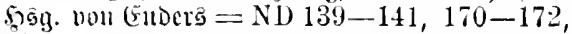
183185.

Ectitein Ermjt, Eatirijd) 3ettbilDer. Reipzig 1876 .

(E) —Elbitbiographie. 1752. 5ुsg. vondiloje 1849.

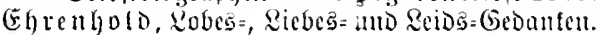
ט. D. 1690

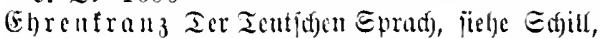
joh. गु)int.

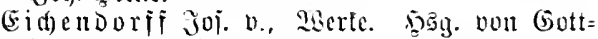
jofall. (Qeipzig, oxije.)

(Eister Ho., Würterbud) ber phitojophijacn Begrifie. 3. Atuil. I-1II. Werlin 1910.
$(E[\bar{B} h o l b$, Gartedt=Bau. 1 tist.

(Em tut Selirig, Nomenclator quadrilinguis. 1592 .

Emier Sieron., Annotationes vber Ruthers nasv Iejtament. Dresden 1525. - Etretichripten gegen Lnther. \$ु)g. von (Ender's $=\mathrm{ND} 8: 3 / 4$, $96-98$.

Éngel, Garten=Deijter. 1695.

Engel Johann Jafob, Soerr Rorenz Etart. $179: 6 ;=$ NI, $136 \%$.

(์̆ Celer Nuncius oder glaubuäroige Eizehlung IIiw. Eölln, bey Peter vou Brad)d. 16:30, 1636,1640 .

[Erot $\mathfrak{H a n t i n , ] ~ A n t e i t u n g ~ j u ̈ r ~ a n g e h e n d e ~} \mathfrak{B}$ ibtio= thetare mid aiebbaber bon \&übern. Hnas= burg 1786.

Erlenmeyer $\mathfrak{A}$., Dic Gebirmatrophic Der $(5$ madjenen. 2. Anjl. 'icututed 1854.

Erat 5erzog - Der frommte, Epecial= ond jonoerbahere Brridgt. Gotha 1642. [3itiert ats "E(f)ul= Miathodus".]

Ertinger Franj Fero., Reijebejdreibumg Durd S̈jterr idf mo Sentid)land. gog. von (E. Tiebe

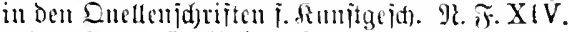

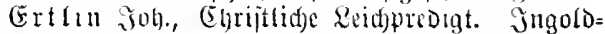
itaot 1592 .

Ettuer v. Eaterił Sol). (5hrijt., Ies getr. Eef= harts verwegener Chirurgus. 2fngsburg nno Leipsig 1698. - Tes getr. Eofharts ent= Iaujener Chymicus. Singsburg umb Qeip= jig 169\%. - Des getrenen Ectharts unwër = Diger Doctor. UMgãburạ un Leipzig 1697.

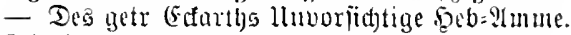
Reipzig 1715.

Euden Huboli, (Sejd)idte oer philoiophijden

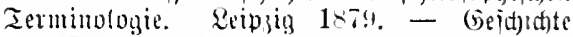
Ind frits Der Grumbegriffe Der Gegenwart. Reipzig 1878 .

(Euleujpiegel j. Pauli.

Europa Sas getröitete, ober die Bünommīen und Siriegs=(bejäjfite $1683 / 4$. o. D. 16-4.

Europa, Ehronil oer qebildeten raelt. 5sg. vou 2. Resuald. 1835 ir.

(Exequien, Rurber Entwurĩ / Was ben jolen= ner Berbignng Der fünjten Denardje 3u Parib bent 20. jun. 1706 merdwärdiges vorgegangen.

Erzerpta, Sintic Excerpta. 2lub einem Eenojerciben cines Ed)weigerijdent (be=

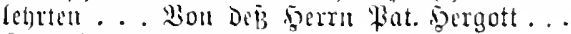
Genealogia. ca $173 \mathrm{~s}$.

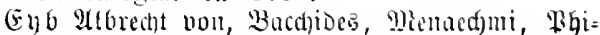

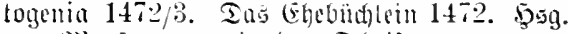

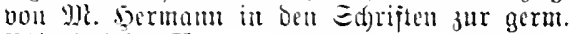
quilor. $1 \mathrm{~V}-\mathrm{V}$.

Eyjillger Mcidfuel, Ier Erit Thayl Relationum Historicarum D. i. Der hijtorijafen Mela= tionen. Röln $1590 \mathrm{fo}$.

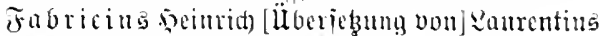
Eming, funbe Ebronit. Söln $15, \mathbf{s}$.

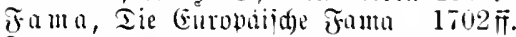

Fanjer johann, Friburici Erijonis füntticher Beridst: Mie bie jtreitbaren liferde geidstat ou maden. Frantiut a. ㄴ. 1573. 


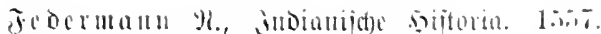

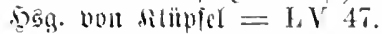

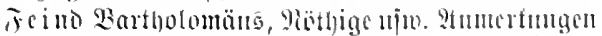
Hiber bic peinl. Sirage contral Dr. Egription sirmmblolts. Somburg 1707.

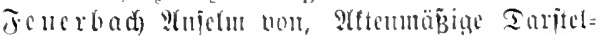

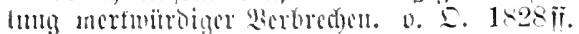

Fidfte i. (6., Wherte. 5igg. nou i. \$). Fithte, Berlin 18450.

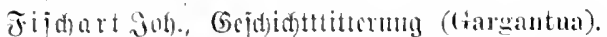

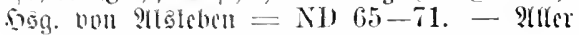
Fratit Grojumtter. 5ogg. bon Brame = ND 2.

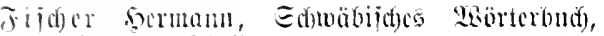
Iibbingen $1904 \mathrm{ji}$.

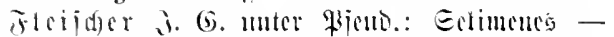

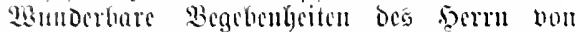
Eboiv. Frantiut mo seipzig I-lll 1730/4.

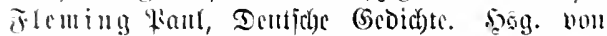
supperibers $=\mathrm{LV}>23$.

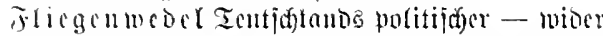

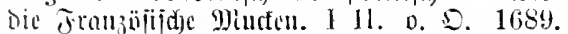

Florentimu de Valentia, Rosa Flonescens, rontra F. R. Menapii calnmmiae / Daz ijt:

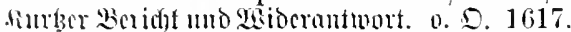

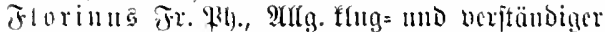
Fonsonter. I 11 . Tä̈mberg 17(12. - Contimatio. Piurnberg 1749.

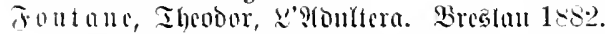
- Eifi Qricit. Dertin 1895. - Sic Poggen= pul)(s. 18:11. - Entt. 1890/1. - Ier Etrdlin 1×9\%. - Ilnwicontringlid 1892. Intidner firicg. - Eamjerien ïber Shenter.

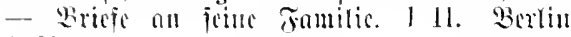
190.;.

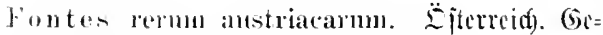
idfict)tsquellu. Wricn 1849 ji.

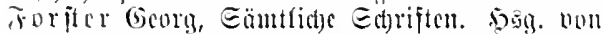

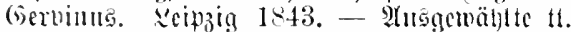
Echriftr. Dog. num seilsmam = LD 46/7.

T) contimatio quinta. Dingoeburg 1603.

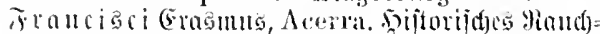

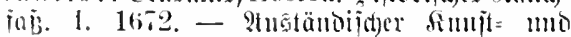
Eitcuiptegrt. $166 \%$ - Iax Trum= Sant.

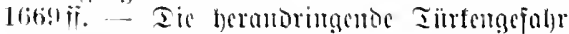

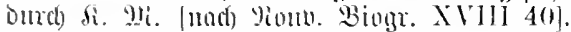

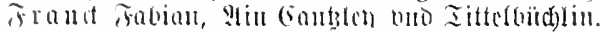

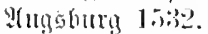

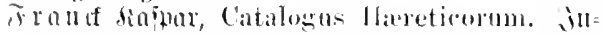
gulitate 1576 .

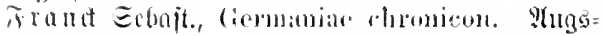
burg 15iss.

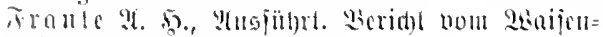

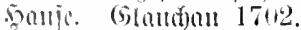

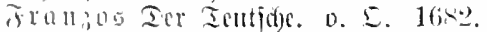

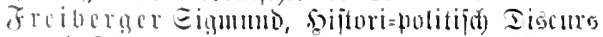
mo Iij(f)roder. Frantint $165 \%$.

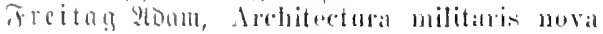

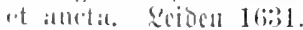

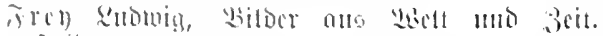
Socidolnery 18.11

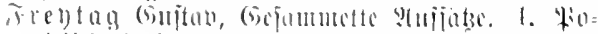

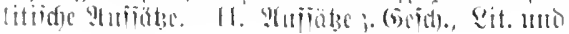

Sumit. Batin 1sse. - Sie Jommalijten. 1854. - Eoll แmD מaben. 1855.

Friderici ioh. Balth., (5rtptougraphia oder Ge: beime correpondenł. \$amburg 1684.

Fricdellsbirg joh. (5ormel. v., Discurás oder

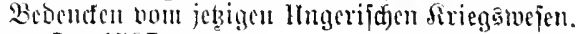
v. S. $159 \%$.

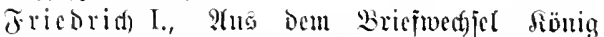
Friedrid) 1. und peiner Familic. sogg. von (5. Bernex. Berlin 1901.

Friç Qamenting [iu Iitcl: Poricicn], Epieger ocr ?trlint). Etrajbutg 1519.

Frij氏liuns gifobrmu, Phasma, jiberi. non Grojer. 1593.

Fritjct) 2(hasver, De Aususta Romanorum imperatrice, ejusque juribus, privilegiis ac premientiis. Diatribe. Mubolitndt 1667.De Stipendiis. 1663.

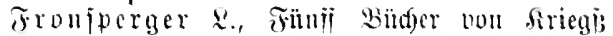
Ricoment. 1. I. 1555.

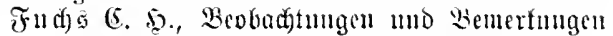
ïber Gehinmerweidfung. Reipjig 1838.

Fudiperger Stholph, Sialeftit. 2lugsourg 1534.

Furtteubadi jojeph, Demes Itinerarium Italiae. llı 1627. - 5̧oipittala=5ebäแล / Ter Bicr = jetjendoc shcif. अugsburg 1655.

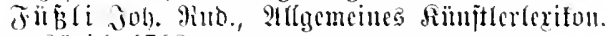
3ürict) $176:$.

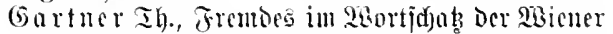

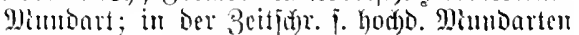
$\mathrm{HH}-\mathrm{V}]$.

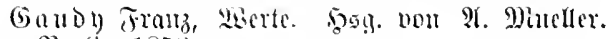
Berlin 1853 .

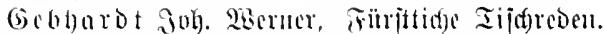
Frantiut a. Mit. 1597 .

(5eblatot lllrid), Won ber Sumpjt Reid) z"

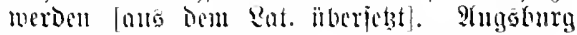
1656.

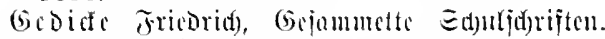
111. Berlin 1789.

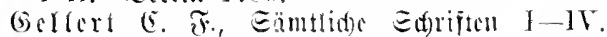
Barlia mo Etctio 1775 fi. - Fabch. Dog. non siander $=$ NL 43.

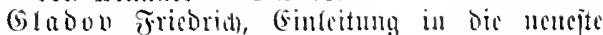
(Gougraphic. v. E. 1716. E. andf Extrander.

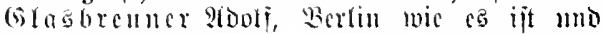
triutt. 11 Incile. 15.5 fi. - Bitber mo

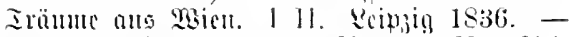

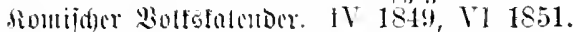

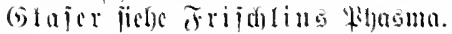

Glaicr Poofi, Eizäblungen min Yovellen. Branomburg 1862.

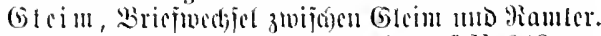
1 11. T)

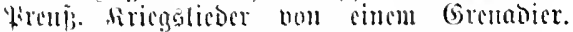
5)

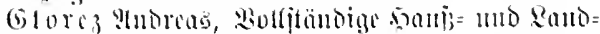
Biblintber. Yicgensbura 1701.

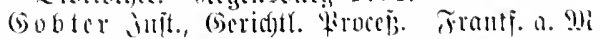
1;ist. - In liedten Eprigel. 1500.

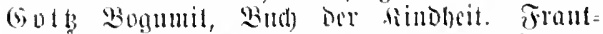

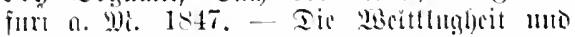

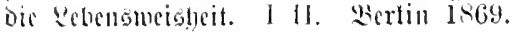

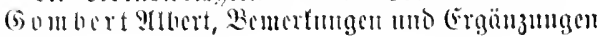




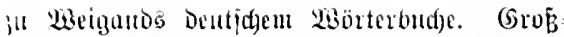
Strel)litzer Effulprouramue $1876-1897$. Wres=

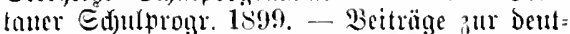
jdyen Wrortyejafidyte. Bresluter Edun(pr. 1908.

(5) örres Toj., (Geiaumelte Edfriften, Mrïnd)en 1854 ff. - Entropa mid die Hevolution. Etntt= gant 1821. - Inutiffland mo Die Ricuolution. (5oblen, 11:1.

(bocthe j. Wh., Werte (Woimarer Masgabo).

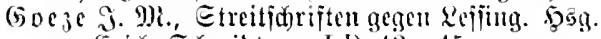
vun (Erid) E(f)midt $=$ I.D $4: 3-45$.

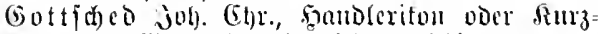

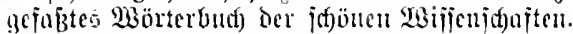
ceritrig $176:$.

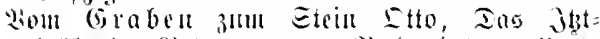
blïhende fiotodau vou betlamintes. Wots= Doul $172 \%$

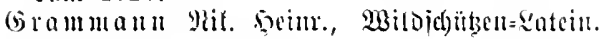
()) 1600 .

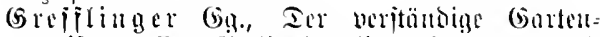

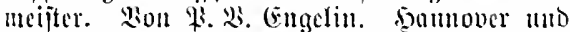
Wolffenbüttel 1695. - Ethical romplemen.

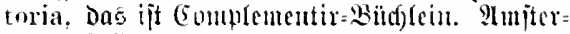
Dail! 1675.

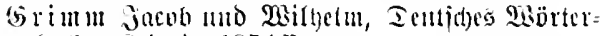
bud). Reipjit? 1854 if.

(5) rimmelbl) aljen 5. S. (it)r. v., Det aheu=

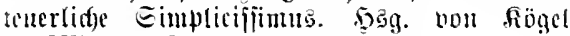
$=\mathrm{ND} 19-25$.

(Grijo, Berid)t wie die itreitbaren Pjerbt nol: fomen 3t madjen. 157\%. ङ. Fatjjer.

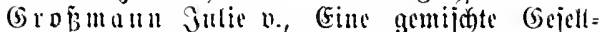
id)ajt. Seit=Momum. Breßla 1:47.

(5) ottuib (Earl Deldaior, Teutian gefleibetw Megiments=-Yath. Etettin 1647.

(5ruber Joh. Eeb., Sie heutige nriegs=Diasiplin. 1-111. $\mathfrak{2}$ ugsburg 1697.

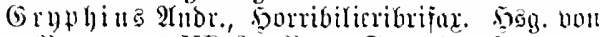
Branne $=$ ND 3. Feter Equenk. Sogg. won brame $=$ ND 6 .

Gutrimoniub Soipp., Die Grenet ber Der= mïjtıng menj(d)lidfen (sejefledfto. Singoljtutt 1610 .

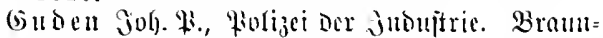
idumein 1768 .

(i) ugeuberger Bitus, Froceiji mo vortrefi =

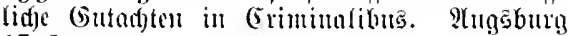
$17 \geq 2$.

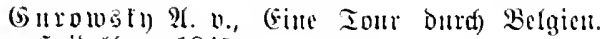
Seidelbera 1845 .

Gutmar Greg., (bemert mo Remueiden ber waldrel Latholipden Religion. Singolftaot 1592.

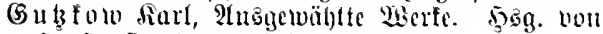

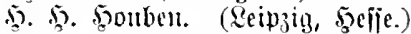

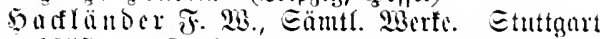
1855. - Rüuptlermoman 1866 . Das Ent

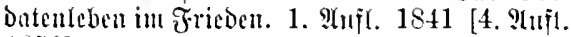
$1850]$.

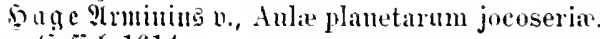
Eaffel 1614.

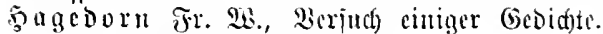
ज) 3ुy. bon Eancr $=$ DL 10 .

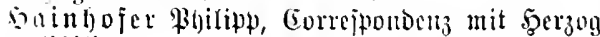
Hhilipp II. non Pommern. 5̧3g. non D. Doer =

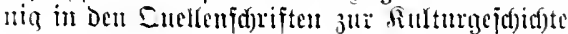

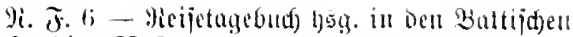
Elmoien II 2.

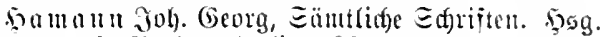
von F. Roth. Werlin 1821.

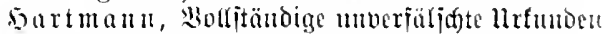
bou Der jujtizgeidjidfte Des I unaut. o. E. $17 \times 4$.

So axtm a $n$ u Jo!). Subun., liationis Status Anatomia. Rüunbery 1678 .

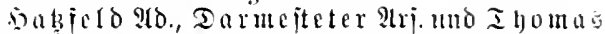
Qtul., Dictionutire général de la langue fran. ģaise. Faris.

5) anfi 2ailbelm, Werte. (Berlin, Sompet.)

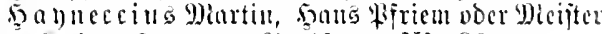

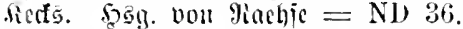

Syeimburg in., Die 2lldere. $1886=$ Ho: mane Bo. VI.

Şeiu Qitizig.

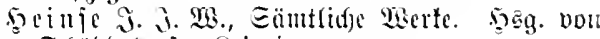
E(f)ïbDelopi. Reipzin.

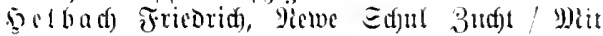
jebr j(f)ünten Tijagebetlein. Inrmitatt 1612.

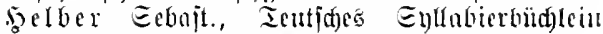
(1593). 5igg. vou (G. Ruethe. 1s82.

Soutidg (Seor(y, Icutidse Eprad) uno Meip̧heit.

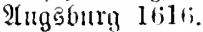

Seppe (5arl nou, Aujridftiger Refreriuz nder

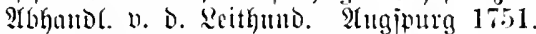

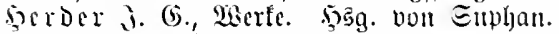

जermeg joh. Tim., Für Eltern nuo Etheluitige. 1789. - 3ween litterarijage glärtyrer mu Deren Franen. Sarlaruhe 1791. - Eophiens

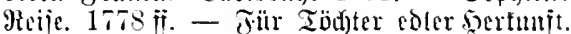
1789.

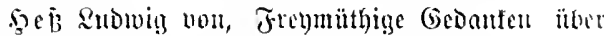
Etautsjadyen. 5ambura 1775.

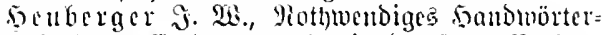

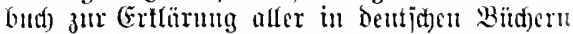
und Jountalen vorfommenoen jremoen Wörter. Inišburg แ⿰㇒⿻ Reipzig 1806.

5e l) fortigung Der Brieje. 2. Pufl. Berlin 1775.

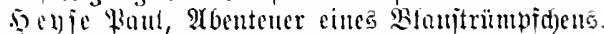
1896. - Sinter ber ISelt. I II. 187:3. Gej. Werte. XI Xll.

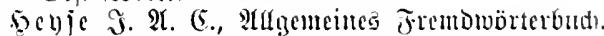
Sloenburg 1804 [und jpütere $\mathfrak{A}$ (tillagen].

5) intmel Juhaun, Castrum Doloris. Ecd gjubut Tramr und flagpredigten. Sena 1635.

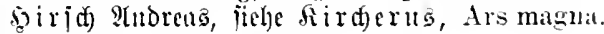
1662 .

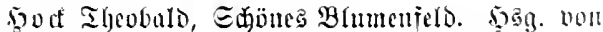
fiod) $=$ ND $15 \%-159$.

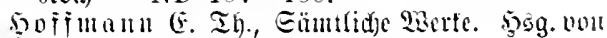
(5rijebarf). (Qcipjig, seije.)

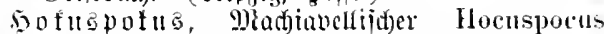

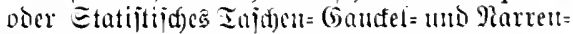

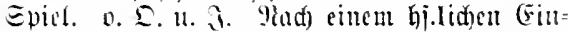
trag in Gryl. Der Sis. Berlin (Yy 2441) ijt

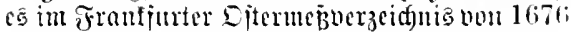
D 2 b unter Libri tuturis numdinis proditmi aujgefïlyrt.

Sollouius Rnom., Speculum vitac humanate. 5is̆g. von Epenglu $=$ ND 9. . 


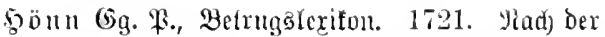
2. शीfl. 1743. [I II.]

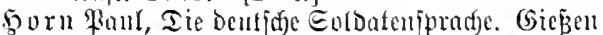
1905.

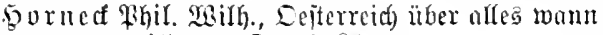
es nur will. D. D. 1484.

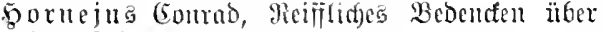
Das Exfulwejer.

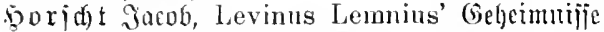
Der Piatur. Zeipzig 1)so.

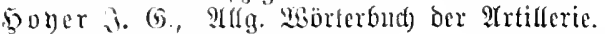
1-1V. Iübingen 1804.

(5) ӥ̆ jations= 2excon. Sctpjig 1717. - Matur=

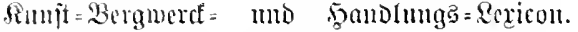
Seipigig 1717.

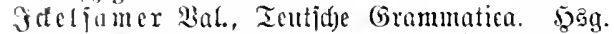
von Rohler. Freiburg mo Tïbingen 1881.

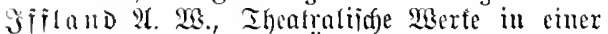
Pusmahl. I-X. - lïber meinte theatralipase

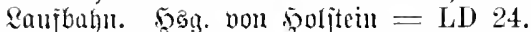

Jumermanu fiarl, Der fiameval mo bie Eonutambule. 1830. Ylovellemid). V 195 if.

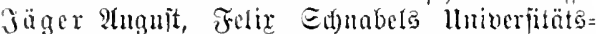
juhre. Etutgart 1835. 3ux Berfajierianait 3.'3 val. Fabrictns in Den Madem. Nomats= heiten $1908 \mathrm{gr} .288$.

Fäjd) Dimbart. Bzreslan 1908.

Sull g gen. Etilling \$. \$ु., Theorie ber Geipter= Eunde. Së̈ruberg 1808 .

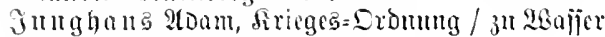
UnD Rand. ภïla 1589.

Su iti 3. 5. G., Bulfit. 9lbhandung von Denen Diannjaturen un Fabriten. 1 II. Sopon= bagen 1758/61. - Rigypical. nno polit. $\mathfrak{B e}=$

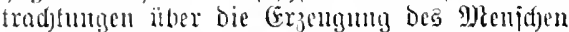
แnd Bevölterming Dex Sunder. Emirna 1769.

Deconomijales Märterbud). I 1762, II I11

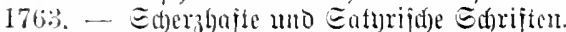

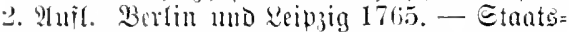
mirtichajt. 1 II. 2. 2lnil. Lecipzig 1758.

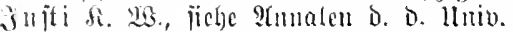

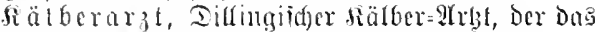

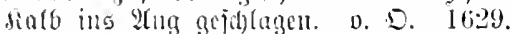

fiall vimm., (Sejammelte Edfriften. 5og. vou

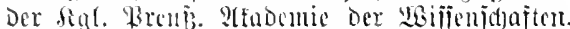

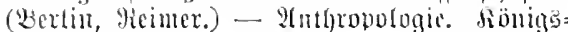

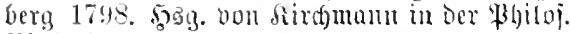
Bibl. 44.

Raruarjof Sart mo soeren Friebridf. Tea)=

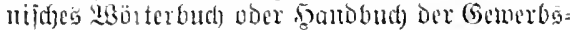
funde. Brag ist34.

fanjunnujdait, Sie iebt florirende - in Ientid)!and. Subitg 1702.

febrein joj̆ph. Frembwörterbut). Etuttgart [1 18 Tit].

ficlas $5(t)$. Tifto, Onomatologia chimica practjea voer nombond der (Ehemie. Lllu I791.

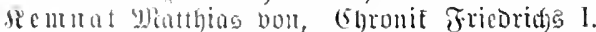
bes Eienreiden. Sog. von (5. Sofmam in Enellen und (Erört. 3. batyr. mb beutid). (6eidficte. 11 .

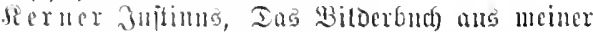

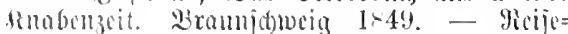

idatten. Bon Dem Edjattenfpieler Rud5. Jeidelberg 1811.

SillDerling jol). Fr. $\mathcal{A}$., ̈̈ber die Reinigfeit Der Deuljaen Epradje. Berlin 1795.

findermann Bulth., Si. Kurandor, Die böle Eieben. Mittenberg 1662.

fird)erus $2(t h$., De Consono et Dissono, überi. von $\mathfrak{A}$. Sirjut. 1662.

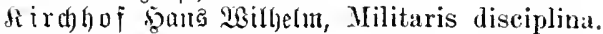
Frantfurt a. MR. 160\%. - Mendummuth. \$ูङg. von Deiterley $=\mathrm{LV}$ 95-99.

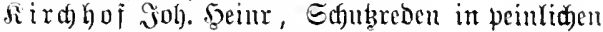
Fälfell. I1 1766 . III 1768 .

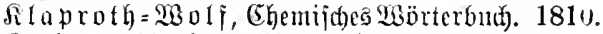

fiteiderafie jiebe Bitfelbering.

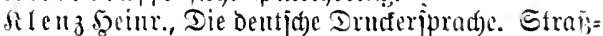
burg 1900 .

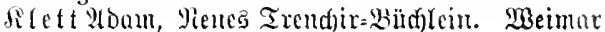
1659.

Slinger Di., Dtto 1775. Şg̨g. von Seuffert $=\mathrm{LD} 1$

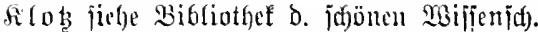

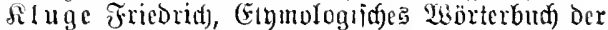
Dentiduen Epradje. 7. 2uifl Errabura 1910. - Deutjde Etudentenipradje. Eträ̈burg 1895. - Eemantipipradie. Salle 1910.

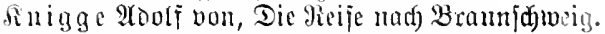
$179.2=\mathrm{NI}, 136$

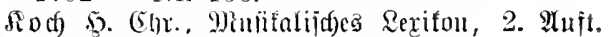
v. 9. v. Dommer, 5eidelberg 1865 .

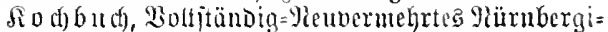
f(t)es. Jüünberg 1702 .

doulfanjer belagerung = Constantia ab Suedicis obsessa à Caesarianis liberati. 1633. Eonjtants [1633].

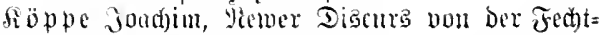
fimit. Mlagoeburg 1619.

fiortum $\mathfrak{R}$ R., Dic Jubjude. Sgag. von Bobe:$\mathrm{tag}=\mathrm{NL} 140$.

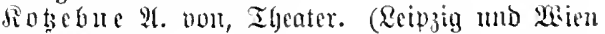
1840.)

Rrämex Matthias, Qeben mo Tapifore Thaten

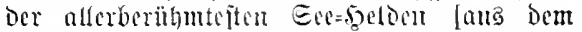
Jol. Des 23. D. B.]. Teïrnberg 1681.

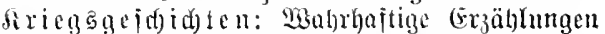

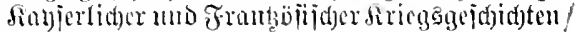

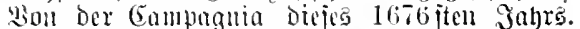
III IV. Etrabburg, F. WE. Edjmun.

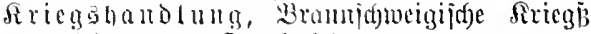
tanolumy. o. S. 1616.

Srïger Soh. Gottl., Diüt voer Reberborbnung. 1750 (mad) Dex 2. Plujt. Solle 1763). — (Se= banten van dinfiec nimo. Solle 1743 .

Sinbua Soham, Ier mujifalijate Duactjalber (1700). 5og. vou Bamtovi = L1) 8:3-88.

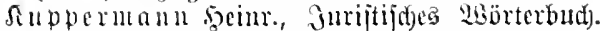
Sripzig 1792.

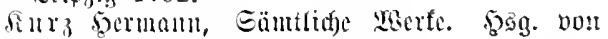
Fijuter. (Reinzig, joije)

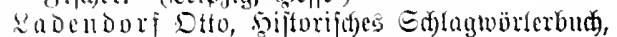
Etrabourg 1 !) 6 .

Eange jobam, :anveijung zu ocr Practic oder Gandung ber allgencillen Diabler=fiunjt /

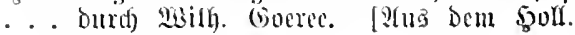
itberi.] samburis 1677. 


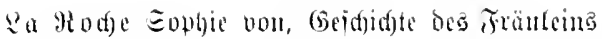

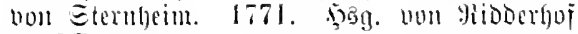
$=$ I.D 13x.

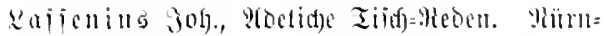
berg 1661.

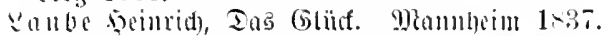
- Heijenovallen. 1836, 1-36. - Iir Ethun= inteterin. 1837.

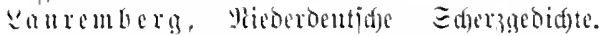
big. vou Brame $=$ XD $16 ; 17$.

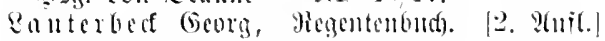
Eeipzig 1559.

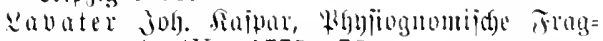
mente. $1-1 \mathrm{~V} .1775-78$.

I.I - Sitteratudenfmale, Dentidec, des 18. und

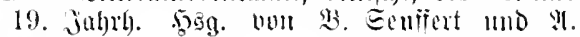
Eaner.

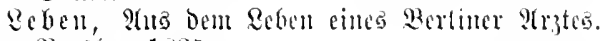
Brestum 1-3.).

Gebentuald Moam: non, Won des Ienfele sijt

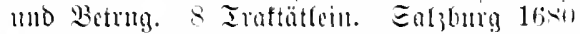
bis 1642 .

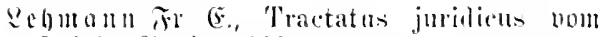
Epic. Bubiiiä 1681 .

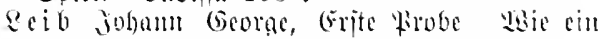

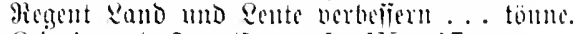
Reipzig mo franfintert. I-JV. $170 x$.

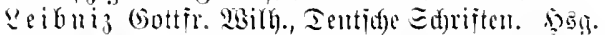

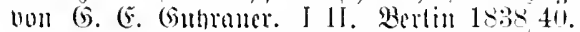

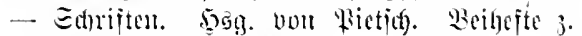
3i. o. Epratfuer. 29,30 .

Sevpulo, Repolos oes Givizen veben mo Ihaten. I 11. Sciplig 1708.

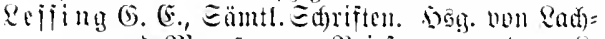
mam amd Mhander. - Briefi bon mo an 2 .

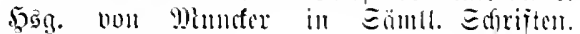
Xill Xill.

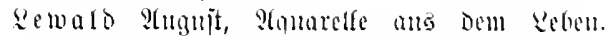
I II (1836). III IV (1837). - I is Mlappe. farlsrube 1843. - Tas malerijt)e Ed)ucizer=

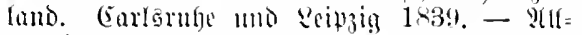

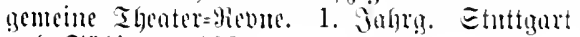
Into Tübingen 183.

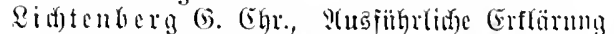

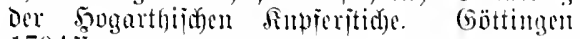
1794 if.

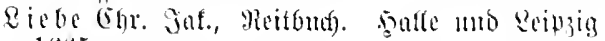
1665.

Zimb a ?rute खyöbden. 1887.

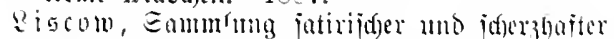
E(f)riften. Frantiut mD Reinig 1739.

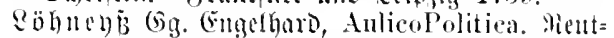
lingin 1622 .

Qonourp Eajp., Acta Publica... nou $11 x=$ jad)en Des Tentiffen Rriegs. I II. Froutint 1629 .

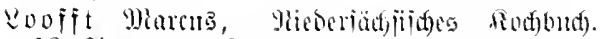
12. Rusgabe. Qübect 17-1.

Sord) (Eaprer non, Histor. Relationis Contintatio. 1605 .

Porid 11. Hi. Hadamarius Reichardus, Wie imuge furjen bno grojier berm fimber redst=

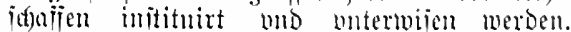
๒. O. 1537. [3itiert als, "Fiiritenfehre“.]
Eutae Frieoridg, Emopäifger betifon. Frant= jurt a. 3)k. 1711.

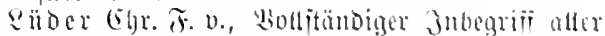
bei bent Etraijenban norfommender fratle. Frantiurt a. 21: 1779.

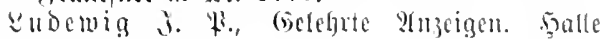
174344.

Sïmig joh. (Egrit., 'Tleatrum ceremoniale. I II. 171920.

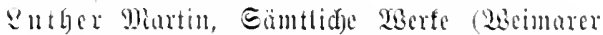
श̆sgabe). Etreitidgripten gegen Emicx. sogg. non (Enders ND 968.

Malberbe I. T., Sas Frembluort im Re= iormationsazcitalter (Siij.). Freiburg 1 soti.

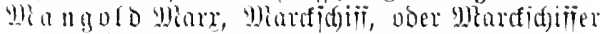

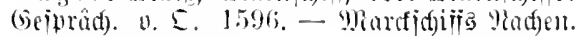
o. E. 1.997 .

Marperger Hanl jatub, Weitreibung ber

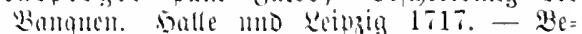

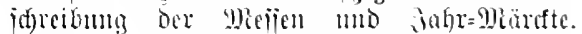

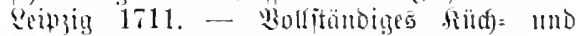
ficler= Iictionartum. somburg 1716.

Wiarr Will., Ias jumge Ientioland in ber E(f)uciz. Ecipzig Jati.

lurtin Ionicl, Les Colloques français et allemans. Etrajourg 11927. 1642. - Parlement nouveau. Etraibura 1637.

Mrartin (E. und Vienbarbt 5)., Wörterbud ber eliäijicfen yimourten. Etraisburg 1-99. 1907.

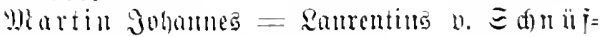

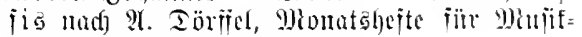
geidfidfte. II $97(1 \leq 70)$.

Mrathejias jobames, Wom Ehejtanot bno

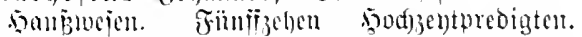
Yürnberg [1563]. - siiturien bon bes $\mathrm{chr}=$ mübigen gottieligen temen Mtantes Gottes

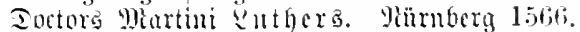
Berghojtilla voer sarepta. Siumbery 1562.1578 .

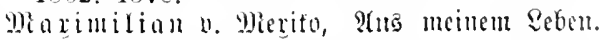
Serpig 1867.

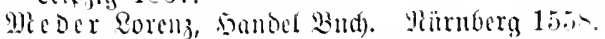

Meier (S). F., P(boildung cimes Rumptrid)ters. solfe 1744 .

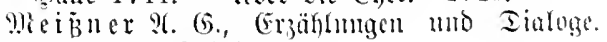
1-111. 1782 89.

Meijer, Flicgende Blatter. Bajal 1783.

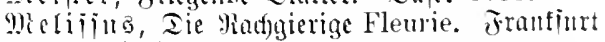
mo seipzig 171.

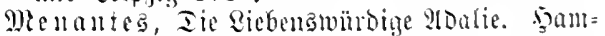
bura 1703. - Sobaediate Des jo genamuten Baner sumbes ju Weiijenjels [1705]. - Tie berliebte uno galante rest. nomburg 170.2 .

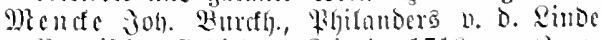

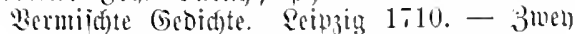
Reden bou Der Egarlatanerie oder Dart= iffererey Der (selebrten. Seinzig 1716.

Me ungring inulo, Informatorium conscientiae evangelicum, Evangelijides (Gemijiens= lieft. Jena 1661. - Rrieg? Belial voer Eotoratenteujel. Ineśden 1633. - Scrutininm conscientiae atecheticum das it Govififens litige mo Eündenregiter. Mltenburg $16+2$. - Buntige Eiegentirome. Reipzig 1638. - 
Suscitabulum ronsciential. evangeliem.

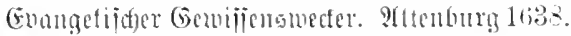

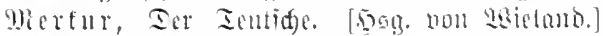
Iseimar 1773 i⿱

Mejieridu m io Gg. Fr., Sapiens Stultitia. Sie

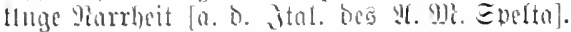
Etrajburg 1615. - Epitat mbeitjamer giarten und gearrimen [a. D. ital. bes Th. (smromil. Etrajburg 16is.

Mejertation Frantruter. 1757 (1 11).

Menills Innio, Ein furbes Bedenten über bic

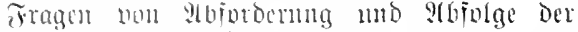
Bamersente. Desmar 165.

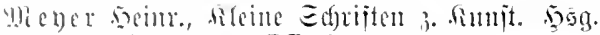
non 28ciziüter = LD 25.

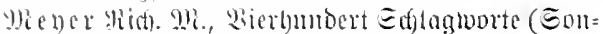

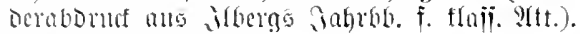
"eipzig 1900.

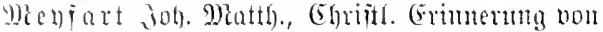

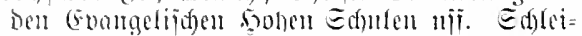
jingen $16: 36$.

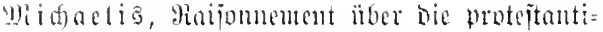
iben llumeritüten in Tentichlamb. I-IV. Fruntiunt mo Peipin 1768 ĩ.

glitteruadst Soh. Echait., Politica Drama. tica. Peipzig 1667 .

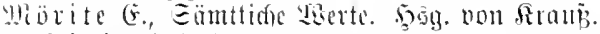

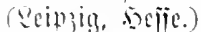

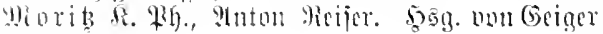
- 1.D 23 .

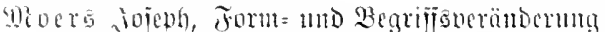

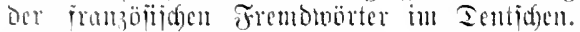
Sommer Firog. 1884.

Wivier Fricor. Eart, Beterzigungen. Frant=

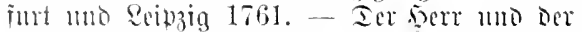
Iiener. Fronfint 1759. - Retianion. Frant= jurt 1766.

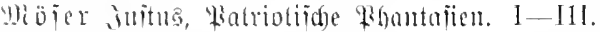
wortin $17 \%$.

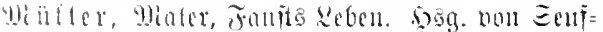

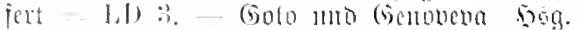

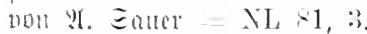

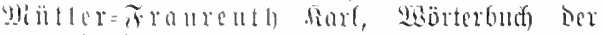

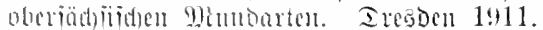

Mundus, Roseas Crucis Frater Thrasonico

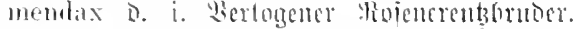
] 1 ili!

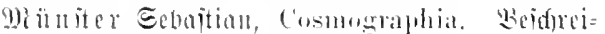
bunte aller écuber. Diriet lift.

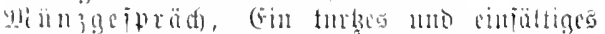

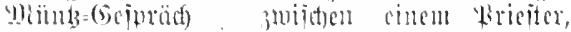

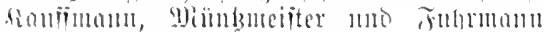

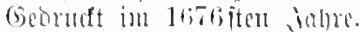

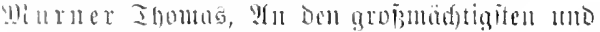

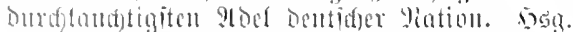

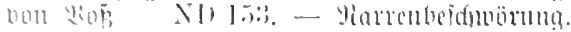

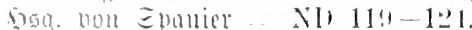

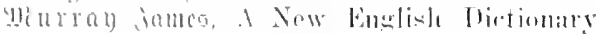

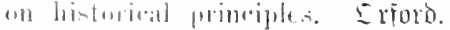

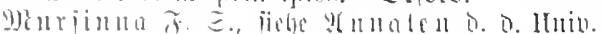

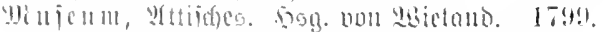

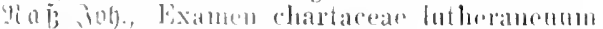
(rollaraliar. 0, E. 15飞].

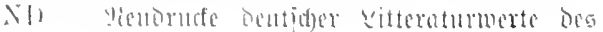

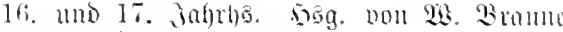
(i)afle, Yicmener.)

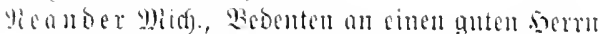
mo Fremo. Wiste cin fimabe 3 leithen und

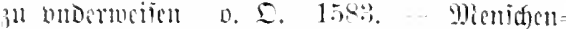
ipieget. Vitimberg 1587.

y[et)ring] S. (5)., Nanuale jurjdico-politicum. Frantiult un Gotha 16-4.

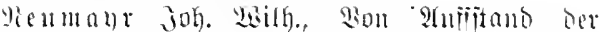
Qintern wioner ibre thegentent uno Ebern. iena

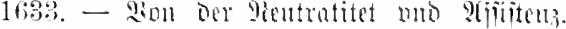
(Erint 1620 .

Ricola i Elino, settrinidar Butrath nno Etrait= geridt. Frandenburg 1621 .

Vicolai Fr., Bejoreimug un Berlin mo

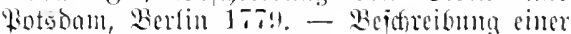

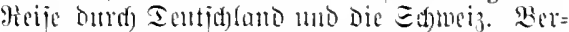
lin 17-8-96. - Eammlung Lerm. Edriften,

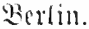

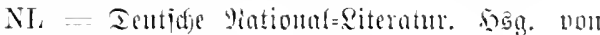
joieph Rimidner.

Yorban 9iar, Sie tomentionelfen Sügen ber

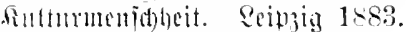

Yoxmann bans, Eeitereich wie ç ijt. I II. veipigig 1838.

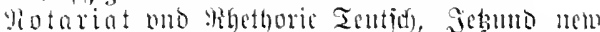
wiberamb eriegen gebejiert but an vifen orten aculbrt. Franfint a. We, bei (ib). (Egenolif $[1546]$.

Onomatologia chimiea jebe fielo.

Onomatologia medico-practica. nag. non ‥ 9. Meber. Yumbera $17-3-8$ -

Epit Miortin, Buf nou ber Deutiden qoeteres. 1624. 5isg. nout Bramte = ND 1.

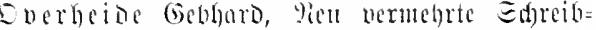

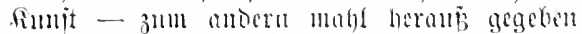
- [Braminguncig] 16:-

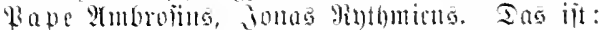
Ier Prophet iomas nim. glagoefura 160..

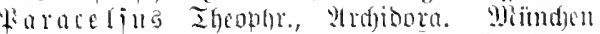

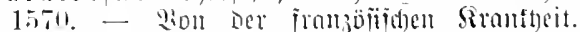
Yitruberg 1530. - Estreiben non ben frant= beiten, io bie Bermunit berauber. 0. E. 156 i.

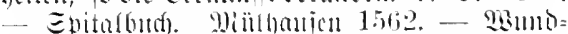

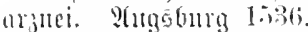

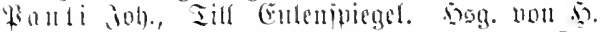

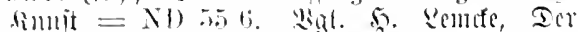
bo. (Entenipicgel. (\$30m 1908.)

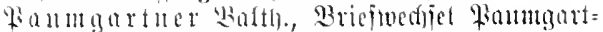

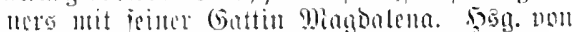
Etrimbaricu $=\mathrm{I}$. $20 . \mathrm{t}$.

Lenther ioh. Fr, texicon Architectonicm

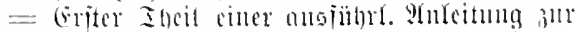
biirgertigfen Ban=dimnt. Q4ngourg 174t.

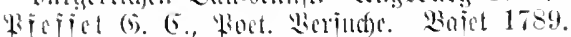

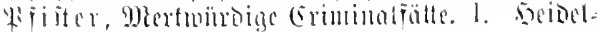
ber? IS14.

4h

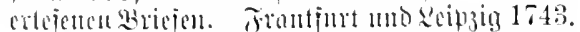

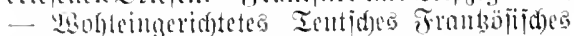

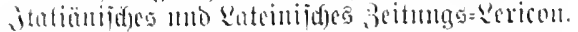
Froutiut mol Qcinjig 1743.

出

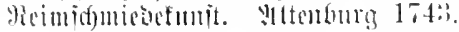


l'hilo de conversationihus, Venas liebutee.

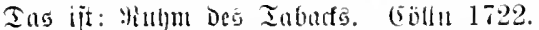

Wicanoer, Eruit=Edferbanite und Enturiade (5coid)te. Ecinzig 172\%. - Tutidje E(f)au= Epiele. Berlin, Frantiurt mo jumburg 1726 .

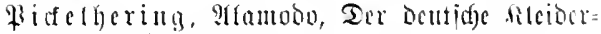
2iie. Seipia 16 : :

Pipits. beim $1 \times 39$.

Hodagra Eentimus, Ier profitable Hpotbefer:

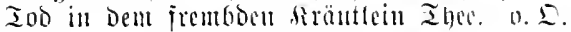
1721 .

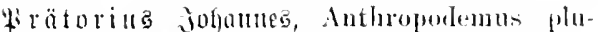

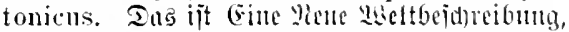
Iei! I HUD II, Tnil III Unter D. Iite! Welt= bej(f)reibutg 2. Teil, 9Jugbebura 166ti: (Ein grimblidger Serid)t nom Equaditgen fuben-2ieit. [1665.]

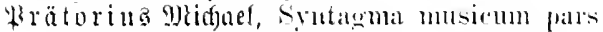
1-III. 1tiIt-1619.

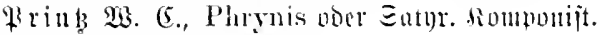
Eucotinburg 16\%t;

Rrivatus, Remigii Daemonolatria Son lI holben und Banbergeritern. Frunfurt 1:8!.

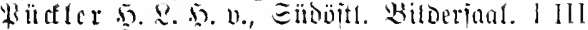
Etuttgart 1840 . - Bricie cines Meritorbenen. l III IV. Etuttgart 18:31. - Morlester Weltgang non Eemifaijo. $1-111$. Etutt= gart 1835 .

Euad Diatt). [u. Rinfelfad)], Enchiristion rosmographicum. (5ollı a. Ha. (160t) 159t.

diabcuer Gottl. Willo., Eatiren. Franfurt tulo Reipziu 1759.

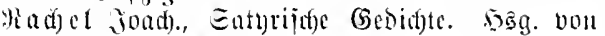
Ireidjer $=$ ND $200-202$.

Ra a ler, jielse (stcim.

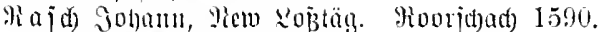
- Vien futender 1:i90.

Ratio Status oner Der isiger Mllamodifieren= Der redter Etantas= Senid. o. E. 166ะ.

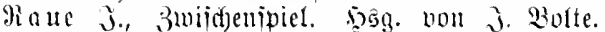

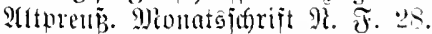

Mecueil, von allerland (Evllectancia.

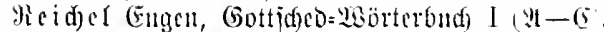
Berliu 1909.

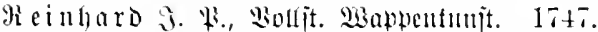

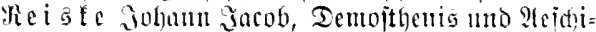
nes dieben verdentid)t. Semgo. I II. 1764:5.

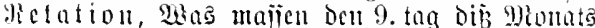

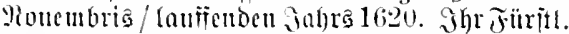
Dur(f)t. Soetsog Mlarintíian in Banern / Die Rönigtide saumtitatt Prog in Büheim wiocrum ervbert. 1620 .

Mens berger Mit., Sitronomia Icutid. Angipurg 1569.

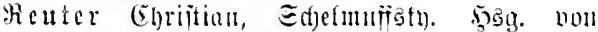
Ed)ullerna = ND $; 7-59$.

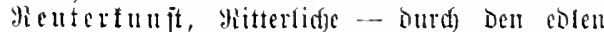

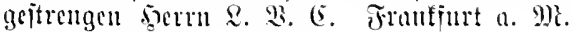
1584.

dihoden (E. v., Irobfoni. 188:.

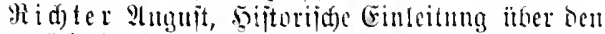
Eximinal Proces. Franffurt mo scinzig 1738. 1748

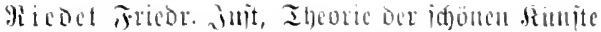

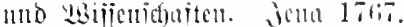

Sticderer, Eptegel der mabren Mibetorit. Fren= burg i. 岁. 149 ?

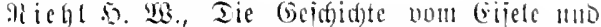
Beijete. Frantiut a. 9gt. 14an.

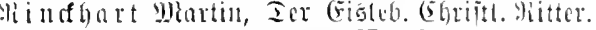

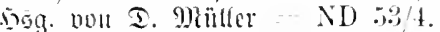

Ring Triebr. Eominicus, Ropjtod in fint:

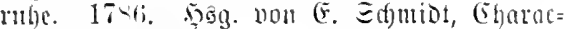
terititen 1160 年.

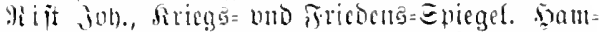

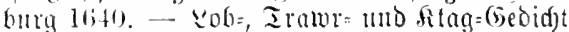
ïber Mkatin Eniben. Dounburg 1640. Inuter bi. Armatus: Sictum der colen Sentided somptimade. Somburg 1642.

Mitteripiel, wann but vatb welder briadjen

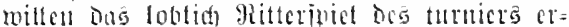

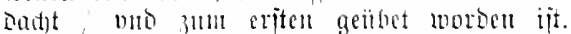
[?uggburg 1:is.

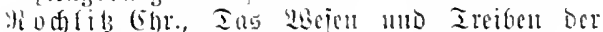
Gunter, Sicbe mnt Betrïger Ientjdylands. Seipsig 1846.

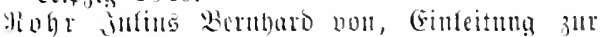
Etaatšnlugheit. Reipjig 17is. - Eintcitum!

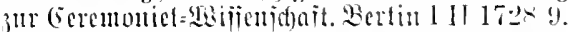

liot Eimon, (Fin teutioger Dictionarins $15 \pi 1$.

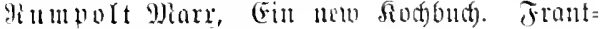
iutt a. Mr. 1587.

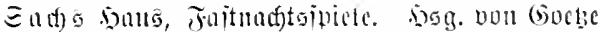
$=$ ND $267,31 / 2,39 / 40,4.33,512,60 / 1$, (ii) $/ 4$. Fabetn und Edtuänt. 5sg. von Gocke = N1) 1111-17, 126-34, 164-69, $193-!) !$

Eammlunq vermingter E(fripten zu Leïurde= rung Der iffönen subijenjdaiten und ber jrenen

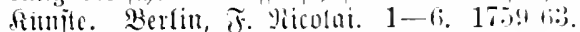

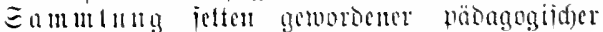
Edriften des 16. mo 17. ihs. \$og. nou 2tug. Sorrad, juäter nou jof. 9lïtler. 3idon= part 1079 fi.

Eanders Danic1, Frembuörterbud. Seipsia $1 \lesssim 71$.

Eandrub Zazarns, Delitiae historicae et

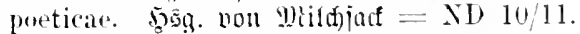

Sattler job. Mi., Ieutide Erthographey umb Whrajelogen. Bajel 1607.

Sd) anipicte ber englifacn fiombianten. Sogg. voll (Ercizentad) $=$ NL 23 .

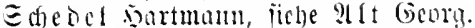

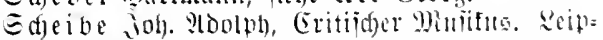
3ig 1745 .

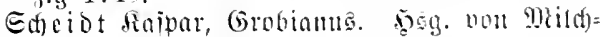
iad $=$ ND $34 \%$

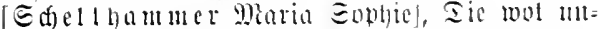

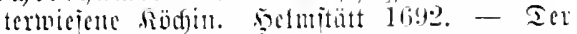

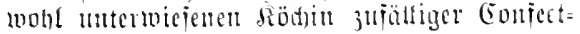
Tiid. Brantaiducia 1700.

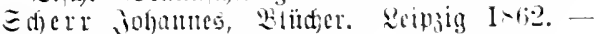
Farrago. Seipzig $1=70$.

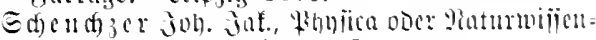
id)ait. I II. Bürid) 1711.

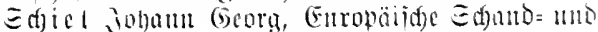
Zuiter=(Entonic. Iltm 1674 .

Ed)ifofned)t Eendelin, Harmonia in forta- 
litiis construendis. Aefendendin. ?tten Etet= tiut 16.52 .

Edifr Sobum somur. In Ientiden Exratt (El)ren=firanz. Etrablutg 1641.

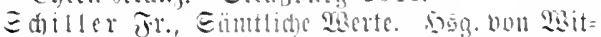
fomsti mo Gimtrer. ¿́cipzig, selife. -

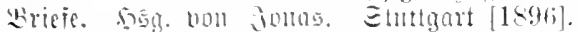

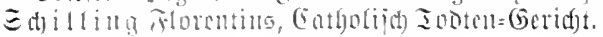
坚ien 16tis.

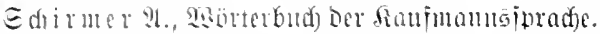
Etraibure 1911. - Nortigab Der Mathe=

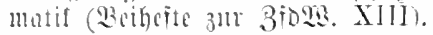

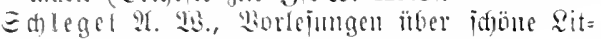

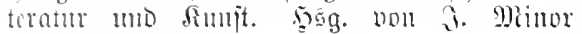
DL, $17-19$.

E(t) leget Jr. D., Putcinto 1799 .

Echlegel joh. (E., Preitheth. mo Dramatmeg.

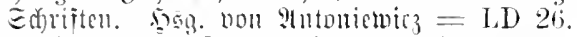

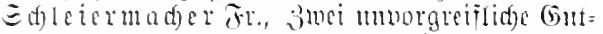

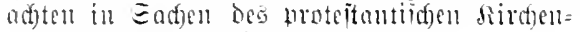

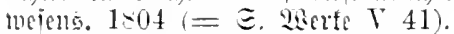

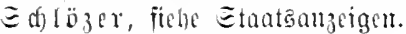

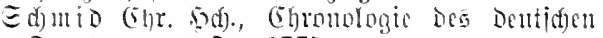
Iheaterg. D. E. 1775.

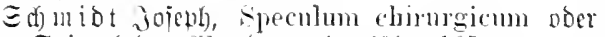

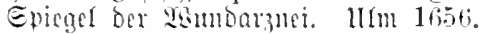

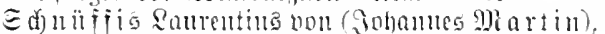
Jirantijues Jlötrein. 16-2. - Futcr ither Die mirantige Nantitrommet. 1699.

Ed) butaid) (Enr. E. n., Iis quuze sithetif in

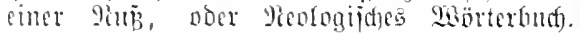
Б5. non 21. Röiter $=$ I,D $70-81$.

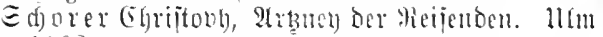
1663 .

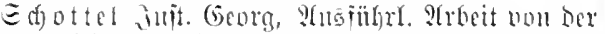

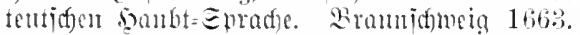

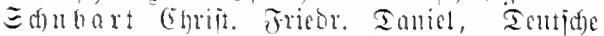

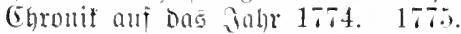

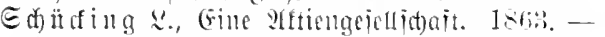

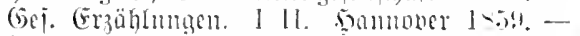
Frament tho thatiet. seipzig 1865.

Ed)uloronumg, (staudfiche. Galle 1699.

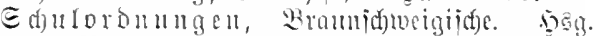
bon 5. fordeney in Den Monumenta Germ. Paed. 1 min $x$.

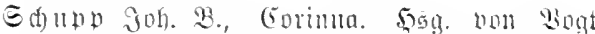

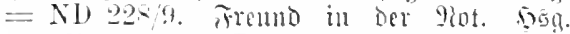
non Prame = ND:. Etreitidntiften. I 11 .

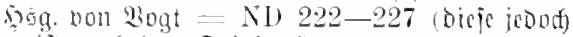
meitt uad) Den Eriginaforuden).

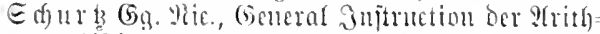

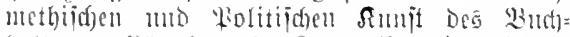

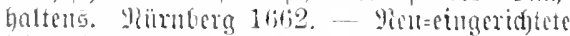
Dhaterial=fammet. Viumberg 16:2. - Viuls=

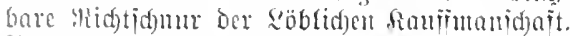
onturuberg 16995.

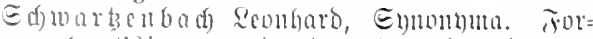

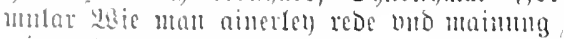
mit andern mels morten . . Bierliog roben

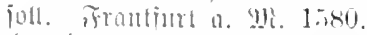

Edfueigbart, l'undura Vlatatis. 0. E. 1617.

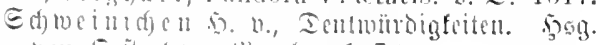
bou Eefterter). Wreolan 1,- -

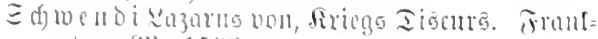
itt $11.92 .159 \%$
Ed) menter. Iantel, Deliciate I'hsico-yathe-

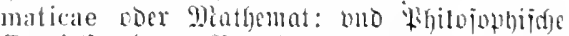
Erquicftumben. 9lünberg 1636. - Geometriae practicae 'Tractatus 1-111. [1618.]

Seriptores rerum Silesiacarmm oder Eamm-

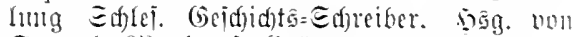
Etenzel, DMarfurai, Grünbagen 11. a.

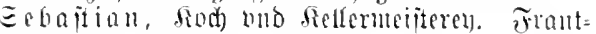
furt a. 29t. 1581.

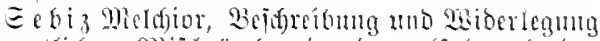

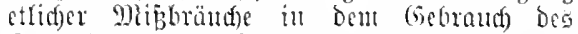
Eamorbumens. Etraburg 1647. - Eiben

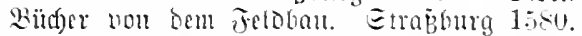

Eeffendorif Esit Subw. n., Egriztentuat. I II. 168.5 - Icutid)er Fitujenlitant. [1656.]

Ecifer Fr., Tie Eutmidtung Der"Dentiden full= tur in Epiegel deg Dentiden Qebunorta $111 \mathrm{~K}$. sinalle 1910.1912.

Eclbamer (Ghritoph, Tuba Analogica [Eomn=

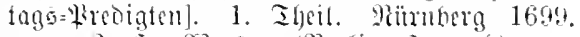

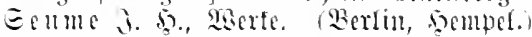

Eleidan gob). Buei Reber an Saijer mo

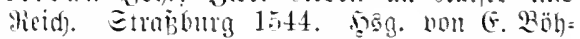
met $=\mathrm{L}, \mathrm{V} 145$.

Eommer iot., Emplastrum Comelianum soeif= nflajter anf bie 9ielandjolite wumben mob tinculensitid). o E. 1609. - Ethograplia mundi burd) ioh. Olorinum Variscum. 1-111. $160 \%$.

En tur an junge fituitter. DBien 1768. - Non Dem weroiente bea Sortraitmalerg. Sein 1768 .

Epangenberg Guriaens, whon der Minfica. 1502 .

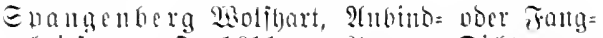
briefs. ․ E. 1611. - 9tuşgem. Iidftumgen. Sogg. nou (E. Martin, Eljäij. Zitteratur= Ient= mülor 115

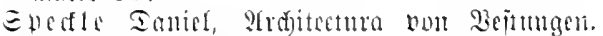
Etrajburg 15-9.

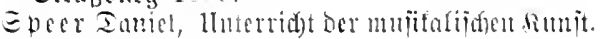
116 m 16- -

Eperander (T. (5tabou), A la Mrobe=Entad Dex Ientidu EDer compendientes sand Eerienn. D̈umberg 17.27.

Epiefhagen Frturta, in Reih mo Gried.

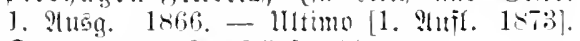

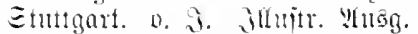

Enohu jafon, Iren Deme Emremic Eractütgen nou Den Irance Eaje, Eimcijiden The, mo ber Gguedata [ïberi. nom I. 4!. 2)?. (5.] WHDijitin 16is.

Enrad)erostber, Ier martig Ientiffer.

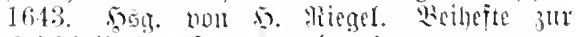

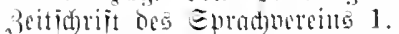

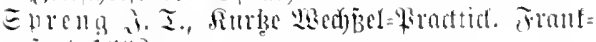
intet 16 itio.

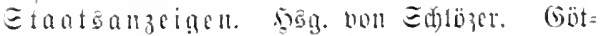
tingen 17-2 ï.

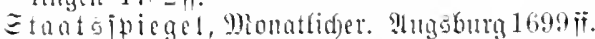

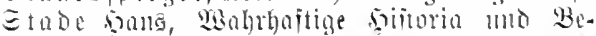

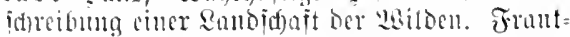

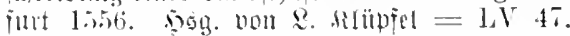

Etatuten wato Bejormationen ber llnwerjität 


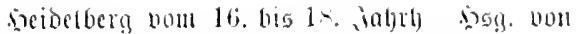
ㄴ. Ilyorbefe. źeipziç 1891.

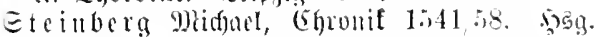
nu Th. Edönform in ben Seriptor. rer. Sil. XI 120 ii.

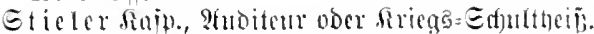
Yüunberg 1683. - 3eitunge suit und 2kut.

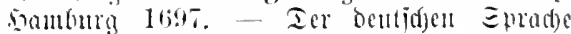
Etanmbanm mb Fortmadjo. 1691.

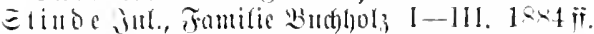
- Iie SGanoertrmne. Bertin $1>-6$.

Etoppe Ianiel, Erite Eammlum bou Ient=

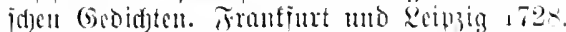

Der Parmaj; in Eätfler. Frantfurt mo Eeripzig 1735.

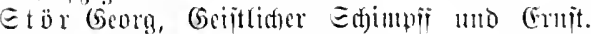
iena 160$)^{\circ}$.

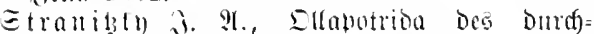

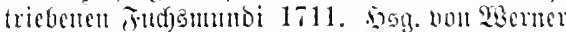
= Misner Veubruefe X.

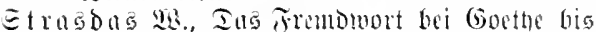

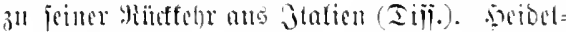
berg 1907.

Etruenjes, 2tnjungsgrüno oer Strtillerie. 1760.

Euljer ioham Georu, Mllgemeine Sheorie ber joünen fïujte. 1 II. Reipzig $1771-17 \% 1$.

Eurins Eanrenting, fiebe Fabricing beimrich.

Iabermanoutanlag Jacob Theodor, Meub Arcuterbud. [Eriter Ibril.] Franlfurt a.9]. 1588 .

Ientel, 9ionatl. Llnterrebungen ciniger guter Trembe non allerhand Büd)ern. 1689 ij.

Il) muntlefre. Solle 1699. — Enitiger unt (Fruit= haifter Sontatsgejpräcte Eriter Ieil. Salle

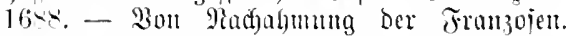
bog. non Eaner $=$ LD $: 1$.

Il) unmenobrjide Familiendronif. 1.541 it. () siles. XI.

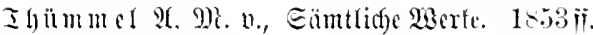
(Rvipzig, Göjúcn.)

Irifter Balentin, (Enriojes Reit= Jugo= Ted)t= Ianb= ooer Ritter=erercitien Rericon. Reip= zitg 17.42 .

Itberlingen: Bberlingijose Belägermug. Eon= jtull an Bobenjee 1634 .

llfid) 3. 5. F., Pragmatif(t)e (Befodidyte Der

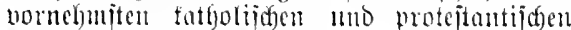
(5)muafien mo Ed)ulen in Entiffiland. 1. 노. veipzig 1780 .

lluger Frieberife Gelene uno Etuts joh. (Ermit,

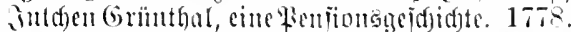

lluiberiallerifon. Seipig, Benler. 17:32 ij.

llnterreoung, llnlängit gepfogene luter=

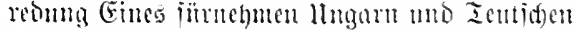
Eavalliers - Durde ben Berbecten. im jabr (Shrijti 1664 .

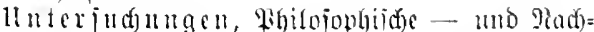
ridften bou cinigen Riebhobern ore lacisheit. ?cipsig 1744.

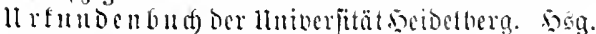
nou (5. Minfelmam. 1. Tio. llifunoen. netoelberg 1886.
Wadian, Lom alten mo menen Goth, Gtanben nito. S5g. non fiüd $=$ NI) 142\%.

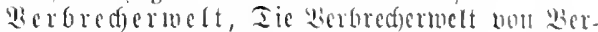
lin. Dertin $18-6$.

Wierthaler Tr. (Eh). Emtumi ber Edylerzichungsurfunde. Ealzburg 1794.

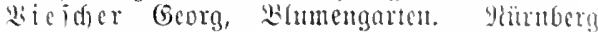
16.4 .

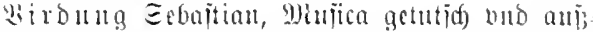
gezogen. D. 5. U. i. [unter Der Morr. 1511].

Bol of v. Deertheim neimrid), (Ein allzeit iertiget

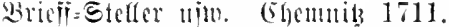

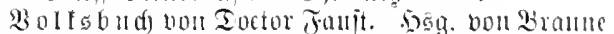
$=\mathrm{NH} \pi \mathrm{T}$.

SBa denlu - Rouge et Noir. 1865. - Was die Etrajpe verid)lingt. $18 \times 2$.

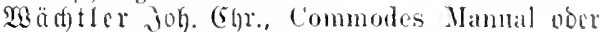

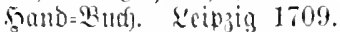

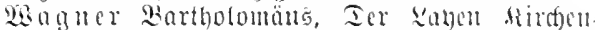
ipiegel. Getrudt im (5ottogatij ju Ihterbounten in Jahr 1594. [Qorrebe unter3. 15.8.]

Tgagner S. R., Iic Rindermötoerin. S5g. nou (Frid) Exmiot = DI, 1:3. - Dottaire am

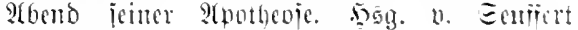
$=\mathrm{DL}, 2$.

Taganer iobaun Iobias, Entwuii cintr Eol= Daten-Bibliothet. seipzig 1724.

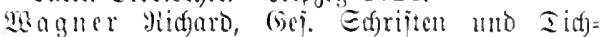
tmingen.

Ta aI Muton, Bagatelten. I II. 17E6 7. Simig.

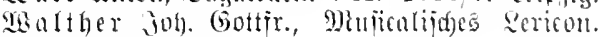
Qripzig 1732 .

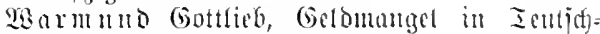
land. Baturenth 1664.

Theigand Fr. R. (5., Tenticfes Dërterbutc). $\therefore$ Pufl., hearbeitet non R. w. Paboer, So. Sirt, f. Siant. Sisg. von S. Sirt. Giesen 190910 .

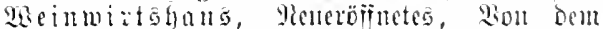
Sutore bes Tarren=falenders. Jut iabre 1719.

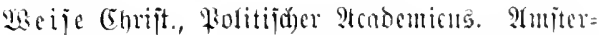
ban 168\%. - Mäter Tejtument o. E. 16-5. - Bertrante Geiprädbe, wie der gelienten Jugend im Informationsmerle ... miodste ge= Dientet jein. Qeipzig 1697. - Iie Drei ärgiten Evomaren in ber ganzen 28ett. Dogy. non Brame = ND 12/14. - Tie orei tliigiten Pente. D. E. 1675.

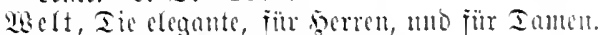
fartsmbe 1-31/:2.

Merner $\mathfrak{X}$. id)reibutm oer veridt. Gebirgourten. Iresden 1787.

2acitentieder $R .$, In Irum in Drenen

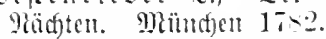

Midumann II. Ter Intitrititus. I II. Sü= bed $176-69$.

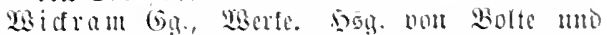

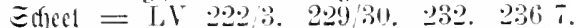

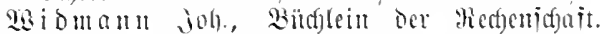
Liporzeim 1.008.

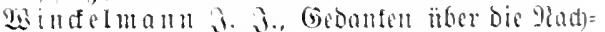
ahum Der grieft. Werte in Der Deaferei uno

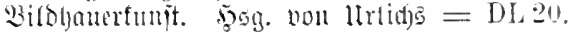




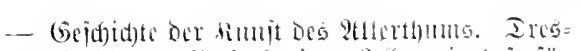

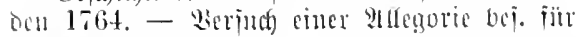
Die fiunit. 1766 .

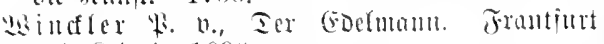
unD Seipzig 1696.

lsit o. Dörring iobannes, Fragntente ans meinem Rebon mon meiner 3rit. séripzig. $11 \times 30.111827$. III 1808.

Whotoer Eintum, Iurtenbüd)!ein. 1558.

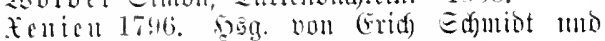
Bernt). Emphan. Weimar 149\%.

3 actariä $\pi$. 2R., Woetijue Edriften. Reut=

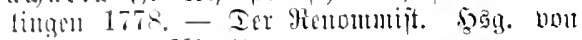
Ilimater = NL 49 .

3eder, itue lluberjalteritom. 3rioler joh. (b., Eieben böje (beiter. (50) moved [ca. 1700]. D. Э.

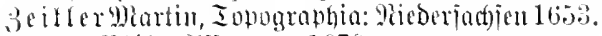
3 ejen Pinil., 9ijesat. 1670.

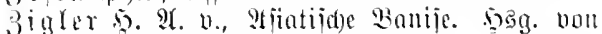
Bobertag = NL.:37 (Had) Der 24âg. vou 1707: verghteden mude bie erite 2hasg. non 1689 , vorbanden in Bonn: Fa 582).

3 i mue r i j the Egronif. Sogg. non Barat. $21-V I$. Zittula $a$ joh). Fricor., Medicina forensis h.e. Responsa Facultatis Medicae Lipsiensis. Frti. a. 917. 1706 .

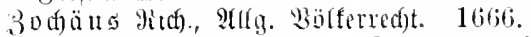

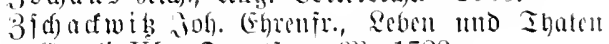
Garoli VI. Franti. a. Wi. 1723. 


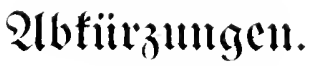

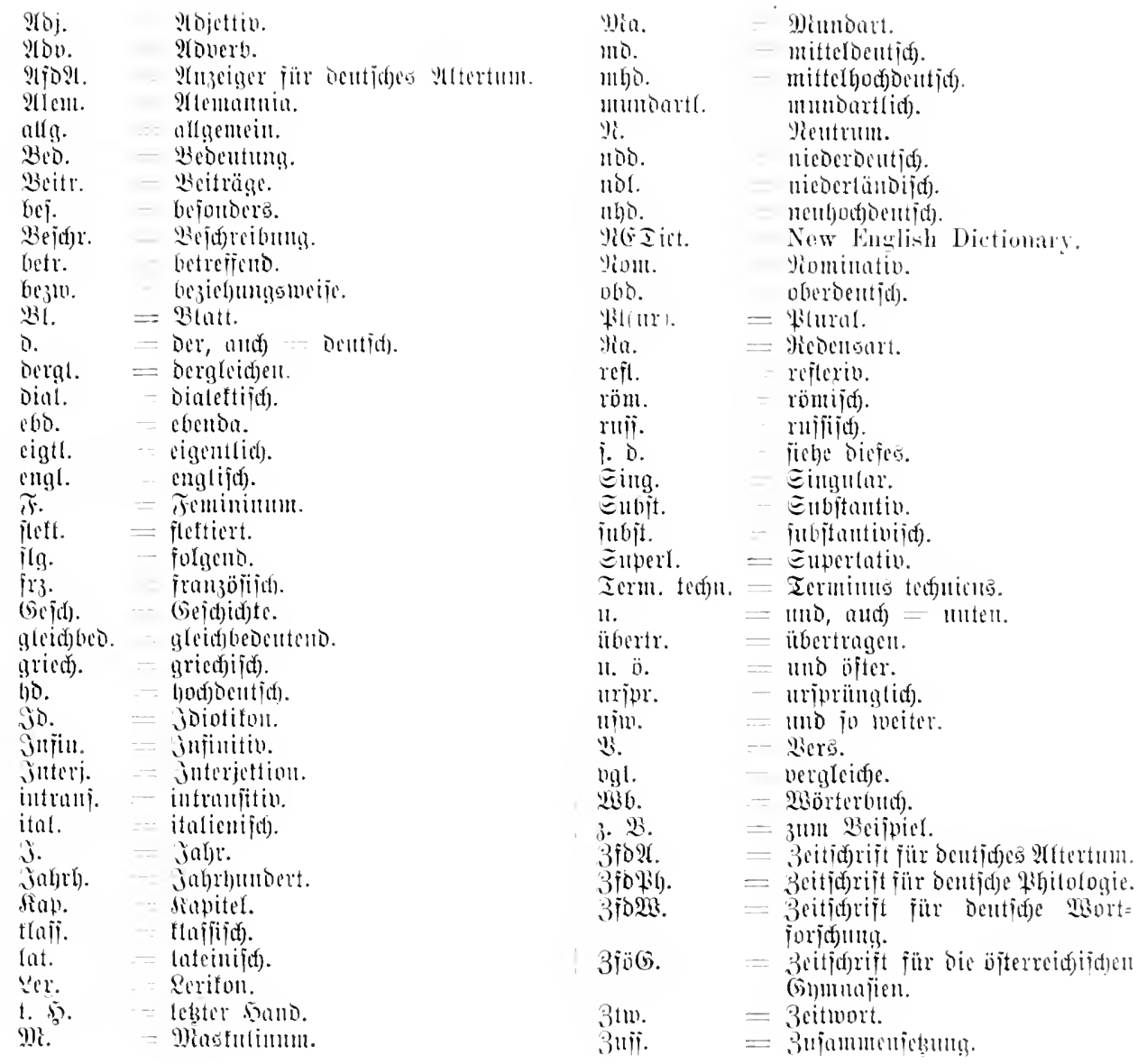


$\mathfrak{*}$.

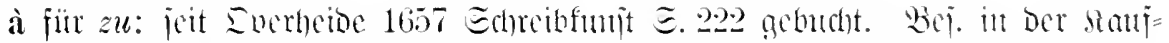

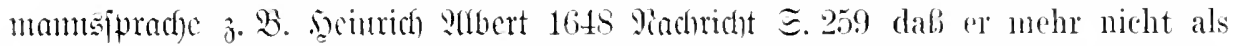
Acht Exemplarien mit dahin gebracht, welche or von einem Buchdruckergesellem

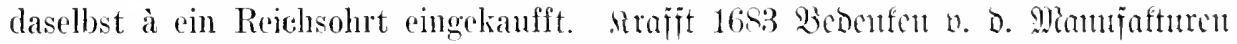
ङ. 239 an Wolle funfftzig Stein à drey Reichs-Thaler - E. 248 die Strimpffe zu

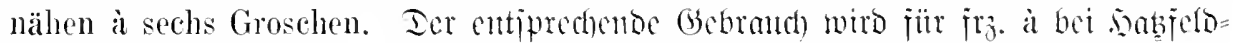

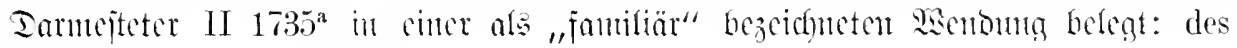
oranges à trois sous pièce.

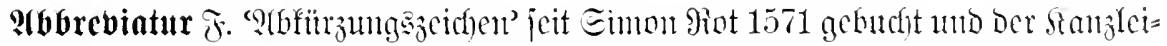

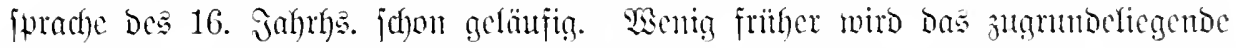
abbreviatura aufgefoumten fein, Das bem \&at. uns Milat. noch fremto ijt und viel=

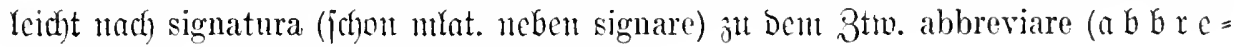
vi i e re $\|$ 15. Jafirf.) gebirset tworden ijt.

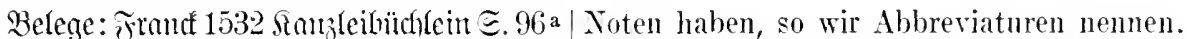
der diüfel vnd abbreviaturn oder verliürtzun- Becher 1668 Methobus bibncticn $\Xi$. $7^{\mathrm{b}}$.

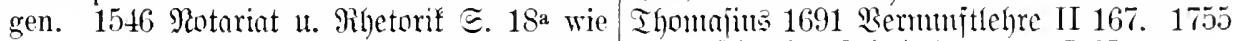
dann wir anch noch inn vnserm Teutschen vil 33 ranuj[chweig. Edfulorbmungen I 351.

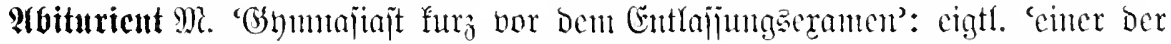

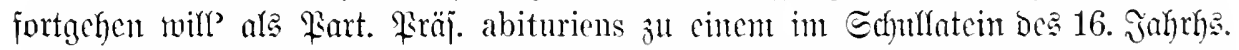

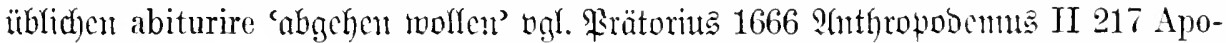
phthegma Anno 1652. zu Halle im Gymnasio auff abiturientem und valedicentem Hn. N. Hartsteinen.

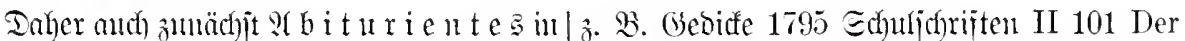

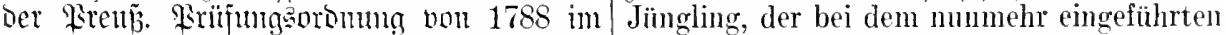

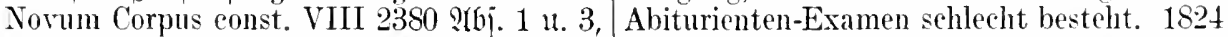
aber S. 2381 9thj. 5 Nach Maßgabe der sowohl schriftlichen als mïndlichen Prïfung wird nun für jeden Abiturienten ein Zeugniß entweder der Reife oder Unreife ausgefertigt. 1824 Bramuj(d). Edhulorommgen II 570 die prüfung der abiturienten ist zwiefach. Fon= tane 1883 Brieje II 70 daß dem regelrechten Preuben, „Abiturient und Reserveoffizier", der Simn dafür verloren gegangen ist. $\mathfrak{Q} \mathfrak{b}$ iturieut ijt erit bei Campe 1813 Fremomb. $\subseteq .74^{\mathrm{b}}$ aus Der, Epradhe Der Edhulen unto spodjed fulen" gebudit.

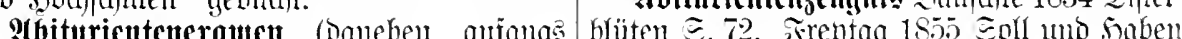
häufiger Maturitätzexame it

(⿻) $\mathfrak{l}_{3}$, fremomörterbu(t). 


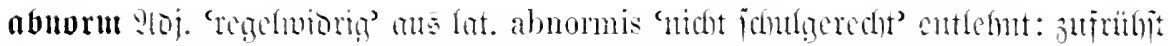

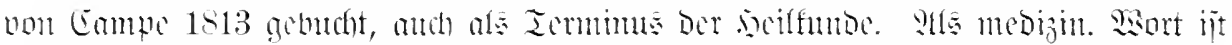

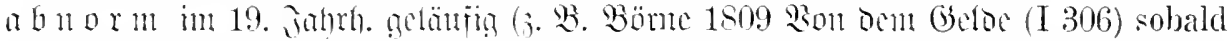

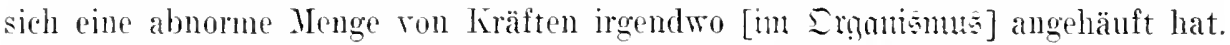
Futh 1838 Genimemeichung $\Xi$. 2. Änsserlich war nichts Abnormes zu bemerken)

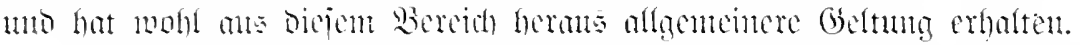

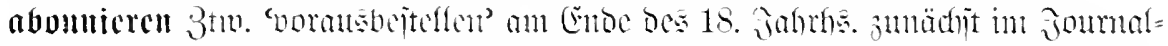

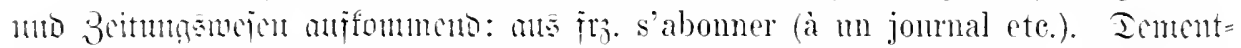

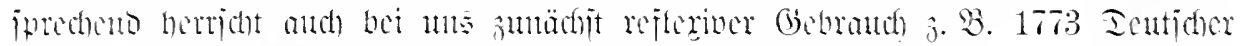
Merfur I sit. Il ${ }^{b}$ Iran kan sich zu allen Zeiten bey den Postämtern . . . oder bey dem Herausgeber selbst abomieren. Iod) and) juon bei Boie 1733 an Bitrger (I 109) Wollen Sie ordentlich mit abonniren?

Qlovitument $\Re .=i r_{3}$. abomnement: jeit Dent 18. juhnth. übtidh

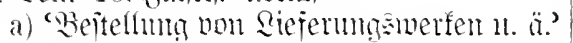
3. B. Echiffer 1796 Brieje 92 ron dem Erfolg des nächsten Abonnement scheint das fernere Schicksal der Horen abzunhïngent.

b) beim Sheater os. Bo. Echiller 1782 an Ialberg (I T-2) den Gewinnst der ersten Vor:tellung meine: Fiesko mit aufgehobenem Abomnement. Sifflumb 1798 Ihentral. \&anf= bafin $\cong 114.115$.

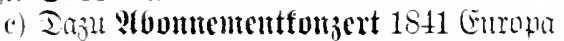

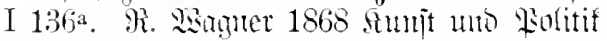
(VIII 143) in den sogenannten Abomementkonzerten.

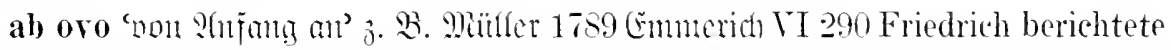
also, indem er ab ono anfieng, daß sein junger Herr gar zu herzensgut sey. Pïffler 1835 Eemulaijo I 19 Doch will ich als guter Dentscher ab ovo begimnen. Epriats=

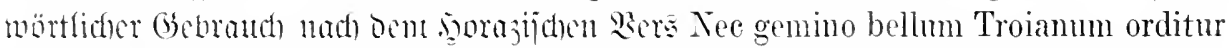

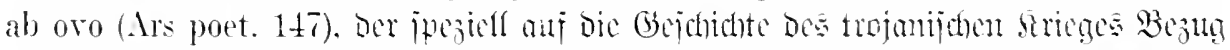

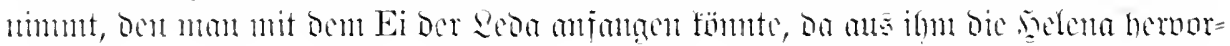
ģinț.

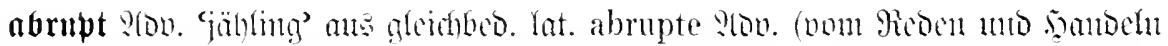
gebraucht). Befege: Crrmer 17i3 an Bürger (I 155) Dem Dialog. mit Erzählung abrupt verkniipft, kamnst Du Dir doch auch nicht zueignen. Wiicffer 1840 Bifder= jiral I 226 des albernen Herm von Müller Antrag in so abrupter Weise [iit] sonderbar. Tontme 1897 Eted)(in $\Xi .83$ bis Dubslar, ziemlich abrupt, iln fragte.

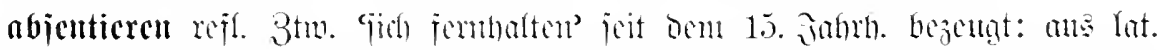

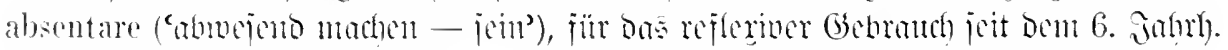
beleat iit.

Belege: 1491 Iübinger lutumoen $\Xi .85$ ron Geroltzeck zn noch ainer gröser verOh aber einer VB redlicher rwatch sich ain achtung uf. Caroha 1614 Fefation lir. $14^{\mathrm{d}}$. kurtz zat absentieren wurt. derselb sol Mengering 1633 Eieqüfrome $\Xi .5$. Whenfart

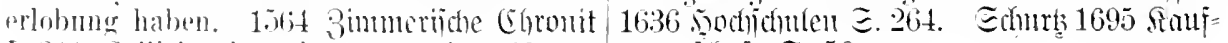
I 311 Sollich absentiren nam her Hamms mamidaft 5.56. 


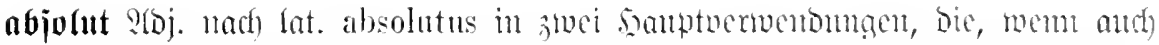

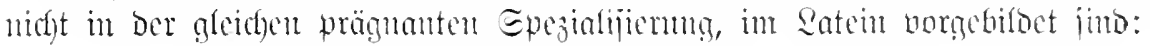

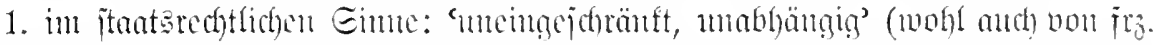
absolu beciuffujt): „Absolutum principem apello eum, qui legum armorumque dominus est, sive iure id, sive inuria habeat: Francišsu Patritius, De Ifistoria.

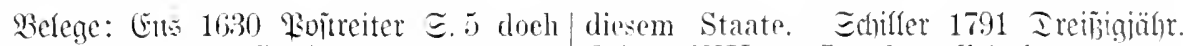
soll für diBmal die Regierung so wol die firteg (VIII fj) In dem Zeitalter, woron Justitiam, als Polizey belangend, in hohen jetzt die Rede ist, regierte in Europa kein rnd nidern Emptern, absolut rund nach Fïrst so absolut, um ïber den guten Willen ihrem bclieben rersehen werden. Seibuiz seiner Interthanen hinweggesetzt zu sein, 1670 serfe I 158 ein absohuter Monarch - wenn er seine politischen Entwïrfe verauch 179. Berdenmener 1712 Shtiquaring folgte.

ङ.378 er ist aber kein absoluter Herr ron

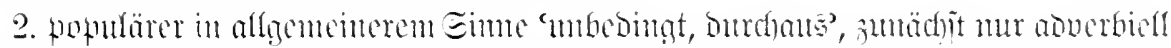

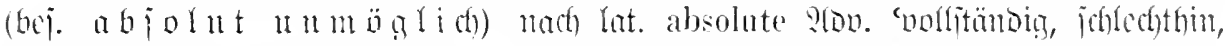

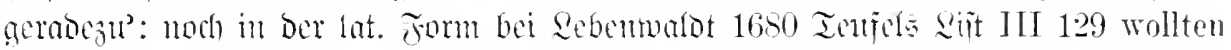
absolute den Glaubeu benehmen. Edurts 1695 Sampumaminaft $\Xi .56$ das JaWrort, welches er zur Bezahlung absolute und freywillig ron sich gegeben.

Belege: 1667 Berifgt an bie Seips. erst nach 20 Jahren Imitationen .... machen.

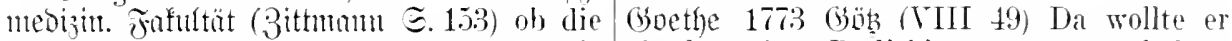
bey dem Entleibten befundene Wunde absolut den Berlichingen rertagt haben. absolut vor tödlichen zu halten sey - im Echiller 1781 gabale un Qiebe I 2 Ich geb

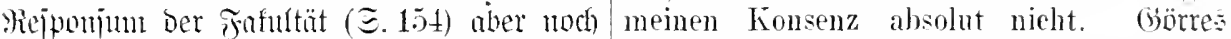

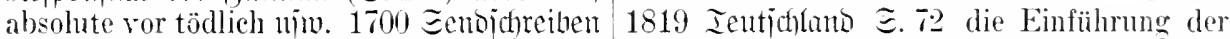
an bern $\mathfrak{B} \ldots$ E... 47 absolut unmöglich. neuen Steuem als absolut unmöglich zu

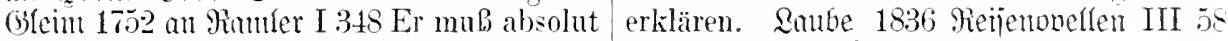
noch ein bisgen Geduld haben. berber es ist aber absolut unmöglich.

1767 Ientiche Ritteratur (I 308) und absolut

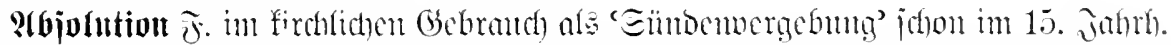

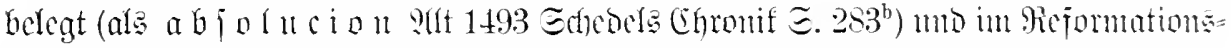
zeitalter jehr geläufig (vgl. Mallycrbe, Diij. phil. Freiburg 1906 ङ. 37. 61):

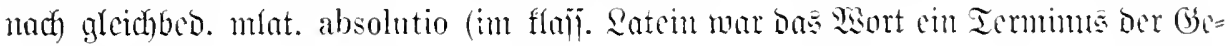
richtsiprache).

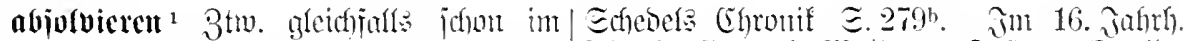

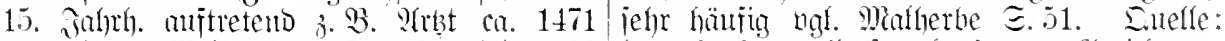

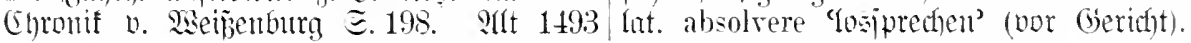

abjolvieren ${ }^{2}$ 3tw. 'erledigen' nach) lat. absolvere 'zu Enbe bringen, nollemben'

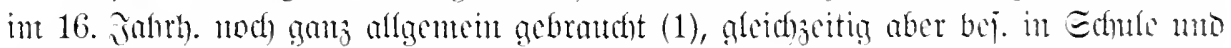

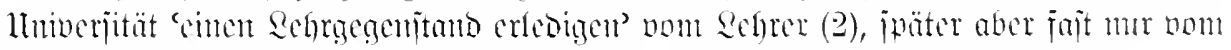
Eefüler "ein Pienimm abjolvieren", merbings bej. "Die Edhule abjotvicrm" (3).

Belege: 1. Futhoberger 1534 Iinleftif absolviert, libellum Ciceronis de amicitia હ. $30^{\mathrm{b}}$ ains reglichen fürschlags natur nnd lesen - 1599 ebo. I 162 In Virgilio [jolf] aigenschafft nach bemelten fragstucken er- ein buch alle halbe jar absolvirt werden.

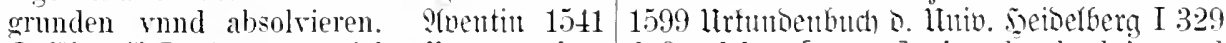
I. Chronif(I37-2) demes nicht aller teutschen daß solches [corpus] niemals absolvirt und könig historien beschleusset und absolviret. auch die allervleiBigsten professores in rielen

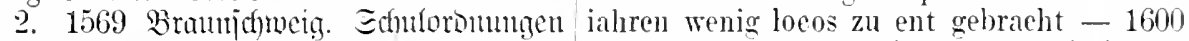
II 37 die praeceptores sollen die erst comoe- ebo. I 342 dab er in den zwei iahren diam Terentii, Andriam, und so solche doctrinam elementorm etc. absolviert. 
3. Bed)er 1668 Mietfodus Dionctica| holet der Lehrer. Mäller 1787 (Enmmerid 31. $\delta 4^{\text {a }}$ ich studirte die Theology, als ich III 136 ein bestimmtes Pensum im Wollediese absolvirt, die Mathesin. 9fbroham spinnen zı absolvireu. Ripitz 1839 Frag= 1688 Juba I 506 Villegrisus ist so fleissig mente $\Xi .80$ Man hat das Gymnasiun vnd ruverdrossen gewest, daß er seine absolvirt und tritt in die philosophischen Studia mit sonderem Lob absolvirt. Bohr Studien ein. Bobenjteot 1888 Crimerumgen

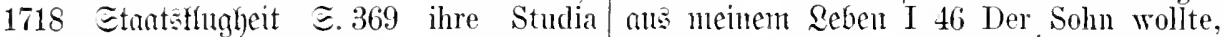
mit Reputation absolviren. 1756 Brann= nachdem er das Gymnasium absolviert, idjueig. Edfulorbmungen II 429 So oft ein Officier werden. eapitel oder pensum absolviret ist, wieder-

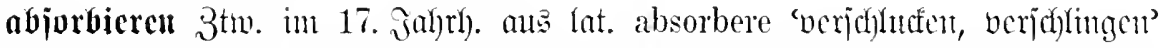

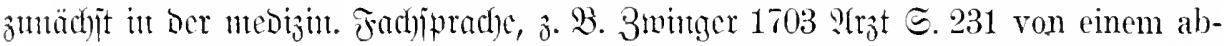
sorbierenden Pulver, so die sauren und rauhen Feuchtigkeiten des Geblüts verschlucken mag, eine dosin eimmehmen. 93 sifpacf 1732 fiux $\subseteq .79$ die aubdünstung des leibs befördere mit denen absorbirenden pulvern. 1783 Dnomatologia med. I 11 Absorbentia. Absorbirende Mittel. Erit int 1S. Jahrt). aflgententer vermenbet: Edfiller 1795 Brtefe IV 116 weil meine jetzigen Arbeiten mich ganz absorbieren. Gocthe 1817 Briefe (XXYIII 225) Weil jene Beschäftigung meine ganze Zeit absorbirt.

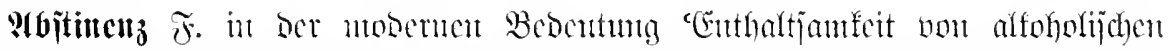

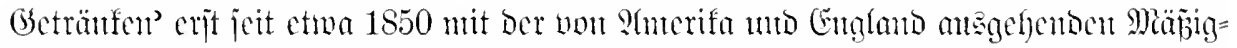
feitsbemegung befant gemorocu: engl. (total) abstinence. जntcjen wat $\mathfrak{Q} b=$

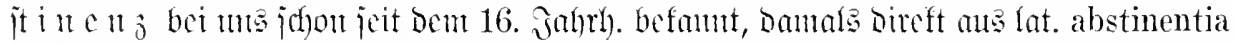

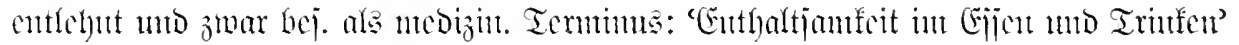
(1), Danchen in firchlidfon (Scbraud): ‘Faiten' (2).

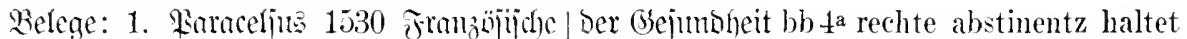
Sronfheit $\mathfrak{S}_{2}{ }^{\mathrm{b}}$ das die Correction nit anderst in der speiß rnd tranck - nuch $\subseteq .30^{\mathrm{b}}$. lauth, damn die abstinentz zu ordnenn - 2. Emjer 1520 Etreitid)r. I 108 mit ¿2a So halten $\mathrm{yr}$ ein strenge abstinentz. gebothen der abstinentz. 5. v. Aettenbad)

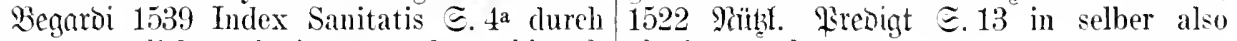
eyn nützliche abstinentz oder abbruch abstinentz thun.

essens vind trinckens. Shif 1544 Eniegel

abitrabicren 3tm. nach Den lat. abstrahere Der philojoplijeden Terminologic

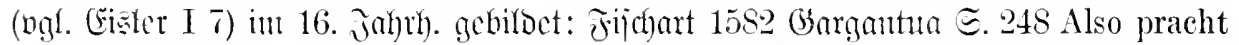
er Heimduckisch mit seim Supponiren vnnd abstrahiren den Plunder heim [uact) ber Dijuntationsizenc].

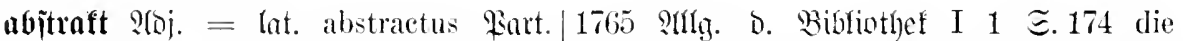

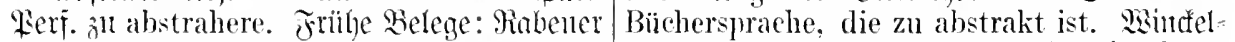
1759 Eatiren I 57 Spuren einer abstracten man 1766 Berjud einer Stlegorie $\Xi .19$ Gelelırsamkeit. Iujch 1765 Shrieje II 337 abstracte Bilder.

allen abstracten Gedanken Leben zu geben.

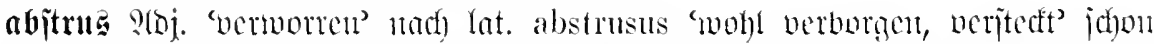
bei sirjid 1662 Sirchere Mujurgia $\Xi 360$ was Anaxagoras abstrus vnd verborgen andentet. Epäter allgenteiter 'Dunfel, abjonberlich'; häufig bei Goethe.

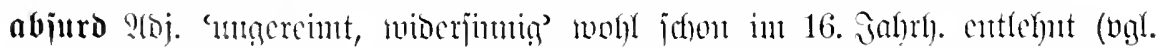

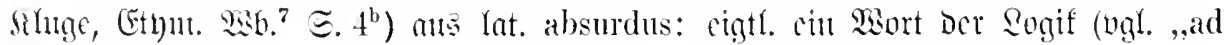
alosurdum fïfrent")? 


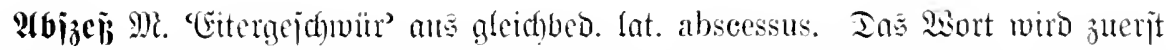
von seuberger 1806 verzeidfuet, ijt aber vorber jefon in medizin. Fadjliteratur belegt;

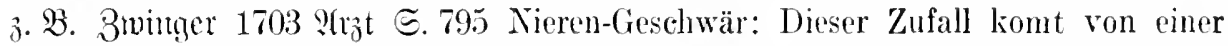

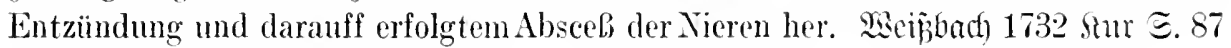
wenn der abscef, aufbricht.

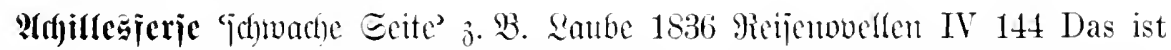
die schwächste Seite Berlins, seine Achillesferse. Epridywörtficher (bebrauth nad)

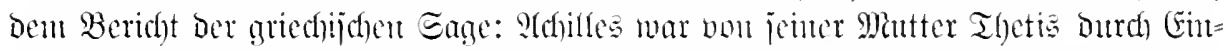

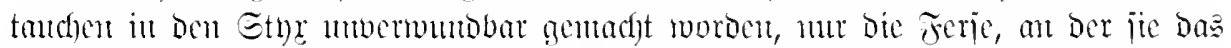

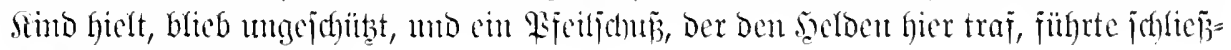
(ich) jeinen Tod herbei.

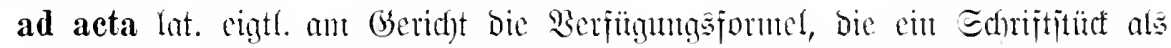

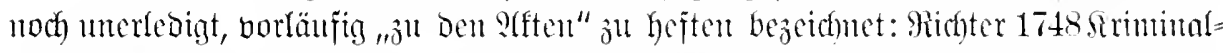
prozen (Addit.) E. 38 wovon umständliche Yachricht ad Acta gebracht werden

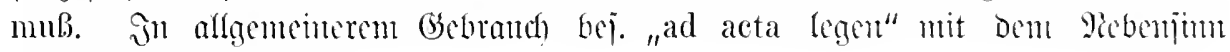
'imberiucfict)tigt lajicu?'.

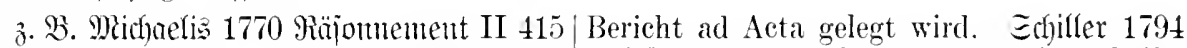
an andern Orten ist dis Vorschlagen eine Brieje IV 31 ich habe von jedem eine schriftblose Ceremonie, auf die niemals rom Hofe liche Einwilligung erhalten, die ich ad Acta einige Rücksicht genommen, sondern der gelegt habe - 1796 ebo. V 131.

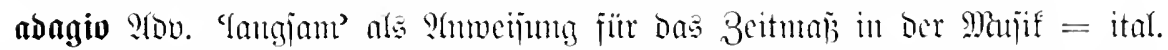

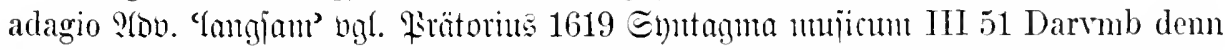
gar ein nötig inventum, daß bißweilen die Vocabula von den Wälschen adagio presto h. e. tardè, Velociter in den Stimmen darbey notiret vnd vnterzeichnet werden. Daum auch bei Epeer 1687 Mnterr. v. D. mujifal. Sumit ङ. 39 Adagio heisst langsam.

Yoagio $\Re$. ceil in Iongjamem Tempo bare Bewegungen in den Melodien anzeigen

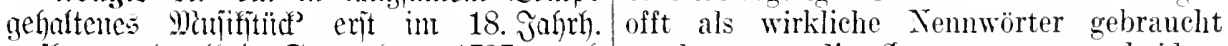
auffonmento (bei Enernoner 17:27 noch) werden, nm die Sätze zu unterscheiden.

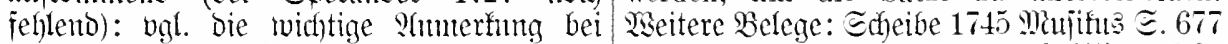
Mattheion 1739 Sapellneifter $\subseteq .208 \mathrm{Da}$ in einem solchen Adagio. Schiller 1784 z. E. ein Adagio die Betrübniß, zum Ab- Rabale II 6 . Bö̌flin 1790 Beitr.

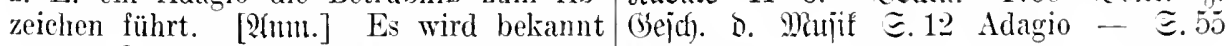
seyn, daß diese Beiwörter, welche die sonder- Adagios.

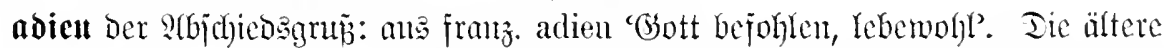

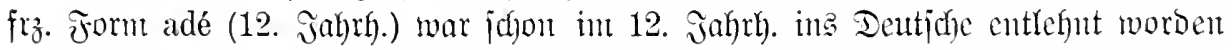

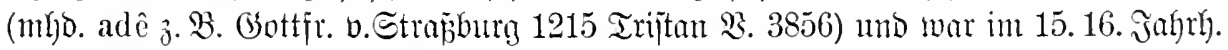

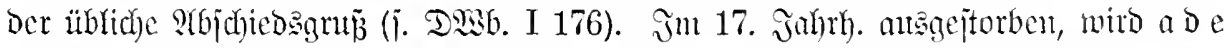

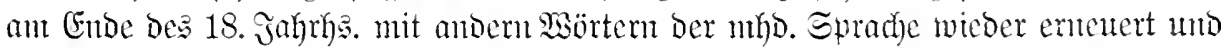

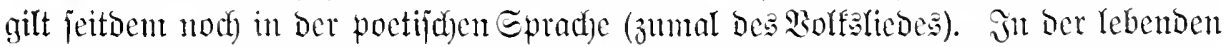
Epradje aher ift an jeine Etelfe Durdfaus a o i e u getreten: as bringt jeit 1600 zul=

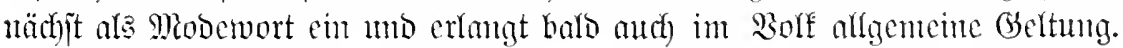

Belege: Rord 1605 Relation ๔. 20 Vnnd Adien. Epar 1642 Seohentwielidje Belagerung

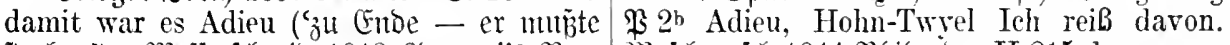

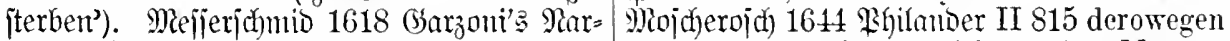
remipital ङ. $195 \mathrm{~A}$ Dieu, dich wohl gehab. ohme Adieu packte er sich an den Mawren

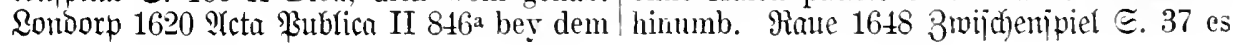


sey so! Adieu, ihr Herren. Qnuremberg 1652

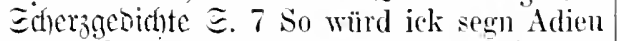
und gahn thom Dohr henuth. Freiterger 1653 Iolitijde Iiscurie Є. 567. 1654 Iisfurs

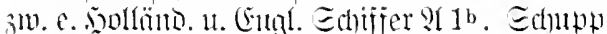
1658 Bitcherdich $\mathfrak{2} 12^{3}-1659$ salender I 12a. Grinmelahanen 1669 Eimplicitimuts ङ. 256 Adjeu Tambour und ihr Corporal ङ. 457 Arljeu Welt [iehr oft]. Ettuer 1697 1 lnumindiger Iuftor $\Xi .526$ ein fremdliehes Adien. Eaflentoad) 1711 llti ante hae こ. 24 adjeu.

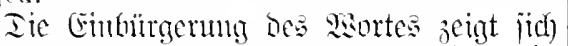
hejuners an ben Reründenungen, bie es in

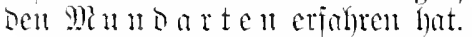

adjc (mit -tch- Plaifuache) in aflet Tin= leften bejeugt; worberricheno mit Endbetomug (baher and all $t$ ch it verfitrst $i$. n.), aher in

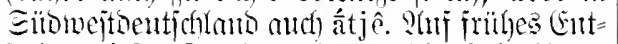
itelyen biejer Santiporm bentet bie Eif)reifung adjeu bei Grimmetsanjen. unt Calfen= bad) (i. o.).

adice Santbariante mit angetretenen, m= erflärtem $s$, bie znerit hei Belennon 1728 Banemlerifon $\Xi$. 8 ula Adis Adeas gebucht wirs. Ier siofal der 2. Eilbe jofwanft in ben

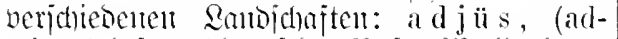

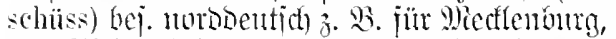
Den Mieserrbein mo bas Roergebiet bejengt
(Beleg: Eafumabe 1745 Tiuteniajij 巨. 42 Adins). a d j e s budt Täbmert 1781 für bie

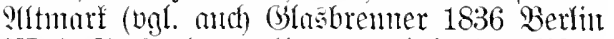
VI $3 \cong .6)$, Dodl gilt es and in ber Pifalo

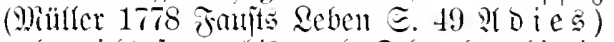
und reidit jogar his nadh Edhwaben hintein (Echiller, SHriefe I 53), wo cs helit populärer als adjê ijt.

$\mathfrak{h a t j e}$ mit angetretenem $h$ wie in $5 \mathrm{~g} u=$

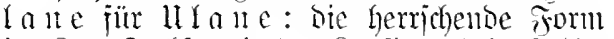
int Sigr. Eachjen, in ber Rauilis uno in Echte= jielt.

trujo berfümat ms adjö, biefleidht ans ber Berbmoming nă adjö: iun Berlituer Slang ge= länfig. Georan 1900 Berliner Ranta IV 13 Ein kurzes: Tchö, Grete! - Tchö, Lotte.

aboio $=$ ital. addio ' eb wohle, im Ient= johen nie wirflich pownlär, aber gelegentlich, zumtal in simntlerfreijen, gebrandst. Belege: noof 1601 Bumuenjers @. 68 Adio ich scheid mit wissen. ?(brabam a 厄. Slara 1688 juon: I 134 A Dio! so behït ench Gott.

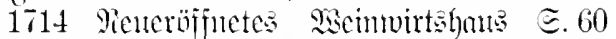
da sich endlich der Academicus gelrebt und unter einem freundlichen adio den $\mathrm{Ab}$ marseh genommen. Eit in Bürgers Briej= medijel 3 . B. 1773 (I 86 Adio), 1776 (I 272). Beethouen 1802 Brieje I 98.

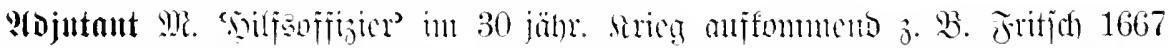

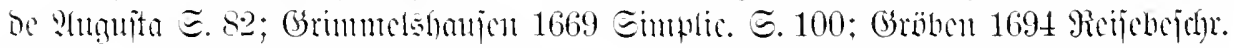

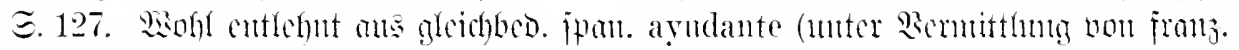
adjudant?), Das mad) Den jugmmorfegenoen lat. Btm. adjutare mungejtaltet mumbe (abce 'viojutaut' ijt lat. adjutor).

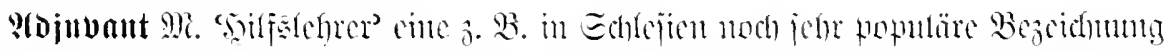

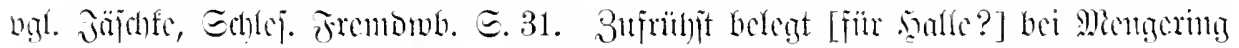

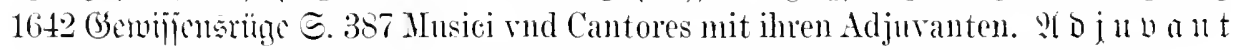
ijt formell aus bom Part. adjurans ju lat. adjurare 'muterititzen' ou crfföron.

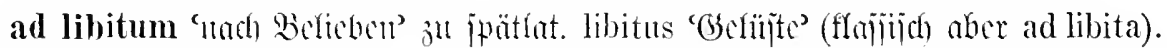

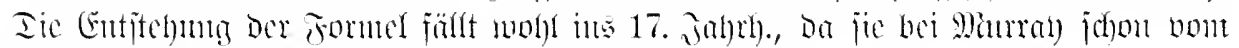
Jalur 1705 belegt miro. Ju Dex Majuf in Gegenjats ju obligat.

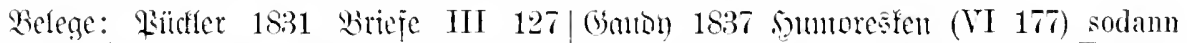
[jęer Eitglänber] wird, arrivirt ihm irgend kann er anch die ammuthigsten Trämme stwas der Rede werthes, ohne Schen damit ganz ad libitum citiren. Fiiffler 1840 Biflner= [non ben Beitungen] ausgestellt und ad ford I 373 das Schießen der Soldaten ad libitum beurtheilt. Iiciterweg 1836 Rehen: libitum.

jugen כ. 6t wie es kommt, alles ad libitum.

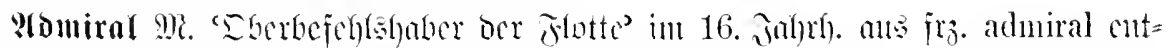

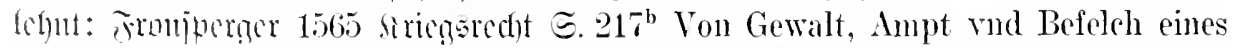
General Obersten, den man auff dem Wasser oder Meer Admiral pflegt zu nemmen.

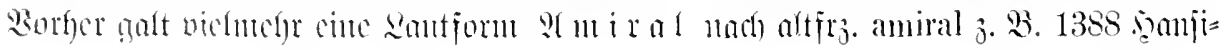




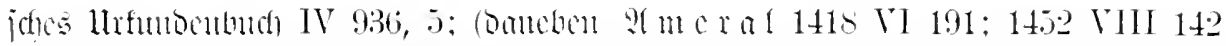

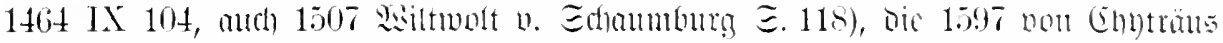

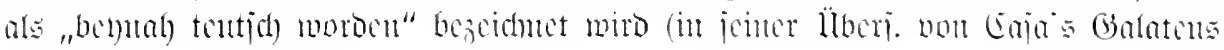
ङ. 92).

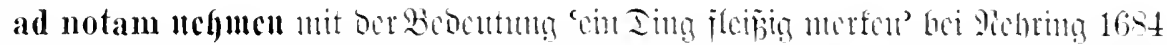

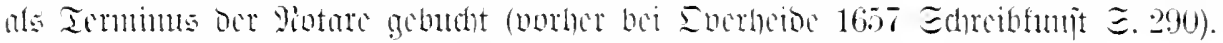

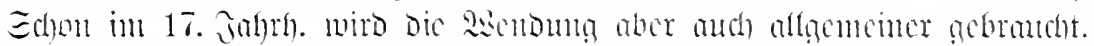

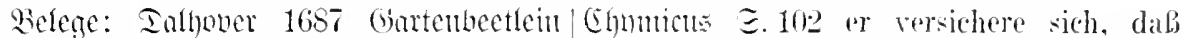
I $49^{\text {b }}$ Als er aber da nit acfunden, was er seine kurtze Rede ich mir ad notam nehmen uesuchet, hat er ihm alle so wol Catholische will. Callenbad 1714 Liner $\Xi .38$ Ich werde Priester, als andere Catholische, wie man inzwischen die Nouvellen anblegen, wats sact, ad notam genommen vid bey den sonderlich ad notam zn nehmen. Gons Statt-Richter der Statt Iendo angeklaget - 1718 Etuatsflughe it こ.152 damit er sich 1689 ebo. II 117b Mit welcher Weise zu solches, wemn er cimmahl zur Regierung reden bedeutet wird, dab dise sünde wol kömmt, ad notam nehmen und hernach ad notam genommen wird. Ettuer 1697 zur execution bringren mögre.

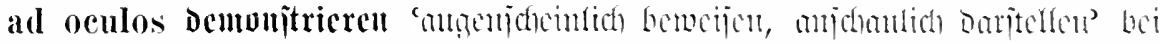

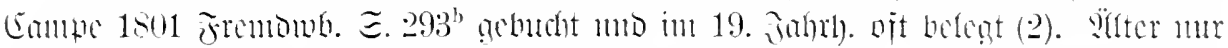

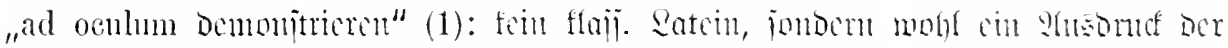

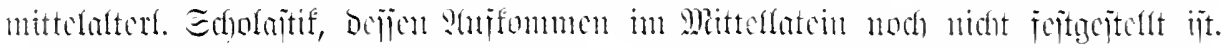

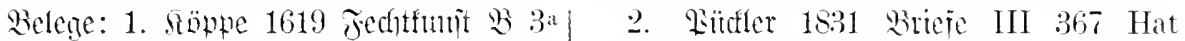
wie ad oculum kan demonstriret werden. man ihnen damn recht ad oculos die ohnEuffover 1689 Gartenbeetlein II $383^{b}$ wie fehlbar ans ihren Handlungen entspringende ich gar leicht ad oculmm erwersen möchte. Riickwirkung demonstrirt - 1835 Ecunilaijo Collenbach 1714 Liner $\Xi .65$ jeh wills ad I 216 eine Yordgeschichte, die eine neben nenlum demonstriren, daß es nicht anders ihm aufgehängte Leinwand ad oculos demonkönne seyn. Rabener 1759 Eatiren III 364. strirte.

Ilïiller 1789 cimmerich YI 271.

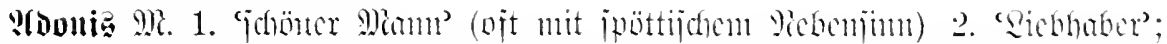

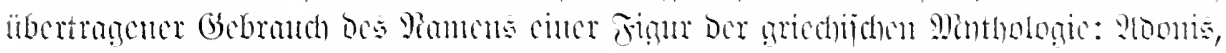

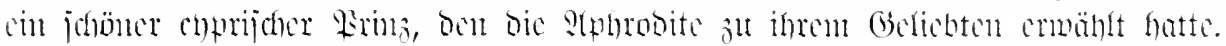

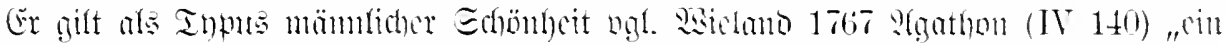

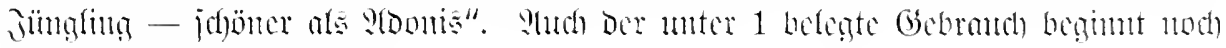
mit bemujtem sergfeide.

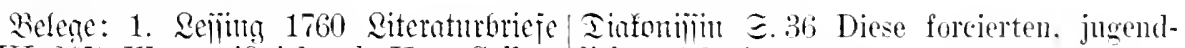
(VIII 265) Was weiß ich, ob Herr Gellert lichen Adonisse.

ein Adonis ist. SEielano 1779 Rervonte 2. Mïller 1789 Emmeridn VI 232 der (XII 30) sey immer ein Adon, Tur muskel- Homme de Chambre war der Adonis der haft dabei, wie Milo von Kroton. Srokehue ersten Kammerjungfer. Bahrot 1790 : Hino= 1812 Raditer Fefofümmel (XXVII 170) vigum I 121 die Toilette des glüclilichen Ihr Tebenbuhler ist ja kein Adonis. Qiuffer Adonis besorgen zu helfen - Sebensbejdur. 1841 Bildocriad III 372 Dieser Adonis hatte I $47 \mathrm{ihr}$ Adonis - 10.5 eine Visite ablegen sich sehr an mich attachirt. Guttifow 1855 und als Adonis glänzen.

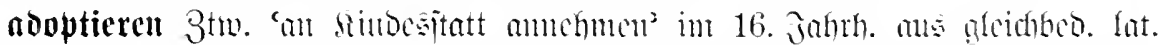

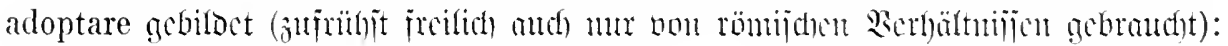
jebucht bei gint 1571.

Belege: Carion 1532 chronica $\Xi 76^{\mathrm{a}}$ |gehabt. 1564 3immerijde Chronif I 561 Julins hatt diesen Oetavium Augustum hat er desselben jungsten son, hern Wilhelmen adoptirt, daher hat er den namen Caesar Törnhern an kinds stat zu aim erben adop- 
tiert und angenomen. Fulfyover 1689 Garten= beetfein II $47^{a}$ der obigen königlichen Tochter rngleich, als welehe den hospes, erst lang darnach adoptiert, alkeit erkennet.

Ianadh jeit bem 18. Jahrh. and ïber= tragen 'anmebmen, jidf meignen' in twijjen= idhajticher Evrade 3 . B. OSfeim 1755 an Kamler II 219 man müße sie [Q⿻eründe= rungen] wohl nur der Musick zu gefallen gemacht haben. wenigstens mögte er sie nicht gern durehgehends adoptiren. Böuftin 1790 Beiträge oे. (Geju. D. Malij 厄. 43 dessen System zu adoptiren. Eufilfer 1792 Ireipingühr. Srieg (VIII 413) Er latte die Maxime seines Vorgängers adoptirt.

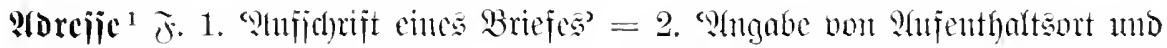

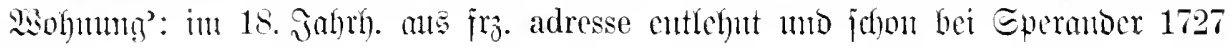
gebudit.

Belege: 1. Edfiffer 1783 Briefe I $95 \mid \mathfrak{i n}_{3}$. adresse in livre des adresses, burean Ich sehicke diesen Brief auf die Post, und d'adresses (ugl. ML

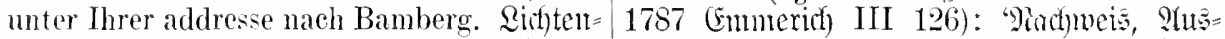
Gerg 1795 songuth II 25 Der Alte ließt die funft', wie Demu (Emme bie Serdentiffuntg Addresse cines Empfehlungs-Schreibens.

‥ Esttmer 1698 Éfinutgus ভ. 944 und brachte ihm Eckarth die Addresse von denen Herrn les Freres Signores. Edfunbart 1774 Ientiche (Éronilu E. 148 Der Verfasser soll sich melden, und Nahmen, Aufenthalt und Addresse bekannt machen. Meiinner 1789 (Eräähtungen III 107 er gab endlich meinen Bitten nach, gab mir die Adreße seiner Mutter.

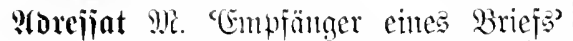
eine Zlwitterbifourng mit einer cigelitliof latein. "Enbung, Die erit in Der Mitte Des 19. Jahrhs. aujgefomunen iit; zufrifyjt ge=

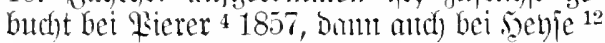
1859.

צ(o rẹ̃ (von benje erit $1835^{7}$ gebutht) für älteres

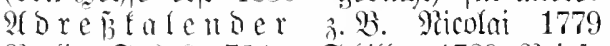
Berlin E. 2019.734. Edfifler 1789 Brieje II 320: ein jachlicher lluteridgied, ba ben

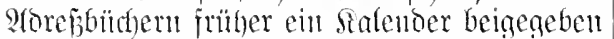
mar (ogl. Campe 1801 Tremtomb. S. 132). Ins 1. Esurtglies hat aber ciatl. eimen weiteren

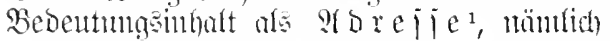

Nachweisekalender vorichlänt. Dfienbar bejdränfte jich aljo oer juhbalt der s(ore $\tilde{b}=$ buid)er nidyt auf bie blope ?higabe ber Mad)= mungert.

adreiiieren Btro. Ceinent Brief mit ber itorefie verjeken' jobon im 17. Jahrh. (als attrejjireu) ars gleichbeo. jly. adresser entlebut, jufrïbit in ber Eprache ber Яalif = leute bgl. $16 \pm 3$ Eprofiberberber ङ.4 da brauchen sie (auch wol die Schneider) das Adi, Attrebieren, datum, passato, vnd so fort an. Edfill $164 t$ Ehrenfranz $\Xi .296$ welcher massen seyn den 10. hujus an mich addressirtes mir ad manus wol geliffert. Thontajus 1688 Monatsgejprö̈he I $11 t$ Der wird ersucht, solche [QBemerfungen] in Deutscher Sprache an obgemeldeten Verleger zu addressiren. Ettuer 1697 Doftor S. 485 wann or [Der Brief] nicht an ihn addressiret ist. Sinflian 1700 Dutadfalber S. 91 nach dem Paccuet, das an ihn gleichfalls addressiret war. 9Marwerger 1711 Bejort. D. Mefien I 373 was vorgänglich an ihn gesandt und addressirt worden.

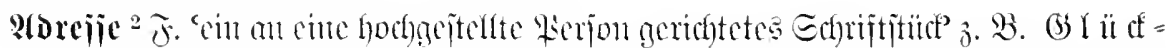

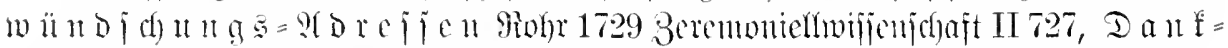

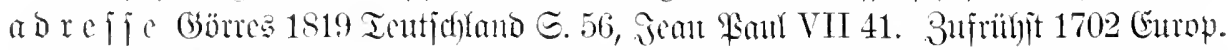
Fama $\Xi .847$.m Beweibthum dessen wil ich aus iluen neulich dem König in Engelland ïbergebenen Addressen einige harte Redens-Arten mitteilen. Entlehnt aus cugl. address (bei Mammat) crit jeit 1751 belegt).

Edhon Epermot 172T bemert nüm(ich: "Jlt Ëngellanto beiīt Addresse ein Bitt= "Ed)reiben, wethes bas verjammlete Barla= ment bem souniog über eil mo andere Materie ïberreichet", Into anf Dasjelbe sielt wohl

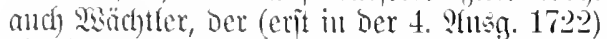
die Bebentun! 'Supplique' angibt.

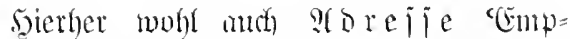
fehtumgarief' (Eampe 1801. Belege: Edhiller 1782 Sirieje I 78 so habe ich gute addressen an grobe Gelehrte, an Fürsten. (boctle 1796 Rehriabre (XXII 63) die Handelsfreunde, an die er mit Adressen versehen war. 


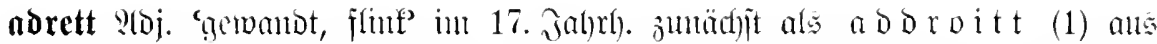
frz. adroit 'gerabe, gejdifft' cutlehnt: in Diejer 3eit hatte fro. adroit, -oite nod bie

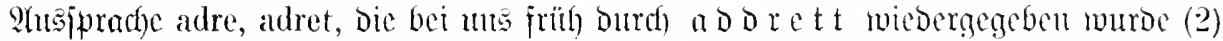

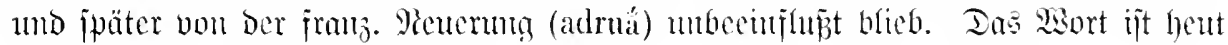
in Den Matourteu jehr gelüufig.

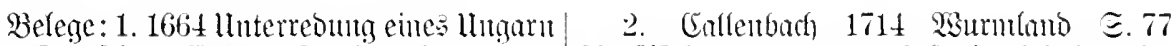
uno Deutichen $\mathbb{E}^{1}{ }^{\text {a }}$ daß die Alten euch Sie [!] ist so addrett, daßs sie sich in aller Teutschen der kurzen und addroitten kleidnng Nensehen Lieb und Estimé kann einpracti-

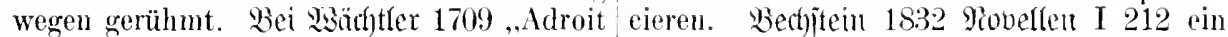
(9loröt)", bei Epermber 1727 "Adroit be= frenndlicher, lieber Bursche, sehr artig und

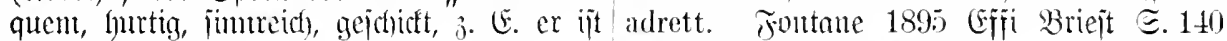
eit adroites Bitridggen".

ein sehr adretter Mann.

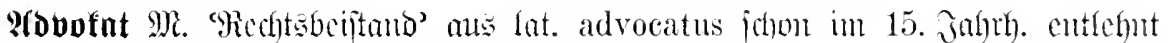
(3. B. Brant 1494 Marremidifi S. $40^{\mathrm{b}}$ wer rnwor seyt sym aduocat wann er will

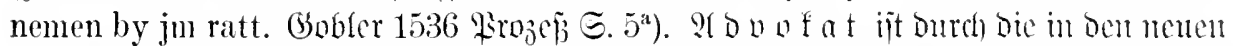

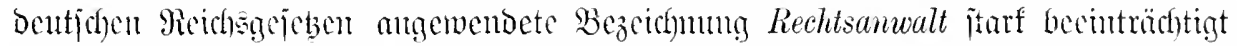
und in Deutjaland fente offizielle Titulatur melor (Dod) bleibt 3. B. Stinde 1885 Fant. Buchlyol II 152).

Peronaut M. heut Dureh Luftschiffer völlig erjetst. (Es mar am Ende des 18. Jahrhs.

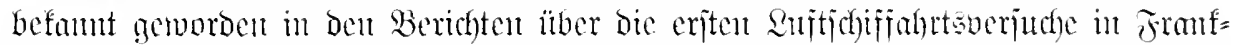
reid) (z. B. Sicland "Die Yeronauteu" 1784 in Teutjden Merfur, Jamuar): fro.

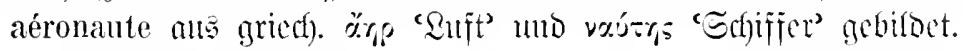

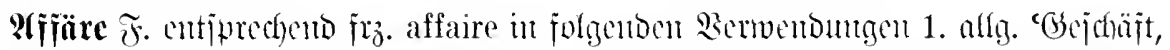

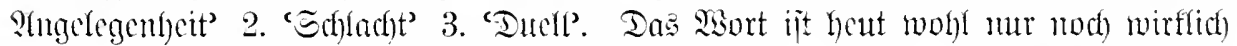

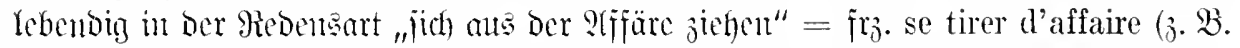
Piüfler 1835 Eemilajio II 39 Ich rangirte mich aber anf Seiten der Humilität und zog mich leicht aus der Affaire. Ganon) 1836 Iagebucf) (I 204) So zog ich mich noch gloriös genug aus der Affaire. Şacflämber 1866 sïuptlerronton IV 219 rasch eine Rede zu halten und sich so auf geistreiche Art aus der Affaire zu zichen), bic an bic

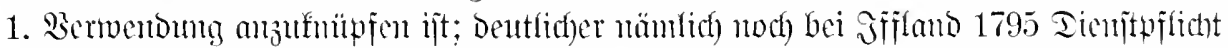
(III 1S6) Auf alle Fälle könnte man auch den Bäcker in der Affäre stecken lassen, und uns herausziehen.

Belege: 1. Büfler $164 t$ in Sursobrffers habt der Affairen zu viel - 1715 Sunij

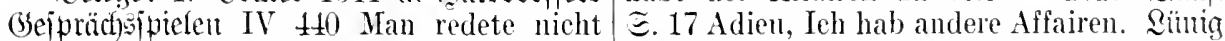
mehr von Sachen und Geschichten, nur 1719 Thent. cerenton. I 784 daß die Affaire von affairen gieng es discurirlich her. Echup nummehro gäntzlich abgethan worden. Reijiug 1659 Shtwort $હ .1$ ich bitte, wamn es ein- 1756 Brieje I 55 Nunmehr zu unsern Affairen. mahl jhre grosse affairen leiden wollen, 2. Zujrühyt Streges=Affairen

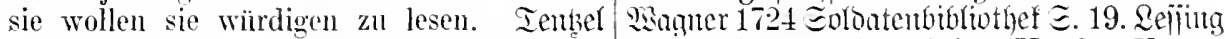

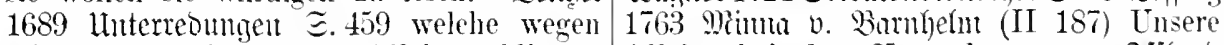
seines hohen Alters denen Affairen obliegen. Affaire bei den Katzenhäusern. Siff́no

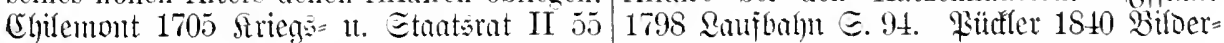
wegen wichtiger Affairen. 1708 Seopolo jual II 325.

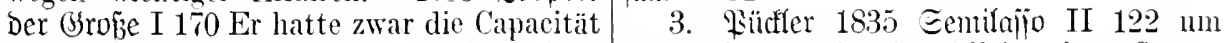
nicht, die Affairen gar zu tieff einzusehen. zu der bevorstehenden Affaire einen SecunCallenbach 1714 Eclipje: $\Xi .68$ Thr Herren danten zu finden. 


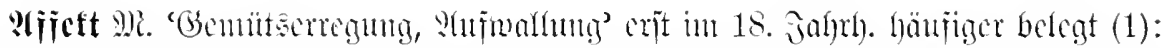

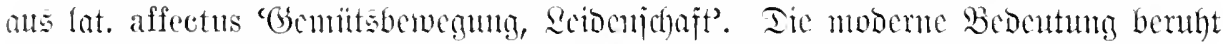

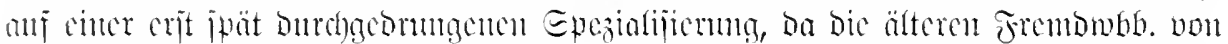

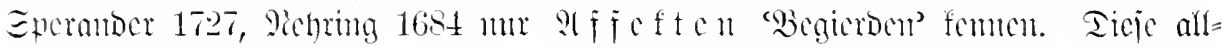

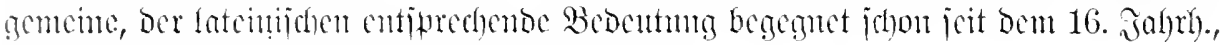
anfangs and) bei fingularijhem (bebrand (2).

Belege: 1. Siscibfod 1732 sur $\Xi .69 \mid 2$ a. If feft Suther 1520 Eermon Also ist der zorn ein [!] plötzlicher affect, v. D. Geburt Egrijti (VII 190) Das ist ron welcher die menschen recht übereilet, ehe dem affect und begir gesagt, wie man sich sie zeit bekommen, sich zu besinnen, und des kindes sol ahmemen im hertzen. Find sich eines bessern zu belehren. Daher herger 1534 Iinleftif $\Xi .20^{\circ}$ die lerdlichen leute, welche dazu geneigt simd, zu klagen affect rnnd aygenschafft, so den menselen pflegen, sie würden daron recht übernommen, etwas zulaid verursachen. Scan Eaşo und wenn sic sich bißweilen un so viel 1553 Fabch I 381 Deckt auf sein anmut begreiffen liönnten, dab sie nu ein vatter vud affect, was im herzen verporgen steekt unser lang an sich hielten, so sey es gleich $1565 \mathrm{cbo}$. II 606 Was fuer pegirde vnd affect vorïber, und sähen sie dic sacbe alsdenn In wendig in seim herzen steck. Sonterbeff gantz anders an, als sie dieselbe rorher im 1559 Regentenbuch $\subseteq$. 5ea Sintemal so viel affect angesehen hïtten. Gieffert $17 \pm 6$ Affect vind wege sein, dadurch der Mensch Fabehn $\Xi .216$ Tnd ich kann keine Worte von der rechten bahn abgeführt werden kan. finden, So leicht man im Affekt sie sonst b. Yf ffefte u Fud sherger 1534 Iia

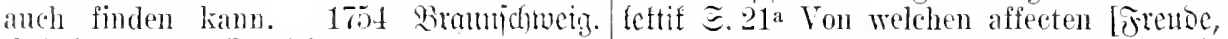
Eonturbumaen I 288 in der ersten hitze des soffmumg, Furd)t] anch ander naiglikait affects. Refinta 1755 Eara Eampion (1I endspringen. Eletion 1555 2. Barrede 343) wie mnatïllich scheint mir des Affekts das ich die affecten hindan gesetzt. Grim = ungeduldige Hitze - 1767/8 Itamatngic nelshanjen 1669 Eimulij. E.389 darüber (X 50) unechte Conrenienz muß keinen hätte mir das Hertz brechen mögen, doch echten Affekt besiegen. Eintenis 1784 verbarg ich meine Affecten. Siuman 1700 Eallo $\Xi .13$ So geschehe denn dein Wille! Eunfialber $\Xi .28$ wie die Mahler pflegen sprach a im stäksten Affekt. Mnorib 1785 durch die änserlichen Lineamenta die

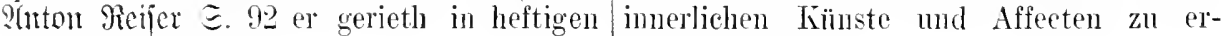
Affekt.

kemnen geben.

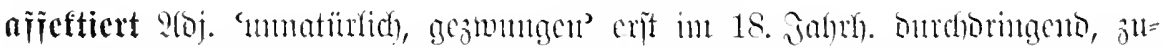

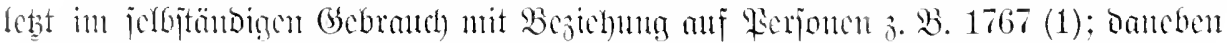

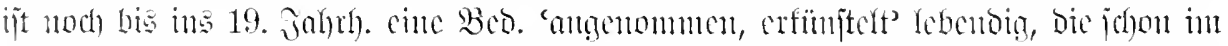
17. Jahrh. bezengt ijt (2). Ias Bejtehen Dicjer Bebentunţ wahet ben 3ujammenhany

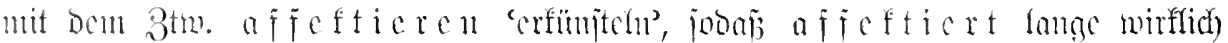

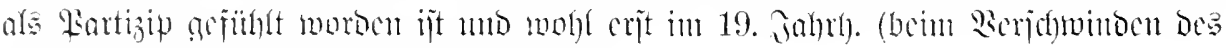

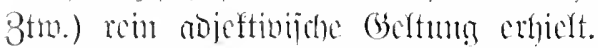

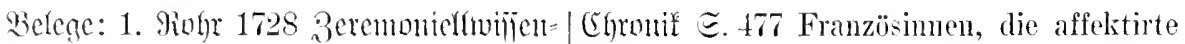
idnoft I 으 man verfällt in ein affectirtes Närrmmen ans euren Töchtern machen. Wesen und durch eine allzu mülsame Greje 1778 Etreitidniften @. 80 die lakoni-

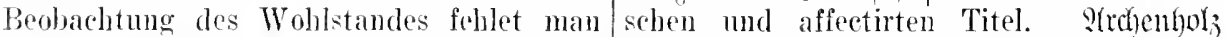
wider den Wohlstand. Injd 1764 Brieje 1787 itolien I 115 ihre affektirte Aussprache.

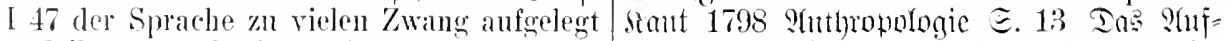
nnd illr dadurch ein steifes, affectirtes und merfen auf jich jeflift macht entweder genirt pedantisches Wesen remelon hat. 1765 Blla. I. Bibfiotbet T 1 E. 243 die Orthocraphis ist desto nener und affectirter. Seïing 1767/s Irounaturgie (X 138) Wo er aber rührend nund edel sery will, ist or frostig und affectirt. Edhubart $177+$ Ientiche (rerlegen) oder affelitirt (gescliroben).

2. Mengering 1642 Gemiljensünge 厄. 860 solcherley eitcler Pracht, Wollust nnd affectirter Zierraht der Loddel- vnd ZoddelHalir - こ. 1208 lauter simulation rnd affectirtes Werck. SEeije 1673 Erantmen 
こ. 188 Sonst lenchtet eine affectirte Art zn schreiben heraub, die einer kleinen Theologischen Hoffart ihnlich sieht. 167Mardiavell. soluspofls こ.13 thre stimme ist natiurlich mnd holdseelig, nicht, slejch deiner affectireten, verdichtig. Inomains 1687 9iad)almumg $\Xi .6$ cine affectirte bauerstoltze gravitiit. Fiohr 1718 Etuntsflugheit ङ.390 affectirte Minen. 1737 siins. Balsober ङ. 113 affectirte Bedanernib. Bochoriä 1744 Fienommiît I 160 den affelitierten \%wang.

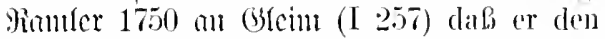
Plinins verschönert, weil er ihm cinige affectirte Schönheiten wegnimmt und die Natur an ihre Stelle setzt. Reiïng 1736 Minna (II 248) mit einer affektierten Kiilte. 1766 SIfr. D. Bibliothef III $2 \Xi .72$ der 3 te Mibbrauch ist eine affektirte Dunkelheit, wenn man die alten Wörter in ungebräuchlichen Verstande nimmt. Echnbort 1775 (Shronif $\widetilde{S} 192$ affectirter Jesuitenton. Miüller $17 \% 5 / 81$ Genoweva $\Xi .6$ affectierter Ernst. Wiejtenricber 17S2 Ier Irmun $\Xi .64$ affectirten Zwanges. Bütfuer 1835 Imiton ToD $\Xi .18 \mathrm{In}$ ihrem affectirten Wahnsinn Brieje ङ. 355 affectirtes Pathos.

aîreftieren 3tw. 'erfünitelu' ans gleich =

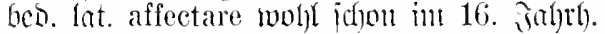

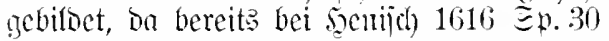

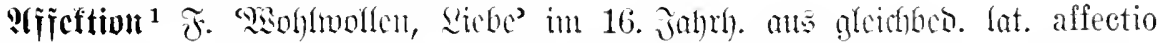

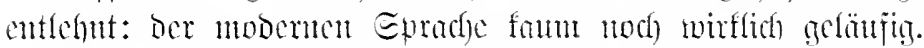

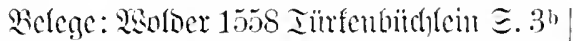
movon fidf feiter] mit gutem gewisen anbschliessen, noch einicher Affection halben absondern kann. E(f)weinichen 1581 Ient= müroigficiten $\Xi .247$ Derowegen ich denn auch sonderlich Affection, Lust und Liebe zu der Franen Tochter hatte und trug.

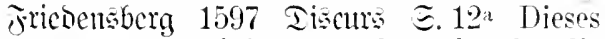
vertrawen vereinigte vimd verbunde die Stiinde vnter einander, die Affection rnd Geniühter wurden erfrischet. Moicheroich 1642 Shilanoer I 66 eine aroße affecktion und Liebe. 1643 Emrachwerncrber ङ. 16 Affection, Amor und dergleichen Wörter seyu jhnen wol bekant. Grinpling 1663 Dortit. $\Xi .6$ sie halten Freundschafft mit mir, mehr ans Furcht, als wahrer affection. Nieije 1673 Erzuarten ङ.97 Enre Edle Wohl-Ehrenveste Herrligkeit ist mir iederzeit mit guter Affection zugethan gewesen. PlGrahom 1688 Jubas I 506 Magdalena hat ihre gröste Affection gegen dem Herrn Jesum wollen erzaigen. Ettmer 1697 Chmmicus $\Xi .163$ sie hätte eine affection und zmneigung auff meine Person geworffen. - Pientere
Affectieren 'nimis exquisite velle facere; item fucare, mangonizare, ornare'. Belege:

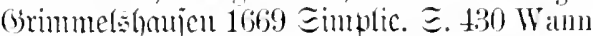
ich die Gesmondheit so sehr affectire. Thomna jins 1691 Rermunttlefre II 90 und damit einen hohen und ansehnlichen Spanischen Stylum zu iffectiren. Pigilo 172.2 3ulum Des Inbaf $\Xi$.60) Mädgens, die einen Eckel affectiren können. Fleijher 1734 soer v. Snoio III 24 sie affectirte von der Zeit an cine ungemeine Scheinheiligkeit. Sa Iod)e $1761 \mathrm{Fr}$ v. Etermbeim こ. 8j) Dieser affectirte, viel von ihrem Yater zal spreclien. Labater 1776 Phbjingu. Fragmente II 49 Demuth affectiren. Edhiller 1789 Egmmut (IX 8) das geringschäzige Betragen, das er gecen verschiedene von den (iroben affektirete. seinie 1794 sifoeg. v. sobenthal $(\mathrm{r}+\bar{\imath})$ affektirt die Natur. Qiditenteris 1795.5ogarth II 312 die keusche Lnsichtbarkeit affectiren. Echlenel $1801 / 2$ Borlejumaen I $30 \mathrm{~mm}$ für kenner zu gelten, cine grobe Kälte affectiren. (biüres 1819 Ientidhlan $\Xi .88$ dieser Aberund Heiligen seinen Gözzendienst zu treiben affektirt. Feuerbadn 1828 Merfin. 2er= bredhen I 158 er affektirte Lustigkeit. Epräter ungebräudf)(ich) gemorden.

Beleae nod bei Gonethe (1790) Sila (XII 4:3) Wich hat er besonders in Affection genommen. Ecume 1803 Epazictganta (II 130) mein Nachbar schien die Deutschen etwas in Affektion genommen zu haben.

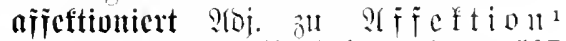

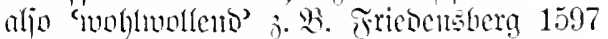
Tiscurs ङ. $33^{\mathrm{a}}$ wie es darmit zugangen, kan der ohn Affectionierte Leser ans nachfolcender kurtzen erzelunge leicht fassen. Everheibe 1657 Edheibfumit $\Xi .291$ Affectionirt 'meneiget, gewogen'.

Enäter aber alfg. 'gciumt' mo baher butch woll aber it bel = bifferenziert ngl. Corolu 1614 Relation 92 r. Fa sintemal sie sich gegen dem Röm. Reich wol affectionirt erzeigen. Miengering 1638 Enfontentenjel 厄. bey rechtschaffenen eifferigen Christen rnd wol affectionirten Patrioten. Sinocmam 1662 Teutifher gieoner $\Xi .429$ darmit sie gegen E. HochEdl. Gest. ihr wol affectionirtes Gemïth darthum; un 1690 soohtheehrtes ?unsurg $\Xi .12$ die um ihres eigenen Nutze: willen gegen dem Haub Oesterreich ïbel affectionirte. Eo and Grimmefishajen glanben, der mit den rebeinen alter Helden 
1669 Eimpliz. ङ.35̃3 ich gedachte bald|(II 25̃3) Ich bin euer wohlaffektionierter wieder unter die Kaiserl. zukommen, als König. Marfgraj farl Friebrich 1774 an deren Partey ich besser affectioniret war. Slopitod (in Ed) ubarts (Enronif II 38) Ich

Daher wiro aud in Der Edflufformel wünsche sie bald persönlich versichern zu füritficher @dhreiben, Die Dem fraız. Votre können, wie sehr ich Ihre Verdienste schätze affectionné serviteur machgeahmt ift, im und mit wie vieler Achtung ich sey Ihr Dentichen woblafieftioniert ge= wohlaffectionirter C. F.

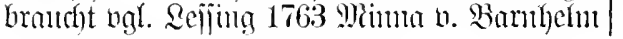

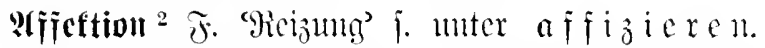

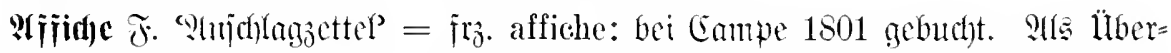

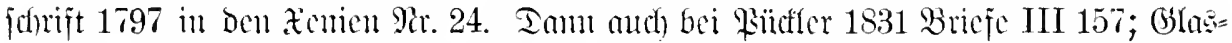

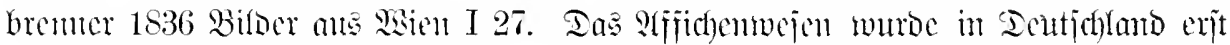
im 19. Jahrb. allgemcincr, ba Böme 1823 Edfilocmugen ans :

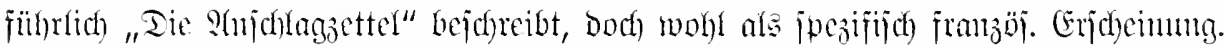

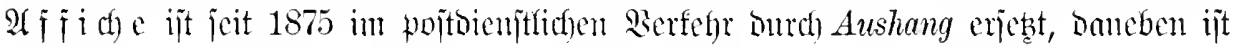
anch) Anschlag(zettel) bäufiger.

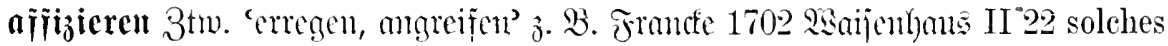
afficirte mich so sehr und zeigte mir eben so durehdringlich die Spur der trenen

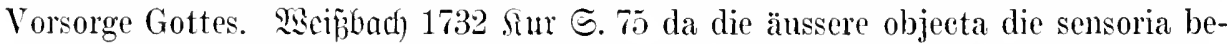
riihren und affieiren. Gocthe 1796 Sefrjabre (XXII 271) Ieh war unbesehreiblich

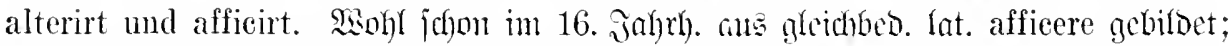

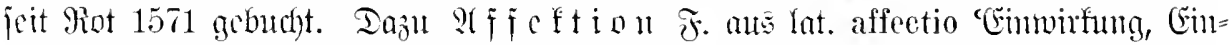

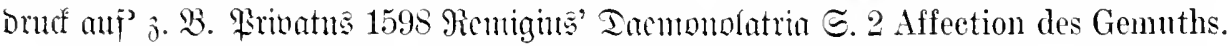

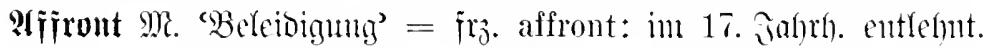

Belege: 1633 Sunitnuzer Belugerung|rebungen $\bigodot .62$ den, der ihm den affront ङ.32 die sach für die Hand nemmen, rnd angethan. Dalfoner 1689 Gartenbeetlein den erwisenen Affront reparieren helffen. II $935^{\mathrm{b}}$ Sehet nur, wie diser rnd dise einen Sieije 1673 Ergnarren $\Xi .21$ Es komme nur schlechten Affront, ein geringes Schmacheiner und klage über einen affront, die Wort erdulden. Eelhanter 1699 Iuba I 429 er sonst mit dem Degen außführen solte. diesen Affront empfand so hart der Fürst, 1689 Folit. Fliegenmenel I $19 \mathrm{um}$ diesen daß er drob einen groben Zorn gefast. Affront zu verhiiten. Tentigel 1689 lluter $=$

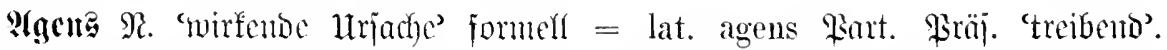
Der jubjt. Gebrand ijt zujrïhjt gebudyt bei Campe 1813. Beleg: Golb 1869 Seltffugheit I 42 sie sind mur die Gegensätze und das Agens seiner Persönliehkeit.

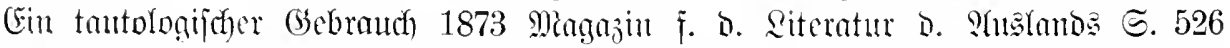
das treibende Agens jener kirchliehen Bewegung. - Eigtl. ein Iarmimu bor chemie?

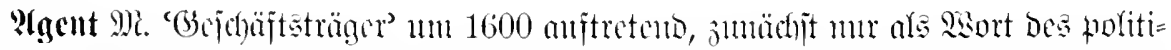

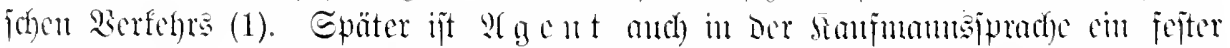

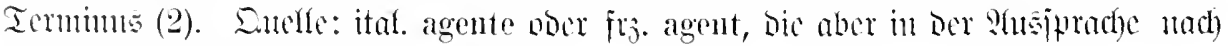

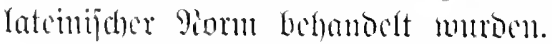

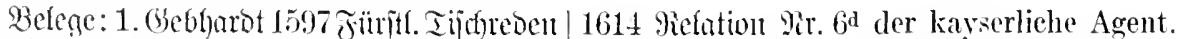
5. 25 Es hatte der let\%te Hertzog von 1620 bei Lonourp I $1659^{\mathrm{a}}$ Ist nun dieses Meyland einen Frantzösischen Agenten zu nieht ein feiner und löblicher Agent deß Jeyland beimlich richten lassen. Earohts Pfaltzoraffen. Strüner 1681 Qeben Der 
Eeehelden 厄.467 Der Cardinal unterliesse seinerseits nit, sich über seine Correspondenten, Agenten und Helffers-Helffer in Sreland schrifftlich zu beklagen. 170S Reopolo Der Grobe $[151$ Georg Fabricins, unterschiedlicher Fïrsten und Reichsständen Agent.

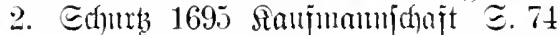
Von Ausländischen Tegotien, Handlungen und Lagern, so Agenten, Factoren etc. anderer Orten verwalten - $\widetilde{\Xi} .75 \mathrm{Als}$ ein Agent zugesandte Güter cinem anderen Agenten zusendet. Frenting 1855 Evdf mio Saben I 58 Wo jeder Kaufmam ans den Seestädten dureh seine Agenten die Waaren tief im Lande verkaufen lïbt. Eo bej. and bein Berichermigswejen i. unten

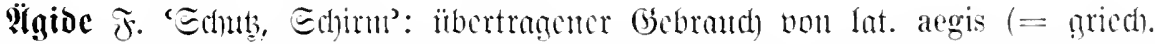

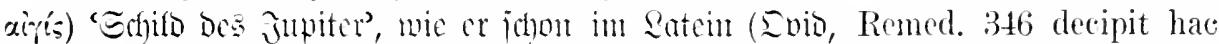
oculos aegide dives Amor) unobereitet iit. Ias sert ijt jeit bem 18. Jahrh. in bor

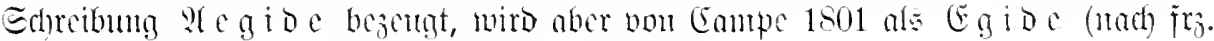
égide) gebudt (ogl. aud) don Beteg bon 1783).

Belege: \$sielano 1766 : (gathon (IV 137) | der entgegengesetzten Partey zu stehen. Demungeachtet seheute sich, unter der 1838 Gonveriationslerifon o. Gegenmart I Aegide der Gleiehgültigkeit, worin ihn damals 132 der unter des Ministers ron Stein ordentlieher Weise anch die schönsten kräftiger Ägide entworfene Plan. Tevrient Figuren zu lassen pflegten, der weise Hippias $1840^{\circ}$ Thenterichule (IV 324) Unter der nicht, seine Tugend öfters dieser Gefahr Aegide Ihres Namens wird meine Arbeit auszusetzen. Mieiter 1783 Frlieg. Blätter vor dem Publikum Entschuldigung finden.

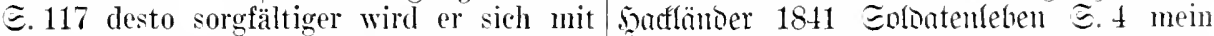
der Egide der Schamhaftigkeit decken. Vetter, unter dessen Aegide ich zum Tempel

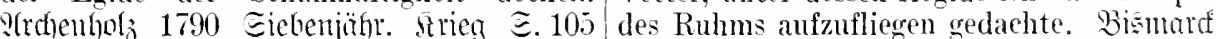
Nie befand sich ein Heer braver Truppen 1851 Brieje . 278 Lvar ist hier als Attaché in einer schrecklicheren Lage, als die unter unter meiner Aegide. (Golb 1869 selt= der Aegide Friedrichs sorglos schlafenden flunheit I 230 unter der Aegide einer sank-

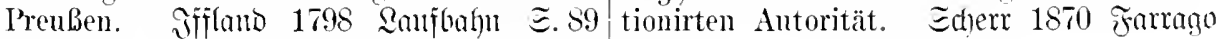
Er ergriff den Anschein, unter der Aegide $\widetilde{\Xi} .454$.

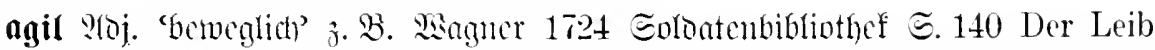
derer, so den Waffen sich ergeben, mu starck, hurtig und agil seyn. Sultle: frö. agile (oocr lat. agilis?).

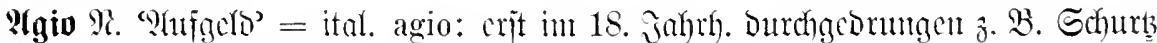
1695 Samfmamidhajt $34^{\text {b }}$ der Agio von obiger Post. Subewiạ 1744 ?ajeigen II 632 das Aufgeld oder agio. "siechjel=Agio" 1765 : vtlg. D. Biblinthef I $2 \Xi$. 76.

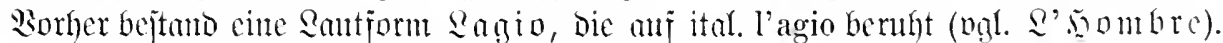

Belege: ca. 1650 YGijetare der Riga=/wissen Lagio oder interesse. 1702 Sanj= fahrer in Bubedf $(=$ Sami. Geichichtsquerlen mam sidhaft $\Xi .168$ hingegen aber wisser $\mathfrak{*}$. . I 350 ) Branntwejn bremerkorm zu die Italiäner die Lagio auff ihre Wahre:

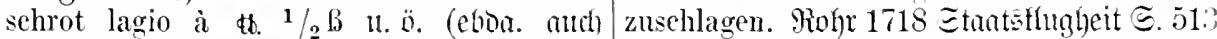

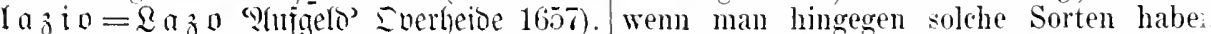

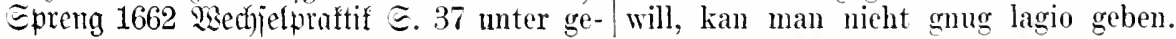

ngitieren 3tw. "(ebhajt jür ober gegen eine Perjon ober Ead) mirfen, auj

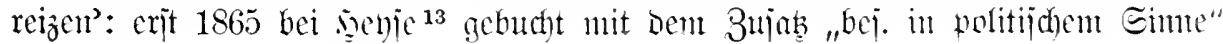




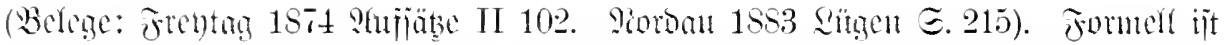

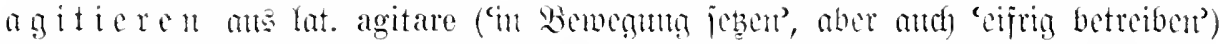

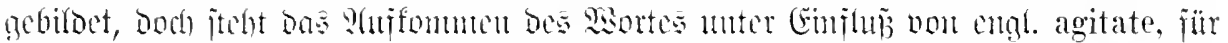

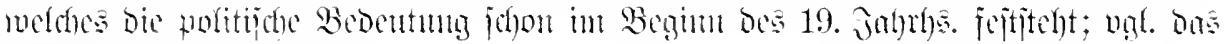
ReEict. I 184.

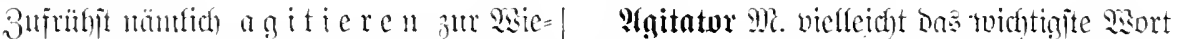
Dergabe bout engl. agitate hei foht 1841 Der gamzen (bruppe: engl. agitator (jeit 1780

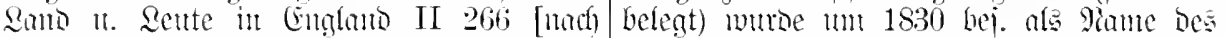

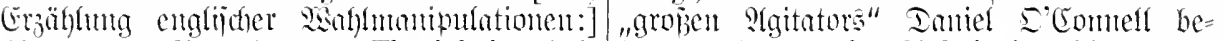
Sie nemen diese Art von Thätigkeit ,Agi- tamut: „Der grobe Sujuiegler (the great tieren" und der Zweek dieses Agitierens agitator)" 1835 Brofthans S VIII. Taher

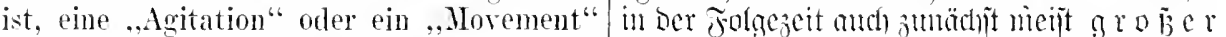

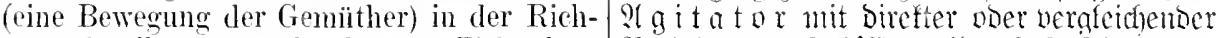
tung des ihnen vorschwebenden Zieles herrorzubringell.

Igaitation $\tilde{x} .=$ engl. agitation (icit 1828

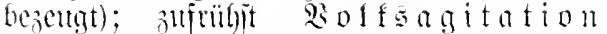
1839 Tie Cinenbahn $\subseteq .472$ Der berühmte ungarische Redner Vesselenyi, der in Folge vorlsergegangener Volks-Agitation zu mehrjähriger Festungsstrafe verurtheilt wurde.

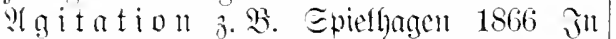

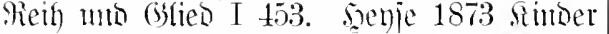
Der ․ㅗeft I 337 Es würde mich mıäglich beruhigen, wenn du nur zwei Jahre lang alle, Agitation" linterlassen wolltest. Fon= tante 1891 Jemm Ireifel S. 27 Wahlagitation.

Bezichman anf E'Comtell: 1838 Die Crijen= bufn ङ. 22. Vulkan dankte einen Gesellen nach dem andern ab, er schlug nur allein auf den Ambos, bis auch das aufhörte und der grobe Agitator vor einer marmornen Säule stille stand - 〔. 258 Thalberg hat als Clarierspieler etwas rom irischen Agitator an sich. Freilingrath 1843 ?fu Georg bermegh Dil trotziger Diktator, Wie baid zerbrach dein Stab! Dahin der Agitator Und übrig mur - der Schwab. Sneine $184 t$ \&utezin (VI 44.5) Ja, er ist hier, der große Agitator, unser Franz Liszt.

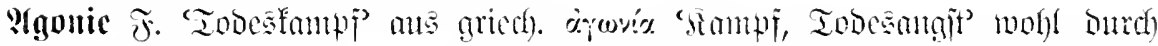

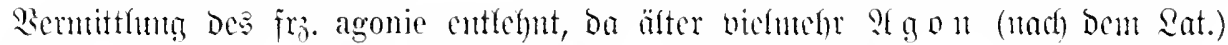
Mehring 1684 ऽ. 112 Agon 'die Todes-Noth'. Also wird gesaget, dieser liegt in agone, das ist in letzten Zingen, oder ringet mit dem Tode. SGuth bei Gttner 1698 Chirurgus

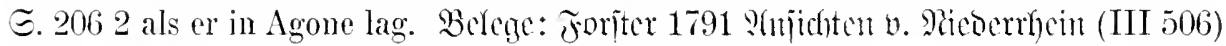
Perey liegt und stirbt und blickt auf zum Sieger in seiner Agonie. Pïfffer 1810 Biberianl II 7 in rastloser Leidensagonie. Metuer $188+$ Seion cines funben હ. 267.

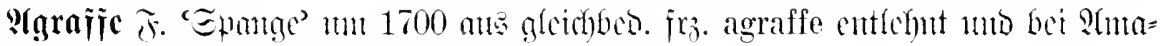
ranthes 1715 jemenjumerterifon $\Xi .40$ gefondt)t.

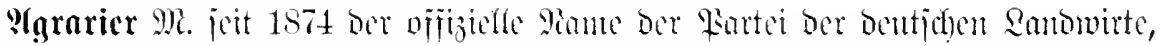

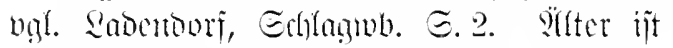

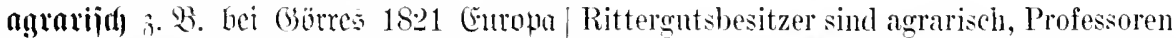
E. 21 arrarisches Geset\% in Eime non sind nationale Mittelpartei. Eneffe: lat.

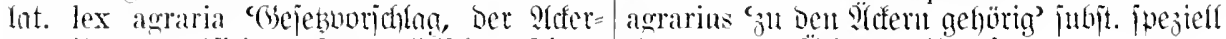

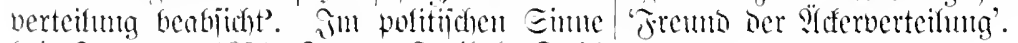

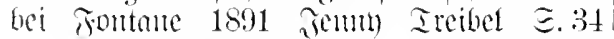

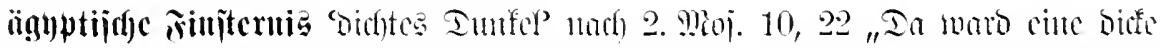

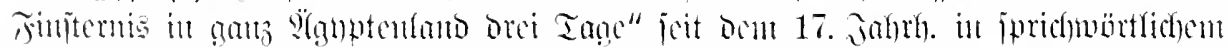

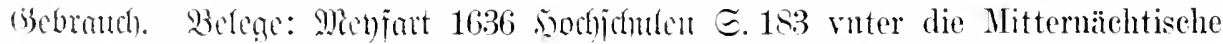
Völcker, wolche in mehr als Egyptischen Finsternissen vnd nichts als Cimmerischen

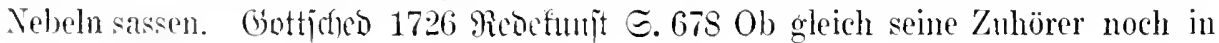


egyptischen Finstemissen tappen. Meijucr 1782 Erzählungen I 47 Egiptische Finstemis ist Tag dagegen. Fïffer 1831 Bricje I t5 bei ägytischer Finsternib.

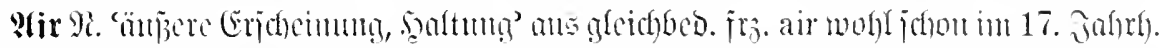

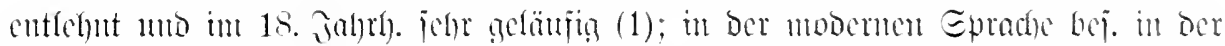

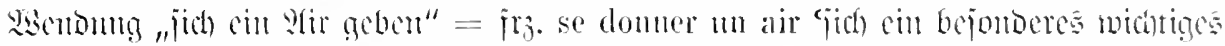

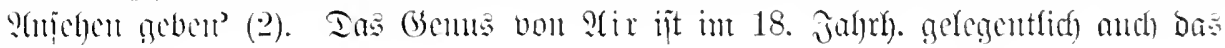
femininte.

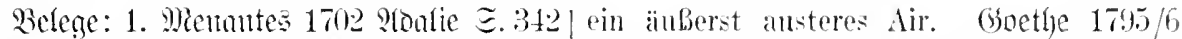
weil seine trefliche Air [für Airs?] und Rebrjahre (XXI 249) und die Erlaubnis gantzes Wesen mehrere Hoheit bezeichneten.

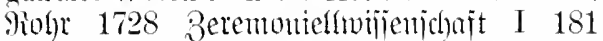
Hat mancher junge Mensch, der im Kriege avanciren will, nicht ein recht finster Soldaten-Air, so ist es jhm bißweilen an seinem Arancement hinderlich. Qeijiting 1760 Qiteruturbrieje (VIII 229) So ein grosses Air hat Herr Cramer gewiß nicht affectiren wollen - 1760 Brieje I 179 ein väterliches Air - 1772 ebs. II 56 Air der großen Welt. Mitün: 1781 Rhnjingum. Sieifen II 78 ein Kaiserair, wenn's ein Privatman annehmen wollte. Sall 1786 Bagatelfen I 223 das Legationsrath-Mädehen wüsste sich recht gut in die Airs einer Dame zu finden. Bahrot 1789 Religionsedift $€ .3$ Sein Air ist brïsk. Miuller 1789 (Enmerich VII 122 nebenher war ihm das Air von Wichtigkeit lächerlich. Bafhrst 1790 2ebentsejechr. I 75 hatte, das Air eines Hofmannes anzmnehmen.

2. Bohr 1728 Berentonielfwijienjart I 26.) davor die Hände in den Rock stecken. sich also eine besondere Air geben und entweder gar nicht, oder doch cavalierement beten. Sormes 1768 Eoph. Sieije I 460 jenes Airqeben, durch welches ein Weib die Unzufriedenheit ïber ihre Abhängigkeit verbergen will. Mï̈ller 1787 CEmmerich IV 345 das Air von Würde, welehes er sich gab. (Gautor) 1836 Iagebuch (I 214) Im Café kommandirte ich, $\mathrm{mm}$ mir ein Air zn geben, die framzösische Zeitung. Rütfler $18 t 0$ Bitberian II 152 er erregt wegen des Airs, das er sich deßhalh gibt, die Eifersucht aller Uebrigen. Frentag 185.5 Goll 11. Sabell I 196 sie gaben sich das Air, älter zu sein, als die Bramen.

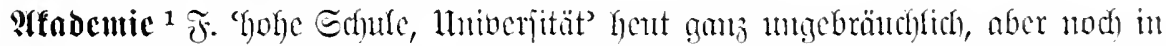

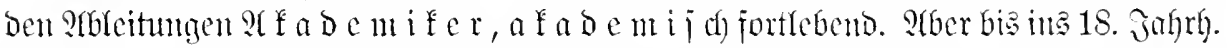

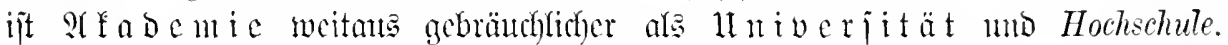

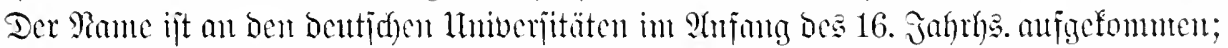

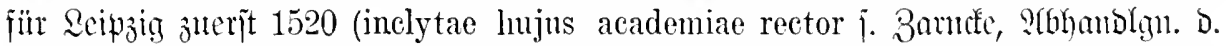
fächj. (Bej. II 564), in Der Mittenberger Matrifer I 38 juerjt 1511 nachgerviejen,

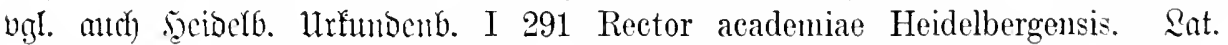

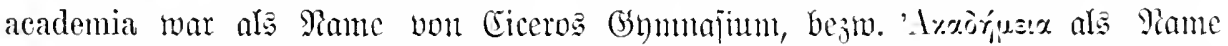
von Rlatos Rebrort befannt: bie libertragung wirb aus ber semmaniftenbetwegung an erflüren jeilt.

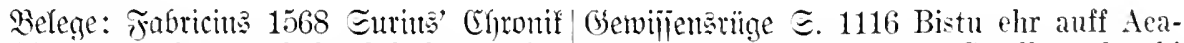

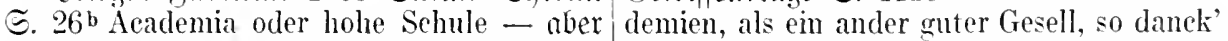

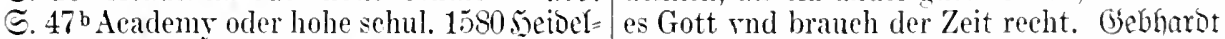

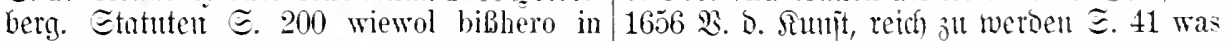
diser wie auch andern mehr academien der er disen verschwenderischen Soln in die Aca-

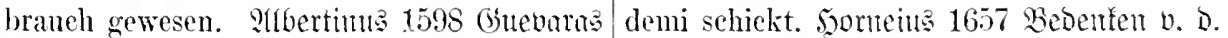
Eentojereiben I 143b in den Academien vnd Eefultwejen E.23 es sind sothaner Professoren Hohenschulen. 1619 bei Sonoorb I $484^{\mathrm{b}} \mathrm{Er}-$ wenig mehr auf den Aeademien verhanden.

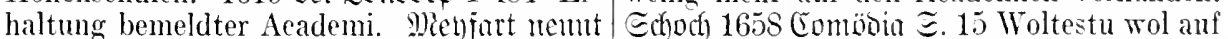
fidf) 1636 anf Dem Titel Der Erimmentug v. D. die Academi mit. Salienim 1661 P(belige Sodjidulen ProfeGor auff der Vhralten Iijdreden હ. 225 wo findet man das meiste Ácademien zu Erffurdt. Mengering 1642 Sauffen, als auf unsern teutsehen Academien. 
Francisci 1663 Türfengejaly 9 2 2 a anf Aca- das wird euch wol verziehn, kennt nicht den demien. 1732 Beoler I 242 Sonsten braneht Geist der Akademien. Meījner 1782 (Grz̆äh) man auch den Namen Academie von denen lungen I 86 In neunzehnten Jahre ging ich Universiteten. Iufti 1765 Edyriften I 162 anf Akademien. Sall 1786 Bagatellen I 85. die studirende Jugend auf Academien. Rifijter 1814 Erimtinalfälle I VII auf unsern Goethe ca. 1774 llrjauft B. 310 mein Sehatz, Akademien.

$\mathfrak{A} \mathfrak{b} \backslash \mathfrak{c}$ it $\mathfrak{u} \mathfrak{u} \mathfrak{g} \mathfrak{c} u$.

afadenijid) nad) nlat. academicus (int ntent III 245 mehr durch die Vorstellung der 16. Jathr). bezeugt ₹. B. 1583 Freiburger sogenannten academischen Freyheit, als Niatrifel I 601 academicum album). Eełr durch die Liebe zu den Wissenschaften be-

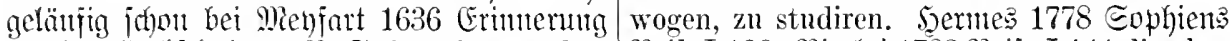

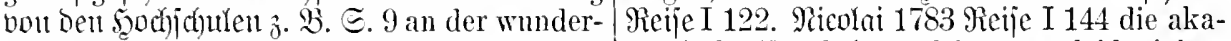
baren Menge der Academischen Bürgerschaft demische Freyheit, welche mann leider! bey - 5.273 Die Academische Würden seyn Katholiken und Protestanten für das erste

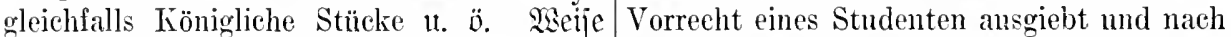
1697 Rertr. (Gejpräche ङ. 328 ein alter Academischer Freund. Miujandor 1739 Der ङtubente ๔. 191 Ein ehemals gewesener academischer Freund.

Fe it e $\mathfrak{B} e \mathfrak{r b i}$ bungeu: afadent= idfe sutgend zur Bezeidymug ber gejanten Etubentemidaft; joll bei Menfart 1636 23. D. 5odjichulen ङ. 123 Die Academisehe Jugend ist fertig zu hönen, vnd außzuhönen, zu nichtigen rnd zuvernichtigen, zu lachen vnd auß zulachen - @. 415 Die gantze Academische Jngend wird von mir nicht verdammet. Sïntig 1719 Theatrum ceremoniale I $1313^{\mathrm{b}}$ zu dem Ende die dasige [ख્ürzburg] Academische Jugend sich des Morgens gegen Retzstatt, zwey Stunden von dar, verfügt. 结itt v. Törring 1830 Fragmente I 17. $\mathfrak{L}=$ wald 1837 Paturelle III 135.

afabenifiche Freilyeit joflon Dïrer 1668 ¿auj Der : jünglings-jahre erreichet und nun gesonnen war, wiewohl mit noch nicht recht pflücken federn, höher zu fliegen, absonderlich den verhasten schul-zwang nit der Academischen freyheit einmahl zu vertauschen. Rohr 1718 Etanteflugheit $\Im$. 416 ob er nur deßwegen anf die Universität ziehe, daß er sich bey der academischen Freyheit divertiren möge.

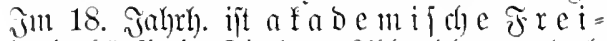
he it häufig im Iiter bou Shblondmugen (vgl. Erman 11. Sport, Biblingraphie D. D. Lluiv. I

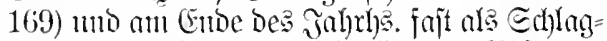
wort gebrautd)t $z$. B. Michaelig 1773 Minjounte=1 welcher man ihm alles dimmme Zeng zu gute halten soll. Geobfe 1789 Edyulintijten I 508 Hüten sie sich besonders vor dem Schwindelgeist der akademischen Freiheit, der oft selbst die hofmungsvollesten Jünglinge ergreift.

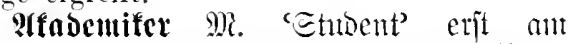
Cnde des 18. Jahrth. (1796 5einelberg. llrfumbenb. I 437 - 1804 ebs. I 453, geläufig

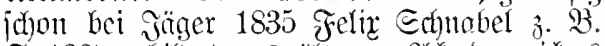

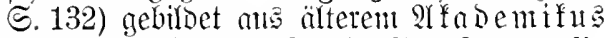
Enener 1675 Pia Dejiberia ૬. 338 dann die Tochter muB bald Jungfer, und der Sohn Student oder Academicus seyn und heissen. Die Bezeirfumng aeademiens fïr 'Student' ift am (Ende bes 16. Jahrb) aufgefomment (3. $\mathfrak{B}$. in academicormm numerum 1584 Frei $=$ burger Matrifel I 608), zuerit wohl in fotholifon Gebieten, in benen Stubent aud 'Mittelid)itler' bezeidnete; vgl. Scugv 1820 Jurift. Enjyflopäbie ${ }^{6}$ (I 447) Die Studierenden (Bur:che in einem bestimmten Sinne, in catholischen Ländern auch wohl Academiker oder Candidaten, auch wohl Juristen). Sigl. Jurift und Student.

Ifabemijt $9 i$. 'Bügling Der Ritterafabe= mieu' aus gleichbed. ' $\mathrm{r}_{3}$. académiste jeit ber

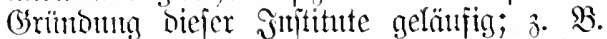
16875 romung Der Mitterafademie zu sisolfen= bittel (= Bramifun. Edfulorbmungen II

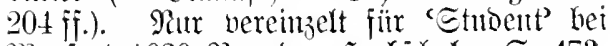

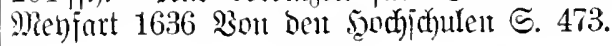

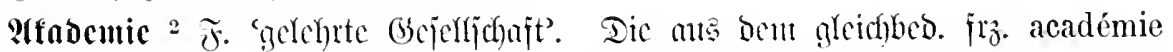

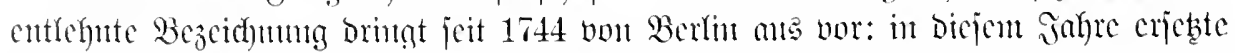

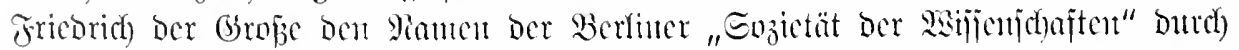

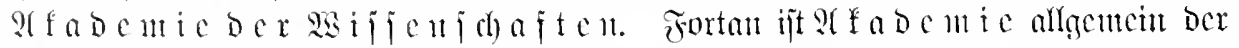

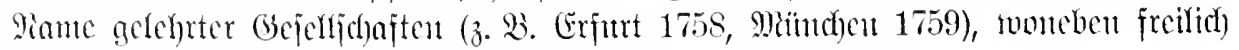
Göttingen 1750 mid seipzig 1768 an Gesellschaft jẹthiclten. 
Be le ge: 1744 Rhilojoph. Unteriud)un= gen $\Xi .77$ Preib, welehen die königliche Akademie der Wissenschaften zu Berlin auf das Jahr 1745 ausgesetzt. Jujti 1765 ङcherz=

8uja

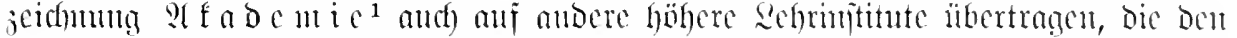

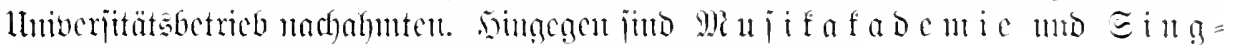

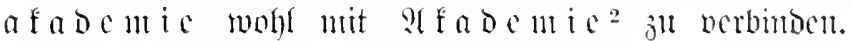

Banafndemic nenerbing ungebräudflid) $\mid$ L. v. Beethoven wird die Ehre haben, gewnrben, als bie Rauafabenten mit best cine grose musikalische Akademie zu seinem

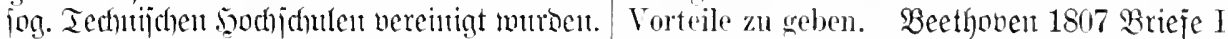
Beleg: Belter 1812 an Goethe I 50 die 169 einen Tag zur musikalischen Akademie ('ollegia bey der hiesigen B. - 51 daß der - 1809 ebo. I 190 Schimpfschriften über junge St. bey der $B$. anfgenonmen ist und noch heute seine Natrikel erhalten wird.

Bcranfadomic jujritlyt als Pame Des 1765 gegriundeten futitituts in Freiherg it Endflent; ithr Tirettor $\mathfrak{A}$. (3). Merner nemnt iidh unter ber Siorrene ju Ehains fabinett (1790) I $2 \cdot 2$ Bergakademie-Inspektor.

Foritafadeutic erĩt im 19. Jaljr). aur= fonmend mit Der Grïndulg ber Forit= atubemien in Mariabrum 1813, Tharanot 1816, Eherstwalse 1830. 2igl. anch Tevrient 1840 Theaterjatile (IV 326) Dem Landwirthe, dem Forstmanne, dem Offiziere grewähren eigne Academien wissensehaftliche Fachbildung.

Sandeleafnocutic bej. in siterreidh ïblich fïr in Teutjoland geltentes Handelsschule.

Mialeraf́ndomic (älter $\Omega$ u n it a f a $b e=$ mie) 3. B. Tstuffelmam 1764 (Gejh. D. Sunit I XXIII. Eulzer 1771 Theorie I \&a Sie werden insgemein Mahleracademien genennet, obgleich nicht das eigentliche Mahlen, sondern das Zejehnen darin fürnehmlich gelehrt wird. Tafür ijt bam wieber cinfaches QI a i e mi ie ïblid) getworben, Das, jeitsem es fïr 'llniberjität' migebräu(d)lich getworden ijt, hent Inr nod) 'Die höhere Simitjdule' hezeidintet. Edyon bei $\mathfrak{x i n d e l m a n n} 1755$ Bedautfen $\Subset .13$ ein gedungenes Model, welches in nusern Academien aufgestellet wird. Bei Enlyer 1771 Thenrie I 8 ein Yrtifel Academien (Zeichnende Kü̈nste). Rigl. tod) seine 1830 Italien (III 286) anf der Akademie zu Düsseldorf. Mar v. Merifo 1851 Reben I 233 ein höchst branchbares Modell für Künstler, wie es auf den Academien so geschätzt wird.

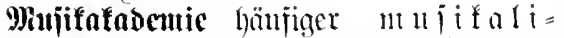
id) $\mathrm{S}$ Sf a d e mi e: Tredibler 1777 Theater= idjule 5.136 die musikalische Academie, das Concert oder die Oper zu eröfnen und anzufangen. 1800 wiester Programm Herr

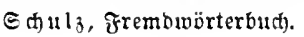

hatte Edrijten I 15 Wenn sie sich etwan einfallen lassen, die Preisanfgabe einer Academie oder gelehrten Gesellschaft auszuarbeiten.

meine letzte musikalische Akademie. Jrentag 1855 Eoll u. baben I 533 es ist hent grobe musikalische Akademie, die Rosalie wird anf dem Flügel spielen. Beethonen brandht in gleicher Beneutung and enjaches if a bent ie: 1801 Brieje I 75 daß ich jährlich immer einen Tag zur Akademie erhalte, deren ich einige gebe - 1812 ebo. I 273 - 1813 I 320. 321.

nouberger 1806 budft untr erît Académie de musique 'ein Encert, Das eiste Gejell= id)ajt won Majifweritänbigen unt হiebhabern auffïhrt': Dastach ift biejer (bebraud an

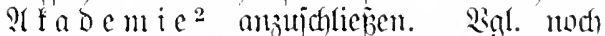
Encibe 1745 sritiigher Minjifus $\Xi .576$ Unter einer Akademie der Musik, oder unter einer musikalischen Akademie verstehe ich eine Gesellschaft verschiedener Personen, die mit vereinigten Kräften für die Anfnahme der Musik sorgen.

Bitterafabemic. Belene: Roldfamer 1714 Rürnberg. Sejperiden II BL. V Anno 1701 hat man eine Ritter-Academie dahin geleget [sc. nad [rrlanger]. Fohr 1718 Etantsflughe tt 厄.369 daß sie von einigen Jahren her hin und wieder Ritter-Academien angerichtet. 1732 Bebler I 241 Man hat auch ferner noch eine andere Art von Academien, anf welchen ledig= lich diejenigen Studia und Exercitia getrieben werden, welche Standes-Personen zu erlernen uöthig haben, daher sie auch mit dem Namen Ritter-Academien beleget sind. Ialtit aud) vou Frijch 1741 SEG. II 1220 1utb Iridfter

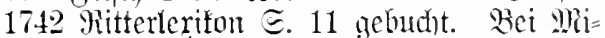
Gaelis 1773 Räjomentent III 127, Renzel. Eteman 1805 Gejpräde in $\Omega_{a b u n t h}$ I 156 Ritteracademie. - Tie Grüntonuy ber ßitter= afobentien beginut unt 1700 bej. unter $\Omega$ eib $=$ nizen Einflü. Slyre ältejte Benenung mar ritteridule, banehen bas emiache If f a b e m i e; ngl. Somedt 1684 Deiterreich $\Xi$. 276 für die sonsten allzulang in der 
Fremde umschweiffende Jugend, Fürsten- ein guter alter Mann, der mir erzählte, und Ritterschulen oder Academien im Land dab er eine Singakademie errichtet habe, selbsten aufzuthun. 1688 Dromung Der $\Re$ itter= in welcher nur junge Mädchen, die sich der af́ndemie zu Edfulorbmmgen II 208) wie alhier eine der- Beruf ausgebildet werden sollen.

gleichen academic und ritterschule establiret werden möehte.

Simanabcutic jeit 1791 als Pame ber

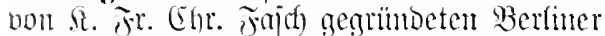
Emmatanemie befumt (Beleg: 3elter 1802 an (bocthe I 54); ipäter aber ïberhatipt gem als game von Geinguereinen ge= brandet: mady Brodflym XIII:" 330 (1817) "litbunganititute fïr Riebhaber". Bgl. aud)

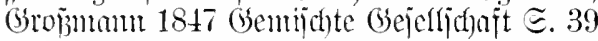

Sienn Damit aud) errviejen ijt, baż bie Eingafabenien mprünglich mirfliche lunter= richtöinjtitute waren, jo ijt bod) mid)t ju verfenten, Dajj bie erjten derartigen S(fabemien ans jeflichten (sejanguereinen ermadjen jimo, wie Dem aud Gocthe 29. Mai 1801 von

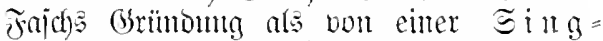

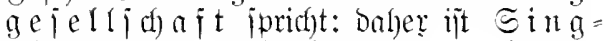

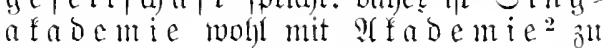

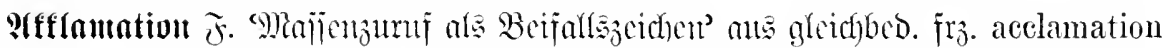
(oder lat. acclamatio) entlefut. Belege: Görres 1800 Eenoung n. Paris (I 72) Angenommen durch die Acelamation des Kleimmuths - 1821 Guropa $\subseteq .335$ autorisirt durch die Acclamation der ganzen gesitteten Welt. Borher in Der Bebentung 'glüu'=

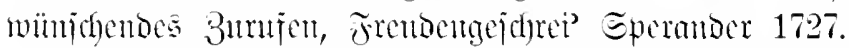

afflimatijieren Btw. meït refl. cigtl. 'jidf an ein Slima gewöbnen' (1): im

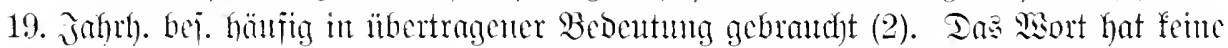

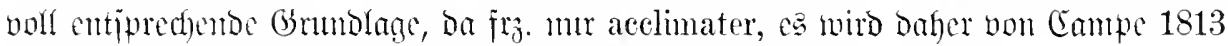

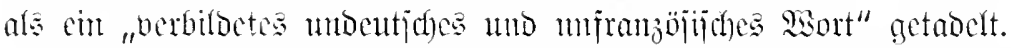

Belege: 1. Jriederife Brun bei Campe 1813. 5oltei 1852 Sagabunden S. 402 Erst muB

2. Ǵaubn 1839 Der Etumme (V 49) ich mich akklimatisieren. Gutb́n 1852 Die jedesmalisige Anrede war junger Herr, ßitter vont Geijte V 316 R. hat sich sogar und als soleher fing ich an, mich zu acelima- an das Zarenthum acclimatisiert. 1857 tisieren. 1841 Guropa I 309 da muB ich $\mathfrak{B a z a x}$ S. $149^{b}$. Epielfagen 1866 In Reil)

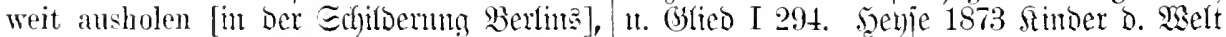
um sie nur einigermaßen zu akklimatisiren. I 206. Fontane 1883 Brieje II 56.

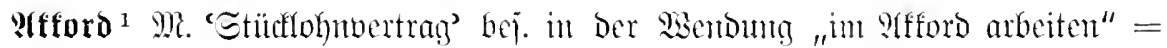

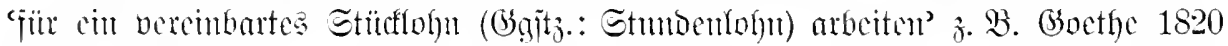
Bricte XXXIII 11 zngleich arbeiten Tüncher .... im Accord gar fleißig. -

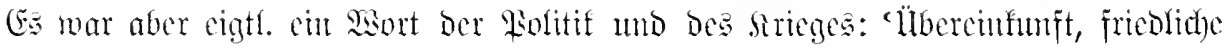

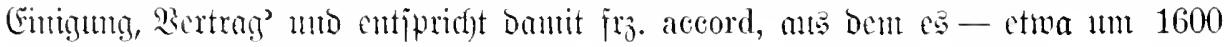
- entfent ijt (1). Später allgemein 'Bertrag' (2).

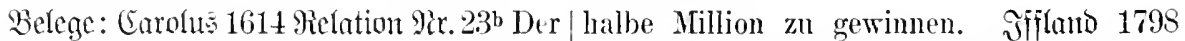
Accord zwischen dem König rnd Printzen. 1631 Beridgt v. Whagbeburg $\widetilde{S} .3$ ein soleher güetlicher accorl [ijt] auffgeriehtet worden. Jientgering 1633 Eiegesfrone $\Xi .35$ durch accord rnd friedlichen Anstand greendet 1638 Eolbatentenjel Ð. 25 Für Belagerung riner Stadt soll er jhr erst fried vold aceord

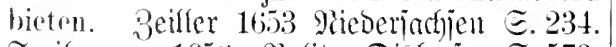
Freiberger 1650 ; Prlit. Iisturje 巳.573.

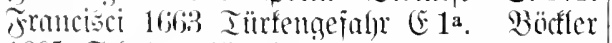
1665 Edhola militaris $\Xi .28$.

2. Wïlller 1787 Enmterich III 64 Er verachtete $\cdots$ durch einen Akkord eine 1 und accordiren wolle. Earolns 1609 Relation

¿aujbal)ı ङ. 61 Schröder erbot sich dagegen zu einem ehrenvollen Akkord für meine Manuskripte. Goetije 1796 Benv. Cellini $(44,60)$ Ich machte einen Akkord mit jhnen, damit sie ganz die Sache übernähmen.

affurdicren 3tw. 'vereinbaren' $=i r z$. accorder. 1. von politijd)en Bertrïgen jadon

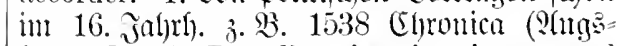
burg) Є.a $3^{\mathrm{b}}$ Desselben jars ist ein anstand deß kriegs und auffhörung der waffen accordiert. 1567 Bimmerifthe (5)ronif I 523 waver er, Bajazet, sich mit inen einlassen 
9x. $11^{\mathrm{e}}$ die sachen mit den Oesterreichisehen | erbotten sie sich zn aceordiren fnd in verLandtstenden vnd 'dem könig zu aeeordiren gleich einzulassen. Ed)urb 1672 \$a ateriafien=

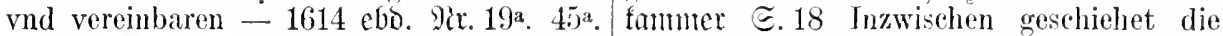

2. in Sianfutannswejen 3. B. Miojd)erojch Handlung von freyer Hand, wie beyde Theil 1642 Bgitamber I 261 weil sie [Dic \$Ban= mit einander accordiren kömen. Mlarperger ferottierer] sahen, das allenthalben eine 1717 Bejchr. D. Banfen $\Xi .323$.

menge der Creditorum vff sie zu trangen,

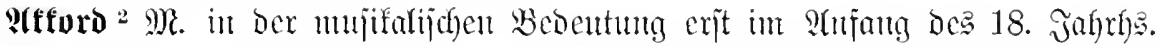
aus frz. aceord (wohl nad) Rameau's Traité d'harmonie 1722) entfehut unto bei Malther 1732 Müiffal. Sexif́lon gebudft; älter (und jo nod) alfeiu bei Eperander

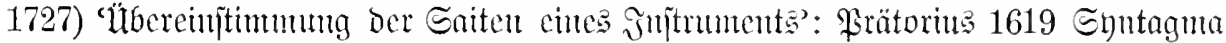
ıuүicun II 151 je näher man es aber mit dem einstimmen zur reinigkeit vnd aceort bringt.

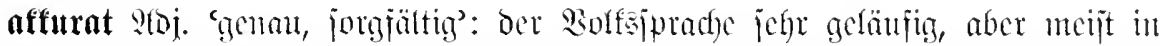

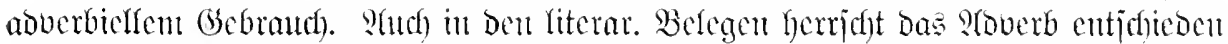
vor, bas jeit dem 17. Jabrh. bezcugt ijt (1). Ter abjeftivijede (Gebraudf (2 a) ijt cinte

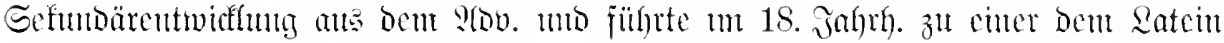

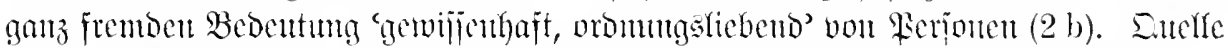
aljo lat. acemrate ?(ob. 'geman, jorgjältig' (aeenratus 'mit Eorgfalt gentadyt').

Belege: 1. פiseije 1673 Erjuartu હ. 136 Setzt inmer dieses Final dazu, ob es gleich nieht accurat eintrifft. 168t Eurö: Etaat: gejpräd) eines Franjojen uno solländer S. D $4^{\mathrm{a}}$ Er würde accurater reden, so er sagete, dass der König ein Mann ist, der sein Wort hält. Tentikel 1689 Innterrebuttgen ङ. 37 Von den Ưbersetzungen der alten Scribenten habe der Herr Huet im schönen Bueh de Claris Interpretibus aecurat gehandelt. Saeije 1697 Bertraute (Seipräche S. 64 so dürffte man alles so gar accurat nicht ansgefïhrt haben. 1699 Ettatspipiegel I 51 dann es jederzeit nach Proportion deB Tags- und Jahrs-Zeit ganz accurat zutreffen wird. Fulbuat 1700 Mdujifalijher Duacfjalber ऽ. $12 \mathrm{als}$ wemn man zwei Sänger unter sich concertiren, und sonst einander acenrat begegnen hörete. Florm 1702 jausbater I 264a Wann die Gewinde aceurat sollen geschmitten werden. ¿eib 1708 2. Probe ङ. 23 eine solche Sitten-Lehre, die das honestum a turpi nicht besser und aceurater unterscheiden könne. Marperger 1711 Bejd)r. Der Meifen I a ${ }^{a}-159$ accurat wissen. Fohr 1718 Etaatsłlugheit $\widetilde{S} .10$ die nicht fähig sind, accurat genung davon zu ur-

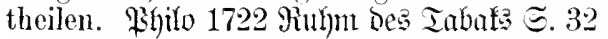
Ein ander rechnet am accuratesten und geschwindesten, wem er die Augen zuthut. Fleijder 1730 serr v. Snow I 147 und ist heute accurat der sechste Tag. 1737 Siito. Ballober S. $2^{b}$ da viele Ertzdiebe darinnen sehr accurat characterisirt sind. Döbel 1746 Эägerpractica I $36^{a}$ er weiß accurat, wo der Baum hinfällt. Midfaetiz 1776 Räjomentent IV 582 accurat bezahlt.

2 a. Thontajus 1691 Bernunftlehre I 288 weil die Gelehrten hiervon selır confus und ohne aceurate Ordnung tractiret II 109 diese aceurate Methode. Etturer 1697 (E)tmicus ङ.641 hiervon kan ich ihnen keme acurate Gewißheit sagen. Francfe 1702 'saijenfing II 24 welches aber bißher noch nicht so aecurat von denen Kindern $\mathrm{zu}$ erhalten gewesen. Rünig 1719 Theatrum ceremoniale I 1319a in ehrbarer und accurater Ordmung bereitet da stehen. Weij̄bach 1732 futr $\subseteq .136$ aus der aceuraten beobachtung der zeit und stunden. Ramler 1745 an (Śleim (I 10) die aecuratesten Abtheilungen. Geflert 1747 zärtl. Echweitern (III 35) Es muß ja nicht alles so aceurat seyn. Seppe 1751 Lefrurim $\subseteq .148$ ganz aecurate und zuverläßige Rapporte.

b. Tenkel 1689 Interredumgen $\Subset .251$ ein Setzer, er möchte auch so acenrat sein, als er immer kömnte. Govethe 1774 Urfaurit 3. 966 Und meine Mrutter ist in allen Stüeken so accurat. Ecfiller 1796 Brieje V 72 Die Paketierung geschieht in meinem Hause durch einen sehr accuraten Menschen.

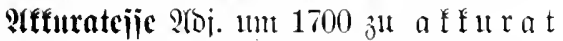
gebilloet mit ber frz. Enoung -esse = ital. -ezza (ital. aceuratezza); aber Beemifujiung burch bas Stal., wie jie jür diejen Typus 
jomit fänjig ijt (ugl. Iclitatcjic), ijt Aecuratesse im Berichten versprechen könne.

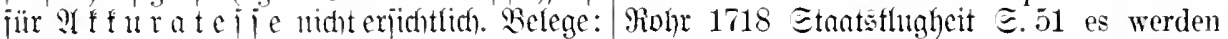
1708 Seopold ber Groje I 114 der Kayser auch dadurch die Räthe in Collegiis zu hat allzeit darinnen eine solche accuratesse einem mehrern Fleiß und Aceuratesse in

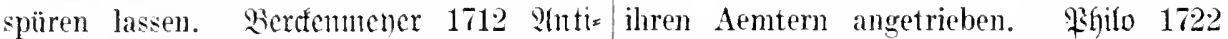

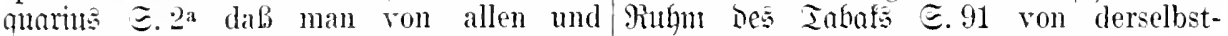
jeden Dingen ummöglich eine untriegliche beliebigen Accuratesse im Stopffen.

afquiricren 3tw. 'erlangen' cigtl. molyl cin fanglcimort: aus Yat. acquirere 'crmerben, gewinnen'. 3nfrïhit gebucht bei Simon Mot $15 \overline{7}$.

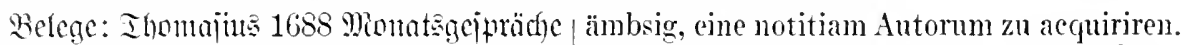
I 461 sich eine gute notitiam von denen Marperger 1717 Beid). Der Banfen $\circlearrowright .19$ Autoribus, deren Schriften Hände und Füße da hingegen eine schöne Gelegenheit. dieses haben, aequiriren - 1691 Bermunttehre oder jenes zu aequiriren ans den Händen II 241 solcher gestalt bemïhet er sich so gelassen werden $\mathrm{mmB}$.

Pfquijition ₹. bei Rot 1571 als "erlangung, getvinn, bberfommung" gefutht = Iat. acquisitio. Eeit Dem 18. Jahrl). aber fonfet 'Die Erwerbung, Das Erworbent' unter Einflup von gleidhbes. jro. aequisition: meben ber Bezichutg auf Eachen (1)

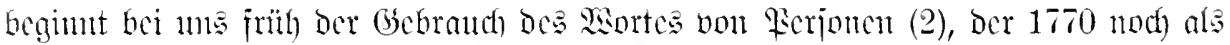

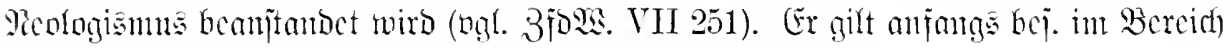
Der llniverjitäten (a) 1mb Der Bübute (b), fpäter alfogencin (c).

Belege: 1. Ramler 1753 an Gifeim (II 50)|Tode ron Karolina Beck machte diese daß ich mich über ihre nene Acquisition Bülne die unschätzbare Akquisition der ungemein freue [betr. bon Sauj cines Demoiselle Witthöft - $匚 .75$ Das Theater "3chnten"]. 3ifland 1795 Echeinveroient hatte das Jahr zuvor an Herrn Julius (IV 32) Dieser Xero [Büjite] ist die Krone Quaglio eme überans schätzbare Akquisition meiner Acquisitionen.

2a. 1769 baflijule gel. 3eitung @. 536 Herr Magister Schirach ist als Professor Philosophiae nach Helmstädt bernfen worden, zul welcher Acquisition wir der Universität nicht anders als Glück wünschen können. Edfiller 1795 Ririeje IV 313 so viel kamm ieh mit Gewißheit versichern, daß unsere Akademie an diesem Nanne keine unwichtige Acquisition machen würde.

b. Edfiller 1796 Rrieje IV 462 sie spricht überhaupt mit großer Kälte ron dieser Acquisition für das Weimarische Theater. 1797 cbo. V $148 \mathrm{Zu}$ der guten Aequisition für die Oper wïnsche ich Glück. ifflanto 1798 Iheatral. 2aufbalin $\Xi .57$ Nach dem gemaeht.

c. Echifler 1795 Brieje IV 98 Ein Mam, wie Göthe, der in Jahrhunderten kanm eimmal lebt, ist eine zu kostbare Aequisition. Sabebue 1806 Ergane Des Gehims (XX 58) Da hab jch eine herrliche Acquisition gemacht. Golth 1847 Buch Der finoheit ङ. 245 Das war so eine Aequisition für meine Phantasie. Grojmam 1847 (bejellidaft ङ. 180 daß eine reiche Frau für einen armen Lientenant eine schätzenswerthe Aequisition sein dürfte. Frentag 1850 Endl 11. Şaben I 171 Eine gute Aeqnisition, rief die gnädige Fran erfreut, denn der Licutenant war, was man einen geistreichen Offizier nemnt.

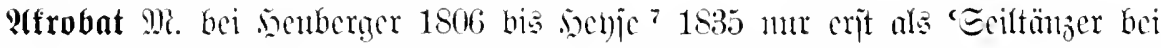

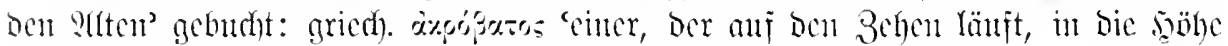

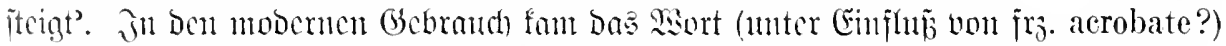

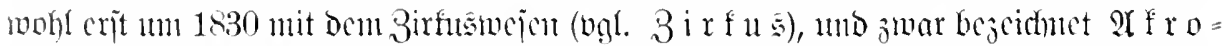

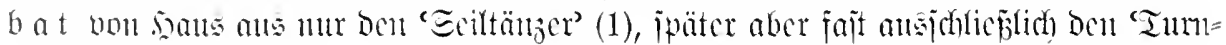
fïntitler' (2).

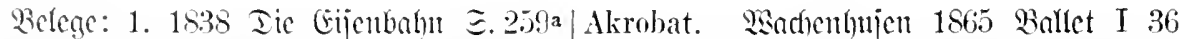
Abwerhsehd mit diesem Seelengennsse pro- die Kunstreiter- und Akrobaten-Gesellschaft. duzirt sich Herr Pietro Bono, der bekanntel (Goltb 1869 siselffugheit I 290 Wir können 
an ihnen Taschenspieler und Akrobaten | er war auch Turner und Akrobat. Etmoe

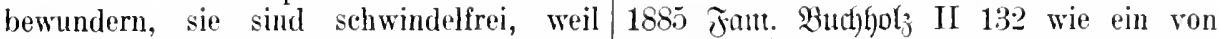
sie eben mit dem Schwiudel umgehen. 2. Fontante 1882 Q'צfoultera $\Xi .134$ ment sucht.

kräften gekommener Akrobat, der Engage-

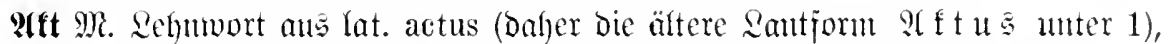

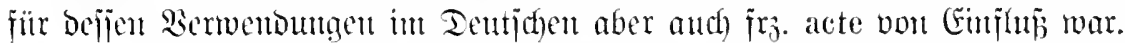

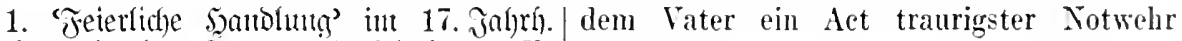

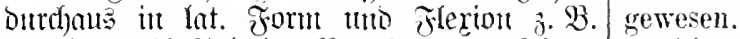

Carolus 1609 Pielation $\mathfrak{M r}$. 38d bey welchem

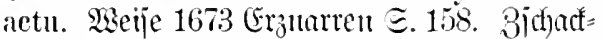
twiz 1723 Sarl VI. E. 663 Nachdem also der Actus der Crömmng vollzogen. $\mathfrak{B g l}$.

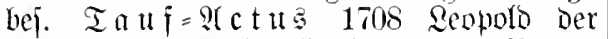
Groje II 164 . Goectingf 1776 ant Bürger (I 320). 2(ud) it Der mobernen Epradhe ift bas wort in biejer Bebentuna nod meijt

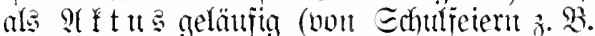

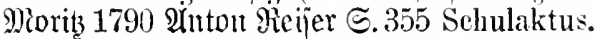
Prnot 1858 sanderungen ๔. 112 zu einem feierlichen actus des G5mmasiums), wonteben aber aud $z$. B. Fe it a $\mathfrak{t} t \quad 1884$ Bühnen= almatnad) $48,113$.

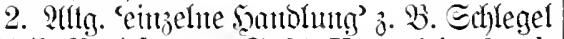
$1801 / 2$ Borlejurgen ङ. 91 Unstreitig durch eimen absoluten Akt, ohne uns auf $\mathrm{Er}=$ fahrungen und Schlüisse zu gründen. Evpielbagen 1866 Jit Reil) unto Gáted I 237 Was

Sjierber nod bie Bujammenjetutugen:

(iscualtaft Frentag 1859 Squïäbe I 217.

(G)aduaft 5acflämoer 1841 Eoldaten= leben $\Xi .86$. Senje 1873 Ginder Der I 126.

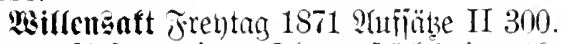

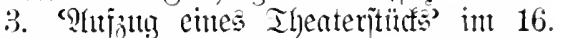
Ialhrf. meift actus. Beleg fïr $\mathfrak{A} \mathfrak{f t}$ : Bape 1605 Tonta $\mathfrak{A} 5^{\mathrm{a}}$ Im ersten Act.

4. :Ul: Terminuz Der Malerei "Etellung eine: 9)obel[s? tmo 'Die Dantach entroorjene Efizje’ erit int 19. Jahrh. bejengt. Belege: Rewals $18: 36$ Saunarlle II 204 die widerwärtigen Zugaben eines Malerateliers: eine Suite ron Todtenköpfen, Todtenmasken, ferner Puppen und Acte, Theaterkostüme. Gutbforo 1852 Ritter vout Geijt III 287 Für die Aufnahme lebender Akte.

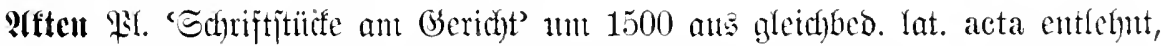

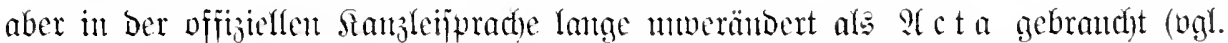

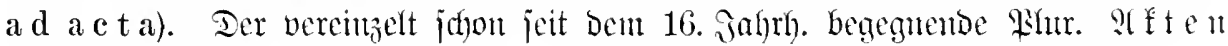
(1546 Motariat u. Rhetorif $\Subset .4^{\text {b) }}$ hat jid erit im 18. Jahrh. Durdhgejebt.

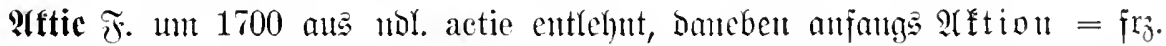

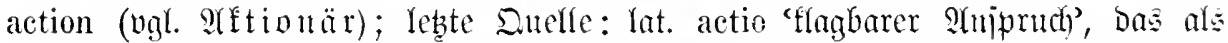

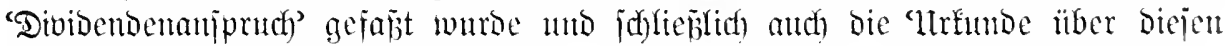

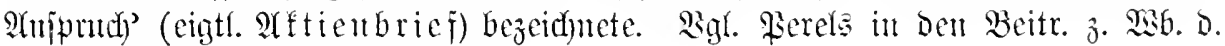
D. Redhtsipracte (1908) Є. 77. 80.

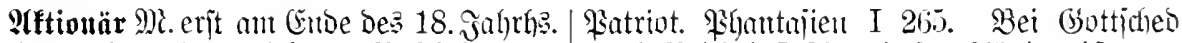

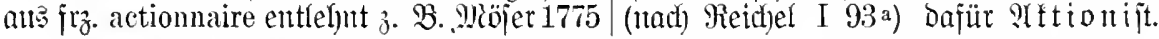

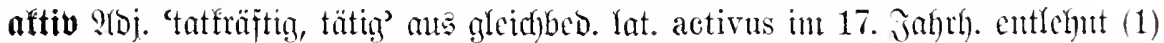

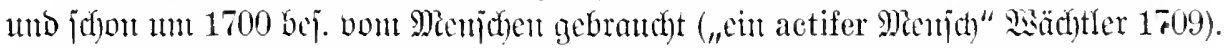

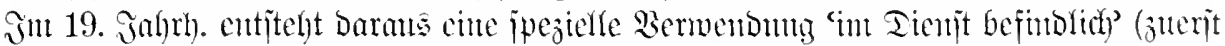

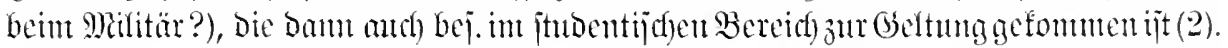

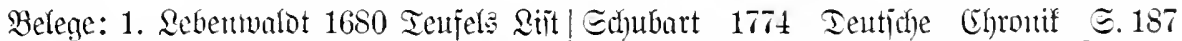
II 17 Wiwolen diser Einflub Corporalisch er ist munter, arbeitsam, activ. Savater rnd materialisch, so ist er doch überanß 1778 Rhgïignon. Fragmente IV 51 ron subtil und spitos, consequenter mehr activ einem lebhaften, aktifen, leicht bewegliehen vnd geschwind mürckent. Miseib̆bad) 1732 গur Charakter.

๔. 58 daher ist ein cholericus immer activ 2. Eforuromef 1895 Biom Fela zum und munter. Ginethe 1774 wiserther (XIX 56) Meer XIV $305^{a}$ daß man bei ejniger Energie Meine Mutter möchte mich gern in Aetivität Aktirsein und Arbeiten ganz gut mit einander haben. Bin ieh jetzt nicht auch aetiv? vereinigen kömne. 
Pftiva 'ansitebende Fojten, Forbenmgen' als Term. techn. Der Sanjmann:

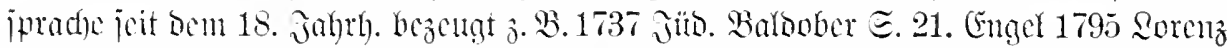
Etarf $\Xi .412$ ob die Alitiva der Wittwe ihre Passiva wenigstens balancierten. Yft $\mathrm{i}$ a iteht furo fïr cight. debita activa (bei Eticler 1691 Ep. 1939), bas aus g)

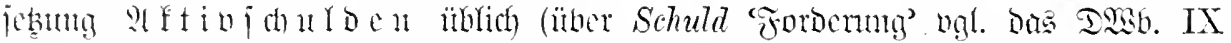
1872) 子. B. Bürger 1773 Bricfe I 160 Ich rerzeichnete sowohl meine Passiv- als Activ-Schulden. 2agl. Pa aji

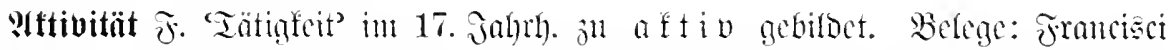

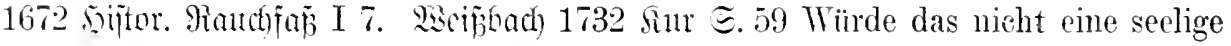
activität seyn, wenn du fleißig wärest und busse thätest. Gocthe 1774 然er领er (XIX 56) Meine Mutter möchte mich gem in Activität haben. Edhnbart 1774 ofrounif

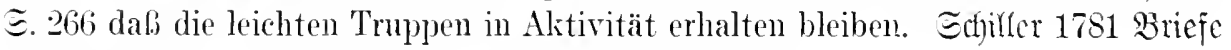
I 33 Bruder! Ich fange an, in Activitaet zu kommen.

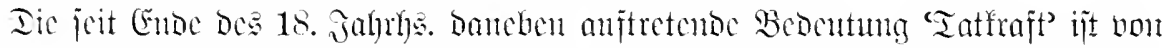

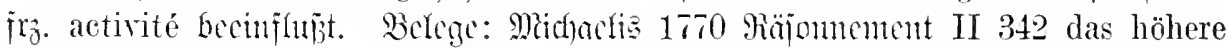

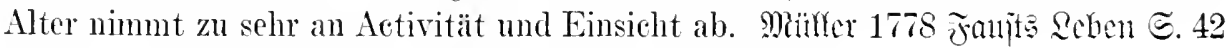
überm Geschwätz verliert man endlich alle Activität.

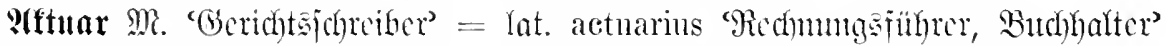

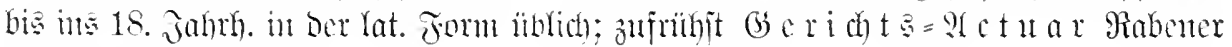
1759 Eatiren III 93.

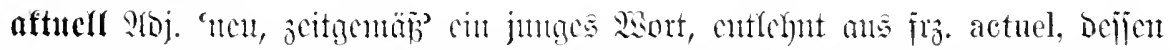

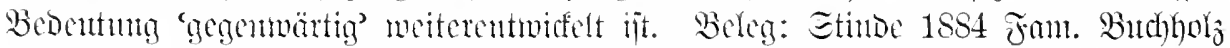
I 172 das ist zwar Alles noch ziemlich neu und aktuell, wie sie immer sagen, aber was weil, ich von diesen Dingen.

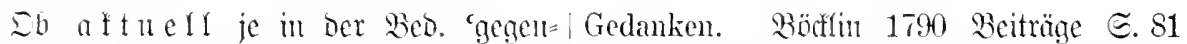
wörtig’ übfich gewejen ijt, wie Eamme 1801 actuellörbar. Echiffer 1796 Brieje V 76 maibt, Darf beztweifelt merben. Anferbings Es wird interessant sein, den actuellen iit eg jifhon in 18. 19. Jahrh). jull belegen, Zustand der poetischen Lectüre in deutschen

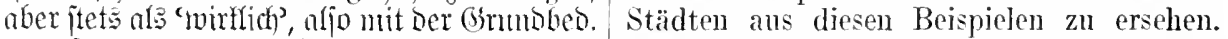
von frò. actuel. Bełege: Eperanber 1727 Snube 1837 Seijenobellen VI 196 Freiligrath Sandicrifon $\Xi .12^{\text {a }}$ eine actuelle und lieine der kühnschweifende ist ein aktueller Heereingebildete Krankheit. Snuater 1778 Frag=| fiihrer dieses Kreises.

mente IV 4 die geheimsten seiner aktuellen

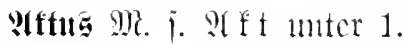

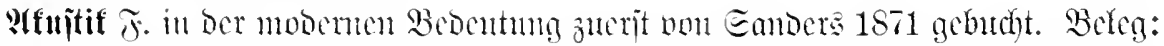
Etinde 1885 Jam. Bubhyoly II 16 Ich rerstand leider kein Wort, weil die Akustik im Wintergarten verworren ist.

QI f u it if iit aher eight. (Gehörlehre daß ilmen die Optik die erste aller Wissen-

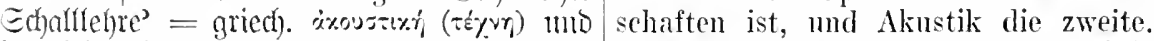
in biejer Bebentung jonon im 18. Jahrh. afutition S(bj. Ed)eibe 1745 Britijer belegt z. B. Eulzer 1774 Theorie II 579a Mnicus E. 90 in den acustischen AusDarum mub der Bammeister den Chor nach rechnungen. Eemme 1803 Epajiergang den Regreln der Akustik oder der Wissen- (II 149) das alustische Kunststïck. schaft der besten Verbreitung des Schalles $\mathfrak{s a n n e r} 1865$ Miujifidule (VIII 131) der einrichten. Bürne 1823 Echilformugen ans scenischen und akustischen Konstruktion Faris (II 144) Die Franzosen sind zu loben, eines mustergültigen Theaters. 


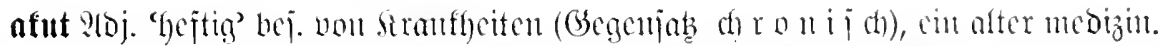
Fadyandrudf (lat. acutus morbus u. ä.), ber aber erjt jeit (Eampe 1,13 gebutd) miro.

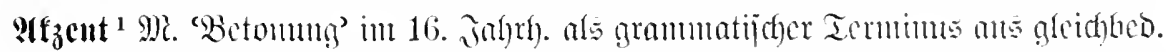

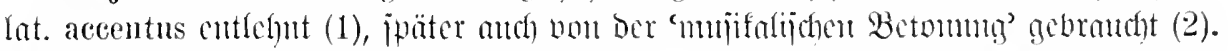

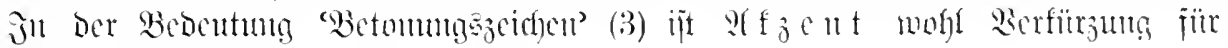

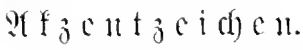

Belege: 1. Ebertin 1521 Bumbesgenvijen (I 60) im läsen oder anbsprechen wissen sie nit den rechten accent auch geneiner wort. ¿nits 1621 Pocterei E. 41 Wiewol die Frantzosen rnd andere, in den eigentlichen namen sonderlich, die accente so genawe nicht in acht nemen. Simter 1752 an Giteim (I 357) sie hat sie den lieben Gleim, mit dem Accent auf das Wort lieben, genennt.

2. Frätorits 1619 Eyutagma nulicum III 147 mit langen Gruppen, Trillen und Accenten zu rechter zeit gebraucht. Print?

1676 政rum $92^{\text {a }}$ zu singen angefangen und die Tocales mit cinem wunderschönen Accent heraub gestossen.

3. Ettner 1715 Gebanme $\Xi .97$ des Hebräischen ABC über- und untergezeichnete Pünctlein, Strichlein, Accente und andere Zeichmungen.

af zentuieren Btw. zuprillit bei Eperanber 1727 gebucht: ans mlat. accentuare. Belege:

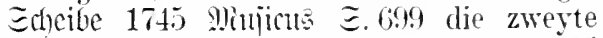
Note aber ist accentuiret. Qiditenberg 1795 sogarth II 212 .

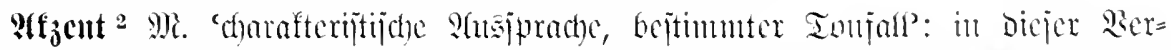

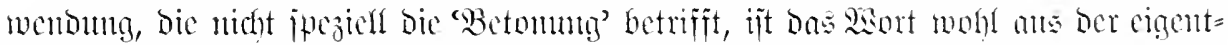

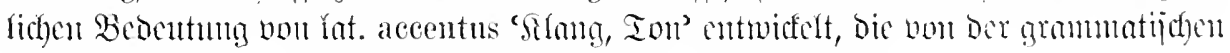

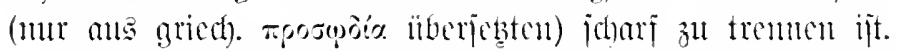

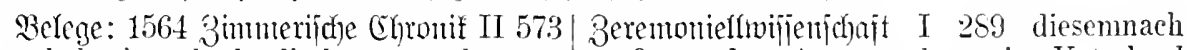
Der hab in oberlendischer sprach ver- mu er den Accent, der sein Taterland stendtlich und in dem accent, wie weilmnt vermuth, weglassen ind sich einen andern graf Endres sellig in seinem leben geredt lat, angewölnen. 1737 §ïs. Balsoher 〔. 198 geantwort. 1684 Teutichlano ïber Franf= warum jie] anch gar keinen Holländischen, reicf) müssen Französisch reden, und hat er den Middaclis 1773 9iäionnement III 7 so lernt rechten accent nicht, heisset man ihn einen er doch den Accent der Sprache nicht.

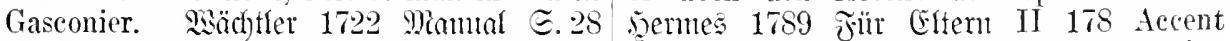
er redet gut Frantzösisch, hat einen guten ist das, was unter Tansenden, welche eine Accent. Etoppe 1728 Geobichte I 128 Wenn Sprache erlernen, kaum zehn haschen können: jch noch so nette reden will; Felılt mir der den Nachdruck nicht dahin zu legen, wohin Accent und das Geschicke. Mohyr 1728 die Muttersprache ihn legt.

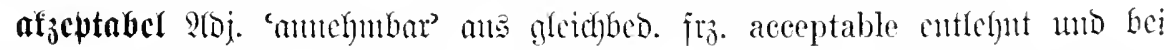

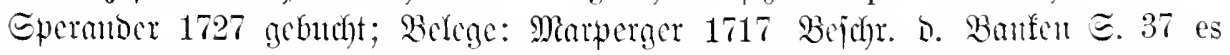
wïrde jederzeit ein solcher Vorschlag anch denen reichsten Potentaten acceptable seyn. Refining 1775 Bricje (XVIII 13). Silter ijt

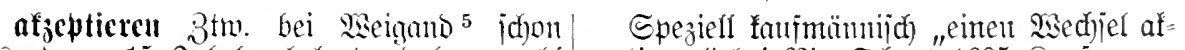

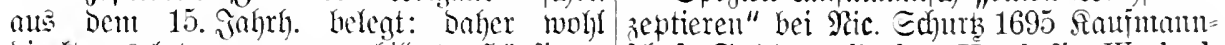
bireft aus lat. acceptare gebilbet. Б口äufigere jofaft $\widetilde{\varsigma} .14$ zur lincken Hand die Wechsel, Belege feit Den 17. Jahth. 3. 23. Carohts so sie einzmnehmen und ihnen aceeptirt

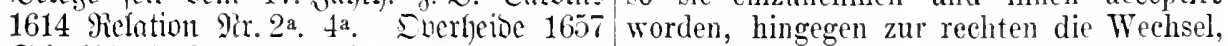

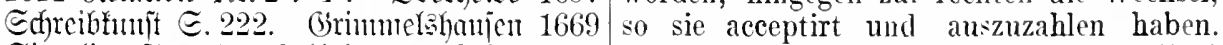

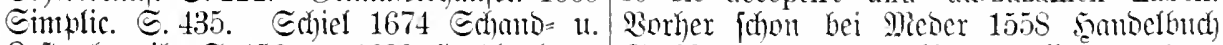

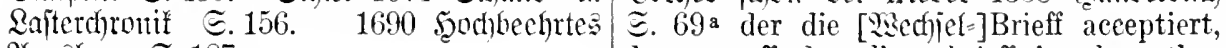
Ifugsturg $\subseteq .187$.

das er auff denselben brieff bezalung thu.

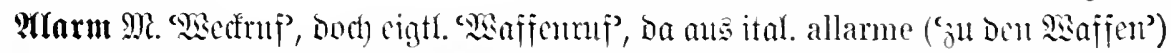

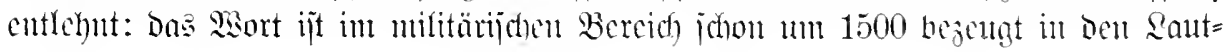




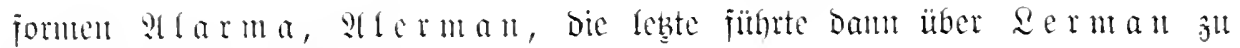
Der Ëindoutidung Lärm.

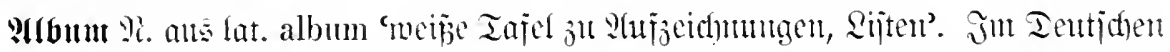

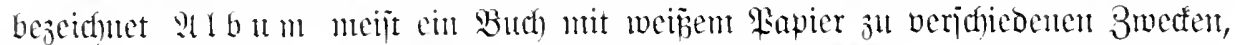
j. B. ijt nad Pehring 1684 Manuale $\Xi$. 112 Album die Matricul, ein Namen-Buch, ein Stanm-Buch .... ein Register, Ingleichen ein Gerichts-Buch, Protocoll, Urtheils-Buch. Plls 'Potizenbudj bei Prätorius 1666 P(nthropodem I 243 wie meum album daron ein hunststïcke hat, in Leipzig verfertiget, im Jar Christi 1654 am 10. August - 244 wie daron mein album zenget. Ju 18. Jahrh. aber meijt un:

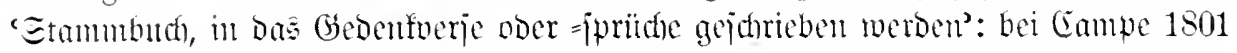

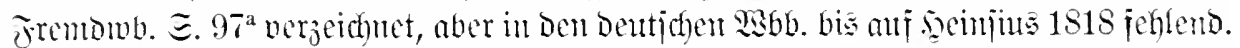

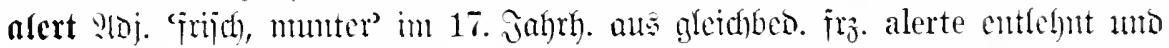

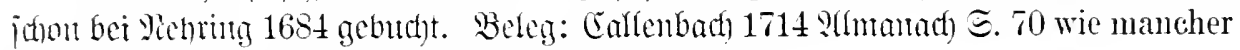
galante homme stellt sich allert, macht fein Figur.

Shuj̣ällig bie ältere Mebenform a $\mathfrak{a} \mathfrak{r} t$, und in guter Positur antraffen, funden sie sich bie allein bei Bold v. Wertheim 1711, neben schröcklich betrogen. Pooagra 1721 S(potbefer= a lert bei Epermber 1727 verzeidmet ijt. too $\Xi .42$ Recipe edlen Thée, der wird dich

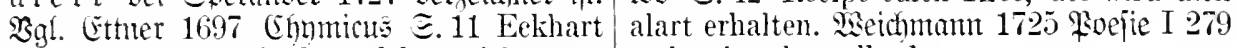
rersuchte sein Pferd, welches sich ganz so ist sie schon allard.

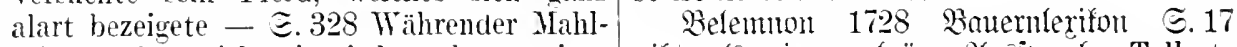
zeit machte sich ein jeder alart, seiner gibt als eine wulgäre ?hajprache Tallart: Geliebten zu gefallen. 1708 Seoporo der jedenfalls twird aud ans modernen Mand:

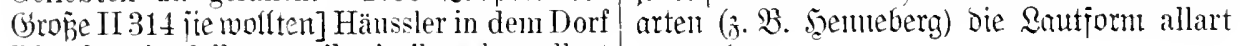
Dinsele überfallen, weil sie iln aber allart angegebent.

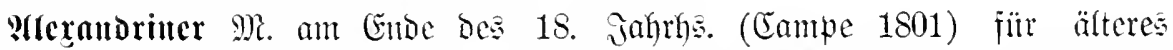

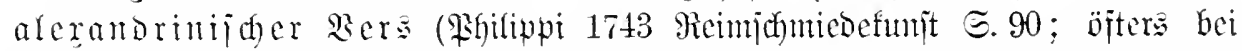

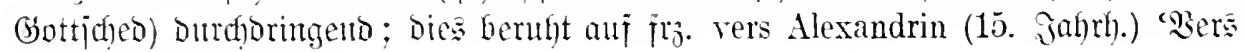
Des ?llerantoerromtans.

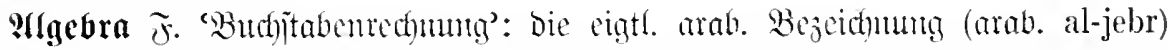
murbe ill ber latinijierten Form herridend (= ital. algebra) 3. B. Edfwenter 1636

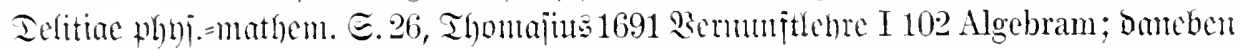

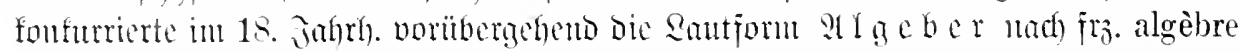

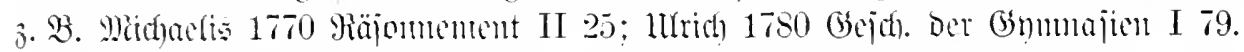

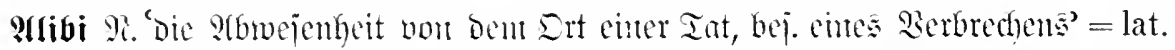

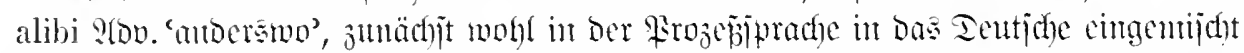

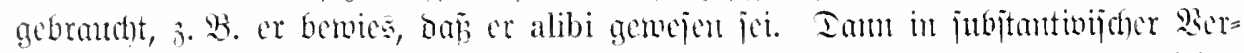

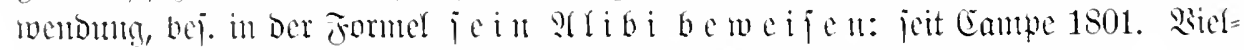

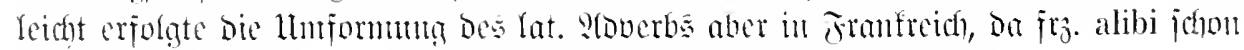

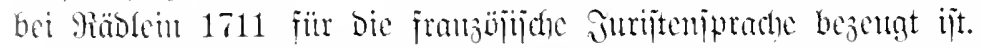

Belege: Meijter 1783 frlieg. Blätter $\Xi .75$ nicht nöthig gehabt hätte ein Alibi zu Dieses kann der Zustand des geschwächten br Iäidchens, besonders auch berm Angeklarten die Lnerweislichkeit des Alibi zeigen. Pitîter 1811 criminaliälle I 93 indem er weil er in der fraglichen Tacht zul Hanse war, der 'That nicht rerdäehtig war, also des Verfassers die Ansflucht des Alibi für behanpten - 193 weil dem H. B. alles darauf ankommen mußte, das Alibi in dem entscheidenden Noment darzuthun - 198 Beweis des Alibi. Bärne 1829 Irantaturg. Biätter (II 3-2) so lange mag das Talent 


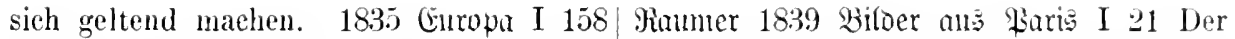
Dieb Alibi wird stark in Zweifel gezogen. Beweis meines Alibi's kam aber leider zu spät.

Ylimente Ril. 'Untergaltsgeloer' = lat. alimenta: erjt bei Compe 1801 ge= budt; vorger bei Eperander 1727 Aliment, Mefring 1684 Alimentum, aber unr in

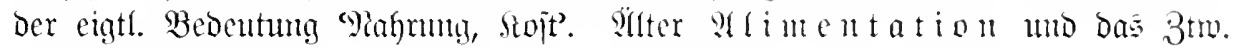
a lime nt i c re aus mlat. alimentatio und alimentare (13. Jahro.).

alimentation $\mathfrak{F}$. Enjutger 1590 Rela= tionen I 28 Alimentation oder viderhalt fïr ihre Predicanten. Miengering 1661 Gerviljensed)t $\Xi .945$ So haben auch die Rechte solchen unehelichen Findern ihrer Vater Erbe versaget, und sie mit einer geringen alimentation abgewiesen. Bahrot 1790 Rindoigins I 238 Letztere bat um ebenfalsige Alimentation ihres Kindes, damit der Herr Magister in Ochsenhausen sie beehrt liatte.

alimentieren 3 trw. Saur 1583 ङtrafbuch ङ. 154 so ist auff erforderung der B. schüldig, sie die $\mathrm{K}$. zu dotiren, das Kind, so eins deBhalben vorhanden ist, $\mathrm{zu}$ alimentiren. 1607 I fommenoori $=$ iche Chronif $\approx .113$ welche alle 85 Soldaten dis pawern haben gratis alimentiren mussen. Mengering 1642 Gentijenstüge $\Xi .902$ Wer eine Jungfrau zu Falle bringt, und ehelicht sie nicht, wil sie auch nicht ehelich begaben, wil auch etwan ein in der Hurerey erzeugtes Kind nicht alimentiren.

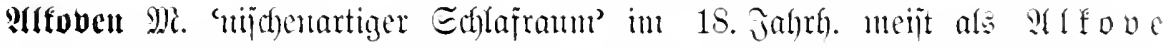
entiprechend frj. alcove (bas aber Femin. ijt) j. B. Decfer 1711 Fürift. Sanmeijter

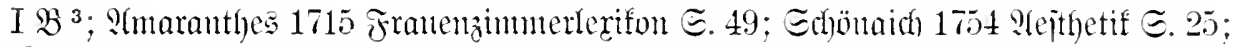

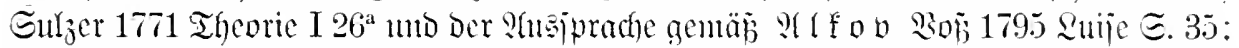
Bifiter $181 \pm$ Crimunaljälle I 116 des Alkofs. Tas siort hatte aber meijt jomadhe Flerion (Sboctingf 1776 an Bürger [I 333] was im Alcofen passirt. Suligge 1792 Reije $\subseteq .21 S$ zu einem mit einem Alkoven versehenen Zimmer. Sokebue 1802 Slein= ftäoter [XV 35̄] hinauf in den Alcoven) und hierans crgab jidh in 19. Jahrh. cin ?tom.

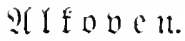

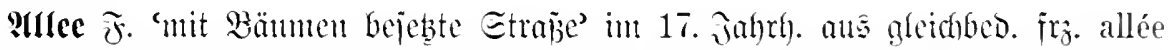

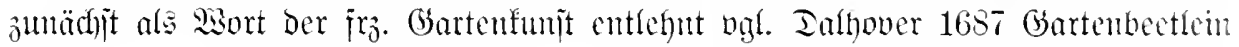
$I \mathfrak{b} 3^{a}$ mit jhren nach wol in Acht genommener Gartens-Architectur angerichteten comportamenten, Blumen-Schulen, Bethen, Gängen, Alleen. Jnt 18. Jahrl). iit:

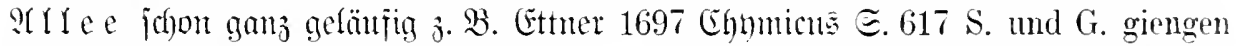
einen andern Weg, in die herrlichen aleen. Mentantes 1702 Merlicbte sidt $\Xi .137$ er ging auff eiue dick belaubte Allée zul.

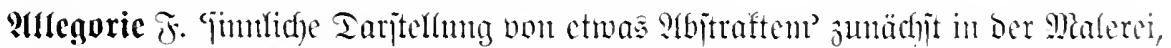

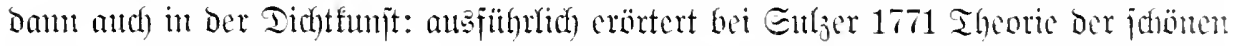
Sïunte I $34^{a}$ Allegorie in zeichnenden Künsten. Bgl. nod) Nimctelmann 1766 Sicrud emer ?flegorie $\Xi .1$ Die Allegorie ist. im weitläuftigsten Verstande genommen, eine Andeutung der Begriffe durch Bilder, und also eine allgemeine Sprache, rornehmlich der Künstler, für welche jch schreibe: Denn da die Kunst und rornehmlich die Mahlerey eine stumme Dichtliunst ist, wie Simonides sagt, so soll dieselbe erdichtete Bilder haben, das ist, sie soll die Gedanken persönlich machen in Figuren.

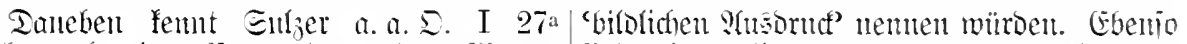

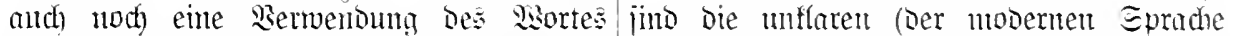

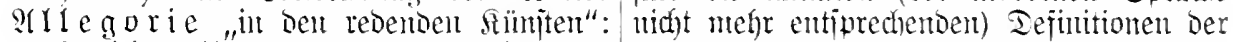

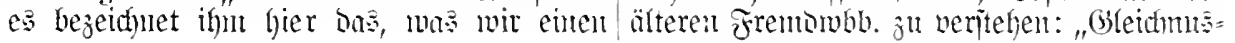


Rebe, verblïnte Rebe" Enerander 1727, / fïlyrt mul bireft anj bie tednijhe (beltung

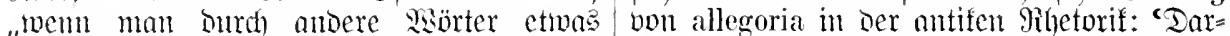
anders veritehet, mo verbiülmmt giebt"

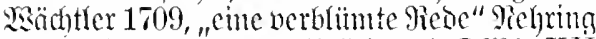
1684 (iiber verblïmt 'Gillolide' bghl. D2: 146. 147). Belege: 2uther 1521 gegen Emier II 88 Darumb es gar ein grob vmuorstand ist, das man die allegorien, tropologien rmnd der gleyehen will geyst heyssen 1543 Edhem somplyoras $53^{\text {a }}$ Was nu etliche Veter in diesem Spruch spielen, mit Allegorien. lassen wir faren. Mathefius 1566 Suther $\Subset .77^{\mathrm{a}} \mathrm{Ob}$ wir aber wol die vergangene jar, auch wol nach grosser leut Exempel, $\mathrm{rmb}$ dise zeyt allegorien wnd lnstige materien gehandelt. Miengering 1642 Gervijjensiüge ङ. 1458 daher kommen seltzame Gedanken and allegorien, heimliehe vngereimbte Deutung, vnd wunderliche Aublegung der Schrifft.

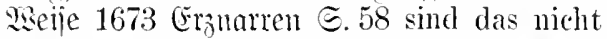
Worte, und wird die angefangene allegorie nicht schön aubgefïhrt.

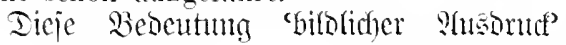
itellutig ciner allgenteinen Salhrljeit unter cinem jumlict)en Bilbe'. Bgl. and folgende Etelle, Dic Dic Etrmologic Des Warte?

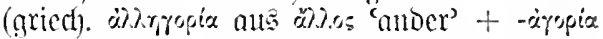
(Epreat)en') antentet: 1529 Borrede z. D. Büricher Fropheten Allegorey ist ein red, in der man rns etwas anders fürtreyt, vnd anzeigen wil, dann die wort lautend rnd gestaltet sind. Jedoch so ist die Allegorische red allweg der maß gestaltet, das man durch sy die warheyt, gleich als ein gstalt in einem spiegel glaß, oder etwas durch èin glaß sicht.

Mnit Diejer rhetorịchen Grumbbebentung ift aber and) Der modene (b́ebraud) zu ver= binben, Der ben gleidhent tedmifichen guhalt (iimuliche Iariterhung von etros lumiun=

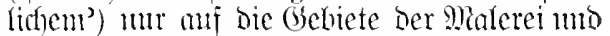
Tidhtfunit übertmig. Tie burch Berall= gememerung entitandene Bebentung "billo=

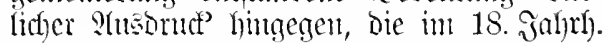

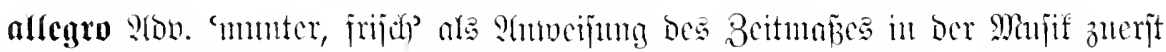

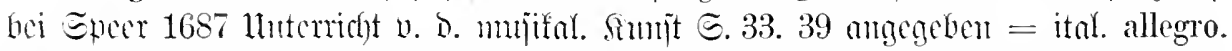

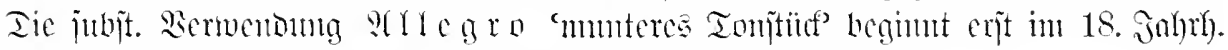

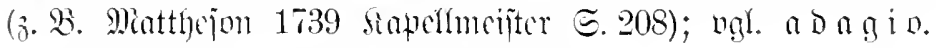

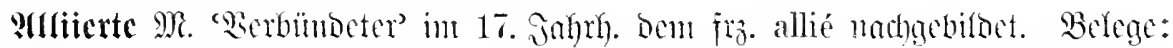
1684 Getrijit. Eutrota $2\left(2^{\mathrm{b}}\right.$ Spanien und derselben Cron Alliirte fanden solche Proce-

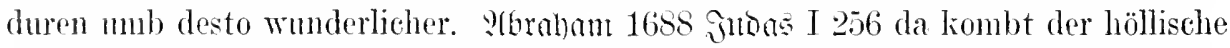

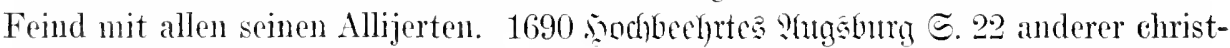
lichen Reichs-Alliirten. Fricorich I. 1700 Bricfe $\subseteq$. 83 dam die allyuten Thre tromppen vom Rhein und Italien werden zurïcke zichen mül.sen.

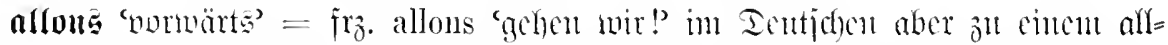

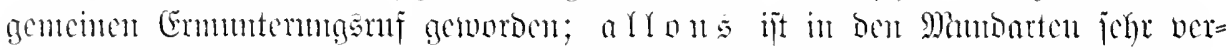

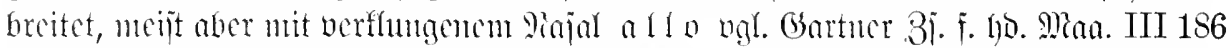

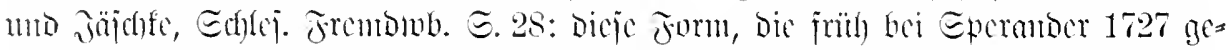

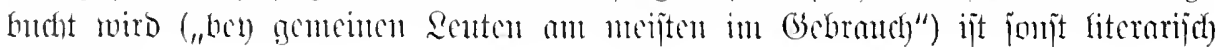
nubezengt.

Belege: Reuter 1696 Edhelmuifsfy E. 15 Nim allons, Bruder Schellmuffsy, ein Hundsfott, der mirs nicht auch Bescheid thut. Ettner 1698 Crimurgne $\Xi .739$ allons, wir müssen ihm entgegen reiten. (Gallenbad) 1715 Enaji $\Xi .48$ Allons, Burß, laßt mere ('ourage hören. SEnguer 1766 stubermöroerin

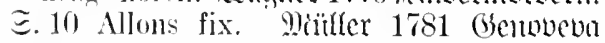
כ. 86 Allons, eins Bramntwein gesoffen. ififlano 1798 Epieler (IV 177) Allons, fort.

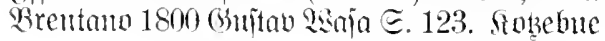

1806 Brombichntimta (XX19) Allons, Sehwiegerpapa, was ist anzufangen. Stener 1811 Sieifejdatten ङ.25. ज̈̈̈ger 1835 Felix હdhnabel $\Xi .215$ Allons, jetzt ruf. Debrient 1839 Fabrifant (II 299) Allons, mein Fremnd, fort mit den Rachegedanken.

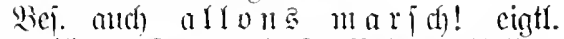
ein militör. Sommtanon? Relege: Callent= bad 1714 llti ante hac $\subseteq .36$. Siflano 1785 Finger (1 12). frotsebne 1812 Sindter Feld= tïmmel (XXYII 206). 


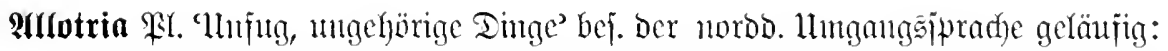

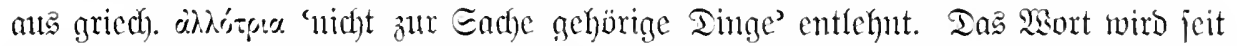
Den 17. Jahrly. In Der Eprache Der (Gelehrten gebrand, bürgert jich aber erjt an

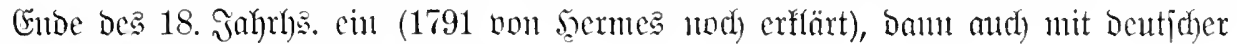
Rhuralending als arlotrien.

Belege: Mengering 1642 Getwijen: $=$ schweife und allotria sich auf sein Hanptrüge $\Subset .1420$ Nein, nein, nuanche Gesellen Thema spielen will. Miculai 1762 Qiteratur= bringen offtmals [iı ben Prebigten] gar allo- brieje VIII 393 Die Allotria bleiben Allotria. tria ein, nnd die sich anff jlıre Zuhörer vnd ந̧ermes 1791 Qiterar. Mä̈rtbrer I 78 für derselben Zustand reimen als wie cin Faust Ãllotria [?H1n.: Fremde Beschäftigungen] aufs Auge. Thumafus 1688 Montatigejpräde also bleibt weder Zeit noeh Geld übrig.

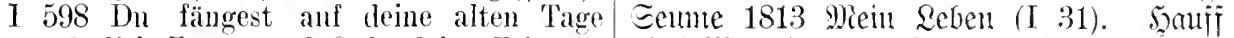
wunderlich Zeng an, daß du deine Zeit mit 1826 mientomen des Entan 1 115. Echaufe Schulbüchern verderbest und also lauter 1834 Bifoer ma ber Wirffichfeit 厄. 25. allotria fümimmst. 1738 Surze Excerpta Frentag 1853 joumaliften ङ. 141 . Marler ङ. 4 und seine monita seynd schlecht, und 1860 milit. Bilberbuth $\Xi .243$ sich mit

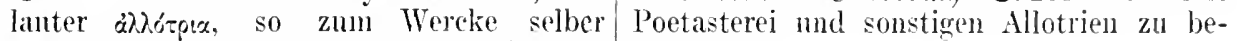
nicht gehören. Wihilippi 1743 Reimidumiebe= schäftigen.

furit こ. 202 wenu einer] dureh viele Um-

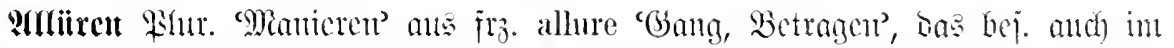

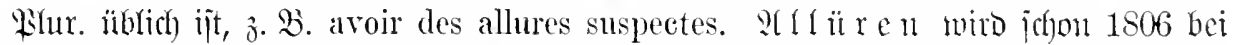

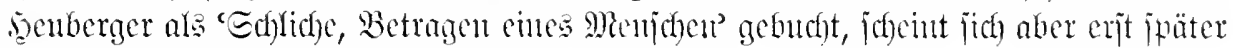
red)t cutzubürgern.

Belege: Fïnffler 1840 Eüoüjtl. Bifoerjan Unternehmungsgeist und untadelhaften AlI 236 So ein scheues Reh ['Miäbchen'] hat lüren. Fontane 1882 Q'?oulter E. 1 die uns ganz unbekaunte Allüren. Frentag seiner Lebensstellnng entsprechenden Allüren. 1855 Eull u. Şaben I 166 beide von großem

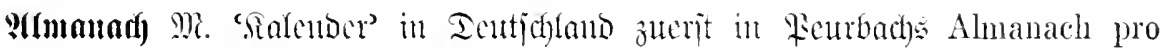
pluribus annis Sicien 1460 unto bei Sïutgsperger 1475 (quas vulgo vocant almanach)

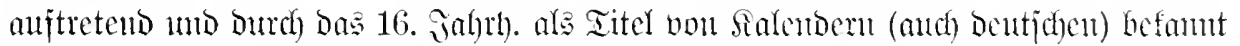
geworben. Friifje Belege für Das sgort (in lat. Sentert) bieten cinerjeits in England

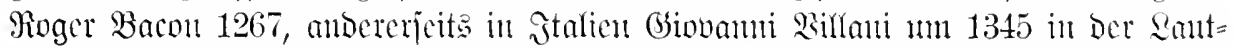

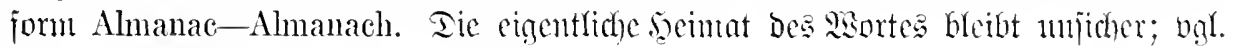
Murray, :eicict. I 246 .

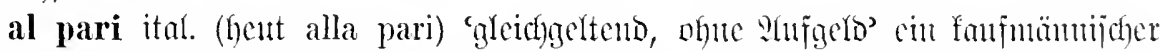
Iermints, Der feit Dem 17. Jahly). bei ma befannt ijt (gebucht bei Edyutb 1695

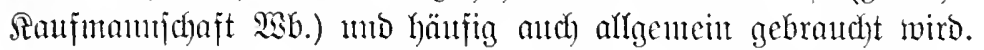

Belege: Etoppe 1735 Parnaj $\Subset .347 \mid$ die Ohrfeigen seien noch ein-oder zweimal Der Cours ist immer einerley Als der von al pari gestanden, wie die Kanfleute sagen, der Verändrung frey stets unter dem alpari wenn ein Weehselbrief so viel gilt als das

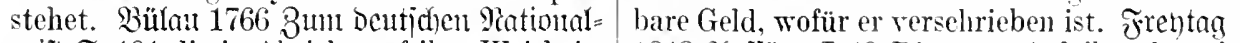

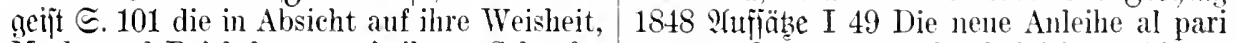
Macht und Reichthümer mit ihrem Sehöpfer zu veräußern, wäre selbst bei 6 Proe. Zinsen so ziemlich al pari zu gehen sieh berechtigt ganz numöghich gewesen.

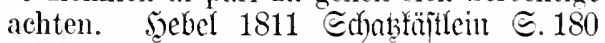

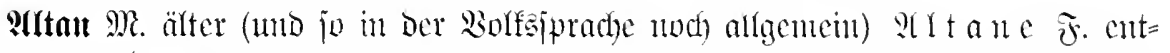

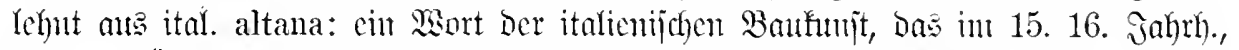

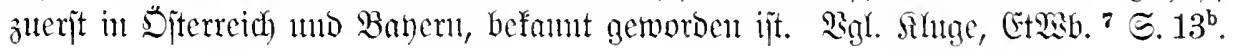




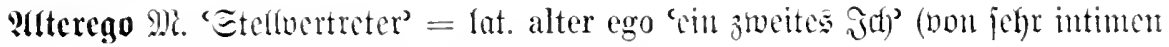
Freutben): crìt in 19. Gahth. hänffiger belegt.

Belene: Böne 1823 Ecrilberungen ans an den Alter Ego des Königs, den Grafen Zaaris (II 142) Überhaupt ist Herr Mayer R. de P. deshalb zu schreiben. Fallmeraner eine wahre Vizenatur. Diese selbst hat inur I 293 In der Umgebung des Alter Ego den Yenschen zu schaffen; für das übrige kaiserlicher Größe. Fontante 1897 Etechliut sorgt ihr alter ego. Wisitt v. Dörring 1827 ङ.154 Hartwig war einfach der alter ego, Trragmente II 33 der jetzige hönig von der mit Jeserich alles Nötige durchzusprechen Teapel, damals Alter Ego seines Vaters - hatte.

1830 ebo. I 400 Alles was er rermöge, sei,

altericren 3tw. meijt reflex. 'jich anjregen' in Der Solfajpradfe alfgemein;

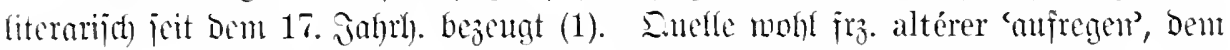
allerbings ber be uns häufigere reflerive (bebrand feblt. Bereinzelte Belege aus

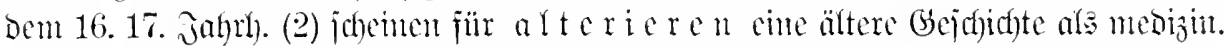

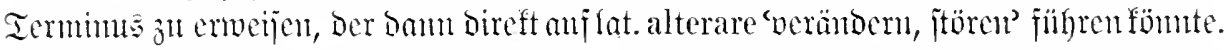

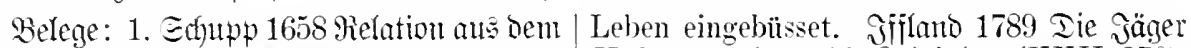

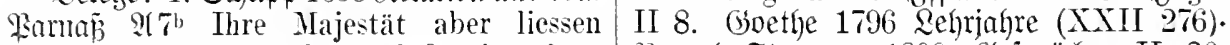
sich offentlich mercken, daß sie einen Berrzel= Sterma 1806 Ǵejprädye II 26. schlechten Gefallen darob hette, wie man 2 . ¿ebiz 1598 Felobaut 厄. 373 Wenn dann spürete, daß sie sich darüber zimlich sie [Bitronenbüume] denn auff das ort, alterirten. ca. 1680 Brubermoro (Eing!. fom. હ. 156) wie so erschrocken? Haben Sie sich vielleicht alterirt? Tentiel 1689 llnterrebungen ङ. $399 \mathrm{Er}$ wird zwar etwas alteriret, läst sich aber nichts mercken. Ettner 1697 Chymicus G.372 Der Fürst

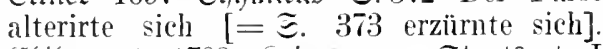
Efilemont 1702 strieg:= u. Etantärat I 286 Lber diesen piquanten Bescheid wurde der Türckische Ambassator sehr alterirt. Eallentbach 1715 Eilaii $\Xi .62$ ist der Kerl auch werth, dab man sich seinetwegen alterirt. Fleijuer 1730 seerr b. Rybio I 335 Thre Frau Liebste hat sich dergestalt darüber alteriret und bekümmert, daß sie abortiret und vor zwey Tagen ihr junges

wo sie hin sollen rnd dahin man sie versetzen will kommen sein, solte von stundan gleich desselbigen Abends dazu sehen, ob sie etwas verändert vnd alterirt sevent. Rrütorius 1666 96ntfrropodemus II 258 Solche werden ziemlich von der fremden Speise .... alteriret und etwas verändert. Reben= warot 1681 Tenfels Sijt VII 57 Man sihet ja, wie die Kräuter in hitzigen Kranckheiten applicirt, gantz außdörren, den Leib aber entgegen alteriren. (Ettner 1715 Seebanume 厄. 199 davon der Mensch alterirt und melancholisch wird. Balyrot 1790 Rebentäbejd)r. II 160 mich an den Wein zul gewöhnen, welches mein Blut sehr alterirte.

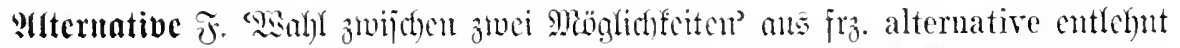

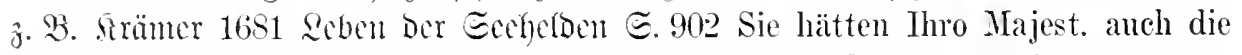
Wahl zweyer Altemativen gegeben [pleonajtijd werwirt]. Rënig 1719 Iheat. ceremon. I 862' er hat sobald in die besagte Alternativ ohne Veränderung eines einigen Puncts gewilligt. Bichacfwiz 1723 Starl VI. S. 99 als legte er ihm diese verdrießliche Alternative für, entweder zu den beyden Königen zu stossen, oder seine feste Plätze

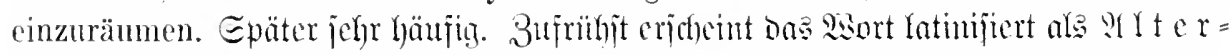
natioa bet Scibuiz 1670 Eccuritas putblica (I 231) Beruhets also auf der Alternativa, ob der Kï̈nig in England stille friedliebende, oder aber monarchische,

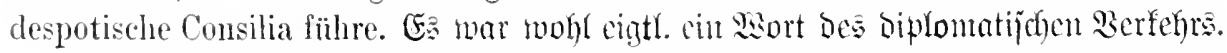

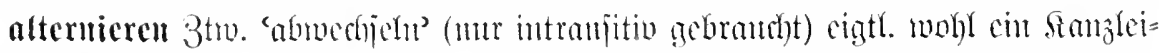

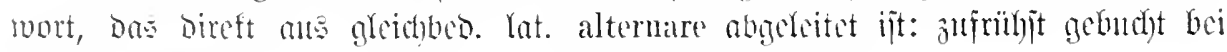
Pefrintig 16 it. 
Relege: Sucoe 1711 (Furnp. Shelicoul mit einander alterniren. Gebiffe 1789

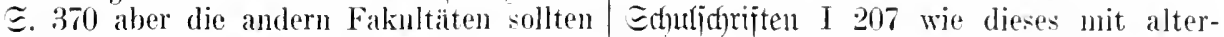
alterniren. Moht 1718 Etantäthtgheit $\Xi .785$ nirenden Lehrern beider Konfessionen beBey determinirung des Ranges derjenigen setzt werden sollte. Gö̈rres 18:1 Guropn Bedienten, die miteinander concurriren, ist $\Xi .37 \mathrm{im}$ alternirenden Vorherrschen der wohl gethan und gebrïuchlich, dab sie beyden chemischen Kräfte.

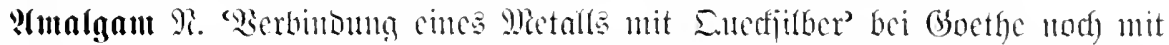

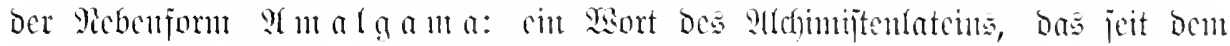
13. Jahri. bezcugt ijt. Ilriptumig bunfel.

aunafganticen 3tw. in ber cigtl. Bes. annalgamirt sich der scheinbare Kontrast

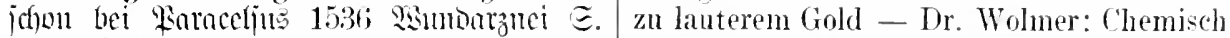

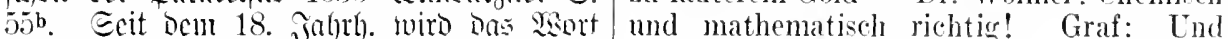
aber auch häufig libertragen als cimnig - was die Hauptsache ist - menschlich

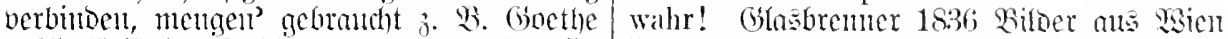
1795 CFifitelu (I 298) so liest er sich In I 207 er amalgamirt Spiel und Gesaner das Buch hinein, amalgamirt sich das so imiq, daß man Eines äber das Andere Fremde. Benzel=こteman 1806 (j)ipräche vergibt.

II $290 \mathrm{Im}$ Menschen und Menschenheil

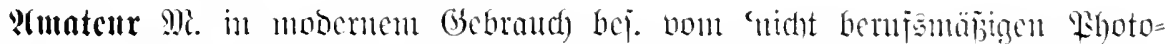
araphen' vgl. 1898 3citjdr. des Epradinercins 5.82.

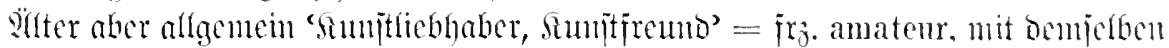

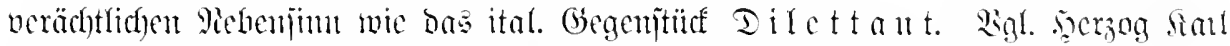
:Hugnjt 1783 an Merde (ङ. 363) die amateurs, Kenner und Gens de lettres. Edfubart 1789 Baterlandschronif $\Xi$. 182 Amateurs und Femmes de bon ton, die alle in drei Stunden Astronomie lernen wollen.

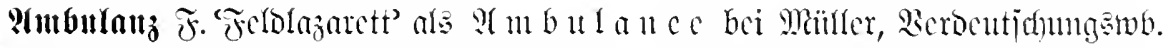

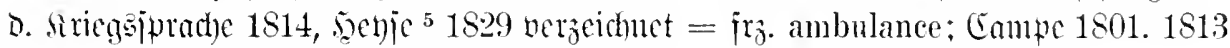
bictet Dafür a mbulantes $\quad 2 a j a r e t \mathfrak{b}$.

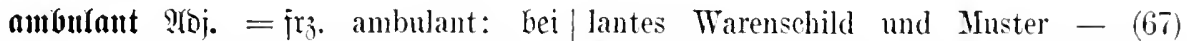
Compe 1801 bej. aud in a $m b$ u $\{$ a n $t \mathfrak{e}$ Wäre dieses nicht eine sehr gute ambulante

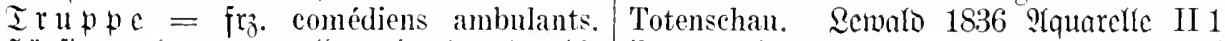
Söufiger aber gantz allgemein 'wanternto', ihren ambulanten Palast. Fontane 1895

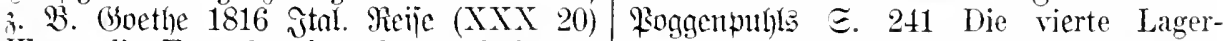
Wenn die Freunde über den ambulanten stätte, von mehr ambulantem Charakter, Wetterbeobachter und dessen seltsame Theo- war ein mit Rohr überflochtenes Sofarien gelächelt haben. Börne 1821 Poit = gestell. idfutede (I 64) seinen Hut, als sein ambu-

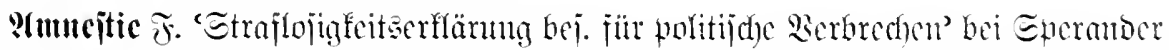

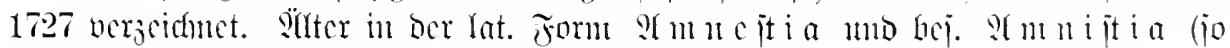

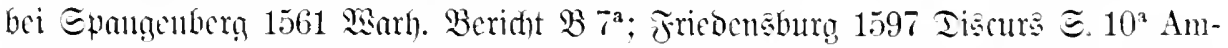
nistiam; 1643 Enradyerberber ङ. 2.2; Freiberger 1656 Folit. Iisfurje ङ. $9 \mathrm{Am}-$

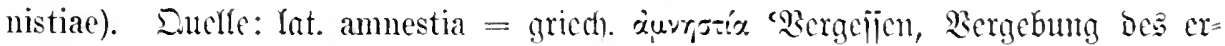
littenen ilured)t:

amortijieren 3tm. 'Edhulben ratenweije tifgen' crit in 19. Jahrh. als fauj= mämijâner Termimus geläufig gemorben. Belege: Gocthe, Fanjt II 6125 Und das Papier, sogleich amortisiert, Beschämt den Zweifler. Frentag $185 \check{5}$ ङoll u. şaberi I 33 dann zahlen sie ein halbes Procent zu an die Landschaft, und durch das halbe 
Procent wird noch amortisirt das Capital. Dutelfe: fro. amortir, mit ber gleidfen

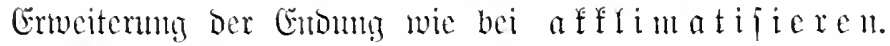

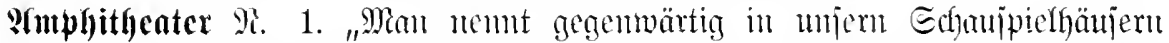

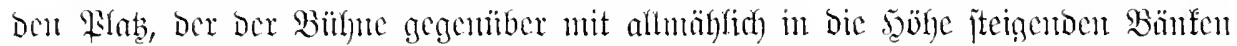

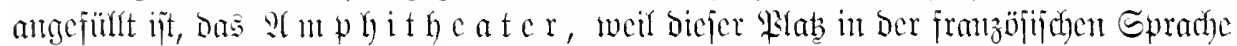

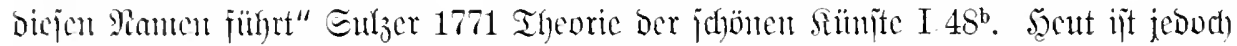

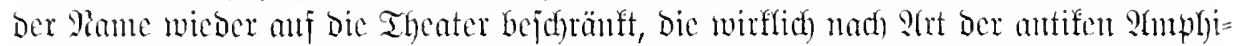

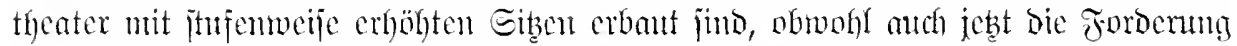

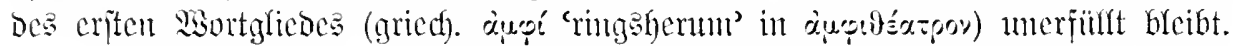

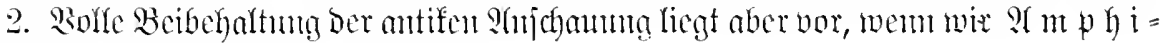
the ate $x$ ïbertragen gebrauthen

3. 3. 3idfactwiz 1723 Sart VI. S. 429 Die Vitte ihres Lagers hatte eine kleine in etwas erhöhete Fläehe, welehe gleichsam ein Amphitheatrum vorstellete. Meifter 1783 Frlieg. Blütter $气 .8$ mit dem Amphitheater ungehenrer Gebürgen begränzet. Goethe 1796 Briefe aus Der Edyweiz (XIX 287) wir sahen das beschneite Amphitheater der hohen Gebirge ror uns zugesehlossen. 1798 Shnaten Der D. Lluiber= fitäten ङ. 479 von dem dortigen Amphitheater von Berggärten die reizende Gegend übersehanen. Eeume 1806 Mein Eommer (IV 69) das ganze Amphitheater des Thals.

amplitheatralija Qroj. aus fat. am-

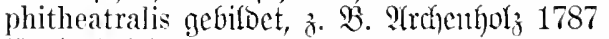
England II 87 die mogeheure WestminsterHalle, deren Höhe einer großen Kirche ähnlich und daher zu a.-en Einrichtmingen sehr bequem ist - V 15 Diese amphithea-

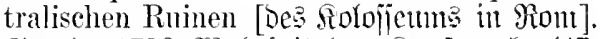

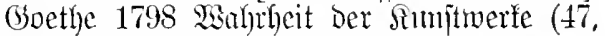
258). Anf einem dentschen Theater ward ein ovales, gewissermaßen a.-es Gebäude vorgestellt.

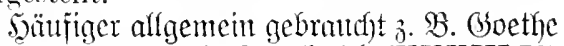
1822 Campagne in Franfieich (XXXIII 72) sie standen a. in größter Ruh mnd Sicherheit. Sgeine 1830 Sturlien (III 283) am Fuße von a.-en Bergen, die den schönsten Meerbusen gleichsam umarmen, $\mathfrak{B i t t} \mathfrak{v}$. Dörring 1830 Fragumente I 190 Ein großer Halbkreis, a. emporsteigend. Bechjtein 1836 Reijetage II 83 der halbrnnde und a.-e Saal faßt 500 Deputirte. Max $\mathfrak{b}$. Merrifo 1851 Rebeu I 120 des a. anfsteigenden, pittoresken Ufers - II 106 die a. gebaute Stadt Gibraltar.

antwuticren Btw. 'wegjichucion, ablöjen' aus lat. amputare in ber gleidyen

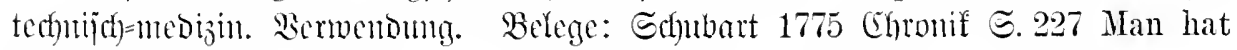
eine gewaltige Amputation mit ihm [ $\left.\mathfrak{B}_{0} \mathrm{olen}\right]$ vorgenommen, und doch fühlt's noch Schmerzen in den amputirten Gliedern. Sermes 1789 F̈̈r CEten II 275 wie ein abgehärteter Wundarzt, der die Säge ergreift, um einen Arm oder ein Bein zu am-

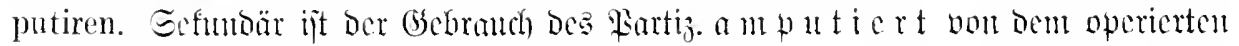
Menjd)en 3. B. Michl 1848 Eijele 5.78 wie zerschossene und amputirte Invaliden. Frebtag 1870 ?nfị̈̈że I 412 da richtete sich der amputirte Musketier in seinen Lager auf.

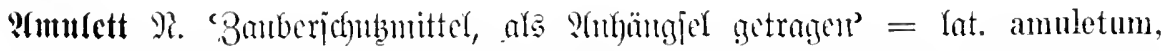

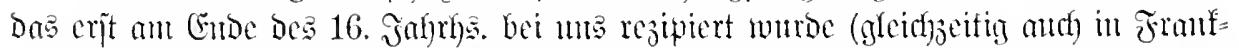

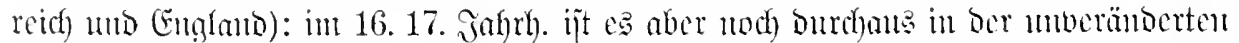

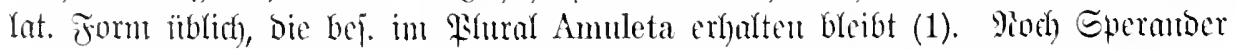

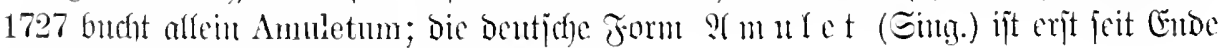
des 17. Jahrlos. häufiger jul belegen (2).

Belege: 1. Tabernännontanı $1588 /$ den Halß gehenckt: dieweil es mun ohne Sräuterbuch I $335^{\mathrm{b}}$ Peterleinwurtzel an Superstition rmo Aberglauben zugehet, 
kann man solehe Artzeney oder Amuletum versuchen. Bapit 1596 ?irmeibuth $\Xi .198^{a}$ die Amuleta (dann also werden die Dinge genennet, welehe man an Leibe tregt) werden für den schweren Gebrechen gebrauchet. Eommer 1608 Ethoaraphia II 123 Amuletum - 124 Ammleta. Echorer 1663 ?tranei Der Sieijenden ङ. 107 man hängt auch allerley Sachen (Amuleta senemnet) an den Hals. Rebembant 1680 Seujels Sijt VII 50 Amuleta. Evenio Marperager 1711 Bejdr. Der Mefïen 1176 mo Ettmer 1715 sebamme $\Xi .116$.

2. 2 mulet jofon hämīia bei Bapit 1596 भrzmeifuch ङ. 92b. 93b $191^{\mathrm{a}} \cdot 198^{\mathrm{b}}$ - auch als Rifur. (bod) E. 198 Amuleta)
こ. 95 Teben dem sein anch wol Amulett (denn also nennet man die Dinge, welchr man von aussen anhenget oder aufbindet). welehe die Frucht zur Geburt befördern. 1677 Mad)iavelf. 5ocuspocus こ. 797 Die Einigkeit wird dir ein herrlich praeservativ und ammleth gegen alle solche SehlagFlüsse. Rebentualot 1680 Ienjets Riöt I 51 Ich hätte bald sein Geistliches Amulet vergessen, welehes er in Forma Crueis mit Hebreisehen Buchstaben bezeichnet. Subnau 1700 Duadjalber $\Xi$. 52 drumb nahm sie das auff den Seiten in Gold eingefaste Amuletgen, so ihr anf der Brust hieng. Wintefmanu 1764 Bejoh. Der Simit I 99. Qejiing 1768 Untiqum. Brieje (X 392).

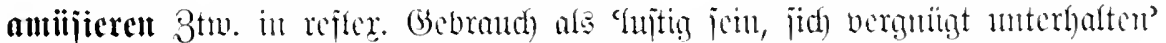

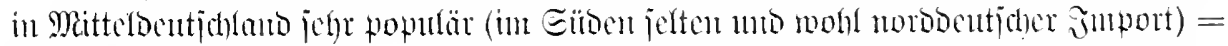

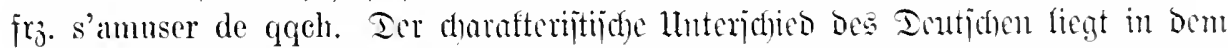

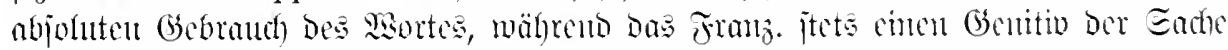

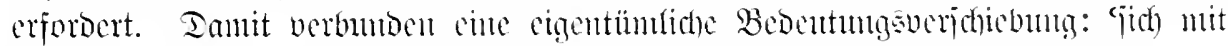

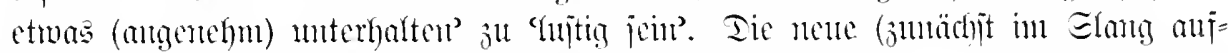

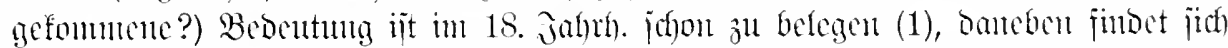

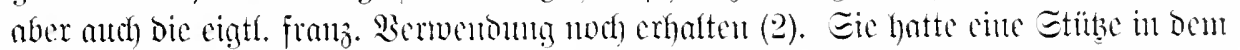

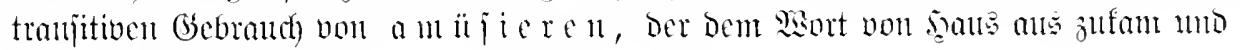

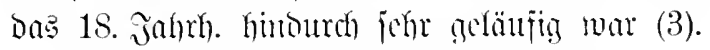

Belege: 1. Mä̈ller 1778 Frants $2 \mathrm{eben}$ ङ. 21 kein wohlgemutherer Teufel durch die ganze Höll als ich - Macht alles die Kunst - amusir mich den ganzen lieben langen Tag. Morits 1786 Snton Reijer $\Xi$. 227 er amüsirte sich mit den Leuten so gut er konnte. Richtenberg 1795 sogarth II 334 Indessen man weiß sich hier zu helfen, man amüsirt sich so gut man kann. fotzebue 1804 Sultan Bimbambum (XVI 284) Du siehst, wie saner mir es ankömmt, zu regieren: D'rum will ich heute mich ein wenig amüsiren. Retwals 1836 Qqquarelle II 118 Man sah ihn in ihren Soireen, wo er sich sehr amüsirte. (Gandy 1837 somto= resfent (VI 178) geh' nur und amïsire Dich. joctlänber 1866 fïntlterroman IV 223 ich habe mich räubermäBig ammsirt.

2. Boie 1775 as Bïrger (I 232) ein paar der Kkleinigkeiten, mit denen ich mich in diesen Tagen zu amisiren gesucht habe. Goethe 1811 Didntumg u. Eahrheit (XXVII 201) Ich amüsirte mich auf eine kindische Art an den seltsamen Namen dieser gehäuften Zeichen.

3. a m ï i i ex e th trani. entiprechento irz. amuser in 3 Bebeutungaitujen: a. 'Gimbalten, aujadten', jo vou bent Frembubb. bis 1750 allein angegeben. Bagl. Sïäbter 1709 "er juthet midh it Diejer affaire vergeblich zu amusieren". Beleg: Sturfüritim Eophie 1710 an zriebridf I. (ङ.215) Mit den friden seheint es, das die Franzosen the aleihrte nur amusieren wollen.

b. 'Die Beit vertreiben, unterfalten' $\mathfrak{z} . \mathfrak{B}$. waguer 1724 Eoldatenbibliotbef ङ. 81 der Zweek dieser Memoiren ist die Leser zu amusiren. Sabater 1776 Phbïloguom. Frngmente II 5 Nieht bloß amüsiren möcht' ich Euch, Leser. Edfiller 1789 Brieje II 244 Tie Histoire secrète] wird Dich sehr amüsiren und aufklären. Babrot 1790 2eberwbejd)r. I 17 mein Vater muBte die Versammlung mit einer Rede aus dem Stegreif amüsiren. jiflont 1795 Reije (II 81) Amüsire Karl. Sâbebue 1806 Eammt= roff (XX 310) die amüsirten mich, die schwatzten mir was vor.

c. 'belujtigeu' Seijing 1759 Siteratur= briefe (VIII 17) schöne Geister, die uns eben diese Religion wegwitzeln, damit ihre geistlichen Schriften auch zugleich amüsieren können. ㄲällfer 1787 (Enmerid) II 300 darauf kömmt es ihnen ganz und 
gar nicht an, wemn sie nur amüsiren - selbst für den Teufel zu wenig anüsant dummodo risum exeutiant. Rutigge 1792 ist. Saube 1837 Reijennellen VI 308 Reije ๔. 233 die Märehen und Possen Darum ist es allerdings ergiebiger und sueht ihr auf, und das, um dessentwillen amüsanter, von den Sehwaben zı hören. das Buch geschrieben ist, schlagt ihr über. Ja! Ihro Gnaden lesen nur, um amüsiert zu sein. Ievtient 1837 Rerirrungen (II 53) Es amüsirt Dich, dab Dir eimmal auf eine ungewöhnliche Art die Com gemacht wird.

antiijant ?(oj. = irs. amusant: int 18 .

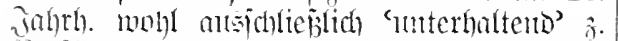

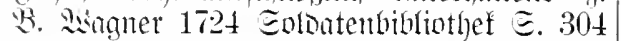
bas 8 ind] enthält viel artige, ammsante und zum Kriegswesen gehörige Dinge. Bahrot 1791 Rebentheidr. IV 227 eine amïsante Dame. Echiller 1796 Briefe IV 463 Die närrisehe Ilixtur ron Galanterie und Crobheit in dem Fremnd Benvenuto ist gar amïsant. Jiffont 1798 \&aupbahn こ. 12 Jedermann vermied es ans Grundsatz, oder weil es nicht amüsant für ihn war. - Y(udh in Delt folgentent Belegen iit bie Beo. 'beluitigento' nicht unzueifelloat: Danif 1826 Mentoiren (VII j4) wie kommst ju denn zu dem langweiligen Volk, das

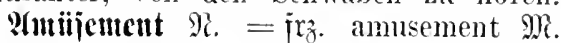
1. 'Zeituertreib' Roht 1729 3eremoutiell= wifjenilhait II 208 In den vorigen Zeiten war unter den großen Herren das Drechseln ziemlich mode, es ist aber dieses amusement ziemlich abgekommen. Fleijher 1734 sjerr v. Snbio III 189 dahero es an täglichen Visiten nicht ermangelte, worimnen wir nach so langer Reise ein sonderbahr Amusement fanden. 1765 : $\{$ lg. D. Bibliothef I 2 E. 14 Wenn wir nur für Zeitrertreib und Amïsement sorgen wollen.

2. 'Reluitigumg, Bermintïgen' Bobe 1726 Eterties 9orid I 159 In Paris aber hat sie in ihren Amnsemens kein Ende gefunden. Stlitger 1776 an Estleiermadher (= Rieger I 395̃) Ich studirte zum Amïsemen[!] die Taktik. 2aube 1837 Reije= novellen V 337 Sind wir anch sonst objektiv genug für das, was man Amïsement nennt.

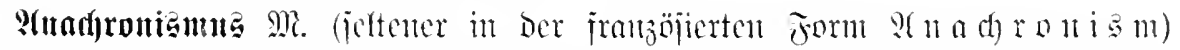

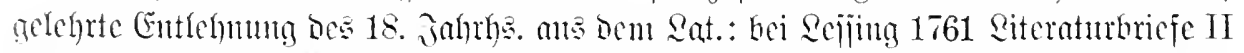

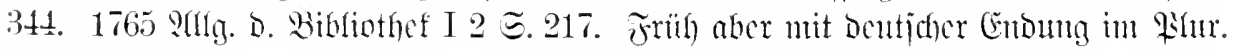

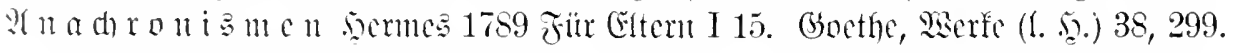

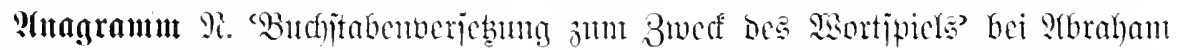

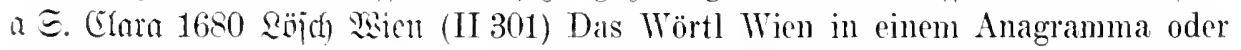
Buchstabenwechsel heibt Wein. Tod) bis ins 18. Jahrh. hämpig in ber lat. Jorm

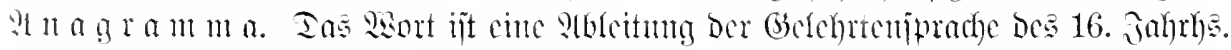

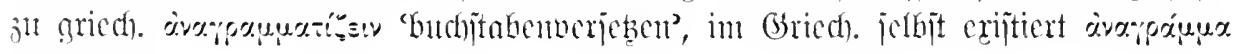
nod) nicht.

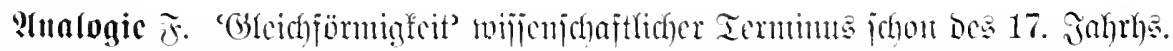

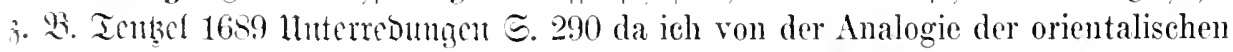
Sprachen rede. Edfiller 1789 ?(ntrittsede (IX 96) Die Methode, nach der Analogie zu schliehen. Euclfe: lat.=grich). analogia. Singegen ijt oas ?oj. antalog ans fro.

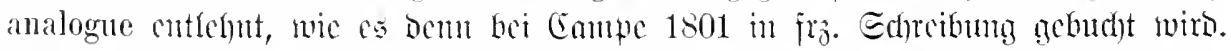

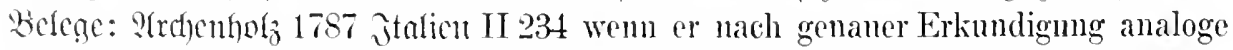
Schlïsse macht. Gocthe 1S12 Tidhtunt 11 . Wahrbeit $(27,133)$ an dem Ende eines jeden Gedichites eine analoge Vignette. Iajür im 18. Jahth. a n a 1 o g i i d 1765

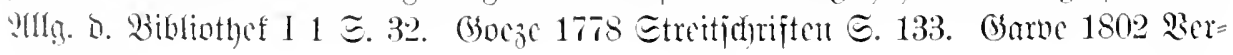
iuche $Y 70$.

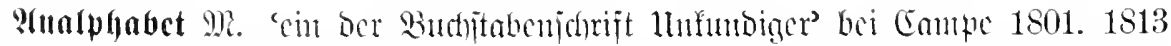

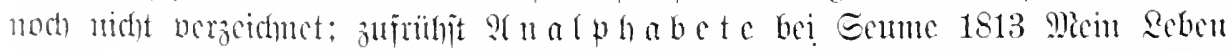

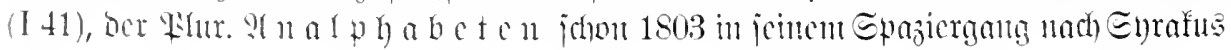




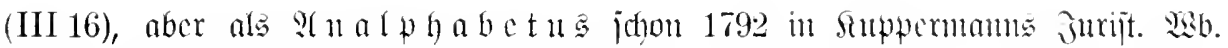
gebuct)t. Duclle: lat.=gried). analphabetus.

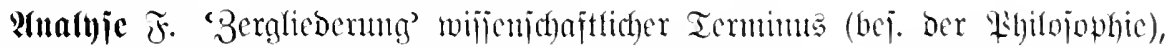

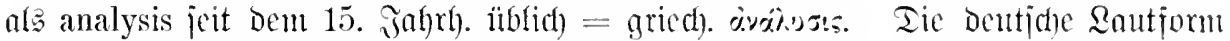
bringt (unter Einflup vou fro. analyse?) erit im 18. Jabrh. Durd).

analyjicren 3tw. in 17. Jahrb. won' etliche lieben das disputiren, andere das analysis abgeleitet ( $\mathfrak{i} \mathrm{r}_{3}$. analyser crit jeit expliciren und analysieren. Fiohr 1718 1746 bezeugt). Belege: Becher 1668 Metho= Etantwfugheit $\Xi$. 435 die ihnen rorgegrDus Didactica $\Xi$. $159^{b}$ dab sie gebrauchen benen Legres so herrlich analysieren. Qejifitg propria voeabula, die construction ana- 1760 Qitetaturbrieje (VIII 241) Er anaIysiren. Encie 1711 Entrop. beticon $\Xi 131$ lysiret in dieser Absicht das ganze Blatt.

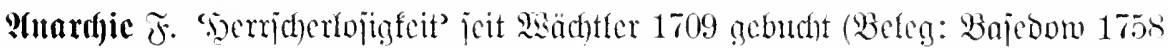

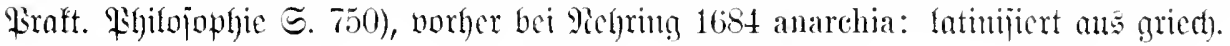
ivapyír.

Fuardiit $\mathfrak{M}$. „Ce nom d'anarehistes Akrostiehon, dab ich cin Blutmensch, ein que depuis dewx ans on affecte de donner Anarehist sei. Grber in Ientiflano fon aux brigands" Raharpe 1797 Lang. révol. Das giebolutionswort erit jett ben 80er

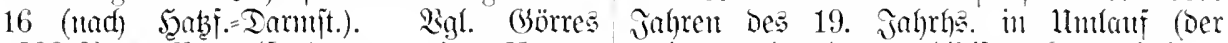
1798 Sotes Bitatt (I 14) ans meinem Namen 1. intemationate anardiitijche fiongrep̈ fanto und meinen Haaren beweisen sic in einem an 14. Julli 1881 in Sonbon ftatt).

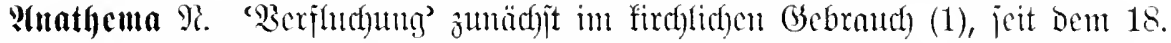
Jahrl). aud) alfgemein (2): anathema (sit! Gei verfudyt') ijt cigtl. Dic Etrafformel

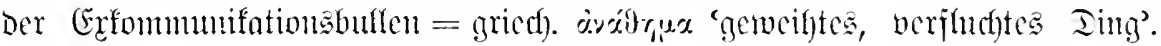

Belege: 1. Emier 1521 gegen Quther I 101 sie werden ym mit der tzeit gar ein alten schilling geben mit dem Interdict veriagen, mit dem anathema vormaledeyen. Edtiller 1800 Maria Stuart III 8 als uns der Mönch das Anathem ansdeutete, worin der Papst die Königin mit dem Entflohenen das Anathema aussprachen. Fluch belegt.

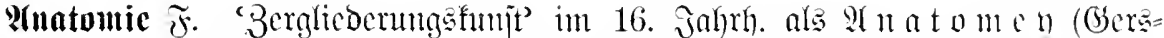

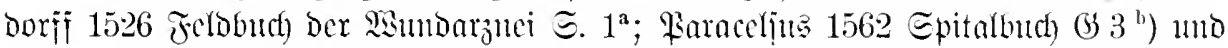

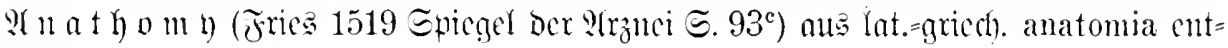
retyut.

anatuntiereit 3 tww. int 16 . Jalhrly. ge $=$ bilbet; häufig jdherzhaft ibbertragen $z$. $\mathfrak{B}$. Edheiot 1551 (orobiam હ. 123 Es näm vil zeit rnd lange weil, wann du die Krebs nach ordnung woltst Anathomicren wie du soltst. Fijhart 1575 Bargantua $\Xi .23$ wie vernünfftig [Der sumb] das marckbein anatomirt.

Inatom M2. erit un 1800 durd)orin= gento $\mathfrak{3}$. B. Brum 1806 Epiponen I 16 diesen berühmten Analytiker und Gehirnanatomen. 1814 Brocfyans I 192 Mekkel, Loder usw. sind als berühmte Anatomen der neuesten Zeit der besonderen Erwähnung würdig. Borker jdyon ühertragen
2. 1784 Thoma joartmant $\Xi .82$ Ist es recht gethan, dab ihr mit eurem Anathema gegen die Commission so stürmisch herausrennet. Jfffano 1798 \&aufahn $\Xi .37$ Tach dem Akte vereinigten sich Hamlet und der Geist in so fern, dab sie über die bei $\widetilde{F}$ Edblegel 1797 Griedsen n. Biomer ङ. 191 Der kritische Anatom [eines Sturit = werf: - - Campe 1801. 1813 fennt nod alleit 9 u a to mifer: hei Phillopi 1743 Reinidomiebefunjt $\Xi$. 69 , Gellert 1746 Fabeln $\Xi .171$ an 1 t o mifus= lat. anatomieus (im 16. Jahrh. If it a $\mathrm{tom}$ i jt Fries 1529 Epiegel Der $94 r_{z}$ the $\Xi .83^{\text {b }}$, Das ein meulat.=gried. anatomista vorausjebt). Tas moderne 9 n a tom crgab jid a as Dem Enbit. Af n a to mi e uad) Dem (iprad)=

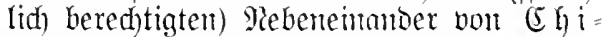
rurg: Chirargie, $\mathfrak{B h i l o j o p h : ~}$ $\mathfrak{P h i l o j o p h i e ~ m i n . ~}$ 


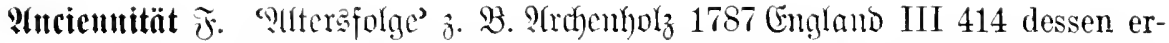
ledigte Stelle auch nicht verkauft, sondern nach der Anciennitït besetzt wird. Goethe

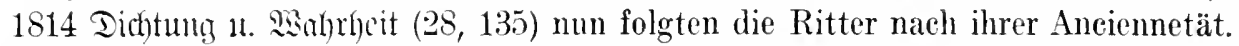

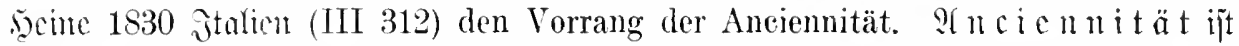

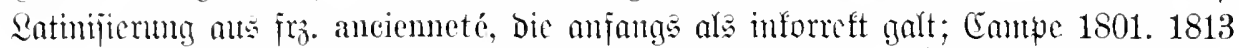

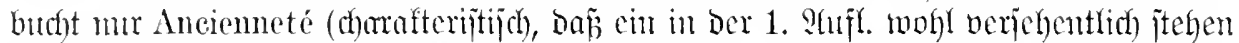

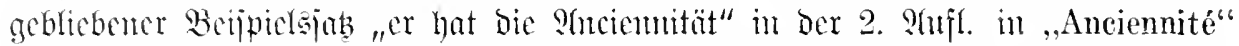

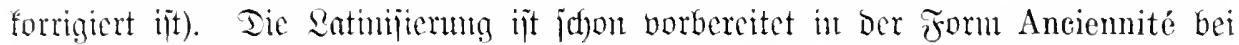

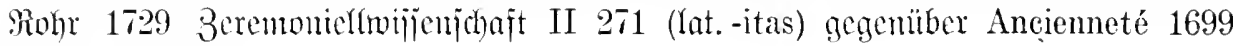
Etantãjpiegel I 6 .

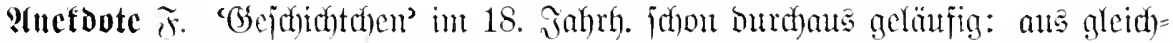

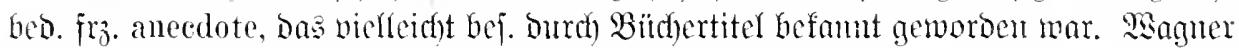
1724 Soldatenbibliothef 5. 79 erwifhnt 3. B. Les Anecdotes de Pologne 1699. Ther

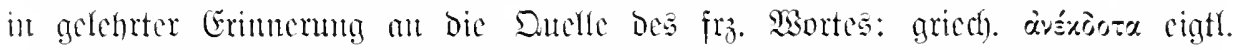

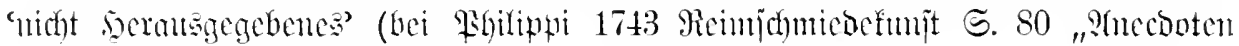
ober unferangegebene Poejten").

Beleae: Bgitipni 1743 Reimidumiebefunit | erdichtete Anekdoten und verläumderische ङ. 79 Wenn ein kriechender Poete sich Ammerkungen zu vergiften. Serber 1767 mit seines gleichen, oder niedrigern, in $\mathcal{D}$. Siteratur (I 477) Man ist gleichsam poetischen Briefwechsel einlässet, bleiben nach den Anekdoten eines solehen Mannes es meistens Aneedoten, die kein Buch- begierig. 1784 Ieutidher Mierfur II 82 Ich händler des Papiers und Druckes werth definire mir Anekdote so, daß sie eine achten will. Famter 1749 an Bifeim I 192 / eharakterisirende Herzens- oder GeistesIch erfahre viele Anecdoten, das Reich der äusserung einer Person enthalte.

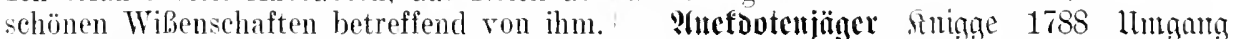

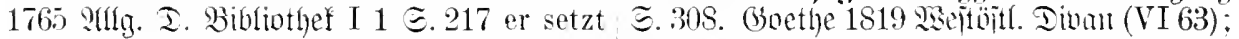

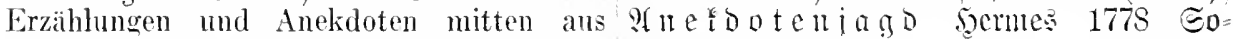
dem Znsammenhang herausgerissen hin. phiens gicife III 530.

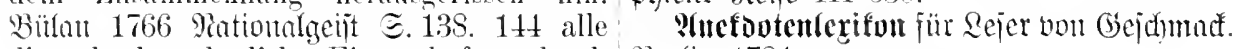
diese höehstrühmliche Eigenschaften durch Berfit 1784.

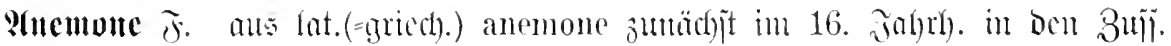

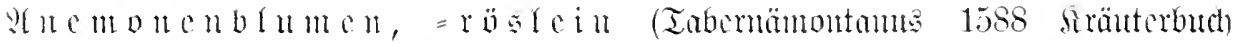

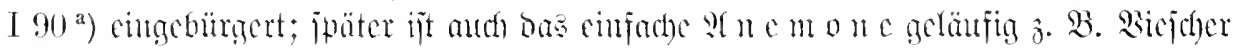
1645 Bhumengarten S. 146; Fleming 1646 Gedichte I 41.

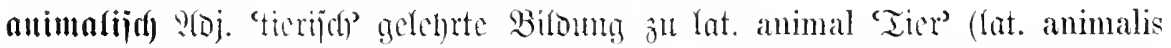

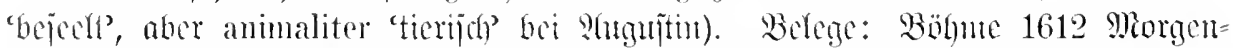

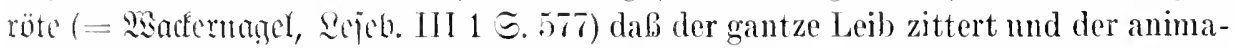
lische Geist trimmphiret. Damalo Erofl 1629 Traftat v. D. imterl. Eignaturen affer Einge こ. 16 sie werden anch von den jenigen sehr schwerlich gefast, welche die Cabalistische Brumen ohne Grund noch nicht versucht, noch anders, als die

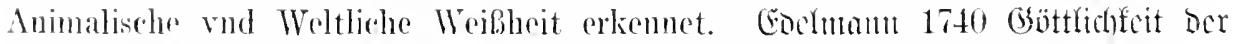
Wemuntift $\Xi .307$ eine Krafft und Eigenschafft des animalisehen Menschen.

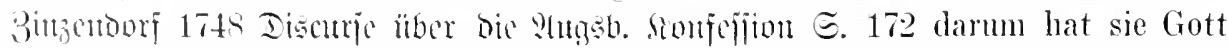
ins anminalische Wesen so weit herunterkommen und mehr an der thierischen

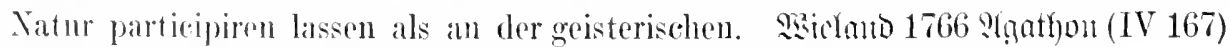
animalische Liebe. Ifümmel 1791 gicife (I 62) in dem animalischen Leben. 
animicren 3tw. 'anregen, in Ettummug verjeb̨en' in abjofutem Gebraud zuerjt

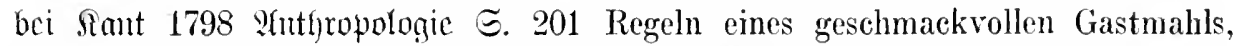
das die Gesellschaft animirt. 5̃adfänoer 1866 . früntlertoman IV 364 jetzt unterhalten sich der Herr Staatsrath auf höchst angenehme, sehr animirte und vergnügte Art. Fontane 1895 E ffi Briejt $\Xi .56$ Ich habe Dich nur in eine animierte Stimmung

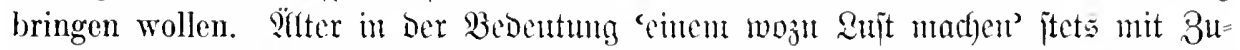
fügung cincs Dbjefts Der Sadhe (1); die Beo. 'ミujt mad)en' ijt aber wieber abgejd)wäd)t

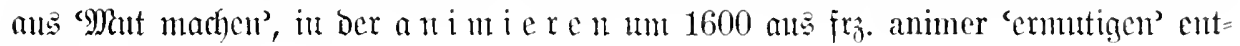
lebint worben war (2).

Belege: 1. Becher 1668 刃hethoous bionct. die Zuschauer zusetzen oder zu wetten. S. 7b was ich vor Ehr vnd Recompens ron Belter 1802 an Goethe I 46 Vielleicht animirt dem besagten Fürsten durch Dedicirung diser Sie die Composition zu deren Vollendung. Invention, darzu Er mich animirt, bekommen werde. Ettner 1697 Doftor ङ.235 ich vermeinte man könte nieht anders als durch Ritterliche Thaten darzu gelangen, und wurde noch mehr darzu animirt, als ich [Rittergeidjichten jab]. 1704 soeidelberger lirfundenb. I 407 auch allenfalls andere cantzleiverwandten zu animiren, daß sie horis extraordinariis die collegia frequentiren. sehnlichen Succurs sehr wol behertyt vnd

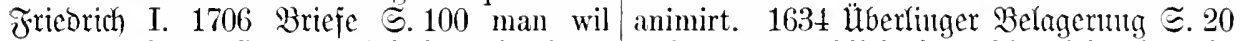
sagen, daß der Landtgraf habe sein Sohn daß man nemblich fürterhin sich nicht in dahrzu animieret. Rohr 1718 હtuatsłltgheit die Mauren einschliessen zu lassen, sondern ङ. 917 was Teutsehland am meisten zur auch in offnem Feld zu feehten resoluirt rnnd Aufrichtung eimer solchen Compagnie ani- animirt seye. Rajienius 1661 aldelige Tijd)= miren solte. Fleijher 1730 Serr v. \&nbio I 2 b reden $\Xi .267$ ihre Temerität, welehe zuweilen haben sie ihn animiret, solehes dureh den einen Bösewicht animiret und anfrischet, Druck zu publiciren. 1768 Der faljhe böses zu thun.

Spieler S. 101 Die Spielersgesellen animiren

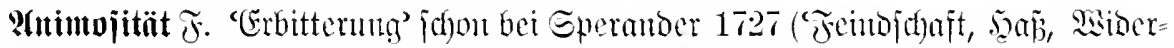
willen') geburbt, aber erjt im 19. Jahrl). belegt $\mathfrak{j}$. B. Belter 1802 an Goethe I $4 \bar{r}$;

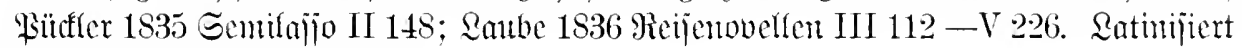
$\mathfrak{a} u \mathfrak{s}$ gleidy)bed. $\left\{\mathfrak{r}_{\mathfrak{j}}\right.$. animosité.

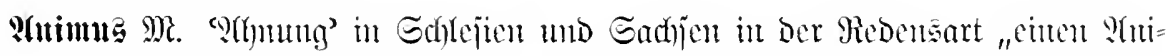
แus lyaben" geläıfig, aber vielleidht im Berluner Slang aufgefommen: fadershafte

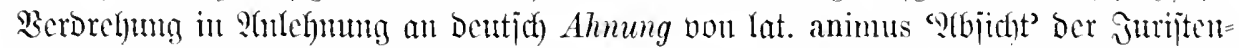

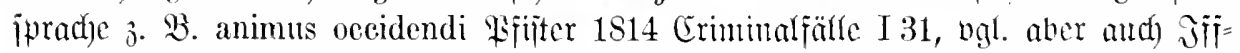
land 1795 Scheinverbienjt (IV 61) Sie sollen debhalb keinen bösen Animmm gegen

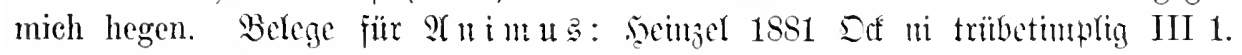
Etume 1885 Fant. Budhlyolj II 87.

ameftieren 3tw. 'cimberleiben' (im potitijacn Eime) cin jutges 2 sort: 1867 Grenjboten XXYI 3 ङ. $14 t$ Saroyen bot das erste Paradigma für das moderne Zeitwort annektieren. Taach lat. anneetere mmgejtaltet ans gleidbed. ins. annexer;

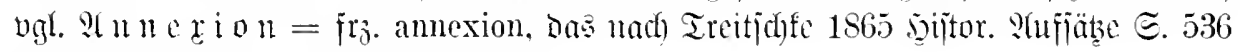
Durd) Mapoleon III. befamnt wurbe.

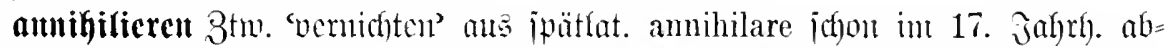
geleitet: Meuman) 1620 Sou Der Mentralität $\left[4^{\text {b }}\right.$ deß Landgraffen zuvor gedachte 
ernennung [warb] ex plenitudine summa annihiliret. Mengering 1642 Berwijiene= rüge ธ. 1064 Zerreissung vnd annihilirung der Zeddel.

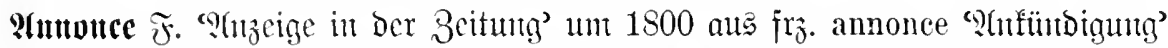
cutfelyut. Ia $:$ (

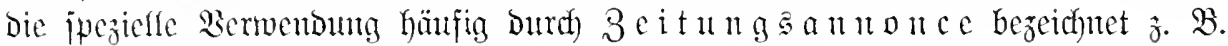
jontane 18522 Brieje I 27; Frentag 1858 Soll u. Şaben I 317.

amtuncicren $3 \mathrm{tw}$. aı $\mathfrak{i r}_{3}$. annoncer. er hat gelogen, da er sich in den Zeitungen

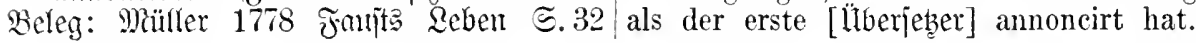

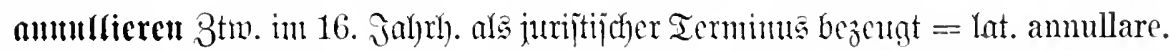
Sigl. Gobler 1536 Piroze $\mathfrak{e} \subseteq 7^{\mathrm{a}}$. Annullirn, Caßirn: Ist ein ding abthun nnd zernichtigen. Als so einer, wes er gehandelt, nichts melır sein wolt lassen, oder so er sein Testament rnd anders wider zerbricht vnd vernichtiget. - Epäter bej. im

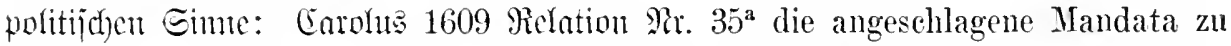

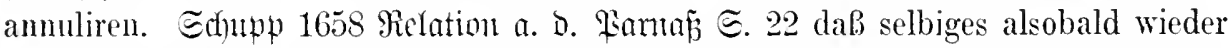
cassiret und anulliret werde. 1708 Reoporo ber Brofe II 257 es setzte noch einen großen Tumult, daß fast der gantze Accord wäre annulliret worden.

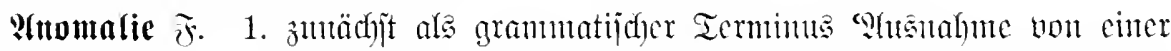
Regel' aus lat.(=griech).) anomalia entlehnt unb bei Eperander 1727 (ale "Echul=

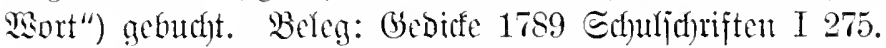

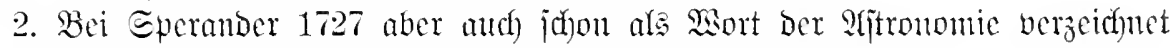

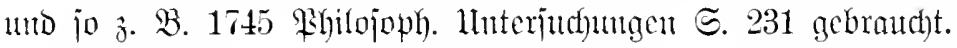

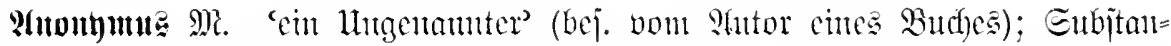

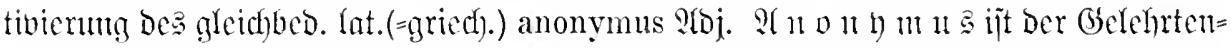

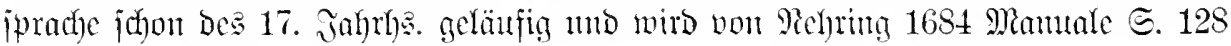
verzeicfunet.

Belege: Munbus 1619 Rojenfreubbruder| mus war j. B. Bülnu 1766 Zum bertidgen ङ. 21 bin jeh anch inn einen Anthorem Pationtageift $\mathfrak{A}^{\mathrm{b}}$ eine Pflicht gegen einen Anonymum gerathen - Auff dise Worte ieden anonymischen noch lebenden Schriftnum habe ich am Rand besagten Anonymum steller, so lange er seinen Namen nicht ilso angeredt. Frötorius 1666 Sinthro= nemnt, ihn ungenannt zu lassen. Echubart

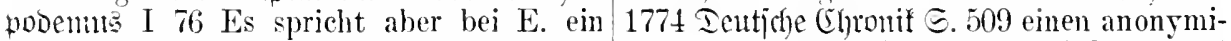
Anonymus also. Tentiel 1689 llnterrebungen schen Verfasser. Whidhaelis 1766 Räjonnement כ. 37 Von den Anonymis haben Placcius IV 2a anonymisch zu schreiben. Bafhrot und Deekerns absonderliehe Schrifften heraus 1790 Rebenwbeid)r. I 325 - II 193. Edjitter

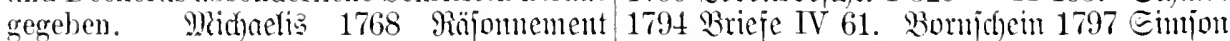
I $4^{\text {a }}$ ein Anonymus zu bleiben - $1773 \mathrm{ebb}$. b. Etarfe E. 115 . Saufhard 1799 Eshifor

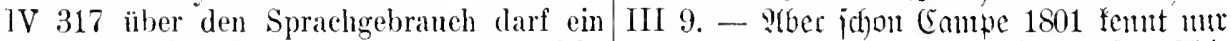

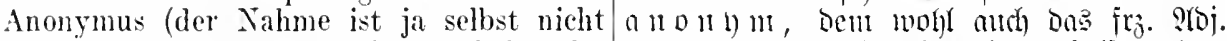
deutsch) nichts sagen, der sieh so oft fremder anonyme zum Durdfheruch berfyolfen hat: Wörter schuldig macht. Edfilfer 1796 3. B.. Бgermes 1791 Riterar. Mä̈rtnrer I 143 Brieje V 99 Hier hat cin chrlicher Anonymus ein anonymes Werkehen. Edjiffer 1794 sich der Horen gegen Reichardt angenommen. Briefe IV 186 der Erscheinung des anonymen

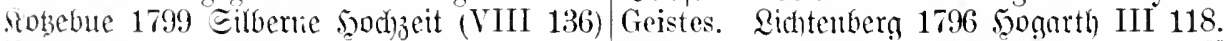

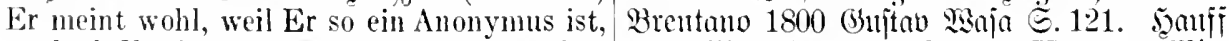
so clïrfe Er sich zum Recensenten aufwerfen. 1826 Mentoiren bez Entans II 117. "'sitt

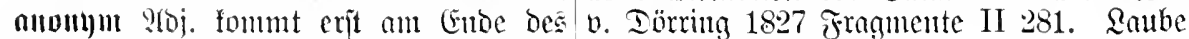

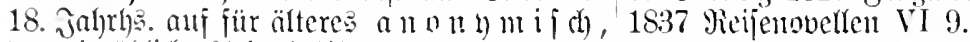

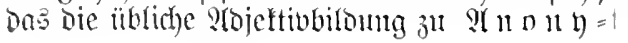




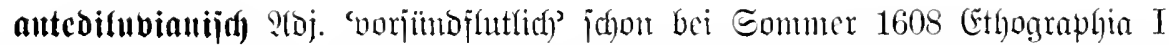
(5 $4^{\mathrm{b}}$ loben jmmerzu jre Antediluvianische Kielhosen vnnd Barete: Bifoumg des

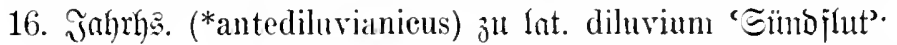

auti $=$ gried). divi- 'gegen' eine jumal in nenerer Beit höbjit produftive

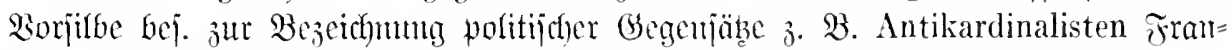
cišci 1681 Trauerjanl IV 487; Anti-Bourbonisten 1702 Europ. Fama હ. 386; AntiDeutsche Rabener 1759 Eatiren II 213; antijesuitisch Echubart 1755 I. (Egronif

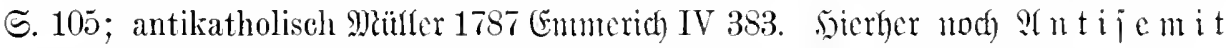

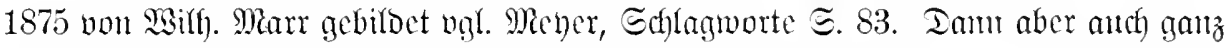
allgemein 3. B. A s t if rit if Thümmel 1791 Reije (I 79) ujw. Borgebiloct war Der Inpus Durrch ipätlat. Bildongen wie Antichristus (3. Jahrh.), antipapa (5. Jahroh.).

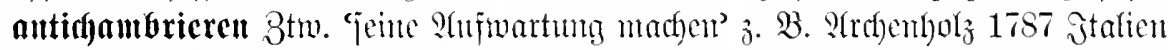
I 175; Jean Paul 1797 Jubeljenior (VI 67): cigtl. 'jich im 3 sor

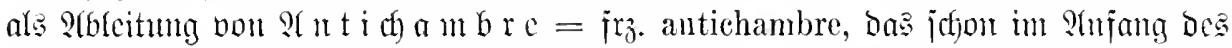

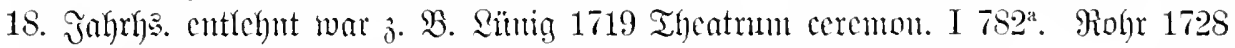

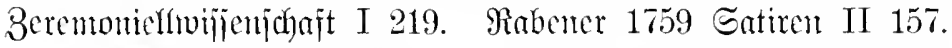

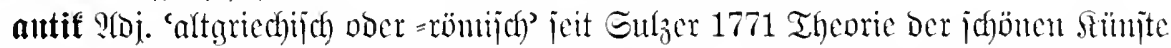

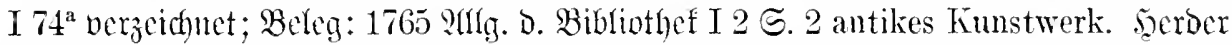
1767 D. Siteratur (I 451) eingekleidet in die Morgenröthe einer antiquen Allegorie.

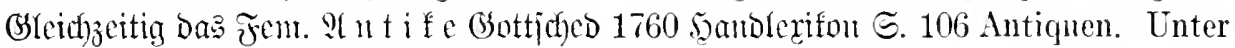
diesem Namen versteht man die Stïcke der Malerey Bankunst und Bildhanerey der berïhmtesten Künstler des Alterthums. Windfelmann $176+$ Gejd. Der fumit

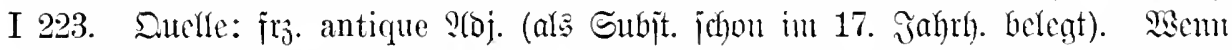

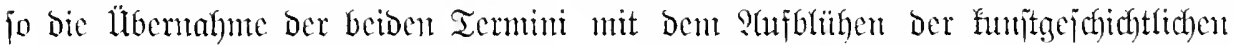

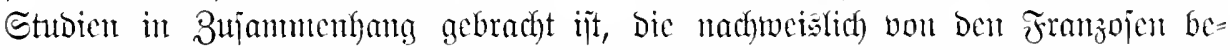

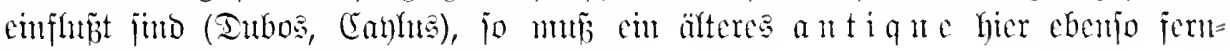
geralten weroen wie antifi $i j$ in (j. n.)

a n $\mathrm{t}$ iq $u$ e ift nänllidy feine äitere Edyreis $/$ ihr viel Feind und machen mein Ding in

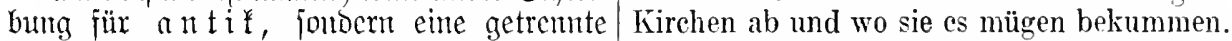
(ipöter untergegangenc) Entlelynmg aus $\mathrm{Fr}_{\mathfrak{z}}$. Toeh schelten sie es und sagen, es sei nit antique in Der eigttl. (oflgenteinen) \$Bebeutung antiekisch Art, dorum sei es nit gut: ber

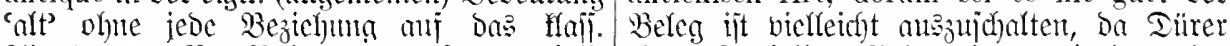

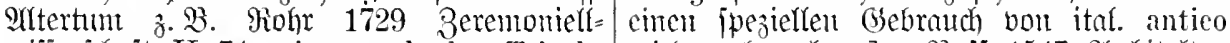

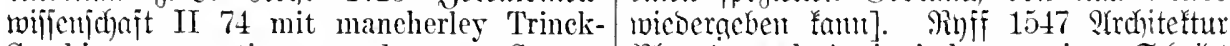

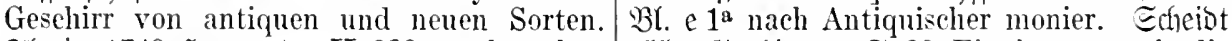

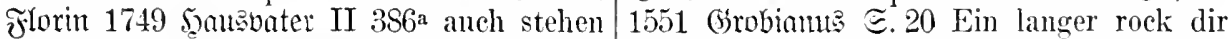
längst der Galerie zwey Reyhen [Ǵcmälfoe] auch wol steht, Der dir biß auff die knoden theils antique, Daher befjantelt Gottidged geht, Das ist auff antiquisch manier, Vnd

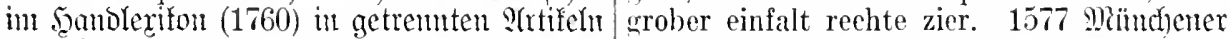

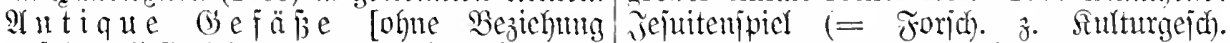

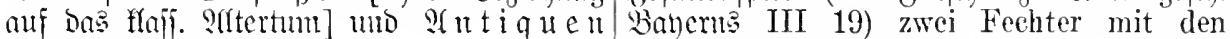
[i. o.].

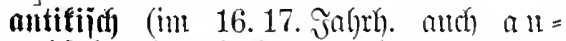
tiquijd) iift bireft bon lat. antiquus

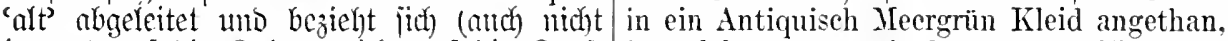

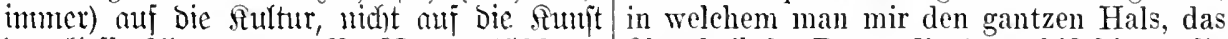
Dez flaif. Altertum! 3. B. [Dürer 1506 an Obertheil der Brust, die Arme biß hinter die

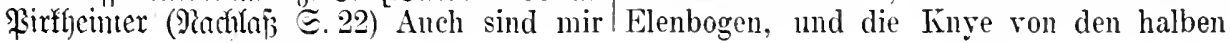




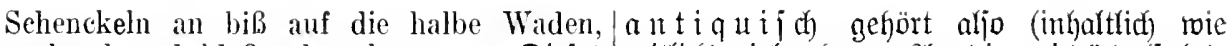

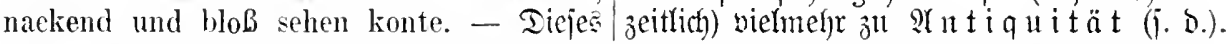

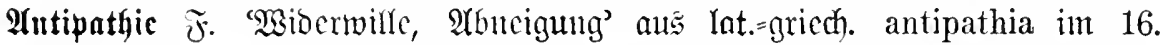
Jahrh. cutlehnt, aber noch im 17. Jahrh. gelegentlich in lateinijoder Sautgeitalt

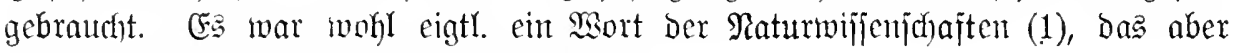
frïl) and in allgemeinten (Stebraud) fan (2).

Bdege: 1. Edfmenter 1636 Telitiae| 2. Secher 1668 Methodus Dibactica $\mathfrak{c} 4^{\text {b }}$ phyj.=math. ङ. 233 also auch sagen etliche Vnd ist gewiß, daß in der Sprach ein grosse erfahrene Musiei, sey eine sonderliche anti- Sympathy vnd Antipathy stecket. Grimmels= pathia zwischen den Wolffs- und Schafs- baujen 1669 Eiunplic. E. 42 derjenigen saiten. Rebenmalst 1681 Telifels \&ijt VI 166 Antipathia, die sich zwischen Soldaten und Entgegen findet man so wohl in den Vegeta- Bauren enthält. 1702 Curop. Fama $\subseteq .164$ bilien als Mineralien rnd Thieren, ja sogar die Antipathie dieser beyden Nationen. vnter den Menschen seltzame Feindselig- Fleijher 1730 Jjerr v. Syoto I 83 als wem keiten rnd Antipathien, deren Grundursachen mein Glücksstern, so zu reden, eine Antivns verborgen seynd. Thonajus 1690 pathie vor denselben haben nub. Figilipp! Deutiche Edyriften I 36 weil doch eine 1743 Reimjdymiebefunit $\Xi .123$ Es ist eine gleiche Antipathie zwischen dem Gifft nnd solche natürliche Antipathie und Feindder Artzney zu sein pfleget. 1702 Gurop. schaft zwischen erhabenen und kriechenden

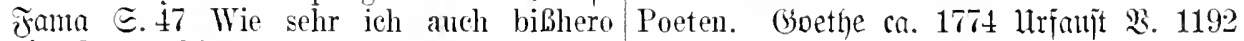
die Sympathie und Antipathie bestritten Du hast nun die Antipathie.

und selbige vor eine Chimere aberglänbiseher Gelehrten gehalten.

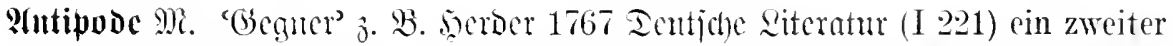
Moser, der auch bisweilen sein Antipode seyn kömute. Edhuhart 1774 Chronif ङ. 107 Herr von Kurz, dieser berihmte Antipode des guten dramatischen Geschmacks.

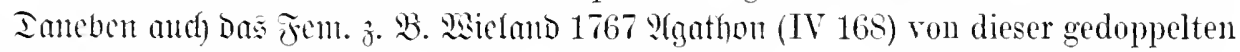
Art von Liebe, woron eine die Antipode der andern ist. - Sou jeans ans cin geo=

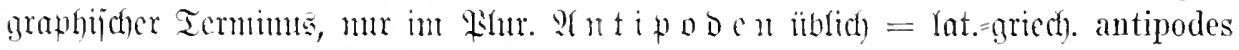

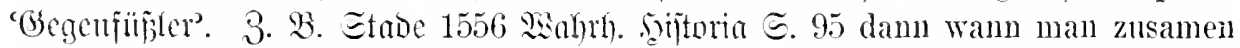
rechent und gegen einander helt die ensserste landtschafft im Occident, das ist Hispanien, und zum Finster stern gegen das Orient, da India landt leit, geben dise eusserste leut vnnd inwoner des erdtrichs beynahe eine Art der Antipoden. Pirä= torins 1666 : Inthropodemus I 76 Vielleicht sind sie dureh den Sehob der Erden

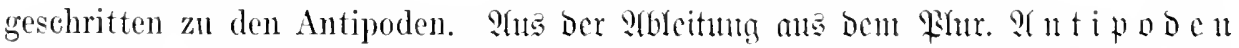

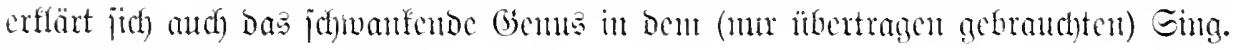

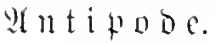

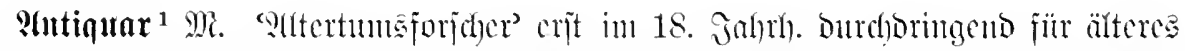

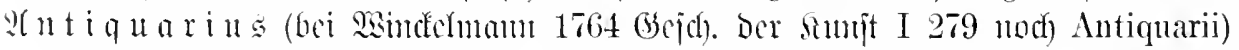

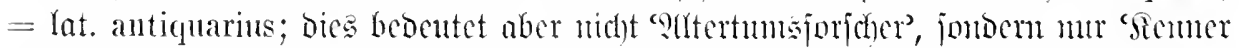

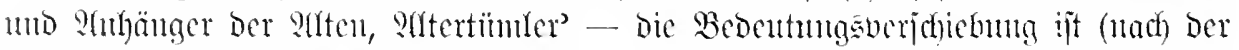
Chronologic von $\mathrm{fr}_{j}$. antiquaire mo cugl. antiquary, beioc feit ca. 1580 bejengt) ipätệtens ins 16. Jahrl). Ju batieren.

Belege: Єdubart 1774 Ehronif $\Subset .65 \mid$ thun kömnen. Seinje 1794 şilocguro v. Scohen= Sonst verdiente dieses Land [Jtalicit] mur thal (VT 132). Eenme 1803 Epaziergantg die Aufmerksamkeit des Antiquars, des (II 133) Ich bin nieht Antiquar. Seeine Mahlers und des Tonkïnstlers. Thïummel 1830 Jtalien (III 245) wie irgend ein An1791 Reije (I 115) Der ausgemachteste tiquar seine ausgegrabenen Ifarmortorsos Antiquar hätte mir schwerlich mehr Genüge betrachtet. 


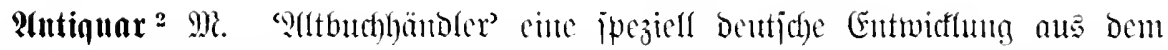

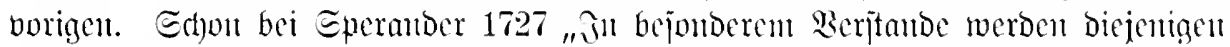
aud Antiquarii genemet, welde mit alten gebutbenen Büd)en umgehen". SBirffich cintgebürgert wurde ber lame wohl aber exjt am Ende Dez 18. Jahrhs.: junächit war

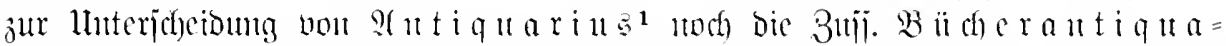

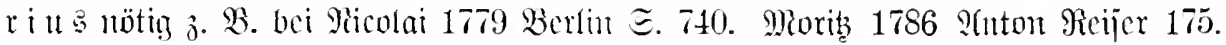
184. 1798 : (mualen D. Dentid)en llumerïtäten ङ. 201.

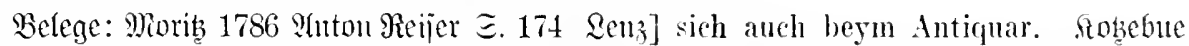
Er ging zum Antiquarius und holte sieh 1799 ङilb. 5odfzeit (VIII 150) er hat viele einen Roman, eine Komödie nach der gute Bücher gehabt; die sind vor kurzem andern. Bahtot 1790 Rintovigin I 54 an einen durchreisenden Antiquarius für ein Der Vater ging nach der Stalt und holte Spottgeld vermöbelt worden. Bamichfe von einem Antiquar etliche sehr schön 1834 bilber $\Xi .47$ den Weg aller meiner gebundene Postillen. Edjiller 1796 Brieje Bücher, den Weg zum Antiquar. jäger IV 445 Vielleicht finden sie [ Iranten von 1835 Jelix Edunabel 厄.197.

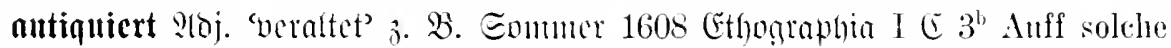
ein geführte exempla antwortet rnser Ethicus, dal. sie sehr alt sein. rnnd munmehr

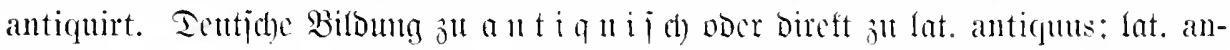

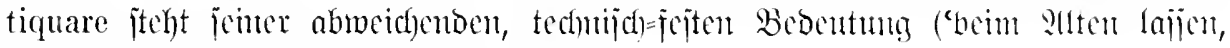

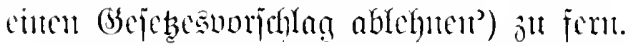

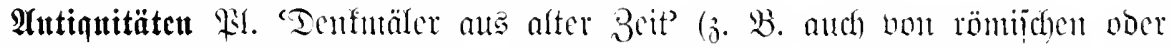

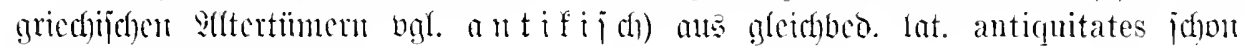
int 16. Jah)rb. gelüufị̣.

Belege: P(ventin 1519 Bayr. Chronit silbern rnnd kupffern, Pfenningen mit andern (I 102) in alten stainen und dergleichen wnd sehr viel Antiquiteten nehr. siuchlor monumenten und antiquiteten des fürsten- 1602 Milit. Iisciplina $气 .51$ darbey mehr tombs Bairen. Federman 1557 Inbian. denn zuviel herrliche Libereyen, Bücher Şijtoria S.3 das E. V. ein sonder liebhaber vnd Antiquiten zu Grundt gehen. Soan= und erforseher der Antiquiteten. Fijohart 1582 hofer 1610 Briefe $\Subset .7$ aine Cunst amer Gargantua S. 275 erwegung allerley zeitung, mit antiquiteten, statuen, gemehlen, rnel discutirung etlicher Antiquitetten. Epeffe allerhand rariteten. Epöter jehr hämigig.

1589 ?(rchiteftur ङ. $86^{\mathrm{b}}$ man findet] gulden,

Putijemit $i$. unter a $n t i=$

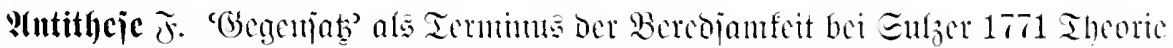

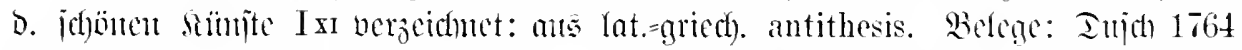
Briefe I 234 Sie sehen Antithesen, welche mehr als Spitzfindigkeiten sind. 1765

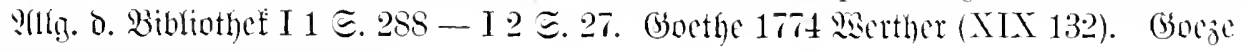
1778 Etreitidfriften $\Xi .5$.

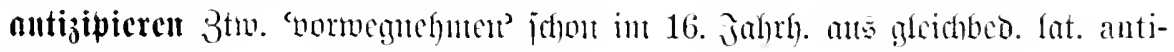
cipare gebilbet.

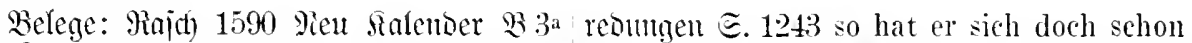
bie Snstage] die eemals im alten calender die vorige Herbst-Messe eingestellet und anticipirten, nach dem requinoctio fahrend, also seine Ankunfft ein paar IIonate antidenen wierd numehr im Neuealender vnuer- ejpiret. Niüller 1787 Eimmeriof II 433 so rucklich zil rnd stell gesetzt. Ectjief 1674 daß er von Quartal zu Quartal auf seinen

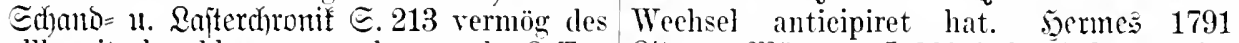
allbereit besehlossenen, aber umb 8. Tag Ritcrar. Mïrturer I 220 indes jede Art des anticipirten Tractats. Ienţel 1689 Inter= Anticipirens einst Nachreu bewirken wird. 


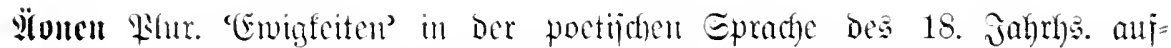
fommento: ans lat.=aried). aeon 'Beitalter, Emigfeit'. Der Sing. gants vercingelt bei Geroer 1765 然erfe I 74 ein Genie, dergleichen es nur jede Aeone eins gibt.

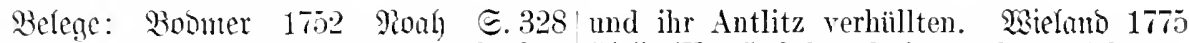
Aber weib nicht, daß er Aeonen geschlafen. (5lelia (X 145) Sehon drei äonenlange Jahre Bacf)ariä 1756 Ingežzeiten (Il 160) Von 1777 an Dlymtia (XII 137) Unid schöpften sie der entsetzlichen Naeht, die einst nach äoneniang hinein, Es würde niemals voller tausend Aconen, Alle Himmel und Welten seyn. Gö̈rres 1821 Europa ङ. 80 nach verschlingt. siorder 1767 Teutiche Siteratur Aeonen endlich wieder zu ihm kehre. Goethe, (I 323) bald gegenwärtig, bald aus weiten Faujt II 尔. 11584 Es kann die Spur von Aeonem. תlopitorf 1773 Miejîn XIX 179 meinen Erdetagen Nieht in Aeonen untergehn. Der mitf)] Auserkor, daß Aeonen es sïhn

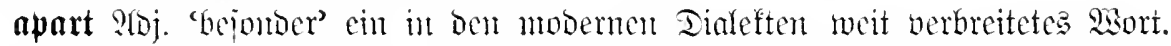

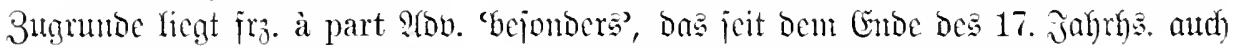
im Ieutịchen, bod) zumächjt mur in abverbielfer Fumftion, gebraucht wirb.

Belege: Bödffer 1665 Schola militaria reden solte. Crttner 1697 llumbirbiger Doftor ङ. 72 mit denselben hat der Bestellende $\widetilde{\Xi} .107$ als die Gesundheit und hernach eines sieh à part zu vergleichen. Becter 1668 jeden à part herumb getruncken. ¿ünig Methobits Difoctica $\widetilde{夭} .127$ and bate mich 1719 Theatrum ceremoniale I $817^{\mathrm{b}}$ à parte der Orator hernach à part vmb meinen Vor- vorhero etwas zu reden. Etoppe 1728 Géebidute theil - $\Xi .157$ à part jedes doch ohne version auff ein Blättlein - E. $164^{\mathrm{b}}$ so man sie à part mo separatim kauffen sollte. Grime metahrajen 1670 Ratio $\Xi$ tatus $\subseteq .81$ wann sie keinen Ehe-Gemahl hätte, der etwas it parte vor sich allein behielte. -1672 Rat

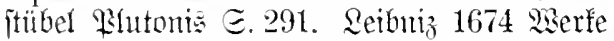
I $15 \tilde{5}$ jeder [iolle] mit den Seinen apart agiren. 1677 gladuiabell. . jedem apart vertrauct. "Riffelfäring 1685 Sleideraffe $\subseteq$. 22 ich wil sie schon à part mit einem guten Trinckgelde versehen. 䏠eije 1697 Rertraute Gépprädhe ङ. 32 Es wäre mir am liebsten, wenn ich mit dem Herrn Yater a part, auch mit dem Herrn Informator a part

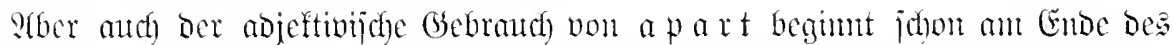

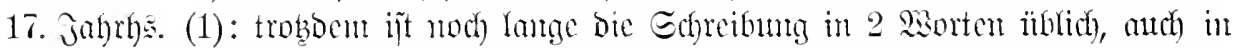

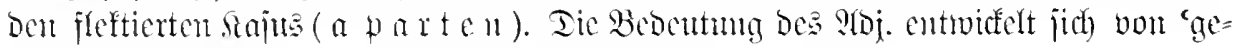

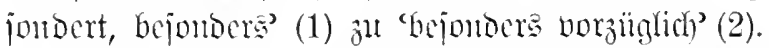

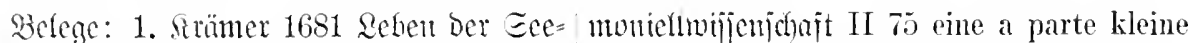

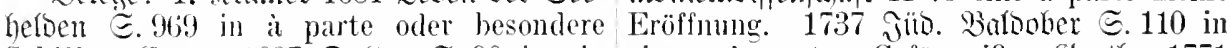
Schiffe. Ettner 1697 Iuftor ङ.90 in cin einem ì parten GefängniB. Boethe 1771

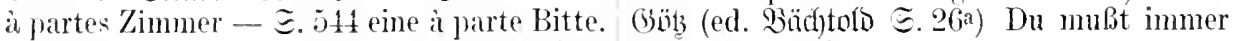
menantes 1702 serliehte sielt $\subseteq$. 40 ihre was aparts haben.

a parte HInsie. 1708 \&eopolo Der (Srroje I 225 in ihrer apparten Kürche. S(maranthes 1715 Franenginumerteriton $\Xi .513$ einen it parten 'Topff. Qütuig 1719 Shentrum ceremontiale I $366^{2}$ bey der T'afel ist kein à parter Yorsehneider -1720 ebo. II 1411 cin aparter

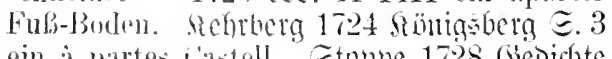

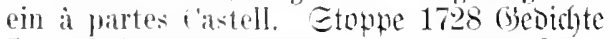
I 167 kein il partes. Maul. Rohn 1729 3ere=

2. 3. 3. Mientuntes (1705) Roligedicht D $3^{b}$ Und dieser Herr, den du zu Weissenfels gefunden, kan sagen, daß er so was recht at partes hat. Etoptre 1735 quartaj S. 481 Yleine Physiognomie hat ganz was à partes in sich, mich bey dem Franenzimmer beliebt z. machen. Riscov 1739 Enchiften 5.434 Soll ieh einst lieben oder frevm, Mub es was recht a partes segn. Bahrot 1791 Reben? 
bej(f)r. III 342 aparte Schuhe. ijfland 1795 | 145 die Aparte oder Reden, die man gleich= Echeinberdienjt (IV 79) Es ist ein apparter sam mit sich sclbst, doch in Gegenwart eines Mensch. ¿aube 1837 Reijenovellen VI 334 andern hält, der sie nicht hören soll. Qeîing weil er etwas Appartes wolle. Qetvalo 1839 III 98 sind in dieser Komödie gar sehr vicle Schreizerlanb S. 22 Wer in solchen Gegenden und lange sogenannte Aparte, welche so etwas Apartes haben will, mag immerhin ungereimt sincl.

bezahlen. Devrient 1841 Ireue Qiebe (III 65) So vornehm und apart in seinen Manieren. Golb 1869 Wertflugheit II 7 Man kan ihnen mto Berwendungaweije Dem Grntmowort ent= nichts Neues und nichts Appartes sagen.

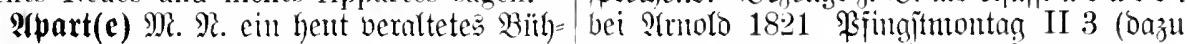

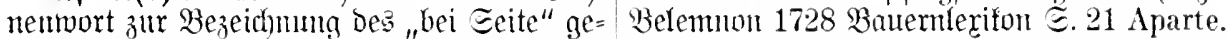
iprodhenen. Wohl nicht Enbftantivierung Der abusive: Obarti, abarti), aber auch auf nob.

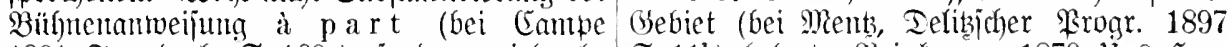

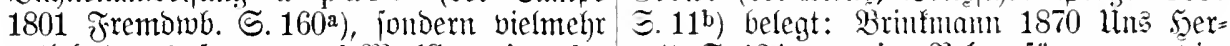
entlehnt aus jrz. aparté $M$. 'Ce qu'un des gott $હ .124$ aparti. Beleg für a partig

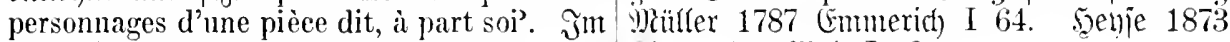
Deutichen ift das soort etwa jeit $1730 \mathrm{ge}=$ stinder ber Wiselt I 48.

bräuchlich 子. $\mathfrak{B}$. Bottj(hed 1737 Beitrüge V

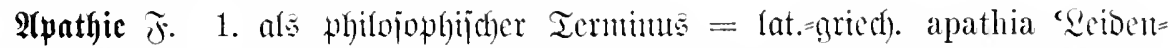

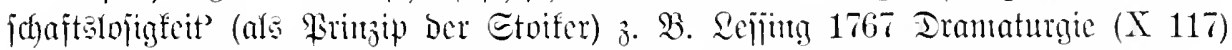
bey einem Stoiker, der immer ein Auge auf die Apathie hatte. Wiclano 1768 Maja= roun (III 28) Die Majestät der Liebeskönigin Bestiirmt auf ein Mal, für die Ehre Der Apathie zu stark, den ïberraschten Sinn — [?fum.] So nannten die Stoiker die vollkommene Gleichgïltigkeit ihres Weisen gegen alle sinnliehe Eindriicke von Schmerz und Vergnïgen. Mülfer 1787 (Enmerif) VII 100 die präsumirte Apathie des Mädels. Stant 1798 P(nthropofogic $\Im .167$.

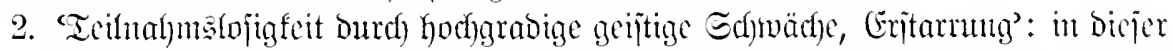

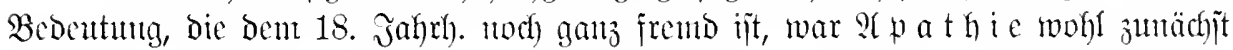

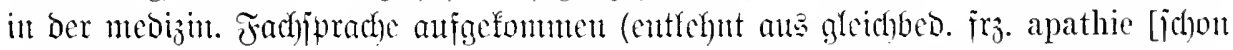
im 18. Jahrh.]?). Dod ijt aud alfgententer Gebraud häufịg. Bgł. Brun 1806 Ept= joben I 228 während ich in dieser Apathie vegetirte - 247 als ich ihm die Apathie klagte, welche meine Freunde und Aerzte im Norden mir zur Genesungs-Bedingung machten. SB̈̈res 1810 Polit. Edyriftent I 130 mit welcher trägen Apathie ohne alle selbständige Gegenwirkung diese in Lob und Tadel die frechsten Urtheile sich aufdringen läßt. \$sitt $\mathfrak{v}$. Iörring 1827 Fragnente II 50 Dahin war mein früherer Gleichmuth, entschwunden die erstarrende Apathie. Fïffler 1831 Briefo I 47 die Hälfte der Unglïcksfälle sei der Apathie der Arbeiter selbst zuzuschreiben. Chow= niţ 1845 Sauf Der selt I 254 Eine Apathie schien sich seiner jetzt in allen persönlichen Dingen bemächtigt zu haben.

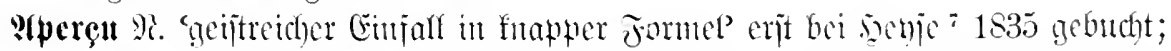
Beleg: Edhifler 1797 Bricfe V 189 dab das Ganze nur aus einzelnen Apperęus besteht und dab keine theoretische vorgefabte Begriffe dabey im Spiele sind. Rücfler 1831 Bricfe III 399 mit einem etwas allgemeinen apperçu schließen. Sutelle: frj.

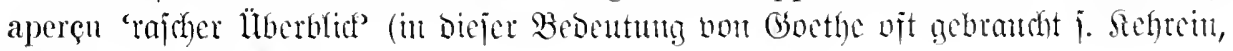
Fuentorub. 厄. $\left.40^{\mathfrak{a}}\right)$.

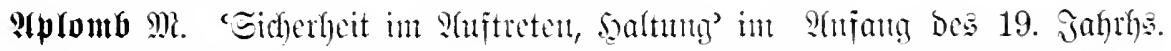

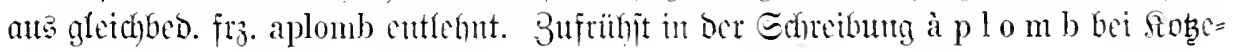


bnc 1811 somübiantin (XXVI 43) mur fehlt ihr noch ein gewisser Takt, ein gewisses höfisches à plomb, wenn ich mich so ausdrücken darf; ehenjo bei Piüffler

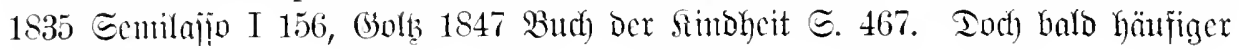
$\because$ P I $10 \mathrm{mb}$.

Befege: Hürffler 1831 Brieje IV $283 \mid$ Meijenovellen V 475 mitunter ruhen sie auf mit einer Laune, scheinbaren Bühnen- dem scharmantesten, humoristischen Aplomb. erfahrung, Aplomb, Volubilität der Sprache Retwalo 1843 Die Mappe $\subseteq .195 \mathrm{mit}$ dem - 1835 Eemilajjo II 216 der sichere Aplomb, vollständigen Aplomb cines karikirtenStutzers

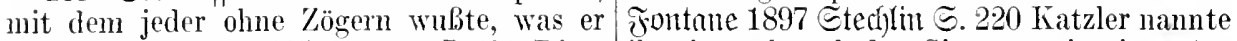
z.n sagen hatte. 1835 Guropa I 401 Diese ihn ja während der Sitzung mit einer Art Ohrfeige wurde mit einem Aplomb und Aplomb.

einer Genanigkeit gegeben. ¿aube 1837!

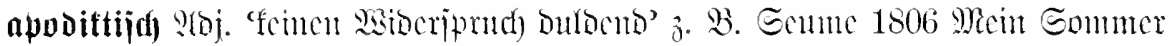
(IV 86) nad) DCM] was man darïber hier und da von rechtlichen Leuten fast ganz

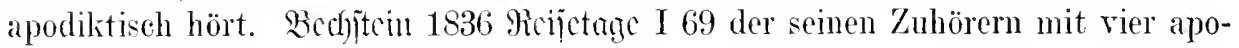
dyktischen Worten bewies, daß die heutigen Hessen von den alten Katten her-

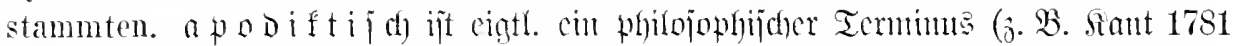

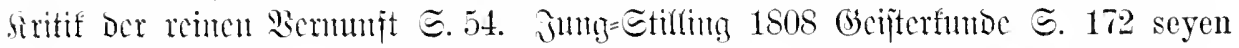
sie anch noch so wahr und apodiktiseh bewiesen) = lat.=ngriech). apodicticus 'un=

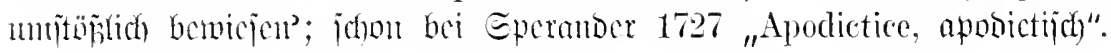

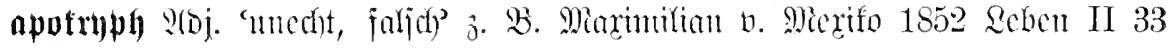
Apokryph dïrfte in diesem wissenschaftlichen Quodlibet die thönerne Giftschale

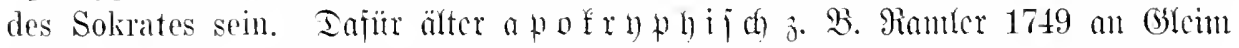
(I 175) wenn die Nachricht nicht apocryphisch ist. Ihiumntel 1791 Recijc (I 90) dab ich deine hentigen Weissagungen noch apokryphischer finde. Ducffe: Fpät=

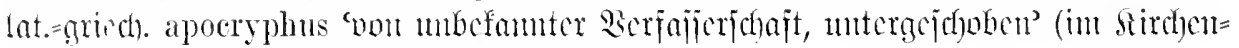

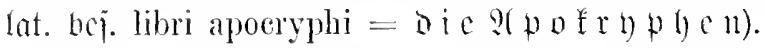

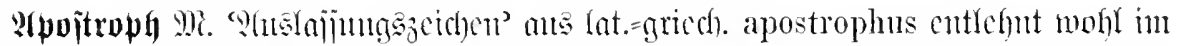

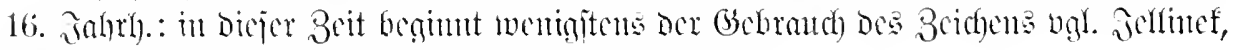

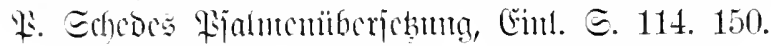

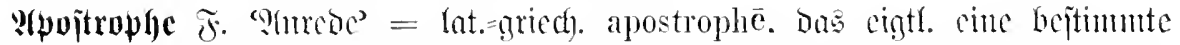

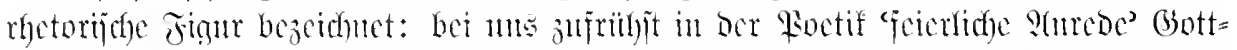

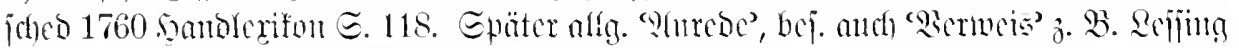
1760 Sitcraturbricfs (VIII 35) nach einer kurzen Apostrophe des feindlichen Feldherrn. Mïtller 1787 Enmerich III 23 E., der von ilurer ganzen Apostrophe eigent-

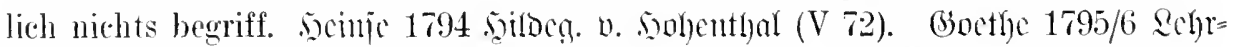
jahre (XX1 54) er erinnerte sich, lab Werner anch seine Apostrophen mit Gelassenheit anzuhören pflegte.

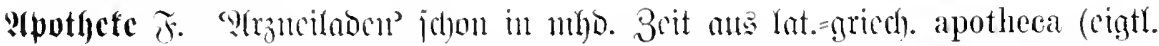

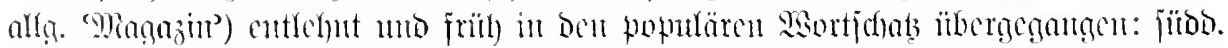

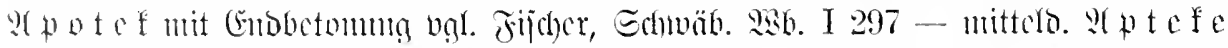

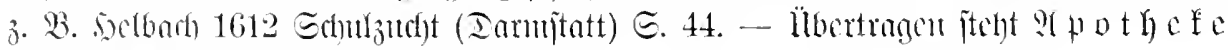

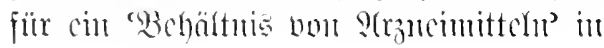




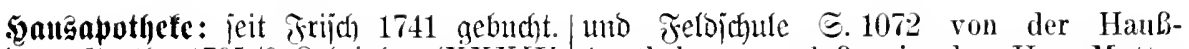
Beleqe: Goethe 1795/6 Qehriahre (XXXIII Apothek .... daß wir der Haus-IIutter 288) Ein Glass flüssiges Opium fehlte in der einen kurtzen Unterricht geben, nemlich, H. des Geistlichen. Sobebne 1799 üble wie dieselbige untersehiedliche bewährte ArtzLatme (IX 150) - 1801 flingsberg (XII neyen praepariren und zurichten, damit eine 227) ich verschließe sie in meiner $H$.

Ias Sort fdyon frïher in Büchertitelu

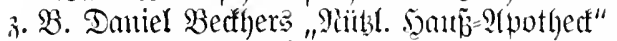

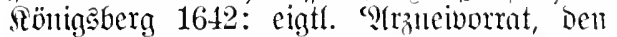
maı zu Şauje hält’ vgl. Börfler 1683 ,ọas=

nützliche Haus-Apotheck ausrüsten solle.

Beijeapothefe 3 . 9 . Ettmer 1715 grebanme $\Subset .647$ Eckarth schickte Andreas mit dem Reise-Apothecklein mit.

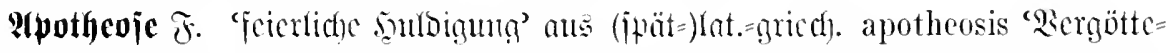

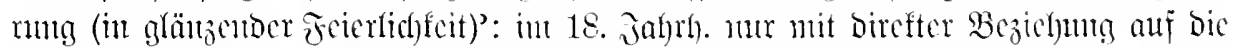

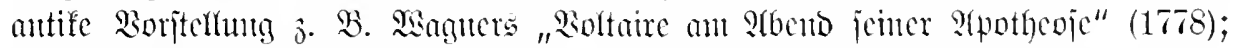

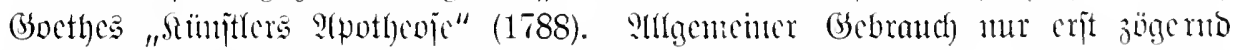
Qtrd)enthol; 1787 England III 166 Es war eine förmliche Apotheose. Fïtfler 1835 Semilafjo II 34 des Könnigs Krönung, gleichsam die Apotheose der Familie.

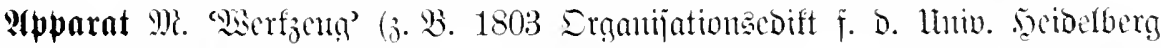
[lltumbenbutch I 441] eintausend gulden für instrumente und apparate. Goctbe, Yus Mafartens :Irchin [4. 5. 23, 263] Der Mensch an sich selbst ist der grölite und genaueste physikalisele Apparat): jutge bebrauthoserengenutg an Der öfteren

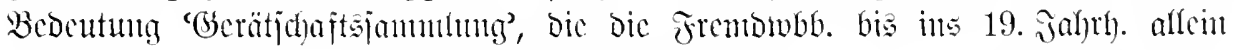

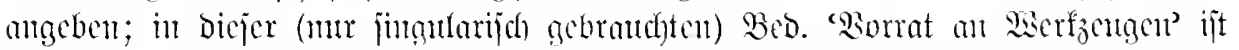

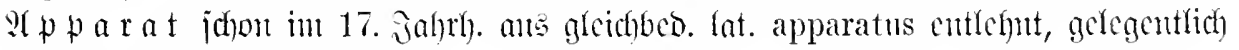
nod) in Der lat. Formt.

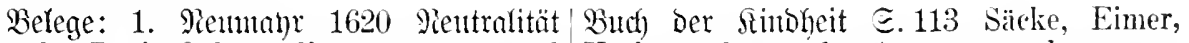
$\mathfrak{R} 1^{a}$ des Doria Galeen, die an apparat vnd Körbe und was des Apparats mehr war.

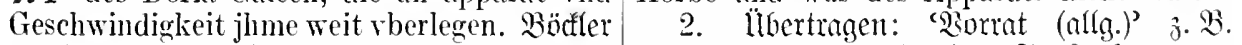

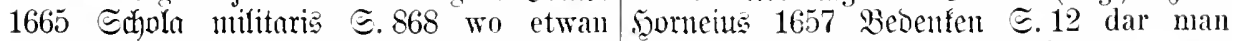
nicht dergleichen species absonderlich unter die Sprachen und den übrigen gantzen eines Feld-Scheerers Apparat berhanden. Apparat, welcher zn rechtschaffener geist1677 Machiabell. Jonouspocus ङ. 617 Dantz-, lichen und weltlichen Geschicklichkeit von Fecht- und Reithäuser oder derer machinen nöthen, zu erlialten vermeinet. Becher

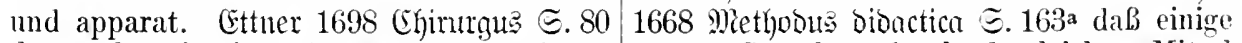
da würden sie einen Apparatum von denen gantze Sprachen durch dergleichen Mittel raresten Instrumenten sehen. 1790 Der in kurtzer Zeit ohn allen apparat von Wör-

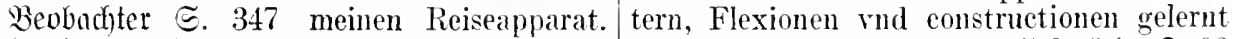

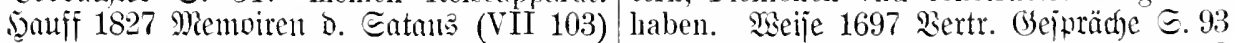
er schien sich an dem ungemeinen Rumglas wer nun die kunst nicht versteht, der muß und dem Rauchapparat, den jener vor sich sich trefflich verwundern, wie man so einen hatte, ein wenig zu entsetzen. Gols 1847 apparat von schönen Sachen hat.

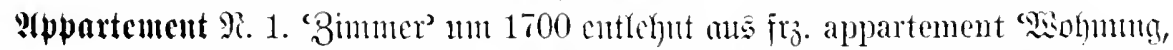

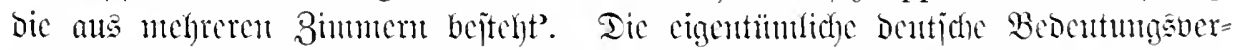

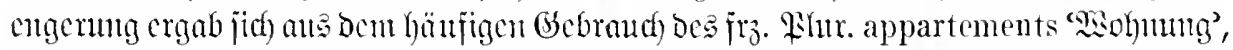

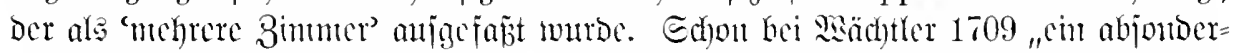

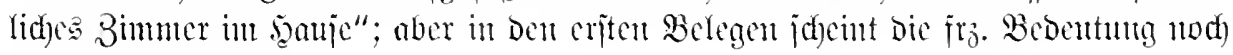
beibchalten ju jein.

Belege: 1. Surfüritin Eoplie 1709 an 1720 Theatmun ceremon. II $1449^{\mathrm{b}}$ er wird Rönig Frieorich I. (ङ. 181) Es ist ein gut sodann in das Appartement der Sultanin apartement express vor I. K. H. undt dero geführt. Biđdacfrviz 1723 Sart VI. §. 523 gemahlin in dem schloss gebaut. ¿ünig Gegen neun Uhr fanden sich die Herren 
Churfürsten auff dem Römer ein, woselbst ein jeder sein Apartement z.1 dessen Ankleidung fand. Rohr 1729 Berentoniell= wijienidhajt II 81 alle Tapeten, Stühle und ander Meublen, die in den Apartemens des vorigen Papstes auf dem Quirinal standen. Florin 1749 5ausbater Il $384^{\mathrm{b}}$ In einem vollständigen Haupt-Zimmer oder Appartement muB zum wenigsten ein Vorgemach, ein Cabinet oder Wolnngemach, ein SchlafGemach und eine Garderobe seyn.

2. Epeziell Deutid) ijt euphentijtijcher Gebraud bor at partement für 'atb= tritt'; jhour bei Campe 1801 gebudt. Beleg:

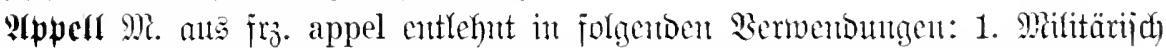

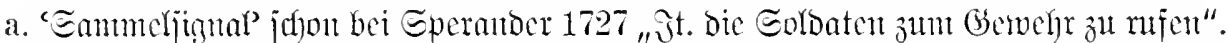
b. "lluter Appel veritelit man aud Das namentliche S(ufutfen Der Eoldaten" Campe

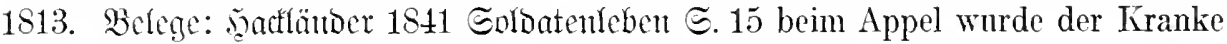
dem Kapitän gemeldet. Mahler 1860 Milit. Bilberbud હ. 47.

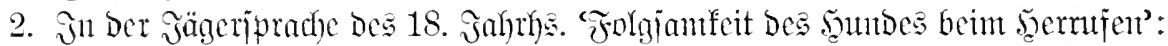
Iöbel 1746 Jägerpractica I 109 ${ }^{\mathrm{b}}$ Wenn aber ein Hund reine dreßiret und gearbeitet ist, und daB er ein Appel (Gehöre zum Ruffe) angenommen. In Diejer Bco.

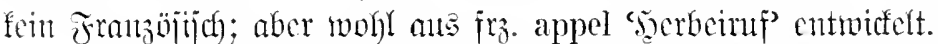

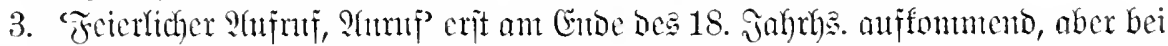
Eantpe 1813 utod nidjt gebucht. Belege: Sdhulfer 1795 Bricje IV 220 Sie lieben, wie es scheint, den Apell an andre Richter - 228 Ihre wiederhohlten Appelle an fremde Urtheile. Goethe 1805 ? : heit ist unerträglich und verächtlich. Epichbagen 1879 Platt Zand III 208 ich hoffe noch, dab dieser Appell an Ihr eigene Ehre nicht vergeblich sein wird.

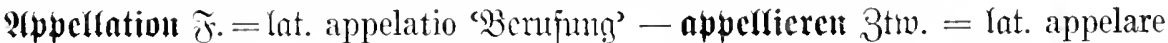

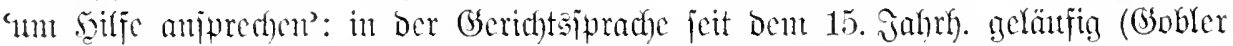
1536 S

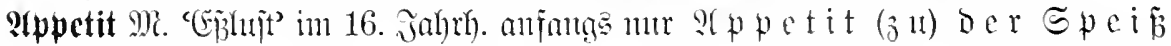
(1), Dam and) abjolut, aber nodh häufig Durd ben 3ujał (Ge-)Lust zu Essen uäher beftimut (2): Derartige Bujäze waren erforberlid), ba lat. appetitus mur allg. 'Ber= langen' bedentet. Sie Eprezinfijterming (appetitus cibi) begimut erjt im Mittellatein Des 13. jahros.

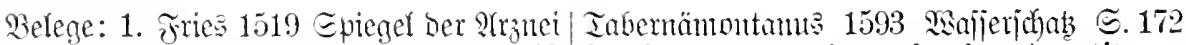
๔. $130^{\mathrm{d}}$ Der lust oder appetit der speiß Gurcken mögen sie auch, den Appetit zur rnnd des trancks seint nit anders, dan ein Speiß darmit znerwecken, bißweilen wol begirlieheit des magens, so er befindet, geniessen - ähntich @. 232 dieweil der

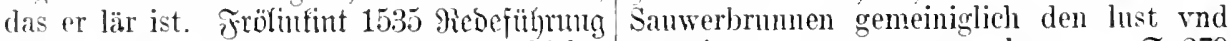
ङ. $1^{\text {b }}$ der wein macht den magen gesehickt, appetit zum essen erweeken - $巨 .279$ bringt appetit der spoiß vnd lust zu essen. wiederbringet den verlornen Appetit zum

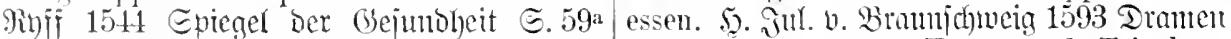
essig ist allein ein beiessen zu einen ein- $\Xi .36$ Appetit zum Essen vnd Trincken. luncken, salsen oder dergleichen, andere kost darmit zumerbessern, ind den lust oder appetit zu der speiß anzureitzen.
Slearius 1647 gieije $\widetilde{S} .4$ in dem man in remein nach derselben einen guten appetit zum Essen bekompt. Q(Gele 1654 Geridyt 
hänbel I 27 den gantzen appetit des Essens genommen.

2. Miünîter 1544 foanographic $\Xi .362$ Das ¿euferbad] sterckt die teüwige Krafft [= Beroaumig] vnd erweckt den appetit.

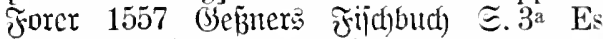
wird auch die sïltz oder brügen taissen vnd gebraucht den appetit danit zu reitzen. Eebaitian 1581 Stod un Inellemeitere ङ. $6^{\text {b }}$ wiewol der Appetit seines Herm nicht leichtlich zu erkennen. Inbernümontamus 1588 fträuterbud I $211^{\text {a }}$ Appetit oder begird zur Speiß - aber ebo. 591 bringen wider den zerstörten Appetit. Sapjt $1596 \mathfrak{A}$ z bud (5. $40^{\text {a }}$ so hette ich keinen sonderliehen appetit, von den Kraut zu essen. ?(lbertinus 1598 Te Convibits ๔. $4^{a}$ Der Frab ist ein vnmessiger appetit vnd begird der speisen vid traneks - 1598 (Suebaras Eenojdreiben I 117a wegen deb appetits rnd lust. Edhwerter
1636 Deliciae phyj.=math. $\Xi .249$ vnnatürliche Speisen mit grossem appetit vnd begiert essen.

appetitlid) 9(bj. 'zum Elijen reizeno' zu ?lppetit gebildet, nachoem diejes die Bed. 'EE⿰纟⿴囗十 Mitte Des 17. Jahrhaz. bezeugt. Edhild = fnecht 1652 Sanmonta III 169 appetitlichen

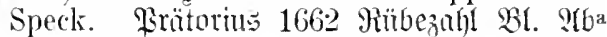
appetitliche Dinge. Francisci 1668 bor= gejpräd $\Xi$. $45^{\mathrm{b}}$ Das Fleisch [von Meer= gämjer] ist etwas ungeschmackter rnd den reichen Leuten nicht appetitlich. Tho= majü 1688 Monatsgejprüche I 369 der Herr beschreibet sein Gastgebot so appetitlich. Gröben 1694 Gumeijhe Reije=

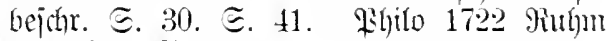
D. Iabats $\Xi .20$.

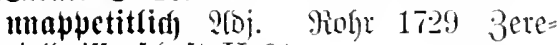
moniellmifienifhajt II 91.

applaudicren Btw. 'Sifafl flatjchen' im 17. Jahrf). aus gleichbed. Lat, applaudere gebilset z. B. Echupp 1659 Stalenber $\mathbb{E}^{\mathrm{b}}$ Als ich erstlich nach Hamburg kam und mir alles Volck applaudirte. - Epäter bej. vom Beijall ber Bujchaner in Theater

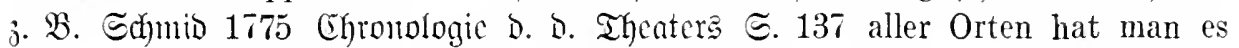
applaudirt. (3oethe 1795/6 2efrjahre (XXI 226) Von der Zeit an applaudirte ihm der Graf nur immer mehr, er mochte seine Rolle spielen, wie er wollte. Grauby 1836 Sebensiberbritijige ( $\mathrm{V} 223$ ).

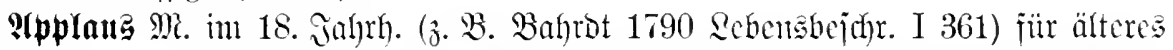

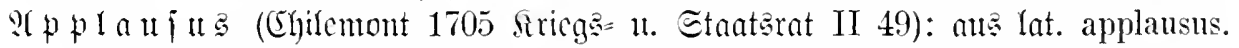

applizicren 3tw. 'beibringen, antwentben' j. B. Seume 1803 Spaziergantg (II 165) Diese Thiere hören auf nichts als diesen Stachel, der ihnen, statt aller übrigen Treibmittel, am Halse applizirt wird. Gols 1869 Seltfugheit I 14 zu rechter Zeit applizierte Ohrfeigen gehören auch zur sittlichen Lebensordnung. Echerzhafte :Hmendumg

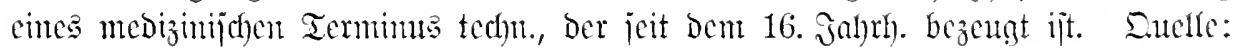
lat. applicare 'etwus swohin f̈̈̈gen, tun'.

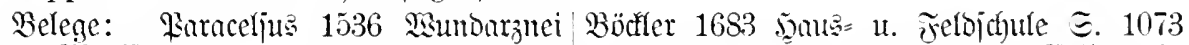

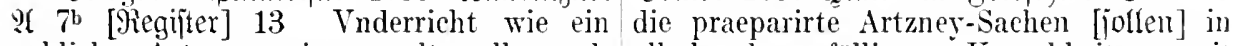
yekliche Artzney wie gemelt sollen ad- allerhand zufälligen Kranckheiten mit miuistriert rnd appliciert werden. Bapit Nutzen gebrauchet und beschriebener 1596 Prgmeibud) $\Xi .183^{a}$ den hinfallenden massen applieirt werden. Ettner 1716 Kindern pfleget man ein Cauterium actuale jebamme $\Xi .798$ übel-applicirte Artzeam Hintertheyl des Haupts zu applieiren. neyen.

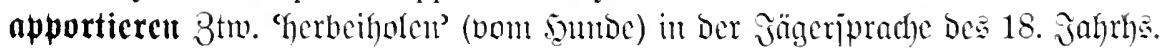

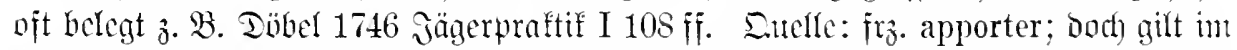

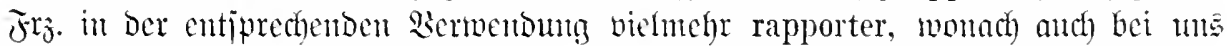

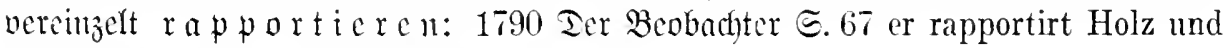
Steine aus dem tiefsten Wasser.

appreticren $3 \mathrm{tw}$. 'Dem Stemebe Glanz verleifen' im 18. Jahth. aus gleichbed. frz. apprêter entlehnt. Beleg: Picolai 1779 Bcrlin $\Subset .376$ Die seidene Zenge appretirt von Clavin. wohnhaft hinter der Garnisonkirche. 


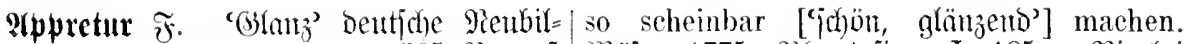

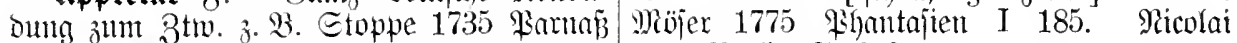
ङ. 321 Man mig die Apretour auch noch 1779 Berfin ङ. 370.

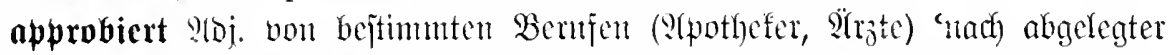

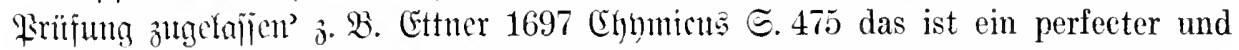
approbirter Chirurgus gewesen. Callenbad) 1714 Murmband 5.112 Academisch approbirte Wurmsehneider. Jnt 16.17. Jafrh. war a p p robicten (= lat. approbare) allgentein als 'billigen, genchmigen' geläufig $\mathfrak{j}$. B. 1558 secibeíberger Etatuteu ङ. 90 das er sich bekanter und approbirter recepten und artznei gebrauch. 1610 1lrf. Des Sönigs Matthias (= Sinf, Miten II 422) von der Facultet examiniert vnd Approbiert.

a priori (fat.) Feit Dem 17. Jahrh). in Der aflgcmeinen Bedeutung 'von born= lyercin' 3. B. Ifomajus 1688 Monatsgcppräche I 786 von einer Sache, die mir a priori nicht bekannt war. Qejping 1760 Siteraturbricfe. (VIII 215) Er wird es solchergestalt gleich a priori wissen, dab die Tranerspiele unsers scherzhaften Liederdiehters nichts tangen. Zabater 1778 Rhyjiognont. Fragmente IV 86 so liebe sich vielleicht schon

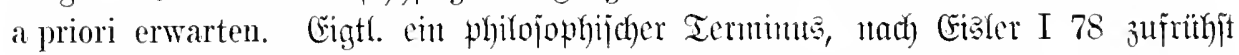
bei ?hbert von Eachicn: Demonstratio quaedam est procedens ex cansis ad effectum et vocatur demonstratio a priori (Bewcis Der Möglichfeit cincs Begriffa burd) $\mathfrak{N} \mathfrak{b}=$ leitnng aus einer "fribheren" Mëg(id)feit); aud ipäter bej. , a priori beweijen" 1744

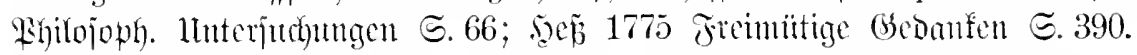

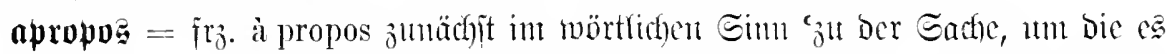

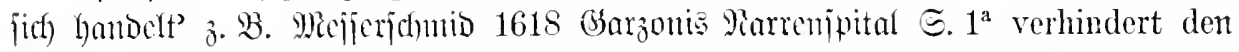

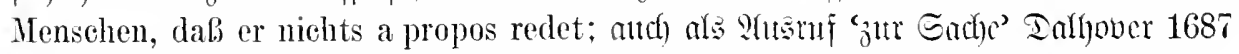
Gartenbeetcin I $278^{b}$ A Propo dann! - 702a aber, à propos. Callenbad 1714 Matrm= fand G. $40 \mathrm{Aber}$ à propos zu kommen, ich wäre gern ein Doetor. Daher Dam jeit

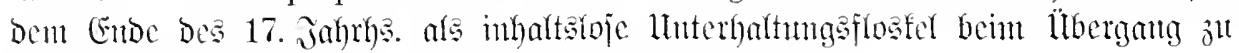
cinem nenen Gegenjtand: “übrigens, nebenbei benterft.

Belege: Ihomajü 1688 Monntsge=|führen. Mall 1786 Bagatellen I 26 Apropos! fpräche I 111 A propos, fing Herr Augustin wollten Sie mir nicht was nenes sagen.

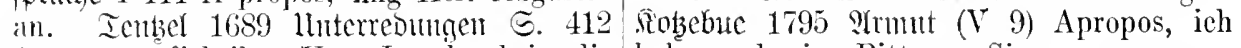
$A$ propos, fiel ihm Herr Leonhard in die habe noch eine Bitte an Sie.

Rede. Callembach 1714 Pater $\subsetneq .26$ A propos, wo kommt der Herr her so tiefsinnig?

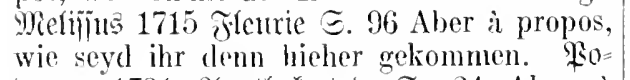
Dagra 1721 atpothefertod $\subseteq$. 24 Aber ì propos, haben Sie die nene Cur gehört. Picander 1726 Echaupiele 's. 83 A propos, was hatten sic denn gestem vor einen Fecher. Mabener 1759 Eatiren III 89 A propos! ich lasse sechs Mitteleichen
fiiller. Jufti 1765 Eatir. Edhriftelt I 144 So bald or [Der Etuber] cine Priese S'chmupftabak gemommen hat, so kann mall nur sicher wetten, dab ein ha! ì propos nnmittelbar daranf folgen werde: und dieses
ewige a propos wird or niemals hinaus- 9mmerfing. Sine bejombere Bebentung 'gelegen' rit fajt burchans auf bic Msendung a propos fo m m cu bejdränft. $\quad B \mathfrak{u}=$ friihjt gebucht bei Diehrima 1684 "Das fömt

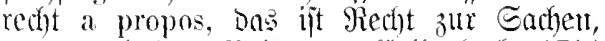
eben reatst". Belege: Crallenbad) 1714 Echipjes ङ. 69 Der Herr kommt mir à propos, ich hab ohnedem Ordre, des Herm Rath ind That zu pllegen. Sfflano 1795 Fieije (II 66) so finde ich es apropos, mich an Herrn Traut zu wenden. Brmu 1806 Epijoden I 2.27 Du siehst, daB unser Pictet sogar apropos krank zil werden weiß. Font= tanc 1869 Siriefe I 166 dieser Gichtanfall kimm mir sehr a propos. 


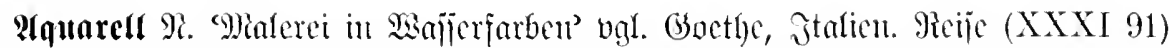

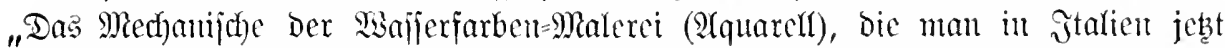
jehr hod) getrieben hat" - 1803 Grthang ju Benb. Cellini (XLIV 386) "Man zeid)uet nod) anj eine andore siseije, indem man nadh vollentotem umrís nit ber

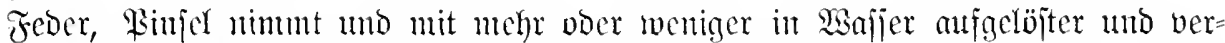
bünnter Tufche nad) Bebürinis befferen ober butffern Echatten anbringt. Dieje

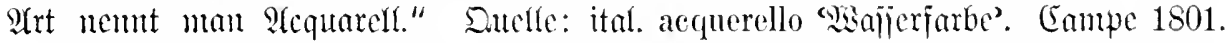

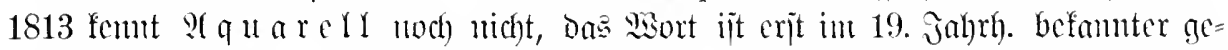

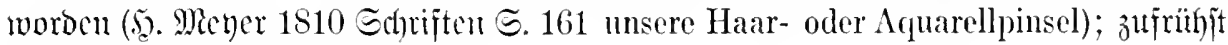
gebucht 1814 Broctifomes I ${ }^{3} 257$.

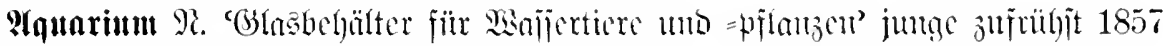

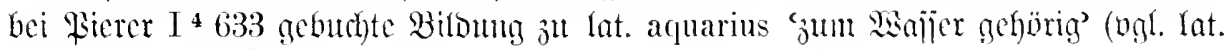
aquarium 'Tränte').

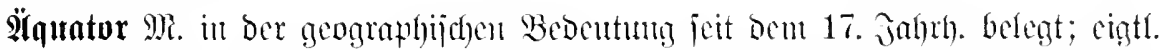
ciu Iermims Der nittelalterl. 9(jtronomie: (eireulus) aequator diei et noctis zur

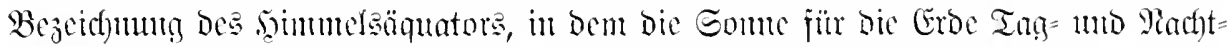

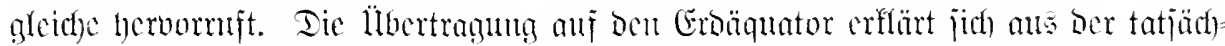

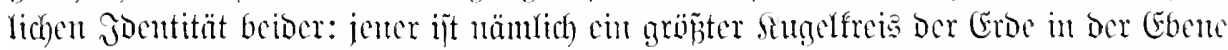

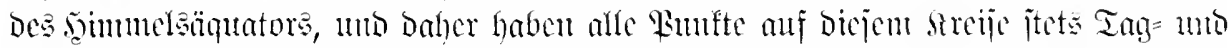

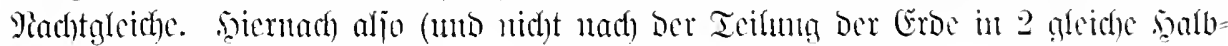

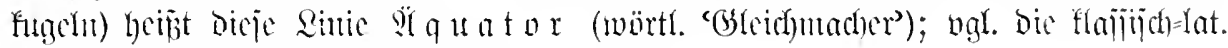

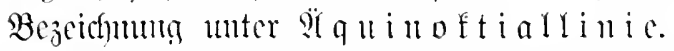

Belege: G(nberjen 1669 srient. Reije=/(oder Ae(quatore). Sogel 1716 Eituro. beichr. ङ. 7 sie lieget unter dem 6. Grad Meijebeidfr. Є. 533 des Äbends sahen wir Sïden vom Äquator - ๑. 86 sie lieget den Norder-PolStern wiederum das erste gegen dem Vorgebirge Comary unter dem mahl, demn man selbigen jenseit dem 8. Grad rom Equator. Francisci 1669 Aequatore nicht sehen kan.

Trauterianal II $100036 \mathrm{Grad}$ von demGleieher

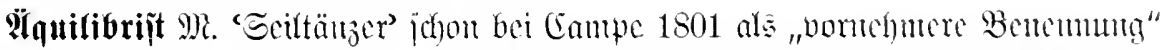

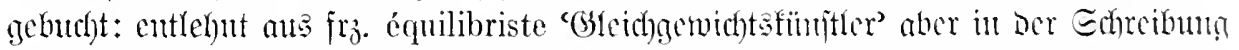

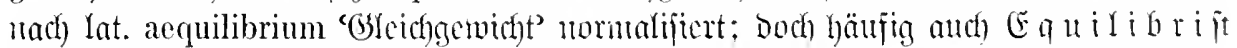
3. B. Schmio 1775 Chrondog̣ic D. o. Theaters S. 166. Bönte 1820 Bricje aus jranfjurt

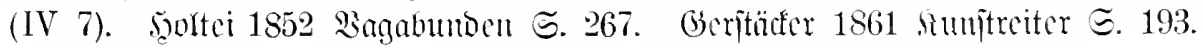

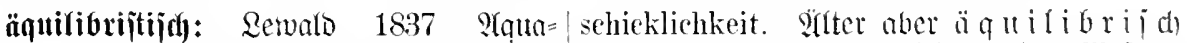

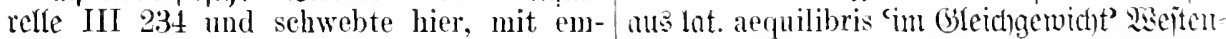
porgestreckten Armen, auf dem äußersten rieoer 1782 Ter Trmm Є. 180 allerhand Rande mit einer equilibristisehen Ge- äquilibrische Künste.

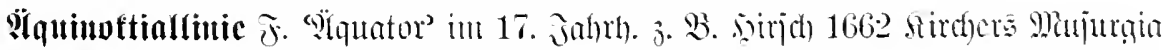

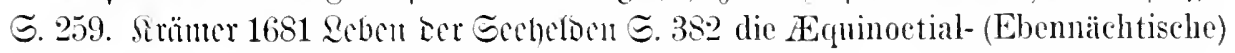

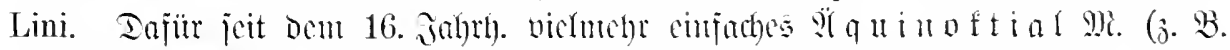
Miünter 1544 sosungraphic S. 692 fuor er [3eipucci] noch ril weiter gegen mittag.

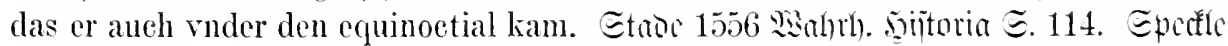

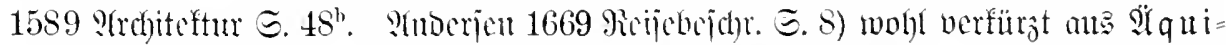

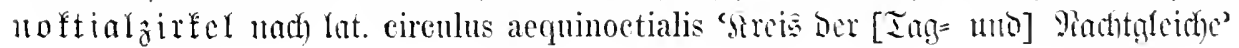




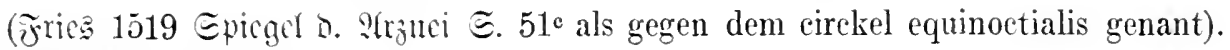
Bigl. î $q u a t o r$.

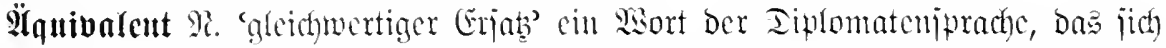

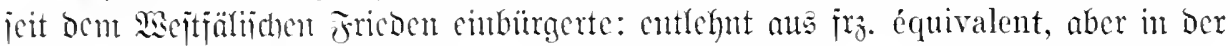
Edfreibung mach) lat. aequivalere gerichtet (1). Meben ber politijchen Bedentung

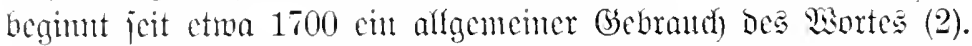

Belege: 1. 1647 Memorial (= Mieiern, | gegen als ein Equiralent die Aempter Acta pacis Westphal. VI 398) dab die im Dannebergischen abtretten. 5erber 1765 Hertzogen zn Braunschweig und Lüne- 恣erfe I $110 \mathrm{Ihm}$ war es leicht, seinem Abburg auch bey ihren dabey stattlich ra- gesandten gegen das Wagspiel auf dieses dieirten Successions-Rechten gelassen, oder eigenen Kopf zum Aequiralent einige dagegen zun Eqniralent die drey Stiffter tansend Französische Köpfe zu versprechen. Hildesheim, Minden und OBnabrück ein- 2. Fflorit 1702 bausvater I 4223 daß geräum werden mögen. $168 t$ betröit. er, wo nicht einen billigen Uberschuß, doch Europa $\mathfrak{Q} t^{\mathrm{a}}$ dab die Cron Spanien ihr zum wenigsten ein .Equivalent oder gleichen die Niederländer gegen Catalonien oder Wertls dafür zu geniessen hoffet. \&ucae einem equivalent abtauscht $-\mathfrak{B} 1^{\text {a }}$ die 1711 Europ. Seefifor $\widetilde{\Xi} .373$ an dessen noch restirende Niderländer gegen ein equi- Stelle ein in Dach und Fach wol condivalent in Catalonien gotwillig abzutretten. tionirtes aequivalent. Marperger 1711 1699 Etantsipiegel I 82 Solte die Cron Bejdr. D. Mejien I 366 erwartende, was Franekreich dem Hertzog kein Equivalent ihnen die Europäer ror ein Equivalent dagegen geben wollen, dörffte diser dic ihrer Waaren dagegen legen wollen. Rohr derseitige neue Frantzösische Nachbar- 1718 હtantšflugheit 厄. 813 den Officianten schafft zu vermeiden, andere Messures zu hingegen an ihrer Besoldung ein Equiuehmen veranlasset werden. 1708 Reopors valent davor ausmachte. Epäter jehr häufig. Der Grof̉e II 206 dieser aber [jollte] hin-

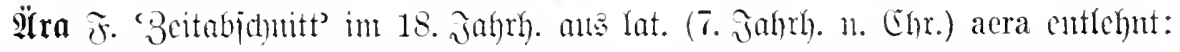

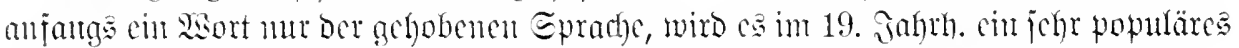
Mobcuort (bej. uc uc if ra vgl. Eancubori, Echlagmb. E. 224).

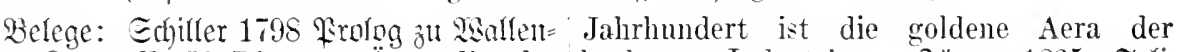
itein 2 ager 3 . 50 Die neue Ära, die der höchsten Industrie. Jäger 1835 F́lix Kunst Thaliens Auf dieser Bühne heut $\Xi$ d)tuabel $\Xi .57$ Ob die Bursehen der silbeginnt. Guethe 1818 Man̈fujug (XVI bernen Aera - die goldene war schon 272) Doch Adrastea zeigte sich, Des Glïckes lïngst vorbei. Edferr 1S70 Farrago હ. 13 Ära war gegeben. Vergangenheit und zu Anfang des ersten Jahrhunderts unserer

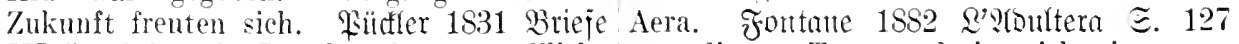
III 5 seitdem in Preußen der vortreffliche von diesem Tag an datirt sich eine nene Niagler eine neue Post-Aera geschaffen Aera des Hauses Van der Straten. hat. Brand 1834 Brestau $\Xi 23$ das jetzige

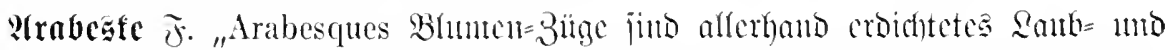
Bhuten=

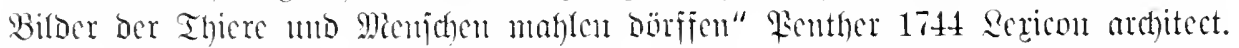

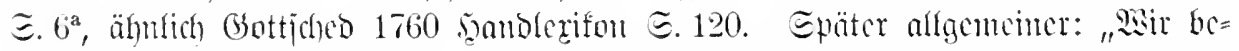

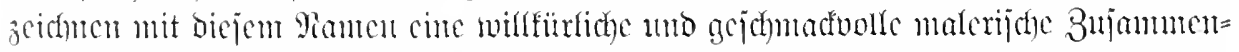

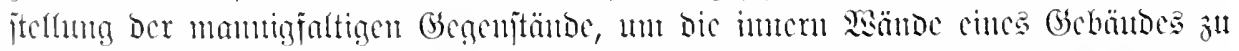

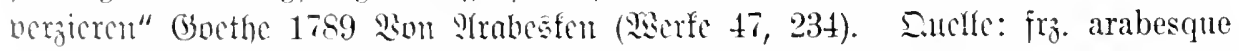

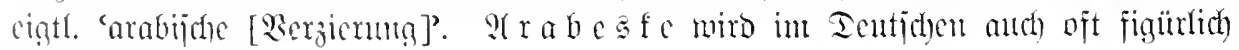
nectroundit.

23elege: [Micolai 1759 Riteraturbrieje mit lauter Hirngespinsten zu verzieren? III 51 wozn ist es denn nöthig, eine Sache Und dabey jeder Verständiger, der da 
fraget, was es denn eigentlich vorstellen 1797 Jutuelientior (VI 78). Brentanto 1800)

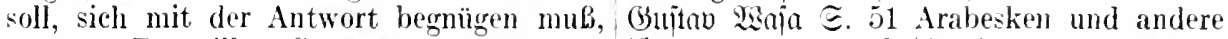
es sey Roceaille, Grotesque, Arabesque, Verzierungen. Edjlegel $1801 / 2$ Borle= a la Chinoise, oder en gout Baroque: kurzum jumgen I 209 Es sind die Arabesken der 's sey so Mode.] Edhiller 1794 Brieje IV Gartenkunst: Ind warum sollten sie da 58 Was alsdann noch auf dem Rïicken nicht eben so wohl geduldet werden, wie leer bleibt, das kamn mit Strichen oder in der Baukunst unter den Verzierungen. Arabesken ausgefüllt werden. Jean Raul

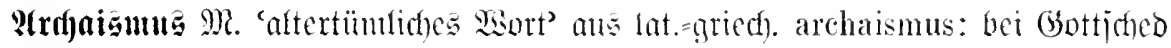

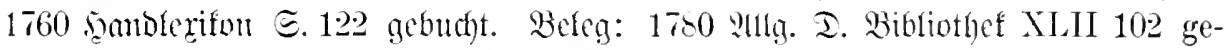
suchte Archaismen, die eines etymologischen Aufschlusses bedürfen.

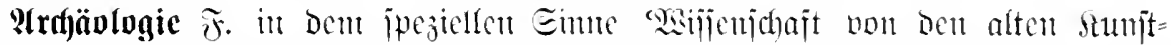

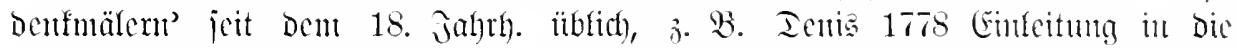

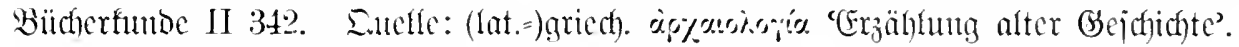

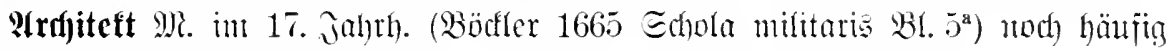

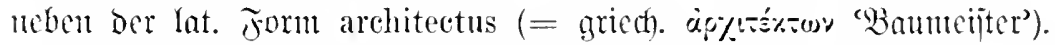

ard)itctoniia) 9(bj. ans lat. architec- von Bejtungen" Eträ́burg 1589, aber in

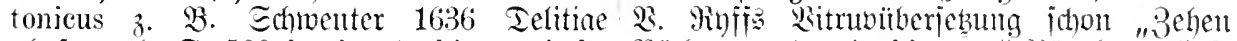
phy) $=$ math. $\Xi 530$ lustige Architectonische Büdher von ber Architectur" Jiünberg 1548. und mechamische Fragen.

Beleg: Ed)wenter 1636 Iefitine $\Xi .52 !$

$\mathfrak{F r d j i t e f t u r} \tilde{\mho} .=$ lat. architectura im Die Geometria thut so viel bey der Ar16. Jahrh. bej. als Etidywort bon Büd)er= chitectur daß es nicht anßznsprechen.

titelu eingefïhrt vgl. Epecfles ,Architectura

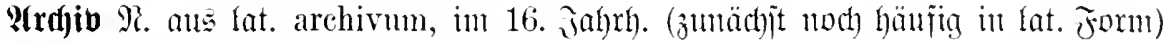

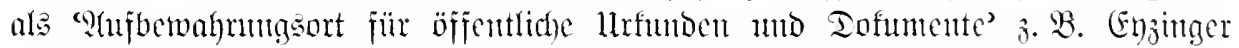
1591 Relationen II 56 den Registratorn zu Bomn, der des Ertzstifft archiumm, Jura, Sigel vnd Brief in verwarung hab - Sigel vnd Brief aub dem Archino. Tału $2 a n b e=$

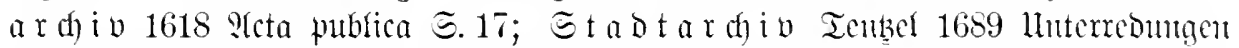

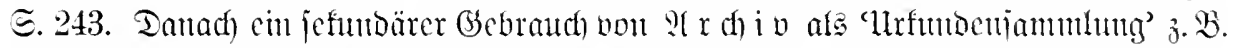
Weijc 1673 Erzuarren $\Xi .116$ Endlich kam Florindo über das Fürstliche Archivum, welches in einem Beykästgen gantz heilig anffgehoben war.

Prena $\widetilde{F}$. erit in 19. Jahrh. allgemeiner gebraud) (2), vorher mur mit birefter

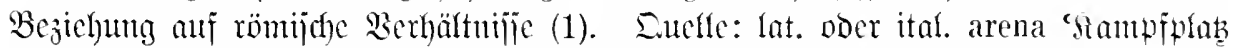

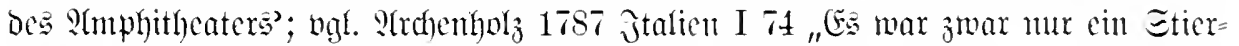

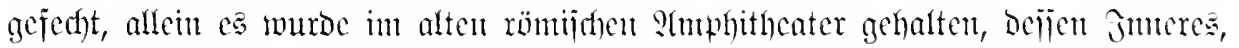
wic befant, nod) ganz bic alte Etructur hat, und jorgfältig unterhalten miro. Man nenut es ficr Arena."

Belege: 1. Eulzer 1771 Theorie I $48^{\text {a }}$ ["2(mphitheater"] Um den Mittelpunkt des Grundes herum war ein großer runder oder ovaler Platz, mit Sand belegt, und daher Arena geheissen. Eeume 1803 Epajier= gang (III 5) Die Arena giebt jetzt einen schönen Garten mit der üppigsten Vegetation. Seeine 1834 હalon (IV 14) die Idee ergreift uns und knechtet uns und peitscht die Arena kaum unter stürmischem uns in die Arena hinein, daß wir, wie ge-Applaus verlassen hatte. Machenfulen zwungene Gladiatoren, für sie kämpfen. 1865 Ballet I $13 \mathrm{Er}$ war ein so trauriger ङ. 293 jetzt sieht man aber bei derselben Gelegenheit abgemagerte Grooms einige Tonren in rollem Gallopp durch die Arena machen. Marimilian v. Merifo 1851 Leben II 34 es ist die Arena, in welcher die weltberühmten Stiergefechte gehalten werden. (jeritüfer 1861 Sumitreiter $\approx 14$ wie er 
Hanswurst, wie je einer die Arena be- II 300 Nun ist die Schneeregion erreicht! treten. $\quad$ Eine tiefe Arena, von schroffen Bergspitzen 3. Ïbertragen: Brun 1809 Epijoden umgeben, empfängt uns.

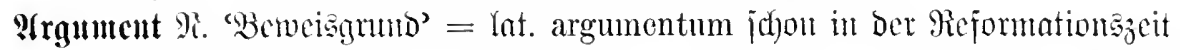

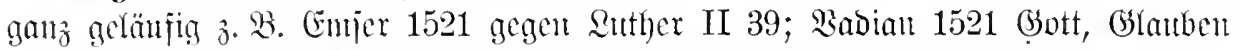

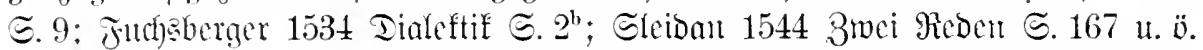

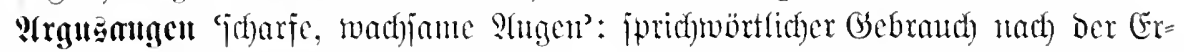

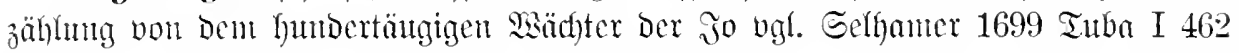
bekommen an der Statt hundert Angen für zwey wic ein anderer Argus. Sifiller 1784 Cabale u. Siebe (III 6) Halten Sie sich deswegen an den Major, der mich den ganzen Tag wie ein Argus hïtet.

Belege: Gichtel (1696) Brieje X 38 ihn Ein feiler Gratulant mit A. Acht. Wir leben in einer wunderlichen Zeit, ( Erfilller 1800 Maria હtuart II 8 Vom Ardie A. wol nötig hat. Bachariä 1754 Ber $=$ gus-Blick der Eifersucht gehütet.

wantungen (I 160) Besonders giebt auf

Pric $\tilde{\mho} .=$ ital. aria bgl. Frätorius 1619 Enntagma mujicum III 17 Aria vel Air. Ist eine hübsche Weise oder Molodey, welche einer ans seinem eignen Kopffe also singet: Sind bey vns auch Deutsche weltliche Licder mit schönen zierlichen Texten. Vnd solche nnd dergleichen schöne Arien nemnen die Itali jetzunder Sehertzi.

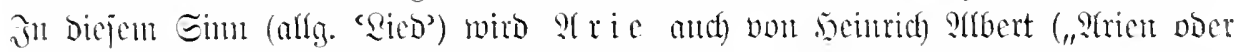

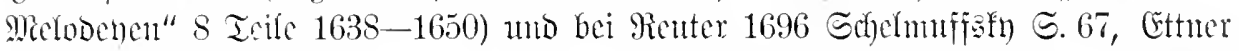

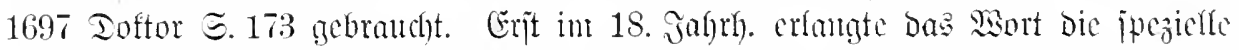
moderne Bebentung in Bereid Der Durefats nad) ital. Borbilo gejtalteten Sper. 3gl. Scheibe 1745 Majifus $\odot .135$ Die Melodie der Arie wird oft recitativmäßig. Jujti 1765 Edfriften I 144 Itzt mumelt er zwey Zeilen ans einer Opernarie. $\mathfrak{B g}$ l.

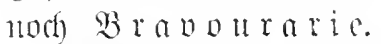

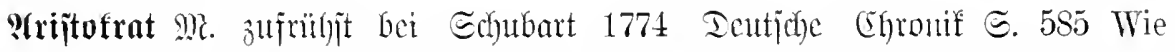
muthlos sind nicht auf einmal diese stolzen Aristocraten [Die Beneziancr] ge-

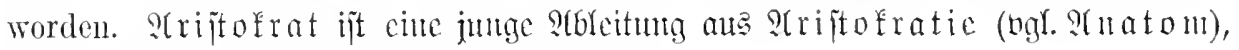

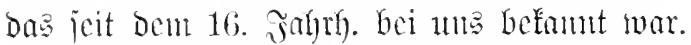

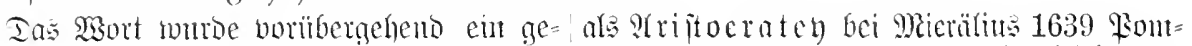

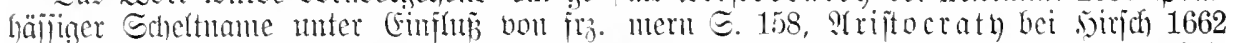

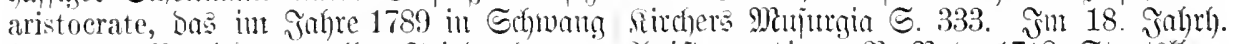

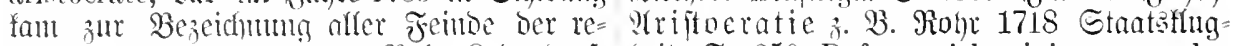
volutionären Qiewegung. Bgl. Rabendorf heit $\Xi$. 250 Dafern sich einige von den כ)lagmb. ङ. 10 .

Vomehmsten [Des Reginentis] aninaßen,

:Trijtofratic $\mathfrak{F}$ ans lat. (= griech).) aristo= wird es die A. genennt. Bajebotw 1758 cratia, im 16. Gahrh. nod) in ber lat. Form Pratt. Philoiophie $\Xi .749$ die A., wo ein

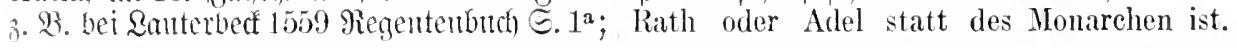

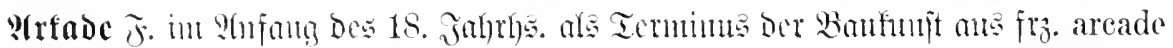

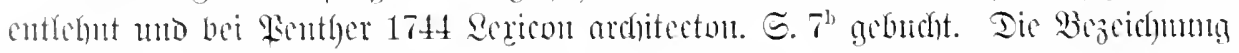

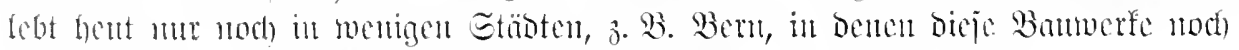

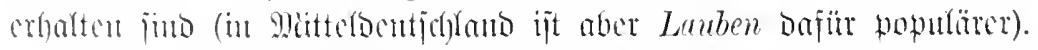

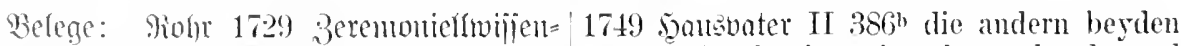
johoft II $32-4$ An der Grufft werden zuweilen werden dureh über einander stehende und rechte Pontails anfuchaluct, mit den schön- an drey Seiten herumgehende Arcaden sten Areadm, Pilastern, Statuen. Fforin oder Bogen-Stellungen formirt. Enlacr 
1771 Theorie I $180^{\circ}$ Diesen Namen [Bogen=|artigen Kaufleuten unter den Areaden [tellung] haben die deutschen Baumeister in Bern allerdings Freude macht. den Werken gegeben, die man gemeiniglich 9(mmerfung. Edhou im 17. Jahrh. ijt mit dem französischen Namen Arkaden bas wort im Gortenbau bejeugt: EEljhol nennt. Brauby 1837 Singetraphad (VI 1684 Gartenbau 5.44 Bogen-Gänge oder 12) Unter dunklen Arkaden, dureh enge Arquaden sind lange von Lattenwerck winklichte Straßen wandelnd [sc. in Berm]. auff den Seiten und oben mit höltern Rewald 1839 Edjtweizerland Є. 7 was den (irckeln beschlossene Gänge.

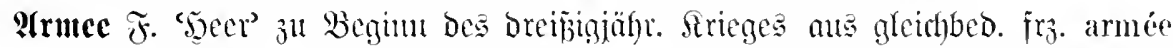

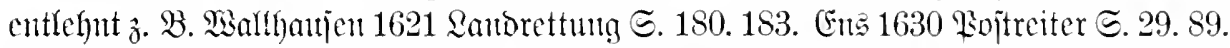

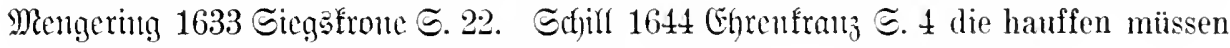
uns trouppen heissen, ein Heer armée.

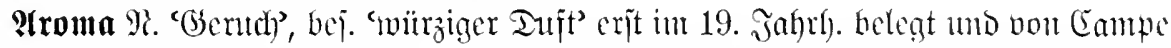

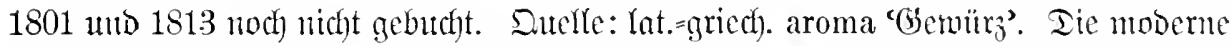

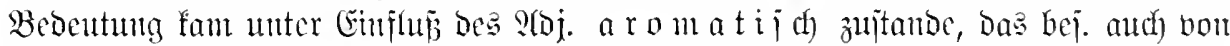

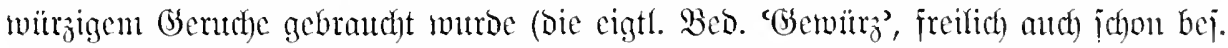

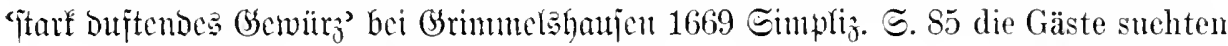
ilıre Bisemknöpffe und Balsambïchslein, auch so gar ihren Schnupfftaback hervor, aber die beste aromata wolten sehier nichts erklecken - $\Xi .477$ es roch um sie herum so starek nach Haarpulver. Balsam, Bisam, Ambra und andern Aromaten).

Belege: Rewalo 1836 ?qquarelle I 153 von den Aromen mehrerer dampfenden Schüsseln angelockt. (B́lä̆bremmer 1836

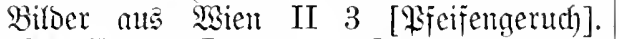
1841 Curopa I 112 der Kaffee in kleinen bunten Tassen, mit seinem lieblichen Aroma. Frentag 1855 Eoll แ. sabert I 195 etwas Stallluft und viel von dem Aroma der Weinstube.

arvutatijo 9roj. 1. entiprechents lat.

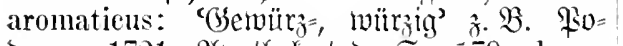
Dogra 1721 Ifpothefertoo 5.179 denen aromatiseh-balsamischen Saamen. Ffleijcher 1730 Sect $\mathfrak{v}$. 2 Uydo I 170 von vortrefflich und aromatischem Geschmack. Forjter 1788 Steine Edfriften S. 75, Eeume 1803

2. Friil audich bout wiltzigen Tüjtert: Eebiz 1580 Felsban E. 434 auß wolriechender vnd Aromatischer süsser Materi. Ettmer 1697 Doftor $\Xi .471$ sie haben einen rechten aromatischen Geruch. 3adfa= riä 1756 Ingeşeiten (II 22) Warum athmet ihr nicht die Luft voll aromatscher Geriiche u. ̈. Bretner 1790 Qebent e. Qüber= liffent I 94 Ein friseher Ostwind wehte ihnen aromatisehe Düfte ron den Hainen und Wiesen entgegen.

3. Daher arout at $i$ id gerabezu

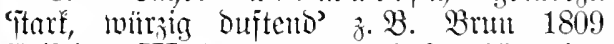
Eviinosen III 41 wo aromatiseher Thymian duftet. Sonuif 1827 Manm im Mons $\Xi .24$ der aromatische Rheinwein.

ভnaziergang (III 40) aromatische Krïuter.

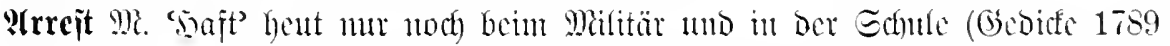

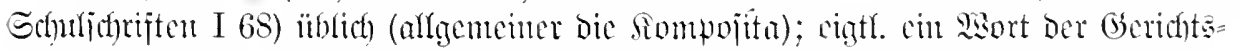

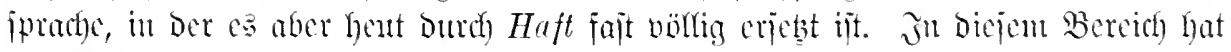
Das s.

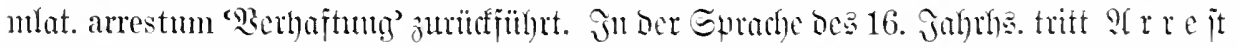

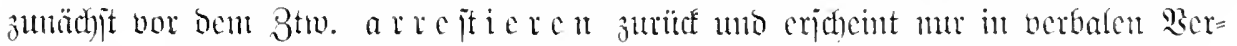

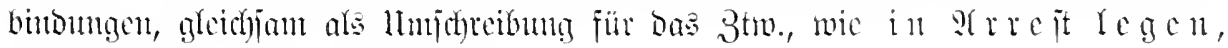

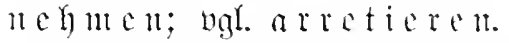

Belege: 1521 Rijü̈nomarft ber Sinti=' mürbigfeiten $\Xi .105$ JFG. mit dergleichen jomen (= Echade, Entiren III 69) so soll Arrest verschonen - keinen Arrest erman alle zehend in verbot und arrest legen gehen lassen. E(jwartisenbad) 1580 Ennt= und im kein Körnlin davon sin leben lang ontmuna $\Xi .10^{\mathrm{a}}$ In arrest oder verbott

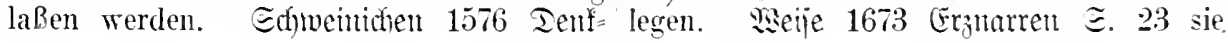


mit allen Helffers-Helffern in Arrest zu nehmen. Ettmer 1697 Toftor $\cong .192$ hieranf wurde der Marquetender in Arrest genommen. Friebrich I. 1701 Brieje E. 19 indem ich meinen Hofmarsehal in arrest nacher Küstrin habe bringen lassen. $\Re a=$ bener 1751 Minjbrauch D. Eatire ভ. 37 man will das böse Buch heraus haben, es kömmt endlich, und man behälts in Arrest.

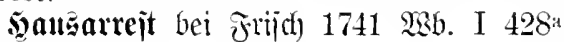
gebndht. Beleg: Bülau 1766 Pationtal= geift $\Xi 205$.

Mittelarreit bei Secimpius 1820 utod) jehlent, wohl erjt in ber neucren Eoldaten= iprache. Beleg: Soatländor 1841 Eoldaten= leben હ. 27. 3gl. Gamon 1837 jumwresten (VI 197) die versehiedenen Subdivisionen ron gelindem, mittlerm und strengem Arrest.

Etubenarreit in 18. Jahrh. jadjon Durd)= aus gelüufig (bei Frijd 1741 unter Hausarrest). Belege: Flleijder 1731 seerr vo. Snbio II 92. 178t Bramidhrweig. Echul= oromungen I 436. Miüller 1789 (Emmerid) VI 206. Brentano 1800 Gujtav Maja E.

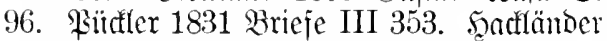
1841 Eoldatenleben ङ. 27.

Busdjelarreit eqrreit weaen einer

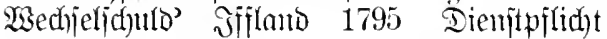
(III 200 ).

Arreitant MR. 'Gejangener' jeit Epe= ramber 1727 gebudt mo in 18 . Jahrh. in Der Gerichtsiprache ryäufig belegt $\mathfrak{j}$. $\mathfrak{B}$. Guggenberger 1722 \$rozelje $\widetilde{S} .145$ dabey dann so vil befunden habe, dab bemeldte Arrestanten Diebstähl begangen. Ricuter

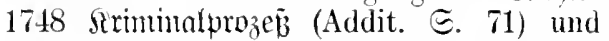
müsser ausser diesem der Arrestanten Kleider aufs genaneste ohne Anstand visitiret werden. Sirdh) 1766 Echuthreden in peinl. Fäflen II 396 der Arrestant [hat]

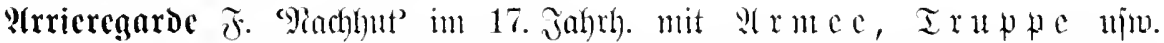

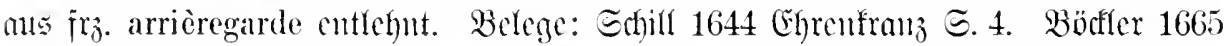
Edola militaris $\Xi .533$.

arrogant 9(Dj. 'ammajpend, Dïnfelbajt' im 18. Jabrh. chtlehnt ans jro. arrogant. Belege: Bocthe 1796 Bricfe XI 156 Eigentlich hat eine arrogante Aenßerung des Herrn Richter mich in diese Disposition gebracht. Edjilfer 1798 Bricje V 339 In einen arroganten Philosophenton finde ich eine recht gemeine Saalbaderey eingekleidet. Eine ältere (Gntlel)mung ijt

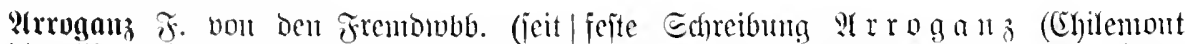

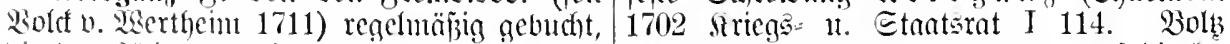

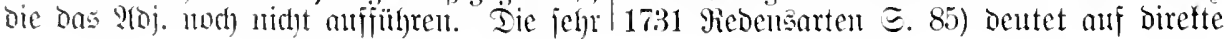




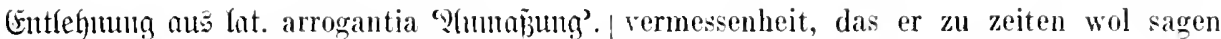
Frithiter Beleg: 1564 Bimmerijhe (Ehronif dörft: Ich bin herr von Zollern.

V 309 er kam in ain solche aroganz und

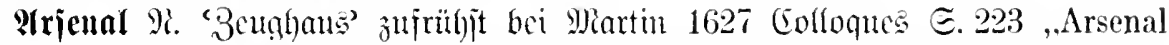

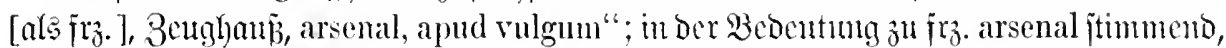

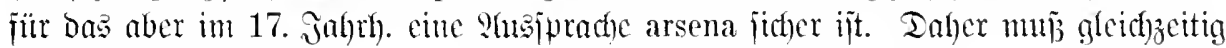
ital. arsenale eutgervirft laben, Das jeit dem 16. Jahrh. als Pame der italienijeden

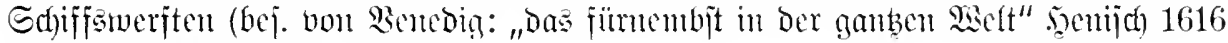
Sp. 122) befamint war.

Sgl. Bruber Felix 1556 Fafurt in Das für die Neer Armada zugericht. Furttenbad) heil. Lato ङ. $215^{\mathrm{a}}$ schlugen wir hinten 1627 Itinerarium Italiae $\Subset .202$ vor der an der Statt [Betteoig] hinumb an dem Statt der Arsenal wo die Galleren gebawen Arschanal. Bei Eneffe 1589 Architectura werden [oon Benta] - E. 249 [bas Bene= ๔. $84^{\mathrm{b}}$ eine Bejdreibung bes Arsenals bijd)e] Arsenal wol zu sehen - bej. Є. 250. nou Der Etabt Saletta in Malta. Carolus borned 1681 Eejterreid ïber alles $\Xi .268$ 1906 Relation 9ir. $5^{\mathrm{b}}$ es werden auch im zu Venedig in Arsenal.

Arsenal [voll Senebig] etliche newe Galleren

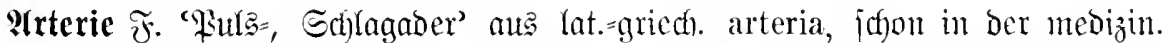
Terminologie um 1500 bezcugt; vgl. Frics 1519 Epiegel D. Pranei Є. $24^{\mathrm{b}} \mathrm{dy}$ schlahung des puls durch die adern Arterie genant - 〔 $69^{\mathrm{b}}$ nach dem sich dy arteri vff vnd zu thut.

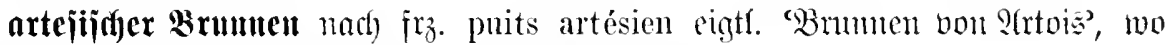
zuerit jolche Brumen gebohrt worben jein jollen.

artifulieren 3trv. 'Deutlid) ausjpredsen' im 16. Jahrh. aus gleidbed. Iat. articulare gebilbet. Belege: Şorjd 1580 \&emmins' Gehcimmije $\odot .110$ die vnter-

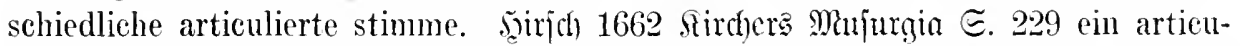
lirte Stimme. Shlegel $1801 / 2$ Borlejungen $\subseteq .207$ artikulirte Sprache. Bej. ge=

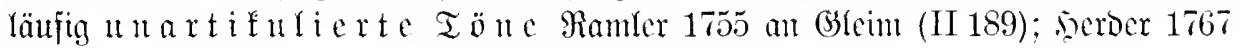
Deutiche Qiteratur (I 386); Eulzer 1775 Theoric II $81^{\mathrm{b}}$.

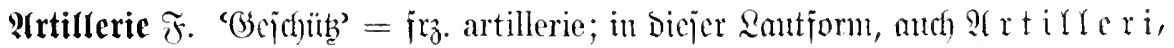

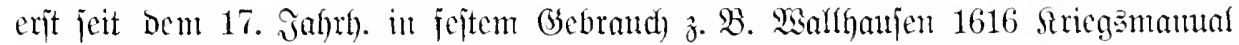

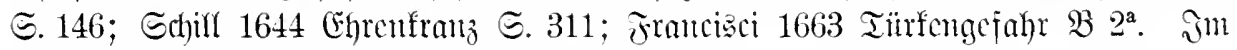

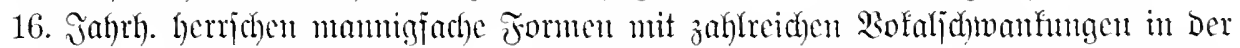

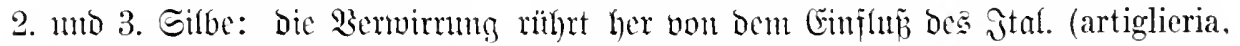

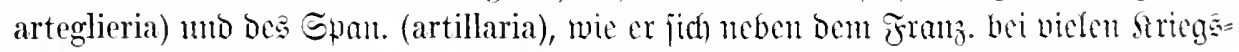

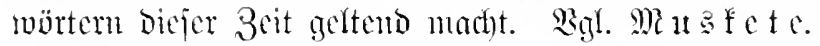

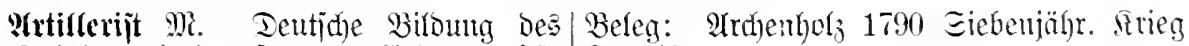

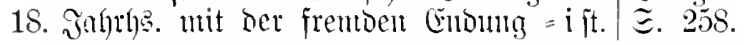

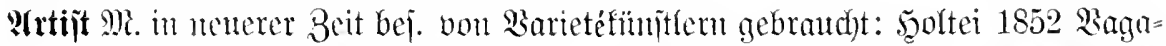
bunben S. 181 Man wiederholte ihm stïndlich als eine Hauptregel des „Metiers", daß der ,Artiste" sich vorzugsweise auf ein Stück richten müsse. Iunger 1884 Frenomörterumejen $\Subset .32$ An einem solchen ,Kunstinstitut" oder ,equestrischem Etablissement" giebt es nicht Künstler, sondern ,Artisten". Borker

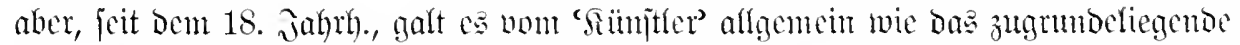
jrz. artiste. Belege: Sorber 1767 Dentfiche Riteraturl (I 427) Der Dichter und Artist 
braucht oft solche personificirte Stüeke der Natur - (437) Am Artisten ist uns Gottlob! im Gedicht nichts gelegen, wenn er nicht durch seine Künstelei sich als wahrer Dichter zeigt. Foriter 1789 Il. Echriften $\subseteq .139$ die laute Beschuldigung, daß Gewinnsucht und Stolz den neueren Artisten beherrsehen.

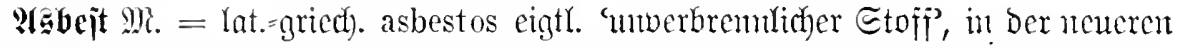
Mineralogie als Mame einer Silajie von fajerigen Bejteitsarten, bie zu muerbrem= lidfen Gemeben verarbeitet merben. Bei Grimmeläbaujen 1669 Eintplic. હ. 515

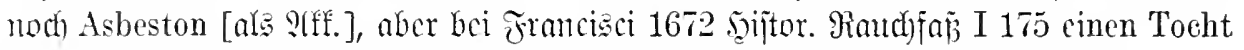

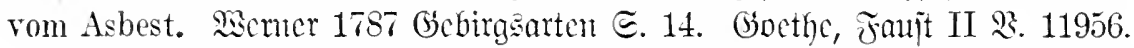

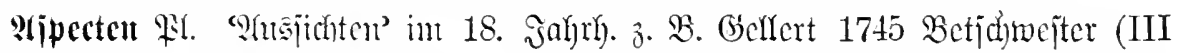
164) Das sind schlechte Aspekten. Sdjubart 1734 Chyronif હ. 524 In Cölhn zeigen sich ebenfalls für den Jesuitenorden sehr günstige Aspecten - cbo. 1765 $\subseteq .180$ aber noch bentlicfer: Seine Gesandten sehen nicht lauter gute Aspeeten am poli-

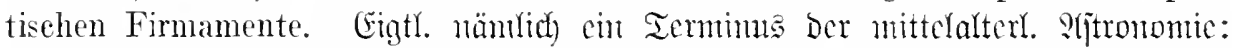

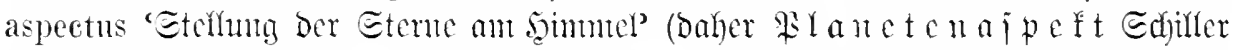

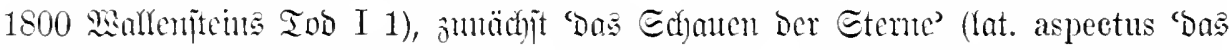

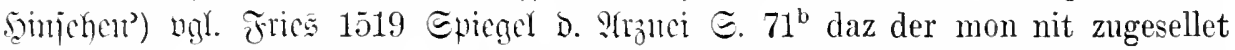
sei einem bößen planeten, welche zugesellung ron den gelerten des gestirns aspect genant werden - - $.84^{d}$ Weiteres ist not, das du acht nemest die angesicht, aspect genant, so die planeten zu dem mon, rnd rnder in selbs zu einander haben.

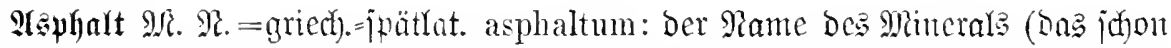

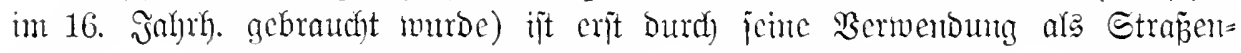

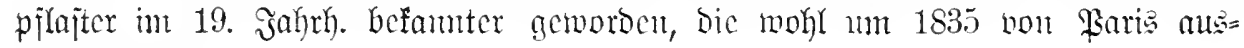
gegantgen ijt.

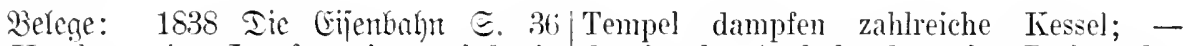
In Hamburg im Jungfernstiege wird ein das ist der Asphalt, der seine Proben den kleiner Versuch mit Asphaltpflasterung ge- Augen der Speculanten vorweist. "Toleov macht - Taghioni und Asphalt sind jetzt 1tadh Ih. Gántfier" 1841 Gurropa I 509 der Gegenstand der Hamburger Salon- wir, verwöhnt durch unser Pflaster von Gespräche. Es ist der erste kleine Ver- Asphalt. Mieiñuer 1863 Edfmarżgelb III such, der in dieser Art auf dem Jungfern- 54 Flanierte anf dem Asphalt der Boulestieg gemacht wird - E. 74 Dennoch vards. Gifnefing 1869 Metre Bifier a. hat sich die Kuhpockenimpfung, die Idee Fiaris I 191 Asphalttrottoirs. Simbenberg der Dampfkraft, die Asphaltpflasterung 1883 berfin I 16 die Reinigungswagen Bahn gebrochen. Rammer 1839 Bifber aus fahren langsam auf dem Asphalt dahin. Faris If 140 Rings um diesen kleinen

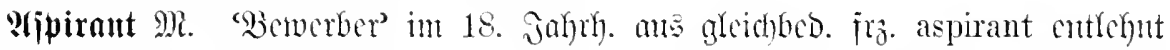
unb bei Cantue 1801 gebucht.

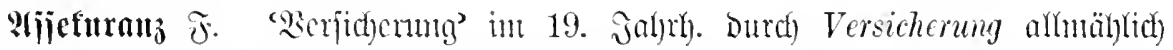

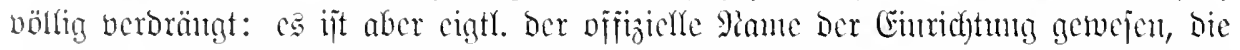

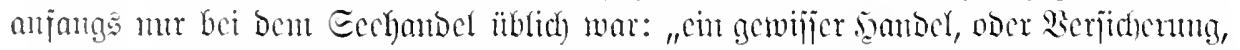

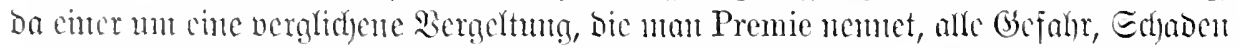

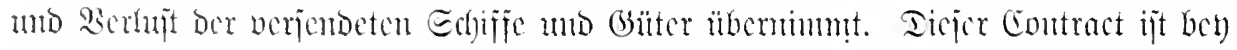

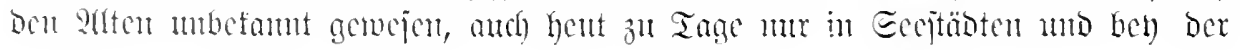




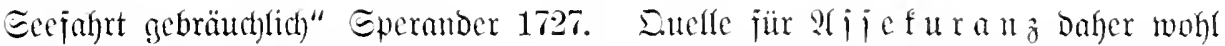

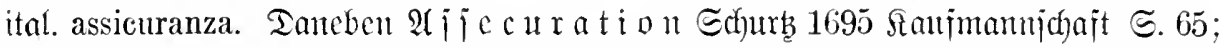

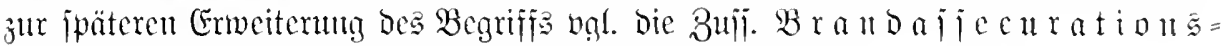

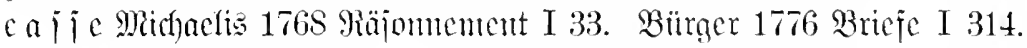

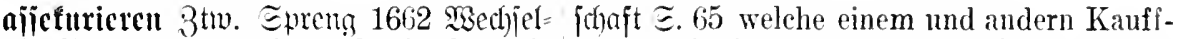
praftif $\widetilde{S}$. 29 es ist nötig, daß diesclbe, die mann sein Gut asseeuriren. Rabenter 1759 zur see handeln oder andere Assecuriren Entiren II $240 \mathrm{Er}$ assecurirt Schiffe. Bürrger die pericul des Wegs wissen - dahero anch 1776 Bricje I 315 das Pfarrgebäude sey in Holland die Assecuranten mehr von der allein auf 300 Rthl. assecurirt. Gilter ver= assecurance, von der Strat als von West- ajjełurieren Beiller 1653 Mco.jnchien E. 45

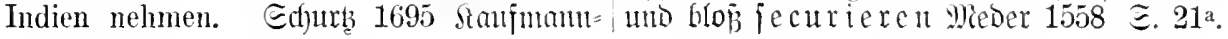

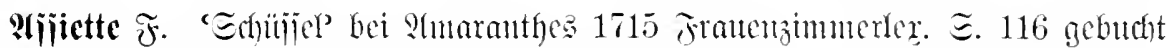

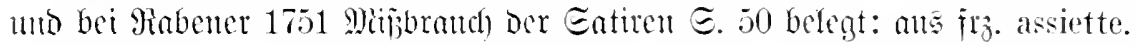

Anumerfung. Fontane 1895 Boggen=/Gesicht in seine gewohnte Assiette zurück-

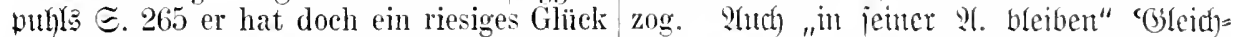
gehabt und sitzt mun über ein Dutzend nut, Fajiung bewahren') gehören ntidnt Jahre in der Wolle, oder, wie manehe ju bent obigent qijiette, jonbern jind sagen, ,in einer guten Assiette". Dieje uno Direft mit ber Grumbbco. bon jiz. assiette

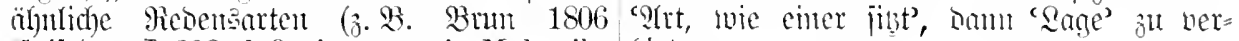
Eqijosen I 308 daß sie nur mit Mühe ihr/bimbent.

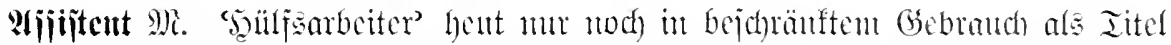
in ftantlichen Betricben, älter im 17. Jahrh. allgemein socher, Fremos. Enclle:

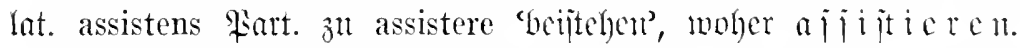

Bełege: 1565 Bimmerijghe (Shronif Hr. Ir. ist des erste Bibliothekar dabei, II 301 alle assistenten ires handels. 1616 seine Assistenten sind zwar schon am

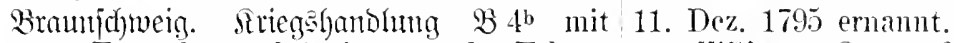

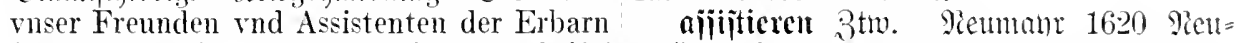
Stätt hierauß zu communieim. Echicl tralitüt $\mathfrak{Q} 1^{\mathrm{b}}$ Welchem Theil ein Fürst $167 t$ E(hantD = 11. Rajterdhronif $\Xi$. 61 Diese assistiren sol, dem sterckern oder schwechern.

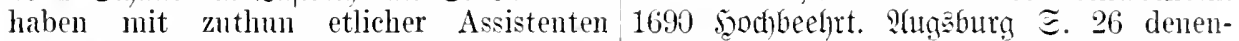
sich anfänglieh in den Rath mit vielen selbigen in solcher Terrichtung zn assiungeräumbten Postulatis getrungen. Reben= stiren. Miarnerger 1717 Bejant. D. Banfen walot 1681 Teujels Sitit VIII 214 der Richter $\Xi .27$ vielmehr animirt, ihm zu assistiren. gienge mit seinen Assistenten in das Zimmer. Gésiffe 1795 Edfulfafriften II 120 in einer 1798 atunten ber $\mathfrak{I}$. lluiv. $\Xi$. 425 der zahlreichen hlasse zu assistiren.

ajportiert aldj. meijt wohlajiortiert madh fro. bien assorti 1. 'pajiemb zulammengejteylt' wie $\mathrm{fr}_{\mathfrak{z}}$. marchandises bien assorties: Rohr 1729 3eremonticlt=

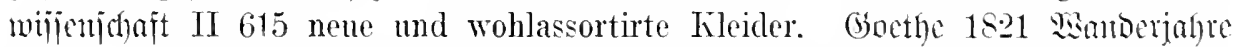
$(24,147)$ Wenn ich sie aber so zusammen sehe, kann ich sie nicht für ein wohl assortirtes Paar halten. 2. "mohlajiortiertes 2 ager" $=\mathfrak{j} \mathfrak{b}$. un magasin bien assorti

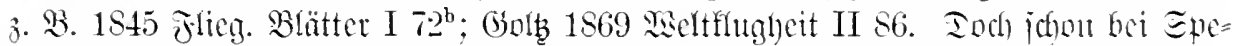
ranber 1727 "er hat cinen mohl assortirten, wohl ausitufifiterten Zabcu" unb bei

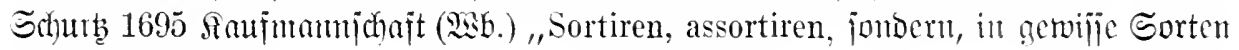
bringen."

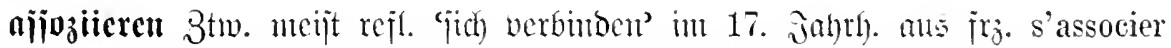
entlefhut, anfanga in alfgemeincus Gebrauch, aber fpäter auj bie staujmanmäprache bejơränft. 
Belege: Stujt 1683 Bebenfen bon Den

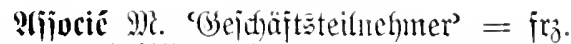
MRaunjatturen $\Xi$. 37 Wenn nun obigen associé. Effiller 1794 Brieje IV 23 [otta] Vorschlag einige ins Werck zu stellen äusert den Wunsch, daß wir seinem Associé Just haitten und zum Exempel funffzig in unserm AusschuB eine consultative Stimme Personen sich associirten. Ettner 1697 geben möchten. (Boethe 1795 lhuterhaltungen

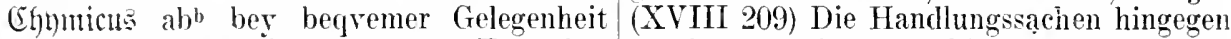
und Associrung eines getreuen Freundes. wurden von einem geschickten und genauen Mijier 1775 qunntajien I $26 \pm$. Frentag Associé sehr richtig besorgt. Beethoven 1855 Eolf 4. saben II 359 Immer hatten 1801 Briefe I 69 . Frentag 1855 Eoll u. Sie einen grossen Widerwillen sich zu şaben I 315. associiren.

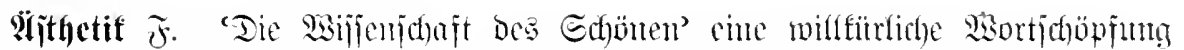

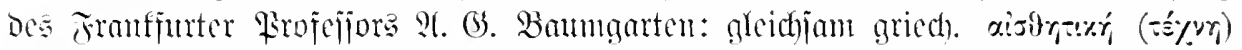

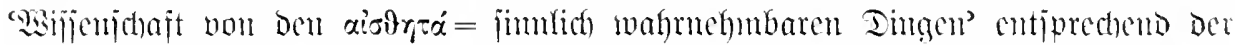
Banmgartnerichen Definition ber S(ejthetif alo ,scientia cognitionis sensitivae". Ier ueue Panne bürgerte jid) jeit Baumgartuers Aesthetica 1750 ff. rajch ein, jobon

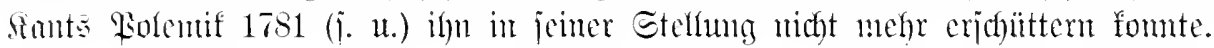

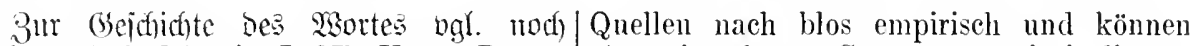
Enfyer 1773 Theorie I 27b Unser Bamm- also niemals zu Gesetzen a priori dienen, garten in Frankfurth ist der erste gewesen, wonach sich unser Geschmaksurtheil richten des es gewagt hat, die ganze Philosophie müßte, vielmehr macht das letztere den der schönen Künste, welcher er den Namen eigentlichen Probierstein der Richtigkeit Aesthetik gegeben hat, aus philosophischen des ersteren aus. Um deswillen ist es rathGrundsätzen vorzutragen. Sant 1781 Sritif sam, diese Benennung wiederum eingehen Der reinell Bernumit E. 49 Die Deutschen zu lassen, und sie derjenigen Lehre aufsind die Einzigen, welche sich jetzt des zubehalten, die wahre Wissenschaft ist. Worts Aesthetik bedienen, um dadurch das wodurch man auch der Sprache und dem zu bezeichnen, was Andere Kritik des Ge- Simne der Alten näher treten würde, bei schmaks heißen. Es liegt hier eine verfehlte denen die Eintheilung der Erkemntniß in

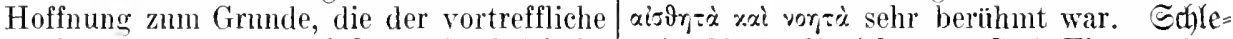
Analyst Baumgarten faßte, die kritische gel 1801/2 Siortejunger @. 4 Eine andere Beurtheilung des Schönen unter Vernunft- von Baumgarten erfundne und seitdem in principien zu bringen, und die Regeln der- Dentschland herrschend gewordene Beselben zur Wissenschaft zu erheben. Allein nemmung, die jetzt auch im Auslande Eindiese Bemühung ist vergeblich. Denn gang findet, ist Aesthetik. gedachte Regeln, oder Kriterien sind ihren

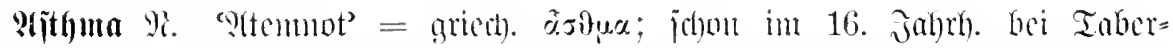
näntontamu 1588 strüuterbuch I $321^{\text {a }}$ Wam einer das keichen[d?] Asthma hette vund neben dem aubwerffen an Leib abneme.

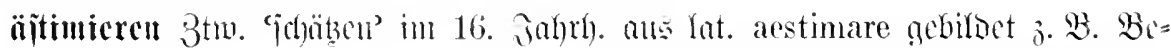

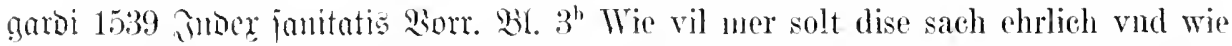

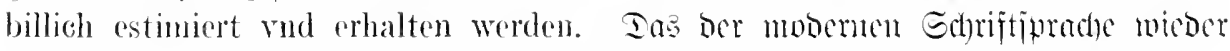

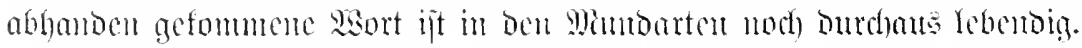

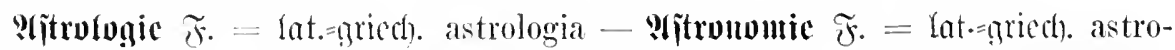

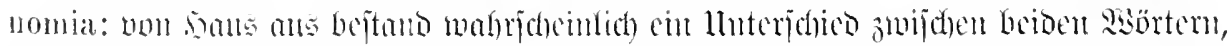

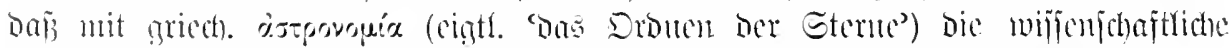

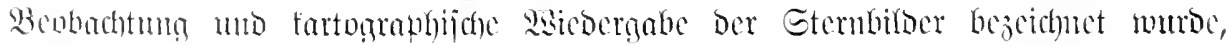

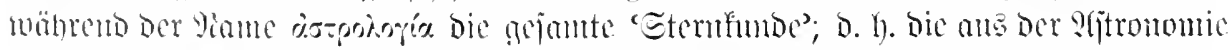

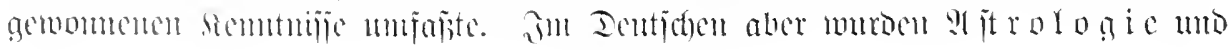




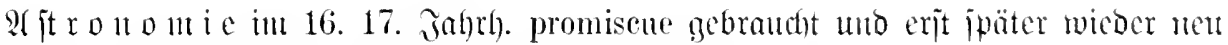
differenziert zu 'Sterndeutere' und 'Sterufumbe'.

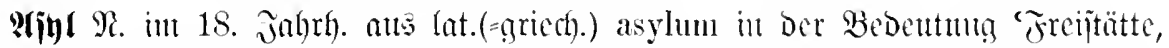

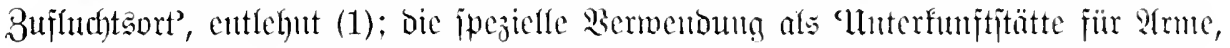
bej. auch arme Srmufe' ijt crit in 19. Jahrh. bezcugt (2).

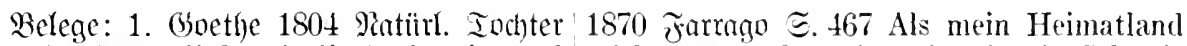
(X 369) Han schließt mir die Asyle, niemand mich ausgestoßen, da gab mir die Schwciz mag Zu meinen Gunsten wenig Schritte ein Asvl.

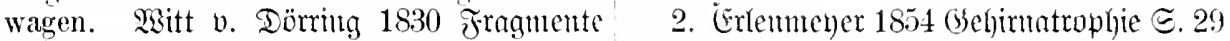
I 59 mir dadırch mein damaliges einziges, in diesem Zustande wurde er sogleich in Asyl zu rauben. Büd)ner 1835 Dantong Ino das Asyl gebracht. Qinbenberg 1883 Berlin ङ. 52 Das Verbrechen hat kein Asyl. Ecterr. I 112 die Ziffern des Asyls für Obdachlose.

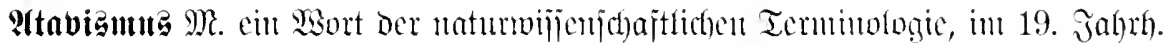

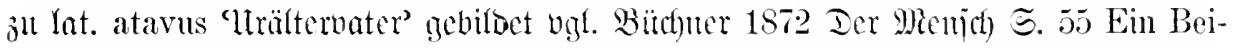
spiel von dem, was die Botaniker Atavismus nennen oder von dem Streben der Abarten, zu einem früheren Typus zurückzukehren; vorher jhou 1859 bei senje ${ }^{12}$ gebutht. Seit etwa 1880 ijt Das Mort Daun in weiteren Sreijen befamut geworden

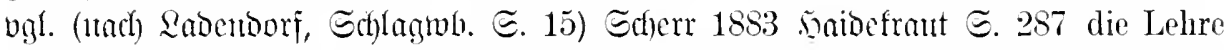
vom Atavismus, womit unsere Zeit, wie mit anderen gleichwerthigen Aufstellungen und Sohlagwörtern, so dickthut. Norbau 1883 Iügen ङ. 129 Anthropologie und Atavismus und Heredität, alle die schönen Worte, die ich zum Verständnif. der Loyalität des unwissenden und gemeinen Volks anrufe.

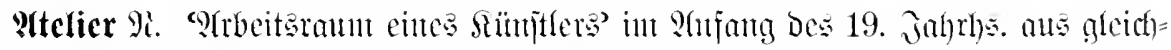

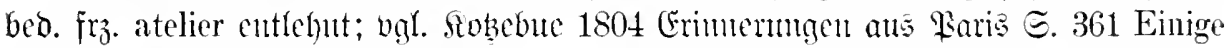
grobe Mahler und ihre Atteliers - S. 367; bcj. auch 1811 Dic Grille I 89 ein Mahler, der seine Kunststatt (die Deutschen sagen Attelier) in der Vorstadt einer belagerten Festung aufgeschlagen. Daun aud bei .5anff 1826 Memoiren I 106; Rewald 1836 :quurelle II 202 - 204 Naleratelier; Gandon 1836 Tagebuch (I 204); Pitffer 1840 Billocrianl I 224. Şacfländor 1866 sümptlerroman IV 243.

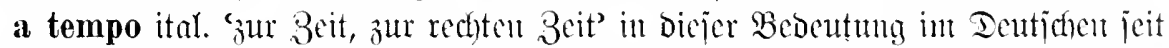
Dem 17. Jahrh. belegt (1). Q(nderjeits interpretierte man aber wohl a te m po als

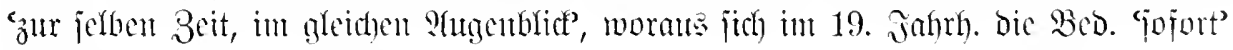
ergab.

Belege: 1. Dilid 1608 Sriegsbud $\Xi .71 \mid$ 2. Mioroor 1835 Bresilau wie es war wie man ein pferdt à tempo straaffen soll, $\Xi .8$ Da erschallt cin allgemcines Wohlals mit des spibrueten, mit den sporen und zuspeisen und die Stühle rïicken a tempo. mit Worten. Chilemont 1707 Sriegse u. Chantijio 1836 Reije um bie siselt I 189 Etantsat III 4 Ist nicht, vermög Eures eine Schlafmiitze, die er, bercit sie a tempo weisen Raths, Barcelona à tempo glücklich abzunehmen, noch auf dem Kopfe trug.

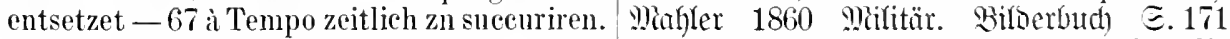
Bahrot 1790 Hinovigius II 267 Pastor wir stürten dann immer a tempo über die Rindvigius hatte rechte a tempo sich eine Schïsseln her. Fontane 1897 હtedhlin ङ. 89 Indigestion erfressen. Pïffler 1835 Eemilaijo Die Prinzessin? fuluren Rex und Czako II 125 flopfweb] das aber insofern noch à a tempo heraus. tempo gekommen ist.

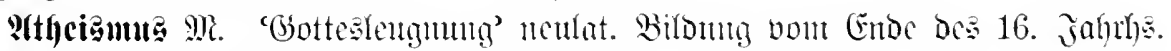

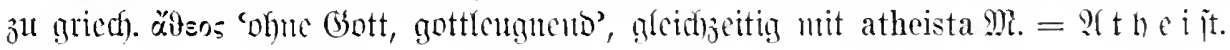


Belege: $\Omega$ un 1596 Reisbuch gen Jeru= angerichtem prechtigen Pancket vnnd Woljalem $\Subset .106$ fommen] auß einem Irthumb leben mit solehen Gottlosen worten heraußin den andern rnd also volgends gar in fuhre. Etettler 1627 Ehronif I $361^{\mathrm{b}} \mathrm{Er}$ den Atheismum. Mienfort 1636 sochidnulen führete ein Epicurisches Leben, were ein $\Xi .3^{b}$ daraus gleichsam ein öfentlicher Atheist, Kïtzer, hochgetragen, ein Spieler

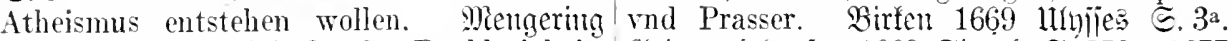

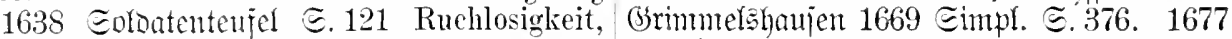
Frevel, Trotz, verlassen anff eigen krafft Machiavelf. Socuspocus $\mathfrak{S}$. 177. Thomaius rnd Vermögen, rnd mit einem Wort Atheis- 1691 Bernmtitlelure II 35 Atheisterer. Mar=

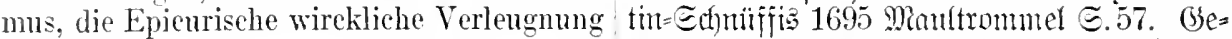
Gottes.

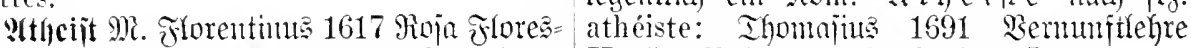
cens $935^{a}$ wie jener Atheist, der bey einem /II 35. Rabener 1759 Eatiren I 101.

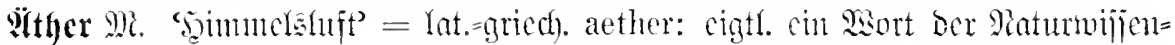

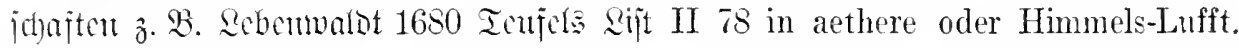

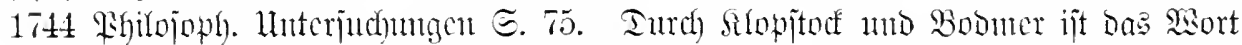

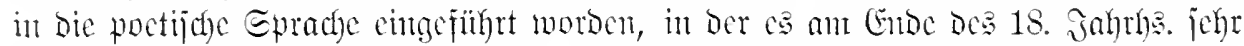

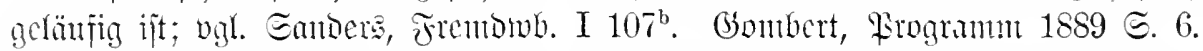

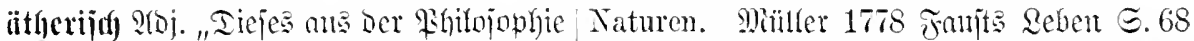
Der Gofomad)er in bie beifige Emmathe über= als einen Gott, ein aetherisches überirdisches

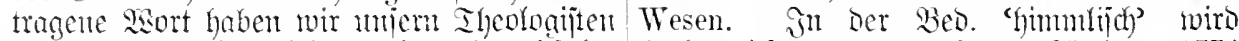

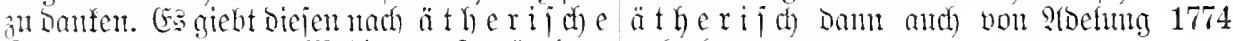

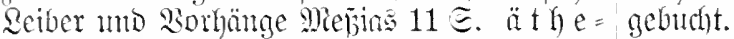

rijd)e Etröme mo was nidht melyr äthe= Tie Bebentumg con hödjter Feinheit,

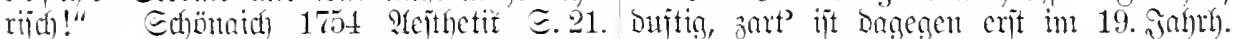

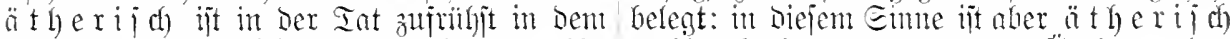
angegehenen Bereid bezengt: (Ettner 1697 mohi itherhaut non Dem sit her ber

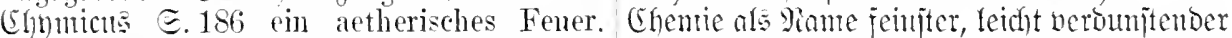

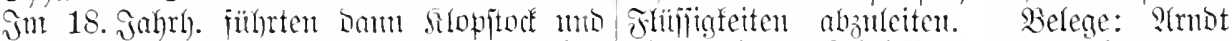

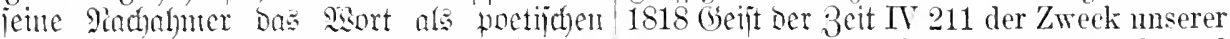
P(nsonuf für "himmitide ein (wohl nadh Gesellsehaft ist so fein und ätheriseh und Wiiltons ethereal) vgl. Silonitod 1748 meifito überirdisch, das was uns rerbindet, ist so I 476 ein ätherischer Leib hellenchtend ïberfliegend und überschwänglich, daß es gebildet. sistano 1751 bermtam I 183 in das Staatsleben kanm eine Einwirkung Dazu liess dich der oberste Gott aus ätherj- haben kann. 5onij 1826 mentren I 72 schen Sphären. Sobmer 1752 Roaf $\Xi .141$ Hier in Norddeutschland gibt es meist mur einer der neidischen Geister ans dem aetheri- Theegesichter, die einen Trost darin finden, schen Reich. Qeijung 1759 Qiternutbrieje ästhetisch oder ätherisch auszusehen. Fon= (VIII 166) Herr Wieland hat die aetherischen tame 1891 Ienny) Ireibel ङ. 47 Etwas Feines, Sphaeren verlassen und wandelt wieder nicht wahr? Meine Frau würde sagen: unter den Menschenkindern. Tujd) 1764 ätherisch.

Srieje I 162 aetherische und menschliche

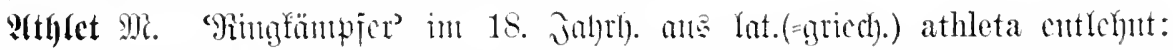

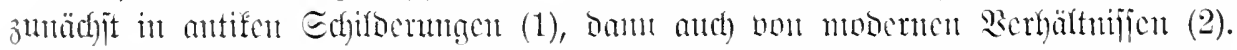

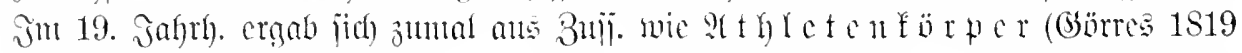

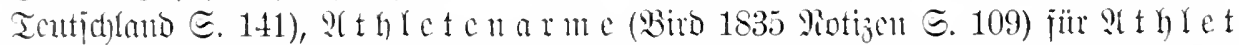

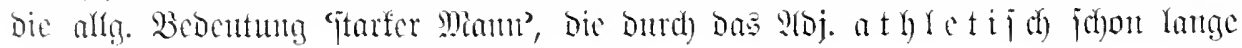
vorbercitet mar.

Siclege: 1. Injch 1764 Bricic I 188 Korinth aufhielt und ein wohlgemachter Souraj] zeigt uns, was ein Athlet lernen athletenmäBig junger Mensch war. Gsörres

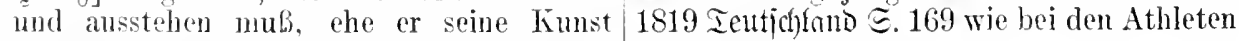

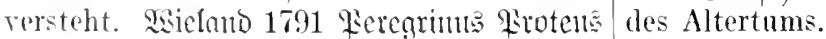

(XVI 77) Menippus, der sich danials zil 2. Bürger 1776 Brieje I 285 Ich frene 
mich dieses Lebens und dieser Fülle, wic sich der gesunde rüstige Athlete des Gefühls seiner Stärke freuet. 1790 Ier $\mathfrak{B} \mathfrak{c o b}=$ achter $\mathbb{S} .367 \mathrm{zwci}$ ihrer Mitolieder traten als Athleten gegen einancer auf und kämpften $1 \mathrm{~m}$ einen unbedeutenden Gegenstand. Thümmel 1791 Reije (I 192) Athletenkrone. Seinje 1794 ?roingtuelto $\circlearrowright .131$ der [Arieg: zug] des Africaners hat mehr Einheit, Nerv und Kernathletengeist.

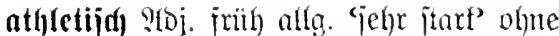
Bezichnna auf bie Ringfunjt bei Lebentwalot 1680 Tcufets Qijt II 83 Ich hab selbst einen Frey-herrn gekennt, wolcher erst $33 \mathrm{Jahr}$ seines Alters, einer gesunden athletischen Natur. Echifler 1795 Sifthet. Erziegung (X 294) durch gymnastische tbungen bilden sich zwar athletische Körper aus. \$itdter 1835 こcmifajio IIl 66 Leute von athletischen Formen.

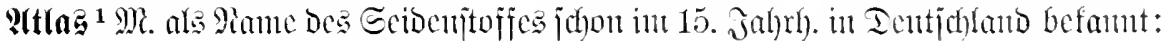

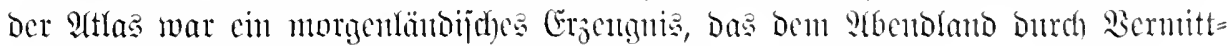
luug ber Yraber zuugefülil)rt murbe (arab. atlas).

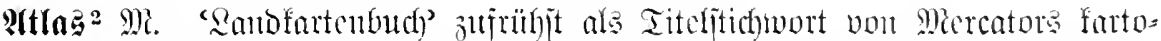

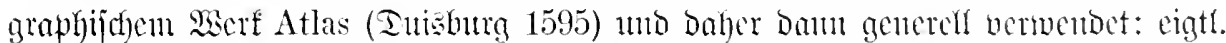

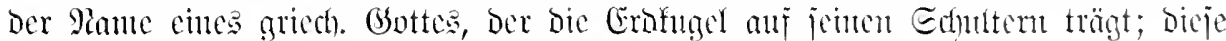
Etelfung mar auf Titelfupjern bon Sttanten befiebt.

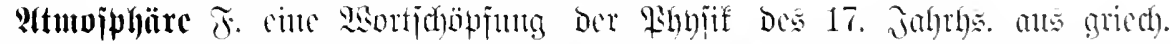

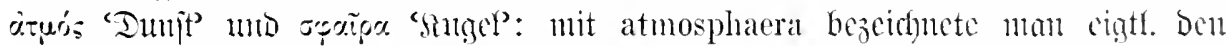

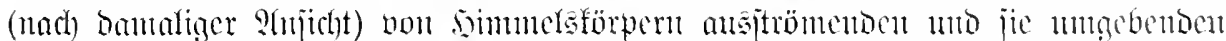

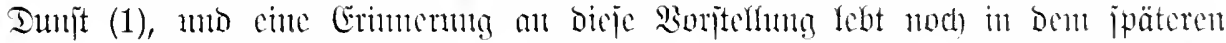

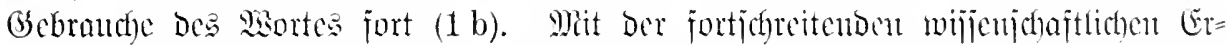

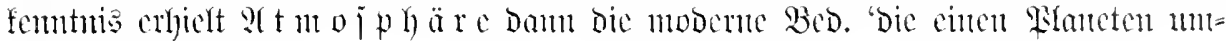
gebentoe ¿uftjchict)t'.

Berege: 1 a. Rebentualot 1680 Teufés Merfur III 141 ein Schränkchen, worin sie Sift II 16 Die Eterme] haben auch ihr Athmo- ihre Flaschen verschloß; die Atmosphäre sphacram oder AuBtimpff-Kraiß - VIII 189 um dasselbe war unendlich siib. Echiffer Die Athmosphaera ist voller Tämpff von 1784 Sabale u. Qiebe III 1 eine Atmosphäre Schwefol vad Sahiter. Bachariö 174t/ von ean de mille fleurs und Bisam. Goethe Renommiijt 13 . 1029 der Stutzer zitterte in 1796 Rebriagre (XXI 22) selbst der wunderfremder Atmosphäre [sc. Denl Tabafäbannff]. liche Geruch, den so mancherlei Specereien wie im Kometenschweif des hangen Erd- durch einander anshanchten, hatte so eine balls Schwere. Bobmer 1752 9ooh 5.248 leckere Wirkung auf mich, daß ich niemals Nicht nur die Pyramide des neblichten versänmte, so oft ich in der Xähe war, Schweifs zu durchwandehn, Sondern dic mich wenigstens an der eröffneten AtmoUfer der Atmosphär des Sterns zu betreten. sphäre zn weiden.

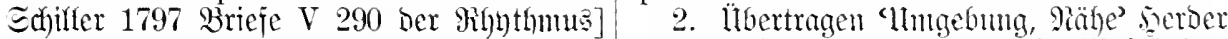
bildet anf diese Weise die Atmosphaere 1767 D. Siteratur (I 419) Die Nille] hat für die poetische Schöpfung, das gröbere sich ans des Sphäre des Lebens in die Atmobleibt zurück, nur das geistige kann von sphäre der Katheder versezzt. Thümunel diesem dünnen Elemente getragen werden. 1791 gieife (I 128) ich eilte mit ihr aus der

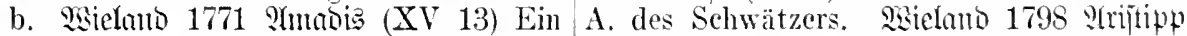
süßer Geruch von destillirtem Jasmin Macht (XXII 222) ich verbamte mich ans seiner eine Atmosphäre um ihn. 1783 Tenticher A, so weit ich konnte.

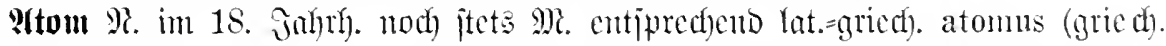

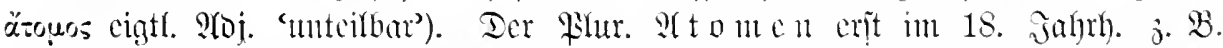

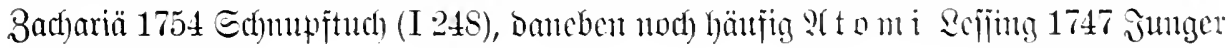
Belehrte (I 366).

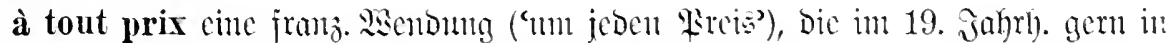
Die Deutjule Rede cingemijeht mirb. 


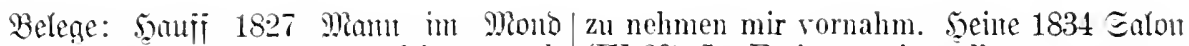
(XII 87) bringe ihn rernünftig zurück (IV 39) Ja, Eminenz, sie wollten uns à tout à tout prix. Sommant 1833 D̈fterreid) II prix vernichten. 1841 Guropa I 345 sie $2 \Subset .91$ so war ich auch schon bei Gimpel wollen à tout prix einen Schauspieler angelangt, den ich à tout prix in Schutz poussiren. Foutane 1882 ¿'Youltera 〔. 84.

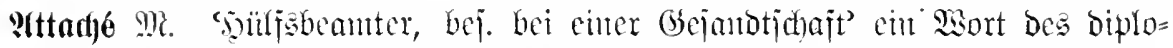
matijchen Berfehrs, entlehut aus fir. attaché. Belege: 5oufị 1826 Memoiren (VII 64) Jeh war mit dem... schen Attaché engagiert. Grojpntam 1847 (bejelljhajt ๔. 72 die Freundin des Gesandten, dem Gaden als Attaché nach Paris folgte. Bei Foutante 1856 Briefe I 60, Wadjenthujeu 1865 Ballet I 125 Gesandtschaftsattaché.

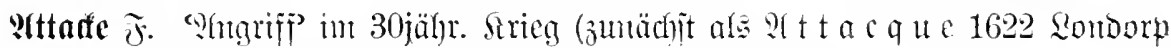

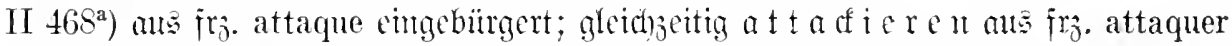
3. B. 1633 Sanjtanjer Belagerung $\bigodot .7$ der Hertzog von Weimar [hat] die Statt Vberhingen etwas attaquiert. $163 \pm$ Bericht $\mathfrak{v}$. Frieblands $\mathcal{B}$ errat $\mathfrak{B} 2^{\mathrm{b}}$ dab er auch Ingolstat attaquiert.

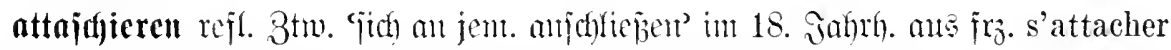
entlebut j. B. Edfiller 1783 Bricfe I 146 An Schwan habe ich mich am meisten attaschiert. Gocthe 1812 Dichtung u. Wahrbeit (XXVII 132) Ich attachirte mich bald an ihn. Büdyter 1837 \&utz $\Subset$. 232 Lenz hatte ihn oft gesehen und hatte sich an ihn attachirt.

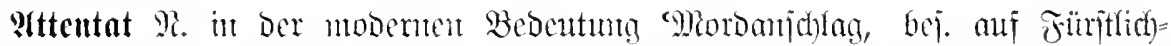

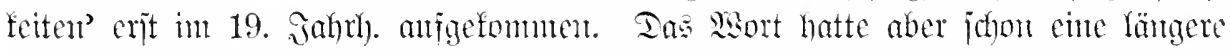

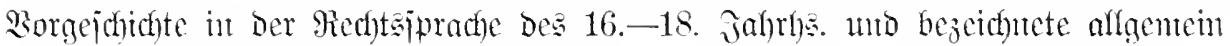

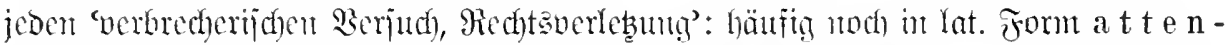
t a $t$ m eigtl. 'verjudtes' als Bart. ju lat. attentare 'berjuchen'. - Tie ueue $B e=$

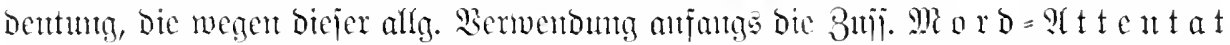

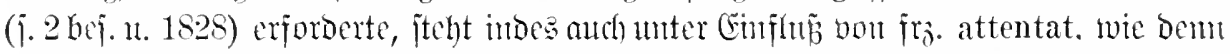

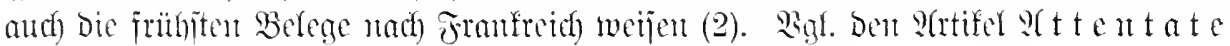

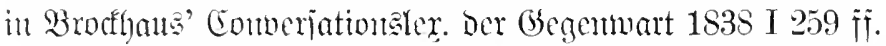

Belege: 1. 5. v. Medel (łum গ. 1579)/wäre ein Attentat gegen die Nenschheit.

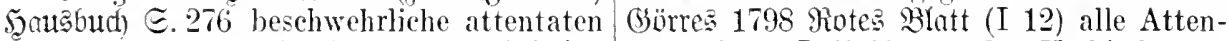
vorgenonmen. Carolus $161 t$ Relation tate dieser Individuen oder Verbindungen Iir. $16^{\prime \prime}$ solehes Attentat nicht vngeendert gegen die Freiheit. Sant 1798 Inthropologie lassen. 1620 Calviu. Mutruill ( $54^{\mathrm{b}}$ mit was $\Xi .173$ bei welchen Attentaten der Selbstvor attentaten sie verfahren. Freiberger mörder, wenn er noch gerettet wird, ge1656 Tolit. Iisurie $\approx .9$ die vorgeloffene meiniglich selbst froh wird. Görres 1819 Attentata in ein rergessen stellen [? 9 (nnt= Teutichlano 5.56 es hob sich ein furchtneitie’]. Inlhover 1689 Gintcubeetlein IJ bares Geschrey gegen ein so unglaubliches 882: in dem Weeg ligenden Feindseelig- Attentat.

keiten, hochgefährenden $\Lambda$ ttentaten rnd Hinderungen. 1699 Etaatsipiegel II 63 von denen sich häuffenden merträclichen Attentatis und allen Thätlichkeiten. 1784 Thomas Sortmam $E^{2} .23$ was vor Kirchenstrafen anf derley Attentatmm gesetzet seyen. Forĩter 1788 steinte Edriftelt G.81 Attentate gregen die Denlifreyheit. [Schiller?] 2. [ङthiller 1794 Frans. Llıtuken (IX 368) Vor und nach dem meucheImörderischen Attentat drangen viele Gutgesimnte in ihn, ron Paris zil entweichen.] Jacubs 1811

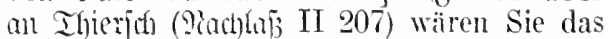
Opfer dieses infamen Attentats geworden, ich hätte mich nie zufrieden gegeben Tm Anfange glambte ich, daB das Attentat 1789 Infurgits (1X 1.57) lin solches Gesetz vielleicht ans Privatrache entstanden sey. 
WSitt v. Türring 1828 Fragntente III 210 | beneidenswerth $u m$ die Herrschaft über Einige Monate vor dem Mord-Attentate dem Krater eines Vulkans, um die gegen erhielten mehrere bedentende Männer ano- ihn geriehteten Attentate. Marimifian nyme Briefe. Büd)uer 1835 Srieje $\Xi .358$ v. Mex. 1852 \&eben III 36 die vermuthlich Ich kann mir das Attentat [Fieschis] anf ron dem Gedanken an ein Attentat herkeine andere Weise erklïren. Bed)itein rïhrende Unruhe.

18.36 Reijetage II 157 Louis Philipp ist nicht

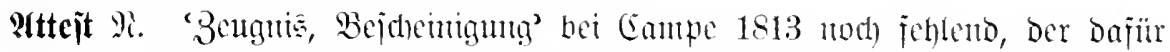

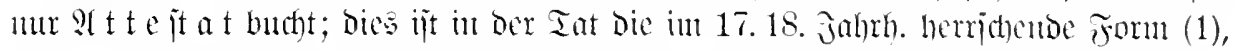
oft aud) mit lat. (Gmomg attestatum (ooch lat. attestatio), mo 9 t $t \mathrm{e}$ it ijt im 18.

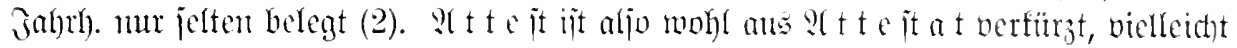
nach) $M i a n$ i $j e$ it, \& $r o t e$ it 11 . a.

Beleae: 1. $\quad \mathbb{A}_{\mathrm{t}} \mathrm{e}$ it a $\mathrm{t}$. 1654 Bericht $/$ beglaubtes Attestat, da $\mathrm{B}$ er redlich gehandelt. an die Reipz. mediziu. Fafultüt (3itfnam Rabener 1759 Eatiren I 178 ein Attestat 5. 43) des Feldscherers Attestatum. Ihoma = rom Stadtphysicus. Goeze 1778 હtreit= jus 1688 Mionatsgeip. I 126 wann sie gegen joriften 厄. 30 daß die Apostel das Attestat cin Attestatum von ihrer Obrigkeit einen wohl gehabt haben könnten. \$isll 1787 Freyzettel erhalten. Berdenmener 1712 Bagatellen II 54. Sniage 1792 Beije 5.272.

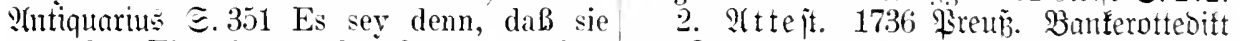
von den Einwohnern des Orts sonderlich (= ¿ubemig II 407) Im Fall aber ein solgekannt würden oder daB sie gute Attestata cher Richter vorsätzlich ein falsch Attest

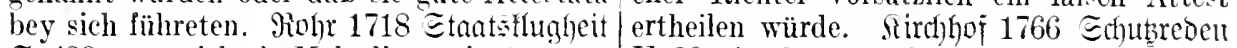
5. 429 wenn sich ein Mohr liesse ein Attestat II 291 in dem angebogenen Atteste. geben, daß er weiß wäre - こ.619 ein

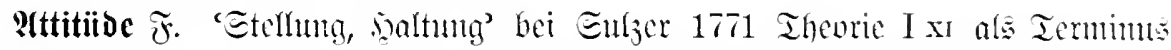
Der 3eidenfunit gebudht: ans irg. attitude entlehnt (ogl. Goethe 1799 Tiberot [45,

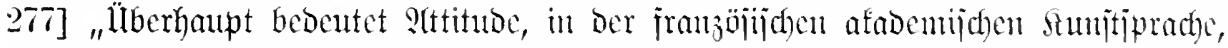

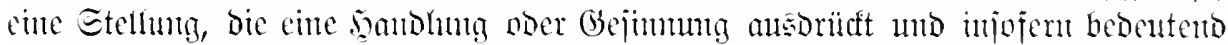

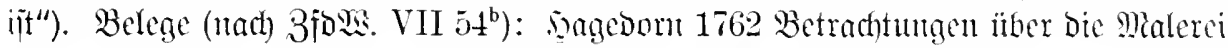
5. 601 Die ruhigste Stellung (attitude). Wicland 177t Ientidyer Merfur I 150 weder Lage, noch Stellung, noch Gebehrde [afs purijtijche Erjaḩwörter] drückt das aus, was Attitude.

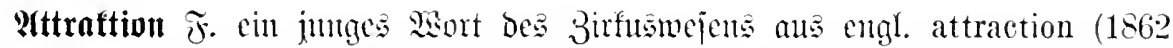
belegt) entfehnt. Beleg: Burg 1901 Jn Der Manege ङ. 70 der Cirkus X. glaubte, mit dieser equestrischen Leistung sich eine neue Attraktion allerersten Ranges zu schaffen.

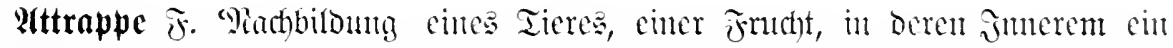

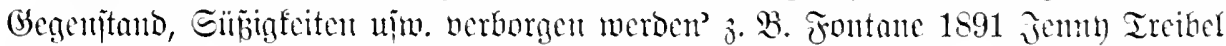
ธ. 8 Ostereier werden in dem Gartell versteckt, und jedes Ei ist eine Atrappe voll

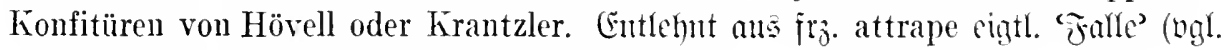
D. flg. 然ort), Dam 'tünj(hender Echerzartifel'.

attrappieren 8tw. 'erwijchen' in 17. Jahrh. ans $\mathrm{fr}_{\mathrm{j}}$. attraper cigtl. 'in emer Falle fangen' 3 . B. Callenbach 1714 Murmland 5 . 22 Dannoch geht ein Kerl aus Hunger durch und wird attrapirt, muß er mit hungrigem Bauch hangen. Iöbel 1746 Jägerpractica III $\$ 9^{\mathrm{b}}$ die Forste werden von ihm auch nicht öffters besucht, um die Holtz-Deuben zu attrapiren. Sobebuc 1804 \&agenjtreidje II 8 Es wäre 
doch ein verfluchter Streich, wenn der Kutscher und der Hausknecht mich hier attrapirten.

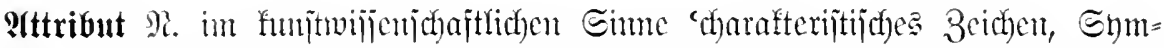

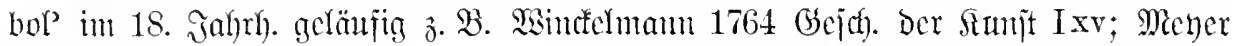

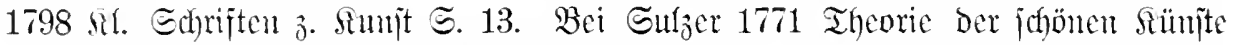

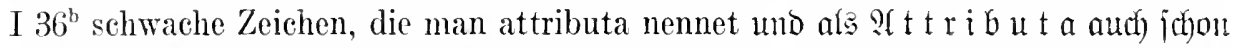
in Gottjocds 5anderexifon 1760 gebud)t. Suefle: lat. attributum eight. Part. zu

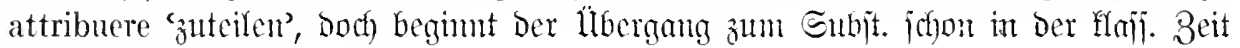
(vgl. Thcjantus II $1165^{7}$ ).

शudienz F. 'Empfang; Interredung mit cinem Fürjten' $j$ (d)on um 1500 cin= gebürgert $\mathfrak{\jmath}$. B. Dürer 1506 Bricfe (Machla $\mathfrak{\beta}$ ङ. 34) Der Markgrof word nit so lang

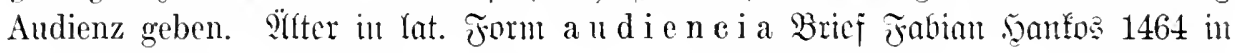
Den Script. rer. Siles. IX 69 noch der ersten audiencia, die ich hatt - häufiger in

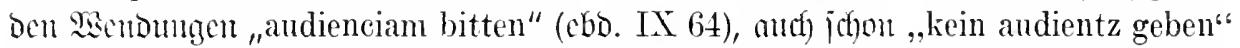
(IX 69); hier hat bas Sart Dam noch die Bedeutung '(Sef)ör', bie zu lat. andientia

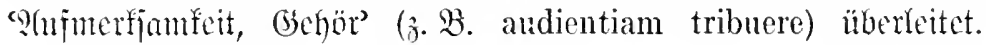

Pubitorium $28 .=$ lat. auditorim feit bem 16. Jahrh. (noch häufig in lat.

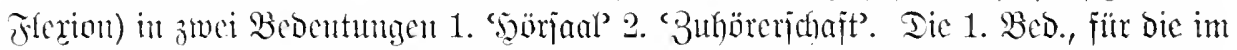

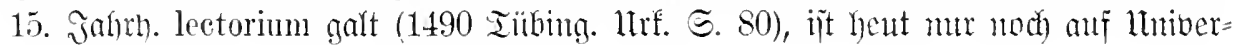
jitüten ïblich).

Belege: 1 a. 1558 Etatuten ber 1 lniv. 1 Meanber 1583 Bebenfen $\Xi .7^{\text {b }}$ wenn man

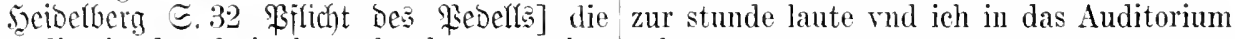
auditoria der drei obern faculteten sauber gehen muste.

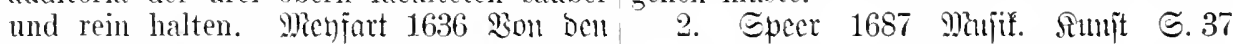
5odfjohlen 5.86 die Studenten weren der- wamus schon nicht in so gar kunstreicher massen fleißig gewesen in Lectionen daß Composition hergesungen wird, wornach mancher gar friie zu den Auditorien eylen das Auditorium gar nicht fraget. Dalfyober müssen, wo er Raum za sitzen finden wolte. 1687 Gartenbeetleir I $51^{\text {b }}$ ein Volkreiches Thomains 1688 9lontatigcipräthe I 331 anditorium, ein grosse Menge der Zuhörer. Da $\tilde{\beta}$ er] als das opponiren an ihn kam, QGmoranthes 1710 \$roben 5.353 Das Audiauffstunde, im auditorio herumgienge.

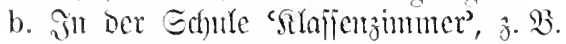

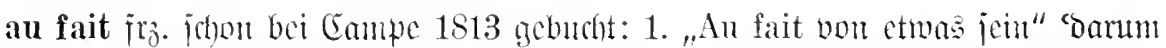

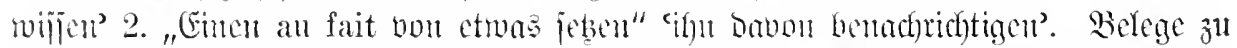

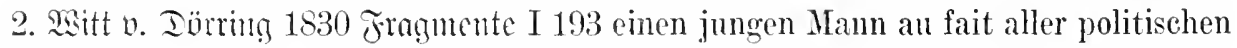
Nenigkeiten setzen. Qerwalo 1837 9quarelfe IV $7 \mathrm{i}$ baj Alle hinlänglich darïber all fait gesetzt sind.

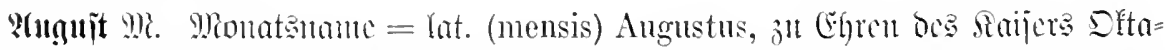

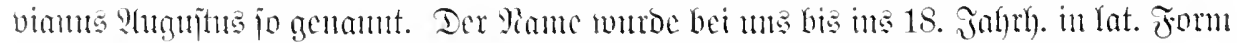

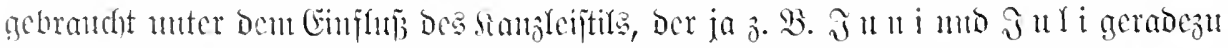

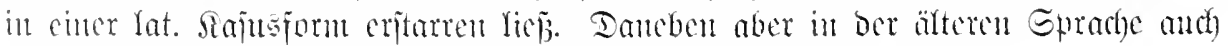

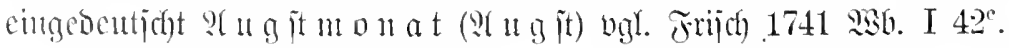

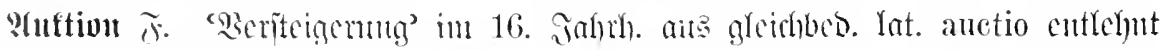

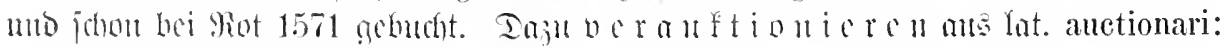




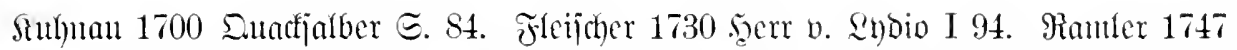

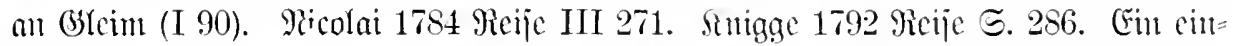

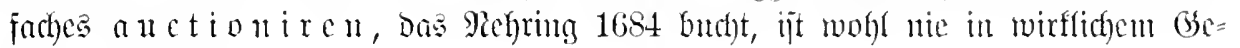
braudf gewejell.

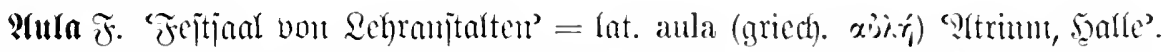

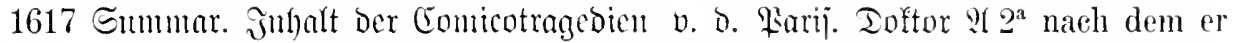
mit Todt abgangen rnd naeh lobliehem branch derselben Vniversitet jhme den gantzen Tag in aula oder auff dem Aeademischen Saal psalliert wurde.

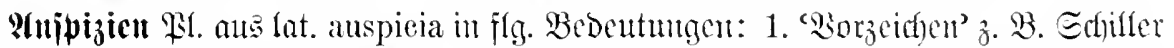
1795 Briefe IV 244 Auf Ihr Mährehen freue ich mich sehr, denn es scheint unter sehr guten Auspieien zur Welt zu kommen. Fïufler 1835 Eemilajjo I 190 so kann man in der That keine Reise unter bessern Auspicien beginnen. Mahler 1860 Bilber= buch) (. 107 der unter so sehönen Auspieien begonnene Tag.

2. 'Qeitung' (lat. auspieia cigtl. 'Das Redht, Dic Bugerfidan anjulteflen', Dam,

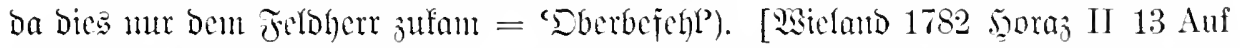
Rechuung desjenigen, unter dessen Auspicien sie würkten.] Witt v. Türring 1827 Fragntente II 15̆ unter den Auspicien ausländiseher Revolutionäre gestiftet. ¿aubc 1836 Sihaupielerin $\odot .149$ welch eine zügellose Gesellschaft sich unter den Auspicien der Frau von Weiden etablirt hat.

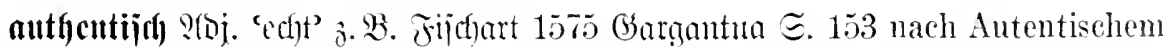
vnwiderspreehliehem Cardinalspruch: Natura abhorret vacum. Eight. cin Sanz=

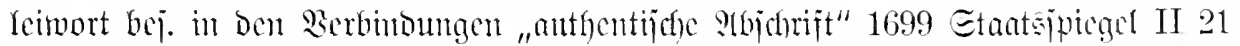

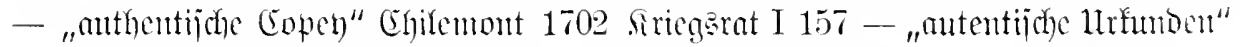

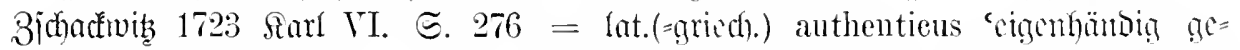

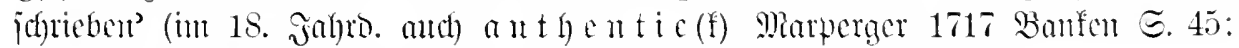

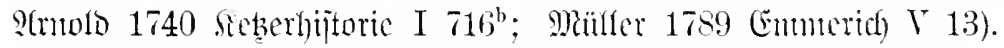

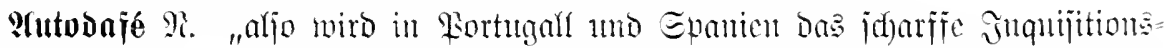

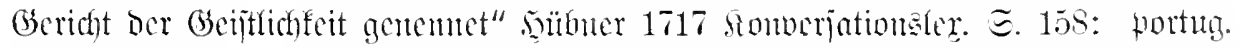

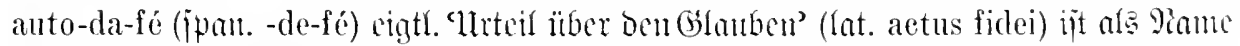

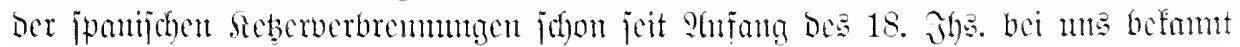

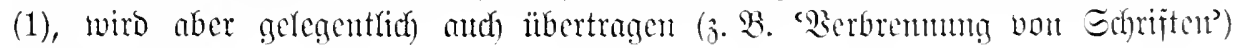
gebraucht (2).

Belege: 1. Babener 1751 Mij̄braud)

2. Eujuller 1785 Birieje I $29-9$ LnterDer Eatire $\subseteq .39 \mathrm{Es}$ ist ein Glück für mieh, dessen, dab die halbe Stadt Jannheim daß wir in Sachsen kein Auto da Fé haben. sich im Schauspielhaus zusammendrängt, Goeze 1778 Etreitidfriften Є. 169 das alte einem Anto da Fé ïber Tatur und DichtSchandlied von Inquisition, Auto da Fé kunst - einer groben Opera - beizuwohnen und Inquisitor. Edhilfer 1787 Eon furtos und sich an den Verznckungen dieser armen I 3 ein Autodafé hat man uns auch rer- Dehinquentinnen zu weiden. (Gocthe 1812 sprochen. Mï̈lfer 1789 Enmerich VII 184 Dichtung u. In Madrid sah er die Zurichtungen zu einem bewog mich, wieker ein großes HauptGlaubensakt (Auto da fè). ら̌aufi 1827 Autodafé über meine Arbeiten zu verhängen.

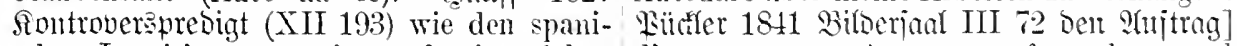
schen Inquisitoren, so ist euch ein solches die rerpönten Autoren aufzusuchen und Autodafee ein Freudenfest.

ihr Auto da fe sofort zu reranlassen. 
Tutodionft 9 . Jufrübjt bei sermes 1787 für Töd)ter II 131 mit Der (Erflärmug

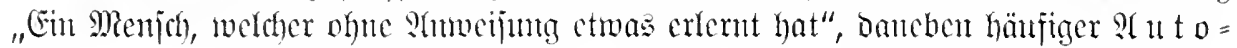

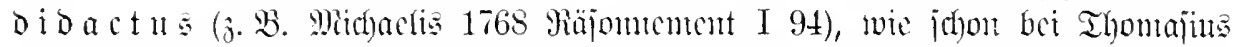
1688 Monatşgcipräche I 353 daß er ein wenig ein autodidactus müsse gewesen seyn:

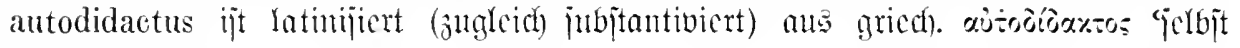
unterrichtet's.

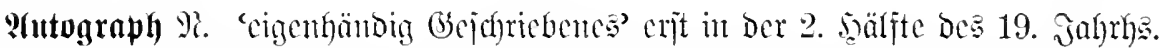

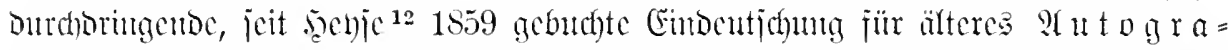

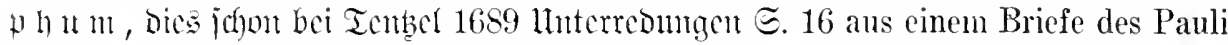
Eberi, dessen autographum ich in Händen gehabt. Suttlle: lat.(=griedf.) autographum sandichrift'.

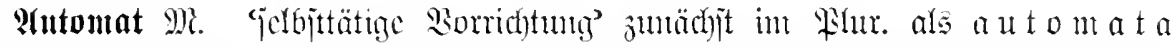
bci Fijhart 1575 Gargantua $\Xi .304$ viel kleine sinnreiche automata, das ist, selbs bewegliche kunstwercklin; Florin 1702 bauspater I $257^{\text {a }}$ Massen ein solehes nicht unfüglich einem liunstwerck, das sich selbst beweget (dergleichen man auf

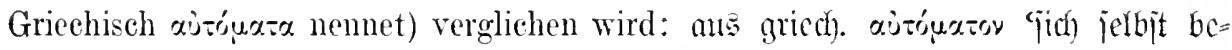

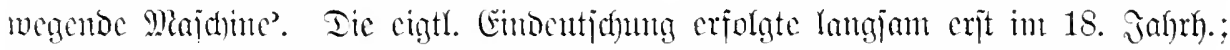

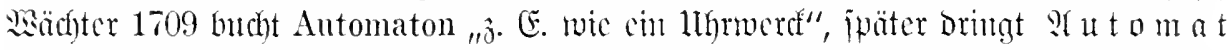

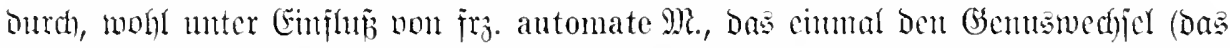

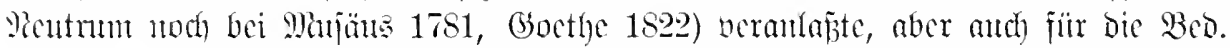

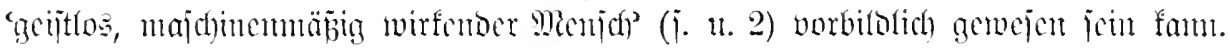

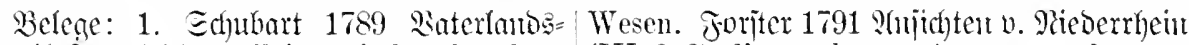
đ)ronlf હ. 176 Unsre Zeiten sind so berühmt (III 213) diese schönen Automaten können durch Zauberkiunste, Geisterbeschwörungen nur sündigen und beten. Soţ̦ebue 1801 .... Antomaten und andere Kunststiicklein. Epiggranmm (XI 194) Wemn es der Mühe immernumu 1830 fiarneval $\Xi .210$ als ob werth wäre, mit soleh einem Antomaten drei Automaten lebendig würden. Bü̈dyuer einen Prozeß anzufangen - Automat? 1836 Qeonie E. 152 die zwei weltberühmten das wird wohl wieder eine andere Gattung

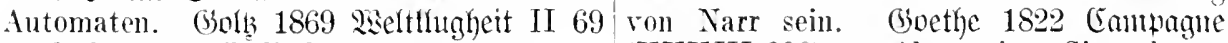
verdorbene musikalische Automaten.

(XXXIII 206) vor Alter seiner Sinne kaum

2. Marjüus 1781 Whyíugnom. Keijen mächtig, als ein bedanernswürdiges Automat. IV 268 Beym Fuhrmam in der Senke Prormaum 1833 sjterreid) I 1 ङ.14 Im dacht ich: Ein wahres Autonat, eine Fleisch Kopfe ist das Triebwerk des todten Antound Knochenmasse, die sich nach einem mats. Qewould 1835 Thenterrebue $\subseteq .146$ yewissen Hechanismus bewegt. Exthiffer Er bildet keine Automaten, keine linkischen 1790 (Erjte Mienjachengejellichajt (IX 128) Nachbeter ans seinen Sehülern. Meuzel des Henseh wurde dadurch aus einem 1835 Geiift ber bejdjidgte S. 177 der Chinese Sklaven des Xaturtriebes ein freihindelndes ist und bleibt dem Europäer gegenüber Cieschöpf, aus einem Automat ein sittliches, eine Art von Automat.

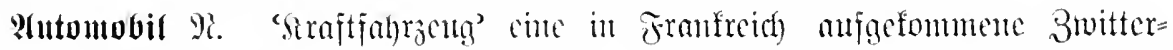

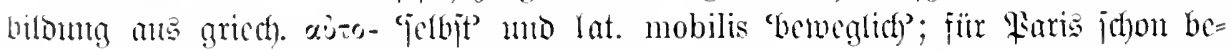
sentgt bei Eiflóin 1893 Madfalyrergejobichten S. 62 In den Straben von Paris wird is bald komisch aussehen. Viele Fiaker fahren bereits ohne Pferde als numerirte Automobiles umher - $\Xi$. 70 Die offenkundige Absicht meines Nachbars war, die ,Automobiles" zu persifliren. Da sich aber bei dem Festzuge in Oloron kein solches hochmodernes und kostspieliges Vehikel befand, hielt sich der Menseh an mich - cbo. Automobilfahrer - હ. 71 Automobilisten. 


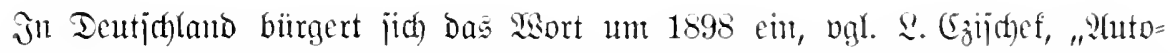

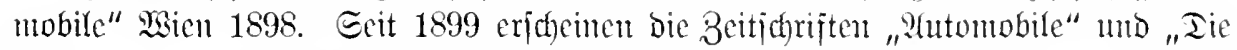
:Utomobilenindujtrie" in Berlin. Sn biejem Jahr begimen aud) in ber Beitjor.

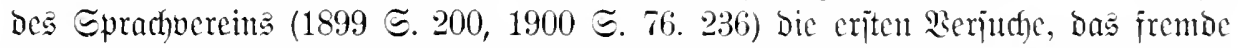
: a t o m obil Durch Berbentichungen zul erjetsen, von Denen Kraftfahrzeug balo offiziell anerfamt wnrbe; vgl. Die "Polizei=:Berorbmug über ben Berfehr mit Straft= fahrzeugen" Berlin 1901. Ter ältere Rame war Motorwagen.

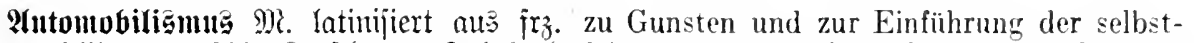
automobilisme; 1899 Stürohers Jahrbuch fahrenden Wagen jeder Gestalt oder Gattung ઉ. 803 Der Automobilismus, wie man nach nennt, liat offenbar auch im letzten Jalır französischem Vorgang die ganze Bewegung mächtig an Boden gewonnen.

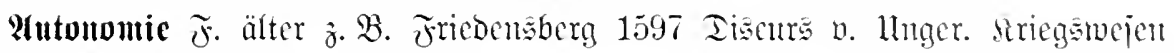

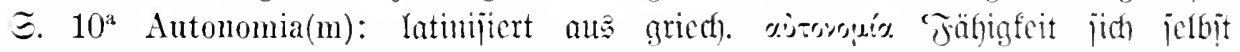

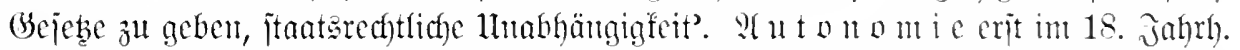
j. B. Gocthe 1805 Rezenipnen (XL 321) der Sohn aber [jochut] die sogenannte Freiheit, die Autonomie der Bürger zu lieben. Y(ud) bei Ecumte 1803 ङpajiergang (III 116). Gö̈res 1819 Ieutjd)lanto @. 156.

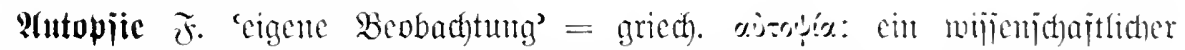
Termimus, zuerit bon Campe 1801 gebudt mit einem Beleg mb Der jenaer atrg. Zitteraturzeitung: Wo ihm Autopsie ganz oder zum Theil abging.

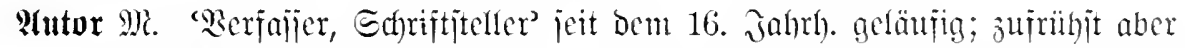
bei Etemhëwel 1473 Bocaccios De claris muliebribus $\Xi .336$ der auctor dises büch-

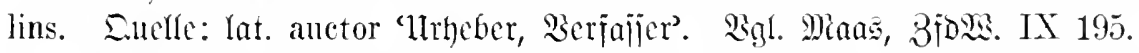

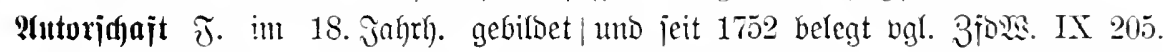

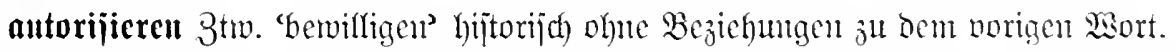
Duelk: mlat. anctorizare eigtl. 'Bollmadyt [= lat. auctoritas] geben', baher zufrühjt bei Emjer 1524/5 ?(mnotat. $\Im f 5^{\text {a }}$ das vil gemelte Epistel ron der kirchen anctorisirt vnd angenommen; aber a uthorijiren 1558 .jecibelb. Etatut'u ङ.29.

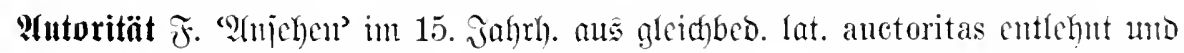

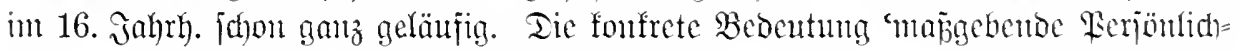

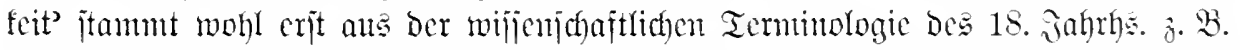
Zavater 1775 Fragmente I 23 Dal Zeugnisse und Authoritäten selbst in Sachen des Verstandes bey den meisten mehr gelten als Gründe, - ist gewil. Inch ngl. Lara= celjus 1530 Franjöj. Sranfhe it $\mathfrak{2} 2^{\text {a }}$ das jch nit pfleg, die auctoriteten der alten zugeprauchen.

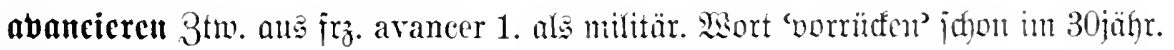
Srieg entehnt 2. als 'bejörbert werben' erjt im 18. Jahrh. bezeugt.

Belege: 1. 1631 Beridut von Magbeburg nötig hat. Seijing 1763 Nimua (II 207) 5.6 zu auanciren befohlen. Grioben 1694 Der Läufer? der ist avancirt. Jujti 1765 Heifebejchr. E. 128 er avansirte etliche mabi Edriften II 423 lasen Sie mig doch nicht mit tausend Mann. 1708 Qeopolo Der (Śró̉e lenger unter den Soldaten, Ig werte doch Il 353 Kurtz hierauf avancirte der Feind. hiehr nicht afonziehren.

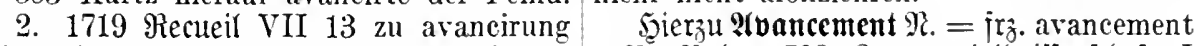
bei Hofe oder sonsten ein Stück Geldes 子. B. Rohr 1728 Beremoniclimijienjdjajt I 
243 an seinen weitern A. hinderlich. Epäter| Seï̈ng 1763 Minta (II 209). Mäjer 1776

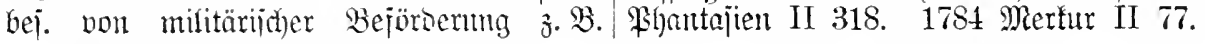

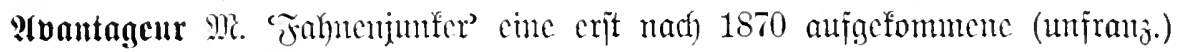

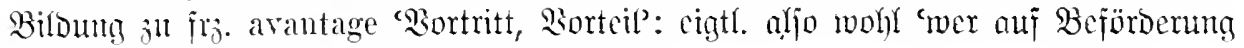
Dicnt?"

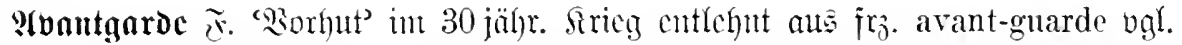

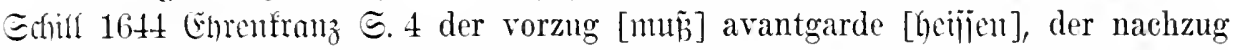
arrière garde, und also viel Wägen voll Frantzösischen wörter. Є(f)up 1663 厄(f)riften ๔. 506 Avantguarde (Vortropp).

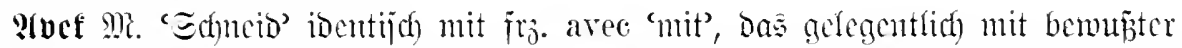

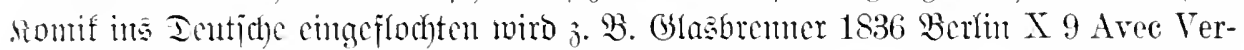
jnïgen. Ianad) Dam mit burjuffojer Iantologie mit a vec, bas Bolmmam 1846 mit Der BCD. 'gut, mit Erjolg' vergeidnet. Tie aus bicjer Saendung gejolgerte

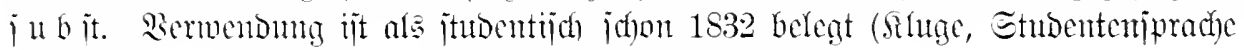

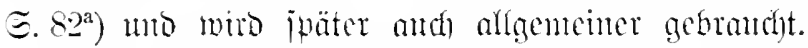

Belege: (Grabbe 1836 Theater (IV T2) 'den richtigen Avec in der Sprache beizuwäre sie ein bischen heiterer und umsichtiger bringen. Fontane 1891 Jemn Treibel bemutzt worden. mehr aree darauf gelegt. $5.229 \mathrm{dem}$ Boten, der es [Das bifaa] mit

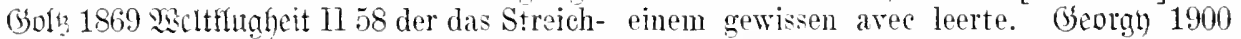
holz mit einem unerlaubten Avee gehand- Berliner Range IV 18 Die haben den richhabt. Etmoe 1886 santiertruppe ङ.88 tigen Arek.

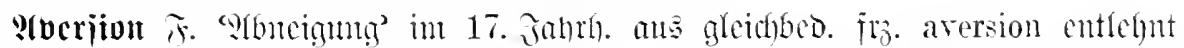

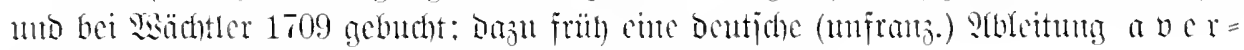
jiren 'verabichenen' Ettuter 1697 Chnmicus $\Xi .587$.

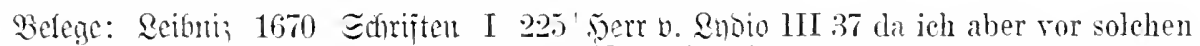
oa $\tilde{\mathfrak{j}}$ Franfreich] die besten Köpfe an sich [Qiebcrfichteiten] eine durchdingende Averziehe, die alte Aversion gegen sich austilge sion empfinde. Goethe (1790) Rifa (XIl 43) und endlich überall Meister werde. Mobr Es ist ein Arzt und darum schon hab ich 1718 Etaatsflugheit ङ.143 Printzen, die eine Arersion vor ihm.

eine Aversion daron haben. Fleijd)er 1734

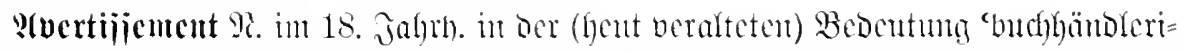

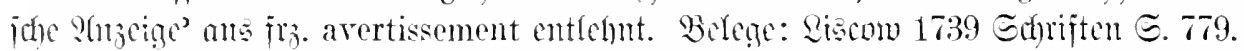

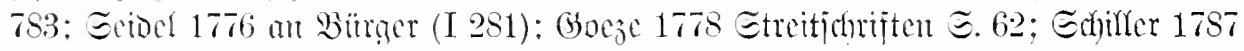

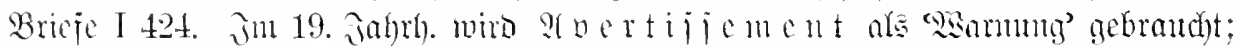

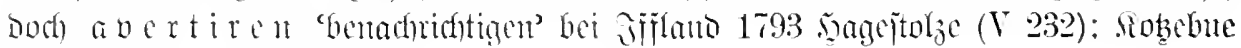
1802 Wimmarr (XV 200).

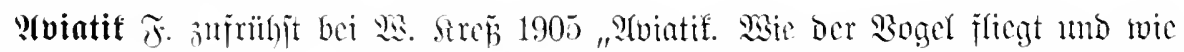

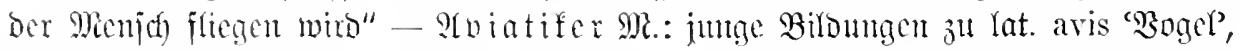

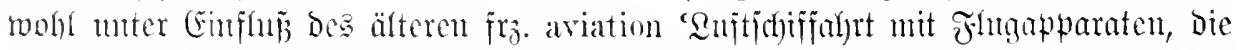

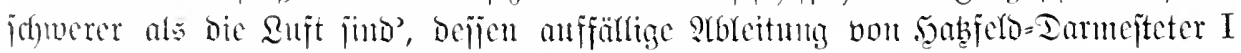

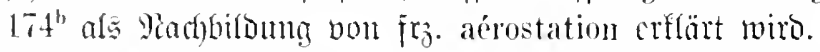

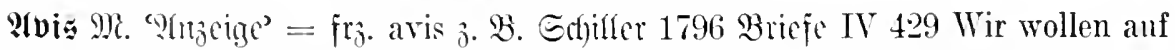
cinmal, ohne den geringsten Avis voran zu schicken, plötzlich damit vor das Publikum

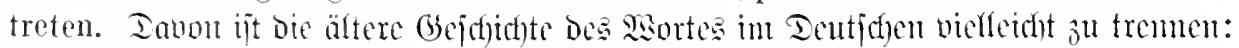

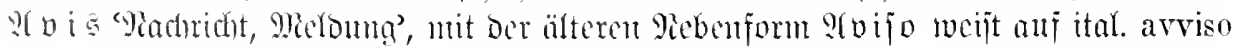




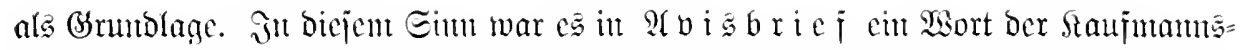

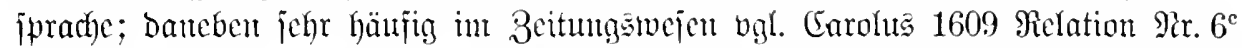

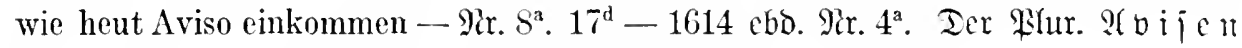

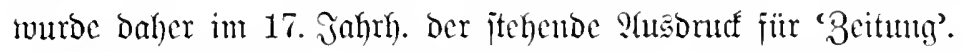

Plviäbriế Ellinger 1629 Steiberteujel 5. 41 Innassen insonderheit die Avis-Briefe anders nichts seyn, als Benachrichtigungen von Abschickung der Wahren, so zu Lande vnd Wasser gesendet werden: Ingleichen betreffen sie die Wechsel und Auszalung, so ein Kaufmann auf den andern zichet. Spreng 1662 isedjelpraftif $\Xi .47$ Laut Avis, bedeut die lettere di spacchio oder Avis Brieff, ohne welcher keiner gehalten zu Acceptiren, daß also Wechsel- und AvisBrieff fast referens und relatum sernd. Sher $\mathfrak{A}$ v i j o b r i e je nod bei sejing 1750 Erhats (II 15S).

P(vijen Pilur. 1. 9(lfg. 'Madfrifhten': E(b)weinid)en 1576 Denfwüroigfeiten $\lesssim .114$ so hatte ieh von ihren nahen Freunden anch Avisen, wo ich die Jungfer begehret, so würde sie mir nicht versaget werden.

2. 'Beitung': Fram 1603 Relationen $V \mathfrak{A} 2^{a}$ weil diese Avisen ..... nichts verdrießliches noch wiederwertiges in sich verhalten, so sein sie zum Abdruck verstattet vnd zugclassen worden. Martin 1628 Colloques $\Subset .25$ hole die Zeitung oder Avisen, dab wir sehen, was guts newes drimnen stehet. Mengering 1642 Géwijien?= riige $\mathfrak{G} .1083 \mathrm{Ob}$ du mit arisen vnd newen Zeitungen weidlich ins Land gelogen. Sauremberg 1652 Edjerzgebictite ङ. 14 Darvan hab ick noch nichts in den Avisen lesen. Etieler 1697 3eitungăluit ङ. 40 Dahero sie [Dic Beitungen] auch Avisen, als gleichsam Anweisungen genennet werden. Ettmer 1697 Doftor $\Subset .47$ vor das unzeitige Avisen lesen. Jit 18. Jahrh. nod häuf̣

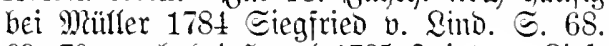
69 . 70; aud hei supel 1795 goiot. v. Rief= Into $\subseteq .14$ gebuctit.

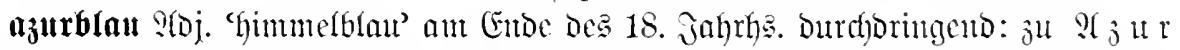

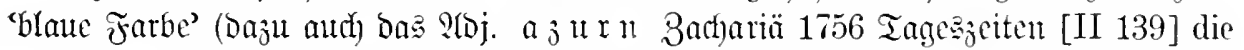
weiten azurnen Gefilde Flimmern umher mit schärfer strahlenden Sternen). Q̈(rter

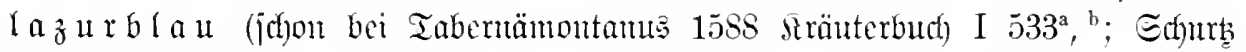
1672 Materialfammer $\subseteq .102$ "Azura, ¿ajïurblau" — uno nod bei Bodner 1752

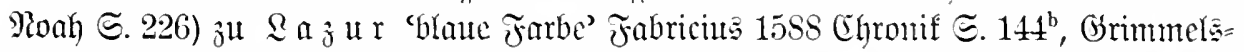

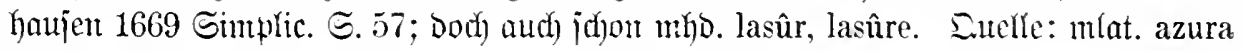
und lazurius (bie 1. Form entjtand it Den roman. Epradjen, in Denen das 1- Des

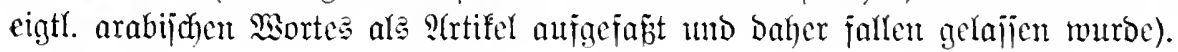

abijieren 3two 1. jofolt im 16. Jahrh. in Der Geridhtäprad)e: Gobler 1537 łroze 5. $7^{\mathrm{b}}$ Auisirn, Ist so einer dem andern zuuor ansagt, wes er in künfftigem gegen jm gedenck zu handlen, das er als dann reschiekt sei - $\Xi$. $2^{\text {b }}$ er mag als bald, ob er wil, daruff sein Zeugen ernennen und [Dab] gegentheyl Auisirn die rff nechsten

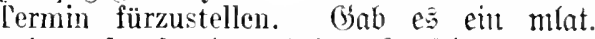
avisare für jpätlat. advisare? Die ing. und ital. Entipred)ungen fommen jür bieje Beit 2. Eeit Ende Des 16. Jahrhs. in Der

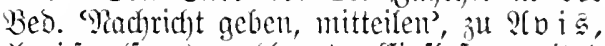

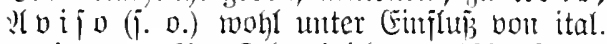
arvisare 3. B. Edfueinidgen 1588 Denf= mitrdigfeiten $\Subset$. 341 Solches habe ich bald F. S. gen Kalmke zu wissen gethan, daß er dies Ch. St. avisiren sollte. Carolus 1609 Relation ir. $4^{\text {a }}$ AuB Neuß wird avisirt, das grosse rneinigkeit zwischen beiden Herren - Ir. $7^{\mathrm{a}}$ Aub Ambsterdam wird avisirt, das alda 7 . Vbelthäter aubgestrichenYr. 7d Brieff auß Spanien avisiren die wider ankunfft n. $\ddot{B}$. Grintmelshanjen 1669 ङimplic. E. 497 welches seinem Vater ron andern Engeländern zeitlich avisirt war.

3. $\operatorname{tranj}$. twie $\mathrm{jr}_{\mathfrak{j}}$. ariser mit Dem 刃ebenjum 'wamen': 1565 Bimmerijde Egronif III 609 so werdens die diener gewar, laufen eilends zum herren cammerrichter, in $[=\mathrm{ifm}]$ dessen $\mathrm{zu}$ avissim.

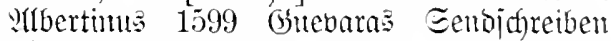
III $96^{\mathrm{b}}$ dann mein Meynung ist nur, sie zu auisiren vnd zuwarnen. Mejieridumio 1615 Epelta's Rarrkeit II 78 habe ich ewere Majestät deßhalben avisirt und gewarnet. 1634 Beridft von Friednus Berrat (5) $1^{\text {a }}$ Als er von Lintz aub von seinem Correspondenten einem avisirt worden. 


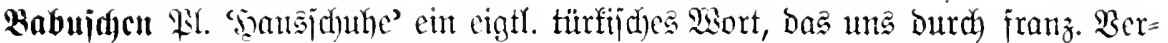

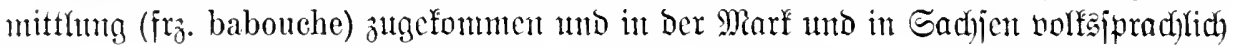

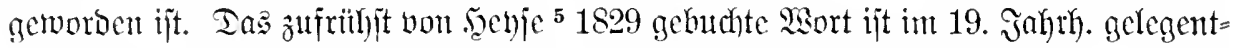

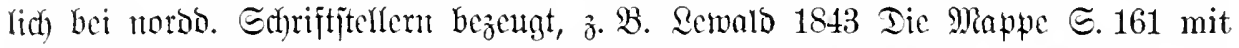
gestickten Babuschen an den Füß.en, im Charakter orientalischer Kauflente (bei Fontane 1870 Brieje I 189 Bambuschen).

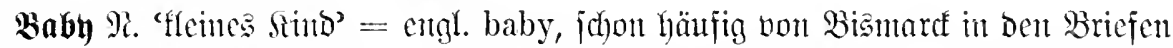
an jeine (battin (z. B. 1849 S. 126) gebraud)t; Dod) gejuah Die Eimbürgerumg bes bei betje ${ }^{13} 1865$ nod) fehlentoen wartes wohl crit nad) 1870: es wirb zufrühjt bei Sambers 1871, bant auth) bei Dunger 1882 Berdeutjuntgamb. S. 12 gebucht.

Belege: 1. Son Engläntoen: Robentberg als ich noch ein klein Baby war.

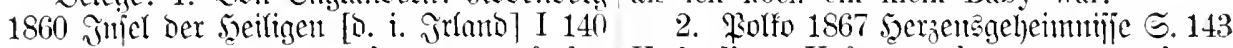
Schweigsam und ernst schaut er auf den Und diese Käfersammlungen ron photokleinen Rundthurm von St. Kevin's Küche graphischen Portraits an den Wänden, bis hinunter. Er sieht ans wie der Vater und in die kaum geborene Generation hinein. jener wie der Sohn - ein „Bäby-Rund- Baby's in allen möglichen Stellungen. Sgenfje thurm", meinte Ellen, - aber ein Bäby 1896 Blauftrümpfhen $\Subset .46$ Sie sind doch mit graubemoostem Haupt, und lange kein Baby mehr. Bierbaum 1896 Edflangen= ewig alte Halne hängen ihm am Bart herum. Dame $\subseteq$. 91 wie er einst als zahnendes Baby Rhoben 1885 Trobfopf $\widetilde{S} .39$ sie starb, ausgesehen hatte.

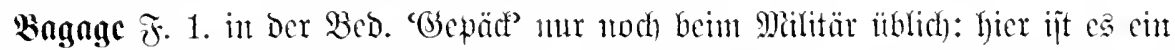

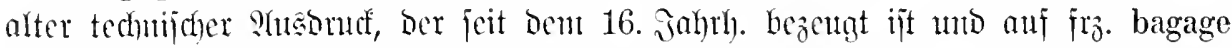

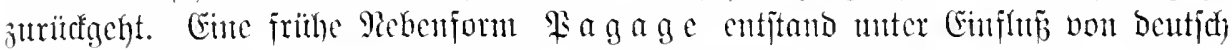

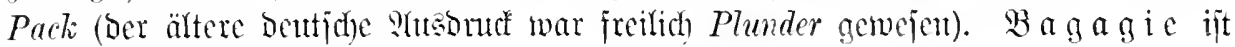
uicderlämo. Edyreibung.

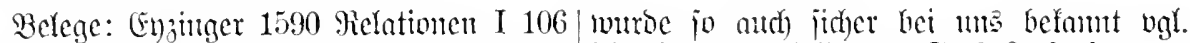
daß des Schencken Reutter zeytlich vor- Martin 1627 Coftoques $\subseteq .218$,le bagage,

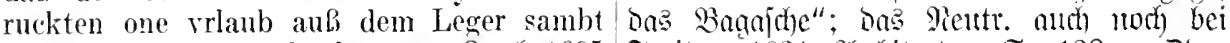
allem jren plonder oder bagage. ¿ord) 1605 Jreitna 1631 Y(ref)itectur ङ. 128 . DDer ReYation E. 13 alle Munition, Bagagien. war für bie (Entitehtung bes Deutichen Fe=

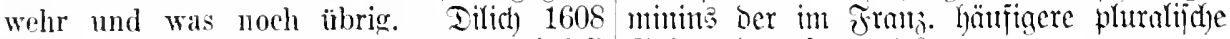

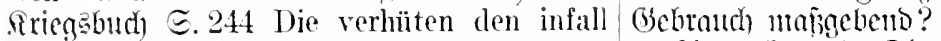

von hinderwarts uf die krancken, geschütz. pagage, so man etwa nachzuführen pfleget --

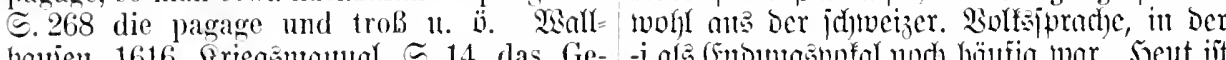

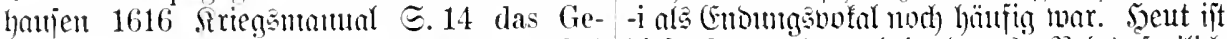
schüitz, Ammunition rnd Pagage. 1616 Dieje Form (zumtal in Der 2. Beb.) freilids

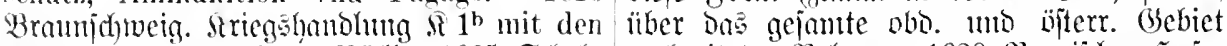

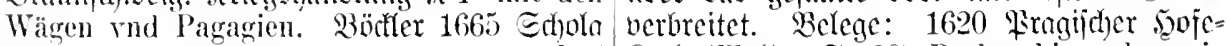

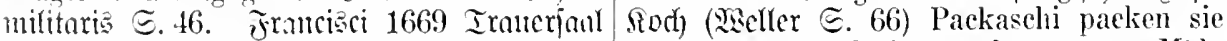

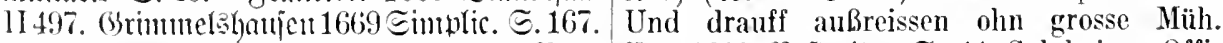

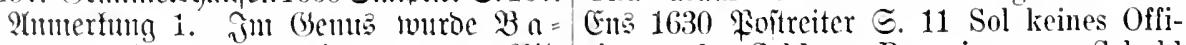
gage ntach) ben itbrigen a $\mathrm{g} e=\mathfrak{B b}=$ eirers oder. Soldaten Bagagi wegen Schuld

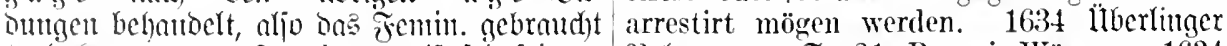

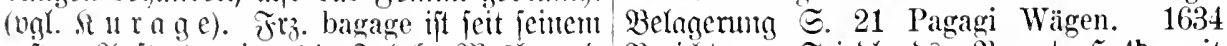

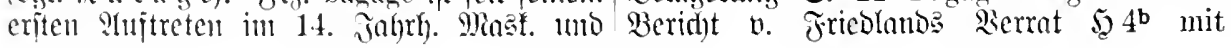




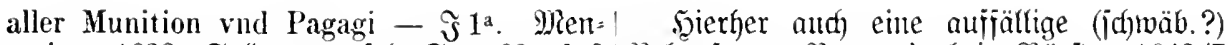
gering 1638 Eoldatenteujel $\Xi .162$ daß Mebenform $\mathfrak{B}$ a gaj bei Bürjter $1643 / 7$

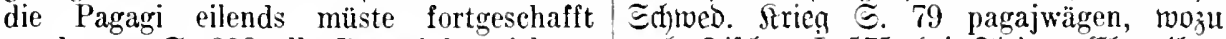
werden - 5 . 208 alle Pagagi in stich ge- nad Fijder I 575 bei Fition, (Shronif v. lassen. Anderjen 1669 Drient. Reijebefd)r.ङ.22. I Reutfingen 厄. 215 Pakoywägen?

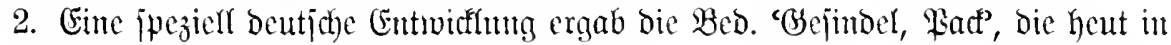

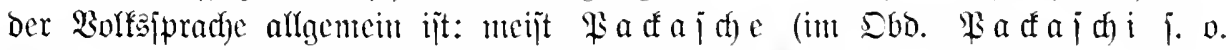

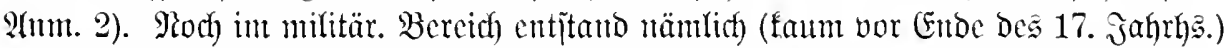

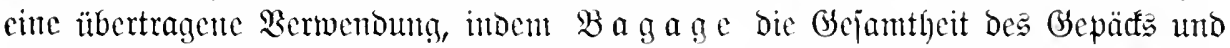
ihre Bebectung in şinblid auf bie Marjobromung bes Seeres bezeidynete vgl. Srämer 1681 Reben Der Sechelden $\Xi .177$ Hiernebenst kam das Geschïtze und endlich die Bagage. Daraus ergab jich) dann (wie bei Den bentichen Snnonymen Pack und Troß) die Bed. 'Šaujen, Schar', dic jufrühjt in aflgemeiner Berwendutg, ipäter mur mit

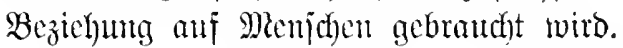

Belege: 1719 Recueil v. allerbando Glañbentur 1836 Berlin VIII $33 \mathrm{Thr}$ Solleft. VII 123 so kömt der Habicht ge- Packasehe, Ihr müßt mir alle in den Himmel flogen, und da er ein Kücken will auf- - IX 33 dämliche Package. (baubt) 1837 nehmen, entführet er die gantze baggage Jubiläum (VI 209) Schülerpakage. Miörifłe

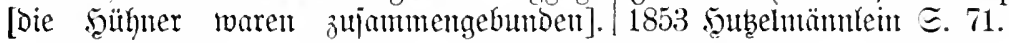

Bagatelle $\mathfrak{F}$. 'antbedeutende Stleingfett' an Ende bes 17. Jahr

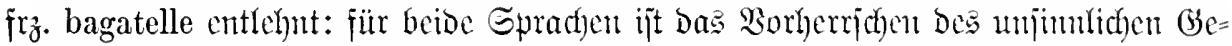
braudhes d)arafterijtijed, während bas cigtl. Sucllwort ital. bagatella jimuliche Bed.

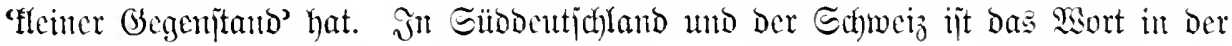
Borfajprache cingebürgert, aber aks Reutr. und ju bakketell und pakketell intge=

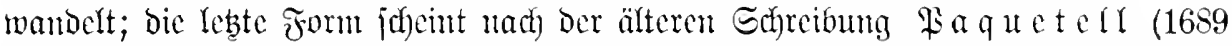
Polit. Fliegentvedel I 77, Ettuer 1697 Doftor S. 878) auf etımologijierender $24=$

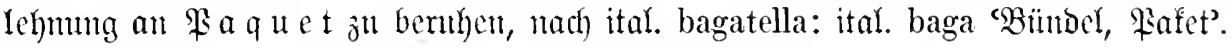

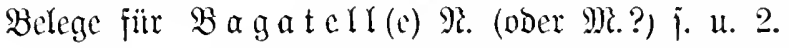

Belege: 1. Thomajus 1688 Monat: $=$ Soplie 1705 an Friebrid) I. (ङ. 80) das gejpräche I 34 so sind es doch, wenn ich ich E. II. so eine Bagatelle haben schicken

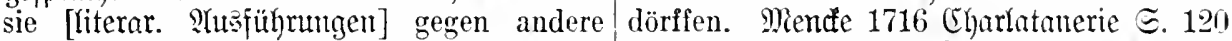
Gemüths Belustigungen halte, rechte $\mathrm{Ba}$ - das schlimmste ist, daB sich diese Mückengatellen - 450 die Zeit in vertirung solcher sauger insgemein nur mit Kleinigkeiten bagatellen zuverderben. Tenţer $1689 M_{D}=$ und Baggatellen müde arbeiten. 秥agner natl. Unterredungen $\Xi .251$ daß ein Setzer, 1724 Eoldatenbibliotbef $\Xi .60$ Sie hielten er möchte auch so accurat sein als er immer sich bei Bagatellen auf, liessen sich aber könnte, dergleichen Bagatellen allezeit in nicht en detail des hriegswesens heraus. acht nehme. Dalfover 1689 Gartenbeetlein 2. Dalhover 1687 Gartenbeetlein I $623^{\text {b }}$ II 692a da andere mit allerhand Bagatell Vmb ein Pagatell nnd Kinder-Spill, ich vnnd Kinder-Possen die Zeit zu bringen. will sagen, vmb ein angenblickliche Be-

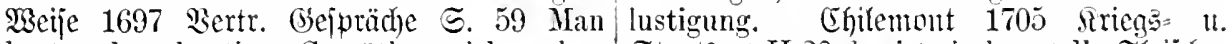
hätte das hurtige Gemüthe nicht eben Etratsrat II 20 das ist ein bagatell. Flleijher mit solehen Bagatellen aufzuhalten. 17021730 Seerr v. Sndio I 304 was Ehren-Sachen Europ. Fanna $\mathfrak{S}$. 358 dem Hause Bourbon anlanget, müsse man ein Bagatelle nicht die geringe Bagatelle der Spanischen Mon- ansehen. Bad)ariä $175+$ હd)mupituch (I 270) archie ruhig zu überlassell. fturï̈rịtiı weil gegen Dich ein Graf ein Bagatell versehn.

Bagno = ital. bagno, als Rame ber Ferfer in ben Mrittelmecrlämbern befamnt

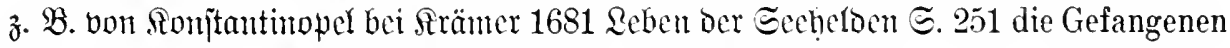
wurden in ein Bagno (Gefangen-Gewölb) gebracht. 


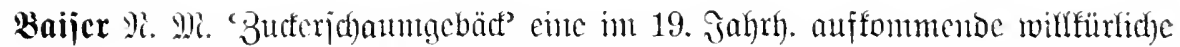

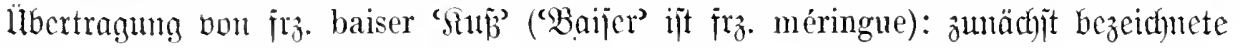

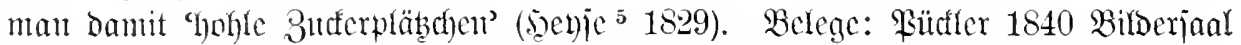
I 78 Ein Offizier der Berliner Garnison liebte ein Backwerk, das man Baisers nennt, auberordentlich - vgl. aud S. 79 der junge Krieger hatte bereits 20 bis 30 der süßen mit Schaum gefüllten Kugeln in sich aufgenommen. Biămardf 1847 Brieje ङ. 48 mit bei Seite gebrachtem Caviar, Baisers u. dergl. Fontane 1897 Etechlin ङ. 233 Baisertorte.

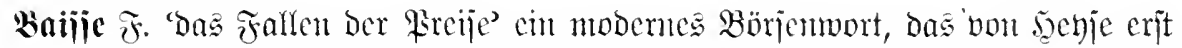

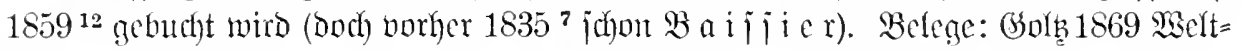
flugheit II 73 Künste und Wissenschaften können dem nichts helfen, den die Hausse oder Baisse am Halse würgt. Rorbau 1883 Rïgen $\subseteq$. 243 Die Waffe mit der er [Der Spcfulant] Produzenten und Konsumenten wie ein Buschklepper ïberfällt, ist doppelläufig und heißt „Hausse und Baisse" - S. 180 Baissespekulanten. Sutteffe: $\mathfrak{f r}_{\mathfrak{z}}$. baisse - baissier.

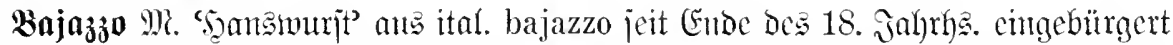

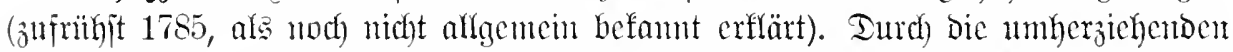

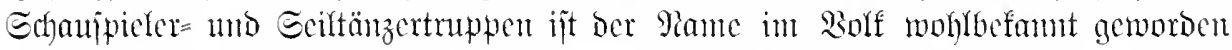
unb ijt in ben meijten Teilen Dentifhlands als Poiatz ober Peiatz gelüufig. Die in Den wejtlichen Mandarten (Erjaż, Echwaben) herrjchende Zautform Bajass ijt von

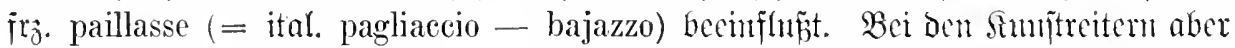

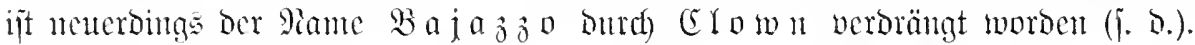

Belege: Tinme 1785 Suftbanmeijter|nur inmer dem Marktsehreier folgt, weil I 193 Sie werden weit besser thun. wens er köstliche Zoten spricht und sein Ba-

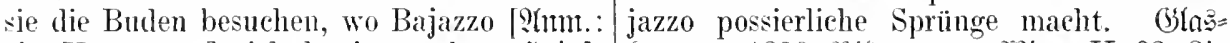
ein Hanswurst] sich lustig macht. beinf brenter 1836 Biber ans wien II 93 Sie 1794 Gribegaro v. Dohenthal (V 215) Er lassen sich gewiß dureh clie Späße der warf sich auf alle Weise überwunden ihr beiden Bajazzos in die Taschenspielerzu Füßen und sagte: ,.Ihr Bajazzo bin ich. Bude locken. Fütfler 1840 Bilderfanl II 160 und weiter nichts". Sautf 1827 Sroutro Seiltänzer-Bajazzo. Frentag 1855 Eoll u.

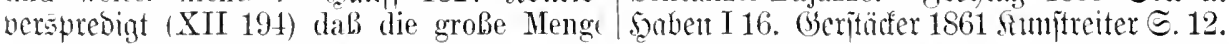

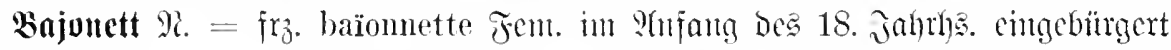
3. 3. Flemting 1710 Eolbat S. 199 . Sisagner 1724 Eoloatenbibliothef S. 225 als

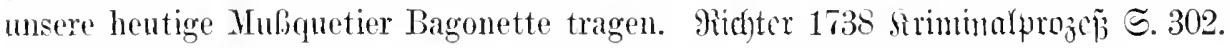

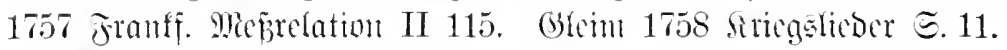

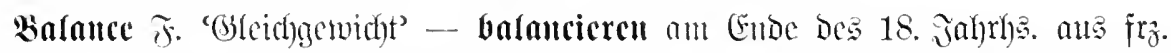

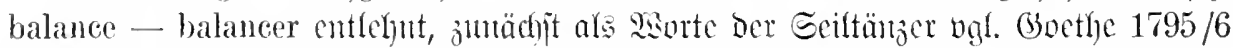
Sehrjahre (XX1 127) sieh nur die Knaben an, wie sie jedesmal, so oft Seiltänzer in der Stalt waren, anf Planken und Balken hin und wieder gehen und balanciren. Srcine 1830 Jtalien (III 351) bei Kunstspringern, die auf dem Seile balancieren. -

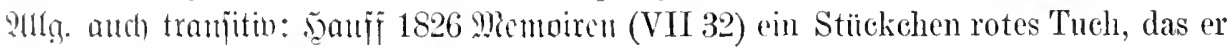
mit vieler Kunst gegen den Wind zu balancieren wubte.

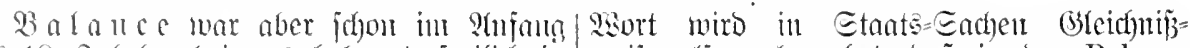

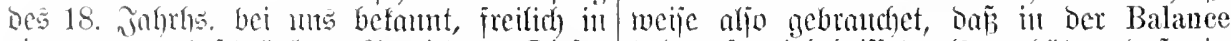

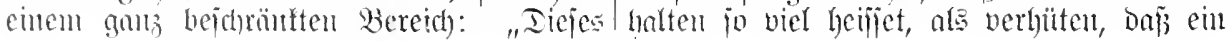




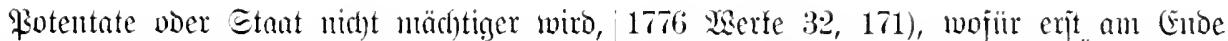

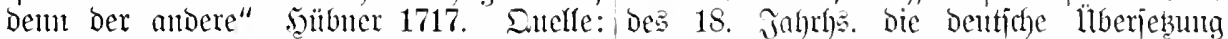
$\mathrm{fr}_{\mathrm{g}}$. balance (des pouvoirs, des nations). europ. Gleichgeuicht geläufig sourbe (bgl. Daker bei. "Die Balance von Europa" (1702 Enbendorf, Ed)lagmb. 厄. 75). Iamit

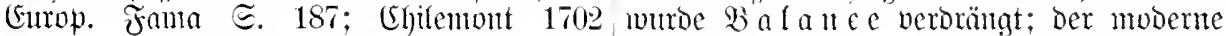

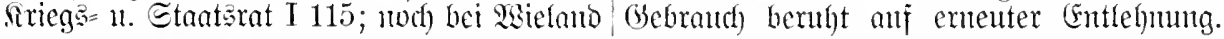

Baldadyin 9l. 'Shron=, Iraghimmel' in 17. Jahrh. ans ital. baldacehino ent=

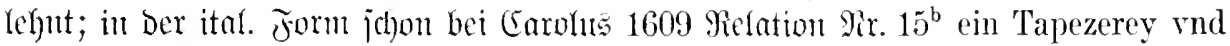
Baldachino zu einem Bett.

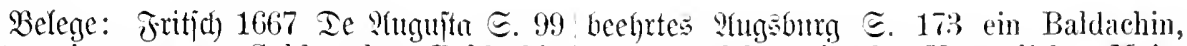
unter einem gantz Goldstncken Baldachin unter welchen beede Kayserliche Majeoder Himmel. Dalhover 1689 Gartenbeetlein stäten einhergiengen. Éhilemont 1705 I 367 die Raths-Herren hielten an 6 ver- firiegsent II 3.1708 2eopolo Der Groje guldten Stangen cinen Baldachin oder II 6. 3ichadfuits 1723 starl VI. $\Subset .685$. Sehirm ron rotter Seyden. 1690 Sgod $=$

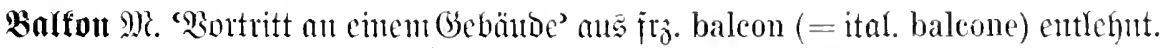
Belege: Sïnig 1720 Ifyeatum eciemon. II $1459^{\mathrm{b}}$ Einer trat hinans auf den Balcon.

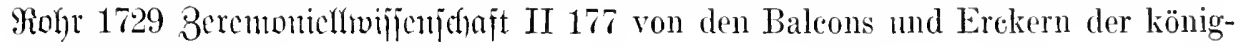
lichen Palläste.

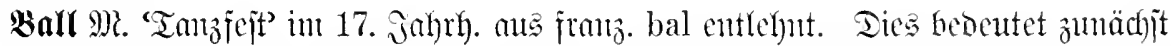

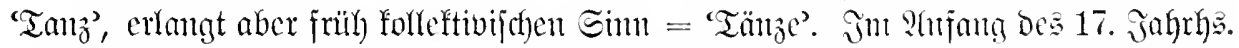

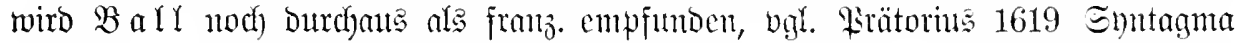
mujicum III 19 (Im Frantzösisehen nennet man es un Ball, das seynd allerley Täntze in genere), und eine Parijer Meloung bei Carolus 1614 Melation Pr. $14^{d}$ (Allhie ist ein stattlich Ballen oder Dantz gehalten worden) hatte viefleicht einc franz. Borlage.

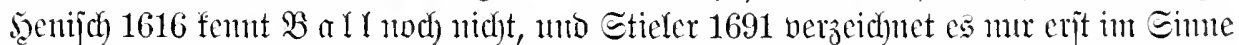

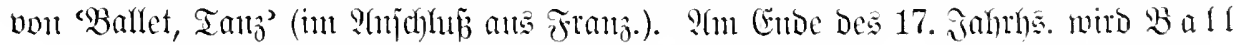

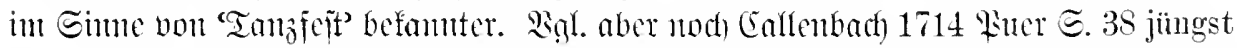
stunde in der Zeitung, ein gewisser Fürst habe den Hoff-Dames ein Ball gegeben. Was ist das für ein Ball? Es ist ja ein schlechte Waar umb ein Ballen. womit anch die Baurenbuben pflegen zu spiclen. - O Simpel: eiu Ball ist ein Kermes-Tantz,

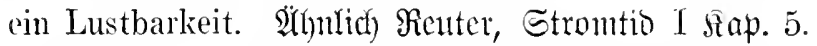

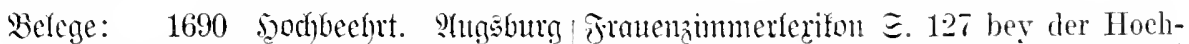
ऽ. 107 eine ansehnliehe Znsammenkunfft zeit oder einem andern Balle. Nijefiijus 1715 Fürstl. Personen, denen zn Abends ein Flleurie 5.17.

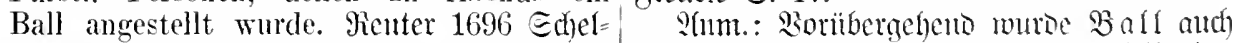

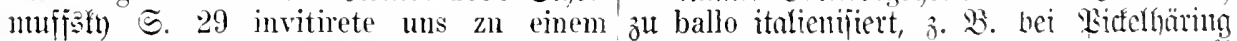

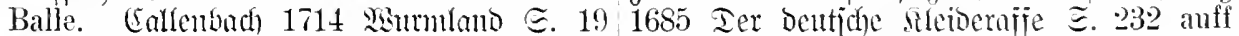
a Dien ich eyle zmm Ball. Q(marunthes 1715 einem lnstigen Ballo - $\Xi$. $7 t$ anf dem Ballo.

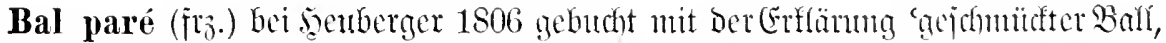

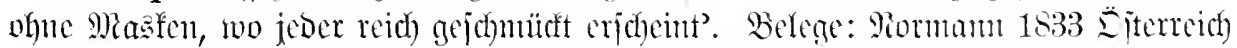

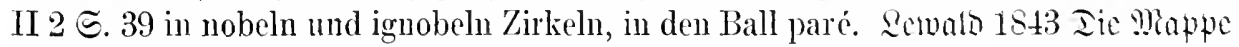
ङ. 153 Nichts Lächerlicheres, als die sogenannten Bal parés.

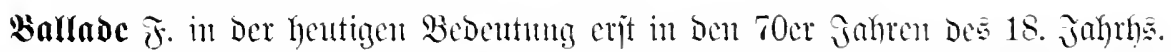

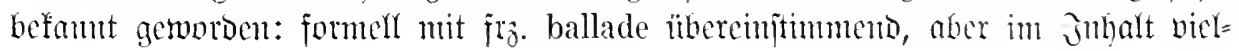




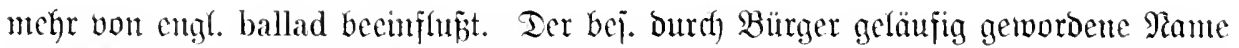

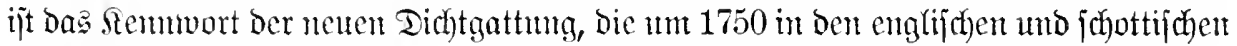

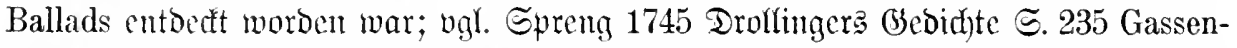
hauer, die man in England Ballards nennt. Sgagedorn 1747 Doen $\Im$. XVI Einige alte Ballads der Engelländer sind unvergleichlich - und . gerberz' $\mathfrak{a}$ "Balladen und Sieder altenglijacer und altjd)ottijd)er Diŏter" 1777.

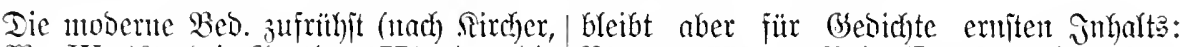
3 fons. IV 10) bei Goethe 1771, der bie Bürger 1773 an Boie (I 110) meine überalten eliajijidien Borkslieber deutsche köstliche Ballade: Lenore - audi 114; 115 Balladen ttent. Bürger jobmante an= den Ton, weleher in der Folge noch po-

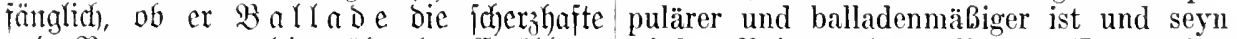

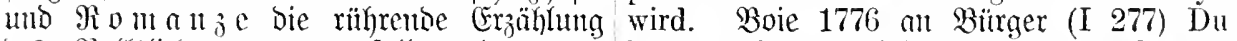
Des Solfsliedes nenten follte ober un $=$ kömmst immer tiefer in deine Balladen-

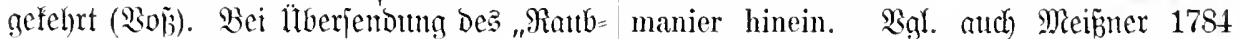
grajen" idreibt er 1773 an Boie (I 105) Imintizmoro $\bigodot .61$ Folgende Anekdote, die Hier empfangen Sie eine Romanze, oder für Ballade und theatralische Bearbeitung wenn Sie lieber wollen, eine Ballade - vielleicht kein undankbarer Stoff gewesen wogegen jidf) Boie (ebo. I 110) für Romanze wäre.

(nicht Ballade!) entid)eidet. BaIfade

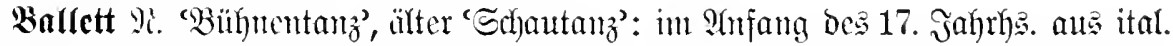

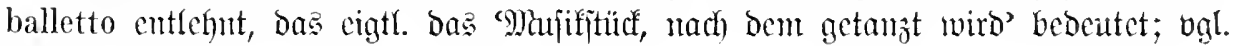
Prätorits 1619 Enntagma muficum III 19 Balli vel Balletti: 2. Der andern Art Balli oder Ballette seynd, welche keinen Text haben: wenn dieselbigen mit Schallmeyen oder Pfeiffen zum tantze gespielet werden, so heist es stampita. Ballet aber sein sonderliche Täntze zu Mummereyen vnd Vffzügen gemacht, welche zur Mas-

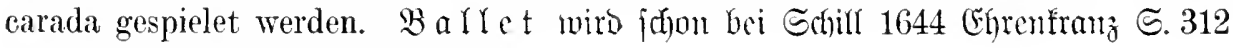
als vörlig cingebürgert bezcidjutet.

Belege: Miengering 1638 Gerwijenz=/ werden sich miteinander schliessen und wedfer ङ. 312 mit Kleidungen, Trachten, dann das Ballet zu tantzen anfangen.

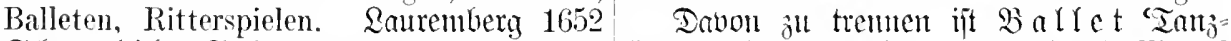
Echerggebidite $\Xi .64$ men schal se ock nicht (ieb' vgl. Prätorits a. a. D. Balli vel singen, Noch na ere cadantz in den Balletten Balleti Erstlich sevnd sonderliche Gesänge, springen. Rajienius 1661 Q(bel. Tijofreben die am Reyen rnd zum Tantze gesungen ङ. 187 Dieses Tantzen hat vielerhand (denn Ballare heist Saltare, das ist Tantzen) Arten und nemnet man dasselbe so auf derer Art etliche gar liebliche vnd anmutige sonderbare Art geschiehet, Ballet halten. Balleten rom Jacobo Gastoldo vnd Thoma

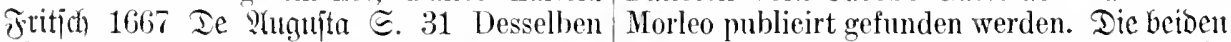

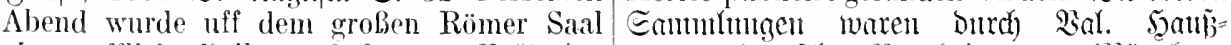
ein trefflich Ballet gehalten. Prätorins mamb Dentiche Bearbeitungen (Yürnberạ 1667 2(uthropodentus III 100 die 16 Genii 1607 und 1609) bei uns befunnt.

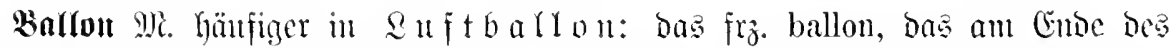

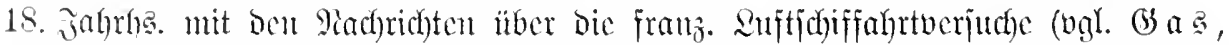

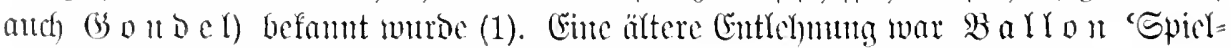
bafl' cigntl. 'mit Suft aufgeblajencr Bafl' (2), Das aber Direft auf ital. ballone (woraus

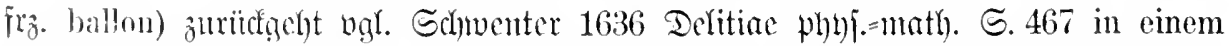
Ballon ode" welschen Ballen. Die Inftbälte maren wohl cin Jntportartifel vgl. Maaler

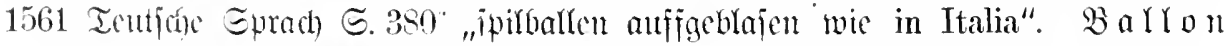
'pila major vento inflata' wirs zulest von Frijch 1741 verzeidnet, ipäter ijt es unter= 


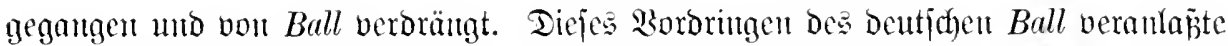

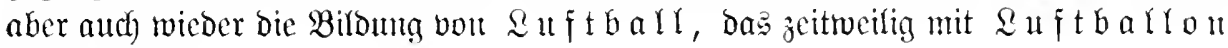
fonfurrierte.

Belege: 1. Wielano 1783 Teuticher bald her tut schlagen. Edfilofned)t 16ว2 Merfur IV 77 bey der Ladung des Ballons , 5armonia III 70 nutzet so viel als ein - 78 die Explosion des Ballons - dab Hand roll Ifflaum-Federn zum Ballon.

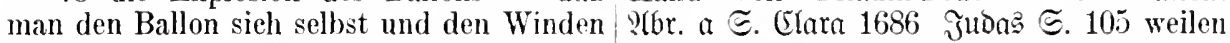
überlassen sollte. Inigge 1792 Reije $\Xi .205$ auch die Faust ein Ballon in die Höhe der Musjö Blanchard sitzt in einem Sehiff- treibt.

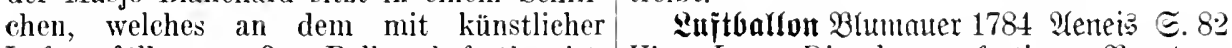
Luft gefüllten großen Ballon befestigt ist. Vier L.-e Die lagen fertig. Brentano

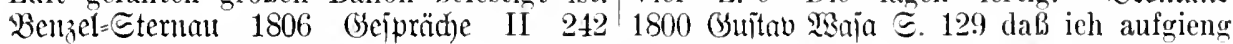
die Hoffnung allein führt übel, zum Auf- wie ein L. Slozebue 1801 Slingäberg (XII blasen des Ballons reicht sie wohl hin. 251) Ieh war wie ein L., der noch ange-

2. Mejierjantio 1618 Garzoni's Marren= bunden ist. (Soethe 1815 an Belter I 408 fpital ङ. 26 mit ihme, als einem Ballon ge- das derbste Gedicht geht, wie ein L., uns spielet. Metyfart 1636 5ochid)ttlen $\Subset .397$ aus den Händen und in alle Lüfte.

nieht instrumentiren, nieht Ballonen sehlamen nicht Ten, nieht spelen. I 106 eiul lustiger Ballon, den immer hinmel- man, $370 \mathrm{f}$

an bald die, bald jene Faust, bald hin,

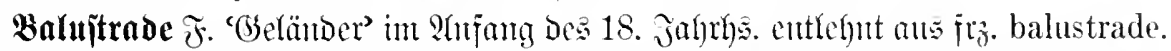
Das জ̧ort feblt Den Frembtwbb. vor Campe 1801, wird aber bei \&enther 1744 Sexicon architect. I $13^{b}$ und bei Sulzer 1771 Theorie I xu als bautechnif her Termima gebudht.

Belcge: 1702 Eutop. Fama $\Xi .1044$ I 1299b Auswendig bezieret mit einer PaRafeten] welche nebst ihren Stäben den lustrade - $1300^{\mathrm{a}}$ unten herum aber eine Umfang des Waldes oder die Balustrade Palustrade. 3jouctwith 1723 Siar! VI.

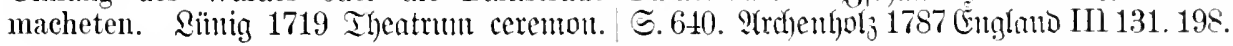

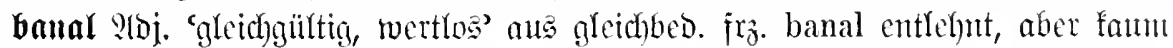

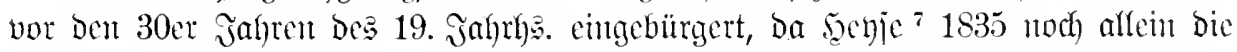

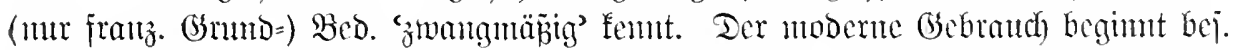
mit Bezichung auf allägliche Redensarten z. B. Şcute 1834 Galou (IV 36) Dies soll keine banale Redensart sein. (Gauby 1839 Iubwiga (V 147) die mur langsam verharrschende Wunde des Leidtragenden durch banale Anfragen wieder aufzureißen. Bismarof 1847 Brieje 5.93 die banalen aufgeputzten Phrasen der rheinischen Weinreisenden-Politik.

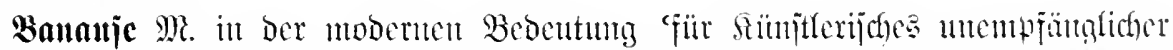

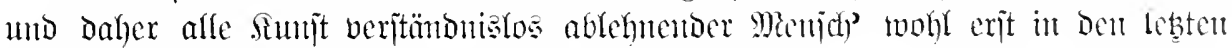

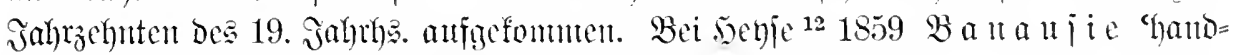

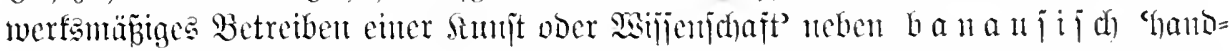

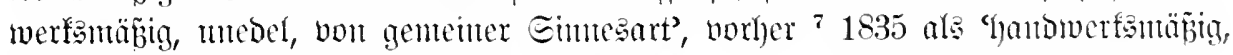

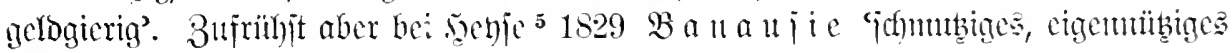
Benebmen bei. von ïraten'.

Das Sort jpielt bereit?

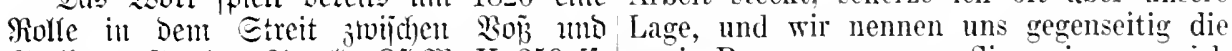

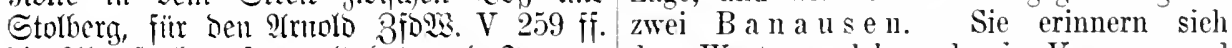

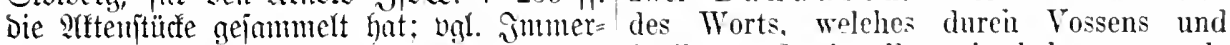
manil 1824 an Grije v. Ritbow: Mit meinem Stolbergs Streit allgemein bekannt wurde Bruder, der in ähnlicher beständiger [?YFten=] und in der ursprünglichen Bedeutung einen 
Menschen anzeigt, der beim Fener ar-| ipäter. Bej. jeblte Dem Wort, wie Der Ge= beitet, in der abgeleiteten aber jeden be- braud) Immermants beutlid geigt, nod) zeichnet, der sich handwerksmäbig abmüht. jeoe joezielle Beziehung anf fimitlerifche

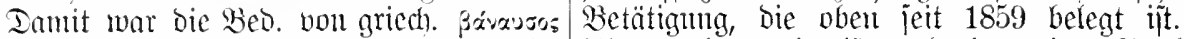

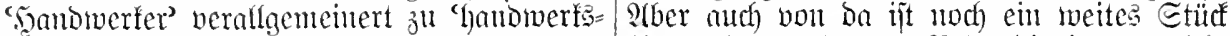

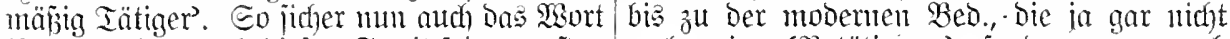

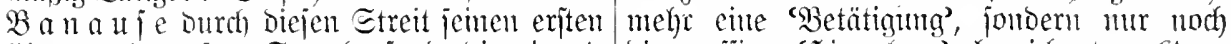

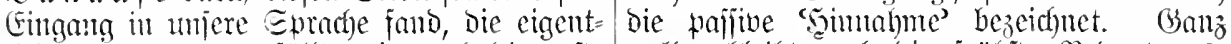
liche (Entbürgermug fällt, wie aud bic erite unflar bleibt auch bie frïbite Bedentutgs= lerifal. Siuchung (1829) beweiīt, erheblich) angabe bei sebje ${ }^{5} 1829$.

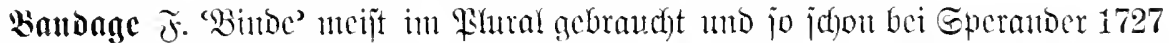
gebucht. Der હing. 3. 3 3. 1732 3coler I 276 und arretirt man also die Bandage am

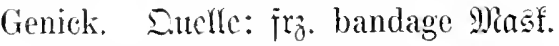

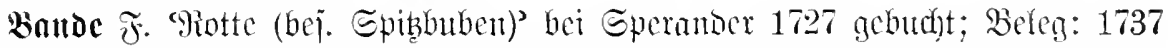
Jitio. Balbober $\Subset .3^{b}$ Diebs- und Rauber-Banden, älter in militärifonen Bercid) 'Echar Solbaten' (Biclege von 1616 bei Stuge ${ }^{7}$ ) cutjpredgend jrz. bande.

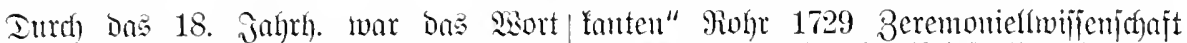

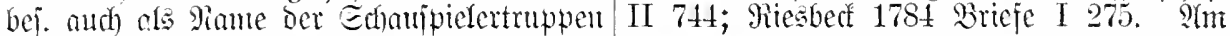
übfid); vgl. Friebrid) I. 1707 Briefe Є. 116 (Enbe Des 18. Jahthe. war aber $B$ a it o e Die bande commedianten haben gestern in Der jollimmen Beo. 'Diebestotte' jofon ein schön stück gespielet. Fleijher 1730 jo vorgebrungen, baj bie Edhauipieler (nad)

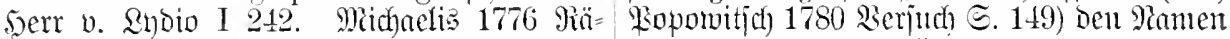

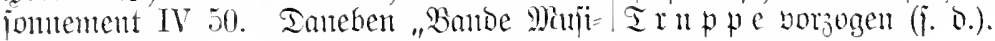

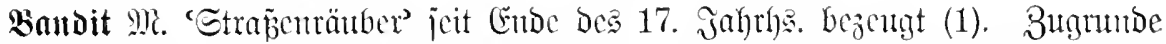

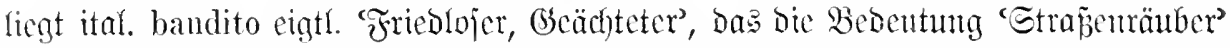

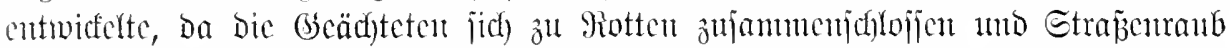

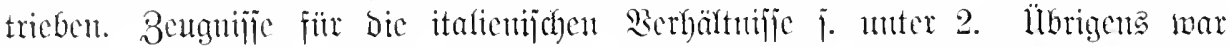

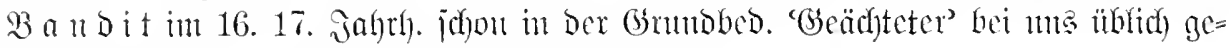
mejen (anfrithjt in oer Echuciz: Joint. IV 1282).

Belene: 1. Iallower 1687 Bartenbeetlein vnd Banditen, deren es ein gute Nottnrfft I 5.5\%b Was würd nit für ein Frend vnd anf selbigen confini abgibt, dann sie sich Trost creschöpffet haben Antonins von dessen getrösten, daß wanns ein Büberey T'adua, als er einest in Gegenwart 12000 anff dem einen Gebiet begangen, lauffen Personen geprediget, allwo fünff hundert sie auff ein ander jurisdietion, allda sie bekante Sünder, als Banditen, Straß-Rauber dann frey - - 43 Banditten oder Meerrnd gemeine Weiber. 1702 Enrok. Fama räuber - こ. 58 das so rauhe gebürg, da ๔. 689 Eine solche Art ehrlicher Banditen stijtigs ein gute Anzahl Banditen in selhat man niemahls gesehen, darimnen sie bigen Wildunssen rud Hölen sich auffes vielleicht manchen Menschen zuvor halten - $\Xi$. 63 Ioh machete andere Gethun, welche doch nimmermehr zu he- dancken nit, damn daß es Banditten weren. sorgen haben, dab nan sie Banditen metrfart 1636 sochifgulen Є. 395 dem es schelten werde. gehet auff Evangelisehen Universiteten wie

2. Riechel (unt 1600) Reije $\subseteq$. 182 dimn $m$ Welsehlande, da seyn öfentliehe Banes in gemeltem landt Calabria sehr viel diten vnd heimliche Menehler, die gantz panditen gibt und micher im landt zu verschlagener weise die Menschen hinzureysen. Jurttenbací) 1627 J̧tuetar. Jtaliae richten wissen.

E. 68 den 6. Sclunch hohen Waldrögreln

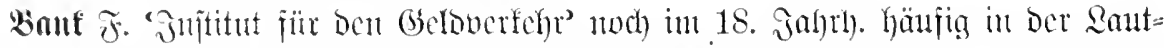

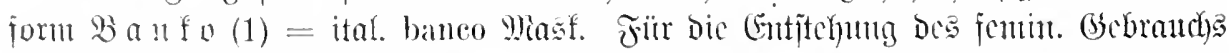

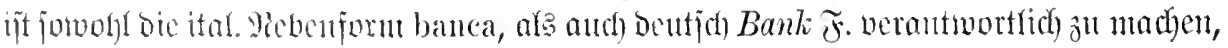




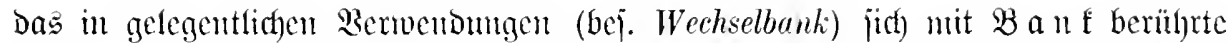
(ital. banco unb banca beruhen jelbjt auj beutjich Bank). Die Berfürzung $\mathfrak{B}$ an $\mathfrak{f}$ aus

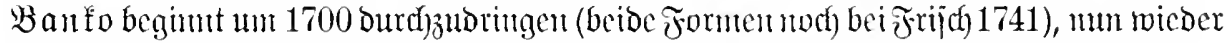

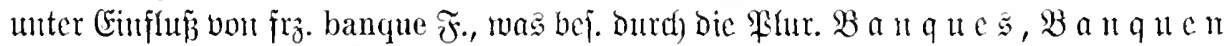

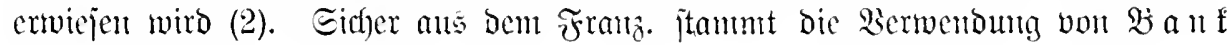
im $\mathfrak{i} \mathfrak{a} \mathfrak{z} \mathfrak{a r b j p i e l ~ ( 3 ) . ~}$

Belege: 1. Carofis 1609 Relation $\mid$ Müllfer 1789 Entuterid) VIII 224 dem sein 习r. $8^{\text {a }}$ weil sich die Kauffleut wegen der Hatusstand des Jahrs zwanzig und mehrere 3. Steur von jeglichem 100. fl. an die newe tausend Thaler Banko kostet. Bifeffel Bancko zugeben beschwert, ist solches 1789 Serjudje I 165 Bankozettel.

abgeschafft, vnd ist mit der Bancko schon 2. Marperger 1717 Beidnteibuta ber ein anfang gemacht -1614 ebo. Mir. $10^{\mathrm{b}}$ Banquen [Dodh $\Subset$. 1 der Sing. Banco].

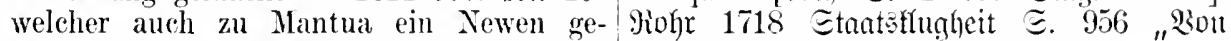
meinen [!] Banco mit viel Privilegien Den Banquen" [nad) Miarperger].

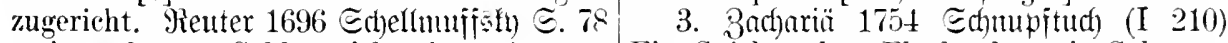
mein ander gut Gelel, so ich mir zu Amster- Ein Spieler ohne Fluch, der mit Gelassendam in Banco zahlen ließ. Etopwe 1735 heit die Bank sich sprengen sah. Ectjilfer

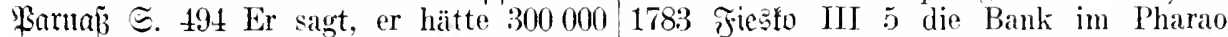

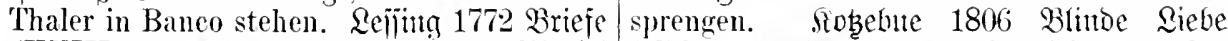
(XVIII 33) 400000 3ik. Banko. Mricolai ( $\mathrm{XX}$ 197) Man sammelt sich um den i784 Reije III 302 die Wiener Stadt-Banko. Spieltisch. Drilling macht Bank.

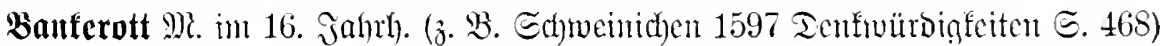

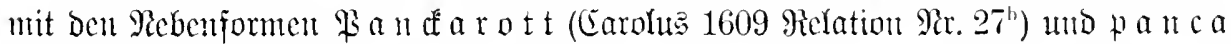

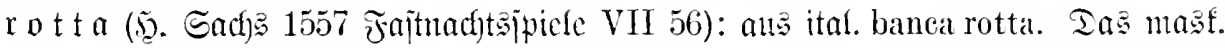
(benus nad) Der ital. Mebenform bancorotto (vgl. Banf-Banfo). YGuffülfig ber

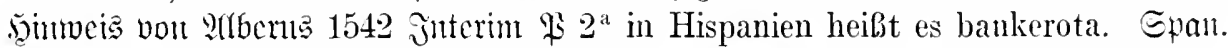

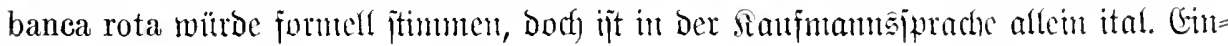

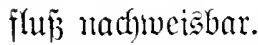

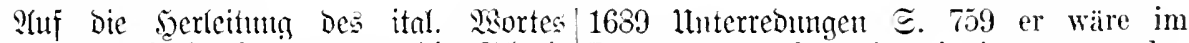

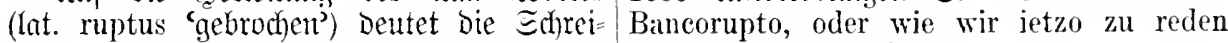
butg pancorupt bei Mengering 1642 pflegen, Banquerotirer.

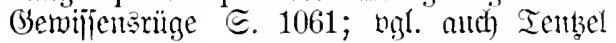

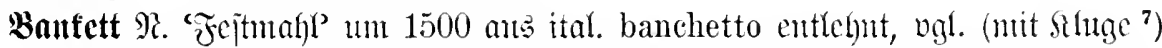
3ringli 1525 Q

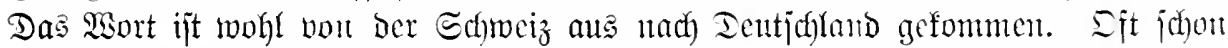
in ber (franz.) Sefreibung panquet bei Ditrer 1520 Iagefuch હ. 66. Tt. 91.

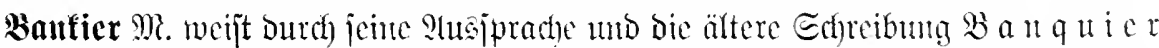
auf $\mathfrak{r}_{\mathfrak{z}}$. banquier als Sutelle fiu (Belege: 1708 Seopold ber Grobe I 107; Marperger

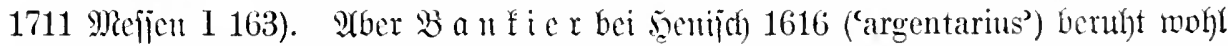
auf ital. banchiere, vgl. Carohts 1609 Relation $)$ ir. $44^{\mathrm{d}}$ hat jhme solches [Sarleben] der König rund abgeschlagen, mit vermelden, er sei kein Banchiero [!]. Iału

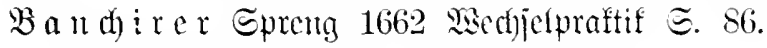

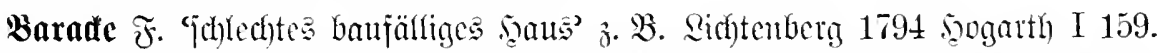

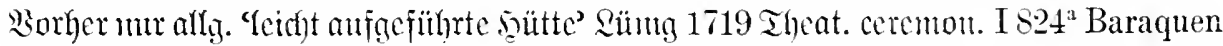

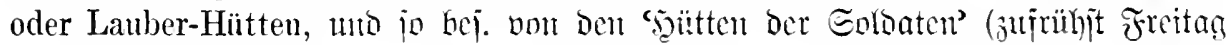
1631 ? (rdjitectur S. 50 Vor die Soldaten werden die baracken nahe an den Wall angeordnet). Entelle: ita!. baracea - $\tilde{j}_{j}$. baraque. 


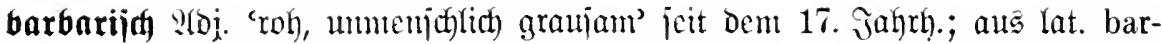

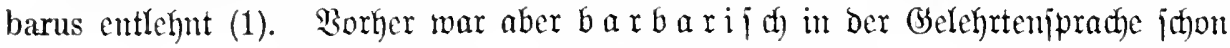

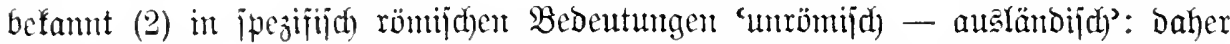

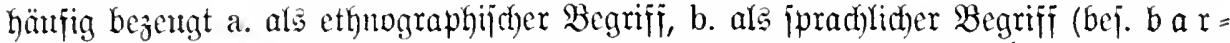

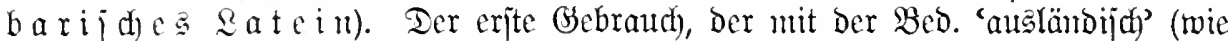
im $\mathfrak{a}$ at.) Gäufing bie vont 'unfulttiniert, roh' berbindet, hat bie jüngere allgemeine $\mathfrak{B e r}=$ mendung borbereitet.

Belege: 1.1634 Seridyt v. Friedtants Berrat ${ }^{2} 3^{\text {b }}$ Thre Kay: May: einer vnerhörten, barbarischen vndanckbarkeit zubeschuldigen - (5) 2a mehr als Barbarischen Tyranney. Freutoits 1667 (B)e $=$ wifiensifragen $\Xi$. $61^{\mathrm{b}}$ sondern auch dasselbe Kind überbarbarisch geschändet. Biegler 1689 Bantije ङ. 320 die barbarische stieffmutter. Elifabeth Charlotte 1702 Briefe I 297 ich kan ihn [Mielac] nicht leyden, weillen er so gar barbarisch undt cruel ist - 1709 ebo. II 109 Der allirten propositionen seindt $z u$ barbarisch.

2 a. Baldemam 1341 Bom röm. Reich (eD. Feter 1812 ङ. 231) ûz barbarischer terre. Mlt 1493 Echedels (Ghronif ङ. 296 Traian hat] anff eim barbarischen erdpodem ein provintzen gemacht.

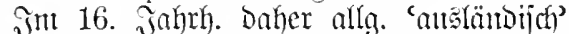
bej. von fremtoen $\mathfrak{B a ̈ l f e r n}$ gebraudht $\mathfrak{j}$. $\mathfrak{B}$. 5am? Earhy 1541 Fabelt (III 276) Hört wunderliche abenteuer, Die ist zwar erst geschehen hewr In barbarischen grenezen [sc. Türfei]. Fitidart 1575 Gargantua હ. 340 auch den Barbarischen oder Ferrfarenden Nationen jhenseit der Zucker Insel Canarien. CEgnträus 1597 Caja's Galateus ๔. 30 wie etliche außländische rnd Barbarische Leute thun - $\subseteq$. 48 welcher gebrauch ohn allen zweiffel von vns keinen vrsprung hat, sondern ist außländiseh rnd barbarisch. 9I(bertimts 1599 Bhtuebara: Eentidgreiben III $104^{\text {a }}$ barbarischen Nationen. Edjifl 1644 Ëhrenfrants E. 196 in mancherley sprachen, auch denjenigen, die wir Barbarisch heissen, als da sind die Welsche, Frantzösische rnnd Hispanische.

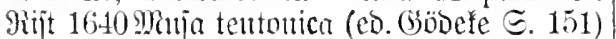
von dem barbarschen Volk, den glaublosen Croaten. Böbtler 1665 Ecthola mili= taris ङ. 18 frembde barbarische Völcker. Leibutis 1696 lluboigreifl. (bedanten $\$ 59$ ob man schon saget, es wären barbarisehe Völcker.

Frül) aber (mohl tur żufälliģ frïher als ill allg. ethrnographijher $B e D$.) aud) im (bje= brauch bon jremben 3ölfern jom 2tusbrut iffrer geringeren Stultur $\mathfrak{z} \cdot \mathfrak{B}$. (Emier 1521 gegen Quther II $210 \mathrm{Ja}$ es ist keyn so grob Barbarisch Volek auff erden gewest, das nit evgen prister gehabt. Bucer 1543

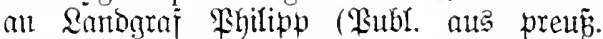
Stant:arch. 28, 212) Welche nation ist aber so barbarisch und onredlich uff erden, da man jeman, ich schweige so fil freien fursten und stenden zumute, im allergeringsten recht zu nemen vou denen, die einer solchen, in der allerhochsten sachen uff das verbitterst feind sein? Fisichart 1575 Bargantua S. 161 sollen sie loie alten Deutifien] drumb im Glauben Barbarisch

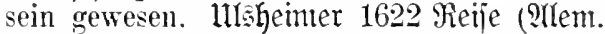
VII 111) Wie diss volekh sonst in seinem thun Barbarisch ist, also seind sie auch unfletig und viehisch im essen. Reibniz 1682 Ermahmung ङ. 309 warumb sind denn diese nationen lange Zeit barbarisch gewesell.

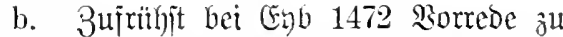

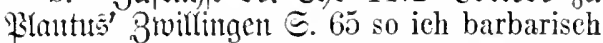
kriechisch vnd nitt rerstendlich reden würd. Später baher barbarij h' 'aegent die Regelli der lat. Eprade berftó̧ento

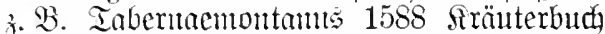
I 296a bey den Apoteckern hat dieses edel GewächB viel zerstörte vnd Barbarische Namen bekommen.

Diejer (jebraturf erfielt jid̆ in ber Ber= bittoutg barbarijales antein, in

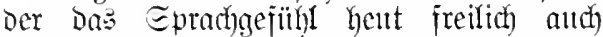

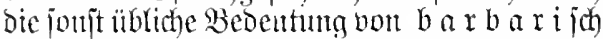
antutunt; \$elege: 1702 Gurop. Fama $\subseteq .263$. 1766 צIlfa. D. Biblinthef III 1 હ. 103. Bggl.

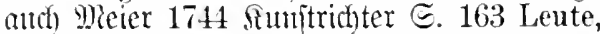
welche vor Aerger blaß werden, wenn sie ein barbarisches Wort in einer lateinischen Schrift finden. Darntach barbarisches Dentsch bei Gileim 1759 ant Ramler II 376.

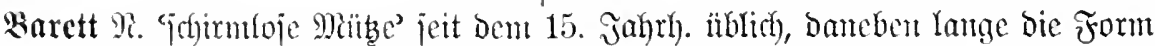
Birett: Dasijetbe Sdywanfen ingon im Mlat. (barretum-birretum), in bem bas sort jeite eight. Sorgejdichte hat. 
Bariton $\mathfrak{M}$. auว ital. baritono vgl. Prätorius 1619 Søntaguna mujicum III 113 BARYTONUS Durch dib Wort verstehen die Italiäner den Tenor oder Quintum in den tieffen Choren, wenn das )|: vff der dritten Linien gezeichnet befunden wird.

barod 2(dj. 'jonderbar' in 18. Jahrh. aus gleidjbed. iro. baroque cutlehnt und

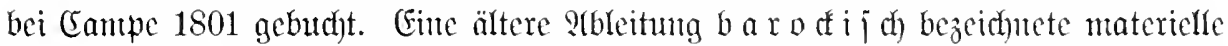

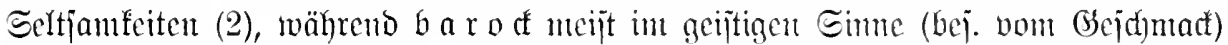

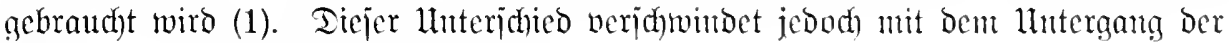
Mbleitung am Ende des 18. Jahrbs.

Belege: 1. [Micolni 1759 Qiteratul=/Verzierungen [eiuer Stirche]. Eenne 1803) briefe III 51 sieh mit der Antwort begnïgen. Epajiergang (II 87) In Imola machte es sey Roceaille, Grotesque, Arabesque. ich einen etwas barocken Einzug - 1813 i la Ċhinoise oder en gout Baroque: kurz- Leben (I 18) meinen eigenen, zuweilen um, es sey so Mode.] Rejewits 1764 Qite $=$ selir barocken Ideengang - (I 30) eine taturbrieje XIX 129 Wenn wird doeh barocke Frage. Lewald 1836; Pquarelle der Geschmack unserer Sehriftsteller ge- I 17 in seinem barocken Anzuge. Füutler setzter und mit sich selbst übereinstimmiger 1840 Birberjaal II 3 anständig, wenn auch werden? Wenn wird er doch aufhören, zuweilen etwas barok, gekleidet.

baroc zu seyn. Gerber 1766 Serfe I 50 2. bar o ffi d): Badhariä 1754 Ber= Dieser, dessen Körper sich mach einem wamolumgen (I 122) der barocksche Schmuck baroquen Geschmack lange Jahre formt: vielfarbger Huscheln - 175t Phaetor hat seiner Seele wahrseheinlich eben diesen (I 314) Ganz im baroksehen Gesehmack Geschmack mitgetheilt. Commenjels 1768 war er [Der wagen] von Künstlern ge-

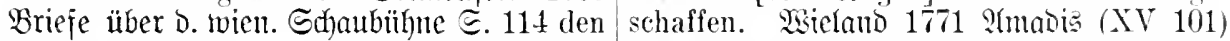
Eigennutz, die Unwissenheit, den Stolz, Barockischer konnte man nichts als Blaffar-

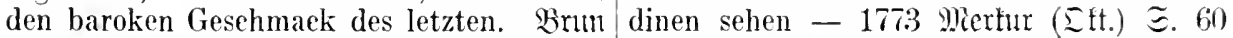
1799 હ(h)riften I 40 barocke gesehmacklose ein barockiseher Einfall.

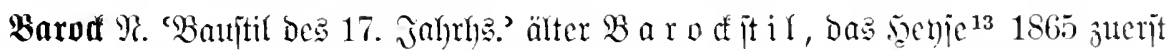

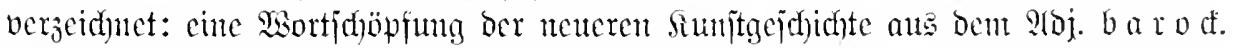

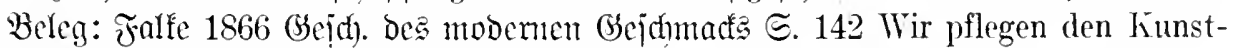
stil, welcher der Renaissance folgte, als den Barock-Stil zu bezeichmen.

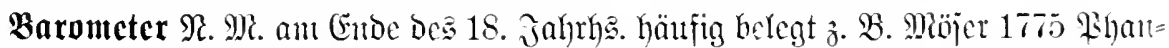
tajien I 40; Dents 1778 Einleitung II 119; Picolai 1779 Berlin S. 412: Dod) 1744

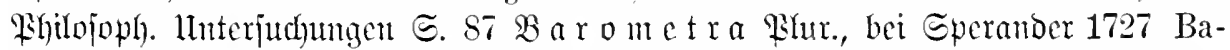

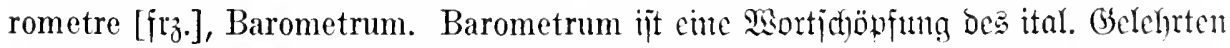
Torricelli, Der das Jujtnment im Jahr 1643 crfand: ciatl. 'Mefjer Der Edywere [se.

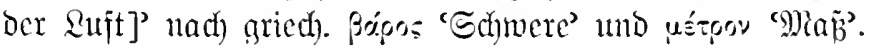

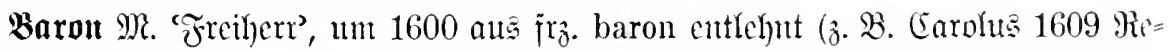

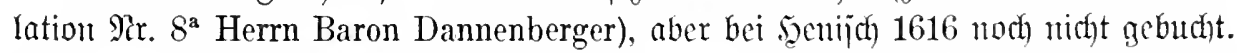

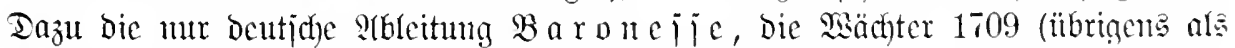

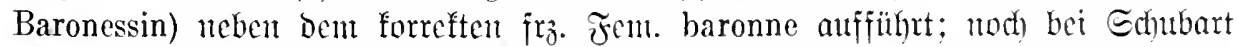

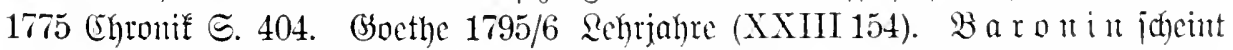

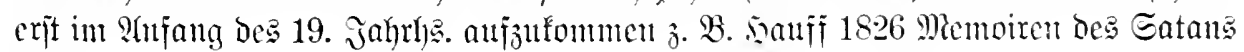
(VII 10).

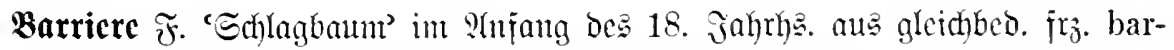
rière entlehnt (1) und wie dics audh ïbertragen gebraudht (2). Iltber $\mathfrak{B}$ a r $r$ ic $\mathfrak{c}$ beim Duell i. unter 3. 
Belegc: 1. Mohr 1718 Etauts̆flugheit/Staaten zu einer barriere, Vormaner, dienen હ. $920 \mathrm{Es}$ wären an vielen Orten hin und können. Piduaeliz 1736 Räjonnement IV wieder, wo auf der Seite der Land-Strassen 434 eine Art von Barriere um die Tugend. precipices sind, barrieren vorzumachen, daß 3. "Barriere: Beim Rifitolenduell die Reisenden zur Tacht-Zeit nicht ein Der Fimft, vou Dem Die Puelfanten gleid) Unglïck nähmen - 1729 Berentoniell= weit entjemt find mo bis auf weldjen jie

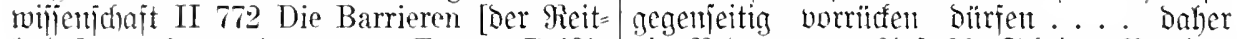
bahit] werden mit grünen Tannen-Reibig Die Rebensart: SUl 20 Edritte Barriere ansgeputzt.

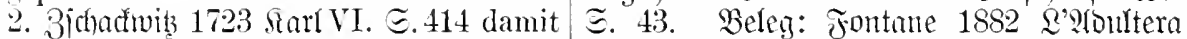
selbige [ङtädte] gedachten Herren General- ङ. 8 Pistolen mnd zehn Schritt Barriere.

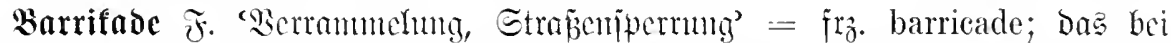

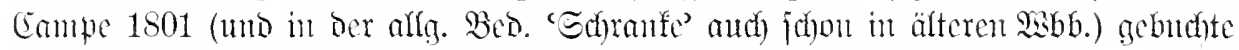

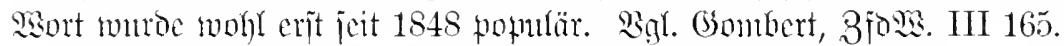

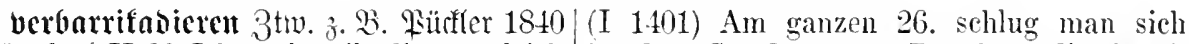
Bifberiaal II 90 Ich verbarrikadirte sogleich in den Straßen von Dresden, die barridie Thïre. Sulter meijt barrifabieren kadirt waren. Ievrient 1835 (Gmujt (I 250) mach $\mathrm{jr}_{3}$. barrieader $\mathfrak{j}$. B. Genț 1813 Brieje Die Thür ist ja röllig barrikadirt.

Bajar Mk. eigtl. der Mame ber orientafijofen Märfte (perj. bāzar): im 19. Jahrh.

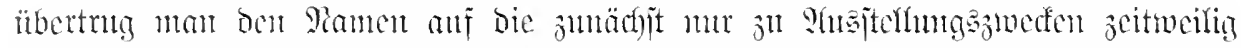

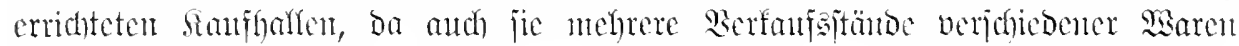

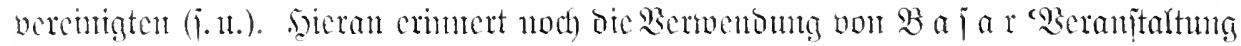

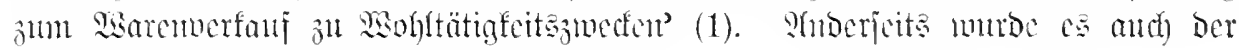
?iante ber nenen sarenhiünjer (2).

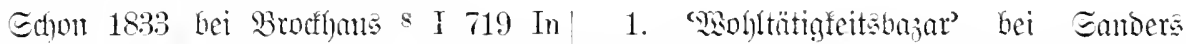
London, Paris, Mïnchen, Leipzig und andern 1871 gebudt. Beleg: joutane 1891 semn)

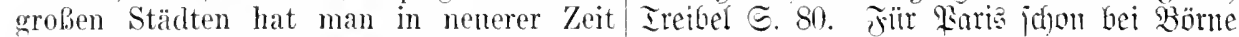
präehtige Bazars eingeriehtet, in denen 1834 Briefe ans Lariz (VI 177) das wäre zu bestimmten Zeiten alle Arten Handels- der Bazar eines Franenvereins, der jeden artikel, vorzïglich Luxnsgegenstände, blü- Winter znm Besten der Armen diese Ware hende Gewächse u. s. w. aufgestellt sind. verfertigte und verkanfte. Engl. baz(a)ar

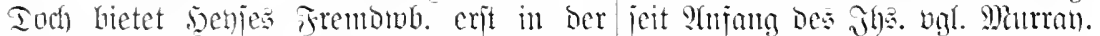

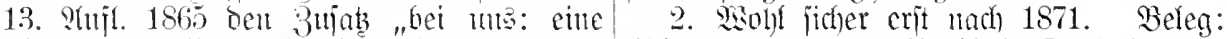

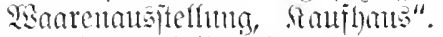

Iie pezielfen serncmoungen jund viel= Fünfzig-Pfemig-Bazaren kaufe ich nicht leid)t vou franz. ențl. bazar beeinflụ̈t: wieder.

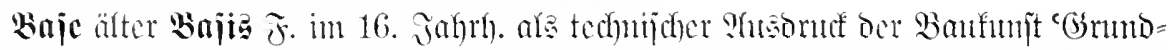

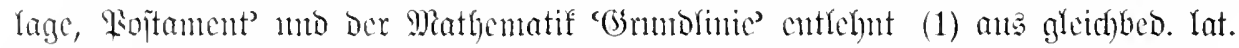

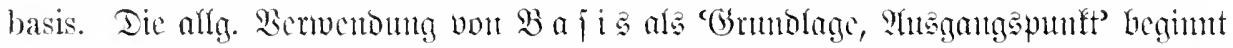

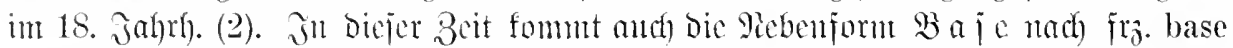
auf in tedunijher (Sulger 1771 Igeorie I xi) und alfgememer Bedeutumg (Ed)ifler 1796 buteje V 121: oft bei (boethe).

Belege: 1. Türer 1525 lntermeijung ber linjschen figuren, die lini, darauff die figuren Rejifung $\Im^{\text {b }}$, die aufrecht lini oben sey stehen vnd ruhen.

das zenit anf dem haubt vund vnden das e. [Der Figuru sey der fues oder basis. Bredtel 1591 Büchlemturiterei $\left(E 5^{\mathrm{a}}\right.$ Mache eine Wissensehaften zur Basis ihrer Briefe gegrundlini, Basis genannt, so lang du wilt, macht. Miiller 1787 Emmeridy III 69 die sey AB. Ednventer 1618 (Beometrie Epefnlationenl die anf die Fitelkeit der I 15 Basis, die srundlini; ist in allen recht- Menschen kalkulirt sind mol den Luxus 


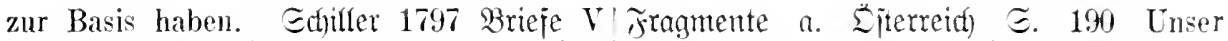
188 aus dieser Erfahrung heraus raisonniert Privat- wie unser öffentliches Leben ist er, uns fehlt größtenteils die ganze Basis gröbtentheils auf Lügen basirt. Füffler seines Urtheils.

bajicren Otw 'uriintoen' ein junges

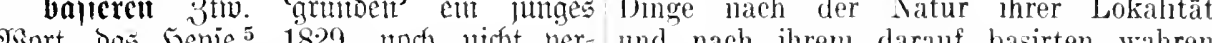
Wort, Das benje ${ }^{5}$ 1829 nod) nicht ver= und nach ihrem darauf basirten wahren

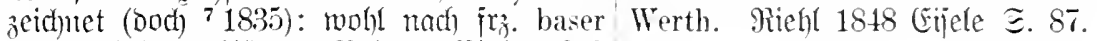

(18. Jahrl.) gebildet. Belege: Rititis 1839

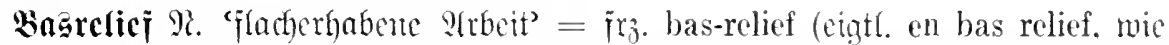
nod) bei Sidfteuberg 1796 sogarth III 34): jeit Dem 17. Jahrh. Gezeugt, aber wohl

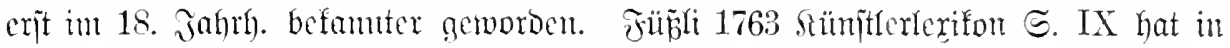

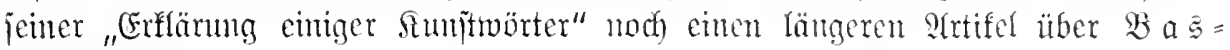
relie $\tilde{j}$.

Belege: Range 1677 (boeree's Mabler=' mit dem französiseben Worte Bas-Relief: funjt હ. 81 auff dem Vorhaupt seiner das ist, wenig crhabene Schnitzarbeit. Bas relief oder niedrig erhabenen Mar- nennt. Mener 1798 Edhriften $\Xi .13$ in dem

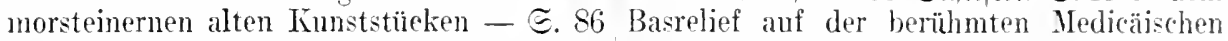
Etiicke] welche ins gemein Bas-Relief oder Vase. Echlegel 1801/2 Derlejutgen ङ. 138 halbe Rundten genennet werden, weil sie llle in der Luft flatternden und überniedrig erhoben und nur halb aus dem haupt bauschigen Gewänder sind daher Grunde auBgehauen sind. Rohr $17293 e$ an freystehenden Statnen fehlerhaft, auf remoniellwijienjdhat II 87 maneherley Sta- Basreliefs ist es sehon etwas anders. Eemme tuen und Basso [!] reliefs. Eulzer 1771 1803 Epaziergang (III 149) Die schünsten Theorie D. jhünen Sïnịte I $388^{3}$ die Ar- Basreliefs sind noch in Rom.

beiten bildender Kïnste, die man inscemein

Baij M. 'ticfinte Etimme' in 15. Jahth. aus ital. basso entfebut. Beleg: 1512

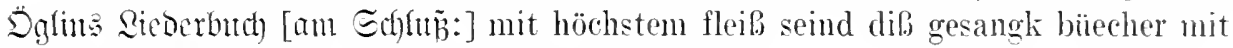
Tenor. Discant, Bass vnd Alt Cor[ri]giert worden.

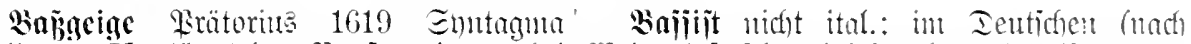

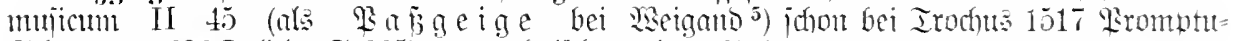

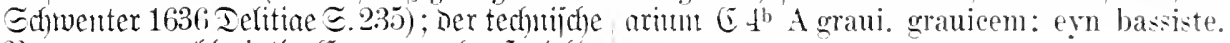

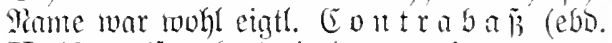

II 46) entiprechenio ital. contrabasso.

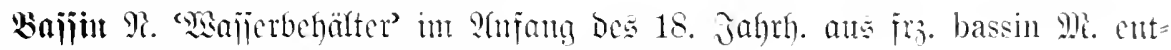
Yehut, aber in Den Frentombb. nor Camte 1801 fehlento.

Belege: Iecfer 1711 ₹̈üritl. Baumeriter' mehrere geräumige Bassins. Echlegel $1801 / 2$ I $\mathfrak{U}^{3} \mathrm{An}$ die vier Ecken der Seiten-Flügel Borlejutgen I 208 Die Bassins mit ruhigem kämen Bassins, mit verschiedenen Statuen klaren Wasser angefüllt sind die Spiegel von Flüssen. Mohr 1729 Berentonelltwijen= dieser offnen Gartenzimmer. Eeume 181:? ichajt II s7 Bey den Grotten sind schöne Epaziergang (III 62) Das Bassin am EinCascaden, welche das Wasser in die Bassins, range, von einem einzigen Stücke gearbeitet.

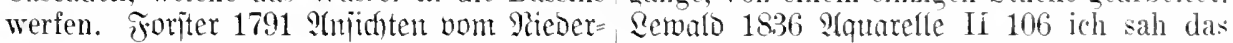
rhein (III 258) In den Hafen öfnen sich Bassin der Alster mit Holzkähnen bedeckt.

bajta in Der Formel ba m it ba it a in ber Bolfsiprache allgemein: Belege: Pormam 1833 D̈iterreid) I 1 ङ.60. Iebrient 1837 Berirmugen (II 88). Q̈lter ein fad)es b a it a! abbredfento 'genug' $\mathfrak{3}$. B. Ettner 1697 Chnnicus $\Xi .197$ Pasta! sprach der von Erden, er sey wo er wolle. Chilemont 1705 striegstat II 144 Basta! wir stehen dem verderblichen Untergang sehr nahe. Sotgebue 1797 Faljde ङd)ant (VI 255) Basta, Herr Vicomte! sonst schicken wir sie nach Hannover. Euclle: ital. basta 'es jei geung!? 


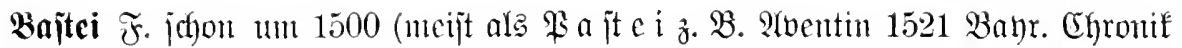
[I 436]) geläufig, Dodf jofon in 15. Jahrh. ala bastîe bezengt. Suelfe: mlat. bastia.

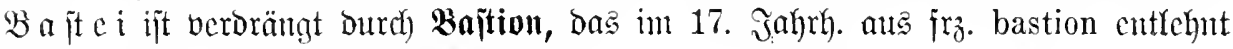

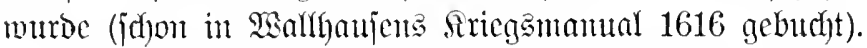

Bajtontade $\mathfrak{F}$. hent nur nod) als Rame der im Drient gebräud)lichen Strafe

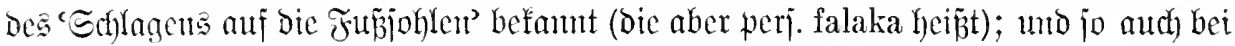

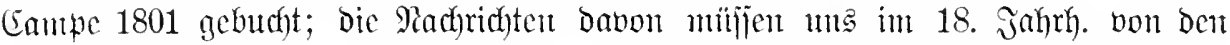
Romanen vermittelt worben jein, bie bie orientalija) Strafe mit einem einheimija)en Mort (ital. bastonata, ipan. bastonada) bezeicfuctert.

Jital. bastonata beo. eigtl. 'Etočfiflag'| Epeltan's Marrheit II 48 so viel Streich,

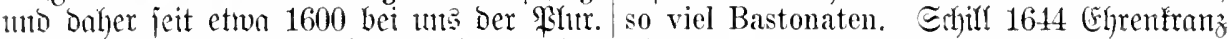

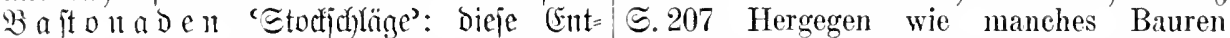

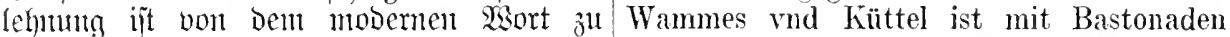

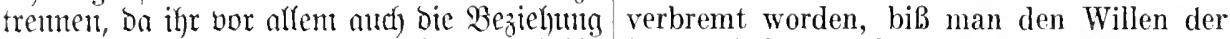

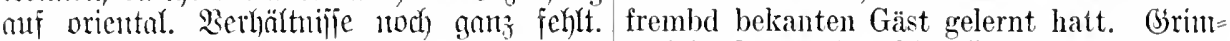
Belege: Entolus 1609 Relation Mir. $9^{\mathrm{b}}$ da- mershauien 1669 Eimplic. S. 85 Solches selbsten hat des Duca di Vienna Sohn einem waren die erste Pastonaden, die jch kriegte. Parisischen Edelmann Pastonato [ï̈r: basto- 1702 Gurop. Famn nate?] geben lassen. Mejieridumio 1619 Personen einander mit Bastonaden tractiren.

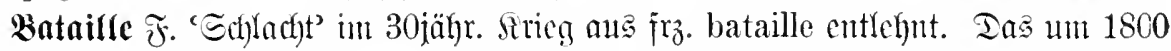

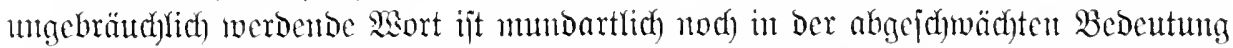

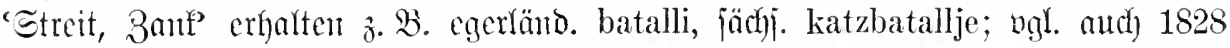

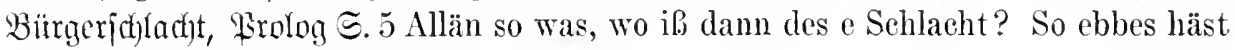
mer jo bey uns [ร̛ranffurt a. M. B Badalje.

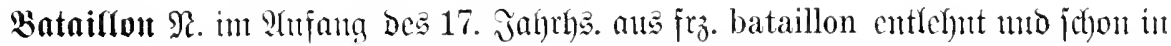

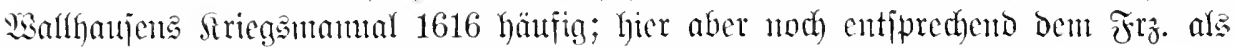

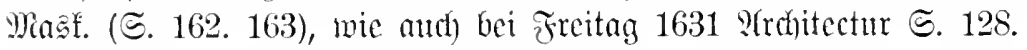

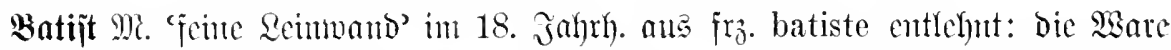

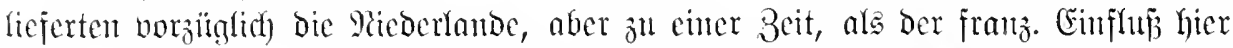
jchon übermächtig war (hingegen beruht bie ältere Benemunng Kammertuch (16. Sho.) anf Dem Ramen ber Etabt Kamerijk nodh vor Der Franž̈jienung in Cambray).

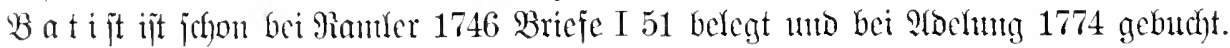

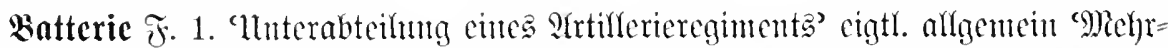

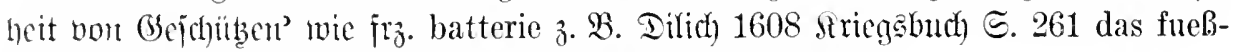
rolck des lincken flügels sampt seiner baterye und renterey.

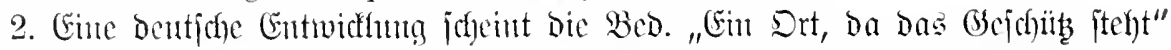

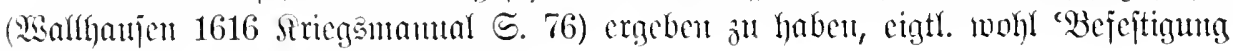

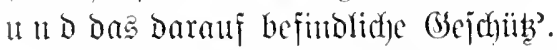

Betege: Iilich 1608 strieggbuth) S. 98 jage, als eine naeh und gewaltsame Batteria. ein stadt zum beschiessen almmessen, Baterey 1634 litberlitger $\mathfrak{B}$ elngertutg S. 6 Schantzen

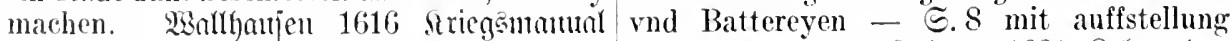
$\Xi .76$ so muß man schen, die Pasthey newer Baterien. Srönter 1681 Reben Der einzunehmen, das Geschïtz darauff stellen, Eeeherben S. 220 ein hohes Werck, so sie vnnd eine neuwe vnd stärekere Batterie Cavalliere [ $\mathrm{fr}_{\mathfrak{j}}$. eavalier], wir aber Batterie in soleher nähe anfangen. Dan es ist niehts, nemnen.

dab den Belïgerten grössern Schrecken ein- 


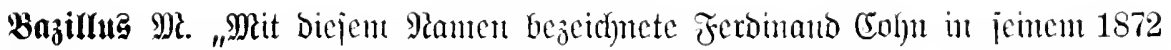
aufgejterften Enftem Der Bafterien [Muteriud)untgen I] cine ju ben 'Faben= bafterien’ gehörige Bałteriengattung" 1894 Rcal=Enchclopäbie D. gcj. Şciffuntoc II

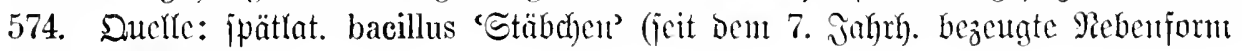
zu Yat. bacillum).

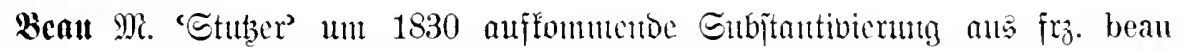

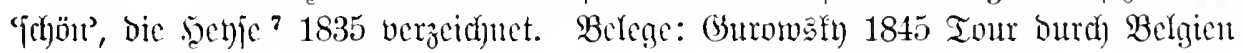
5. 31 Noch jetzt maeht der Herzog, der gar nicht mehr jung ist, den Beau bei dem schönen Geschlechte. E(herr 1862 Bhütcher I 186 Zuerst ein Beau von damals und dann eine Belle. Fontane 1886 Bricfe II 138 Das Tollste, was es gibt, ist ein Beau.

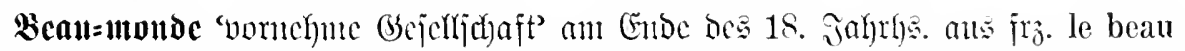

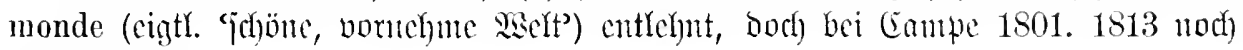
nicht gebutcht.

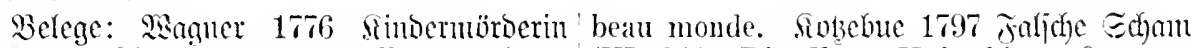
ธ. 6 wemn hier nicht täglich alles, was beau (VI 244) Die Frau Hofräthin saben um monde heißt, zusammenkommt. מoerme? Mitternacht in einem Zirkel von beau monde.

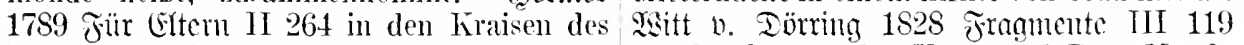
Beau-moude [?:nn.:] d. i. höherer Bürger- wo Basels und der Umgegend Beau-Honde stand und noch weiter hinauf vom Kauf- versammelt war. Piücfler 1831 Briefe III 388 mann an. (Gedide 1789 Éfuulfidriften I 291 In diesem Hause sieht man nur beau monde. die Assembleen und Cercles des römischen

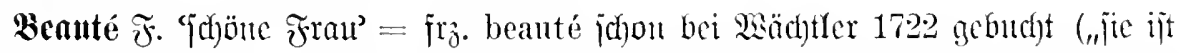
cine rechte Beante"). Belege: Michachis 1776 Räjomenent IV 492 so kann man ja doch auf der Universität diese Gefahr nieht ganz vermeiden, so lange man kein Gesetz hat, das jede Beaute, wenigstens jede intriguante, gern Geschenke nehmende

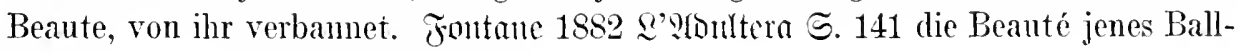
abends - 1891 Jemur Ireibel $\subseteq .195$.

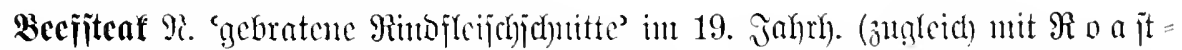

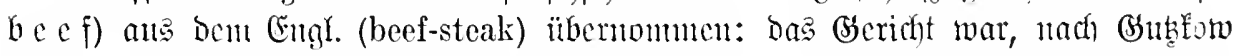
XII 44, un 1830 "nod) cine Reuerung für Berlin". Belege: Brocthe 1830 (1811) SGutaYen $(36,71)$ Daß seine Köehin die trefflichen Beefsteaks zu bereiten wußte.

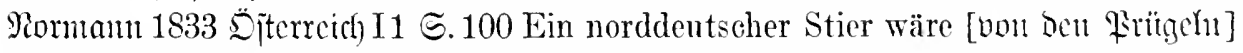
ein Befsteak geworden. Fontante 1897 Stedflin S. 335 Alles fast noch blutig, besonders das, was wir hier ,englische Beefsteaks" nennen. - $\mathfrak{B g}_{\mathrm{gl}} \mathrm{l}$ wed $\mathfrak{I} \mathfrak{a} \mathfrak{r}=$

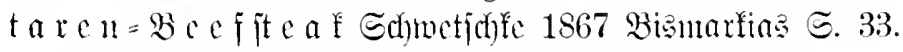

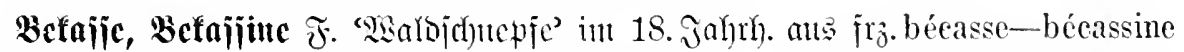

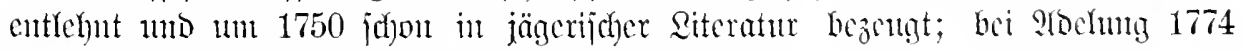

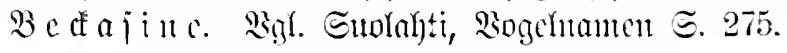

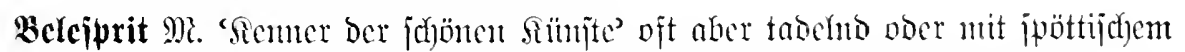

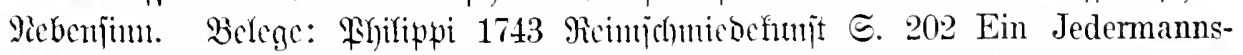
Tadler muß ein sehr grofer bel-Esprit seçn. Sejjün 1756 Bricfe (XVII69) mit was

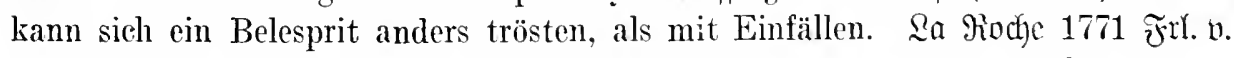
Sternheim S. 119 den Eindruek, den der fade bel-esprit auf ihn machen mußte. 
Miiffler 1789 (Emmterid) VII 95 Was gern für Belesprit gelten wollte, drängte sioh sogar den Sclranspielern auf. Dncfle: fro . un bel esprit, für bas intocs früh bie litber= jebung Schöngeist ïblicher murbe.

Beletage F. " criter Stoc": „Premier Etage voer Beletage nemuen. bie Frantbojen

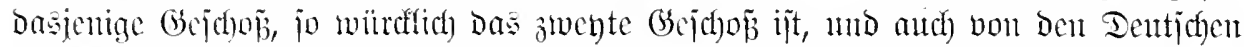

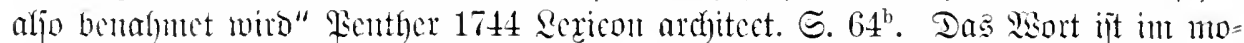

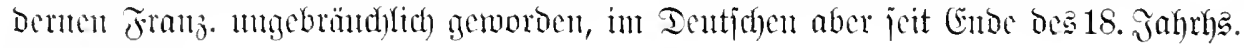
joht häıเfig.

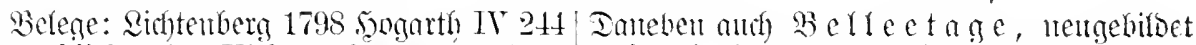
vermuthlich ein Hieb anf andere Zier- entiprechents Dent fentin. Gétrauch bout

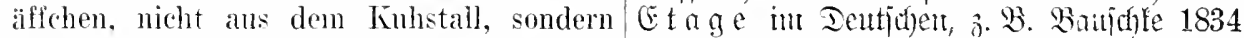
aus der bel-étage des Hauses sellst. Sanifi Bitber $\Subset$. 81 die Reichen in der belle étage.

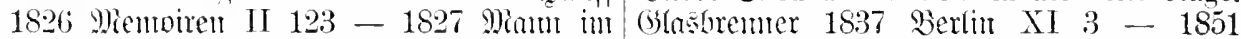

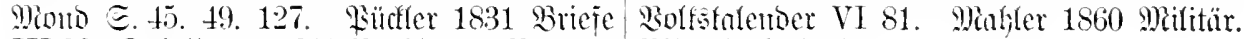

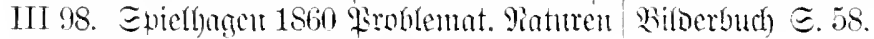

VIII 84. Foutmue 1897 Eted flin હ. 38. -

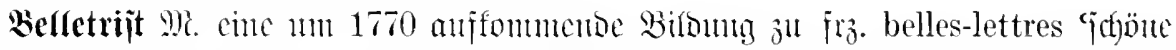

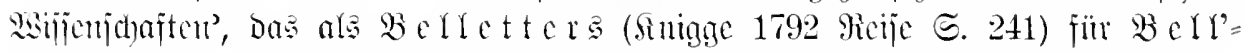

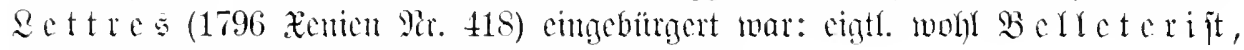
wie nod) bei Timme 1785 smitbanmeifter I 194.

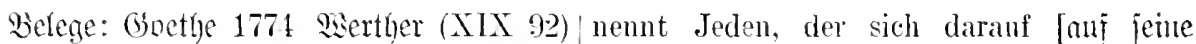
doch an griundlicher Gelehrsamkeit mangle sistijerijd)nft] nicht gelegt hat, verächtlicheres ihm, wie allen Belletristen. Edyufart weise einen Belletristen. Mïlfer 1789

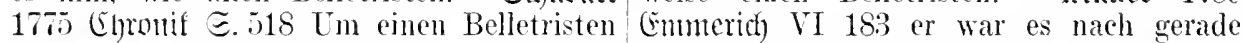
ists gar ein tänschend Ding .... Alles in eben so gewohnt, als wäre er ein großer der Welt. nur keinen Belletristen zin einem Belletrist gewesen, von seinem Geschleeht Lehrer gemalcht. Das sind Geschöpfehen beneidet und von den Weibern fetirt zu zmun Vergniigen nud nicht zum Nutzen. werden.

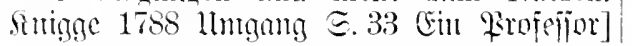

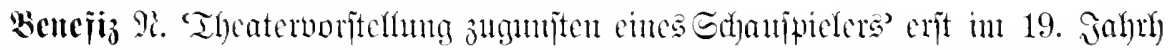

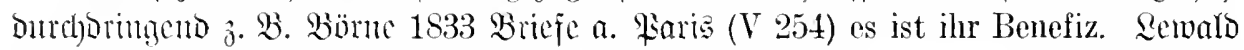

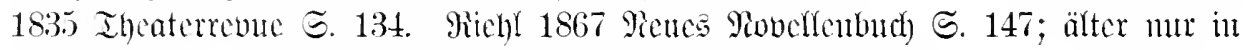

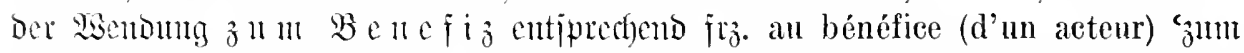
Sortcil': Mozart 1787 bricfe $\subseteq$. 266 Gestern wurde sie zum viertennal (und zwar zu meinem Benefiz) anfgefülnt. Riehl 1867 Mienes Poveffenbuch S. 137 er kïndigte Egmont an zum Benefiz für Fräulein Sylvia. F̈̈̈r 'Buncfiz' aber svaren meijt Bujanmenjeţungen ïblid):

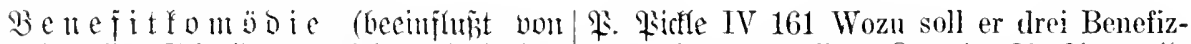

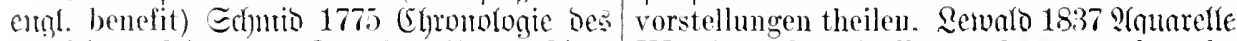

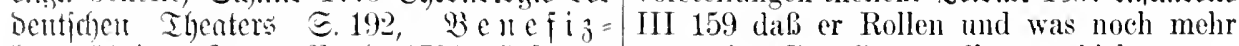

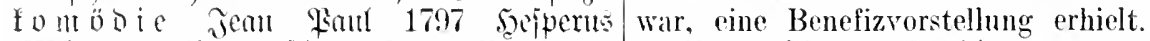

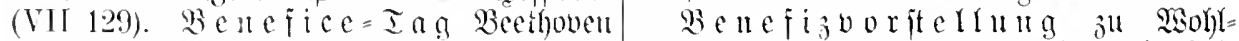

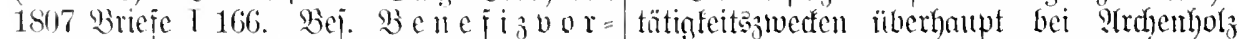
fi e f

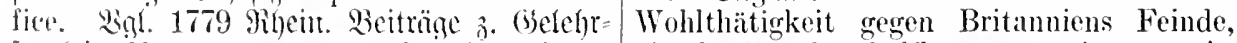
fantfeit it 231 anderswo sind in solchen dle als Menschen hülflos waren, ging so weit, Fïllen die so genannten Benefiz-Vorstellungen dia selbst die Unternehmer der Schauspiele zur Betolmung : inserordentlicher Taulente Benefiz-Vorstellungen zu diesem Behuf gaben. erdacht worden. Minfius 1785 Entolfets 


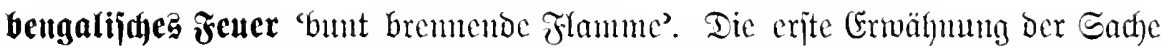

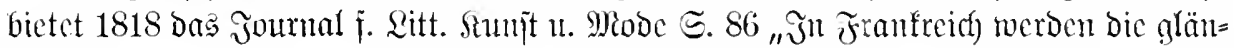
zenton Richter, weldye man bei Fenerwerfen antwendet, Bengalis gename". Tod)

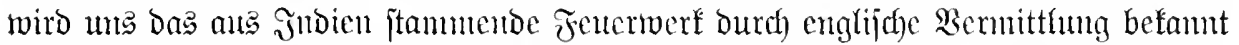

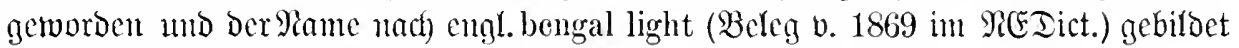
feim. 2(uch Der frülyjte beutjche Beleg legt engl. Uriprung nahe.

Belege: Retwalb 1837 Stquarelle IV 212 blanes nnd rothes Feuerchen vorgemacht. Er hatte nemlieh die nummehr so alltïglich (B́lasfrentuer 1846 "1845" im Berliner (Sindf" rothe bengalisehe Flamme zum erstenmal tnịten $\subseteq .34$ Hür, meine Herrschaften, prae[1828] von dem englischen Pantomimiker sentiert sich lhnen das Wort Vorwärts in Lewin in Wien anwenden sehen. 1839 Dic benjalisches Fener. Epielfagen 1866 in

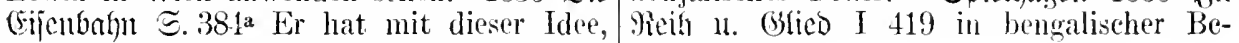
die er durchführen wollte, seinen Verehrer- leuchtung.

massen, ein reeht hübsches bengalisches

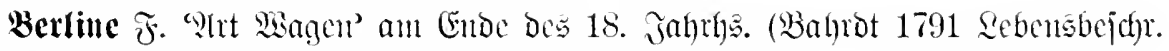

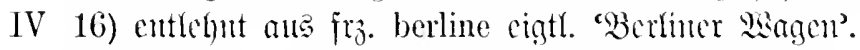

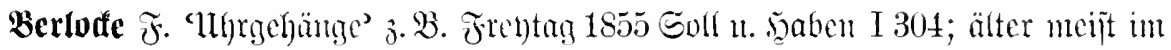

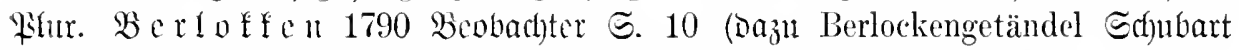

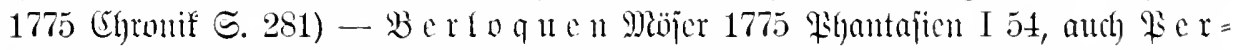

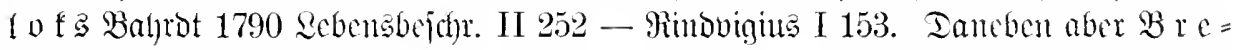

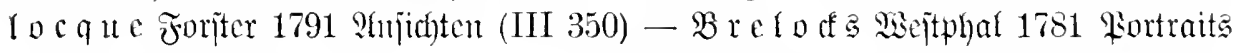

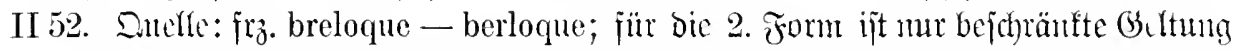

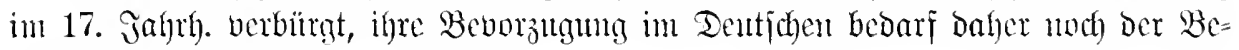
grïtmbint?.

Bibi M. als 'Bilmocr' bci Stmoe 1886 Fam. Budfhyol III 16 fïr Berlin, gleich=

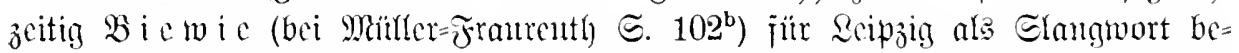

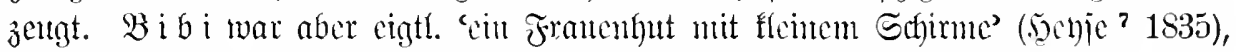
wie jie um 1830 auffamen: 1831 Gfegante 2 Sult für Damen $9 \mathfrak{i r} .23^{b}$ Die Hüte, welche wir schon früher unter dem Namen Bibis bekannt gemacht haben, werden immer zahlreicher. Bgl. auch Piüffler 1810 Bildocraal II 416 eine Art Spitzhut, den Pipi's nicht unähnlich - [Y(um.] Kleine Hüte der Damen, die wahrscheinlich damals Mode waren. Die serfunft des jedenfalls undeutichen sisortes ijt ounfer.

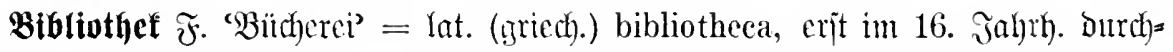

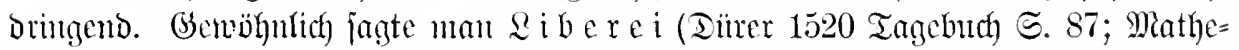

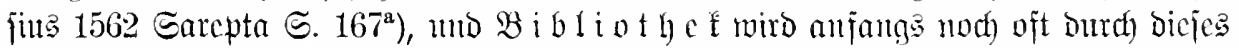
93ort crläutert bgl. 1558 secibelberg. Statuten $\subseteq$. 34 nit eins ieden vermogen, ein eigene bibliotheckh oder librari fur sich selber zu zeugen. Lauterbed 1559 Rigentent= buch $\subseteq$. $52^{a}$ Bibliothecken oder Libereyen einzurichten. Raja 1590 Pieu Salcnder E $2^{\mathrm{a}}$ in der alten groben Libreyen oder bibliothec. Früher Bileg: Carion 1532 (Sh)ronica $\subseteq$. $139^{2}$ der hat die Römische rechtbücher jnn Bibliotheken gefunden vnnd widder an das liecht bracht.

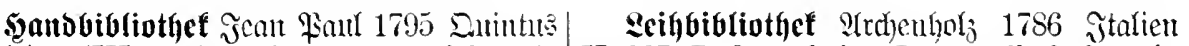
Firlein (III 125) seine ganze falrende II 237 Dab es keine Lesegesellsehaften in Habe - nicht etwan seine Handbibliothek, Italien giebt, die meines Wissens nur Dentschsondern seine ganze Bibliothek.

land allein eigen sind, jst nicht zul ver- 
wundern; daß aber das anfgeklärteste Volk der Erde keine Leihebibliotheken hat, die bey andern, nach Herm Jagemanns Maasstabe minder aufgeklärten Völkern, den Engländern, den Franzosen, den Deutschen, den Holländern, Schweden und Dänen im Gebrauche sind, dürfte billig befremden. Dajür anfanga and 2 ejebibliotlef: Gontbert, 3fors. II 261.

Etnotbibliotfet Edhubart 1775 Ientiche Crrutif $\Xi .219$.

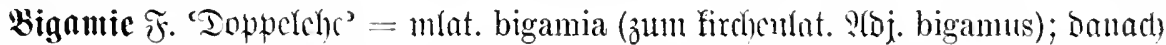
jd)on im 16. Jahnh. B i g a tiren u. Fasquilfe III 189) Das verwundert mich nit minder, daß auch die veter die bigami so groß geachtet haben. Jm 18. Jahrf). (jeit Epcrantor 1727) $\mathfrak{B}$ i g a m ic

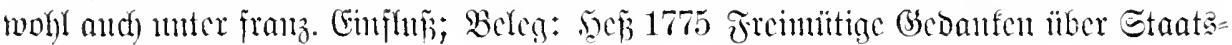
jachen ङ. 421 .

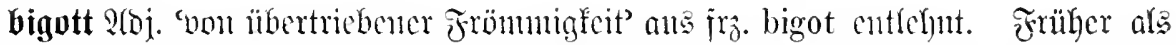

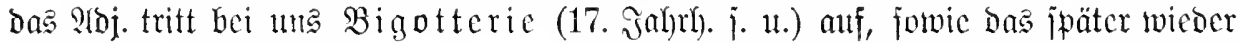

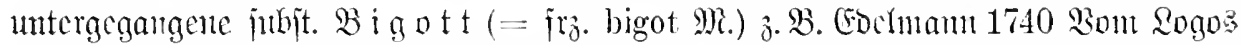
ङ. 236 halten sie vor aberglämbische Bigotten — Mojcs I 28 den Layen und andern Bigotten - 1746 (blaubersbefemutis હ. 179; Dod) aud) Edubart 1788 Bricje II 260

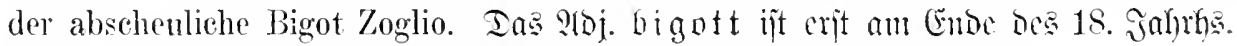
bäufiger belegt, aber fdon bei :(belumg 1774, Scennab 1775 gebudt.

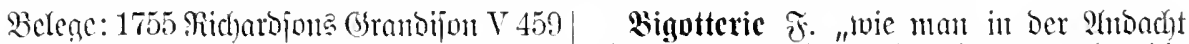

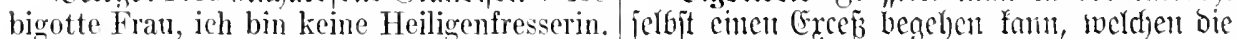
Eefilller 1781 Rüuber II 3 Mir ist bang für Jranzojen bigotterie neutmen" 1708 Reopolo die Stalt. Er hat schon lang eine Pique Der (Grof̉e 199 . Toch als Edhlagmort Der auf sie, weil sie so schändlich bigott ist. "Etanoesperionen" ja)ont bei Eecteriborfi 1685 Timme 1785 Quftbanmeiñter I 470 ein Cryriftenjtont I 24 der Gottesfurcht, oder, bigotter Mönch - 473 alle bigotten Mönche. wie sie es nennen, dem Aberglauben, der

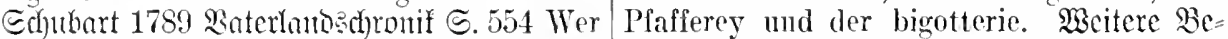
predigt doch den bigotten Kölnern einmal lege: Ravater 1775 Phiffiognum. Fraquente Verträglichkeit. Goethe 1796 Brieje a. D. I 102. 210. Jacohi 1780 Bitiefwed) fel I 302. ङdyueis (XIX 299) mit dem Ton ciner Edmbart 1789 Siaterlandostyronif E.570. bigotten Belehrungssucht.

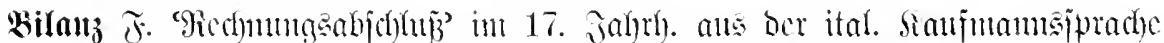

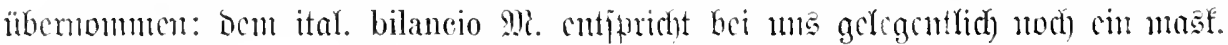

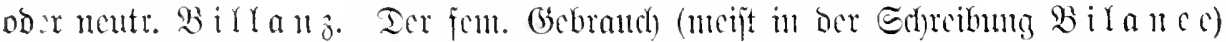

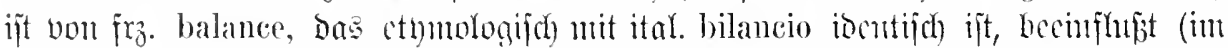

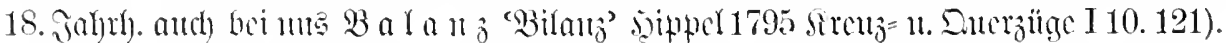

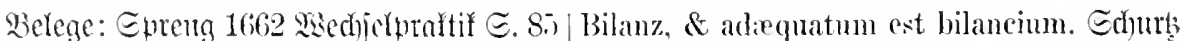

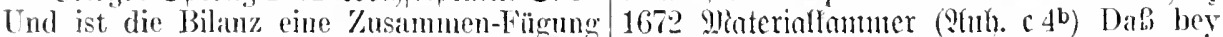
aller Partiten so wol in credito als in debito, Schliessung der Alten und Anfang der Nenen darinn alle tratte und remisse gesetzt werden. Bücher es allezeit sein verbleiben hat, wie Seynd mehr tratte als remisse, so ist ein der letzte Billanz besaget, und werden alle Mancannent, sevnd aber mehr remisse als Debitores und Creditores nach dem Billanz. tratte, so ist is cin avanzo, welchen fals in die nenen Bücler transportirt - wird das 1!] Bilan\% bilanzirt: Seynd aber die auf das Nene, umb der nenen Charta willen, tratte und remisse gleich, so bilanzirt das/ wider ein Billanz gezogen. Sfbele 1675 


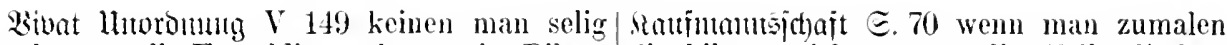
rïhmen soll, Er schliesse dann sein Bilanz die bilance ziehct gegen die Holländischen wohl. Dalfover 1687 Gartenbeetlein I 227b Stoffe. Qumaranthes 1710 Proben $~ § .356$ daraub macht man die Conto oder Rech- I)ie Rechnung ward gemacht und die Bilance nung, bilancien vid Schluß-Rechnung. Ettuer geschlossen. Marperger 1717 Bejar. Der 1697 Doftor $\Xi .882$ che eimmahl noch die Sauten

seringste bilance gezogen worden. 1702 .

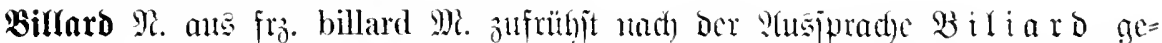
fdricben z. B. Ficander 1726 Sdampiele $\Xi .54$ hernach auf das Caffee-Haub und

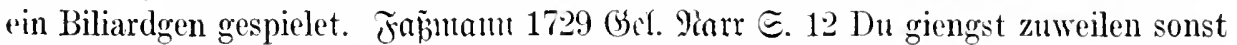
noch anf das Biliard. Ias Epiel war bei ms jofon im 16. 17. Iahrh. befanmt, hatte nber beutjac Ramen bgl. Tues 1663 Yomenflatura $\Xi .183$ joner an billard: auf der trucktaffel oder bilckentaffel spiclen.

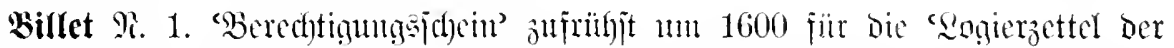
Eoldonten' ans fra. billet (de logement) entlebut, wofür aber nod bei Dilich 1608

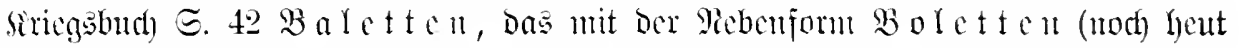

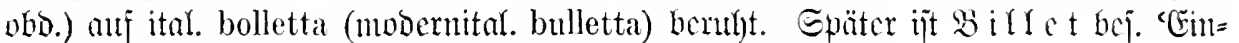

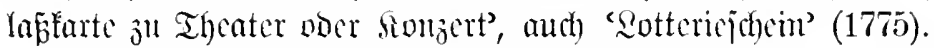

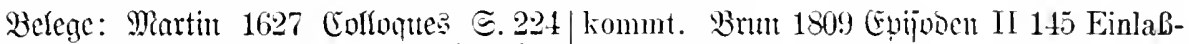
les etiquettes des Soldats logez par fourrier, billets.

der Soldaten Billet, darauff ihres Losaments Freibillet Srotzebte 1806 Earolus (XX Nam stehet. Bjoldafwits 1723 Siart VI. 275) Eine allgemeine Gewohnheit in Deutschङ. 524 wo hinein niemand ohne ein von land. Man pflegt einige Lente mit Freiseiner Gesandschafft vorhabendes Billet kanı. billets unter das Publikum zu mischen, Miöjer 1775 Phontajien I 166 ["Gedanfen rlamit sie zu rechter Zeit schreien. Sicnter ïber Die vielen Rotterien"] Gewiß Sie werden 1811 Reijejd)atten $\Xi .220$. Rormm 1833

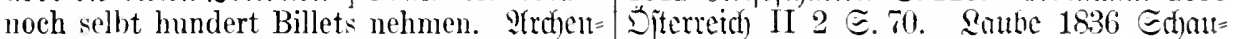
holz 1787 Englano I 74 Hunderte von Zu- ipielerin 5.66.

schauern bezahlten ihre Billets mit Gold. Hetwurbilfet Exhelfagen 1866 in Reih

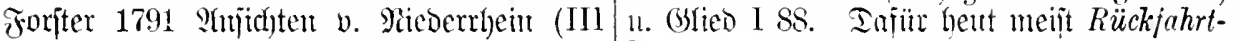
331) wo niemand Zutritt haben kann, der kiarte.

nieht von den Theilnehmern Billets be-

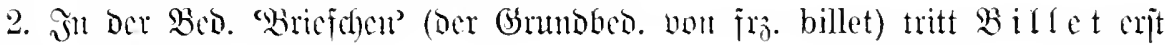
umi 1700 auf.

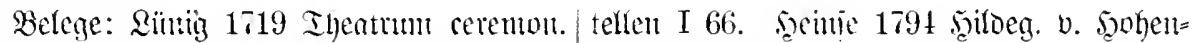
I 783a wenn der Printz nur durch ein Billet thol (VI 77).

oder Briefgen ihn den Gesandten zum Be- Billet=bour $=f i_{x}$. nu billet doux '

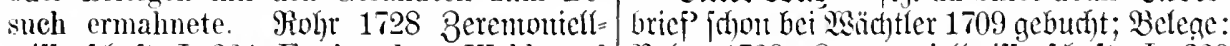

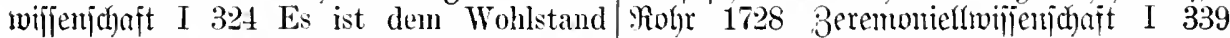
zuwider, wemn sich der Geringere untersteht, cliese Künsteleyen oder vielmehr Tändeleyen an den Höhern ein bloß Billet oder zu- schicken sich eher, wenn man seiner Lisimene geknüpfftes Briefgen zn uberschicken. Gellert ein billet doux überschicket. Göfingf 1780

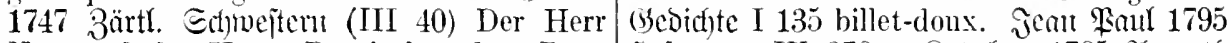
Vormund des Herm Damis hat dem Papa Soiperus (IX 378). Sivtebue 1795 YIrmuth in einem Billette gemeldet. ¿a Rodje 1771 (V 27) - 1802 wirrwart (XY 191). Frl. v. Etertheim E. 23. Wafl 1786 Baga=1

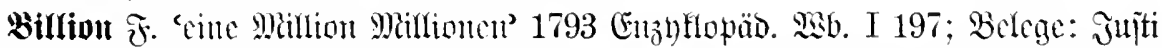
1769 Erzeugumg dcs Mkenjaden E. 10 Billionen Menschen. Jean Paul 1793 Un=

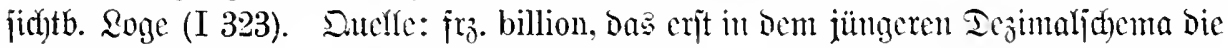
heutige (Scltumg als 'taujend Mirfinnen' erlangt bat (ñabfeld= Tarmejteter I $237^{2}$ ). 


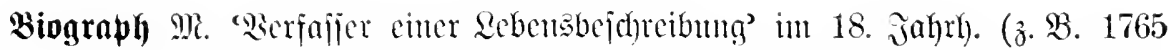

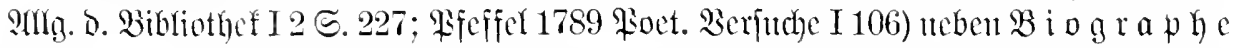
(24bbt 1763 Siteraturbriefe X 211) weift auf jrz. biographe als Suelle lin. Dazu

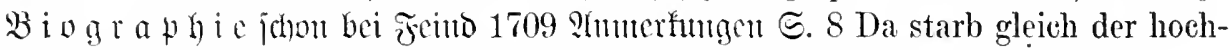
verdiente Theologus Winckler, und Feind, da er seine Biographie heransgab. . . .

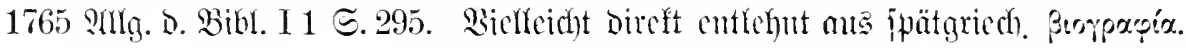

Sigl. 1wod) Yroelung 1790 lleber ben oder wenger sagt, als der gute Dentsche Teutfichen EtnI II $^{3}$ if Sehr unselicklick Ausdruck; noeh unschicklicher und willist es, daß man die Lebensbeschreibungen lührlicher aber ist der Untersehied, welchen scit einiger Zeit lieber mit einem anslëndi- manche zwischen bevden machen wollen, schen Worte Biographien nemen will. wozu weder in der Sache selbst, noch in den da doch dieses nicht das geringste mehr Nahmen der geringste Grund vorhanden ist.

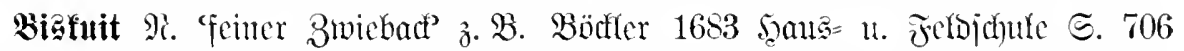
gutes Pasteten-Becker-Brod, so man Biscuit nemnet. Ettner 1697 Ioftor S. 647 ließ er dureh Andreas Biscuiten und Frontiniac ['Migfatwein'] holen. Sîtter für

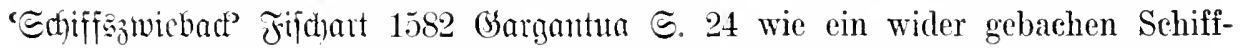
brot vnd Biseuyt. Mejicrianto 1615 Epelta's Sarrheit II 212 keine Bolwölckehen, Brettstellen ['Birzecyn'] wnd Zuekerbrot, sondern grobe rauwe rnd harte pisquit. E.uctle: fro. biscuit in beiden Bobentungen.

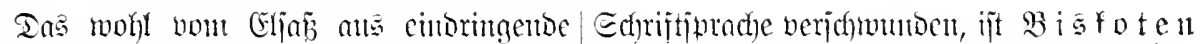

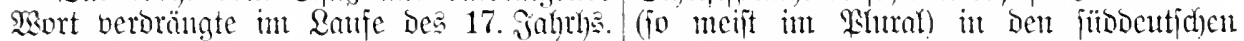

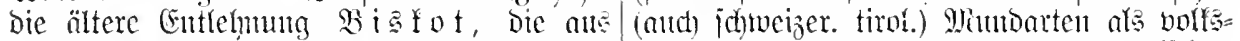
ital. biscotto ftammit. Tabennaemontanus tï̈nliche Fom erhalten geblieben (Fijher,

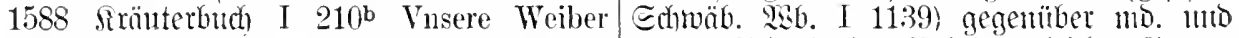

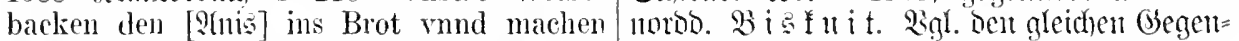
das Zuckerbrodt, Biscot genandt darmit. fotz bon jitos. (= itnl.) zall norob. (= fro.)

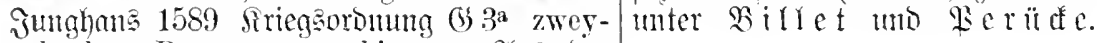
gebacken Brot, genant biscot. Sug ber

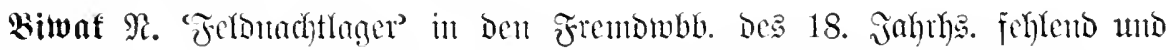
erit bei Compe 1801 (als bivouac) gebudt: aus gheichbed. frós. bivouac.

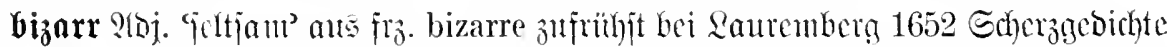

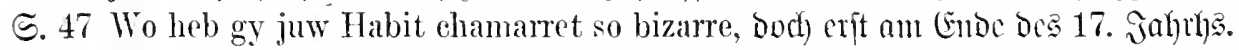

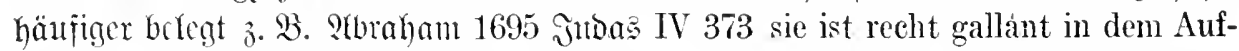
zug, sie gelret recht sauber, alles ist Bizarr an ihr. Thumajus 1696 Sittenthere S. 455. Sultran 1700 Entadfalber $\subseteq .12$ bizarres Wesen. 1719 Recucil IX 58 in den bizarren

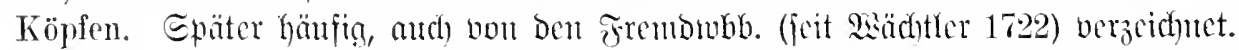

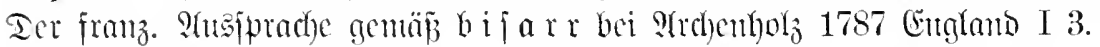

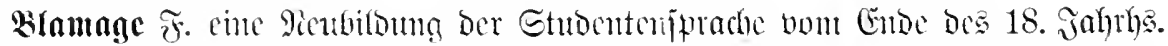

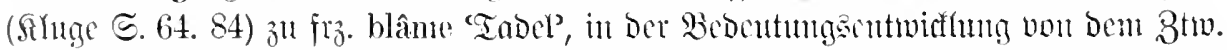

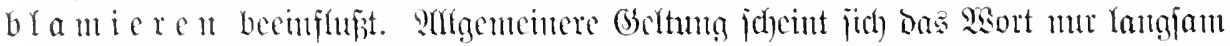

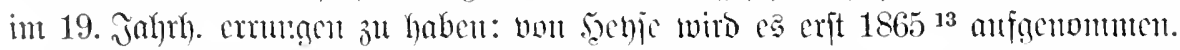

Belege: Scine 1830 gtalien (III 262)| was hast Du damn von der Blamage. Scoff=

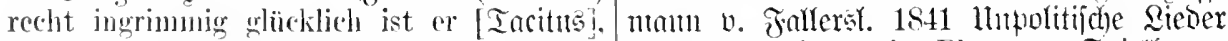
wenn er irgend eine senatorische Blamage. II 133 Doch ist es eine Blamage. Evielhagen etwa ejne verfehlte Schmeichelei zu erzählen 1866 in geih u. Gítico II 427 . Fontane hat. Tevrient 1833 Serimmagen (II 26) 1886 Brieje II 143. 


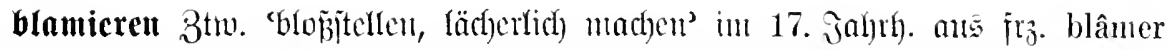

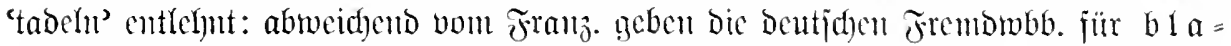

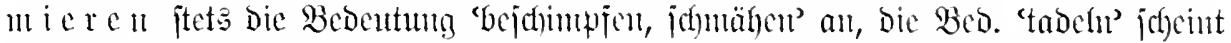

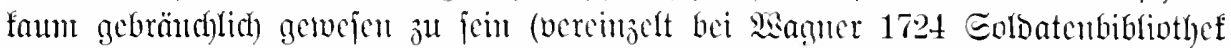

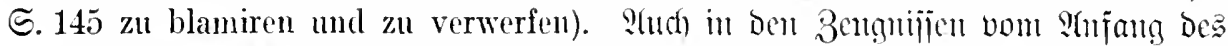

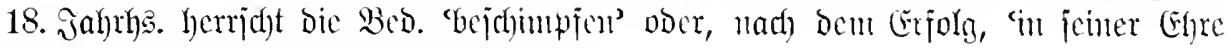

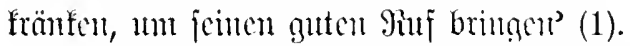

Der moderne Sprad)gebranth) (2) zeigt mur cine geringïingige Berjejicbung, indom

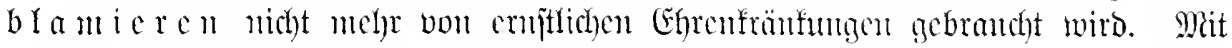

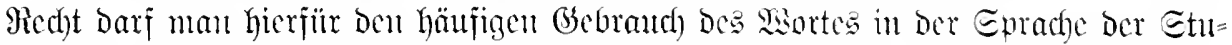

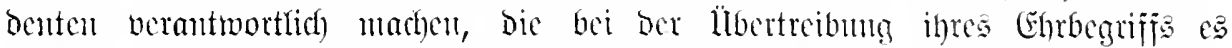

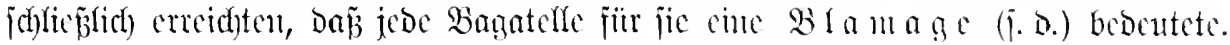

Belege: 1. Tharanthes 1710 Proben Der Poepie ज. 418 wer vor der Welt nicht will blamiret seyn, Der lasse sich mur nicht mit solchen bösen Frauen und alten Hexen ein. Melijitus 1715 Fleurie $\subseteq .31$ Wollet ihr aber das Letzte erwehlen, so wißet, daß ich dahin trachten werde, ench mehr zu blamiren, als eure Ehre zu erhalten. (Sallenbad) 1715 こuaji $\Xi .82$ es ist nicht umb den Todten, sondern umb mich zu thun, ich werde blamirt.

2. Bectjeteit 1832 Povellen I 217 Blamirt bin ich! Das fehlt mir noch. Chomnit3 1845 \&anf ber 2 selt II 170 er kann es nicht ertragen, vor Käthen so blamirt zu erscheinen. Mialler 1860 Biberbuch $\Subset .54$ mit der gewissen Aussicht, drei Mimuten später der blamirte Mann zu sein.

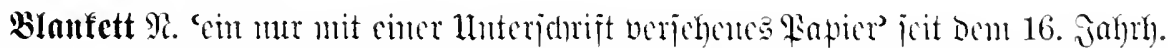

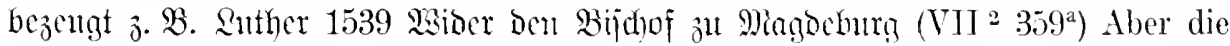
Blancketen oder so Hans Schenitz einen Brieff hette, sollen nichts gelten - Daju Dic Ranbuntc: Blancketen sind blos papir mit eigner hand vind Pitschafft verzeichnet, darin man sehreiben mag, was man wil. Mathcjuts 1562 Earnta Є. $146^{\mathrm{a}}$; früh)

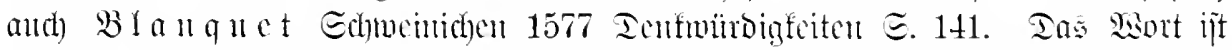

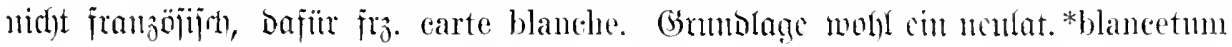
Der Siangleijprache (ju beutich blamk).

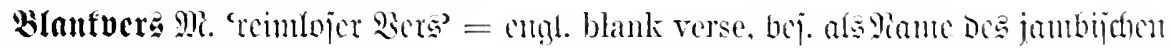
Pentametcrs im 18. Jahrl). ans Dex cugl. Tramatif (junal Ehafcipcare) bofamt

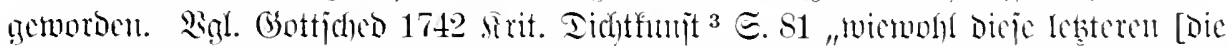

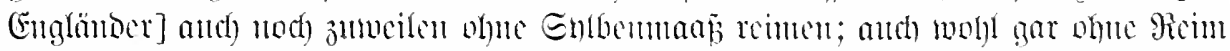

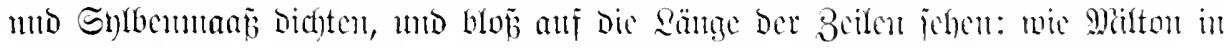
jeincm Paradise lost gethan Gat; weld) ?(rt Der Nerje jic blank Verses nemen" -

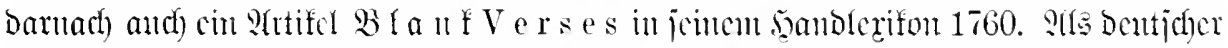

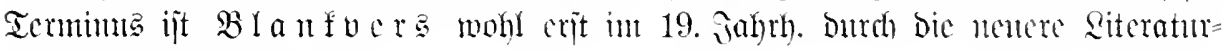
mijjenjejaijt eingebürgert. 


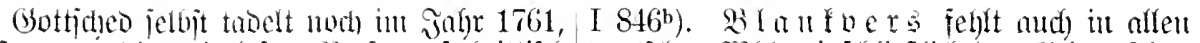
Daj man "Die reintojen Berje auf brittijh Deutichen

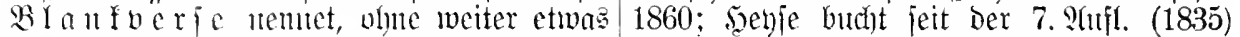

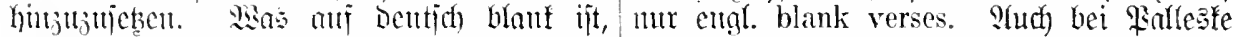

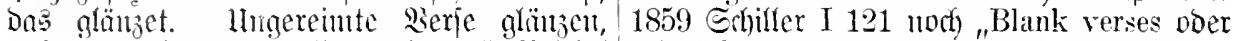

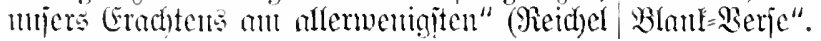

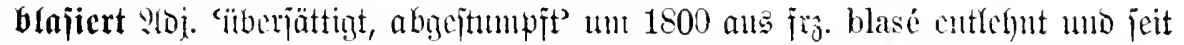

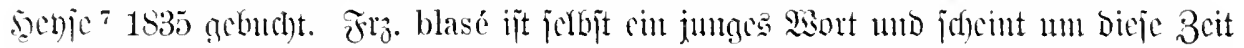

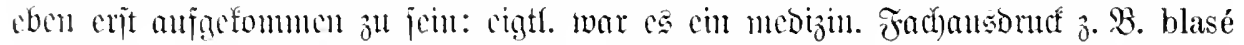

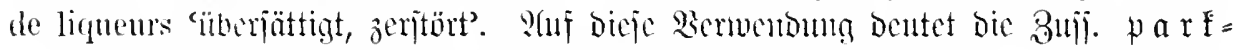

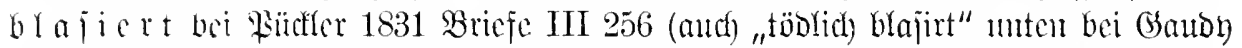

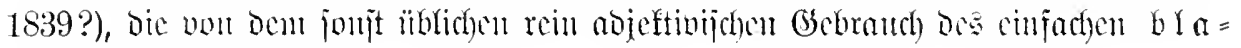
i i e r t unteridjicoen ijt.

Belege: Jacobi 1804 (Pad)laij I 352) Qtehe (III 91) blasirt und gleichgültig gegen in diesem ermiideten, blasirten, entnervten Alles. Rewald 1843 M?aphe 巨. 279 der Jahrhundert. Ranthe 1836 Retienovelfen geselisehaftlichen Formen dieser blasirten IV 178 er empiand es schmerzlich, dab die Welt. $184 t$ wiener Thenterjeitung (= 3fós. Welt auf solcher Bildungsstufe blasirt sein VIII 26) Da das Blasiertsein num einmal müsse - 1837 ebo. V 435 er kemt alle znm Bon-ton gehört, das Blasiertsein aber hübschen Mlädchen, alle Opern, alle Wein- nicht ans der Luft gegriffen werden kann häuser, er wäre blasirt, wenn er Geist und uim. Golth 1847 Litd Der Simbleit @. 285

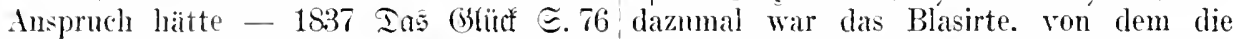
eine kokette oder blasirte Dame. (Ganton moderne Bildung ihren sittlichen Staat 1839 Rntomiga (V 149) das böse Zucken der macht, nicht eimmal dem Namen nach Lippen verrietlen ihm als blasirten Roué - bekamnt. Grobjutan 1847 Gejelfjuajt

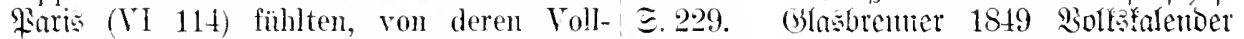
genuß übersätigt, sich tödtlieh blasirt und IV 62 . Frentag 1855 Eoll tmo Saben I 174. zom Hängen reif. Tevrient $18 t 1$ Trent

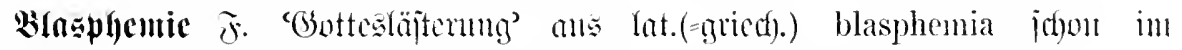

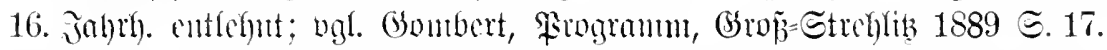

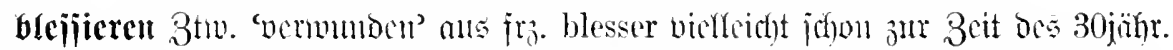

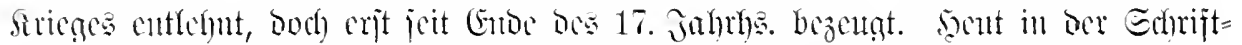

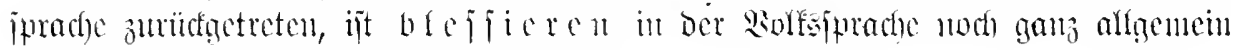
mid geradosu ber Erjats fïr verwunden.

Belege: Sränter 1681 Qeben Der Ece= Gassen und Hänsern todte und blessirte berloen bey die 60. erlegt, viel blessirt und wol 70. nealogie $\Xi .86$ der Herr sieht memen misegefingen worden. 1688 Stamidgweig. Sdhul rablen Stand, ich bin bey Ramely blessirt -

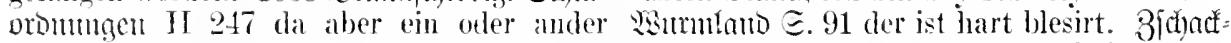
von ihnen hessiret, verwundet oder gar wits 1723 sian VI. E. 136 die Gefangenen, umbs leben gebracht würde. Eellonter die meistens blessiret waren. 1757 franff. 1699 Tuba I 300 wie hart blessirte Soldaten. Meprelation ङ.31. Echubart 1775 (Ehronif

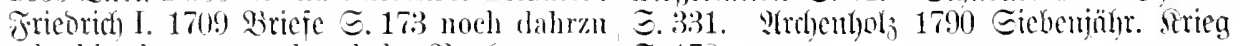
sehr blessieret an schenckel. Bertfenumener

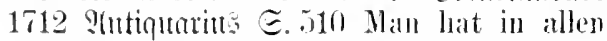

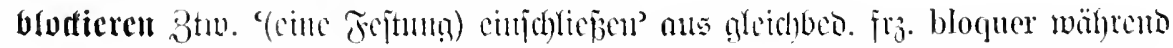

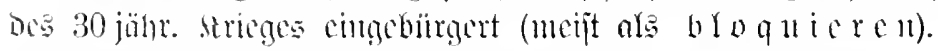

Belege: En 1630 Softreiter $\Subset .57$ die Statt Magdehurg abermaln mit hermmbheyserische hahen die Statt Hanlw, Wormbs legung einer anzahl Kayserlichen Kriegsvoleks

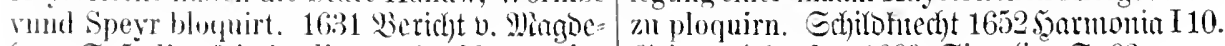

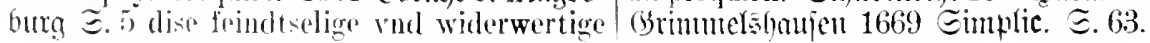




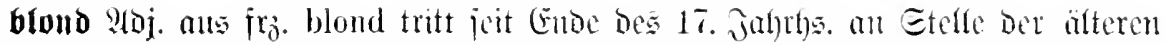

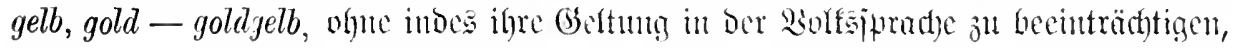

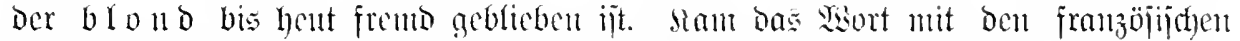

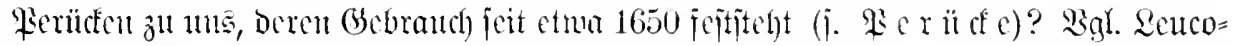

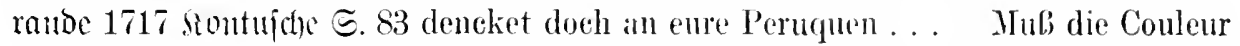
nicht bald weib, bleu, blond, cendré. braun, schwartz, grau seyn? Yuäufị blonde

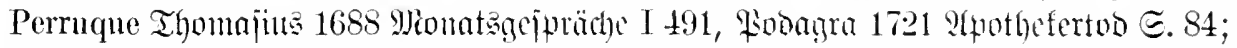

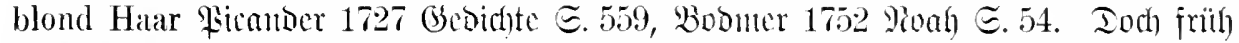

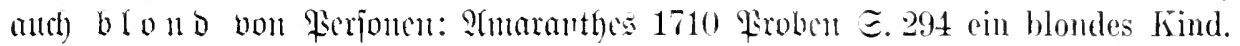
Sagner 1724 Solbatenbibliothef $\Xi .83$ mit einer blonden Dame.

ajd)blond cin junges Sisort. Bas nod | Famzosen nemen). Sei Sinn 1809 Epijoden

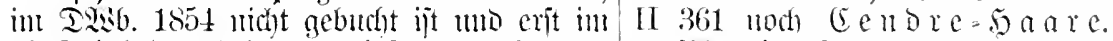

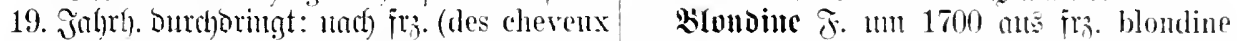

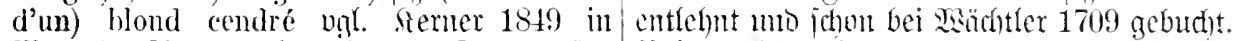

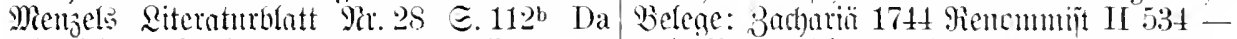
sah ich anf eimmal das Brustbild eines 1754 Perwanohungen (I 140). (36lein 1757 an wunderschönen jungen IIannes vor mir mit Ranter II 264. ¿a Rođe 1771 Frl. n. Etern= aschblonden Haaren (cendré, wie es die heim @.254. (jocthe 1774 Merther (XIX 28).

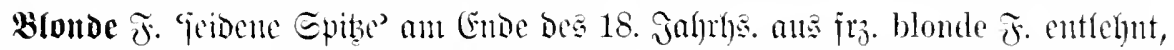

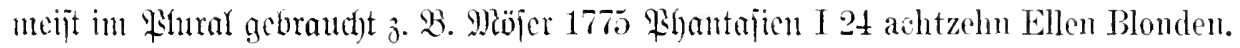

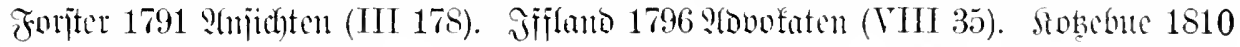

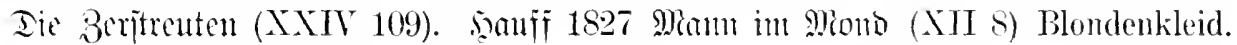

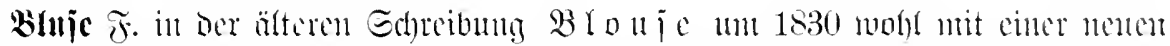

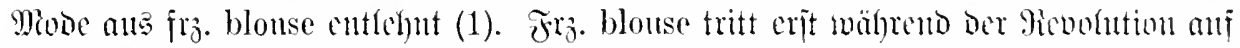

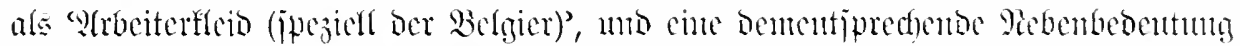

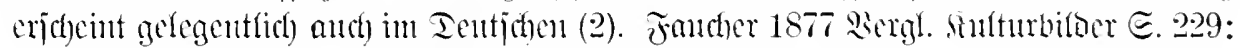

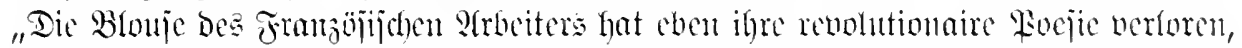

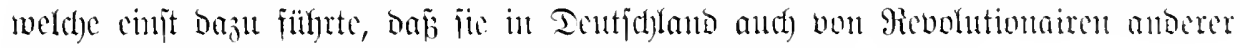

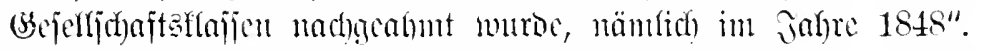

Belege: 1. 5amif 1827 Minu im Miono Blouse. Frentag 1855 Eoll n. Saben I th (XII 178) der Gürtel, welcher den wunder- Fuhrlente in blanen Blonsen. Poroan 1883 niedlichen Blonsenleib zusammenhielt. 1832 2ügen 5.262 Ier Etudierte] läßt die Blonse Eleg. Siselt $\mathfrak{f}$. Ionten Mir. 11e die kleinen die Lniform des Kafferthmms bleiben. Knaben tragen eine Blonse von Merinos. Rimbenberg 1883 Berlin I 88 Arbeiter in Qetwoll 1836 Qquarelfe II \& bic Iamen] blanen Blousen oder kalkbespritzten Röcken.

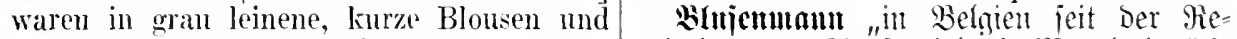
eben solehe Pintalons gekleidet.

2. Seine $18+8$ Febunarebolution (VII 380) Die Franzosen sind der poetischen Livree des Royalismus entwachsen und sie vertauschten dieselbe mit ler republikanischen Blouse. Ring 1849 Bertin II 53 Ein fliegender Buchhändler in der knappen (Gombert, 50 fl. Bemerfungen હ. 8).

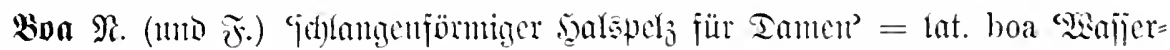

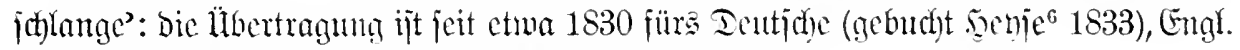
u. Tranj. bejentgt, aber mohl in Paris anfgefoumen. 
Belege: $18: 31$ Eleg. Siselt i. Iamen oder ein grober schwarzer Cachemire-Shawl.

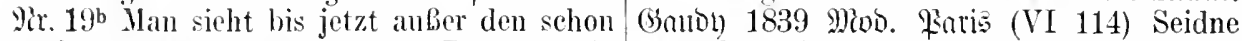
vorigen Winter getragenen Boas wenig Mäntel, Boa's, Shawls. Fontnue 1889 Briefe nenes ron Pelzwerk - Mir. 20b ein Boa II 226 ein Boa von Fé.

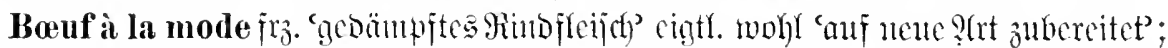

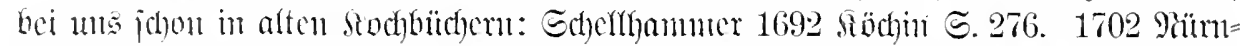
berģ. Sochbuch S. 535. Bei Miöicr 1775 Phantajicn I 267 Böf alle Mode. Magner

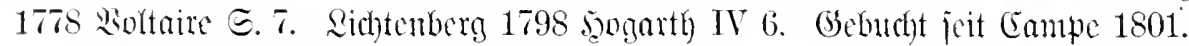

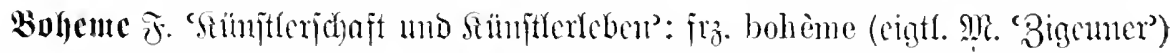

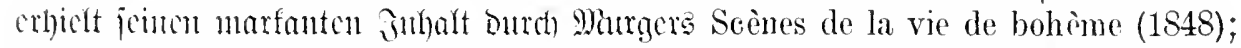

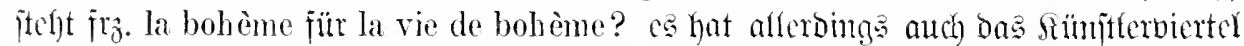

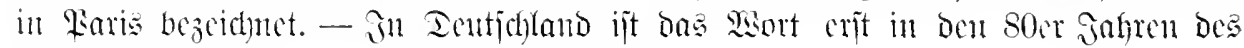
19. Jahrbs. befaunt gemorden; pg̣l. Zabemborf.

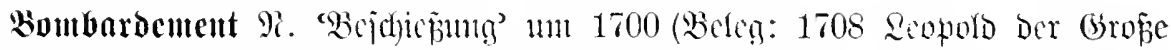

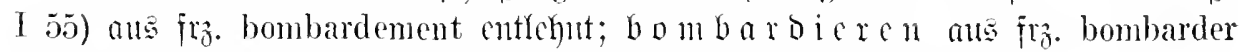
jofon bei Eticler 1691. Eine ältere Entichnumg ijt $\mathfrak{B}$ o m $\mathfrak{b} \mathfrak{e}$.

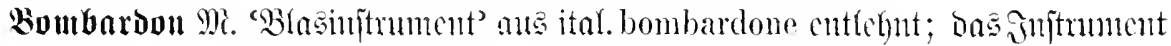
hicép seutich Pommer ngl. Prötorius 1619 Enntagnu mujicum II 36 Pommern, Bombart, Bombardoni - Italice: wird der grosse Babpommer Bombardone, der rechte Bal. Bombardo genemet.

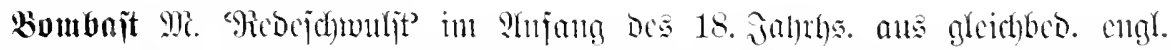

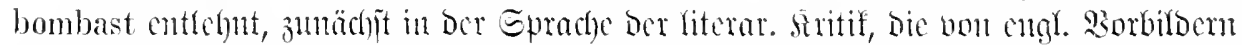

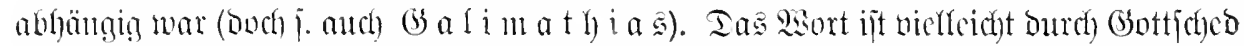

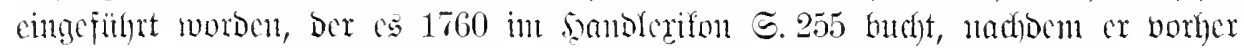
vieberholt auf ben fremben Iemmints anfmerfinam gemadit hatte:

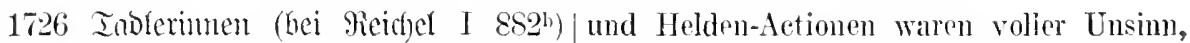
"Eine E(t)wulit neme ich, iprad) er, mas jomit Bombast, Schmutz und Pöbelwitz - 1767/8

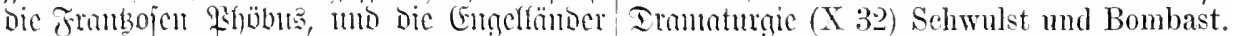

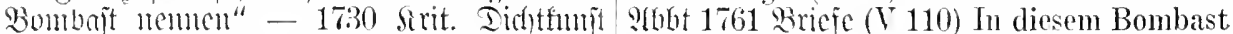

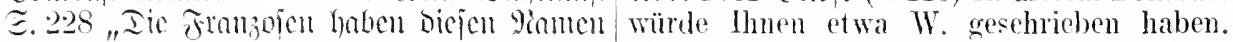
[se. \$hibu Dunds, jo biel mir wijiento, juerit behgelegt ron tragischem Bombast und bürleskem

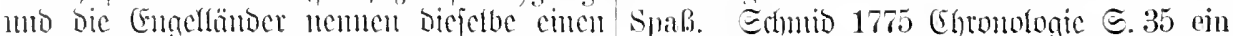

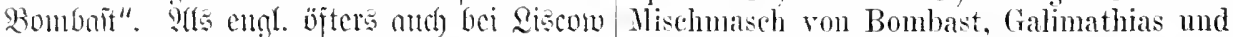
1739) Edyriftell ভ.77. 78.

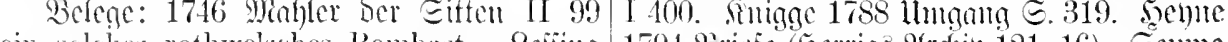
ein solches rothwelshes Bombat. Sefïng 1794 Briefe (Serrigs ?trhin 121, 16). Eemme

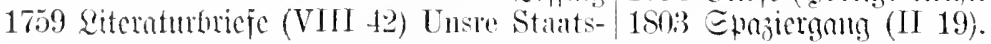

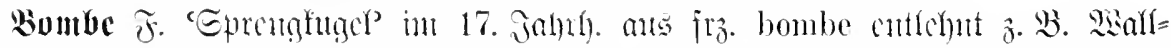
Gaujen 1616 Stricgantamal E. 94 Pechring, Feuwerlantzen vnd Pomben. - Dic

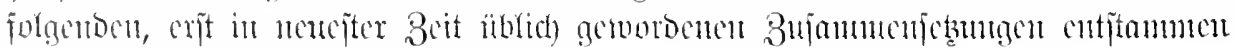
woht alle ber Theateripradic.

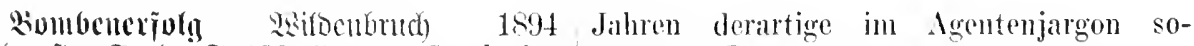

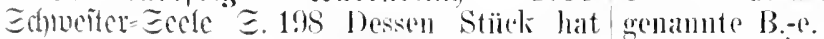

einen 13. ermugen. Edhlenther 1896 Shenter

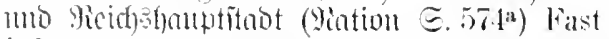
jedes moerer Theater hatte in den letzten

Sumbenicoürftnia Fontanc 1897 Etechlin ङ. 30 wer niclit ein B. lat, muls da notwendion 'reinfallen. 


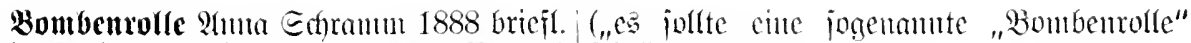
nach) Berl. Ingebl. 10. IV. 1910 9ir. 179 fein").

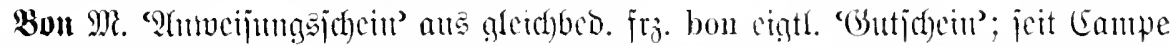
1801 gebucht. Belege: (Bosthe 1822 (5ampaguc $(33,22)$ Han hatte Bons drucken lassen, die der Commandirende unterzeichnete. Qemars 1837 Qfquardfe III 61 rejchliche Bons auf Fleisch und Gemüse.

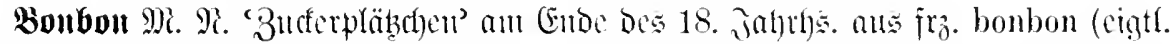

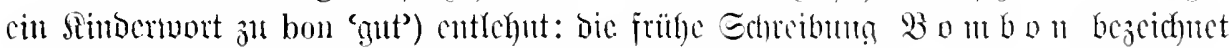

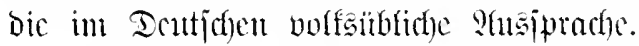

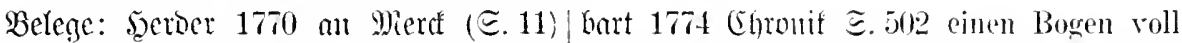
wir essen alle Bombons. Sonmel 1773 Pompons - E. 503 Es ist kein sïber Tändler, Siappereien Є.480 Allenfalls mögen mit der lauter Pompons in der Tische führt. dergleichen Bon-bons junge Schüler der Sijlanto 1795 gicije (II 51). Stobebue 1812

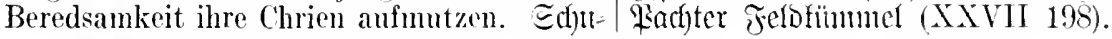

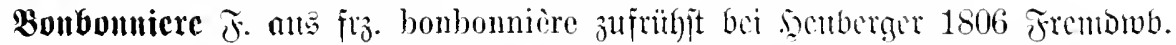
ऽ. 85 Bon-Bon, Zuckerwerk, welches man in Dosen nachträgt, die man Bonbonnières nennt. Befege: Rewald 1837 gfquarde III 323. Börte 1840 serfe III 117.

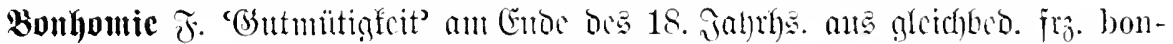

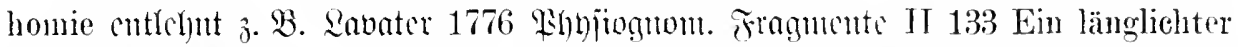
schlanker Jüngling voll Bonhomie - 1778 cbo. IV 19 mit der Bonhomie eines Reichen. Srbiffer 1788 Briefe II 9. Më̈lfer 1789 (Emmerid) VII 92.

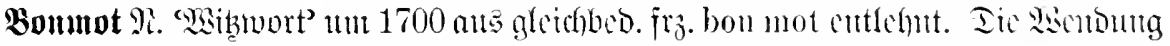

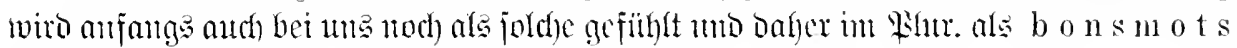

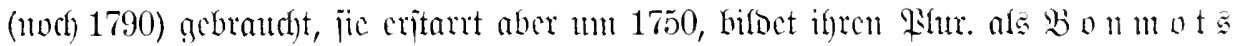

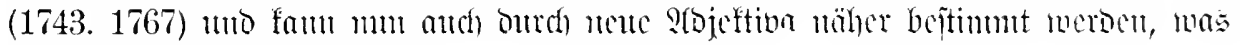
franzöfijch nicht möglich) ijt.

Belege: 1708 2copolo Der Groje I $227 /$ er worlte] viele Stïeke ausmer'zen, worimnen Er pflegte bonsmots zu reden, welche eine etwan ein bon mot von Pfarrern vorkont.

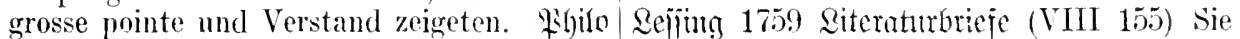

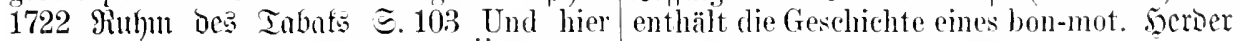
muß man suchen, dasjenige in Úbung zn 1767 D. Qiterutur (I 287) wemn die Frantzosen bringen, welches die Frantzosen Maniere ihre Aesthetische Bon-Hots uns dann oft nemnen, und welches gemeiniglich mit einem genur wiederholt haben. Michnelis 1776

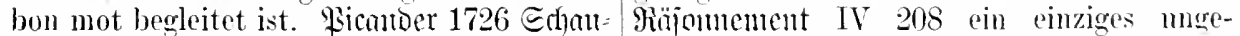
fpiele $\widetilde{S} .48$ Latuter bons mots, dn soltest schicktes und grobes bon mot. wagnter dich in die Zunftt der hiesigen Bommotisten 1778 Soltaire $\Xi .8$ ein solches bon mot. und Rajomnenr-Lade wohl sehicken. Edylegel Edjifler 1784 stabale 1 II 2 Ein Bommot 1741 Edhriften 厄.92 Eben deßwegen ver- von vorgestern. Suligge 1788 lungang こ. 34 bamet man daraus alle gemeine Reden Redensarten und Bonmots. Bahrot 1790 großer Herren, auch so gar alle bons mots Rebentisejdr. Il 11.2 mit Bons Hots nnter-

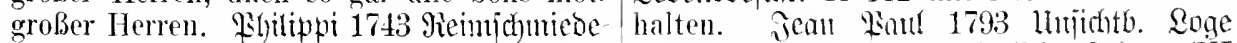
funit ङ. 59 wenn man in wenigen Zeilen (I 287). Sotsebue 1797 Falidhe Edtant (VI artige bon-mots und scharfe Gedanken an- 255). Stut 1798 :(nthropologie $\Xi .110$. bringen kan. Famler 1745 an Ghleim 1 17

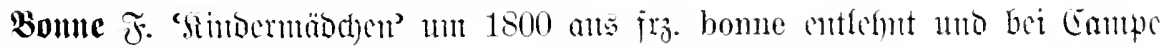
1801 gebucht. Beleg: Bengcl= Eteman 1806 (jejpräche II 208.

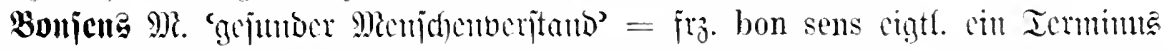
Der fromb. Rhilojophic (I0scartos 1637 Discours de la méthode 1 ,La puissance 
de bien juger et distinguer le vai d'avec le faux, yui est proprement ce qu'on nomme le bon sens"), Der fich im 18. Jh. in Der Epradge Der literax. Stritif embürgert.

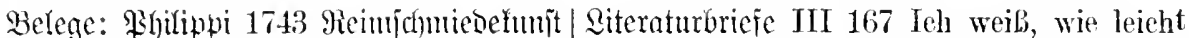
〔. 27 Tie neutu Poeten] reden von einem man aus jedem philosophischen System poetischen Geschmack, dadurch sie .... Folgerungen ziehen kann, die dasjenige fühlen können, was ihrem sogenannten bon Ding, das man gesunde Vermunft, oder sens und bon goût entgegen - $\Im .188$ Der Bonsens nemnet, für ungereint erklärt. bon sens, oder gesunde Witz, beurtheilet, Müllfer 1789 Emmterich) VI 197 in all dem was wohl klinge, und gut sehmecke. 9lecer schalen Gewäsche steckt nicht ein Gran 1744 Simnitridyter $\subseteq .218$ Es lehrt dieses Bonsens. Qubtentherg 1794 5ogarth I 77. anch so gar der so genannte bon sens. 1759

Bonton ⿱ㅓ. = fro. bon ton 'gute Sitten' in 18. Jabrh. johr häufig, jpäter aber

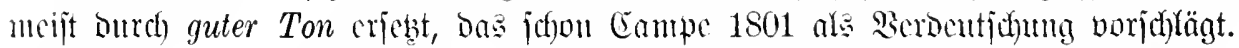

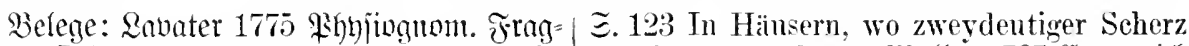
mente I 20 es gehört anch zu dem respek- zimm bon ton gehört. Mï̈lfer 1787 (cmmerid) tablen philosophischen Bonton des Jahr- II 312 den armseligen bonton und den hunderts. Denis 1777 Einleitunt I 246 kriechenden Jargon der Kotterien. Bahrot unter dem Joche des bonton, der Etiquette 1790 Lebenşbejthr. II 10 Also dachte ich, und Aisancell. Secmes 1778 Eoph. Reije das sey der Bon-Ton. Seermes 1791 Märthrer IJI 500. Ealymam 1787 , geiml. Eümben $1346^{\circ}$ ob er bon ton, also ganz nell ist.

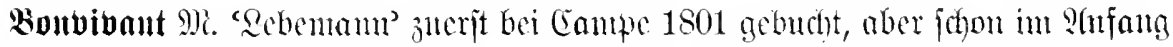

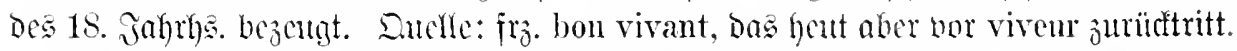

Belege: Callenbach 1714 Buer @.79| Das ist er: ein Spieler, Bonvivant, Egoist, kommt jemand zu ihm ein bon vivant agiren, Grobthuer. Gíngbremer 1836 Biloer aus als wäre bev ihm alles wohl anf. Ravater wien I 139. Saube 1837 gieijenovellen V 205. 1775 Fragniente I 222 weibliche Bonvi- Rïtfler 1840 Bifloerfant I 360. vanterey. Sfflanto 1795 Sus̃teuer (VI 97)

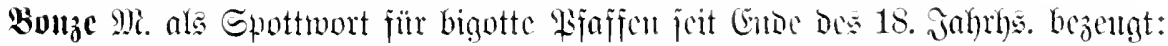

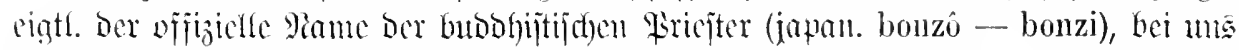

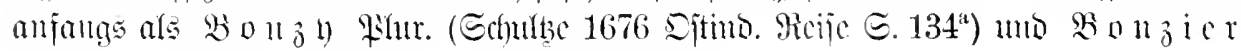
(Francisci 1681 Irancrjaal IV 387) gebraucht.

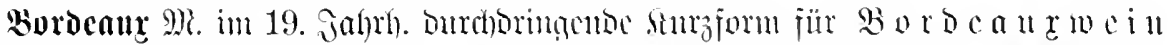
j. B. Zewalo 1846 Mapue G. 121 Mittags eine Flasche Bordeaux und zum Nachtisch eine halbe Flasche Champagner. Fontane 1856 Sricje I 73 Ieh hatte Suppe, Filet, Fisch, Huhn und eine halbe Flasche Bordeaux. SBox oc a x w e in war Der

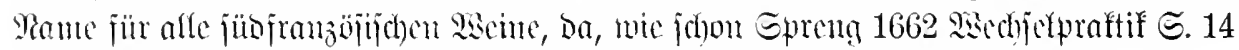

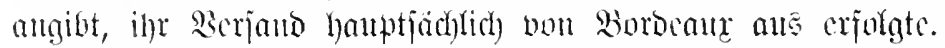

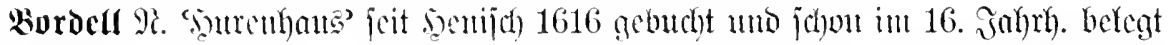
ว. 2. Fijhart 1575 Gargantua ङ. 90 Hellegablische Bordäl, Sixtische Mummenheuser. Ufbertim 1599 Gmevaras Emojereiben III 106: Bordel vund Kuppelhaub. Garjoni 1653 Echauplats S. $687^{a}$ Huren im Bordell. Siltefle: fra. bordel uno ital. bordello - ober ummittelfar mlat. bordellum?

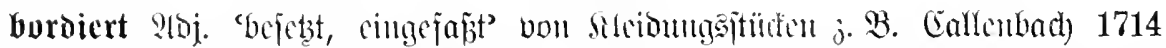
Funer $\widetilde{G} .75$ mit den rothen Scharlachen bortirten Rock. Dancben bei Mohr 1729

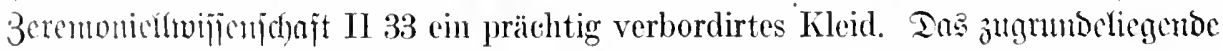

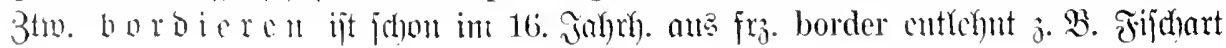




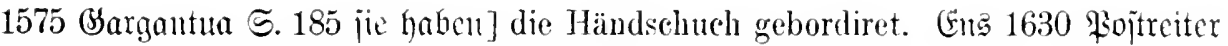
5. 31 Da ward ein Stul mit gulden Lacken geborduret.

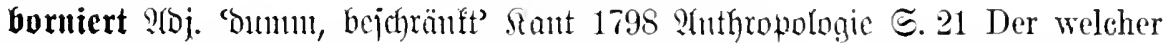
nicht selbst denken, wenngleich viel lernen kamn, wird ein beschränkter Kopf (bornirt) genannt. Bocthe 1829 Jtal. Reije (XXXII 161) Und wie sonst für krank und bornirt gehalten zu werden, geziemt nir weniger als jemals. (Gauby 1836 Tagcbud) (I 184) fragt er bornirterweise. ¿aube 1836 Reijenovellen III 57 sehr bornirte Lente. Devrient 1839 Bricfe aus Raris (IV 215) Rachel sei bormirt und spreche ganz un-

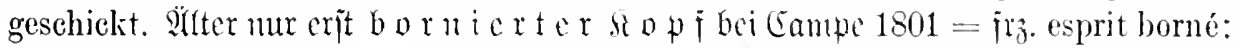

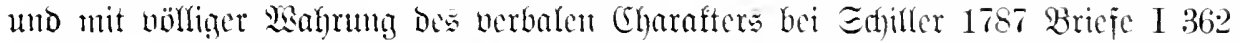
Ihr Geist ist änserst bornirt. Enefle: jrò. borner 'bejchränfen' - bormé 'g̣eijtiq be= j(ł) ränft's?

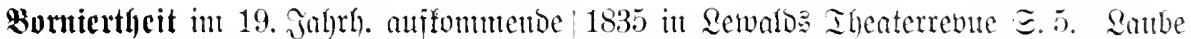

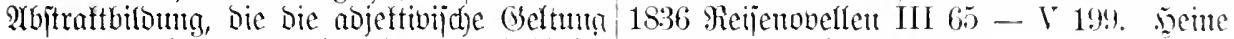
von borniert ermeijt. Belege: Echfeiter 1854 Geitünonijie (VI 66).

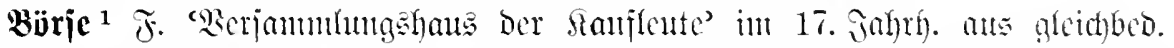
แol. beurs (,Brugis Flandrorum sic primum dicta" 5ecuijd) 1616) cutflehnt: Der Pamte

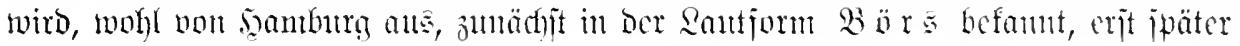

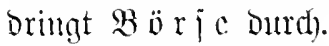

Belege: Lauremberg 1652 Edherzgebichte den Namen Börse erhalten. 3achariö 1756; ङ. 43 De Fohrlïde am Strande, de Jungens Sagesieiten (II 65) Auf der Börse verup der Börs. Beiller 1653 Topographie sammelt sich jetzt der emsige Kaufmann.

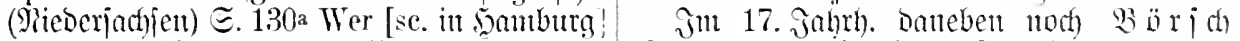
unb den Mittag oder auff den Ábend, in (巨d)upp 1663 Ed)riften ङ. 195. 196. 1684

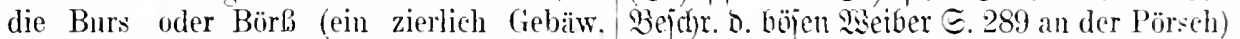

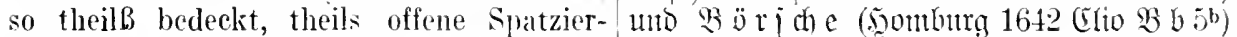

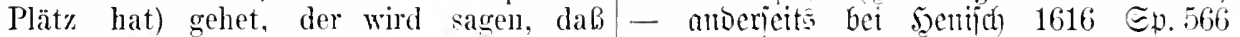

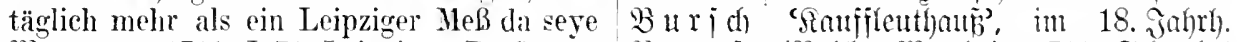
Marperger 1711 I 71 Leipziger Börßh.

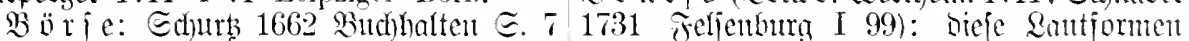
was täglich gehandelt wird, in Hanf, auf entītanoen unter (Emjiltij von uhbo. Bursche

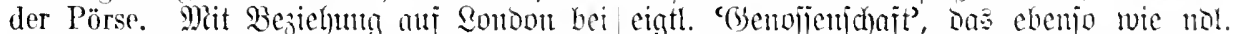

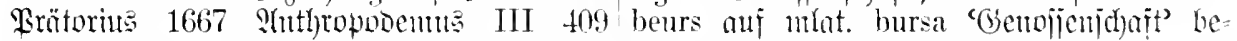
die alte Börse - 410 war die Börse rer- rubt. Sie ältere Beseutumg bes mlat. bursa

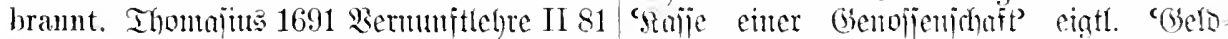
auf der Börse, in Buchläden, in Gewölben. Geutel' vernittelt Den 3uiammenthang mit

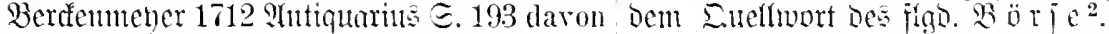

nachmahls alle Oerter der Handels-Lente

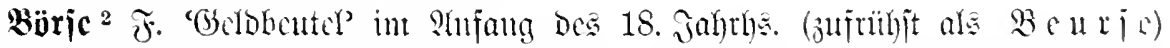
aus glcichbed. nol. beurs (geldbeurs) enflehnt: ohne Bmjammenhang mit ipätmb.

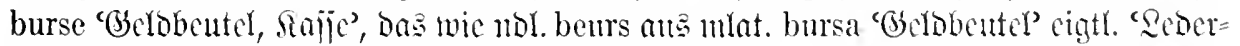

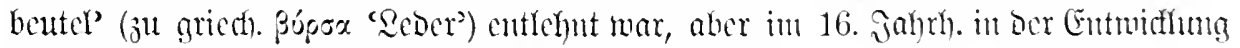

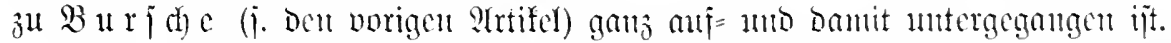

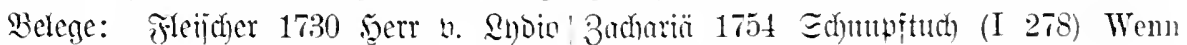
I 18 ich kleidete mich rein und propre meine Börse dam das Gold nicht mehr

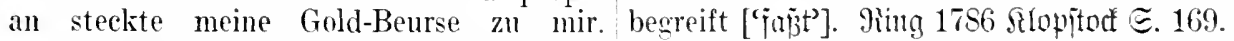

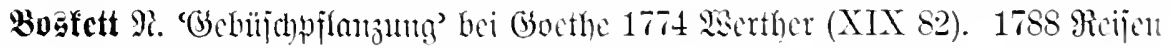

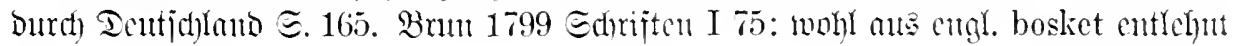




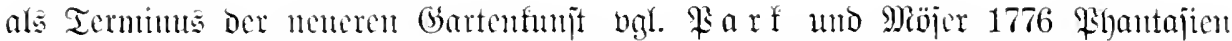
II 465 es heibt num auch, wenn ich es recht verstehe, eine Schrubbery [cugl. shrubbery [(Scbüija)'] oder wie andere sprechen, ein englisches Boßkett.

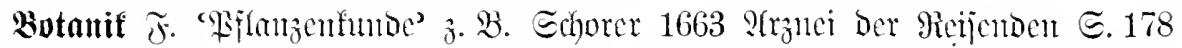
in der Botanic oder Kräuter-Wissenschaft. Suclfe: nculat. (scientia) botanica

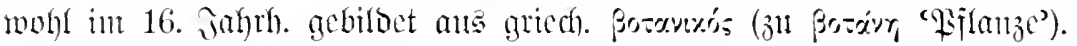

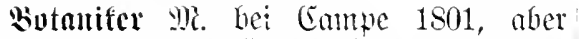

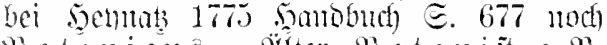

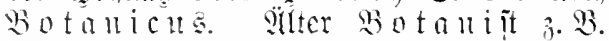
Enthort 1774 (érouif (Beil. E. 60). Thïm= nuel, Reije (T 21) madh irs. botaniste.

botantijieren 3tru. ans aried). Boravtsen 'Bílatzen faumteln' untgejomt. Be!eg:

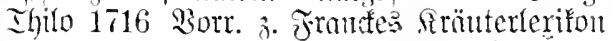
こ. $7^{b}$ loent jie] das eine [Eremplar] bey dem botanisiren gebrauchten.

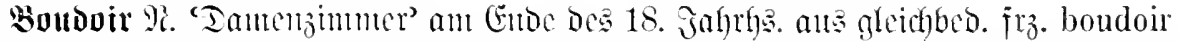

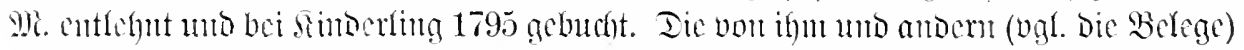

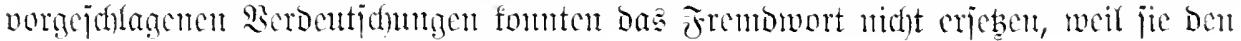

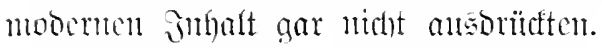

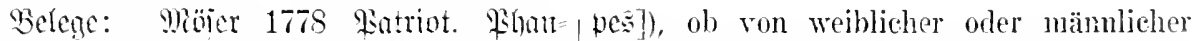
tajien III 132 dab man würklich die Seele Lästerzunge. wer mas darüber entscheiden.

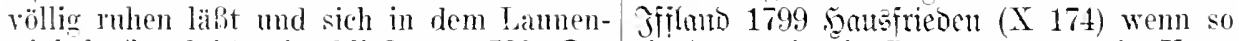
winkel (boudoir) einschließt. 1790 Ier ein Ange, wie ein Passe-par-tont, ein KänBeobahter $\Xi$. 3 alle skandalösen Anek- merlein meines Herzens nach dem andern doten ans allen Kabinetten. Klosets und anfschlieBt, zuletzt bis ins Bondoir dringt.

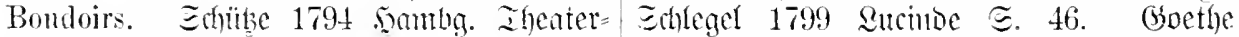

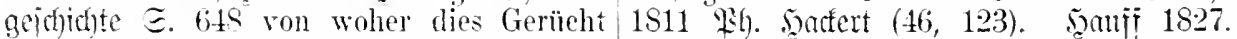
kim, ob aus den Konlissen oder Bondoirs Mann im 9iond (XII 33. 34. 106). Bönte (Schmollwinkel nach einer nenen, hier 1829 Tramat. Bhätter (II 336). wenigstens passenden Verdeutschung [C

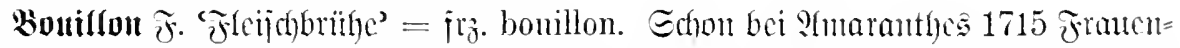
jintuterlex. $\odot .109$ bouillon oder Rindfleisch-Brühe - $\subsetneq .246$ Bonillon Ist eine aus

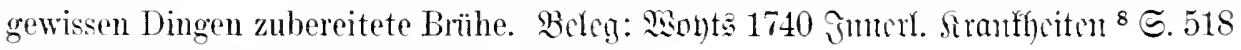
gute Hüner- und Fleiseh-Brïhen, Boutllons.

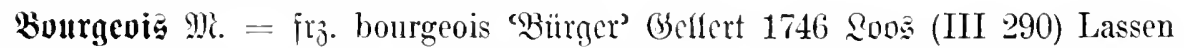
Sie den alten Gecken gehen. Es ist ein Bourgeois. Er taugte in Frankreich zu keinem Thiirsteher. - Tie Eimbitrgerung ocs wartes fällt aber erit in bas 19. Jahth., juerjt

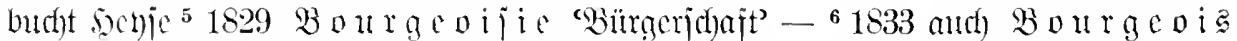

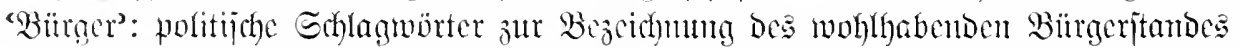

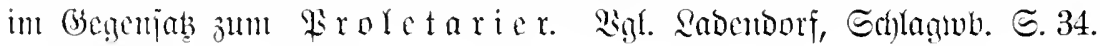

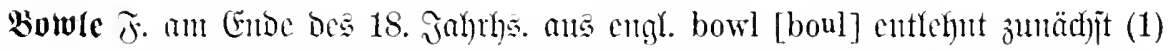

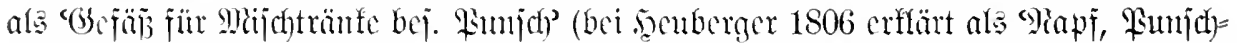

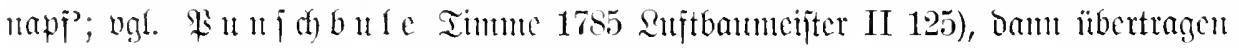
vou deut 'Getrüuf' jelbjt (2).

Betege: 1. Sichtenterg [1769 Sqhorimen| $\Xi .653$ bej einer Bohle Punch. Rokebue (I 96) Ein Göttingisches Duell erfordert 1798 sitbjang (VI 72) haben wir nicht die nehmliche Herzhaftigkeit, die man drei Bowlen Punseh zusammen ausgenöthig hat eine bowl of punseh auszu- trunken. 5nuj 1826 Memoiren (VII 20) trinken - 1773 Shphor. II 130 anf der Eine lieblich duftende Bowle Punseh. Seite sab. Judas Ischariot bey einer Bowle Büduner 1833 Brieje $\Xi$. 334 Die Lente

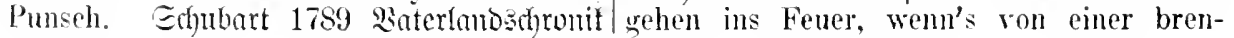


nenden Punschbowle kommt. 18:35 Europa ( Frobpapa wohl wieder Gelegenhejt zu einer I 214 Vierhundert Bowlen wurden geleert. Bowle nehmen. Frentag 1853 journalijten Fiüfler 1840 Birberjaal I 289 eine Bowle $\Xi .87$ dort braue ich eine Bowle, mal wir

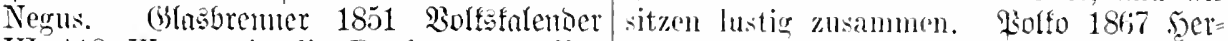
VI 118 Wenn wir die Bowle ausgesoffen jentsgehemunije $\Xi$. 118 dal Du uns an haben.

2. Fontane 1852 Briefe I 13 da wird bowle giebst.

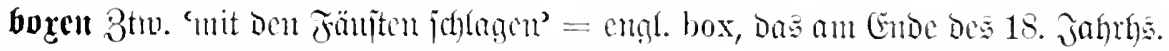

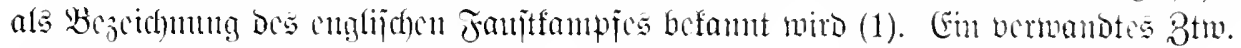

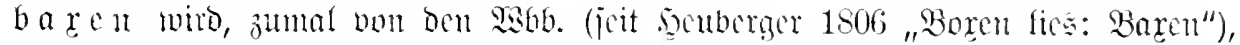

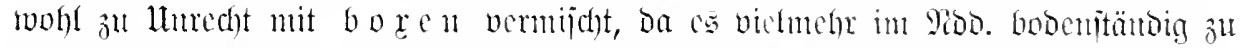

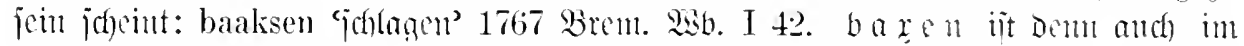

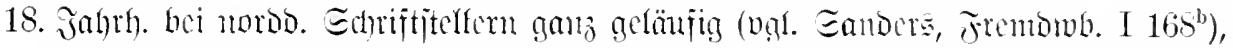
während bo re legt ijt $(2)$.

Befege: 1. Tiebuthr 177t Reijebejdr. Somnenstrahlen Bü̈ehei boxt... Solche II 175 Hiebey sab es keine Stöbe oder Fünste haben in England den Werth von Schläge, als wenn die Engländer sich Worten.

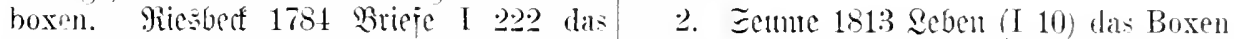
Boxen der Britten. T(rebenlyol, 1787 Eng= sing fort, und bald las Jikob oben, bald fomb III 4:) Diese Boxkmnt hatte ihre Gottfried. (Goethe, Bahme .Emien IX Regehn. Girtamer 1791 Janj. Revolution Zwei Gegner sind es, die sich boxen, dis I 106 das Boxen in England. Qidftentberg Arianer und Orthodoxen.

1795 sogarth II 111 wie er sich mit eine'n

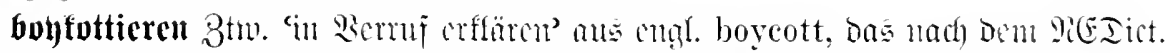

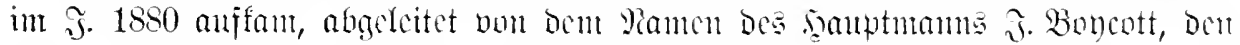

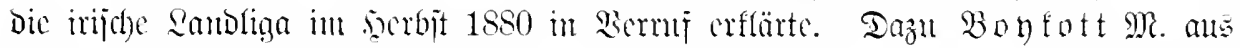
sugl. boycott: Bimarcf, Gisanfen u. Erimerungen II 117 es blieb 1870 mir gegenüber, bei dem militärischen Boycott, wie man heut sagen würde.

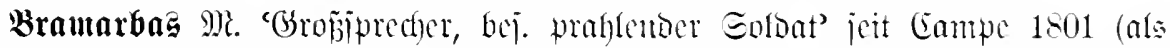

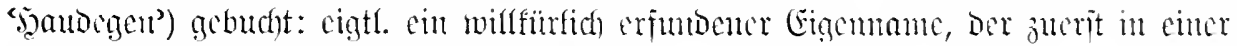
anontyment Eatire ,Cartell oes Bramarbas an Don Quixote" (hersig. b. B. Mende,

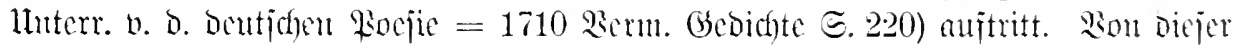

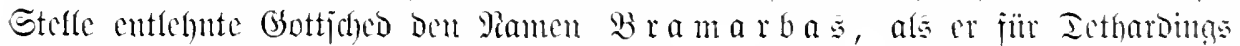

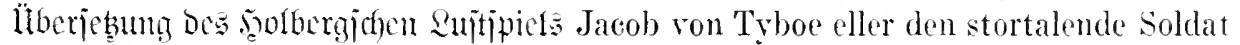

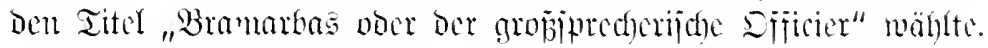

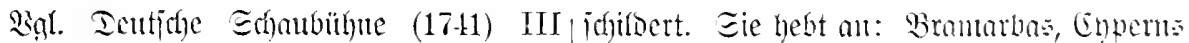
xu "Ias vierte Etücf ijt $\&$ r a ma $x$ bu

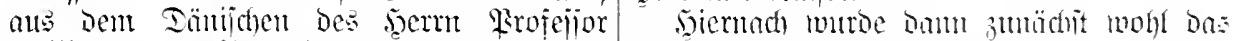

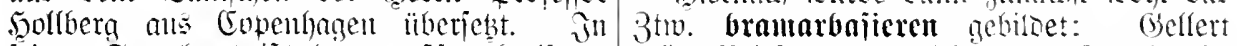

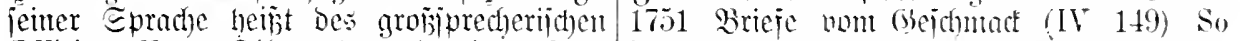
Sfficiers Rame Tiboe, Der aber in unjerer könnt ich ron der Liebe sincen, Wie sie Eprache feine stmmut gehabt haben wïroe. yom Feld an Hof, die Großen zu bezwingen,

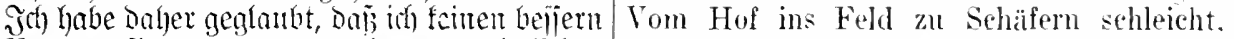
Ramen finden fömte, einen pralerifhen Bald ans der Jugentl lacht, bald aus den Minomadyer an Genemten, nis Denientigen, Alter keucht, Ans dem Bramarb bramarDen id) in Prilanders vou Der Qmbe lluter basiret, Aus dem Peclanten meditiret. redung von ber Poejie in einer EDe ge= Epäter bum allg. 'prahlen' midft mur vou

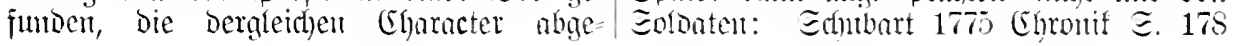


eine Sorrejpontionz] die von den Helden-| Mä̈ller 1789 (Enmerich VII 150 aber der thaten der Spanier vor Melilla bramar- Bramarbas taugte so wenig zum Mueker, basirt. Widfacliz 1776 Räjonnentent IV 381 als der Heilige zum Renommisten. Echifler wenn der ohne Montur gehende Laquai 1798 פaflentemi ager 8. $\mathcal{A}$. So ein Braden Burschen vorstellend bramarbasirt. marbas und Eisenfresser. Solzebue 180t Ecfiller 1781 Räuber I 2 Der Wein bra- Pagentjtreiche (XVII 98) da ist ein Bramarbasirt ans deinem Gehirne. Sfflanto marbas gekommen, der soll mein Mrann 1784 Berbredjen (V 29) dein Sohn bra- werden. Qaube 1836 Reijentovelten IV 233 marbasirt in Spielgesellschaften.

Bram arbas in ïbertr. Eimue int Bramarbas pfiff das Mantellied. erit jeit Ende Des 18. Jahrhs. bejentat:

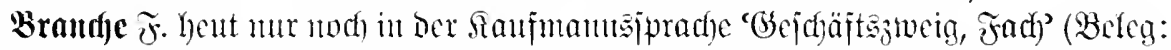

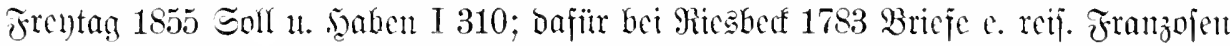

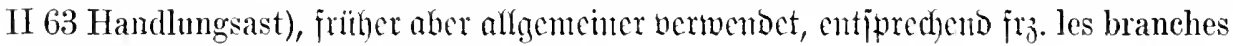
de la science, de l'art, du commerce.

Belege: Echiller 1795 Brieje IV $274 /$ des Lebens - 1837 Reijennvellen V 390 Deine philosophische Ode halte ich für unter dem Worte Erziehung versteht die keine Grenze, bloß für eine Branche meines übrige Welt noch eine besondere KulturFaches. Qidjtentherg 1794 joganth I 102 branche, nicht blos ein moralisch Ding. Branchen der Heilkunde. Jäger 1835 Riüfler 1841 Bitberinal III 239 wo es noch Felir こchubel ङ. 278 er muBte alle theolo- an einer Menge der wichtigsten Institugischen Branchen von Anfang an beginnen. tionen in jeder Branche fehlt. ¿aube 1836 ङraupielerin હ. 32 Branchen

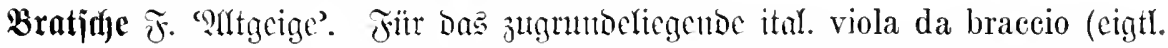

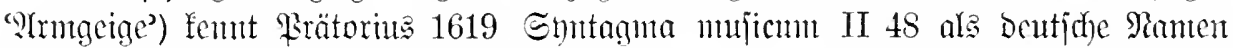
ınur Geige, beim gemeinen Volck aber eine Fiddel - III 155 eine Violdabratio oder

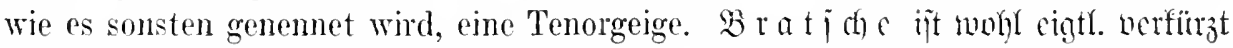

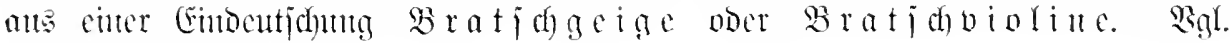
(6) a

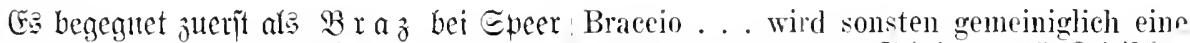
1687 unterr. v. D. mufif. Sumit 5.84 Von Bratsche genemet. Echeibe 1745 Stritidher einer Viol Braccio oder Braz. Wie hoch und Mitifus $\Xi$. 431 Die Instrumentalbegleitung tieff gehet eine Braz? . . Eine Braz hat eben einer Arie besteht insgemein aus zwo Geigen wie ein Violin vier Saiten. E.91 Brazen- und einer Bratsche. Q(ts Dentich jeit Frifd)

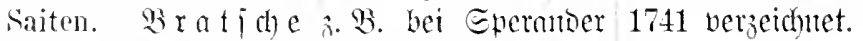

1727 Ala Moule Entacl) $\Xi$. 782 a Viola di

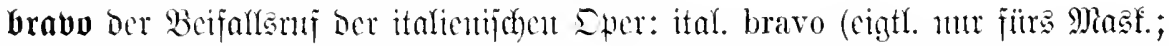
sem. brava - Ffur. bravi) bei uts int 18. salgrh. cingebürgert mo frïh aud alfg. als Beifallamif gebraucht.

Belege: Eulger 1774 Theorie i. ichönen noch ehe sie Deutseh sprach, daran als Silinite II $881^{\text {a }}$ da ein so großer Theil ihrer Landsmämnin erkannte, daß sie bravo statt Zuhörer den willkührlichen Passagen so brava schric.

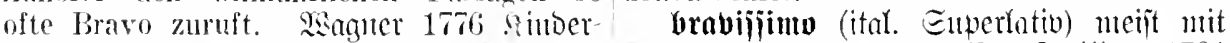

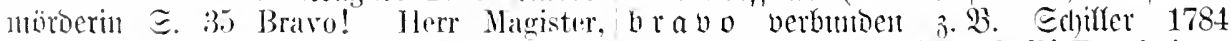
das ist bras. Edfuler $178 t$ Sabale 1112 Sabale III 2 Bravo, Marschall! Bravissimo. Bravo, Narschall. (bsoethe $1795 / 6$ Qehr $=1784$ Merfut II 90 Ey bravo! bravissimo. jalure (XXII 2.27) Bravo! rief Philine, swowebue 1797 Falidje Echan (VI 2S2)

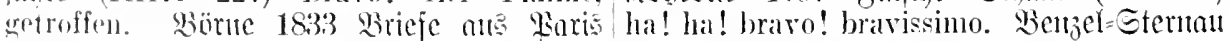
III T.5 bine dicke dentsche Dame, und 1803 Gejpräche II 295 Brarissimo! walhrscheinliche Berlinerin, die ... ich, 


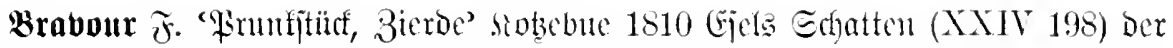

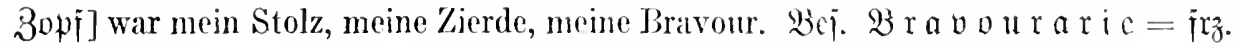
air de bravour, ital. aria di bravura: Eefubart 1774 (Egronif E. 101 . Jicolai 1783

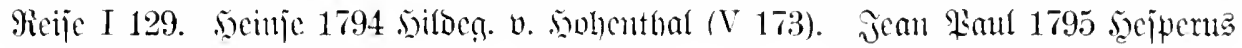
(VIII 228).

Frz. bravour in icher eigtl. Bed. Sapjer 1806 Ergane (XX 103). Tiettelfect 1821

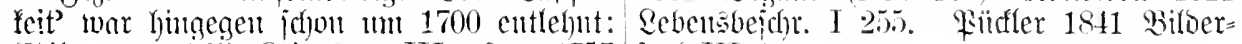
Ehifement 1707 friegsent III 49.1757 janl III 31.

Franff. Mep̈refation Il 13. Tod) bei Sotzebue

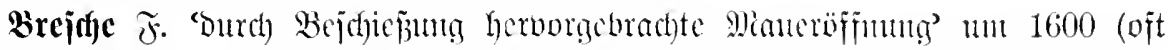

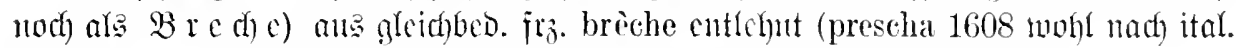

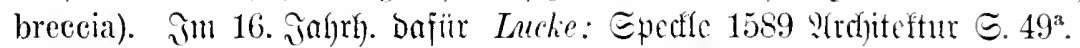

Belege: (bebharot 1597 Fïnịtl. Tijd)=/der Maner, ein Pressa, in den Avisen. Sic= reben ङ. 205 nach dem die Statt an et- Yege: Sord 1605 Relation $\Xi .50$ nachdem lichen Orten dermassen beschossen, dab er 140. Schub darauff gethan vnd ein ziem-

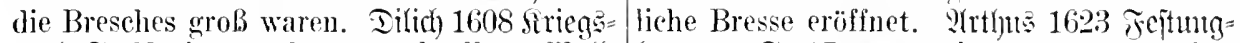

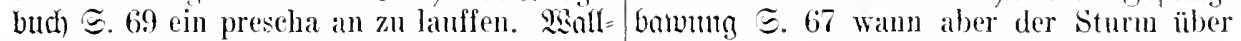
haujen 1616 Siriegsmmutal $\Xi .76$ hinder ein Pressa oder mawrbruch geschicht der bresche verschantzet - Є. 99. (5n હ. 96 zum Abfallen der Pressen oder Wall1630 Foitteiter Є. 13 durch die Breschr brüche - モ. 97 Pressa u. ï. (obmohl cr

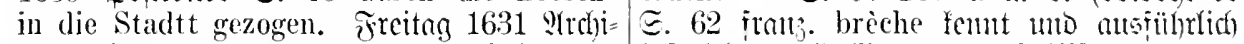

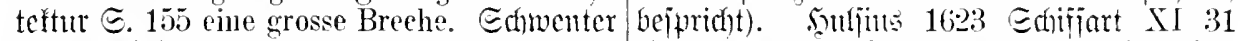
1636 Ielitine 5. 429 eine Breche schiessen. ein Pressa schießen. 1631 Ier Pojtreiter Edjilbfined)t 1652 Sonmonin II 65 Prech- 9ir. 24 Die Wähl und andere fortificationes

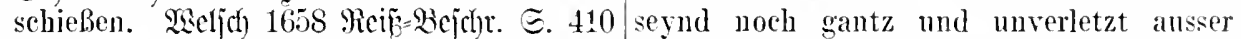
eine große Breehe geschossen. Shtoerjen der gesehossenen Pressa, die vor allon 1669 Dricut. Reijebejchr. $\subseteq .160$ geschossene Dingen wider zugemacht wird. Bürjter Breehen. Srämer 1681 Qehen Der 巨ee=1647 Beidhr. D. idhwes. Arieges E. 41 gegen hetoen S. 430 die durchs Geschütz gemachte der geschoßnen Pressen - $\Xi .46$ Preß Bresche.

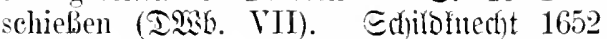

Tie populäre Form war aber in 17. Sammonia $\Xi$. 8 geschwinde eine Presse

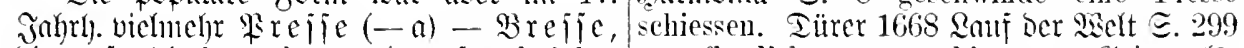
Die auf nol. bres, bresse (ans $i r_{j}$. brèche; unanfhörlich presse schiessen. Gímmelós=

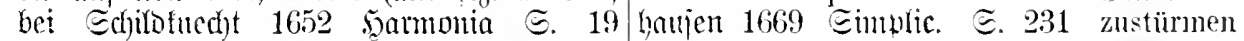
wird geradeju Niederl. Presse nugegeben) ohn eine Presse. Etho $166+$ Enang. Stranfent= jurïfgeht: jie war bej. in Den 3eitumgen trojt 厄. 350 Pressa. 1677 Bermathojtez bie herjhende Form ogl. Martin 1628 Jormoja $\Xi .166,168$ Bresse.

Colloques $\Xi 21.1$ la brethe: ein Loch in

Brigabe $\mathfrak{F}$. 'Tuppenteil $=j^{\text {wei }}$ Regimenter' in 17. Jahrh. aus fig. brigade

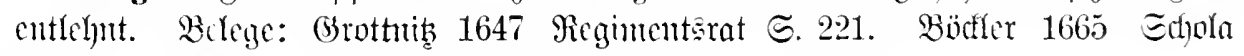
militaris ๔.518. Grinmulshanjen 1669 Eimplic. હ. 176.

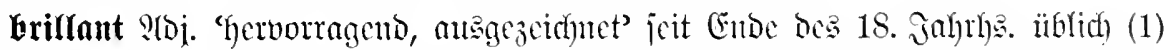

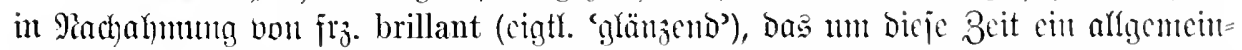

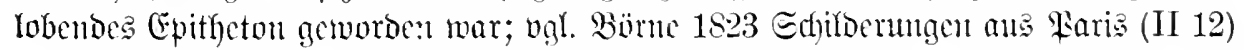

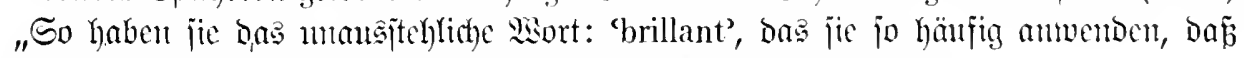
rinem bie ?hgen ïberlaujen. ?tues, was jie loben, ijt brillant".

Sancben galt briula ut aber anfangs and nod in ber cigentl. Bebeutung

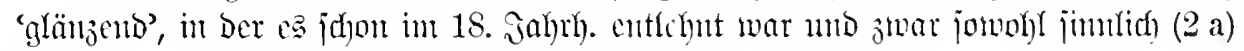

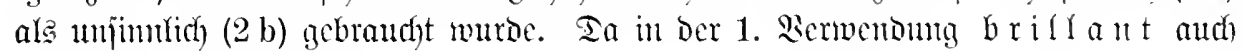


als Malcrausond (won feuftendon Farben) auftritt, ambererjeits briflante

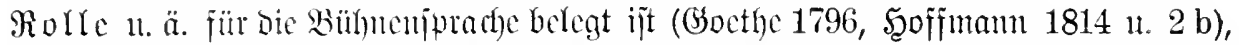
fömute neben Den fro. Savert ital. brillante eingemirft haben, mit Dem jedenfalls bie moberne shosprache überculutimut.

Belege: 1. Wall 1787 Bagatellen II 24 vrient 1843 s:er bin idi (III 179) die ich hatte bey der ersten Vorstellung meine brillanteste Jagdpartie.

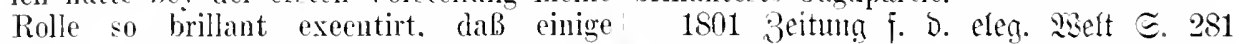
Grifinnen mich mit den Eventails schlugen, daß der möglichst brillante Effekt der und mir sauten: ich wäre der grölte Ränber wesentliche Zweck des Dekorationsmalers muter der Sonne. Piintfer 1831 Brieje I 229 Nachdem dieses herrliche Pferd die ersten zwei Sprünge auf das brillanteste zurückgelegt hatte. Jïner 1835 Fetix Edmabel こ. 253 Die Wohnungen sind nicht brillant, aber auch nicht thener. (Banton 1836 Tage= butch (I 196) Nun hatte ich doch die brillantesten Aussichten - 1939 Faris (VI 127) ich erwartete den brillantesten Erfolg. Frentan 1848 Qnitiütie I 30 trotz seincr brillanten Teehnik, mehr Virtnose als Künstler. Mar. v. Merifo 18501 Reben il 6 worauf wir die ziemlich sehwierige Einfahrt brillant ansführten. soultei 1852 2agabunoen ङ. 175 Sie hatten G. bald in i). erreicht, wo er , ,brillante Geschäfte ${ }^{6}$ machte - $\Xi$. $4 \$ 1$ sein brillantester Erfolg. Geine 1856 Reije um Die Eroc II 196 sicherlich brillante Geschäfte machen. Fontome 1897 Etedflin ङ. 21 Fr ist ja brillant angeschrieben.

2 i. Ravater $177 t$ an Gothe (Bfose. III 169) brillante Henge Grafen und Grifinmen. Didfaclis 1776 Raijomement IV 531 einer der brillantesten Höfe. Mijier 175 S Rhan= tajien III 8 sich nicht in die Oekonomie des brillanten, galanten und magnifiquen Lebens misehen. Echiller 1789 Srieje II 219 Hier sind die Redonten zuwrilen recht brillant. Ifïmmucí 1791 Sicije (V 130) brillante (iesellscheft. Goethe $1795 / 6$ Qeb) $=$ jafre (XXII 28:3) ein briliantes liest. 1801

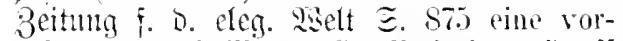
nehme und brillante Gesellschaft. somij 1826 Memoiren (VII 60) Im Wagen, den ich, $n$ m brillant anfzntreten, für diesen

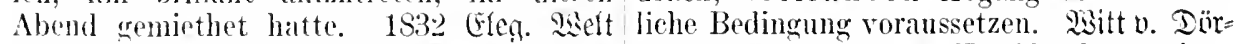
j. Damen Mir. 2 der grobe Ball wird als ring 1827 Fragmente II 166 ohmen einen einer der brillantesten beschrieben. Iiüm= eigentlich brillanten Verstand zu besitzen.

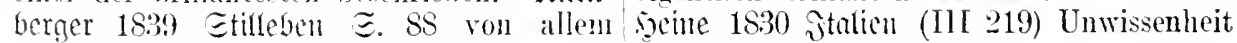
Glanze einer brillanten äußern Jage. Ie= wird brillanter Witz.

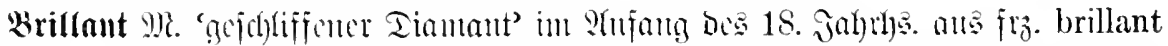

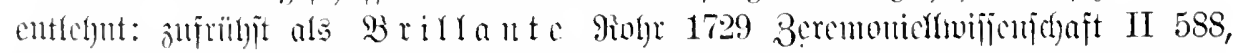

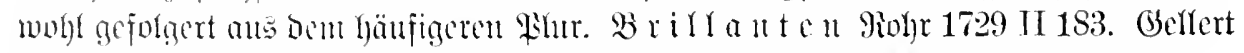

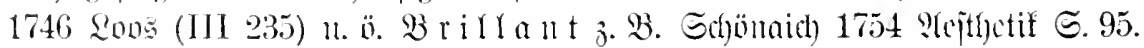




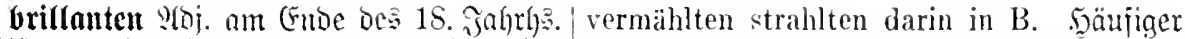

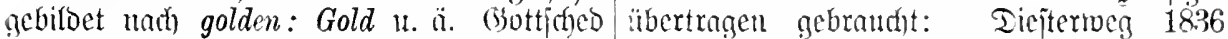
1763 (bei Sicidbel I 913b) eine brillantene Sebenajrngen $\Xi .66$ Schleiermacher, der Prunkmadel. E(b)ubart 1774 Chronif $\Xi .443$ täglich drei Stunden hinter einander in mit einer brillantenen Dose. SEejtenricoer B. strahlte. Socite 1840 Bärne (VII 40) 1782 Trnm ङ. 163 brillantenen Rinr. so schlossen die humoristischen Reden

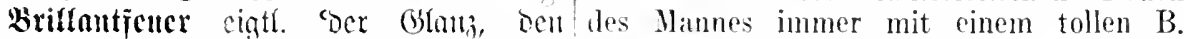

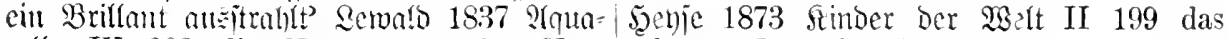
relle IV 203 die Taumenszïge der Tell- schönste 13. meines Humors.

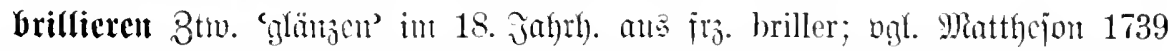
Sapdlmeijter $\Xi .457$ Wers recht aufführet, dem wirds eine gute Wirkung thun. Brilliren mub es. Ich kann das auf Teutsch mit gläntzen und funckeln nicht sagen, wenn ich auch ein Vorsitzer aller teutschen Gesellschafften wäre.

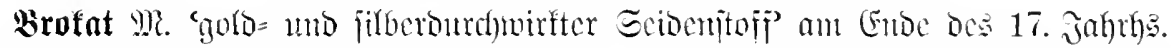

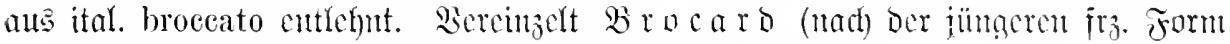
brocart) P(maranthes 1710 Proben der Poejie $\Xi .361$.

Beleac: Fraucisci 1681 Traterian IV|köstlichste ausländisehe Broccat. QfGrafram 1054 etliche Stücke Sinesischen gemödelten a $\widetilde{5}$. Cfara 1688 Juba: I 265) der Rock Satins (Brocats). Soorneff 1684 Diferreich mub von geblumten Procat seyn - 482 -

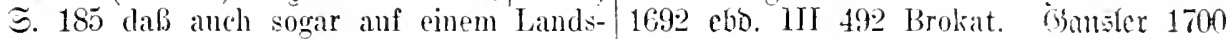
fürstlichen Leib ein inlïndisches Tuch weit Sugenjomio III 15i-17.5 Procat. mehr Glanz geben wïrde, als der aller-

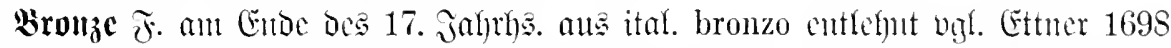

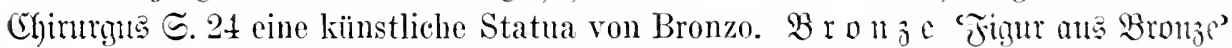

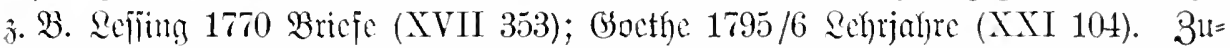
frübjt 1755 ltberj. von Richarbjons Grambijon VII 38 Statuen, Busten und Bronzen (= cugl. bustoes, bronzes).

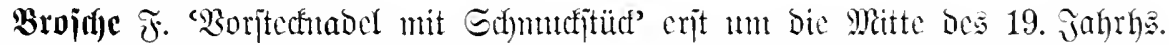

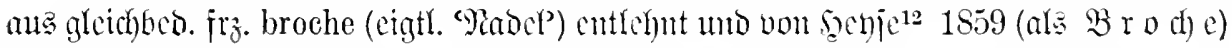
gebudft. Belcge: Madfenthujen 1864 Rouge I 128 Diamant-Broche. Echürfing 1865

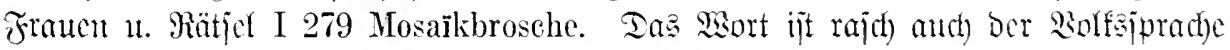
(meiịt als brosch) geläufig geworben.

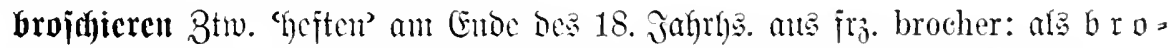

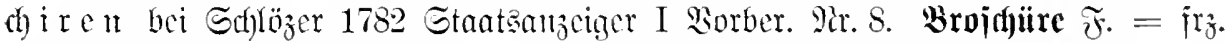

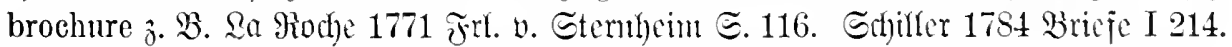

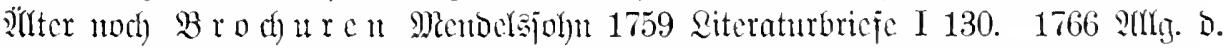
Bibliothef III 1 S. 11. Denis 1777 Einlcitung in bic Büdferfunde I 238.

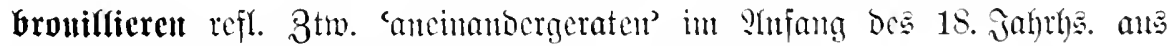

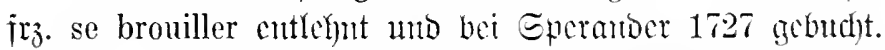

Belege: 3idnafruitz 1726 Rart VI. $\Xi .108$ Magister Knellins wegen brouillirt hat. daß Großmuth und der Consens nient Dermes 1791 Maituner I 200 So? sich immer in guter Intelligenz stehen, sondern bronilliren (ich dachte gar rompre).

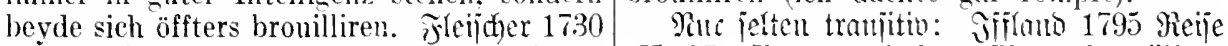
Seerr v. Sndio I 10 selbiger num vermissete (II 97) Ihre närrischen Plane brouilliren solche bald, derowegen er sich mit mir mich immer mehr. (boethe 1796 Lefhr $=$ bronilliren wolte. \$intler 1775 Fanits jahre (XXII 323) Leider war jener nur über Qeben $\Xi$. 41 der sich mit seinem Weib des äußere Umstände mit der Gemeine brouillirt. 


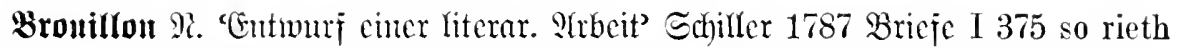
er mir, schnelle Broutillons hinzuwerfen und dan erst langsam dariun nachzuarbeiten. Echon bei Epcramber 1727 "B. nemet man Den eriten Entwurff cimes Rififes, che

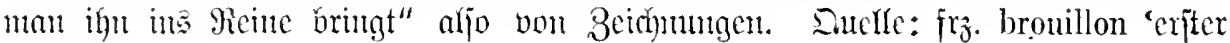
Entwurf?.

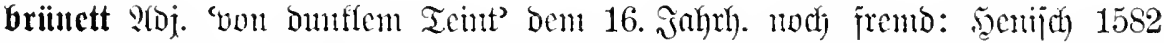

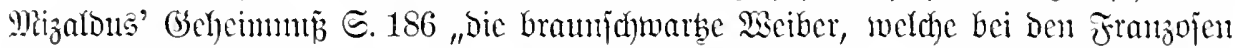

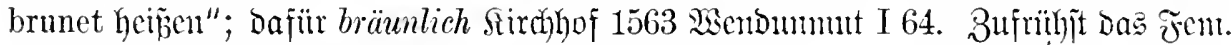

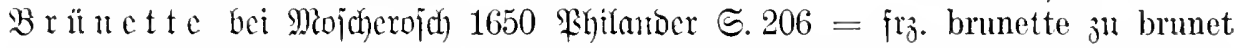

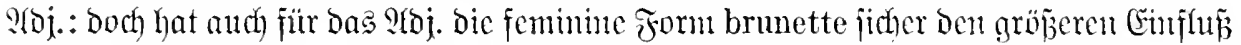
gehabt, wie bem brünett junädjit mur bon Franen gebraucht miro. Befege: Smaranthes 1710 Froben $\subseteq .295$ weil ein Brunettes Kind ihm Fleiseh und Blut

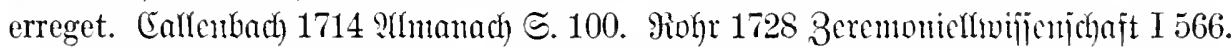

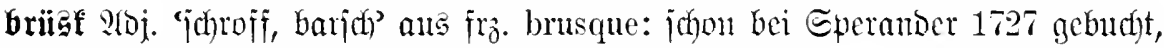

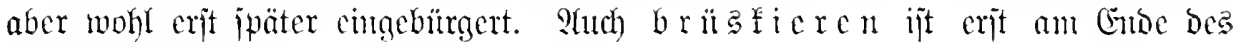
18. Jahrig. belegt.

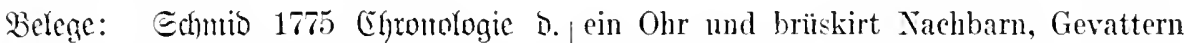
D. Thenters S. 283 seine Rollen sind brus- und Schwäger. Sfftant 1792 s.artbera que Officiers. Michaetis 1776 Röjonnement (X 78) mich hat er nicht brüskirt - 1795 IV 203 von so brüsquer Redlichkeit - - Reije (II 97) Man mmb sie brüsquiren. 450 der Schritt ist brüsque. Bahrot 1789 Epäter mehr 'einent rüuffichtö̌log behanbeln,

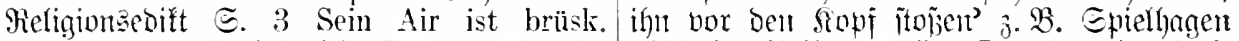

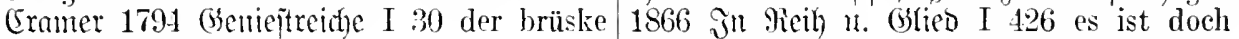
Herr Leutnant.

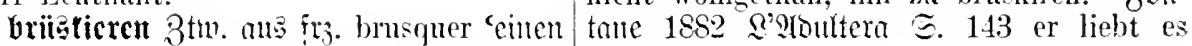

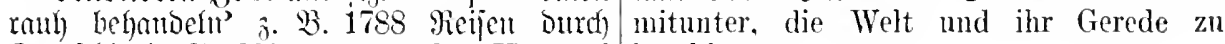
Teutighlant ๔. 380 er setzt den Hut auf brüskiren.

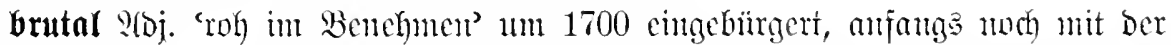
Rebenbedentung 'muvernünftig' entiprechend ipäffat. brutalis 'mbernïnftig'. Die

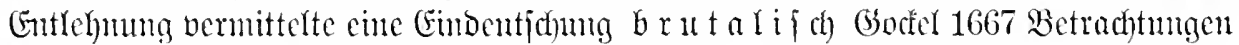
Des Zonns E. 10. 14. Thomajus 1690 Edyriften I 67. Ettner 1697 Ehmmicus E. 45.

Belege: Thumajius 1688 Mountage= Jugend rom Kindes-Beinen an in allen ipräđge I 61 das brutale Verfahren des Kriegs-Fxercitien. Marperger 1711 Bejdjz.

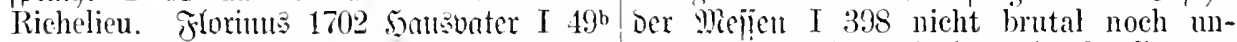
So wäre es eine recht unvernünfftige brutale bescheiden. Callenbash 1715 Duafi vero Sache. Rucac 1711 Selicon $\Xi$. 181 Die $\Xi$. 73 warumb tractirst du deine liebe sonst brutalen Tiüken unterweisen ihre Haub-Postill die Frau so brutal.

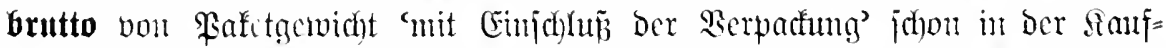

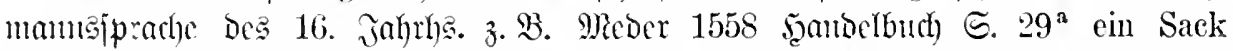
Besuet wigt Brutto 18:3 $\mathscr{H}$, Tara $2^{1} / 2 \mathscr{Z}$, rest netto $178^{1}: 2 \%$. Duclfe: ital. brutto 'roh', bej. brutto peso 'Bruttogetwicht'.

Bubdel $;$. 3 ut t e r.

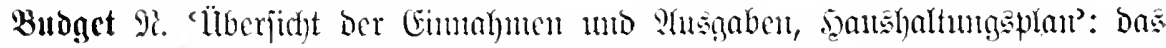

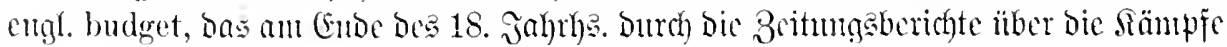

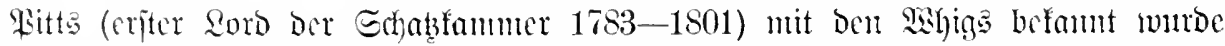

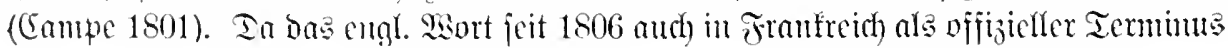




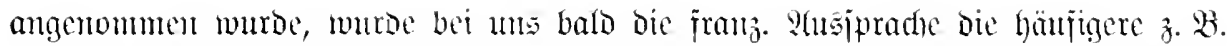

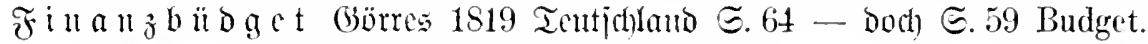

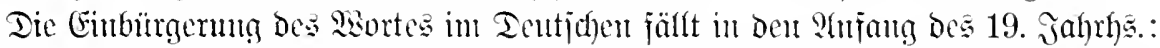

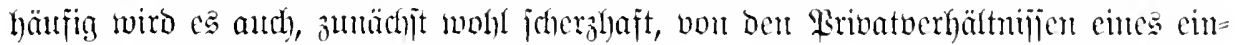
zeluen gebraudit.

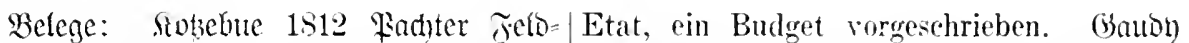
fïmmel (XXVIl 160) Ei! zu geheimen 1837 fubiläum (VI 210) eben so viel hilft Ausgaben, die werden im Budget nicht cine Verwerfung des Budget, d. h. gar namhaft gemacht. Goethe 1830 über St. nichts. Frentag 1818 afuifäse I 14 wo im Hilaire Principes de Philos. zool. (Sierfe Budget ein Fond für geheime Ausgaben 1. 5. 50, 211) Von einer andern Haupt- durchzusetzen ist, wird tliese Summe viel wahrheit ist er gleichfalls durchdrumgen: nütalicher in Havamats als in Spionen daß die haushälterische Natur sich einen augelegt.

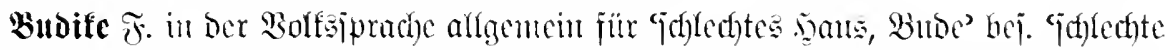

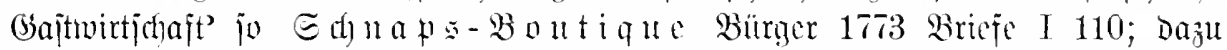
BuD iffr 1868 Gartenlanbe XVI $410^{a}$ Schenkwirth, sogenannter Budiker [f̈ür

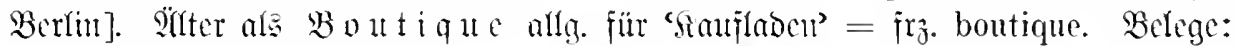

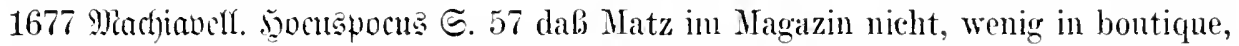

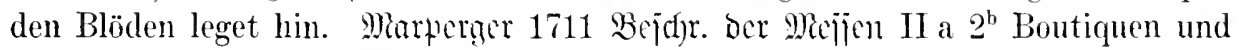
Gewölbe. 1719 Recucil V 6 Boutique oder Krahm-Laden. Wagner $172 t$ Eoloaten= bibliothef S. 4 auf seiner Werckstat oder in seiner Boutique. Ricise 1767 Iemojthentes IV 55 eine Werk- und Handelstätte, ein Butikgen.

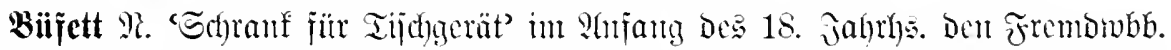
nod) fehlemb, aber johon wieberholt belegt: Sünig 1719 Theatmm ceremoniale I 1158 ein Bufet mit allerhand schönen Credentzen. Rohr 1728 Beremonielfwijienjafift I $\check{3} 37$ In den Tafel-Zimmern werden ausgesehnitzte Buffets aufgesetzt. Subowig 1744 Gil. Qqujeigen II 627 was vor Unrath findet sich auf buffeten und toiletten.

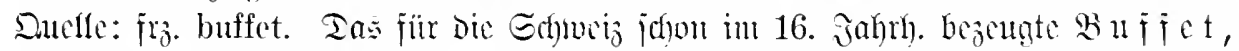

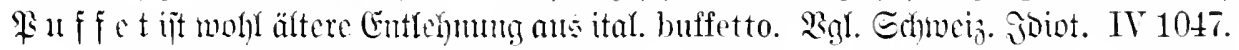

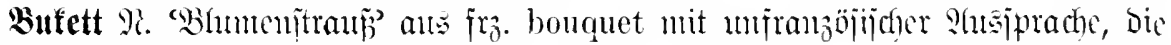

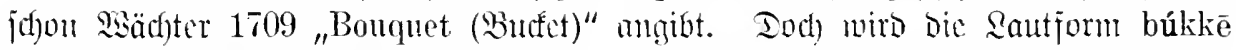

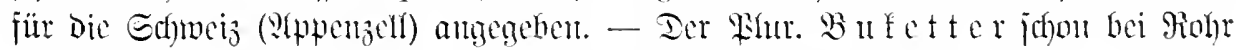

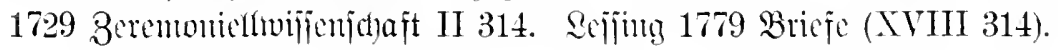

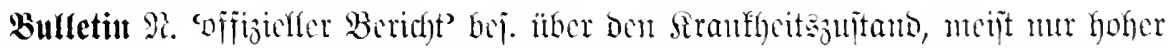

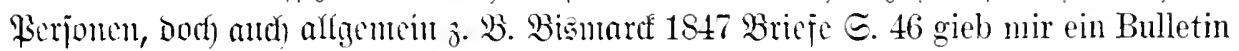

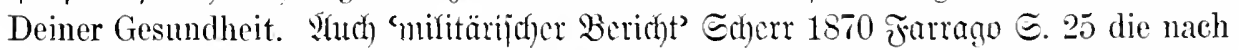
Rom gesandten Siegesbulletins des Cäsar. Sutcle: $i_{j}$. bulletin (médical, militaire).

Ltu 1800 galt $\mathfrak{b}$ ulletin für 'Tnges: Tagesblatt, ein Bulletin literarisehen und zeitumg' Fintorling 1795. Campe 1801. weltgefälligen Inlualts schriftlich zu rer-

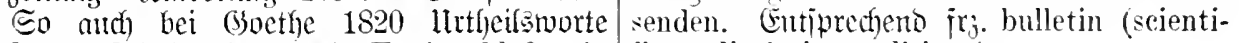
franj. Sritifer (41, 145) Er beschloß, ein/fique, littéraire, politique).

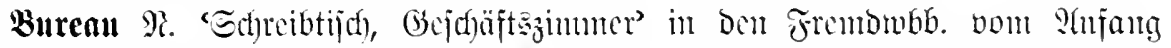

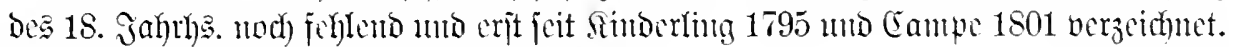
Duclle: fro. bureau in beiden Bedcutungen. 


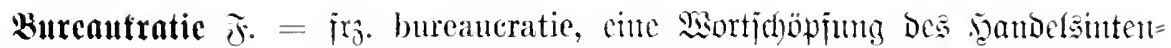
Danten \$. De (Gournay) (1764) nach) aristocratie und démocratie, bie während De:

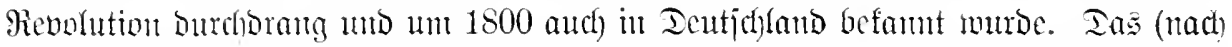

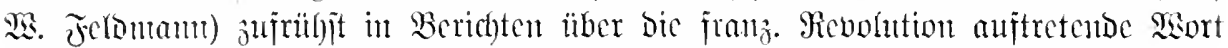

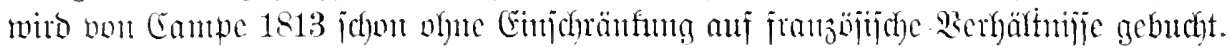

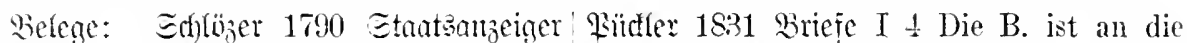
XY 393 Hr. Maury fürchtet daher, die Stelle der Aristokratie getreten. Menzel

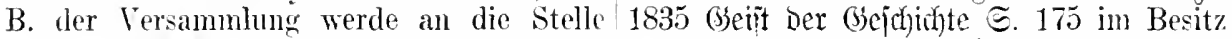
der B. der Minister kommen. 1791 Peuet der vollendetsten B. Chomutis 1845 Inuf

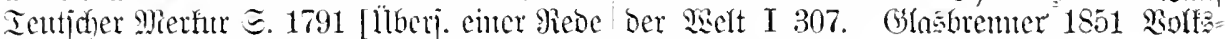
Maury's] Es wäre seltsam gemug. wenn folcnder VI 53.

die $B$. dieser Versammlung die Stelle der B. der Minister eimmähme. Bjơfle 1796 M. T. Mierfur ङ. 166 [als 9usipnth cimer Rarijerin] Wir seufzen unter dem eisernen Joch der B. Görres 1821 Guropa $\Xi$. 147 reien ihre Macht fühlen lassen wollende-

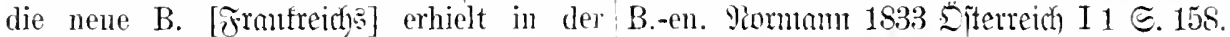

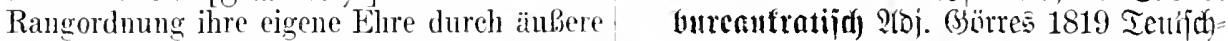
Dekorationen ausgezeichuet - 1822 Эn Lono $\circlearrowright$. 161 dab die Ministerien b. geordnet Enchen Der Rifeimproving $\Xi .32$ die Napo- sind. Frentag 1865 antiätie I 257 zumal leonischen Gesetze über persönliche An- unsere Preuben leider als Befehlende b. griffe, womit eine allun̈elhtige B. sich/mgeschickt sind.

gegen jegliche Unbill zn decken wubte.

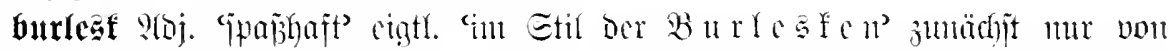
Dichtwerfen gebrandyt: aus jus. burlesque - ital. burleseo. Sigl. Miorlyoff 1682

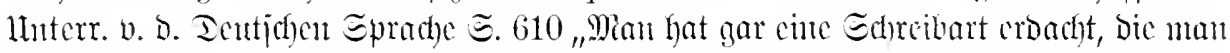

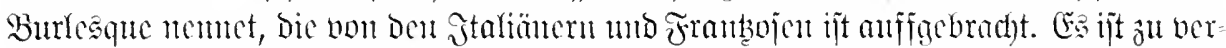

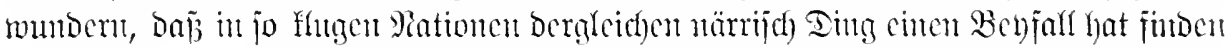

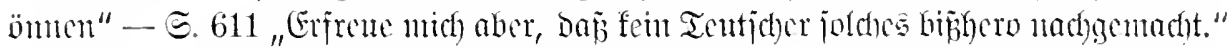

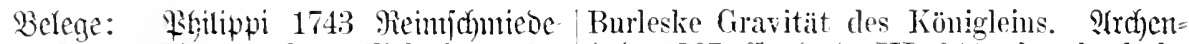
funit $\widetilde{E}$. 27 Man mub endlich bey den hol, 1787 England III 244 eine burlesk. Reimen und Einfällen einen Unterschied Ovation. Babrot 1790 Rebentabejtr. II T unter der ernsthaften und sclierzhafter mit burlesken Verbeugungen. Edhleget oder burlesquen Possie machen. (isottjches $1801 / 2$ Sorlejumen I 306 Ableitungs1746 Rener Bütherjat III 136 in den sylben, theils burlesk und von komischer sogenannten burlesquen Gedichten. Ramler Energis.

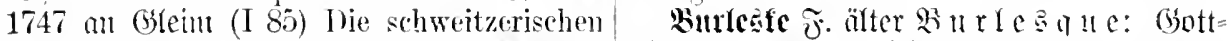
Erzählungen sind rechit artig und die Natrone jofed 1730 Sirit. Tirhtfunit $\Xi$. 42 So lange ron Ephesus ist recht gut burlesque - 1754 man lauter jtalienische Burlesquen auf(II 156) In dieser burlesquen klemen Fabel, führen wird. Fhilippi 1743 ßeimidnutede= die auch eine burlesque Melodie hat. Tujd funt $\Subset$. 155 Zur natïlichen Poesie aber 1764 Sirieje J265 einen watürlichen Un1- gehört die Burlesque auch nicht. Eprentg stand, die Abwechselung der Tacht und 1743 Drnffinger: Gedidte $\Theta .133$ nachdes Tages, anf eine burleske Art mit einem folgende drey Stïcke welche in so genannten sehr gemeinen Gleichnib simmlich gemacht. Burlesques oder Knittelreimen bestehen.

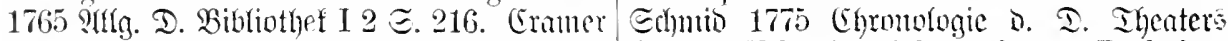
1773 an Bürger (I 83) Ihre letzte Ode ist $\underset{\Xi}{ }$. 34 Veltheim führte ferner Burlesken parodirt worden, ganz verflucht burlesk. auf, dic or... den Italienern abborgte. Éfubart 1774 Deutide (E)ronif $\subseteq .350 \mathrm{dic}$

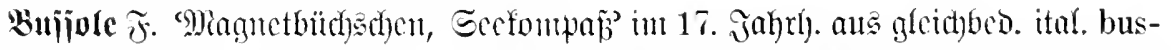

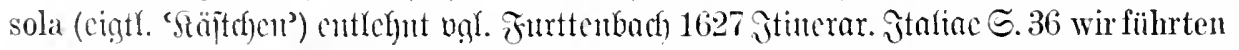

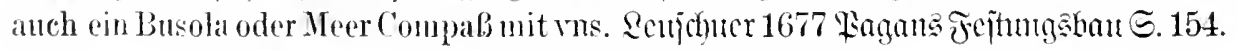




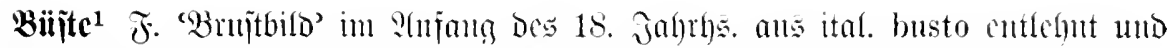

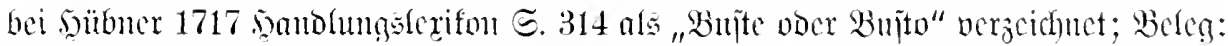
FFloriu 1749 , Soutsvater II 386 ${ }^{a}$ Gemählde, Statuen, Busten oder Brust-Bilder.

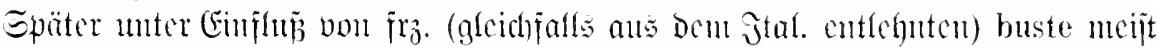

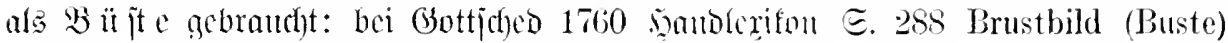

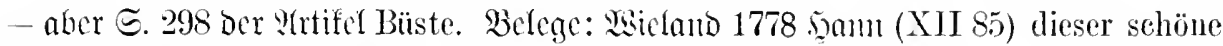
warme Leib, Von Todesfrost in eine Büste [: müsste] Verwandelt - 1780 Eberou (XX 120) blab wie eine Bübte [: küßte]. Siciter 175 an Birgex (I 248) kalt wie eine Büste. (Gocthe 1796 Sefrjabre (XXIII 154).

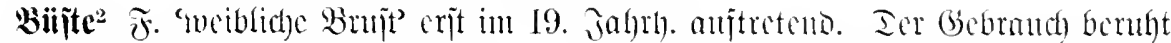

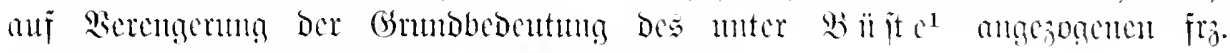
(=ital.) buste: "Sberfibrper"; aljo Iicuentefmung?

Belege: Srönig 1861 Etillehen I 40 Gegenstand, den es bezeichnet, durch die Josephine besab für eine Lnise Miller zu Erimnerung an Varmor und Gijus für die wenig schlanken Wuchs und zn viel - Phantasie abzukühlen liebt. Esfiten 1876 .Büste" - Man verzeihe beilänfig das Eatir. Bettbilber ङ. 3 wir singen , die schöne Wort, das in jene Zeit nieht passt, wonit Bisste", ohne uns lylar zu sein, dab wir aber unsere prüde Gesellsehaft den warmen eigentlich mu das Hiedor im Auge loaben.

Butife ¡. $\mathscr{B} u$ d i f e

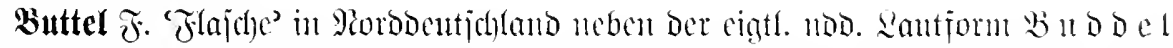

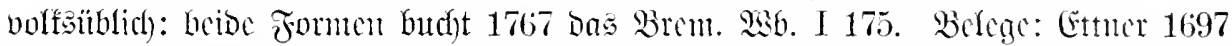
Doftor $\Xi .578$ I3udel. Jeander 1724 Briefe I 3, 321 Boutellen-Bier vulgo [in Eadjeru]

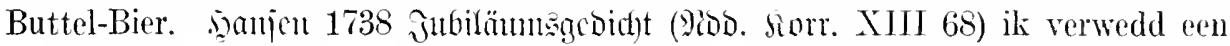
Buddel Wien. Frentay 1855 Eoll amb seaben II 241 die Buddel ganz gefüllt. Spicthagen 1879 Platt Sano I 255 eine Buddel Champagner.

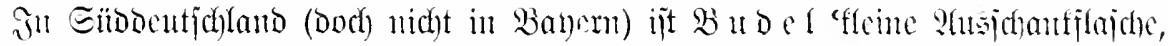

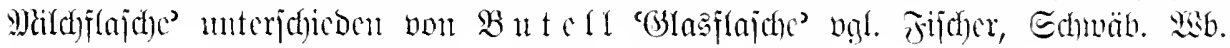

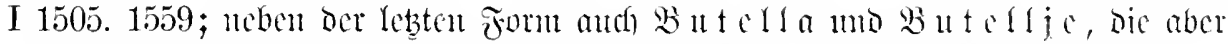

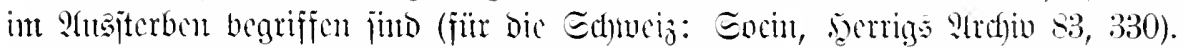

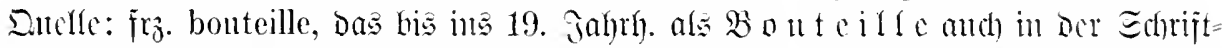

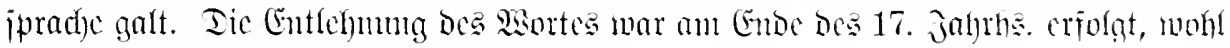
mit Dent jumport Der ausländijd)en Miciuc.

Belege: Ettner 1697 Chymicus こ. 108 Wein. Gstem 175.) an Ranter 15 201 sie

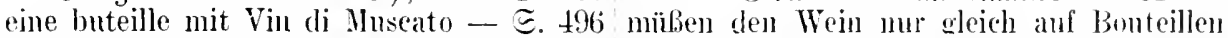

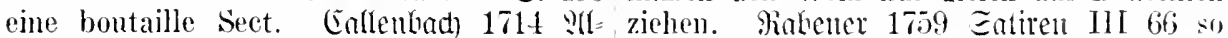
mannd ङ. 38 Indessen wurde ein Butellge trinken sie nu ein pair Boutcillen von nach der andern und zwar per posta, anf meinem Wein. Siganer 1766 findermiöberin meine Kreiten ansgepfiffen. Mnelijfu $1715 \cong .11$ wir trinken noch eine Bonteille.

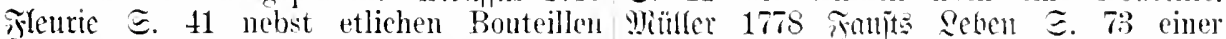
Spanischen Wein. \$SGilu 1722 Muthm Des halben dutzend Bouteillen. Echifler 1781 Tabats E. 103 einen Krug, Bouteille oder Brieje I $36 \mathrm{Ich}$ will mir ein paar Bonteillen sonst ein Glab. Giohr 1728 3ercutontell=| Burgunder drauf schmecken lassen. Bahrot wijenj(hajt I 446 dals ein Becher mit Bier 1790 Rebensbeja)r. II 241 Butellen -und eine Carafine mit Wein oder eine III 360 Buteljen. Sutiage 1792 reije $\Xi$. andere Bouteille hingesetzt wird. 1737 213. Sout 1798 9hth)ropdogic 5.46. Siito. Balboher ฐ. 30 eine Bouteille Kauscher- 
C.

Bgl. and $\Omega$, Sal unt 3.

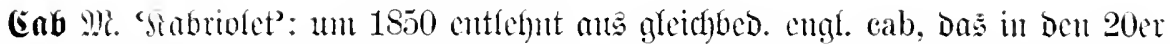

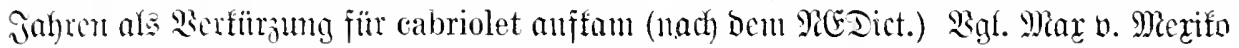
1852 2 \&eben III 30 unter ihnen saht mein Auge zum erstenmale einen Cab, jene unsichere Beförderungsmaschine, die ich bei meiner Rückkmnft in Wien, der Stadt der Fiaker par excellence, schon ganz gang und gäbe finden sollte. Die-Einführung der Cabs ist ein geschichtlich wichtiger Moment, ja einer der vielen Todesstöße, die die Cultur des aufgeklärten Zeitalters dem gemüthlichen Wien versetzt hat

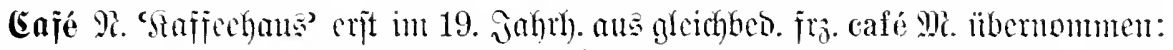

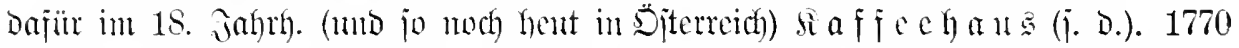

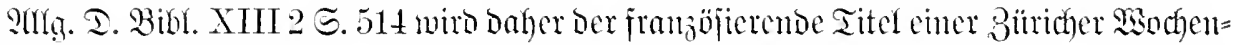

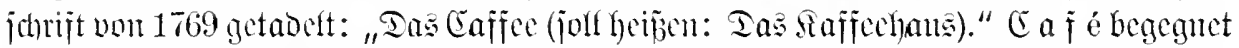

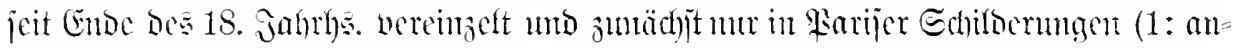

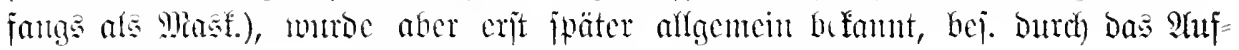

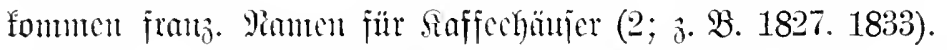

Belege: 1. Etmr; 1769 Edhriften I 169 Royal zu Berlin. Dürring 1830 Fragn.

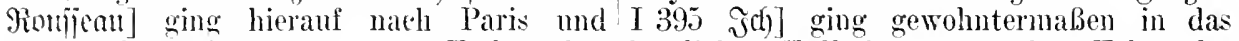
lebte iuberst eingezogen.... Er besnchte herrliche Kaffeehans an der Ecke des zureilen den Caffé de la Regente und Platzes St. Charłes [Turin]. Meine Wobsprach fremullich und gerne mit Jeder- nung stieß hart an dieses Caffé. Böme

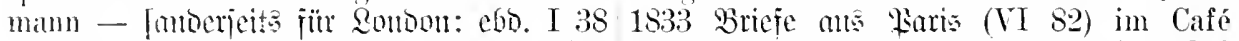
in dem Calfé zu st. James]. 1795 Beitr. Français unter den Tinden. Bantoy 1836

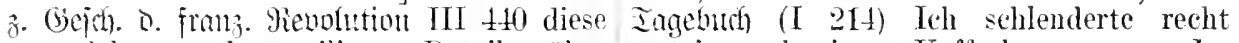
ansgedehnten, langweiligen Details über trotzig nach einem Kaffeehanse ... Im den Kaffe Corazza. Devrient 1839 Birieje Café kommandirte ich, um mir ein Air au Par (IV 9) Freilieh ist man hier zu geben. die Französische Zeitung. Fon= in den Café's wie zu Hause. Guthfon 1846 tanc 1870 Briefe I 205 in guten Hotels

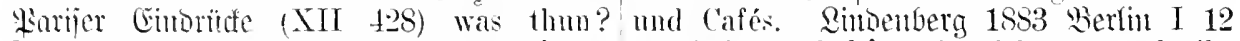
In Café sitzen und Domino spielen! die Wiener Cafés, die sich so rasch ihr 2. Seine 1827 goeent (III 154) in Café Terrain in Berlin erobert haben.

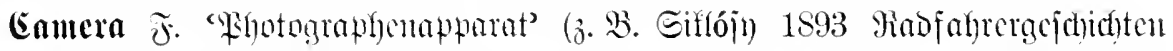
Є. 33 Das ganze Hans sah wie anf die Sammellinse ciner Kamera): juntge Berfiürămtg

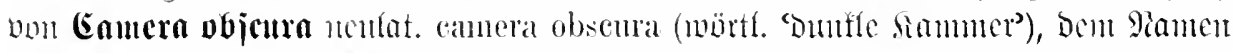

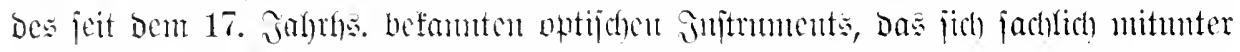

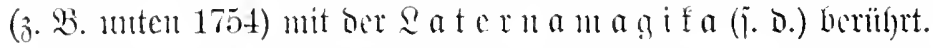

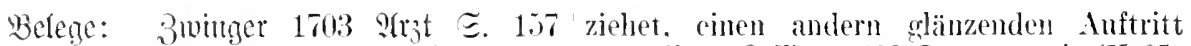
wie die cörperlichen bing in einer ver- vorstellet. Sejïm 1768 Sramaturgie (X 95) fincterten Limmer, obseura camera op- so mub uns Shakespear das seyn, wals dem tire anff wrissem Palpier oder Tuch er- Landschaftsmahler die Kamera obscura ist.

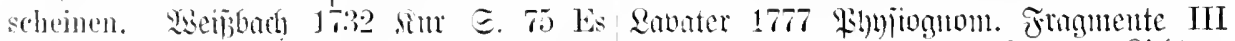
ist aber tal: alluge einer cimerale obscuran 180 eine lebentige Cantera obseura. Riditen=

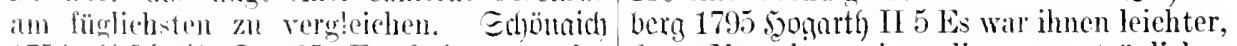
1751 Uejetgetif $\Xi$. 295 Es haben sonder den llenschẹ! in dieser untrüglichen \%weifel der tleer Rath die Camera ob- Camera obscura nachzuzeicinen, als nach scura sich diabey vorwestellet, welche so der Nitur.

oft der schwarkiuinstler ein Blatt werg- 


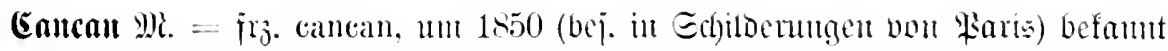

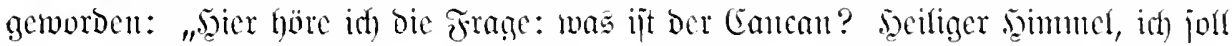

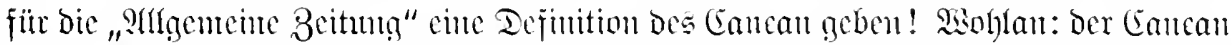
ift ein Tauz, ber nie in ordentlicfer bejelfjedaft getangt wirb, jonbern mur auj ge=

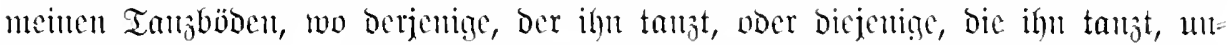

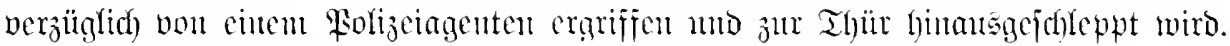

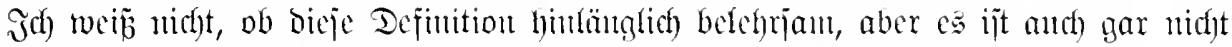

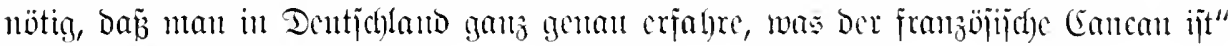
scine 1842 2ntezia (VI 298).

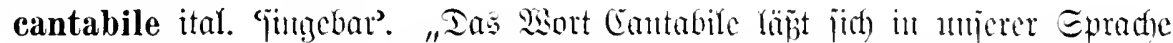

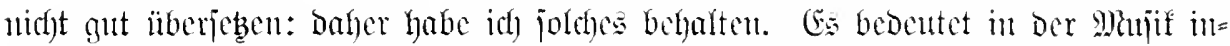

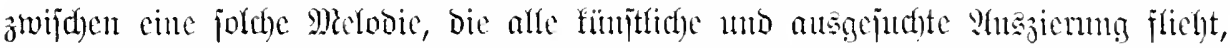

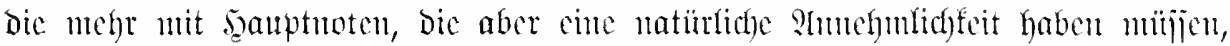
Jut thun hat" E(heibe 1745 strit. Majifus હ. 397.

captatio benevolentiae lat. wörtf. ‘ Streben uad)

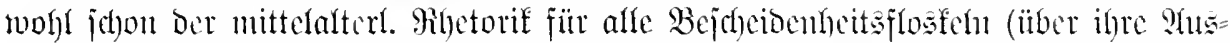

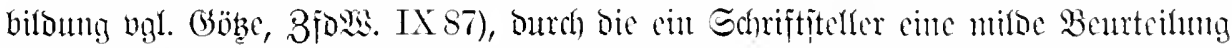

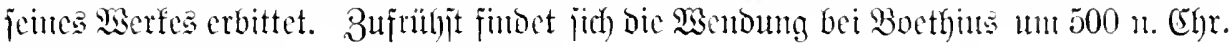
(Il)efaurus III 363). Neuere Belege:

(Eallenbad) $171+$ Puter $\Xi 40$ anf dab sehr nervösen Rede, welehe sich mit der ich durch keinen MiBtritt den Stiffel der zierlichen e. b. anfieng: ,ihr Ochsen!" 蚔itt Gnaden krümmer trette. Ecce das ist v. Iobrritug 1830 Fragntente I XVII eine

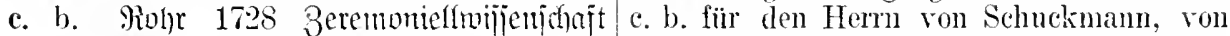
I 309 Hacht ers aber schlecht, so wird dem man weiß, daß er mir feind ist. er seine captatio benevolentiae wahrhafftio Mormam 1833 Diterreich I $1 \cong$. V der ohne anch vergebens anbringen. 9ticufai 1763 e. b. und ohne Vorbehalt ,höherer Einsichtt" Qiteraturbrieje IX 5 und was derghejehen es sagt, wie er denkt und sieht. (6has -

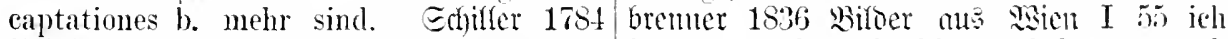
Brieje I 213 Sehen Sie indessen diesen Vor- fü̈ge noch als c. b. hinzu, daß man auch bericht ja nicht für eine sogenannte C. b. Wienerin sein kamm, ohne gerade in Wien an, weil ich jetzt zu einer Bitte übergehe. [geboren zu jein].

(5. (3). Cramer 1794 (bseniejtreidhe I 38 in einer

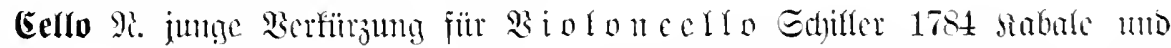

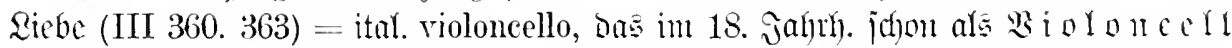

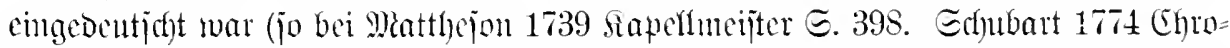

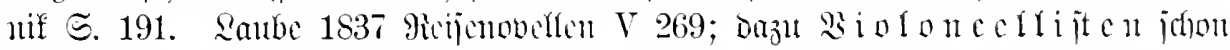

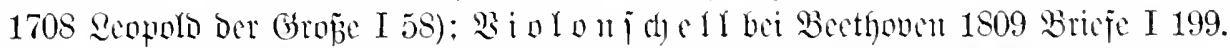

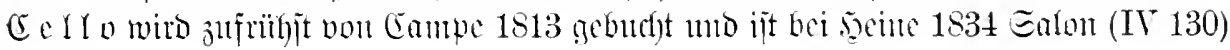
betegt.

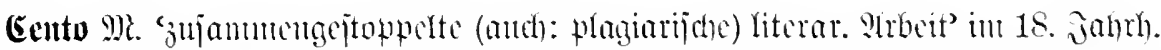

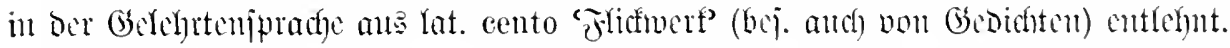

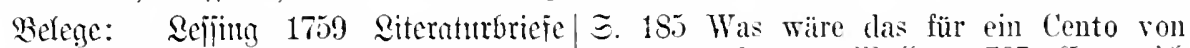
(VIII 95) Ich wenigstens kann seine Sehil- Widersprüchen. M!hüffer 1757 Emmerid) derungen für nichts anderes, als einen I 111 jede seiner Predigten war ein Cento beständigen Cento aus Pope, Thomson. von abenthenerlichen Bildern und Blumen. Hervey.... halten. Edjubart 1755 (Shronif 


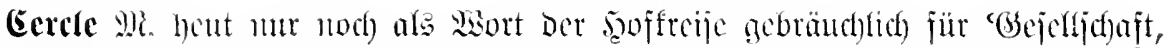

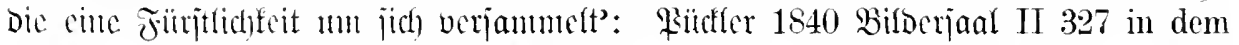
groben Saal ward Cercle um den Monarehen gemacht. Fifter alfgemeiner 'vontebme

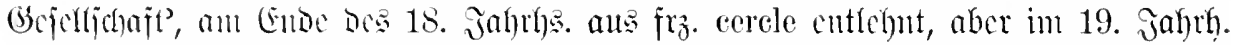

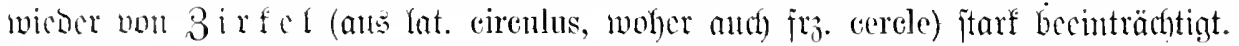

Belege: Meinter 1777 Beitr. ă. Obejch. D. ein Cercle, eine Assemblee unterhaltender. Deutichen Eprache II 10 Wie weit frucht- Jean Foull 1793 lunjidftb. Loge (I 34) im barer ist nicht z. B. in Paris oder London vornehmsten Cercle, den es vielleicht gibt. ein geistreicher Cercle für den Witz und das, Qnube 1836 Reijenobeften IV 18 Es wird Genie. Mïllfer 1789 (Emmerich) VIII 226 Niemand so thöricht seyn zu behaupten, Lnd um wie vicles ist wohl eine Hofgalia. daf die vornehnen Cerkles geistlos seien.

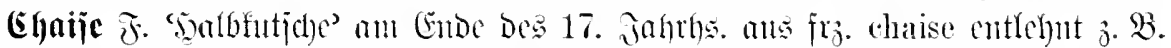

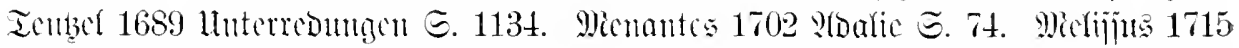

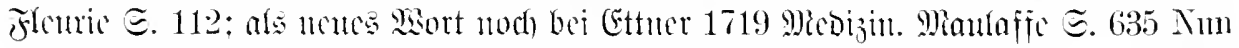
aber ein Wagen eine Chaise, eine Hure eine Dane und ein Schelm ein Politieus heisset. Bei obo. Edyriftitelferu (Salhover 1689 Gartenbeetrein II 1209". 1250". Ecthamer 1699 Inta I 602) Yhünfig italienifiert zu $\Xi$ d)

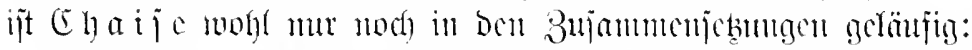

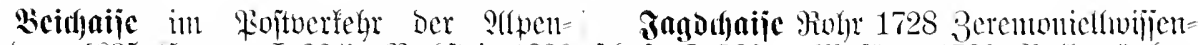

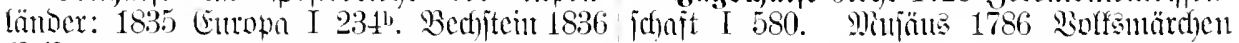
Reijetage I 194 Dem dort z.1 Lande ist V 163. von Beichaisen keine Rede.

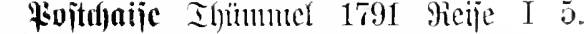

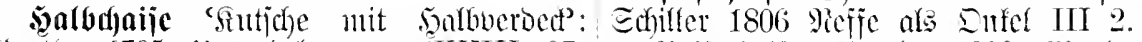
Goethe 1795 lluterfaltulgen (XVIII 97) Becijedfaiie Goethe 1829 simberjabre Kammermädchen mo Kanmerdiener folgten (XXIV 163) Eine zweisitzige, nene, ganz in Halb-Chaisen. neueste Reisechaise.

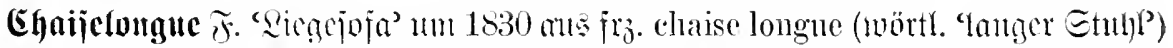
entfer)ut; anjangs (Füefler 1831 Bricfo IV 38. 413. Ievrient 1839 Fabrifant [IL 209]

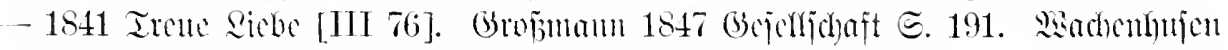

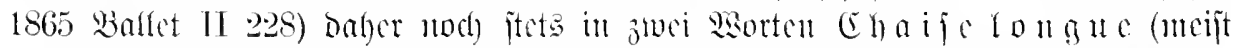

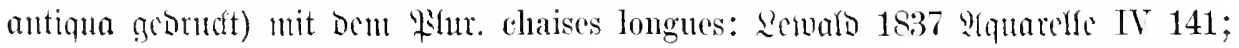

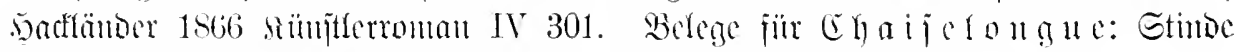

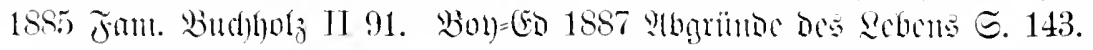

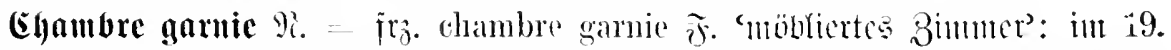

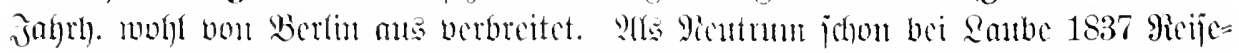
noveffer V 424 in eins der chambres garnies, wo noth hente bewegliche Garcons zu finden sind. Bimard 1849 Bricfe ङ. 136 Iehs schwanke noch, ob ich mit ihm zusammen im chambre garnie wolmen soll. Fautchen hänfig auch of)ne ?(rtifel gebranteft:

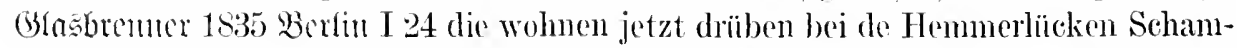
berjarnie. Epiefhagen 1860 Probremat. Miaturen VIJI 40 Sie wohnt chambre garnie.

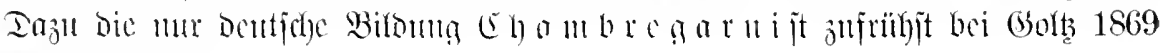
然eftthinghe it I 256 .

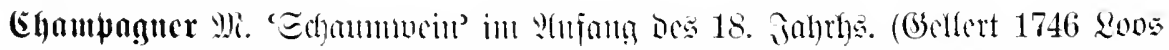
[III 282]. Finnter 1747 an Brein [I 71]. Rabenter 1759 Entiren IIl 65. 88. 150)

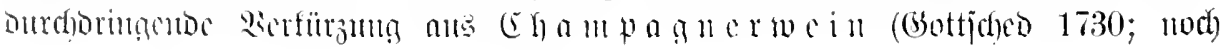




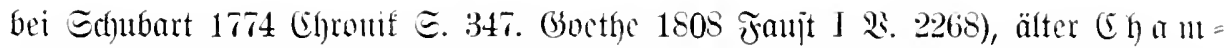

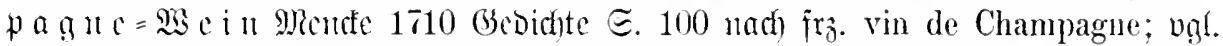

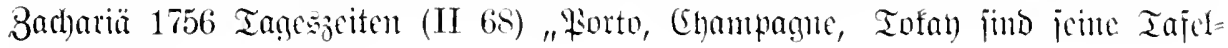
provingelt."

Champiguon 9 ?. un 1700 ans $j$ jo. champignon cutlehut: "Dic Gartcu=

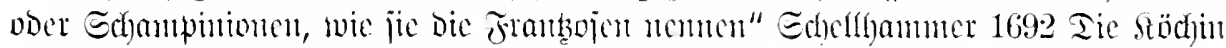

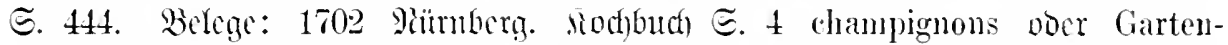
Schwämme -

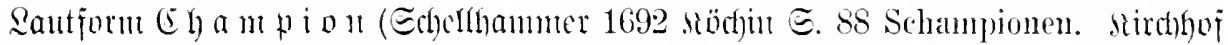

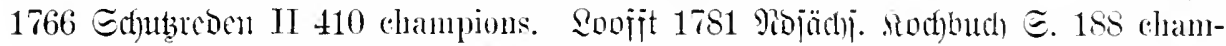

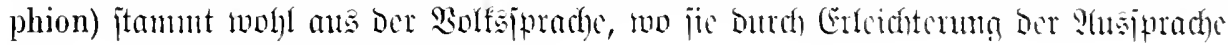
von $\mathrm{fr}_{3}$. champignon cutitantoen ivar.

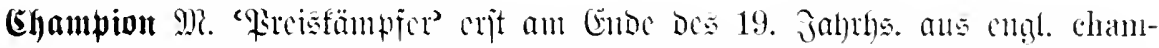

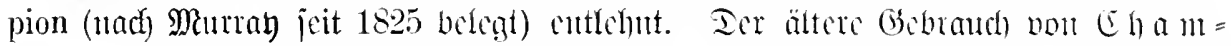

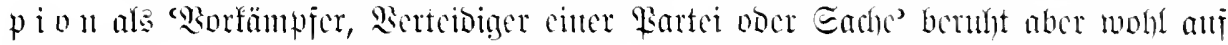

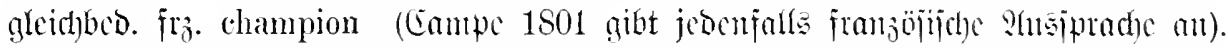

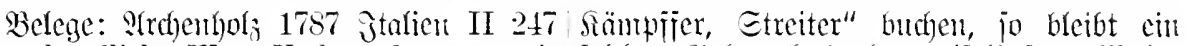
das schändliche Wort Verläumdung, womit joldher (bebraudh boch jueifelhajt. Weahr= sich der Champion Italiens nicht entblödet jafenlidg liegt Darin wieder ein abgctürster hat, meine Urtheile zu bezeichmen. Edhiller sumweis auf bas Engl., ipeziell ani Dent 1796 Brieje V 108 von einem Champion ,King's Champion", bejien Funftionen bei

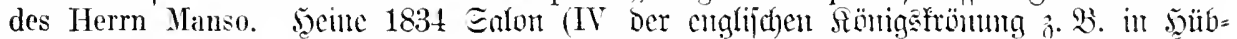
125) der kleine Simson blieb doch der be- ners fonverjationsilerifon ${ }^{8} 1717$ ङ. 386), ständige Champion des Deismus.

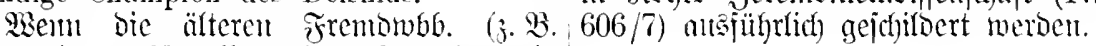
Eperanber 1727) allgemein "(hampion, ein

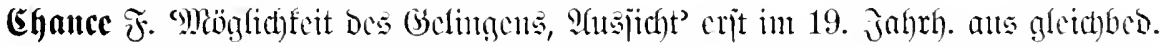

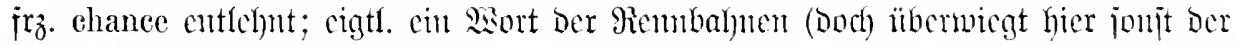

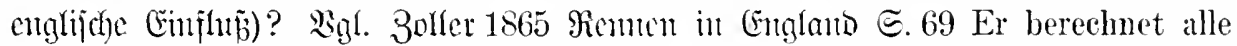
chancen. ¿ntoan 1887 Mmuc Wï̈dyen $\subseteq 30$ Die Herren unterhielten sich lebhaft über die Pferde, die beim nächsten Frühjahrsrennen am meisten Chancen haben wiirden.

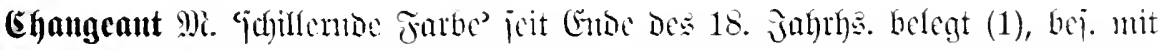

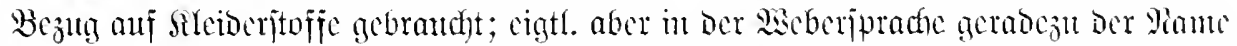

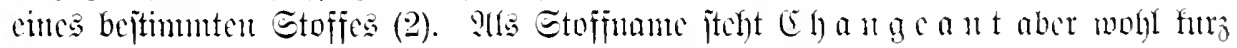

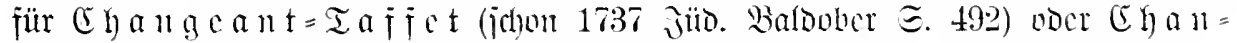

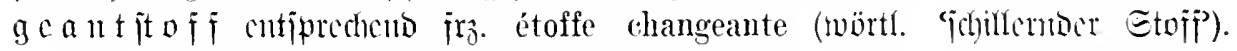

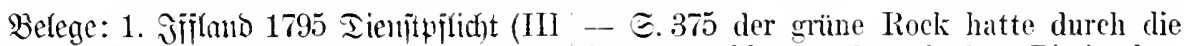
182) Die Welt und ich sind von einerlei Sonnenstrahlen und auf den Bierbänken Farbe, changeant! - Changeant! So? einen eigenen Changeant angenommen.

Nun, spielt Ihr heut ins Dunkle oder ins 2. Qejjing 1767 . gamburg. Iramaturgic Helle? - Aus dem Silbernen ins Goldene (X 309) Aus der beständigen Durchkreuzung und umgekehrt. Jäger 1835 Felix હdhuabel solcher Fäden ron ganz rersehiedenen ङ. 202 dessen Kleidung, als Beweis der Farben entsteht dann eine Contextur, die gesunkenen Kunstliebe des Volks, einen in der Kunst eben das ist, was die Weberei sonderbaren Changeant angenommen hatte/Changeant nennt: ein Stoff, von dem man 
nicht sagen kamn, ob er blan oder grün, ein Spielwerk der Mode, ein Gankelputz grün oder gelb ist; der beides ist, der ron für Kinder.

dieser Seite so, von der andern anders ist;

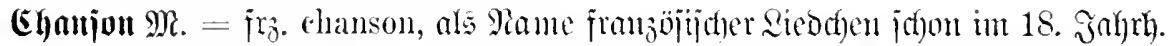

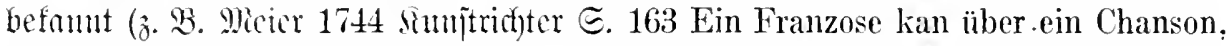
das in einem Paar Zeilen einen nuttelmäBigen Gedancken ausdruckt, vor Freuden hïpfen und springen), boch faum je wirflich cingebiltgert.

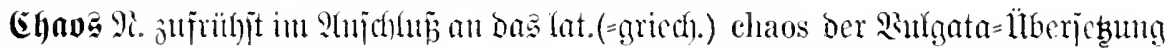

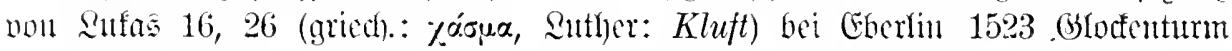
(III 113) O Petre, wol dir, das du zwischen disen obgeschribnen vnd angezergten baliamitischen priestern rund dein, ein grob chaos hast. SUber ber häufigere Be=

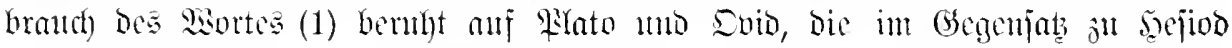

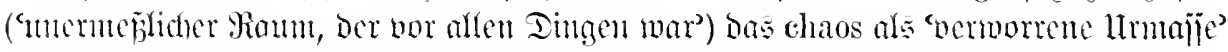

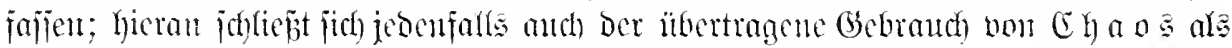

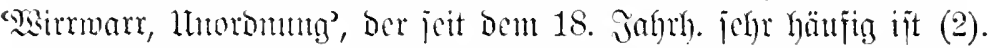

Belege: 1. Chr. Wirjung 1559 bei şöpjuer, vernachlässigter Handlungsbücher. 1799 Rejormbejtr. ङ.28 Du ligst ye vergraben :Itt. Muifeum III 173 Chaos von Nachwol Im Chas, da kein end noch grund Der richten.

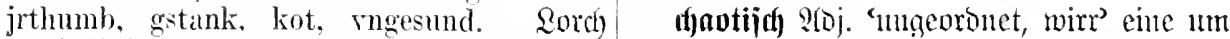
1605 Felation $\Xi .13$ weyl in der gantzen 1700 anftretende Biloung (gleid)zeitig engl. Statt kein einziges Haub zufinden, rnnd chaotie), bie wohl cin neutat. chaoticus alles mehr einem Sumpff oder rerwïsteten voransietit (nad) Dem Manter gried). Werbal=

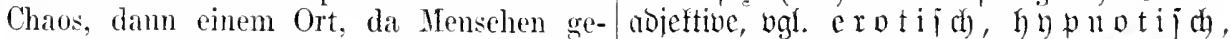
wohnet, gleich sale.

2. Gottiched 1741 Banles 2 se. I 123 sem ganzes Werk ist ein Chaos. Wieter 1744 Simmintrichter $\Xi .114$ Thre Begriffe sind ein Chatos. Rabener 1759 Entiren II 5 Von Blumen aller Art ein gantzes Chaos. 1765 Utlg. I. Sibfiothet I 1 巨. 270 Jede Erminterung ist ein confuses ('haos. Echiller 1789 Sutritterebe (IX 91) wemn das rerworrene Chaos sich sondern und die streitenden Mlachte des Staats in dem gesegneten Gleichgewicht ruhen sollten. Gediffe 1789 ङ(f)uljuriften 116 Historic ohne schon daseiende geographische Kemntnis ist ein verworrenes Chaos. Q(rehenthol, 1790 Eieben $=$ jähr. Sirieg Є. 110 das Chas seines Heers. Eurgel 1795 Qurenj Etarf E. 374 das Chaos der Gefühle.

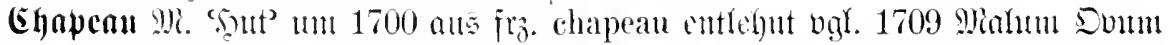
๔. 295 Der Hut heist jetzt nit mehr auf gut teutsch Hut, sondern Schappo. Das

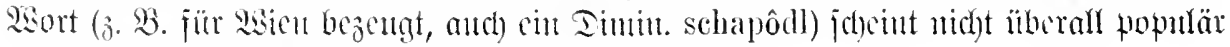

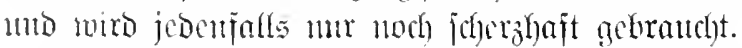

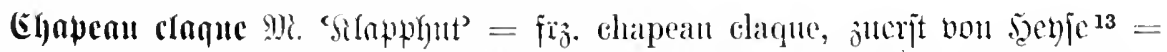

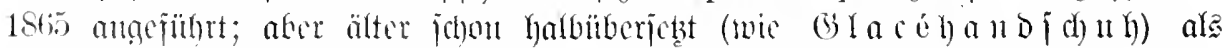

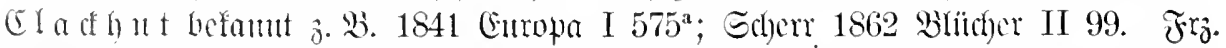

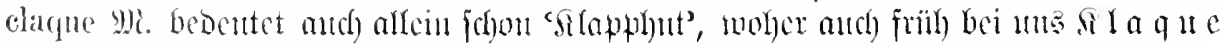

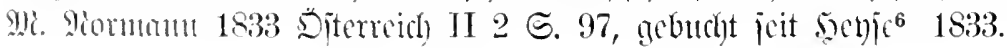




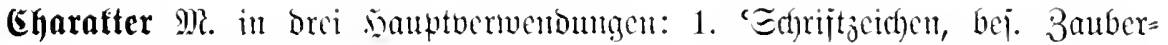
jeichen' jeit Dem 15. Jahrb., vereinjelt auch jobon in mbo. Beit. 2. 'amtliche (Eigen=

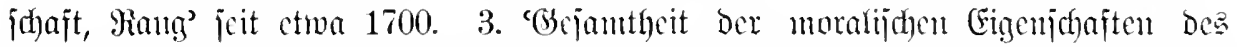

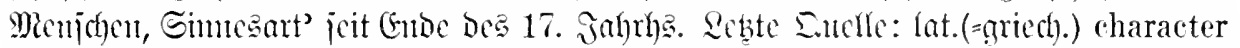

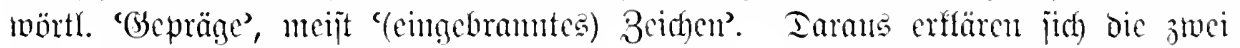

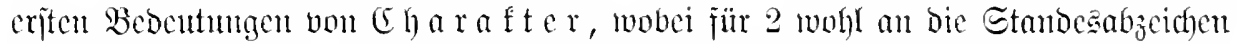
crimert werben barf (bgl. er ist seines \%eichens ein Schuster; Das Frembroort murbe

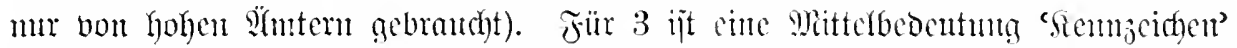

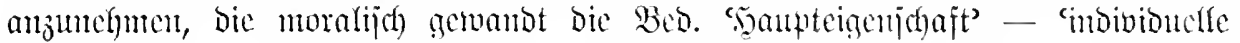

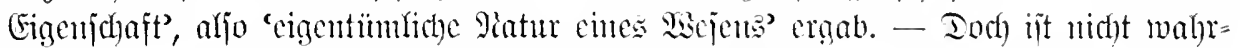

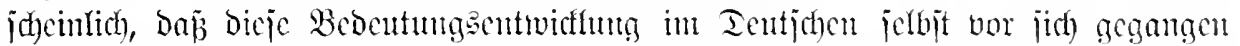

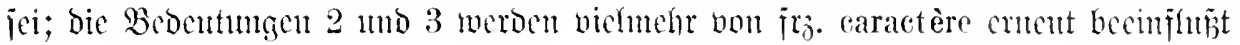
jein.

Belege: 1. Brant 1494 Parrenijhiff $\cong .40^{\mathrm{b}}$ segen jn den dott Mitt kracter rnd mit narren wurtz. Emjer 1521 Etreitjar. II 175 die tzouberer mit yren caracter, vnbekanten worten vud aberglouben. Fudf : $=$ berger 1534 Dialeftif $\Xi .83^{\mathrm{b}}$ durch etlich verborgen character vund buchstaben gemalt. Fabricius 1588 こurims? (Egronif $\widetilde{\Xi} 174^{\text {b }}$ mit worten, schrifften, druck, erdichteten characteren oder sonst auff cinige ander weiß. Soof 1601 Błumenfeld $€ .41$ Caracter, Kraut noch Segen, Ja gar sein Wehr ind Schild. ¿ebenwalot 1680 II 36.

2. Ed)on Etiełer (3eitungaht 1695) butht bic Ses. „ein Eenremuan, Etand uno 2rmt". Sigl. "aud) Callentad 1714 (Ge $=$ nealogic $\Subset .10$ ein character bedeckt viele sonst infame Commissiones - Wiurmilano ङ. 41 Du wärest aber ein Doctor ohne Rang: dann du stïndest in keinem Charactere. Edelmann 1752 Reben $\Subset .137$ Ich stellte demnach meiner Gräfin geziemend vor, daß ich mit einem so schlechten Gehalt mich unmöglich meinem Character gemäß würde aufführen können. Głteim 1755 an Fumler II 189 Jifopitoff] soll nächstens einen andern Caracter als den eines Hofpoeten bekommen. Miöjer 1776 Phantaijen II 341 Charakter eines Assessores. (Goethe 1796 Rehriahre (XXI 261) Er habe den Charakter als Major. Bujrïhit bei Eectendorif 1685 (Ehrijtemitant l 403 so ist ja der Obrigkeitliche Charakter, Hoher und Mittler, kein solcher Stand, der die Personen von der Schuldigkeit der Christen befreyete.

3. Thomajus 1688 Monat:gejpräd) I 795 zumalen, da er seinen caracter selbsten so exprimiret lätte, daß er kein Gemüthe habe, welches jemand zu Schaden trachte.
Reibuiz 1700 Echriften II 405 Der Character einer jeden Person ist sehr wohl hieimen

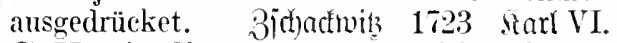
S. 77 sein Character erreget vielmahls bey gantz indifferenten Personen eine sonderbare Curiositaet. Gottidjes 1741 Edjoubiilyme III xrir eine Ode, die dergleichen Character abgeschildert. Gellert 1747 Bärtl. こd)weiterı (III 87) Sein Charakter ist edel. Sinctel= mam 1755 Gesonufen $\Xi .40$ Aristides hat sogar, wic man sagt, den Character eines gantzen Volkes ausdrücken können. Iuj( 1764 Brieje I 60 Woher kömmt es, daß es gottlose Charactere gibt, welchen die Bühne durchaus verbothen ist. Jerber 1765 sierfe I 110 die Charaktere der Männer, die auf der Bülıne der Begebenlleiten cine Hanptfigur machen.

darafterifieren 3 tw. entjprecheno Den bei Charafter gemadten llnteridhei= Dungen 1. 'mit Beichen verjeken' Echottel 1663 sauptipracte 5 . 568 Characterisiren und rund bezeignen [wohl fiir: bezeichnen]. Rebentualot 1680 Ielfels Qijt I 52 mit einem Characterisirten kupffern Plechl.

2. 'eimen Titel verleihen' Callenbach 1714 Murmlano $\Xi 41$ Die Doctor müssen characterisirt seyn - $\Xi .45$ Eine characterisirte Person mub nicht so bas tractirt werden (jenealogie ङ. 9 Man wird ihn zweiffels ohne besser characterisirt haben.

3. 'nach) jeiner Eigenart Daritellen, femm=

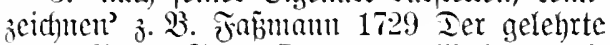
Yarr Borr. ङ.32 Indessen will ich doch probiren, ob ich sie characterisiren, oder denenselben solche Merckmahle beylegen kan, daran man sie gar leichtlich erkennen mag. 1737 Ӭï. Barbober $\Xi .2^{b}$ da viele Ertzdiebe darimnen schr accurat characteri- 
sirt und ihre Ubelthaten gerichtlich protocollirt sind. Philtipi 1743 Meimidniede= funit $\subseteq$. 69 Wer einen poetischen Mist-Käfer in einem Gedichte gern characterisiren mögte, darf nur alles so platt zu nemmen. Meier 1744 Sumptrichter $\mathbb{S} .194$ da will ich es meinen Lesern überlassen, dieselbe an deni vorhergehenden zu characterisiren. Duid) 1764 Brieje I 159 Wie erhaben ist die Yorstellung, wenn er den Schöpfer characterisirt. 1765 offla. I. Dibfiothef I 5.71. Sherber 1767 Deutjo Riteratur (I 144) Beobachtungen über Fehler nud Tugenden, diese characterisiren den hohen kritischen Geist - (431) wie sie in der Anlage des Plans, in der Fortführung der Ideen n. s. w. sich charakterisirten. Edubbart 1774 Chronif ङ. 238 Tiefsinn, ummmschränkte Belesenheit charakterisiren diese Geschichte. Bürger 1776 Brieje I 288 Seine meisten Arbeiten characterisirt ein heller philosophischer Geist.

Eharafterijtit $\widetilde{F}$ jeit Denl 18. Jafurh. bejentat 1. "Echillocrumg ber Merfmale, Sient= zeichen' aus einem neulat. (ars) characte-

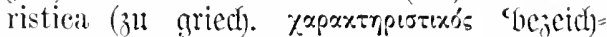
nend, unteridheibeno'? Bufribjt bei Meier 1744 Lebre b. D. Gemilitsbemegungen 5.9 Der dritte Hauptabschnitt der Aesthetischen Lehre von den Gemüthsbewegungen kan die Characteristik der Leidenschaften genemnt werden. Sie ist eine Wissenschaft der Zeichen unserer Leidenschaften. Zn diesen Zeichen der Gemïthsbewegungen ge-

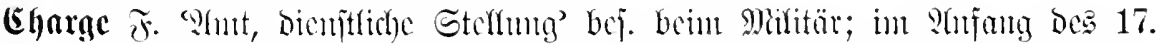

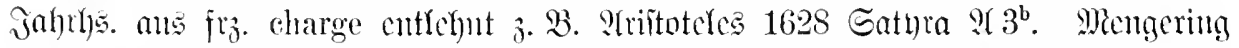

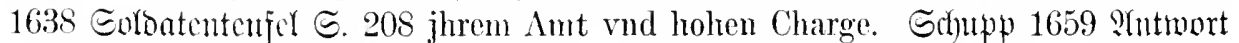

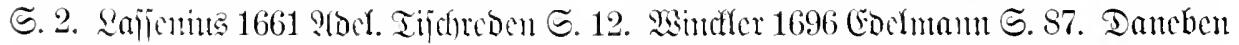

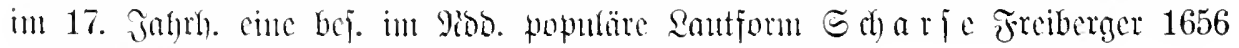
Polit. Iisfurje ๔. 477. Frätorins 1665 Satsentocit $\Im 5^{\mathrm{a}}$.

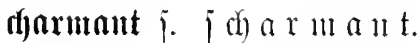

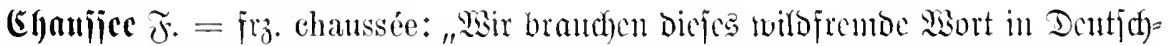

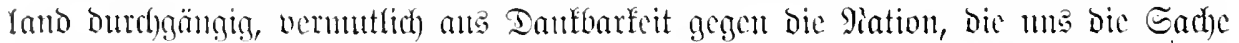

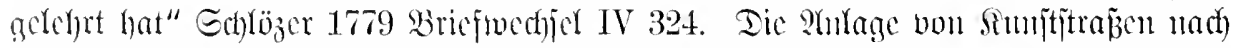

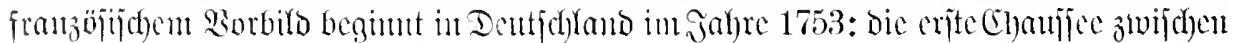

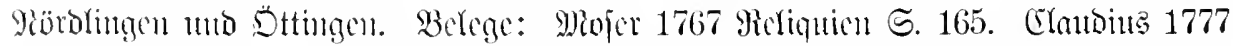

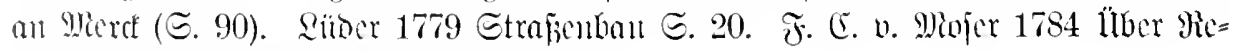
gentin (Siorr.). Micolai 1784 Sicije III 85.

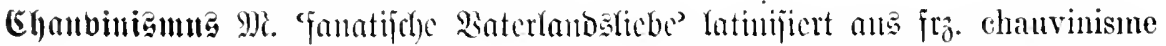

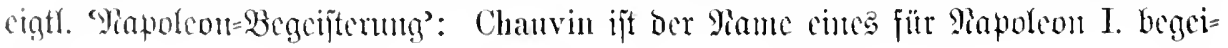


iterten Gefuten, bej. befunut getworben Durd, Gogutiatos Suitjpiel La cocarde tricolore

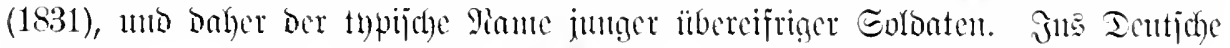

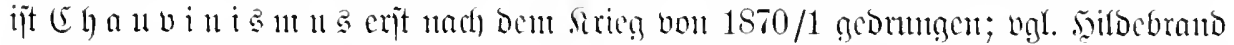

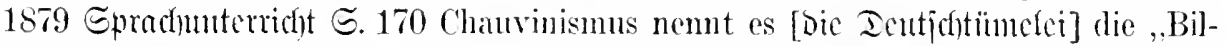
dung" gern, es ist noch nicht lange her. die schöne Pariser Pflanze mulite doch gleich auch in den dentschen Geistesgarten versetzt werden, dab wir nicht zurïckblieben.

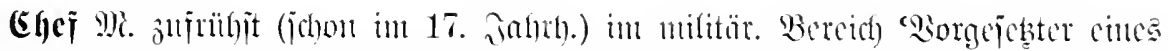

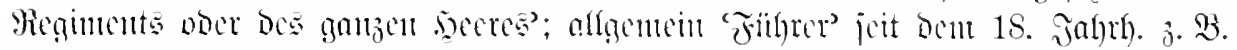
Eodmam 1741 Chriftu: 2 . Butal $\Xi .19$ Chef einer nenen abgeschmackten Secte.

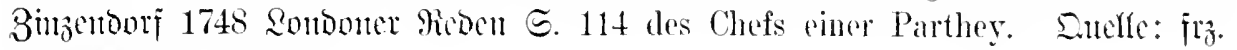
chef 'Scallt, Fithicer'.

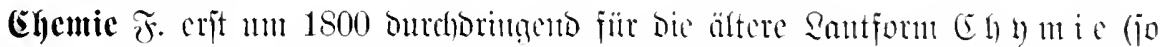

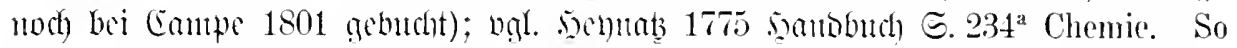
schreibt man besser, als Chymie od. Chimie. Sncfe: gried) \%rusíx, moneben,

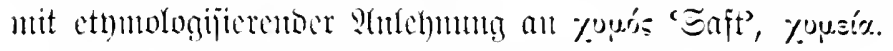

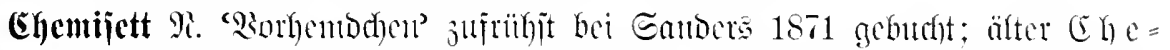
mijette $\mathfrak{F}$. (jofun bei sobje 1804), bas beul frö. chemisette entjuricht. Belea: 1838 Dic (Eijcubahn @. $115^{\mathrm{b}}$ Etwas feine Wäsche, wormuter Chemisets von inländiseher Leinwand - $\subseteq .155^{\mathrm{b}} \mathrm{Als}$ im Jahre 1828 die Vorhemdehen, die sogenannten Chemisettes, in Wien so sehr en rogue kamen.

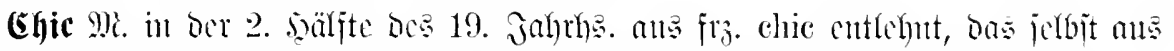

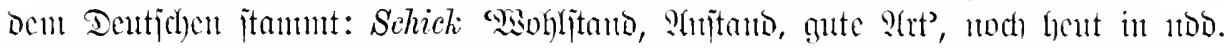
Mantbarten geläufig, aber in der Echriftiprade in 18. Jahth. veraltet. Ier moberne

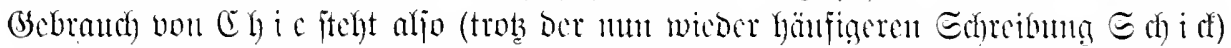

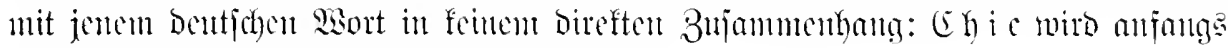
Durdhan als Rarijer Mobcwort empinumben.

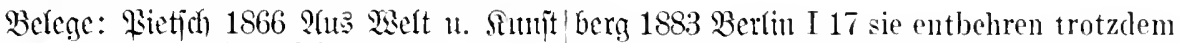
I 159 Mit leiehtem Pinsel ist alles dekorativ nicht eimes gewissen Chie. Jontane 1895 hingeschrieben, ein Meisterstück des, ,chic". Effi Brieit ङ. 34 Es hat alles so viel ehie.

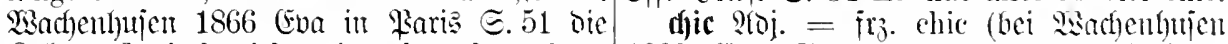
Sofotter] sind nicht einmal mehr sehön, 1866 (Eva $\Xi .36$ femme ehie). Belege: aber sie haben ein ,chic", das auf den Pariser Dohn 1880 2ierfümferin (bei Imtuger, Jrento= Viveur einen unwiderstehlichen Zauber aus- wörterumbejen ङ.57) mieh, die ich chik

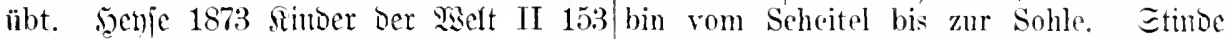
das hat wehigstens Tournure, Chic, Unver- 1885 Fam. Buhholy II 43 Ieh finde ihn schämtheit. Fontane 1882 R'खoultera $\Xi .55$ sehr chic. Fontane 1891 Tenun Ireibel Sie hat so ein bischen Genfer Chic. SEachen $=\approx .93$ eine Sommerjacke, daran alles chic

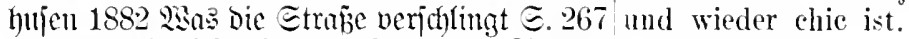

mit dem Schick einer Weltdame. Rintont=1

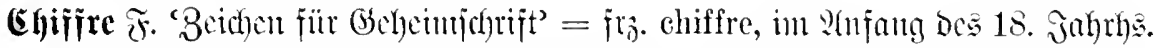
von beutjden Frentotobb. jdyon melyrjady gebudgt; in ben Belegen herrjed aber bis

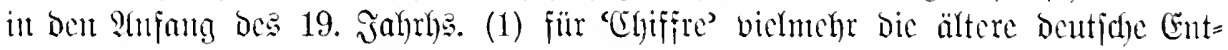
ipredung 8 iffer, bie wie jrz. chiffre urjprgl. 'Zahlzcidhen' bedentet: bie Chiffrier= 


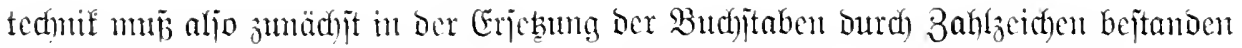

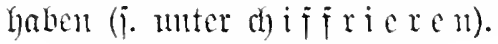

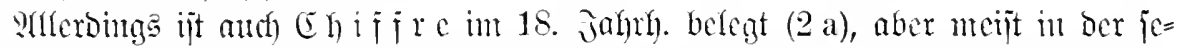

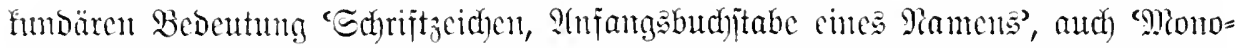

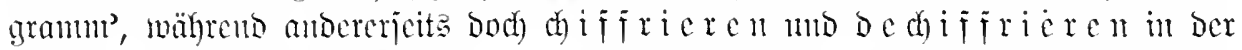

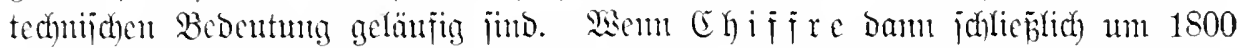

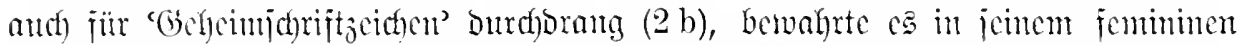

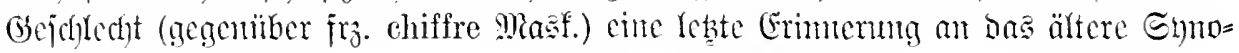

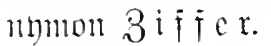

Belege: 1. 3 i j 1637 Pieu Ratrement $\Xi .331$ [irz.] chiffres: ziffern oder mbekante buchstaben. Garzoni 1659 2fflg. Echauthlat ङ. 282b Zipffern rnd verborgene Buchstaben. Sträıter 1681 Reben Der Ecehelben $\Xi .456$ mit Hinterlassung der Zeit und des Orts, allwo sie einander ror der Abreise wiederum sehen, und zu ihrer vorhabenden Correspondentz die Zyfer (geheime Schreib-Art) abreden konten. Sieir)= mam 1722 Roejie Der Rieberjadjen I 234 Als Chloris Ihm einen in Ziefern geschriebenen Brief zuschickte. Meiz̄mer 1789 Erzählungen III 85 zwar stieß ich auf eine Menge Stellen. mit einer Zifferschrift geschrieben. Erthiller 1803 Maria Etuart II 4 Geheime Briefe hat man ihm vertraut in Ziffern. Sobebue 1811 Tie Gritle $\Xi .5$ So zum Berspiel erwähnte sein Vater eines Tages zufällig der Kunst, Briefe in Ziffern zu schreiben, und alsobald quälte ihn Woldemar so lange, bis er den Knaben das Dechiffriren lehrte.

2. Chifire a. 'Zeidhen': Rünig 1719 Theatrum cerentul. I $783^{a}$ des jetzigen Grob Sultans seines Vaters und Grob Vaters Tahmen in einem Chifre zusammen gezogen. Savater 1778 Phnjiognom. Fragmente IV 56 eine Chifer ins grobe Alphabeth der Pbysiognomik. 1779 : gacin. Reiträge II 393 Sie gruben sich also eine ('hiffre oder ein Zeichen in die Haut. Goethe 1796 2ehriahre (XXI 325) es ist die ('thiffer einer Freundin. Echiller 1797 Bricje V 209 Auch bitte ich um den Tahmen Ihres Freundes oder um deBen Chiffre, wenn er unbekannt zu bleiben wünscht. Grubbe 18:36 Theater (IV 83) ich bin leider zu stoly, meinen Namen unter fremder Chiffre zu versteckell.

b. 'Geheimidnriftzeidhen' \$gilippi 1743 Reimidnuticbefumit ङ. 254 wenn solche ChiferSchriften gefunden oder aufgefangen werden. Edhfegel 1801/2 Sorlejungen I 91 Kant spricht einmal ron der Chifferschrift, wodurch die Natur in ihren schönen Formen figürlich zu uns spricht. (socthe 1811 Tidg= tung 4. Maghrf. $(26,59)$ Tame und Offen= barung waren in Chiffern geschrieben - 1819 : Sendung - Mir von der Herrin süße Die Chiffer ist zur Hand. Daufi 1826 Mientoiren D. Eatan: (VII 117).

dififricuen aus fry. chiffrer; Fijlippi 1743 Reimjchntedefunit હ. 254 Xach den mathematischen Wissenschaften ist die Cryptographie, oder Chifrirungs- und Dechifrirungs-Kunst auch heut zu Tage eine bey hohen Standespersonen sonderlich im Schwange gehende Wissenschaft, und lehret auf verdeckte Art zu schreiben, durch Verwandlung einer Schrift in abgeredte Zahlen, oder versetzte Buchstaben, oder verworfene Lese-Arten, daß man sie ohne Sehlüssel nieht füglich lesen kann. Floriu 1749 Jaus= bater II 31 $31^{\text {b }}$ einen Brieff des Frantzösischen Abgesandten in Pohlen, so mit Zahlen geschrieben war und den er chiffriret mit anführet.

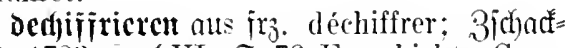
wib 1723 Sarl VI. E. 76 Er schickte Courriers aus, einerley Schreiben, die gar leicht zu dechifferiren stunden, zu überbringen. $\mathfrak{Q} \mathfrak{i} \mathfrak{i}=$ Lippi 1743 Reimichutedefunt $\Xi .254$ Dechifrirungs-Kunst. Edhubart 1755 Chronif $\Xi .74$ Wer kann, der dechifrir mir diese Schrift. Snatif 1826 Miemoiren des Eatans (VII 25. 26).

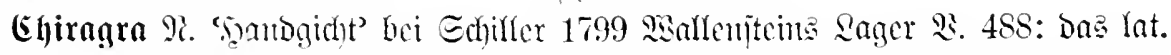

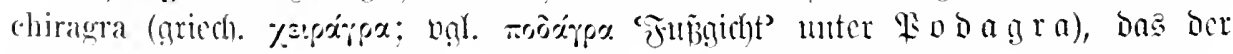
medizin. Terminnlogic idnou in 16. Jahrh. angehört j. B. Fries 1519 Epicget D. Qnguci $5.154^{3}$ wan er [oer Sdhmerj] in den henden ist, heißt er Chiragra.

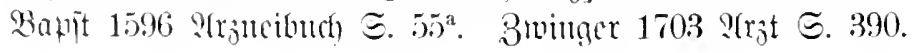




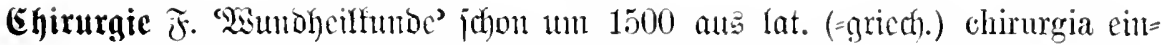

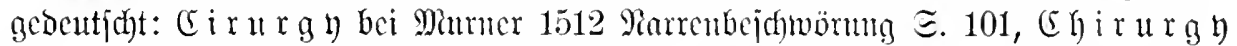

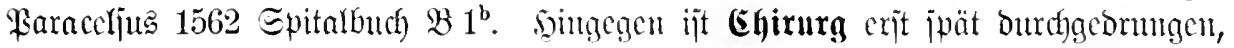

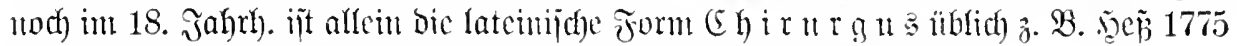

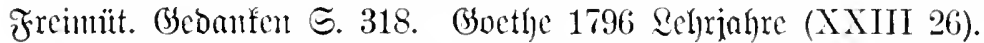

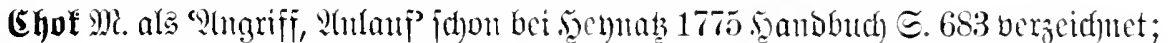

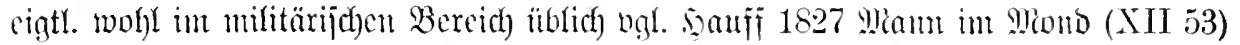
den Dienst der schweren Kavallerie, die in Carriere gradans sprengt, das feindliche Viereck durch ihre eigene Wucht und Sohwere im Choc zu zerdrücken. Gsols $1 S 47$ Bud Der Simbheit $\Xi .453$ beim ersten Chok der Kosaken. Fuelle: jry. choc

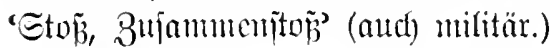

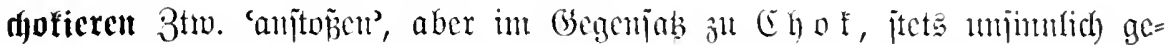

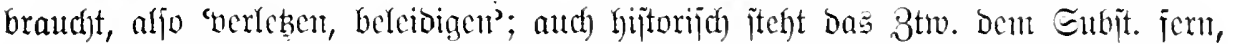

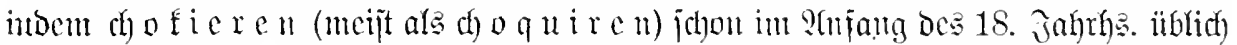

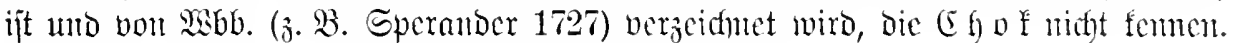
Duclle: jrz. choquer (aud) in ber ïbertr. Bebcutumg).

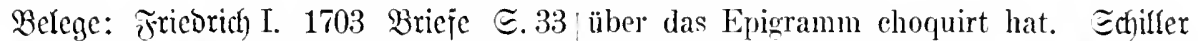
man suchet Braunschweigischer seite nuhr 1789 Brieje II 418 So fällt also alles weg, alle gelegenheit, Mich zu schocquiren. Mientfe was meinen Vater oder eure Mutter oder 1710 (Sedic)te $\Xi .309$ daß nicht allzuviel die Welt choquiren könnte. Jifland 1795 Consonantes zusammen kommen, welehe $\mid$ Reije (II 88) Mir kommt es vor, als ob ihn die delicaten Ohren nothwendig mehr cho- unser Anfwand choquirte. Piüfler 1831 quiren müssen, als die Vocales - Hernach Bricje IV 337 die meisten angeblich sehockichoquirt es die Ohren überaus sehr, wenn/ renden Dinge. Seine 1840 an Campe (VII man die kurtzen Sylben lang und vice versa 548) das Ganzaussehreiben meines Vorgebraucht. Qejijing 1772 Brieje (XVIII 10) namens Heinrich chockierte mich hier. welches auch sehon in den Abhandlungen

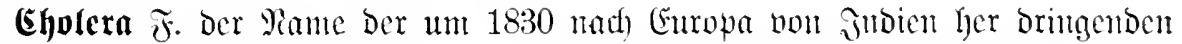

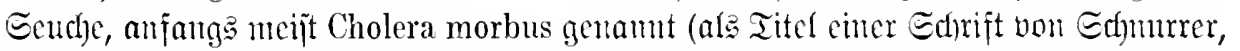
Etuttg. 1830; vft aud) bci Börne 1832 Bricfe aus :

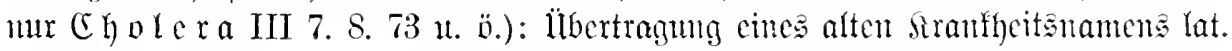
(=griech.) eholera (morbus) 'Gallenbrechnulf)r' (ber in ber ntedizin. Riteratur bis

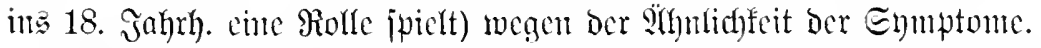

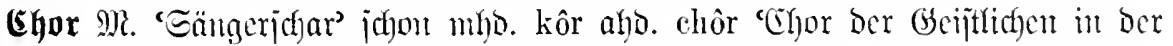
Sirche'. Enclle: Iat.(=griedf.) chorus: dic lat. Form (Chor

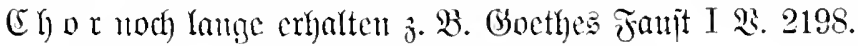

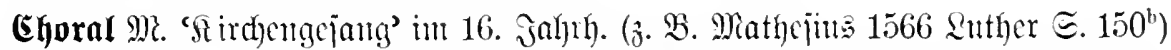

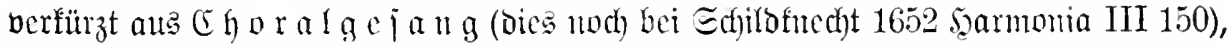

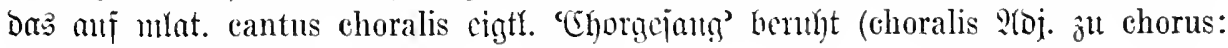
‘um (shor geflürig').

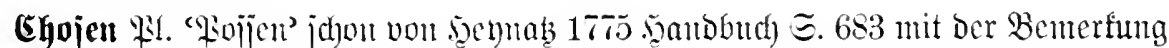

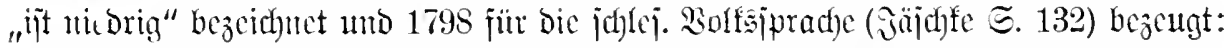

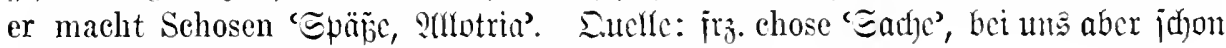

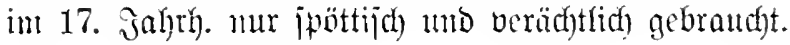


Belege: Mojateroja 1645 Qhifanoer III es nimmermehr gemernt. Bolts 1731

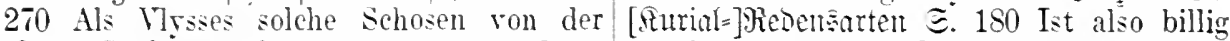
alten Spülmagd hören muste. wurd er zu bewundern, daB gegentheiliger Angantz Fewerroth. Smaranthes 1710 Proben wald solche abgeschmacke Chosen in einen ङ. 310 Die Weiber streiten $u m$ die Hosen. so hohen Gerichte fürzubringen sich nicht Dic doch des Mannes eigen sernd, Lnd entfärbet. machen ihm offt solche Chosen, Dab er

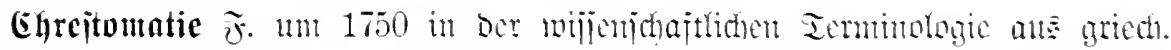

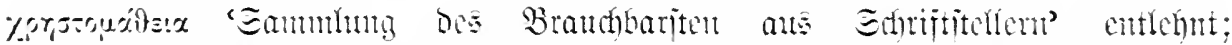

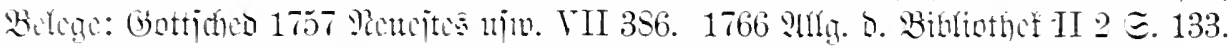

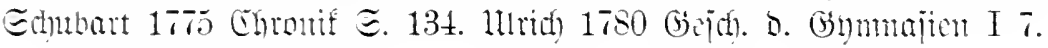

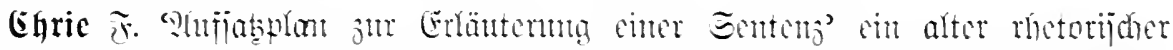

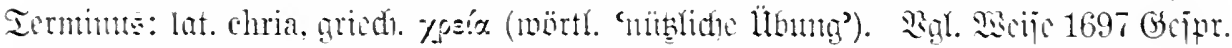

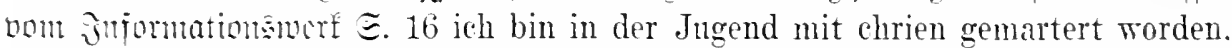
daf ich manchmahl nicht wuste wo mir der hopff stund, da solte ich ein Gleichniib haben, und wuste keines, da solten Exempel und Sprüche vorhanden sesn

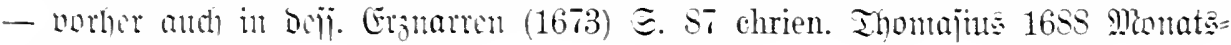
goipräd) I 650 .

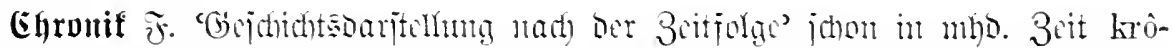

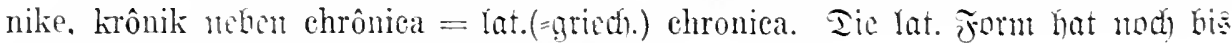

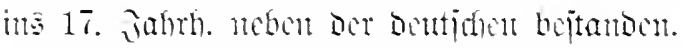

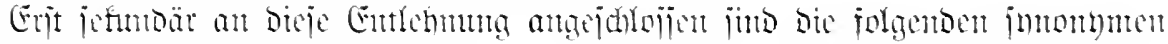

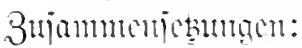

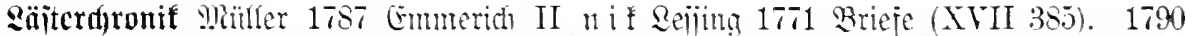

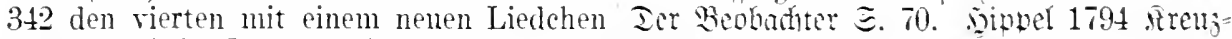
[ju unterbulten]. den fünften mit der u. Energïne II 171. Góthe 1795 Inter= Lïsterehronik.

Edjatodyronif Seijing III 194 wenn man in gesitteten Ländern ron Anfange an alle dicse Abwechselungen [De: Beitgejomads] in besondern Büchern anfgezeichnet hätte. so würde man diese Bücher nicht besser als die Schandehronike des menschliehen Geschlechts nennen kïmen.

Efandald)ronif Etterr 1870 Farrago letzten Balles Erfuhr ich gern durch Sie. E. 338. Vülter Dafiur if a

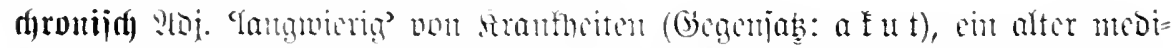

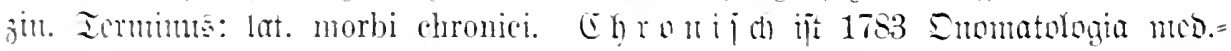

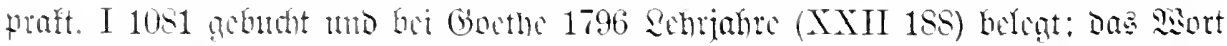

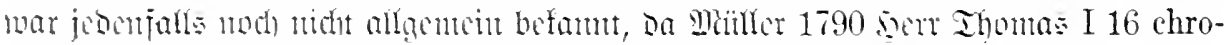
nische Krankheiten nod) mit Dor : Immorknt Langwierige crflïrt.

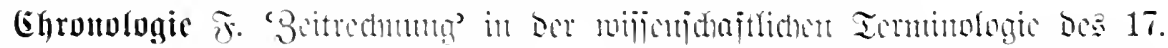

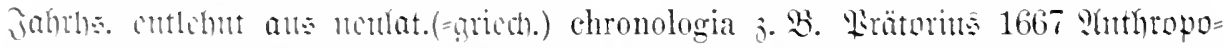

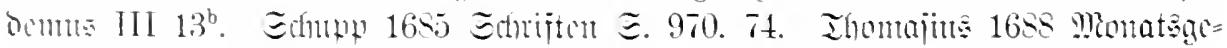

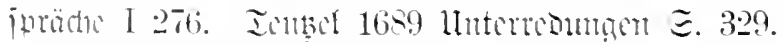

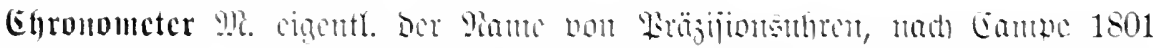

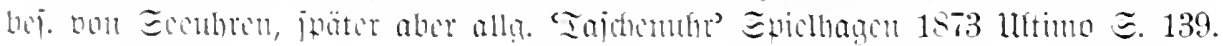




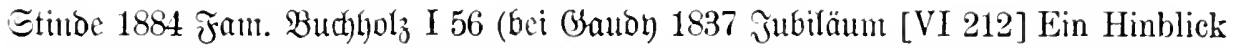
auf die Uhr, mehr aber noch die Unruhe des innerliehen gastrischen Ch.-s). Dutfle: neulat. ehronometrum (bei Marray von 1715 belegt) aus gried). ypósrs '马eit' und $\mu$ śspo" 'Mejier'.

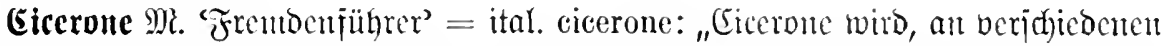

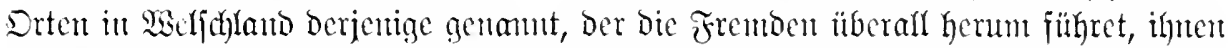

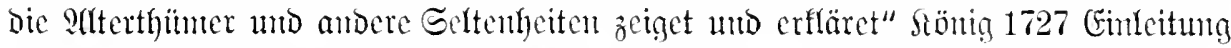

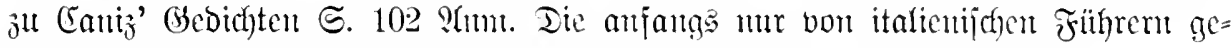

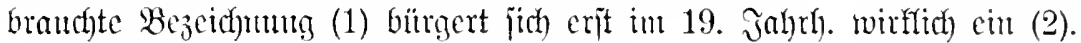

Belege: 1. Bürger 1790 Brieje IV 32 2. Rntigge 1788 lumgang m. Menjichen schreibt mir doch auch viel hïsches von $S_{5}$. 77 mit diesen mehrenteils sehr geRom. Ich höre, Ihr macht den C. Mever schwätzigen und von lustigen und ärger1790 an $\mathfrak{B u ̈ r g e r}$ (IV 52) C.? warum nicht lichen Märchen aller Art vollgepfropften

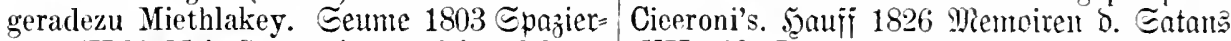
gang (II 86) Mein C. war ein gewaltig gelehrter (VII 168) Ich bot mich den jungen Herren Kerl - (88) Ein entsetzlich zudringlicher als C. an und führte sie glücklich dureh das C. verließ mich mit seiner Dienstfertigkeit Gedränge ins Parket. Weine 1830 Эtalien nicht. Brum 1806 Epijoden I 86 vor dem (III 261) mein Herz ist der beste C. P3üffer Pförtchen, wo der zaudernde C. des Al- 1831 Briefe III 63 mein weitgereister C., baner-Sees die rostigen Sehlüssel langsam Herr Tournier. Baujhfe 1834 Bilfoer હ. 15 . aus- und einsteckte - 1809 ebo. II 48 \&aube 1837 Reijenvoellen VI 133.

Reinhart dieser verständige C. dieser Naturgallerie.

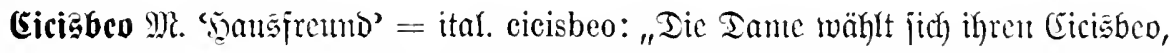
ber aud) ojt in Ehecontracte bejtimmt wird, unb biejer wirb ihr unzertremticher

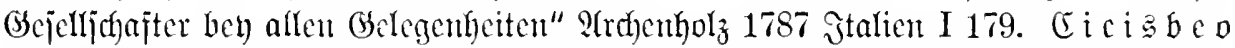

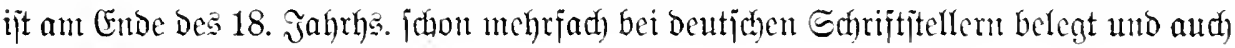
bei Campe 1801 gebudtht.

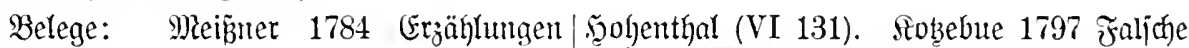
II 9 wenigstens zehn Cieisheen wurden $气$ fam (VI 260) Sie werden mich verbinden, den Damen ihres Herzens ungetreu, um wenn Sie den C. meiner Frau machen bei der meinigen sich eine absehlägige wollen .... Der ami de la maison wird Antwort zu holen. 5̧einje 1794 Seiloeg. v. Immer willkommen sein.

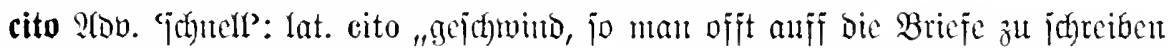
pfleget, Dantit fie bald bejtellet werben" Mehring 1684. Beleg: Picander 1726 Schau= ipiele S. 96 Herr, es ist ein Brief an euch eingelauffen, und weil eito citissime drauf geschrieben, so daehte ich, ieh dürffte nicht sachte gehen.

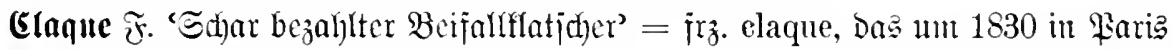
aufgefommen war (Devrient 1839 Briefe ans $\mathfrak{P a r i s}$ [IV 101] die bestellte claque war freilieh aueh thätig) mo balb barauj and in Deutjolano befanut wurbe.

Bgl. 1841 Brieje aus Franffunt (in zuwider und Frankfurt auch nicht Paris Retwalos (Europa I 345) Ausser diesem hat ist, wo eine Einrichtung des bezahlten sich hier ein Institut ausgebildet, das sich Beifalls nicht beachtet wird, so ist die in solcher Weise nur in Paris vorfindet, Frankfurter Claque nicht eine Stütze der nämlich eine hinlänglich organisirte Claque. Direktion, sondern ein Werkzeug der In Paris bemächtigen sich die Direktionen Leidenschaften jedes Einzelnen: die Schaudieser Claque; da eine solehe Manipulation spieler bedienen sich ihrer zum Teil sogar aber dem ehrlichen Sinn der Deutschen gegen die Direktion. Şoltei 1852 Bagabumben 
ङ. 184 Dazu benützte Madane Adelaide ihre dienstwillige Clique und Claque. Madjen= hujen 1865 Ballet I 169 Und dann diese fürchterliche claque, die ihre Courmacher bezahlen. Fontane 1879 Brieje I $270 \mathrm{Als}$ die claque sie zum vierten oder fünften Mal an die Lampen haben wollte, zischte das Parket.

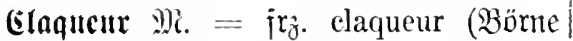

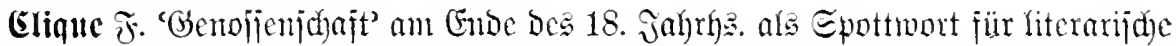

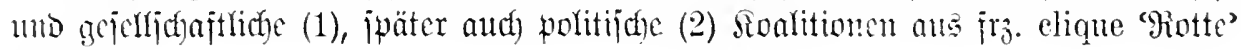
entrohnt.

Belege: 1. Wilelanio 1782 Eenbidreiben/darin gehuldigt hatten. (joetfe 1812 Didf)= an e. jungen Pidjter (XXXIII 284) ein tu Schriftsteller, der, ohne von einer Clique zu seyn [Qherfenumg fänbe], wäre eine noch riel größere Seltenheit. Mäller 1789 Emmerich VI 198 Habt Ihr erst Einen am Halse, so ist es schon so gut, als wemn Thr die ganze Clique aufgesackt hättet. 1796 Xenien E. $81 \mathrm{Sag}$ mir, wo ist denn die Klicke? Da drüben ist sie beym Nachbar. Fidute 1801 Friebr. Micolai (VIII 88) Die von dieser Clique haben die Religionsaufklärung und einen Volkslehrer sattsam gelobt. frobebue 1809 Gottlieb Mierfs (XXIV 41) Weil Sie einer gewissen Clique im Wege.

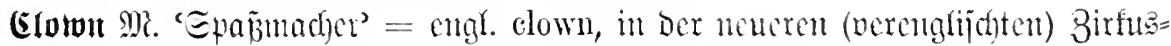

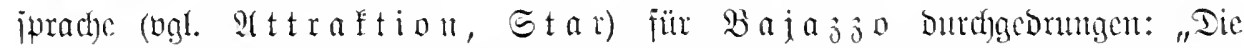

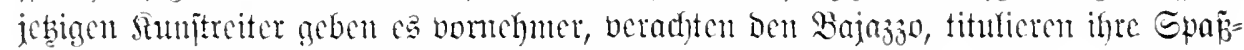
madyer "clown" boltei 1852 Bagabumocn ङ. 196.

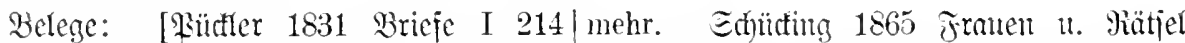
Toch ergötzlicher waren (se. in Iubfii) I 294 einem Clown einer herumziehenden zwei unnachalmmliche Clowns (Bajazzi)]. Kunstreitertruppe. Foutane 1870 Bricfe Sewalo 1836 Tquarelle I 3 [. Ter alte I 187 Hinter allem Ernst klingelt ein Clown ङtaberl"] Das bunte Bild meines lieben her. Porbau 1883 Rügen $\Xi$. 34 Man erseheint Clown. Beritäfer 1861 ßumitreiter $\Xi .198$ sich selbst wie ein Clown, der Alles lachen Royazet hat keinen ordentlichen Clown macht - 5. 128 Circuselowns.

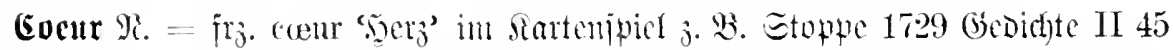
Studir' ich nicht erschröcklich sehr Und seh' ins Buch hincin, Wo Treffle, Caro, Piqu' und C'our Die besten Blätter seyn. Jm 16.17. Jahrh. Daf̈̈r bor beutjo Tame Herz.

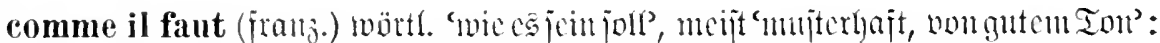

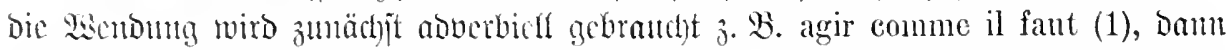

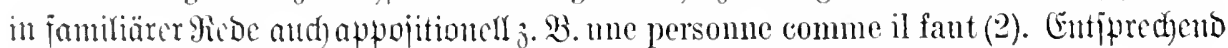

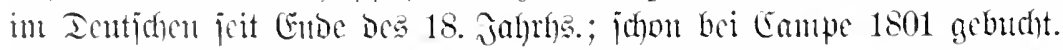

Belege: 1. Savater 1778 Pinjinguom. Qiaerit 1836 Sabalierperipettive こ. 225 Fragnente IV 429 Er hat sein Buch comme. um die jungen 'Töchter comme il faut zu il faut in der Hand. Er schaut, comme il verheiraten. Gamb 1837 5ymureglent faut, in die Höhe, ohne zu wissen, wohin. (VI 204) ber [Gjel] macht seinen Parade- 
marsch comme il faut. Tevrient 1841 il faut. Bürute 1823 Echilderungen (II 118) Trette Qiebe(III 150). Der Graf benimmt sich in deutsehen eleganten Blättern comme bei all seiner Verkehrtheit doch comme il faut. 1835 Europa I 404 Fin Ladenil faut.

besitzer, der sich mehr comme il faut dünkt.

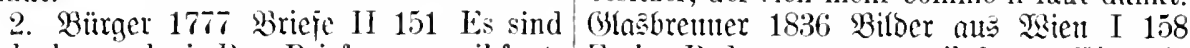
Euch aber auch ein Paar Briefe comme il faut. Er ist Redacteur comme il faut. Chowutits Savater 1778 \$abjiognomijdse Fragmente 1845 Samf ber \$Belt I 302 des würdigen IV $429 \mathrm{Es}$ ist ein Erangelist comme il fiut - Sehneiders und Sängers comme il faut. das heißt: Es kann keiner seyn. Müller 1789 Wachenhujen 1869 Ballet I 188 den Welt(Enmerid) VIII 319 daß ich immer eins mann eomme il faut. (Golk 1869 weltflugheit zwey drey fertig war und dennoch comme II 191 ein Social-Genie comme il faut.

Comptoir $\bar{i}$. St $\mathrm{o} u t \in \mathrm{n}$.

ron anore (ital.) wörtl. 'mit Sicbe': cigtl. cim fämitletausbut, oer un 1760 (bon

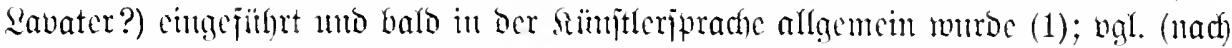

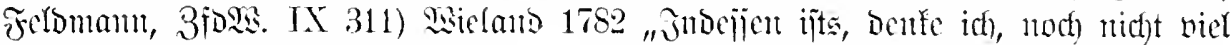

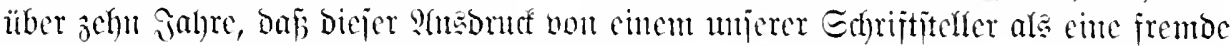

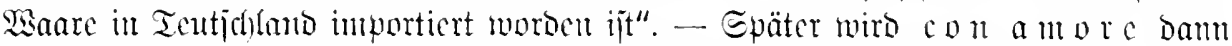

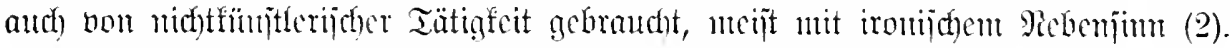

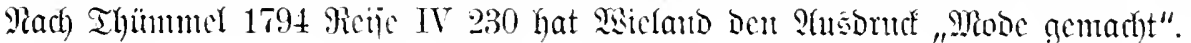

Belege: 1. Sawater 17 Tignjiogunu. Iramaturg. Blätter (II 381) In dieser Fragmente III 95 Alle Stïcke von Boucher Rolle soll num Herr Wurm vorzüglieh waren mißstimmig mit meinem Gefühle. geglänzt und den israelitisehen Burschen Ich konnte kaum Eins con amore ansehen. ,reeht was man eon amore" nennt, gespielt Bürger 1777 Brieje II 170 Kurz diese haben.

Stelle gehört zu denjenigen, die ich vor- 2. Echiller 1785 Birieje I 243 Ueberdem züglich con amore übersezt habe. $\mathfrak{B}$ ie $=$ habe ieh ja die Nedizin ehemals con amore lano 1782 .jora' Brieje II 136 Sie studirt. Qaufluaro 1798 Echilon I 395 da sehreiben con Amore, haben wahren Re- die Gemeinde es [Das Sies] so reeht con spekt vor ihren Werken - Daju bie $\mathfrak{A} u m$. amore herplerrte. Sitt v. Iörring 1830 ङ. 163 Große Künstler - zeichnen, mahlen, fragmente I $66 \mathrm{er}$ schlenderte eine Flasche bilden, dichten, componieren u. s. w..z11- nach der andern reeht con amore gegen weilen con amore und gewöhnlich gelingts die Quadersteine. Bï̈đfler 1831 Brieje I 3 ihnen dann am besten. Hing 1786 Stopitof ich gab mich dem Gefïhle des Comforts in Sarlsnhe S. 166 der Alte sang und recht con amore hin. Retwalo 1837 Squnarelle spielte reeht con amore. 52erme 1790 IV 142 Als ich ihn besuchte, stand er im Fiir Elteru V $\mathfrak{B l} 3$ ich mus rielleicht durch Hemde in Entréezimmer und wusch sich das Gegenteil des sogenannten con amore- con amore. (bolk 1847 Bud ber finoheit malens die Scheuslichkeit dieser Gestalt $\Xi 56$ aber man frol auch con amore in sehr richtig getroffen haben. B̈̈rne 1829 der Schneebnde.

conditio sine qua non (lat.) mörtl. 'BRebiugunta, ofme welche [cin Ercignis] nidft

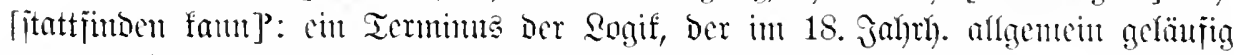
แurbe j. S. Mohr 1716 Etaatsflugheit Є. 277 Die Bewerber müijen] doch endlich aus Begierde zu der Pfarre diese conditionem sine qua non sich gefallen lassen und eine offt hebliche und lasterhaffte Quarre heyrathen. Echiller 1789 Brieje II 269 unter der Bedingung (sine qua non) - 1798 cbs. V 318 Fertigkeit des Blicks und der Feder, was zu solchen Arbeiten conditio sine qua non ist.

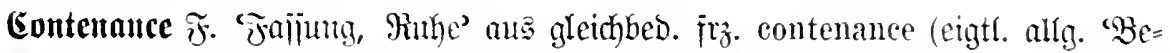

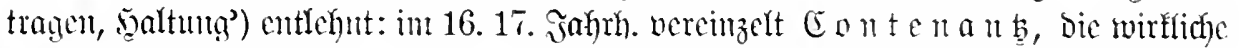

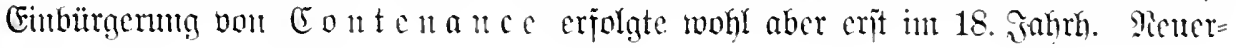




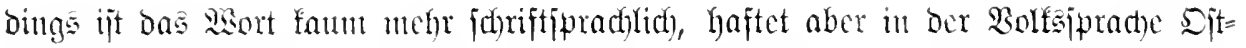
mittelocutidylantos.

Belege: Enjinger 1591 Relationten das Publikum auf. Ecániller 1789 Brieje IV 21 zu denen, welehen es scheint, durch II 291 Mit den zchn ersten Worten war Ewr. Contenantz oder gelassenheit, das ich im ganzen Besitz meiner C. Jffflno 1796 jhr jnen vbel vind böses gïnnet. Rnurem= \{rovofaten (VIII 38) Gernau faßt um einer berg 1652 Echerzgebidyte 厄. 11 Mit WyB- C. willen nach dem Atlaß. Sobebue 1802 heit, gentilesse und braver contenaniz. SBirrwarr (XV 249) Halten Sie C. Eeume Qefing 1767 Dramaturgie (X 17) Der 1803 Epaziergnug (II 124) Ich nahm meine Schauspieler kann ohnstreitig unter der ganze Kontenanz zusammen. . Jauff 1827 Maske mehr Contenance halten. Miduelis Mann im Miond (XII 98) wie sie von An1776 Räpmement IV 60 so glaubt sich der fang durch seine doch etwas gar zu inRespondente doeh nun sicherer und ant- diskrete Aeußerung sehr auBer C. gekommen. wortet mit mehr Contenance und Gegen- $\mathfrak{B u ̈ f f l e r} 1831$ Briefe I 20 sonst hätte ich wart des Geistes. Waiclano 1784 Merfur schwerlich gute contenance erhalten. 5getje

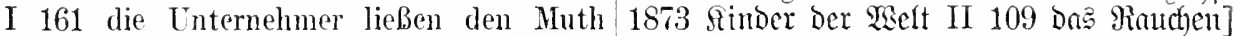
nicht sinken; und die gute Contenance, ist manchmal sehr nützlich um C. zu bedie sie hielten, richtete anch bald wieder wahren.

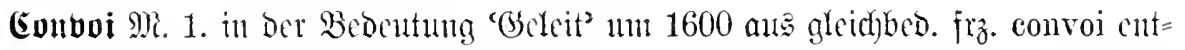

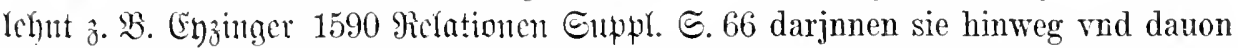
fahren sollen, mit solchen Conuoy (oder gelaite) das sie sicher ohme anfechtung seien. Carolu 1614 Rulation $\mathfrak{M r}$ 26 $6^{\mathrm{e}}$ vnd ist gedachter Herr Collonitsch versehiener Tagen von der Newstatt mit starcker Convoy in einer Kutschen nachts nach Wien geführt

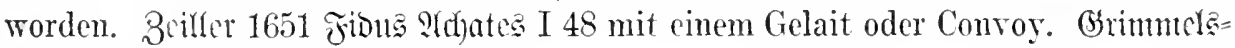
haujen 1669 Eimplic. S. 213. 429.

2. Der periönliche (Gebrand vou Co n v o i als 'Geleitsmanu' ijt Dem Franz.

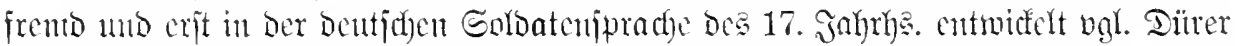
1668 Zauf ber s\&ut $\widetilde{\Xi} .197$ Etliche kanfleute hatten von unserm Feldherrn gegen erlegung einer ziemlichen summa geldes einen geleitsmann (convoy nemnen ihn die soldaten) erlanget. E(t)on bei Dilid) 1608 Siriegsud E. 207 Wachten, die anb rnd inreisende betreffendt, Sindt Conroien - ebentoa: Convoien sindt alf die geleidt, wamn man die Gesandten, ankommendes volck in und aubführet.

cormu i. fiol ta m.

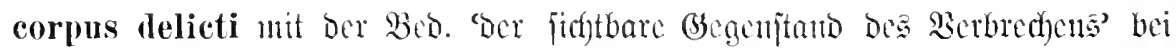

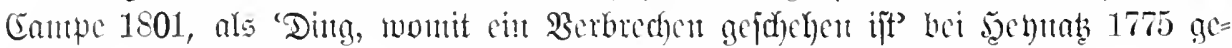

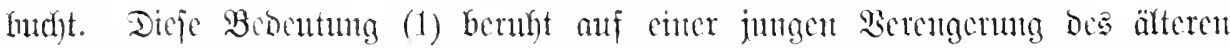

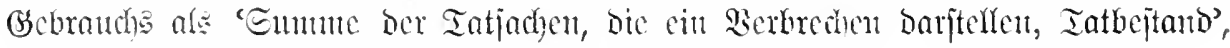
Der bis uts 18. Jahrh. gans gewölyulid tijt (2).

Belege: 1. Ettner 1697 Chnnicus $\subseteq .503$ die gewißheit des corporis delieti wie man Jer Rath schicket lin, läst den Butler es nemet, beliümmert seyn. 9iichter 1738 holen und gefangen setzen, hernach allen Sriminalprozef3 $\Subset .47$ Es ist aber das Corpus seinen Haubrath untersuchen, ob sie ein Delicti ein solcher nöthiger Beweif, ohne corpus delicti finden könten.

2. Subovicne $1707\left(1714^{4}\right)$ Einl. J. Peinl. Prozeís S. 5 Wenn es nun mit der Denunciation oder auch mit dem gremeinen Ruff Jo seine Richtigkeit hat, so mub der Richtel bey der eneral-Inquisition, sonderlich um welchen mit der sonst auf jedes Verbreehen resetzten Straff, nieht verfahren werden

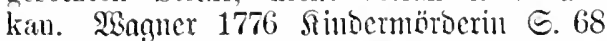
Jetzt abcr gehört sie [Dic Doic] zum corpus delicti. Miüller 1789 Emmerid) VIII 300 von dem Gericht die Nittheilung der Rela- 
tion fodern, aus welcher allein das Korpus bie veritas delicti . . - Wias 2 abertus Delikti hervorgehen konte.

Ganbimus mit ,veritas delicti“, 2hugutimu?

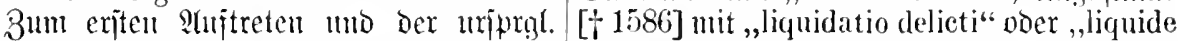

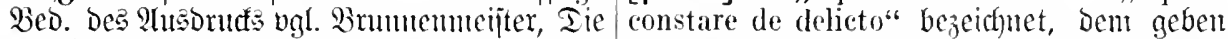

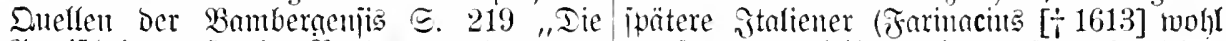

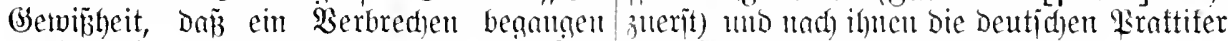

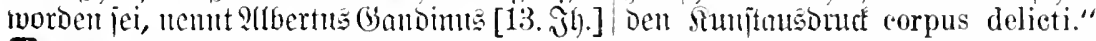

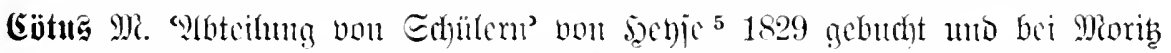
1786 Inton Reijer હ. 167, Gando 1837 Edhillcrlicbe (V 12: Schul-Coetus) belegt.

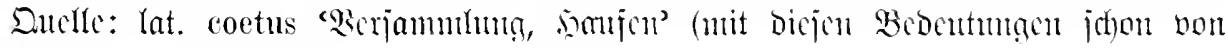
Scyuab 1775 gebuct)t

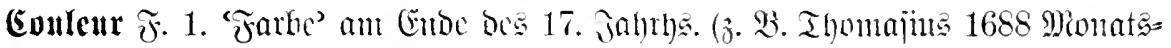
gejpräd) I 531. Cĕttner 1697 Toftor E. 215; Dancbu C ol ö r Picfelbäring 1685

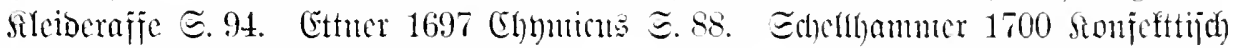

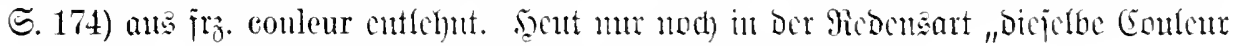

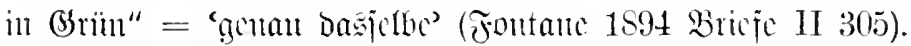

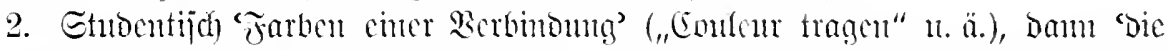

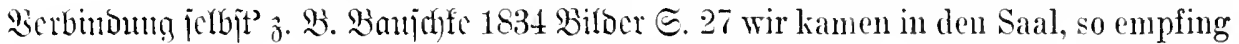
uns sogleich der frendige Ruf unserer schon rersammelten „Couleur". Gubfotw 1835 in Remalos Tluaterevue $\subseteq .100$ Poiten] die du am Schuldenbrette unserer

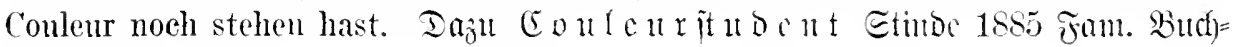
hold II 118.

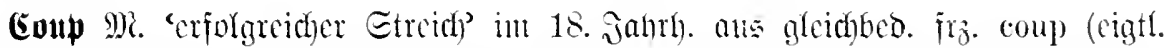

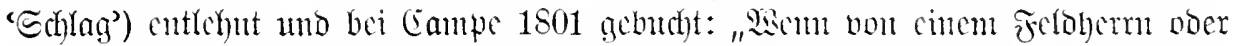

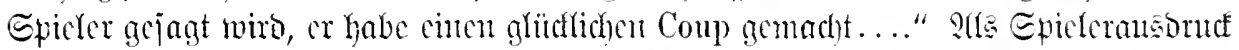

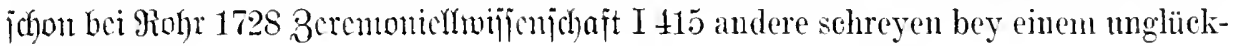
lichen Coup.

Belege: Benzel=eteman 1806 (jejprö̈che II 121 Ohne diesen Bundescenossen bleibt die Schönheit nur Partheygänger: glückliche Koups werden ihr gelingen, doch den Frieden diktirt sie nicht leicht. Sewalo 1837 Sfquarelfe III 275 Sie fühlte, dab sie einen Coup ausführen müsse, wenn sie
sich zu jhrem friiheren Glanze emporraffen wollte. Souttei 1852 Bagabumben 厄. 328 Kein Coup wollte mehr gelingen, nirgend eine Aussicht. Fontonte 1882 stiefe II 75 Ich glaube, der Schluß des 12 . Kilpitels ist ein guter Coup.
Theatercout ein Temtints ber fran= sojicichen Iromaturnic: $\mathfrak{f r}_{j}$. coup de théatre.

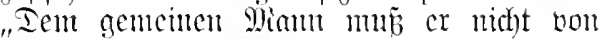
Stufünoigung, von finoten, von Cbarafteren, Mionologen, vou Coup de Theatre und Dergleidjen Dingen inredhen, Davon er nidyts verifteht" Euber 177t Theorie D. idhönen Siunfte [Ofrtifel: ,gimmtwörter"] II $63 t^{\mathrm{a}}$. in frans. Form and nod bei sejimg 1767

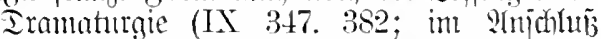
an Soltaire), Edjuller 1789 sirieje II 208. Iheatercoup jurrült bei Merd 1765 Brieje E. 124.

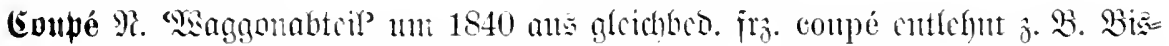

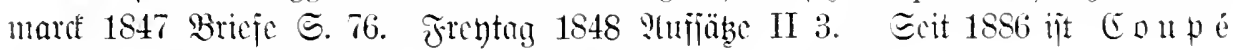

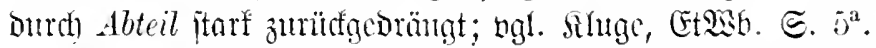

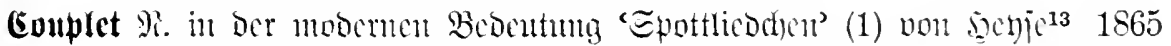

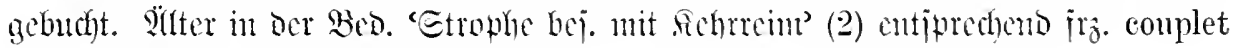
johou bei cramte 1801 gebucht. 
Belege: 1. 1868 Bictims Mantlofale / eingelegt wurden - 1837 ebo. IV 2 die Є. 11 der scharfe Berliner Witz, der in bei- Couplets gegen die Minister waren verBenden Couplets seine Hauptablagerungs- stummt. Debrient 1839 Brieje aus $\mathfrak{B a r i}$ stïtte gefunden - $\Xi .12$ die Soubrette für (IV 11) Dazu ist ihr Vortrag der Couplets komische Liedervortrïge und Couplets.

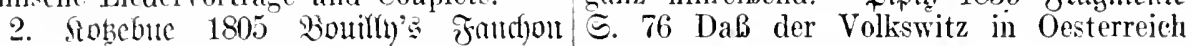
(XIX 185) welch eine Menge Couplets. doch nicht so ganz harmlos sei, zeigen Qevalo 1836 : Yquarelle II 30 jene Couplets, folgende Couplets.

die damals oft zu Ehren der Verbindeten

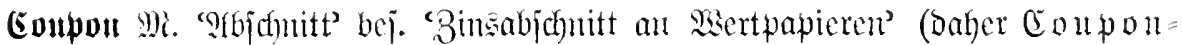

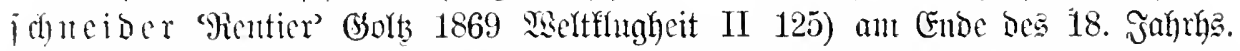
ans gleichbed. fro. coupon ontlebut un bei Campe 1801 gebucht. Beleg: Meöjer 1776 Patriot. Fhantajien II 142 Coupons oder Theile des Looses, Erbes.

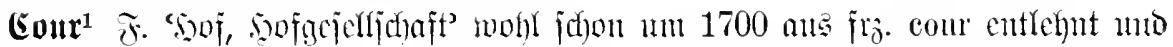
bei Eperantoer 1727 gebutcht. Belege: Weöjer 1775 Patriot. Fhantajien I 158 die umnïtze Zeit zwischen dem Nachtische bis zur Com. Siafl 1787 Bagatellen II 114 wentu er] sich deswegen morgen früh bey der Cour beurlaubte. Daju $\mathfrak{c}$ o $\mathfrak{u} \mathfrak{r} \mathfrak{f} \ddot{a} \mathfrak{h} \mathfrak{i} \mathfrak{g}$

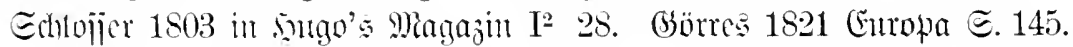

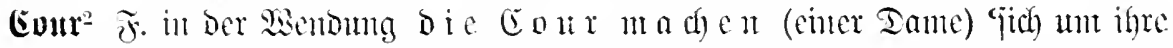
(bunjt bemerben' Durd) Das 18. Jahrh. jdyou gelüufig (1); Daneben aud nod) in ocr

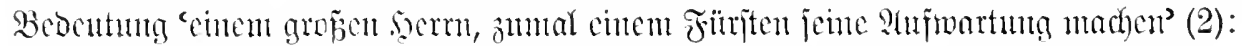

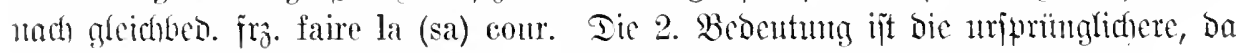

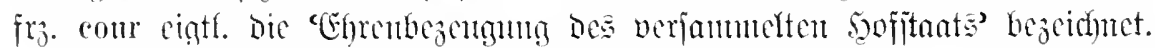

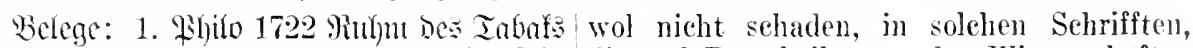
E. 52 eimem muntern und hitzigen Fräulein die auf Beurtheilungen der Wissenschaften die geheime Cour zu machen. Bachariä gerichtet sind, mit den Ausdrücken, und 1754 Sermoutumgen (I 190) Er macht absonderlich mit den Einschaltungen unSelinden Cour. Möjer 1778 gibantafien richtiger Gedanken eines andern, dem man III 18 die ihr chedem, und wie die Medi- die Cour machen will, etwas behutsamer sance sagt, nicht ganz vergeblich die Cour zu verfahren. Qefjita 1771 B̉reje (XVII semacht haben. Sfif́nto 1800 Manu von 381) um bevher der Herzogin von Braunsisnt (III Fe) Ich mache num Julien un- sehweig meine Cour zu machen. Nicht ausgesetzt die Cour. Solzebue 1805 Fandhon war, Sie mïssen lachen, wenn Sie mich (XIX 115) - 1806 Ergante bes Gehimn und Cour machen zugleich denken. Edfint (XX 103).

1778 Marioucttenthenter $\subseteq .47$ macht Eurem

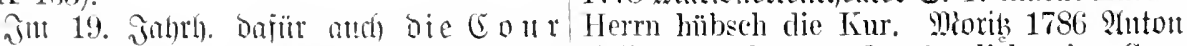

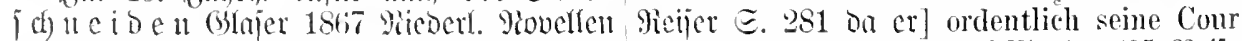

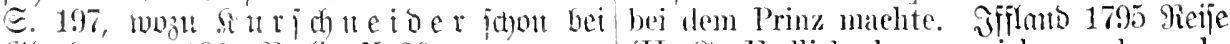
(3)

2. Miatthejon 1739 Stapellucipter Sorr. Jahren Cour machen. eines schönen Nach(.) it Beilïufltig zu arinnern, könnte es mittags heim.

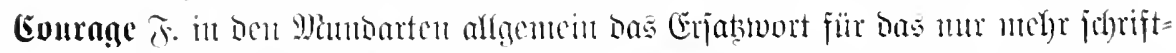

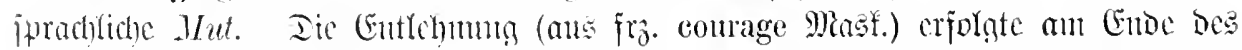

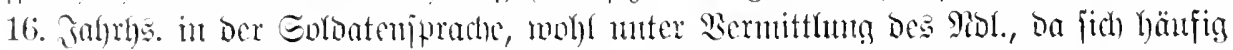

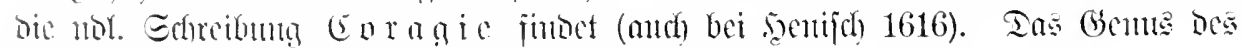

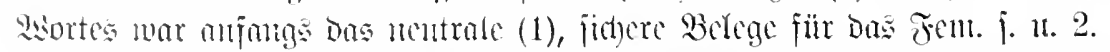

Welege: 1. Enzinger 1590 Gielntionen/liehkeiten vnd das Courage nicht also mehr

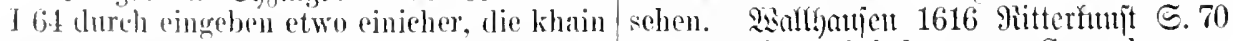
hertz oder conraige haben. Miejeridmio ein Coragie vnd beherzteres Gemüth.

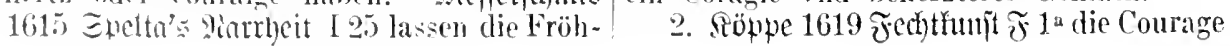




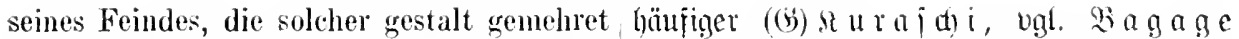
wird - (3) $2^{\mathrm{b}}$ Dieses erfordert aber auch QHum.2. Qiteraturbelege: Miengering 1638 eine geschwinde Faust wnd ein Hertzhaffigen כoloatentenfel $\Xi .444$ ewer Curaschi vnd Mannes muth oder courage. 1629 Bejchr. Heldenmuth — $\Xi .469$ daß man die Soldaten ๖. Belagerung b. 5ergogenbujd $\mathfrak{B}^{2} \mathrm{~b}$ Die bei Coraschi vind guten Willen erhalte. Englische, welehe allda die Wacht hatten, gtbele 1673 Wivat lluoromma IV 235 in fielen mit grosser courage an. Ecfildofnedft den Hosen ligt die Couraschi samt der 1652 sarmonia III 240. Grimmelshanjen Blumaschi. Contin 1708 Parrentwelt III 68 1669 Eimplic. E. 360 daß ich keine solche dab alle guraschi durchfällt. Ed)wabe Courage hätte wie er.

1745 Iintenjä̈̈l E. 15 so ist ihnen für Angst Tamerfung. Jat Dbo. und Edyueizer. das Guraschi in dFueb kumen.

Coujiu Md. 'Better' $=f r_{j}$. cousin; un 1600 nodh mbefamt mo bei sirdhof 1602 'Scnounmut II 251 ["Iriboulet ciu nar"] noch crflärt: ,cousin (das ist vätter oder angewandter)". Iic Entlehmung gejuah erit unt Die Mitte bes 17. Jnhrhs.

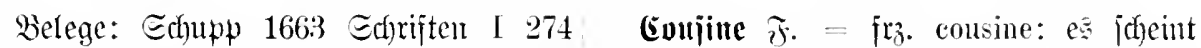
mit never Lieb und neuer Freundschafft erjt im 18. Jahnh. enttlehnt ju jein, ijt aber gegen euren Cousin und Anverwandten den raidh eingebiurgert mo hat bas beutjole edlen Sehäfer Philander (nach) Sseigano 5). Base völlig verorängt. Belege: G̈́teim 1750

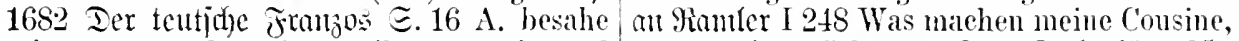
mit unverwandten Augen ihren cousin und und meine Schwester? Zachariä 1754 dessen Frantzösisehe Kleilung. 1683 Iraur. Wibaeton (I 295) Morgen will ich meine Beituutg aus Cabix S. 6 diesen seinen Sohn, Cousine besuchen. - Edyou gebutht bei nebst seinem Cousin an ein ander Schiff Wäntler 1709, Bold v. Sisertbein 1711 u. a. zu setzen.

(Ereme MR. 'Sdfaumgericht' im 18. Jafuhumbert ans gleichbed. fro. crème

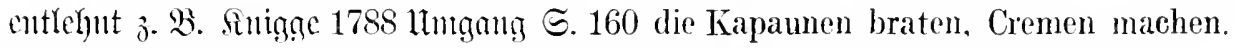

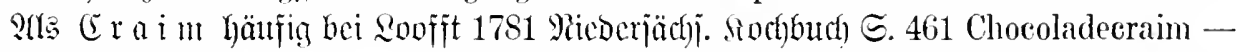

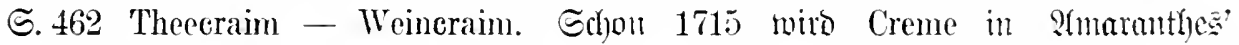

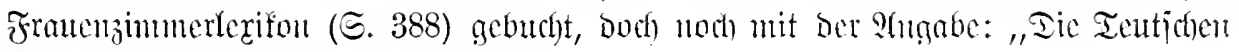

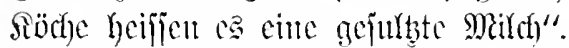

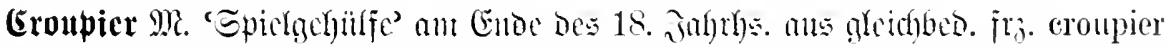

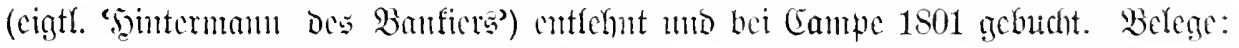
Jeau Raul 1789 Stuswahl a. D. Tenfels Lapieren (IV 61). Sfiflanto 1798 Ier Epieler (IV 131).

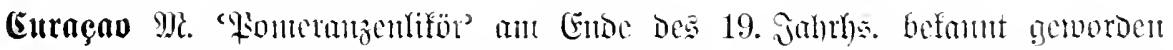

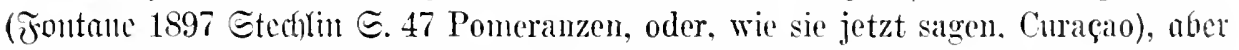

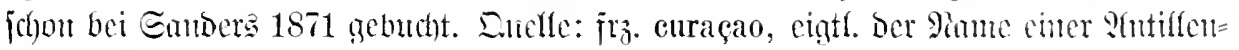
infel, nou ber bie Frtichte jur Bercitumg bes Qiför bezogen merbent.

\section{D.}

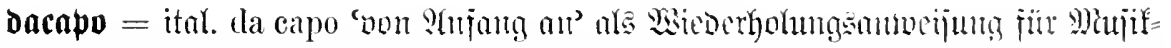

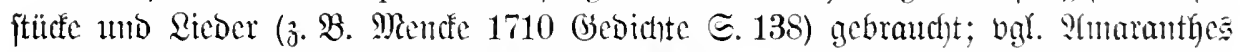
1710 Proben ber Pocjic S. 448 Weil ieder Musicus: Da Capo pflegt zu lieben, Sie

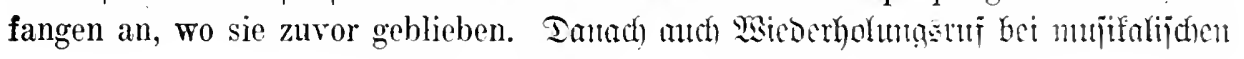




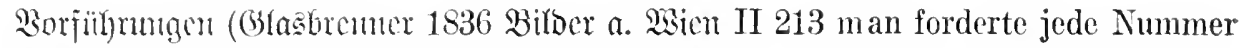
da capo); übertragen bei Miulfer 1778 Faults $2 c b c u$ ङ. 95 Wie oft möcht man durch's Leben bei süben Augenblicken rufen, da Capo.

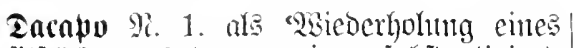
Manjiftïcks ans Dent vorigen jubitantibiert, aber tod härfig in zivei sisorten gejdricben. Echeihe 1745 indifus 5.92 Wir haben uns erbine 1 t5 rerliebet, daß wir es Arien erzwingen, die doch, ohne den Ver- vor einem da Capo. Brebier 1791 Reben e. stand der Worte entweder abzubrechen, Sibcrlidjen II 4 in Puncto sexti ein Dakapo oder gantz und gar zu verwirren, selbiges zu machen. Sokchue 1799 l̈ble Rnune unnöglich vertragen. Edhmid 1775 Chrond $=$ (IX 234) dab du in der nächsten Minute logie D. D. Theaters E. 263 Er erlaubte sich nicht für ein da Capo stehen kamst.

daher keine ausführlichen Arien mit Dacapo.

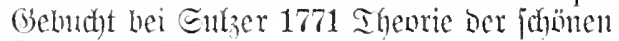
siunfte I $235^{\circ}$.

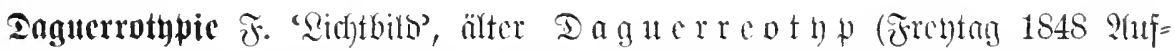

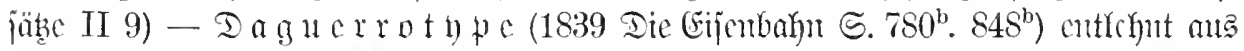
fro. daguerréotype, gebilbet von ben Panten Iaguerre's, ber bas (heut gan un= gebräuchlicfe) Berfahren in ben Jahren 1835-39 crfunden hat. Die sfbertung

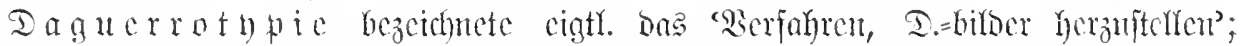

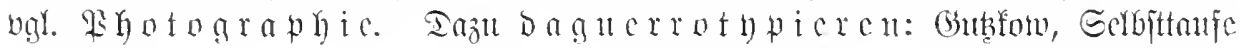
( 1 242).

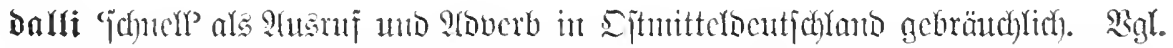

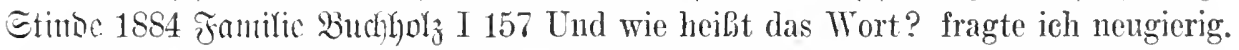
Dalli, dalli! antwortete sie lachend. Es ist ja eigentlich polnisch, fügte sie hinzı, aber es sagt sich so leicht, viel bequener als flink, flink, und klingt dabei lustig. Euclf: poln. dalej 'wociter, portwärtes' (bcj. auch) Ermuntermughnf).

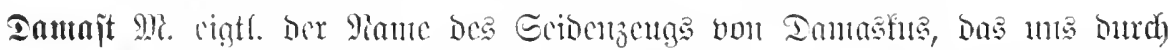

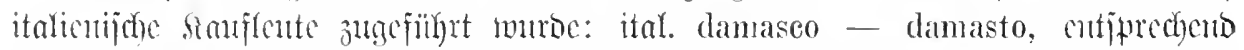

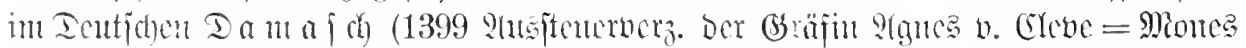
Shis. VI 248) und Da $n 1$ it (Sitrer 1520 Tagebuch S. 69).

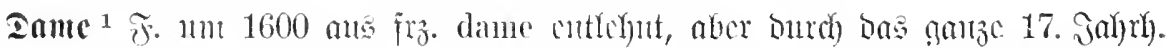

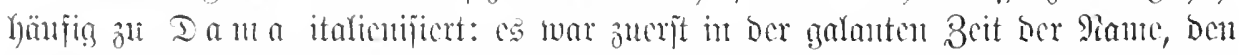

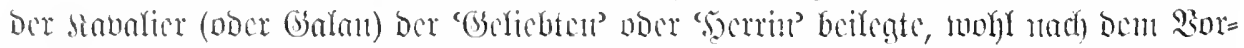

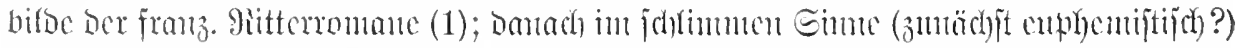
'Gelicbte' = 'Dime': ..nostrum Iame hodierno tempore vocabulum suspectum fere

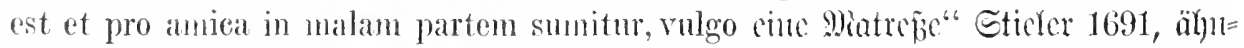

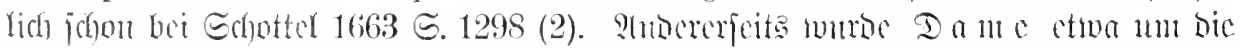

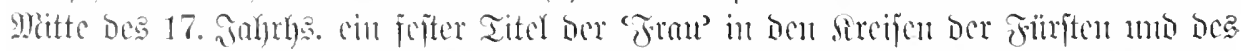

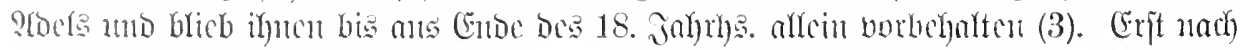

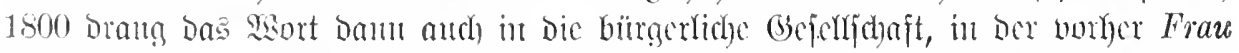

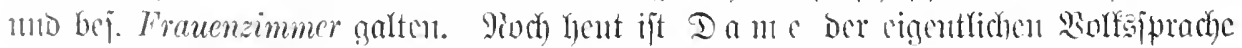

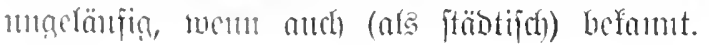


Belege: 1 a. .̧od 1601 Bhuncujelo 5. 41 Ein Dama schenckt vind schicket Ihrem lieben Galan [ín sillo]. Bangung 1611 Dentidye Ricber II ${ }^{12}$ Ein Dama schön im Garten gehn thät früh an einem Morcen. Mefjeridmio 1618 Garzonis Sarrenjpital ङ. 142 einer vberaub schönen Danma Favor. S(f)wenter 1636 Ielitine $\Subset .151$ was sich mit einer Dama begeben, vor dieser stund ein alter Mamn vnd ein junger Geselle, jeder vngefehr 10 oder 12 schrit weit von der Dama. 1644 Epradjwerberber ङ. 34 Mein allerliebste Dama, mich erfrewet sehr hoch, dab sich diese brave oecasion praesentieret, euch zu besuchen. 1647 Yánuos. Lolitifus 5. 92 damit er etwa seiner Dama Tarrendank möchte darvon tragen.

b. Dpits 1622 Pnmuhe Serct)mia (II 255) eine stoltze abgeführte Dame (damn also nennen sie vnsere Auffwärter), die nirgends sehöner ist, als in jhrem eigenen Spiegel 1628 Iaplne I 69 in was für noth ein Cavallier und eine Dame sich kan bringen, die nicht nach Liebe fragt. 3cien 1612 Soet. Rojen=

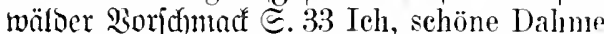
(dem also nemnen sie ilure Buhlsehafit) sollte wohl Thre unvergleichliehe Sehönheit mit stillschweigen verehren. Micngering 1642 Gerwifjensiöge હ. 387 jhren Damen rnd Löffeloänsen zu refallen auff der Porkirehen nach den schönen Damen gaffen. Miojdyeroid) 1650 Pyilamber (ङ.98) Wann vor diesem eine neue Narren-mode kaum auffkommen, seinem Schatz, seiner maistresse, seiner Dame zu gefallen. Gander 1697 Ingenjochmio I 370 Schönste Dame! 巨đ)wabe 1745 Iintenfäbl $\Xi .71$ Einer Dame den Hof machen. (Socthe 1796 isander= johre (XXIV 96) Felix [jollte] als Page seinen ersten Ausritt der Dame seines jungen Herzens zu rerdanken haben.

2. ca. 1650 Eatr)ra (经cim. Jahrb. I 298) des Abends geht er aus zu Damen und Maitressen. 2auremberg 1652 厄cherzacoidhte ङ. 43 Ick bin keine Dame, du lichtferdige Finck, Dine Noder de Hoer was sülck ein Dinck - Se meenden, Damen wehren Sögen edder Teven, Edder eine de Horerie hadde bedreven. ङchupp 1663 Ehrbare Sure (ङd)riften $\Xi .488$ ) daß ihr eine Dame serd, welche die Frantzosen habe - $\Xi .491$ eine in der gantzen Stadt bekante Dame - Daju S. 471 Die grobe plumpe Tentschen, welche nicht wissen, was Höflichkeit ser, pflegen dieses grobe Wort zu gebrauchen, und wann sie ein Weibsbild sehen, das freundlich in Worten, Wercken und Gebärden ist, sagen sie alsbald, daß sie eine Hure sey. In Franckreich, da die reehte Civilität und Höflichkeit ist, nennet man sie eine Maitresse oder eine galante Dane. 1677 Madfinbell. 5ofuspofuz ऽ. 207 die Hure (oder Dame, bösen verdacht zu rermeiden). (Ettner 1719 Maulnịe 5.655 Nun aber ein Wagen eine Chaise, eine Hure eine Dame, und ein Schelm ein Politicus heisset, so ist die Redligkeit aus der Welt geflohen. Jn bicjem Einu hout noch bolfsmäbig: Edymeller I 369; ver= breiteter im Iimin. Iäm do c n Eticler 1691 Ep. 27t. Qimbenbera 188.3 Berlin I 14 Damen oder sagen wir lieber ,Dämchen".

3 a. Edjilling 1669 Stathor. Iotengeriijt e $4^{a}$ Die schöne Dama wol bekannt, In Oestreich diesen Landen, Maximiliana genant, Ist nichten mehr vorhanden. Der Todt nimbt diese Dama hin ujw. 9(braham 1686 Jtho $\Xi .162$ Ein vornehme Dama. 1709 Malum Evum E.141 Ein Adelichs Weib wird insgemein genemnet ein Dama. b. 1630 Iragifomösie (Creizenach) 厄. 227) Glück zu, guter Freundt, vnd jhr, $O$ eale Dame dazn. 1635 mïllerin=Etimme (Sit. Ber. 83, 554) der Spieß vnd Schwert nicht wider sondern für alle wackere Damen

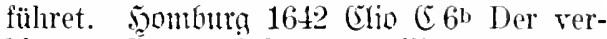
klugten Damen-Schaar - 2li $3^{b}$ Darumb, aller Damen Zier, Trawre nicht so für rnd für. Eeifert 1647 Gervijienänd Є. 155 Hierauff kan keine grosse Danie, die nur in wollusten sitzet, vnd für zärtligkeit jhren fuß nie auff die erden gesetzet, ein vrtheil sprechen. Echröter 1660 Eitterithule $\Xi .53$ Die Dahmen hat el [ber Floh] lieb und geht in schwartzer Tracht. Rajiening 1661 T(Del. Tijd)reoen ङ.311. Stautjid 1685

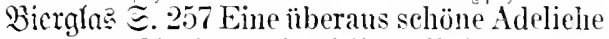
Dame. Biegler 1689 9lïat. Baimie $\Xi .45$ eine junge Dame. Edfeflhammer 1692 Iie

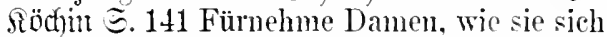
untentsch genennet wissen wollen. Citmer 1715 5ebamme $\Xi .444$ eine Adeliche Dame. Eonlin 1725 Siarrenfur $\Xi .61$ mit einer von Hoch-Adelichem Geblüt und absonderlicher Schönheit begabten Dame. Nielano

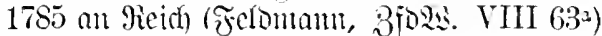
die Dames in der engeren Bedeutung lassen sich nieht gern unter die Rubrik Frauenzimmer stecken; ind die übrigen mögen es wohl leiden, wenn sie (nach französischer Sitte) Damen geseholten werden. $:(r d) e n=$ folz 1787 Cinglanto III 88 eine Stunde darauf war das Küehenmensch eine Dame. Müller 1789 Emmerich V 158 Dame! - Eine Dame! - Herr, das beginnt von der breiten Basis 
des angetraueten Weibes des Krautjunkers, Benennung, welehe die adliche Weibersehaft und endigt in den Gipfel des Thrones. Nur sieh vindiciret, wodurch folglich eine brave was zwischen diesen beyden Aussenlinien Bürgerinn nicht geehret wird. \&nube 1837 begriffen wird, das ist Dame in Deutschland. Reijenovelfen VI 146 Göthes ,Frauen= Alles ïbrige ist Frau oder Franenzimmer - zimmer" ist nichts mehr und nichts weniger, 159 Bezeichne mir also der Herr das Weib als was der Dandy jetzt „Dame“ nennt. eines Deutselien Biedermannes durch keine

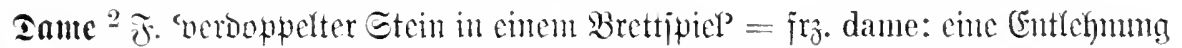

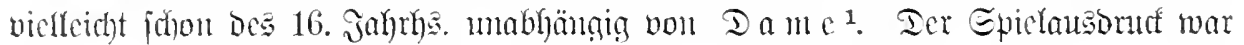
vou vornherein im Solf befant, meijt in ber populären Sautform Da m m, Das

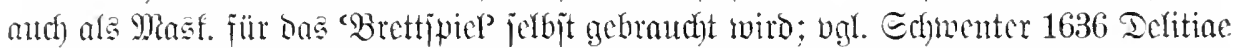

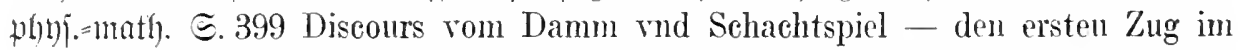

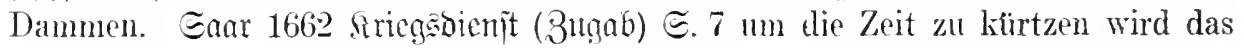

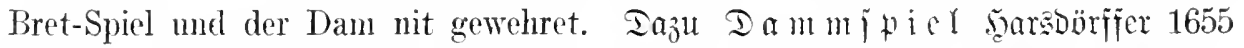

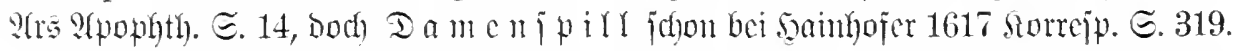

Danoy Me. 'eleganter junger Mam' aus cugl. dandy. Das mgl. Wort ijt nad)

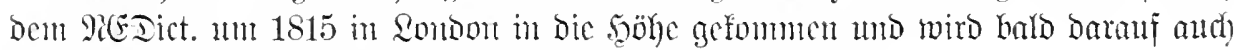

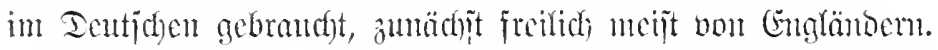

Belege: $\mathfrak{3 i t t} \mathfrak{v}$. Dörring 1830 Frag= nieht an einigen norddentschen Dandy's mente I 90 Mein Dandy hatte seinen Zeit- V 269. ¿ewald 1837 Yquarelle IV 166 nicht punkt schlecht gewählt [in Rondon]. Seeine mit der Sorgfalt eines fashionablen Dandys. 1830 Stnlien @. 269 [Mifiter River] war ganz 1841 Europa I 429 bin Dandy ron hohem als Dandy gekleidet - 1834 Ealon (IV 50), Range [in einer Seja)r. Rontons]. Bismaref das Kostïm seiner Bewohner ist maleriseher, 1847 Brieje 5.29 mit dem Stolz des dandy als das unserer Dandies. Raube 1836 Reije auf seinen Rock. Marimilian v. Mexito novellen III 12 Wie gewöhnlich fehlte es 1851 Reben II 14.

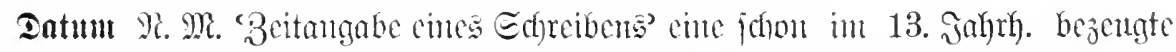

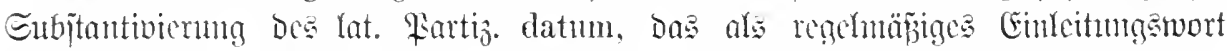

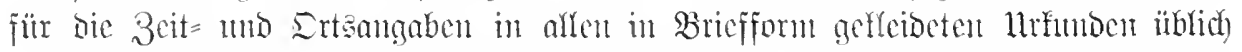

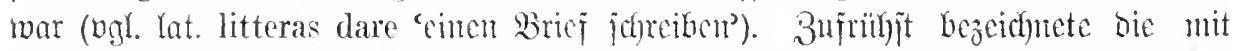
datum (banchen auch) data [se. littera], moher fro. date Fem.) cingeleitete $\mathfrak{2} n=$ gabe in Sen Cerfajen ber römijenen Saifer Den Beitpunft, an bem bie Conjtitution

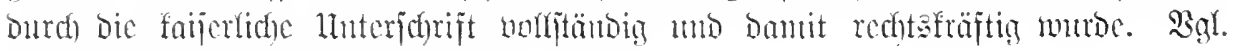
Brep̈lan, santob. Der lirfunocnlebre I 846.

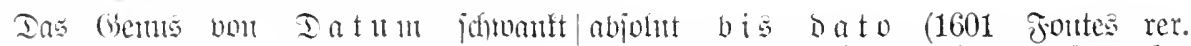

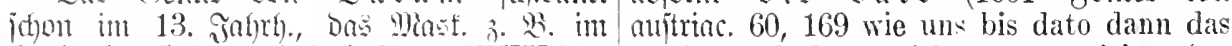
Sartuncinct 539,1 und) Bed), (Serm. XVIII 266, wenigste darhero nicht communicirt; da= auch 1523 sofit. Storrejp. IS6. 1546 9otariat neben bis a ui $D$ a to 1608 Ifontmen=

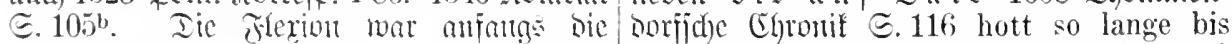

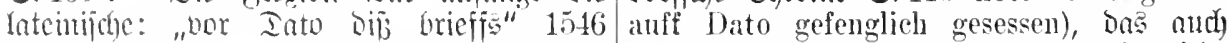

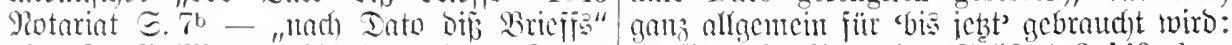

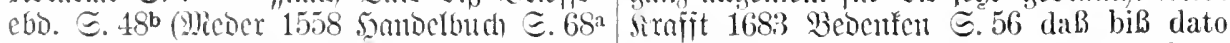
nach dato des Wechsselbrieffs) - jo anch die Wohlfahrt des Landes nieht am rechten "Gis Iato bicjes Briefes", woher bann Orthe.

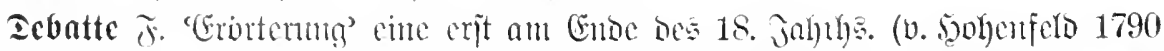

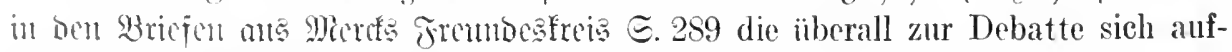

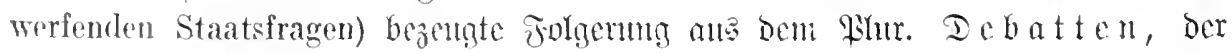

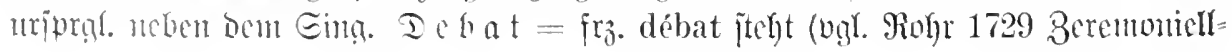


tvifjenj(b)ajt II 435 nach vielen bey den Westphälischen Friedens-Tractaten gehabten Debatten - 490 so satzte es unter den Holländischen Provintzen einen und andern Debat). Der łulur. Debatteu entitand wohl aber unter Euffup bes älteren

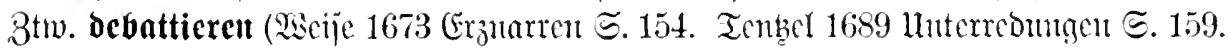
477), Dả nach $\mathfrak{i} r_{\mathfrak{z}}$. débattre gebiloct ijt.

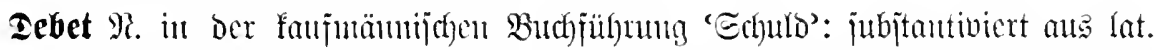

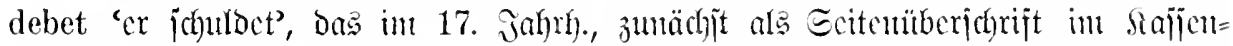

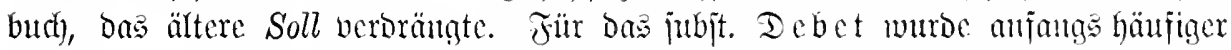

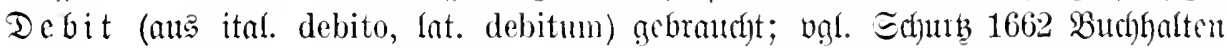
ङ. 71 ,Debit ijt aud cin Wort, weld)en che fan wiberjproden werden; cs heijt cigentlict) Debet, weilen aber von Debitor uto Debitum Dả Wert Debit

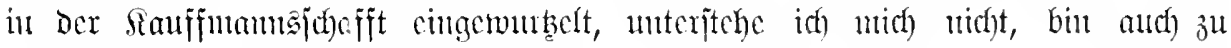

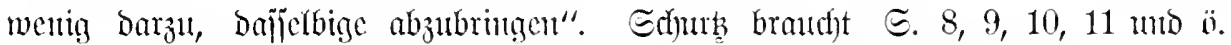

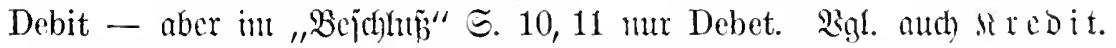

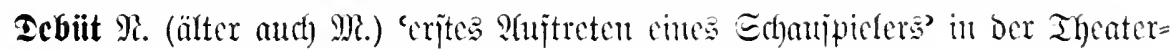

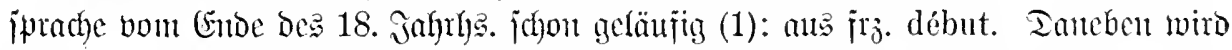

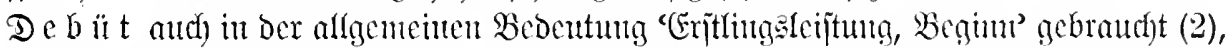
Dic eigtl. Die Grumbbed. Des fram. Wortes ijt, bei unz aber meijt als llbertragunty Des Theatergebraudja cmpfunden toirb.

Belege: 1. Edymio 1775 Ehronologie D. D.|dem Debüt des Journals gewib nïtzen Iheaters S. 324 er war vordem in seinem 1794 ebo. IV 40 Mein Debuit in den Horen. Debüt bey Herrn Koeh nieht glüeklich dełiitieren 3 tiv. $=\mathfrak{i r}$. débuter 1 . in

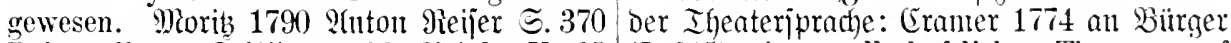
Debütrolle. Edjifler 1796 Brieje V 25 (I 215) ein gesellschaftliehes Theater, auf Warum, möchte man fragen, treibt man dem wir mit Emilia Galotti debütirt haben. Wilhelmen von der Einen Seite von dem Echmid 1775 Egronologie D. D. Theaters Theater, da man ihm doch von der andern $\subseteq .51$ Hier debütirte Prehauser als Don zur Auführung seines Lieblingsstücks und Philipp im Don Juan. 178t Mierfur II 73 zu seinem Debüt behülflich ist. Goethe es ginge eimmal nicht an, daß man gleich 1796 Refriagre (XXII 263) Man soll ja mit hohen Rollen debütirte. Morif 1786 keinem Schauspieler übelnehmen, wenn er $\mathfrak{A}$ uton Reijer 5.318 daß er nachher mit bei seinen Debüts vorsichtig und eigen- eben dieser Rolle unter Eekhofs Augen sinnig ist.

2. Echiller 1787 Brieje I 390 Es ist gleichsam mein erstes Debut in der Gesehichte -1788 ebo. II 73 er selbst ist ein armer verrufener Sünder, dessen erster womit Du bei Wieland debutirst - 1795 Debut Dir alle meine Vorerrinnerungen ebo. IV 215 So debütirt dieser Jensch in ersparen wird - 78 weil sie auf einer Seite dem Buehhandel.

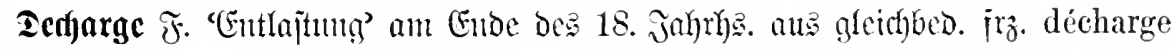

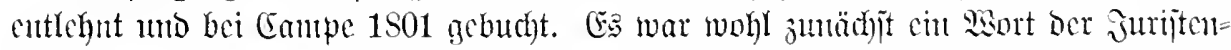
iprache: Bürger 1778 Brieje II 205 daß dem Bürgen alle Jahr die VormundschafftsRechmungen und die gerichtliche Decharge vorgelegt werden könne. ฐ̃ermes 1790 ₹ür Elteru III 124 Ënes Kummers hat die genaue mit beiden Anwälden angestellte Untersuchung mich entlastet: ich habe eine bleibende Deeharge. Б̃cut ijt

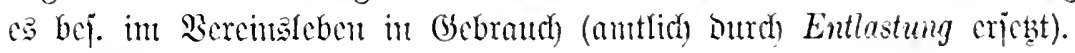

ocajifirieren 3two. i. unter Chifíre. 


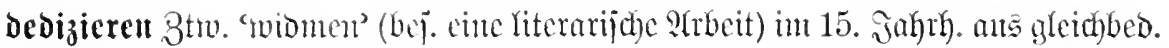
Int. dedicare entfchnt: Sirbung 1511 Mujica $: 3^{4}$ eïwer fürstlichen gnaden das selbig

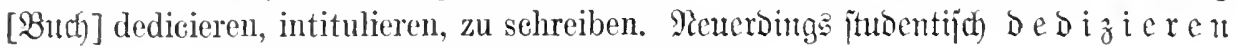

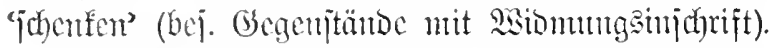

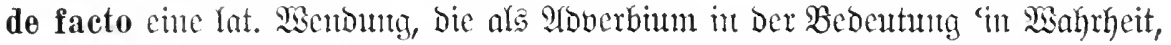

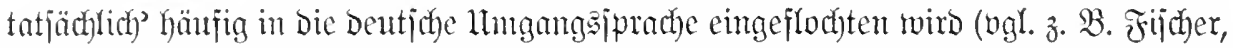

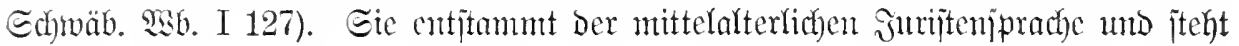

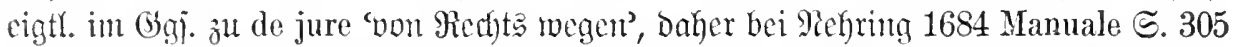
De facto \& absque Jure, eigenthätlich, aus eigener Gewalt und ohne Reeht; vgl. auth Calfenbach 1715 Sutaji vero $\subseteq$. 36 Herr, hab ich nicht vorgebaut, wir reden de facto, nieht de jure; bei Eperantocr 1727 'eigenmäehtig etwas unternehmen,

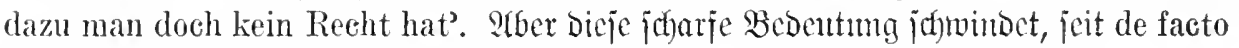

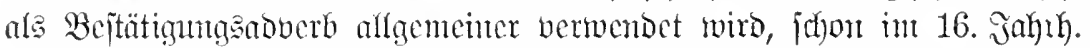

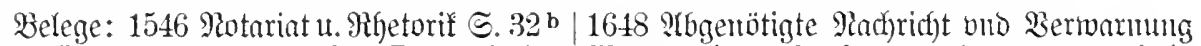
doch pflegt man de facto, solche Renuntiation 1 segen eints de facto buto zur ungebuirht auch etwan den Instrumenten zu Inseriern. gejhehenten Madjonulas. Becher 1668 MeFriebensberg 1597 Discurs $\widetilde{S} 9^{\mathrm{b}}$ in allem thodus didactica $\subseteq .26^{\mathrm{b}}$ wievil Radices dem, so er de facto besitzet. 1601 Fontes seyn können, ind de facto gebräuchlich seyn. rer. austriac. LX 162 die sollen der F. D t Frriebrid) I. 1703 Briefe S. 26 daß man de facto....verfallen sein. Carolus 1614 Zellischer seite de facto ist hin gegangen Relatiout $9 i{ }^{4}$. $9^{\circ}$ das er solle stranguliert vnd und hat sich der Stadt Hildesheim bemächdie Lande de facto eingenommen werden. tiget.

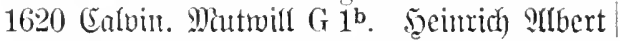

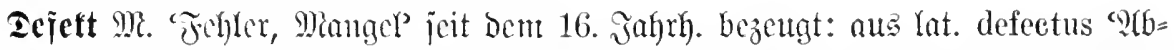

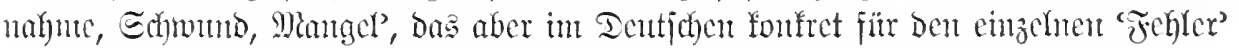
gebrautyt rutroe (1), jeit ben 17. Jahrth. boj. vou Mängclt int Büchern (2).

Belege: 1. Gintrag ill einer $\mathfrak{J}$ weinhando=/gezogenen groben Defecten vor diesesmal fankift (Bermania XXVI 364) 1531. 11. Sept. nicht judiciren.

hab ich den defeet erfilt aus aim alten buoch. 2. Martin 1637 Farlantent 5.470 es 1558 Seibelberger Statuten $\subseteq$. 132 anch ist ein defect in diesem Buch. Mengering was sich fur mangels und defect mitler zeit 1642 Gemifienlarüge $\subseteq .1524$ wenn sie jhren der facultet halben zugetragen. Meifer $=$ guten Freunden vnd Kunden jhre defect

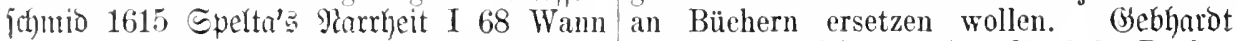

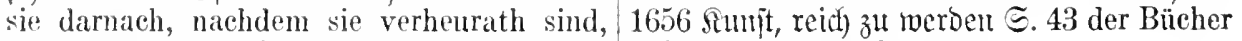
z.u genaw rnd fleißig warnehmen, vond ein defect vnd mängel.

stätes Auge auff alle defecten haben. Fiäto= rills 1619 Eyntaguma I[ 157 Vund was der vielen Mängel vnnd defeeten, die sich von einer zeit zur andern vernemen lassen, mehr

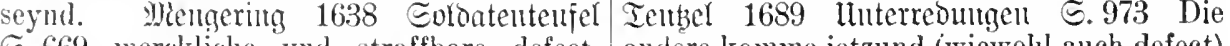
S. 669 merekliclie vnd straffbare defect. andere komme ietzund (wiewoll auch defect)

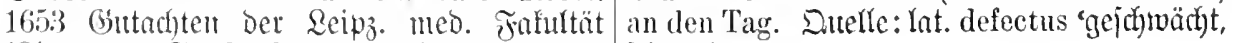
(Bittmlaul S. 33) können wir derowegen idftuadt)

bey so gestalten Sachen und ins jetzt an-

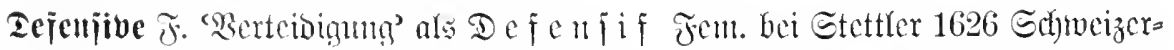
d)ronif II $189^{a}$ sich im nothfall zu einer deffensif vnd gegenwehr zurüsten $-195^{\text {a }}$ als aher entzwischen der König von Franckreieh mit einem grossen Volk sich zur

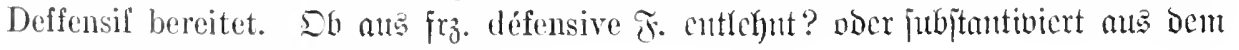
meulat. Nloverb defensive. 


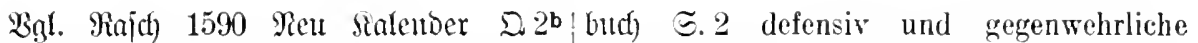

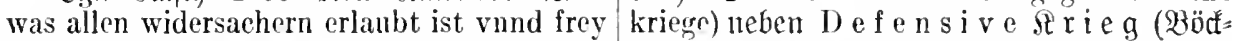
offen steht, defensiue vnd nit offensiue zu ler 1669 Edfola nilitaris ङ. 108), Das aber kriegen. Freiberger 1656 \$olit. Dišlurje vielleidnt ali neulat. bellum defensivum

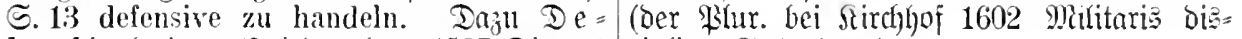

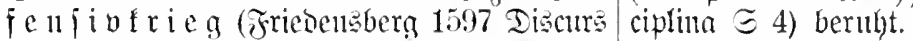

ธ. $20^{a}$ "defensiv Serieg"; Dilith 1608 Siriegs"

Deỹilicren 3tw. 'reifhenweije vorïberzichen' un 1700 als militär. Termimts an frz. défiler entrihnt: 1702 Europ. Fana $\Xi .903$ ungeachtet man sich den 2. dieses zu Abends um 9. Uhr auff den Marsch hegab, und ïber den Rhein nach Bonn paßirete, welches lange defiliren den 3. von frühmorgens an bib um fünff Uhr währete. ¿ïntig 1719 Iheatum ceremou. I 1279 die 14 bürgerliche Quartiere defilirten.

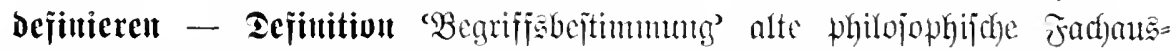

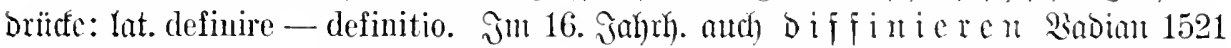

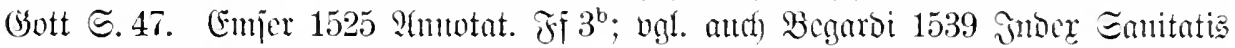
ऽ. $1^{\text {a }}$ die weil die kunst der Artznei vilfeltig bei vilen Aertzten wirt diffiniert, wil ich bleiben bei der diffinition vnd dargebung Auicenne.

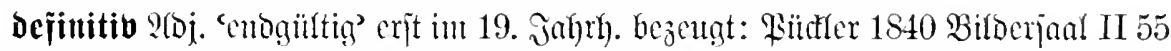
eine definitive Ehescheidung; älter (nod) allen bei Eampe 1813) abverbiell: Chile= mont 1705 Rricgs= u. Stantsrat II 123 deme der Herr Vice-Director mit diesem Definitiv abfertigte (hier vicllcid)t aud jubjtantibijad) fïr Definitiv-Bescheid).

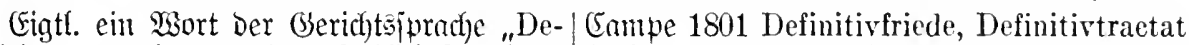
finitive sc. erfenten, bauptjachfid) ipredien" bucht, Denen Dann allgemeinere Bujammen= Nebring 1684; Daju $D$ e $\mathfrak{i}$ in it $\mathfrak{i} \mathfrak{i}=\mathfrak{l l} \mathfrak{r}=$ jebungen folgten wie $\mathfrak{z}$. B. Definitivantwort the il (1598 Romoorp II 480: = lat. sen- (Sthilfer 1801 Brieje VI 268): dieje haben tentia definitiva). Şiernad) muroen cinige die (Entjehung Des abjeftibijden (5e= völferrechtliche Termint gebiloet, von Denen/braudbs von s e i $_{\text {in }}$ i $\mathrm{t}$ i v begünitigt.

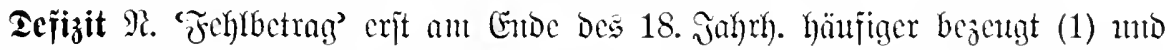

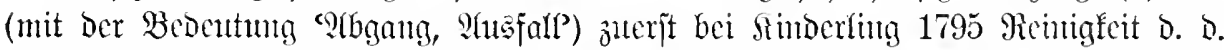
Spradhe $\subseteq .248$ gebud t: wohl cher cin Sanjleimort, als cin Saufmanmsterminus.

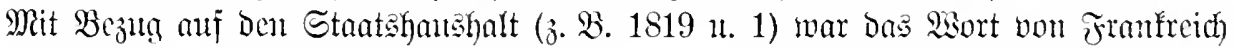

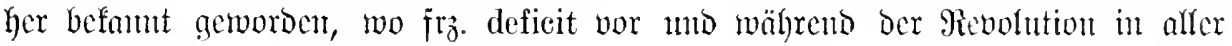

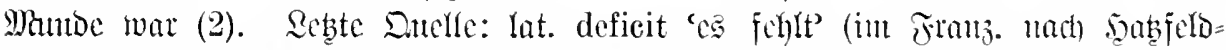
Darmejteter I $657^{\mathrm{a}}$ jeit Dem 17. Jahrh. als Formel gebraud jur Bejciofumg vou ¿ücken iu Juventaraujuahntu).

Belege: 1? Bürger 1788 Briefe III $195 \mid$ res 1819 Teutjglano Є. 63 als bey den Sollte es Ihnen bey einer näheren Bezichung Verhandlungen über das Deficit zu seiner der Cathegorie Gemeinschaft oder Weehsel- Deckung allzu reichliche Sprossen der Civilwirkung auf uns Beide, auf ein beträcht- liste wie billig beschnitten wurden. Govethe liches Weficit in der Bilance nieht ankommen 1830 ?Inalen $(35,93)$ Die Kosten einer - 1792 ebo. IV 189 Gern setzte ich einen wohlbesetzten Tafel vermehrten das Deficit, Sommerlang meine Geschäfte aus und reisete das der alte Pachter zurückgelassen hatte. ins Carlsbad, wenn dadurch nicht ein so Geine $183 \pm$ Galon (IV 42) manchmal ist großes Defieit in meinem ohnchin erschlafften er nur der Fallitenbuchhalter des gebrochenen Bentel entstände. Jiflano 1799 sausigrieden Herzens, der das Defizit ruhig ausrechnet. (X 232) weil ich selbst eine Art von - wie 2. Sieland 1789 2lorejie a. b. jranz. will ich sagen, von Deficit in der honetten Rationalverjammunng (5)mper 34, 49) Die Ehestandsrechnung meinerseits merke. (6ïr $=$ Staatssehuld und die traurige Notwendig- 
keit, sie bei dem fürchterlichen Deficit der franzäj. Revolution 1109 Da wurde denn Staatseinnahme immer noch vermehren zu die jährliche Blösse der Finanzen kund, müssen. Gjirtamer 1791 Franjöilidge $\Re e=$ so berüchtigt unter dem Namen des Defizit, volution II 181 Das Wort D ef ic it ist, ein Wort, das aus dem Sprachgebrauche seit einigen Jahren, in Frankreich ein Mode- der Kanzelleyen in die gemeine Sprache wort geworden. 1795 Bciträge 3 . (ǰcjc). D. übergieng.

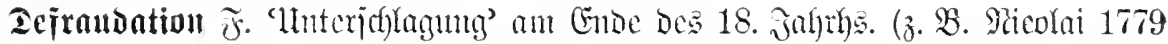

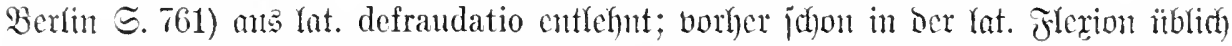

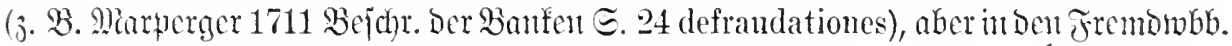
vor nentrats $17 \% 5$ jehlesto. Qülter ijt

ocĩrandicuen 3tı. jogon in 16. Jahrh. eigenuitzigen Beambten. 1643 urf. $u$.

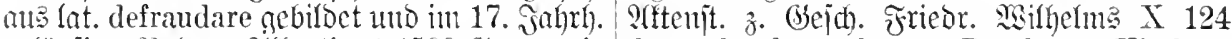
neläufig. Belege: Rrubertimus 1599 (buevara's dass durch sothanes Begehren Kirchen, Eentidireiben III 197b bie 2[ntojen] werden Scliulen, Wittiben und Waisen defraudiret nicht gemindert noch defraudirt ron den und un das Ihrige gebracht würden.

Degeneriert 2(Dj. cin Iermints Der Rjochiatric, Der am Enbe Des 19. Jahrbs. befant getworben ijt (1): ju begenexiereu, bas jobn im 16. Jahrh. aus lat. degenerare in ber allgementuen Bebentung 'entarten, ausarten' (auch tranj.) cut= lehnt morben roar (2).

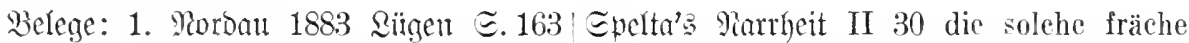
der männliche Theil aber ist das, was die Stïcklin reissen, die degeneriren vnd sehlagen l'sychiatrie einell ,Degenerirten" nennt, das auß dem Adlichen Geblït. 1616 Braun=

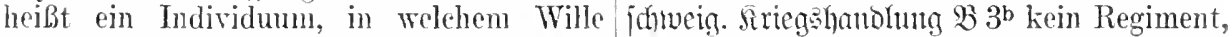
und Vernunft verkïmmert sind, der morali- wie schwer es dann auch seyn möge, ob es sche Sinn rudinentär ist und die geschlecht- anch gleich gar zur Tyranney degenerirte liche Leidenschaft, oft in seltsaner Ent- vnd hinanb schluge. Warfinaujert 1616 artung, allein das Scelenleben beherrscht - Sricgumantual $\Xi .68$ lasset den Vralten, daß der Mann ein „Degenerirter" in wissen- fur so viel tausent Jahren löblichen Namen schaftlichen Sinne, eine schwache simnliche der Teutschen nieht ron euch getadelt oder und impulsive Xatur ist.

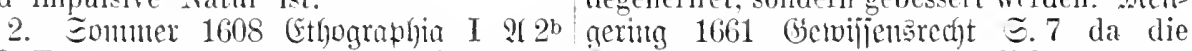
daß Teutschland so geschwinde in Sitten Päpste noch nicht so gäntzlieh von der rnd Kleidung degenerirt. Mejierjantio 1615 Christlichen Kirchen degeneriret.

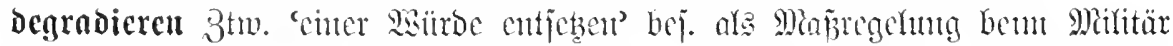
(jd)on bei Tilich 1608 Siricgsbud $\Xi .127$ ), älter (jeit Dem 13. Jahrh).) non Der $\mathfrak{B e}=$ itrafung ber (jeijtlicten (vergh. Berm. XVIII 267). Duclle: (ipät=)lat. degradare.

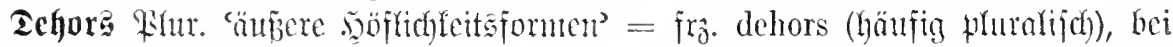

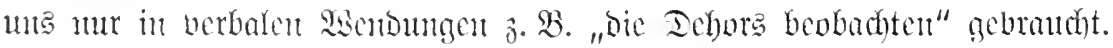

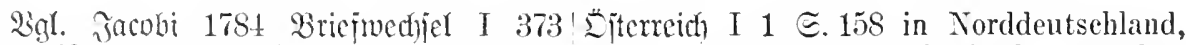
Ich weib wohl, sagte Göthe, daB man, um wo nur die Dehors mehr beobachtet werden. die dehors zu salviren, das dedans zu Grunde Devrient 1837 Berirmugen (II 17) Weiß richten soll; aber ieh kann mich denn doch die Dehors zu menagiren.

nicht wohl dazu verstehen. Mormanu 1833

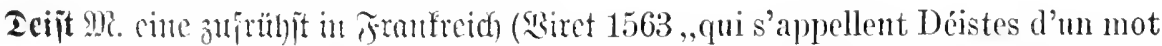

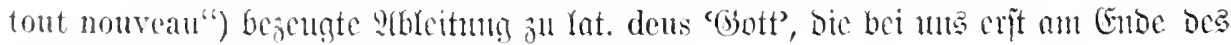
17. Jabrty. Gefonnt gemorden ou jein jochemt.

Relege: Eectenourifi 1685 Chriftentant und daß ein Gott sey, gar leugnen, die II 4 dab wider die Atheisten und Deisten andern aber ihm nicht nach der Art, wie geschrieben werde, deren jene Gottes Wesen, er sich offenbahret, und in heil. Schrifft 
zu finden, erkennen, sondern nur eine natür- Menschen bezeichnet, der weder atheistische liche Wissenschafft behaupten, oder an seiner noch dämonistische Grundsätze hat - (36) Vorsehung und Regirrung zweiffeln wollen. daß man unter dem Worte Deist, in seiner Lejïng 1749 Freigeijt (II 52). Serber 1766 gewöhnlichen varhabten Bedeutung einen

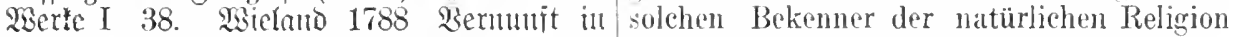
Blanbenjadjen (XXX 35) das Wort Deist verstehe, der nicht an die Dogmen der oder Theist, welches (so viel ich weib) einen Christen glauben kann.

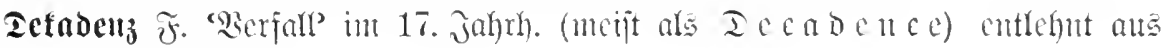
gleidjbed. firz. décadence.

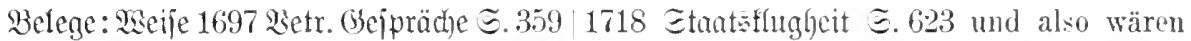
Als die Stadt Rom in Decadence kam. 1702 sie in Decadence gerathen. Fleijher 1730

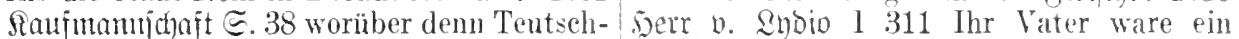
land und dessen Inwohner nachgehends in hauffmann gewesen, durch seine negligente merekliche Decalentz an seinem Reichthum. Aufführung aber gantz in Decadence geNahrung und Handel verfallen ist. Mohr bracht.

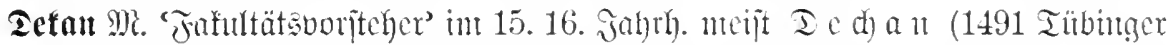

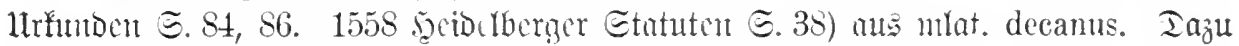
Defan at (1558 5xcidorb. Etat. હ.65) an mlat. decanatus.

beflamieren 3tw. 'vortragen' jonon im 16. Jahrh. aus lat. declamare enttehut,

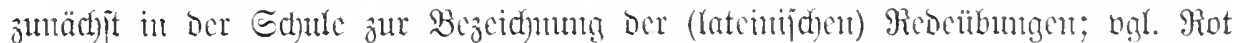

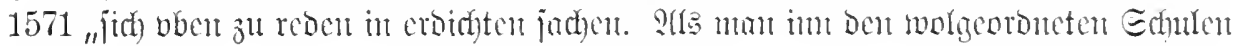
tiflegt zutlum".

Belege: ca. 1550 (beipräch des serm

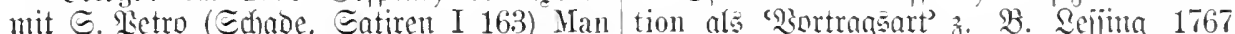
thut den Grobianum declamiern. Mathejus Dramaturgie (IX 215) In ihrer Deklama1565 Earepta S. $81^{\text {b }}$ Vber diß disputirt oder tion accentuirt sie richtig, aber nicht merkdeclamiret man alle wochen. 1596 Birum = lich - (216) seiner Deklamation eine höhere (d)weig. Eduntoronungen I 129 dass man/Vollkommenheit zu geben.

im jahr drey oder vier mahl declamire. libertragen 'unwahre Echümederei' val. Menfart 1636 5ed jojulen (53 $3^{3}$ Gibt Er jhm Savater 1776 Pignjingnom. Fragntente II 273 nicht die Gabe zu disputiren, Er gibt jhm Was ich hier sage, ist nicht Deklamation die Gabe zu declamiren - \$.99 können eines in die Wissenschaft Verliebten - 1778 nur zimlich syllogismiren, declamiren vnd ebo. IV 25 Daß dies alles nun nicht Deklaplappern. Seroer 1767 Seutiche Riterntur mation (ein Hodewort unserer untersuchen(I 175) könnet ihr Hexameter deklamiren? den Zeit, womit man alle Wahrheit, die

Ieflamation $\widetilde{F}$. erit bet Eperanber 1727 nicht gefällt, zu Boden gebieten will), daB gebutht: atts lat. declamatio Gedeitbung, dieß mu nicht Deklamation - sondern Sortrag'. Seleg: 1708 Seopolo Der Grobe Wahrheit ist, weib ich, denn ich habe VerII 113 worinnen dem Käyser zu Ehren eine suche gemacht.

Declamation gehalten wurde.

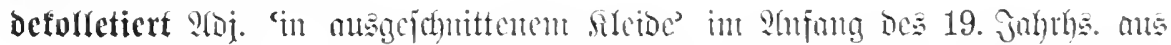

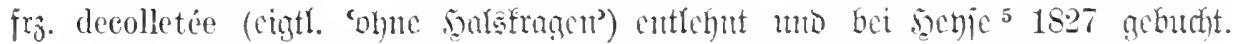

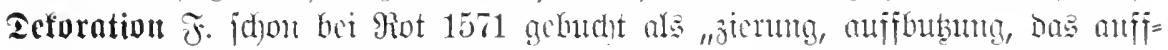

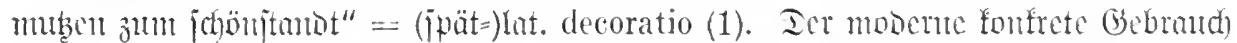

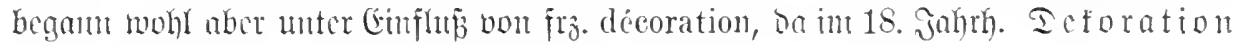

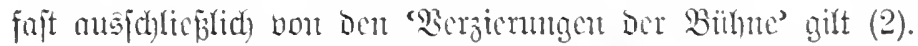

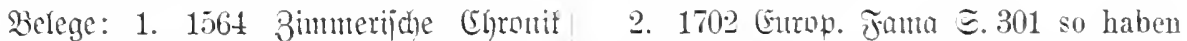
II 102 unangesch ${ }^{\prime}$ irs alters hat sie wol Se. Königl. Haj. schon wiederum an neuen schmeckende wasser und alles anders, so Masquen, Scenen, Machinen, Decorations zu ainer decoration oder bezierung des und dergleichen zur Vorstellungs-Kunst beleibs dienstlich hat sein megen, gebraucht. nöthigten Dingen arbeiten lassen - [aber 
ङ. 9 Iatinijitert theatralische Decorationes]. Ihenterz ๔. 149 Sorgfalt für den äußeren

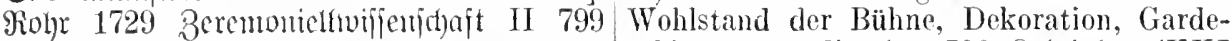
Die Decorationen des Theatri wedken den robbe usw. Gocthe 1796 Lehrjabre (XXI Geist der Zuschaner auf. Eufzer 1771 I gevric 158) Ein guter Schanspieler nacht uns bald I xir Deeoration (Schaubïhne) - Ver- eine elende unschickliche Dekoration verziermng. Echntio 1775 Conronofogie D. D. gessen.

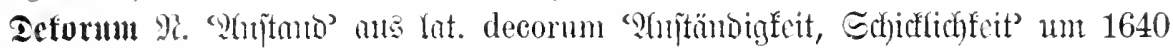
übernommen, aber crit bei Epermber 1727 geburt.

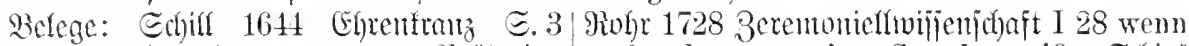
das decorum in acht genommen. Prötorius er das decorum seines Standes weiß. Schut 1666 Anthropodemus I 272 damit sie ihr 1778 Marionettenthenter હ.37 2um. ein decormm oder $\tau^{r}$ resisor in acht nehmen. Lump von Genie, das Mores wüste und 1719 Reeucil VI 5 das war wider das decorum. nachm Dekorum früge. Erot 1786 Mnlleitung

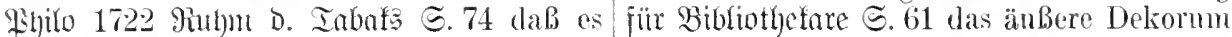
nach Beschaffenheit der Umstände sehr beobachten. Qfochengof 1787 Eraglano I 153 wider das Decormm würde gehandelt seyn. Die Diebe beobachteten ein gewisses Dekorum.

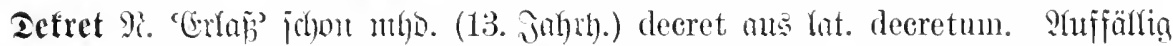

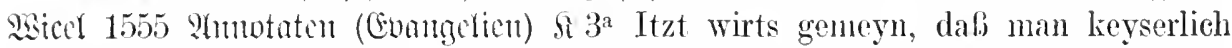
Decret sagt, wenn etwas im Rhat beschlossen rnd folgends in die Lande aubgeschrieben vind gebotten wirt.

Defretieren 3tw. in 16. Jahth. von was I. Kays. M. decretiret und erkennet, Defret abgeleitet 3 . $\mathfrak{B}$. Ed)weinichen $1580 \mid$ ins Werck gesetzet worden möchte - ebo.256. in Ecript. rer. Eiles. IT $7 t$ damit dieses

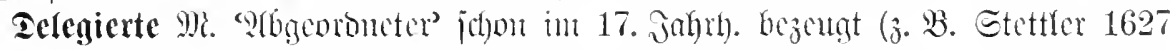
Erfyeizerffroniff I $263^{\mathrm{b}}$ mit den vbrigen Eydgnössischen Delegierten - $312^{\mathrm{b}}$ gemeiner

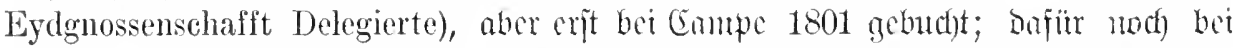
Sedunta 1775 Delegat = lot. delegatus cight. 'Benuftragter' ju delegare, bas

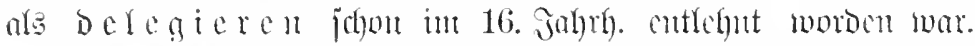

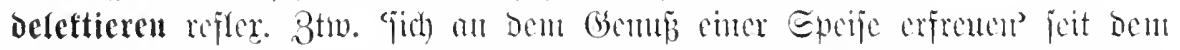

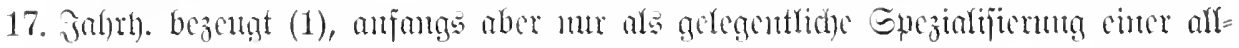

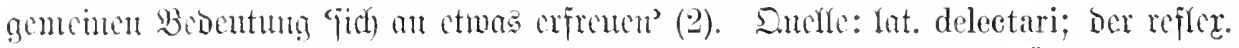

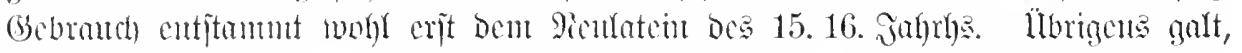

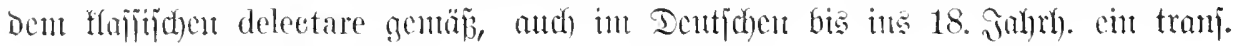
Derefticter (3).

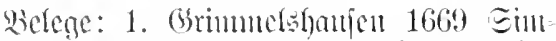
plicipintes s. 403 mein Weil) delectirte sich stindlich mit Wein. Etimbe 1884 Taut. Winch)= looly I 135 wenn die Somne schien, singen wir in den Wald und delektirten uns an den griten Sachen.

2. Subertum 1599 Gutebaras Eento= felreiben III 12b bise delectiren vind erfrewen sich in Zaschawmig - 1600 soo = follte $\Xi .14^{\text {a }}$ das Hertz delectirt sich nur mit deme, was jmo eigentliümblich zugehört.

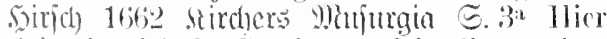
delectirt sich der Gottlose multitudine amri ङ. 79 woil David ron Jugend anf cin mosicum gelon, sich damit höehliels delectirt. Edupp 1609) ofutwort $\bigodot .37$ als ich awer lling anlff dom Bett durchlesen, lab ieh

mich höehlich delectirt. (Grimmelghanjen 1669 Eintulic. E. 471 mit solehem AnBsehen und Betrachtungen so schöner LandesGegend delectirte ieh mich mehr, als ich

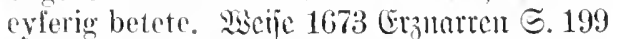
Absonderlich deleetirten sieh alle an der schönen Klage. Ettmer 1715 Jachamme E. 328 und sieh sonderlich über die Aussicht delectirte.

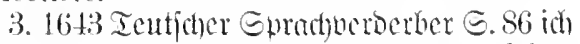
habe] scine Gesmulheit vernommen, welches mich sehr delectirt. Siscije 1673 (5ronaren E. 188 dab solche Prediger zwar delectiren E. 189 man deleetirte sie mit geistlichen Wevnacht-liedern. Thomafus 1688 Mo= motengintäche I 2.3 so delectiret mich der bekannte Hereur Calant über die massen. 


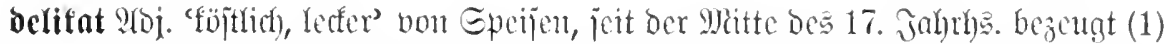

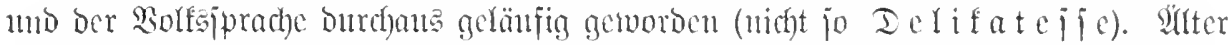

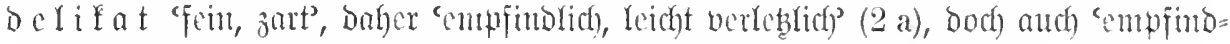

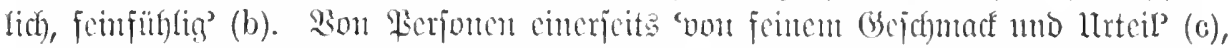

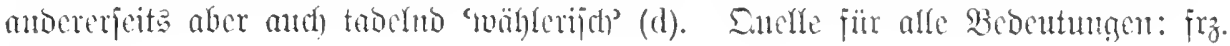
délicat.

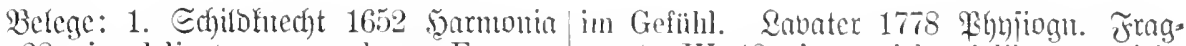
III 28 rin delicates angenehmes Fressen. mente IV 48 einen nicht delikaten, nieht

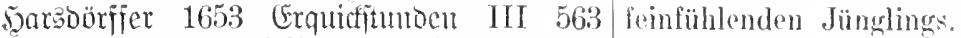

die stärcksten und delieatsten Weine. Grrint= melshaujen 1669 Eimplic. E. 182 sehr delicat Rindileisch. Edhutra 1672 Materialien= fommer Є. 99 dib sonderlich delicate Rel-

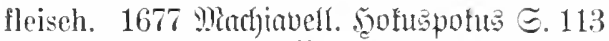
cin heisser, doch delieater Brey. Böbler $1683.5045=$ u. Feloidule $5.68 t$ die delicatesten Fische. Epohn 1688 Som Saffec ङ. 175 ein delicat Bischen. Echellfoummer 1692 Die siödin $\Subset .59$ cine gute delicate Speise. Gröben 1694 Drient. Peijebejd)r. ङ. 365 ein delicat Fleisch. Ettmer 1697 Entunicus E. 265 die delicatesten Speisen.

2 a. Wrbertims 1598 Guevara's Gend= jorreiben I 114a Die Elır deß weibs ist bey weitem vick delicater vnd häckler als die Ehr des Manns - 1599 ebo. III $78^{\mathrm{b}}$ die Sachen deß Gliicks seynd delieat rnd subtil 1601 (35.'s Geijtl. Spiegel S. 2915 dann der göttliehe Trost ist dermassen delicat rnd häckl, dah sie keinen andern Trost zulest ธ. 29:b Dise Wort seynd gleichwol delicat vind subtil. (Ealfenbad) 1715 Duaji bero 5.38 es ist gar cin delieate Hatery, man kann leichtlich anstossen. 5erber 1767 Dentide siteratur (I 386) eine delikate Materie der Philosophischen Sprachliunst.

b. Prötorius 1619 Enntaguta III 99 jre sonderbahre profeßion von cim reinen delieaten vnd saubern Gehör machen. Epec 1649 Intbuctigall (Borr. 6ª ) daB hie ein delicat oder zart gehör von nöthen ist. Ihomajus 1691 Bermuntlehte II 145 gelehrte Leute von delicatem Geschmack. Meier 1744 Stuptrichter ङ.67 Er muß, an einer jeden Sache. sehr vicles unterscheiden können, und daher entsteht eine neue Vollkommenheit seiner Beurtheilungskraft. Iels weiß nicht, wic ich dieselbe, mit rinem guten deutschen Worte, ansdrucken soll. Eine Beurtheilungskraft, die mit derselben ansgeziert ist, ist delieat.

d. Enyorer 1663 צranei Der Reijenden ङ. 156 den Reichen vnd delicaten leuthen. Biffelbärina 1685 Stciderafje $\Xi .222$ daß selloige so delieat und stolt\% gewesen. Ihoma= ïu 1688 Mronatågcipräd)e I $7^{\mathrm{a}}$ (3. Sorr.) Ich bin ein wenig delieat in Ceremonien. Bercfenmener 1712 Intiquarius $\Xi .10$ In der Kost [jei] der Frantzose delicat. Eallen= bad) 1714 Eclipje S.31 kostbahr in der Kleidung, delicat in der Kost. Ramler 1757 an Gýcint (II 297) Aber diese EBer werden viclloicht zu delieat sevn, als dab sie Erbsen eben wollen.

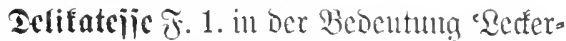
bijen' im 17. Jahrh. ans $i x$. délicatesse cutlehnt; Die Ulbleitung (rwie Der gange Birbungatypus) iit aber cigtl. in vatalien heimiijch (ital. delieatezza) und daher wurbe in 17. Jahrh., wie es jofint, von Diterreid ans cine form Deficateso a bulich j. 2 . Somed 1684 Diterreich 0.104 diese West-Indische delicatezza. 1685 厄dhlei. Fïritenfrone $\mathbb{S} .785$ von allerhand Gewürtzen und andern Delicatezzen. Salfyover 1689 (3artcubeetlein II 90 ta Delicatezza 1320a Delicatezen rnd Leeker-BiBlein. Iod überwiegt bald Delicatejie: 1664 Interredung e. Inigarm u. Deutidjen $B 1^{\mathrm{b}}$ iic] verzehrte die gebratene Delicatesse

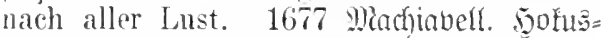
pofus ङ. 632 Orangen Aepfel, welche ihre delicatesse waren. Envhn 1688 Bom Raffee 5. 134 rare Delicatessen. Thomaïu 1688 Mronatageipräbe I 138 weil leicht niemand dats Brodt zur Delikatesse und straffwürdigen Überfluß gebrauchete. Grrïben 1694 Erient. Meijcbej(y). 5. 356 ron Jugend auff ron D.-en abgehalten. Edhellimmter 1700 Sonjefttid $\Xi$. $2^{\text {a }}$ mit allen D.-en angefüllte Taffeln. Reib 1708 \$iterte Frobe こ. 26 Aquavit, Wein, auch andere D.-en.

2. 'Feirfübligfeit' $=$ fro. délicatesse

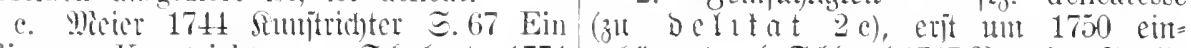
delieater Kunstrichter. Ed)ubart 1774 gebiurgert, vgl. Schlegel 1747 Borrebe (Sd)rif = Deutithe Chronit ङ. $218 \mathrm{Er}$ ist mehr als ten ङ. 181) so sehr unterscheidet sie [oie Theokrit, reicher an Erfindung, delikater Rebe Des Bajazct] sich durch diese Feinig- 
keit, und, daß ich mich des Französischen $\mid$ ein wunderlich Gezier von D. Echubart Wortes bediene, delicatesse des Vortrages. 1774 Deutjue Chrontif 5.278 die höchste D. Dufd) 1765 Briefe II 71 die D. beleidigt des Geschmacks. Wagner 1776 תinder= finden. 1765 grlg. D. Bibliothef I 1 $\subseteq .25$ mörberim $\Xi .50$ da ich ihre D. kenne. wiefern er die Freyheit und den Charakter (Boethe 1796 Lefriabre (XXII 7) Ich opfere des Originals mit unserer D. vergleichen die D. ciner höheren Pflicht auf.

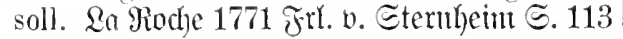

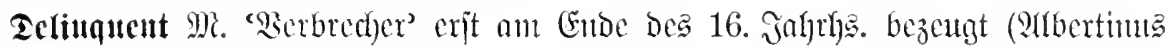
1599 Gycuaras Sembjoreiben IJI $4^{b}$ Es ist ein Ignorantz, die entschuldigt den delinquenten vnd verbrecher), Dafür in Der älteren Rechts̄ptad)e Geiäter, Frevler,

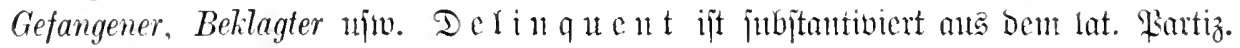

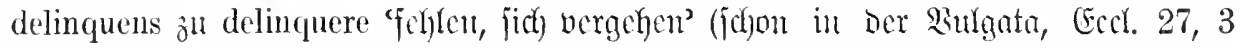
Contereretur cum delinquente delictum un bei Bambinus [um 1300] Tract. de Malefieiis: Ubi puniatur delinquens; iod) bgl. nod) persona delinquens ๔aur 1580 Peiul. Prozeñ S. 1, neben Qui delinquenti opem praestat, pari poena puniendus est હaur 1583 Strafbud ङ. 260).

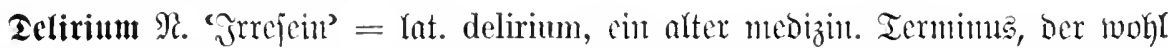

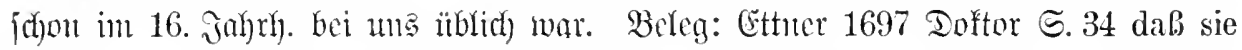
darüber in ein delirium gerieth. Der 跑. Defirien tritt erjt im 19. Jahrh.

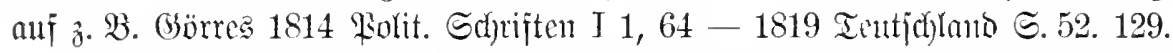

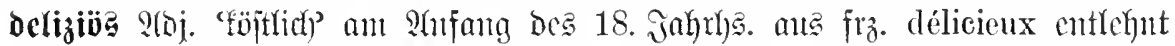

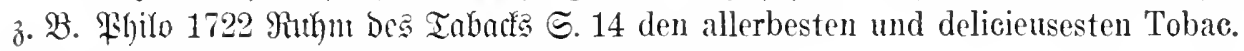
Rohr 1728 Beremoniellwiffenfaraft I 298 delicieus.

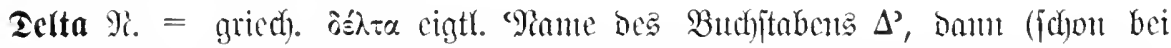

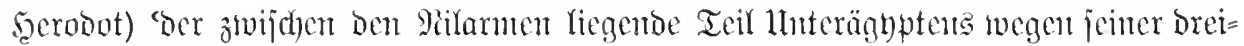

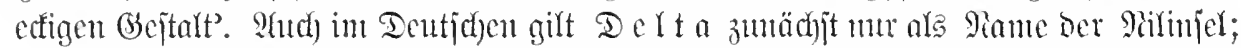

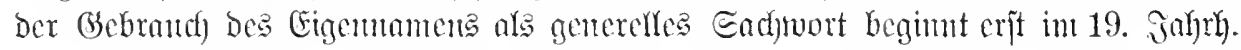

Belege: Miüniter 1550 Sogmographie|s ethicher massen gleich gelegen, Delta ธ. 1258 vnd was lands zwischen jenen genant) in jrem rnlkreis nicht viel weniger [Den Rilarmen] begriffen wird, ist so reil als 300 Meilen. BSLlnov 1716 Cinl. in b. als ein insel, ist trefflich fruchtbar rnnd beographie $\subseteq$ S. 1113 wo er [Der Sil] bey mit veilen fleckenn besetzt vnd heibt das Cairo die Insul Delta macht und ins Mittelvnder Egypten, die züginer oder Heiden ländische Meer fällt. Dittruberger 1827 Geo=


nennen es Deltan von de dreiekichten zwei Arme bildet das Delta (eine grobe form so es hat, in gestalt des Griechischen dreieckige müchte Insel) am mittellänbuchstaben delta, der ein triangel macht. dischen Meere. Pïffler 1835 Eenifajio Duad 1604 Entfirioion cosmograph. E. 208 III 165 ein Thal] über das die Gave und Helt also diese gantze Insel (welche die Alten Lousse hier eine Art ron Delta bildend ihr dieweil sie dem griechischen Buchstaben Netz von hundert Silberstreifen ansbreiten.

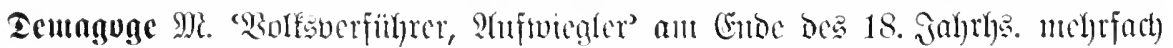

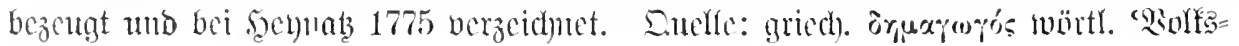
fïl)rer'.

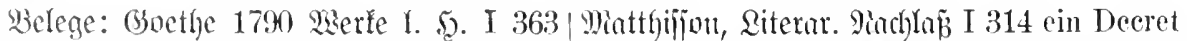
Könige wollen das Gute, die Demagogen eines entmenschten Demagogen.

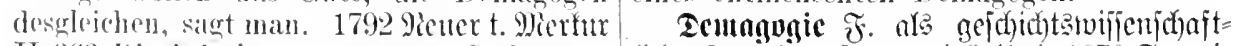
II 363 Die Déraisonnemens und Sarkasmen ficher Iermitute fdont bei Qeibuiz 1670 Eecurietlieher marktschreyerischer Demagogen.| to publica (I 243) Tiepublifen, in denen] 
Niemand müßig, und also keimer Demagogie, | Gehör gegeben wird. Suelle: griect). welehe Rom und Athen verderbten, kein ory p.ajwia.

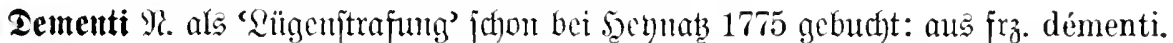

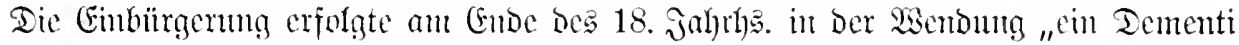
geben" = jrz. donner un démenti, anjangs mit Berwahrung Der franz. P(us̃prache, die andh Echillers Edfreifung Dö ma hut $\mathrm{i}$ (1786) wiedergeben will und (5ampe 1801 ausonöidflicf) verlangt.

Belege: Wielanto 1776 an Merrf (ङ.81) seinem System ein Démenti zu geben. Ich denke, was er Ihnen etwan selbst ge- $\Xi$ hiller 1786 Brieje I 294 die ganze Natur legentlich davon sagen wird, soll mir kein "giebt sich ein öffentliches ,Dömahnti". démenti geben. \$̧ermes 1778 Eophien: Jifland 1799 Leichter Eimn (V 157) Ich gebe Reije V 725 der Mann, der nie ein démenti mir kein Dementi gegen den Minister sich gebe. 1784 Merfiur I 169 dab man einem 1801 Sö̈hen (VII 107) ich gebe mir kein Philosophen ebensowenig zumuten kann, Dementi.

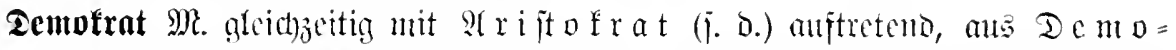
f $x$ a t i e gebildet. Beleg: Sdfilfer 1802 Bricfe VI 433 , serber] hatte sich immer als der größte Demokrat herausgelassen.

Demofratic $\mathfrak{F}$. aus mlat. (= griech).) Dem ocratic j. B. Brottmibs 1647 Regi= democratia, in 16. Jablh. noch in Der lat. mentsant $\subseteq$. 4 ein $D$. oder des Voleks regierung.

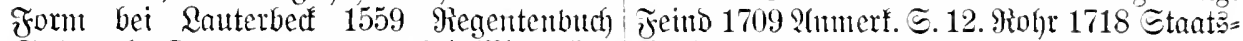

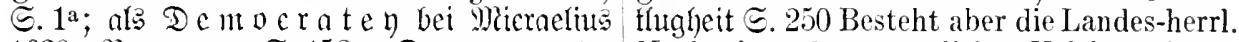

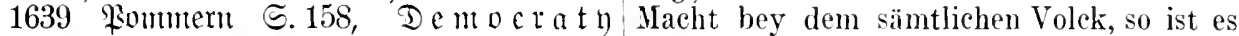

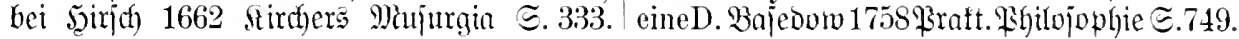

bemolieren 3tw. 'zeritören' in allgenteinem (bebrand erit im 19. jahrh. be= zeugt (1); Dod vouger jofon wohlbefant aus ben friegaberidften (2): D c m o l i e r c n bezeidnete (jeit Dem 17. Jahlh.) Ipezicll Das 'Beritören, Schleifen von Jejtungs= werfen'. Duclle: ¡̈rz. démolir (oder lat. demoliri?).

Belege: 1. Deinte 1834 Calon (IV 55) geschleifft vnd demolirt werden. 1633 wogegen die rohe Menge etwas unförmlich Fonitantzer Belagerung $\Xi .45$ daß die allprotestierte, als sie jüngst die Kirchen bereit gegen vnsern Eydgnosschafft andemolierte. Riug 1819 Berlin u. Breslau gefangene fortificationen demoliert werden.

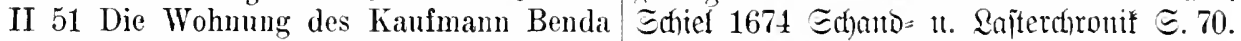
wurde von der erbitterten Nenge gestürmt Ehifentont 1702 siriegsrat I 162 . loch bei und demolirt.

2. Carolus 1614 Relation $\Re$ r. $9^{\mathrm{a}}$ alles ein unverzeihlicher Fehler der Landespolizei, was bißhero daselbsten gebawen worden, daß man nicht die Wälle demolirt und in wurde innerhalb 6 . wochen gewiß demolirt, Gärten verwandelt. Forīter 1791 ifujichten abgebrochen werden - $\mathfrak{M r}$. 49a die newe (III 39) Vor zwei Jalıren ließ der Kurfürst fortificationes sollen demolirt werden. Cn: einen Theil der Festungswerke demoliren. 1630 Rojtreiter હ. 65 Solten die Vestungen

Temonitration ₹. 1. 'Sunbgebung' bef. im politijenen Ginne (eigtl. 'Sifenbanmg jeiner Mcimmgy) im 19. Jahih., wohl erit nach 1848, befamt geworden. Ias sart ftamut, wic : g itatiou, aus ocm Engl.: ,what, in their own conventional cant, they call a demonstration" 1839 bei Maurray.

Belege: Bisnard 1849 Briefe $ミ 125$ Deutjaer frieg I 12 Die D. der ,6000 streitVon pöbelhaften D.-en hielt sich alles mit baren Mämmer" unterblieb. Miç) politif̧

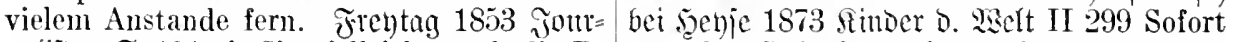
nalijten $\subseteq .121$ ob Sie vielleicht auch die D. war der Gedanke aufgetaucht, durch eine geleitet haben. $\mathfrak{B a d}$ enthujen 1865 Ballet I feierliche D. der Gefahr, den theuren Freund 87 zu einer politischen D. Fontane 1870 zu verlieren, womöglich vorzubeugen. 


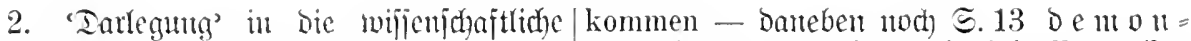
Terminologic aus lat. demonstratio auf $=$ it $x$ at iones, wic aud bei Paracelfus

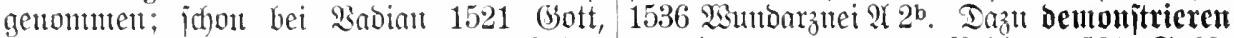
GIlauben $\Xi .11$ erzalten $v$ künstlicher aus lat. demonstrare Babiaul 1521 ङ.60. demonstration, das es vnmüglich were einem 1569 Braumichtv. Edhuloronungen II 39.

toden mensehen, wider zum leben mögen

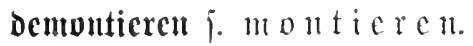

Dentoralijieren 3tiv. 'Des jittlichen Riuthalts, Des Eclbjtbertrmens berauben'

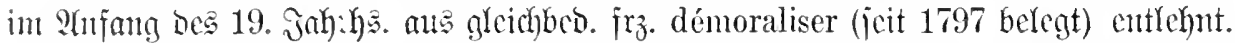

Belege: SBitt b. Iörring 1827 Fragutente Fragmente a. Siterreich 厄. 98 Das Volk II 345 Das französische Heer ist dagegen ist im Ganzen rol, unwissend und demodurch das Unwesen der geheimen Polizei ralisirt. Pücfler 1841 Bilberjaal III 404 gänzlich demoralisirt. Bectijtein 1836 Reije= ich war so demoralisirt durch das Geschehene.

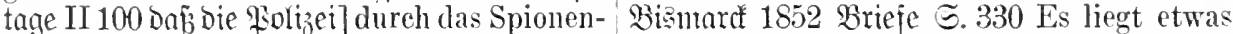
wesen Tausende demoralisirt. Wipib 1839 / reeht demoralisirendes in der Kammerluft.

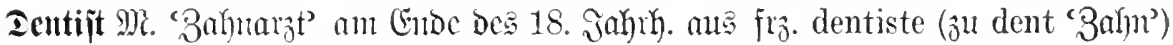
entlchut und 1800 in Enăbflopäd. \$2:

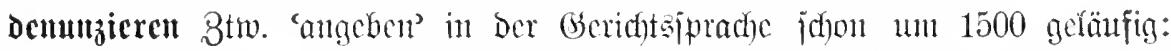

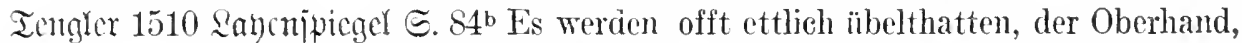
denunciert, verkïndt vind angesagt. Entefle: lat. demmtiare allg. 'anžcigen' (baher anjangs auch dic Sautforn de 1 u $u$ itereu).

Die ipcziclle Bebeutung hat im 16. Jahrh. wo er einige hett oder vermeynt zuhaben, noch nidht die alleintige Beltutta, bgl. (jobler zuthun, Oder sunst jme etwas verkündigen,

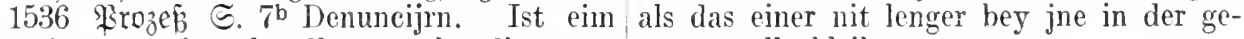
andern zu einer handlung verkündigen, zu meyn wölle bleiben.

erscheinen, sein gerechtigkeyt vnd intrag.

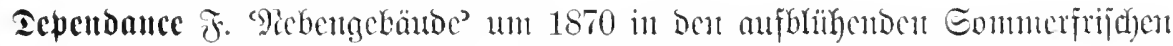

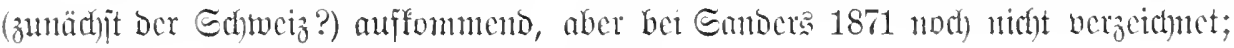
cutrohnt aus frz. dépendance cigtl. ' $B u b c h o ̈ r$ '.

Belege: 5zebje 1873 Siutber D. Welt II Fontanc 1883 Brieje II 53 Sie bewohnt $266 \mathrm{Es}$ versteht sich, daß der ,Stern“ nämlich ein anderes größres Haus mit einer nur eine Dépendance unserer Hütte ist Milch- und Ackerwirtschaft und läßt die in Fällen, wo hohe Reisende eintreffen, die „Dependance", in der ich wohne, dureh die wir bei uns nieht nnterbringen können. vorgenannte kleine SchleiBerin verwalten.

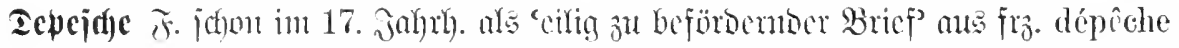

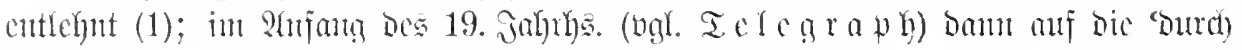

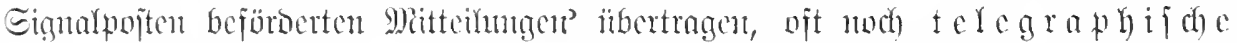

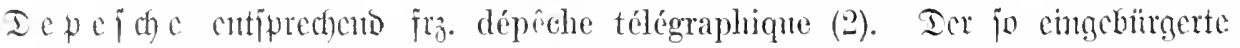

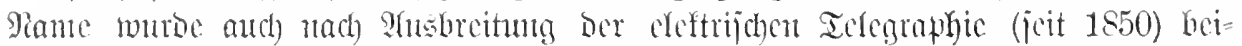

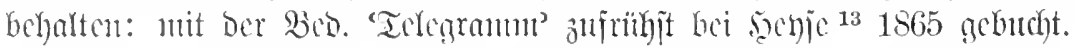

Belege: 1. Jreiberger 1656 Lolit. Dis Depesehen, die er nach seiner Ankunft aus furje $\Xi .4$ meine Depeschen vnd vielfailtigen der Residenz erhalten hatte. Sobche 1799 Correspondentzen. Sirämer 1681 Lebest D. lïble Saune (IX 213) warte unten auf Ecehelben こ.474 dab man eine Königliche Depeschen. Sauff 1826 Mienuiren (IIII Depesche (Ordre und Vollmacht) an den 149) Dieser prüte die Depesehe genall Harechal d'Ammont ansfertigte. Edhubart, das ist äehtes. Kaisersiegellack, wie es nur 1774 (Egronit $\underset{E}{E} 73$ Dn[j] von Zeit zu Zeit in Wien selbst zubereitet wird, und was schr interessante Depeschen cinlaufeu. 然all Eingeweihte zu solchen Depeschen zu ver1787 Bingateflen II 176 ans den ersten wenden pillegen." 
2. (3rabbe 1831 Tapoleon $\Xi .46$ Eure Couriere und telegraphischen Depeschen waren stets langsamer als er. 1852 , Fliegento Blätter XIV 159 Telegraphische Depesche aus Paris. Gutkfotv 1854 Reijeeinorücte (IX 263) seine Ankunft in Berlin vermittelst telegraphischer Depesche anzeigen. în Der "Eijen= bahn" 1838 eitte jtättoige :Hubrif: Fliegende Depeschen.

beplaciert 2(Dj. 'unamgebracht' in 19. Jahrh. gcläufig (2), im 18. jahrh. aber

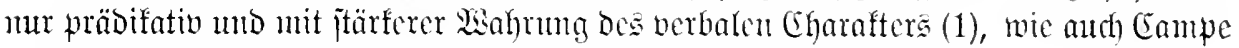
1801 mur erjt "Deplacirt jein" butht. Eutulle: ¡irz. (itre) déplacé.

Belege: 1. 1765 \&llg. I. Bibliothef I 2 ธ. 77 Deplazirt in eine Rolle. die mir nicht zukommt, sehe jch das Schicksal derselben voraus und zische mit. 1769 Eriurter gel. Zeitumg $\subseteq .375$ Und auf der andern Seite, wo etwas neues soll gesagt werden, so deplacirt ist.

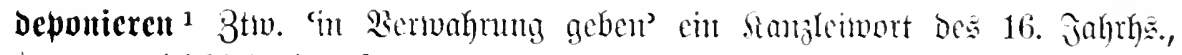
entlehnt aus gleidhbed. lat. deponere.

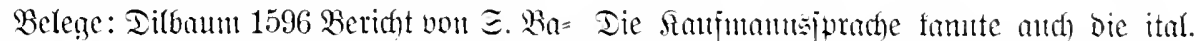
tori $\mathfrak{B} 3^{\mathrm{a}}$ begert ermanten von Sibenbürgen, : jährlichen hundert tansent Gulden zuCaschaw : Rtätorius 1666 Qutbropodemuz 1335 man eines jeden Jars zu deponieren. Carohis solte die 3000 Kronen in depositum legen;

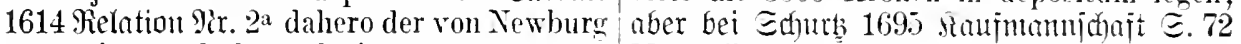
protestirt, rnd das gelt in gute gewarsam Jan gibt oder nimmt Gelder à Deposito. deponirt.

2epoiitengeldor bei ßabener 1759 Eatiren

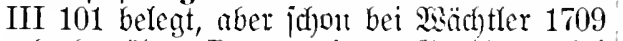
gebucht; älter De posit o- (j) elder bei Dverheide 1657 Eatreibfunt $\Xi .223$, worin ital. deposito M. ‘ginterlegtes, 5einterlegung'. beponicrell $23 \mathrm{tw}$. 'ansajagen' in Der Gerichtajprade: Gobler 1536 itroseb $\Xi .8^{a}$ Deponirn. Ist zelugen oder kundtschafften, Daher der Zengen sage Depositiones genent werden. Euelle: lat. deponere 'eine Erilärnta abgeben' - depositio 'quajage'.

Deportation $\mathfrak{F}$. 'Berbamumy' im 16. Jahrf. ans lat. deportatio cutlehnt, $\mathfrak{j}$. $\mathfrak{B}$. Tengler 1510 Sanenipiegel $\cong .84^{\text {a }}$ on deportacion und lands ewig verstossen. De $\$$ or $=$

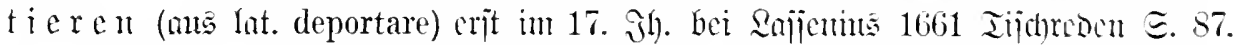

Tie jurijtijhe Fadhliteratu Des 16. Jahrhs. das in latern herßht Deportatio. Lienteder

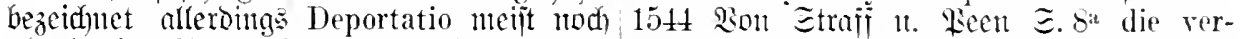

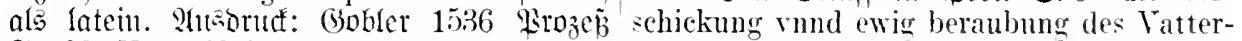

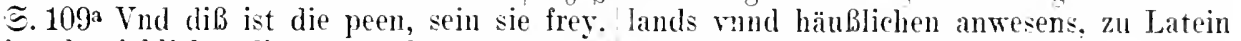
jn sol ewigklichen die statt verbotten werden, Deportatio genant.

rnnd alle jr habe gemeyn geteylet werden,

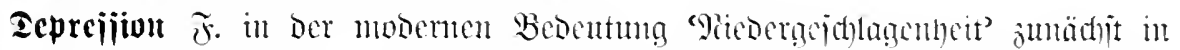

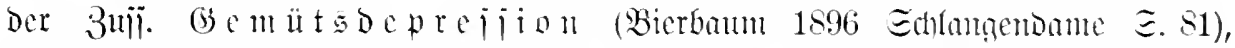

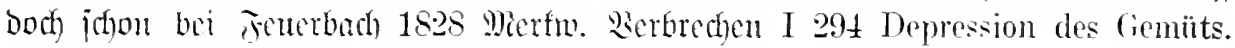
Eutlle: irz. dépression 'Eenfuntg'. (B)läufiger war

Deprimieren 3two. añ $\mathrm{ir}_{\grave{3}}$. déprimer: sein in voriger Woche -1891 ebo. II 246 Mahler 1860 Bilberbud) $\Subset .10^{\circ}$ Mir ahnte daß ihr Znstand auf die Ankömmlinge etwas nicht, wie deprimierend der Tag enden deprimierend wirken muß. Brölíj 1891 sollte. Etimbe 1884 Fam. Subbhol I 70 Moselle E. 44 Tatürlich deprimierte dieses es war sehr deprimirend. Fontone 1889 Urtheil unsern Freund gewaltig.

Brieje II 222 nach einem starken Deprimirt- 
Deprezieren Btw. ans lat. deprecari cntlehnt in folgenden Bebcutungen: 1. 'un Berzeifung bitten, abbitten'; 2. 'bittemb ablebuen, verbitten'.

Belege: 1. 1569 Brammithweig. Echul=/ berg (XII 220) Ah so! dann habe ich alleroronungen II 67 für solehe beleidigung umb dings zu d.

verzeihung und begnadigung zubitten und 2. Sünia 1719 Theatnm ceremon. I $801^{\mathrm{b}}$ sein eulpam zu d. Sobagra 1721 Ppothefer $=$ ob sie gleich diese Ehre depreciret hatten. tod $\Xi .109 \mathrm{ich}$ habe auch zu d. Tohr 1728 Sotsebue 1812 Felofiummel (XXVII 175) Beremonielfuijienjofift I 242 seine eigene-Ich deprecire, mein sehönes Mamsellchen; Fehler d. Sffflano 1799 Erimernug (VIII ich bin noch müde von der Reise.

204) und ich soll d. Solsebue 1801 flintg

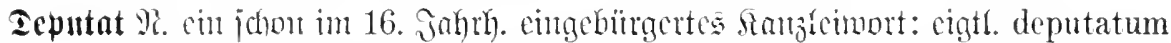

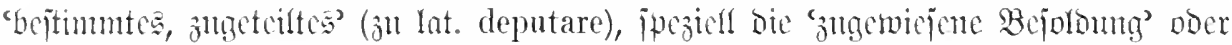

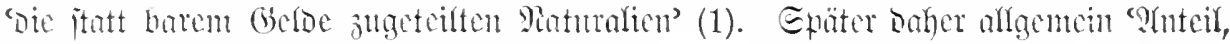

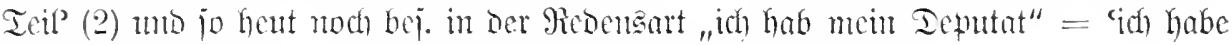
geuntg getrutfen' (j. แ. 1715; Dod) aud $=$ 'gemug gearbettet').

Belege: 1. 1529 bei Iiefentbach= $=$ siullefer 2. Francfe 1702 פisaijenthau I 15 da sie ङ.343 sein depntat. das sich dam an ein [Die Etudenten] kamen und ihr Deputat grosse summe ertregt. Eefrueinichen 1561 abforderten. QTmaranthes 1715 Frauen= Ienfmitrbigteiten $\Xi .15$ demnach JFG. eine zimmerler. $\Xi .277$ wöchentlich ein gewisses gewisse Anzahl Wein aus Herzog Heinrichs Deputat von friseher Tisch-Butter durch Keller zum Deputat hatten. Gird)hof 1602 ihre Mägde in gewisse Häuser liefern. Ettner sendmmut II 121 Jetzt verlieb er sieh 1715 gebanme $\Xi .146$ ein Weibsbild, welches auff sein gewiB deputat und besoldung. ihr gut Depntat trincket. Bismaref 1847

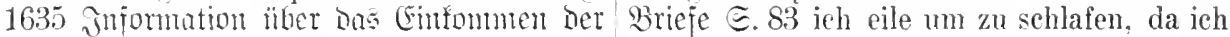
Univ. . Esien ( Deputat seiner Jahrs besoldung. gehabt habe.

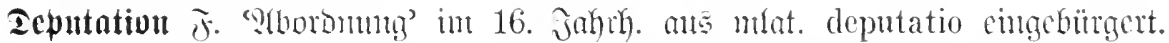

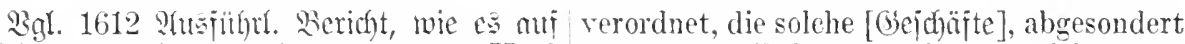
Reidfätägen biflegt gehalten zu mersen II 19 der ander Räht, tractiren; welche vervmb mehr befürdernng willen werden ron ordnung man ein Ausschuß oder deputation den Ständen sonder Lent deputirt vnd neunt.

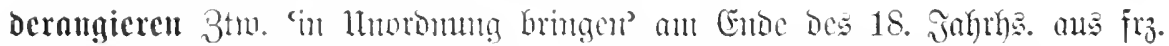

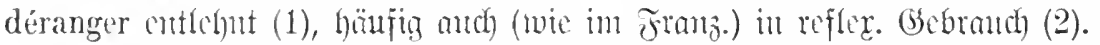

Belege: 1. Magner 1766 simbermbiberin

2. Rejing 1771 Briefe (XVII 405) Sich Є.9 Wie göttlich schön dir das derangirte weiter dernngiren müssen sie freylich nicht. Haar läßt. Bürger 1786 Biriefe III 173 germes 1791 Miürturet I 348 Vor zwanzig Eine solche Abwesenheit wenger Tage ron Jahen trugen wir offne Brust, so daB wir hier würde mich gar nicht derangirt haben. kann ein Hündehen aufheben konnten ohne Eramer 1794 (bentiejtreidhe I 17 Lebrigens uns zu derangiren. Epielhagen 1862 Brobh. derangirte ihn ein solcner Fenltritt noch Patmen III 39 Derangiren Sie sich nicht! lange nicht.

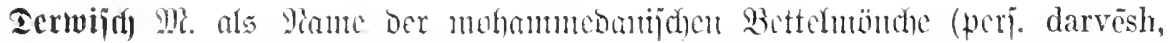

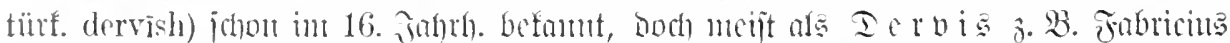

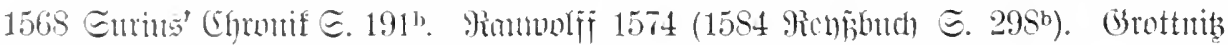

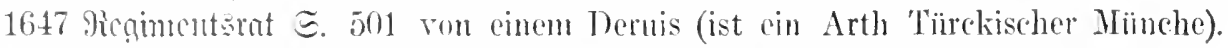

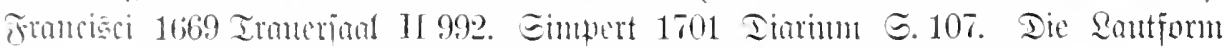

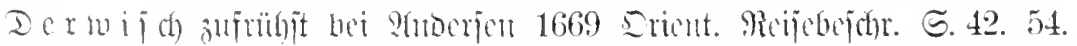

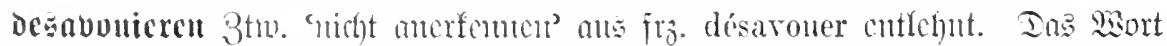

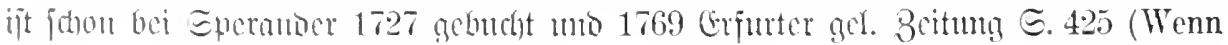


ein ehrlicher Namn rin Buch offentlich desavouirt) belegt, wito aber nod in fahr

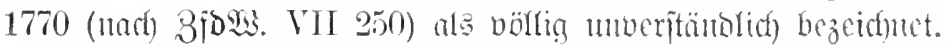

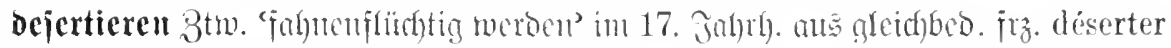
cntlehnt, 3. B. WEagner 1724 Eolontembibr. E.5 im Kriege aber hanget das Leben dran, wenn man desertiret.

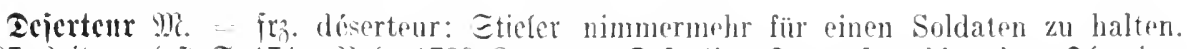

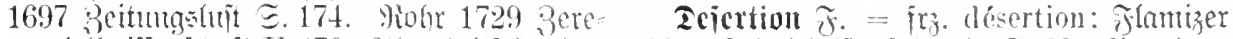

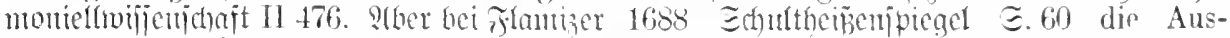
1688 Echultheipenipiegel $\Xi .37$ dab ein reisser, wann sie nach verïbter Desertion Desertor und Pflicht-briichiger Anserisser wiederun betretten und erhaschet werden.

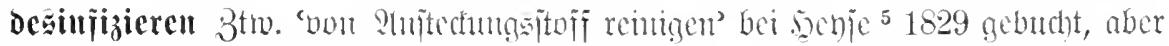

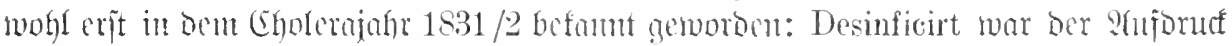

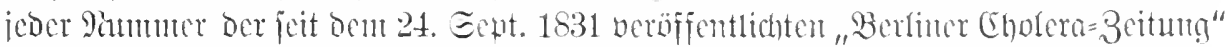

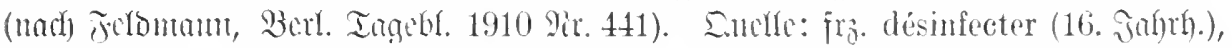
aber nach infizieren umageftaltet, bas der medizu. Iemmologie jeit Dem 16. Jolyth. getüufiţ mar.

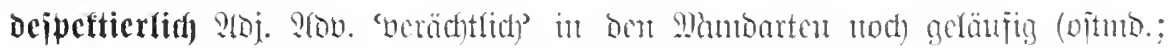

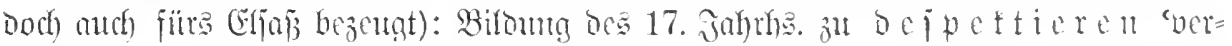

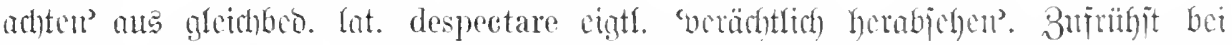

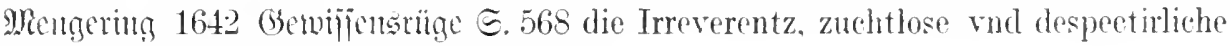
Verhaltung junger Leute gegen die Alten.

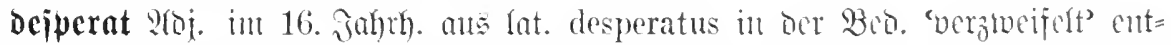
Ichnt; Baraus argab jich gelegentrich (3. B. 1748) bic Bes. 'wittento, crbittert', bie jids)

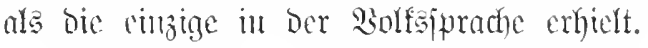

Bdege: Meijerionto 1615 Epelta's Rarr=! an einer gantz desperaten Kranckheit.

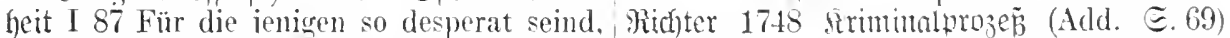
bey denen alles rmb sunst vnd rergebens ob sich gleich die Delinguenten dargegren

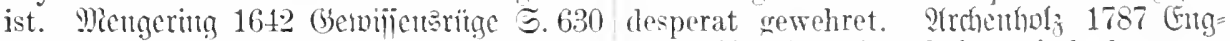
also blöde, schew rnd furchtsam, verzagt Lamb III 389 Die Werber sind desperate vnd desperat. Bübfler 1665 Edfolin mithturis Kerls.

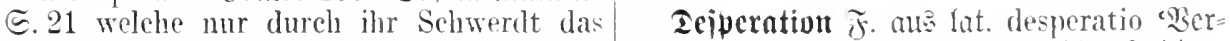

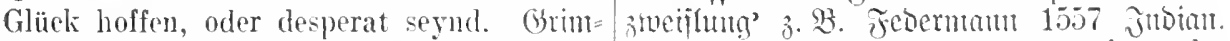
melohatjen 1669 Eimplic. $\Xi .241$ ich war sitoria $\Xi .21$ aub einer desperation oder anch so erzörnt oder vichurehr so desperat verzweiffelung. mejieridunio 1615 Enelta's (dan ich weiß selber nicht mehr, wie mir Parrbeit I 119 entlichen aub Desperation gewesen ist). Frantfe 1702 senjeuthas II 30 rnd rerzweifflung dahingerathen.

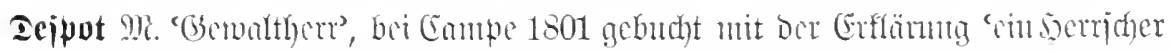

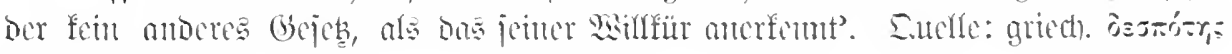

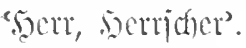

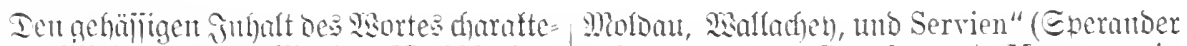

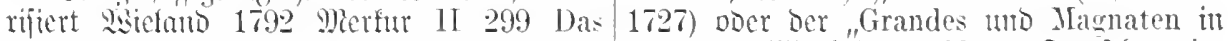
Wort Despot und Despotismus ist nun Itugarn" (然äd)tler 1709). Eo jefon in

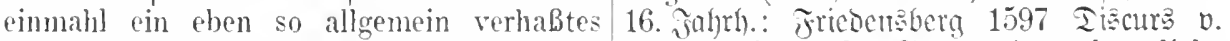
Schimpf-Wort als Kotzer, Pfaff, Deist. - ungar. Stregancjen $\Xi_{0} 14^{3}$ wie auch etzliche Dejpot war jhon frither bei uns befamt, Despoten oder Fürsten in Bulgarien vnd nber peziell als Titel ber "च̈irjten in Der Serrien gantz Tyrannisch tractiret worden. 




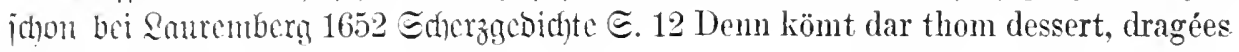
veler sort.

Belege:1766 2fllg. I. Biflinthef III 2, 106 Bursche trïgt die letzten Teller vom Dessert

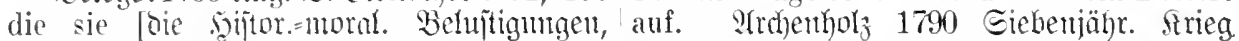
5amburg 1765]. naeh ihrem eigenen Aus- $\Xi_{2} 299$ unter dem Desert befand sich ein druck, als ein Desert zuletzt aufsetzen. großer verdechter Aufsatz. Bahrot 1791

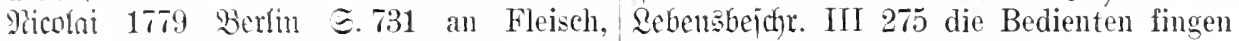
Fischen, zahmen und Wildbraten, nebst an, das Desert anfzutragen.

Desserte. Jifland 1785 ¿ie Gäger IV 1 der

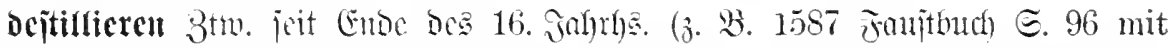

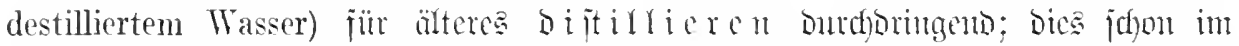

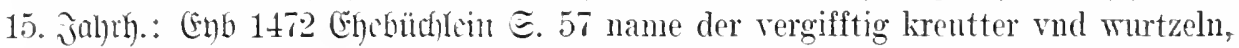

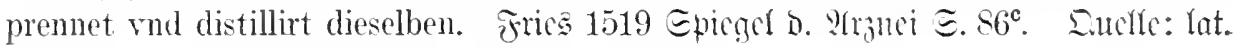
distillare - flaijij(c) destillare 'Gcrabtrüufc(rn'.

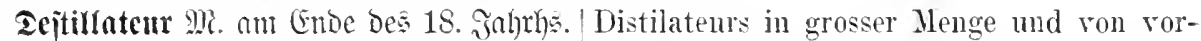

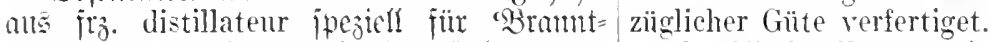

meinbrenter'entfegnt, mit llmigeitaltuntg Der

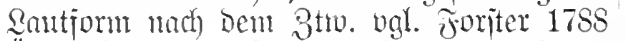
Ḧber Rectereien (ङ. 76) die so gerïhmte Zunft der Wiener und Pariser Köche, das

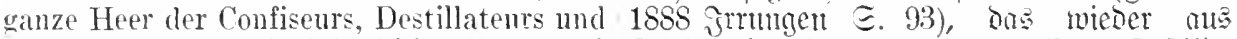

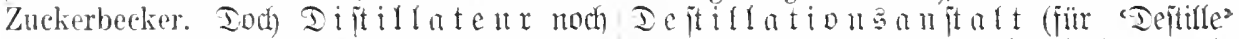

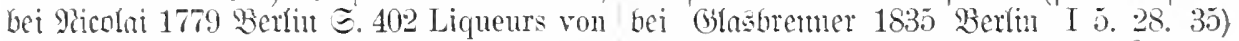
allen Gattungen, sowohl ron Brantwein, entituntien itt. Bei Bahrot 1791 Qebens als aneh von Wein, nach Französischer, bich)r. III 267 Destillateurladen. auch Danziger Art, werden ron den hiesigen

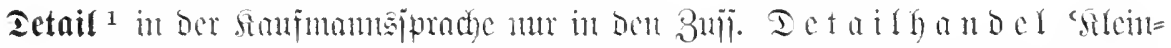

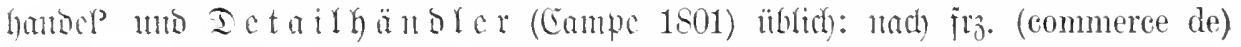

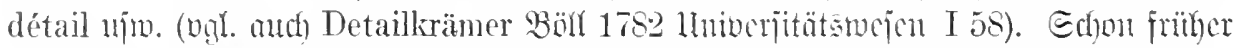

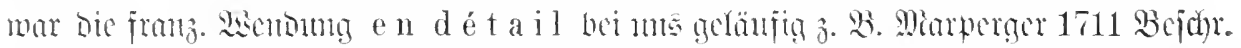
D. Ineijen I 74 dab fremde Kanff-Lente sich melur auf den Handel ins gros als en detail legen müssen. Inch en gros jofon in 17. Jahurh. (j. B.).

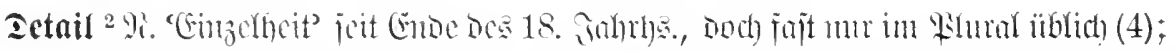

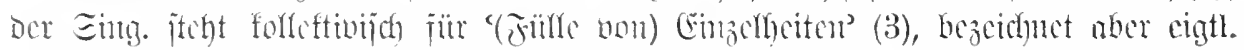

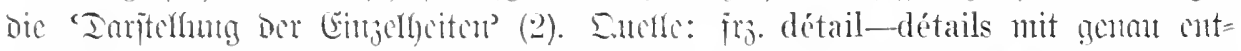

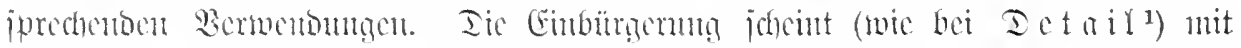

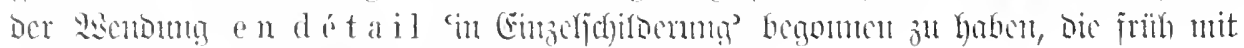
"im Ietail", "ints Ietail" miebergeneben tumbe (1).

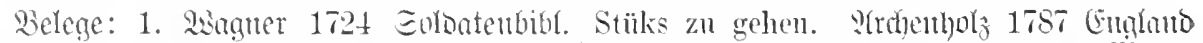
E. 60 Sie hielten sich bei Bagatellen anf. 'IIl 395 sowohl im (ianzen als im 1). wiener liessen sich aber nieht en detail des Kíriegs- 1795 Echriften $\Xi .78$ der kleinliche Geist

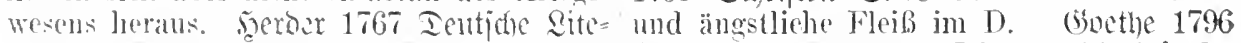
ratur (I 267) daf sie sich ins D), der kleinsten Rehrjahre (XXII 266) Jch war his in's D. fresezze cinließ - (320) im D). müßte sich der Wahlrheit getren.

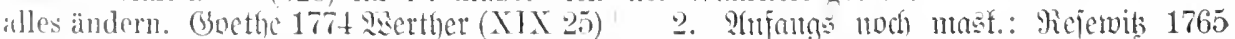
ich will mieh zwingen in's 1). zu gehen. Qiteraturbriefe XXII 85 Dies erfordert aber

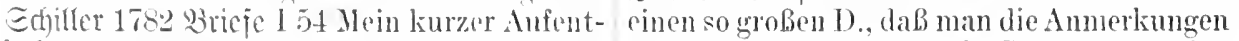
halt rerstattete mir nicht ins D). mrines iiber das Kilima nur anfs Ganze anwenden 


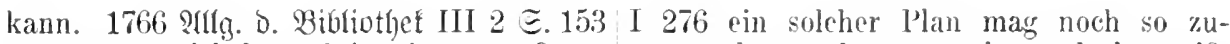
genauer entwickelt und in cinem grïßeren sammenhängend seyn, so ist es doch gewib, d. vor Augen gelegt. Gerber 1767 D. Diteratur dab er sieh bis auf sein letztes D. in Stellung (I 465) nach den Schönheiten des D.-s. der Bücher selbst, nicht befolgen läßt. Labater 1776 Phyjiognum. Fragmente II 220 Ein Genie des D.-s. Miüller 1789 (Enmerid) V $165 \mathrm{Thr}$ dispensirt mich rom D.

3. Lejiung 1767 Brieje (I $2: 34$ ) cin worinn viel gutes kritisches D. ist. Miofer 1767 Ratriot. Briefe $\Xi .29$ ein unendliches D. von Besorgungen, Aufsicht, Wahrnehmungen. Bürger 1776 Bricje I 308 Wie so gar herrlich weiß ar doeh das D. seines Süjets aufzudecken und darzustellen. Lavater 1777 Fragmente III 296 sieiber] belustigen sich mehr an D. 1779 Rhein. Beiträge II 77 mehr aufs Ganze als aufs D. sehen. Morim 1786 : Inton Merier こ.243 er lernte zuerst das Große im Leben von dessen D. unterscheiden. Echleael 1801/2 Borlejungen I 46 mit einem D. vigner Bemerkumgen.

4 a. Sin g. Ients 1777 Büd)erfunde

b. 准 u r. Jiẗller 1787 (Emmerich III 69 sich in unzählige kleine 1).-s cinzulassen. Ectiller 1788 Brieje II 74 Ich will mich nicht mehr so sehr um D.-s bekümmern. (bocthe 1796 Qebriahre (XXI 273) auf die so erwünschte Einheit einer Composition und anf alle schicklichen D.-s Verzicht zu thun. Jifflano 1798 Sambabn ङ.46; Sorgfalt für die kleinsten D.-- -1799 Qeichter Eimu (V 140) Der Hofrath Raning wird alle D.-s verabreden.

detaillieren Btw. 'im Eimzeliten dor = itellen’ aus frz. détailler. Belege: Bürrger 1773 Brieje I 185 Ich kann und mags nicht detailliren, was ich dabey gelitten habe. Gall 1787 Bagatellen II 246 einen detaillirten

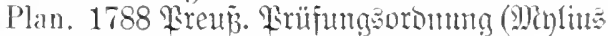
VIII 2378) ein detaillirtes Zengniß.

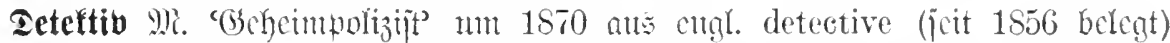

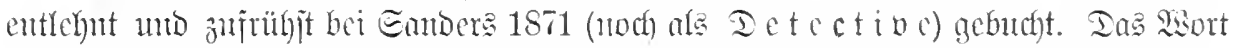

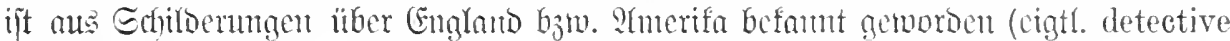

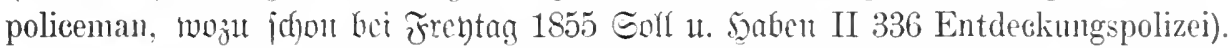

Bgl. Geritäufer 1868 Piene Reijen $\Xi .67$ der Deteetivpolieist Tiemann aus Tenyork. Es wurde eins jener englisehen Stïcke Faudher 1877 Bergl. Aulturbiloer $\Xi$. $38 t$ gegeben, in denen jeder Act nur aus einer, Wo ist Ihr junger Mann'? Das bedentet drastischen Scene besteht und ein Deteetive nämlieh den wachthabenden Aufpasser der die Hauptrolle spielt. 1872 Meuer Ritabal geheimen Division - detectives — der 36, 11 ["Ier [ijenbahmmori in Ronon"] Polizei - ebo. der Detective.

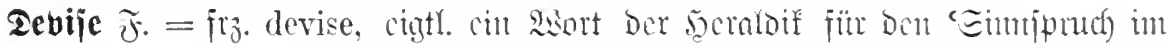

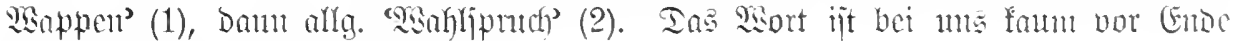
Des 17. Jahrhes. befumt gemorben.

Divis bei ojifchart 1575 (jargantuta $\subseteq .185$

2. Miendfe 1710 Giebidite E. 97 Da sie ijt mur Beibehaltung von Rabelnig denise! die Perle sich ließ zur devise setzen, Wornn (bäufiger diuise) unb betweift nichta fitt ben die Cbersehrift dir noch wol wissend ist.

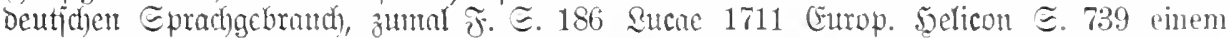
in jren Ritterreimen vnd Thurnirsprüchen anständigen Denkspruch, sententz oder devise.

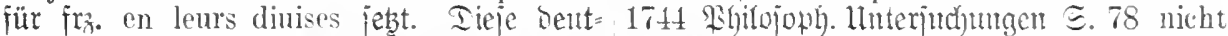

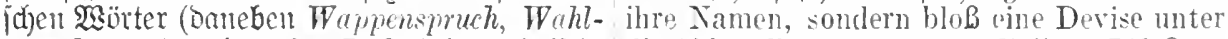

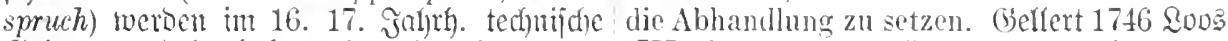

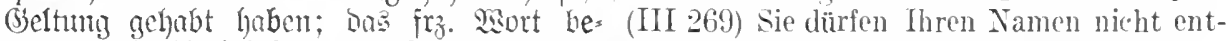
gegnet 3ufrïlyit bei Epener 1680 Opus heral- decken. Es geht nach der Tummer und

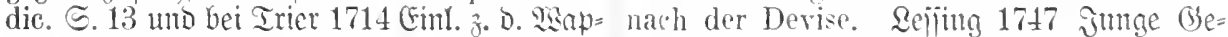

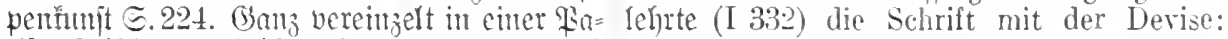
rifer Edjildoerung bei Cimptinger 1610 Piaisbud), Unum est necessarium.

5. 213 mit mancherley devis ooer symbolis.

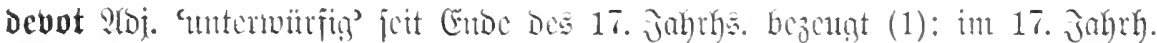
aber häufiger in Dor Bos. 'fromm, gottergeben' (2). Eutle: lat. derotus in beiben Bebentungen. Wifter it Senotion aus lat. devotio. 


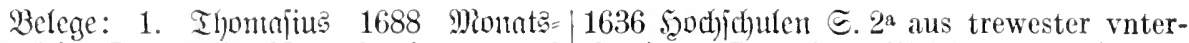
gejpräche I $4^{\text {b }}$ mit Unterthänigster und thänigster Devotion. Siejđjer 1645 Blumen= devotester Hochachtung. (Eallenbad) 1714 garten $\mathbb{S} .9^{\text {b }}$ daß solehe anß trewtragender Fuer ङ. 102 Der gute Menseh ist so devot, gehorsamer devotion geflossen.

hat dem Herren niemahls was leyds gethan.

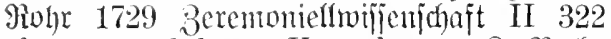
als treue und devote Unterthanen. \&a Rodhe 1771 Tr. v. Eternfeim 5.125 in jedem spröden, coquetten und devoten Affengesicht. Ravater 1775 Fragmente I 202 die allertiefste devoteste Ehrfurcht.

2. Meijerjumio 1615 Epelta's Marrbeit II 26 Don $\mathrm{B}$ ] ] devot vind fromb sey, jhme den Gottesdienst lasse lieb vnd angenem sein. Mengering 1633 Eiegafrone S. 67 weil er in seinem heiligen, wahren Gottesdienst derot und eyfferig. Surfiurptin Eophic 1709 an Fricorich I. S. 194 Bin aber bang, J. M. werden mich nieht devot genung finden, den es seheint, ein ihder dint Gott wie er es verstehett.

2evotion $\mathfrak{F}$ 1. 'Ituterwitrfigfeit': Dpitz 1624 D. Poeterei $\subseteq .27$ Nemt an die courtoisie, vnd die devotion, Die euch ein cheva- derselbe stünde schon gäntzlich in seiner lier, madonna, thut erzeigen. Mleufart Devotion und Eigenschafft.

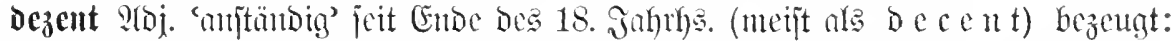

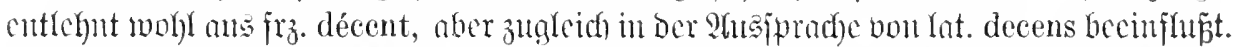

Belege: Witelano 1790 Sortox (XXI 271) (XVIl 399) den französischen Tragikern die sehr decente Dame Zulika - 1800 machte ihre angebetete Deeenz vollends ganz 2rriftipp (XXII 170) weil ieh gern alles auf unmöglich, die Menschheit in ihrer Wahreine decente Art mache. Edtifler 1794 heit zu zeichnen.

Bricje IV 19 Bsoethe] las mir seine Elegien, die zwar schlüpfrig und nicht sehr decent sind.

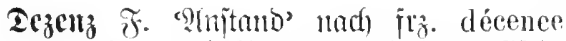

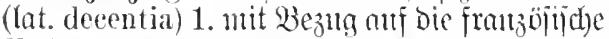
Bitbue: Sherber IX 71 (bei Sebreit) Daher die beschänkte Deeenz dor französisehen Bühne. Edbilfer 1793 litber bag Sathetijche

2. Amfancin: Edfifler 1795 Q̈ithet. Er jiefutig (XVIII 19) Die affectirte Dezenz unserer Sitteu. (jovethe 1797 Iriumph D. Empfindanteit (XVII 58) Man bittet, daB alles mit der gröBten Decenz geschehe. Qidytenberg 1796 , ongarth III 39 Decenzwälhter. Edhlegel 1799 \&ucitioe ङ. 17.

deziunieren 3tw. 'Den zelluten Manu töten' aus gleidbed. Int. decimare, erit fpät iun 18. gahrf). üblid) gerworben.

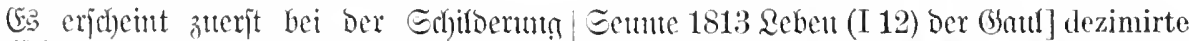

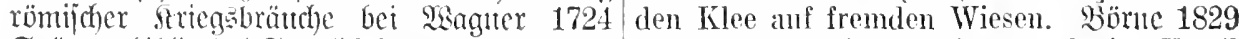
Eoldatenbibliotbef S. 3335 Waren viele solehes Dramaturg. BHätter (I 224) Mein Urteil Verbrechens schuldig, so decimirte man war cine Art Kriegsgerieht, es war ein Decisie, das ist, man lieb sie losen und strafte mieren.

den Zehenden. Qtulg. gelüutig aber erjt ipäter:

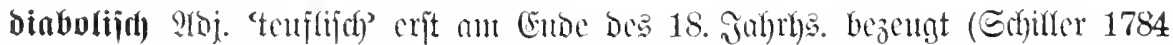
Sabale II 4 mit deinem diabolischen Junker) aber älter wohl fon in theologifder Spradye. Emelle: Yat. diabolieus (in ber Bulgata).

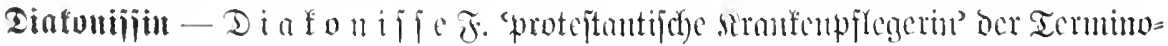

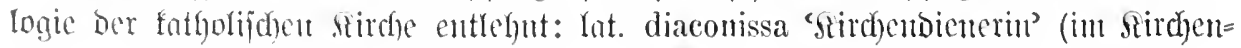


latein jeit deu 4. Jahrgunbert bezengt). Das Qfuffonmen Des Mortes beginut 1836

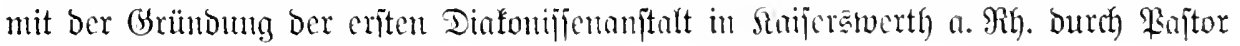
Fliconer.

2igl. nod) Ghuţfow 1855 Sinfontijïu (VII häuser sind unter dem Namen von Dia39) er fragte noch eimmal naeh dem Worte konissenanstalten begründet worden. Eine Diakonissin, das Freydank genannt hatte IInsteranstalt derselben befindet sich am und das ihm unbekannt war. ,Eine Dia- Rhein im Düsseltal. Dort sind unter geistkonissin“, erklärte Freydank, ,ist eine licher und ärztlieher Anleitmng Diakonissen protestantische barmherzige Schwester. Wir oder Diakonissinnen vorgebildet worden .... haben den Katholiken in etwas nachahmen diese Blüte der immern Mission ist im vollsten wollen, das keiner konfessionellen Mißdeutung Triebe.

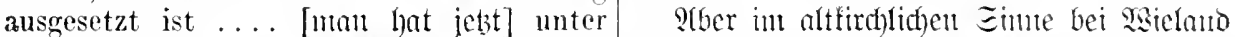
dem Namen der inneren Mission cin künst- 1791 Peregr. Proteus (XVII 33) die gelich verzwejgtes System von Heilungs- nnd wölnnliche Kleidung der Diakonissen, das Verbesserungsversuchen der Gesellschafts- ist, der ältlichen Wittwen, die sieh dem schäden angelegt. Öffentliche Kranken-! Dienste der Brüdergemeinde widmeten.

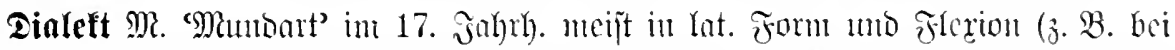
Schottel 1663 I auch wie die Teutsche Sprache in Dialectos getheilet sey) mib aud bei Eperander 1727 noch ars D i a lectus gebucht. Beleg für Di alect: Ramler 1749 an

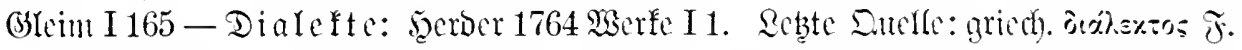

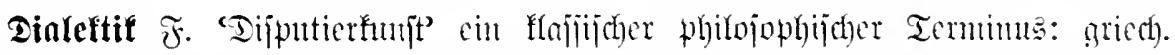

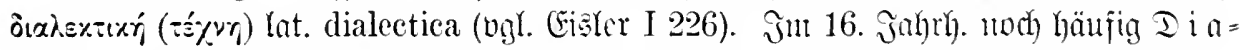

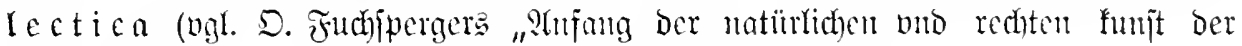

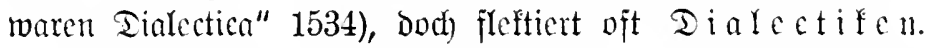

Belege: Fudbberger 1534 Dialeftif $\mathfrak{H}^{\mathrm{b}}$ nach der mainnng Alberti Magni in seiner Dialectiken - $\subseteq .2^{\mathrm{a}} \mathrm{Als}$ wenn ainer nach

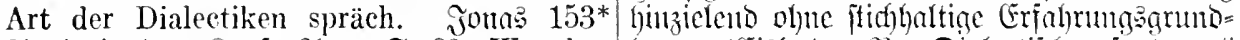

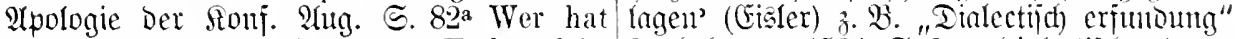
die groben vmuerschampten Esel solehe Fudjaberaer 1534 ङ.2." "bialectijhe Argu-

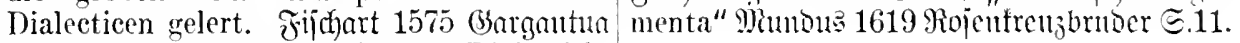
ธ. 269 lehrnet man doch inn der Dialectick.

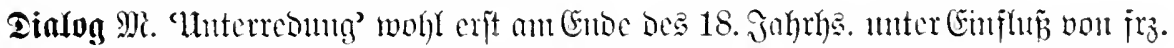

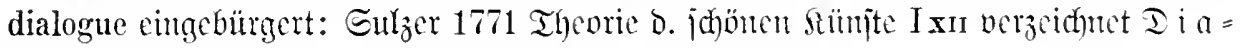

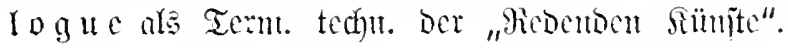

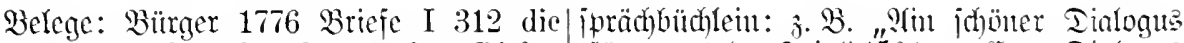

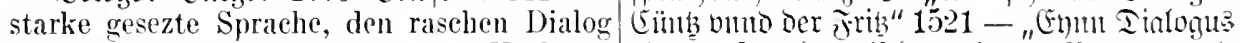

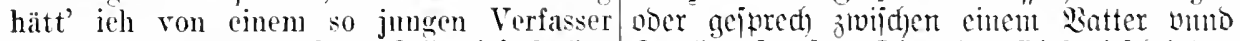

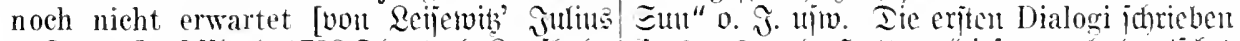
v. Tarent]. Siffand 1798 Theatral. Raufbahn Erasmus mo sutten (bicjer aud beutide)

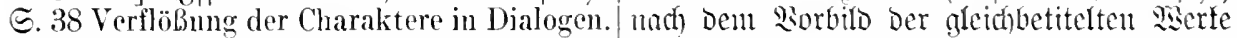

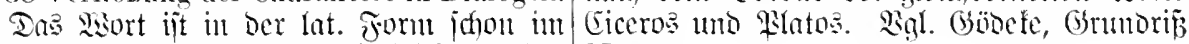
16. Jahrh. jelgr häufitg als Titelitidfinort ber II 264.

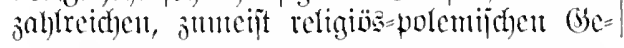

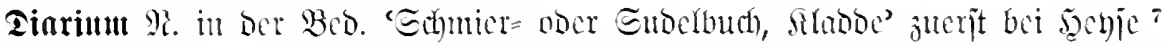
1835 gebucht; älter aber (jeit Dem 17. Jahrh.) allg. 'Buhch für tüglidh Cënträge, bef. audh 'Tagebuch' entipredhend lat. diarium (žl dies 'Tag'). 
Belege: Fiffelgäring 1685 steiberaffe! Suppliquen in ein diarimm notiren lasse. ๔. 92 so nahm er sein Diarium, setzte sich 1755 Bromidfweig. Edhtorbungen I 304 gantz stillschweigend an den Tisch, känete Sie [oie Reftoren] sollen ein beständiges

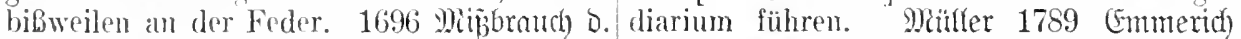
Medizin $\Xi .107$ ein schönes absonderliches VI 225 Man findet hier. demmach kein geistliches Diarium (Tagbuch). Eintpert Diarium. Stant 1798 Antl)ropologie $\subseteq .15$ 1701 Diarium voer Reijebejor. S. $7^{\mathrm{b}}$ ein bei seinem lange geführten, of t auch unterkurtzes Diarium oder Tag-Beschreibung. brochenem Diarium seines Seelenzustandes.

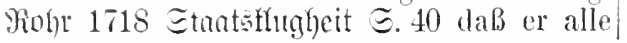

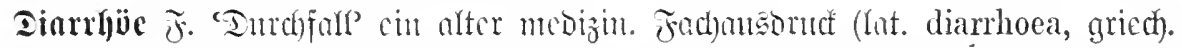

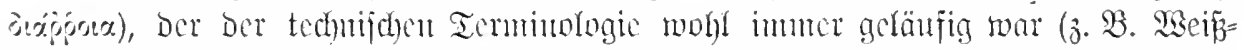

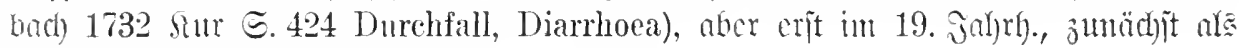
Euphcutianus, allgentiner befomut rourde.

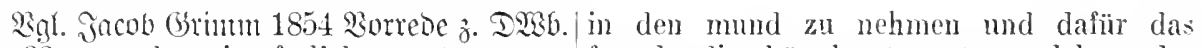
Ep. 33 von der zimpferlichen art unserer fremde diarrhöe lernt, unter welchem der heutigen feinen welt, die sich $\%$ b. scheut Grieche genan verstand, was jene dentschen ausdrïeke wie durchfall oder durchlauf wörter besagen.

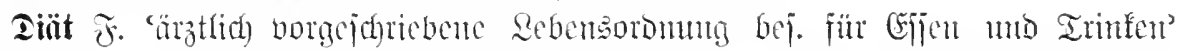

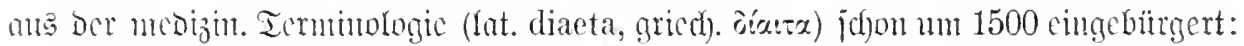

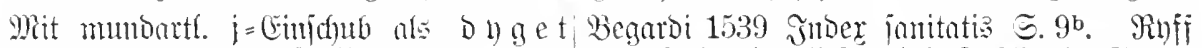

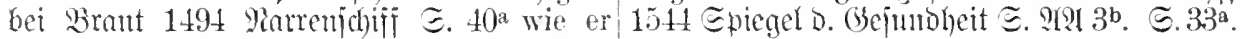
recht halt syn dyget, Die jm der artzt $33^{b}$ ) und D $i$ ät (Fijhart 1575 Górgantut

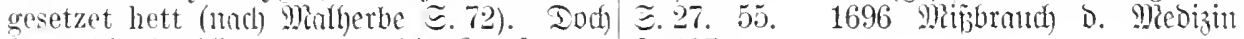

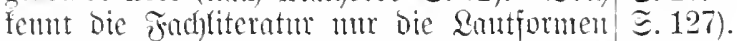

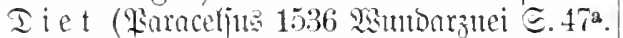

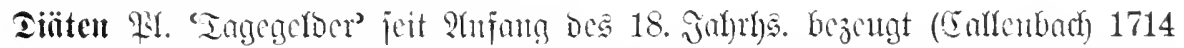

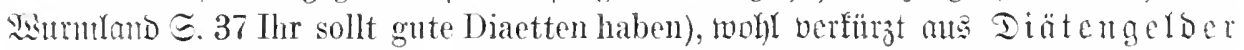

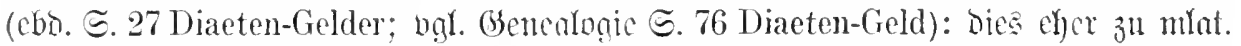

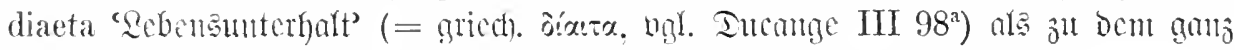
vereingelten mlat. dieta 'merees diurna' (3u Yat. dies: Duc. III 110 ).

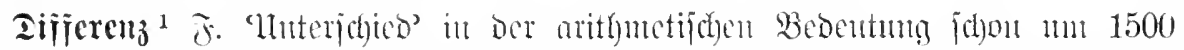

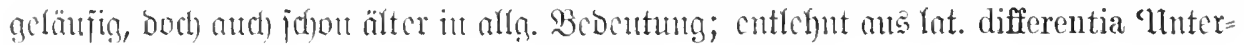
f(d)tCD.

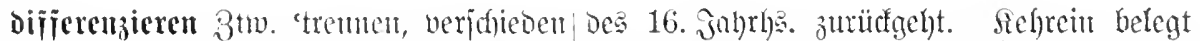

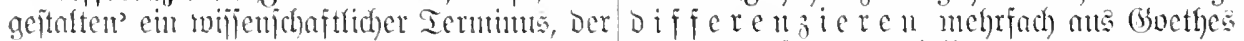

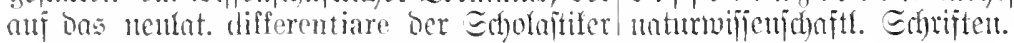

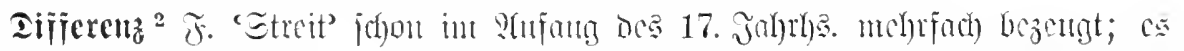

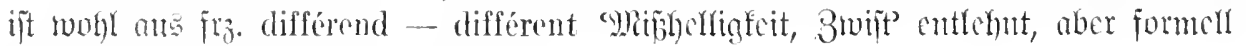
nad) Dean borigen signt mugejtaltet.

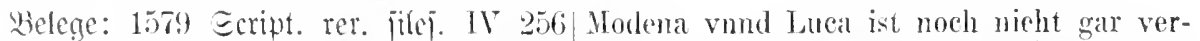

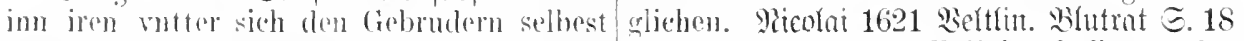
sthwobenden bifferentien. Carolus 160 g clie differentz so der Religion halber inder

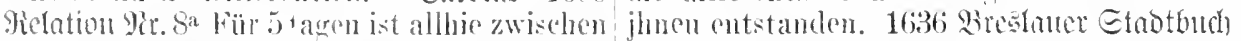

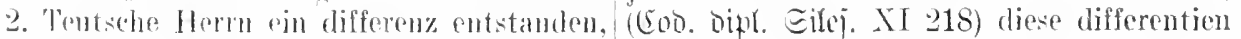
dabsin mit dor Klingen rinander gefordert - durch unsere bewegliche interposition dahien 161.4 ebo. Jir. $3^{\text {b }}$ Die Differentz zwischen vormittelt und zu grunde vorglichen.

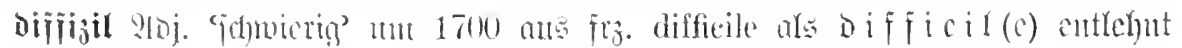

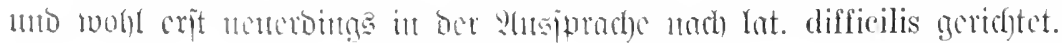


Belege: 1. 2allg. 3. B. Marperger 1717/ Ð.115 Es gibt eine Art Menschen, die man Bejdr. Der Banfen E. 2:3 dadureh die Be-- wunderliche (difficiles) Lente nennt. Edhiller zahlung ihme diffieil könte gemachet werden. 1794 Brieje IV 38 Dies macht ihn etwas Pücfler 1831 Brieje I 181 die difficilsten difficile in Ansehung der Alsüsse. Iebrient Stellen. $18+1$ Ireue Riebe (III 40) auf diesem Punkt

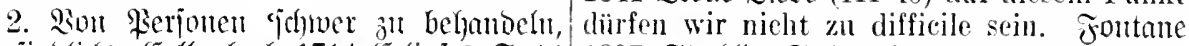

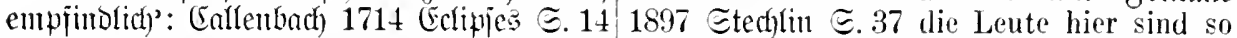
Wann auch ieh solle attestiren, werde ich difficil und legen alles auf die Goldwage. nieht difficil seyn. Smigge 1788 Umgang

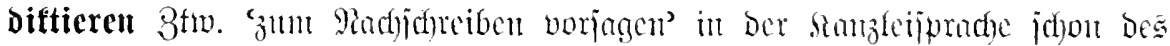

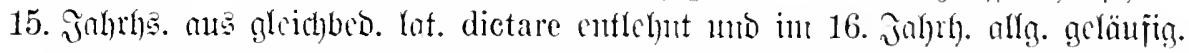

Sclege: Siefler, Fajtuad)tâjpiele II 740, mit vergeblichem und unnöttirem dictiren mit geblumten worten dictiren. Duclfe oder ad pennas lesen die zeit himpringen.

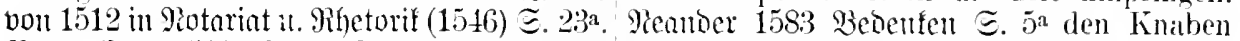
Baracelits 1530 Frantzoj. Sirnuffeit $s 2^{\mathrm{b}}$ zu schreiben dietiret.

Damm nit dictirn, sonder wissen ist die Diftat $\Re$. nus lat. dictatum 'Diftiertes̃:

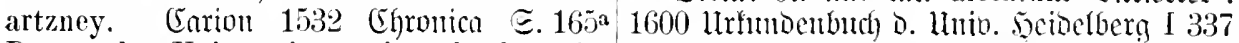
Da nu der Kaiser ein wenig ruhe hatt ju dictata zu concipiren. Sisirflich eingedeuticht

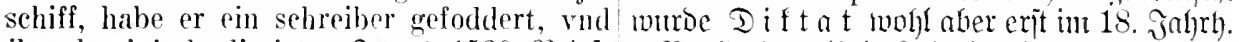
jhm lateiniseh dietirt. Jonas 1539 Briej $=3$. \$3. Serber (bei Sehrein) Lange Dictate. recfjicl I 314 Iclu yermag itzund in meiner sinut 1778 Brieje (X 225) dictatenmäbig schwacheyt nit vil zu sehreiben oder zu nachschreiben.

dietiren. 1558 5eibelf. Etatuten $\Xi .62$

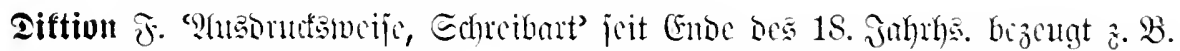
Boic 1781 an Bürger (III 66) Das Nenseeländische Schlachtlied hat deine Dilition. Brun 1806 Epijoden I 195 Ammuth seines Vortrages und seiner Diction. Enclle: fra. diction ober laf. dictio.

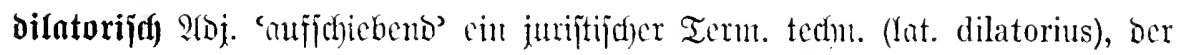

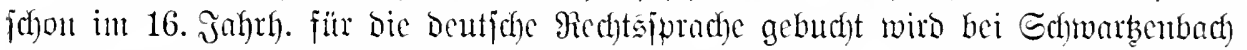

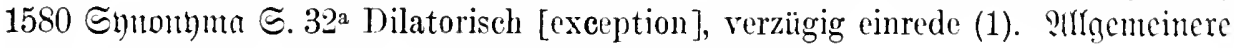
(Sicltung crhiclt Das Sisort wohl crît int 19. Jahlyh. (2).

Belege: 1. un 1620 in Rondorps icta| 2. Osoethe 1821 simberjatre (XXIV 203) publ. I $260^{\text {b }}$ was für ein resolution zu Würtz- Er antwortete dilatorisch. Bïmardf 1870 burg auff der Vnion Werbung gefallen, (bei Büd)maun ${ }^{23} \Subset .565$ ) Im Interesse solche sey weder eathegorisch noch d., oder des Friedens bewahrte jch das Geheimmis gar einschneydent vnd empfindlich. 1622 über diese Zumutungen und behandelte sie

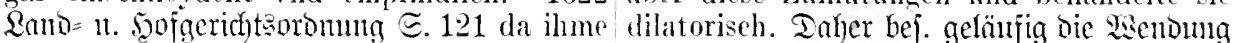
solche d.e oder peremptorische exceptiones bilatorijd) bebanbeln.

aberkand.

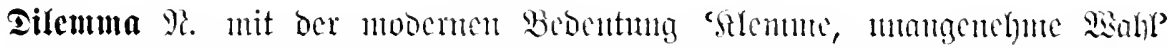

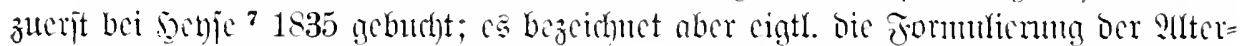

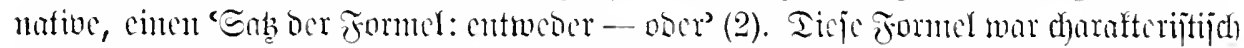

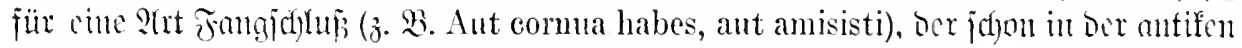

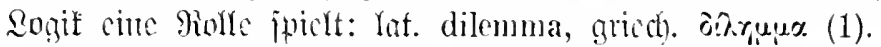

Belege: 1. Tulfober 1687 (burtenbeetlein habes, ant amisisti, antworten sollte. 然e I $654^{\mathrm{a}}$ vind zu einem derselbigen folgendes famb 1764 Ion Evlvio (I 116) Xun sag ich dilemma gesetzet habe: Ihr Catholisehe so: entweder ist der grüne Zworg ein Zahnseyt entweders Narren, oder die alleroröste stocher oder er ist keiner; ist er keiner. Bösewicht. Ihomaju 1688 Montatseiprönc so hat die Fee - ich will nicht sagen was: I 212 dab ich auf das dilemma: Ant cormua ist er aber einer, zum Henker, seit wamn 
seh' jeh denn einem Zahnstocher gleich? auch auf Ihr dort Oben, oder das gerühmte Dieß ist ein Schlub, hoff ich, woran niehts Dortoben sey weiter nichts als ein ausauszusetzen ist .... Gibst du dich auch damit ab, Dilemmen zu machen?

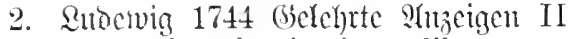
901 Sein Trost bestehet in einem dilemmate: entweder es ist cin anderes Leben zu hoffen oder nicht. Foriter 1791 S(mijuten (III 325) in dem Dilemma: ob es besser sei, dem Volke auf die Gefahr seiner Sittlichkeit, etwas mehr ästhetisehes Gefühl einzuflöBen, oder ihm mit seiner Unmanierlichkeit seinen fest ansgesprochenen Charakter zu lassen. Sictytenberg 1794 seggarth I 233 Die armen Passagiere haben sich mehr auf sanften Sehlaf als auf das Dilemma geschickt, das hier schnelle Entschließung fordert: ob sie sich wollen wässern oder sengen lassen 1798 cbon. IV 4 die höhere Welt selbst soll sich, wie man sagt, vielleicht aus Patriotismus, nieht ganz ungerne zwischen das aut, aut eingeklemmt gesehen haben: entweder zugeben zu müssen, Hogarth verstände sich

geputztes Dortunten und im Ganzen selbst eine Art von Gesindel-Welt. DaB man dieses Dilemma beym vordersten Horn faßte, versteht sich von selbst. Mieland 1801 2rriftipp (XXIV 211) Mit der dilemmatischen Formel ,Seyn oder Nicht-Seyn" ist gar nichts gesagt. Sceitte 1851 Romanzero (I 487) In derselben Weise tanchte in Deutsehland die Ansieht auf, daß inan wählen müsse zwischen der Religion und der Philosophie, zwisehen dem geoffenbarten Dogma des Glaubens und der letzten Konsequenz des Denkens, zwischen dem absohiten Bibelgott und dem Atheismus. Je entschiedener die Gemiiter, desto leiehter werden sie das Opfer solcher Dilemmen. Strekser 1880

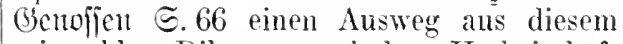
miserablen Dilemma zwischen Herbeischaffung neuer Kapitalien oder Preisgebung der freien Liebe.

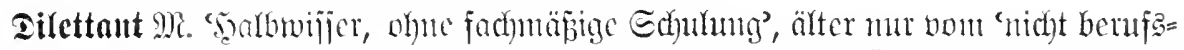

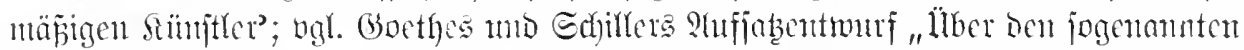

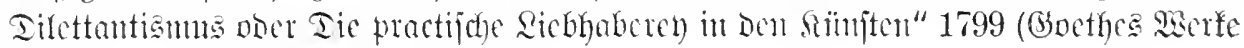
47, 321). Sullile: ital. dilettante.

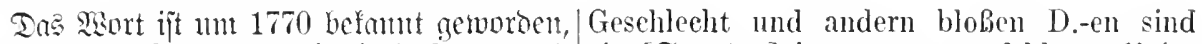
wird aber anfangs nod) it ital. Form und sie [Eonaten] immer zu empfehlen. Itar Flerion gebrandt: Eing. Dile t taut c. 1777 an Bürger (II 187) Als D. der schönen wieland 1764 ltutcil bce Paris (X 29) Wissenschaften. Sermes 1778 Eophiens geübt in solehen Fragen, Ein Dilettante Feije III 52 Dann giebts auch noch herumund zugleich ein Kenner (B广ons. VIII 65a). streichende Musicos und Sänger: Prager, Enlzer 1771 Theorie o. idbünen Stimfte I Waldhornisten, Virtuosen, oder, wie man Borr. כ. 7 Für den Liebhaber, nämlieh sie neumodisch in einem sehr entbehrlichen nieht für den curiosen Liebhaber, oder italienisehen Wort nennt: Dilettanten. Bür= Dilettante, der ein Spiel und einen Zeit- ger 1779 Brieje II 364 der Rechte Beflissener, vertreib aus den schönen Künsten macht, der Poësie D. Sinigge 1788 Hmgang @. 319 sondern für den, der den wahıen Genub reiche und mäehtige D.-en und Mäcenaten. ron den Werken des Gesehmacks haben Forjter 1791 ?(njichten (III 33) Es reieht soll. Satelanto 1778 an Mercf (ङ. 143) Secken- über den Kíreis des D.-en hinaus, der Humadorf, der blos als dilettante und Jann von nität des Künstlers ein Denkmal zu erriehten Geschmack liest und urtheilt. - PLnr. - (317) Das Paturarientabinett] verdient Difettanti. Etur 1779 Edhriften I 148 in jeder Rüeksicht die Aufmerksamkeit des nicht durch Hïmner vom Handwerk, sondern D.-en und des Kenners - (486) Die leichte durch betitelte Dilettanti. 1838 Die Eijen und wohlfeile Befriedigung des D.-en dureh bobut $\Xi .13)^{\mathrm{a}}$ des italienischen Haschens gutgestochene Blïter. Edifller=(G)octhe 1796 und Treibens nach dem momentanen Bei- Xetricu Wir. 152 Dem D.-en - 1799 (jobetbes fallsurepringe der Dilettanti und ihrem siserfe 47, 302 Der D. selent allemal das

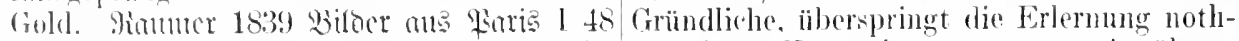
Cionden, mit bilettanti besetzt. Lï̈fler wendiger Kenntnisse, $11 m$ zur Ausübung 1841 Biberjan III 461 Ohgleich nur l)ilet- zu gelangen, verwechselt die Kunst mit dem tanti spielten und simgen.

Dancben aber aud f(d)on bümịg $I i$ lettant- Difetianten 3. B. Echu=

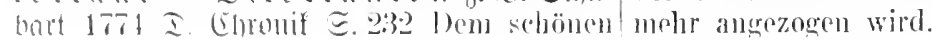




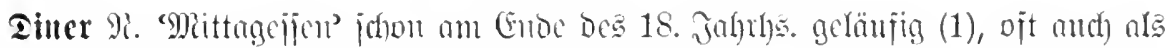

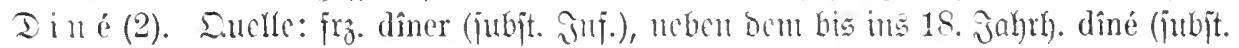
Part.) bejtomiocu hat.

Belege: 1. Erhiller 1788 Brieje II 25. 1831 Bricje IV 5t-1835 Eemilajio II 20.

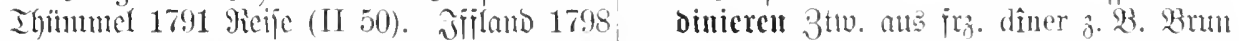
Epieler (IV 134) - 1799 Ermmermig (VIII 1799 Edriften I 199 ich aber blieb eigen126). Sogucbue 1810 büns. Broijt (XXIV simig dabey, man müsse im Angesicht der 144).

2. (Gocthe 1774 "Diné ju Coblenj" (I 266). 1801. bofimann 1814 Sireisleriana (I 23). Riüfler

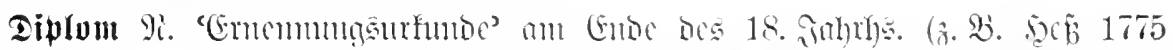

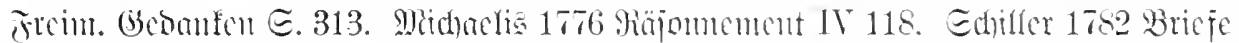

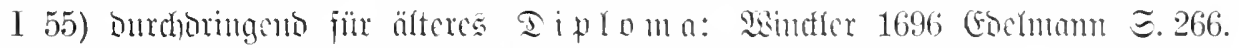

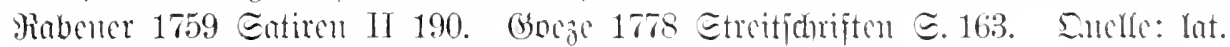

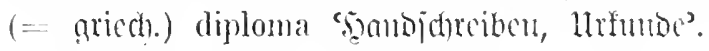

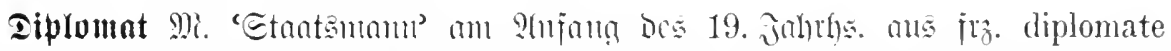

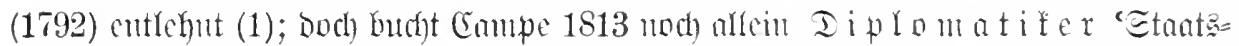

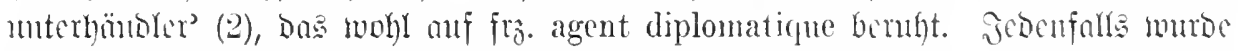

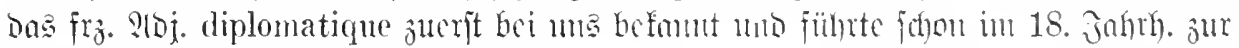
Bilburig vou diplo ma tij h).

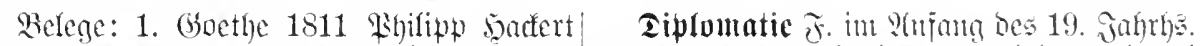
$(46,322)$ Man hätte wohl in seinem Wesen an $\mathrm{ir}_{3}$. diplomatie (1791) entfegnt und bei etwas Diplomatisches finden können, welches (Emme 1813 (noch nidit 1801) anjaejührt. in dem kalten Gefälligen der Hoflente be- Ianeben girt noch lantge I i f l o m a t i l steht, ohme das Submisse von diesen zu (inbitontiviert ms fro. diplomatique?) $\mathfrak{3} . \mathfrak{B}$. haben, weil der Diplomate sich immer anch Ectiller 1803 finrajit (XI 323) Sie sollen gegen die rornehmsten Personen, mit denen in der Diplomatik und im Staatsrecht sehr er umgeht, eine gewisse Würde geben mub - bewandert sein. Börne 1832 Siricje a. Laris

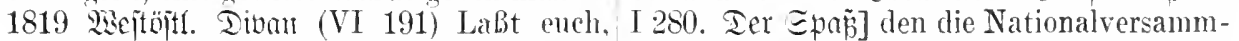
o Diplomaten! Recht angelegen sein. Ganfï lung in Brïssel mit der europäischen Diplo1826 Mientiren (VII 11). Fene 1827 Bud) matik treibt.

D. Sieber ([ 111) - 1830 Sitalien (III 275). Diplumatija s(bj. Boethe 1796 Rehr= Börne 1832 Briefe a. Lari II 246. Ranmer jafte (XXII 270) in der diplomatischen 1839 Birner a. Zaris I 280. 281. Tanfbahn. Siffond 1798 Zanjbahn $\Xi .64$

2. Echiller 1803 Panajt (XI 313) Der Er dachte an keine diplomatische SchwierigVinister muB also zuerst gewomen werden, keit. Gents 1806 firagmente a. D. neuejtu und da gibt man sich mm die Miene eines (jejot. $\Xi .89$ in der diplomatischen Gegeübten Diplomatikers. Bürne 1832 Brieje schichte jener Zeit. Göirres 1821 Enropa ๙. Paris I 223 Man meinet es wären I)iplo $\Xi .330$ diplomatische Kunst. matiker - 280 .

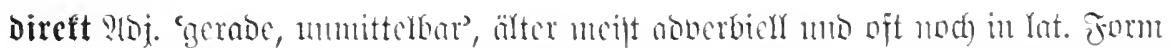

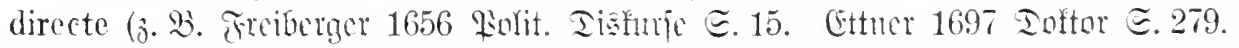

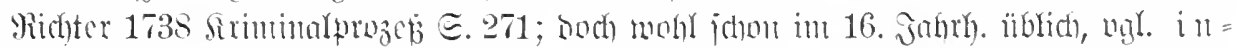

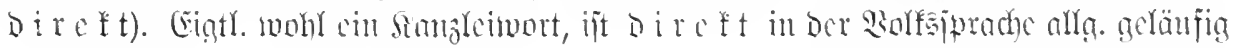
gerworben.

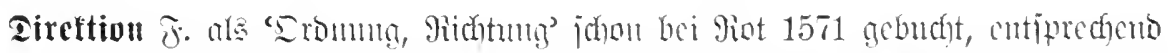

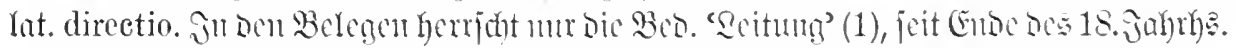

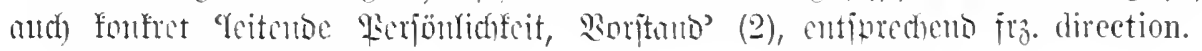


Belege: 1619 bei Ronoorp II 829b in|XXVI 3 ङ. 267 Ein Votum, das der Reder gantzen Böhmischen militia wie auch gierung eine D. gebe. Fontane 1882 Q'2roul= bey den confoederirten ist große confusion, tera $\mathcal{S} .87$ vorausgesetzt, daß Du mir, um mangel an guter clirection vnd aller noth- mit unserem leider abwesenden Freunde

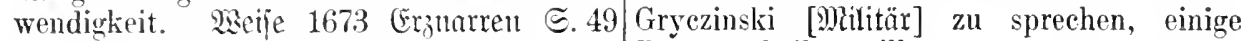
man miisse die endliche $d$. soleher wunder- D.-en ertheilen willst.

bahren Fälle Gott zuschreiben. Frandfe 1702 sisaijentuats I 58 Die Anordnung und D. so virler Schulen und Anstalten. iseei $\tilde{\beta}=$ buct) 1732 Stur $\Xi .363$ sich der d. seines artztes gïnzlich überlassen. Bsoecfintgf 1776 aır Bürger (I 319) um dereinst der D. unseres Instituts vorzustelien. (boethe $1796 \mathrm{Qeb}$ r $=$ jafre (XXII 329) kleine Spiele waren von seiner Erfindung und standen unter seiner D.

2. Goethe 1796 Rebriabre (XXI 170) Melina hatte sich indessen nach den Trümmern der vorigen D. genau erkundigt.

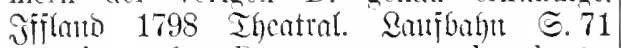
was eine andere $\mathrm{D}$. germ gut vergolten hätte. Börue $18: 8$ werfo I 346 Theaterdirektion.

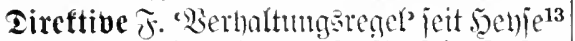
1865 gebucht; in älteren ?tuff. jeit ${ }^{5} 1829$ als "githt=2ierfatren" neben Directio =

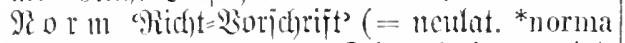
lirectiva?

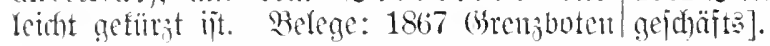

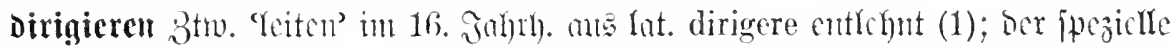

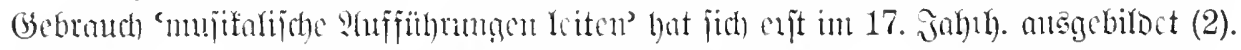

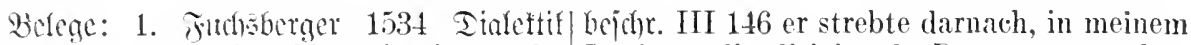
Є. $33^{\mathrm{b}}$ ain kurtzer fürschlag aintziger rede, Institute die dirigirende Person zu werden. zu welchen aller schmuck wortrejeher sen- 2. Prötorims 1619 Sinntagna mujicum tentzen oder ander notturfftig anzug Diri- III 152 anch selbstes solche vnd dergleichen giert. gewendt vnd gebraucht werden. 1580 Concert per Choros besser anzuordnen vnd

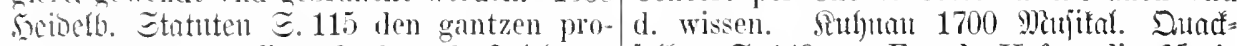
cess und wals dracelbe erfordert, d. Frieben forber $\widetilde{S} 149$ an Fürstl. Höfen die Music berug 1597 Disure $\Xi .25$ die jenigen, welehen als Capell-Meister zu d. 1708 Reoporo D. das Werek zu d. befollen. 1600 Tontes rer. (Groje I 60 der Capell-Heister dirigirt sie anjtrinc. IX 91 die sathen dahin zu d. [oie Dper] auf Gewinst und Verlust. Qanbe 5olfontm 160.5 Eomutum $\Xi .73$ Gott wolle 1836 \%eijcuovelfen III 33 Stranß dirigirt die

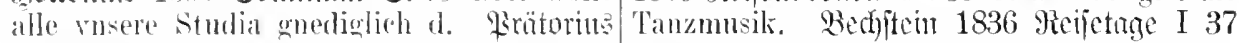
1619 Enutaguta II 87 Der Reib] welcher in Kapallmeister Guhr dirigirte cine Symphonie.

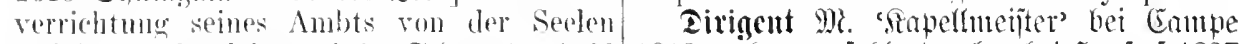

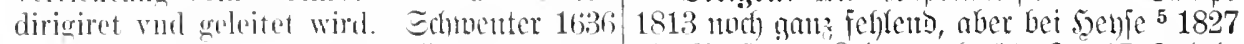

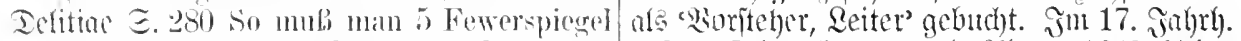

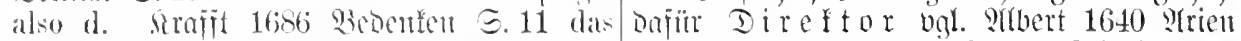
gemeine Vatertand also zu d. Weitler 1789 E.68 ein l)irector eines Chors. D i $\mathrm{r}$ ige nt

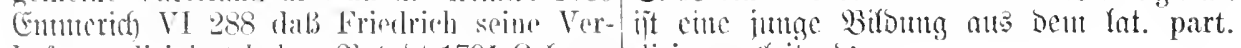
haftung dirigret habe. Skatrot 1791 Qebens / dirigens 'Tciteno'.

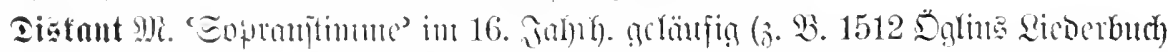

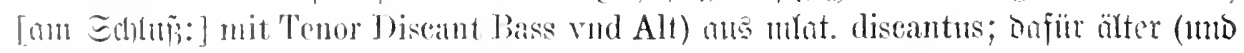

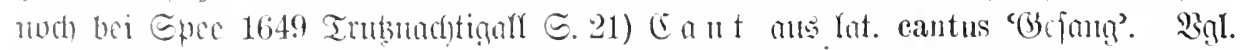
Bharcant 1547 Dobccat)urbou $\Xi .240$ Vulgus crebrius Discantum vocat, ut differat a communi nomine cantus. 
Mlat. discantus ijt nämli(t) eigtr. (jeit| übergeoronet war, ergab jiđ für discantus

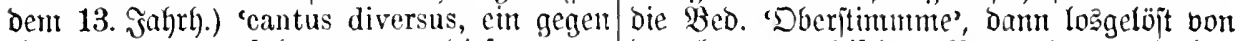
einen andern gejührter, von Diejent ver $=$ ber fontrapunttij(ben Berwenbung 'hödjite [djiedener Gejang, Bregengejang, Contra= Stimme, Sopran'. Durchgebrungen ift die punft' $(\mathfrak{R o d})=$ Dommer, Mujifal.Rerifon S.239) neue Bermendung woht erit um 1500 , da unb roar in biejer Bes. jhont int 14. Gahrh. jie aud in (Engl. nidht vor bem 16. Jahrh. alg discante, discant eingebentjoht (Belege nachgerviejen ijt (ogl. Murrat) unter desbei Bed), (Sermania XVIII 267). Da biejer cant 2).

Bsegengejantg aber zumeijt eitter Bajportie

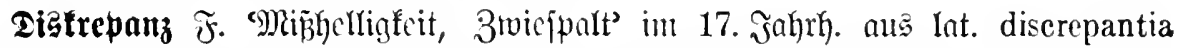

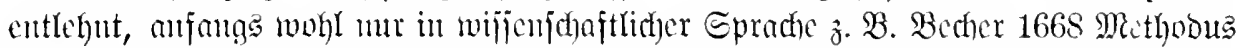
sionct. S. $33^{\text {b }}$ die Discrepantz der Sprachen mit der Cardinal-Sprach. Sucac 1711 Europ. Solicon 5.694 derer chronologischen Discrepance. Schillir 1796 Bricfe IV 407 die Discrepanz der Charactere.

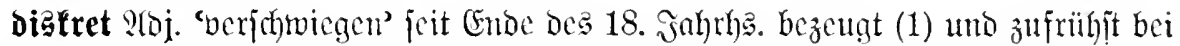

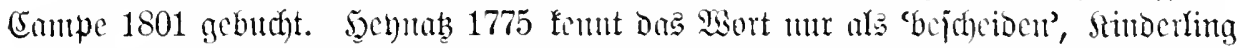

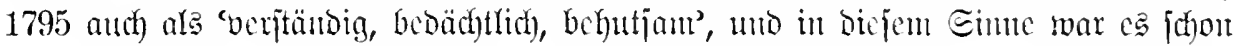

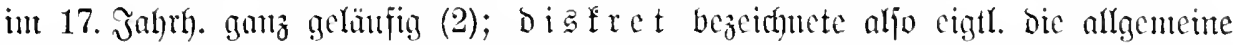

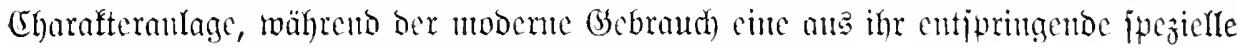
Eigenjafyat ijoliert hat. Duelle: frz. diseret.

Belege: 1. La Roche 1771 Frl. v. Stern=|Zinß nicht zu sehr forciren. Dalfover 1687 heim S. 159 unter der Leitung des d.en F. (Bartenbectlein I 760` mit d. bescheidenem Mid)nelis 1776 Rïjontement IV 237 Soviel wolergibigen Nachdruck. Thomajü 1687 unter seinen Collegen die Stelle kennen $\mathfrak{R}$ xhahmung $\subseteq$. 33 D. seyn ist ein nothund d. sind, .... sagen ihm nicht leicht wendiges Stücke der galanterie - 1688 etwas. Seermes 1789 Fïr Ertern II 136 Monatzgejpr. I 51 ein wahrhafftig d.-er

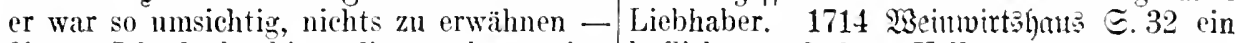
PInm.: Ich denke hier: diseret, kann aber höflicher und d.-er Kellner.

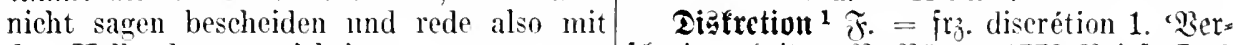
den Holländern omzichtig.

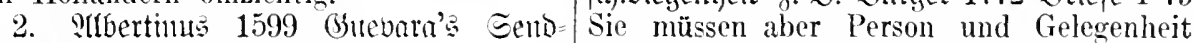
j(d)reiben III $138^{\mathrm{b}}$ Ein guter Freundt sol mit der Ihnen eigenen D. verschweigen. auch secret vnd d. seyn, das ist, er soll Midhaelis 1773 Räjommentent IlI 221 Ich nicht allein bescheiden sondern auch ge- bin von seiner $D$. versichert, daB er keinen

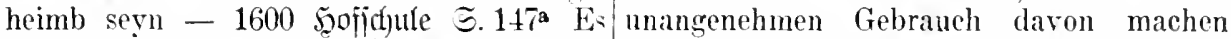
seye ein Weih so Fürsichtig, Weiß, d vnd wird. Qejitng 1775 Brieje (XVIII 134) ich bescheiden, wie sie wölle. Sïppe 1619 weis, daß ich mich ganz auf Ihre D. verlassen Fechtfunit $\widetilde{F}^{\text {b }}$ zum Balgen, dazu kein recht kann.

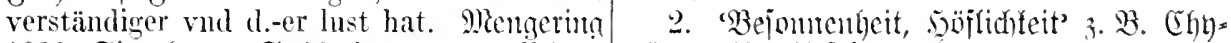

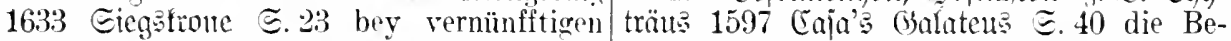
rnd d.-en Lenten. 1643 Evtadineroerber scheidenheit oder D. Yutbertintis 1599

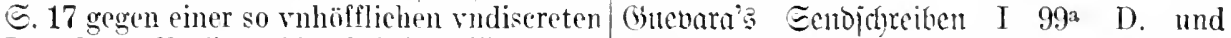
Persohn. S̈̈̈fter 1665 Edhola milit. E. 32 Bscheidenheit - III 132a. Miengering Ein kluger und d.er Commendant. Grint= 1661 (Gesvifientäred)t $\Xi .891$ dergleichen Bümelohamien 1669 Eimplic. ङ. 188 darneben cher mit d. und Fürsichtigkeit zu lesen. erzeigte ich mich gegen meine Gefangenen Obrinundshaujen 1669 Eimplic. E. 254 der überaub d. - 5.208 so lentselig und d. Herr Obrister würde mich seiner weit-

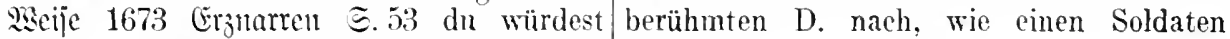
loch d. seyn. und wiirdest mich mit dem tractiren.

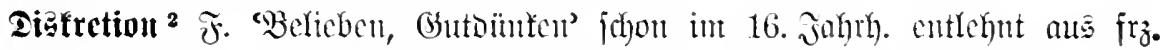
discrétion ilt jeiner cigtl. Beb. 'Berfïgungemadt' (ober direft als ipätlat. mlat. 


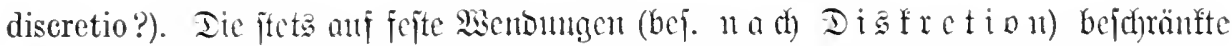

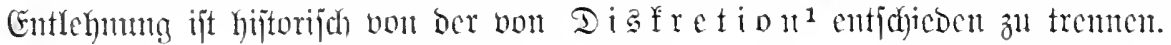

Belege: 1550 ¿eipz. Rativerhandung/Jedoeh kan ein jedweder nach seiner d. (Prafjib $\tilde{j}$. (Gejd). D. D. Buchly. I 48) was selbsten zusehen, was er für ein Feind für die Megdleinn Sehulen anlangett, wirdt sich hat. 1634 Bericht b. Frieolnomb Berrat in des Ratths $d$. gestellt. Eanorub 1618 D $3^{\mathrm{b}}$ zu seiner selbst eignen d. gestellt. Delitiae $\Subset .124$ der verständige Leser wird Edhuthart 1774 D. Chronif $\Subset .367$ anf D. naeh seiner d. jhme die vinglossierte Historien leben. ந̧ofimam 1814 Berganza (I 126) rnd Gedicht wol wissen Nutz vnd Heyl- Dies Mittelgut überlasse ich unbedingt der sam zu machen. Söppe 1619 Fechtłunft $\mathfrak{F}^{3} 3^{\mathrm{a}}$ D. des Regisseurs.

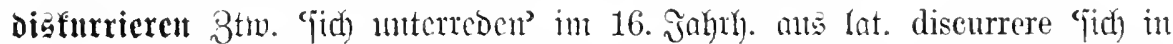

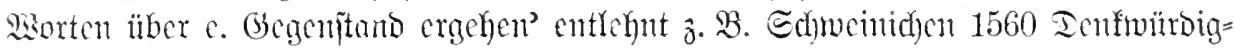

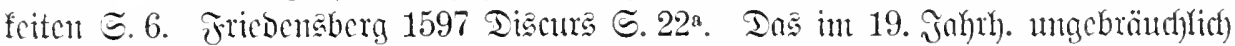

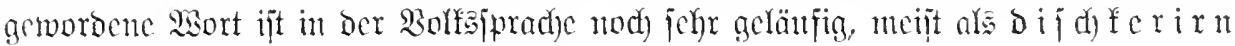

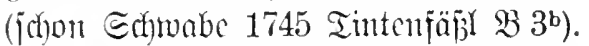

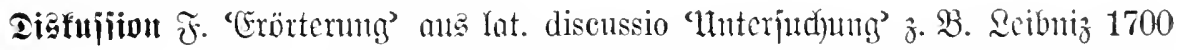
Briçe (II 143) wenn ich mit andern, auch rigidioribus, doch bene animatis in grünliche, doch freundliche Diskussion kommen sollte. Qber bišfutieren aus Yat. discutere 'crörtern' jobon bei Fijdart 1582 Gargantua $\subseteq .275$ mit erkündung rnnd erwegung allerley zeitung, discutirung etlicher Antiquiteten.

Dijparat ?(bj. 'ungleidyartig, verjebieden' cin Term. ted)n. Der Sogif (Gieler I 241),

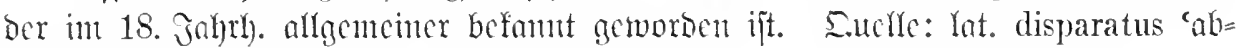

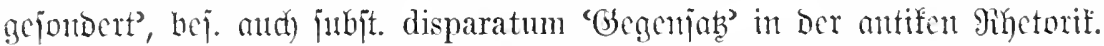

Belege: 1765 qulq. ๖. Biblinthef I 2 S. 134. I und dessen groBer Herr legten es auf eine Miiller 1787 (Emmerid) I 218 ihrer Kindereyen sehr d.e Manier aus. Thümuld 1791 Rerje und ihrer schwarzen Galle, so d.-e Sachen (II 258) ich sehe um deinen globum terrestrem das scheinen - IV 256 der Justizminister sehr d.-e Dinge herliegen.

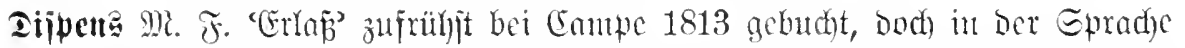

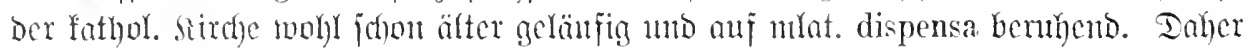

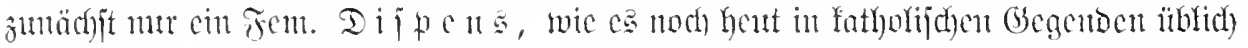

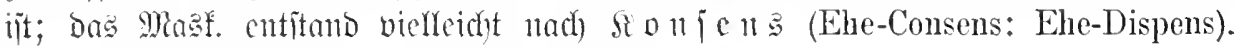
Bgl. Seintuer, 3eitjd)r. j. D. Epradye IX 111.

dipeniferen Btw. "bon ciner Bertinolidy= Feit befreien' in tranfitibest Gebrauch ben

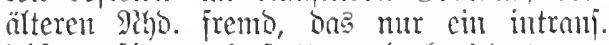
dijpenjieren 'gcitatten, erlanben' (entgegen einer beitehentren Beftumumg) fennt: e? jteht bämig abjolut (1), ein Dbjeft Der Rerjon twiro meift nit wider oder mit angefú)lofjen (2). Das sisort ijt eir Firdylicher Termume: mlat. dispensare (bej. d. cum aliquo ut possit) 'Freiheit von vorbantonen Beplinumungen

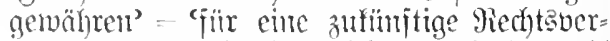
lebung Etraflofigłeit zupithern", eight. wohl aber "ene Etrafe für begangene Bechtover= lesuma nidyt in Straft treten lajpen, nadjichtig borgehen' uno jo mit lat. dispensare 'einrichten, regulieren' su verbinden. 2igl. Dait= Tant im gicsict. TII 483a.

Belege: 1. Brant 1494 Parrenjoriff ธ. 326 Aber man dut yetz dispensieren [bei Der Pifrünoenthäu Bumbagenofien (I 90) dureh dispensation vyl [qifritnoen] in ein hand kummen]. ¿uther 1520 Son guten sierf̌en ๔. 81 die geystliche vbirkeytt vorhengt itzt: dispensirt, nympt gellt rnd lessit nach mehr dann sie vormag nach zeulassen. Mumer 1520 Sum Den Mdol E. 4 mit maneherley schinderey, ablaß zugeben, selen vB dem feg feür zu verkaufen, alpplaß hrieffen, dispensieren. Mit forgentom on $\tilde{B}=$ Ent: Earolu 1614 Tie= Intiont $\widetilde{E} .4^{a}$ das der Bapst auff anhalten de B Königs in Spania dispensirt, das der jetzige Hertzog von Mantua, so ein Cardinal gewest, seines rerstorbenen Bruders Gemahl 
ehelichen möge. Mit ï ber: Carolu $1614 / \mathrm{jr}$ bottschaff, vnd dispensierten mit Othone.

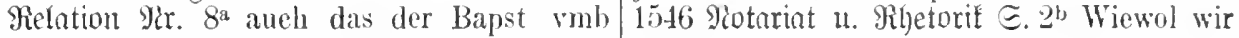
Fried vnd Einigkeit zuerhalten, ther den doeh in solchen gnediglich nit vis selber Heuraht zwisehen ietzt regierenden Hertzogen dispensiren. Ḧberus 1550 Fabeln $\asymp .55$ zu Hantua vnd deß Hertzogs von Savoia wemn ein armer hat gethan lin kleine sünd, Doehter, seines verstorbenen Bruders Gemahl dispensirt habe.

2. Wabtan 1521 Gott, Gianben $\Xi .148$ so hand ir schier wider $2 y$ all dispensiert das ir keine halten. Frantc. 1538 Germumiae Ehronicon $\widetilde{S} .186^{b}$ Dal worben die Legaten

Dijponicren 3tw. 'anorbucn, verfügen' in 16. Jahrh. ans lat. disponere entlehnt.

Belege: 1587 Famptbuch $\Xi .5 t$ ob sie nod würdig macht. Ialhover 1687 Garten= gleich solchs nicht sichtbarlich, sonder naeh beetlein I $357^{\mathrm{b}}$ so seynd auch die Vegutdüncken, vnd den Büchern oder den opi- lincholische Henschen zu tergleichen Armnionibus disponiern vnd erforschen kïndten seeligkeiten mehr disponiert rnd geneigt Friebensber 1597 Discurs $\Xi .12 \mathrm{~b}$ was dergleichen sachen seind, welchen jhrer keyserlichen Mayestet auch ror sich selbest disponieren können. 1634 serifht v. Trrieblando \$errat $\$ B 1^{a}$ was Er verner erobern wurde, lhme gelassen werden vmnd Fr damit zu disponiren macht vnd gewalt haben solte. Sdump 1659 Yutwort 5.51 Ein ieder weib semen Zweek und darnach muB er die Mittel disponiren. Grimmelagamien 1669 Eimplic. ऽ.379 er möge num mit diesem Geld nach seinem Belieben disponiren. Franciaci 1669 Tramerjaal II 947 seine Geschäfte zu disponieren.

Dipponicut 2 doj. 'aujgelent, gejtintme' be= ruht mit gleichbed. irs. disposé (13. gahn.). uno entogl. disposed (14. Jahrh.) wohl ait einem mlut. dispositus eigtl. 'cingerifhtet' als Termum Der mittefalterl. Edyolatif vgrt. Dijpojition ${ }^{2}$. Beleage: Prätorius 1619 Snntagma III 182 jhre Häls vnd Stimmen darzu nicht dercestalt Disponiret rnd abgerichtet seyn. Sorich 1662 sirfher: IInumaia $\Xi .67$ diese vernimt man bej den Kmaben und Jungframen, wamn sie fröhlich seyn und der Natur nach wohl disponiret. Rebeutwalot 1680 Ienjels 2ijt I 69 bott gibt] die Elementa, dem Menschen, weleher sich zu diesem EinfluB disponirt als andere.

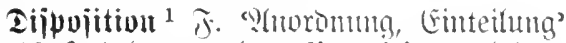
int 16. Jahrh. an lat. dispositio entlebut:

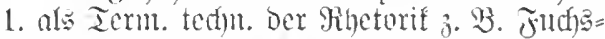
berger $153 \pm$ Dinlettif $\cong .6^{\text {b }}$ des Vrtels oder formlichen d., mitt denen die erfunden mainmo offenbar geredt rnd mit recht georndten worten vnd an tag gelegt würd. Dpits 1624 Soeterei $\Subset .19$ von der invention oder erfindung, rnd D. oder abtheilung der dinge. von denen wir schreiben wollen.

2. Salgemein. 1620 Ealvin. Mutrwill $53^{b}$ Das ander Privilegium ist die D. weyland König Vladislai, im 1510. Jar auffueriehtet. sidojidervid 1642 Philander I 137.

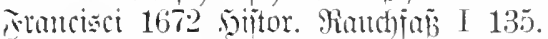

Dippoition " 2 . "Vulage des Erganismus" 3. B. Fijchart 1582 Gargantua $\mathbb{E} .272$ alle rerruckung vnd verschrupffung, alteration rnnd verkehrte d. vnd rnwesenlichkeit des

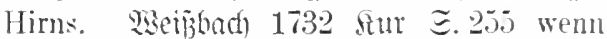
sie von ihren eltern eine d. dazn ererbet haben. Eigtl. cin Iemimus Der mittelalterl. Edfolatif 3 . 23. intellectus dispositio bei

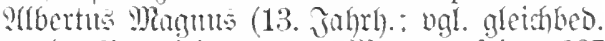
engl. disposition, vou Watraty jeit 1387

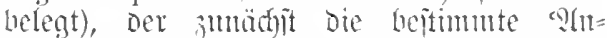

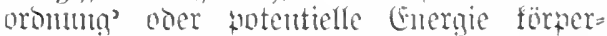
licher Glemtente beicidnete (Gisler I 24?).

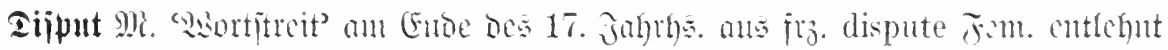
3. B. Ihomajus 1688 Mountageipräche I 668 diese zanksüchtige Wissenschaft und

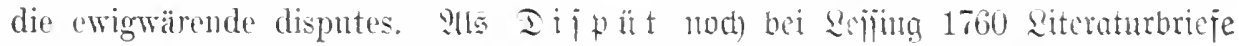

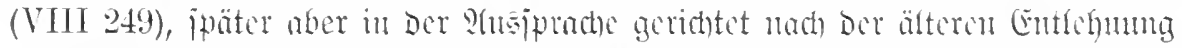

Dipuntation $\tilde{F}$. an hat. disputatio: als populär: in Dieje Beit jällt die Enttitehung

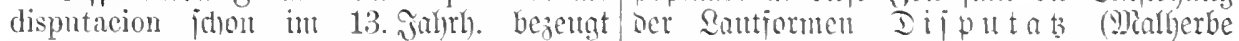

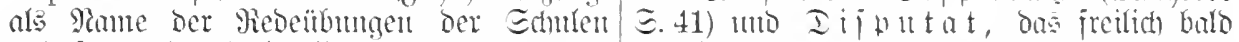
und ipäter ber lniverjitäten. Ias Fremo= als Rentrum gebranthit murse. Belege:

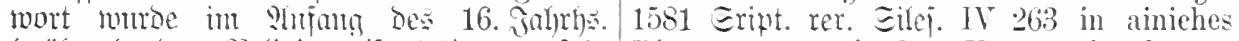
(mähreno ber Mełigionsoijputationen) jebr Disputat vns mit dem Herzog einzulassen. 


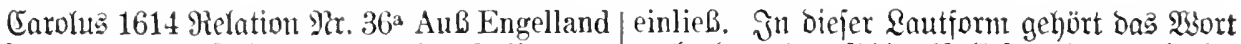

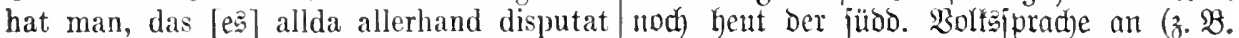
gibt, weil der König sich der Güllischen Fijcher, Echwäb. ㄲab. II 230, wiener. Disch-

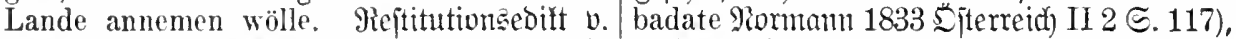
1629 (2ondorp II 1428b) in ein gantz unnöthig wäbrenb in norob. Maa. Dis p u t und disputat gezogen. \$scije 1673 Erznarren $D$ is p it t eingebürgert find (Mentz I $15^{\mathrm{a}}$ ). ङ. 81 an statt, daß er sich in ein disputat

Dijjertatiou $₹$. 'Doftorarbeit' crit feit Ende bes 18. Jahrbs. geläufig, Gej. in

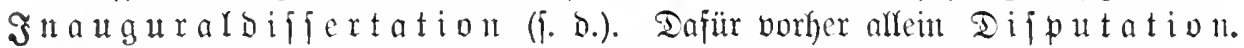

Iod) ijt Dijertation in oer allg. (decipiat per philosophiam inanem, disser-

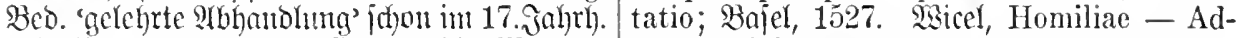
geläufig (子. B. Thomafus 1688 Monat: = jecta est Dissertatio de Arbore Bona, de Antigejpräd) I 337), bezcid)ncte aber eigtl. nur christo; Reipzig 1538), häufiger jüt Dialogus, eine Edhrift, Die als Dissertatio betitelt war. Disputatio, Enehiridion ujw. Dissertatio Beifpiele für dicjes Iitelitidywort find in hatte aber in biejer Serwentoung zunächjt 16. Jahrh. nod) jelten (giclanththon, In mur dic flajijichlat. abjtrafte Bed. 'Erörterung'. locum ad Colossos: Videte ne quis uos

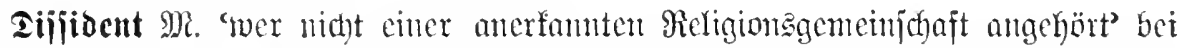
Sennab 1775 und fimberling 1795 gebudht. Foch bei Epcrander 1727 mur erft: "Dissidentes werden in \$oblen bie Evangelijd)en ober Protestirenden genemet".

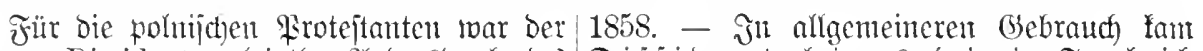

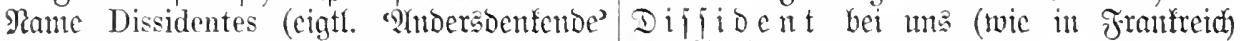
zu lat. dissidere) in Jahre 1573 geprägt und England) erft am Ende Des 18. Jahry):; worben, während Der Berhanblungen des Belege: Mieland 1788 Bermuft in Blanhens:

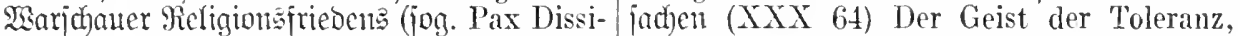
dentium), Der ilnuen bofle Religionsifeiheit der in unseren Zeiten herrschend geworden zuijicherte. Bei Der günitigen @timumung ist und ... die Art, mit den Glaubensdissifür bic Sirotejtanten juchte man cinen mög= denten zu verfahren, sehr gemildert hat -

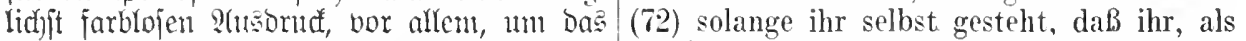

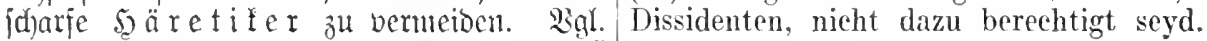
Qübtfe in weber u. weltes Stirchentex. III

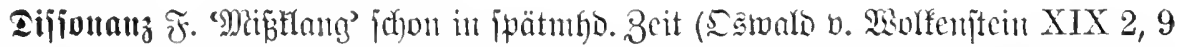
dissonantz) cingedenticht aus lat. dissonantia, Das jucrit um 500 bei Bocthius, De instit. mus. ale mulifialifacer Tern. tedun. belegt ijt.

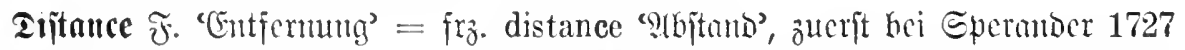

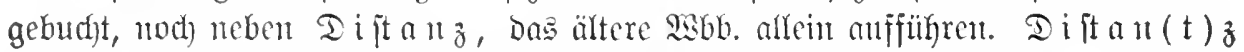

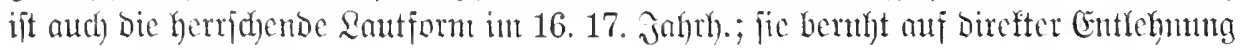
auß lat. distantia.

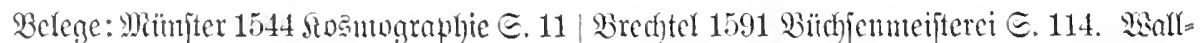

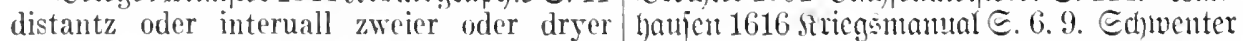
stett - wo die landschafft birgig vnnd 1618 Geontetria 1 2. 74. Enfirofned) 1652 oneben ist, oder ein grob distantz oder ein Sarmonta I 101. Epreng 1662 sictbjel.

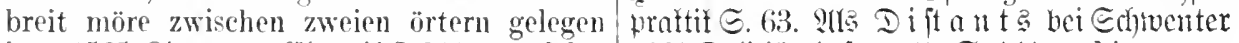

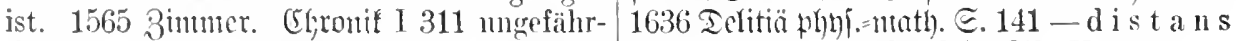
lichen in gleicher distantz gelegen, Ebenjo Rebenmalot 1681 Teujele Rift V 129.

Difitinguieren ${ }^{1}$ 3tw. 'unterfocisen' in 16. Jahth. (Emjer 1528 Serlegung D.

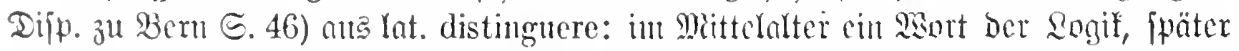

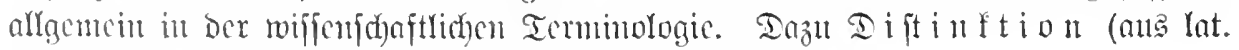
distinctio) bei ßabian 1521 (Sbott, Glauben 5.59. 
difitiuguieren ${ }^{2}$ 3tw. 'anszeidhnen' in 18. Jahrb. aus gleichbed. Frz. distinguer entlehnt; in 19. Jahrh. Gat jich Der (Gebraud ses Sortes auf bas Rartiz. D i it $i \mathfrak{n =}$

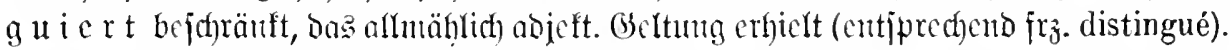

Belege: Goethe 1774 werther (XIX 101)| sehr d. aussehender Mann. Fontane 1882 der Graf v. C. liebt mich, distinguirt mich 1796 2ehriahre (XXI 261) er werde überall sehr distinguirt und das mache inn einbildisch.

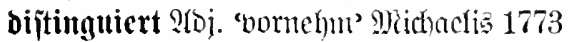
Räjonmentent IV 154 die d.-este Ehre, die eine philosophisehe Fakultät wïnsehen könnte - 338 das Gefüngniß d.-er und zugleich junger Bürger. Thïnmel 1791 Teije (I 103) ohne daß ich mich im geringsten darmm für dazu bitten ließ, dieß ist gar nicht der hierher d.-er gehalten hätte als vorher. Jobebue gehörige Ausdruck, sondern er hatte die 1806 Carolus (XX 273) das ist ein d.-er Gnade, mam ließ ihm die D. angedeihen Platz. Püitfler 1835 Eentilaijo II 45 ein oder so was ähnliches.

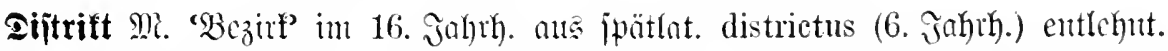
Beleg: Siepler 1605 Spera I 465 Alle diese Lande $11 n n$, so in erwehntem district gelegen. 1616 Bayr. Rambred)t $\subseteq .644$.

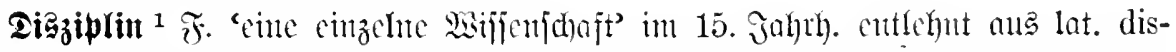

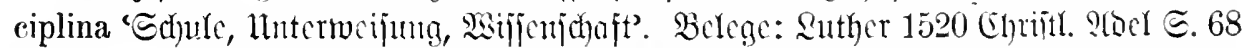

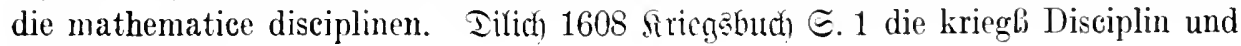
wissentschaft.

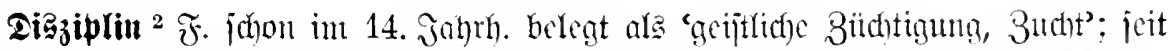

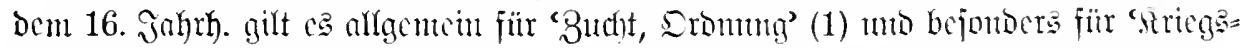

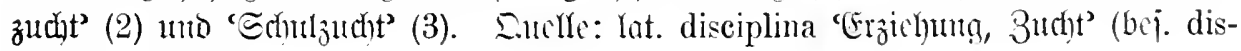
ciplina militaris).

Belege: 1. Wanlser 1558 Türfenbünlein/d. gehörig. \$lenaering 1638 Genijjen: ऽ. $19^{\mathrm{b}}$ sie nit anders damn in guter D. vnd weder $\Subset .64$ Vnser Hauptmann aber weiß heiliger Religion erziehen. 1558 seibelb. von D. zu sagen. Francišci 1663 Türfent= Statuten $\Subset .137$ Von erhaltung der d. und gejabr M $3^{\mathrm{a}} \mathrm{D}$. ist die Seele deb Kriegs.

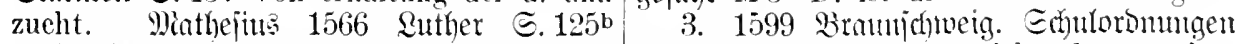
drüber Kireh, Schul, Regiment, alle d. vnnd I 163 soll es anderst nicht das ansehen erbare haubzucht gar zu drümmern gehn. gewinnen, als woll man alle d., vor alters

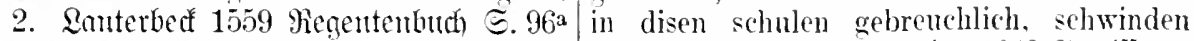
was die alten Heubtlent fur D. vnd Zncht und fallen laßen. Miengering $16+2$ Gerviljen: vnter jrem Kriegsuolck gehalten. Gebharod rïge $€ .766$ dab die Schüler jhre Rachgier

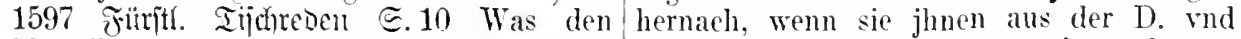
Mutwillen der Soldaten anlangt, kan dem- Zucht-Joche entkonmen an sie anslassen. selben dureh ein gute Kriegsd. gewehret Eecfenoorif 1685 Ehriftenltant I 597 unter werden. Friebenßherg 1597 Discurs $\Xi .25 \%$ der sauren gezwnngenen D. ihrer Rectorn Was sunsten zu guter liriegsordnung vnd oder Praeceptoren.

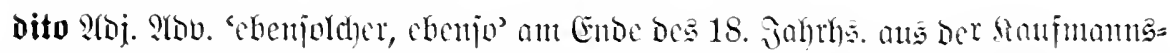

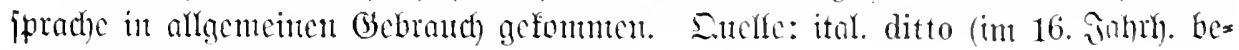
zeugt; Yout detto) cight. 'Der Gejagte'.

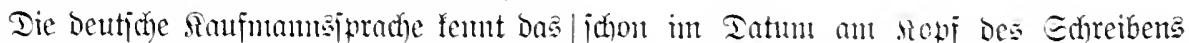

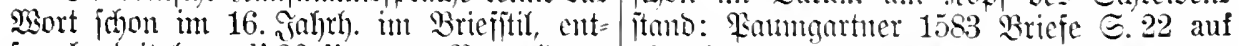

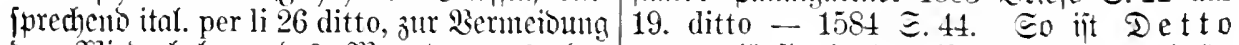

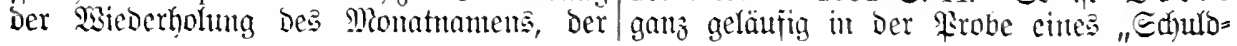




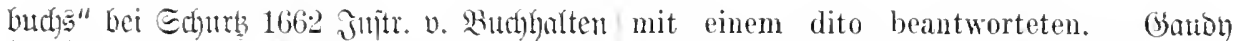

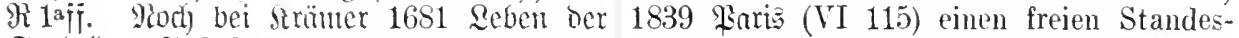

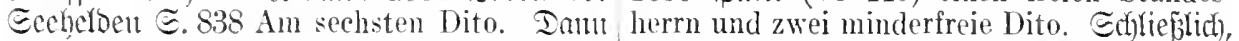

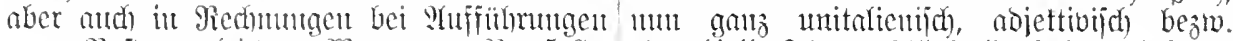

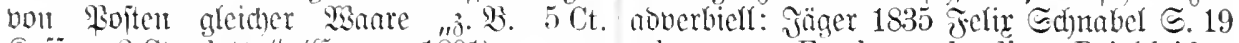
Staffee, 2 Ct. detto" (Campe 1801).

schwarzen Frack und dito Beinkleider.

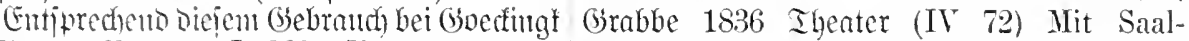
1776 an Bürger (I 289) Threr ehelichen baderei in 5 Aufzügen, wobei wir Zusehauer Hausfran ein gantzes Dntzend Küsse, Thnen dito aufgezogen wurden. Troutane 1882 aber eine halbe Dosin dito. Tafer jubjtanti= Brieje II 9 die Luft ist herrlich, der Anblick vijd: Baldrot 1791 Reberiskeidr. III 306 des Meeres dito.

einer that einen Senfzer, welchen die andern

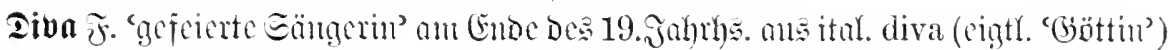

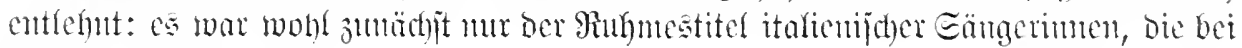
itm Gajtipicle gaben.

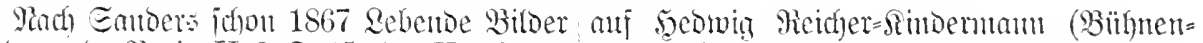

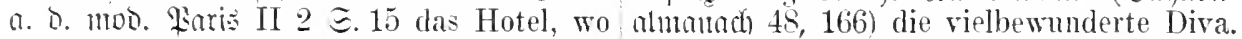

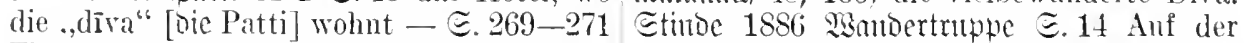
Theresa, die Volksdiva. Sion Deutichen Probe instruirte mich die Diva auf das Ë̈ugerintuen wird Diva aber wohl crit Genaneste.

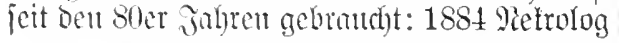

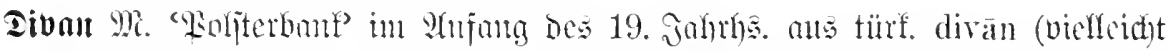

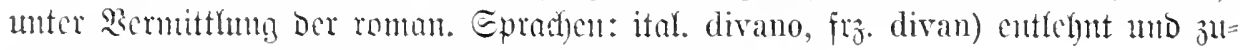

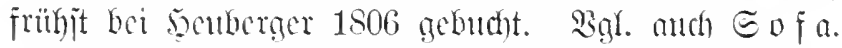

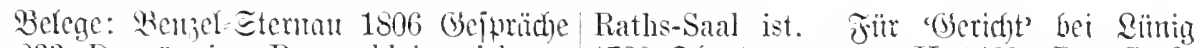
II 233 Der ïppige Rasen bläht sich zul 1720 Iheat. ceremon. II $1460^{3}$ Der Groß-

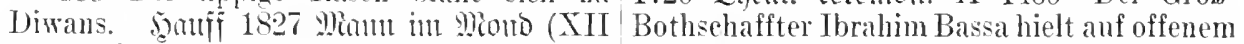
163). Jïger 1835 Jelir Ethitubel $\Xi .267$. Hofe Audienz oder Gerieht, so man Diran Reroalo 1837 ?quarelle IV 16. Riehl 1848 nennet.

Eijele E. 31 eines jiingeren glatt bepolsterten türkischen livan.

Qunt. 1. Camine 1801 unt 1813 fent

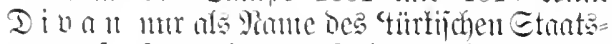

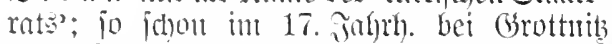
1647 Tegumentsrat $\Xi .121$ dann an dem Orth, wo der Dixan (in ihrer Sprache) oder die Raths-rersammlnng gehalten wird. In= Heben war es als 'türfijhes Ratshan' be

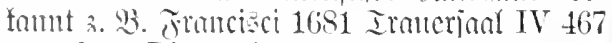
ror dem Divan (oder kesserlichem Raht-

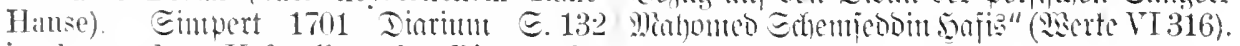

Tum. 2. Die cigtt. Geintat des sartes

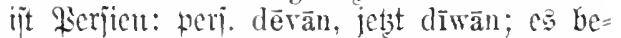
bentete amä̈fjit 'Blattionmlung', Dann '(B)e=

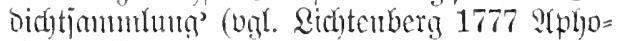
rismen III 197 Die Perser nennen ein gutes Buch Diran). In Ieutichen ijt Dieje Grumt: bedentunt bon Divall burd Goethe's

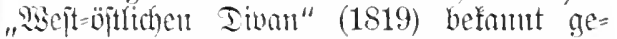
morben; bgl. and ben Titelentwurf bou 1815

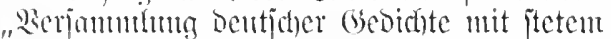
Bezug anf ben Divan des weritiden Eüngers in den antern Hof, allwo der Divan oder

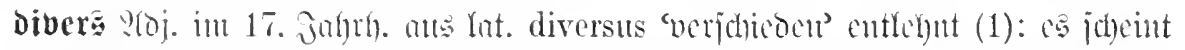

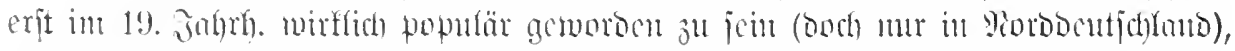

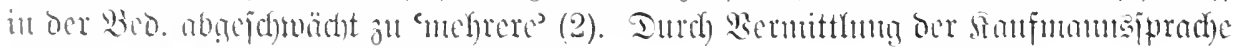
(Compe 1801 butht .diverse Minaren")?

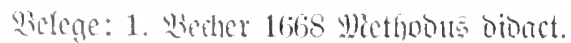
こ. 27a (1) solelu [P(Lphabete] zwar von eine schön gustickte T'ulpe nebst diversen diversan Figuren hestehn. seynel sie doch Vergissmeimieht und Veilehen. seme 1826

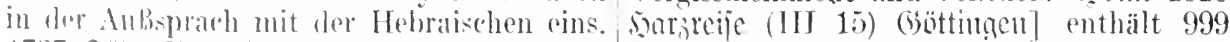

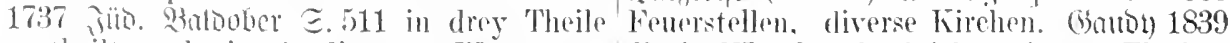
vertheilt mult in 8 . diversen Wegen im Liris (VI 118) er fand sich zudiversen Flüchen dunckelen. Dhendaufhiesige Staltznkommen. veranlaBt. 


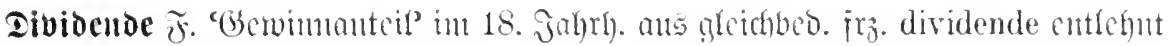

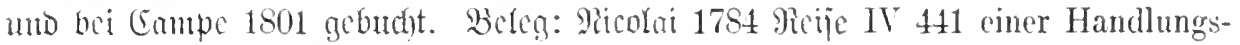
gesellschaft, welche jährlich nene Versendungen machen mul., weil jhre Alitionisten auf eine jährliche hohe Dividende rechnen.

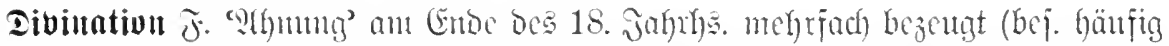

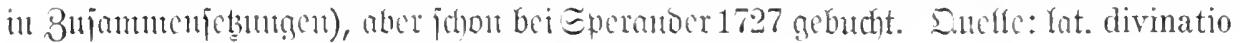

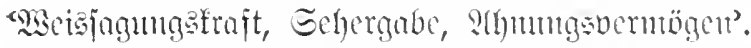

Belege: Sistelant $176+$ Don Enlvio (I 238) da ihm Donna Folieita sehr gern erlaubte,

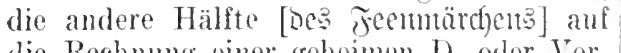
die Rechmung einer geheimen D. oder Vorwissensehaft seiner Seele zn schreiben. Sunt 1798 P(nt)ropologie こ. 85 demm meigentlich wird jele scharfsinnige Errathung des Küinftigen auch I). genannt. Echleget $1801 / 2$ Borlejugen I 22 Freylich wird unse histori- [ 232. ein besonders reiches Jab dieser. sche Kenntnib nie vollendet, es mu immer divinatorisehen Genialität.

durch D. ergänzt werden.

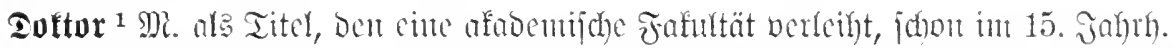

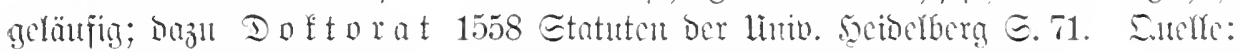
nilut. doctor - doctoratus.

jun mittelalter galt lat. doctor 'Rebrer' zunüchit als Etantieşbejeidyum Der Ge= lehrten, die eine anjanga rem private, jäter

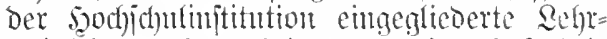
tätigfeit ansübten; bei uts nodi in 16. Jah)rh.

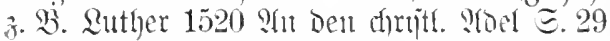
die Doctores der Vninersiteten (banebcu attel Mi a a i jter). Eeit (Ende de 12. Jahrbs. maditen aber bie jocfidfulforporationten Den Benium Der 2ebrtätigleit vou beitumuten

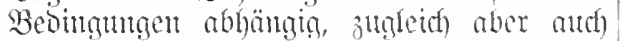

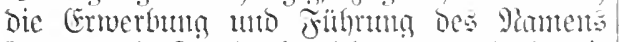

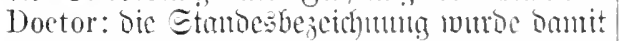
cine offizicle Iitulatur des lluverjitäts=

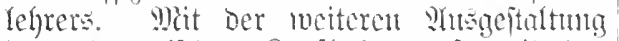
ber atadenijall Samigabu, bej. mit ber

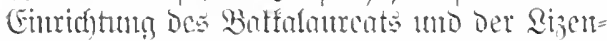
tiatur mutoe die Beocutung oes Iottor= grabes geringer: auth , non doctores" ivurben auj grofeifuten berufen, währeno pronto=

vierte Dottorest gelegentfict miener in bie Prariz ïbergingen. Iurch bieie Entmidtung mubte aber Das sisort Doctor notrucndig

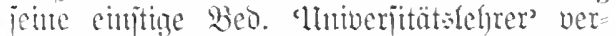
lierent mo zul ememt blojsent afademijgent Iitel toerdest, bejien siert aber moht erit ant Gne Des 18. Fahng. herahgentmoert moroen it: Midhelis 1776 giaijonmentent über D. proteit. LIniw. IV 99 , int Dent bou Der lntwerïtüt hutänglich entlegenen sater= lambe gill jobst ber Ioctor, wol gar ber auj lluiberitäten immer almboijher twerbende Sicentiate mo Saccalanrens viel nehr, tmo mtan itellt jich beh bent Elfall etwas ge= Echteres uno arjehulicheres nor, als oie

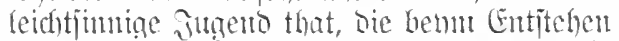

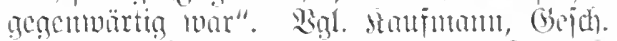
ถ. о. Intiwerjitäten I 99. II 212 uno Bentral=

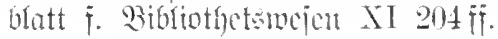

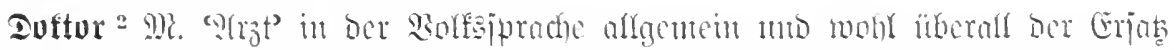

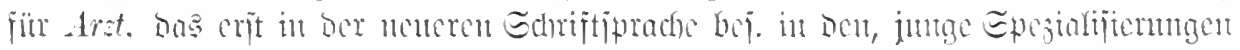

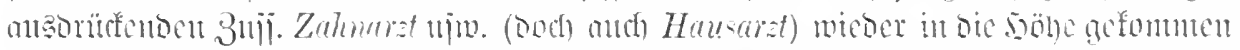

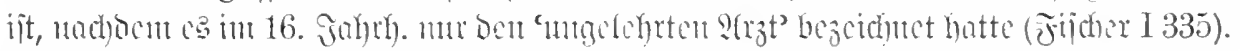

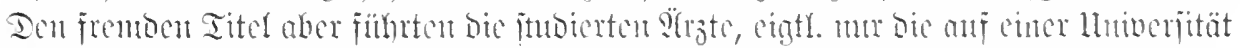

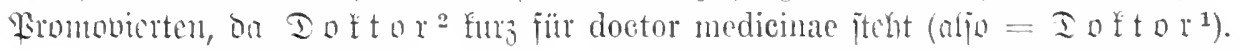

Daber aelegentlid) now ,ein ooctor it 1521 Bair. Enronit (I 337) irer gnaden

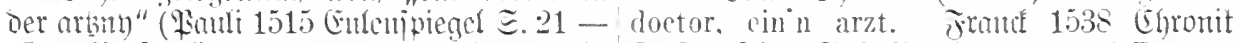

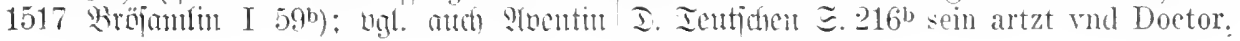


Dadh ijt jafon am Ende Des 15. Jahrbs. [ Hrzneibücher jmb nötig] Angesehen, das aud $D a g$ einfache $D$ oftor jehr geläufig: Doctores nit an allen orten werden befunden.

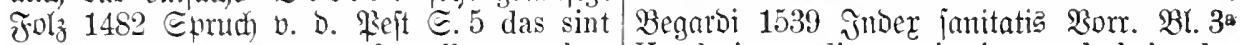
drey krewter in der not für all apptecken Vnnd jetzt diser zeit in sonderheit der und doctor - $\mathbb{S} .11$ keym swangern weyb selbigen ärtzet so vil seind, die sich der sol man sie geben, die sulln der doctor rat artznei vnderziehen, Doctores vnd Meyster geleben - $\Xi .19$ do raten all doctores zu. schelten lassen.

Fuch)

Iottrin $\mathfrak{F}$. 'QChre' int 17. Johrh. aug gleid)bed. lat. dostrina entlehnt (1); baneben and in Den päter veralteten Bebcutungen 'Unterweijung' (2) uns '(Belehrjamfeit' (3).

Belege: 1. Mengering 1642 Gevifjen: / was bißher für Doctrinen vnd Formular, rïge $\subseteq .95 t$ es ist auch mehrertheils vmb so Notarien belangen, geschriben.

die doctrin vnd Lehre zu thun. Freiberger 1656 Solit. Disfurje 巨. $4^{\mathrm{a}}$ also muß man ein jeden seine vernünfftige Me vmung vmnd Doctrin darüber lassen. Becher 1668 Metho= Dus bibact. C $4^{\text {b }}$ dieweil von so vil hundert Jahren hero alle Doetrinen vnd Seientien in besagter Sprach beschriben. Thomaium 1688 Monatsgejpräche I 332 fürnehmlich seine doctrin vom Wesen der menschlichen Seele - 1691 Bermunftlehre I5 Dureh blosses zuhören eines diseurses eine doctrin vollständig zu fassen. Buggenberger 1722 Prozeile @. 129 dise Doctrin und Rechtslehr.

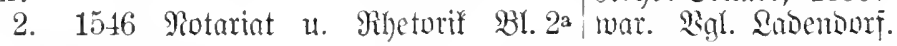

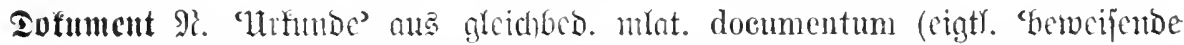

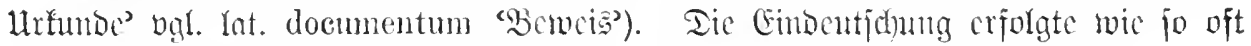
vom Rhural ans, Dex als Do

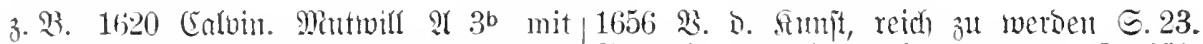
bewcißliehen unwiderleglichen documenten - Rrötorin 1666 Anthropodemus 1253.

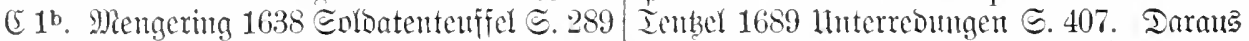

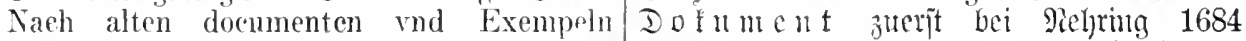
wollen wir hie nicht lange fragen. 16:34 Hanuale 厄.349 Documentum, ein Docu-

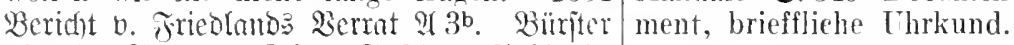

$1643 / 7$ Entwed. Frieg 厄.34. (bebhardt

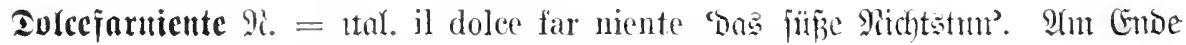

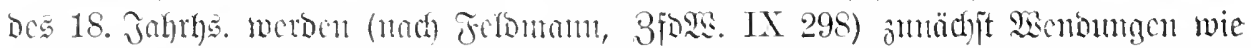
il divino far niente, nuch) il sacrosante far niente $1 t$. ̈̈. gebtaucht (1), währono dolce

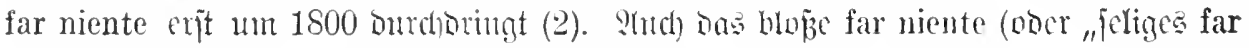
niente") ijt noch in 19. Jahrery. üblicl) (3).

Belege: 1. Mielard 1776 an Merd (ङ. 70) $\mid$ seligkeit in einem beiben Lande. Gotter Ich bin nun, seit ich meinen eignen Garten 1787 Giottin Farniente (= Gesoidgte I 456 hahe, ganz und gar in der Stimmung des :(nnt.) Die Apotheose dieser Göttin ist neuer divino far niente - 1777 (ङ. 107) Wär' als Hederichs mythologisches Wörterbuch, ich klug, wenn ich meine selige Ungebunden- und sehreibt sich eigentlich von den Italienern heit und das sacrosanto Far Niente ... gegen her, die das Nichtsthum zuerst il divino die Sklaverei ... vertansehte. Bimmer= far niente genamnt haben.

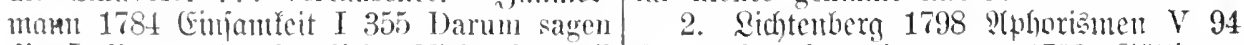
die Italiener, das köstliche Niehtsthmm (il Das dolee far niente - 1799 G3öttinger

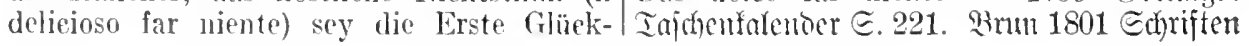


IV 293 welches Dolce far Niente sich mit und Zypressen leben ihr Pflanzenleben in diesen hesperischen Sonnengluthen über reiner Luft und seligem Far niente dahin. mich ergossen hat - 412 ich fange an, allen Eeume 1813 Mein Leben (I 36) in das Reitz des Italienisehen dolce far niente zu sogenannte selige far niente, den behagliehen, empfinden. Rewald 1836 2quarelle II 128 halb dunkeln, ziemlich reinen, bloßenExistenzHeine schlenderte tagelang im dolce far genuß. Füctler 1831 Briefe III 169 dieses niente umher - 1843 Tie Mappe $\bigodot .75$ Leben ist cin ziemliches far niente. Serwald Der Italiener, dessen größter irdischer Genuß 1837 Squarelle IV 56 so denkt der alternde im dolce far niente besteht.

3. Brun 1809 Epijoden II 175 Pinien far niente zu rütteln.

Dom ${ }^{1} \mathfrak{M}$. 'Gijhöjliche firche' im 17. Jahrh. Durdhoringenbe Entlehnung aus

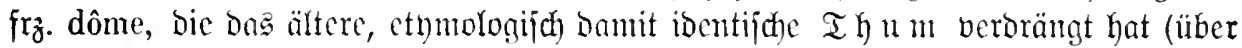

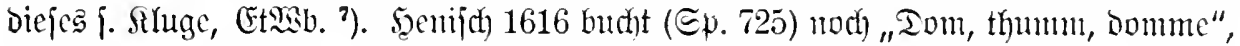

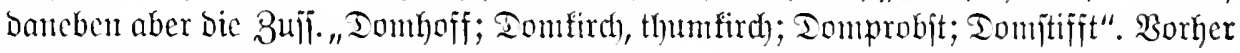
fadon bei Djtermam 1591 Bocab. aualnt. I 10 Ein Domkirche, oder fürnembste Kirchen.

Do m foheint zuntächit in Rorobeutjchlanb | Domwereke zu Halberstadt - $117 \mathrm{im}$ Dohm üblid) geworden zu jeit, jedenfallz beziehen zu Magdeburg [Doch $\subseteq .98$ Thum zu Magde-

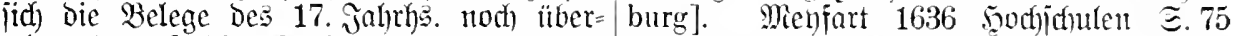
wiegend auf bie Sirchen norbd. Etäbte. ein Domherr zu Würtzburg $-厄 .78$ in dem Bgl. Eommer 1608 Ethographia III $\mathfrak{B} 3^{b}$ Domstiff zu Strabburg. Mengering 1642 den Domthurm zu Magdeburgk. 1616 Gervifjensinüge હ. 404 der Domkirchen zu

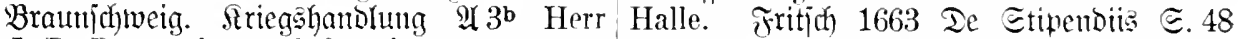
J. B. Domprobst vnd Syndicus zu Lübeck. in denen Dombstifftern - 1667 Ie Iftgujta Prätorilı 1619 ङyntagmia II 103 an diesem @. 17 in das hohe Domstift.

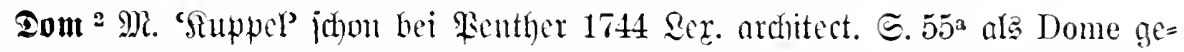

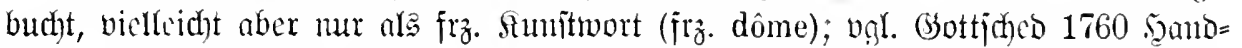

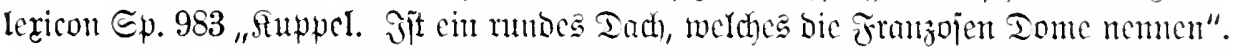

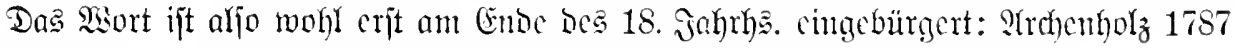
Jtalien I 123 ein sehr zierliches Cabinet nit einer domartigen Decke.

Tomtäne $\mathfrak{F}$. 'Iondeşherrlidhes Gut' im 17. Juhrh. als $\mathfrak{T}$ o m a i ne aus gleichbed. jrz. domaine cutrebut.

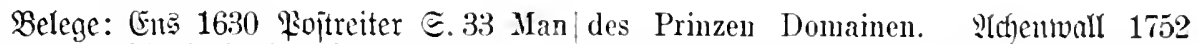

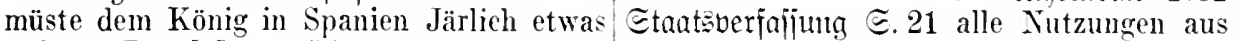
auß den Dom[a]ynen (Kammergütern) vnnd seinen Patrinonial- und Cammergütern, andern Einkommen der Prouintzen folgen welche man auch Domainen nud Tafelgüter lassen. Damiel :seiman 1660 Relation (Ürf. zu nemnen pflegt.

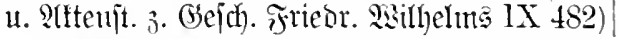

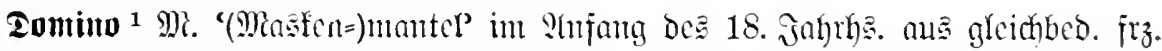
(= ipan. itul.) domino enteflent. Ier Iomino war nach mijerem frühjten Belea

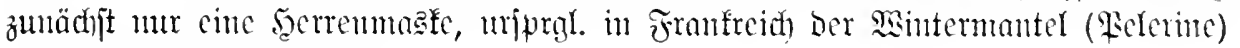
Der Geijtlichen (Ducange).

Belege: Matthejon 1739 Rapellmeijter Er geht. Sa Roche 1771 Frl. v. Etembeim ङ.9 unter der Verkleidung eines D., zur $\Xi .174$ Seymour in einem schwarzen D. Verbergung ihres schönen Gesehlechts. জiagner 1776 fimbermöroerin $\Xi .5$ die 3achariä 1754 Bermandhungen (I 160) Auch Franenzimmer haben D., Er eine Wildschur Zephir trat jetzo verlarvet in den Saal. an, alle noch ihre Masken vor.

Und mischt im D. sich zu der Masken zahl.

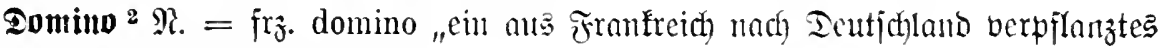
Spicl" 1844 Brodfyas IV ${ }^{9} 416$. 


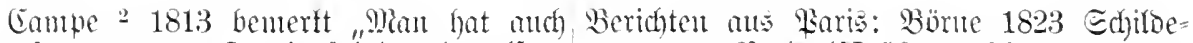
ein jogenantes Iomtuojpiel mit eljen= rungen a. Paris (II 58) da klapperten die bememen oder fitöhermen Eteinchen, welches D.- und Damensteine. Devrient 1839 Brieje

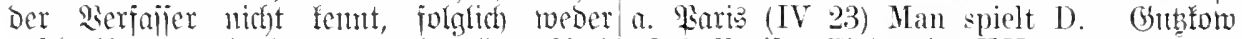

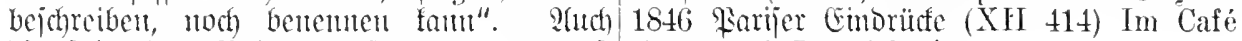
bie folgenten Belege entĩtommen nur erit/ sitzen und D. spielen!

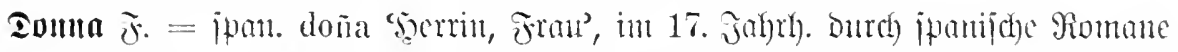

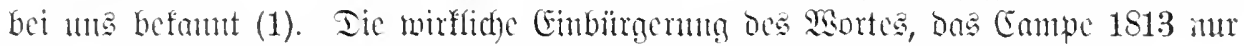

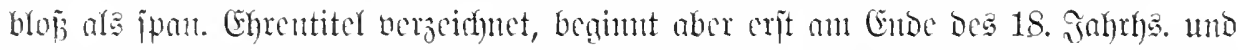

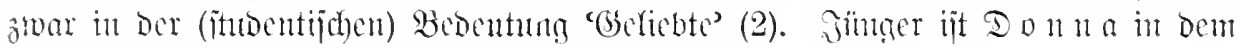

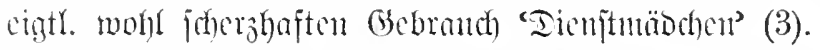

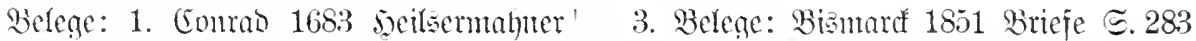
E. 123 zu Paris hab ein Hochadelicher die [oie Paulsfird)e] zeigende Donna wubte Cavalier sich verheiratet mit einer edlen nar nicht, weß Geistes Kind sie aus mir

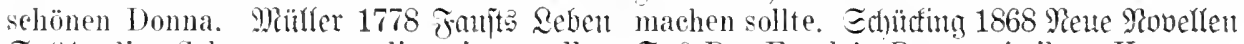
モ. 64 die Schammiunze, die einer edlen ङ. 6 Das Fränlein Brant mit ihrer KammerDonna aufm Busen schwimmt.

2. Babrot 1790 2ebensbejchr. I 214 nene Donna läßt sich gut an und kocht ausMeine Phantasie nahm ganz natürlich das reichend. Etimbe 1886 Fam. Budhbolz III 87 Bild meiner Donna mit nath Leipzig - weil ich nicht mag, daß Lente meine Briefe $1791 \mathrm{cbo}$. II 89 daß ich in allen Gesellschaften achtlos herumtreiben lassen und die Donna's mit meiner Donna aufgezogen wurde. ¿auf= sie Morgens früh beim Stubenscheuern lesen. hard 1802 Qeben V 194.

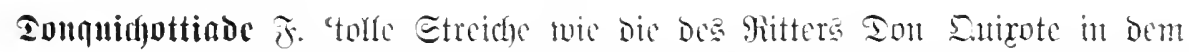

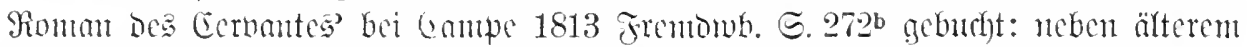

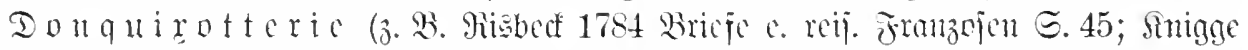

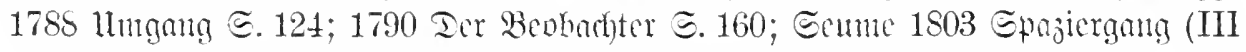

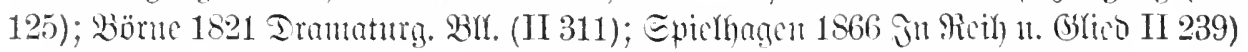

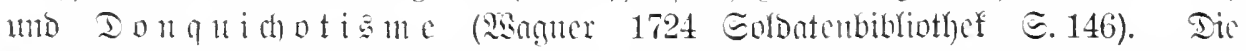

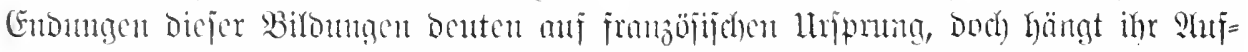
fommen jedenforfs mit Dem Befantermerden Deg Don Enixote= Romang in

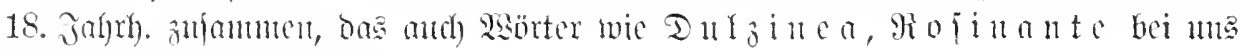
ciugebiurgert hat (j. bicịe).

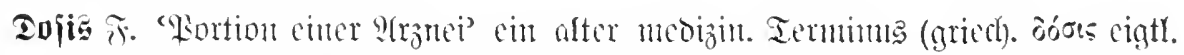

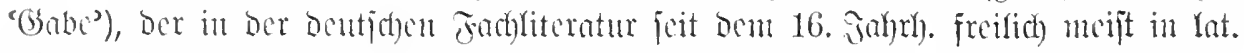

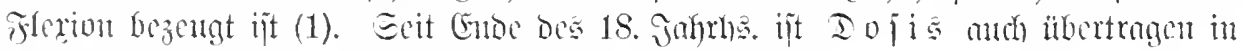
Bezichung anf menjd)

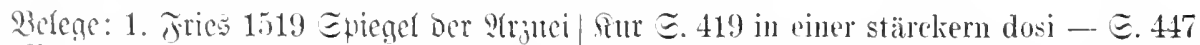
ङ. $4 \delta^{\mathrm{b}}$ Hat or gesagt gewisse ordenmm vermittelst etlieher dosen vom gereinigten der gaben in sweib rond artzny. Vnd dise Salpeter.

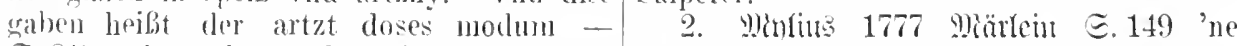

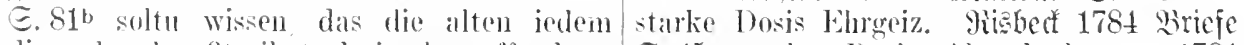
diner. das da vitreibet, drei gaben off gelegt, $\Xi .45$ starke Dosis Aberglauben. 1784

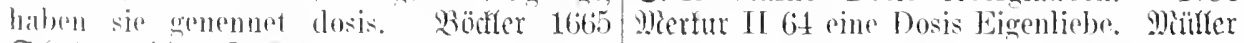
Edjota milit. כ. $8633 \mathrm{zmm}$ Brechen 300.2787 Emmerid) II 333 eine gute Dosis

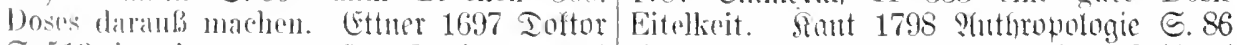
5.513 in rincr so uroben Dosi - 1715 cine gewisse Dosis von Tollheit. Echlegel

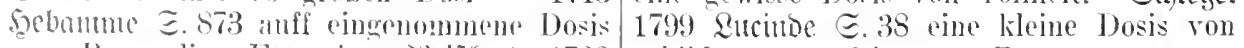

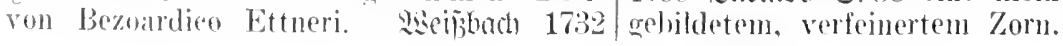




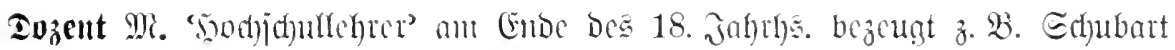

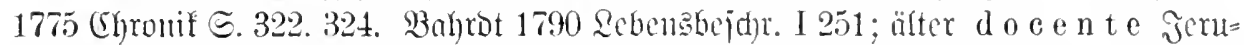

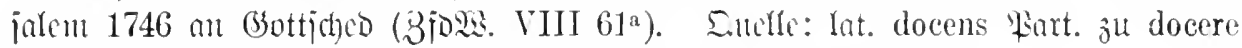

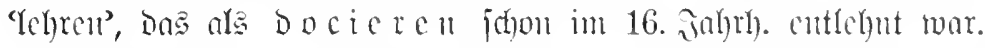

dozicren 3tw. ‘fehren' 1558 Etatuten/vnd ins Werck setzen. Becher 1668 Diethon.

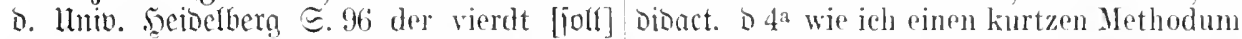
mathematicam und der funft poetieam und zu dociren finden könte. Thomajus 1691 oratoriam publice lesen und dociren. Simmel Bermmftefre I 7 als ob er so thöricht Zene, 1636 Eajtrum Ioturis $\Xi .103$ dieses lesset als dieser nacheeschricben, dociret habe. sich ehe doeiren vnd sagen, als praticiren

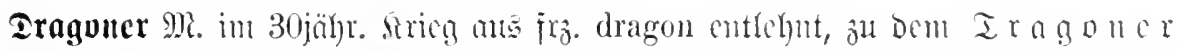

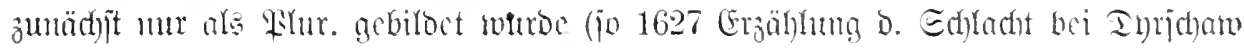

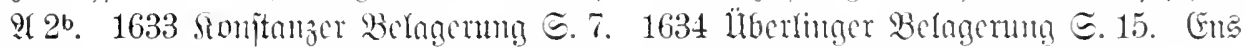

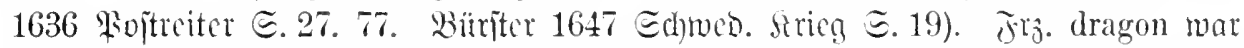

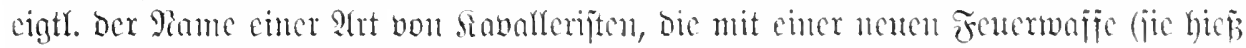

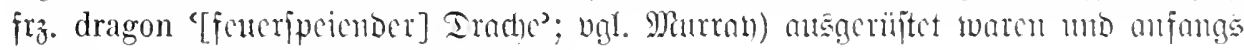
and) als Fuñtruppe verwenoet muden.

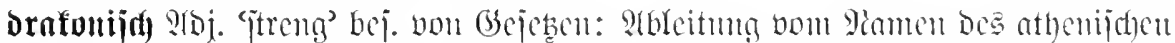

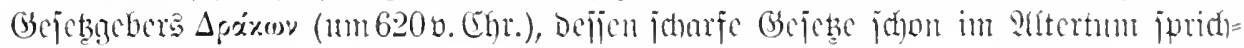
wörtlich warem.

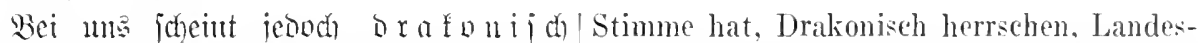

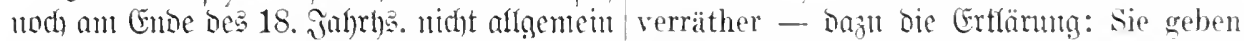

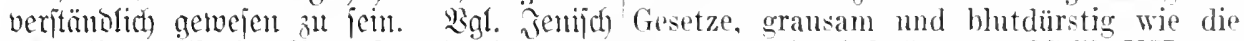

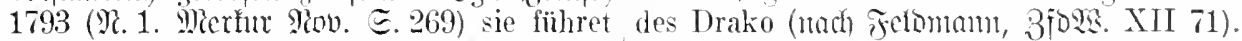
piner jener Hochverräther Der Mensehheit, $\mathfrak{J}_{\mathfrak{r}}$. draconique ijt idou im 16. Jafhrh., die im Volkssenat. Wo Pöbelwuth nur engl. draconic jeit 1708 belegt.

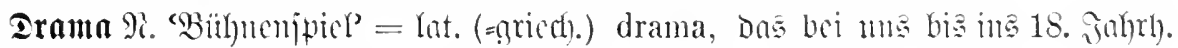
nod) mit fremoer Flexion gebrand imuroc.

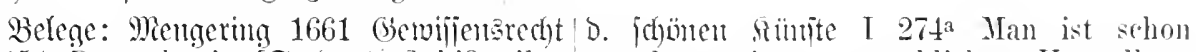
5.154 Darumb sie [Etubenten] bißweilen gewohnt, ein $z$ w wöklicher Vorstellung gar unfletige Dramata auff die Bahn bringen. einer Handlung verfertigtes Gedicht. mit 3rbbt 1763 Riteraturbrieje XVI 96 neue dem griechischen Worte Drama (eine HandDramata nach Regeln. Eulger 1771 Theoric lung) zu benemnen.

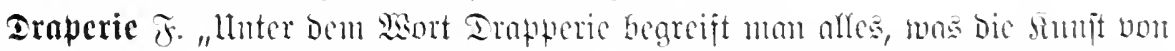

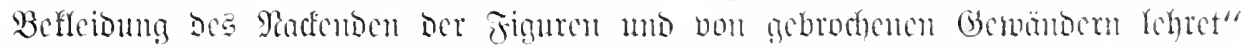

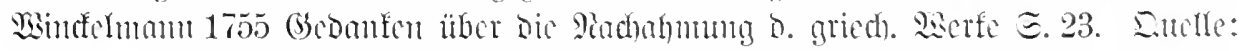

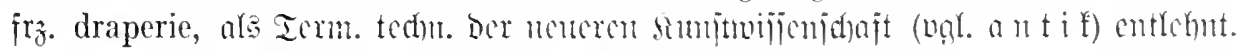

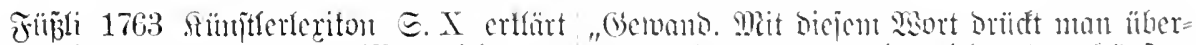
"Draperie, Getwänoer; hegreiffen nidgt mur baupt alles ans, mas un zeidnenden süujten

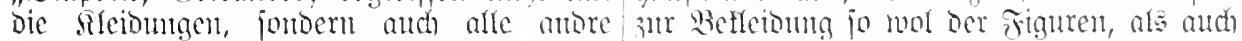

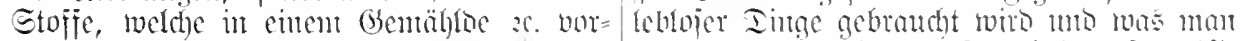

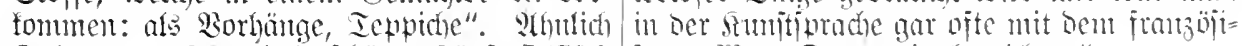

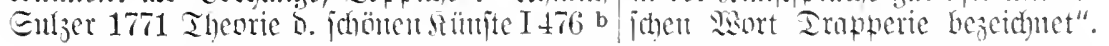

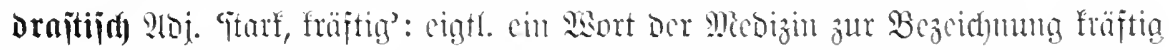

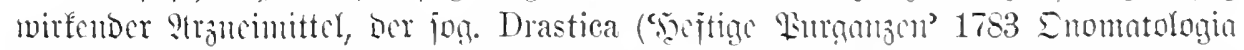

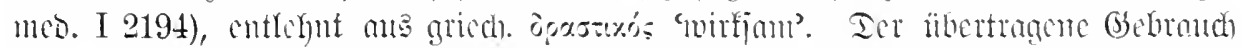

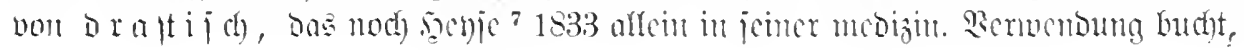




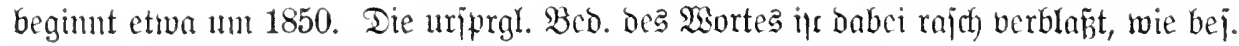
aud) bie jrühbezeugte Wenoung "Draftifh wirken" crweift.

Berege: Soltei 1852 Bagabumben S. 211 außerordentlich drastisehe Sprache - 154 Humor, welcher um so drastischer auf mich zur drastischen Belebung des scenischwirkt, aus je zerrisseneren Herzen er hervor- musikalischen Vorgangs - 181 durch die dringt. (Gentuit 1862 Iagebutd) e. $\mathcal{E}_{\text {chan }}=$ drastische Steigerung des thematischen Kon-

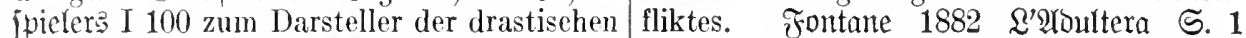
Figur, welche der Kapuziner abgeben würde seine Vorliebe für drastische Sprichwörter. - 1866 ebo. IV 283 durch drastische Komik 1884 Bïfntenalunattad 48, 133 im drastischund kernigen Humor. Marimilimn v. Merrifo sten Kunterbunt.

1867 Qeben II 148 um auf ihr sehon etwas ?hum. Ganz ifoliert jteht der bebrauch

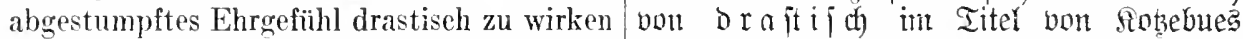

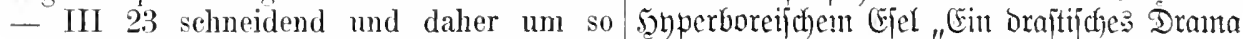

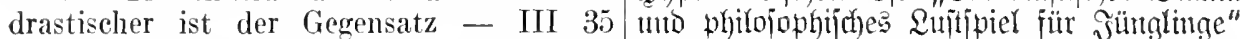

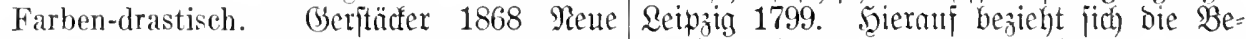

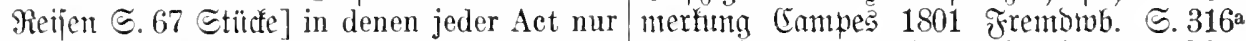

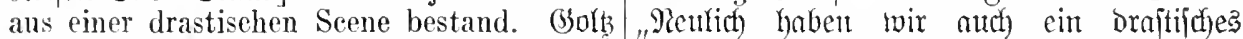

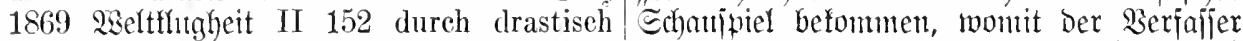
aceentuirte, stark gefärbte Urtheilsfassungen. cin joldyes bezcidynent worlte, welches gleidy

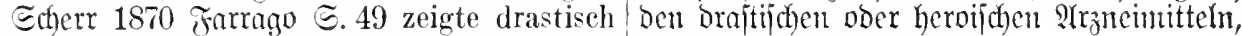
genug der Hofhalt Karls des Großen. anf Reben unb Iobt geht".

Ridcharo $\mathfrak{3 n g u t e r} 1879$ Schriften X 153 eine

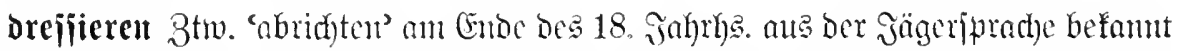
geworben, zunäd)it imuner bom S(brichten vou sumben (1), fpäter auch vou antorn

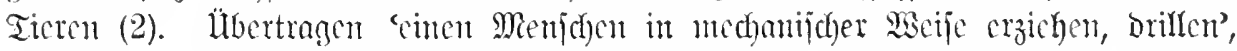

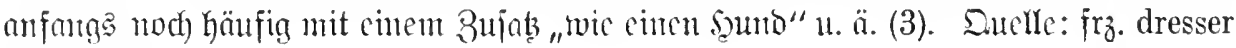
'abrictsten'.

Belege: 1. Döhel 1746 Jägerpractica I I 243 Ich will Ench dressiren wie die Hunde. $108^{\mathrm{a}}$ Den Hühner-Hund parForee abzurichten, Gbothe 1796 Lehrjahre (XXIII 185) Therese oder durchs Dressiren zu arbeiten. Şeppe 1751 dressirt ihre Zöglinge, Natalie bildet sie.

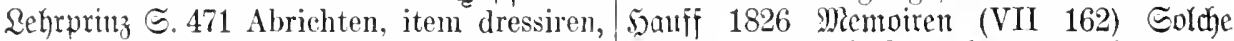
bedentet: einen Hühnerhund usw. zum Ge- [ente] sind auf den Mann dressirt trotz branch bey dem Weydwerk gut und niitzlich der besten Dogge. machen.

2. Piinfler 1831 Brieje I 263 einem gut dressirten Pferde. Büchuer 1835 Danton ธ. 32 wie ein Kutscher seine dressirten Gäule [amljält].

3. Biltrger 1773 Briefe I 121 Da haben wir ihn aber, wie einen Hühnerhund, mit Sehlïgen dressirt. Më̈lfer 1787 Emmteridf I 217 Dá̉ er] keineswegs aber einen IIühnerhund, noch weniger einen Rekruten z.u dressiren habe - 1789 ebo. VI 256 so viele Dressur aufgegangen ist.

dressirte Krieger. Bahrot 1790 Mintovigius

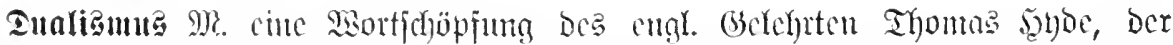

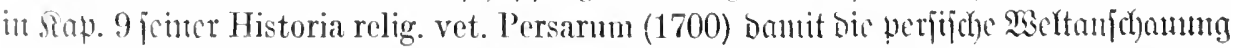

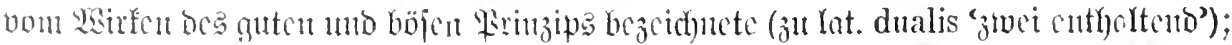

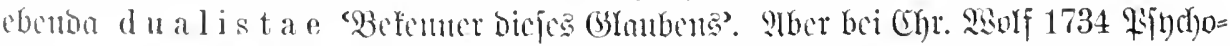
Iogia rat. \$: 39 Dutalistae sunt, qui et substantiarum materialium et immaterialium

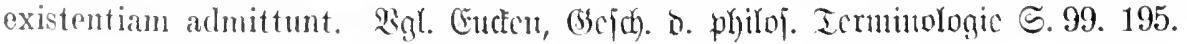




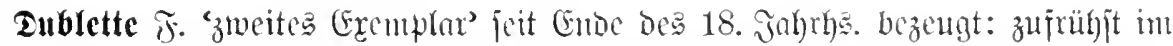

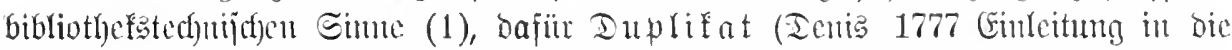
Büd)erfunde I 190). Dann aud) in allg. Bermenomng (2), bafür in d u plo (Ettner

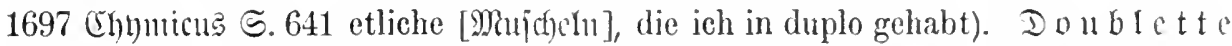

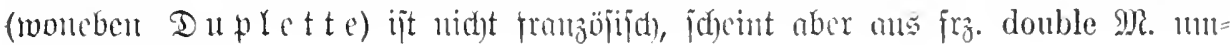
gejtaltet zu firit.

Belege: 1. Michaelis 1776 Raifontentent I Fagntente III 79 eine Doublette des geIV 687 die Bibliothek, die aus der Bülowi- dachten Briefes. Pittter 1835 Semilajio sehen, der gewesenen des Göttingischen I 119 er vertauschtr entbehrliche DouGymnasii, und den Doubletten der Königl. bletten gegen andere der [Raturafien=]SammBibliothek zu Hannover zusammengesetzt lung noch abgehende Exemplare. Scine war. Lejiutg 1780 Brieje (XVIII 343) die 1856 Reije un Die Croe II 54 daB Hakotade bey hiesiger fürstl. Bibl. befindlichen Dou- seiner Lagre nach fast eine Doublette von bleten. Genme 1806 Mein Gonmer (IV 141) Gibraltar genannt werden könne.

Es waren [in Der Stopenthagener Bibliotbet] eine große Nenge Doubletten bei Seite gelegt.

2. Schiller 1786 Briefe I 281 ith habe] das Mscrpt., da Sir mir schickten, als pinte Douplette [!] verbrannt - 1789 Brieje Il 239 Ich will Dirs beilegen, weil ich just eine Dublette [Der Rezemijout] habe. Foriter 1791 Qunichten (III 24) Das Konchylienkabinett . . . enthält mur die gemeinsten Sorten und eine Menge Dupletten. Eeume1806 Mein Eomurer (IV 71) Die Doubletten [oer Paturnlien= [ammlung] wird man mit Vortheil ver- holte worte' bei Marrat v. テ. 1553 beleat. tauschen kömnen. Witt $\mathfrak{v}$. Dörtutg 1828

Plum. Fitr die llmgejtaltung tam fròn. doublet m. cimitierter Ederitein, der aus 2 Etituen sujommengejest ijt", faum mas.

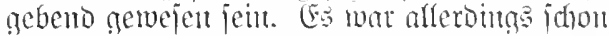

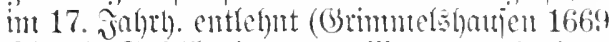
Simnt. E. 245 cin paar silberne und übergoldte Duplet. Rebentualot 1680 Temfels ¿iit IV 9 Christallen vud Tubleten. Bunded 1689 Glasmad)erfmit ङ. 189 Von den Doubleten) utu twiro aud nod bei (Sampe 1801 gebutht, iteht aber in ber Beo. bod zil ferir. Suffällia engl. doublettes 'wieder

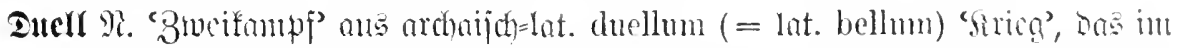

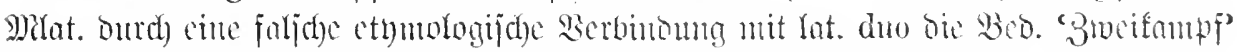

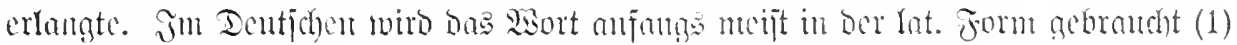

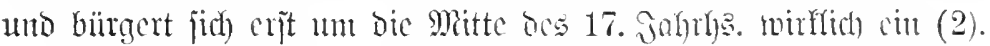

Belege: 1. 2ubertimts 1599 Gutebnra's: Sentojureiben III $11^{3}$ daß Duellum oder ein Kampff von zweyen Personen vnrechtmessig

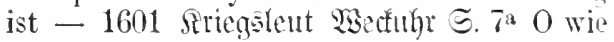
vil Herm, Edellent vind Soldaten findt man, welche von wegen eines einigen schillichten oder krumpen worts, einen duellum vond kampff anfangen. Earolts 1614 Relation 9ix. 9c also das man die Duella nit gar ver= hüten kan. Bzjoldus 1629 Ihejmuts 5.62 a AuBforderung, Duella. Moch 1688 erichicu

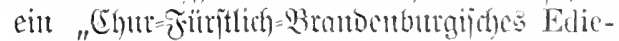
tum, wiber bie Duella".

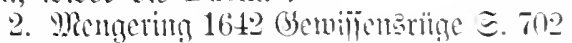
$\mathrm{Ob}$ du dieh mit deinem Neehsten in ein Duell, Kampff vnd Balgerey eingelassen 1661 Getwifientaredyt $5.868 \mathrm{Ob}$ man seine Ehre, Ruff und guten Namen zu behalten und defendiren, sich in Duel, Kampff und ausfordern cinlassen soll. Qujjentits 1661 Ydel. Tiịtheden S.146 Dannenhero man einen solchen Streit pin Duell genennet. weil er yon zweyen verrichtet wid - $\Xi .151$ clab er darauff die Duelle abgeschaffet habe, Sebentualot 1681 Ienjels siit VI 186 in einem Duell. Eecfendorff 1685 Ebriftenitant I 39 das muB im Duell ansgefïhret werden. Das ist das Cavalliers-Reeht. P(br. a $\Xi$. Chom 1686 Jubu $\Xi .284$ höltzernes Duell.

Dublant m?. ant bem milat. Partiz. duellans (bol. o u elfieren). Sielege: Nengeting 1642 Gemijiensitige $\Xi .1364 \mathrm{In}$ specie Edollente rnd andere Duellanten.

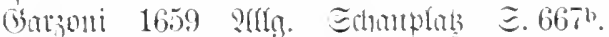

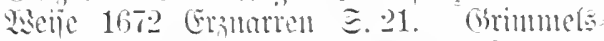
homicn 1672 Qnogelneit (netler II 533).

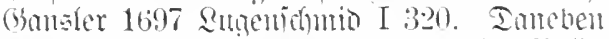
Iuelli it (z. Si. Freiberget 16.56 Rolit.

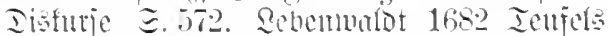
Siit VIII 142) nach fro. duelliste.

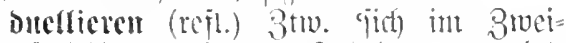
Emmpi idtagen' im 17. Gahrh. aus mlat. 


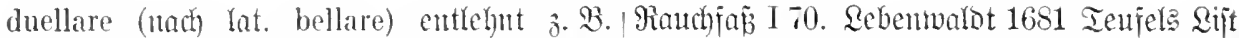

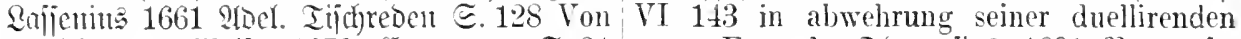

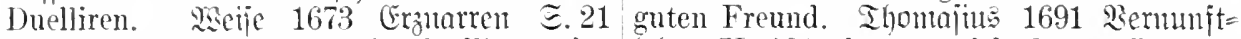
daß einer nicht anders als im duelliren seine lehre II 121 da man sieh des rerfluchten Revenge suchen will. Francisci 1672 sciftor. duellirens nicht zu befahren habe.

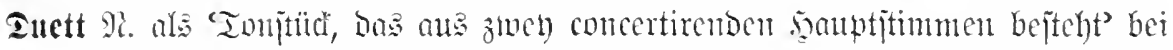

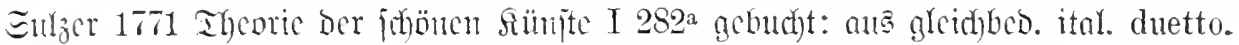

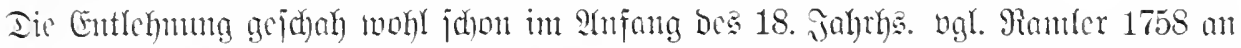
Gícim (II 35̆t) Hier ist wieder die alte Weihnachtscantate aufgeführt, ich habe noch ein Duett hineinflicken müssen.

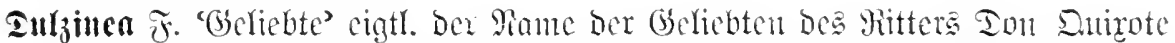

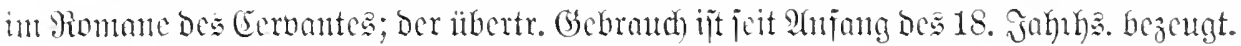

Belege: Riscov 1739 Entix. Edyriften'1767 Begean. e. Reipziger Etubenten II 186.

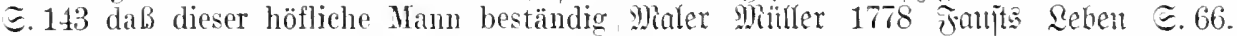
mit seinen Zuhörern liebäugelt, nicht anders, Bahtot 1790 Sebenồbejdr. II 105. Engel als wenn er seine Dulcineam vor sich hätte. 1795 Qorenz 巨tarf @. 441.

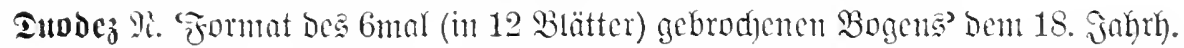
id)on Durd)aus geläufig, abor im 17. Jahth. nod in lat. Form, in duodecimo" nad)

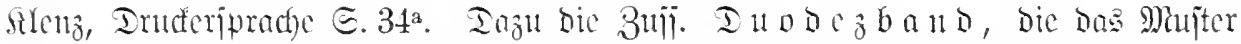

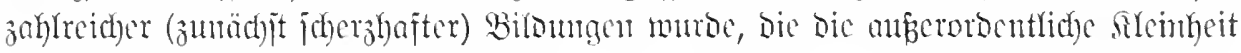
cincs Iinges njw. ausbritcen jorlen.

Inboejband Edubart $177 t$ D. (Shronif ms $\Xi .25$ Landbürger- und Menschenrechte

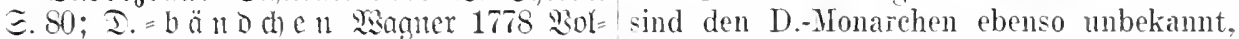

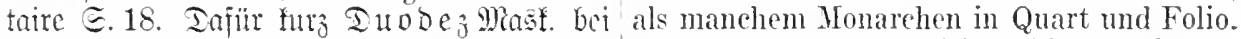

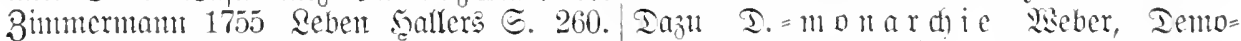

Znudezofturlein Eerz 1797 Tentide fritus VII ‘ 204. 225.

Jobiotismen 厄. $32 \mathrm{~b}$

Invoejijirit Gente 1854 Rutezia (VI 25̌6)

Enodeztünim Eerz 1797 厄.32b

THodezlnud Berffentmener 1712 2utti= quarius こ. 489 Dithmarsen, da wurden 1495. viel rormehme Dänen erschlagen, welche es ein D.-Ländgen namnten. Sumfi 1826 Mientoiren (VII 56) D. -länder

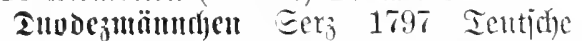

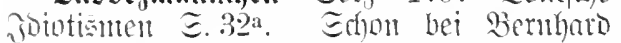
1718 sijtoric D. Gelehrten $\Xi .113$ cinige dnodec Mämnergen.

Zuodezmunard Sauthard 1798 Cark Mag=

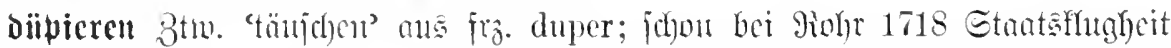
ङ. 459 Im übrigen wäre wohl einigen .Jonrnalisten, damit das Publicum nicht dupiret wïrde. das Handwerek gantz und gar zul legen.

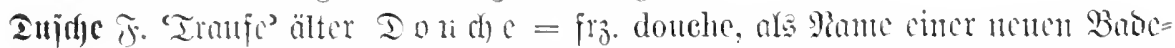

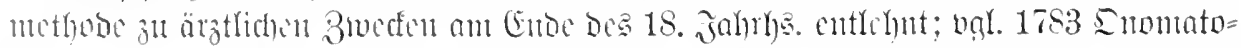

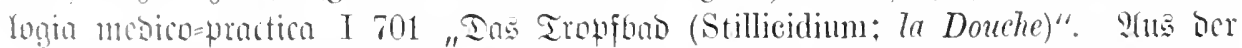

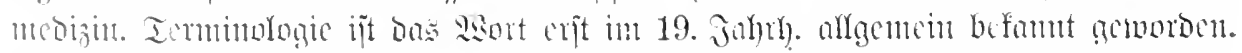

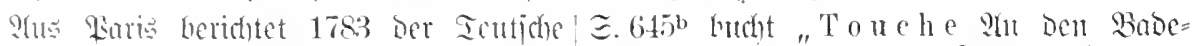

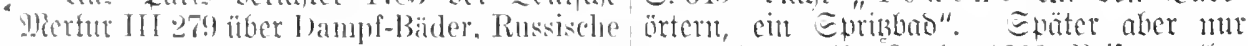

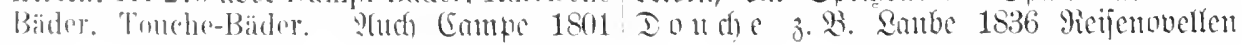


IV 248 wer nicht laufen hann, wird mit Berlin u. Bres̆lan II 33 Die kalte Douche, Ochsen zur Douche gefahren. (Sjanot) 1837 5rumoreafen (VI 202) Stahl- und Inischbäder,

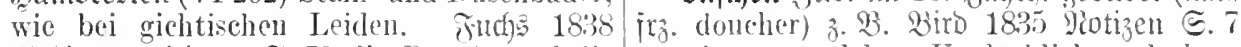
Gehimerweidnut E. 79 die Douche auf die wer könnte solchen Englücklichen drohen, gelähmten Glicder angewendet. Iing 1849 drücken, douchen, kurz - strafen wollen?

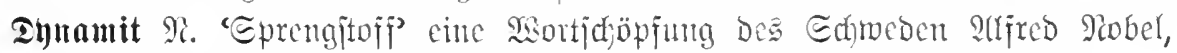

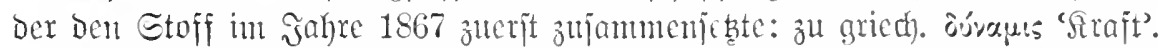

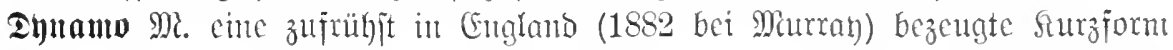

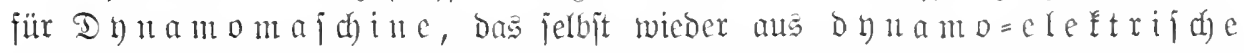

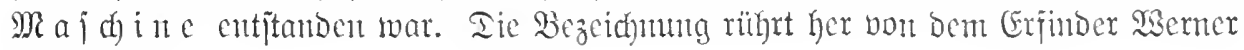
Eicment:

,İh habe in meiner Matteihng über borhanbenter permanenter Magnetismus zur

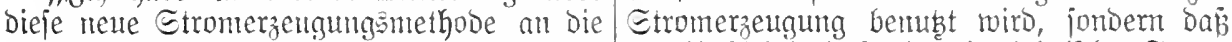

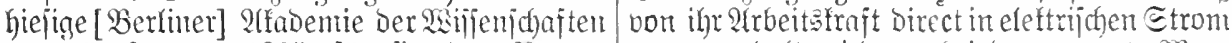
am 17. Jamuar 1867 für fie Den Mamen umgetwandelt wiro, wobei Der erzeugte Mag=

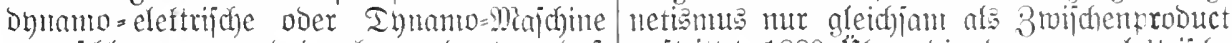

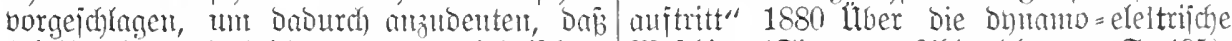

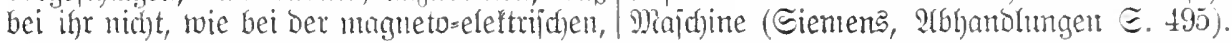

Fyuait Me. 'Machthaber' 子. B. Möjer 1775 Patriot. Phantajien I 292 der erste, den die späteren Zeiten zum Dynasten oder auch belehnten Gerichtsherrn aufstellten.

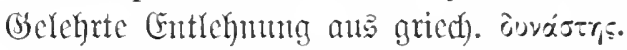

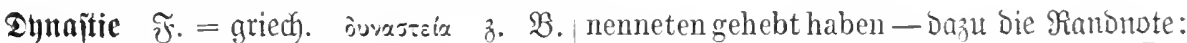

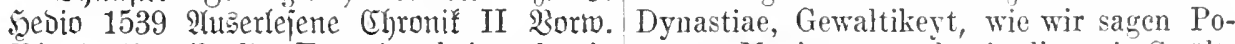
BI. 1 dieweil die Egyptier keine künig testat, Magistrat - durch die xvj. Gwält, gehebt haben, aber yedoch als in einem die sie Dynastias genant haben. künigreich jre Gewält, so sie Dynastias

\section{(̇).}

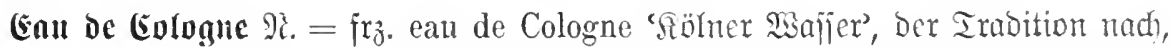

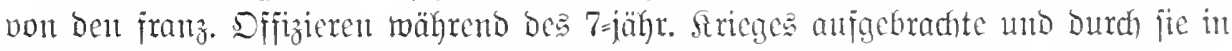
Deutjaland befant gemordene Bencmung des (jett 1709) von Joh. Maria Farina

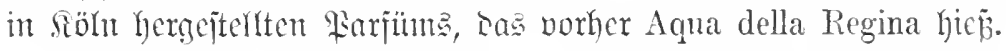

Jeboch fehlent für Eau de Cologne nodh von Campe erit -1813 (nod) nicht ${ }^{1} 1801$ ) Belege Des 18. Sahrbs.; es tritt zufrühit/gebucht. Tie fra. Bezeidnuntg ijt in mittel= bei Sotzebue 1806 Bhtinde Riebe (XX 135) mo Norobeutjaland jegr populär getworben,

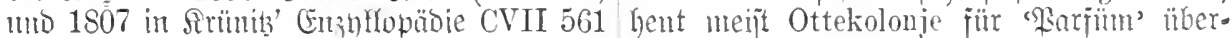

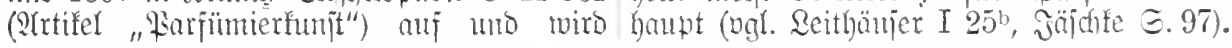

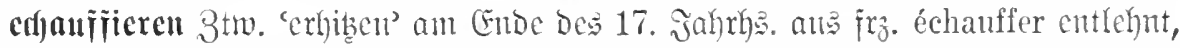

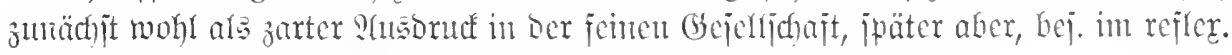
Gebraud aud Der Soltsipradye geläufig gemorocn.

Bgl. Thomajus 1691 Bemumftehre II 169 aus Unverstand und allzugrosser affectation Wenn man sich fremder Wörter bedient, solche Wörter nicht eimmahl recht anzudie in anderer Sprache weniger bekant sind. bringen wciß. Als: Er hat mich überaus Als wenn man sagt: Dieses Ding hat mich coëffirt (echauffirt).

sehr echauffirt. Zu geschweigen wenn man

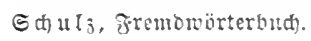




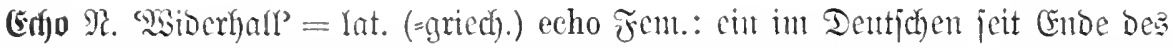

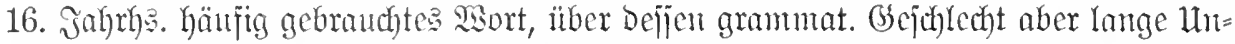

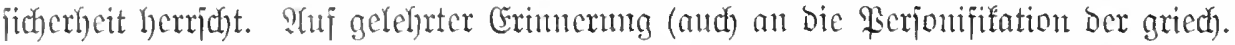

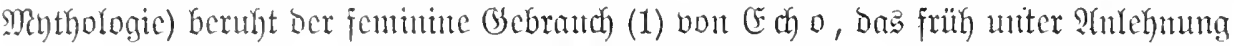
an Dic älteren Snnontyna Widerschall, Widerhall, (auch an Ion) zum Mał́. geworben

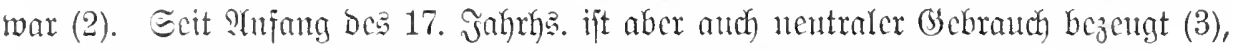

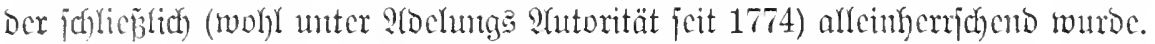

Belege: 1. Fif daß die Magisnostrisch Eeho widerhall. hören lassen, gleich als wann es einen NachDpith 1624 Bocterei S. 24 Das ich der Echo klang oder Widerschall ans dem Wald, oder oder des Widerruffes zuc ende der wörter zwischen den Bergen herfür gebe. Echeuduzer gedencke. S. v. Birfen und Soly. Iflaj 16451711 Phnjica I 210 des Dons Vervilfältigung, in: Fortj. Der Peguib Schäjerei $\mathfrak{S} .24$ sihe, welches wir in gemein lueissen einen Widerda brachte mir die schwätzige Echo sobald schall, oder Echo - nicht eine jede Zuruckherwieder den letzten Lant. Angelus Silejus kunft der Stimme einen Echo formiert 1657 . Girtenlieber III 13 Wenn die Echo 213 der Echo. Etrmißn 1711 Dllapatrion

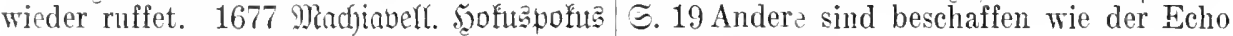
5. 783 wie seine Echo annoch ersehallen oder Widerhall.

lässet. Serber 1770 an Merf (Brieje E.5) 3. Prätorius 1619 Enntagma muicum mit halben Worten der Echo - 1771 (ङ.18) III 137 vnd sie also gleichsam ein Echo mit wenn jene Eeho rief.

2. Dilich 1598 Beichr. D. fürttl. Simbtanfe 5.30 rnd bliesen dieselben gegen einander einen Echo. ?tuertimus 1598 Gyubaras

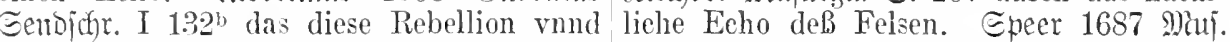
auffstand anders nichts sey alß ein heller $\mathfrak{s u m}$ t S. 92 so gleichsam im Gethösc ein Echo vnnd Schall, der ein groß geschrey hat, Echo vorstellet. Berfenmener 1712 Stuti= aber keinen Herrn findet. Prätorius 1619 quarius ङ. 508. Echutiot 1728 Crureuje Enntaguta muficum II 70 zum fünfften kan Gstillen S. 130.143.

Eĩ̃eft M. 'Mirfuntg, Erfolg’ aus lat. effectus im 16. Jahrh). cingebürgert: anfangs cin gelchrtes şort, iüt c⿱ im 17. Jahrh. allgemein gelänfig (1). Ju 18. Jahrly. wiro

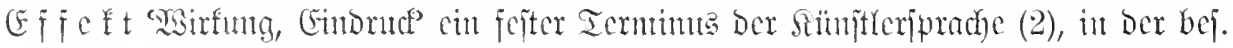

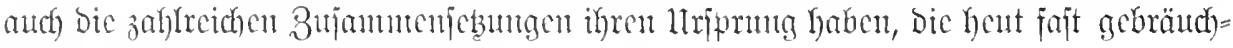
lidfer als bas cinfad)e \$sort find.

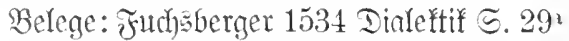
zum Seehsten wird hinwiderumb ain endlicher effecte oder würkung in die ding getailt, dadureh er wird erobert - $5.123^{\mathrm{b}}$ Durch dic würckliche vrsach, so natürlieh anß not etwas rolgen macht, wirt ler effect oder was da volgen soll, nit allain mit ainer jared eingefürt. Corohus 1614 Relntion Rr. $9^{1}$ es soll vnser Landtag sein gewünschten effect erreichen - $\mathfrak{R r} .36^{\mathrm{d}}$ ausser den dann man in diesem Wrek zu keinem Effeet gelangen köndte. Riebe 1665 Reitbuch) $~ S .52$ wann die straffe jhren effect erreicht. Böcter 1665 Echola milit. ङ. 30 Der Anschlag ist ain besten, welcher biß zu seinem Effect dem Feind ohnwissend kan angebracht werden.

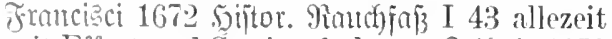
mit Effect und Gewinn fechten. Scibuiz 1670

Securitas publica (I 252) daß darans nothwendig, wo manns nicht verstöret, der Effect folgen müsse.

2. WGiclani XIX 250 ( IN⿴囗十).) beide Stücke hatten den erstaunlichsten effect gethan. (boethe 1787 Irimmph D. Emmfindamfeit (XVII 23) Da muß ich Sie noch ein Kunstwort lehren, mit dem weit zu reichen ist. Scharmant! Allerliebst! das könnten Sie allenfalls auch von einer Florschürze, von einem Hüubchen sagen. Nein, wenn Sie etwas erblicken, es sei was es wolle, sehn Sie es steif an und rufen: Ach was das für einen $E$ f f e e t auf mich macht! - Halten Sic sich aber nur an das Allgeneine: Ach! was das für einen besonderen Effect auf mich macht! Morits 1790 Anton ßeijer $\subseteq .424$ wobei er sich dann immer die wirkliche 
Aufführung des Stücks, und zugleich $d$ e $n$ E f f e e t dachte, den es anf die Znschaner machen würde. Goethe 1796 Sehrjabre (XXII 118) Er sehien hingerissen, uud lanerte auf den Effeet - (183) ihr lebhaftestes Gespräch über den Effect, den man hervorgebracht hatte. Sauff 1826 Memtoiren (V'II 103) das Auge hatte einen Ausdruck, der, wie ein gut angebrachtes Licht auf einem grobschattirten Holzsehnitt, keinen übeln Effect hervorbrachte.

Eĩ̄efthajucrei 尔rentag 1848 Sarjiäbe I 22 denn dem Effect fehlte jede Spur innerer Wahrheit, es war nichts als eine numotivierte E., wie sie keiner von unsern Theaterdichtern wagen würde. $\Re$ obenberg 1856 ßariper

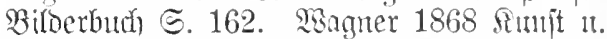
Bolitif (VIII 45). Dafïr re i Fren 1841 Bilber 5.46 ; vgl. auth Brabbe 1835 Theater (IV 4) Effeetmacherei, Localund Zeitanspielungen waren desto mehr.

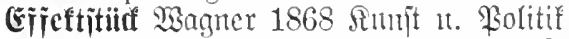
(VIII 94) jene immerhin unvergleichlich besser gemachten französischen Effektstïeke.

cĩ̄ettuoll Boethe 1811 Difft. u. Wahrh. (XXVI 40) in effectvollen Feuersbrünsten [nt. Malcreien]. 5oijmann 1814 Berganzå (I 115) indem sie alles tief Ergreifende der Darstellung auf die effektvollen Anordmungen des Dichters und des Musikers schob.

Sinallerifeft in Der Thenteriprathe um 1800 aufgefommen zur Bezeidumng 1. Der SBirfung Des Fenterverfas. B. Bedjütein 1832 Ronelfen I 78 Der fünfte Akt begann mit seinen Schauerscenen, seinen K.-en und Höllenjubel. Eimenonrf 1854 Bejch. D. Dramaz S. 104 Gelegenheitsstücke, die gewöhnlich mit dem K. eines Fenerwerks abschlossen. - 2. Der

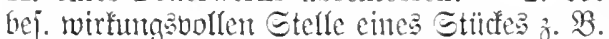
1803 Prolog (= 3 Fo' III 314) Er spielt die Clavigo, die Posa, die Maxe, Ich kriegt' ihn gestern ganz frisch per Axe. Und wemn er nur noch thäte jugendlich brennen! Denn er hat auch erfunden und entdeckt, Was man so nennt den K. Seine 1821 Tajiog Tod (VII 163) je mehr in einem Drama das Streben nach solehem K. sieht- bar wird, desto miserabler ist es -1823 llber ßolen (VII 211) K.-szene.

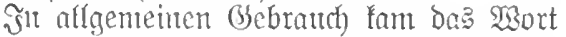
in den 30er sahren: 1. nod wortipielend bei Debrient 1835 Gutiti (I 210) Erstens haben wir uns dann geschossen - Und dieser $\mathrm{K}$. stellt Sie zufrieden? (Bolt 1817 Bud d. Sintheit ङ. 199 die fertige Masse ward erwartungsvoll angezündet; aber von dem verhofften K. nichts in Erfahrung gebracht. 2. allg. 'herborragente Reijtung' Sgelo 1844 Cenjurtana $\subsetneq .113$ als ich gerade mit einem rechten $K$. zeigen wollte, wie servil ich plötzlich auf Befehl geworden sei. Frrentag 1855 coll u. Saben I 232 Du bist mit einem K. ausgetreten. Mafler 1860 Bitberbud 5. 56 so sollte das Examen mit einem K. gesehlossen werden. Gebje 1873 fintor D. জelt I 50 Auch Du warst einmal ein K. der Natur.

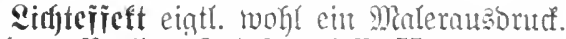
Belege: Bütfler 1835 Eentilajio II 34 der L., welcher die Figur Amors so germndet hervortreten läßt, als sej es eine gemalte Statue - 1840 Billoerjaal II 492 Wir ließen große Feuer anzünden, um uns zu wärmen und an den wunderbaren $I_{s_{0}-e n} z u$ erfreuen - III 177. 5adfländor 1847 俧erfe VI 125. Mar. v. Mexifo 1851 Reben i 67.

Theatercijeft Böne 1829 Iramatura. Blätter (II 342) der ganze Th. berulit darauf, dab sie im letzten Akte aus dem Charakter stirzen. Mrlg. bei Büffler 1810 Bildocianal I 436 Der Mann liebt Th.-e.

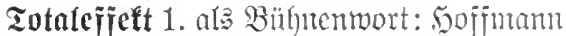
1814 Ireisleriana (I 54) Dekorationen und Maschinen müßten ummerklich in die Dichtung eingreifen, und dureh den Total-Effekt mïßte dann der Zuschaner ganz aus dem Theater heraus in das fantastische Land der Poesie getragen werden. - 2. als Malerwort: ฉ. Richter 1880 Rebenzerimmenumgen 5.159 Stets mahlten sie aus einer gewissen Entfernung, um nur einen Totaleffect, oder wie wir [3um Epott] sagten, einen Knalleffeet zu erreichen.

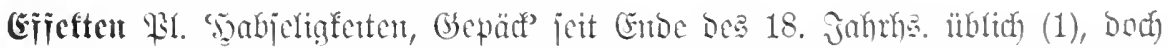
älter für 'Slumpammaren' (Bold v. Mertheim 1711) bezengt (2). Suelle für beibe

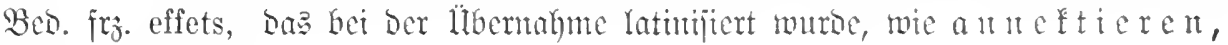
î́ $\mathfrak{q}$ u $\mathfrak{i} \mathfrak{v} \mathfrak{a} \mathfrak{l} \mathfrak{c} u \mathfrak{j}$ u. $\mathfrak{a}$.

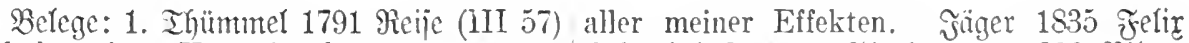
es habe seinen Untereinnehmer angewiesen, Sdutabel 5. 77. Gläbremer 1836 Bilder sich an unsere Effekten zu halten. Sffflano aus :

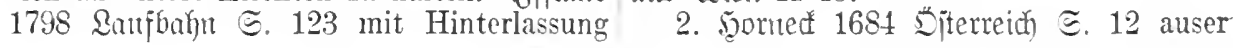


Lands fabricirter Seiden- Woll- und Leinen- manns-Effecten. Marperger 1717 Bejđr. D.

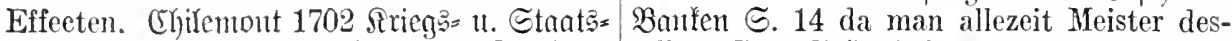
rat 1179 Stihlt ein Dieb in der Kirchen, selben [Des (beloe?] bleibet, und entweder in Herrn-Häußern, Schlößern u. s. w. bringt solehes in natura, oder sonst an guten Efer die alienierte effecten den Juden umb ein fecten in der Hand hat. geringes pretium - 1707 ebo. 1 II 173 Kauff-

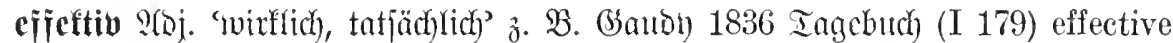
Galgengesichter. Bismaref 1847 Bricfe $\subseteq .71$ in effektiven Zorn. Suter mur abverbierl

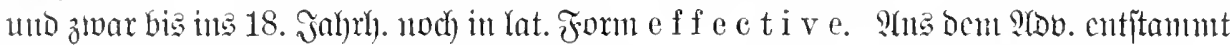

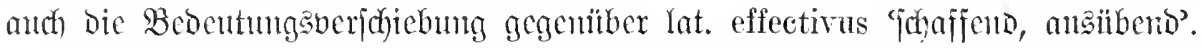

Belege: Mefferjchntio 1618 Barzoni's fective gegenwärtig vnd praesentes seyn. So Sarrenipital ङ. 22 deß Todts, den sie ihme aud bei Etieler 1683 PYubiteur ङ. 360. wïnschen vnd bißweilen effective verschaffen. Thontajtus 1688 Monategejpräche I 134. -

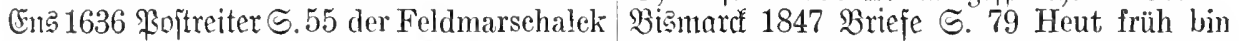
Kniphausen mit 200 effeetive Mußquetieren. ich effectiv hier eingetroffen. Wadhenfujen Mengering 1638 Eoldatenteufel S. 64 Die 1864 Rouge II 138 Diese 100000 Franken so an Offieirern vnd gemeinen Soldaten ef- trug er effeetiv bey sich.

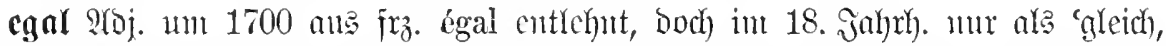

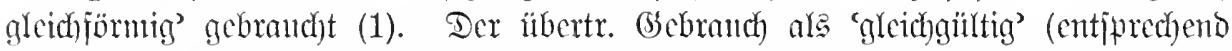
frz. c'est égal) trift crit in 19. Jalyrh. auf (2), ijt aber raju) (jumal voit Berlin und

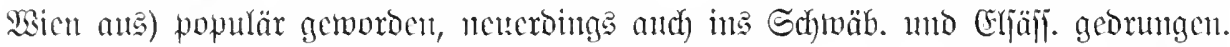

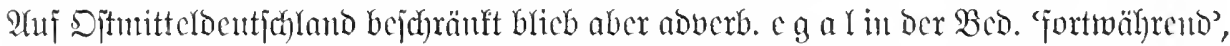

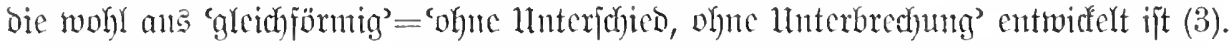

Beleqe: 1. Bercentmener 1712 Sntiqua= rius $\subseteq .576$ Die andere Etage war egal auf-

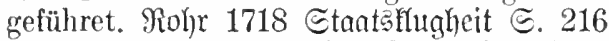
von denen, die sonst einander egal sind S.939 da der Preiß, wemn sieh aie Umstände nicht sonderlich verändern, ziemlich egal ist. Rumig 1719 Iheat. ceremont. I 1227" alle propre und egal in blauen Röcken. $\mathfrak{P}$ itfo

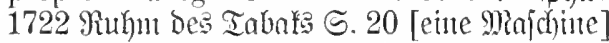
die ihn so ega! schneidet. Bidsactwits 1723 গtarf VI. ङ. 596 die Bürger-Compagnien in ihrer sehönen und egalen Montirung. Lefïitg 1749 orreigeiịt (II 123) Ich wollte jedem zu seinem Rocke egales Futter geben. Mitfler 1787 (Enmerich IV 261 Sie waren schön, egal von Haar. Edjiffer 1796 Brieje V 59 weil es mit dem übrigen Papier nieht egal zu sein braucht. Sffiland 1800 Mam von MEort (III 6) lege Sie alle Fältchen hübsch sauber und egal.
2. Romtant 1833 Sfiterreich I 1 ङ. 81 das ist ganz egal. Schlefier 1835 in \&ewalds Thenterrevue ङ. 4 Ihnen ist eigentlich alles recht, oder egal, wie sie sagen. (Srabbe 1835 Rezcujion (IV 134) daß ihm alles egal seyn wird. Frentag 1855 ธoll 11. 5abest I 269. Fontanc 1861 Sriefe I 115. Etinde 1884 Fant. Budflyolz I 67.

3. Eeit Den 70er Fahren des 19. Fahrbs.

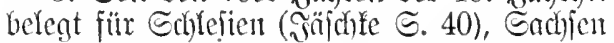
(Mailler= Framenth $\Xi .275^{\mathrm{b}}$ ), Marf Bramben= burg (Mniuller 1878 Der richtige Berlitter $5.11^{\mathrm{b}}$ Ejal weg, hintereinander, immerfort. Stmoe 1884 Fant. Budfyor I 124 Betti ging egal mit Emmi. Fontane 1897 ङted)lin $\Xi .252$ Damn sind wir egal raus); nuch) in Mictfen= burg, Ihüringen mo seffen befant (Ments Fraug. in medlenb. Hilatt I $16^{\mathrm{b}}$ ).

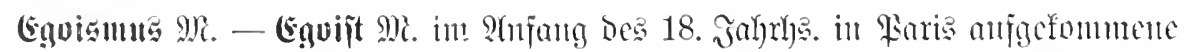

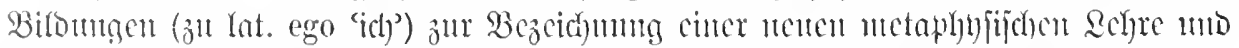

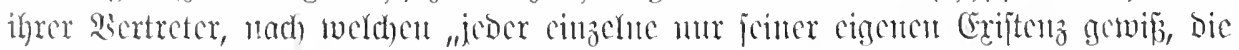

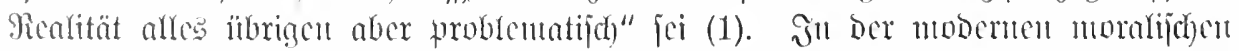

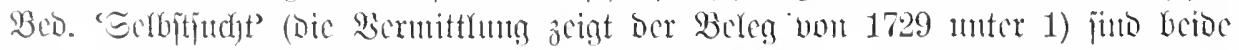

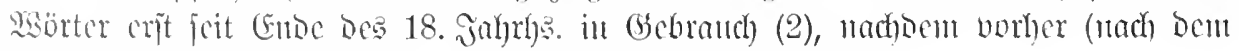

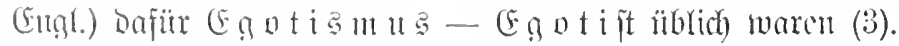


Belege: 1. Mgolf 1721 Gedomfen v. Gott 5. 2 Daher anch dic allerseltsamste Secte der Egoisten, die vor weniger Zeit in Paris entstanden, und von allen Dingen gelengnet, daß sie sind, doeh das Ich bin zugegeben \$orw. 3ur 2. Thufl. G. 4b die Idealisten geben entweder mehr als ein Wesen zu, oder halten sieh für das einige würkliche Wesen: Jene werden Pluralisten, diese hingegen Egoisten genennet. C. M. Tifaff 1722 Oratio de Egoismo, nova philosophica haeresi ( $=$ Mantbuer,

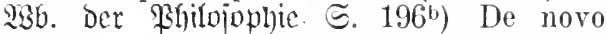
quodam spectro philosophieo, de Eqoismo mudius tertius in Gallia, Anglia et Hybernia nata (nova haeresi) ubi hodie ad vos verba facturus sum ..... nolite mirari aut frontem corrugare ad vocem barbaram, ineonditam atque in hisce aris, in hoc anditorio hactenus inauditam, qua primus egomet jamjam auras vestras pulso. 5ageborn 1729 ß3erjud einiger (sebirfte S. 56 So sieht man jederzeit die neuen $\mathrm{E} g 0$ i s $\mathrm{t}$ e $\mathrm{n}$ Sich in dem süssen Traum der Eigen-Liebe brüsten. Sie rührt kein ander Ding, als nur ihr eignes Ich: Sie finden auf der Welt nichts treflichers denn Sieh.

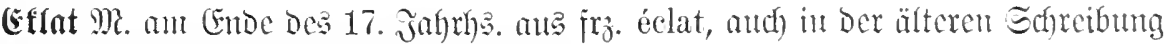
esclat, cutlehut, in folgenton Bcoeutungen:

1. 'plötsliches 2rtabrechen, auabrechendes Berede, Suffeken': 2eibniz 1699 Briefe (II 127) Er besorgte nicht ohne Ursach, dergleichen Conferenz werde Eclat machen, der werde anch Wohlgesinnete alieniren und vor den Kopf stoßen. Sublongfi 1699 an Reibuis (II 130) wie wohl anch dieses incognito und ohne Eclat gesehehen muß. 1737 siüb. Baldober S. 188 damit durch Zeit-Verlust oder andern Eclat die Juden nicht zur Flucht Gelegenheit bekommen möehten. Sernte 1778 Eophiens Reije V 178 Das Eclat wäre dann vermieden worden. Mütller 1787 (Emmerich IV 259 was ein Eclat anch für den unsehuldigsten Mann Entsetzliches haben muß. Buhrot 1790 Rindovinins Il 194 zur Vermeidung alles Eklats. Eifhiller 1798 Briefe V 333 Wir werden beim Anfhören [Der joren] keinen Eelat machen.

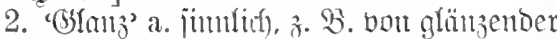
Schöntheit: Rachel 1677 Satir. (Geobichte ऽ. 116 Was hab ich nicht erlitten, O Cloris, dein amour und Schönheit zu erbitten? Weil dein eselat so weit die andern übergeht, Als wenn ein Diamant bey einem Kiesel steht. Bom Sofintuat: 1708 Reopolo ber Brofe I 223 ob nicht Threr Majestät belieb- 2a. Fant 1798 2uthropologie $\Subset .8$ Vom Egoismus. Von dem Tage an, wo der Menseh anfängt, durch Ich zu sprechen, bringt er sein geliebtes Selbst, wo er nur darf, zum Vorschein, und der Egoismus schreitet unaufhaltsam fort. (Goethe 1821 Samberjahre (XXIV 275) Fürwahr, wenn dies auch Egoismus ist, so ist er der liebenswürdigste.

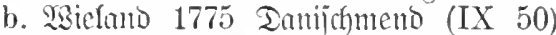
die gute Perisadeh war, mit aller ihrer Zärtliehkeit und Güte des Herzens, eine kleine Egoistin. Thtummel 1791 Reije (I 8) einen größern Egoisten des Unmäßigkeit fand ich nie. Foethe 1792 (3)rofis=cophta (XVII 182) Alle Menschen sind Egoisten.

3. Meier 1744 Jumitriditer $\Subset .119$ Der Egotismus. Dieses Vorurteil ist ein Kind des Hochmuths und der unordentlichen Eigenliebe. Ein Kunstrichter, der von diesem Vorurtheile regiert wird, verachtet alles dasjenige, so er selbst nicht an sich hat, wozl er selbst nicht geschickt ist und was demjenigen widerspricht, so ihm selbst zukommt - Ieh will wetten, daß, wo nicht alle, doch die meisten Kunstrichter Egotisten sind.

ten, etwas mehr eelat bey der Audientz des Ambassadeurs sehen zu lassen. furfüryittin Eopfie 1709 an Trieorich I. (ङ.170) Die Taufe] so Nun noch mer als sunsten mit so ein esclat vor gehett.

b. unfiumlich), von glänzendem 2hiftreten mo sandeln; oft and ironijd) (bej. mit

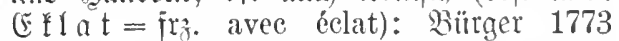
durchzugehen. Richtenberg 1799 5ogarth V 15 am Ende mit Eclat gehenkt werden. giüffler 1835 Eemilaijo II 208 nur haben sie nicht immer Gelegenheit, mit demselben Eelat im Guten wie im Schlimmen aufzutreten. Bedjitein 1836 Reijetuge I 112 das Stück fiel mit großem Eelat durch.

cflatant 2roj. ats fro. eclatant cigtl. 'anß̈rechemo', bant 1. 'muchbar, ?ufjehen

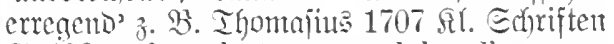
ऽ. 428 mehr eelattanter und kundbarer zu

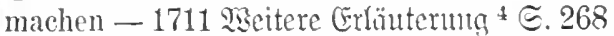

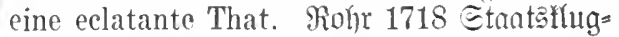
heit $\Im .26$ daß manche MiBstände so eclatant und notorisch sind. Bïrger 1773 Briefe I 140 wo er wieder etwas eclatantes begeht. Bahrot 1791 Zehengejdir. III 393 keinen eklatanten Schurkenstreich. Brieje I 133 Die Sache scheint mit éclat 


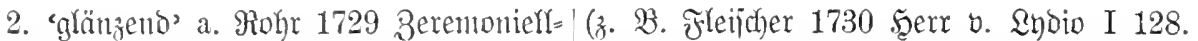

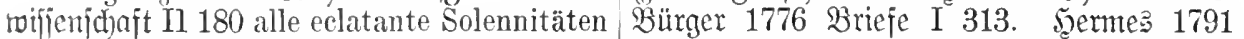
[werben] dabei vermieden.

b. Bürger 1776 Brieje I 284 daß ich dem teütschen Publikum eine eclatante Ehrenerklärung werde thun müssen. Michaelis 1776 Riöjomement IV 85 so eclatante Proben von ihrer Beredsamkeit - 445 einen eclatanten Verlust. (Soethe 1796 Qehriafre (XXIII 50) Der erste Liebhaber ward auf damn auf die eclatanteste Weise widerlegt. eine eclatante Weise ungetreu. Jim 18. Erfenmeyer 18504 Gehinuatrophie $\subseteq .42$ ganz Fafhrf. Gej. aud ,eclatante Satisfaction" eclatant nachgewiesen.

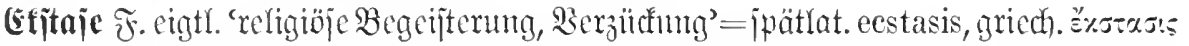

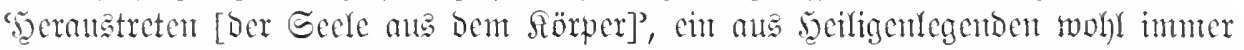

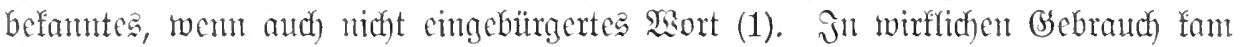

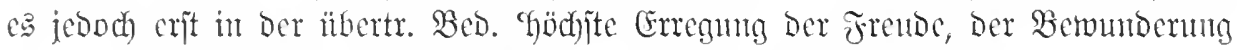

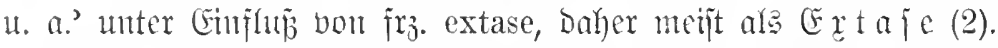

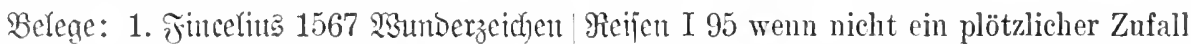
III D $37^{\mathrm{b}}$ Verzückung, welche extasis genannt mich ans dieser empfindsamen Ekstase ge-

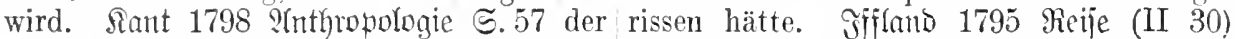
Mensch ist, wie man sagt, außer sich, in mit Extase [Bühnentaneijuna]. Goethe einer Ekstasis, wenn man sich in einer An- 1796 Rehrjahre (XXI 169) mit Ekstase eine schaumg, die nicht die der Sime ist, be- solche neue Erscheinung aufzunchmen. 5antif griffen zu sein glaubt. Seume 1803 Spazier 1826 刃niemoiren (VII 138) in poetischer gang (II 133) den brünstigen Franziskus mit Ekstase.

der heiligen Klara in einer geistlichen cfitationg 9roj. 'begeiftert, verziüft' nach) Ekstase,

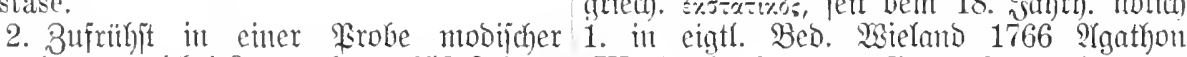
Eprachmengerei bei Qauremberg 1652 Echerg= (IV 166) in dem c.-en Zustande, worin er zu gebichte 厄. 47 De Damen und Signörs all in seyn schien. Serwer 1766 2Berfe I 127 von Extase syn, Wen se considerern juw genereux der e.-en Reise seimes Schwärmers. - 2. maintien. Geläufiger erít jeit Gnde des ïbertragen: Boie 1772 an Bitraer (I 62) 18. Jahrfa.: Echubart 1767 Brieje I 86 ein der e.-e Liebhaber. Echubart 1789 Bater=

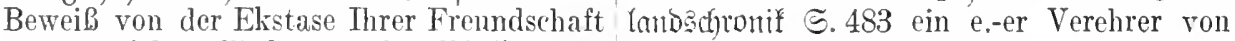
gegen mich. Majüus 1781 Paybitogunn. Gustav Adolph.

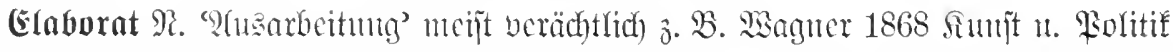
(VIII 63) besondere Schwäche ihrer dramatisehen Elaborate. Ecfjteiu 1876 Eatil. Beitbilscr $\Xi .37$ ein lächerliches Elaborat Eurer Phantasie. Jumge afbleitung (wof)l mad) Diftat: Diftiereu) zu elaboriereu=lat. elaborare 'aubarbciteu',

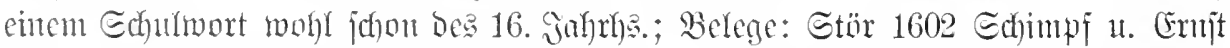

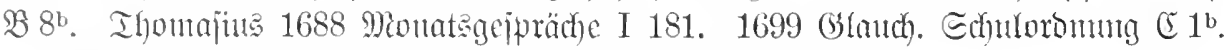

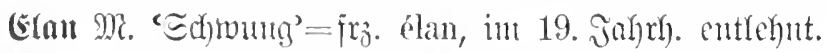

Bgl. Rürfler 1831 Briefe I 263 so über- welcher die schönste Nationaleigenschaft springen sie auch diesen [6rabert, indem der Franzosen ist - 287 da beginnt sich der sie sich auf der Ilöne der Nauer, oder des französisehe ,Elan“ in den Herzen zu Walls, einen neuen élan geben. Eđ̆jerr 1862 rühren.

Bitucher I 280 mit jenem Schwung (élan),

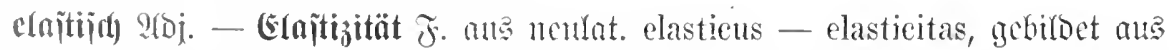

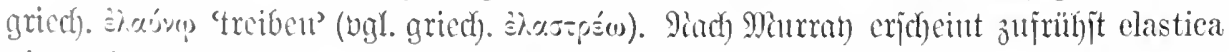
virtus in Recquets Dissertatio Inatonica (1651) jutr Bezcichung Der Ireibfraft 


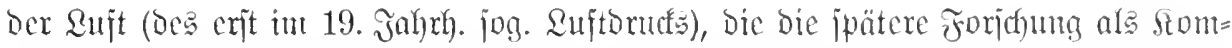

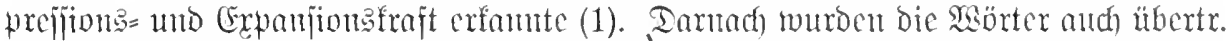

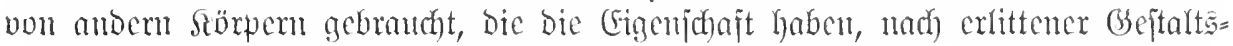

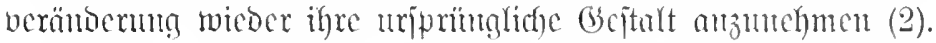

Belege: 1. Edfendhzer 1711 Phtjica II 21 Eigenschaft, so die heutigen Natur-Weise auch ist mit diser Zusammentruekbarkeit Elasticitatem, virtutem Elastieam, Elaterem vereinigt die Elasticitet oder gewaltige Aus- oder Elateriam heissen, da nämlich etwelche dähnkraft der Luft - daß die Elasticitet Cörper so sie getruckt oder gekrümmt werden, oder Treibkraft der Luft zunimmt naeh der alsobald zuruckschnellen - 69 Von der mehreren Schwere des aufliegenden Ge- natürlichen Cörperen Elasticitet, oder wichts - I 24 die elastische Luft.

2. Echeuchzer 1711 Sinnica I 56 Eine schen Dingen, als Uhrfedern. besondere Schnell- oder Treibliraft oder

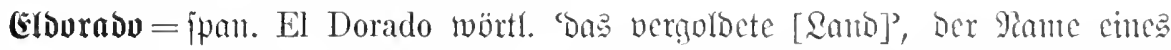

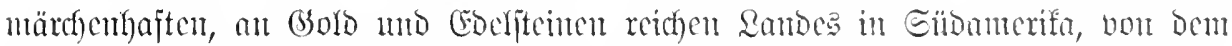
jeit Dem 16. Juhrf. gejabelt worben ijt (1). Jn neuerer Beit wirb Der Mame übertwagen

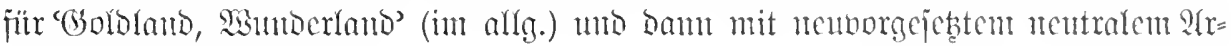
tifel gebraudht (2).

Belege: 1. Siscianto 1782 bejpräche (31, damals vielleicht noch mehr als jetzt das 333) warum wünschen wir nicht lieber gleich E. derjenigen, die in ihrer augenblicklichen mit Einem rroben Zauberwunsche das ganze Lage sich bedrängt fanten. Säger 1835 Geschlecht Adams nach E. oder ins Severam- Terix Edntahel $\Xi .126$ S. sah den neuen

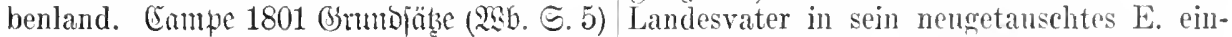
von allen andern Völkern der Erde, gleich ziehen. Bechjtein 1836 Ricijetage I 67 jetzt dem Feenlande E, durch miïbersteigliche thut sich das E. der schönsten Aussichten Vormauern abgesondert.

2. Edhuffer 1804 Etutzinoc II 135 da durfte anch ich wohl einen verstohlenen bleibts ein Traum, wie Plato's E. BSoethe Blick in jenes mir sonst verriegelte E. Dichtung 4. salyr). $(29,156)$ Amerika war werfen.

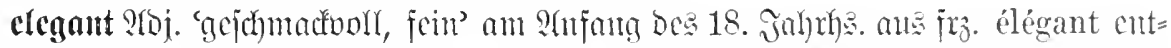

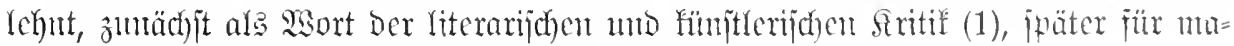
terielle Rorffommentheit bej. Der Sleibung (2).

Bclege: 1. bon Rerjonen: 'jeingebildot'. nicht eleganter denken kann. Groetbe 1792

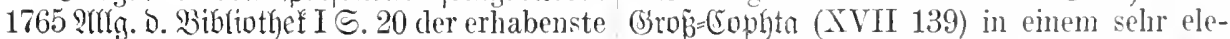
und eleganteste unter allen Rednern. $\Omega(a=$ ganten Frack. Richtenberg 1798 jogarth IV 93

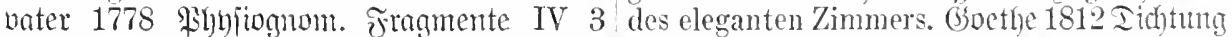
sein eleganter Geschmack. Erfiłfer 1797 u. Małhrheit $(27,154)$ die Möbeh, elegant Bricje V 275 von einem sehr eleganten ohne Ziererei. Sonff 1826 Miemoircu (VII 6) französischen Sehriftsteller.

2. von Probnftionen: 'Formbollentiet, zier=

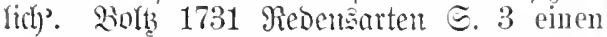
eleganten Stylum und Schreibart acquiriren. Edfutio 1775 Ehronologie $\subseteq .101$ der eleganten Sprache der Franzosen. F(thent= Golz 1.787 Englano I 80 das eleganteste Produkt der englisehen Prose. Baylrot 1791 Rebensejchr. III 84 Sein Brief war minder elegant. Miener 1799 Rajael (E. 222) es kam wirklieh nicht zu den elegantesten in Rafaels Werken gezählt werden.

2. Sovie 1777 an Bïrger (ङ. S3) ein Sommerhans, das man nicht lachender, (bebraudf non Eleganz, Der vielntefr 


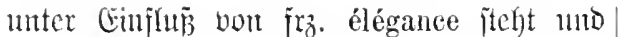
Die gleidhen Ilnterichiede wie ong $\mathfrak{r o j}_{\text {. }}$ anf $=$ weift: 1. Siterarifa). Duj(h) 1764 Briefe I 82 in der E. seiner Sclreibart - 142 Die E., die nette Sprache und der leichte Vers sind seine größten Schönheiten. 1765 Vulg. D. Bibliothat I 1 S.21. Ridhtenberg 1795 5ogarth II 307 mit E. demonstriren.

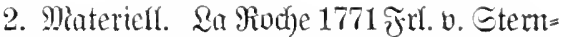
yeim $\subseteq .124$ mit aller der E., die, wie du weist, mir eigen ist. $\mathfrak{A}$ rof entyoly 1787 (Eng= land II 213 mit E. und nach der neuesten Mode gekleidet. Forjter 1791 inficiten (III 117) Französische E. in den Kleidungen. Edfleger 1802 פorlejungen I 202 E. der Formen und harmonisehe Anordnung.

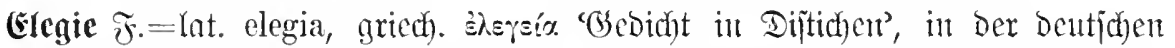

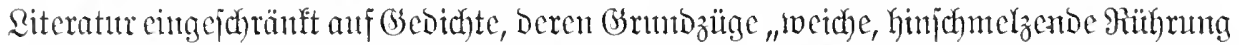

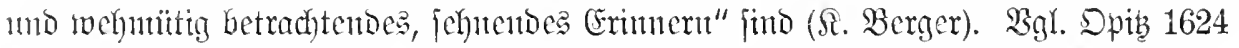

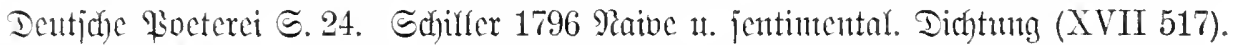

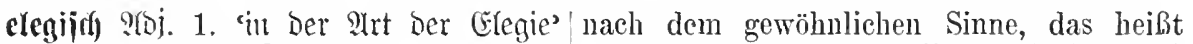
Serber 1767 Deutjche Riteratur (I 480) sonst in erbärmlichen angetroffen. Ġaubn 1839 kann die Poesie Bildervoll und tiefsinnig, Batr. Felfuterin (V 186) Das Mädchen schütaber ganz und gar nicht Elegisch werden. telte elegisch den Lockenkopf. Golk 1847

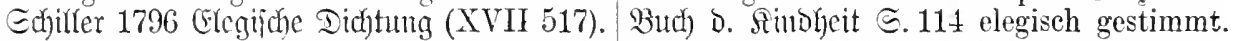

2. ïbertr. 'mehmuitig, traurig' bgl. Gbethe Frebtag 1866 2ufjäbe I 318 ein leiser, ele1795 Brieje $(X$ 255) Die Sendung der gischer Zug.

Elegien hat mich in elegischen Umständen

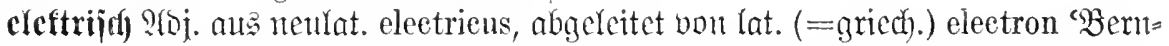

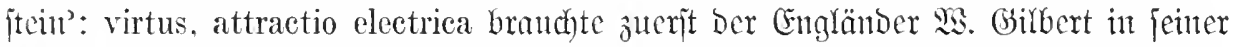
Echrift De Magnete (1600) mit Bezug auf 巨toffe wie Gifas, Sicgellad, an Donten er bie gleidhe Sraft, leidhte Sörper anzuziehen, entbedft hatte, Die bor ifun unr vom Bern=

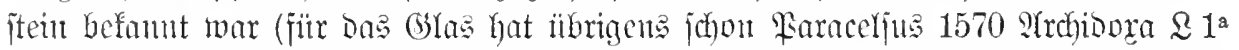

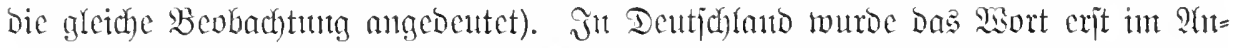

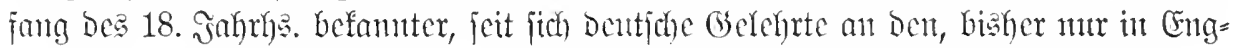

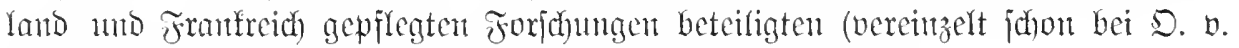
Ginerife 1672 Experimenta Nova $\Xi .136$ Eleetrica Attractio).

\$gl. 1744 PGilojoph. Iluterjudfungen|ङ.5 So einem solchen Körper die durch

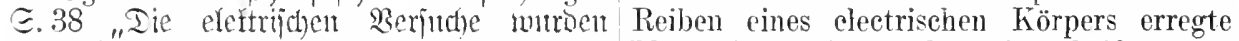
cigentfich in Dentjchlano erft int jahre 1734 Electricität mitgetheilet wird, heißet man Durch bie Miscellanea Berolinensinm befount. ihn electrisirt. Danten anjantg aud

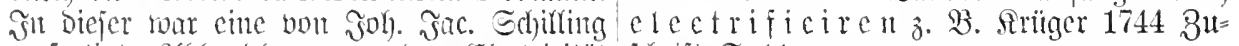

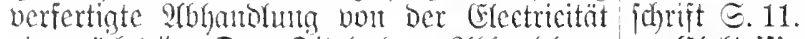

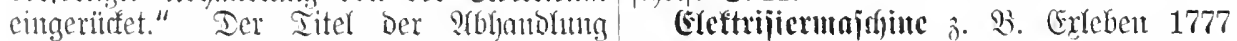
lantete: Joh. Jae. Sehillingii Observationes Anfangagrïnoe D. Ihaturlefre @. 390; Sdjifler et Experimenta de vi electrica vitri alio- 1789 Geijterjeber (XIII 127). Dnjür bei rumque corporum (Mise. Berol. IV 334). Wintufler 1744 Gebanfen b. D. Electricität

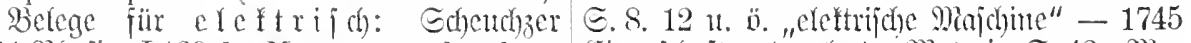

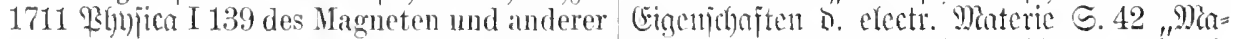
"lectrischen Cörpern Anzeuch-Kraft. 1734 johine zum Electrifiren" - Bl. b1 "electri= Beolor V1II 708 Electrische Krafft -713 Electrische Körper. Sirïger 1744 Butichrif̣t ङ.10 Wir nennen einen Cörper electrisch, der entweder durch reiben, oder dureh Annäherung eines Cörpers, den man gerieben hat, in den Stand gesetzt werden kill, andere Cörper an sich zu zichem, oder von - sich zu stossen.

fircube Miajofine".

Eleftrijität ate nettlat. electricitas (Echil=

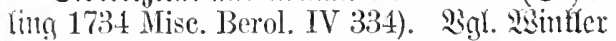
1744 Gebanten G.7 Indem num das Glas und viele andere Körper mit dem Electro darinneı übereinkommen, das sich durch das Reiben eine. Wirkmor an ihnen crregen lässet, wodiurch leichte Sachen sowohl an eleftrijicren nach fry. électriser bei Gboron sie anfliegen, als anch von ihnen weggestossen 1744 Sicrinch e. Erflümutg ber Celectricität werden: so hat man diese Bewegnng die 
Electrieität, und einen Körper, an welchem tripartitum bamit die 'magnetijche fraft be?

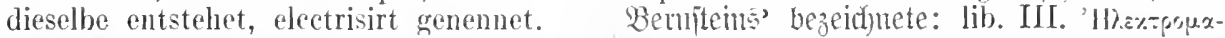

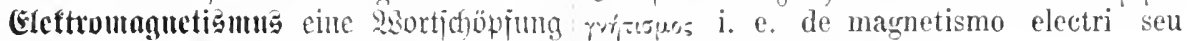
Deg ?(th)anajin Sircher, ber $16 \pm 1$ in jeiner electricis attractionibus.

Schrift Magnes seu de arte magnetica opus

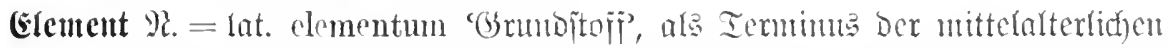
Taturlefre jobon in 13. Johrh. cingebïrgert (bej. die vier elemente). Biel päter

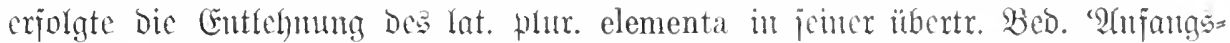

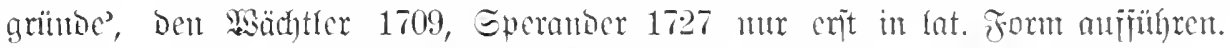
Belege: Shiller 1787 Dou harlog (V 212) Die Elemente der Honarchenkunst. Scinje 1794 Şildegaro (V 56) Die ersten Elemente dieser Kunst. Gulcichzeitig

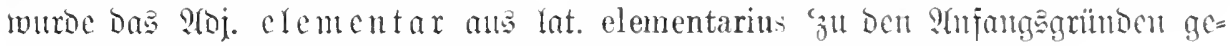
hörig' entlehut unb bej. in 3ujammenjebunges gebrand)t.

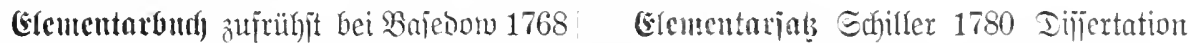
Boritellung an MJenjchenfreunde $\$ 55$ Ein E., (XVII 115 Alle Anstalten scheinen sich zuein Abc-Buch der realen und nominalen letzt in den Elementarsatz zu rereinigen.

menschliehen Erkenntnis, ein Werk, dessen Elementarifunle Pormam 1833 Siter= Vorstellung bisher sogar fehlt. $23 e$ itere $\mathfrak{B} e=$ reich I 2 S. 43. Frentag 1855 Eoll u. 5jaben

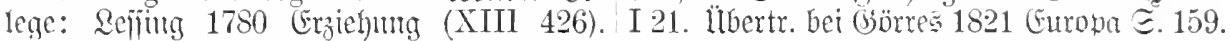

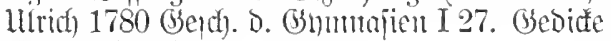
1789 Eduljutrifter I 121.

Elementarunterridht Gedide 1789 छchul=

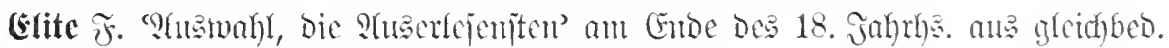

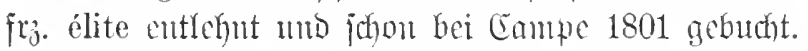

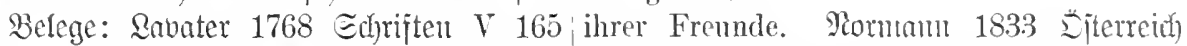
der E. des ganzen Menschengeschlechts. I 1 こ. 125 die E. des Corps. 5erwegh 1839

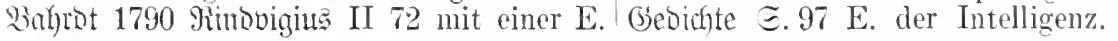

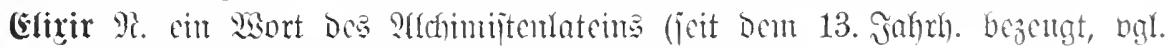

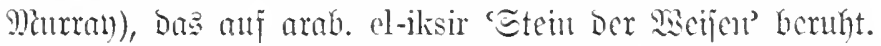

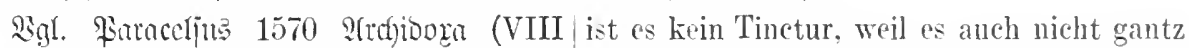
De Elixiris) $24^{2}$ ein Elixir ist ein inwendig feist vnd obschwimbt, ist es kein Oel, Derbehalterin des leibs inn seinem wesen, wie halben aber, daß es nicht klar, schön, durches denn begreifft: Als ein Balsam ein auß- sichtig, vnd lautter wirdt, so ist es auch wendiger behalter ist aller Cörper vor aller kein Essentz, dieweil es aber das mittel feulung. Thurnenjier 1578 sijtoria 5.42 zwischen dem Oel. rnd der Essentz. auch Es seindt aber solche Elixir nichts anders, von wegen seiner ticke oder truebe, Welche dann wie wir hienornen von den Essentzen, im ein Colur macht, ein mittel zwischen Olien, Tincturen, rnd dergleichen Extractio- der Tinctur vund der Essentz ist, rnd mer nen geredt haben, allein ist dises der vnder- einem Liquori, dam neischwas anderem scheidt, daß weil das Elixir kein sunderliche gleich, heissen wir dises ein Elixir.

farb von dem dorauß es gezogen, behelt,

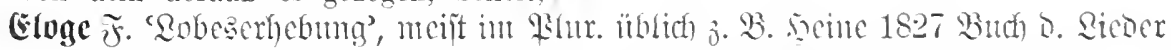

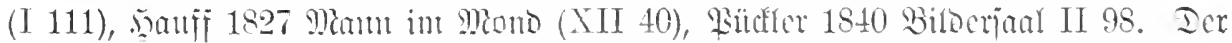

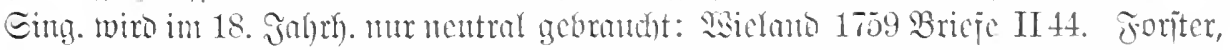

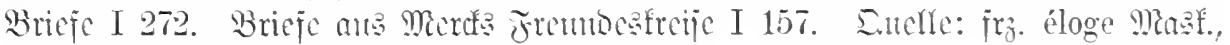
ncben bem lat. elogium, enlogium cingervinft bat (ältere Excmbrobb. buchen Elogium

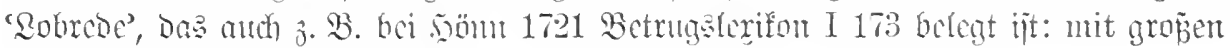
Elogiis - unverdiente Elogia.

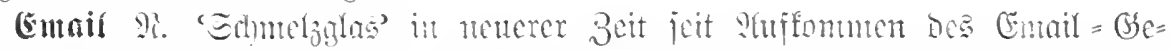

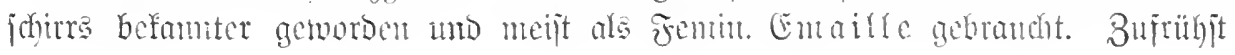




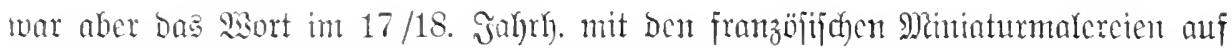

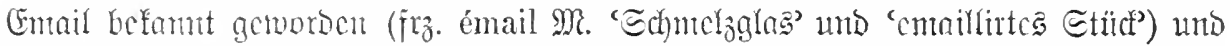
Em a il bezeidunet bayer bas cinzelne 'Echntelzglos' (Epcramber 1727) ober über=

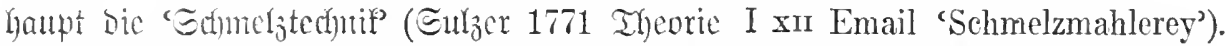

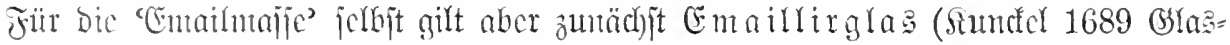

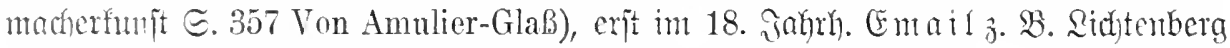
1795 sogarth II 78 wie aus Email geschmolzen. Belege für E ut a ill $\mathbb{c}$ : Eufiller 1787 Gsifterjcher (XIII 134) das Porträt eines Offiziers in Emaille; vgl, auch bic $B C=$ mcrfung Gocthes zu Joham fiutcl (XII ${ }^{2} 151$ ) Das sechste Buch trägt num die Bereitung des Schmelzwerks, neuerlich Emaille genannt, deutlich vor.

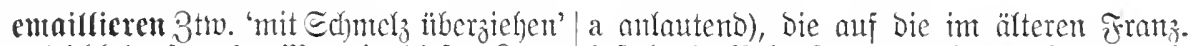

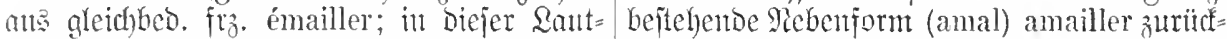

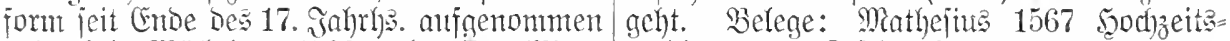
tmo bei

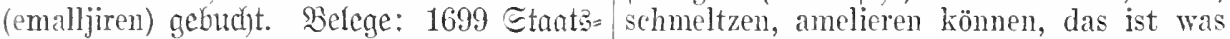
ipiegel II 72 roth emallirten Lilien. 1708 sonders $-\underset{\Im}{ } \mathbf{S} 186$ die cappe am corpns

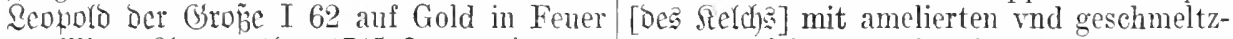
emaillirt. 2(ntaranthes 1715 Frattentmuner $=$ ten angesichten rnd schönen gesprengen. lexifon હ. 250 einen schwartz von Gold Taue 1648 Origines populi Romani 5.26 a emailirten verzogenen Nahmen ['Monto = blaue ammolirte Bruststücke - 3wijchen= aramm'] - ङ. 1403 mit weif emaillirten ipiel ङ.30 ef sind eitell VergiBmeinnicht Buchstaben. Fohr 1729 Berentonielímijent= dranff [auf Dem Ring] amulirt. Freiberger jhaft II 314 einen auf das zicrlichste email- 1656 \{olit. Disfurje 2.666 nach den natürlirten Hamiseh. Ramler 1757 an GSleint lichen Farben amaillirt. Suntfel 1689 (6) ala II 309 emaillirte Dosen. Eutzer 1774 macherfunit ङ. 133 zn dicken amulieren oder Iheorie II $735^{\text {a }}$ die Schmelzmahlerey oder Schmelz-Wereken. Ettner 1697 Chnnicus das Emailliren. (Socthe 1775 2madis I 14) $\Subset .519$ Ich habe in amuliren was sonderliches Rings mit Sonnenschein War sie emaillirt. erfunden. 1734 Bebler VIII 978 Emalliren Mällfer 1789 (Enmterich) VI 235 cine sehr ist eine Arbeit der Mahlerey, welehe auch schöne goldne Uhr mit seinem emaillirten amuliren genennet wird. 1737 fiild. Baroofer Bildnisse.

Ecit Dem 16. bis in 18. Fahrif. gilt aber

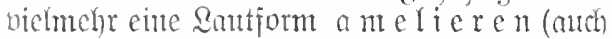
mit $u, 0$, a, wi in Der 2. Eilbe, Dod) ftets mit

ङ. 514 drei ammalirte Ringe.

CEntoifutaferei Eulzer 1774 Ibeoric II 1035 Die Selmelzmahleres, die man auch insgemcin Emailmahlerey nemnt.

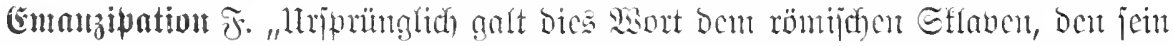

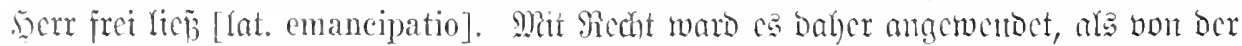

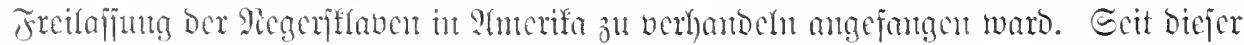

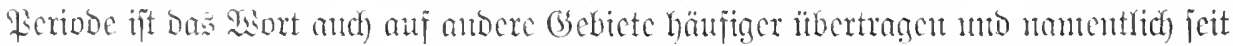
Der franjöjifhen Julirebolution ju cinent jester biclocutigen Mobenörter getworben,

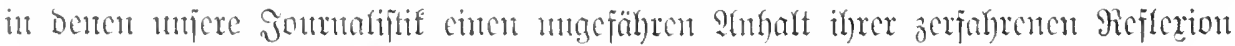

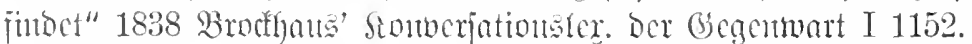

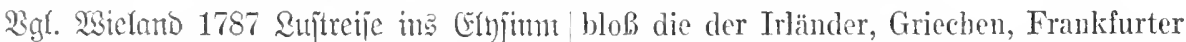
(32, 428) Immerwährende Terwirmung, Jnden, westindischen Schwarzen und derAnarchie und Rückfall in die alte Wildheit gleichen gedrückten Volkes, sondern es ist würde die unausbleibliche Folge einer E. die E. der ganzen Welt, absonderlich Europas, desselben [se. cines Boffes] sein. Görres das mündig geworden ist und sich jetzt los1819 Ientjolano ๔.94 wie an den Bestand reibt ron dem eisemen Gängelbande der Beder Liberalen in Frankreich zum Theil die vorrechteten; der Aristokratie. Gauby 1836 F. Teutschlands geknïpft ist. Sche 1830 Iagebuch I 203) aber wir leben in den ZeitĜtalien (III 275) Was ist aber die grobe Auf- alter der E., wo alle Barrieren und Vorurtheile gabe unserer Zeit? Es ist die E. Nicht über den Hanfen gerannt werden. 


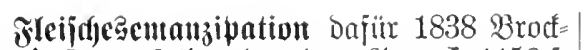
hau' Sonwerjationster. Der Ben. I 1152 F.

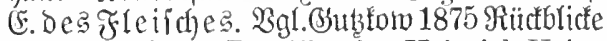
(XI 155) einem Begriffe, den Heinrich Heine von Frankreich herüber in die Literatır der Deutschen geschlendert hatte, dem Wort von der "E. des Fleisehes".

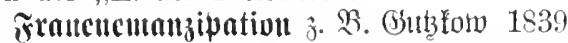
Bergangentheit (XII 86); we i ber $=$ (E.: Fren 1844 Bilder S. 334. Dodh älter john E. Der Fra u en (als Titel einer momment Echrift "über Die E. Der Frauen. Ein wohgemeintes

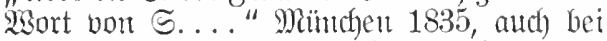
Remalo 1836 2qquarelle I 55, (jumtínom 1836

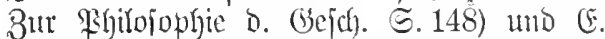
Der tur IV 265), Die Da: frz. l'affranchissement de la femme wiebcrgeben, Das Rojunganort Der feit 1831 vierbejprodjenten Eamt=Eimt=

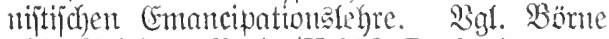
1831 Brieje a. Paris (V 328) Doch einen andern Grundsatz sprechen die Simonisten deutlich aus: den der E. der Weiber. - Jin Deutichen hat fpäter auch einfaches (E ma $\mathfrak{n}=$

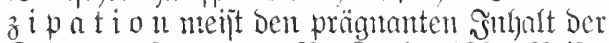
Bujammenjebung o. $\mathfrak{3}$. Saube 1837 Reije= novellen VI 203 Die Dame des Hauses hat Zeit und Lnst, ästhetisch zol sein und von E. zu sprechen. Debrient 1837 Berirmutgen (II 34) die große E.-Frage. 5eine 1854 Rutezin (VI 163) die Weiber, selbst die emanzipationssiiehtigen.

כubencunajipation bon Rabendorf jert 1834 belegt, häufiger (E. D e r Ĩ D e u ž. $\mathfrak{B}$. Börne 1833 Bricfe a. PHis (V 292). Den

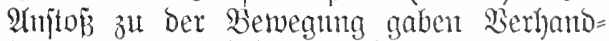
lungen im englifden Parlament, über bie Das Stuttgarter Morgenblatt fichon 1830 einen Beridht bradyte (ङ.592DieE. der Jnden).

Satholifencutanjipation Dafiir bet seinte 1830 startien (III 270) fathorif che E. und fdjou 1815 bet Brodffans III 3365 ff. E. Dereatyolifen, fete nit Bezteyung auf Die Freihcit:abitrebungen Der Fatholifen in ?̧rland, Die 1829 in ber Catholic Emancipation Act ifr Biel erreidjten.

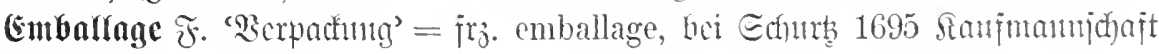
(MSG.) gebuct)t.

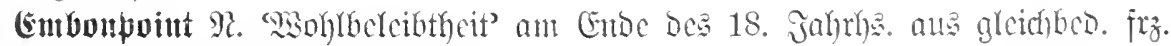
embonpoint (16. Jahrl).) cutlchnt.

Belege: Mieiter 1783 Jfieg. Blätter $\Subset .162$ das bleiche E. der Xiederländeriunen. Rich)= bey wieder erlangtem E. Sffrmo 1785 tenberg 1795 segarth II 260 den E. eines Miübel (X 244) ich bin ganz untröstbar Rat d'Eglise. Senzel=Eterntau 1806 (je= über mein E. Miüller 1789 Conmeridy V 24 ipräche II 255 fremdes E. macht ihn imme dem das deutsche Brodt zu einen nicht mager. unebnen $\mathrm{E}$. verbolfen hatte - VII 187

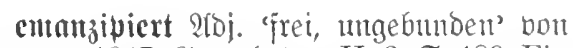
Fraucu: 1847 Grenzboten II 3 $\subseteq .189$ Ein Wesen, das sich die Haare kurz schneitlet, das Cigarren raucht, Männerkleider anlegt und sonst nachlässig, geschmacklos und verstört in ihrem AuBeren anzusehen ist - dis nennt man eine 'emancipierte Frau'. Riegl 1848 Eijele $\Xi .35$ keine e.-e Dame. 顸gge 1851 Logt $v$. Enlt હ. 174 sogenannte enancipierte Frauen. Bum 3tw. e manz $i=$ piereu, bas, aus lat. emancipare "ants der väterlichen Gewalt geben' entlebut, jeit Dem 17. Sal)rh. fïr 'befreien' in allg. gebraudht (1), aber jeit 1830 im Eimme Des Degriffo $\widetilde{f}$ a $u=$ cue ma uzipatiou (j. o.) emgejdränft tourde (2).

Belege: 1. Eecfentoriff 1685 Egriftenfitant I 24 sich von solehem Zwang [Der Religion] sehr weißlich und muthig frey gemacht und enancipiret. Reibniz 1699 Briefe (II 126) und würde ich mich nimmermehr soweit emancipiret haben. Mojer 1767 Retiquien ธ.328 Man wird dureh zwo Wege von seinem Vaterland emancipirt, durch eine fremde Erziehming und dureh die Verwandlung der Denkungsart. WBielono 1792 গ2. t. Merfur I 24 und nun auf einmal emanzipierter Sklave.

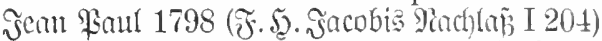
mein Selbst-Emanzipieren von allen Doktorhiiten. Göprres 1819 Teutidtlando $\Subset .80$ der kleme Krieg der sich emanzipierenden Zeit (VI 120) daß er sich ron dem Bann, welcher die gesammite Reisecompagnie umstrickt hielt, zu emancipiren wagte.

2. Guthtom 1839 Bergangentyeit (XII 8;) Nundt wollte einen Bund stiften, in welchem die Frauen emancipiert würden. Fren 1844 Bilber ๔. 333 die Franter] sollen auch bürgerlich und politisch mit den Hännern gleichgestellt, d. h. sie sollen eman-

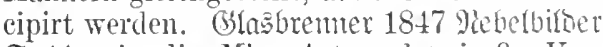
ভ. 11 wie die Mies Aston det jroße Verbrechen bejeht, det se sich emancipirt hat. Was heebt denn des? - Emaneipiren? Des heeßt Cigarren rooehen m Hosen tragen. 


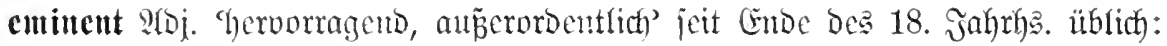
latiuijiert aus $f r z$. éminent.

Belege: Inigge 1788 Unngang $\subseteq .322$ fast immer nur unterwärts zu sehen haben. wenn in unsern Schauspielen eminentes Riditentherg 1794 Sjogarth I 151 die eminente Laster in Glanz und Hoheit auftritt. Mä̈lfer Trockenheit des Subjects. Sdhlegel 1801 1789 Emmerich V 118 die eminenten Wesen, Borlejungen I 30 in einem eminenten Grade. die, weil über ihnen schwerlich etwas steht,

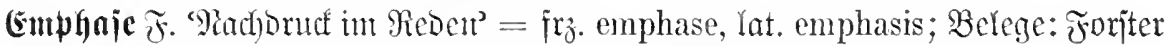

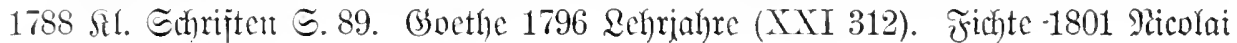
(VIII 41). Qifter ijt

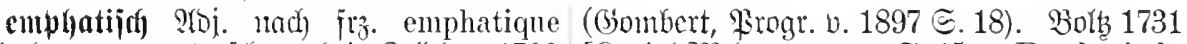

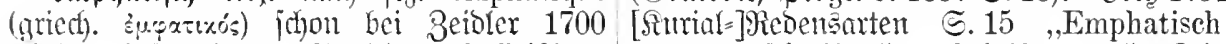
Eieben bojle Greijter ङ. 105 so befleifigen etwos bejdreiben". Edjeibe 1745 forit. sie sich einer gantz gravitätischen, patheti- Miujifus 5.271 der Sänger aber soll auf eine schen und emphatischen Aussprache, nur heftige und emphatische Art mehr reden, daß sie die Emphases nicht recht anbringen als singen.

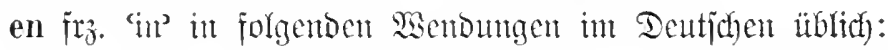

en bloc eigtr. beim $\mathfrak{B e r f i n u f ~ ' i m ~ S ̧ a u j e n , ~ s i c h ~ m e h r ~ a u f ~ d e n ~ H a n d e l ~ i n s ~ g r o s ~ a l s ~ e n ~}$ im (Banjen', bei un in Der parlamentarifhen detail legen.

Sprache 'in Batich u. Bogen' (.5ebje $\left.e^{5} 1829\right)$ D. h. ohne Detaildebatte; bgl. Bisntaref 1851 Briefe G.247 Das Strafrecht wird wahrscheinlich en bloc in Einer Sitzung angenommen werden.

en détail $j$. minter Detail.

en face 'von vorm' (im mobermen Framy. Dafür vielmergr de face 3 . $\mathfrak{B}$. un portrait de face, être posé de face). Belege: Brum 1800 Edriften III 265 En Face erblickt, scheint die Last der Schultern zu drücken - 1801 c6㔾. IV 329 En Fâce finden die neapolitanischen Weiberaugen unter jeder Vermummung Gnade. Ftobebte 1802 ftcin= jtäbter (XV 72) die aus den Fenstem Schanenden [müjjen] von den Zuschanern en face gesehen werden. Grobbe 1835 Theater (IV 26) und man hatte den sämtliehen Hof en face, nicht seine zugewendeten Rücken. en famille Bafled 1791 Reberifhejchr. IV 231 Wir speißten en fanille. Tevrient 1839 Fabrifant (II 250) wer wird sich denn en famille geniren. Bisnard 1851 Bricje E. 276 Ich kamn mich anch hier nicht wohl eher en famille cinrichten, ehe ich meine zukünftige Stellung kenne.

en gros 'im groben' 1. als frammamistuort

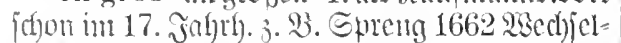
praftif $\Xi .9$ denen, so engros und in ferne Land handeln. Eibuts 1695 Stamimamidaft (isb.), En grob, im Gropi, das ift Ballen voer Tan tweig". Etoppe 1728 (bebidyte I 61

- Wer nicht en gros Verkehrung hat, Der. wuchert billig in dem Kleinen. Iafiix, ins gros" Mankerger 1711 Bejar. D. Meffer I 74 cincil Luther en miniature. Qewalo 1836

2. 9rlgemein: Bhilippi 1743 Reimidyiede= fumjt $こ .216$ weil er eine Fertigkeit besitzen mïBte, alle Universalköpfe en gros zu überschauen. Bsothe 1795 Jünitlers Fug (II 193) Wic man den Menschen demn selbst nicht scharf, Und nur en gros betrachten darf. sitt v. Döring 1828 Fragmente III 38 er trieb sein Bhuthandwerk en gras. F̈̈ger 1835 Felix ভanabel ङ. 169 Dies murde im Sommer en gros betrieben.

en masse 'in Mienge' fäger 1835 Felix Edinabel Є. 198 die gebildeten Musensöhne wagten es doch, en masse Attentate auf die Tranben zu machen. Dicjterweg 1836 Rebengfragen こ. 64 Die Herren Commilitonen werden en masse citirt, en masse eingeschrieben.

en miniature 'in Der SYrt ber flein= und

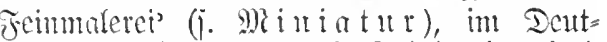
ichen jeit 9utung Des 18. Falyrhs. in eigtl. Eime itblich (1), frith aber and inberti. ge= brandst (2). Belegre: 1. Mohr 1728 Zere= montiellwifjertichajt I 534 bey uns sind aber die Brustbilder, oder die kleinen en mignature gemahlten mehr in Gebrameh. Rigilipwi 1743 Geimjumiedefunt $\Xi .140$ So mühsam es nun ist, etwas in mignature zu zeichnen. EDel= mann 1752 Eelbjtbiogr. S. 217 daB er mich hernach en miniature mahlen kunte.

2. E(f)ünaich 1754 Yejthetif S. 10 MeBiaden en mignature. meifter 1783 Flieg. Blätter ङ. 16 Unterwegs sah ich von der Anhöhe anf das Klöstergen hinunter, ganz en Mignature. Witt v. Dörtity 1830 Fragmente I 12 
Aquarelle I 224 Tempel en miniature. Dafür zugesendet haben. Edjiller 1784 Jabale (IV

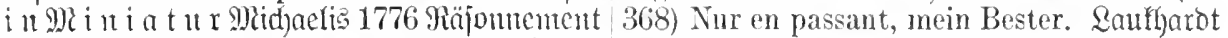
IV 627 der Kaufmamn in Miniature. Echlegel 1810 Eteins atbentener II 240 Neugierige, 1801 Borlejungen I 155 die Münzen sind welehe so en passant kamen.

historische Monumente in Miniatur.

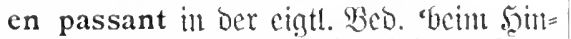

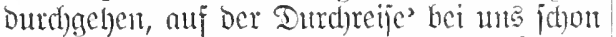
int 17. Jahrł). geläufig (1), im 19. Jahth). auch iibertr. als 'voritbergehend, flüd)tig' ge= braudyt (2). Betege: 1. Wirfen 1669 Brandent=

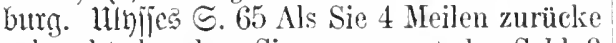
gebraeht, besahen sie en passent das Schlob Verger. Thomajus 1688 Monatsgejpräche I $1 \mathrm{cr}$ mollte] bey dieser Gelegenheit nur in Leipzig sich ein wenig en passant aufhalten. ア̊önig Friedrich I. 1706 Sricje E. 94 Ich werde en passent durch Rehnen in dero Hause logieren - 1711 cho. $5.251 \mathrm{Es}$ ist nuhn die beste zeit zu Reisen, möchte wïnschen, daß Ich daß glück hätte haben können, E. Ch. D. en passant die hände zu küßen. Callenbad) 1714 Eclities Є. 69 en passant wird sie mit ihrer Chaise still halten. Jieifacr 1731 \&ndio II 266 andere Curiosa des Landes mehr, die uns so en passant vorfielen. Bürger 1772 Bricje I 74 Neülich soll
ein fremder Herr mir en passant einen Gruß

Energie F. 'Iathraft' erit am Gmbe Des 18. Jahrha. aus frz. énergie cutlehut; bgl. (5ombert, Bciträgc (1908) E. 10.

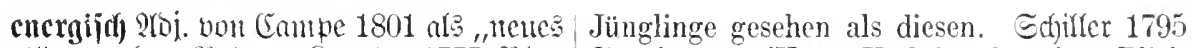
Sort" gebud)t. Belcae: Zavater 1777 Phy= Epajiergang (II 41) Und den durstigen Blick jiognom. Frngmente III 156 Ich habe noch labt das energische Licht. wenig edlere, wenig Genievollere, energischere

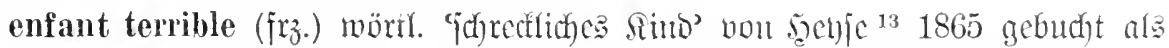

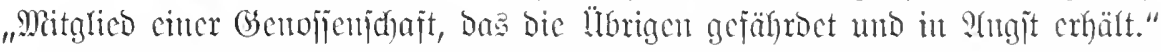

Belcge: Edüufing 1863 rfftiengej. II 45 Sie wurde im vollsten Sinne das enfant terdiesc vorwitzige Bemerkung des enfant rible des Hauses. Fontane 1876 Prieje I 235 terrible. Ranbe 1864 Sgungerpaftor $\odot .199$ sich als Familien-Enfant-terrible aufzuspielen.

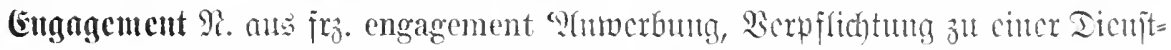

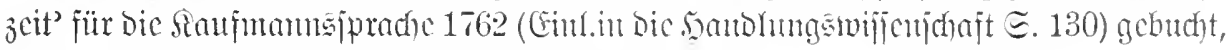
Dancben bej. von Edhampictern gebrancht.

Belege: 2eijing 1776 Bricje (XVIII 207) Die Theatral-Commission hat nehmlich einfliessen lassen, daß das E. nicht länger als bis Ostern 1777 danern soll. Echiller 1783 Briefe I 151 den ersten Schritt zu einem E. Q(rechenthorz 1787 Stalien I 98 Schanspieler die E.-s suchen. Whorik 1790 Q(nton Sicier S. 374 ans seinem E. beim Theater. (Gocthe 1796 Rehriafre (XXII 121) Hoffnung zum E. Sfiflam 1798 Theatral. Sambahn હ. 40. 78. 103.

cugagicren 3 tw. aug frz. engager cigtt. 'in Eord nehmen', Dam 'verpflichten' (1):
Dancben anth) refiex. (3sebraud) mit Der Bed. 'Werpflichtungen übernehmen, gebunden jeir" (2). Belege: 1 a. 2ulla. Cettuer 1697 Ioftor こ. 780 mm bin ich bey dem Durchlauchtigsten Fürsten von Rautenkrantz engagirt. Edfith 1789 an Bitirger (III 220) wenn man ihn als einen Nothknecht engagiren würde. b. an Iheater: Edhmid 1755 Ehronologic ๖. D. Theaters こ. 310 ङ. 310 Herr Hübler ward zu konischen Opern engagirt. midcha= ch 1776 Riojontument IV 486 die des Winters anderwärts engagirten Comödianten. Moris 1790 ?utnon Reijer $\Xi .373$ iln für das Theater 
zn engagiren. Gnethe 1796 Rehrjahre (XXII 75 daß jener sieh bey den Kayser, dieser aber 122). Jifland 1798 \&anfbahn S. 40. 77. 80. bey Frankreieh sich allzusehr engagirt habe. e. beim Innze: Raube 1837 Reijenonellen Bahrot 1791 Rebensbejur. III 270 ein $\mathfrak{B e}=$ VI 55 die Bergen ward eben engagirt. (5anony bienter] der auf ein Jahr sieh bei mir enga1839 Farig (YT 134) ich bin bereits zum girte. ersten Walzer und Cotillon mit Alwinen b. Sdumio 1795 Chronologie o. o. Tfye= engagirt.

2 a. Thoulafus 1688 Montatigeipräde I auf ein ganzes Jahr engagirte.

en gros j. unter e n.

en masse i. unter e $n$.

en miniature $\uparrow$. unter e $n$.

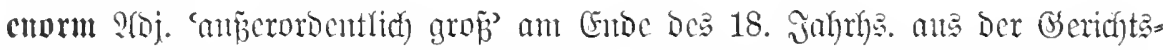

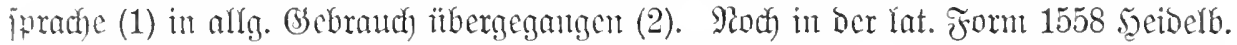
Statuten $\odot .165$ Da aber einer solch enorme facinus und laster begangen; wie fajon

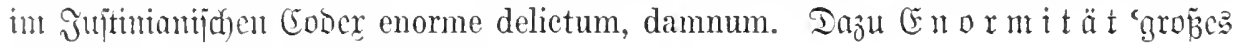
Berbredjen' fofor im 17. Jahrf.

Belege: 1. Rohr 1718 Etaatsflitgheit|eonsideriren, was für enormiteten auB $\Xi$. 362 wenn sie enorme Gotteslästerungen solchen ineonvenientien treue entspringen geredet. 1736 Prenti. Banferottebift (= würden. Forjter 1791 \{rijid)ten (III 247) ¿noemig, Gsel. Y(nzeigen II 406) sollen, wann die wenigen unvermeidlielıen Unglïcksfälle, das Verbrechen gar enorm, mit dem Strange die eine Revolution nothwendig mit sich bestraffet werden.

2. Slloł 1771 an Bürger (1 20) seine (norme Gelehrsamkeit. midhaelis 1776 R̈̈= jontement IV 529 bey den enormen Ausgaben. Sĩfland 1792 v̛rauenítand (VII 169) in einer so enormen Gesundheit. Cramer 1794 Genieftreiche I 39 dieser enormen Pracht.

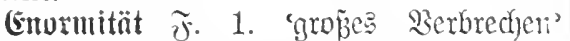
bringen mußte, als Enormitäten der ersten Größe und als Sehandfleeke der Gesehiehte darzustellen. Eeume 1813 Mein ̊eben (I 14) einen Vater, der seinen Liebling in einer solchen Enormität ergriffen glaubt.

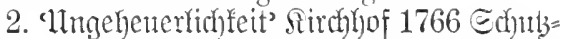
reben II 411 Die Verwegenheit [Des Diebe: ist, bey allen daron in den anliegenden Inquisitionalaeten rorkommenden Umständen Mengering 1638 Eorontenteufel $68^{\text {a }}$ daß sie ron der sehier unglaubliehen Enormität. mit ihren exeessen vnd enormiteten Gott Forjter 1788 Secfereien (ङ. 63) zu allen Enorrnd den Menschen so hoch beleidigen. Mift mitäten einer raffinirten Sinnliehkeit.

1642 Rettung $245^{\text {a }}$ aber dabey gar nieht

en passant i. Huter e $n$.

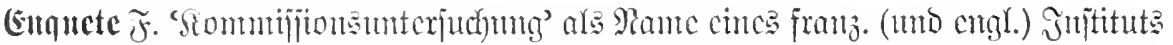

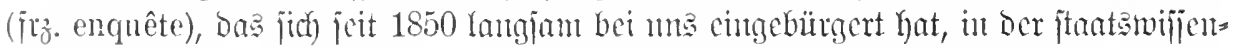

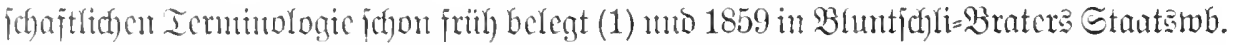

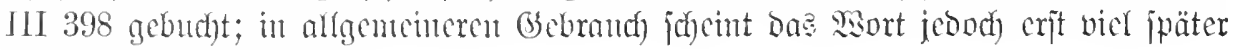
gefonuteu zu jein (2).

Belege: 1. Fallati 1846 (= 3i. F. D. ge . Welehe daron reden, ron dem Wesen einer Etaatänifienjchaft III 517) Nicht leicht Enquête im engeren Sinne des Wortes einen kïnnen daher solche Commissionen, deren klaren Begriff haben... Wir haben den Untersuchungen man mit dem Tamen En- Begriff der Enquête dahin festzusetzen gequêten zu bezcichnen pflegt, zu warm empfoh- sucht, dass darunter eine voriubergehende len werden - (523) in dem Institut der statistisehe Erhebung gewisser Verhältnisse Enquêten - (724) Man hört in neuester Zeit durch eine ausserordentliche Commission zu aueh in Deutschland nicht selten von sta- verstehen sei: Emboen 1877 Edhriften D. “ tistischen Enquêten als einer empfehlens- B̉er. F. Eozlapolitif XIII 1 nieht den franwerten Einrichtung sprechen, und das sind zösisehen terminus technieus haben wir sie gewiss. Vicl zweifellafter ist, ob alle, recipirt, sondern unser Sprachgebrauch be- 
dient sich der „Enquête" als eines elastisehen es gibt jetzt nur noch Enquêten - 1897 Gelegenheitsausdruckes.

Etedhlin ङ. 442 und weil heutzutage so

2. Trontane 1882 R'groultera $\Xi .105$ Er vieles schwer festzustellen ist, haben sich ist zum Minister befohlen in Sachen einer ja die Menschen auch das angeschafft, was Enquête. Sie wissen, meine gnädigste Frau, sie ne Enquete nennen.

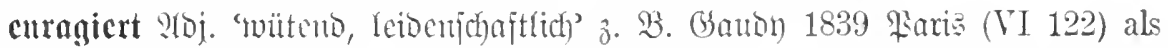

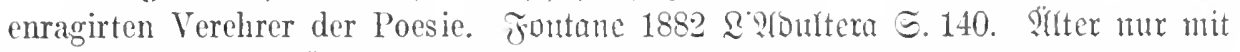

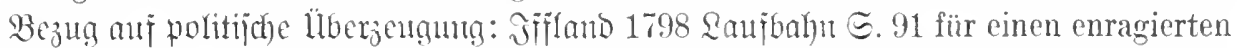
Aristokraten. Eđü̈ffing 1859 Erzählungen II 165 ein enragirter Demokrat. Suelle:

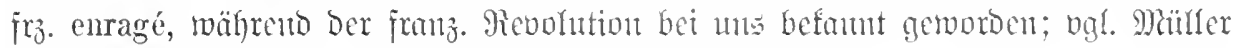
1792 , jerr Thoma: IV 12 den Jacobinerelubb des Fleisches und Blutes, der Eitelkeit, des Fïrwitzes und andrer Enragés. 1794 2 . Icutjđer Merfur II 48 alle französische und deutsche Jacobiner, sogenannte und wirkliche enragés.

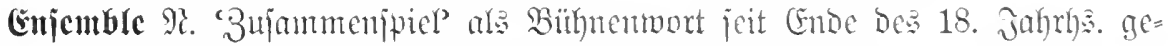
läufig. Sultle: frz. ensemble 'Bereintgutg, Bujammentrirfen'.

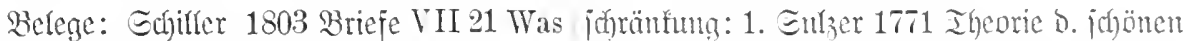
das Publieum etwa an den einzelnen Lei- Siunite I XII "Q'enjemble (Edjöne Stüjte)

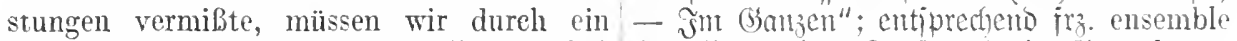

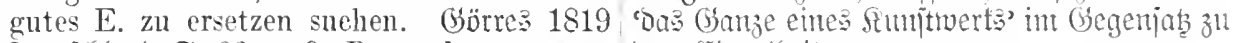
Ieutichlano S. 93 große Bürgerdramen wur- Den Cinzelfeiten.

den mit dem besten E. anfgeführt. Sgoltei 2. Sn Der Minjif: 'Tomitüefe, weldje von

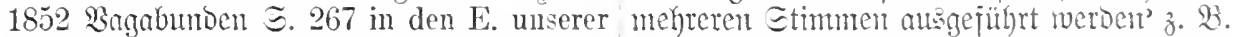
kleinen lustigen Pantomimen. Freytag 1868 jofimam 1814 Areišlerima (I 25) Ensembles, शtụ̈äbe II 341 E.-wirkung.

Meitere Berwendungen in ted)niforer $B e=$

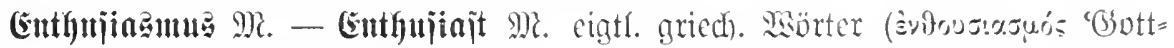

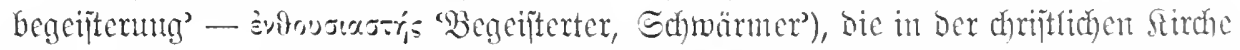

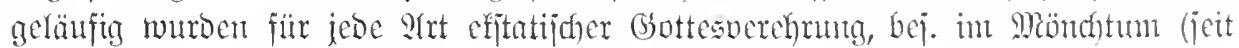
Den 4. Jahrh.); jpäter Daher gerabezu Sesername, uno jo auch bon Suther fejtgehalten,

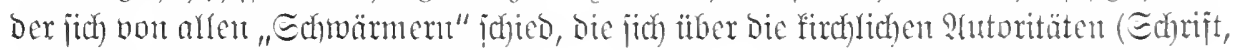
Irabition, S(mt) Gintwegjegten (1).

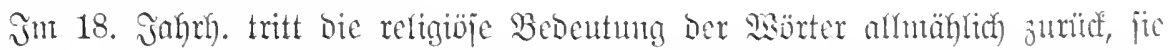

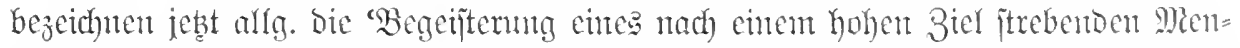

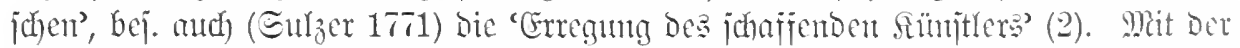

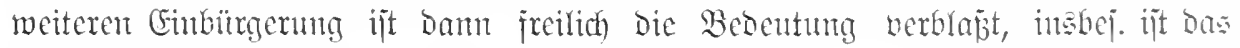

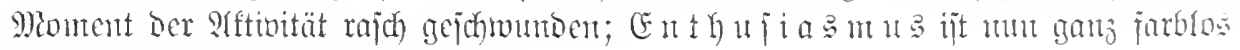

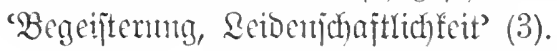

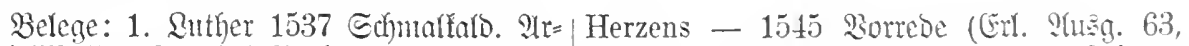
tifel (Müller, Symbol. Büd)er ङ.321) Danit 386) so ist er ein Enthusiast oder Geister. wir uns bewalıren für den Enthusiasten, das dem niehts gefällt, denn Geist, Geist. Geist, ist, Geistern so sich rühmen ohne und vor der vom Worte, Sacrament, Predigampt, dem Wort den Geist zu haben, und dadureh nichts hält, sondern naeh dem Geist soll die Sehrift oder mündliehe Wort richten, man leben - ein Geister und Enthusiast, deuten und dehnen ihres Gefallens, wie der der nieht will unter Gottes Wort oder der Münzer that und noch viel thun heutiges heiligen Sehrift, sondern Riehter und Meister Tages - Denn das Pabstthum auch ein uber sie sein aus dem Geist. 1577 STontoroiert= eitel Enthusiasmus ist, darin der Pabst formel (Maitller ङ. 525) Enthusiasten heißen, rühmet, alle Rechte sind im Schrein seines die ohne die Predigt Gottes Worts auf himm- 
lische Erleuchtung des Geistes warten. Menl= geritg 1642 Bervijfenßrüge ๔. 438 den Weigelianern, Methisten, Rosen-Kreutzern rnd andern Enthusiasten. Eecfenoorff 1685 (EG)rijtenitaat I 174 daß es [Gottes siont] mehr vor eine Regul des Lebens und der Nachfolge zu gebrauchen, als zur Erlangung der Seligkeit mit Glauben zu ergreiffen sey, daraus zuletzt ein solcher Enthusiasmus entstehet - II 326 von dem Enthusiasmo, das ist, unmittelbarer Erscheinung und Erleuchtung - Regifter: Enthusiasten schädliche Einbildung und Lehre. Sormes 1778 Eophiens Reije I 76 Heissts iezt Enthousiast? vormals hieß es ja Pietist.

2. Mieland 1775 Ienticher Merfur IV 153 es giebt auch eine Erlitzung der Seele, die nicht Schwärmerey ist; sondern die Würkung des ummittelbaren Anschauens des Schönen und Guten, vollkommenen und Göttlichen in der Natur, und unserm Innerstem, ihrem Spiegel! Diesem Zustande der Seele weiß ich keinen schicklichern angemeßnern Tahmen zu geben als Enthusiasmus. Denn das, wovon unsre Scele glüht, ist göttlich. 1776 Teuticher Merfur III 114 Enthusiasmus ist heißes Ringen und Dringen nach einem Gegenstand, der hoch und helir dem Geiste

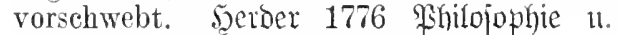
Edjuärmerei (IX 504) mit Enthusiasmus in seinem Herzen, d. i. mit umfassender, handelnder Wärme. Stant 1790 firitif Der

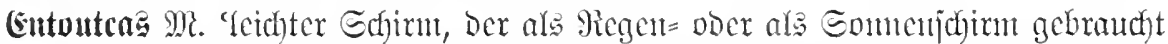

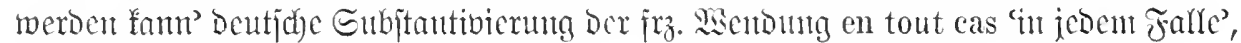
jeit joctje 1865 gebudft.

Selege: 1857 Der Bazar V 137c man Stiitze, wie zum Schutz gegen Regen und bedient sich noch häufig der großen seidenen Somnenschein. Echücting 1863 gfftientei. II 33 Schirme, „Zweifler" oder ,en tout cas" durch einen leichten En-tout-cas geschützt. genannt, welche gleich brauchbar sind als Stimbe 1886 sandertmppe 5.106.

en train j. unter e $n$.

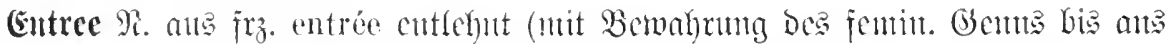
(Ende Des 18. Jahrly.) in folg. Bedeututgen:

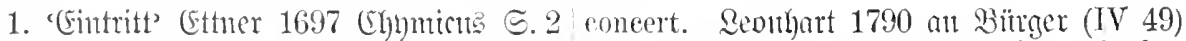
In meinung, dab ihr Mebiats etwann in ciner wir suehten dureh Kauf einiger Bücher solchen Witterung sein entree halten mö̀te. Entré. Sotzebue 1815 giefbocf II 4 eine so (Eallembacf) 1715 Dutajt 厄. 41 Das Franen- hübsche Dime hat überall freie Entrée.

zimmer bedienen, des macht zu zeiten die 3. 'Eintrittenelo' Thümmel 1791 Reje Entrée. Mohr 1728 Betemuniellwifienjohat (I 127) Sprach mit dem festen Mann von der I $157 \mathrm{ob}$ ar wohl bey der ersten Entrée die Entree des Praters. 1798 ?Gmafent o. Deut= Erläubnif, habe, cim mündlich Compliment joden lniv. 5.68 das Entrée kostet 8 Gr. zol machell.

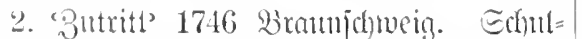
vromumgen I 248 Sämmntliche studiosi haben ich jhm das Entree bezahlen - (III 136) für dagegen dio freye entrée ins wöchentliche 36 Sols Entrée. Wormann 1833 D̈fterreich) II 2 
こ. $96 \mathrm{da}$ das Entrée sehr theuer ist. Zanbe 1837 Das B́liict E. 180 daß hier schon kcin Entree zu zahlen war.

4. 'Torjpeije' E(t)urts 1695 Saufmant=

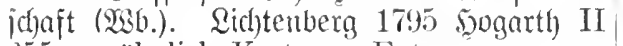
255 gewöhnlich Kost, zur Entree.

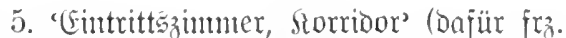
antichambre) jobon bet (cante 1801 gebuct)t. Releg: Raube 1837 Reijentovellen V 351 die Thür des Entrées war nicht verschlossen. Dazu Eutreetür Frentag 1855 Eoll u. 5aben I 47. 541.

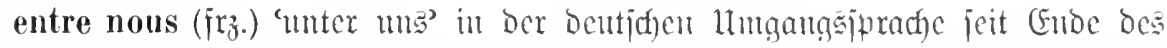
18. Jahrly. übrich. Belcge: Bürger 1775 Bricfe I 256 Der Weygand ist entre nous ein rechter Filz - 1780 cbo. III 2 Also bleibt das entre nous. Wobl 1789 an ๔đüb (I 449) Kurz heraus - aber entre nous.

en vogue $\lceil$. unter e $n$.

eo ipso eine Wendung DCs fanzlcilatcins, die jeit Dem 17. Jahth. in Den Deutjhen

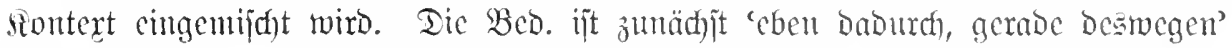
D. h. auf Brumb einer vorher crwähnten Tatjache, fpäter verbläpt zu 'ohne weiteres, jelbjtberịtändich).

Belege: Mengering 1638 Eoldatenteufel Sermes 1789 fïr Gitern II 42 so wird er ङ. 347 es hätten solche Ketzerische Ständte [Sffizier] eo ipso cassirt. Echiller 1796 eo ipso, das sic Ketzer scyn, jhr Land vnd Brieje V 19 denn sobald er das Ziel sich Leut verwürckt. QGbele 1654 Gerichtöhändel dächte, so hätte or es eo ipso auch erreicht. I 17 und eo ipso was hieraus unverhofft 1796 Seibelberg. Urfumbenbuct I 137 daß erfolgt, nur ihme selbsten zu imputirn habe - derjenige, welcher zuerst geschlagen, eo ipso 528 und eo ipso, indem ihm erlaubt worden, in eine mehrtägige carcerstrafe verfallen herum zu fahren, so seye ihme auch erlaubt sei. Säger 1835 Felix E(t)uabel $\Xi .80$ die worden, aufzusitzen. Epreng 1662 Med jel = den Hallenser - eo ipso ihren Dutzbruder puraftif $\Subset .89$ Wie auch, wann der Commiß zu den Lausitzern brachten - $\Xi .196$ Bescin Stand verändert, eo ipso die Commission kanntlich zerfällt die Logik in Winter- und erlischt. Reib 1708 3weite $\mathfrak{B}$ robe $\Subset .31$ Sommerlogik; erstere friert, diese hat co wenn solches [Bier] starck consumirct wird, ipso keinen rechten Gehalt. Qaube 1837 nothwendig sich eo ipso dadurch des Regentens Feijenovellen V 363 daß einst jeder zum Trancksteuern, Accisen vermehren mï̈ssen. Christenthum übertretende Jude dadurch 1739 Prenf. Banferottedift (= \&udewig 1744 eo ipso polnischer Edelmann geworden sei.

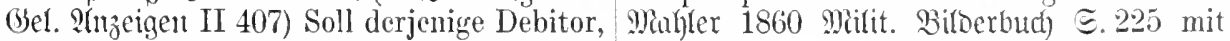
welcher flüuchtig wird, co ipso vor einem einer mehrtägigen strengen Arreststrafe ervorsätzlichen Banqueroutirer gehalten werden. freut und eo ipso degradirt.

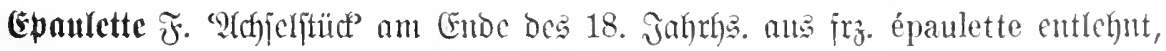

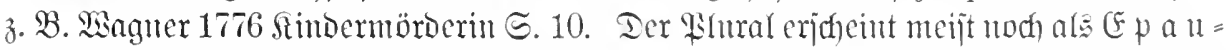
lett 3 (5ernes 1791 Riterar. Märtnrer I 349, (Eramer 1794 (bentejtreide I 85), bod)

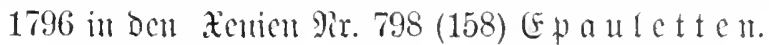

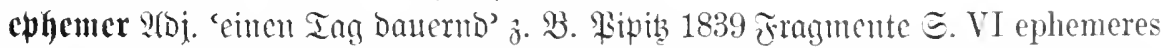

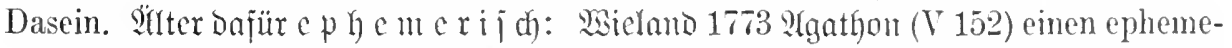
rischen Roman. Edymio 1775 (Ghronologic $\subseteq .73$ die ephemerischen Gesellschaften. Siligge 1792 Rcije $\subseteq .279$ während dieser ephemerischen Existenz. Euclle: gricch. Èçruepos 'fïr DCH Ing'.

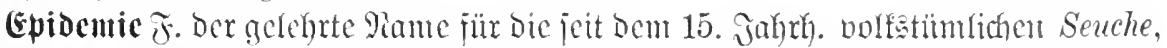
Plage, Krankheit, erjt im 2ufang bes 18. Jahrhe. eingebürgert $\mathfrak{z}$. B. J. Eaintclo

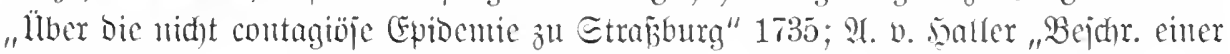

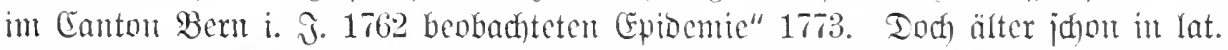

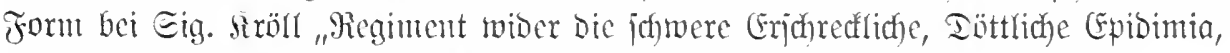

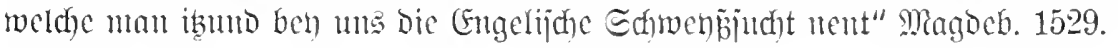


M(at. epidimia, epidemia (15. Salgrh.) bie anth für Den Deutf(j)en Spradgebraud)

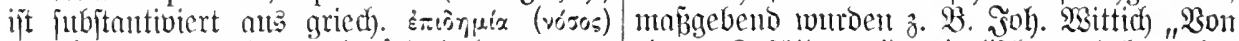

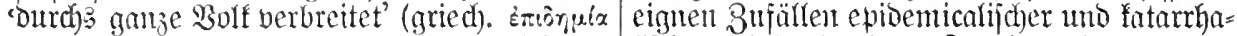

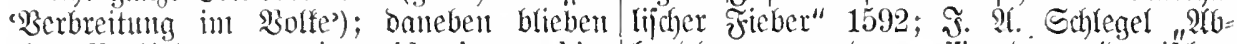
aber Berbindungen wie epidemica scabies Gandungen von der grajïrenton epioemijiden (uljentu 1496), sudor epidemialis (Cajtricus Seuche" 1681. Bej. "Epidemijche frram

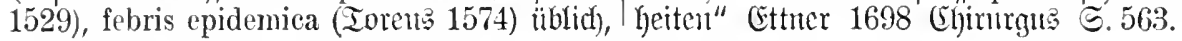

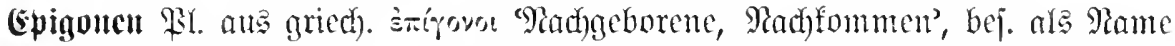

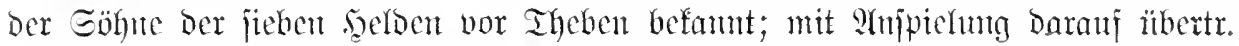
für 'jatwade Madytreter bebeutentoer Borjahreu' gebratudt. Das Wsort ijt Durd) Эunnermants Roman "Die Epigonen" (1836) in IImlauf gefommen, Doch braucht .jeine johon 1834 die Spätergeborenen in gleidger Bobentung (Salon II 234).

\$gl. Smmnemumus Bricf vom 2 pril 1830 | der Mühe und des Fleißes unserer Altvorderen (jempel $\mathrm{V}$ v) Der Roman] hat jetzt den $\mathrm{Na}$ - erhebt, krankt an einem gewissen geistigen men bekommen Die Epigonen und behandelt, Ueberflusse. Die Erbschaft ihres Erwerbes wie Du aus dem Titel vielleicht ahnest, liegt zu leichtem Antritte uns bereit; in den Segen und Unsegen des Nachgeboren- diesem Simne sind wir Epigonen - onju bis seins. Unsere Zeit, die sich auf den Schultern entipredjende Etefle des Rontans I 123.

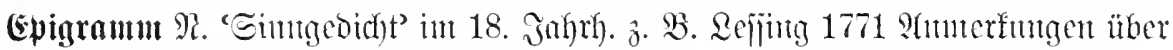

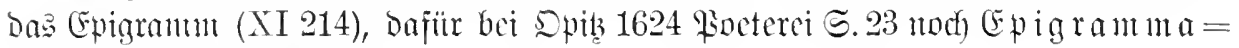
lat. (=griech.) epigramma.

epiju 9xoj. bei Gottjuco 1760 Şanblexifon 5.624 gebucht. Beleg: Meier 1744 Simptridyter $\subseteq$. 12 eines epischen Gedichtes (im 18. Jahy d). Dafïi häupig Heldengedicht,

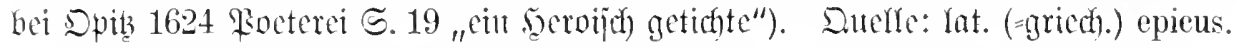

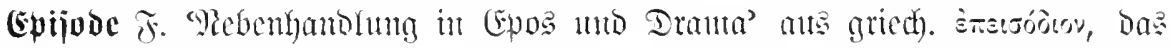

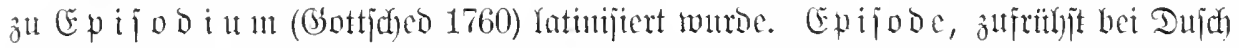
1764 Briefe I 20, serder 1767 D. Siteratur (I 145), Sejing 1767 Dramaturgie (IX

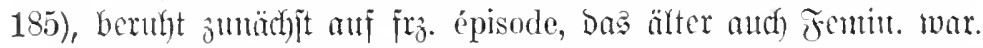

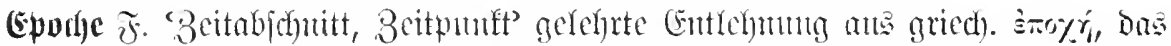

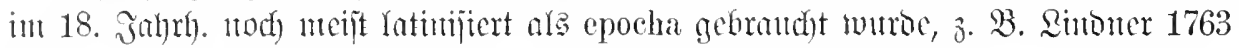
Betrachtutgen ïbex die Epartan. Géchgebutg (Bfos. VII 155) "neue Epochas".

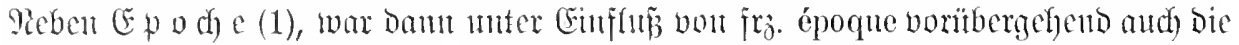

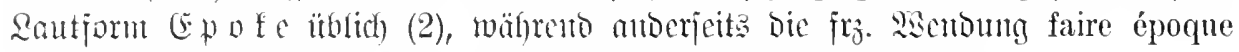

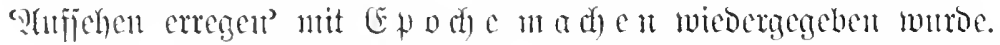

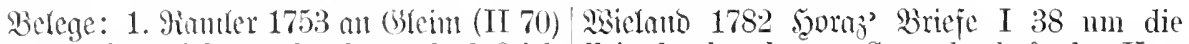
Ich kill dabey nichts mehr thun, als daß ich Zeit der berühmten Gesandtschaft des Karauf die rechte Epoche warte. Sisielano 1771 neades, welche die Epoke ist, worinn die Briefe III 47 die schönste Epoche meines griechische Philosophie [wicber zur Obertung

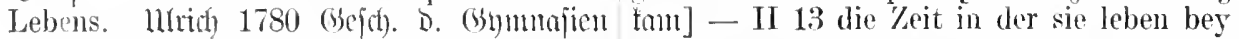
I 5 Hauptepochen. Gibiller 1787 (beifter = der spaitesten Nachwelt als Epoke auszujeher (XIII 175) in den ersten Zeiten dieser zeichnen. Echnhert 1789 Baterlandeshronit

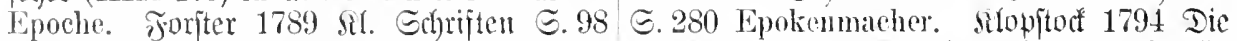

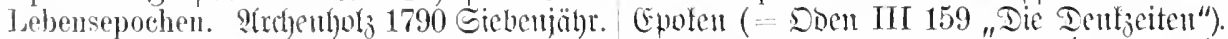

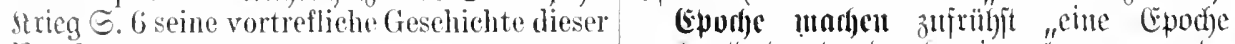
Epoche.

2. Miofer 1775 Satriot. Bhantafien I 64 die Vergleiehung der versehiedenen Epoquen 1767. Berjud) über Das Gente (Bitat in ben in der Handlungs- nnd Staats-Gesehichte. Siteraturbriefen 22, 43) ob derjenige allein 
den Namen eines Genies verdient, der eine F. macht, d. i. der eine Kunst oder Wissenschaft zu ihrer Vollkommenheit bringt, wie Helvetius in seinem Buche de l'Esprit meynt. 1767 Riteraturbriefe XXII 44 Wer aber einer Erfindung den Anfang giebt, und sie zugleich anch zur Vollkommenheit bringt, folglich eine E. macht; der muß gewiß ein seltenes und großes Genie seyn. Yiach Fero= man, 3fD约. VI 316.

"Epodye madjen" zujrithit (nad) Borit,

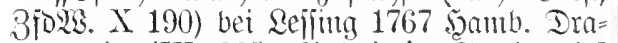
maturgie (IX 225) Soltaice's Eemirami ] ward im Jahre 1748 anf die französische Bühne gebracht, erhielt großen Beyfall, und macht in der Geschichte dieser Bühne, gewissermaßen E. - 226 die Bühne in Paris, für die, wic gesagt, Semiramis in diesem Stüeke, E. macht. Erfubart 1774 (5f)ronif

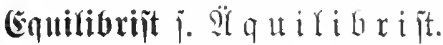

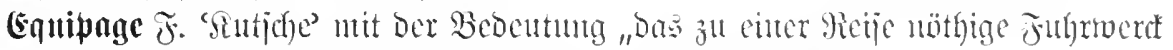
utb Geräthe" Gei Sperantor 1727 gebucht: aus jrz. équipage.

ergo (lat.) 'alfo, folglich' in 17. Juhrh. aus Der Eprache ber Sogif cingebingert.

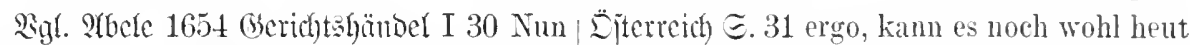
bekenne der Klïger selbsten den letzten auch unterwegen bleiben. Ihontajü 1688 Puncten, ergo müsse er sieh auch zu der Dontatigeppräche I 137 ergo müsse es nothsehuldigen Abfindung bekennen. Mengering wendig durch die Universalaceise geschehen.

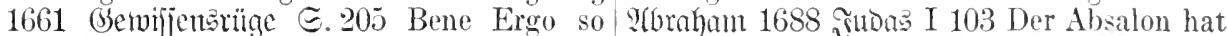
kan aus solehen Periodis keine fatalische gekrauste Faar gehabt; ergo, alle die krauste Vrsach gesomen werden. Donneff $168 \pm$ Haar haben, seynd rerruckte Bösewicht.

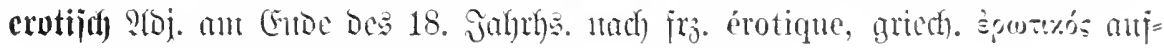
fommento, zunächjt mu zur Bejcidumutg von Didftwerken.

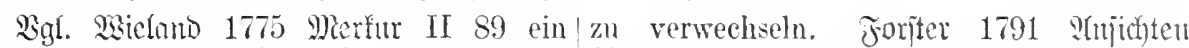
Werk von einer gewissen Gattung, Sie er- (III 347) erotisches Gedieht. Miüller 1791 rathen leicht, daß von der erotisehen und Serr Ihoutas II 313 diese Fröhlichkeit, die komischen Gattung die Rede war - 92 îhm ganz wider alles erotische Kostume durch ein paar neue scherzhafte Erzählungen schien - IV 38 sein erotisches Stratagema.

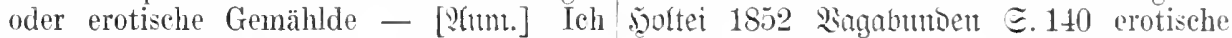
bitte erotische Gemählde nieht mit asotischen Seherze.

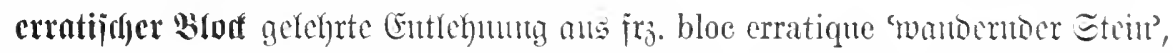

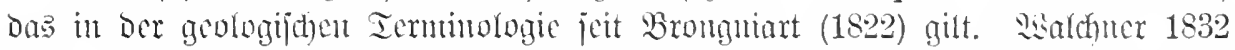

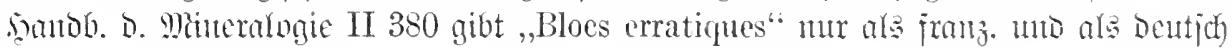
(II 381) Findlinge, wie sie der Süddentsehe und Sehweizer heißt; aber in beuticher

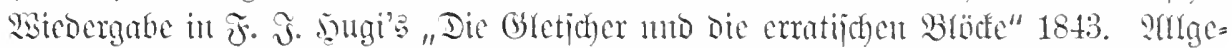

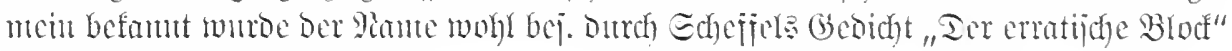
(iil Gaudeamus 1864).

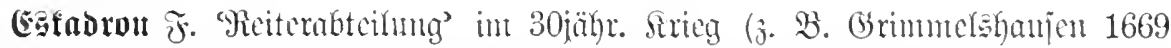

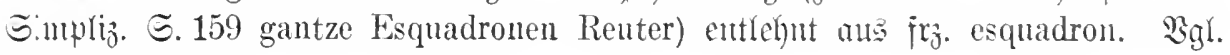

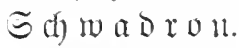

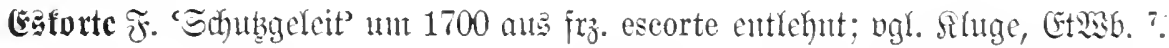




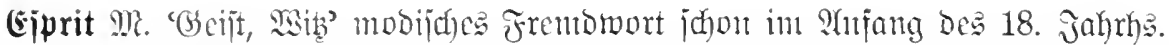

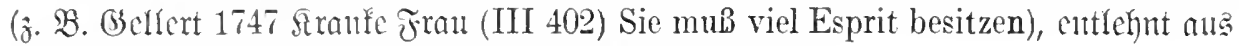

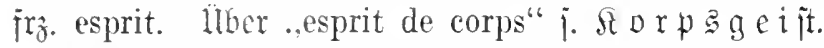

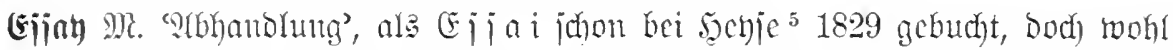
nur als frans. Stmitwort, wie aud) Cramer 1773 (an Bürger I 178) "franzöjijoter Essayjurciber" braudjt und becine 1834 (Ealon II 251) bou Der "ATrt Der fran=

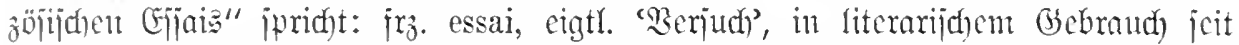
Mentaignes Essais 1580; in Deutidfut Des 18. Jahrhe. Dajür bielmidhr Versuch.

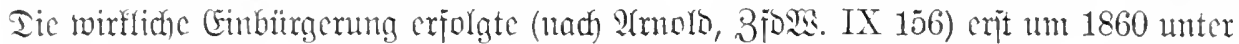

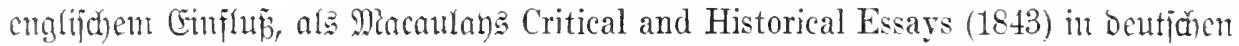

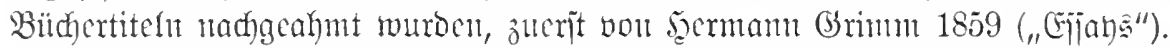

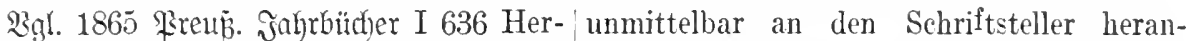
mann Grimm hat sehr recht gethan, das tretende Frage oder Thatsache in dessen Fremdwort 'Essay' in unsere Sprache ein- Seele eher lebendig anregt, als zu vollem zuführen. Seit Steeles und Addisons Zeiten Abschluß gebracht hat. Siller 1874 Reute bis auf Yacaulay hat der Begriff sich so ver- v. Eeldonnla (V 98) Bald schrieb er rerfeinert, daß das hausbackene 'Versuch' schiedene Ablandlungen, welche er seiner des vorigen Jahrhunderts ihn weder ganz Gattin als „Essays" bezeichnete.

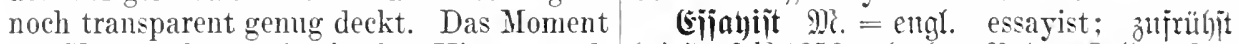
des Untersuchens tritt in den Hintergrund, Gei bevje ${ }^{12} 1859$ gebucht. Beleg: Seller 1874 die Hauptabsicht geht auf die künstlerische হeute v. Eelowyla (V 98) er glaubt, er sei Darstellung einer Anschaunng, welche eine : seiner Anlage nach ein Essayist.

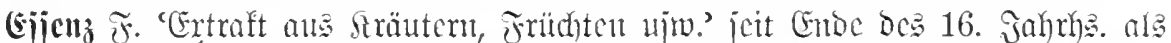

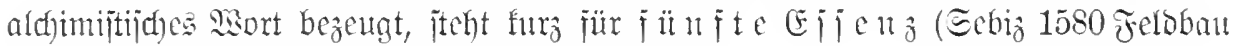

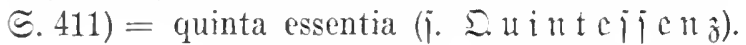

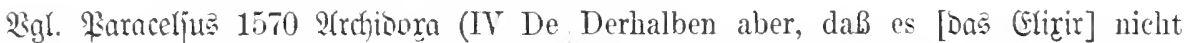
Quinta Essencia) $\widetilde{\mho} 3^{\mathrm{b}}$ nimt die Q.E. in ein klar, schön, durchsichtig vnd lautter wird, ander Phiol.....so geuß von der Essencia so ist es auch kein Essentz - S.118 Also herab - O3 $1^{\text {a }}$ Dam vil Essencia ist in der wirt auch hierauß ein Essentz vonnd höchste humiditet auffgestiegen - so ist in der krafft, oder (wie es etliche nemnen) ein farb die Essencia - b t $t^{\mathrm{a}}$ die Essenciae rnnd fünftes wesen, vnd ein wolgereinigts, scharpfs Extractiones - $c t^{\text {a }}$ das wir mögen in rns rnd etzendts Saltz bereitet - $\widetilde{\Xi} .136$ Bericht fassen die Essencias der Kreutter. Thutr $=1$ vom 5 . wesen - mit einem kleinen rndermenjier 1578 , bijtoria bon Erogewächjen Є. 5 richt, was die Essentz sey - ein jedes Corpodie Essentz diser Wurzel - $\Xi .6$ Ein Essentz ralischs wesen, es sey feist oder Feücht, kann wird am fueglichsten al:o zubereitet — $\Xi .42$ kein Essentz oder fünfftes wesen seynl.

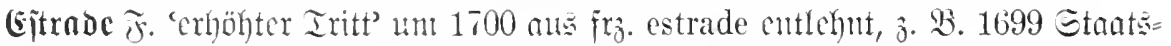

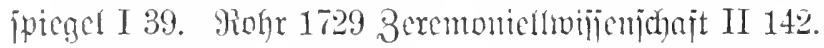

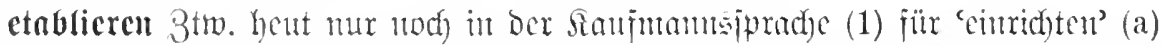

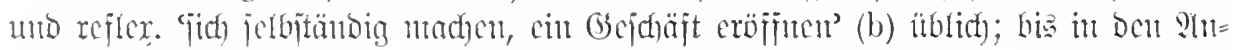

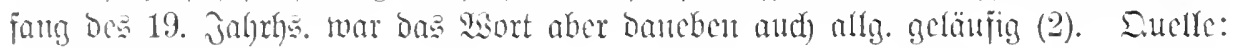
frz. ( $\left.\mathrm{s}^{\prime}\right)$ établir.

Belege: 1 a. Thontaim 1688 Mionate rung einer Heß oder Jahr-Harekts resolvirt.

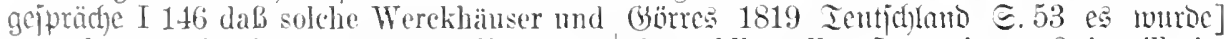
mannfacturen in einem Lande etabliret wür- ! ein wohlbestelltes Lager jener Quineaillerieden. Miarperger 1711 bejd)r. D. Micjicn I waaren etablirt, die uns die Revolution gea 3 ' durch die in ihnen etablirte, Welt-bekante bracht.

und an gantz Teutschland ersprießliche Com- b. Micolai 1799 Berrin ङ. 348 Wenn sich mercia - 53 eh ein Landes-Herr zur établi- ein Kaufmam etabliren will, meldet er 
sich bey seiner Gilde. Wall 1786 Bagatellen I 59 ich entsage augenblicklich den P'lanen, mich selbst zu etabliren. Frrentag 1855 Eull u. 5aben I 43 der aus dem Geschäft geschieden ist und sich selbst etablirt hat 480. Edhücting 1859 Erzähhmaen II 70.

2a. 1688 Braumintweig. Erfuloronungen II 208 wie bey dero fürstl. hoffstadt alhier zu Wolffenbüttel eine dergleichen academie und ritterschule establiret werden möchte. Şzblonsfi 1700 an Qeibniz (II 149) weil allhier seit einiger Zeit ein Collegium medicum etabliret worden. 5ூe 1775 Freintiit. Be $=$ Danfen $\widetilde{G} .117$ so würde er seine jüngsten Kinder nicht etabliren können. Edhiller 1742 Brieje I 78 wenn es nicht meine Pflicht wäi e, zuerst mein Glüick zu etabliren. Eeume 1803 Epaziergang (III 107) um ein Zwitterding von Republik wieder zu etabliren.

b. Ranter 1750 an Gleim (I 233) Schwartz hat mir neulich aus Dantrig geschrieben, wo er sich etabliren will. Juitt 1769 Exzeu= gung D. Mestichen 厄.97 die Fremden finden wenig Neigung, sich in einem despotischen Lande " etabliren. 2(rchenthols 1787 Eng= Ianti II 50 die nach London kommen, um sich daselbst zn etabliren - Stolien I 83 Wenn ein Fremder sich in diesem Lande etabliren will. Brum 1801 Edurifter IV 193 Meine Reisegefährten etablirten sich zwischen dem Pferdestall und der Tränke. Pïiffer 1840 Bitberjaal II 88 so ließ ich wieder einen ' Teil meiner Sachen auspacken und etablirte mich ron neuem.

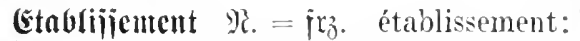

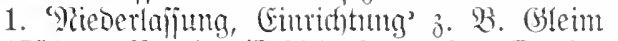
1751 an Ramler (I 304) da er dem Brnder.

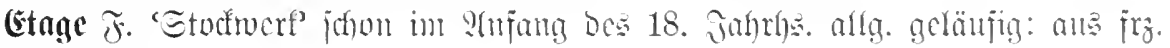
étage Mast.

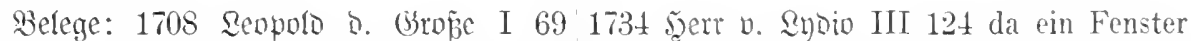
Diese sind drey Etagen hoch. Berffesmener geöfnet, liesse mich daran feliciter eine 1712 Sntiquarius $\Xi .576$ Die andere Etage Etage hoch himunter. Pionther 1743 Ban=

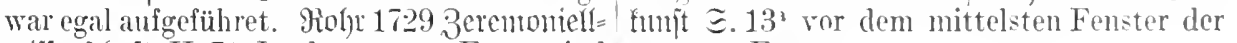
wijienjhaft II 71 In der untern Etage sind zweyten Etage. gemeiniglich die Dienst-Gemächer. Fleijcher

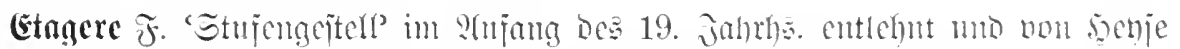
crit ${ }^{7} 1835$ gebuct). Beleg: s̃anfi 1827 Mam im \$lond (XII 34. 179).

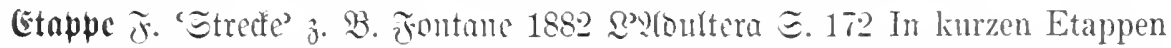

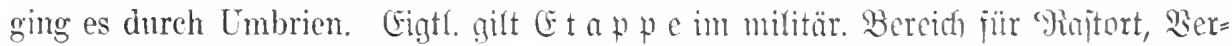

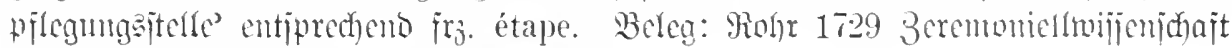
II 477 an Etappen-mäBiger Verpflegung.

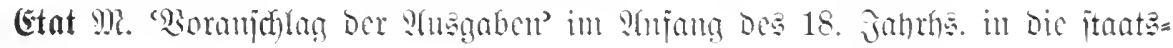


wijienjogaftlidge Iermintologie aus irg. état aujgenommen (1) und vou ba aus arlg. geläufig geworden (2). Daneben tritt im 19. Jahrh. Das engl. $\mathfrak{B}$ u b ge t (j. ১.).

Belege: 1. Ditfmat 1731 (1745) CEin=1 2. Mäjer 1775 Batriot. Phantaiten I 78 leitung E. 283 Gleichwie auch ein jeder In der Stadt London sind die Almosen von Haus-Wirth einen Uberschlag seiner jähr- jedem Hause fixirt und zum Etat gebracht. lichen Einnahme und Ausgaben machen 1783 Merfur III 180 fixirt dadurch seinen muB, so hat auch die Landes-Fürstliche oft schwankenden Finanz-Etat sehr heilsam. Cammer einen jährlichen Etat der Landes- Edjuffer 1789 (Seifterjełer (XIII 222) den Fürstl. Eimnahme einzusenden. Juiti 1758 Etat seiner Schulden. Jnigge 1788 Ulmgang Staatärijienichajt II ${ }^{2} 508$ Von der gerechten Eintheilung der Ausgaben oder dem allgemeinen Wirthsehafts-Etat - 515 Man muß in diesem Etat zuerst alle Einkünfte berechmen - 527 Von den Ausgaben für den Militair-Etat - 540 Artillerie-Etat - 558 Civil-Etat.

ङ. 162 Man mache sich einen genauen Etat, wie man dem Haushalte wieder aufhelfen will. Bebicke 1789 Echulijdriften I 174 Schuletat. Babrot 1791 Rebensbeidr. III 121 Besoldungsetat. Raube 1837 Reijentovellen VI 37 Der Spieß̈bïrger] faßt sich ein Herz und giebt einen Groschen über den Etat aus.

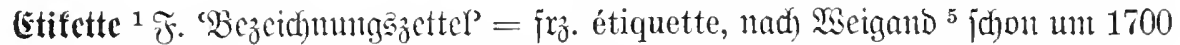

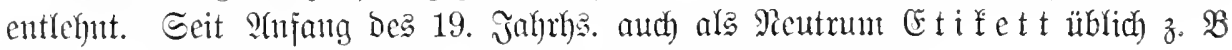
Bflasbremter 1836 Berlin VIII 5 anf jeder [Flajde] ein Etiquett.

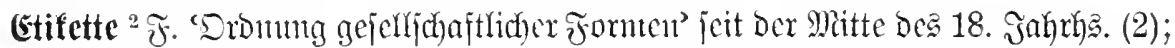

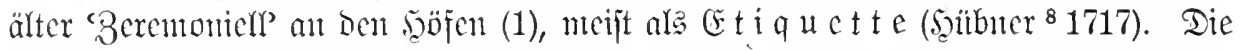

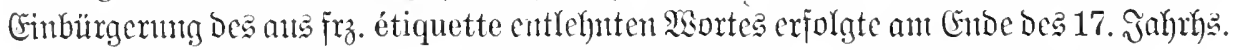

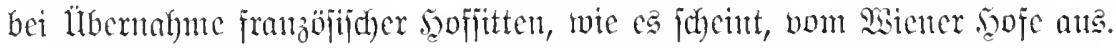

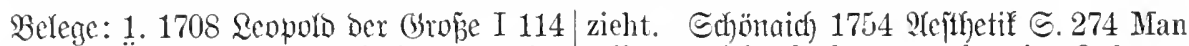
Von der Österreichischen Etiquete oder sollte es nicht denken, was für cine Ordnung Ceremoniel hier etwas zu erinnern, leidet der in Würden oder E. die Meistersinger bey Platz nicht. Dieses erforderte ein gantz ihren Höfen halten. Seffing 1760 werfe besonderes Buch. Rünig 1719 Iheatrum VIII 286 daß beider ihre Talente auf handceremontiate I $3^{a}$ an dem Ceremoniel des werksmäßigen Zwang, auf kalte E. hinausRöm. Hofes, der in dem Hause Oesterreich laufen. Mliendelajolgn 1760 Riteraturbrieje so woln in Teutschland als Spanien cingeführ- VI 246 wenn unsere Weltweisen die Schnlten Burgundischen Hof-Ordnung, oder so etiquette vergessen, und sich einen freyern genannten Etiquete des Wienerischen Hofes - $6^{\mathrm{a}}$ Am kayserlichen Hofe war man zu Zeiten des grossen Käysers Leopoldi in der Etiquete oder Ceremoniel so singulier und pointilleux, als an keinem Hofe in Europa $6^{\text {b }}$ Als er [Jojeph I.] den käyserl. Thron bestieg [1705]wurde die Etiquete destogenauer beobachtet - 299" die Wienerische Etiquette.

2. Bunzentorf 1748 ?tugsp. Sonfejition ङ. 179 da hält man im Geistlichen ebenso ernstlich über seinen Ordnungen in den Chören, als man die weltlichen natürlichen Jungfern und Junggesellen über ihre natïrlichen Ordnumgen halten sieht, da gewiß einer, der der Ordmung und E. seines Orts im geringsten mugnab handelt, sich aller beten, anf das spanische E. Threr Vasallen seiner Lands-Leute Gelächter anf den Hals, zu sehen.

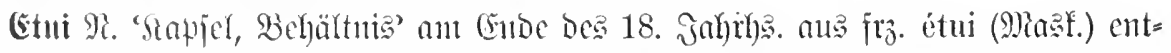

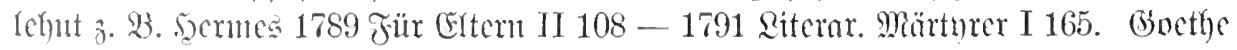
1796 geluringre (XXI 88). 


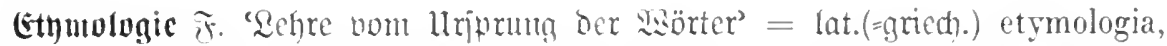

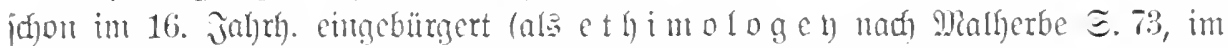

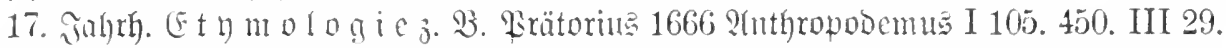

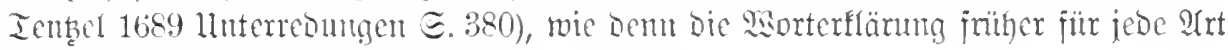

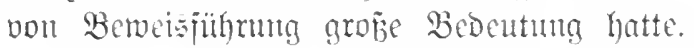

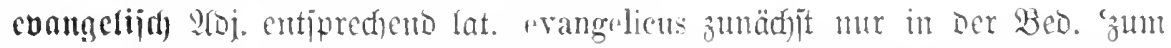
Evangelium gehörig' (jeit Dem 11. Jahrh).). Ruther aber veriteht unter Evangelium Die ganze Bibel, jooaj ifm das alojeft. 'Giblijh, Der Bibel entpredend' bedentet; Daher bezeidnet er jeine Schre, Die überall vom biblijhen Iert ausgehen roilf, al evangelische Lehre. Echon in bem erjten Gebrand) Des

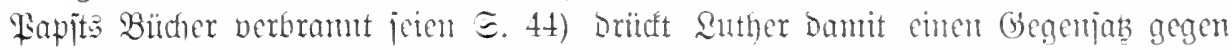

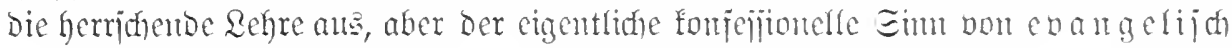
Gat jidf erjt mit Dem Fortidneiten ber Rejormation mb Den Entitehen emer jtarfen

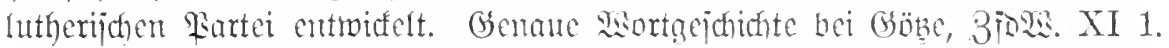

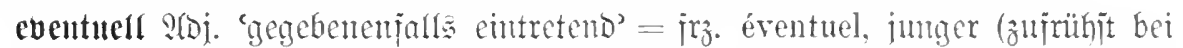

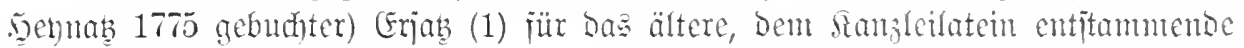
eventual (woher Eventualitäten), bas inoejen nod) für bie lautlide Behandung majgebend wurbe. Ianeben hielt fid lange das won. e ventu $a=$

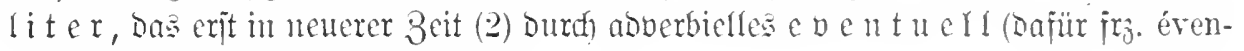
tuellement) berorängt twurde.

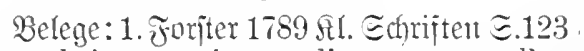
Nur scheint es mir aus diesem eventuellen Falle, wie ans allem Bishergesagten, bis zur unleugbaren Evidenz zu erhellen. Grabbe 1836 Theater (IV 98) ein Jahr Zeit zur Besserung und eventuellen Aussöhnung.

2. Simbentherg 1883 Berlin I 98 Er glaube uns mittheilen zu können, daß auch die Eltern die Wahl der Tochter ,eventuell" billigen würden.

cocntual an menlat. eventualis: Rejijng 1778 "Eime Parabel nebit eimer flemen $\mathfrak{B}$ itte und "entem eventualen 2 bjagungis an Dell Seerm Pajtor Góze" (XIII 91).

eventualiter jon bei Pebring 1684 Manuale juridico-polit. Є.373 gebucbt. Belege: abere 1654 Bherichtänätocl I 493 ihme dasselbe anf gewib und ungewiß, anf Gewinn und Verlust, eventualiter abzuliandlen. 1779

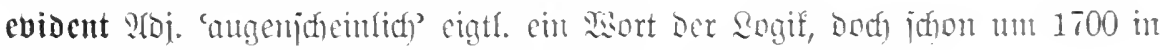

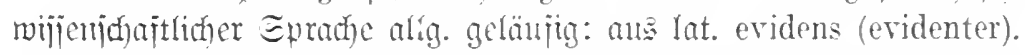

Belege: Reib 1708 3reite Probe $\Xi .14$ ist ein philosophisches Küunstwort. und man da sich der Tutzen so evident zcigt - $\Xi .41$ weiß es aus der Vernunftlehre, daß eine Leberbevoraus die Sache nicht sehr evident ist. zeugung klar und deutlich, und doch nicht Rohr 1718 Etuatäfltgheit ミ.163 Practica, erident seyn könne. Jene Wörter erschöpfen die einen evidenten und handgreifflichen Nutzen haben. 1737 jüb. Baldober $\Xi .243$ so wird sich gantz evident zeigen. 1772 Qrig. D. Bibliothef XYII 1 ङ. 304 evident
Sentiches Mujeum II 533 Eventualiter ist freilich ein Scharwenzel, aber manchmal mub der Begrif doch gesagt sein, und damn fehlt ein gleichlantender Ausdruck. Mitiller 1789 Emmerich VIII 304 in seinem Vorsatz, e. selbst der Mann zu seyn der es thäte. Grabbe 1835 Theater (IV 67) er wird dies Urtheil ïberlegen, e. widerlegren. Golbs 1847 Bud D. Sindyeit $\Xi .54$ und kriegte $C$. Prügel - 5.159 - 1869 sedtflttgheit II 79 um e. ein Loch zu rerstopfen.

Eventualität $\tilde{5}$. mäglidher Fall' erit bei sonjer 1835 gehucht. Belege: Gingfow 1845 Sitener Eindritce (IX 238) von dieser voraussichtigen Beherrschung aller an einer solchen Anstalt rorkommenden E.-en. Gols 1847 Buक D. Jimbheit $\Xi .50-1869$ 急lt= flugheit II 68.

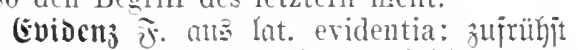
(nac) freloman, 3702 john 1759 Siteraturbrieje I 145 Die unum- 
stößliche E. in der Mathematik beweiset 1765 YIlg. D. Bibl. I 1 S. 138 - 1766 ebo. niehts für die allgemeine Wahrheit ihrer III 1 ङ.11 - 2 ङ.25. Sđhubart 1774

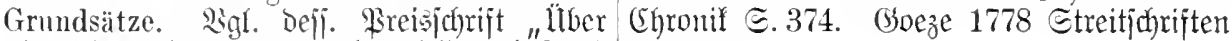

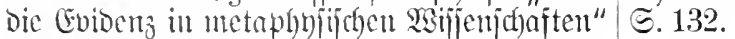

1763 (Gej. Echr. IT 13 ff.). Siscitere Belege:

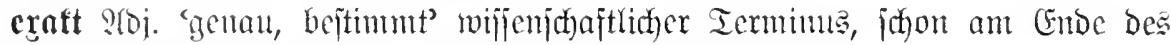
17. Jahrf). cingebihrgert: aus lat. exactus 'genall, piunftlicf)'.

Belege: Sinüler 1681 Leben der Cee= helocn $\subseteq .959$ daß gegen solche Delinquenten ohne einige Verschonung exact und unverzïglich fortgegangen werde Ettuter 1697 Doftor $\subseteq .880$ keine exacte Explication (5)bnicus $\Xi .326$ Die Reinigkeit kan bey Ehelenten nicht also just und exact gehalten werden. Reib 1708 Dritte Probe S. 29 wenn Treu und Glauben iederzeit exact beobachtet

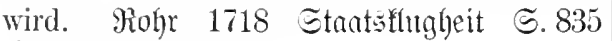
einen exacten Bericht.

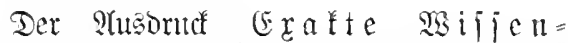
i d) a f ten für jolde, bie nuf Mathematif (und Logif) beruljen, z. B. bei (3opthe (1824) ভtiedeurothy Pindfologie (XI 75) ein MIann, zu den sogenannten exacten Wissenschaften geboren und gebildet. Dod bgí. (đ)on (Ettner 1697 Doftor 5.64 die exacte Wissenschaft der Medicin - Entmicus ऽ.849 eine genaue und exacte Wissenschaft der Bergarten.

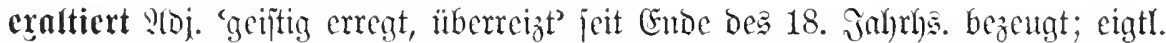
wohl cin medizin. S(usorucf. Euclle: lat. exaltare 'erhöhen'.

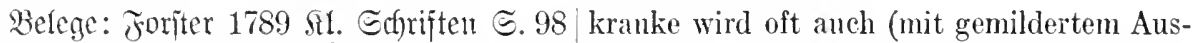
einem e.en Denker. Ridotenberg 1798 drucke) e., auch wohl excentrischer Kopf 5oggarth III 165 mit e.-er Gravität. Echiller genannt. ₹mutg=Etilling 1808 Geifterfumbe 1798 Briefe V 370 eine Schwärmerey oder $\stackrel{\Xi}{\Xi} 73$ wenn irgend ein Mensch, oder gar irgend eine e.e Stimmung. Sant 1798 Kinder, in Entzïekung, oder auch sonst YIntfropologie S.104 Der letztere Kopf- in einen e.-en (erhöhten) Zustand gerathen.

Erancu $2 .=$ lat. examen 'Prüfung', bei uns fpeziell nou Der Priffung gelef)rter Scuntuijie gebraudit (Ed)ule, Iniverjität).

Belege: Sirtïginger 1555 siftorin v. reichen examiniret werden. Siscije 1697 \$ertr. Mann $04^{\text {a }}$ Ich dacht, ich wil auch doctoriren Bcjpräche Є.57. Michaetis 1770 Räjonte= Ein höhern stand mit ehren füren. Da ich mtent II 51.

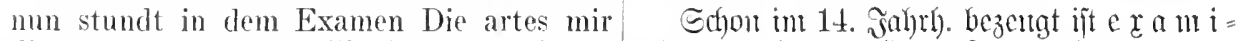
die quer so kamen. Menfart 1636 B. D. uieren in Der (Dem Rat. entipred)enden) .50 djoulen $\Xi .27$ ob sie schweren, sie wollen allgemeinen Bedentmig 'prifjen', die nod) diesen oder jenen Ehren-Grad auff andern int 15.-17. Fahth). Dnr(t)ans gewobhulich ijt

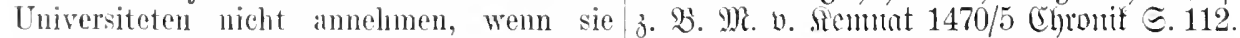
aber eine newe Vrach laben, anch ein Qorith 1537 Füntenlebre E.59. Fabricius newes Examen, können sie solches thm. 1568 Eurits' (E)ronif E. $183^{\mathrm{z}}$. 230 ${ }^{\mathrm{b}}$ Frantaf Eectenoorif 1656 Finritemftant I 338 die Er- 1576 Catalogus Haereticorum E. 411 . Sdhwei= forschungen oder Examina der Jugend.

craminieren 3tw. ans lat. examinare 'prifien'; im joultednij(hen Eime jeit bem

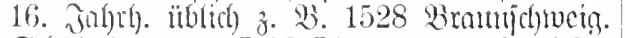
Echullorontutgen I 33 Id schadet ock nicht, dat me se up etlike tielt examinere linde höre, wo se diidesch reden. Sieanoer 1583 Bedenfen' כ. $16^{\text {z }}$ einen Knaben alle tage reisig examinieren, Eommer 1608 (Etho= grophia II 15 Ich hatte gestern meine lieben kinderlein für mir, exanimiret sir, vud lase jhnen die lection, damit sie etwas lernen solten, fiir. Mienfart 1636 23. D. Soudridulen כ.28 Ein Student, dessen Würdigkeit vnd Ceschickligkeit iffentlich bekant, sol nicht

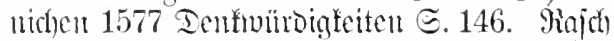

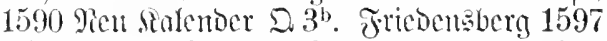
Discurs $\Subset .38^{\mathrm{a}} 1600$ Fontes rer. austriac. LX 3. 1602 Thommenourijthe Ehrontif $\Xi$. 108.116. Edhucighart 1617 Pambora ङ. 111. Son hier me gab es banu mieder zuei be= jondere servenomigen, bie nod) his ins 18. Fahrh. beitanton haben 1. in Etrafprozej

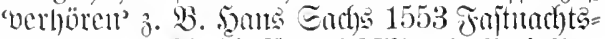
ipiele V 36. Stirchhoff 1602 Militaris disciplina 5.256. Francise 1669 Trancifan II 1152. 2. chemp in firchlidten (bebrauth boun Fragen in Der Seichte 3. 3. Sanorub 1618 Delitiae 5. 16 Der Pfarrer thet Examinieren [oas Miäochen]. 


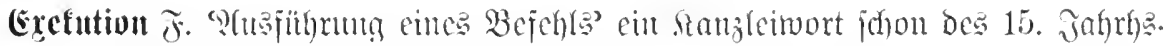

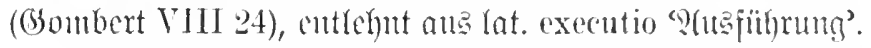

1. Duclle bou 1453 bei Ranfe, Ricfor= soll die execution oder rolstreckung der mationsgejdjidfte VI' 12 Item zu zuuollen vrtail, dem vrtail fellen mit vor sonder furunge des rechten, sullen dry werntliche nach geen. Stirdilgo 1602 Militaris disciplina fursten geordent werden, das die sien Capi- $\Xi .219$ Langsane Execution vnd Volltanen in dryen enden des Rychs, vnd sullen zichung deß Sententz retrahiert, mildert, sin die dry werntliche kurfursten, der iglicher und endert offt, die in Zorn und Eiffer gesin Capitanus der execution sin sol in dem sprochene Vrtheil.

teyle dentsehen landes, las yme betirmet?

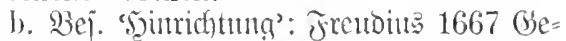

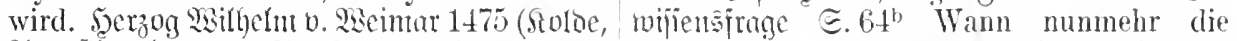
P(uglifinerfongren. E. 421) das ir nch mit / Execution soll verrichtet und sie zum Gericht befolner execution enthaldet. Mathcius aubgeführet werden. (Brimmelahaujen 1669

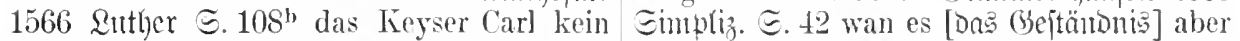
execution [jeines Coiftu] ergelsen ließ. Caro= nicht herfür wolte, so striegelten sie die lus 1614 Relation Ir. $8^{\mathrm{a}}$ solle dem Ertzhertzo- Commissarios mit Besemen, die man militagen Alba vnnd Clunrfürsten von Cöllen die rische Execution nennet. Francišci 1681 Execution befohlen sein. Atrdyentyol 1790 Tramerjaal IV 1064 zwo oder drey Stunden

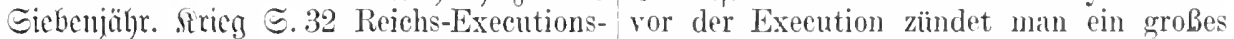
Armee.

2. Plu beridft: a. Die "Sollitrechung cines Feuer an. Ettuer 1697 llnwürbiger Ioftor C. 123 wann sie einen Delinquenten ergreiflluteifar 3. 3. Fubsherger 1534 Dialeftif fen, der erste Baum bey dem sie kommen ธ. 128 Dam nach ordenung der rechten, ist zur Execution am bequemsten.

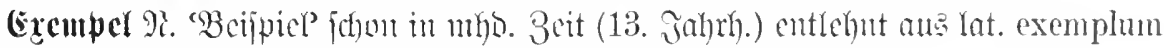
unb bej. in ben folg. Berbintomigen geläufig gemorocm:

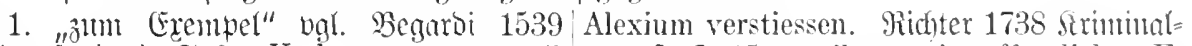

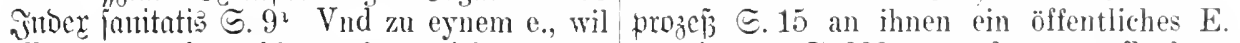
alleyn eyn kranckheyt für mich nemen. statuiren - モ.330 gegen dessen verfuchten Muljulus 1555 5ojenteujel 5.19 den Regen- Cörper ein E. zul statuiren. l̈lbertr. bei bogen am Himel, an welehem Gott vns Mieier 1744 fumftrichter $\Xi .192$ daß man, zum e. vnd beispiel, teglich für helt, seinen um ein E. cinmal zu statuiren, sie auf eine erzeigten Zorn. Rirdhof 1563 Saendumunt critische Art todt schlagen muß.

I 270 aller welt zum sehawspil und e. Bicllert 1746 Fabelı $\subseteq .131$ Wir zum E. gehn itzunder.

2. "ein (Exempel nefuten" ’. B. 5oof 1601 Bhumenfero $\widetilde{E} .76$ Du solt E. nemen, dich regieren, Nach disen gutten Thieren. (3e $=$ bud)t bei Sacrifed 1616 巨p. 960.

Entiprechend oft and "eit Erentucl geben"

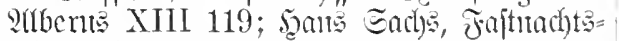
ipicle 65292.

3. "eit Exempel ftatuiren" cin $(a b=$ -

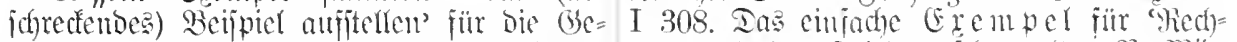

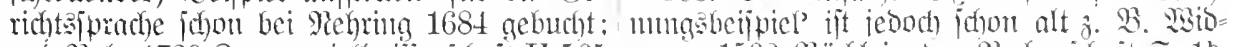

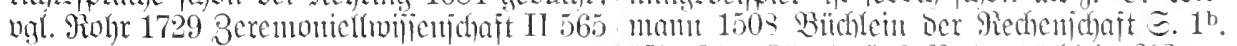

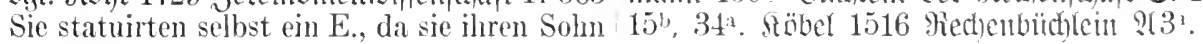

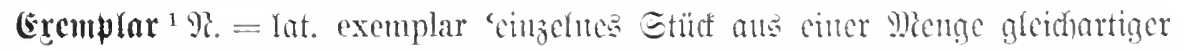

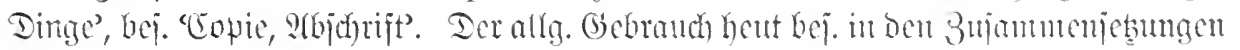

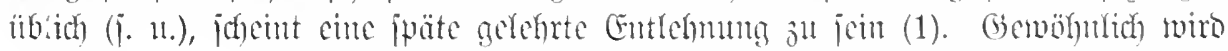

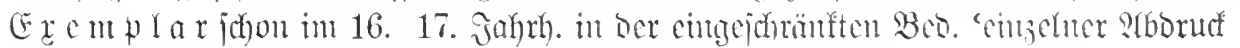

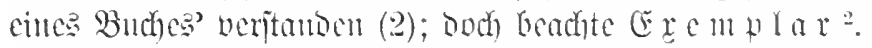

Belege: 1. Seume 1803 Epajiergang(II59) habe. Golts 1847 Buch ber Simobeit E. 144 eine Art ron Eidechsen, von der man erst seit Feldsteine, worunter E.-e mit sogenanntem. Kurzen den Naturkundigen E.-e eingeschickt Katzengold. Dorher john ïbertr. bei Edjiller 
1784 Rabale (IV 332) Das schönste E. einer Blondine.

2. Tengler 1510 Rniempiegel $\mathfrak{A} 5^{\mathrm{a}}$ wie ir ab disem E. vernemen - solch $\mathrm{E}$. nit lenger bey meinen laanden verhalten. Cimicr 1521 gegen \&utber ङ. 27 Nach wölichem eyn itzlieher leßer seyn e. corrigiren mag. Paraceljus 1536 sisumarzmei if $1^{\mathrm{b}}$ lch hab dise Wundartzney geschriben in zway $\mathrm{E}$. ob bayde e. nit gleich wurdenn sein. - 1136 ebo. 1 216. 222. Siepler 1603 Spera I 439 -

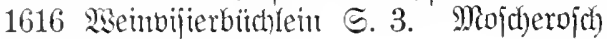
1642 Prgilander I 275.

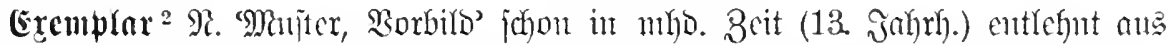
gleichbco. Yat. exemplar (cigtl. cin Ding im Serbältnis zu einer Menge gleichartig Gerzuftelfender Dinge) unb im 17. Jahrh. noch Durchaus grlänfig. Epäter Yebt Das Tart nux in Der G(bleitung exemplarifd fort.

Belege: Davio von 2lugghurg (um 1250)|gabeten Flyss. Edjilling 1668 Totengerüjt bei Pfciffer, Deutidje Mijitifer I 344 wan du ङ. 19 e. vorgeleuchtet. 1677 Madjiabell. ein gemeinez und ein volkomenez exemplâr f̧ocuspocts હ. 544 weil die Herren ihnen e.

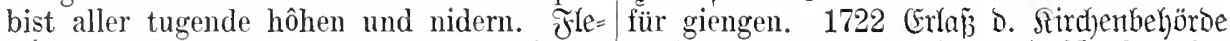

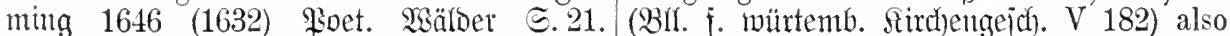
O Modul aller Angst! o E. zu dulden! Rauten= im Leben e.-er sich bezengen. Rabner 1759 berg 1652 厄dherzgebidyte $\Xi .10$ Van juw man hebben moet da rechte $E$., Vnd dat Original, darna men sick sehal kleden. Echilling 1668 Totengerüift ङ. $290 \mathrm{zum}$ einigen E. vorstellen.

exemplarija) 2(D) "vorbild lide) jeit Ënde Des 16. Falyths. bezengt (1), neuerbinge fait völlig ant bic Serbindung "eremplatijche Etrafe" (val. (Exe mpe ( 3) bejoräntt (2). Belege: 1. 2llbertinus 1599 Gúbatas Eemb= idreiben III 64 $4^{\mathrm{b}}$ Einem e.-en Priester 1601 Geitit. Epiegel ङ. $91^{\text {b }}$ ein e. klöster-

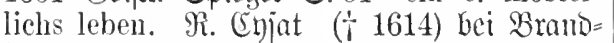
Itetter $§ 12$ durch diser würdigen Vätter Jesuitten flyssige Leer, e. Läben vnd be-
Frciexentplar (孔山 2) 子. B. Schiller 1795 Brieje IV 123.

Pradtcrentular (วu 1) Şeine 1830 Stalien (III 220) mit einem P. dieser Gattung, mit einem Demagogen von Handwerk. $\mathfrak{P} u$ uffer 1835 Eemilaffo III 15 der Weg von Baguères hierher wird ewig ein P. in dem Bilderbuche meines Lebens bleiben. Shomnits 1845 2alt siselt I 83 das P. eines Studenten der Hedizin. (3olb 1847 Bud) D. Stimbheit E. 266 $P$. von Verstand und Gemûth.

Picịcucxcuplar (孔น 2) z. B. Fontane 1883 Briefe II 51 . Eattren 11120 sem landublicher Wucher und seine e.e Sparsamkeit. Laufbard $17^{* *}$ Molfitein I 62 dessen vortreffliche, e.-e Auffülurung. Rettelbedf 1821 Rebensbejd)r. II 280 ein e.-er Bürger.

2. 1628 Bemegl. Ermmenng wegen Der 5ugentoten $\left[t^{\text {a }}\right.$ Exemplarisehe straff. Stbele 1654 Gerichtshändel I 1471658 ebo. II 386 die e. Bestraffung - Saijenitus 1661 (5r= örtentug Der Duader E.212 - 9roel. Itijh= reben E. 156. - Ebenjo "cremularijd) ftrafen" 3. \$3. Böffler 1665 Edjola militaris $\Xi .74$. Dalgover 1687 Gartenbectlein I 621 ${ }^{\mathrm{a}}$.

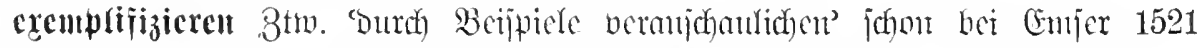

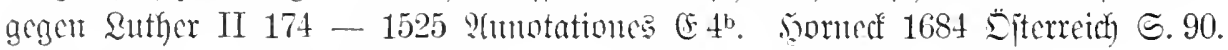
Ducle: mlat. exemplificare.

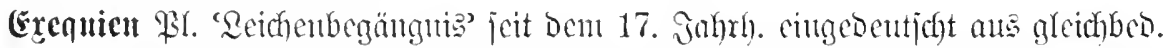
lat. ex(s)equiae cight. 'Bug Der Reiotragenden'. Belege: Edhilling 1668 Sathol.

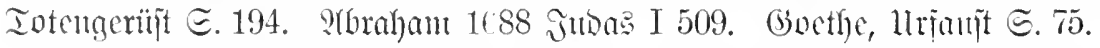

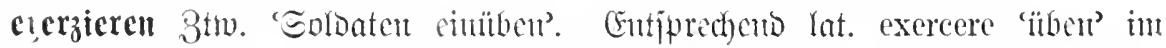

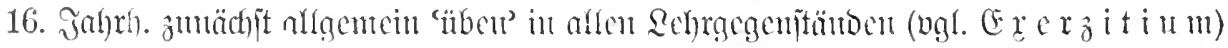
3. B. Prätorit: 161? Syntagma musiem II 53 Daruff [auf Der Mamboline] etliche dermassen exercirt seyn. Licbe 1665 9icitbuch) $\subseteq .12$ so müssen solche Pferde wohl in traben exerciret werden. Für bie lïbutgen ber Solbaten ift bafher anfäuglich ciu

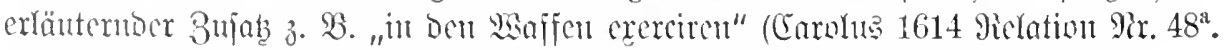

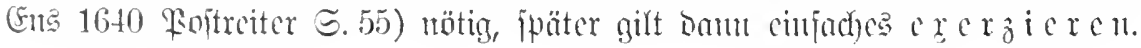


Belege: 1664 llnterrebung eines llngan und Dentichen (s) 3 a $/ u$ der \%eit waren gute exercirte Völcker rorhanden. Böfler 1665 Schola militaris $\Xi 28$ seine Völcker exereiren zu lassen. Echiel $167 t$ Ethand= 1. Raiterchronif ङ. 132 exereierte Schiitzen. 1684 Getröftetes Guropa $\mathbb{C} 3^{\text {b }}$ exercirte Mannschaft. Bolfoner 1714 Yiümberi neiperibes II D $4^{\mathrm{a}} \mathrm{zum}$ täglichen Exerciren der Soldaten.

Ererzicrulat3 M. 3. 边. Iridter 1742 Ritter

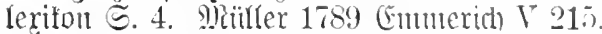
2(rchentholz 1790 Eiebenjähy. S̊rieg $\Xi .45$ mit einer bewnderswïrdigen Ordnung, als ob sie auf dem Exercierplatz gewesen wären. Dafür älter Exelsitien=pla sib Siltch 1608 siriegabud ङ. 118.

Exerjitium $\mathfrak{R}=$ lat. exercitium aflg. 'übung' 子. B̉. Enzinger 1590 Relationen I 167 das öffentlich Exercitium Göttliches worts. Mlbertims 1599 (suctaras Eend=

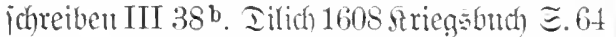
Von den Exercitien and Kriegsübungen.
Ianu in ber Eduliprache bes 16. Tahrha. ani

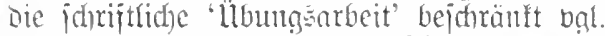
exercitium styli 1569 Braumidneia. Echul= orommugen II $37-1596$ ebo. I 129. Saeife

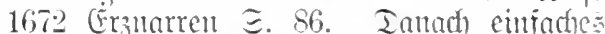
Erercitin un sicije 1697 Bertraute (be ipräche RI. 21 7 b in etliehen Schnlen, da man alle sech: Wochen mit einem Exercitio zufrieden ist. Etonwe 17:28 Brebichte I 197 Denn als mein schwacher Kiel lateinisch schreiben sollte [in Der Ectule]. So dirigirtest du das Exercitium. 1755 Braumdirs. Echullorbungen II 389 ein kleines exercitium, welches die schïler zn hause elaboriren. 1765 ?tla. stich. Bibliothet I 1, 7.2 Schulexercitien - 1766 ebo. II 2, 13.) Exercitien-Schreiben. Soctoer 1767 T. Rite= ratur (I 412) nach Horaz Exercitien zu machen. Woritz 1786 Yuton Reijer $\Xi .133$ sein sogenanntes Exercitium. Stokebue 1803 llhr u. Miantoltorte (XVI 271) Exercitia.

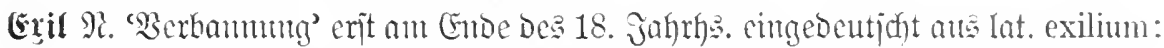

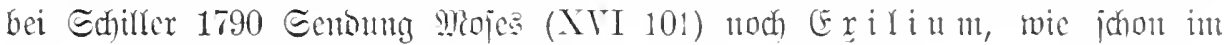

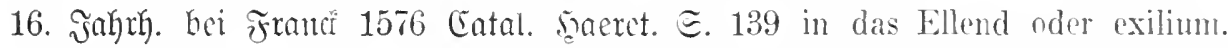
1600 Fontes rex. auftriac. LX 2 in das exilium rerstossen. Fortunanoer 1706 Der galante Menjch こ. 331 ins Exilimm weichen müssen.

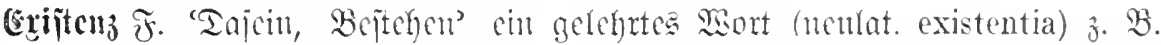
Secfenoorff 1685 chrijtenjtaat II 11 der Atheismus oder die grobe Meynung wider Gottes Existenz, reden und Eigenschafiten. crifticreu (aus lat. existere) ner= zeidunet Sächtrer 1709.

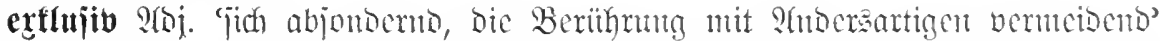
um 1830 ans engl. exclusive übernommen und als Sort Der "mobernen llmigang

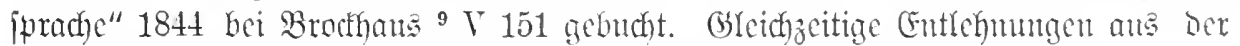

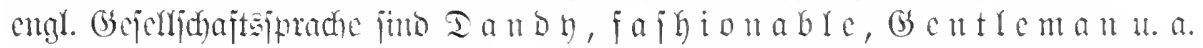

Belege: [Fürtler 1831 Bricje I 187 In I siven" zählen sich die alten, hochadeliegen der exclusiven Gesellschaft Londons.] Raube reichsfürstlichen und reichsgräflichen Häuser, 1837 Reijenonellen V 470 Der Berliner ist deßgleichen etliche aus Polen, Frankreich, grob, zanksüchtig, ohne Sentimentalitit, England und Italien eingewanderten.

eitel, exklusir. Das letzte Wort liebt er sehr, ohne zu wissen, was es bedeutet; „Dies find' ich sehr exklusiv" ist ein gewölunlicher Ausdruck, wem er sieh in die Brust wirft. Remald 1813 Iie Mappe $\Xi .82$ Sie sind so exclusiv wie möglich. Eđüuting 1859 (Exzäblungen II 148 einer sonst so exclusiven jungen Dame.

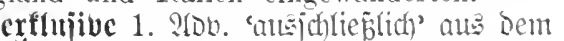
Stanzleilatein (exclusive 9fov. ztt mlat. exclusivus) ichon jriily in Den bentichen sontert eingefingt 3. 3. 1558 5eibelberg. Etatuten ङ.46 ron dem montag nach Estomihi inclusive biß uff den montag naeb Invocavit exclusive. Böffer 1665 Eđhola milit. 5.72 hohe Officirer biB auff die Rittmeister und

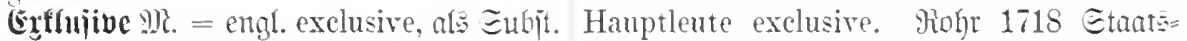
bei M)urray feit 1825 belegt. Belege: Gamon flugheit E. 617 Bluts-Freunde biB zum dritten 1839 13:ob. Siaris (VI 121) die Eleganz des Grad exchsive. Nitiller 1789 Cmmerid) VI Anzugs zeigte in ihm den Exclusiven. Ehorv= 232 bis zur Küchenmagd exklusive. Ђ马a iٓ

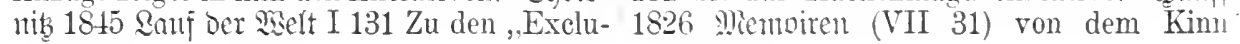


inclusive bis auf das Brustbein exclu- (I 193) exclusive der Gerichtssporteln. (ónethe sive.

2. Geit Enbe Des 18. Fahrhe. aud als 1780 Brieje IV 244 mit 130 rh. jährlich,

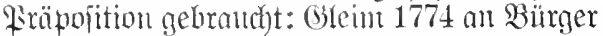

(Exfonmmutifation F. im 16. Jahrh. meijt nod) in lat. Form 3. B. 1525 Wegiprech gen Regensburg (Schade III 173) excommunicaziones. Carion 1532 Chronica 5.155

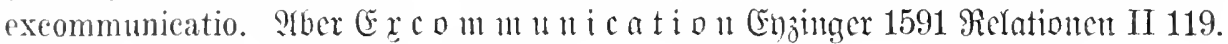
III 58.

crfoumuntzicren 3 tw. ein Den Sirchenbon deins patrimoniums, excommuniciern. Ca= tun" nadh Dem firchenlat. excommunicare rion 1532 Chronica E. $134^{\text {a }}$ Bapst Gregorius 'au Der (semeinfofift [Der Sirdse] aus= VII. zuvor Hiltebrant genant, der Henricum

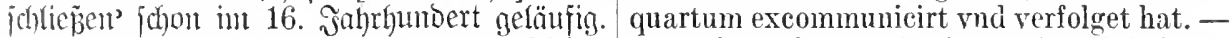

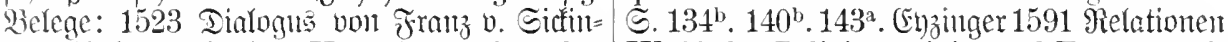
gen (Echade, Entiren II 47) Du meinst den IIl 62 der Religion privirt rnd Excommunigewalt der schlüßel, zu binden, uf zu lösen, cirt.

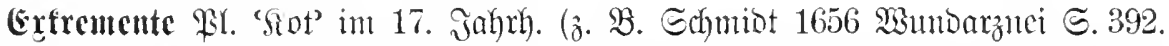

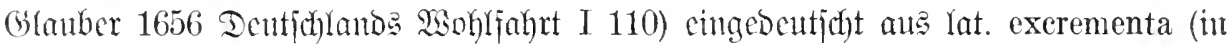
biejer Form noch bei Dietenhaujer 1599 şaubud) $\mathbb{S} 1^{\text {b. }}$. Brimmelshaujen 1669 Eimpl. ૬.91.520).

Exfure M. 'beigegebene Thbanolung, Shbang' erjt im 19. Jahrh. aus Der (be= lehrtenfprade (flaij. Philologic?) befannt geworben; vgl. Jean Paul 1797 Jubeljenior Є. 236 Ieh will wie Heyne und Heidenreich die Abhandhungen Excursus nennen. Mein Erster Excursus über den Kirchenschlaf ist dieser — $\subsetneq .242$ Mein dritter Excurs soll den vornehmen Unglauben berïhren. Duelle: lat. excursus safbidweifung in Meben'.

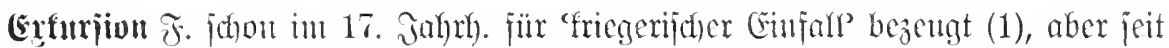

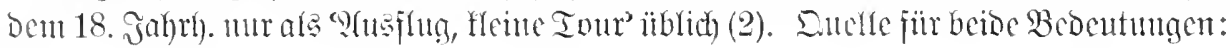
frj. excursion.

Bclege: 1. 1689 Bolit. Fliegenwedel II 71 im Sommer eine kleine E. anher machen. eine Barbarische Nation, welche die Christen- (Bteim 1774 ant Bürger (III 55). Qfrchenholz heit mit keinen offentlichen Kriegen, oder 1787 Staliest I 128. Edhiller 1796 Briefe rauberischen Excursionen verfolget. IV 451. Brun 1806 Epijonen I 37. (Gopethe

2. 2eijing 1770 Briefe (XVII 360) Wie 1809 sablbertuanojhaften (XX 287). sehr wünschte ich, daß Sie selbst einmahl

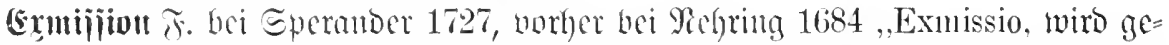

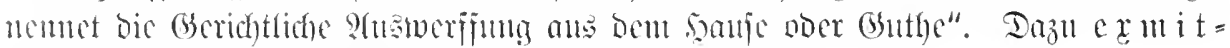
t i e r en (aus fat. exmittere) bei wäd)ter 1709.

crorbitant 9(oj. 'anjergenöbulidh, ïbertricben' ciu sanjleimort: ans lat. exorbitans zut exorbitare (bgl. gleidber. fro. exorbitant).

Belege: Rohr 1718 Etaatsfughe it S.917/ Yuzeigen II 401 seinen PaBionen, anf eine dits augenscheinliche Monopolium, welches e.-(2 Art, nach gehangen. Reffing 1771 Briefe die Hofländer mit ilıren Gewürtze treiben, (XVII 403). Eeume 1806 Meent Eommer und zwar so e., dab Teutschland billig die (IV 60).

Augen alufthun solte. Subervig 1744 (Bel.

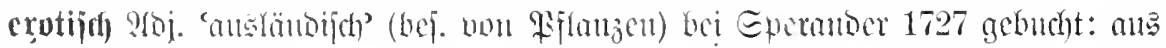
lat. exoticus.

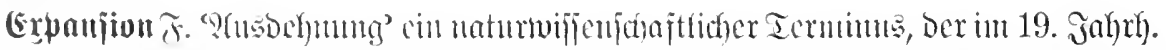

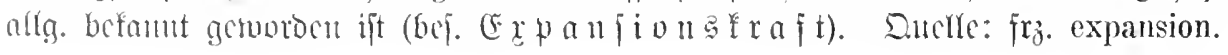


Bgl. Görreß 1821 Europa $\Xi .37$ wie Vorherrschen der beyden chemischen Kräfte dort jene wechselnde Contraktion und Ex- sich entwickelt.

pansion des Besitzstandes im alternirenden

expedicren 3tw. "Fertig madjen' an Ende des 16. Jahrhe. aus lat. expedire 'in Stano, in Bereitjchaft jeben' cuttehnt; neucroing bejonders als 'zum Fortgehen

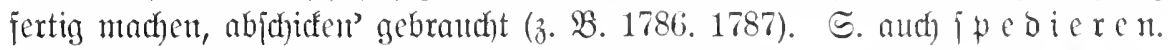

Belege: Fijd)art 1575 (5)argantua $\subseteq .270 \mid 1670$ Eecuritas publica (I 224). Belege er] nam die Paternoster für sich: welehe für blopes Expedition: Mefierjumid förmlicher zu expedieren, vnd darauß zu- 1618 Barzoniz Yarrenipital $\Xi .102$ zur Zeit kommen, saB er auff ein alten abgeribenem der E. vnd Kriegszuges. 1633 Stomftanzex Maulesel. Bredtel 1591 Büdjemmeifterei Belngerung E. 39 bei dieser E. vor Costantz.

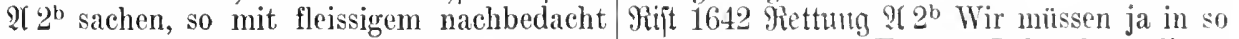
expedirt und verrichtet werden müssen. mancher schwerer E. vnser Leben hasardiren. Soct 1601 Bhumenfeld $\subseteq .55$ wart auff der Sehreiber gnadt, Die jhm sollen expediren. YGele 1658 Geridytägünel II 316 ich bin nm expedirt, ich reise nach Haub. Edjilling on 1668 Totengeriift $\Subset .271$ alBdann expedirt der Todt jhn. Grinmelahaujen 1669 Simplic. ङ. 86 wan einer expedirt ward, daß er weder sitzen, gehen oder stehen mehr konte. Gdjuffer 1783 Briefe I 98 weil ich mein Schauspiel gern expediert hätte 1786 ebo. 279 das dritte Heft auf das schnellste zu expediren. Miüller 1787 (Enmerich III 181 Als der Domestik expediret war. Bahrot

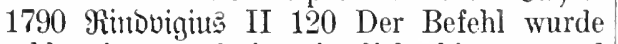
schleunigst und in ziemlich bittern und hämischen Ausdrücken expedirt.

Expedition $\mathfrak{F} .1$. im 16. Jahrh. ans lat.

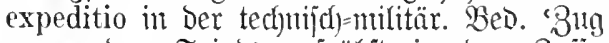
gegen Den Feind zufrült in Der 3 uif. Siriegserpedition: Enzinger 1590 Relationen I 2. Difbaum 1597 2qurilis $\mathfrak{B} 1^{\mathrm{b}}$. Mengering 1638 巨olnatenteufel $\Xi .208$.

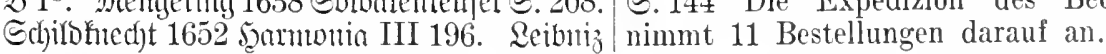

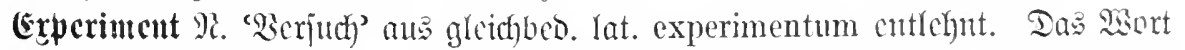
bünerte fid ein mit bem ?affonmen ber Erperimentalphnjif (jeit Bacon von Berulam

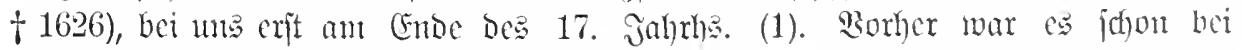

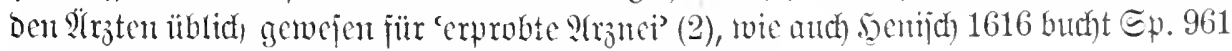
„Experiment verjudgt :Hentene; medicina experta."

Belege: 1. Reiuniz 1671 Biriej an $\mathrm{D}$. v. Ghericfe, Den Erfinder Der Ruftpumpe (I 264) jeber] wird dennoch, wemm er anders eine Ader der Billigkeit in sich hat, der Experimenta (welche so beschaffen sind, $\mathrm{da} B$ sie nicht von ungefähr, sondern durch reifes Nachsinnen gefunden) hohe Wichtigkeit bekemnen müssen. Gorbon 1746 Eve

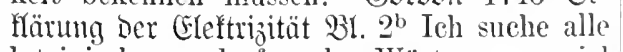
lateinische und fremde Wörter, so viel möglich, zu meiden: dahero brauche ich das anjetzo gewöhnliche Wort Versuch für Experiment, versuchen für probiren.

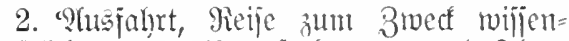
jojaftlicher u. a. linterjuchungen' vgl. Fing= blatt v. 1596 ,20nt Francisci Draci Jntiiche ober 2(merijhe Expedition." 2(rohenfolz 1787 Gngland III 285 Man schickte eine E. nach der andern, sowohl nach dem Südmeer, als nach dem Nordpol. Fittfler 1840 Bifloer= jaal I 340 Nordpolexpedition.

3. Saur Deutidy ijt Der (bebraud) bon Expedition "für Den Srt, wo etwas $a b=$ voer zugejertigt twirb" (Campe 1801): jo bej. in 3 eitungacpedition: Edfmid 1775 Énronologie des $D$. Theater ङ.197. ๔d)lözer 1782 હtantsanzeiger I 2orber. Mr. 9. 24ud Po it exped it i on Sampe 1801.

4. „werben aud) Diejenigen Perjonen Darnuter verjtanden, welchen die ?Yusfertiguny ober afbjertigung zufonmm, twie wenn man jagt: Die Expedition der Literaturzeitung" Cantpe 1801. Beleg: 1790 Der Beobahter ভ.144 Die Expedizion des Beobachters

2. Tries 1519 Eniegel Der 24rznei $\Xi .107^{\mathrm{d}}$ Magst du dan wol brauchen dise nachgeschribuen experiment - $\Xi .166^{\mathrm{b}}$ Andere empirische experiment seint mit not zuschreibell. Paracelju 1536 isundarzmei 5. $29^{\mathrm{b}}$ sollicher stuck sind vil, die der mensch erfunden hat, rnd also ein Experiment gehayssen wurden. Es sind auch durch die Allchimisten, die mancherlay vertucken rnd mancherlay jnen zu handen stoßt, vilerlay experimenten erfaren. $\mathfrak{B} \mathfrak{e}=$ gardi 1539 Jinder fantitatis $\Xi .17^{b}$ Experimenta, das ist erfarene stücklin der artznei - 


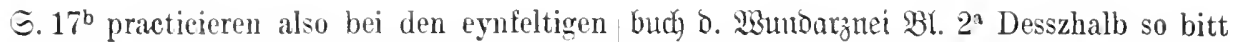
leuten mit jren Experimenten vnd meyster ich den lesser gar vss demütiger meynung, stücklin - $\Xi .2 t^{\prime \prime}$ Experiment stïcklin. mein Feldtbuch (als das zu feld, land vnd Tabernaemontanu 1588 Sträuterbuct) I $221^{\mathrm{b}}$ an allen orten zubruchen ist) nit lyederlich ein gewisses heylsanes Experiment - $155^{\mathrm{a}}$ verachten wöll, sondern $\mathrm{dz}$ vorhyn durch es hilfft sehr wol, vnd ist ein Experiment. vnd dureh wider lessen, experimentieren,

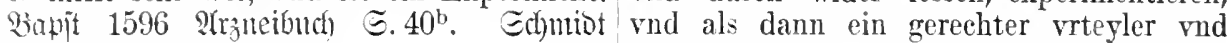

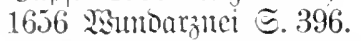

crperimentieren 3tw. 1. 'Erperimente

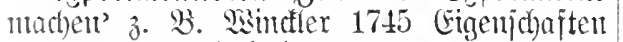
D. eleftr. Materie b $6^{b}$.

2. allg. 'verjuchen, exproben' nach mlat. nicht werde verzehrt). experimentare 3 . B. Gersouff 1526 ₹elo=

erplodieren 8tro. 'jerftallen, loggehen' erjt im 19. Jahrh. betamut getworden (bas sisort foblt noch bei ñube 1801 Paturlefre II 453 die Erscheinung, welche wir

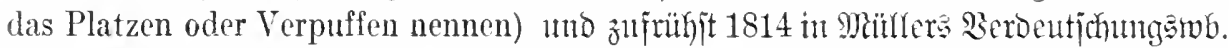

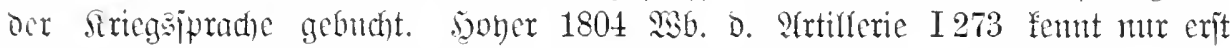
Explojion. Duelle: Iat. explodere 'flatictend forttreiben" (mur tram.).

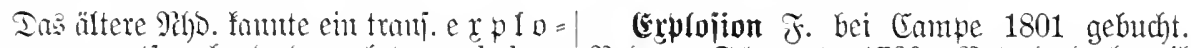
Dieren entjprechento Dem lat. explotere, Beleg: Edhubart 1789 Baterlandadhronif Das, eight. ein Theatertwort mit Der \$20. E. 222 die E. des Pulvers. Bzentano 1800 'ansflatichen, auszijden', übertr. als 'ver= Gututav \$iaja $\Xi .93$ Eine ganz sonderbare E. werfen, zurï̋weijen' gebraucht morben lvar: in Friedenszeiten. Das kömmt von dem

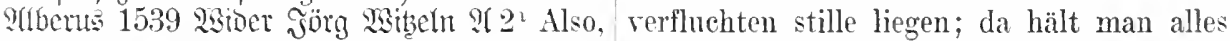
das dureh Mahomets lere die heylige schrifft Feuer beysammen, und ein kleiner Funke gar vffgehoben, explodirt vud verstoben ist. kann einen dann in die Luft sprengen. -

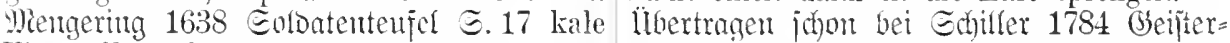
Einwürff, welche gründlich rentilirt vnd jeher (XIII 168) jugendliche Neigungen, explodiret seyn in den Kriegsfragen Herrn denen ein derber Körper und eine blïhende D. F. Gesundheit um so kraftrollere E.-en gab.

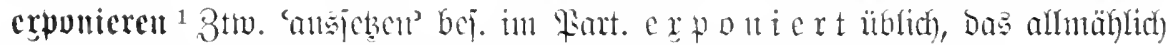

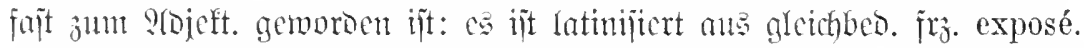

3elege: Fflorin 1749 santsvater II $416^{2}$ wie die hohen Waldbäume. Dhne aus=

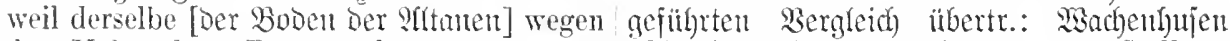
der Höhe dem Regen sehr exponirt ist. 1864 Rouge I 133 Van Geert, dessen Stellung כifflano 1796 2(0ovkaten (VII 23) Die jetzt mehr exponint war.

hohen Stellen sind dem Sturm exponirt,

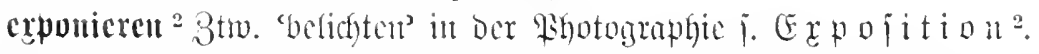

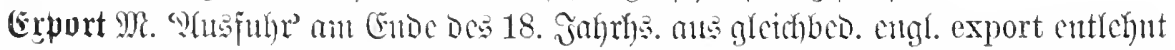

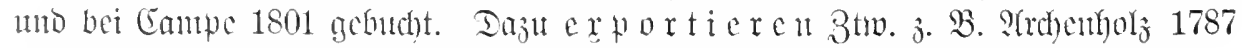
Englomo I 121 Glasgow allein exportirt jührlich 30,000 Faß Heringe.

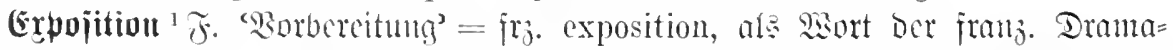

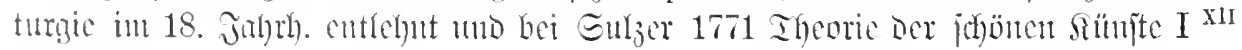
gebuct)t.

Belege: Deịing 1767 Dramaturgie (IX $\mid$ E. und Verwicklung hinweg und eilte dem $225)$ von uns Franzosen, sagt er [230ltaire!] interessanten fünften Acte zu. N⿴囗十) 1798

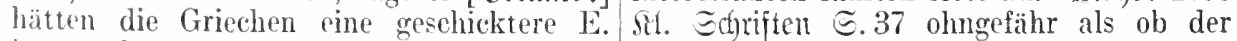
lernen können. Goetfe 1796 ¿ebriahre rierte Act eines Schauspiels, von E. und (XXI 38) meine Einbildungskraft sah ïber Auflösung getrennt, vorgetragen würde.

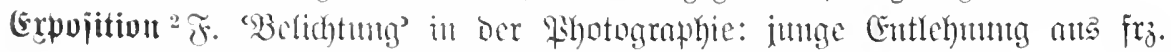

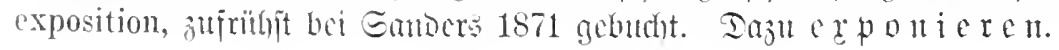




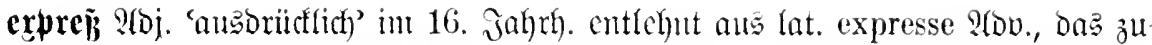

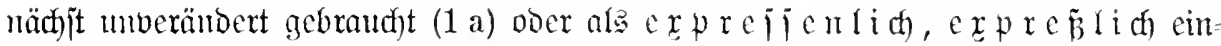

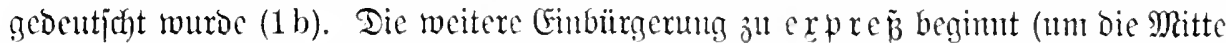

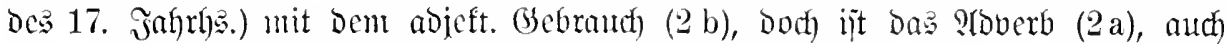
heute nod in ber Bolfajprad)e bej. gelüufiģ. SRur in literar. Gebraud) lebt fort

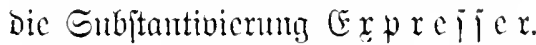

Belege: 1 a. 1600 Fontes rer. Puitriac. Mäller 1787 (Emmurich III 155 Ich bin LX 19 daß nit allein er Keplerus sich expresse expreß deswegen mit heransgekommen. in landthauss vernemben lassen. Afnoreas Gation 1837 Faben=fiaphad (VI 12) sich 1630 Gs müp̈t wohl ein Sulh lachen 5.73 expreß Deinetwegen zu bemühen. Ievrient expresse, außtruckenlich rnd deutlich. Mien= 1841 Trene Qiebe (III 66) der hatte ihm ein gering 1642 Bewijiensrïge $\Xi .1257$ expresse Fräulein expreß ausgesucht.

vnd benammentlich. Sureng 1662 weetjel= wraftif $\Xi$. 41 es sey dann, daß dieser Variation expresse gedacht. Rebentvalot 1681 Teujels Rifit VIII 71 da er doch expresse sagt. Francfe 1702 saijentians I 54 man hätte sich expresse in Halle erkundiget. Callen= bach 1714 (Eclipjes $\Xi .73$ Es ist zwar expresse befohlen.

b. Meder 1558 Grambel(bud @. $24^{\mathrm{a}}$ Auch sol einer in die Licentia expressenlich alle Wahren schreyben lassen. Sisalf amien 1616 Ritterfinit $\Im .23$ ob dieselbige Wort nicht allein anff die Kinder Israel, sondern auch rns meistentheils expreßlichen seyn geredt worden - 5.55 da dann expreßliehen auch dieses gemelt wird. 巨ticler 1683 Suditör ङ. 469 weil N. N. die Disposition expreslich vorbehalten haben.

b. Sorne 1641 Eomultatio \& $1^{\text {a }}$ ein expres verbot des Allwaltigen Gottes, Eecfendorif 1665 süujptenjtat II 169 dennoch wird von den meisten Regenten auff jhren [Der Räte] expressen Beyfall gedrungen. Sirätter 1681 Reben o. Eeehetoen ङ.401 wider gegebene expresse Ordre. Dallyober 1687 Gattenbeetlein I 257 $7^{\mathrm{b}}$ Ein offentlicher oder expresser vund ein heimblicher Fürsatz. Gruber 1697 Srieģobiaziplin II 49 ohne expressen Befehl. Finlitau 1700 Duactialber 厄.131 einen expressen Bothen.

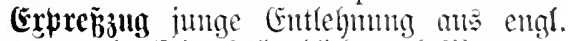
express train (jeit 1845 ïblich), Mad) Miurrab): bei Edjüffing 1865 Franen นt. Miätjel II 311 Einen Express-Train-Reisenden.

Exprefie M2. 'Ërfbote' all Endo des 17. Salhrb: anfommende Eubitantivierung aus

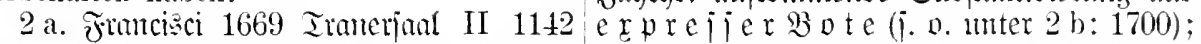
er begab sich auf cin Holländisch Galleot, Balege: Francisci 1681 Iranerjaal IV 362 so dazu expreb bestellet. Bnethe 1774 Er hat demnechst eilends einen Expressen Elabigo (Xl 69) vor diesem Herrn, der an den Toxogunsana abgefertigt. গ̊rämer expreB mit mir aus Frankreich gekommen 1681 Qehen D. Eeeheloen ङ. 309 . Ienţel ist. Edfiller 1781 Briefe I 33 so schrieb ich 1689 llnterrebungen $\Xi .71 .1699$ Etaat express Deinen Nahmen zu den unsrigen. Jipiegel II 98. Siürger 1773 Brieje I 143.

Expropriation $\mathfrak{F}$. heut jajt böllig Durd Enteignung erjest: im :

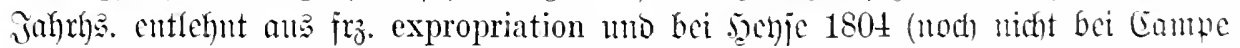

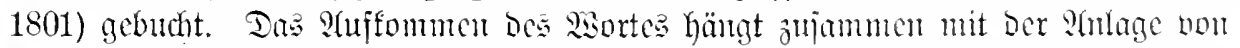

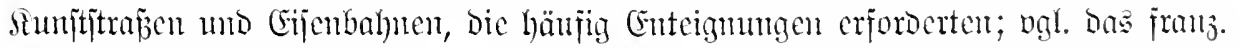

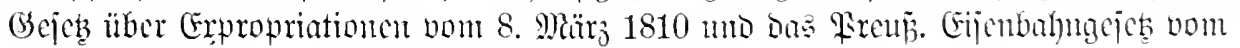

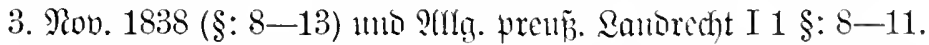

Bgl. 1838 Iie Ëijenbahn $\odot .217^{a}$ Glück- Fremdwörter nach der revolutionären 'Exliche Geschlechter, die ihr in die Grube ge- propriation' rergebens suchtet, wie seid fahren seid, ohne das infernalische Gebraus ihr zu beneiden! - $115^{\text {a }}$. die Berathung des der Locomotiven vernommen zu haben! Expropriations-Gesetzes Behufs Anlage von die ihr in Petris Handwörterbuch der Kinnststraßen.

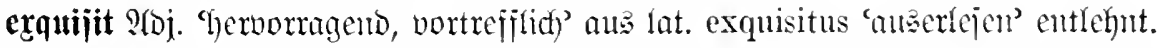

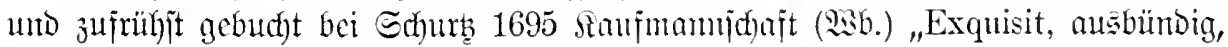
auserlejen." Beleg: Podagra 1721 :(pothefertod $\subseteq .5$ von ihren exquisiten Tugenden. 
ex tempore ?lon. cinc lat. Formel, bie in Dex Bedentung 'ans bem Etegreif'

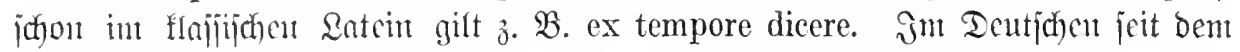

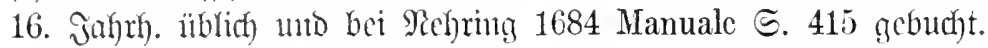

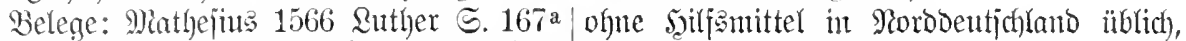

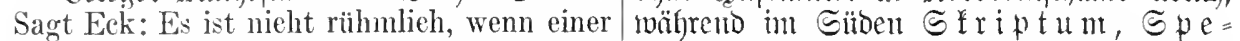
nieht bald rnd ex tempore antworten kann. 1580 5jeiberb. Etatuten 5.205 der ex tempore zimblich lateinisch reden und schreiben konde. 1596 Braunf d)weig. Sdyloromungen J 136 das sie dieselbe ex tempore vertirn. Prätorius 1666 inthropobemus I 240 der ex tempore allerhand kleine gläserne Bilder blasen kundte. Becher 1668 Methodus bibactica $\widetilde{\varsigma} .123^{\mathrm{b}}$ ohn einiges weiter nachsinnen, außwendig, alsobald ex tempore. Şeije 1672 Gronarten 5.79 daß er mit dieser artigen Rede ex tempore auffgezogen kam. Thomajüs 1691 Bernumịtlehre II 131 indem sie sieh solehergestalt angewehnen ex tempore von allerhand Dingen zu raisonniren. Weije 1697 Bertraute Beipräche S. 15 wer zur Rede soll angeleitet werden, der soll sich extempore dazu schicken kömnen. Rofrr 1718 Etantsflugheit $\Xi$. 141 ex tempore bey allerhand ihm vorfallenden Fällen zu reden. Bicanber 1727 (bebichte S. 478 Ich hielt die Predigt her, und zwar ex tempore. Matthejon 1739 Sapellmeijter $\subseteq .474$ eine Fuge nach vorgesehriebenem themate, alsobald, stehenden Fußes, oder (wie man redet) ex tempore durchzuarbeiten. Michaelis 1773 Maijome= ment III 304 ex tempore gründlich beantworten.

Ertempurale $\Re$. cforriftliche l̈tberjetang Verse extemporirte. zime $u$, aud $\subseteq$ til gilt. Extemporale jteht verfürat fitr seriptum extemporale (bgl. Lat. oratio extemporalis); es jeflt nod) bei Campe 1813 unb Szeming 1818.

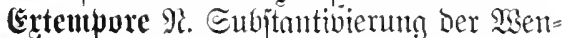
bung ex tempore, sie im 19. Salhrh. in Der Theateripradie Durd)oringt 3 . B. Düringer 1841. Theaterlerifon $\Xi .204$ Censurwidrige E.-s. Etinde 1886 æimbertruppe ङ. 17 Das E. war von mir selbst.

extemtworieren 3tw. 'ans den હtegreif tun': Peubiloung bes 17. Julgrbs. zu ex tempore (ygl. imirovi i ere n). Bunädjt galt es in ber Sdutte z. S. SBeife 1697 Bertr. (Sejpräche v. D. Snfurmation 5.145 Allein es ward aueh oben vom extemporiren gesetzt, da muß ich bekennen, daß ieh fast den Terminum nicht verstche.

Epäter aud am Thenter: Edylegel 1741 Edfriften S. 36 der Comoediant, der ihn vorstellet, muB extemporiren. Rejijing 1759 Siteraturbrieje (VIII 42) (sottidfeb] legte seinen Fluch auf das extemporiren. Echitler 1785 Briefe I 226 daß sie [Die Edaupieler] ihrer Bequemlichkeit mit Extemporieren zu Hülfe kommen - 1789 (Geifterjeher (IV 278) extemporiert dasselbe schmelzende Adagio. Bahrot 1790 Lebensejuichte I 39 daß er

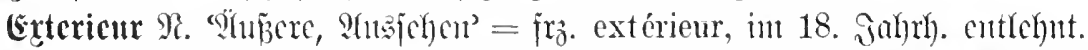

Belege: Iridter 1742 9itterlerifor II 367 es muß immer ein Mamn von einem 5. 2079 ein gesetztes und wohlgeordnetes E. gewissen E. seyn, das einem leidtragenden annchmen. Edytller 1783 Brieje I 104 Herzen keine Schande macht. Sauffarb Zweifeln Sie, daß Herr v. W., wenn ilmm alle 1804 Eulerfapper 5.226 daß Mosjeh und jene Umstände, mit meinem E. verbunden, Madame in Rüeksicht des E.-s einander gesagt werden, den Augenblick auf mich vollkommen ähmlich sehen.

fallen werde. Ridtenberg 1795 seggarth

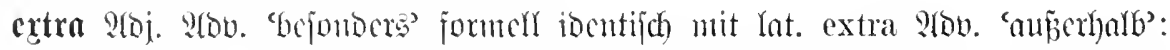

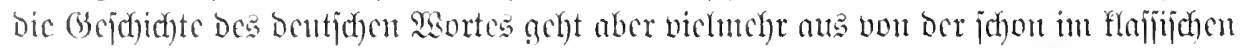

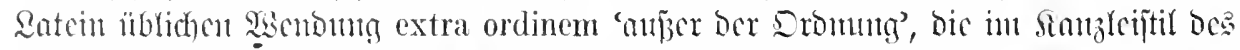

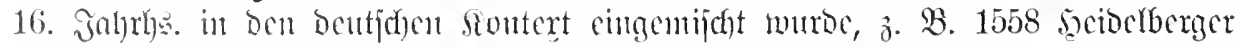
Etatuten $\Xi .144$ demselben mag extra ordinem ettwas weiters umb sein bar geld zugelassen werden - $\subseteq .146$ so iemand extra ordinem wein und brott begert bereingelt aud) ciufad)s extra (S. 138 kein wein weder extra noch zum dische zu

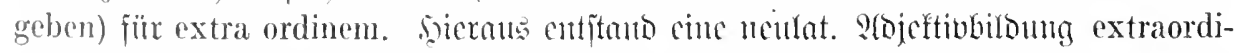

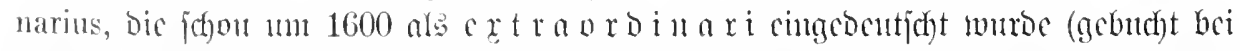

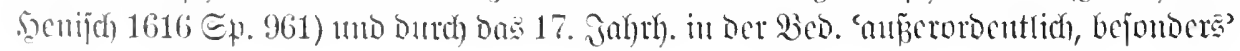




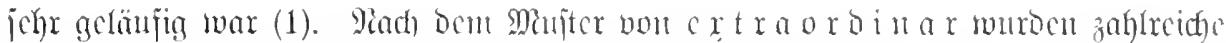
hybribe Bildungen gcjefaffen, bou bencu extrafleifige, Extrakurier mo Extrapost

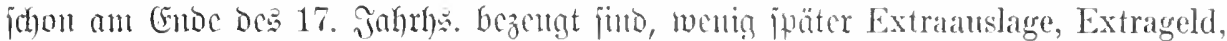
Extrasteuer, Extrastunde (j. 11.) Bei Der llmjekung vou Bifommen wie Extraauslage

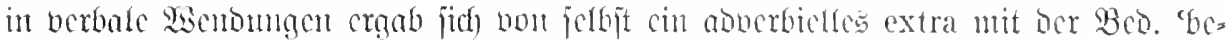

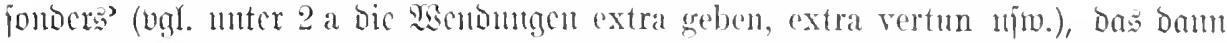

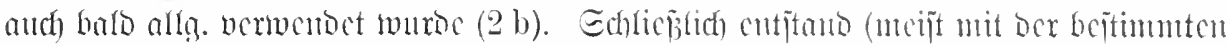

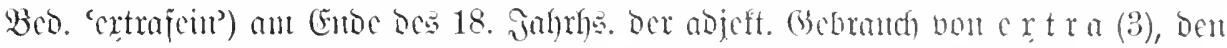

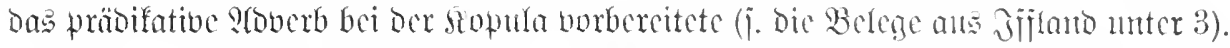

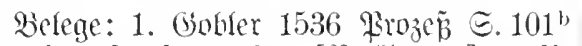
Wo aber der bürg den [Berffagtent] arglistigklich nit bringt, so mag er extraordinarie grestrafft werden. Eaut 1583 Etrojbuch $\odot .458$ mitlere vud extraordinari Straff. Tilbaum 1597 Tamuar $203^{\mathrm{a}}$ zul lieser Extraordinari vnterhaltung. Difish 1608 striegsbuch 5.265 Es sind die hanlfen Ordinary oder Extraordinary. Corolus 1614 Retation Sir. $10^{\text {b }}$ so ist ein Extra Ordinari Currir beim selben Gubernator ingelangt. Temmahr 1633 ‥ Nuffitano $\Xi .381$ daß sie vber die vngewöhnlichen extraordinari Steuern geklagt haben. Wartin 1637 Ratement $\Xi .115$ ein andere extraordinari Reichssachen. Miengering 1638 Gervifjenstweder $\subseteq .113$ in extra ordinar Fällen - 1642 Bewijjenstïge $\Subset .959$ oft ist hierüber ein extraordinari Anlage herans kommen. Echun 1659 Salenoer $\$ 312^{\mathrm{b}}$ Nun plegt man an einem solehen Tage wohl etwas extra ordinari zu thun. Grumelshaujen 1669 Simthl. હ. 310 mein extra ordinari Glïek. Francisci 1669 Iratterjal II 877 mit einer extraordinar-Assistenz. 1689 Folit. Fllegen= twebel I 40 bey so vielen extraordinari Auf-

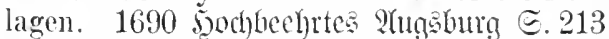
Die Zimmer von Jh. Kayserl. u. Königl. Majestät waren extraordinair herrlich. 夥all 1786 Bagatelfon I 17 Der Manm gefällt mir mit sant seiner extraordinären Liebeserklärung. Siffland 1795 Reije nach o. Etant (II 70) Es ist nichts Extraordinäres.

2 a. Menantes (1705) Rofgebicht $\left(53^{b}\right.$ Und Küch und Keller darf dir wenig extra geben.

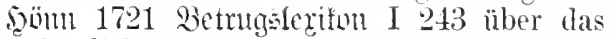
ordentliche noch etwas extra begehren. Pi $=$ eander 1727 (bebidhte E. 482 und was ich extra noch und zwar sehr viel verthan, das schreib ich nieht eimmahl mit auf dem Zeddel an. Eperander 1727 Є. 250". Was man extra brauchet, ist, was man nieht an ordentliehen Ausgaben verthut.

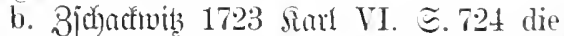
Stände wurden in einem besonderen Hause extra regalirt. Goethe 1776 Etella (V'I 129)

(d) $\mathrm{l}_{\mathrm{z}}$, fremowörterbud.
Du hast auch was extra verdient - 1796

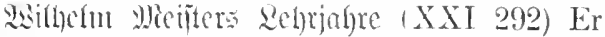
wubte den Schanspiclern manche Bouteille Champagner extra zu verschaffen. Echiller 1794 Brieje IV 77 da das Avertissement noch extra vorgedruckt wird. Gotzebue 1803 Toditer Panranuis (XVI 1901) Da ist eine Rolle von fünfaig Louisel or, und hier sind noch fünf extra.

3. Miüller 1778 Tautit: Qeben E.42 ey! ey! was Extras! Jffland 1792 Jumenitand (VII 138) Ja der Pariser [Inbaf] war inmer extra - 1801 soubgen (VII34) einen 48er Hochheimer, der war extra. Sacflümber 1852 Etill= fried II 34. Fontane 1859 sirieje I 107 Diese Extraanrede mub natiurlich was extra s bedeuten.

Gmerfung. Gn Der Eprade Des 17. Juhnth. erjocint eimfaches extra bereits in smei Füllen, die indes noul ber eigentlidfell (jese= ichichte bes gavortes zu tremuen jinto:

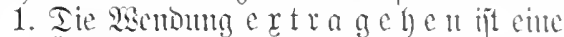
hatbe llberietumg vou nlat. extravagari ans fitweifen' (bgl. extrabagant). Befege: Tleming 1646 Geoidhte I $69 \mathrm{ob}$ sie sei extra

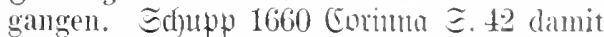
sein alter Vater nicht erfahre, daß er extra gangen sey. Simmun 1669 (jelomangel in Ieutjdylamid E. 391 Dagegen das Weib extral geht und den Mann zum detäons Bilde und Bruder machet. Ihomajus 1688 Mnomats gejuräche I 305 weil sonderlich seine Liebste ein wenig in Geschrey wal, dab sie extra gienge. Litfelgäring 1685 slemeraje $\Xi .187$ Sein untergebener Edelmann war extra gangen, vielleicht siell bey seinem Ursel-Blondinchen nene Affection zu erwerben. Qfmarmthes 1710 Proben ber Poejte 3.425 Julia nirft ihm vor, er miste ohmfehlbar extria gehen. 1719 Recueil V 84. Ríantoer 1727 Gesidute 厄.24t Was Extra-Gehen heist, das sey ihr Fest. Etopte 1735 Lama $\Xi .427$ la ${ }^{\circ}$ mich extra gehent.

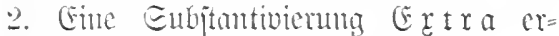

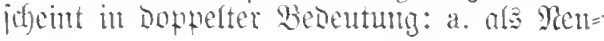


trum fïr 'Gejondere 2Usgaben' 子. B. 1549 Seibelberger llifindenbuth I 242 soll furter der famulus das extra von den schuldigen personen einpringen. Mienfort 1636 B. D. 5jodfiduten $\Xi .197$ sey ihm aber von Tisch vnd extra rber die sechszig oder achtzig Thaler schuldig - 5.322 Nun setzet ein Academischer Banckethierer keine geringe Summa was des Jahrs auff Tisch, Extra, Fechtbolen, Reitschul, Lanten-Schlager, Sprach Meister nsw. gangen. $230 n$ setue nod) ans Miojcheroidf 1650 \$ifilander I 348 mn Somupins 1669 Edfriften $\Xi .54$; nathae=

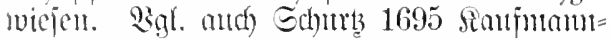
jofhaft (296.) ,Extra, aujerfalb, oner jonjten aujeronsinari Stuggaben". Go nod) in

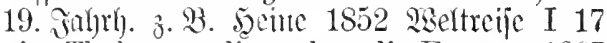
vier Thaler per diem ohne die Extras. 1867 Reb. Bifoer a. o. mod. Rariz II 2 ङ.29 Achthundert Franken die Extras nicht gerechnet. Fontane 1883 Brieje II 47 Wir würden an dem Wegfall eines selbstverdienten und für Garderobe zu verausgabenden Extras micht zugrunde gehen.

b. „Extra. St. Der bejte ssein" Echurb

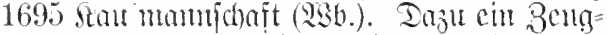

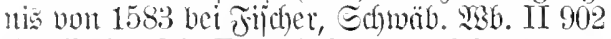
So vil die Wein Extra belangt, welche ansserhalb des ordenlichen bestimbten Weins gegebenin.

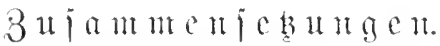

Ertranımabe bei Cambe 1801 s. v. Extra; aber extra A us lagen ichou bei (Sallenbach 1714 Qnasi ङ. 11. Fleijher 1731 Serr v. Sndio II 90 zu meinen jährlichen Extra-Ausgaben hundert Reichsthaler. 2QRitt v. Dörring 1828 Fragmente III 123.

Extrablatt bei Beitutuen 'mäer=

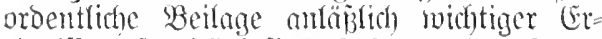
cignifie' erit bei sompins 1818 gebucht. Fret)= tog 1866 SUffiäbe I 288 Extrablïtter melden fast zu jeder Stmude Botschaften. Toutane 1888 Briefe II 191 immerzu werden Extrablätter insugerufen.

extrajein mumbartlich bef. berbreitet: nach

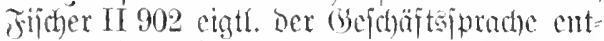
Ftanumeno. Beleac: Stubener 1759 Entiren $11 \mathrm{I}$ 88 leh erwarte künftige Nenjahrsmesse etliche Körbe Champrenuer, otwas extra feines [Brief cines şembänolers]. Bürger 1777 Briefe II 120 Die Waare, wie du weist, ist

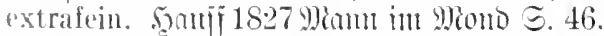
5ecime 1830 Jtalien (III 332).

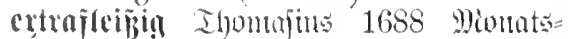
gejpräble I 461 wemm einer ein Jahr oder viere anff Universitaten hat $\operatorname{sein} L=D_{0}$
Seine?] extra fleiBig gemacht. Miffer 1778 (Bejd). St. v. Burgheim IV 151.

Ertrajorderm! Eeume 1803 Epazier= gatta (II 95).

Ertragerd Picander 1727 (Sebichte 5.557 die giebt mir allemahl 2. Thaler Extra-Geld. crtragut cigtt. weiomtïmifich nad) Sgeppe 1751 Rebrprinz S.64 Ein extragutes Stück heisset ein einzelnen Stück Wildpret von ausnehmender Stärke, Güte und Gestalt.

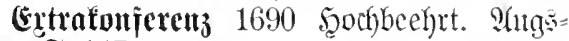
burq ङ. 147.

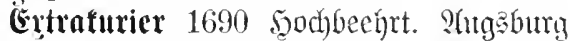
5. 147 Auch wurde gar spat ron den Chur-Bayrischen Hof ein extra Courier spedirt.

Ertrafuit Ettuer 1715 5ebamme Є.81 die armen Mägdchen machen ihnen manchmai eine Extra-Lnst. Epäter Ertraber= gु

Ertrapuit jeit, Frija 1741 s.6. II $67^{\text {b }}$ verzeidnet. Belege: Sieije 1697 Bertroute (bejpräche 5.5 Es hatten sich gleich zwey Personen resolviret, mit einer Extra-Post

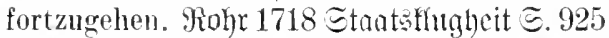
weun ordinaire und Extra-Posten einander begegnen, so haben die ordimairen den Vorzug und müssen die Extra-Posten diesen ausweichen. Rosagra 1721 \$rothefertod ङ.219 daß er mir mit der Extra-Post eine Sehachtel voll zur l'rob heran sende. Hicander 1727 (be" Dichte S. 461 eine Extra-Post nach Buxtehnde. Fleijher 1730 serr v. Eydio I 93 Ieh nahm derowegen sogleich Extra-Post. 17370utbed = ter Gilioijder Baldober ङ. 35 Sonntag Abends sey er per extra-Post von hier wieder abgrereiset - - eine Extra-Post nach Meiningen. sermes 1791 Riternt. Miärtyrer I 427. Sif =

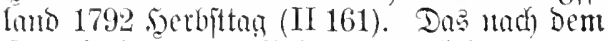
Buriadgeher bes 'Poftwagentwerfehrs unge= bränd)lid suerbentoe siburt erbält fid muto= artlich in oer Formel pere ext $r$ a p o jt mit Der ïbertr. Bebentumg 'jehr j(d)nell'.

Extrajteuer Eallenbach 1715 Duafi vero ङ. 65 merträgliche Contribution, Accisen, Don-Gratuiten, Extra-Stener.

Extraitumbe 1704 Sechelberger llufutoent. I 407 msere cantylisten, welehe olme daß die mehrste zeit und extra stundten mit mïssig gehen himbringen.

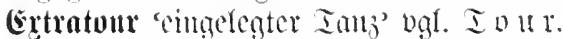

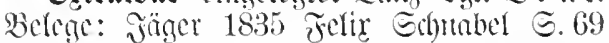
als ein kiuhner Knote voll der ermattenden Lisette eine Extratour begehrte. Devrient 1835 Grunft des ?tngenblids (I 183) die sich um einen Tanz für den nächsten Carneval, un eine einzige Extratour im Cotillon be- 
mühen - 1841 Irene Qiebe (IIT 111). Gro B̈=

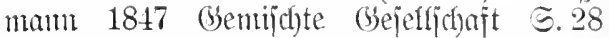
Klara, etwas fatiguirt vom Tanz, der, wie sie äußerte, in den vielen Extratouren sie ermüdet habe. Frentag 18555 Eolf und saben I 191 alte Herren vom Spieltisch zn Extratouren holen.

Crtrammiform Frentag 1855 zoll it. jaben II 140 in den Uberresten seiner 1894 \$son mix $\Xi .11$.

Extrauniform, die er sorgfältig anfgehoben hatte.

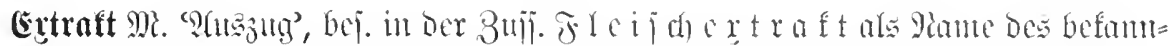

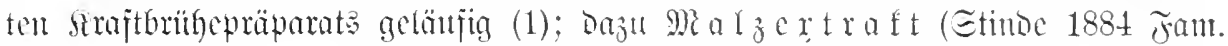

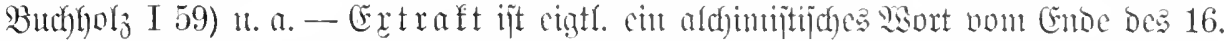

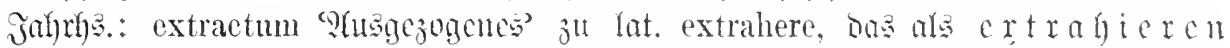

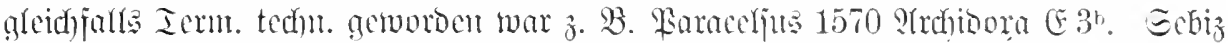

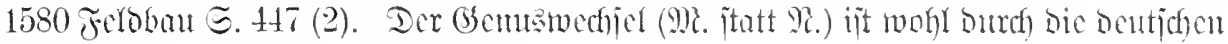
St)monnma Auszug, Saft veranlaijt.

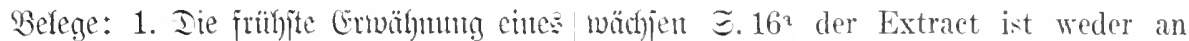
Fleijhertiafts bietet Reibuiz (in ben lltredyter der Subtilitet, Krafft noch wirckung so

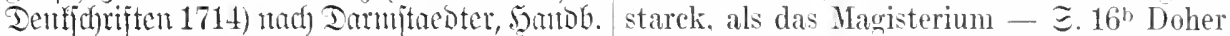

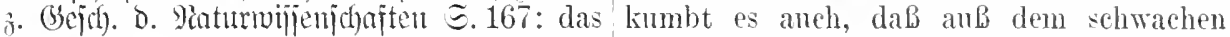
Extrakt aus Fleisch, dessen Komposition gleich starcke rnnd rermögliche Essentzen, mir bekannt. Tie moderne Fleijd)ertuft= Magisteria vnnd Extracta Extrahiret, ge-

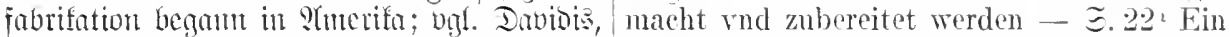

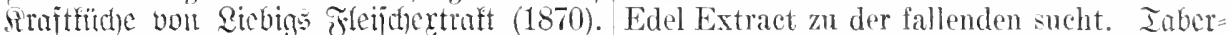

2. Ihumenfifer 1583 Enomajticon $\Xi .77$ mämontam 1588 strüterbud I 18 so findet das extract oder Essentialisch wesen des man den Extract vnden am Boden deß Eybenbaums - 1587 gijtoria v. Croge= Kolbens in der dicke eines Honigs.

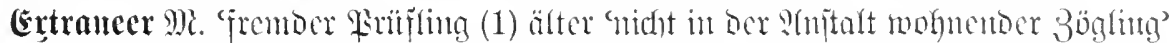
(2). Duefle: lat. extranens 'Frember'. Dafïr (j. B. ant Iharejiamm in seien) in Ber 2. Bed. E e t e r u e r.

Belege: 1. 1815 Progranm Des Gom= I 86 de extraneen, de by unseren borgern

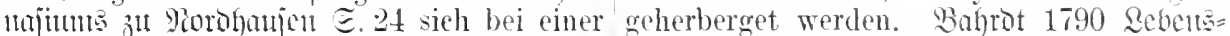
andern Anstalt als Abiturienten oder Ex- aejh. I $8 \pm$ Die Extranei, welche sich ron tranëen zur Maturitätspröfung melden - den Alumnen dadurch unterscheiden, daß 5. 25 ihre Zulassung als Extranöer. sie Kostgeld bezahlen und bei einem Lehrer

2. 1547 Bramijhineig. Edhuloronungen im Hause wohnen.

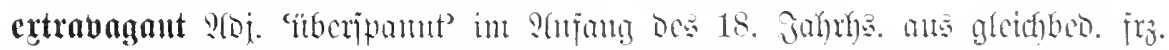

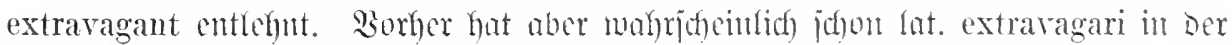

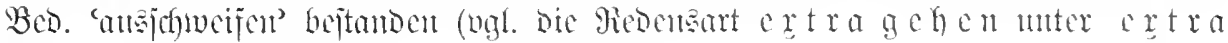

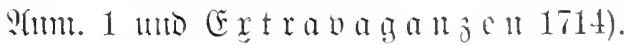

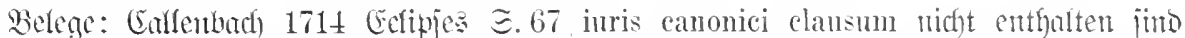
Sie ziert die Gesellschaften, wie der Esel mo Daher nidgt bie noffe ?hutorität des Ge=

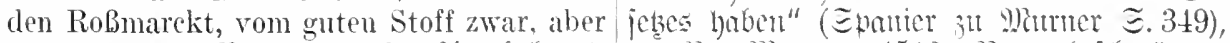

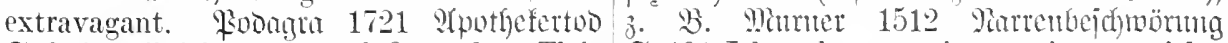
ङ.214 weil ich merkte, daß er dem Thée $\Xi .101$ Ich wolt gern wissen, wie man richt, gar zu extravagante Dinge zuschreibt.

Qumerfung. Edyon in 16. Juhry. tritt was ['exijtierte'] extranagandt, Do was gut

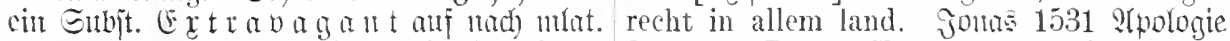
extraragantes "Defretrlien, Die in Corp. $\mathfrak{J}^{3}$ des Bapsts Extranagant röhmet vnd 
lobet solche Mönchische heuchlische armut mantad) $\subseteq .110$ ausser meines Herren Diensten viel zu hoch. Whathejü 1566 \&uther $\widetilde{S} .14^{\mathrm{b}} \mid \mathrm{zu}$ dergleichen Extravaganzien gebrancht Drauff leget jhm der Legat ein extrauaganten, werden. 1714 Reneröffnetes seintwirtshaus das ist ein Canon auß des Bapsts rechten für. ङ. 49 weleher dises oder jenes seiner Extra-

Extravagauzen nach $\left[\mathfrak{r}_{\mathfrak{z}}\right.$. extravaganees vaganzen und Excessen gebührender massen

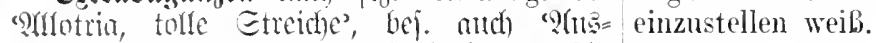

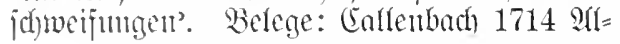

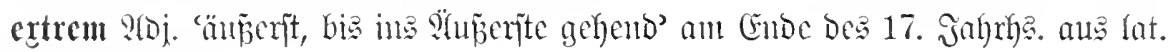
extremus cutlehnt.

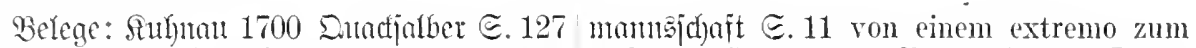
Solches redte sie mit einer extrem ver- andern. Jönn 1721 Betnigs liebten Stimme und Mine. Qabater 1778 Wemn wir von einem Extremo und äussersten Prgjiognom. Fragnente IV 126 gewisse zum andem fallen. Sejüng 1767 Itam extreme Linien. joutante 1897 ङtect)lin @.6 turgie (IX 274) dieses kömnte leicht das Er hörte gerne eine freie Meinung je drasti- andere Extremum werden, in das unsere seher und extremer, desto besser.

komischen Dichter verfielen - (321) die

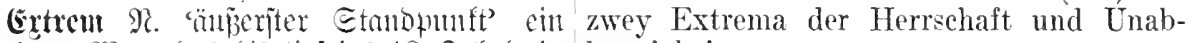

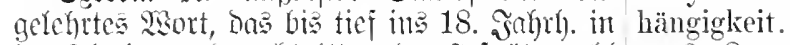

lat. Flerion gebrancht (1) unb erịt jpät, molsl auch unter Gimflnis von fro. extrème, als Extrem eingebuirgert wurbe (2). Dilefle:

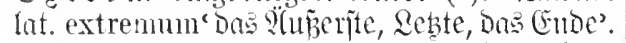
Belege: 1 . Eecfendorif 1665 Fïritenitant II 82 Es were auch $\mathrm{zu}$ wüntschen, daß man ron beyden Extremis abliesse - 175 ein Extremum. Gireffinger 1675 fomplimentier= bitchlein ङ.9 Diese nun hat gleich andern als Uebergang ron Einem Extrem zum Tugenden zwo Extrema. Reibuiz 1683 Andern. Goethe 1796 Refriagre (XXII 99) Émulymung $\Xi .311$ zu dem andern iber- ieh verfiel auf ein ander Extrem. schritt oder extreme fallen. 1702 stani $=$

2. Rabater 1775 Rghjingunur. Frag= mente I 60 die stark abstehenden Extreme von Schönheit und Häßlichkeit - $1776 \mathrm{ebo}$. II 8 so giebt es dennoch gewisse Extreme, gewisse Gestalten, Physiognomien. Edjiller 1784 Bricje I 207 zwisehen zwei Extremen. গungge 1788 ulumgana ङ. 89 diese beiden Extreme. Doitller 1789 (Emmerid V 114

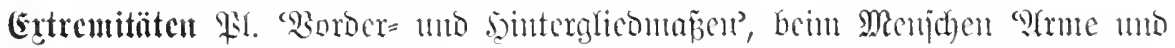

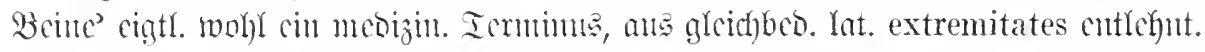

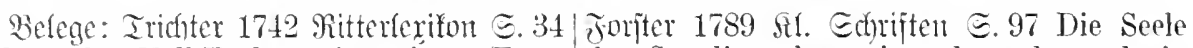
Licht- oder Hell-Fuchs, mit weissen E. - des Sänglings kan nirgends anders, als in S. 1054 schneeweisse Pferde, welche ent- seinen Füßen wohnen. Aueh beim Kinaben weder weisse oder gelblichte $E$. haben. verweilt sie noch in diesen E. Miener 1794

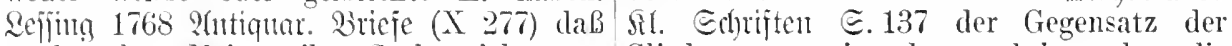
es der alten Meister ihre Sache nicht war, Glieder nuter einander, nul besonters die dergleichen E. so zerbrechlich auszuführen. Vertheilung der E.

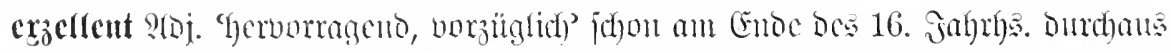
cingebürgert; cigtl. cin franz. Moocwoort (frz. excellent), bas aber früh latinificrt murbe (nach) docul gicin: genent 11. 1597).

Belege: Miangord 1596 Marfichiff \& $^{\mathrm{b}} 1^{\mathrm{b}}$ \& $6^{\text {* }}$ kömnen wirs nicht excellent machen. mit excellentem Wein - 1597 giatid iffís

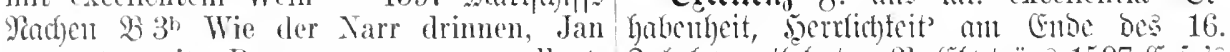

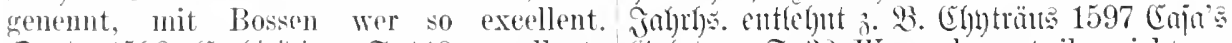
¿ntad 1598 Enchiridion $\Xi .119$ excellunte Galatens $\Xi .32$ Warumb sagt jhr nieht zu Köpff - E. 129 ein exeellenter sehiffhauen. mir, euwer Excellentz oder Elrenvest.

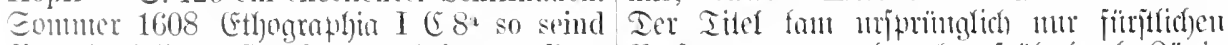

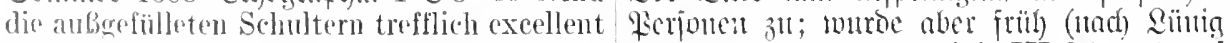
wat - I2: so sind obsemelts Hlosen excellent 1720 Theatum cercmutiale III $9^{2}$ ) aud auj gut. Rollenfagen 1614 Shuntes amenteg bie Gejanden oer fürjten ïbertragen. 


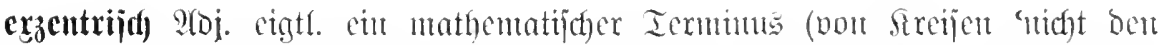

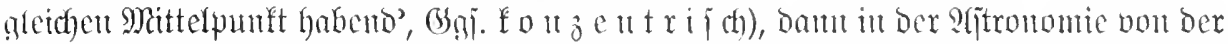

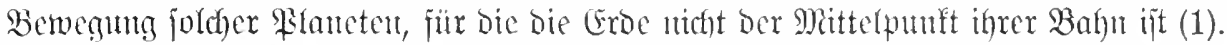

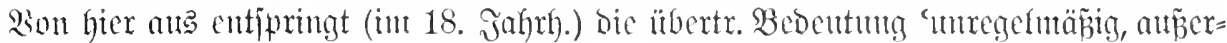
nedentlid), üforjpamt' (2). Duefle: meulat. excentricus für jpätlat. eccentricus.

Belege: 1. Edyentbjer 1711 Phy fiea II 59 hoch versteigen, endlich excentrisch werden. Sic Ptolentïer haben] von den Planeten- Sunigge 1788 llmgang $\Xi .124$ Kraftgenies Kreisen selber geurtheilet, dab sie excentrici und excentrisehe Lentr. Edhubart 1789

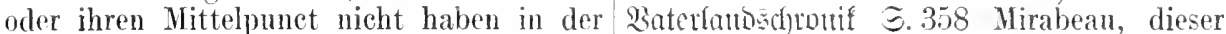

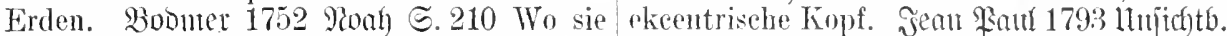
[Biancter] in ihrem excentrischen Weg Qoge (I 131) an ihren excentrischen Empfinunendlich umschweifend sich ron Himmel dungen - 1795 5ejperts (VIII 280) wiewol zu Himmel bewegen. Görres 1800 Siolit. exzentrische Menschen in die Wahrheit, Edriften I 83 die Ellipse eines excentrisehen wie die Kometen in die Sonne, als Nährstoff Cometen.

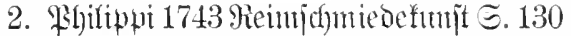
zuriickfallen. Stant 1798 inthropologie wemn sie [Foeten] manchmal sich gar zu

exzerpieren 3tw. 'Wußzüge, Motizen aus Edyriften machen' im 17. Jahrh. aus

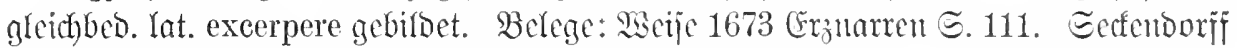
1685 Chrijtentatat I 8․ Thomajus 1688 Monategejpr. 1388 - 1691 :ermuftebre II 253.

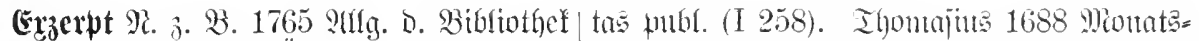
I 1 S.217 Excerpte. Sulter mir erit mit lat. gejpr. I 388 . Iented 1689 llnterreoungen Entoutg, hej. Excerpta: Leibuiz 1671 Sectri= E. 109. Dutelle: lat. excerptum.

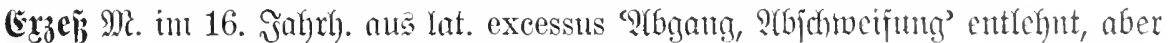
mur in folg. wrägnanten (unflofififgen) Bebeutungen übliç:

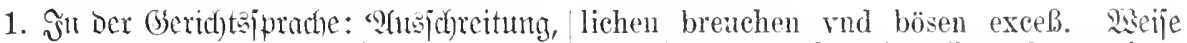

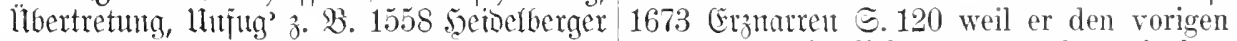
Etatuten ङ. 14 mit dem kercker ettlich Tag einen ziemlichen excess im trincken zeitlang nach gestalt des exceb gezuchtiget. begangen. Gröben 1694 Gsuineijd) Reijes

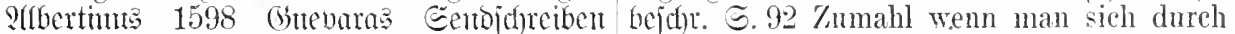
I 62a jhre excessen vnd verbrechen zu ihre Früchte zu erlaben sucht, und im Essen straffen - 1601 Deij. Geijtl. Epiegel ङ. 152: einen geringen Exceß begehet. Gónethe 1774 die groben Excef - 1603 Beitfinzer (5.29" \$iserther (XIX 123) Sie hat mir meine wann wir oder vuser Freund begangen Excesse vorgeworfen! ach, mit so viel haben etwa einen exceß. Sirch hof 1602 Liebenswürdigkeit! Heine Excesse, daß Mifituris bisciplinta $\$ .60$ welcher Exeeß ich mich manchmal ron einem Glase Wein schon vor anffgeruhtem Regiment begangen. verleiten lasse, eine Bonteille zn trinken.

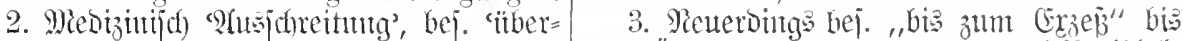

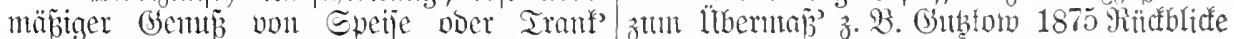
3. B. Baracelitt 1567 Ethreibent ?t $4^{2}$ AuB (XI100) aufbransend und unumgänglich bis schweche der spermaten vind vnordent- zmm Exceß.

๘.

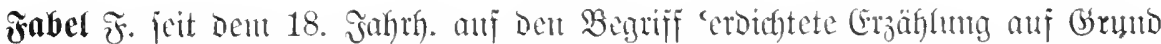

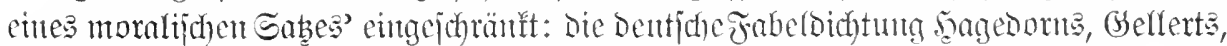

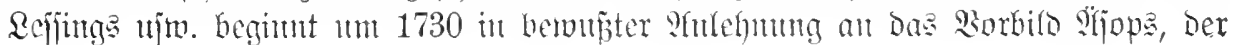




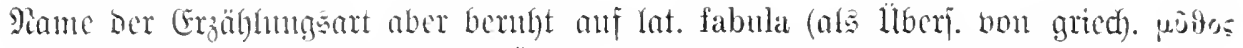

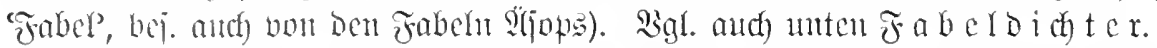

Echon tm 1200 aher war lat. fabula inn Srüger 1750 Iiät $\subseteq .411$ Diese Begebenheit allgemeinen Einn vout 'Eage, Eroichtnng, ist gewiß, sie mag uns anch noch so fabelhaft Eräthluma' eingebirgert (mbo. fabel) uto jo vorkommen.

ntod) bis ins 16. 17. Fabrh. ïblich. Epäter aber lebt bieje allg. Bebeutumg mur modh in

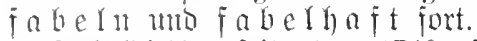

Fabeldidfex jeit etwa 1740 oft bezengt.

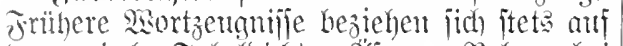
Den gried. Fabeloichter sijop. Belege bei

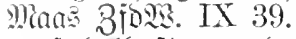

jabelu Btm. 'Fabeln madien, Didjten'

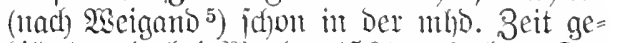
bildet mis bei Manler 1561 gebucht. Da= neken beftand lange

fabulicren ans lat. fabulari; jojon bei Pianti 1515 Eulcmipiegel $\Subset .3$ Kurtzweilige fröden vnd schwenck daruß fabulieren. $\Re_{i 0 c h}$

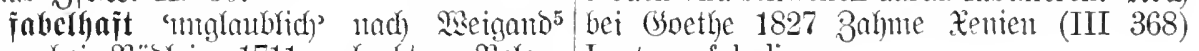

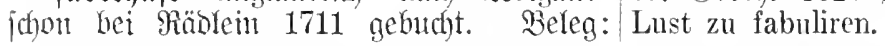

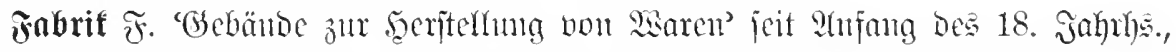

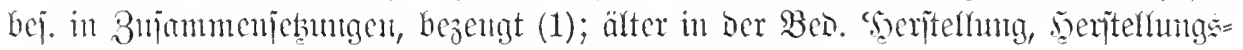
art' (2). Sucle fitr beide Bebeutungen: frz. fabrique.

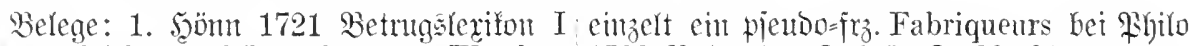
184 dergleichen auf ihren Hanmer-WTercken 1722 Rulm Des Iabafs 厄. 20. 21.

oder Fabriquen arbeitenden Leuten - 232 Kupfer-Fabrique. Etoppe 1735 Fama jam ein lat. Fart. fabricatum rerfertigtes') Fabrifat $\Re$. Dentiche Meubiloming (gleid)=

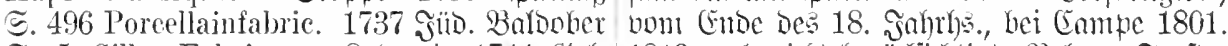

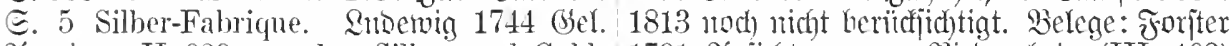

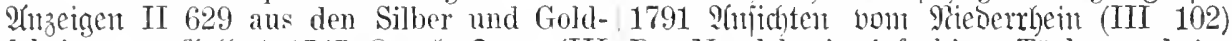
fabriquen. Geflert 1747 গranfe Frau (III Der Handel mit einfarbigen Tüchem scheint 416) Seidenfabrik. Florin 1749 Jambater indessen mngleich sicherer zu sein, indem II $380^{2}$ Glas-Fabriquen. (Goethe 1796 Qehr $=$ jahre (XXI 137) Es ist eine grobe Fabrik in dem Orte, the viele Lente ernährt.

2. Srafft 1683 Bedenfen v. D. Miamifal= turen $\Subset .163$ Ein sonderbahrer Vorschlag, welcher gestalt die Fabricq des Beutel-J'nchis ins künfftige also einzurichten. Som 1684 ¿̋terreich @. 184 So würde solche nachmals durch die einheimische Fabric so viel reichlicher und profitlicher ersetzt werden. -

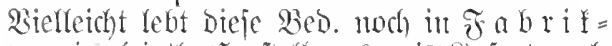
preis (eigtl. "Seritellumgsprcis??) jort; vgl. frz. prix de fabrique.

Fabrifantt M\%. nach) frò. fabricant (ältere Edyreibutg bei mis wie int Fro. mit qu). Belege: Sraffit 1683 Rebenten v. D. Mann= fafturen $\stackrel{\Xi}{\Xi} 49$ denen Fabriquanten, so solche Seyden verarbeiten lassen. jeorned 1684 sterreic $\approx 249$ den liinstichten denen Fabricanten in gewisen edlen Manu- 1684 zjterreid $\Subset .12$ anser Lands fabricirter facturen. - Jm 18. Jahth). allgemein, ber= Seithn-. Woll-, mnl Leinen-Effecten.

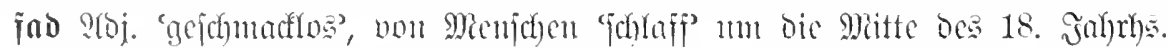

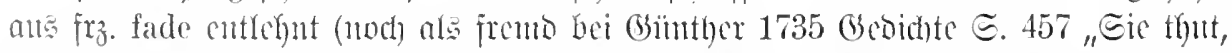

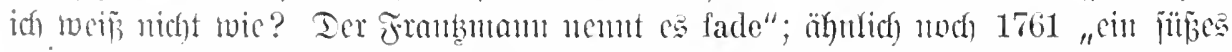

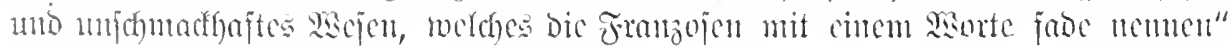
390mi. VIII 68.) 
Tas 2isort woiro icton 1767 in Rirent. (VII 21) der witzigen Moustasche und ihres

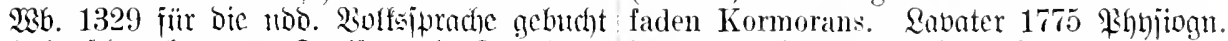

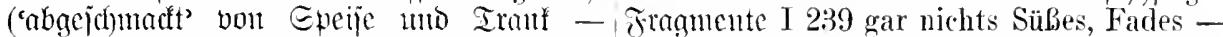

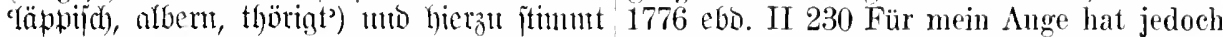
Der friilyte Seleg in Fichet) Bichr. Ter alte der änssere Gränzumrib des Gesichtes etwas

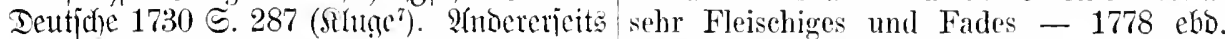

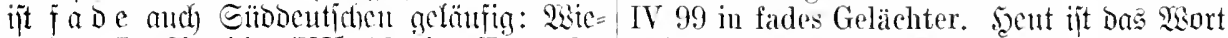
land 1771 Sfundis (XV 16) im Tone der (mit Beztehung anf Mienidhent) hel. in bayr.= fadsten Galanterie - 1772 (Gold. Epicgel ijterr. Eprachgebiet populör.

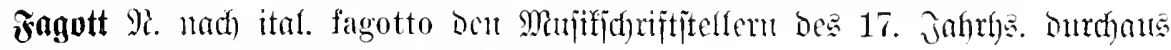

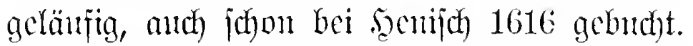

Belege: Frätorius 1614 Enntaqua mu='Fagott. Evere 1687 llnterr. v. o. muniffal.

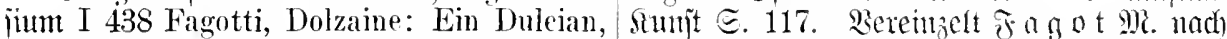
Fagott - $1619 \mathrm{ebo}$. II 14 Posaunen, Fa- frz. fagot Mi. Pooagra 1721 Spothefertod gotten - 46 Doppel Fagott. F̧irich 1662 હ. 168 So offt ich den Vagot nur blase. Rirders Mujurgia E. 114 dulcini oder Edyubart 1787 (Gebichte II 357.

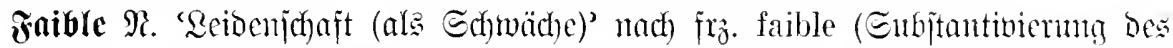

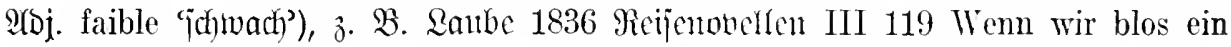
sogenanntes Faible für ein Mädchen gehabt haben, und das Stïckchen Leidenschaft aufgehört hat. $\mathfrak{B g l}$. anch $\mathfrak{T} \mathfrak{e} \| \mathfrak{d} \mathfrak{x}$.

$\mathfrak{F}_{3}$. faible $\mathfrak{M}$. bebcutet von 5 an a

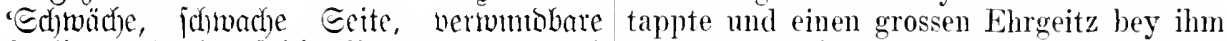

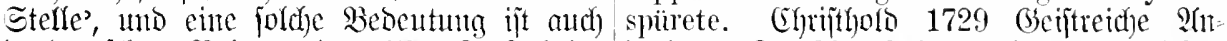
in Deutjden Belegen Des 17. 18. Jahrbs. Dadyten $\Subset$. 331 Wie derjenige, welcher Deutlich 3 . $\mathfrak{B}$. Thomajits 1688 Mconatsge= seinen Feinde beykommen will, dessen ipräd)e I 496 so that er anfänglich eine foible oder, wo er an sehwächsten ist, rergeraume Zeit der Königin Olympias Liebe stehen und ibn daselbst angreiffen muß. den höchsten Widerstand, biß ihn endlich

Fait accompli $=\mathfrak{f} \mathfrak{r}_{\mathfrak{z}}$. fait accompli 'vollentbete 2atjache', im 19. Jahrh. entlebut.

Belege: Fren 1844 Bilner Є. $120 \mathrm{Nm} /$ accompli himnehmen. Golk 1869 Kielt dürften sie bedenken, daß das was ich ffugheit II 124 ein welthistorisches fait wenigstens erlebt und durchgemacht, nn- accompli. Echerr 1870 Farrago $\Xi .14$ Segest widerleglich ein fait accompli ist. GŚä anerkannte dies ,fait aceompli" und halbrenner 1851 Zorfsfalentoer VI 40 als fait kulirte also.

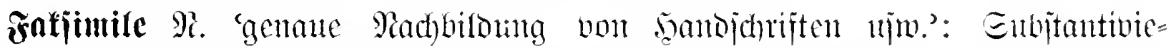

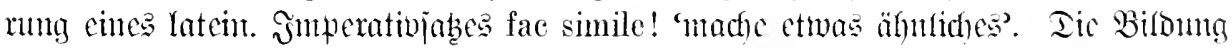
ift in England jobn im 17. Jahrh. bezengt; Den Dentjchen wsbb. ijt Das sisort nod int 18. Jahrh. vörrig fremb, Campe rämnt erit 1813 "bicjen jeltiamen ?hasond einen

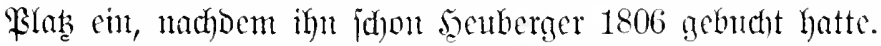

Beleg̣c: $\mathfrak{A}$. Crnmer: Individualitäten aus und über Paris, mit einem Fac simile von Klopstock. Amsterdam, Rohloff. 1806. (joethe 1816 গitulien. Reije (XXVII 86) -

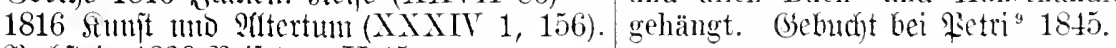
Bechjitein 1836 ßieijetage II 15.

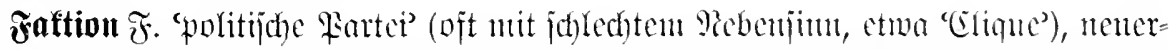

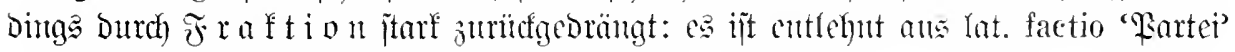
und jeit Dem 16. Jahrh. johr gclüufig.

Belege: Tranf 1538 Cryronif ber Teutjhen reutten vermöeht, das weschahe - $5.278^{\text {a }}$ 5. $194^{\text {a }}$ welche $\mathrm{f}$. die ander vertrucken, auß-Anno 1511 erhub sich ein f. vnder den 
burgem zu Costentz. Sleidan 1557 Chronica ङ. $183^{3}$ der Kerserischen vnnd Bäpstisehen f.-en. Mathein 1568 Siatm 133 ङ. $14^{a}$ to henget sieh ein jeder an sein $\mathrm{f}$. (Gebharb

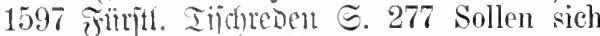
derhalben alle Freystätte befleissen, solchen f.-en bey zeiten zil begegnen. Siculai 1621 Weltrin." Bhtutrat $\Xi .23$ Rädelfïhrer der Venetianischen f. 1623 Bejdr. Der Ediladit bei Etuttloo $\Xi .1$ die Calvinische f. Grott= nits 1647 Regimentsat ङ. 516 Von Partheyligkeiten oder F.en. Francisci 1669 Itauer= fial Il 94, $1681 \mathrm{cbo}$. IT 486. 1684 Getröit. Europa of $4^{\text {a }}$ - Penere Belege nod bei Echubart 1775 Dentide Chronif E. 148. 185.

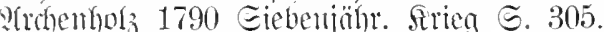
Görres 1819 Ientidhlano E. $20.129-1821$ Enropa E. 349.

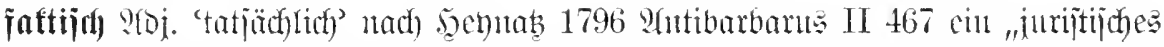

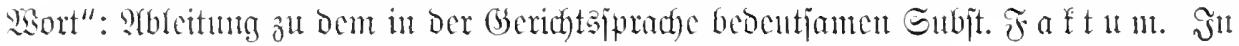

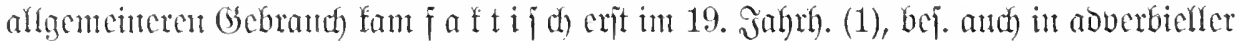

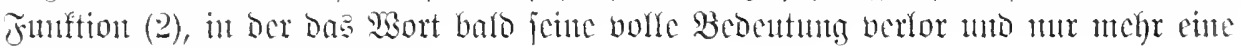

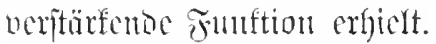

Belege: 1. Govethe 1798 Brieje XIll 325 so werden sie das Hypothetische vom F.-en besser tremmen - 1820 \inturiv. E(r)r. XI 131 Das Höchste wäre: zu begreifen, daß alles F.-e sehon Theorie ist. Geumte 1803 Epajier $=$ gantg (III 154) Glanben verdient nichts, als was in sieh konsequent und dureh rechtliche Zeugen f. erwiesen ist. Gibrres 1819 Tutfich = Into こ. 12 den f.-en Besitz - 1821 Emropa 5. 27 sie ist cinmal $\mathrm{f}$. in die Erscheinm getreten. 然itt n. Iörring 1828 Fraguente III 23 nur die Waluheit veranlaBt mich zu nachstehenden f. zuverlïscigen Bemerkmngen. Vormann 1833 Eiterteich I 2 ङ. 3 wollte ich ubenfalls erzählen als f., was möglich wäre

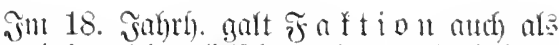

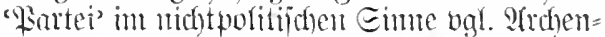
hulg 1787 Englamb III 156 Man lian ron dieser bewunderungswürdigen Künstlerin wohl sagen, daB sie alle F.-en und alle Kenner anfs rollkommenste befriedigt. Stuggge 1788 lutgang $\subseteq .77$ Laß dich weder darauf, noch überhaupt anf das ein, was Partei oder F. genannt werden kann. פigie= Iant 1789 Incian IV 443 Die Virtuosen dieser Art hatten, wie es scheint, damals anch ihre Partheyen mul F.-en, so gut als man vor und in unsern Tagen das Publikum zu London, Paris, Wien und andern großen Orten sich für Aktenrs, Sänger, Tänzer und Componisten in F.-en theilen gesehen hat. zu sehen, so könnte ich versichern .... . Gíasbrentuer 1836 Bifoer aus sien II 5 Man halte diese Erzählung für keine Fabel sie ist f. Bismard 1846 Briefe $\Subset .3$ Thr

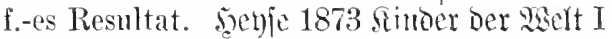
267 nach dieser kleinen f.-en Berichtignng. 2. (Gocthe 1828 giserfe II, XI 10 DaB ich diese Betrachtungen verfaßt, kann ich mich f. zwar nicht erimern. seine, Gebanfen (VII 425) f. sind wir also spracharm. Fion= tame 1856 Sriefe I 79 Ich wïrd' es auch f. nicht ertragen könmen, wenn diese Art zu leben nicht einigermaben zn meinen Neigungen stimmte.

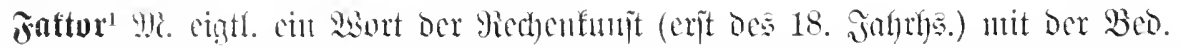

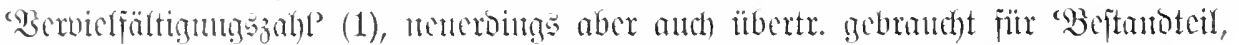
Dinn, das in Serbmoung mit ambert cin Probuft erzengt' (2). Duelle: lat. factor 'Urheber, Echionfer'.

Belege: 1. Seguter 1747 Borlejungen über gedfenfunjt E. 333 Derowegen unterscheidet man auch die zwo gegebene zahlen, leren eine clurch die andore zu multipliairen ist und giebt der einen sowolnl ais der andorn den Tamen rines Factors des herauszubringenten Products, wolches min anch ein Fartum nemet. Spingler 1772 Rechenfunt $\widetilde{G}$. 15 diese beyden werden dureh einen beylen unmeinen Namen die Faktores senemint. 


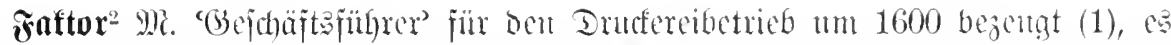

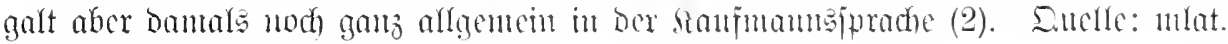

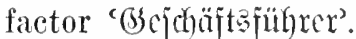

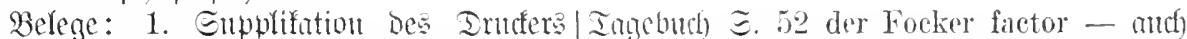

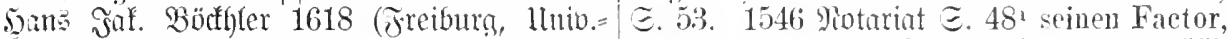
?(rchiv) daß mir, Seytemahlen ich solche Diener und Anwäld. Tébermann 15507 Druckherey wegen junge der Jahren allein Snbianijhe siitoria こ. 10 Daselbst fandt ich noch nit Regieren khan, ein getreïwer factor meiner herren der Welser factor. Mecer rnul Director Verordnet werde.

2. 1466 somilifhes Mrfundentud IX $296^{2}$ was bursijr unde factoer van den vor- Miejerjomid 1615 Epeltas Marrfeit II 40 noemden schepe gemaket. Diner 1520 Er verweset einen Factor oder Hauptvogt.

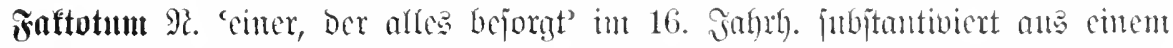

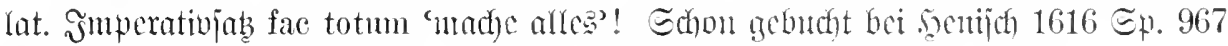
"Fac Totum, cin Ratcintije phrasis. Er ijt Das fac totum, ex ijt alles".

Belcge: Bucer 1540 Siriejuedfiel I $154 \mid$ uber maß unruwig und gesehefftig. Dit

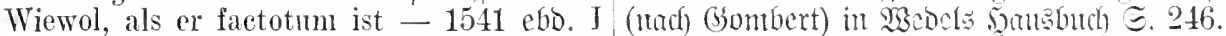
531 doctor Braun, der anch gantz director 313. 391. 45t (1560-1600).

negocii und, wie man sagt, das fac totum,

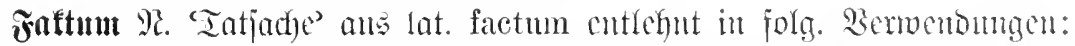

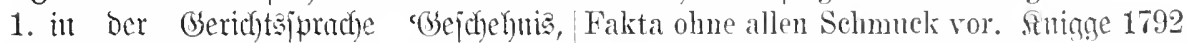
samblumg', bei. aud 'Defift' (bgl. aud) Reije ङ. 221 das F. war nicht zu leugnen, fattif (b). Belege: Santerbed 1559 gie= das Ehepaar drohte mit geriehtlicher Klage. gentenbud S. $157^{\mathrm{b}}$ da der Trabant das F. Pifinter 1814 firmtinaffäfle I 209 Erörterung

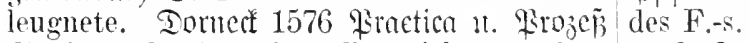

ธ. $4^{\text {b }}$ wo das $f$. an jum selbst nicht notorimm

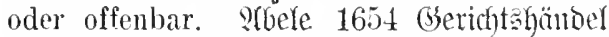
I 148 daß er das geklagte $\mathrm{F}$. begangen. Etieler 1683 ?tubitür E. 436 das f., d. i. die Streitsache, der Rechtshandel, oder die Geschicht. 1736 ighl. meuj. Esift (= 2noctwig (6) Y. Tuzeigen II 315) miüssen die Richter mit allem Fleiß daran seyn, daß das f. und der Thäter erforschet werde. Sisagner 1776

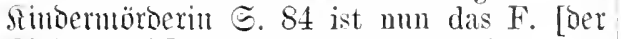
Simbesmoro], wie es der Anschein gibt, anch klar. Goeze 1778 Streitidyriften ङ. 61 daß man seinem Bedienten, in Absicht anf ein gewisses F., worauf aber sehr vieles ankïme, eine Lïge aufgebunden hätte, und derselbe solte mun vor Gericht anftreten und das aussagen, was er daron wüste. Mitfler 1789 (Emmerich VIII 309 zu dem Ende entschlob er sich, ein halbes Dntzend Rechtshändel durch den Druck bekannt zn machen. Er (VIII 23) die Wahrheit des F.-s zn kongieng dabei ganz simpel zu Werke, trug die statieren.

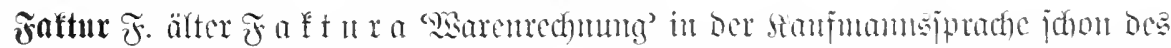
17. Jahrly. uiblid). Dnelle: ital. fattura, bas bei ber libermalyne latinifiert murde.

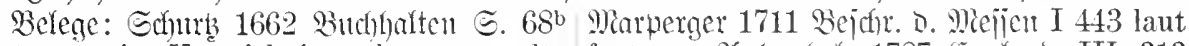
Factura, ein Verzeichniss über versandte factura. F(rd)enhols 1787 (Enalmo III 313 Wahren, Kosten vnd Vukosten - E. 11 In dieser kanfte die Weine laut Factura. Ter dieses Factura-Buch pflegt man zu speci- Rint. Fa a tu r c n bei Debrient 1839 Fobri= ficiren alle Wahren, so man pro seine Prop.- fint (II 265̃).

Handlung empfängt, nach laut der Factura. 


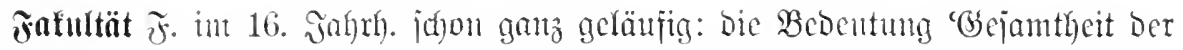

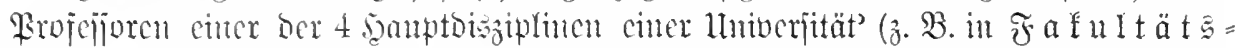

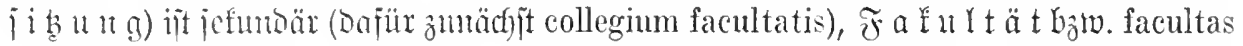

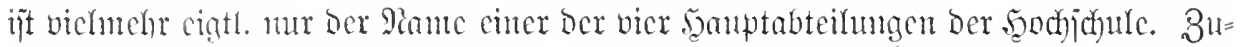

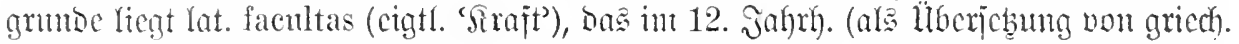

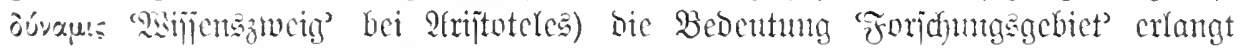
hatte. 2igl. Mnamay, ReSict. IV $16^{3}$.

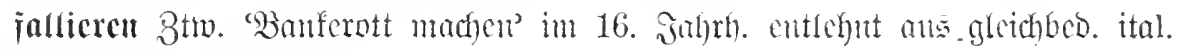

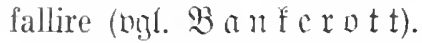

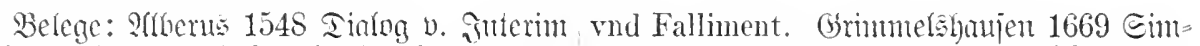
$\mathfrak{P}^{2} \mathrm{2}^{\mathrm{a}}$ die kaufleut heben ire händel so hoch pliz̆. . 282 Falliments-Sachen. Miarperger an, daß sie ihn nit hinauß kömmen führen 1717 Bejej)r. Der Banfen $\subseteq$ E. 213 Fallement. und müssen darüber entlaufen, welches man $\mathfrak{Y}$ (rchenthor 1787 (Englons II 57.

aufstehen heißt oder gefalliert; in Hispanien heißt es bankerota. CEarolus 1609 Relation शir. 51 a vmb 300000 fl. fallirt haben 1614 cho. 9ir. 32 zu Amsterdam soll ein vornemer Apotecker vmb $100000 \mathrm{fl}$. fallirt haben. Miengering 1642 Bestuifienterüge ङ. 1061 falliret vid panceornpt gemaclit. 1650 Ruĩt. Temớritus હ. S Ein Kaufmann so Panckerott gespielet oder wie man es heut etwas subtiler nennen thut, fellyret [sic! wohl Imuffehler] hat.

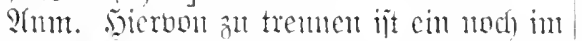

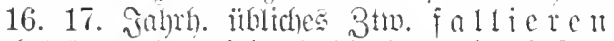

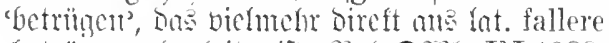

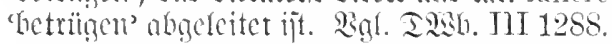

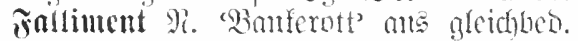
itul. fallimento. Belege: Raumbartner 1594 Briefe E. 232 Am sontag [huhe idf] von des Carl ImHoffs in Angspurg fallimentt allhie anch zeittong gehabtt, ist ein grob fallintent. Earnhis 1609 Relation 9ir. 27b Panckarott

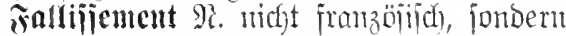

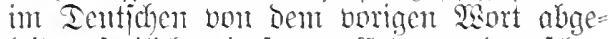
Ieitet, freilich mit jrans. Cortoung: bas iction hei Compe 1801 angejührte siont (,Falliment, ionit aud Fallisement") hat im 19. Э̧.

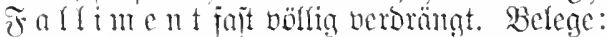

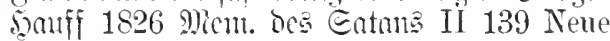
Fallissements, waas! - Ietrient 1839 Fabri= fant (II 281) das Gerücht von seinem Falissèment hatte sich verbreitet. Gutifow 1855 Iia= fonitijin (VII 38). Fontane 1891 Dutt ङ. 177. Dic Bildung entifamunt ichon bem 17. Gahrf.;

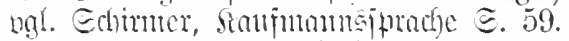

jallit luerden nach ital. andar fallito “Butferott madfen' (wobrti. 'gehen'). Belege: Ettner 1697 Toftor E. 907. Mlarperger 1711

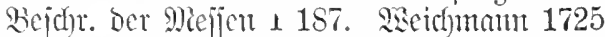
Roefie bet Ricberiachifu I 241. Rubewig 1744 (Bet. Qtuzeigen II 755. Tod) bei Edjurb 1695

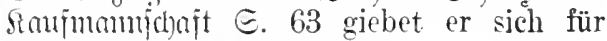
fallit oder insolvent aus.

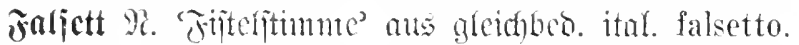

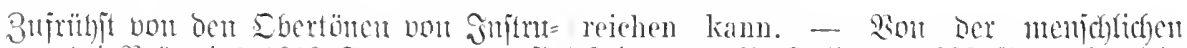

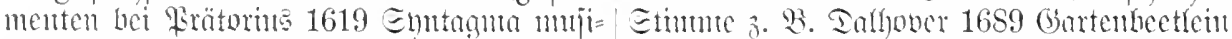
cunn II 12 Falset Stimme in einer Pfeiffen II $315^{3}$ jhre Stimme ist gemeiniglich nur

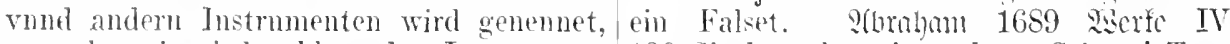
was vber eins jeden blasenden Instruments 196 sie hat aber eine scloöne Stimm! Trau natïrliche Höhe oder Tieff", von ein guten nicht, es ist nicht selten ein Falsett darunter

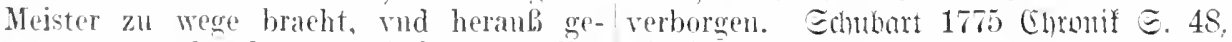

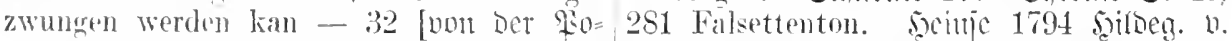

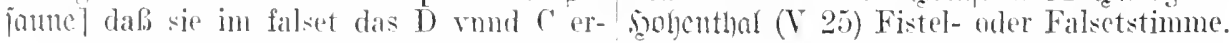

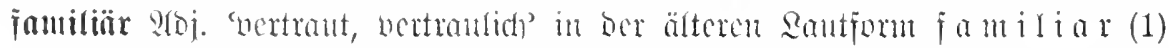

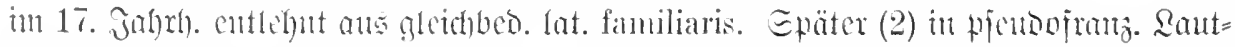

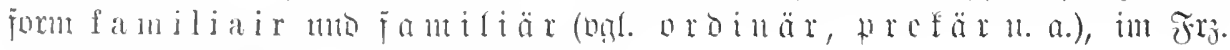
aber viefmethe fannilier (j. tunter $2: 1714$ ).

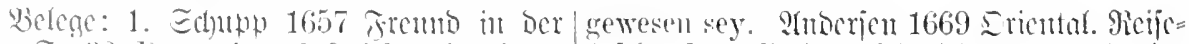

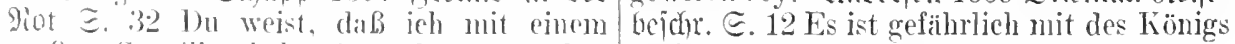
grolon Cavallior bokandt und gar faniliar Ireibem all zu familiar umbzugehen - 
ธ. 21 damit sie nicht mit anderen Manns Personen zu familiar werden. Ifyntojus 1691 Bermmftelye II 62 weil er mir in Leipzig so familiar gewesen, daß "r mir seine meisten Heimligkeiten vertraut. Ettner 1697 Chnnticus S. 29 dieses num ron ihm aus zu kundschaften machte ich mich gantz familiar mit ihm. Suhnou 1700 Eutucfiafber ऽ. 76 eine rechte Pedanterie, wemn man in familiaren Gesprächen mit einem so hohen Stylo auffgezogen kömmt - der familiare Stylus.

2. Girbtel ca. 1680 Eenojdreiben Sorr. durch eine sehr angenehme familiaire und also unaffectirte Sehreibart. SEeije 1697 Bettr. Bejpräche Є. 73 daß ich mich gegen alle freundlich und bescheiden, gegen wenige familiair erweisen soll. Calfenbad $\mathfrak{c} a .1714$ Ilti ante hac $\Xi$. 44 Das will sich gar nieht schicken, es wäre zu familier. Rütig 1719 Theatrum ceremontale I $848^{2}$ sich so familiär gegen den Cardinal aufzuführen $-1720 \mathrm{cbs}$. II 1456b 1737 গitio. Baldober ङ. 193 einen ziemlich familiairen Ungang. 1745 Braun= idhroeig. Echulorbunngen I 219 gegen die aufwärter sollen sie sich bescheiclen, nicht aber vertraut und familiär bezeigen. 1765 Mfla. D. Sibtiothef I 1 ङ. $174 \mathrm{~m}$ familiären Ungange - E.177 familiären Ton. Michae= lis 1768 凡ajomtement I 130 Auf dem Catheder soll man familiär und munter reden.

fantiliarijieren 3tw. im 18. Jahrh. aus irs. familiariser. Sielege: 1766 glla. D. Si bliothef II 2 ङ. 66 wenn er sich bey seiner patristischen Belesenheit mit den Vorstellungen und Ausdrücken der dunklen Kirchenväter nicht zu sehr familiarisirt hätte. Erhubart 1774 Chronif $\Xi .596$. Entlfer 1788 Brieje II 164 - $1796 \mathrm{ebs}$. V 7.

Familiarität $\widetilde{F}$. mach lat. familiaritas: johon in 16. Jahrh. eingebürgert. Belege: 1564/7 Bimmeride (5hrortif III 170 so streckt sich doch die selbig familiaritet so weit, das sie zu zeiten mit einandern nachts uf der gassen umbher gingen. Wecdel 1606 5atts= butc) Є. 512 Denn bei solchen kinderspielen und übermässiger familiarität abbruch der fürstlichen reputation erfolget. 1627.5015 Pumbiact $\mathfrak{A} 3^{a}$ dab sie mit einem jeden $: 0$ grosse Familiaritet nicht halten. Böffer 166. Eifola militaris ङ. 36 Freundschaft und Familiarität.

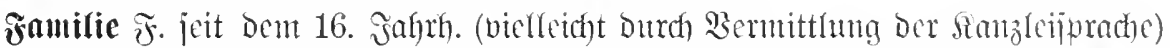

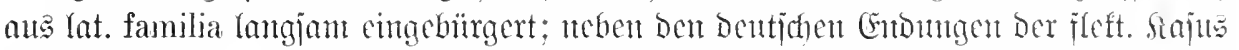

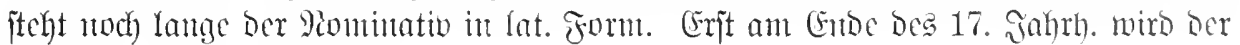

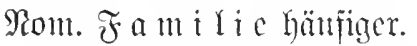

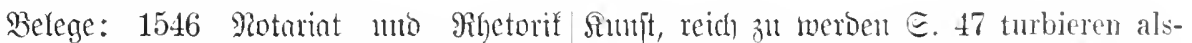
ธ. $116^{a}$ auff den eltisten der Familien rnd dann die Familien. Echup 1659 fatenber geschlechts $N$. vnseren vnd des Reichs $B^{2} 4^{\text {a }}$ Es kam einsmals eine Frau ans einer Burger zu N. Mengering 1642 betwifien

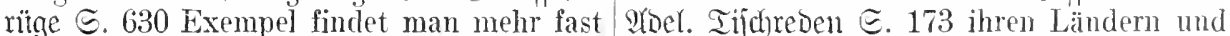
in allen familien - $\subseteq .643$ an manchem Orte familien. Eecfentoorff 1665 Friniftenfiftnat II 198

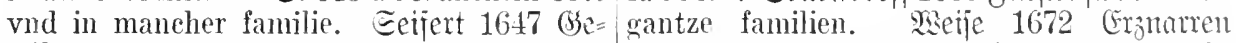

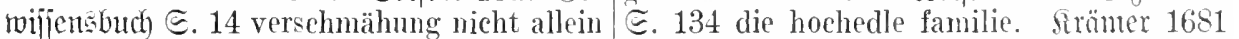
vieler Edlen familien, sondern der christlichen Eeekeroen Є. 823 den Consul zul sant seiner Religion selbsten. Gebjarot 1656 ‥ D. Familie.

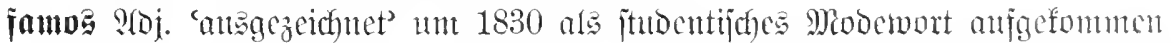

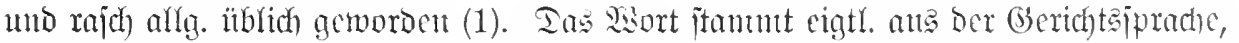
die ces jefon im 17. Jahrer). (2a) in Der Bed. 'Gerüchtigt' fante (cntiprechento lat. famosus

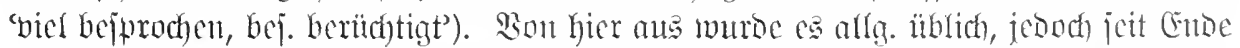

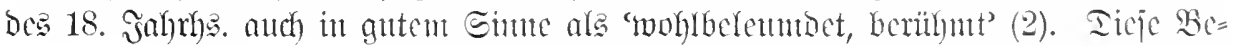

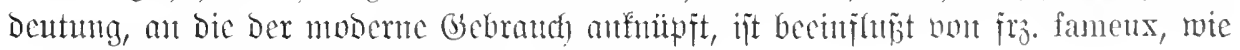

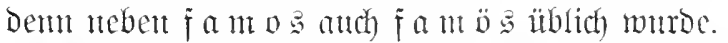

Befege: 1. (Gantory 1836 Ingebutch (I 164) famöseste Liebesbrief. den ich in meinem so einzig flimmerte und funkelte der Narmor Leben gesehen labe - 1837 verimungen - ganz famos. Nota bene: das Wort f a - (II 27) Wirklich eine famose Stimme. mos ist jetzt modern und mu so oft als 1839 Die Eijenbahn ङ. $343^{2}$ Ein famöser möglich angebracht werden. Icurient 1835 Vorschlag, bemerkte ein anwesender Stud-

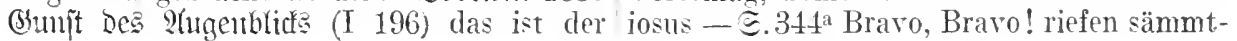




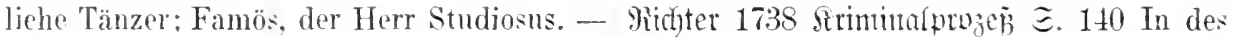
Tebrient 1841 Qiebe (III 106) dieser rasche famoesen Lips Tullians Leben. Bürger 1776 Wechsel. es ist famos - 1843 sier bin ich Brieje I 313 Ich bin mit dem famensen (III 268) es ist famos fals Qeibwort eines Pastor Zuch in Gellichansen in eine Affaire Pijentonharvis] - (III 240) Ja, sehöne, fa- d'Homeür gerathen. Młitller 1787 Emmte= mose Tiere, auf Ehre. Entêlhagen 1866 S̆n rid) III 125 Xie kommt ein famöses Geschicht-

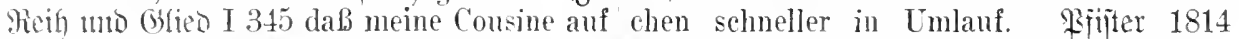
Ehre ein famoses Mädchen sei - 1873 ul Srmimaffälle I 263 Die famose Frage.

timo $\Xi .137$ es ist gerade jetzt ganz famos.

2a. Girdhor 1602 ngemoumunt II 323 Anf hente Abend hatte ich mir den famosen dab sie die famos gesellen nicht bey ihnen Gesang der Schiffer bestellt: Geine 1830 \%n tisch leiden wolten. Mehring 1684 Mnum = Stalien (III 221) den Kragen dieses famosen ale jurioicospolit. E. 421 Item wird famos Rockes. Bäffer 1831 irreje III $122 \mathrm{ihr}$ in gemein gesaget, wenn einer in einem Jann der famöse französische Tänzer Vestris bösen Beruff ist. 1714 Reroromutg $=5 \mathrm{sec}=-1835$ Cemilajp II 210 ziemlich bïrgerlich riga ?frdiv XXXIII 205 famose jauner. erschien mir dagegen der famose Ritter sans

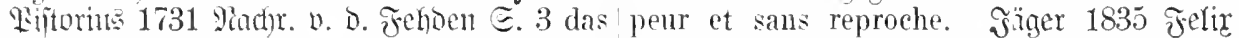
Leben eines der famosesten Fehde-Helden. Sentabel $\Xi .337$ nach Kallstadt, wo der

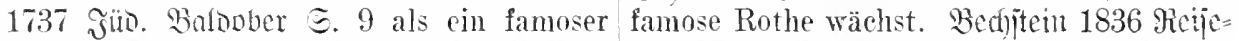
Wildprot:-Dieb beschrieben - 5.24 . 422. trge II 175 Ich sah das fameuse Stück.

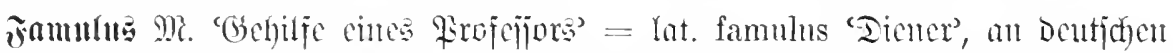

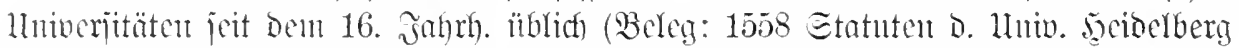

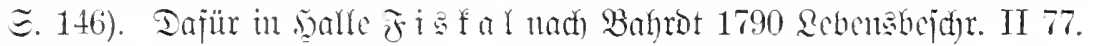

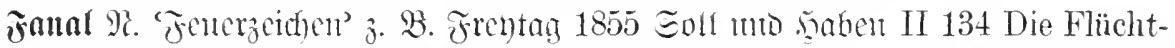
linge erzählten von Plïnderungen, ron Fanalen, welche durch das ganze Land brannten. Echon bei Campe 1801 gebudt ut Ben Bebentutgen (Echiffistend)te, Reuctiturn'. Eucle: irj. fanal.

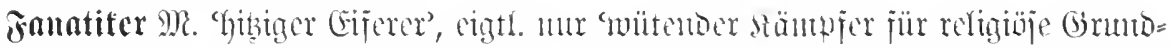

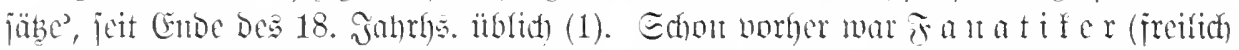

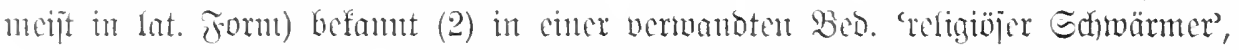

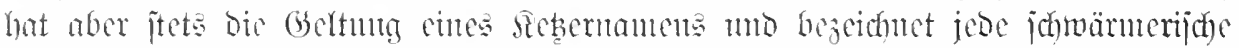

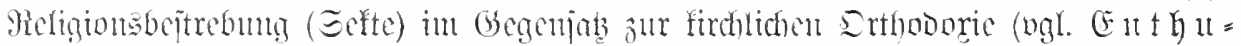
ji a neriebts.

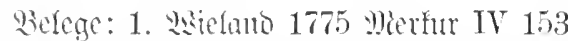
Der Fanatiker geht in rler Sehwärmerei bis zur Wuth der Zerfleischung seiner selbst und anderer. QTrchentgol 1787 Einglano I 228 Jer Stifter dieser Sekte war Whitefield Nle Kinnelı ertönton gegen diesen Mann, ler dem Volke als rin Imsinniger Fanatiker beschrieben wurde.

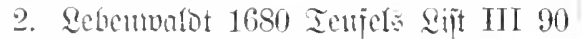
Derglejchen Fanatici oder vasimnige Wilursager waren tie colophonij. Trophonij. Soractini; zu vnsern Zeiten die Wieder-Täuffer. Sohr 1718 Etantsflualch 3.322 Der erste (iradus fanatieorum zeiget uns diejenigen, so nur rinen Anfaner des fanaticismi machen. Yiarom 1739 Eatix. Edrriften E. 31 1)a kamm man sehen, was die Fanatici vor gefährliche

Absiehten haben. Coelntom 1740 Mojes II 4 sie mit den verhaßten Titeln der Quäcker belegen, oder wenn sie sie noch gelinde tractiren wollen, Fanaticos und Enthusiasten heiben. Sönu 1743 setrunglex. II 28 Wem sic diejenigen Lehrer und Christen, so nebst der reinen Lehre auf ein thätiges Cliristentum dringen, als Irroeister, Fanaticos ete. ausschrevell.

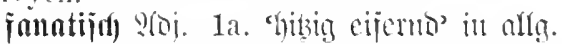
Qied. crit un 19. Jahth.: Pinffer 1835 Eeni= Injio II 25 Der f.-en Tories. Zaube 1836 Feijenvocllcu IV 249 keineswegs f. für seine Ileilmethode.

b. Silter in religiajer Bed.: Edjuller 1793 30iähr. Strieg (XV 51) ein f.-cr Abt dieses Iilosters. Görtes 1821 Curopa @. 265 
in f.-en Religionskämpfen. \$sitt u. Döring weil der politische und religiöse $F$. in jener 1827 Frnguntente II 55 ans f.-em Religionseifer. Commission bisweilen noch den Geldreiz

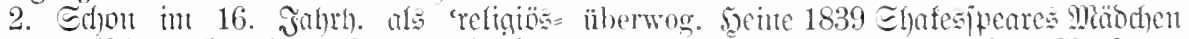

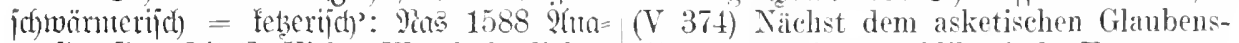
neofis [im Iitet] Vieler Wunderbarlichen eifer war es der republikanische F.

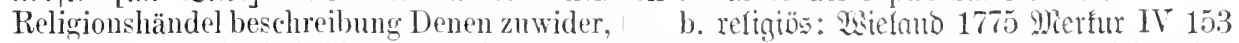
So dieses Jar Christi 88 zu gar Fanattisch Den Worte Sehwïrmerei entspricht das haben verdacht, samt es alles müst zu Wort F.ziemlich genau; wiewohl dieß letztere, Boden gehen, darmub solche Sterngücker, durch den Gebrauch, einer besonderen GatGschriffte, Bücher, Sectenmacher, Zeugnuß- tung von Schwämerei nämlich der relidichter ete. Sämptlich durch Gottes Geist giösen, zugeeignet worden ist. Edhubart 1786 bestritten werden. Mertgerig 1661 Ge= Gentate II 404 Aber der Held achtete wijfensedyt $\widetilde{S} .132$ etliche mnzeitige Refor- nicht der Acht, die iln des F. Höllenwuth

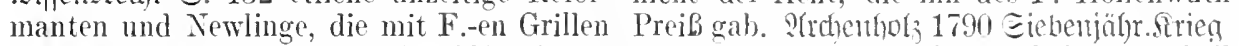
schwanger gehen. Tentsel 1689 lutter $=\Xi .263$ Der F. hatte jedoch keinen Antheil rebungen $\Xi .997$ viel andere falsche und f.-e an diesem Verbrechen; dem Warkotsch war opiniones. Ettner 1697 Ioftor $\Xi 560$ Solch Intherischer Religion - E. 269 die proPhanatisch Vorgeben. Rohr 1718 Etnat: testantische Kirche gegen den F. zu beflugheit ङ. 286. 289. 295. 323. Frau Gott= schirmen. Forjter 1791 ?Gujthten (III 38)

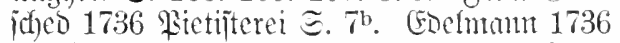
Unidulo. Sabrheiten XII 2 ङ. $1238-$ 1740 Miojes II 117. Eulzer 1774 Theorie II $614^{\text {b }}$ der verkehrte Geist f.-er Sekten.

ein schwarzgalliger $\mathrm{F}$. in der Andacht.

2. Jieben F a th a t ifer 2 jteht vicmehr

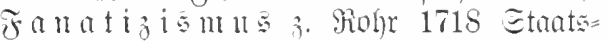
flugheit ङ. 322 Anfang des fanaticismi -

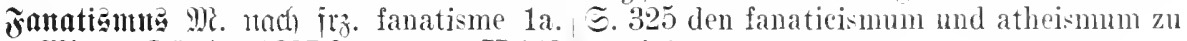
allg.: : : Sitt v. Dörring 1827 Fragmente II 149 rereinigen.

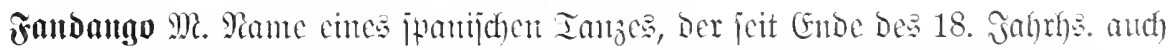
von Deutichen fomponijten uachgeahmt murbe (z. B. 1786 in Mrozarts Jigaro).

Belege: Goethe 1795/6 Sehriahre (XXI/ so lange vorzusingen, his er ihn habe spielen 184) Von dem Musicus erfuhr er, daß sie sich kömen. Edhlegel 1801/2 Bortejmgen હ. 259.

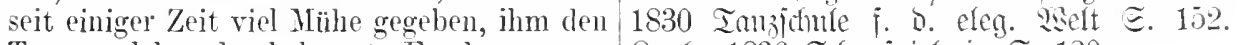
Tanz, welches der bekannte Fandango war, Raube 1836 Echanjpielerin こ. 120.

Fanjare j. in 18. Juhrh. ans jrz. fanfare entfehtt in folg. Bedentuntgen:

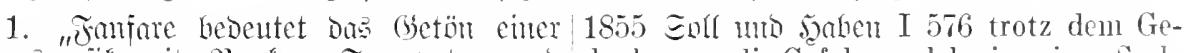
fricasmujif mit Ranfen, Trompeten mo danken an die Gefahr, welche in seiner Seele Bjeifen" Gottiched 1760 samblerifon $\Xi$. 672. fortwährend Fanfare blies.

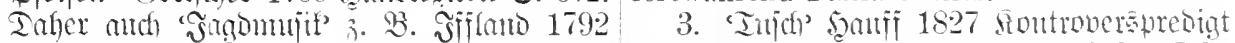
Serbijttag (II 148).

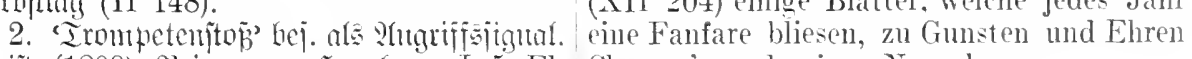
fleift (1809) Prinj bou Somburg I 5 Eh Clauren's und seines Teugeborenen.

wird er nicht Fanfare blasen lassen. Frettan

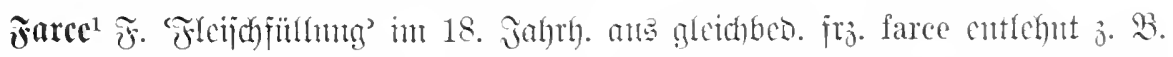

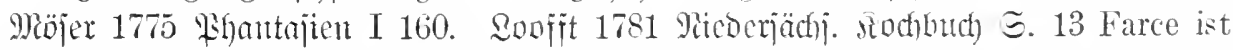

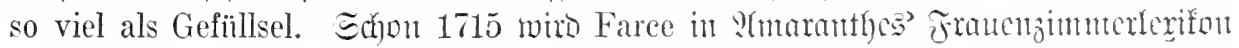

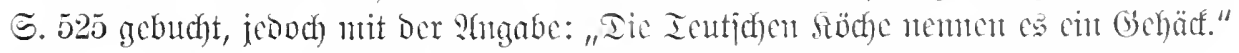

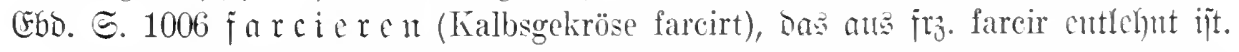

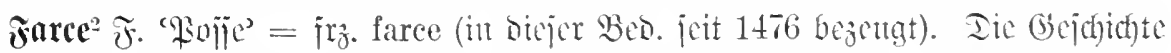

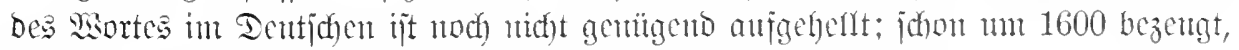

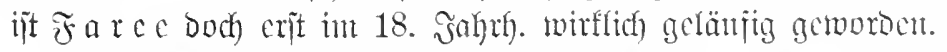

Belege: צtbertim 1599 Gincoura Eents= singen - 79. noch das man den Theatris: id)reiben III $70^{2}$ wann sie Proplanische rnd spectaclen bey wohnen solle, seytemalen farssen repraesentiren, rnkeusche Lieder anff denselbigen allerhandt farssen represen- 


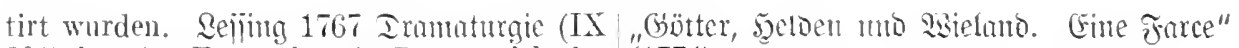
301) für eine Farce, für ein Possenspiel, das (1774).

zu lachen macht - Stolfeftuncen 124. Boethe

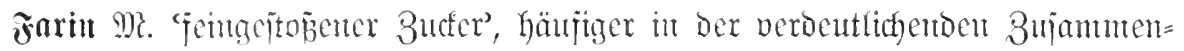

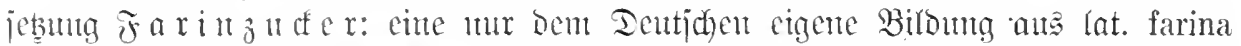

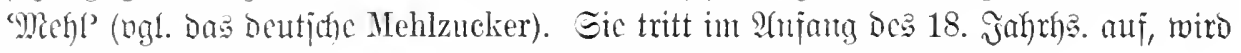

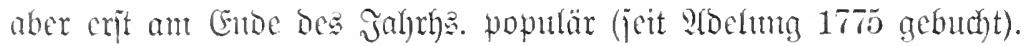

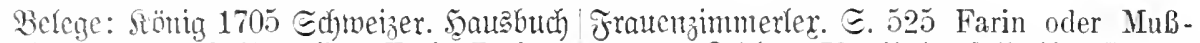
ङ. 536 Andere heißen ihn Farin-Zucker, covat. Bebler 1732 Univerjallerifon I 1497 weilen er nicht in Hüten, sondern großen und Der braune Zucker oder Farin.

kleinen Stïcken kommt. P(maratthes 1715

Farnicute i. Dolecjaruteute.

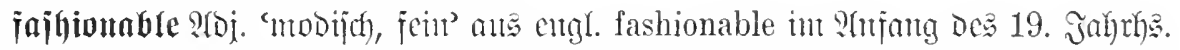

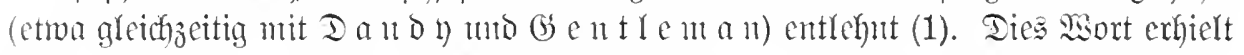

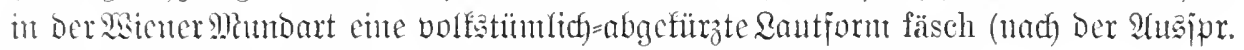

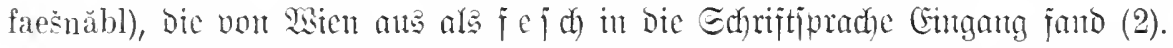

Belege: 1. Brun 1809 Epifoben II 147 Subjecte unter sich heißen sich aber fidöle das [ßtojter] der Ursulinerimnen, worin die Buaben, fäschi Buaben u. d. gl. \$oltei 1862 H. Giacinta lebte, und welches das fashio- Ejelgfrefier III 163 Flotte Wiener, die man nableste von Rom ist. (Gaudy, sierfe I 16 im Jargon der Kaiserstadt mit ,fäsch" beNamachen sieht am fashionablen Schnitt, zeichnet, ein Wort, welches die brittische am feinen Tuche: Der Iensch hat Geld. Abstammung schon vergaß und ebenso wieneЭäger 1835 Fefix Echnahel $\Xi .299$ dab man risch deutsch geworden ist, wie famos, klas-

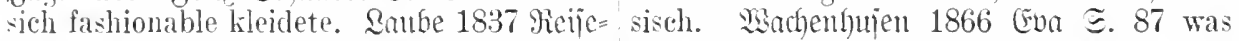
nowelfen V $36 \mathrm{Er}$ ist der Mittelpunkt der recht comme il faut ist, was der Wiener mit fashionablen Batewelt.

2. Tormann 1833 Mien II 119 derlei,

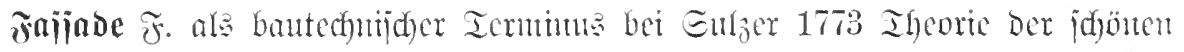

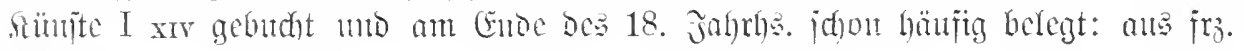
façade.

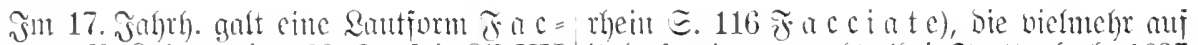
ciade 3. 3. Rebentwafot 1681 Ienfel 2it VII ital. facciata bermth (bei Furttenbad) 1627

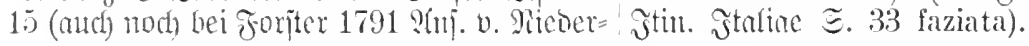

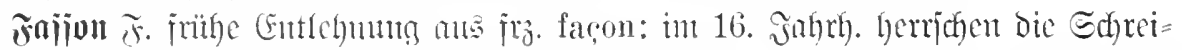
butgeu $\widetilde{F}$ a c o $n, \widetilde{F} a z o n$, jett bem 17 . Jahr

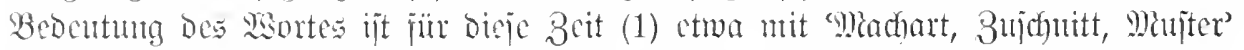
angugeben (beachte dic häupige serbindung u

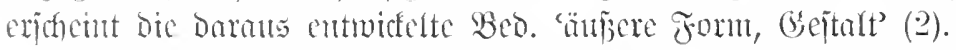

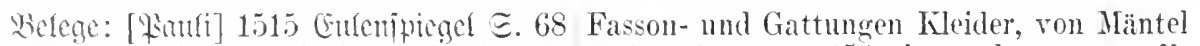
Dex Echuhntacher] hieb Vlenspipgeh zn und anderm - 154 sintental man so offt chmeiden. Vlenspiegel fragt, was facon or rnd dick, newe facion [Ëtreibumg noch ital. haben wolt. der schmmacher sagt, sehneid fazione] nnd Gattungen sicht auff die Ban

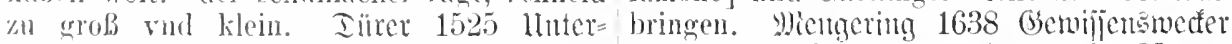

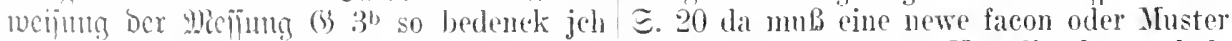
dor drntschen gemät, danı gewonlich alle ans Frankreich, ron Tenedig her geholt

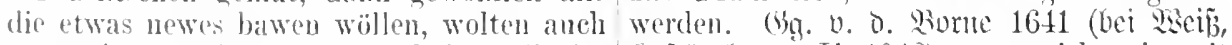
gerne ein newe fatzon dar zu haben, die for Sojtïntunoc II 1048) man sticke sie mit nye geselhen wer. $\widetilde{y} a z 0 n$ noch oft bei Gold, und wähle alle vier Wochen neue

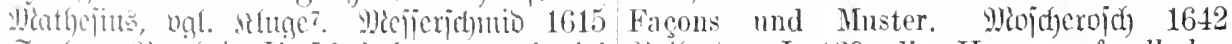
Epelta Sarrbeit II 53 lraben mancherlei fibilander I 139 die Haare auf allerley 
monatliche fagons zuschneiden. Qunrem= gleich umschmeltzen und büben vieles an

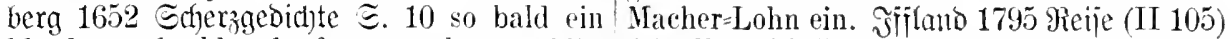
kleedt werd oldt, de fatzon ock verschlit. Die Rerücfe] Ist auch ganz aus der Facon

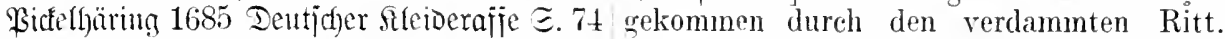
die neueste façon. Ientzel 1689 Unterredungen sans façon oftue Ceremonien, ohne :ieit= 5. 891 wobey doch der Harnisch auf eine läuftigfeit' Eperanoer 1727. Belege: 1702 ziemlich neue facon gemacht ist. Wincfler Europ. Fama 厄. 359 einander sans façon 1696 Edelmann $\Xi .35$ davon ich mich fein in die Haare gerathen. Mcendfe 1710 Geoichte sauber auf die neueste Faeon kleidete.

2. Leīing 1749 (1754) Lie Juben (I 394) Die Fason [Der Doje] ist vortrefflich. - Ja, sie wiegt ganzer fünf Loth. - Nur der Fason wegen möchte ich so ein Döschen haben. 1765 Iffg. D. Bibliothef I 2 ङ. 278 den Mangel neuer Werke durch die Façon zu ersetzen. Sierker bej. Die wisenoung "ans

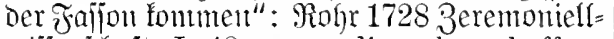
wifienj(d)aft I 48 wem diese lasterhafften vernehmen, daß das Silberwerck, Zinn usw. aus der Façon gekommen, so lassen sie es

$\Xi 51$ Iie Reidfent] müssen in den alten Jahren wol sans facon zu Fusse gehn. Waa= ner 1724 Eoloatenbiblinthef $\Xi .28$ fein soldatisch, das ist gantz kurtz und sans facon.

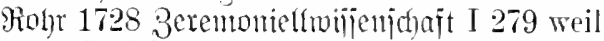
er auch nicht sans façon leben darf. Büffler 1831 Brief̣e I 89. Gauton 1837 sumtorezten (VI 167). Infïr o bue Ta ço dt Ettmer 1697 Chnuticus Ð. 110 . Sturiuritu Eophie 1709 ant Frieorich I. (ङ. 183). Jifland 1795 reije (II 82).

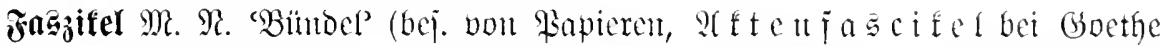
1797 Bricfe XII 309) inl 17. Jahrh. (bei Suthiling 1668 frathol. Totengeriiit ङ. 93)

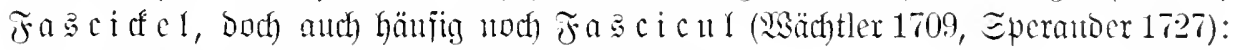
aแß lat. fasciculus 'B̈̈̈ndel' (ว. B. von Briejen).

jaszinieren 3tw. nach lat. fascinare 'beheren' int 18. Jahrh. nod in ber cigtl. Bebcutung 'bezaubern' (bej. "Den Blicf fazzinicren" 'Durch Zauber cutfräften, blendon'). Später bann allg. 'cutzütêten, übermäp̈ig anzichen'.

Belege: Wicland 1774 ?fnor (III die magisehe Gewalt des englischen Ge182) ïberall Mit Grazien gamirt und tota stims fascinirt worden. Edjerre 1870 Fur merum sal In deinen fascinirten Blicken, rạo @. 242 daß gerade wildeste Bösewichte Die dir, wie uns, sobald du nüchtern bist, anf ihre Ungebung einen fascinirenden EinEin sehr altäglich Thierchen ist. Goethe fluß ausüben. Fontante 1888 Jrmugen $\Xi .177$ 1808 Farbenlehre (IV 129) Alles das war für einer faszinierend schönen Spanierin.

die Franzosen verloren, deren Blick durch

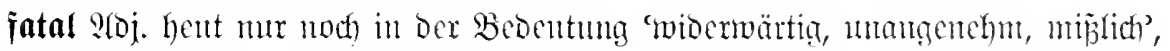

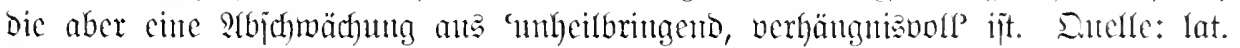
fatalis 'verbängnisvoll, veroerblich)'

$\mathfrak{J}_{n}$ bicjeu Eim zujühjit mit beuticher Velten gefällig ist, durch das gantze Jahr vor

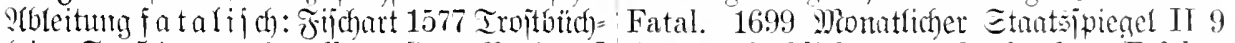
lein $\Xi .54$ aus derselben [oer Rambora] des unglücklichen und fatalen Erfolgs. Fatalischen vnglückssprüche. Mengering Bolb 1731 Redensarten $\Xi$. 185 über ein 1661 Gerviljentsrecht ๔. 205 keine fatalische fatales Evenement seine Traurigkeit an den Vrsach der Zerrüttung und Verfassung der Tag legen. EGhinf 1778 Marionettenthenter Reiche. Wammmo $166 \pm$ Gelomange! ङ. 348 ङ. 5 Hätt unser erstes Eltermpaar, Nicht eine fatalische Tothwendigkeit. Edhilling 1668 gebissen in'n fatalen Apfel gar. - Sn Diejer

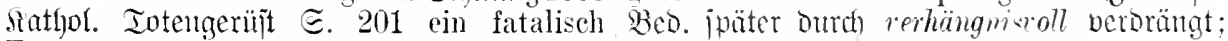
Totengerüst. Eeit Dem 17. Gahrf. bam aud) vgl. Sluge, llıjer Ieutich こ. 23.

in tal in gleider Bedentung.

2. Iie abgeichnoüchte Bebeutung swiber=

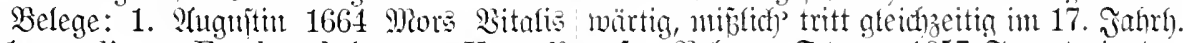
$\mathfrak{B} 1^{\mathrm{a}}$ zu diesem Fatal und letzten Kampff auf. Belege: Echmp 1657 Freumb in Der - E $1^{\text {a }}$ O Fatal und tödtlicher Monat. Not $\Xi$. 32 Und das ist mir fatal, daß ich Sieije 1673 Erznarren $\Xi .123$ etliche halten offt andern Leuten Ratte fangen kan, aber deri Tag, auf welchen der ehrliche Sanct mir selbst kan ich nicht eine einige Mauß 


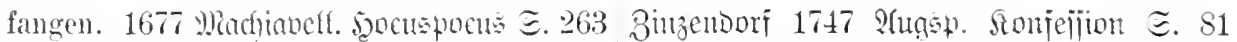
seine Gebrechen, von welchen keiner be- weil der Ungang mit Gott und götthichen freyet, durch einen Brill angesehen: Dieses Dingen fremde, gespensterhaft, fatal und ist gelehrten Leuthen gar fatal. Ettner 1715 unangenehm wird -1750 Eendidir. ฉ. D. Gebomme $\Xi$. 755 heut ist mir schwartz, Mähr. Briiber $\Xi$. 158 Wann endlich dem schwartz und weiß und bram so fatal ge- Leser der gezierte stylus fatal wird wesen. Cólmam 1740 Mojeg III 142 wie $\Xi 159$ Über dies sind gewisse Wörter fast die Lutherische Bibel wohl recht fatal die allen Nensehen verständlich, e.g. das hier Lubeständigkeit ihrer Anbäter exprimirt.| befindliche Wort fatal.

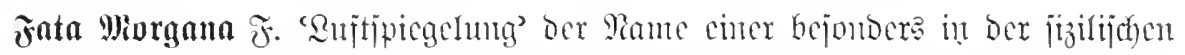

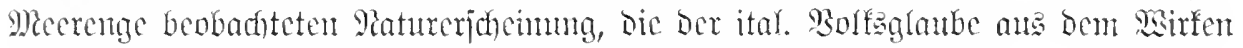

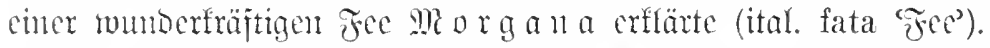

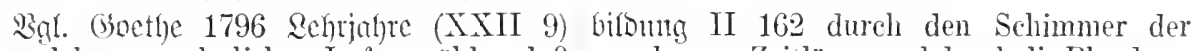
cin solches wunderliches Luftgemälde, daß mieheuern Zeitlänge und durch die Blendung Fata Morgagna [sic! vgl. u. 1808] selbst es der Fata Morgana der Einbildung, die um nicht seltsamer hätte durcheinander wirken alles ihren erhöhenden Heiligenschein werfe.

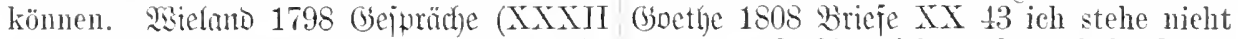
123) wie leichte Wolkengebilde und Luft- davor, daß Sie nicht gelegentlich daron schlösser der Fee Morgana. - Tic liber= eine phantastische Abspiegelung in einer

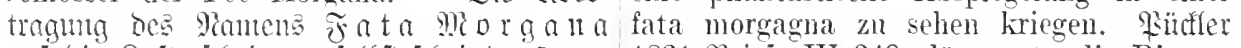
auj bie Sufterijheimng jelbît jofeint crịt un 1831 Brieje IV 349 dämmerte die Riesen1800 Durd) zubringen. Bei Sean Sanl 1804 stadt wie eine fata morgana - 1835 EemiFislegeljalye I $183 \mathrm{Der}$ ] wie von einem Actna lajio III 163 eine in der Luft abgedrückte in ein so weites Leben voll morganischer fata morgana des gegenüber liegenden Ge-

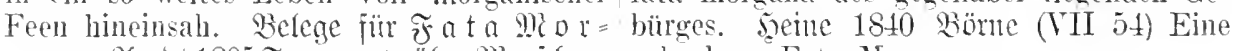
g a 4 a: Qmot 1805 Fragnente ibber Menjuen= gebackene Fata Norgana.

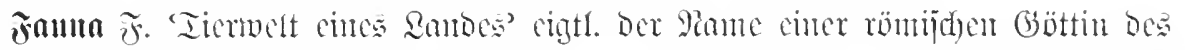

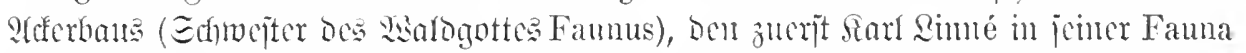
Suecica (1746) afs Iitelitidmort ciner Iierbejareibung bermendete. Inrch hänfige

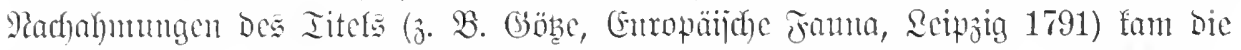

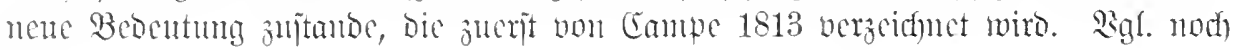
Jarara.

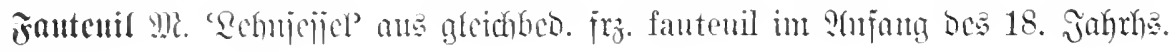
cutlefinst.

Belege: Qünig 1719 Ihentrun ceremoniale er nuß denn auf einem weichen Fauteuil

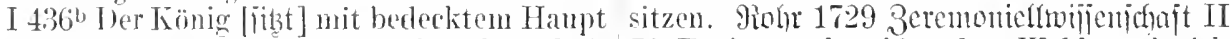
in einem Fauteuil oder Lehn-Sessel $-87^{2} 76 \mathrm{Es}$ ist auch wider den Wohlstand sich Hierauf setzte sich jeder auf einen Fauteuil auf die Fürstlichen Lehn-Sessel oder Fanteüls nieder. Rhilo 1722 Jubm des Inbaf: $\Xi$. 32 niederzusetzen.

Clorindon kan also keine gute Verse machen,

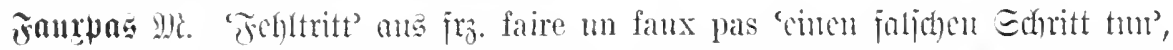

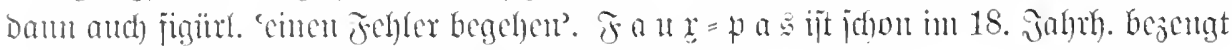
und 1801 bei Campe (muter Faus frais) getudft.

Betege: Echünaich $175+$ 9(cithetif こ. 256 wuBte, ob sie dies Unglïck der Karten-

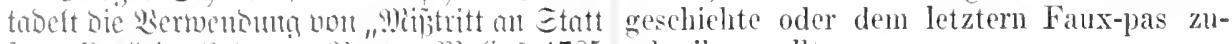
fanx P'as" in Wobuets Yoab. Mibrus 1785 schreiben sollte.

Emoltets liet. Riffle III 344 da sie nicht

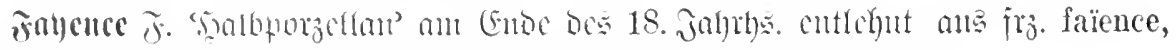

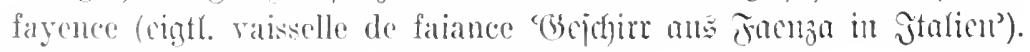


Beleae: Picolai 1779 Berlit E. 413 dieser deren die Stadt gegenwärtig nur acht besitzt. hat auch eine Niederlage von Potsdamisehen fokebue 1802 flleimitäter (XV 20) Heute unächten Porzellan oder Fayance. Forfter wird nicht von Zinn gespeist. sondern von 1791 2únjuften v. Siederthein (III 305) In Fayance.

Delft besuchten wir eine Fayencefabrik,

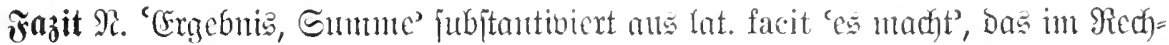

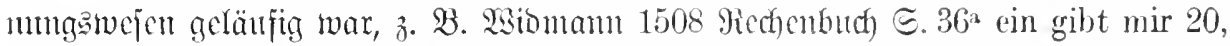

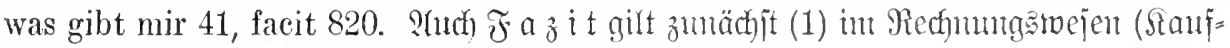

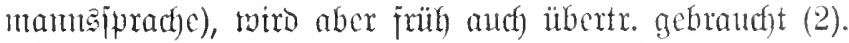

Belege: 1. Sith hof 1563 Wembumut I 2. Micolai 1621 Belthin. Bhutrat こ. 17 267 Rechnet und übersehluge aub dieser der wirdt leichtlich befinden, vnd das facit vermeinten ursach auffs schlechst oben hin dahin vngefahrlich machen. Grimmetiganjen alle seine hab, stellet sein facit jährlich auff 1669 Eimuliz. Є. 80 zuletzt kam das Facit etlich hundert cronen zu verzeren. Nangold über den armen Simplicimm herauß. Bovethe 1597 Marchdjifig Machen (5 $1^{\text {a }}$ Das Facit, 1796 Rehriagre (XXI 51) Gewöhnlich vermacht $\mathrm{jhm}$ vnd sein Erben, Das zahlen $\mathrm{jhn} \mid$ geßt ihr aber auch über eurem Addiren und bringt zu verderben. Martin 1637 Ratle= Bilanciren das eigentliche Facit des Lebens. ment $\subseteq .43$ Herr Wirth, macht vns das faeit.

Felonie $\mathfrak{F}$. 'Untreuc'. Mehring 1684 bucht Felonia: wird genennet die Untreu des Lehnmannes wider seinen Lehn-Herren: in Mefat. ift bas siort jeit Dem 13. Jahrh.

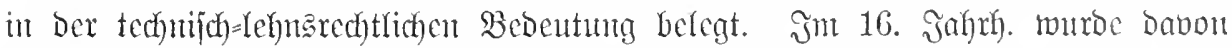

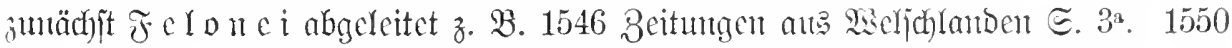

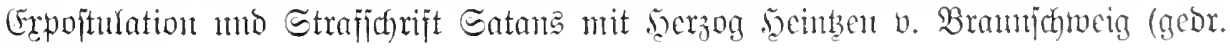
in 11towia).

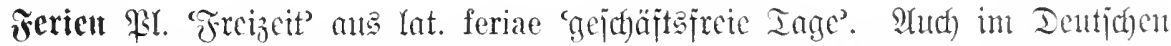

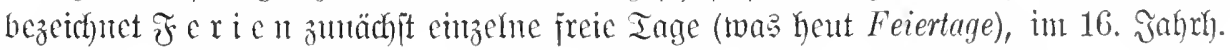

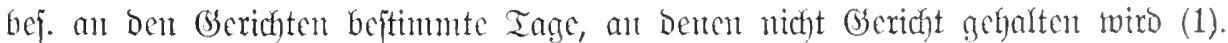

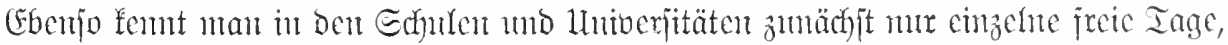

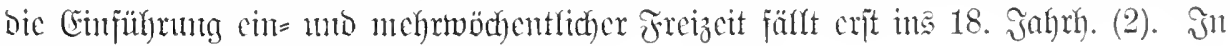

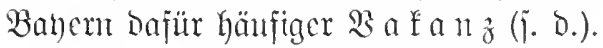

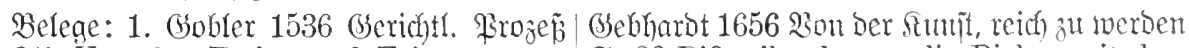
ธ. $21^{\mathrm{b}}$ Von den Ferien vnd Feiertagen - $\Subset .88$ Bißweilen hetten die Richter nit darక. $133^{b} \mathrm{Ob}$ jemand auff Heylige Tage oder weil, bißweilen sagten sie es wären die zu gebunden zeiten, so Ferien weren, für Hundstäg und Ferien.

Gericht gefordert, der mag außziehen vind 2. 1580 seibetberaer Etatuten ङ. 182 fürwenden soliche Heylige tage vnd Ferien. Von den vacantien oder ferien in diser Vnd es sei dann das beyde Parteien offentlieh facultet. 1596 Bramidnmeig. Edhutord = sich solicher Ferien verzigen hetten, sunst mungen I 138 Von den feriis seholasticis oder were der Proceß vnnd handel, in den selben einstellung der seluularbeit. Mientgering 1642 tagen gehalten, vntüglich vnd von vnwerden Getwilienentïge $\subseteq$. 1511 wenns Hänsichen - Etliche sind offenbar vnd beucrisch oder Töffelchen nicht eben ist, in die Schule Ferien, als die auffgesetzt sein zu zeiten der zu gehen, so hat er ferien, bleibt daheim.

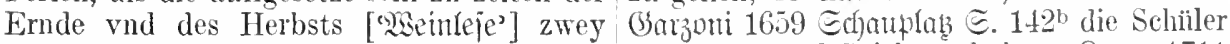
mal jm jar. [ङ. 134 ] Ferien der Erndte gern ferias rnd Spieltage haben. ¿ucue 1711 werden gemeynlich gehaiten auff den achten Europ. Seficon $₫$. 736 Sie sollen keine getage des Monats Julij, das ist sanct Kiliani wisse Ferien halten. Ettner 1715 Gebamme tag, bis auff den fünfften Tag des August- $\subsetneq$. 639 daß sie allerseits die Heil. Pfingstmonats. Ferien des Herbsts werden gemeyn- Ferien in aller Zufriedenheit zubringen lich gehalten, von dem Achtzchenden tag mögen. 1754 Bramifhrveig. Schulorbmungen des monats Septembris anzurechnen biß auff I 278 Die so verderblichen schulferien finden den zwölfften tag des Monats Octobris, bey dieser sehule gar nieht statt - 1756 
ebo. II 437. Mithadis 1768 Räjomement I jorijten I 110 Vornehmlich werden für die 5 die in den Ferien nach Hanse reisenden nützliche Anwendung der Ferien dergleichen Studenten - $1773 \mathrm{ebd}$. III 383 Ferien müssen Arbeiten aufgegeben.

auf Universititen seyn. (Gebide 1789 Edul=

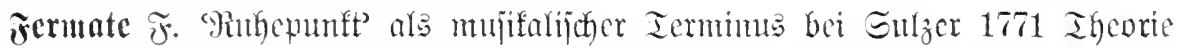

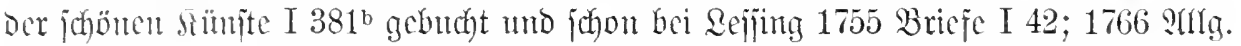

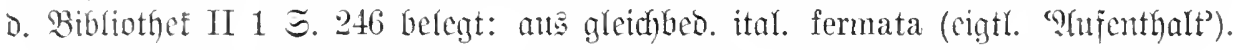

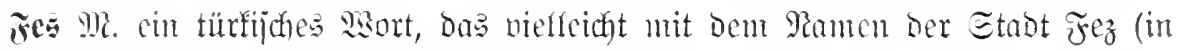

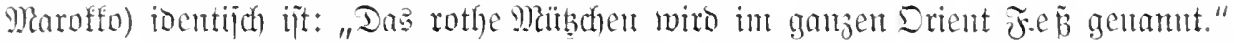

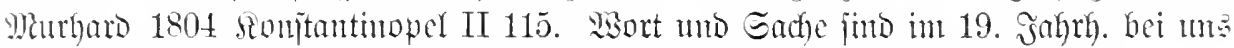

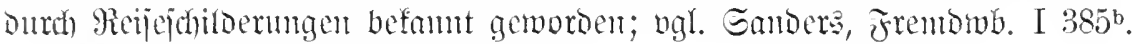

iejo j. unter fajhi o na b l c.

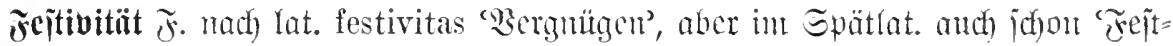
(idffeit. Das sort fhent um 1600 bereits cingebürgert. Belege: Reijetritt 1567

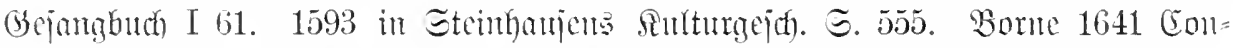
jultatio (D 2. 1699 Stantajpiegel II 44. Coulin 1706 Marrenwelt I 34.

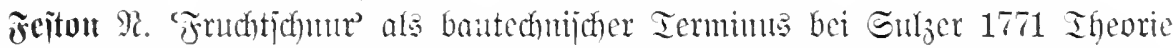

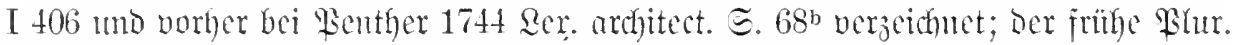

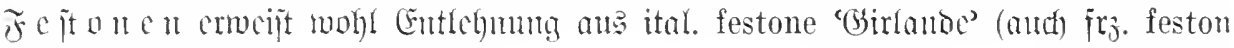
ijt ital. Rehnmort).

Belege: Düntig 1719 Iheatmm cermon. umgekehrte Hohlleiste. Trahenhoh 1787 I 1300: mit Muscheln, Festonen, Corallen, Englond III 209 mit Guirlanden festonartig Tuberosen [angeziert]. Echubart 1775 geschmïckt. (E)rontif $\Xi .37 \cdot 2$ Üher den Festonen liegt die

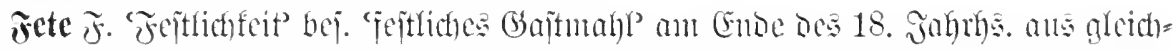

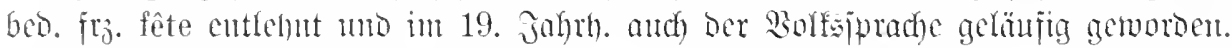

Belege: Sa Rodhe 1771 Frt. v. Sternheint こ. 132 der Fïrst gab unter dem Nahmen des Grafen F. dem Frïulein Sternhein eine Fête auf dem Lande. Echitfer 1783 Brieje I 96 anf die diensttiigige F ête wäre der Fund vortrefflich. Whitl 1786 sagatellen I $213 \mathrm{Er}$ war gelieimer Legationsath gewesen, hatte eine eigne Equipage gehalten, hatte vierteljährlich eine grobe Fete gegeben. Jean Piant a

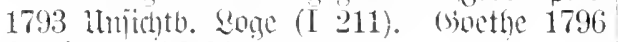
Sebriabre (XXII 329$)$.

jenbal ?(bj. 'vormelnm' in bicjer Bebeutum bei Eander: 1871, fichrein 1876

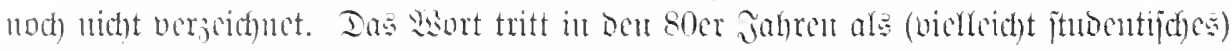

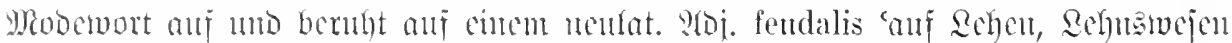

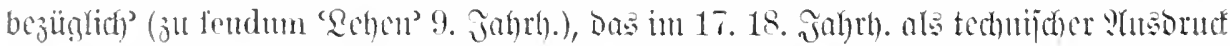

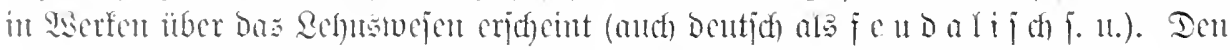

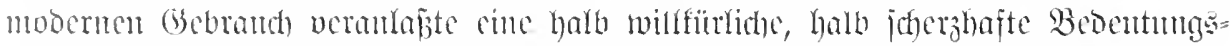

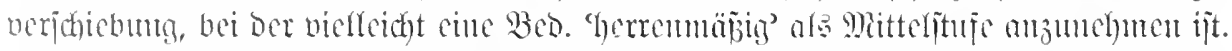

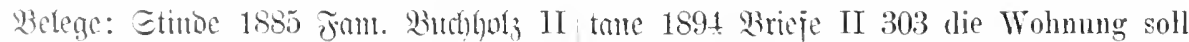
61 glaubt du, dab Ihr don riehtigen Schliff ja reizend sein, beimahe ,feudal" — 1897

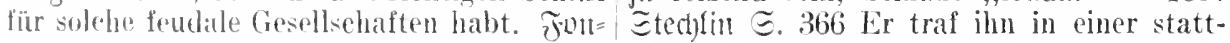


lichen Herrichtung, oder, wie er sich geäıßert gegen das feudalische, wie gegen das hierarhatte, ganz feudal. chische Joch. Echiller 1797 Brieje (V 207)

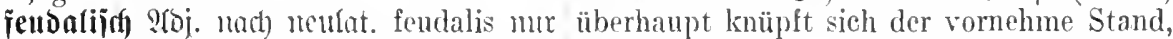

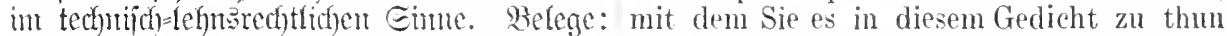
Foriter 1789 \&I. Edriften $\Xi .148$ durch fen- haben, an etwas Tordisches und Feudalisches dalische Tyranney und immerwährende an.

Kriege - $\mathbb{5} .155$ Regungen der Freiheitsliebe

Fenilletwn 22. "Sie jebigen Farijer Beitungen oder Zageblätter Gaben die Girs

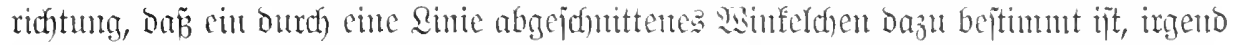

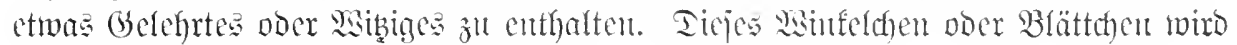
Das Feuilleton gemamt" Campe 1813.

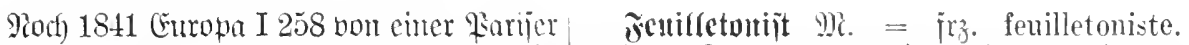

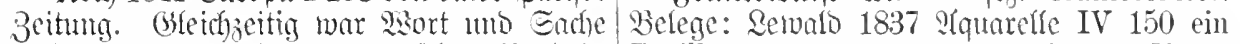
wohl aber aud joun it Deutjhen Berbält= Fenilletonist miisse immer auf dem Platze mijen befant gemorben. - Belege: Fren sein. Fobenberg 1856 Furijer Bif́berbuch

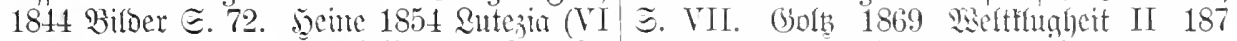

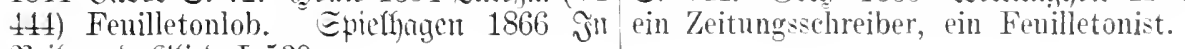
Reif) atmo (B́fico I 539.

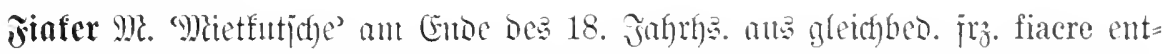

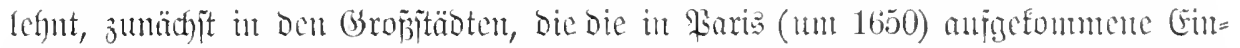

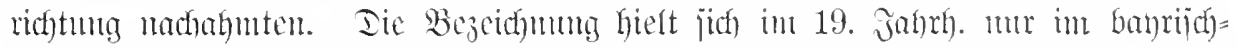

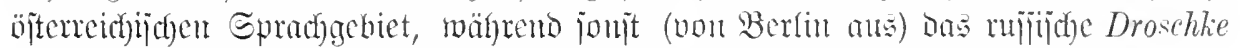
Durfbrany; vgl. beine 182.) Berliner Bricje (VII567) Hier gleich am Thore stehen Droschken. So heißen unsere hiesigen Fiaker.

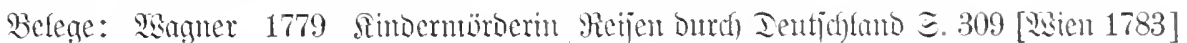
5. 112 geht jetzt und hohlt uns einen Fiaeker. ein unbändiges Gewïhl von Karossen, FiaMicolai 1779 Berlin હ. 735 Die öfentlichen kern und FußBängem. 1790 Ier Beohaditer Yiethkutschen oder Fiacers sind mit Num- $\Xi .99$ er ward gezwungen einen Fiaker mern bezcichnet und stehen auf dem Sehlob- (Miethwagen) zu nehmen. fiokebue 1806 platze der Stechbahn gegenüber. Ritiber 1784 Blinde Riebe (XX 135). Plormam 1833

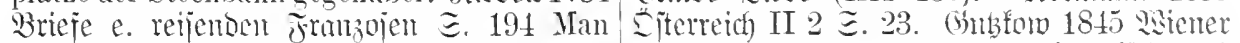

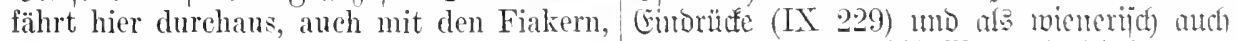
im stärksten Trott, oder im Galopp. 1783/nod) bei Gartner, 3fgoNa. III 195 bejeugt.

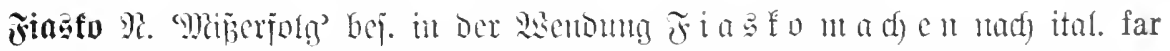

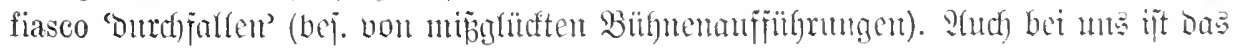

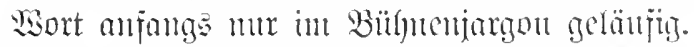

Belcae:5cine 1837 Salon (IV 524) die Vor= ebenso brillante F.-s wie in der Großen Oper. würfe, die bei dem F. eines Stüekes dem jontane 1857 Brieje I 81 ich werde mich Dichter gemacht werden. Goltei 1852 Bang=, nie den Eseln zugesellen, die hinterher das

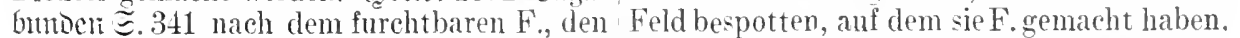

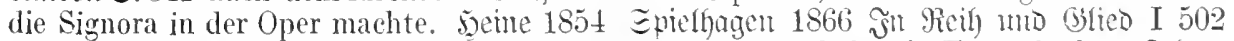
Sutezia (VI 45t) wem in der Académie de wem er eigentlich sein $\mathrm{F}$. verdankt. Edferr musique oder bei den Buffos eine Oper 1870 Farrago $\Xi$. 24:2 ein Unterfangen, durchfällt oder sonst ein ansgezeichnetes $F$. welches ummöglich anders als mit einem $F$. gemacht wird - (457) Bei den Italienern, enden konnte.

in der Opera buffa, gab es rorigen Winter

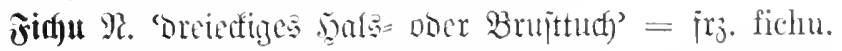

Belege: Mäjer 1776 Phantajten II 90 ein fiehu von Filet. 1832 cöleg. Wselt jür Dies Stück hieß ein Pet en l'air, jenes ein Damen 9ir. 20 ein Fichu von gestickter Fichu. \$sagner 1779 fimbermberderin $\Xi .111 \mid$ Monsseline. 


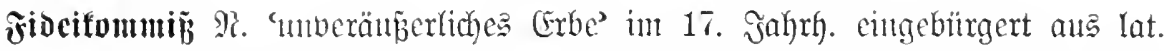
fideicommissum eigtl. 'in Bertranen anf Die Reolichfeit Des Erben gemad)te lests willige Buwendung, dic moderne Bed. erit jeit ber Rezeption.

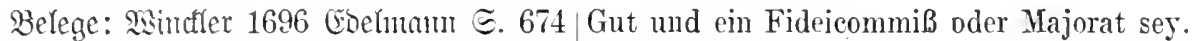
Bey dieser Schale wird berichtet, daß solche (Eallenbad) 1715 Duaii bero $\Subset .29$ Es riecht ein Fidei commiss aus aus dem Hause Bur- ehnder nach einen Fide-Commiß, der Testator gund und nicht vereussert werden könnte. hat die Nacht nicht gehabt.

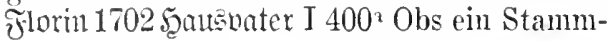

fidel 2(bj. 'Gujtig' un 1750 in ber Stubentenjprache aujgefommen (1) und am

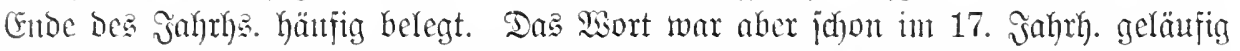
in Der Dent lat. fidelis entprectenden Bed. 'treu' (2). Ten burjefifojen Gebrauch vermittelte wohl eine $\mathfrak{B e d}$. 'vertanensjeelig', die nnter 2 v. $\Im .1715$ belegt wiro.

Belege: 1. Michnełi 1768 Räjonmement I fidel extrahire, als die Scribenten selbst 106 das in der burschikosen Sprache soge- würden gethan haben - 1691 Bernumitlehre nannte Fidelseyn - [QHm.] Dis heißt in der II $70 \mathrm{BiB}$ treu und fidel in deiner UnterUniversitätssprache so viel als im ungelehrten weisung. Iutuau 1700 Duacfifber ๔. 257 Deutschen liederlich und ein determinirter wemn er denen Leuten mit fideler Information Verführer junger Studenten. $\mathfrak{B g h}$. Slltge, dienet. Ehilemont 1702 friegarat I 133 hold Etudentenjpradie હ. 34.

und fidel. Meliijus 1715 frleurie E. 213

2. Böfler 1683 Jaus $=$ u. Feldidule Dieses [Das Butrinfen] machte Silchmaliel so ๔. 576 Als haben wir dieses gantz fidel und fidel, daß er sich gefallen ließ, auf die Geverträulich hiermit communiciret. Ihounajits sundheit seiner beyden Herren Brüder gantze 1688 Monatsgepräd) I 229 daß man sie so, Gläßer aus zu leeren.

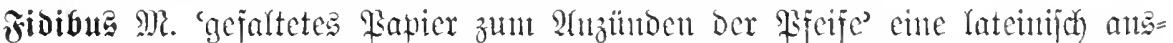
jehende Bezeidyung, fïr bie aber eine Entjpredung in Satein ober in anderen Enradjen

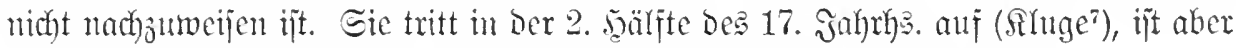
jdyon den folgenden Generationen Dent lirjprunge nad unveritänblid).

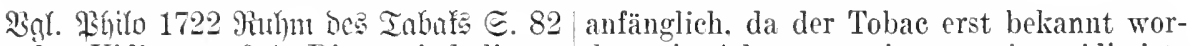
Von den Vidimus. $\S 1$. Dieses sind die so den, ein Advocatus einstens eine vidimirte genannten Fidibus. Was das für ein Wort, Copey mag entzwey gerissen, und dabei seine und woher es seinen Uhrsprung leite, dar- Pfeiffe angezündet haben, welches daher über haben sich bereits 24 Critici die Köpffe andern Anlaß gegeben, solche Papierchens, zerbrochen, und doch endlich ohne Nutzen Vidimus zu nemnen, denu solches passiret aufhören müssen, weiter zu dencken. Wenn itzo noch täglich, daß wenn in einer Comes sich in os endigte, so vermuthete ich, es pagnie diese oder jene Sache mit einem gewäre mit dem Tobac zugleich über die Pyre- wissen possierlichen Nahmen belegt wird, naeischen Gebürge gekommen. Diejenigen dieselbe nachher allezeit selbige Benennung aber, die das Wort: Vidinus aussprechen, behält.

haben noch einigen Grand, weilen vielleicht

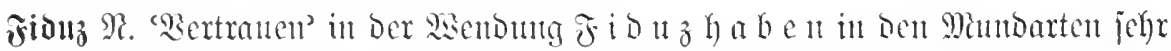

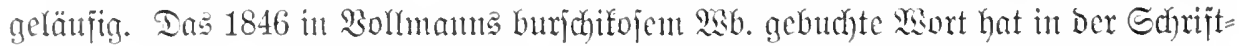
jpracte noch feine rech)te Quterfemung gefunben. Beleg: Fontante 1893 Briefe II 282 Rechtes Fiduz habe ich nicht. Sllelke: Yat. fiducia 'Buverjicht' mo Daher zumächjt

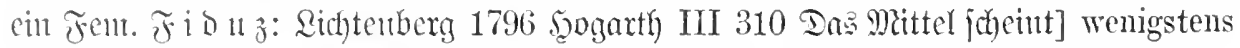
nicht ganz von dieser Welt zu seyn, und die Fiduz in ihrem Gesicht anch nieht.

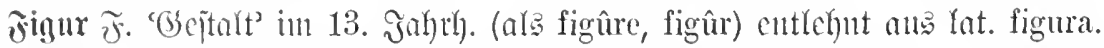

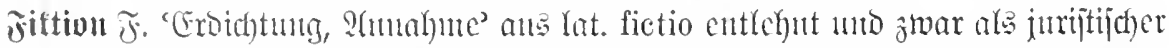

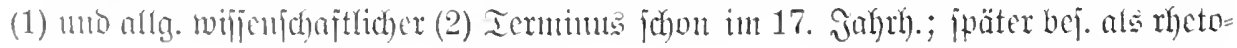


rifdyer Terminus (3), zumal, "poetijghe Fiftion", bas aber vielleidyt audy vou jrz. fiction (poétique) beeinflufint ijt.

Belege: 1. 1677 Machinvell. Gokuspoftu daß die alte Mythologie eitel Fiktion ist.

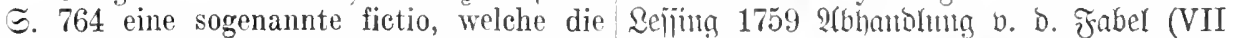
Herren Jurgisten verstehen. QYU Fictio auch 427) Wenn Richer das Wesen eines Ge1684 it Mehrings Mantuale juribico=polit. dichts in die blosse Fiction setzet: so bin verzeidnet. ich es zu'rieden, daß er die Fabel ein

2. Thomajus 1691 Bernumftełre I 140 Gedicht nennet. Seroer 1765 W3erfe I 116 Giebt man dasselbige [ou Falfche] aus ernst- dab es mit der poetischen Fiktion oft konlicher Meinung für wahr aus, so nennt man trastire. Echifler 1793 Som Erbabenten (XVII es cinen Irrthum; läßt man es aber für eine 121) L'nser Wohlgefallen an idealischen Kablosse Würckung des Verstandes passiren, rakteren verliert nichts durch die Erinnerung, so nennt man es eine fiction oder ein Ge- daß sie poetische Fictionen sind. Gópthe 1796 dichte.

¿ehriahre (XXII 195) Es ist aber ein Mähr-

3. 1765 2rlg. §. Bibliothef I 1 S. 203 chen, eine poetische Fiction.

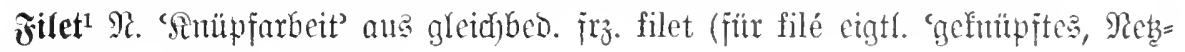
wert's) in 18. Jahrih. entlehnt.

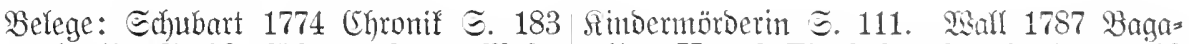
- 1775 ebo. E. 281 Filetstricken. Mëjer tellen II 143 Filethalstuch. Foriter 1788

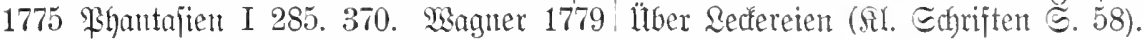

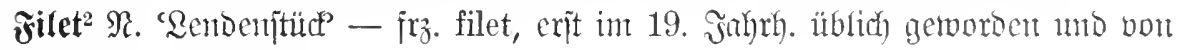
sebje ${ }^{6} 1833$ aufgenommen.

Filiale $\widetilde{J}$. 'Zweiggejchäjt' juntge Entlebtung aus jrz. filiale, bei Bumber 1867

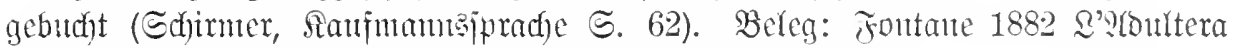
5. 129 eine Filiale des großen Frankfurter Bankhanses.

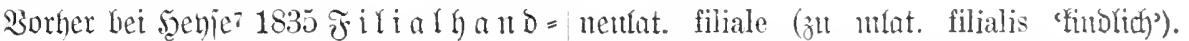

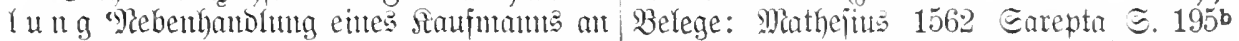

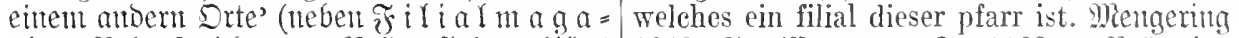

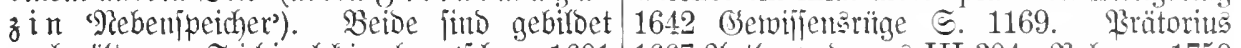

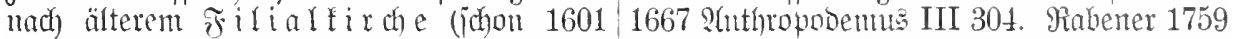
in ben Fontes rer. auftriac. LX 201). Echon Eatiren III 43. Ihümmel, Reije (VII 152).

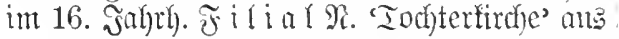

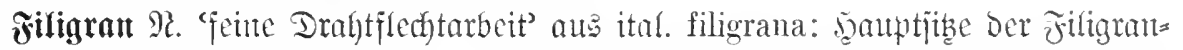

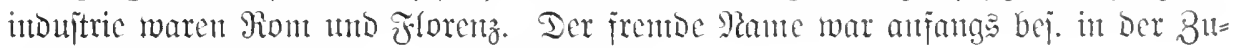

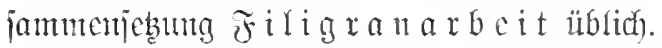

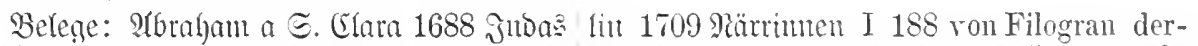
I 283 die Hosen seynd durchbrochen mit gestalten zerrissene Hembt und Hosen. 1737 Philagran-Arbeit - 1695 ebo. IV 111 sein Jilio. Balonber $\Xi 527$ Ein Schächtelgen von Kleid wie Filogranarbeit durchbrochen. Cont= Veligran-Arbeit.

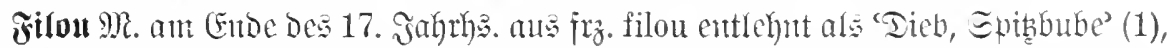

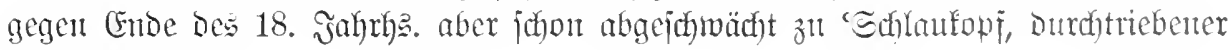
Mentid) (2).

Bełege: 1. Ettıter 1697 Ehymicus daß durch solche Verzögerung einer von föme]. Menantes 1702 2ierliebte wielt beyden Bedienten nicht jemand, denen weil sie meinte, daß es ein Filou sey, der sie Filonen nachzucilen, wïrde auffgesucht haben berauben wollte. Caflenbad) 1714 gìnurmland - Є. 410 beyde zusammen aber [jeien] ङ. 38 die geht dann mit Kauf- und Verperfecte Filous gewesen. Chifemont 1702 känffern? - Da gibts die grösseste Fillou.

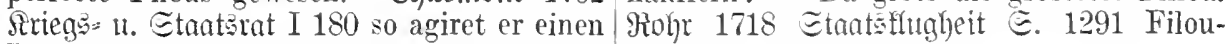
Filou und Spieler, schanet wie er den Christen Streiche. 
2. Sean \&anl 1795 5ejperus ๔. 429 als $\mid$ auf den Kammerherm: Dieser sei ein kleiner dies nieht durehging, nahm der Filou eine Filou und ein großer Hofmam. andere Stimme an - $こ .587$ er wälzte viel

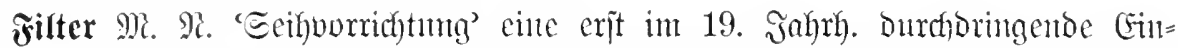

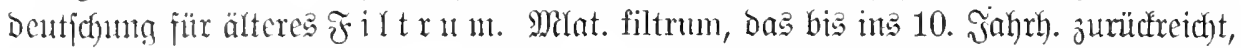

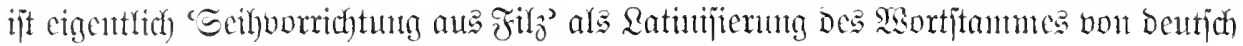
Filz, bie in Miederbentichland entítanden jein mun.

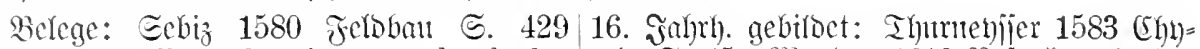
Welcher gestallt rnd weise man durch das mia $\subseteq$. 45. Mundus 1619 Rojenfreuzbruber

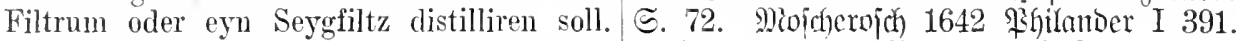

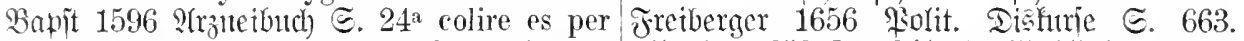

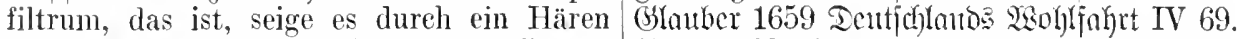
Tueh. Ettuter 1697 Cinnmictis S. 242 filtrum - 1715 scbamme $\subseteq$. 210 ein Filtrum von Pappier.

Ettuer 1697 (Ehnmicus 5.242.

Filtrierpapier (jllauber 1659 Deutidilands

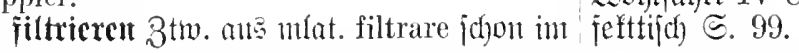

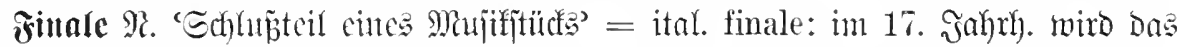

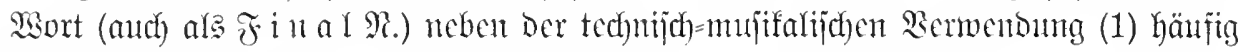
aud) allgentein fïr '(Entbe' gebraud (2).

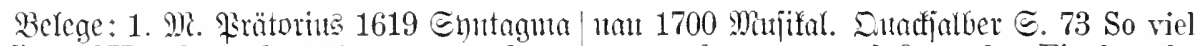
mujicum III 149 der Organist gantz vid gar verstund er zwar, daß er das Final recht auffhören muß vnd in Final sich befindet. nach dem Anfange einrichtete.

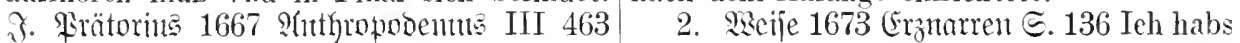
der Oberste aber hält mit seiner groben gesagt. Setzt immer dieses Final darzu, ob Stimme allein auB und macht das Finale. es gleich nicht aecurat eintrifft, was bey den

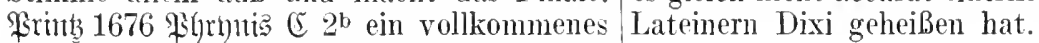

Final einer vollkommenen Melodey. Sulh=

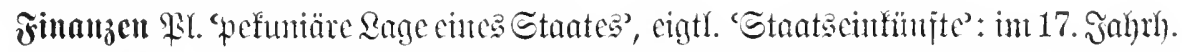

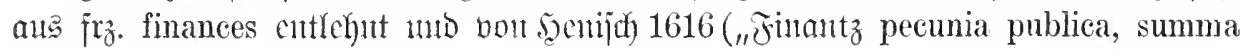
rei quaestoriae") gebucbt. Beleg: 1708 Reopolo D. (3rof̧e II 312 der KammerPräsident ward beschuldiget, daß er mit denen käyserlichen Finanzen iibel umgegangen.

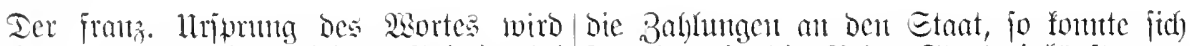

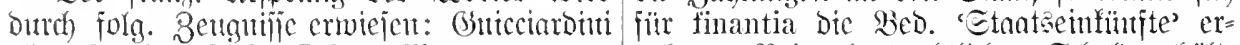
1562 Storia d'Italia I 31 dell' entrate regie geben. Bei privatrechtlichen Edbuldover)ält=

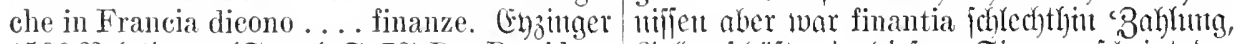

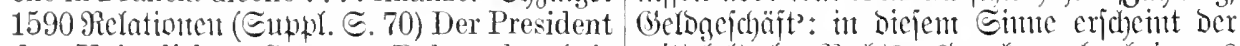
des Kaiserlichen Cammer Raht oder (wie mittchalterl. Redhtsanesond and) bei uns mans sonst in Niderlandt vold auf Franzö- friil cingebitrgert, freilich bie Sebeutung

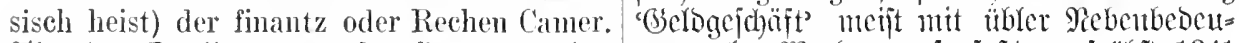

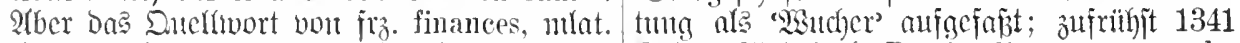

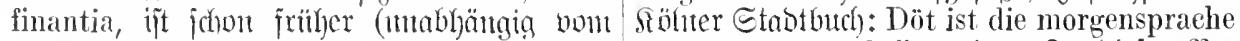

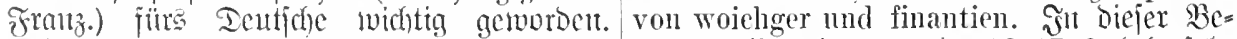

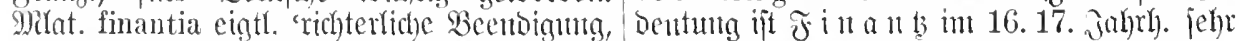

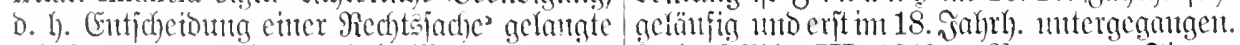

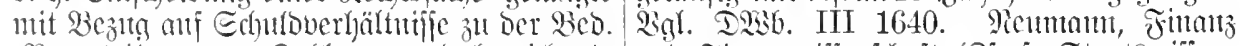

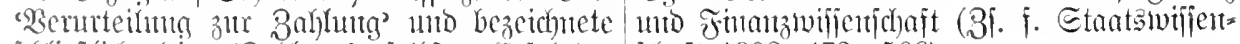

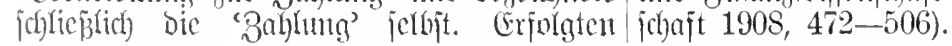

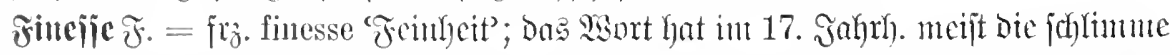

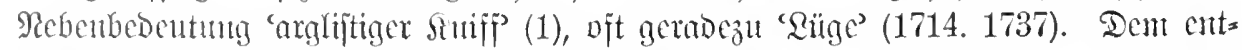

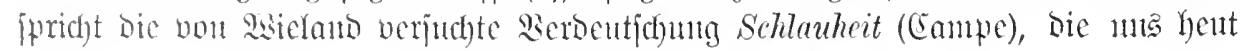




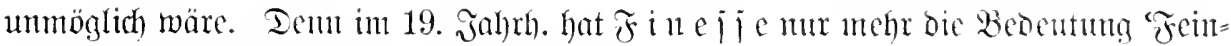
heit, ichnierige Eimzelheit einer Siunt' (2).

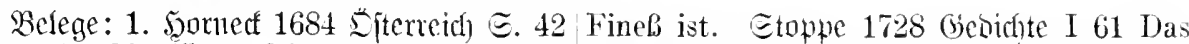
Dann der Kaufflente Finesse ist unendlich. Vermögen, Wind zu machen ist die gröbte Ettner 1697 Chymicus $\subseteq .836$ daß man unter Kunst der Welt, Die man in der Art zu dem Sehein dureh Verrätherey dem Publieo leben vor die Haupt-Finesse hält. Philippi zu dienen, seine eigene finesse darunter sucht 1743 Reintomiebefunt $\Xi$. 236 Ein stilles - Doftor $\subseteq .623$ mußten derohalben aller- geruhiges Leben in einem mittelmäßigen hand Finessen erfinden. EGilemont 1702 Stande übertrifft alle Finessen und Cabalen Sriegs= und Etaatsat I 180 So ein Jud wird [Der Sochgeitellten].

grossen Herren und vornehmen Leuten aller- 2. Fokebue 1810 Eorgen (XXVI 226) Das hand Finessen sagen und anzeigen, wie sie kommt Dir nur so vor, weil du die Finessen Geld machen könten. (Eallenbad) 1714 (Genea $=$ vom Spiel nicht verstehst.

Ioggia $\mathbb{S}$. 66 Ich zweiffle sehr, obs nicht ein

fiugieren 3tw. in 16. Jahrh. aus lat. fingere gebilset, zutächit in ber Bebeutung 'erbichten', bej. vou Poeten (1), Dann 'fälịchlich vorgeben' (2), entide anth in wijjen=

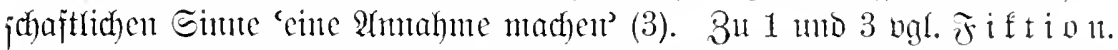

Belege: 1. 1587 Fauitbud) $\Subset .44$ er muste der Hencker fingirt im Foltern, wenn man derhalben fingieren, was jhm gedauchte, das nieht fort bekennen will, eine Marter über

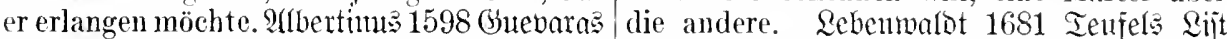
Eendfdyreiben II $7^{\text {a }}$ fingirten die Poeten. VIII 360 alsdam solle dieses Teuffels-Kind Edywenter 1636 Delitiae BL. $5^{\mathrm{a}}$ wie anfangs tödtliehe Wunden fingiren. (5hilemont 1702 gemeldte Poeten fingiren. Mengering 1642 Sricgs= u. Etaatsat III 119 aus andern

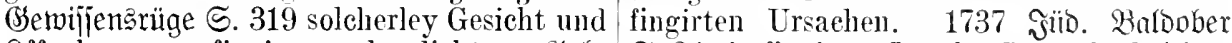

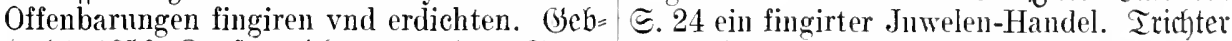

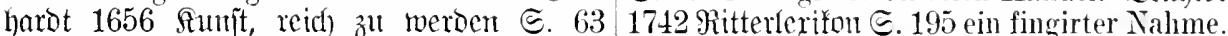
Die Poeten fingiren, dab die Innwohner des (Goethe 1795/6 Rehriahre (XXII 153) als er Himmels ...

2. 2rlbertimu 1602 Şauspolizei I $169^{\mathrm{b}}$ Das

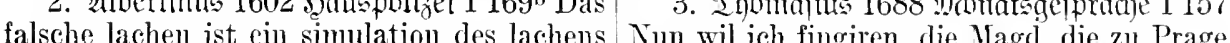
vnd der frewd, welches etliche menschen gebeichtet, sey nur alle Viertel Jahre zur fingiren vad erdichten zum betrug jres Beichte gegangen. Rofr 1718 Etaatsłlugheit

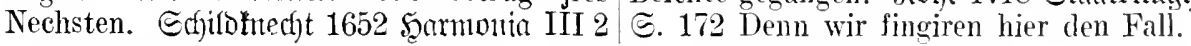

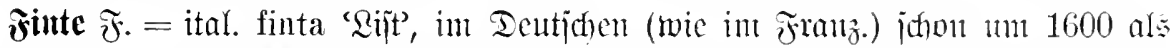

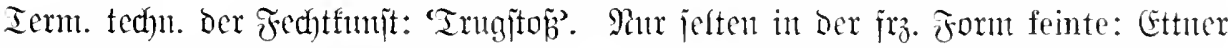
1697 Chymicus ङ. 389 Wie sie mit den Degen aneinander kamen, hat man die kïnstlichsten paraden und feinten gesehen.

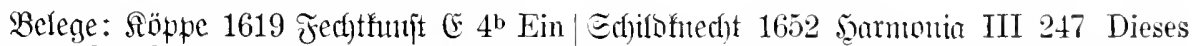
guter vnd wolgeübter Fechter braucht sieh Finte machen gehet über alles, was man in selten einer finten, sintemal er wol solchen Fällen jemals erdenken nöchte.

neher vnd mit geringer mühe vnd gefahr iintieren 3tw. Stöppe 1619 Jed tfunjt

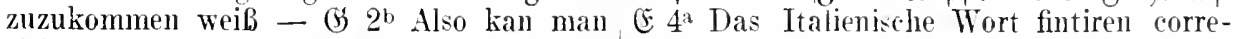
sich auch stellen, als wolte man offtmals spondiret vnserm Teutschen verfülıren, da einen stoß oder finten pariren, da man doeh man einem an einem Ort wineket. vnd sieh nur eine ligation machet. Martin 1627 stellet als wolte man cla hinein, vnd wendet Colloques E. 207 vne feinte: eine Finte, aber an einem andern Ort, dessen sich der wann man sich stellet, als wolt man stossen. Feind nicht versieht.

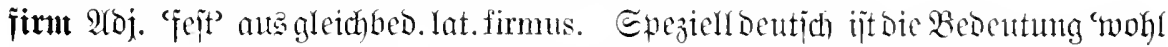

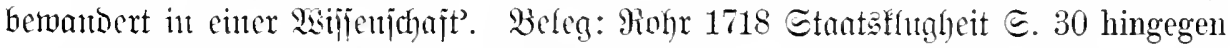
ist man auch nicht so firm und gewiß, als bey dem, was man aus der Erfahrung. gelernt hat. 


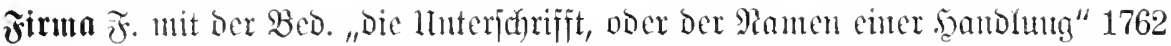

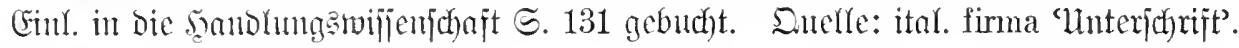

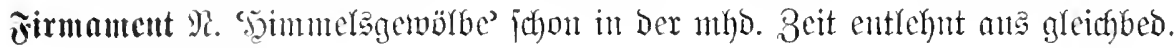
ipötlat. firmamentum.

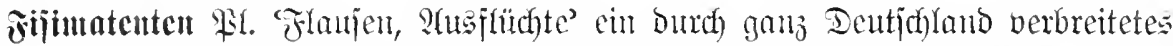

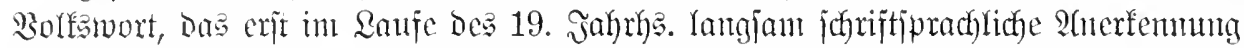

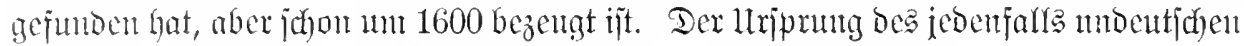
然ortes ït Dunfel (Grunbbedeutung 'nichtige, wertloje Dinge'?).

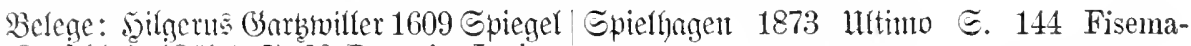

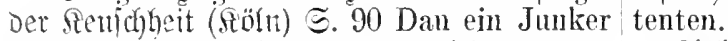

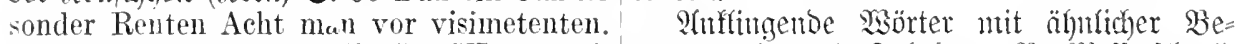

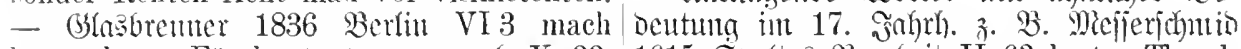
keene lange Füselmatenten - aud X 33. 1615 Epeltas Parrheit II 63 lauter Thand,

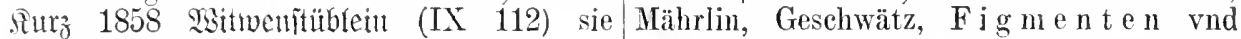
lachte mich wieder wegen meiner „, Physima- Gedichten der Einbildungskraft. Prätorius thenten" aus. Dies ist zwar keine gotisshe, 1665 Inazen=Beit $\left(\mathcal{D} 3^{\mathrm{b}}\right.$ daß allhier aber jene aber doch eine ländlich-sittliche Redensart, Spiel-Katze kein ander $\mathrm{f}$ i s t e r m e nt t könne die man anwendet, wenn jemand sich ziert. gehabt haben, als dieses Katzen Gezüchte.

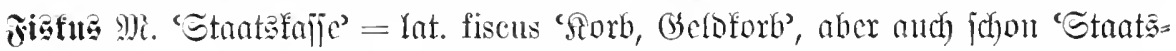
fajie. Schon im 16. Jahrh. geläufig (gebud)t bei Schwarbenbad) 1580 Synonnma

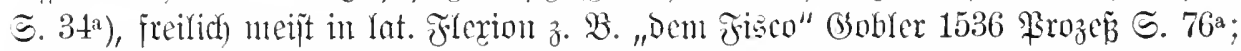

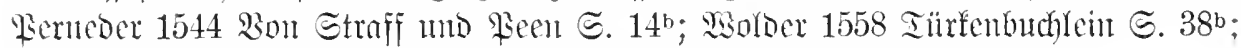
Bboffer 1665 Sdyola E. 431; Grimmelehaujen 1669 Simplic. S. 549.

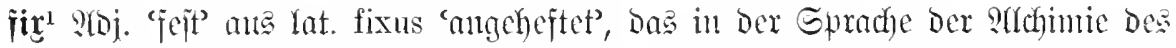

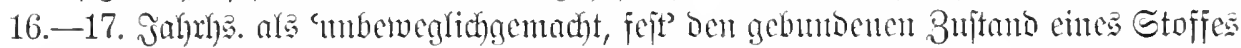
bezeidfnet; ugl. S. Rot 1571 Dictionaritum (5) $3^{2} \mathrm{~F}$ ix Stät, gehefft, vnbeweglich, wol eingesteck, steyff. Ist ein wort, das die Alchimisten vil brauchen, als wenn sie auß dem Mercurio ein fixe materie machen. Sha Dem alchimiftifchen Bereich (1) tritt

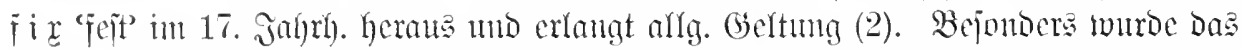

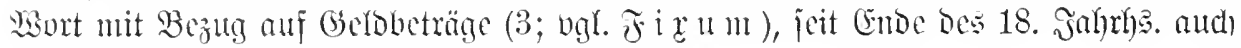

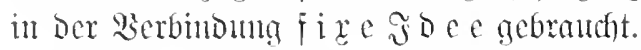

Belege: 1. Parncelitus 1570 Sircfiboxa

3. Frouste 1702 sisnifonfyus II $12 \mathrm{E}$ : e $3^{\text {b }}$ die substantia vnd corporalis argenti, könne das Werek nieht bestehen, weil e: die anb fixer art ist - D $1^{\text {a }}$ rnnd bleibt kein fixum oder keinen gewissen fundum etlichs theils am boden, wölche da fix habe. Ist dem Gott nieht gewiß genug. ist - $\mathfrak{P}^{\mathrm{a}} \mathrm{es}$ ist fix wie das Glas im Fewer, Ist der Himmel nicht fixer als der Menschen das sich nit v'mbwendt in seiner natnr. ihr Capital. Eeffiffer 1783 Briefe I 115 tixe Rebentualot 1680 Tenfers Rift IV 18 das Pension. Babrit 1790 Rebensbejthr. I 27

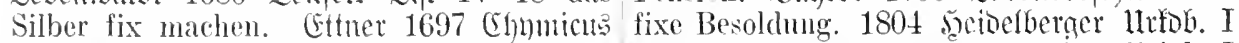
5. 394 fixes Pulver. 1783 mierfitr III 14450 fixes gehalt. Bectboven 1807 Briefe I fixes Alkali.

2. Echiffer 1793 ? ?hunut (XVII 313) von der fixen Schönheit, die mit dem Subjekte selbst notwendig gegeben ist. Fitt) 1838

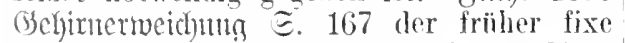

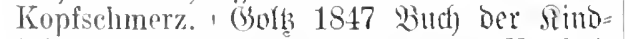
heit 5. 249 Viemeln soll diesen Erscheinungen gar nichts Fixes, Stabiles nud Absolutes inhïriren.

168 fixe Besoldung. Epräter bei. fixc Itreifes. 3. 1835 (Enropa I 142. Bed)= ftein 1836 Feijetage II 63.

fire soec 'Sluangsourittelfung' cigtl. cin

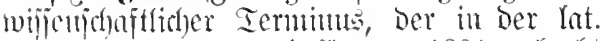
Jorm (idea fixa) hei Campe 1801 gebutcht

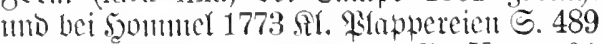
(Die Idea Fixa überwältiget die Vermunft) belegt ift. Die Dentidge form zufrutgit bei 
Finte 1801 Paicolai (VIII 11). Gnethe 1812 Didftuntg und Takntheit (XXVII 126). (Görres 1819 Tentifhtand $\widetilde{E} .67$. Seine 1831 Stalien (III 426). Dafïr "fire 2uficht" (Socthe 1812 Didftuntg u. Walnt). (XXVII 263).

firen 3tw. "unter Feftieburg eines be:

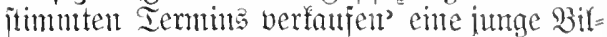

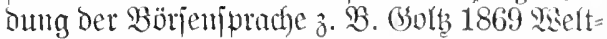
ftugheit II 66 jeder Lump von einem Krämer darf den Telegraphen in Bewegung setzen. à la hausse und baisse speknliren, fixen und den Weltwirrwarr vermehren.

fixieren ${ }^{1}$ 3tw. 1. als aldimiftijher Ter $=$ minus in 16. salyrh. aus einem mlat. fixare gebildet z. B. Begardi 1539 snder janitatis ธ. $19^{2}$ den Mereurium etwan soluiert, ealcioniert, sublimiert, coaguliert, fixiert. Snt 19. Salurly. murbe fi i i e re $n$ bam Durdh

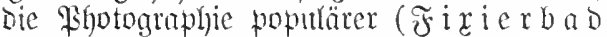
uīm.).

2. IIIg. 'feitntaden, feitlegen, feitigen'. Belege: Edytbart 1774 Chromif S. 508 ein fixierter Dümmling. Sabater 1777 解jio= gnoun. Fragmente III 195 Momente zu fixiren. Böll 1782 llniverítätşwejen I 31 ihre Honorarien zu fixieren. Edhiller 1784 Stabale (IV 368) unser beider Glïck zu fixieren. Bahrot 1791 Lebersbejchr. IV 123 fixirte wich in mir der bestimmte Zweck. Fichte 1801 Micolai (VIII 14) dieser noch nicht fixirte Geist.

firieren ${ }^{2}$ two "fitorm anfehen' am Ende Des 18. salurbs. ants gleichben. jrz. fixer ent= lebnt. Das frants. Wsort berult auf Der sisen= Dung fixer les yeux sur quelqu'un, Dic ž fixer qu. avec l'oeil (entipred)ento im bentidfen "mit Den Tugen firieren" j. u. 1799. 1800) umgeitaltet wume. Belege: Sfffland 1789 Reve verjöhnt (I 176) Er fixirt Ruhbergen - (152) Karoline fixirt das Bouquet. Echillfer 1799 Piccolomini (VI 130) Ihn scharf mit den Augen fixirend - 1800 Maria Etuart (VII 60) Paulet fixirt ihn mit ermstem Bliek - (77) Sie fixirt mit den Augen die
Maria. Benzel=sternan 1805 Gejpräche I 168 Hektor (sie sanft fixirend) $-1806 \mathrm{ebo}$. 11 161 fixirt ihn lächelnd -217.275 . flleift (1809) Rirnz bon 5ontburg I 5 Der Prinz fixirt die Damen. Tean Ban 1814 Mntieum ङ. 51 durch bloßes Blick-Heften (Fixieren). goffimam 1814 Berganza (I 97) indem sie meine schöne Reiterin scharf fixirte. Seine 1822 Berliner Brieje (VII 565) Er fixirt sie mit der Lorgnette.

?am. Sbrwohl fro. fiser quelqu'un nod beut nidyt als forreft girt, ift jein Bejtehen

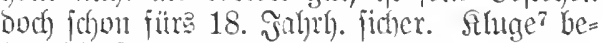

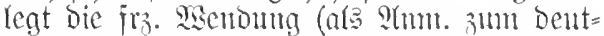
jifen fiontert) j(fon au sermes 1778 巨o= Whiens Sicije VI 363; Dasu 1802 foumul des

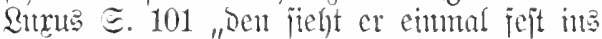
(beficht, was bie Frantzojen fixieren nenten". Bgyl. auch bie Fmbnote bei Rourboueir 1818 Les folies du siècle Є. 57 Fixer: regarder avec attention (Dictionnaire de Boiste [1801]). Cette locution n'est point académique; mais l'Académie ne nous donne aucun autre verbe pour rendre la même jdée.

Firitern zufrifgit bei fenler 1598 spera (eD. Fritid) I 406); bei Menbberger 1569 QYjtronomie $\subseteq$. $73^{2}$ auß den stern, so man fixae nemnet. Duerle: lat. stella fixa.

Fixmu 92. 'iejte, bejtmmte Emmnte' ans

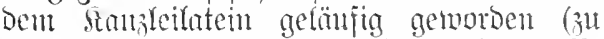

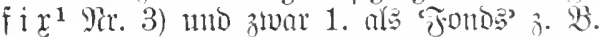
Reibnis 1701 Briefe (II 201) mich durch ein zulängliches Fixum (auber der Cassa Societatis) in solchen Stand zn setzen. Francfe 1702 sidajenhan: II 12 Es kömme das Werk nicht bestehen, weil es kein fixum oder keinen gewißen fundum habe.

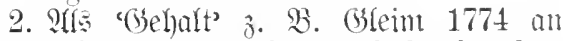
Bürger (I 193) Alles frey und dreyhundert Rthlr. Fixum. Edhilfer 1788 Brieje II 189. Fontane 1859 Briefe I 101. 183. Iazn als

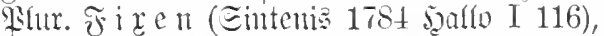
älter mod) fixa an geld 1755 B́ramijhmeig. Edintoromingen I 319.

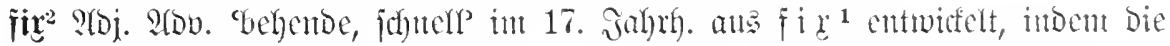

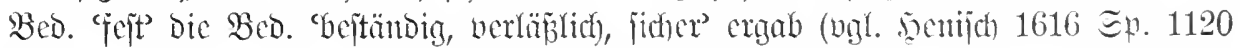

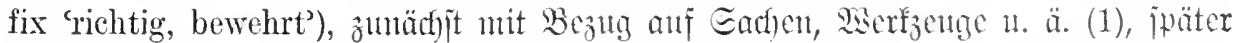

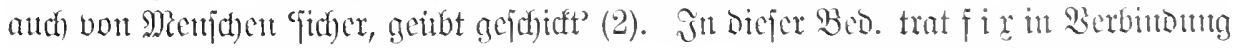

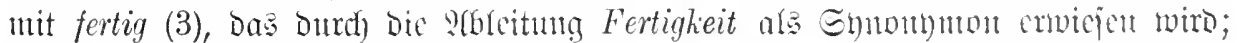

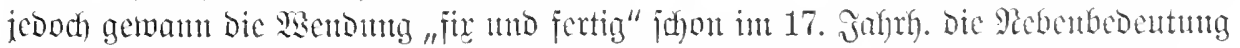

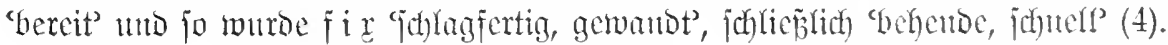

Belege: 1. Bufruffit bon entem nemen die kunst nit fix vund tenglich; von ber

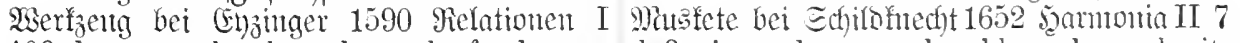
109 da mans aber brauchen solt, fandt man daß sie weder zu schmahl noch zu breit, 
sondern just, fix und eben recht sey. Iakex fix und fertig hatten - 厄. 429. 518. 565. allg. 'jicher, genme 3. B. Echilofnecht 1652 Eectenoorij 1685 (Shrijtenjtant I 593 daß die Jarmonta III 30 die kugel träffe daun fix junge Pürschlein im 18ten Jahrs ihres Alters auff einen Eychen Pfahl - 142 die machen oder noch wohl ehe, ihrer Meynung nach, fix just und fix 100 Mann. Francisei 1669 und fertig sind. Tönler 1693 Echauplah Trauerjanl II 85 ihre Kunst fix studirt. $\Xi .531$ daß er in seiner Kunst fix und fertig

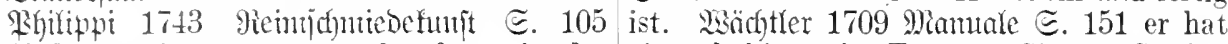
Alsdenn reimt man was drauf, so ist der einen habitum im Tantzen, Singen, Spielen Leber-Reim fix.

2. Sirtoteles 1628 Eatnra $21^{\text {b }}$ In Rob Artzney auch gewaltig vix War Er. 1630 Tragifombobie (Engl. fromöbianten G. 224) Mit zu den Damägens zu gehen, darzu bin ich fix vind Ackermensch willig. Mentgering 1642 Getutifentistige Є. 1109 das gibt dann bey andern scheele Augen, die lassen sich viel fixer, fertiger vnd geschickter düncken. Rauremberg 1652 Edjerzgebidte ङ. 8 kan ick den nicht vel mehr, so bin ich darup fix. Grimmerafinalen 1669 Eimuliz. S. 184 er übte sich täglich mit mir in allen Gewehren, wovon ieh so fix ward, daß ich mich nicht scheuete ihm Bescheid zuthun wan er wolte. Srrämer 1681 Reben Der Eeehelden $\Xi .38$ sie sind mit ihren Wurffpfeilen so fix und gewib, $\mathrm{daB}$ sie treffen, wo sie nur hinzielen. Tie Bed. 'gejoricft' ijt nod) ergalten in sien= Dungen mie "firer Säger" Mï̈ller 1787 (Em= merich) I 67. "firer Sierl" Fontane 1882 R'Poniltera હ. 120.

3. ?rundo mengermg 1612 Gemijiensiüge ङ. 640 Wo man nur den Kindern was zu Wasser machen kan, da ist man fix ynd Sonoplung Der neuejten Beit. Beleg: Fertic fertig dazu. Jromer 1681 Leben Der Gee= was ihr an gesundem Menschenverstande belDen $\Subset .405$ Thre Waffen, welche sie allezeit fehlt, durch 'Fixigkeit' zu ersetzen.

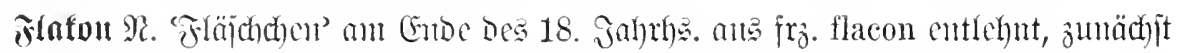
als Maśf. bei Salf 1787 Bagatellen II 118; Mülter 1787 CEmeridh III 152 - als Reutrum bei Jiffam 1795 Bormumb (IX 136).

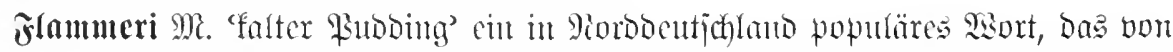

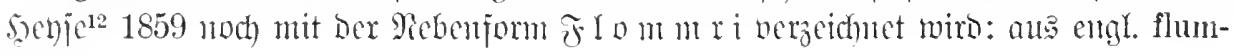
mery.

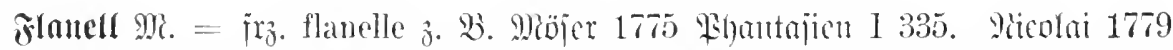

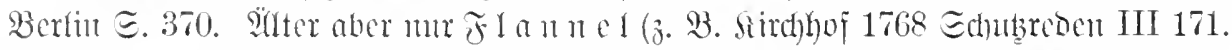
$177)=$ engt. flamel. Bigl. S(morantfges 1715 Framenjumerlex. Є. 547 "Flannell.

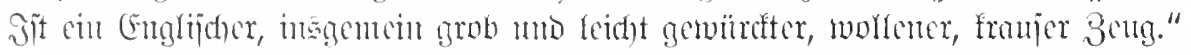

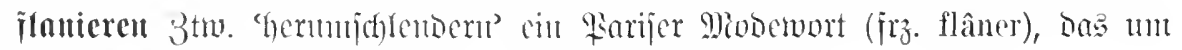

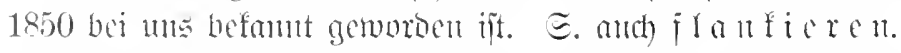

Belege: Syeine 1834 Ealon (IV 175) wie länber 1847 Meije nach) Parts (VI 254) Als "twa ein Dancly, der mit gelben Glaceehand- ich auf dem klassisehen Boden des Flaschnhen anf dim Boulerard Coblenee flaniert nirens in dieser sehweren Kinnst einen - 1840 sibnc (VII 34) als wir in den sehwachon Versuch zu machen begann Strabon yon I'aris umherflainierten. Seat= (255) da ich von dem L'ngeheuren dieser 
Stadt mich so ins Flaniren rertieft hatte. und gaffen. Returb 1843 Iie Manpe E. 236 Meipuer 1863 Echwargelf III 54 Flanierte fast zu jeder Stunde thromen hier [in Baben= anf dem Asphalt der Bonlerards. Senje 1873 boben] elegante Lente, Flaneurs, Schach-

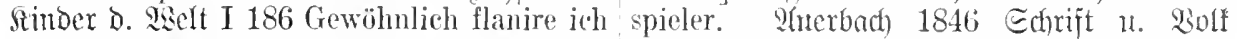
bis nach Mitternacht planlos durch die e. 202 Die Flaneurs der Boulevards Straßen. Fontane 1883 Briefe II 67 Ich ङ. 222 Allerdings heißt im Dentschen der flanierte erst am Strande, damı in den Dünen. Flaneur ein Stroleh oder Pflastertreter, di»

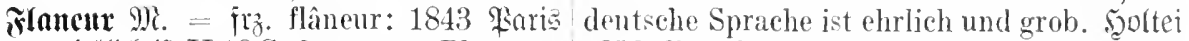

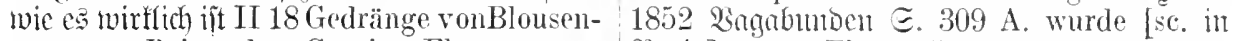
männern, Poissarden, Gamins, Flaneurs usw. Rari: zum ,Flaneur" in weitesten Sinne - [?(nm.] Flaneurs: Hernmschlenkerer, die des Wortes. Wisadentün 1865 Wallet I 94. in einem süBen Nichtsthum umherschlendern

Flante $\mathfrak{F}$. 'Ecite' un 1600 ale milit. Iermints ans fro. flane Maśl. entlebut;

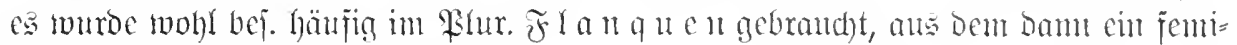
miner Eing. gemonnen murbe.

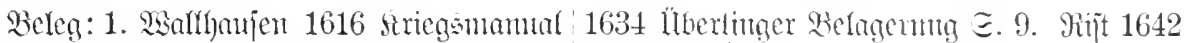

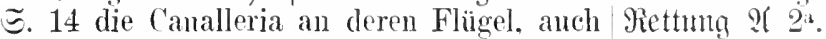

in vnderschiedlichen Squadronen vmod nach gelegenheit deß Orthes entweder in die Front, oder an die Flanquen der Schlachtordnung.

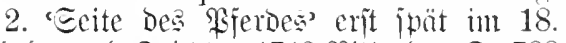
Jahrly.; bgl. Iridter 1742 Ritterlex. E. 788 "Flanc, cheval qui a peu de flanc, Engt man bon einem Riferde, das menig bey Qeibe, jachal uno mager ift."

flantierent ${ }^{1}$ Btw. entiprechend ixo. flanquer 1. eight 'mit Geitenwerten veriehen' groving quer 1. eigtl. 'mit Eeitemverten veriehen', Provinzialmb. I 116 Flankiren 'müßig herum-

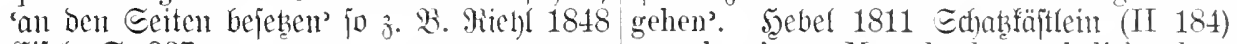
Eifele S. 237.

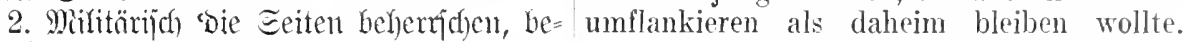

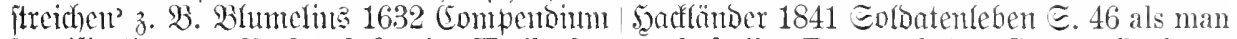

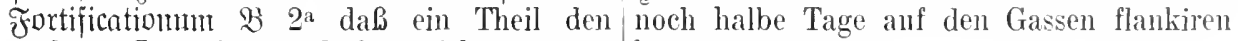
andern flanquirn vnd bestreichen möge. konnte.

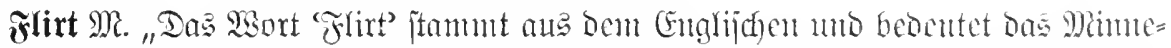
ipiel Der jungen Selt" (El. Biegler 1894 Flirten $\subseteq .16$ (tach Rabendorf). F I i $x$ i ift

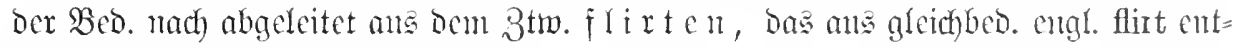

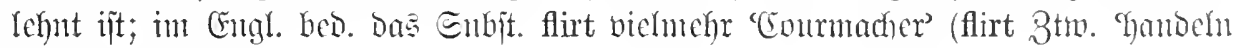
wie ein flirt').

Flor $\mathfrak{r}^{1}$. 'blïhender 3uitano' 1. in eigtl. (Gebrand) erit im 18. Jahrf. belegt (bgl. Eambers, Fremonf. I 398). Sutle: lat. flos, floris 'Blume, Blïte.

2. İbertragen z. B. Seibuiz 1696 1nnorgreifl. Gebanfen § 31: Das HanptAbsehen wäre zwar der Flor des geliebten Vaterlandes. Sifter mux in ber isendung

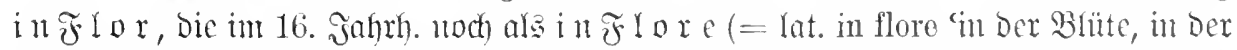

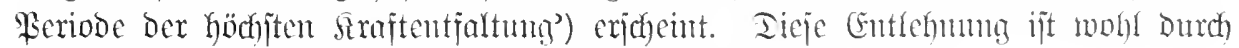
bie Sommaniften vermittelt. Bgl. nod in floribus.

Belege: 1563 Bimmer. (Enronif IV 355 seines alters vnd alles glucks - $€ .182^{\text {b }}$ in Insonderheit er sich wider Herr J. Truch- der flor vnd blum seines alters. Rättel 1585 sessen, der dozumal in aller Flore und Uf- Curent' Echlej. (Shronif II 21 Deßgleichen gang ware nit uflainen dörfen (nad) Fijicher stunde das Königreich Behem zur selben II 1580). Fabricin 1568 Eurus' (Ghronif zeit in flore. Eommer 1608 (Ethographia II $5.148^{\mathrm{b}}$ ein jüngling von 17 jaren, in der flor 139 in Flore vnd esse erhalten. Ondengering 
1638 Eordatenteufel $\Subset .449$ daß Policey vnd im Aprill. Nhbraham 1688 Subas I 449 Haußwesen nimmermehr in Flor vnd esse warumb der Baum noch grünt vnd florirt. wieder kommen sol. Edfild fited)t 1652 jear= monia III 194 in höchstem Flor. 5omeiu 1657 Bebenfen હ. 13 in herrlichen Flor. 2. litbertr. 'glälzen, in fraft und $2 \mathfrak{m}=$ Tranciäci 1663 Iürfengejahr D $1^{\text {b }}$ in grösse- $107^{\text {a }}$ Zun zeiten der Kayser Neronis Galbae rem Flor. Sedjer 1668 Micthodus ङ. 52 in rnd Vitellii florirte vnd galt die Medicin in den besten Flor. Grimmelahauja 1669 Italia viel. Eommer 1608 Ethographia II こimpl. こ. $395 \mathrm{im}$ Wohlstand und Flor. 150 Dannoch haben jhre Kinder vnd Kindsstrafft 1683 Mamufafturen $\Subset$. 11 in Flor kinder in grossen königlichen ehren, macht

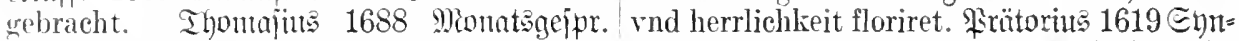
I 98 in Flor gewesen. Francfe 1702 saajen= tagma III $8^{a}$ Damit die Edle Mrusic je mehr hau I 71 im besten Flor stehen.

floriexen Btw. 'blïben' aus lat. florere 1. itt eigtl., hent weraltetem Gebraudh ieit (Ende.

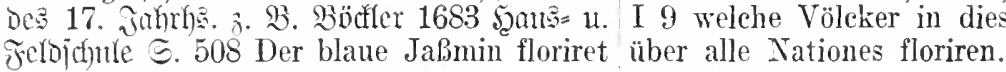
vnnd mehr möchte floriren. Pricolai 1621 Blutrat હ. 18 die Römer selbst, da sie am maisten floriert. Edjilofned 1652 Saarmonia

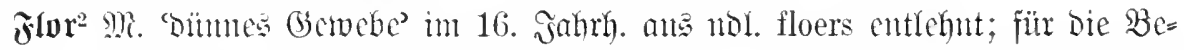

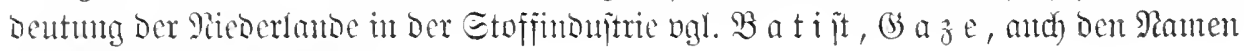
Kammertuch (Cambray).

Befege: Dilid 1598 Bejd). D. Simotanje Leinwad rnd Cammerduch anff die Brüste ङ. 51 schurtz von grünem Flor. Mejier= gelegt.

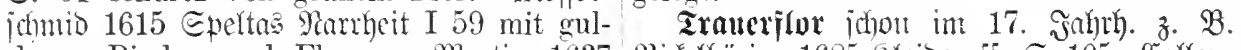
denen Binden vnd Floren. Martin 1637 Riffelhäring 1685 Aleiberaffe $\Xi .105$. Callen= Rarlement $\Subset .404$ mein kretsch oder flor bad) 1714 (jonealogie $\Xi$. 72 - 1715 Duaji

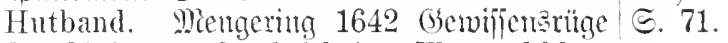

$\Xi .786$ dünnen durchsichtigen Flor vnd klare

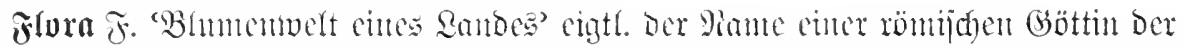

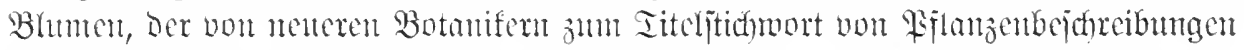

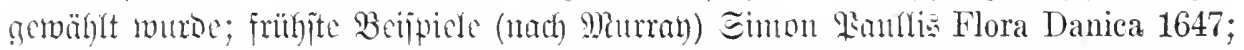
Ruph Flora Jeneusis 1718; ¿imés Flora Suecica 1745. Iurd Diejen Gebraud

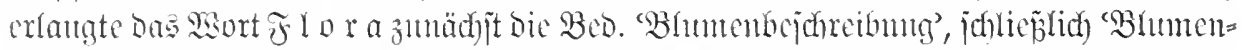
wolt'. Beleg: Crome 1784 im Tentjofen Merfur II 179 da blos ïber die Pflanzen

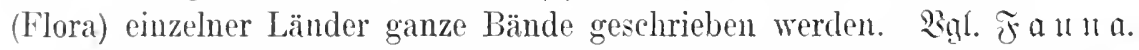

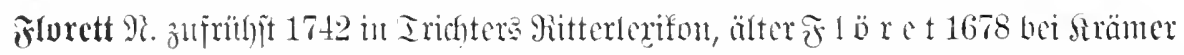

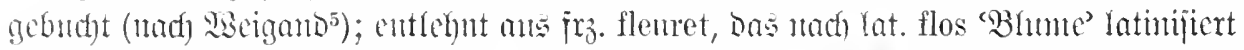

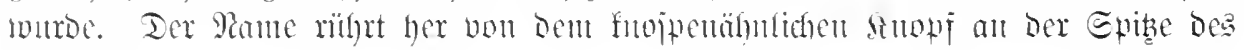
Iegent.

\section{juricren j. meter ま}

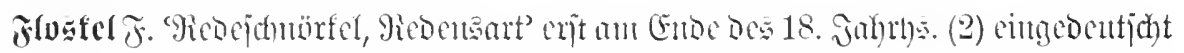

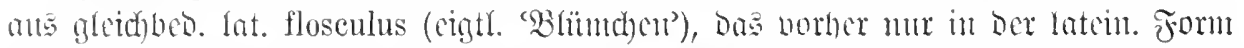

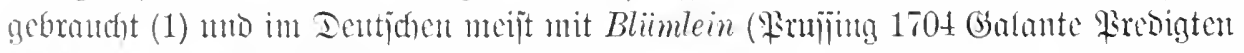
(5. 43) ober Wortblumen (s)erber 1767 Siteratur I 438) wiebergegeben wurbe. Das

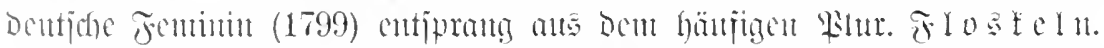

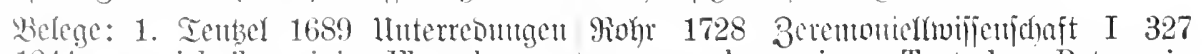
E. 1244 wem $\mathrm{ich}$ ihm einige Flosculos ans wenn or bey seinem Teutschen Patron in len Discoursen selbst vorlegen werde. $\mathfrak{X} \mathfrak{b}=$ einem Latcinischen Schreiben, und ob es

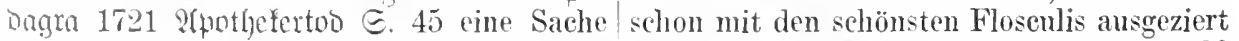
mit so viel erlogenen floseulis vorstellen. wäre, um eine Pfarre anhalten will - 1729 
ebD. II 128 Flosculis der Beredsamkeit. Botł Floskeln - Stalien II 211. গutigge 1788 1731 Surialredensarten $\Xi .15$ schöne Epi- Untanitg ङ. 126 nachgebetete voltairische theta und Flosculos, damit man N. beleget. Floskeln. Bahrot 1790 Lebenjbeichr. II 135

2. Schubart 1774 (Shrontif (Beifagen $\subseteq .39$ ) fünf bis sechs Floskeln. Şermes 1791 Mär von rhetorischen Floskeln und witzigen Luft- tyrer II 5. Bürger 1792 Brieje IV 188. sprüngen. Edjiller 1786 Briefe I 316 die frobebue 1799 Ueble Laute (IX 216) Eine Floskeln im Style. Arrchenholz 1787 (Englatid Romanenfloskel.

I $59 \mathrm{Er}$ würzte diese Vorwürfe mit allen

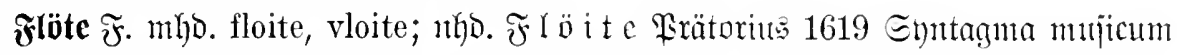

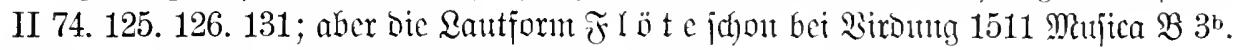

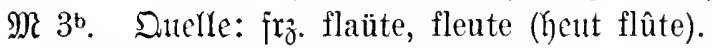

Fliotuje $\widetilde{F}$. in Den pitmo. nob. Munoartent fleute douce. (E⿱ bezeidhnete eigtl. cine be= vielfach Das (Erjatztwort fïr $\mathfrak{F} \mathfrak{l} \ddot{\mathrm{o}} \mathrm{t} e$, identijch fondere Flötengattung; vgl. Goethe 1828

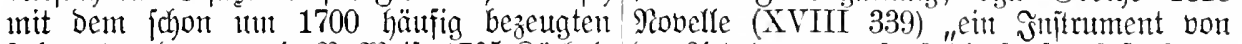

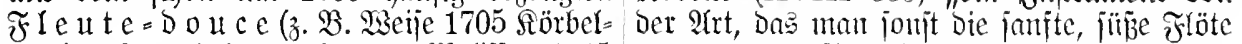

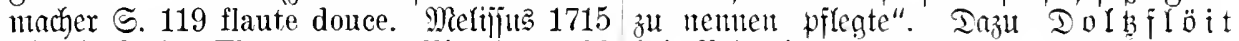
Fleurie $\subseteq$. 222 Fleute douce. Bicanber 1726 bei \$rätorius 1620 Theatrum intrumen= Edjauipiele Є. 64 "Flleute=Toutce") = fra. torm IX 2?

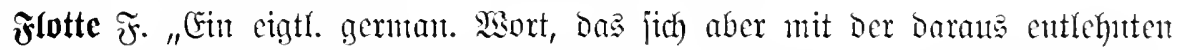

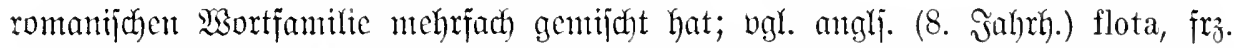
flotte, ital. flotta. Tie älteren nos. Qautjormen juto vlote, vlate, aber in 16. mo

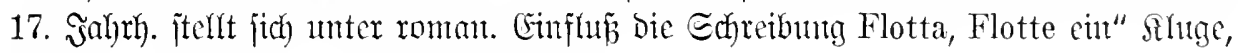
Scentantipipradye S. 272 (mit Belegent).

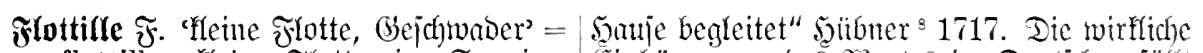
ipan. flottilla "fleine Jllotte in Epanient, Einbürgentuta des \$sortes in Deutichen fällt

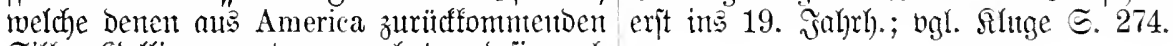

Silber= (Sallionen entgegen gehet, und jie nad)

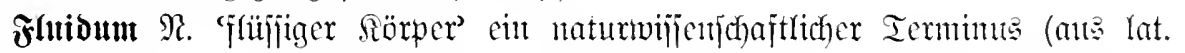
fluidus 'f(üjjig'), Der an (Ende Des 18. Jahrhs. allgemeiner geläufig wurde.

Belege: Schiller 1780 Difiertation (XVII mehr als humdert Meilen dahin in einem 117) den Nerven als einen Kanal betrachtet, Augenblicke zurücklegte. Brum 1800 〔đurif= der ein äußerst feines, flüchtiges und wirk- ten III 338 Ueber allen Hügeh Roms sames F. führt. Thimmel 1794 Reije (VI schwimmt ein halbdurchsichtiges, halbeon127) daß ich, wie ein elektrisches F., die sistentes F., wie halbgeronnene Dickmilch.

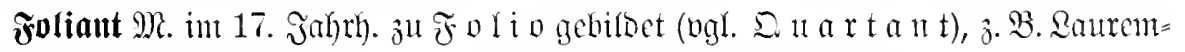

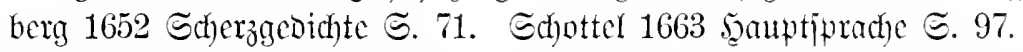

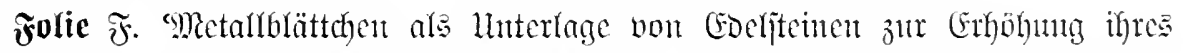

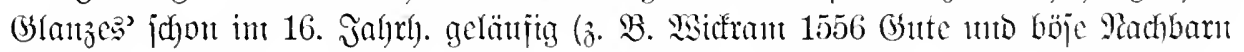

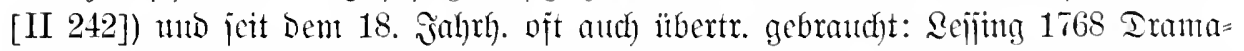
turgie (X 137) die Folie, die dem Laster untergelegt wird. Dutelle: mlat. folia $9 \mathfrak{M e}=$ tarlbbättçen?'.

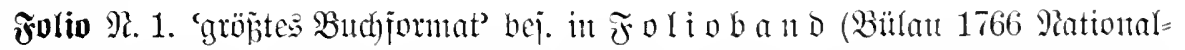

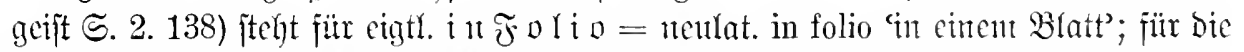

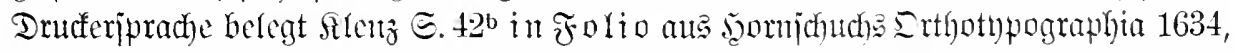
es war wohl aber johon in 16. Salyrh. eit Term. techu. (Beleg: Santhojer 1610 Bricje ङ. 20 Ain gar alt gerissen buch in folio), Da um 1600 bereits ber itbertr. (Gebrauch) ber Sisenoung häupịg ijt. 
Bgl. 1593 Sätze v. D. Rüfielei (Scheibles Schaltiahr III 653) Löffler in folio. Rituf= hart 1613 Eisteb. Hitter Є. 80 Erst war ich Stutzer in folio. wecioner 1644 3imfgrefs Spophthegmata III 243 wie man sagt, ein Narr in Folio. Saräörfier 1655 Ire apophth. כ. 264 Etliche lügen in folio.
2. 'Blattjcite (aud) Geitenzahls' bej. it Der faumäntijchen Budjü̈hrutg; Beleg: Edjurb 1695 fanjmanuid)aft S. 14 das Folio, worauf die Rechnung in Banco steht, wird allemal oben bey Anfang einer Seiten gesetzt. S(h) im 14 Jahry. in folio 'auj Dem Slatte'; vg!. Shirmer, Saumanmiprache E. 64.

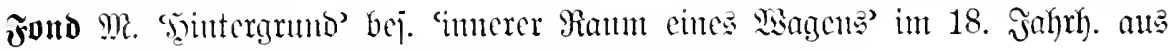
irz. fond entlebut. Beleg: Seume 1803 Spaziergang (II 70).

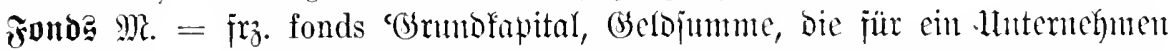

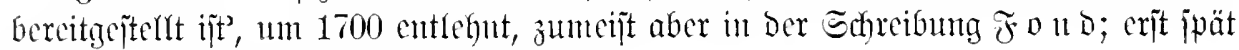
テ゚

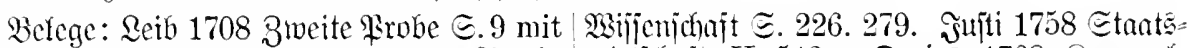
benöthigsten Capitalien, wozu ebenmäßig ein wirtjuafit II 512. Darię 1768 fameral=

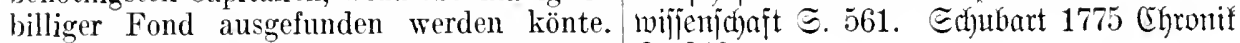
1708 Qeopold D. Grofie I 106 Der Fond ist Є. 346. zwar sicher genug. Ditbutar 1745 ¿foumom.

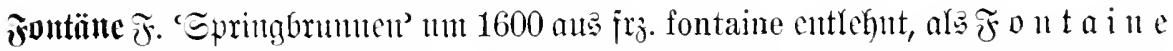

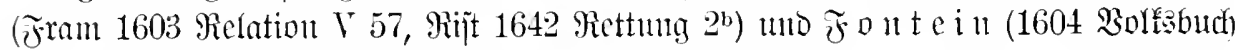

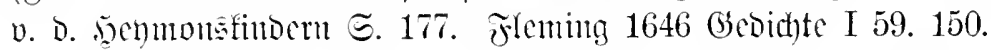

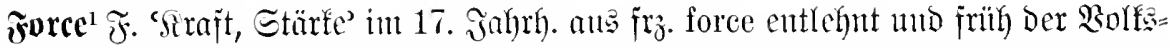

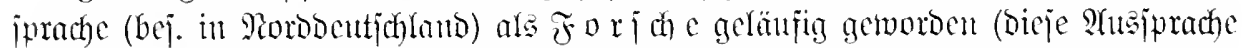

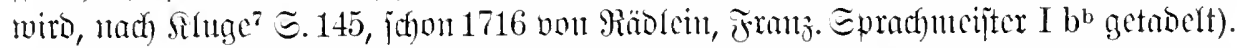

Belege: Francisci 1663 Iürfengejahr (5) $2^{\mathrm{a}}$ itcigen, ïbermitrengen' ist doch die rechte Forze oder Stïrcke von narrent $\Subset .152$ wann sie in der Jugend ihre ihrer Armee ein solches Volck. Thontajin gesunde und stareke Naturen nicht so sehr 1688 Monatşgeipräche I 67 damit ich des foreirt hätten. Mohn 1728 Beremonielfuvijicn= Herrn Augustins seine Politischen Wercke johajt I 424 so muB man sich lieber bey Zeiten mit grösserer force anpacken möge - 317 vom Spiele reteriren, als daß man sein Glück als wenn der Autor selber an der force seiner mit Gewalt, wie sich einige einbilden, forGrïnde gezweiffelt. Eochant 1752 Eelbjt= ciren wollte. Sokebue 1806 Rfinde Liebe biographie $\approx$. 81 dab was mich attaquirte, (XX 171) Ich foreirte sogleich mein Glück, mich gleich mit der änßersten Force angriff. verdoppelte den Satz, gewinne abermals.

forcieren 3 two. (populär for $j$ d $i$ ite

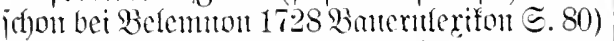
ate $\mathrm{j}_{\mathrm{r}}$. forcer entlelynt in jolg. Bibcutungen: 1. 'ergivingen' bej. mifitärijold 'mit (Gewalt in Bejits nehmen, vernichten' jobn 1616 in

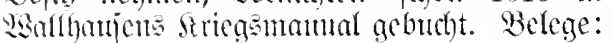
De Bry 1617 Bajtas Wacjtro di compo ङ. 59 die Bresche gar zu steigen und zu forciren. Leibutiz 1698 \&ierjonalia (I 353) da er den Foind in einem Paß forciren wollen.

2. 'grvingell' a. 'Tühtgfeiten gewaltiam

b. 'mit 3 wang, mit âjtrengung ctwas tur' Bürger 1778 Brieje II 308 dureh forcirtes Auf- und Absteigen des Berges. 1784 Merfur II 202 ein forçiertes Lachen. 9rofen= $\mathfrak{h y l}_{3} 1790$ Eicbenjühr. Strieg 厄. 74 von einem langen forcirten Marsch abgemattet. 5eine 1822 Bertinter Briefe (VII 178) mit forciertem Lächeln - 1837 巨alon (IV 319) der forcierte Patriotismus unserer Teutomanen. (Golts 1869 Richtflugheit I 55 eine heitere Miene annehmen und Witze forciren.

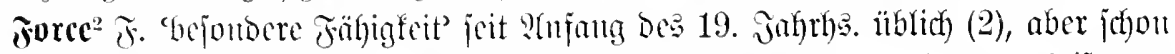

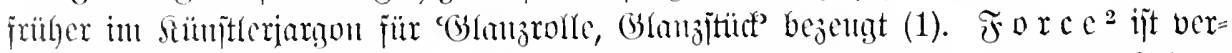

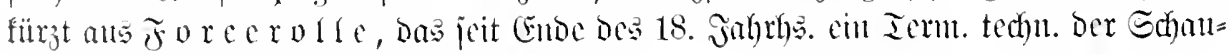
ipicteripuade war $(=\tilde{\text { frzy}}$. rôle de force).

Belege: 1. 1796 teutch Sir. 824 (298) glänz ich als Brandteweinfrau. Deine 1823 Schatuspiclerin. Furiose Geliebten sind meine lither \&olen (VII 212) Ich habe leider keine Forcen im Schauspiel, Ind in der Comédie Tragödie von ihnen gesehen. Ich glaube, 


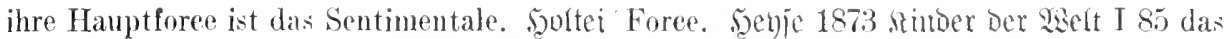
1852 Bagabumen $\Xi .144$ Damals hatte sie Springen ist nicht gerade meine Foree.

diese Force [Das Dectertaujert] noeh nicht. Stinde 1886 wandertrupke $\Xi .94$ Das Sterben ist meine Hauptforce.

2. Şauff 1826 Memotren I 61 ThreHauptforee besteht aber im Walzerspielen. รä̈gex 1835 Fetix Erfmabel ङ. 207 S. hatte cine eigene Foree, seinem Gesichte ganz verschiedene Formen zu geben. Frentan 1855 Soll u. Sgabeu I 366 Orangenpunseh ist eine ron Deinen Forcen, die Du mir verdankst.

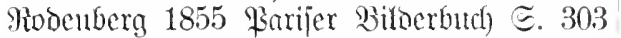
Gleichwohl ist das Schlachtenlyild nicht seine Force. Epicllyagen 1860 Problem. Daturen IV 64 Ein Walzer, das ist so meine Force. Troutare 1869 Bricje I 182 aber das nüehterme Erkemnen der Situationen war nie Deine

Furecrolle Edfmio 1775 Egronologie o. D. Ihenters $\Xi .199$ Yeuerlich ist Tellheim seine Foreerolle geworden. 1779 Rheinithe $\mathfrak{B e}=$ trïge II 233 Geront in diesem Stücke ist eine von den, wie es unsere Herrn Dramaturgen nemnen, Force-Pollen des H. Marchand, der dergleichen Carakteren eine ganz ungeneine Wahrheit zu geben weis. Exhiller 1786 Sirtefe I 316 Schröjder wird den Mensehenfeind, welches eine Force-Rolle für ihn ist, in Ilamburg geben. 23ect)ittein 1832 Wovellen I 38 da möchte ich gern den Fremden spielen, das ist immer meine Forcerolle. Devricut 1839 Briefe an Paris (IV 209 Rachel jedoch hatte in dieser Vorstellung wieder eine ihrer Forcerollen.

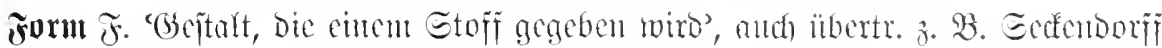

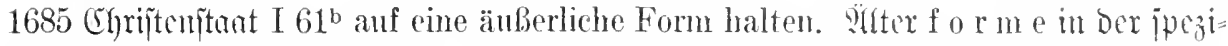

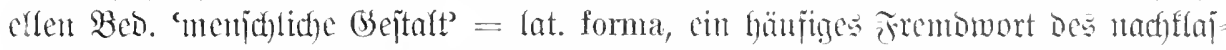

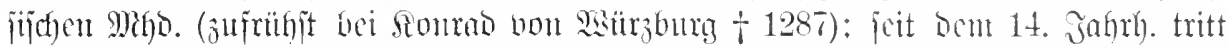

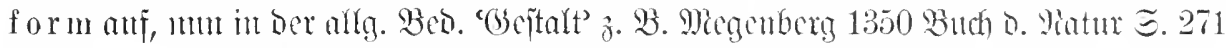
wan der tenfel mag sich verkeren in aller tier form. Sgl. Grimm, D然. III 1897.

jurmar ?roj. ans lat formalis: Eritller 1793 ?fumut 1t. Sisurove (XVII 318) die formale Kunstmäßigkeit. S̈litere Siernendutgen: ein formaler Pietist (Pobagra 1721 ?(pothe= fertud $\Xi$. 86), formale Herrenhuter (Coel= Imanu $17+1$ (Ehriftus a $S^{b}$ ).

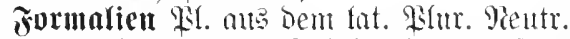
formalia fifoun in 17. Sahrh. eingebeutidht: Eenfendorff 1665 Tiurtesijtant II 78 Die Erbhuldigung betreffende, wo sie in solchen formalien geleistet wird.

jormalijieren refl. 3tw. cïch ïrgerlich

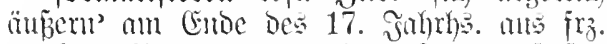
se formaliser 'wegen eines Formberitobes verfebt jein' entfehit. Belege: Reibuiz 1701 Briefe (II 191) Dannit sonderlich Auswärtige sich nicht etwa formalisieren, als wenn man ihnen Leetiones gebe. 1719 Recucif V 5 Drittens formalisiren sich mentionirte Briefe sonderlich darüber, daß jeh theologian mit unter die lustigen historias und passagen mêliret. Mod) gelüufig bei Gocthe j. \$1. 1792 iil Den "2uffgeregten" (XVIII 47) gegen den blinden "Haß, der sich über Formalitaeten formalisirt.

Formatität $\mathfrak{F}$. aus mutat. formalitas int 17. Şnhrh. cingebitrgert. Belege: Eecfendorfi 1685 (Ehrijtenjtuat I 625 die Schlüsse, entweder (nach der Gelehrten Art) aus der Logica und in solchen formalitäten, die man billich gelten lässet. 1699 Etratäpiegel I 40. Fohr 1729 3eremonicllmiffenfont II 531.

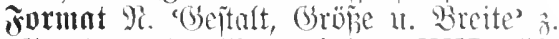
27. Goethe 1821 isantorjahre (XXI 358) Eine Lante in kleinem Format. Erigti. cin

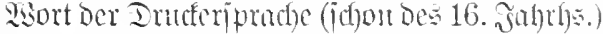

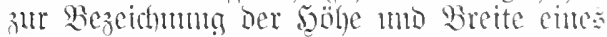
Buthes'. Donelle: lat. formatum 'gejtultet' (utant jagte wohl: volumen in quarto formatım o.

Formation $\mathfrak{F}$ als geologipger Termims zufrübjt bei (3). Chrift. Füdjel 1762. Iod älter jichon in allag. (Bebranch) 1685 Chripteniftuat II 84 die Formation der Welt-Geschöpffe. Eutelle: lat. formatio "Bie itultumig, Bifromig?.

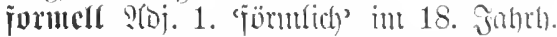
ans fro. formel entrefut 3 . 93. Bolt3 1731

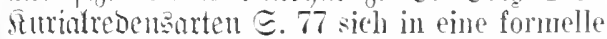
litis contestationem oder processum ordinarium eingelassen. Frteorith ber (Grobe 15. I. 1745 Sorief a. D. vilmiten v. Q(uthalt: ob hätten Ew. Liebden ordre bis in Jähren zu poussiren, Olmütz den Winter zu bloquiren und im Frülijahr, sobald es die Saison leiden würde, formel zu belagern.

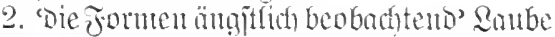
1837 Ias Gútu活. 301 ein formeller, etwas öder Manı.

formicren 3tm. in militïr. Bereid) unter 
Cinfluñ vou jro. former: "ein Räger zu for- formieren in ber allg. Beb. 'bilben'== miren" (Earolus 1614 Relation $\mathfrak{i r}$. 36 "Dab Siarree formicren" nach frz. se former en carré. Gruber 1697 Sriegesdişiplin III 212 Wie eine Bataillon quarré olme Mannschafft

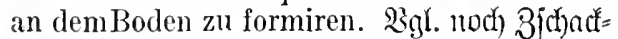
wib 1723 Jarl VI. S. 133 Dic 2. Brigaden Infanterie formirten zur linken eine neue Colonne. Dancben beftand bis ins 19. Sahth).

Formutax $\mathfrak{*}$. 'Morbrutefblatt' eigtl. 'vorge= juriebene Form' jdyon bei Frant 1532 গanz= leibüchlein $\mathbb{E} .3^{\mathrm{b}}$ auß den selben Formularien des brieff dychtens.

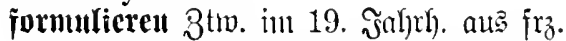
formuler gebildet uno bei $\mathfrak{X}_{\mathrm{e}} \mathrm{etri}{ }^{9} 1845$ gebudyt.

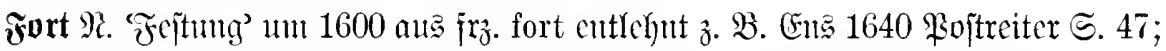
vorlecr bei Dilbaum $1597 \mathfrak{2}$ prifis $\mathfrak{B} 4^{\text {b }}$ Die in Blanet nemmen ein Forte ein - ein

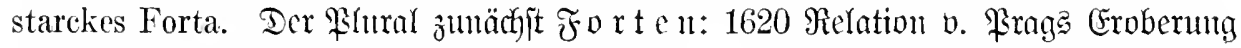

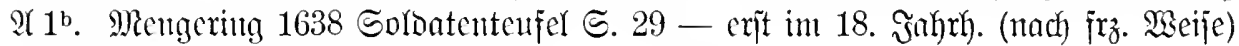

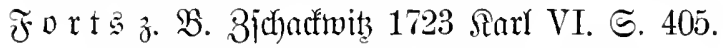

jurte YDo. 'Yaut, jtarl' jđyon bei Rrätorits 1619 Synfagma mujicum III 112

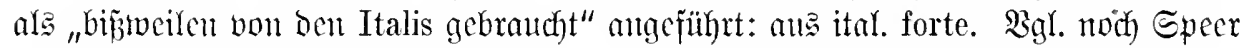
1687 llutcricht v. D. mujifal. Sumft S. 39 F. heißt forte, starck. Daju fort $i j=$ i i m o = ital. fortissimo 'iehr itarf'.

Fortepiano i. Fi a no jorte.

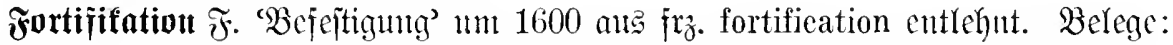

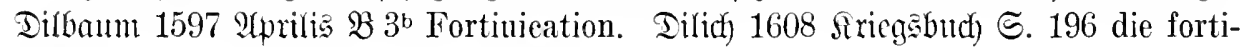
fication und befestigung eines Lägers.

fortifizicren $3_{\text {two }}$ latinifiert aus $\mathfrak{f r}_{\mathfrak{\gamma}}$. forti- Castel tag vnd nacht zu Fortiuiciren. Carolus fier (bgl. lat. fortifieare). Belege: Dilbanm 1609 Relation $\mathfrak{M r} .49^{2}$ vmb etlich ort zn $1597 \mathfrak{S}\left(p r i f i s B^{b}\right.$ ein altes zerschlaipfftes fortificiren.

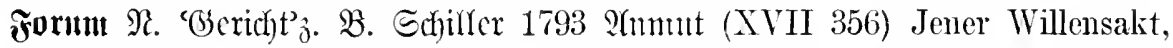
der die Angelegenheit des Begehrungsvermögens vor das sittliche Forum bringt. 1835 Europa I 245 da das Privatleben nicht vor das Forum der Oeffentlichkeit gehört. Duelle: lat. form, Der Mame bes Marftplabes in Ront, Der audb Der (Se= rid)taplab war.

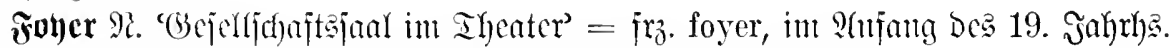

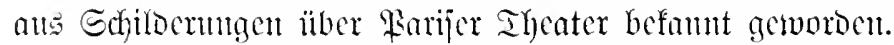

3gl. Miatthijןon 1803 Edhriften VI 87| II 180: Nach dem ersten Akte ging ich ins Wer von diesen die Reitzendsten bey- Foyer. Patmer 1839 Bitber aus Garis I 138 sammen finden will, der besuche den Ge- Der Graf und seine Gefährtinn hatten den seilschaftssaal (Foyer) dse Theaters Montan- Foyer verlassen. Simmerbin bucht jchon sier im Foyer von Montansier. Sobzente 1804 Campe 1813 ohne Cintchräthung: Foyer

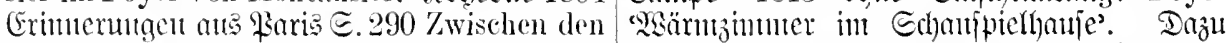

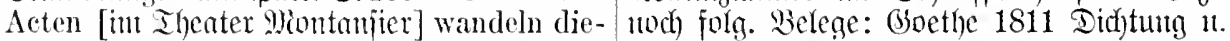
jenigen, die für diesen Abend noch unversorgt $\mathfrak{i}$ angrheit (XXVI 144) Er führte besonders sind, in einem schönen großen Saale umher, mich in die Foyers, wo die Schauspieler und der foyer huibt - $5.519 \mathrm{In}$ dem nemlichen Sehauspielerinnen in der Zwischenzeit sich Geschmack ist anch der große Foyer [Des anfhielten und sich an- nnd auskleideten. Théâtre Olympique] erbaut, wo oft Bïlle Süntc 1829 Iramaturg. B̉ätter (II 289) gegeben werden. Börte 1832 Brtefe aus während die Zuschaner im Foyer Limonade Pariz I 312 der große Foyer der Oper - trinken.

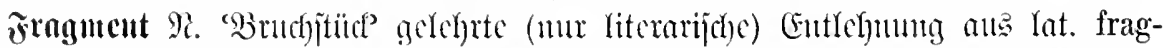

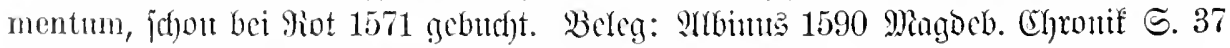
wie ats etlichen alten fragntenten der Recessen vnd anderer rechnungen zusehen. 


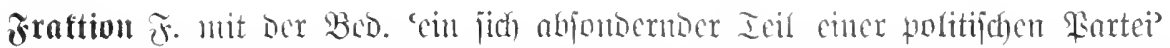

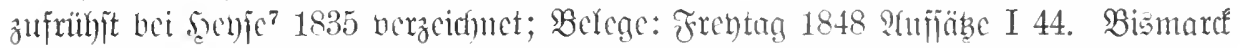
1850 Bricje $\widetilde{S} .174-1851 \mathrm{cbo}$. $\Xi .239$ Fractionssitzungen. Das wort ijt cutlebnt ans

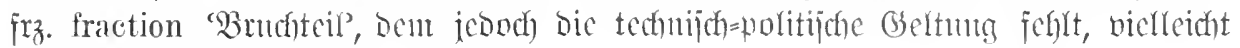

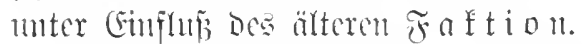

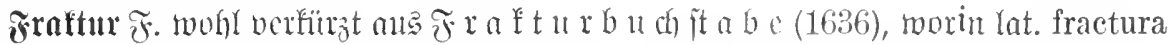

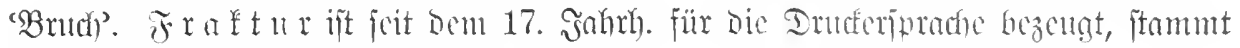
aber mohl cigtl. von ben Edoreibern her.

Rot 1571 erflärt "Fractur wirt jemale grossen Buchstaben geschrieben - $〔 .518$ für ein art Der hambtichriften genommen, oie mit Fractur zu schreiben. Dtho 1664 (1671) in etfichen Guchitaben gebrochen jeind". Bgl. Sranfentroit $\Xi .1383$ schreibets mit gülauch Mefjerifmis 1615 Epelta?s Parrbeit II denen Fractur-Buchstaben anf die Tafel 54 ein Versal Buchstaben, ein Cantzeley- eurer gedächtniß. Thraham 1688 Эงunas I Schrifft, ein Fractur. Edywenter 1636271 vnd gleichwol schreibet die schlimme Delitiae ธ. 302 mit Fractur oder sonsten Kreiden mit völliger Fractur.

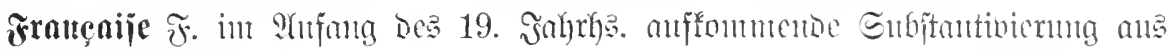
frz. danse française.

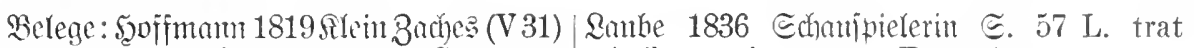
tanzte die nenesten Françoisen und Gavotten. mit ihr zu einer neuen Francaise an.

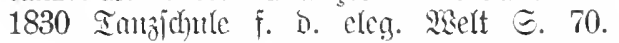

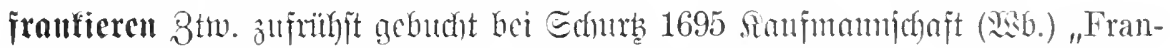
chiren, frex machen, bejrenen, jo wol bon Infoiten als Bricffporto zu veriteben". Qfbleitumg boul

frantio $=$ ital. franco (eight. porto franco $-\mathfrak{5} \mathfrak{5} 4^{\text {a }}$ sandte er mir auf mein Begehren 'Treie Beföronenu' \{. Porto). Belege: franco anhero - wab. Francò, frey, befreyt,

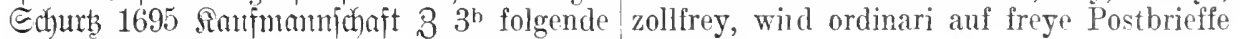
waaren sandte er franco Fracht anhero gesetzet.

irappant Proj. 'treffend, cindond

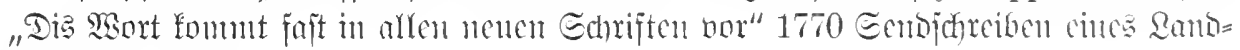
wriciters ๔. 26 .

Belege: Refing 1758 Bricfe (XVII 155) ale bas 9oj. Belege: 1719 Recueil V 7 was eine Wirkung seiner frappanten Art zn diesem nicht gefällt, das frappiret jenen. mahlen. 1766 ?tlg. D. Bibliothel III 1 E. 77 Bingmonf 1741 serming Є. 152 es ist der faßlichste und frappanteste [Bereis] - eine Naterie, die frappirt und lebendig

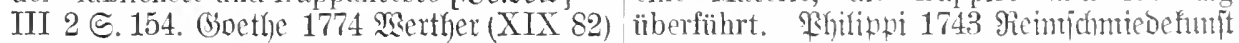
ein herrlicher Anblick, der um so frappanter $€$. 70 Je unmöglicher und unnatürlicher war, weil uns rings eine tiefe Dämmerung eine Begebenheit scheinet, desto mehr frapeinschloß. Subater 1775 P̧h mentc I 65 den frappantesten Beweis - mom 1752 Eelnithiographic E. 183 Meine $1776 \mathrm{cbo}$. II 33 eine frappante, freilich ver- Fermeté frappirte ihn - Є. 192 so frappirte gnïgte Aehnlichkeit ihres Profils.

mich sein Discurs nicht so sehr. Rirut 1800

frappieren 3tw. 'rïinren, Eintonuce madyen' Echriften III 63 wurdest nicht anch du ans frz. frapper; ce jheint früher cntlehnt durch eine rührende Aehnlichkeit frappirt.

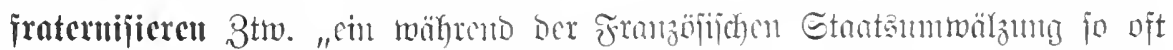

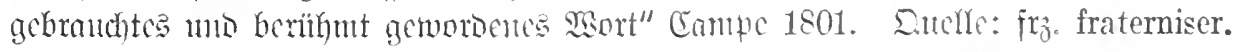

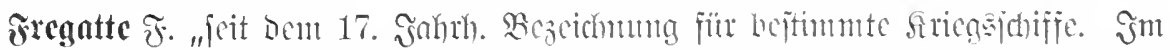
16. แnd 17. Jahry). Für Das 


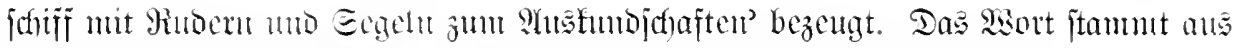

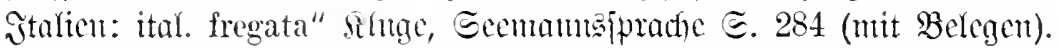

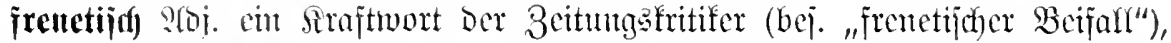
Das erit in Den 60er Jahren Des 19. Jahrhs. vou Wien aus (j. nt. 1869) in Lumlauf ge=

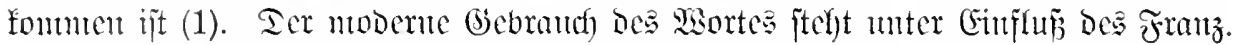

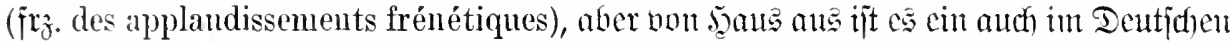

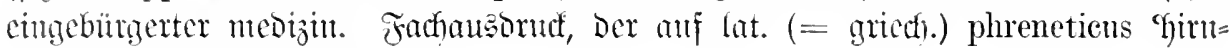
mütig, rajend’ zutüüffigeht (2).

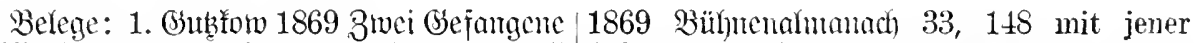
(XII 134) Das Publikum am Abend ,raste" vor Begeisterung und spendete ,frenetisehen Beifall", wie sieh die aus dem Französisehen ïhersetzte Wiener Fenilletonistik des heutigen Tages ausdrücken würde. Sircb̧er 1880 (Sentijen Є. 47 eins ihrer Lieblingskouplets tisches Haupt, gehöret ins Tollhaus; denn das immer einen frenetischen Beifall des es ist ein verrüekter Kopf ein phrenetisches

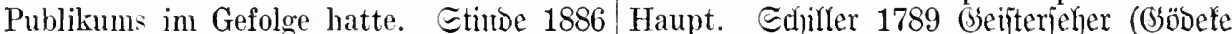
Manbertuppe ๔. 95 Totenstille im Hause IV 305) der Schwärmer ist einem phrene- dann frenetischer Beifall. 3um $\mathfrak{Q} \mathfrak{u} \mathfrak{m}=$ tischrasenden gleich, der sieh in wüthenden

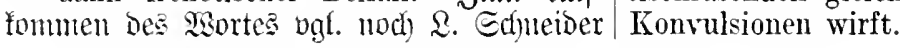

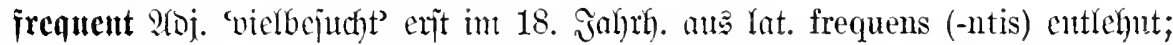
Beleg: Eeume 1803 Eprajicrgang (II 69) Von Conegliano aus ist der Weg schon sehr frequent. Siltere (Entlebunutgen fino

îrequentieren 3 two. als lat. frequentare häuffiger vnd in grösser frequentz sich an ‘hältfig bejudhen'. Belege: Eanbrub 1618 solehen Orten betreten lassen. Frätorius Telitiae ङ. 36 daß diese Blattenhengst das 1666 Guthropobcmus I 179 weil da die Hurhauß so fleissig frequentieren vind be- gröste frequentz der Lente täglieh ja stünd-

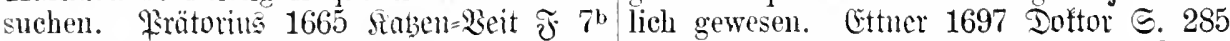
wie ich zu Hall frequentirte [sc. Dic Ec()ulc]. bey grosser Frequenz des Volcks. \&ucue

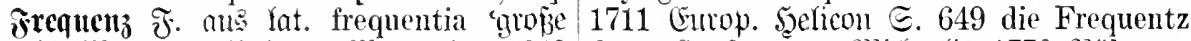

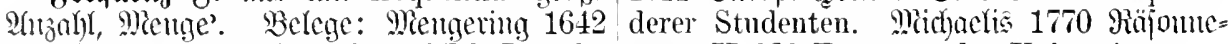
Gévififensruge $\subseteq .551$ daß die Welt-Bursele ment II 282 Frequenz der Universität.

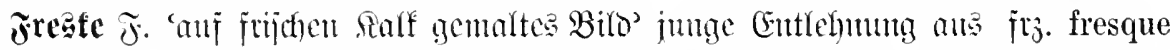

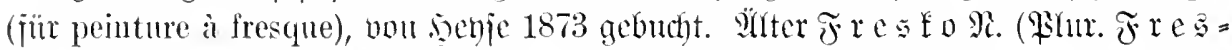

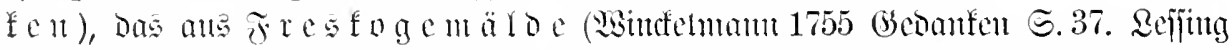

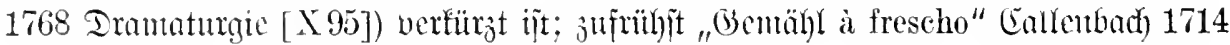
Fuer E. 107. Sullte: ital. pittura a fresco.

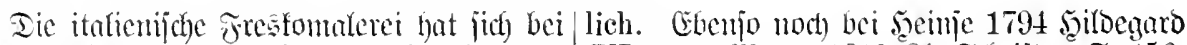

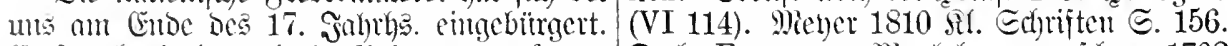

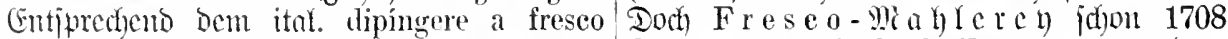

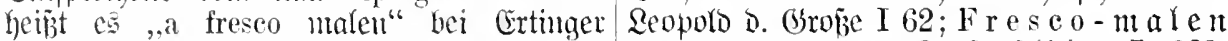

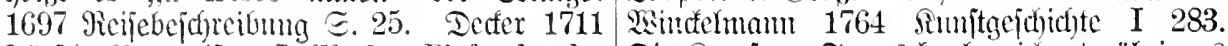

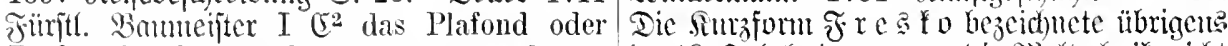
Decken-Stuek, we'ches man entweder à im 18. Gahrh. immer mur bic Mialtedunif, nicht

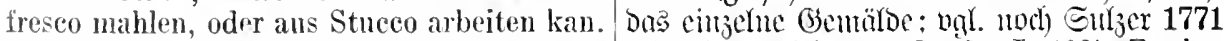

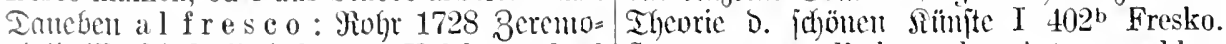
nielfmififenfifuft I 540 vom Kalehe und al So nennt man die besondere Art zu mahlen, fresco gemahlet, oder von Gips, wie es in welehe auf einer friseh mit Mörtel überden neuesten Zeiten mehrentheils gebräuch-' worfenen Maner geschieht.

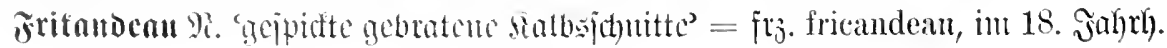




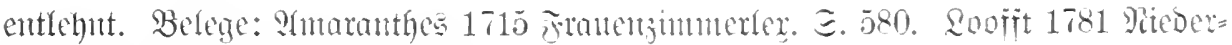

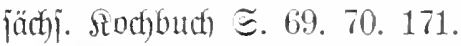

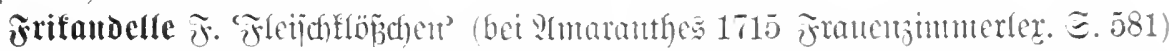

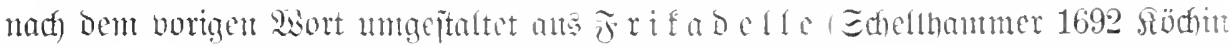

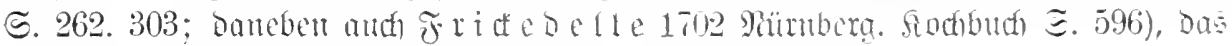

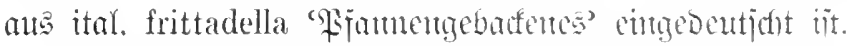

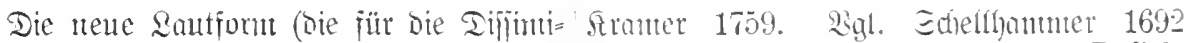

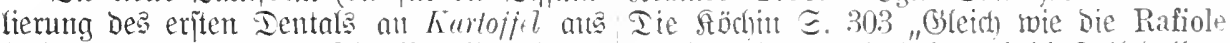

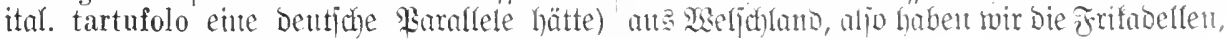

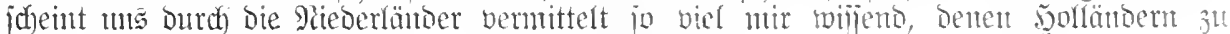
morben ju jein: nol. frikkedil, frikkadel bei, Danfen".

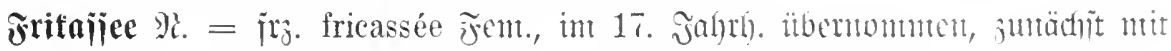

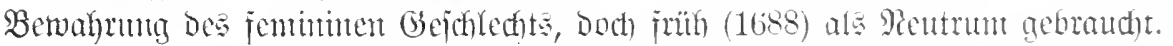

Belege: 1677 Miachiabell. J̨ofunpohts diese Art speisen erstlich ron dieser Nation €. 284 eine fricassée in eine Pfanne bringen. gelernet haben und bedentet eigentlich ein

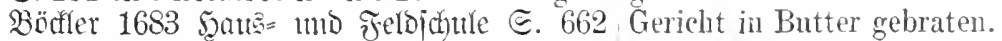

Eine Fricasse von jungen Hühnerm. Thontu= irifaipieren Btiv. aus ing. fricasser ichon

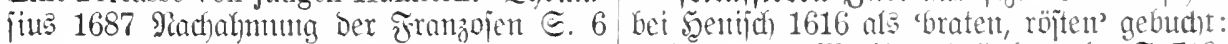
sehr geschickt von einen Frantzösischen Belege: 1677 Madjiabell. Softupofus 厄. 718.

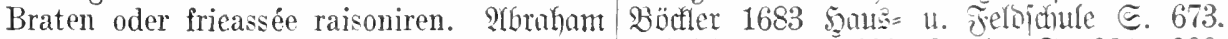
1688 Jubas I 347 Ein Ciocollada auß Spanien, Edhellfammer 1692 söd) E. 231. 299.

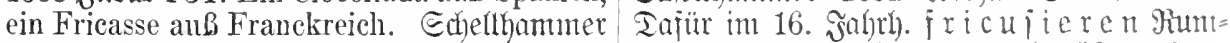

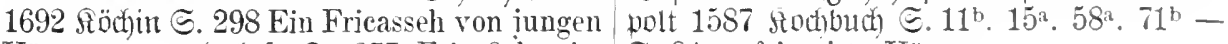
Hünern - vgl. bej. こ. 277 Fricaßeh, ist $\Xi .84^{\text {a }}$ gefricusirte Hünner. eigendlich ein Frantzösisch Wort, wie wir

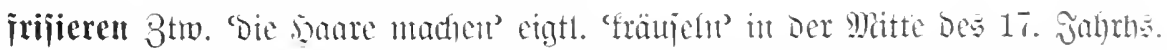

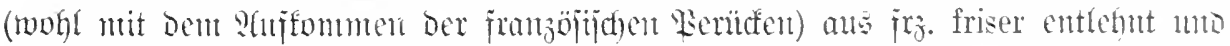

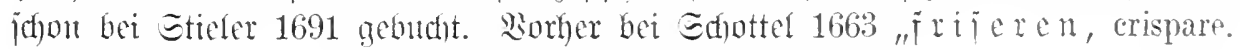

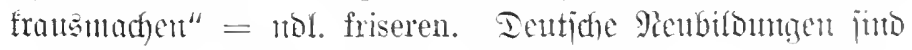

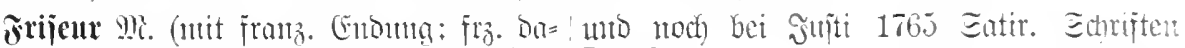

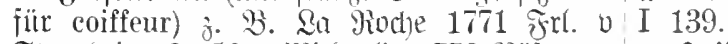

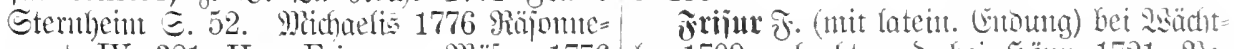

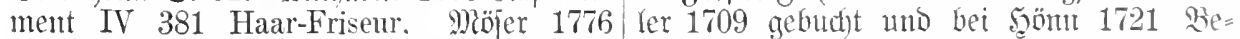

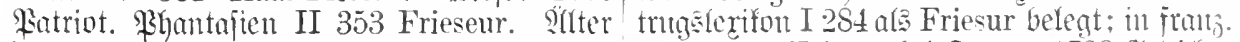

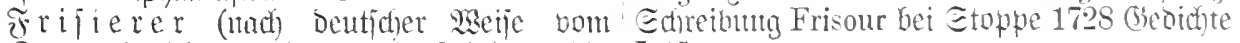
3tw. abgeleitet) jofjon bei Etieler 1691 I 15.

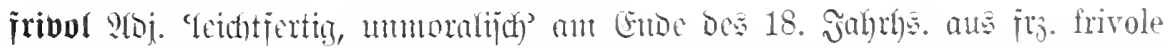

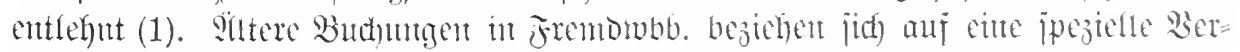

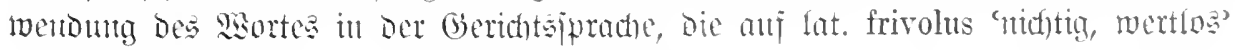
zuriufigeht (2).

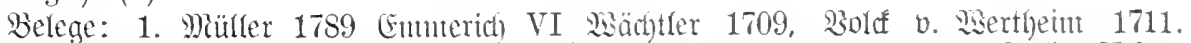

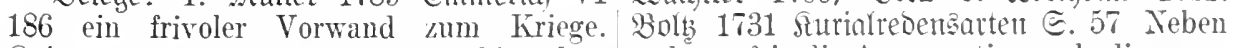
Snigge 1792 gieije $\Xi .278$ unfähig. dem anderen frirolis Argumentis, auch diese anfalschen, frirolen Geschmacke zu schmeicheln gebracht. 1748 5errent)ut in Iunore I 568 Šffland 1792 serbittag (II 256) weil ich in daB das Kind nichts fürwitziges, unnützes, Ihnen die ganze frivole Race züchtigen will. friroles, sondern lauter reale Sachen gefragt.

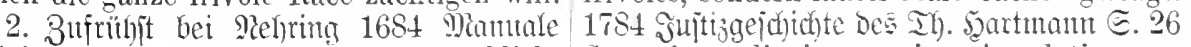
juridico=pol. $\subseteq$. 448 Frivole 'vergeblich, So weiters die interponirte Appelation annichts werth' - Frivolus - Frivola Appe- betreffend, müBte solche als frivola und für latio seu Leuteratio - Frivola exceptio null angesehen werden.

seine vergebliche Ausflucht'; ebculo bei 


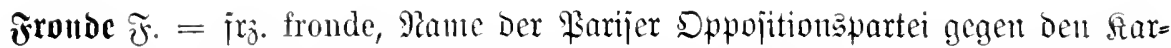
Dinal Mazarin während ocr Minbcriäl)rigfeit Subwiga XIV. Bci uns wurbe Das

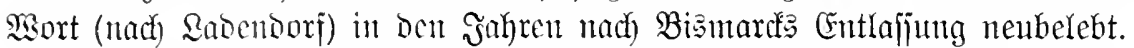

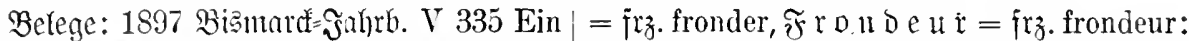
ähnlicher Mißbrauch wie mit dem Fremd- Fontane 1897 હtechlin $\subseteq$. 168 ich kann das wort "Agrarier" wird von der reichsfeind- Frondieren nieht leiden. Frondeur ist doch lichen Presse mit der Bezeichnung ,Bismarek- immer nur der gewohnheitsmäBig Unzufronde" getrieben. - Dazu fro t o i e r e $\pi$ friedene.

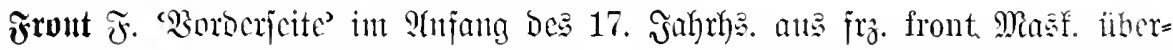

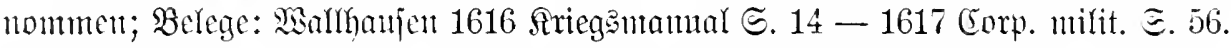

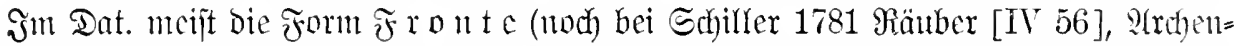

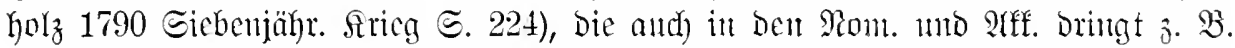

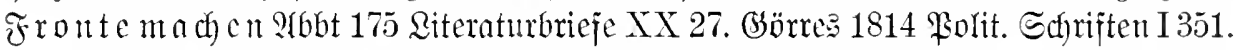

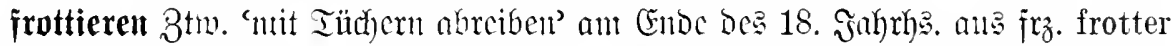

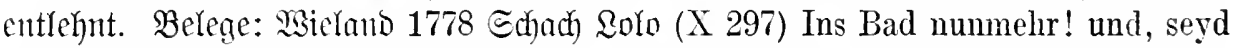
ihr da genïglich gewasehen und frottirt, dann flugs ins Bett. 1783 Merfur IV 95 frottirten ihn mit erwärmten Handtïchern.

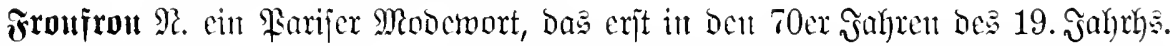

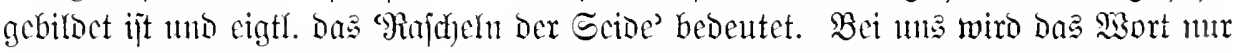
in übertr. und jegr crwciterter $\mathfrak{B}$ weutung gebraucht; Beleg: Fontane 1892 Untwiedr= bringlid) S. 114 eine merkwïrdige Mischung von Froufrou und Lady Macbeth.

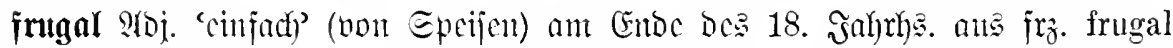
entrefint. Belege: S(rdyentholz 1787 (Englano III 89 bey seiner höchst frugalen Lebensart. Echiller 1789 Geijterjecher (XIII 207) ihr frugales Mittagsmahl.

Fuge $\mathfrak{F}$. in Der modernen Bedeutung zufrühjt bei Prätoris 1619 Enntugnuta mujicum III 21 Von den Praeludiis vor sich selbst: Als da sind, Phantasien, Fugen,

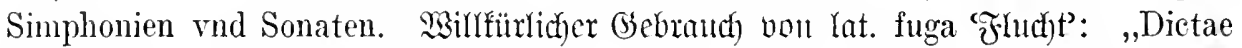
sunt autem a fugando, quia vox vocem fugat" Rucius, Musica poetica (1613).

Früher hatte ntan jeodod Dag Yat. Wort [chon 1656 Isagoge artis mus.: Fuga ist ein soleher auj eine verwande Bofattonjorm ithertragen, , gesang da etliche Stimmen aus einer singen,

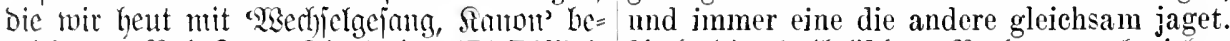

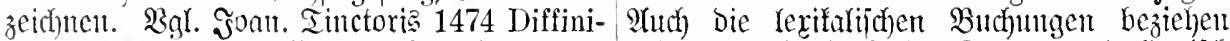

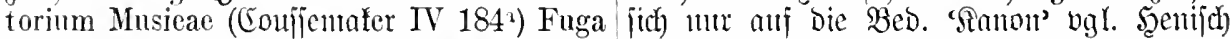
est idemtitas partium cantus quo ad valorem, 1616 Ep. 1276, ,Filga inl jillgen, eadem nomen, formam et interdum quo ad loeum modulatio alternatim", ühnllich bei EtieYer notarum et pansarum suarum. Demantins 1691.

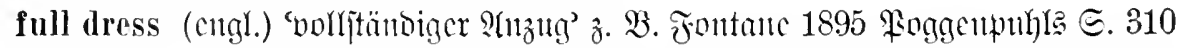

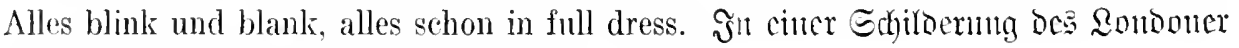

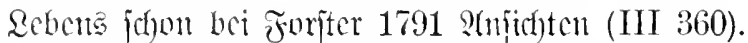

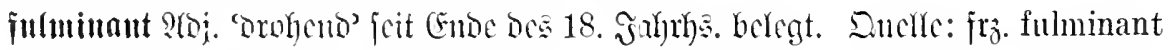
(oocer lat. fulminans cightl. "blititeno').

Berege: Esfiller 1796 Brieje Y 115 von 1837 Echjillerliebe (V 16) er dommerte mit

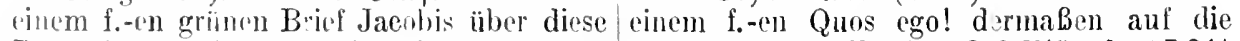

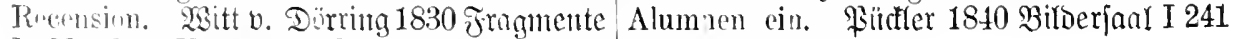
] 89 dent Verfasser des hentiren f.-con ein f.-es Ultimatum.

Artikels in dom Norning Chroniele. Gandon 


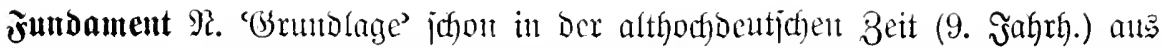
lat. fundamentum cutlehnt und jeit ocnt 14. Jaf)rf. anch in übertr. (uicht bauted)=

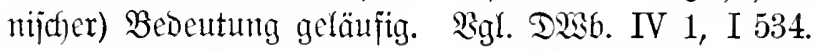

intmbamental $\mathscr{C}$ Dj. 'gründlidf' an Ěnde man hentzutage redet, f. sey. Weije 1697

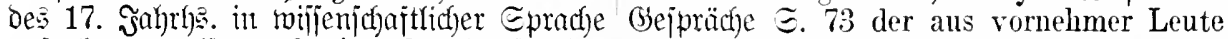
aujgefonumen (j. u. 1671!). Duelle: jpätlat. Discursen was f.-es gemerkt hat. (Ettner fundamentalis, ba: jedod nur materiell ge $=1697$ Toftor $\Subset .146$ seine Wissenschafft,

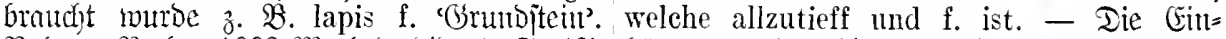
Belege: $\mathfrak{B e d}$ er 1668 method. Dibact. S. $48^{\mathrm{b}}$ bïrgerung bes r(bj. erleichterten ältere $3 \mathfrak{u}=$ wann man alles nach der Ordnung thäte, jammenjełumgen 3 . $\mathfrak{B}$. Fundamentalsatzun-

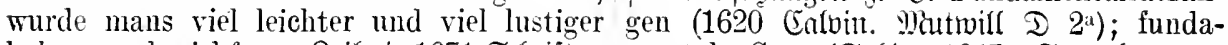
haben, auch viel f.-er. Reibuiz 1671 હch)riften mental Cur (ङebiz 1647 ङauerbrumnen I $275 \mathrm{dab}$ in der That der Unterschied gering $\mathfrak{S}$. 136); Fundamental-Gesetz (Warmund und zum wenigsten nicht capital, oder wie $166 !$ (Gefoulangel $\Xi .7)$.

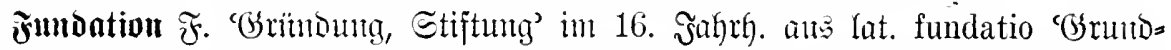
legunţ’ entlchnt z. $\mathfrak{B}$. Mänjtcr 1544 fosntographic $\subseteq .372$ desselbigen closters Fun-

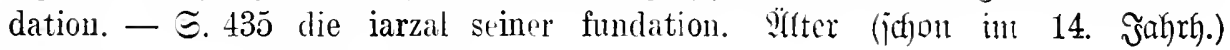
f t

jungieren 3tw. 'cin ?ut vermalten' zujrühjt bei Pebring 1684 gebuchte Bildung aus lat. fungi.

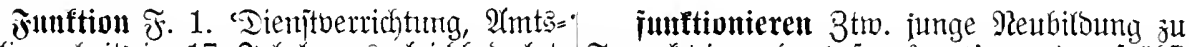

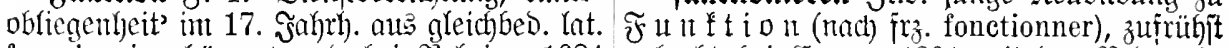

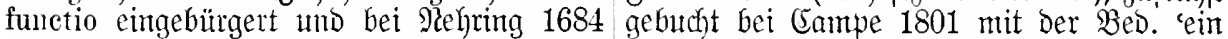
gebucht. Belege: Weije 1673 (Erznnrren/ant verwalten' (bej. "Der functionirende ङ. 176 es mangelte mir auch an Patronen Prebiger" $^{\prime \prime}$. Siel jpäter begimut ber allg. (Ge= nicht, welche mich schon zu verschiedenen brauch als ciente Tütigfeit berrichten' mit $\mathfrak{B e}=$

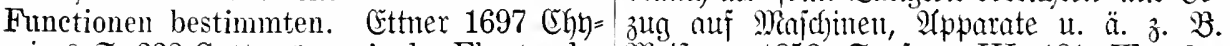
micu乏 Э. 332 Gott müsse sie des Ehestandes Meipner 1858 ङarjara III 181 Wo das nicht würdig achten, und hätte sie zu einer Gehirn seine Arbeit ausetzt, nur mit einer andem function ausersehen. Frantfe 1702 zuckenden Thätigkeit funktioniert. $\mathfrak{i}$ ber

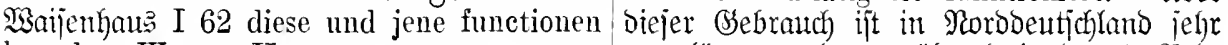
bey dem Waysen-Hause.

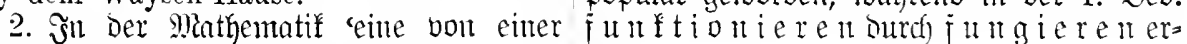

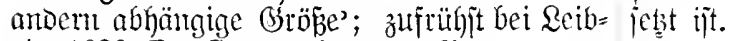

niz 1686 De Geometria recondita.

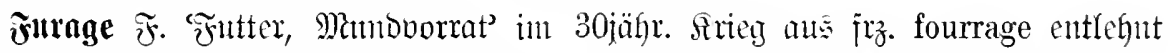

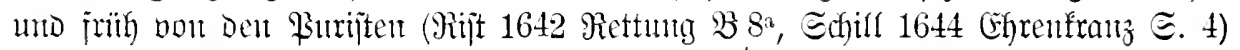

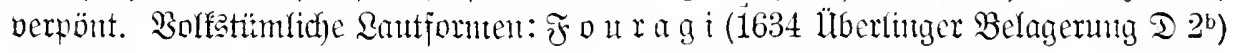

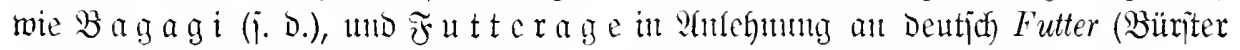

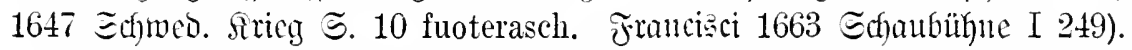

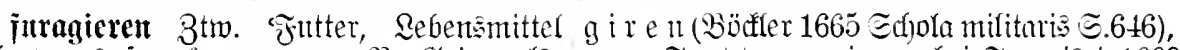

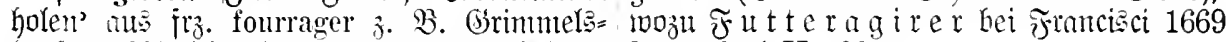
haujen 1669 Simpliz. E. 139.1676 Srieg: Irameriant II $103 \pm$.

gejohidtert III 5 . Dafïr aud i ut $\mathrm{t} \mathfrak{a}=$

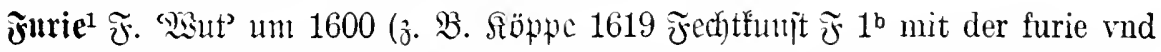
geschwinder eil. Edhilshnecht 1652 jarmonia III 127 in der Furie) eingebürgert

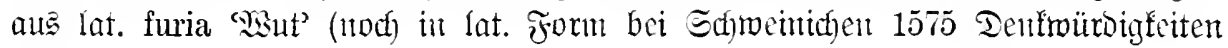
ธ. 60. 61).

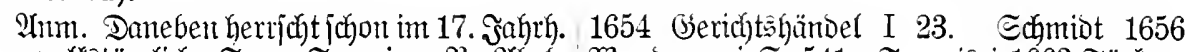

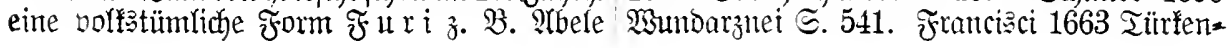




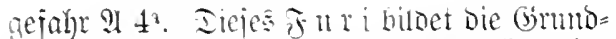
lage für Die in Den mobernen Tinleften ke= itebenten jomen 3 . R. jollei. Fure - furisch; ichtoüb. furen - furig (meben Furie); eliäij.

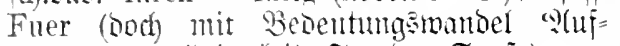

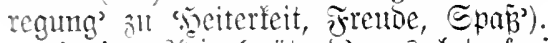

jurio: ?(Dj. 'multeno' ans lat. furiosus

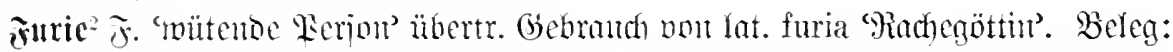
1719 Rucucil VII 125 Des folgenden Tages kam sie wie eine tolle Furie wieder ins Hans.

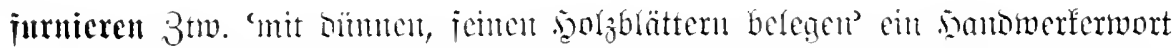

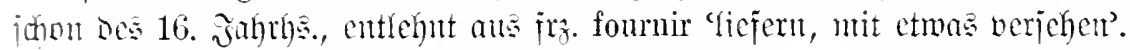

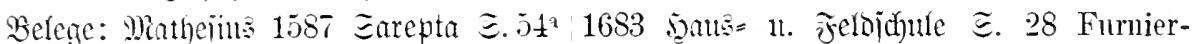

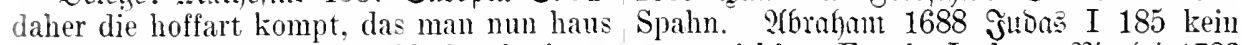
und stubendecken mit gold beschmieret, wurmstichiger Furnier-Laden. Ricolai 1783 kupffer rerguldet und die stuben mit dün- Reije I 262 da jemand mit einem Tischler-

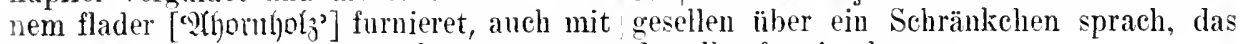
papier wie die bachanten ire kammern ver- derselbe fumirt hatte.

kleistert (Dish. III 1709. IV 783). Büffler

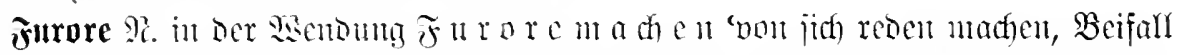

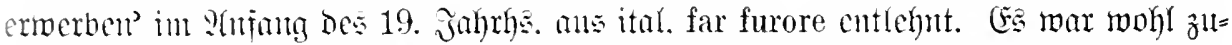

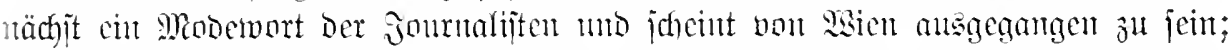

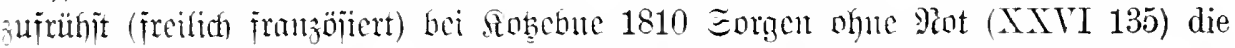
Silhouetten sind aus der Mode. Aber das Reisen macht furem, wie man in Wien zu sagen pflegt.

Belege: Seine 1822 Berlmer Brieje (VII 1827 frontroverwnebigt (XIl 213) Mit Recht 572) In Wien. Dresden. Hamburg macht er könnt’ er in einer pompösen Anzeige sagen: [Der Freiīhinti] ebenfalls furore - (576) Der Das ist jetzt der Mamn des Tages in DeutschRoman Kennilworth hat gar besonders furore land, er macht Furor [!], den mïßt ihr semacht. 5anif 1826 Memoiren (VII 63) lesen. Bütcler 1831 Bricfe III 122 Die bees stehe zu erwarten, daß es [ein belnen= rüchtigte Madame Vestris war ebenfalls hier gebicht] allgemein Furore in Deutschland engagirt, die ehemals so viel furore machte inachen werde - (122) den großen Furor[!], - 1835 Eemilaijp II 99 das Gehen auf welchen sie [920velfert] in der Welt machen - den Fußspitzen machte das meiste furore.

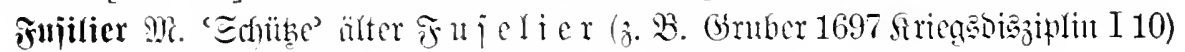
:tad) $\mathrm{Tr}_{\mathfrak{z}}$. fusilier (iut 17. Jahrfy. fuselier).

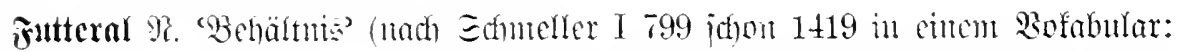
futaer vel futral, futrmm) ans mlat. fotrale, Dos jelbjt vom Dentid)en Futter abgeleitet

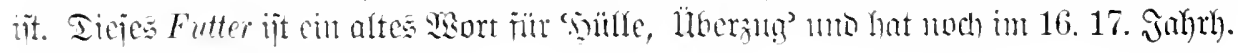

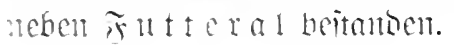

(6).

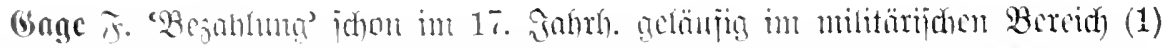

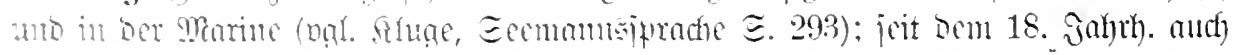




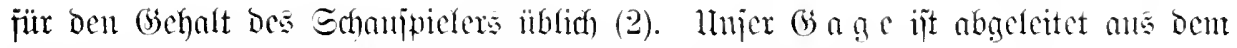

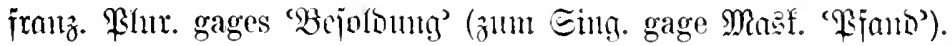

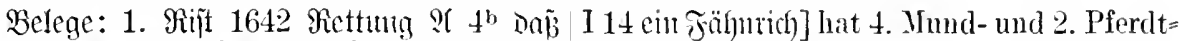
jie] niemahls jhre Gage empfangen - $\mathfrak{i f}^{\mathrm{a}}$ Portiones zur Gage.

die ordentliche Bezalung [heif̈t] Gage. Edhito-

funtht 1652 Sarmontia II 51. Grimmels ters Seine Garderobbe war sehr prächtig

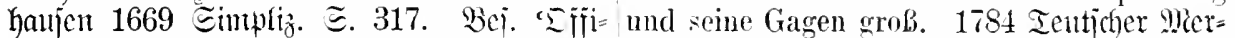

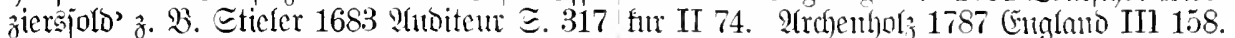
Nachdem auch die Services, gleich wie bey (joethe 1796 Sebrjahre (XXI 89). Jiffland andern Officiren, unter der Gage und Tracta- 1798 Theatral. Sanjhahn $\Xi .48$ Wochengage. ment begriffen. Gruber 1697 điriegsoisinglit

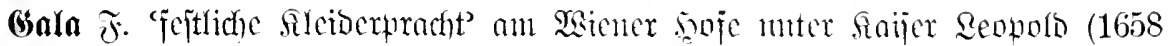
bis 1705) aufgefommen als :

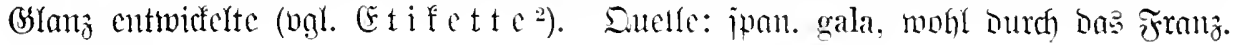
bermittelt.

Belege: Chilentont 1705 fricg: 11 . Etaat: $\mid$ man etwa seinen Geburths-Tas celebrirte, rat II 3 als sich alle convocirte Herrn Adses- gieng er gantz schlecht, das gantze Kaysersores in schönster Galla zur ersten Intrade liche Hauß aber und der gantze Hof in bereiteten. 1708 Reopold D. Brofe I 113 Pracht; und also thum alle Käyserl. PerDie Angen vergehen den Anschauenden, sonen, derentwegen Gala gehalten wird. wenn man an einem hohen Gala-Tage die Galafleid nach ipon. vestido de gala = goldene Gala sieht. Mentefe 1710 Gebichte irz. habit de gala. Selege: Hbraham a ङ. 290 Er schaut der Blumen Heer in ङ. Clara 1689 jtlons II 58 ein Kirchenschönster Gala stehn. (Ealfentad) 1715 klayd, ein Rathklayd, ein Hochzeitklayd, Duaji ธ. 3 beyde finden sich Sonn- und ein Galaklayd. Eimpert 1701 Siarium Feuer-Tag ein in der Kirchen in der schönsten $\cong .47$ Gallakleidung. Coullin 1709 Rär= Gala. Rïnig 1719 Iheatrum ceremontale I rimten I 331 er ist mit dem spanischen $295^{\mathrm{a}}$ Wenn er [Reopolo I.] in Gala gieng, Mantel angekleidet worden [bon boun be= so war dieses entweder die schwartze oder fannten hözzemen Etrajmerfzeug], in welchen die goldene Gala - 296 ${ }^{\mathrm{a}}$ Weil das Wort höltzernen Galakleid er forderist gespöttlet. Gala zum öfftern vorkommen, so ist zu Gifaketh Eharlotte 1715 Brieje @. 535 ich wissen, daß diß ein Gala-Tag, wenn man dacht nicht, daß die österreichische gallewegen Geburth, Nahmens-Tag, oder anderer kleider anch in Engellande der branch fröhlichen Begebenheit bey Hofe im Putz erscheinet, da denn allezeit denen Ministern von dem Hof-Fourir angesagt wird, was es nach proportion für eine Gala sey, damit sie in behörigen Kleidern erscheinen. Es ist dabey merkwïrdig, daß, wemn des Kaysers

Leopoldi wegen Gala gehalten ward, als daß

weren.

(Balatag nach ipan. dia de gala j. $\mathfrak{J}$. 1708 Scopolo D. Groje I 113 [i. o.]. Callen= bach (1714) Eccipies $\approx$. 35 der Jud lehnte ihr [Da: 厄tartsfleio], biß der Galla-Tag rorbes. Dijeijel 1789 Serinthe I 139.

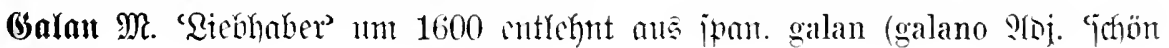
gefleidet').

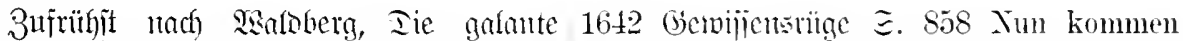

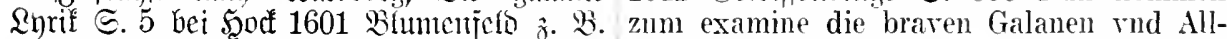

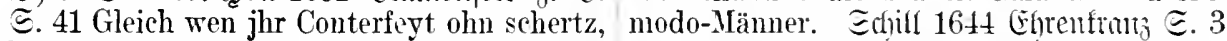
Ein Dama schenckt und schicket Threm da die Dame den Galan anredet. Ojifauber

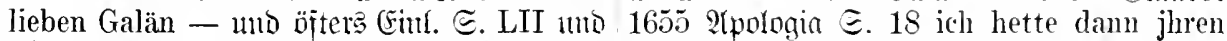

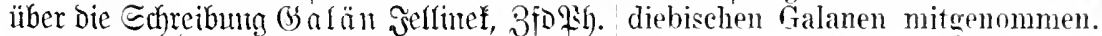

XXXIII 155. WSeitere Belege: Mengering

galant 2roj. Gäjlich gegen Damen' jeit ben 18. iahrh. begrugt (1), Daneben

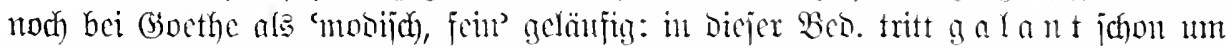

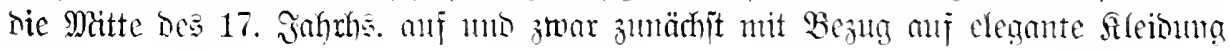




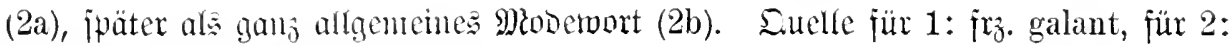
ital.=ipan. galante 'forin genutit'.

Belege: 1. Gellert 1746 Roos (III 308) daß bey uns mur die Musquetier so g. thäten, wemn sie in der Schenke wären. ĞLim 1751 an Famler I 306 Aber nehmen sie ihre Mädchen für ihn in acht, er ist der galanteste und witzigste Mensch auf dentschem Boden. Givetfe 1775 9ener भimatis (I 13) Und ich

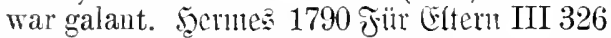
Das schmeichellaftste Betragen ron der Welt verbunden mit allem was man g. nenuen kann, hat er zwar. Yuijüllig frtien. Brtul 1806 Entifoden I 212 Dieser g.e Ton (laß mich das veraltete Wort brauchen, da wir es inl Deutschen nicht haben, wo auch die Sache immer seltner wird) mit den Franen.

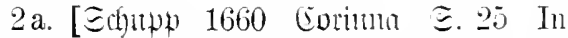
Franckreich, da die rechte Schnle der Civilität und Höflichkeit ist, nemnt man sie [eime bume] eine Yaistresse oder eine G.-e Dame.] Grimmershanjen 1669 Simplis. ङ. 157 so dan keine politische Alamode Cavalliers und gallante Dames. Reben= mallot 1681 Tenfels Rijt V 97 eine schöne

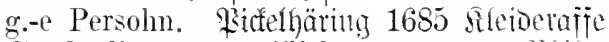
ङ. 181 diese war trefflich g. geputzet. 将gilo=

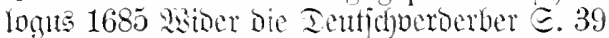
Das ist merklich, daß unsere Lente mur die= jenigen gemeiniglich g. nemen, so schon nette Kleider tragen.

b. Chr. Thontailus 1687 Disen vou Der 9andahmung D. Fromzojen હ. 10 Aber ad propos was ist galant und ein galanter Mensch? dicses dürffte uns in Warheit mehr zuthun machen als alles rorige, zumahlen da dieses Wort bey uns Teutsehen so gemein und so sehr gemißbrauchet worderll. daße es ron Hund und Katzen, ron Pantoffeln. vonn Tisch und Bäncken, von Feder and Dinten, und ich weib en!llich nicht, wh nicht anch ron Aepfon und Birn dab die Teutsche in Galanterie-Waaren, so zum offtern gesagt wird. Menter 1696 gut als die Franzosen arbeiten kömen.

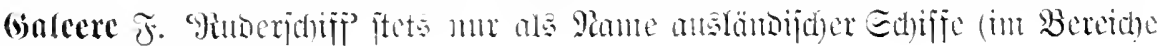
Des Mittemeris) gebratudt.

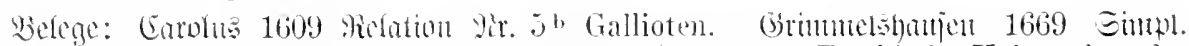

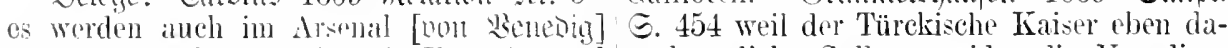
etliche newe Galleren für dir Heer Armand maln etliche Galleren wider die Venediger

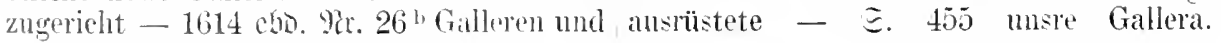

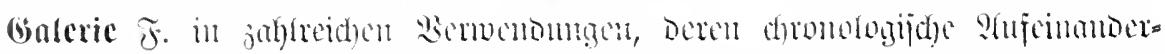

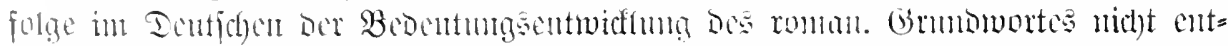

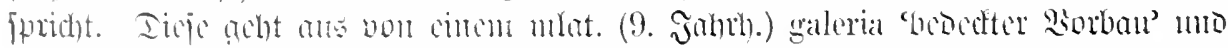

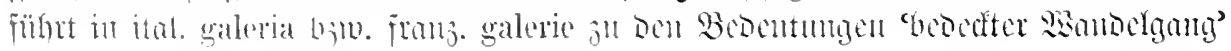




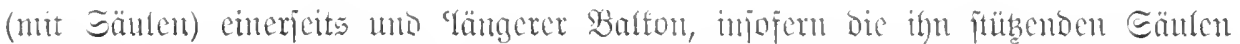

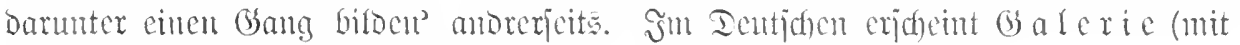
ber älteren Rebenform (s) a l D c r e i ) in folgenocn Berwendungen:

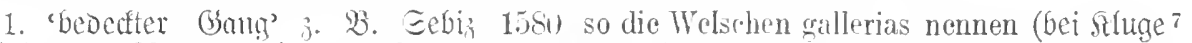

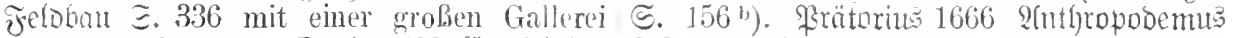
oder Spatziergang. Duto 1598 Enchitidion I 316 wie in Welsthland in den Gallereyen.

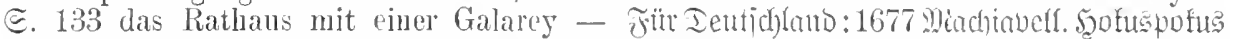
nit einer lustigen Galarey oder spacieroang. こ. 694 Wie hoher Fürsten Galerien, raritäten

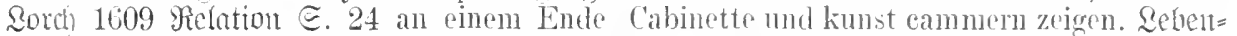
der Galdereyen, so insonderheit dazn ge- malst 1681 Tentels 2ijt VII 14 Gallarien von macht, den Printzen bedeckt aub dem allerley Ridriteten vnd Antiquiteten. Sintefler Pallast in dir Kirchen zu tragen. Biegler 1696 Edelntum ङ. 661 die H. Margareta zu 1689 kaniic $\Xi .47 \mathrm{er}$ ist getrost nach denen Wien in des Ertz=I Lerzog Leopold Wilhelms begrünten gallerien hineingegangen - $こ .51$ Gallerie, in welcher Gallerie denn ein derer gieng die gallerie etliche mahl auf und ab. gleichen Ansung so vieler kustbaren ge-

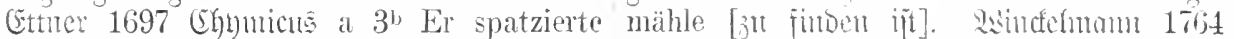
auff der gallerie seines Schlosses herumb. (3́cid). D. Stmint I xIx. jorjter 1791 Un=

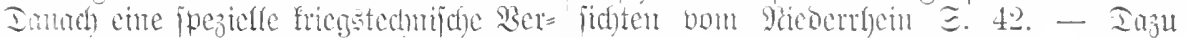

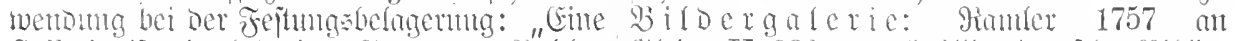

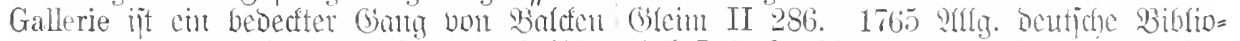

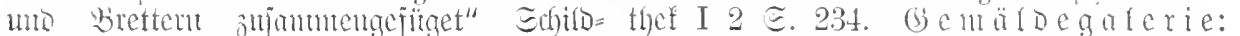
fncent 1652 Sammonia III 43. Belege: 3achuriä 1756 Iagnseiten (II 74) Ein

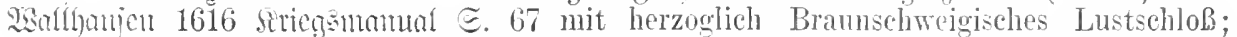
der Tinen oder Galerien. Eattler 1627 wegen seiner Gemäldengallerie merkwürdig.

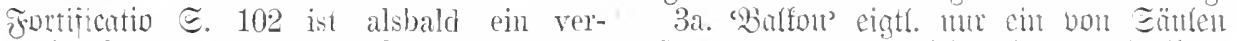
deckte knustlich gemachte Galderey hart an gejtübter, Dunt aber joocr längere Barfou:

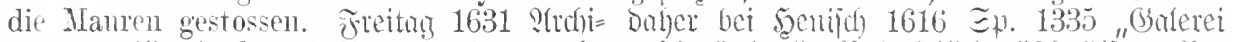

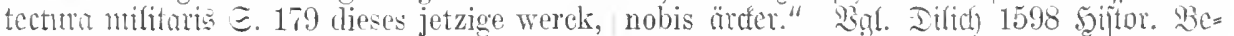
welches man eine Gallerie nennet. Schil = joureibung $\Xi .66$ In mitte desselbigen ist ein frecht 1652 5amnonia III 43 Daher heissen lustige gallerey [um eiten Tum herum= wir Tentschen ein Schirmdach noeh hentiges lantiend] — こ. 78 Galleri oder Umbgang. Tages eine Gallerie, weil in gantz Germania Berfenmener 1712 2futiquorins こ. 414 Auf sonst kein kürtzer Wort zufinden ist.

2. "Riliocriat?: aus Dem borigen cut=

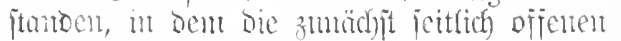
Galerien verghit mo itberfantht Den Saanpt= gebäuse arduiteftonijal cingejïgt mumoen. Sant entitanden fonggeñtreate 2 sandelfäle,

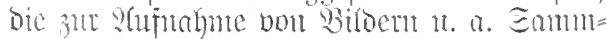
fungen jehr gecignet waren. Jir bicjem Sinte surübit ital. galeria; bal. Jumttenbach 1627 Jtmeratum Stulare $\Xi .87$ die rechte Kunstkanmer, oder Galleria, ein Gang so 8 Schritt braitt rnme 200. Schritt lang ist, da stehen zu beyden Seitten ein grosse Anzahl ron Stein rnnd Metall gar alte sehr künstliche Effigic orler Figuren, treffliche Antiquiteten, sampt einer grossen Anzahl ron den besten Künstlern gemahlte tafflen. dem Horizont [eintes Ricjenglobus] ist eine schöne Gallerie, auf welcher man herumgehen kan. Frenting 1855 Eoll mid Szuben I $5 t$ cine hölzerne Galerie, welche längs der Gaststube an der AuBenseite des Hauses lief.

b. Inter jeit bent 18. Juldul. boj. von Dem hödniten Sartun in Theater, Der jonjt

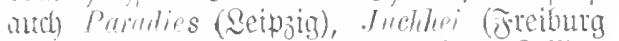

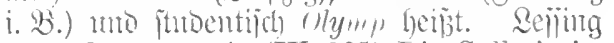
1767 Iromatumic (IX 205) Die Gallerie ist freylich ein groBer Liebhaber des Lernenden. Echiller 1781 strieje I 42 hier mußte ich an sich gute Züge den Gränzen der Bülnne, dem Eigensinn des Parterre, dem Lnverstand der Gallerie anfopfern. sojfman 1814 Rernania (I 12:2) einerlei, ob ar ans der Loge oder aus der Galerie in das Theater schaut. Beiffer 1641 Epijtefn II 353 Tiunstkanmern,

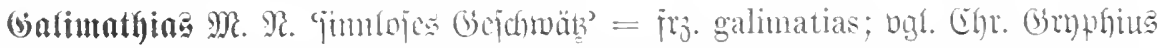

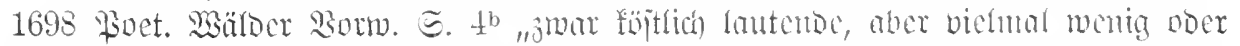

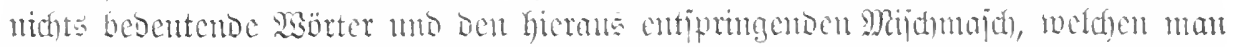

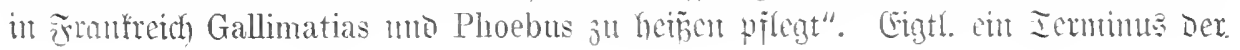




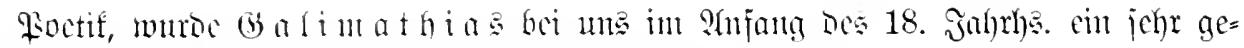

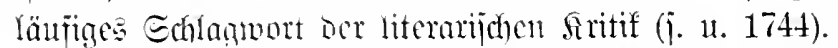

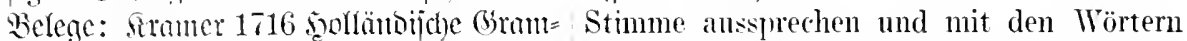
matif $\Xi .107$ dieses Gewire und anderes G. Galima tias, Schwulst, krjePoongra 17.21 ?pothefertod $\Xi .33$ alsdann chend u. s. w. mit einer satirischen Mine macht man noch so ein schön G. daher. um sich werffen kan, der setzt sich auf den Qiscom 1739 Eatir. Edyriften 厄. 170 einen Richterstuhl. Seifing 1748 Ier junge Gre= verdrießlichen und unertrïglichen $G$. $\mathfrak{B h} \mathrm{i}=$ Ichrte III 8 Und wann ich das G. eines ripui 1743 Remrichuiedefinit $\Xi$. 30 Die jungen Gelehrten verstehen darf, so haben neuen Poeten nemen es: Phoebus und G.; Sie es getroffen. 1766 Mrg, Dtijh. Biblio= welche Wörter uns als kauderwelseh ror- thef III 1, 216 Von der Art sind die meisten

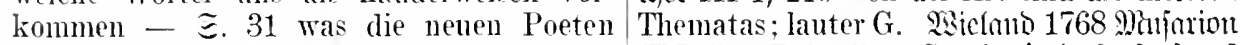
einen Phöbus und G. nennen. gehört unter (III 50) Bei allen Grazien! (ruft lachend die größten Zierlichkeiten der kriechenden Phanias). Vor wenig Stunden gab dieß Poesie. Meier 1744 fumtrifhter 巨. 2 wer G. Dir Stoff zum Spott - 1777 (Gedichte nur ein halb dutzend eritischer Flüche und an Elympia (XII 130) Zeus, gib mir dieB, Schimpfwörter mit einer gebietherischen Zens, gieb mir das! Ein tolles G.

galoniert ?ajj. 'mit Irejien gejdnmïft' von Perjonen (1), älter nur von bem

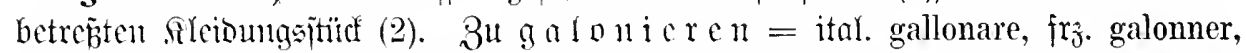

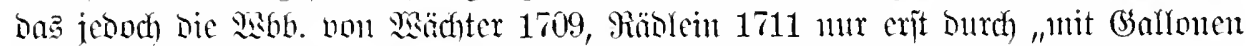

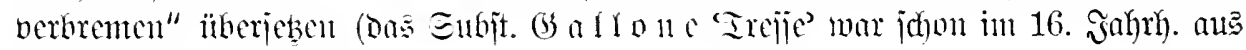
ital. gallone cutlefunt).

Belege: 1. Trafjenholy 1787 Emglano III und bordiret hast. Bachariä 1754 Ber= 25 Ein g.-er Fußgänger. Ǵanon 1839 Ier manolumgen (I 184) Hier hieng ein deutseher Etumunc (V 53) g.-er Diener. Frentag 1855 Graf [D. h). jeim Softium] mit Silber g. Möjer Eolf u. Syahen I 70 g.-e Bediente.

2. 1719 Recueil IX 86 Wenm Du Dein Richtenherg 1794 jeggarth) I 175 g.-en Kleide. Kleid über und über mit Golde galomiret

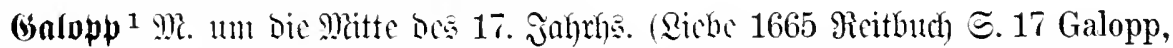

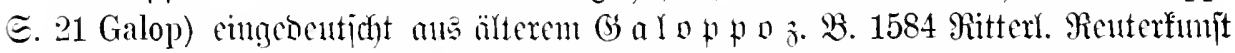

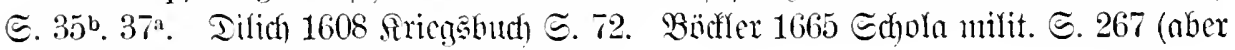
๔. 265 Galopp). Euterle: ital. galoppo.

galoppicren $3 \mathrm{tw}$. int 16. จal)rly. ans ital.

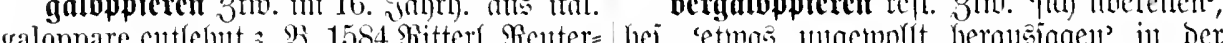

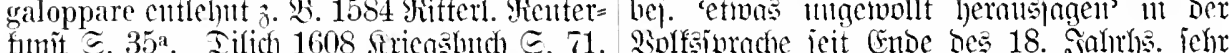

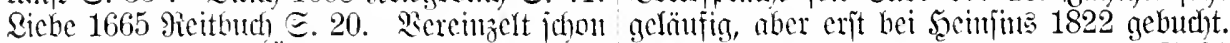

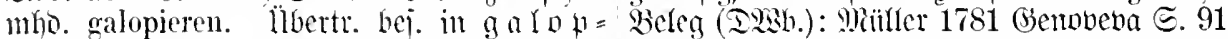

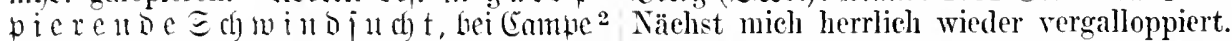
1813 gehudit, Dod jobn bei ífflano 1799 Gut, daß ich so allein bin. Der Teufel auch, Comet (IV' 265) galoppirende Jungen- wie man sich leielit vergaloppieren könnte. schwindsucht.

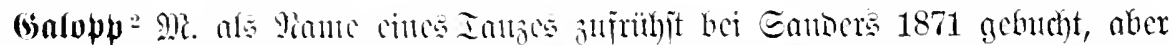

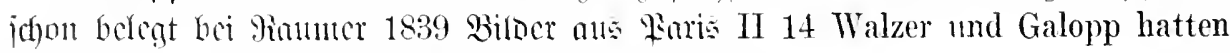
ihren Krois immer mehr erweitert auf Kosten der Spieler.

Q̈́ftere Fremombí. butchen bichuegr of a = Galop ou Galopade (choréographie). Tout

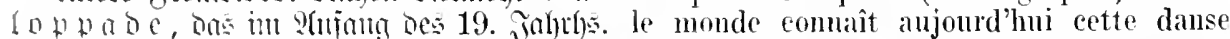

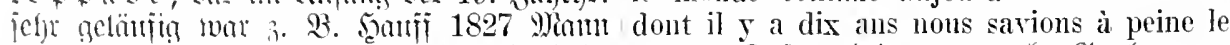

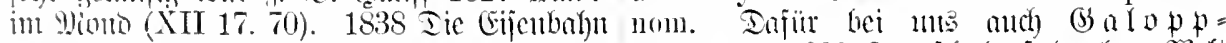

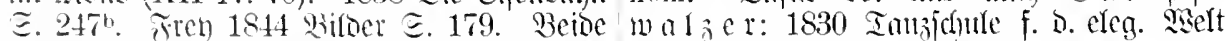

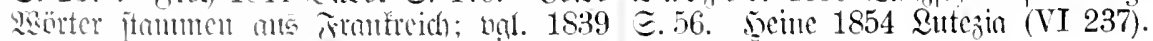

Encyclopédie des gene du nonde XII 79 


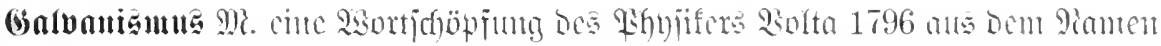

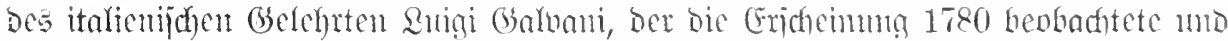

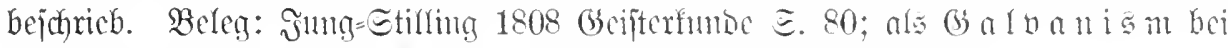
Beethoven 1801 Bricje I 84 man spricht Trunder rom Galranism.

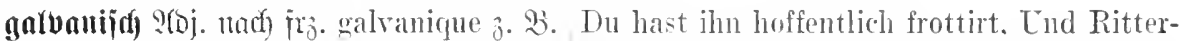

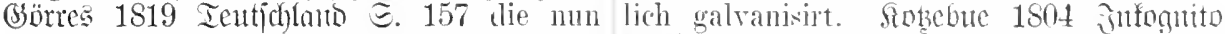
vom galvanischen Reize aufgerichtet, herum- (XYI 236) da war mirs, als ob mein Herz

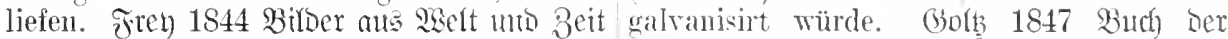
๔. 40 gleichsam wie berüht vom Trog- fimblect ङ. 80 vom Metallreiz galvanisirt.

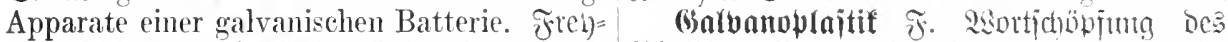

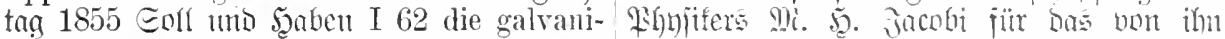
schen Zuckungen eines Frosches.

galvanijieren 3tw. nach irz. galvaniser "Die (5)." 1840.

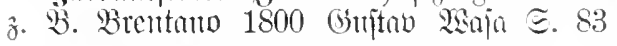

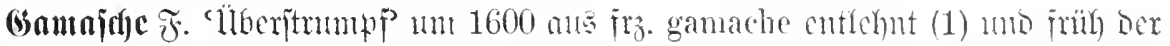
Borfsprache meijt als $\AA$ a maj Dafiur guêtre.

Belege: 1. Mejferdinto 1615 Enelta's bald ergeben, dab derselbe Mechanism, in Rarrbeit II 157 Gammachen oder zuge- dem die Verfassung erstarrt, auch in nichschnierte wullin Strimpff. Martin 1637 tigem Kamaschendienst mnd eiteln ParadeRarlentent હ. 331 Gamaschen.

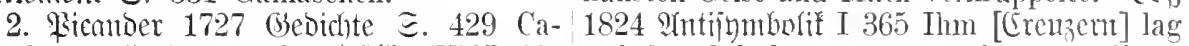
maschen. Jecrber 1778 Ríafitif (VIlI 63) auf den Schultern, sagt er eloquent, dieser Kamaschen. (Goctbe 1822 Camprane (‥ l. ganze 'Gamaschendienst', ein bedeutsames 5. XXX 140) Camaschen $=($ I. ‥ 33,138) Wort des Gevatters Görres.

\section{Gamaschen.}

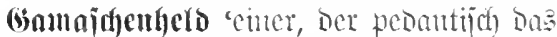

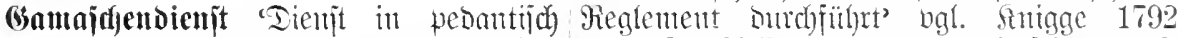

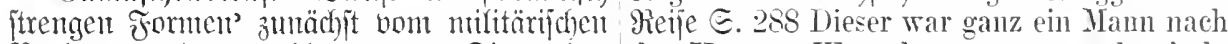
Reglentent, bas wohl genaues Eiken ber des Herzogs Wunsche: strenge, pedantisch, Gamajatr berlangte. 2iclege: 1814 Rgein. ein Gamaschenheld, der von untenanf geMerfur (23. Eept.) ङ. 122 Kamaschendienst. dient hatte, und seine T'ntergebenen wie (Söbres 1819 Ientichlano ङ. 166 als sich Sklaven behandelte.

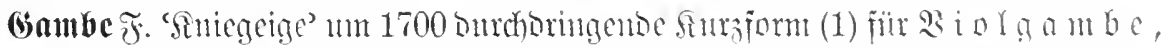

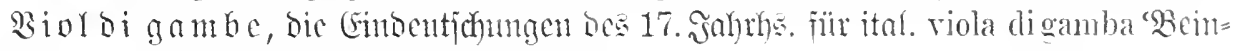

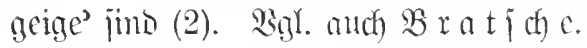

Belege: 1. Etoppe 1729 (Gedichte II 115 werden voll dell Kunstpfeiffern in Städten Sagt, was die Gambe sey, die Ohr und Hertz also rntersehielen, daß sie die Tioln de ergötzt? Ein Mädgen, daß sich gern auf gamba mit dem Xamen Violen nemnen. Männerknye setzt. Ricunder 1737 Gedidte F̂teming 1637 Entette E. 489 Violgamme.

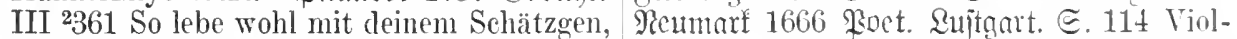
Und gönn ihr nun dasselbe Plätzgen, Das digamm. 2loraham 1688 Jnbas T 317 Viol deine Gambe sonst gehabt.

2. Frätorins 1619 Enntugma nujicum II Violdigamben.

4 Violn de Gamba - 44 Diese beyden Arten

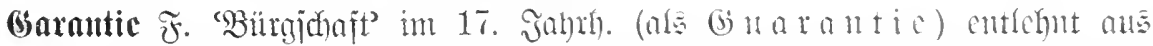

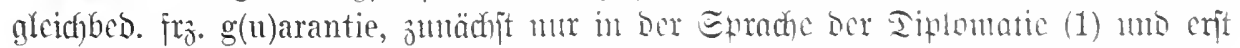

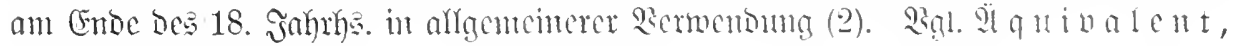
Präriminaricn.

Belege: 1. Surfïnjt Fricorich) $\mathfrak{Z}$ Billyelm betrifft-unsere Acceptation der Guarantie.

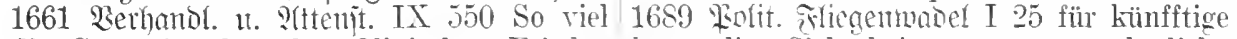
dic Garantie über den Olivischen Frieden beständige Sicherheit gnugsam annehmliche 


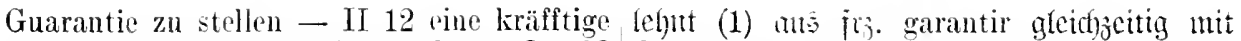

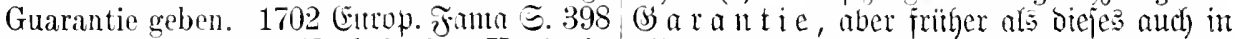
Er wolle vor seinen Enekel, den König in alfgementerer Bertwendung (2). Belege: Spanien, die Garantie leisten. Rol)r 1729 1. Reibnis 1670 Sccurita: publ. (I 175) Beremontal(milicuid)ait II 506 die Puis- so sehe ich gleichwohl nicht; wie Lothringen sancen mög’n in ihren Tractaten die Grentzen $\mid$ zu garantiren, bei gegenwärtigen Zustand noch so dentlich bemerken, die allerbün- müglich sey.

digste und sicherste Guarantie ror die allgemeine Ruhe stifften. Bülau 1766 3uı 2. Ettrier 1697 (chynticus $\cong .260$ Wann

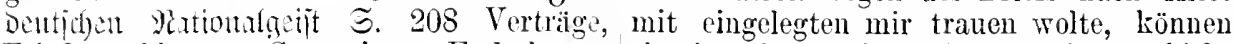
Friedensschlüsse, Garantien, Eydschwüre sie imnerhalb einer Stunde fortgeschickt geben keine Sicherheit gegen seine [Do werden, ich grarantire davor. Marperger

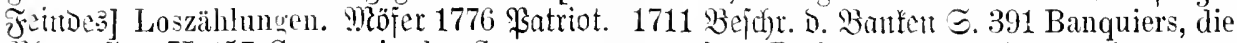
Hinutaicen II 157 Guarantie des Staates.

2. Mich) xelis 1776 Rajomement IV 616 unter der Guarantie eines solehen Creditediets.

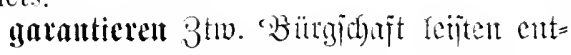

von dem Rath und der Stadt einer ron ihr authorisirten und garantirten Banco vorgesetzet waren. Ealtenbach 1761 Genentogia ङ. 68 Ich guarantir, Papa.

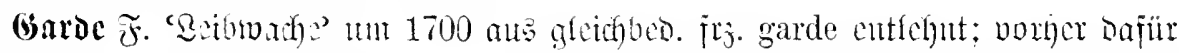

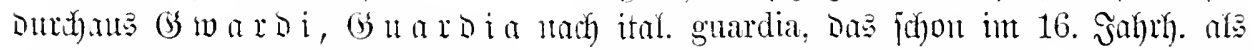

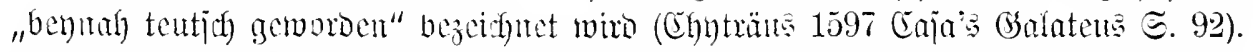

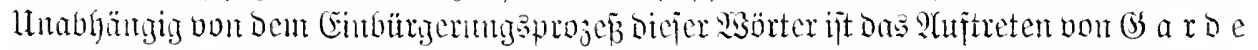
ats Cigentante von Rand

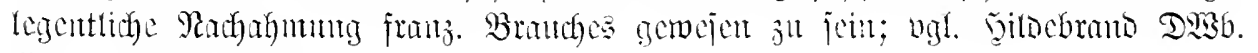
IV 1, 1 Ep. 1341.

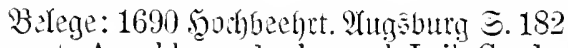

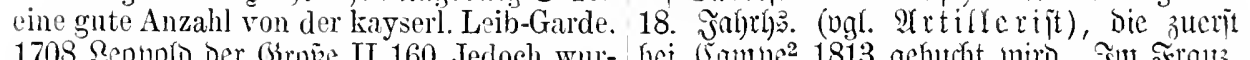

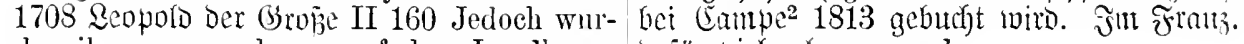
den ihrer neune davon auf dem Landhause bafiür vielmelyr un garde.

von der käyserlichen Garde ertapp't.

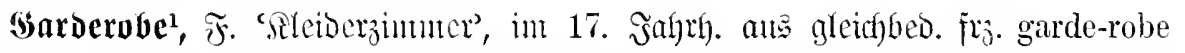

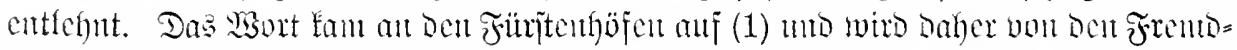

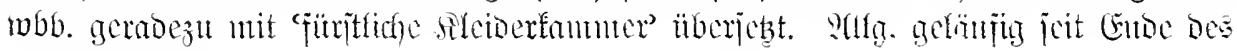
18. Jahnd (2).

Belegc: 1. F́lorin 1749 5̧answater II 381' wo man durelı den Haupt-Hof nicht allen und jeden innern Theilen zumahl den Garderobes und Stiegen genugsames Licht zubringen kan - 3852 die Garderobe liat zwar ihren Namen von Bewahrmng der Kleider. Windefunam 1764 (bejd). D. Stunt I 47 Es kam dasselbe aber nachler in der Garderobe des Farnesischen Palastes zum Vorschein.

2. Suljer 1771 Iheorie I $26^{\circ} \mathrm{Zu}$ beyden Seiten des Alcovens werden noch kleinere Versehläge gemacht, die zul Nachtbequemlichkeiten mud zu kleinen Garderoben dienen könuen. Denis 1777 Einteitung I $247 \mathrm{Es}$ hat Lrnte gegeben, die cine Büchersanmlung glrieh ihrer Garderobe und Gewehrkammer als cin standmïibiges Mruble ansahen. Mior= mann 1833 Diterreicl) II 2 ङ. 93 wirklich

rannte er, bestürzt úber meine Belehrung in die [ Iljeater $=$ ] Garderobe, um Mantel und Hut zu holen. Zaube 1838 Edfauppicterin כ. 137 daß Georges noch gar nicht da gewesen, seine Garderobe leer sey, solchergestalt kömue das Stück nicht zu Ende gegeben werden.

Prmu. 1. Tie Beodentung von $\mathrm{fr}$. garderobe war almächjt 'Rleiberidhanf' (nod) bei Mroliète 1671), Daher andl) vereinjelt früly= Hho. (S) a de tirobbe (1564 Bimmer. Chront. III 238 ॥adh Fijdfer III 67) itt ber gleidjen Berivembung; anch bei siäbtler 1722 Mionual

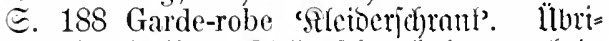
gens ijt bie Beo. 'SReiberidgrate' bent nuch in ber Edyuei; lebendig (引̂n. II 416).

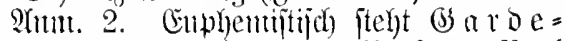

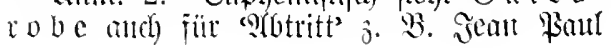


1797 Jata II 151 Mußte ich nicht in Karls- Bebcutung (eightl. wohl allgemein 'Sännmer= bad einen Gulden für den bloben Garderoben- chen') icfon bei Miartin 1628 Colloques

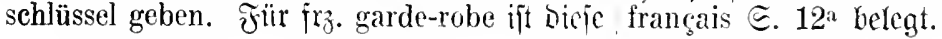

Garberobe $\mathfrak{F}^{2}$. 'fleiscroorrat': Dicjc 2. Bebentung non fra. garde-robe fommt

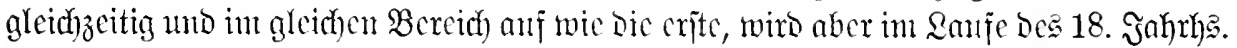

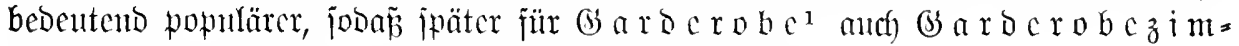
mer gejagt wiro, j. B. Remald 1836 aquarelle II 69.

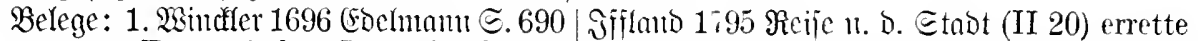
des grossen Französischen Ludewigs Garde- uns von der G., die der alte Karl mitnehmen robbe und darinnen sein Kleid, so 5. Millionen will. Sokebuc 1797 Faljoce 厄diam (VI 276) Francken gekostet haben soll. 1708 \&eopold Sie schämen sich Ihrer G. Wieland 1798 Der (5rof̧e I 222 Des Käysers Gardarobba \$rriftiph (XXII 77) der kurze öfters ziemlich wurde von sechs Jahren zu sechs Jahren schmutzige Mantel, der gewöhnlich seine

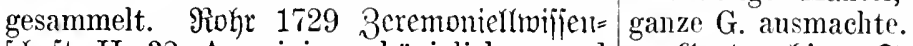

idafit II 32 An einigen königlichen und andern grossen Höfen ist die Ober-Aufsicht über die königliche Garde-Robe eine besondere ansehnliche Charge.

2. Sejfing 1763 Mimua (II 207) Er hat des Herrn ganze G. mit. Bülau 1766

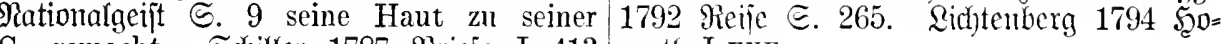
G. gemacht. Edfiller 1787 Briefe I 413 garth I xvH.

da ich keine $G$. habe nach Hofe zu gehen.

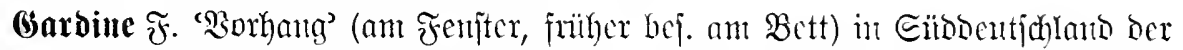

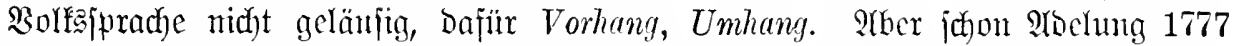

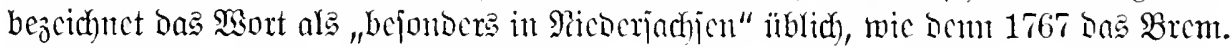
约. II 489 "Gardine oocr Gordine“ ars noD. Tialcftjormen bucht. Nob. gardine hat fich bom Sicoerrhein aus verbreitet mo bcrubt auf (Entlchmung ans mbl. gardine,

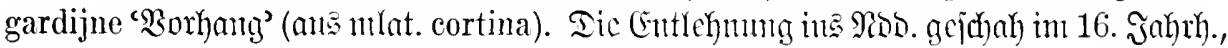

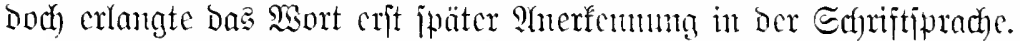

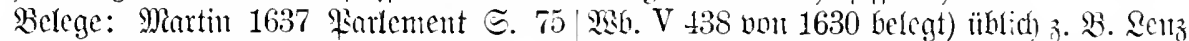
gardinen oder vmbhänge. Ettner 16971777 Edfriften III 119. Qidftenberg 1794

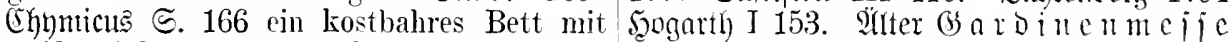

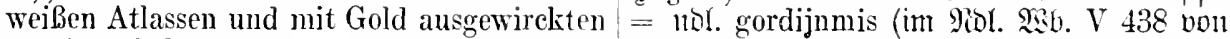

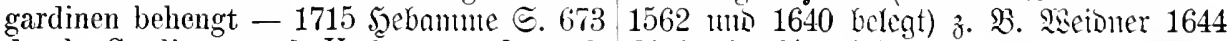

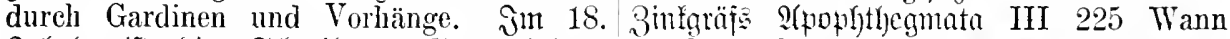

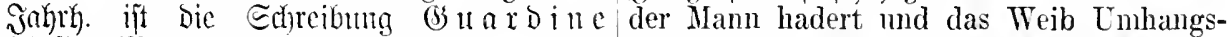

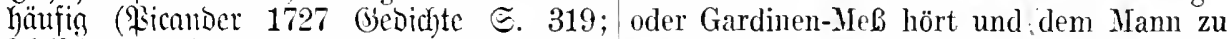

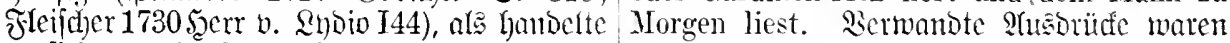

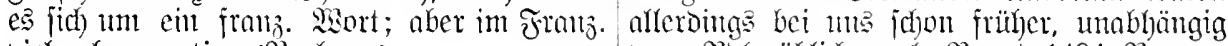

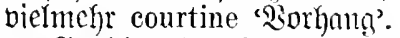

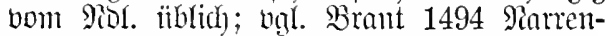

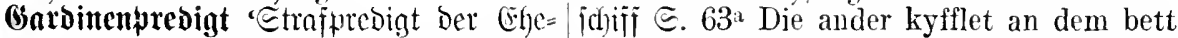
frau (eigtl. Ginter Den (Gorbmen Des Bettes) Der eeman sellten fryd do hett Musz hören

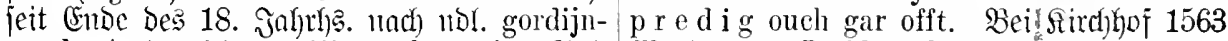
preek (ogl. nol. gordijnpreeken, im sid. Sembumut I $409 \mathrm{jm}$ bett c a p i t ul i re n.

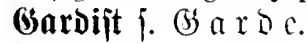

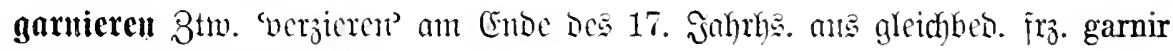
entlehut. $\mathfrak{B g l}$. (5) a $x$ u it $u x$.

Belege: 1699 Etaatsipicacl I 36 das ten und Speisen auf den Schüssel-Rändern Portrait Ihr. Maj. deß Römisehen Königs, umleget, garniret und angeputzet werden. mit Diamanten garniret. Smuranthes 17151737 viib. Balsober @. 492 Mams-Hemder Frouenjimmerler. $\subseteq$. 621 wormit die Trach- mit Spitzen garniret. 


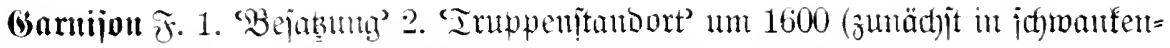

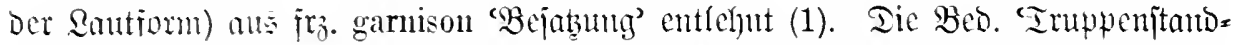

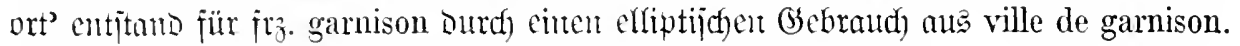
Jn Deutjonen tritt Dieje 2. Bebentung gleidyseitig nit ber 1. auf.

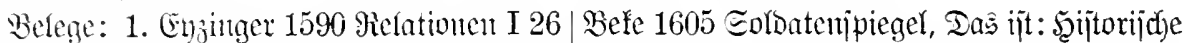
solche örter, die ron allen zeiten her garnison Ŝtnweijung, welober Gejtalt ein Guarijon

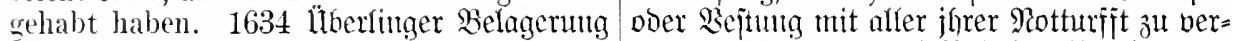
ङ. 2 das Obrist ron Scherffenberg einen jorgen. Carolus 1605 Relation $\mathfrak{i r}$. $5^{\mathrm{d}}$ demguten theil seines Volcks zur Guarnison nach aber dieses Vests wegen daselben 2000 hinderlassen. 1643 Epradfuerderber ङ. 42 Spanier in Guarnison liegen. 1623 Befdur. Quarnison, Besatzung. 巨ctifofnedyt 1652 D. Ed)ladt)t bei 巨tattloo હ. 3 ausserhalb Sarmoutia I 9 die Vestung nachmals mit not- etlich wenig Compagnien, so inn den Guarmitürfftiger Grarnison mnterhalten. (jrimmel: sonen ligendt verblieben. Mengering 1638 haujen 1669 ङimpl. E. 74 einer ron unserer ङolDatenteufel ङ. 65 nach Stetin oder die Guarnison kamnte einen von den Gefangenen. nechst angelegene königl. Guarnisonen -

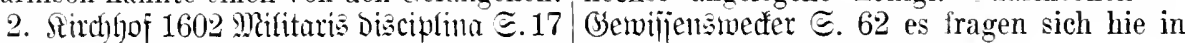
der Abrechsel der neuen vund inmer specie die in guarnisonen ligen. anderer Soldaten in etlichen Garnisomen.

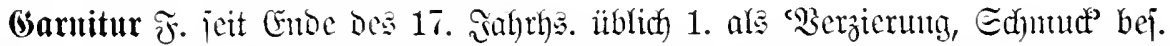

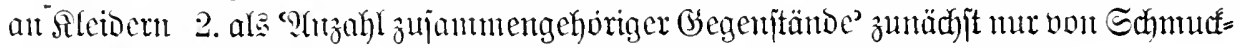

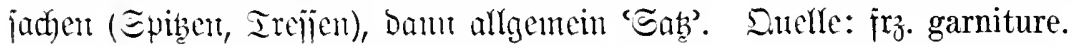

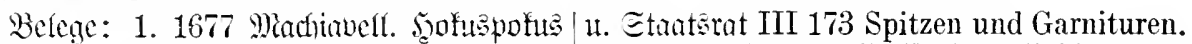

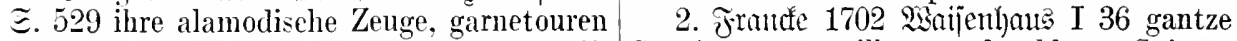
und andere façonen willig an- und auff- Garnituren von silbern und güldenen Spitzen nehmen. 5orned 1684 Siterreich) $\circlearrowright .119$ - II 16 eine silberne Garnitur (Denn sie ihre Weiber Anfsätz, Garnituren-Bänder hatte sie von ihren hoffärtigen kleidern geKätten, Schuh, Strümpff, endlich gar die schnitten, die sie ehemals getragen). 1737 Hemmter seynd besser, wann sie die Fran- Jïb. Buloober $こ .519$ eine goldene Garnizösische Lufft perfumiret hat. Piffelfäring tour durchbrochene Tressen. 1790 Drigines 1685 Sileiderafie ङ. 233. Mienante: 1707 Bacfel II 311 meine Garnitur seidene SchnalUlfemente $\mathfrak{U} \mathrm{rt} \Xi$ ङ. 588 lieine Garnitur von len.

Spitzen oder Band. Chilentont 1707 fricg $=$ :

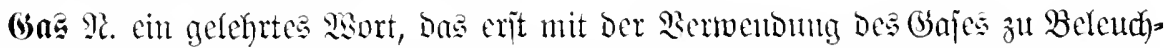

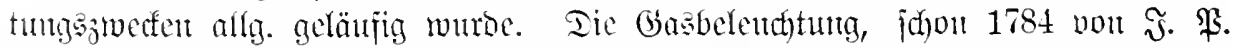

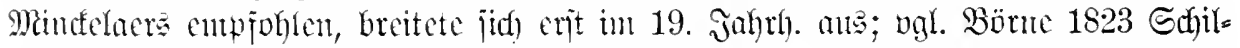

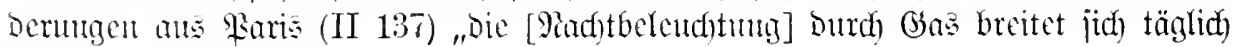
mehr mid melyx ats."

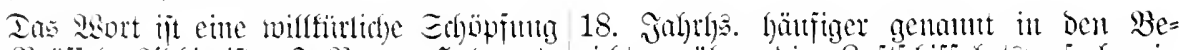

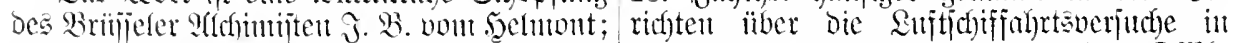

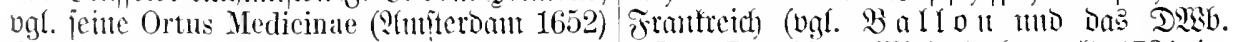
E. $86^{b}$ hunc spiritum, incognitum hactenus, IV 1, I 1428). WSielano benterft 1784 in

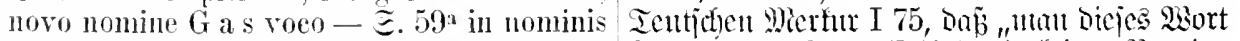

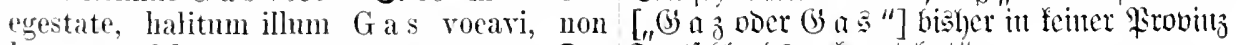
longe a Cha reterum secretum. Ier Tentichlanos gefanut lat".

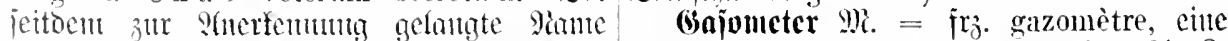
blieb aber lange ani bie engiten jachtreije

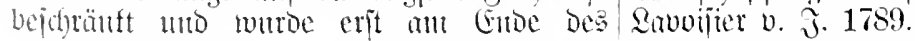

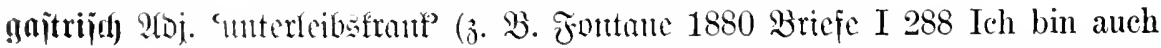
ein bißchen orkältet. cin bißchen überarbeitet und ein bißchen gastrisch), öfter iut

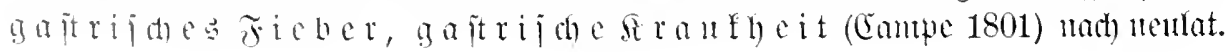


febris gastrica 'Unterleibsficber' j. B. Egerel 1791 Etolls sjteberlefre III 1. Franf

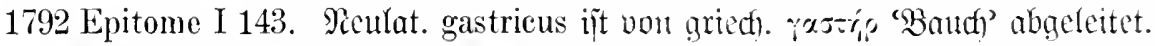

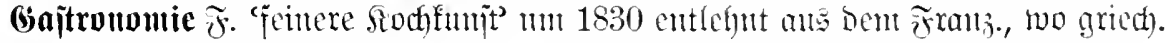

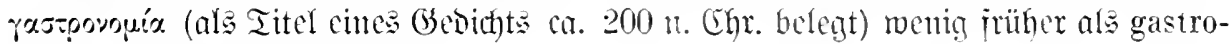
nomie üblich gerworden war.

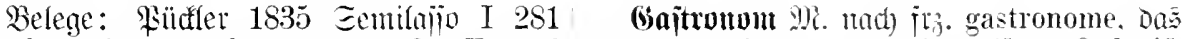
Semilasso ist uns als ein zu grober Freund aus dem Fent. abgeleitet ijt. 3ujritgijt

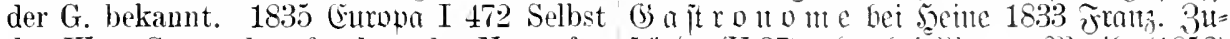
das Wort G. wurde erfunden; der Yame fül jtäuloe (V 37), aher bei Mtar. v. Merifo (1852) eine halb gemichte Wissensehaft. நुeite Qebeu III 34 Als Gastronom war ich höeh-

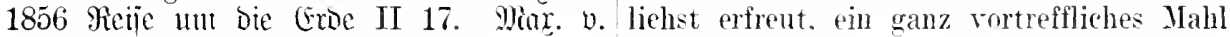
Merifo 1867 Reben IV 109. einzunehmen.

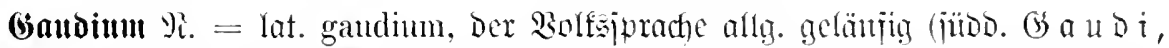

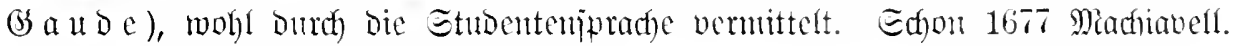
Şofuspofn: $\Subset .628 \mathrm{im}$ besten gandio.

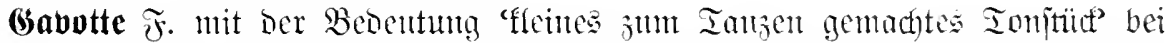
Sulzer 1771 Theorie der jobuten Sïnjte I $424^{\mathrm{a}}$ gebud und jofon bei Edhethe 1745

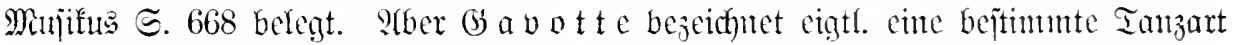

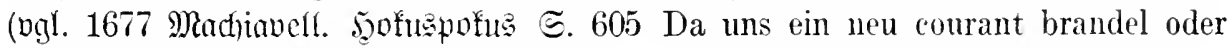
Gavotclien so viel Mühe und Geld kostet). Sulle: jug. gavotte, Pame entes pro= vencalijaten Bolfatanjes.

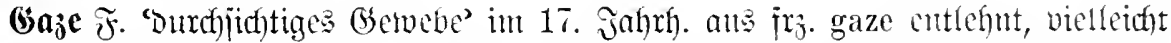

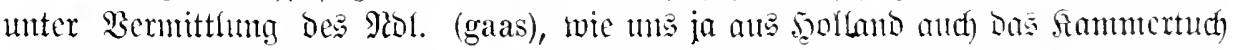

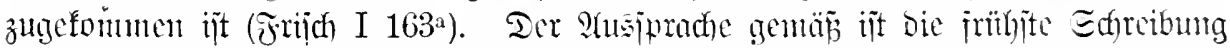

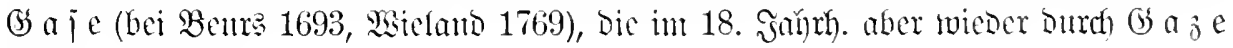
verorängt wirò.

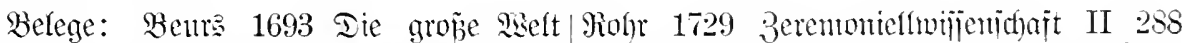

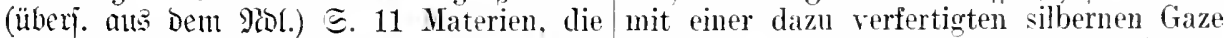
mehr oder weniger weiß seyn, so viel mehr bedeckt. 此ielatio 1769 Girajien (III 110) oder weniger sie kleine Löchlein haben, da- Sie tanzen. umschattet ron flatternder dureh sie die Liehtstrahlen kömen lassen Gase - 1780 Eberon (XX 314) Die Gaze, durchstrahlen oder nicht, wie dieses augen- die nur wie ein leiehter Schatten, sie hier seheinlich in dem Kammertuch, Gaße und und da umwallt - 1783 clelia (XI 162)

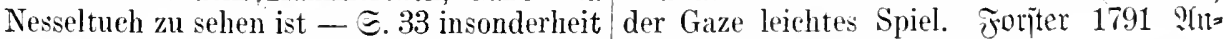
Leinwandt und noeh mehr Floret, Gase. fidften vont Nieberrhein こ. 332.

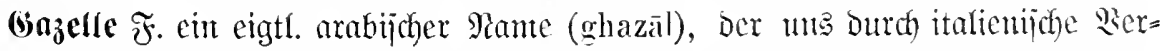
mittlung (gazella) befannt geworoen ijt. Beleg: şaumbojer 1611 Brieje ङ. 166 einen abriß von aim tier, welches man gazella neunet.

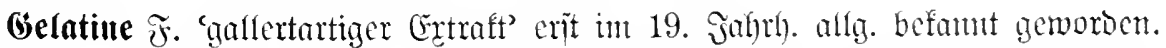
Duclle: Meulat. gelatina (ju lat. gelatus 'gejroren'), cigtl. wohl eit aldfimijtijcher

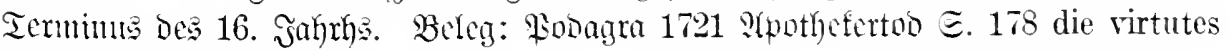
bestehen in der gelatina - sieden biß man eine gelatinam zu wege bringet.

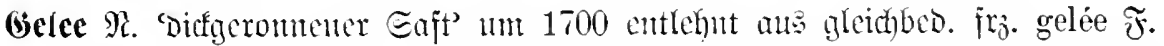

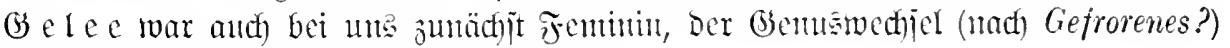
jefcint crit in 19. Эahrl). Durchjubringent. 


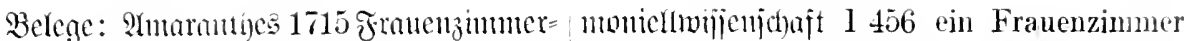
ler. Є. 641 Gclee, Ist ein gestandener Safft verlangt von ihm, er soll ihr etwas von der - Є. 645 wie bey voriger Gelee. Rünig Gelee u. s. w. reichen. Roojt 1781 Rieser= 1720 Thentrum ceremoniule II $1458^{\mathrm{b}}$ Gelées (jöchj. Siod)buch 巨. 55 Gallert oder Gelee von allerliand Couleur. Bohr 1728 Bere $=$ — 〔 57 Mandel-Gelee.

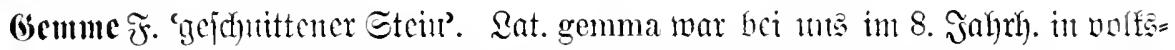
tünlider Santgejtalt ale gimma, gimme mit ber mipringlichen allgemeinen $\mathfrak{B} e=$

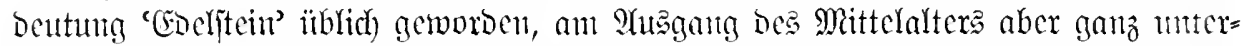
gegangen. Der moderne (sebrouth Daticrt etwa jett 1750 , als bie italienifjent Eamm=

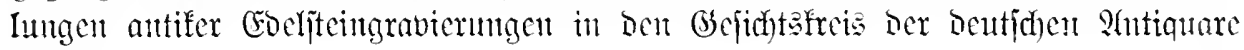
traten.

Belege: Scjintg 1768 SYntiquar. Bricje/die Gemmen und Münzen anfbewahrt. (X 307) Doeh von dieser eoneaven oder (3oethe 1795 Qchrialye (XXI 276) Die convexen Form der alten Gemmen, einmal Sammlungen antiker Statuen, Gemmen und in einem besonderen Briefe. Stinger 1775 Münzen. Ridgtenberg 1799 5ogarth Y 181 Stto $\subseteq$. 7 wie er die Stime runzelt, wie ein Gemmen-Köpfehen. 1832 EFlen. Medt fïr Weiser auf einer alten Gemme. Nicolni 1779 Damen $\mathfrak{R r}$. 46 der Gürtel ist vornen mit Berfin 5 . $591 \mathrm{Im}$ dritten Zimmer wurden einer Gemme gesehmiickt.

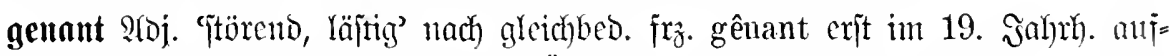

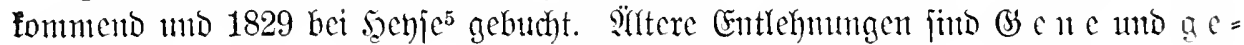
ni e $r$ e 11 .

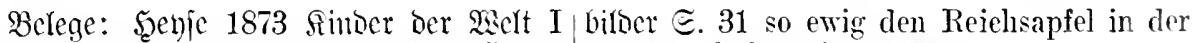
197 Es kommt nur darauf an, ob es Ihmen Hand zu halten, ist gênant. nieht genant ist. Exfein 1876 Eatir. Beit=

Genoarm M. 'berittencr Sambpolizift' ciu ber Bolfajprad) jehr gelänfig ge= worocnes Frembmort, Das Dialeftifch meift schandarm lautet, aber auch ôu schandâr,

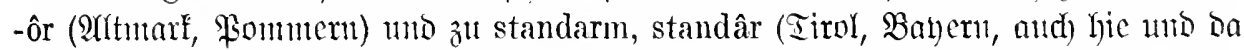

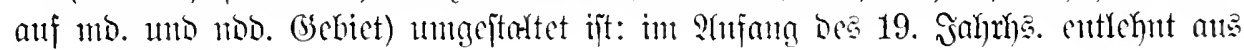
frz. gendarme.

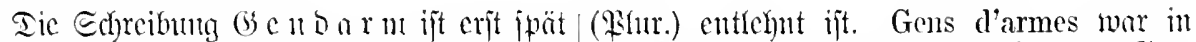

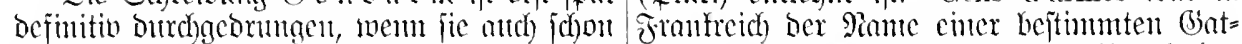
bout Senberger 1806 (,Gendarme, nid)t tumg j(f)werer Sinvallerie, jeit Der Secolution

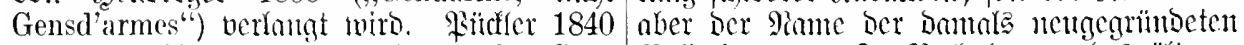
Birberjan II 174 Der vorderste der Gens Folizeitruppe. Sn Radhahmung bes älteren

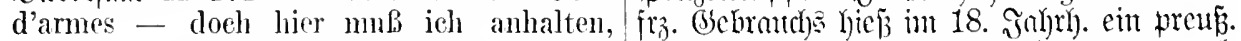

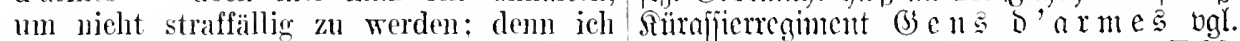
habe vernommen, dab vermöge eines baieri- Qcjiug 1780 Siricje (XVIII 364) der Feldschen Rescripts, welches auch in Griechen- prediger bey den Gens d'armes in Berlin: land ein Eeho gefunden, das obige Wort in fo bis 1806. llm Dieje Beit wird Das siont

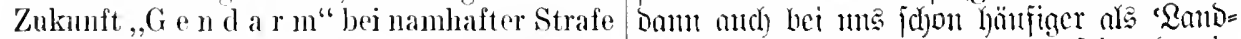
geschrieben werden mub, weil mun̈tze Witz- f(b)timami' gebrandyt worben jein, on in linge die Mitglieder des respectabeln Corps ben Jahren 1809-1812 in Den meiften bent= durch die Benennung "Gänsdame" (naeh johen Etanten Dic Eimrichtung Des bicn= der alten Schreibart Gins d'armes) schwor

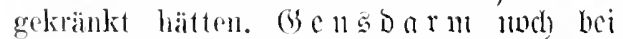

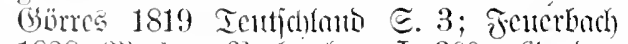

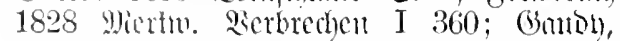

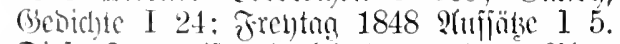
Tieje Jorm ijt abgereitet an bent gilur.

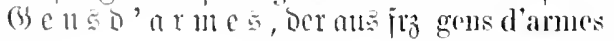

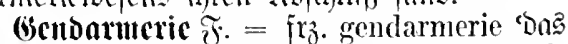
(Sorps Der (Bembames' Seuberger 1806.

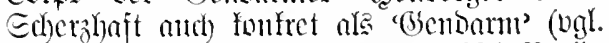

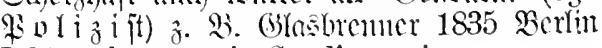
I 21 so kommit ein Gend"armerie. 


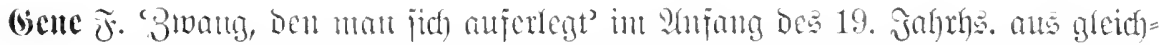

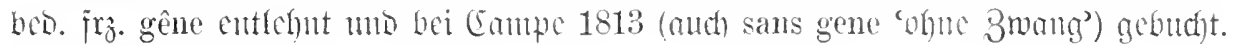
Bgl. gculcren.

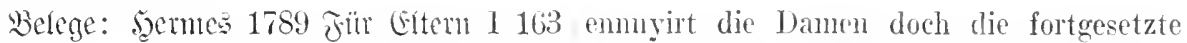
Was in dieser Vermuthming mich bestärkte, gêne" (Gominn 1836 Ingebuch) (I 169) Hier das war die Aengstlichkeit (ich will sagen aber brauchte ich mir kejne gêne anzuthun. Gène) mit welcher sie auf ihrer Stelle blieb. Ientient 1837 Berimungen (II 28) Ja die Pürffer 1831 Briefe III 169 anf die Länge verwünschte gêne in den Gesellschaften.

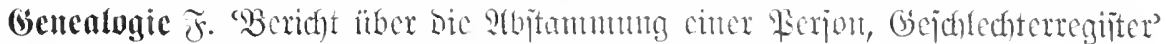

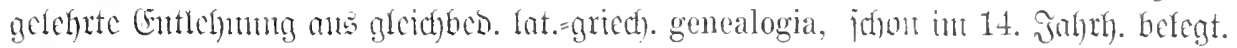
Bgl. Nesciganto ${ }^{5}$.

general Qroj. 'allgement' im 16. Jahrh. an lat. generalis cutlefnt (Belege: 5enijd) 1616. Bedrer 1668 Methobus b2b da doch das Trort Obrigkeit gantz general

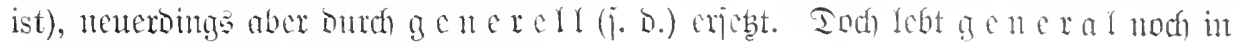
zahlueiden Bujanmenjegungen fort:

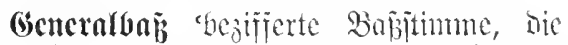

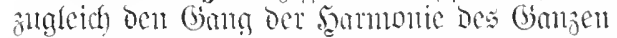
andentet' au ital. basso generale; idjon

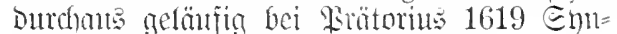
tagnia mïicum III 135. 137. 141.

(biencralbcidyte nach mlat. confessio generalis jom in 17. Jahrh. eingebiügert mb

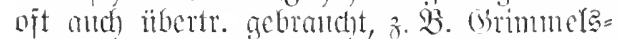
hatjen 1670 Coutnge (III 10). Rgl. bifioe= bramb, ISs.6. IV 1, I 3380.

(Bencralmarids mit oer Bes. 'totins 'xercitus expeditio' jon bei Etiefer 1691

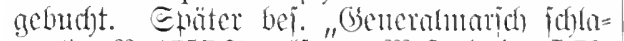
gen" 3. B. 1757 Franfunter Meñulation I 72.

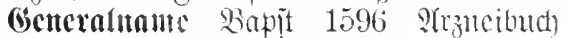
๔. $122^{\mathrm{a}}$ als ein general namen.

(isencralprube eigtl. 'allgeneme Rrobe', onutu 'Samptprohe'. Beleg: Entiller 1781 Bricje 1 50. Iafür Hauptprobe be (boethe 1796 Rebriate (XXI 280).

Gencratregel Beder 1668 Whethobus อ. 92. Grnber 1697 stregsobisinlin III 28. Qeibuiz 1700 sierfe II 412 .

Gioncraftevipion Govethe 1782 an Birnex (III 70) eine G. meiner Briefschulden.

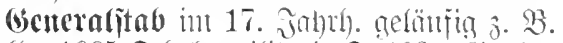

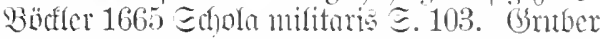

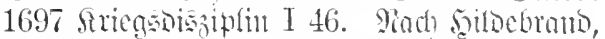

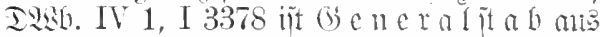
(b) eneralit a a tumgebilot, bas jemer= jeits vou fro. état-major, ipont. estado mayor 'Generalftab' ablängig ijt.

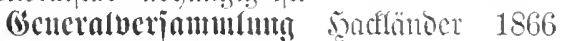
sibifterrontant IV 21.

generafijieren Btw. "veralfgentement im 18. Jahrh. ans fro. généraliser entlehnt. B $20=$ leg: 2efing 1767 Iramaturgie (IV 322) ilme Empfindung wird sie anf manchen Handgriff leiten, den noch kein Kritikus zur Regel generalisiret hat.

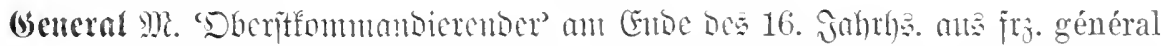

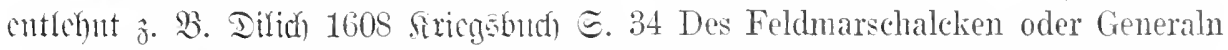

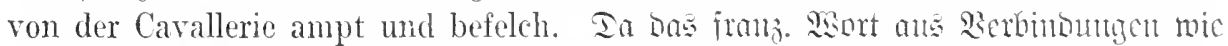
capitaine général, lientenant général entitunben ijt no bicje neben Den jubjtonti=

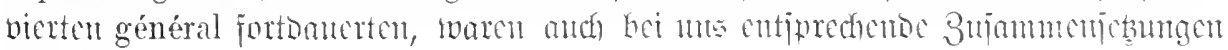
üblión:

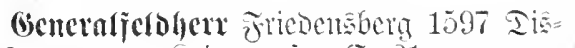
futre v. mant. Strequbejen $气 .21^{\text {a }}$.

Gencrafífolduridall 1627 in Titel ciner

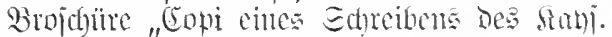

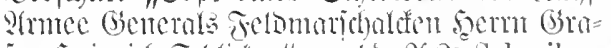

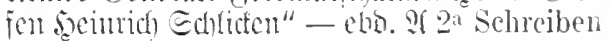
deß General Feldmarschalck.

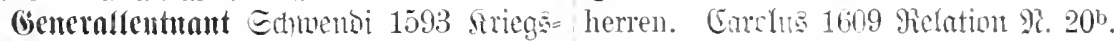
Disfun $\Xi .24$ deb Tiriegsherren General 
Bencration j. 'Pladffonmenifhaft, Gejantheit aller um biejelbe Beit geborenen

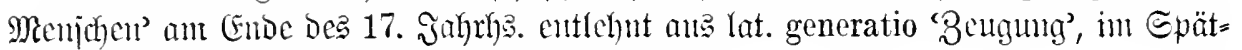

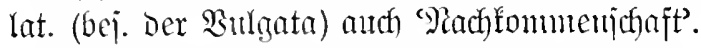

Belege: 5ronted 1684 Difterreidf $\subseteq .86 \mid$ ihren Kindern gleich in der ersten generation daß unserer Vätter zu denen Manufacturen so mächtig abgeartet. A̛rchenfoll 1787 Gng= natürlich geeignet gewesener Verstand in I Iand III 273. 1796 Xenien $\mathfrak{R r} .593$.

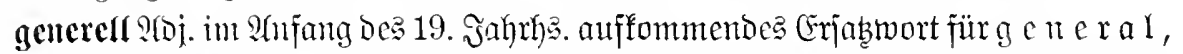

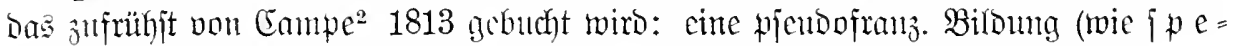

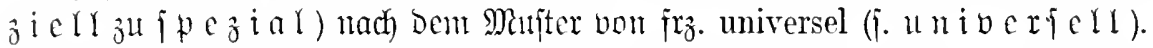

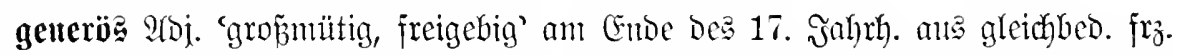

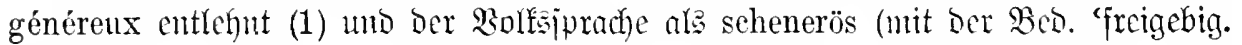

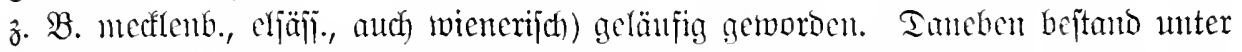
Gimflum von lat. generosus '

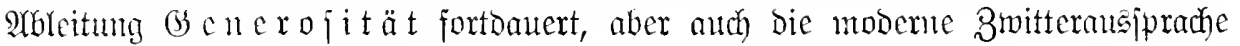
generös (nicht uit ž) veranlä́t lyat.

Belege: 1. Srünter 1681 Leben Der Cee=| generoser Herr seyn, der den Land-Städten helDen S. 351 Worauf er auch, ohne ferneres zu ansehnlichem Vermögen und Freyheiten Bedenken so generenx war, daß er alsbald behülfflich ist. 1690 jochbeefyrte? $2(u g g=$ den einen [Bedfer] dem Generalen Draeck burg $\subseteq$. 14 generosse Gemüther, wann sie verehrete. Thomajitı 1688 Montatge $=$ die lobwürdigen Verrichtungen ihrer Vor[präche I 565 Du jollift? von dem Aristotelis fahren sich fürstellig machen, spüren gesagen, daß er das genereuseste Gemüth hat meiniolich einen Antrieb der Tugend bei sich. unter allen in Macedonien. Sulfnut 1700 Muilifal. Dundfialber ङ. 134 Zwar sind die Musici sonsten von so generensen Gemüthe, daß sie sich das Geld nicht selir lassen an das Hertze gewachsen seyn, sondern sehr freygebig damit umgehen. Mentúc 1707 Reopold 厄. $912 \mathrm{Er}$ hatte von Natur ein genereuses Gemüth. Siobebute 1801 Espigraumu (XI 189) Heute bin ich gencrös. Bruldyłe 1834 handeln würde, sahe sich um funfzig schöne Bilber S. 21 mein generöses Betragen. 1841 Gulden geschneuzt. Siffano 1795 Erbein= Europa 125 Mit so schenerosen, nobelen, berbierrit (IV 42) nimm den Ring. Er ist gnädigen Herrn.

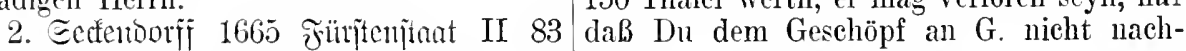
Und mus ein sehr großer, reicher und stehst.

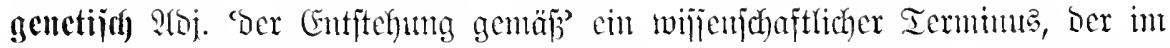

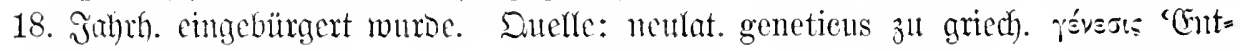
\{tebluty?.

Delege: Gerber 1767 Deutiche Riteratur ist. Edhiller 1795 Briefe IV 294 eine neue (I 415) Jian kinn zu einem Begriffe kommen, Art von Critik, nach einer genetischen Mewörtlich, wenn der Name genetisch und thode. Wsielano 1801 ?(rijtipt (XXIV 173) aus dem Wesen der Sache hergenommen eine genetische Schilderung.

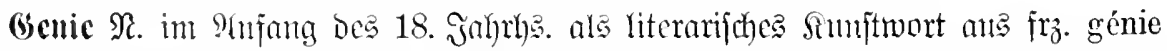

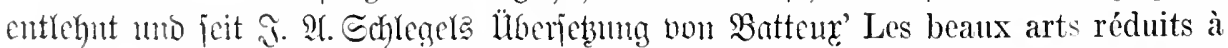

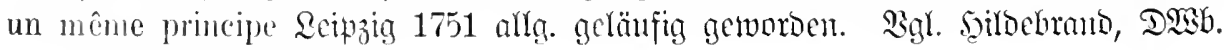
IV 1, II ธึ. 3396-3449.

Belege: 1719 giccuteil v. alferh. Collectanteis militaire verstehe wol zu grössern Dingen I 23 Ich bin der ILeimung, daß wer l'oeconomie eine [!] Genie habe. Bertran 1728 Eimleit. 


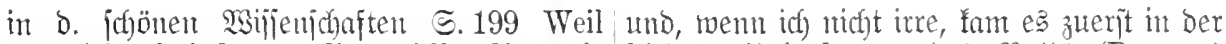
nun nicht ein ieder von diesen Affen Ciceronis jchötren Heberjełung Des Batti (Batteux) auch dessen Genie und Kopf hatte. PGilippi uno ben noch fđjönern Abbanolungen ror,

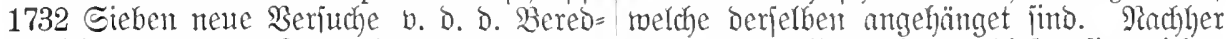
jamfeit IV Von großen, mittelmäßigen und ijt cs bon allen, bie zu biejer jimreichen

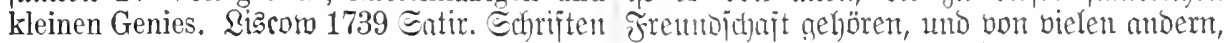
ङ. 741 die grossen Genies zu hofemeistern. Die ifmen nadjiprechen, aud on, two man gern

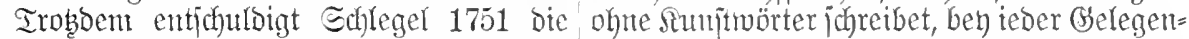

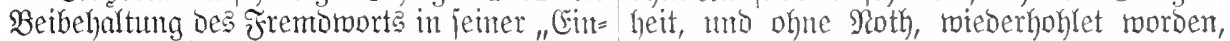

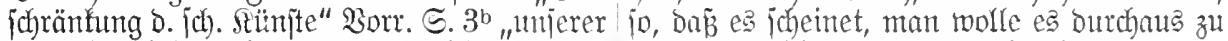
Eprache jeglt ein wort, welches" bieja:

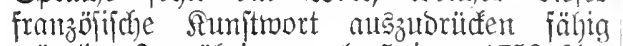

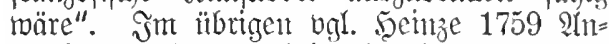
merfungen $\subseteq .30$ "CËmige berülnnte Mänter, benest abjonderlich unire Didytfunjt jebr viel jabuldia ijt, uno reldje bie bentiche Eprache

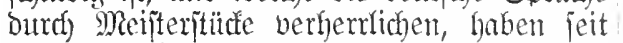
einiger Beit bas wort genie häuffig zu braudjen angejangen, weil jie fein Deutiches gefunden, fo Den Begriff diejes fremben Mortes völlig un überall bequen ausorïcfte.

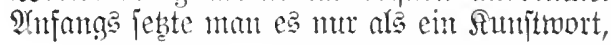
einem Dentijen \$sorte madjen".

genial 2(D). zufrïgit nad) Dem DWb. bei Echiffer 1797 iverłe (Gśöbefe) XI 141 dem genialen Geschlecht. Dafiur int 18. Jahr rh. g'enialijd) z. B. Sabater 1777 Phyjids. gnom. Fragmente III 220. Da: 柋ort ijt eime Dentjol Bildung (nidgt jranz!!), formell Inach lat. genialis, bas aber in ber $\mathfrak{B} e \mathrm{~d}$. ("er= Freulich, heiter') ganz jermiteht.

Gentalität $\tilde{F}$ gleidfortles eine dentiche Bildung. Beleg: Rabater 1778 \$inhjiognom. ₹ragmente IV 91.

geniercu Btw. 'beläitigen' (2), geläufiger als reflex. Btw. “̈ich Bmantg antum,

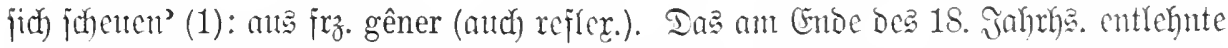

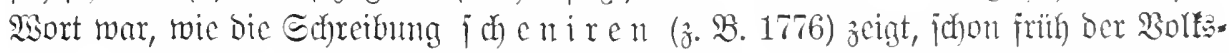

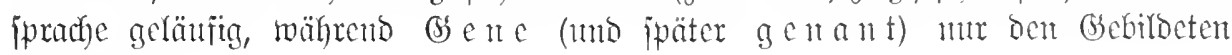
befaumt rour.

Belege: 1. Grothe 1776 Claudine ( $=$ D. i. (4). III 563) Schenirt euch nicht. Wir machen euch Platz. Nielller 1787 (Enmerich II 309 Geniren soll man sich deswegen nicht täglich. Sobebue 1806 Drgane Des (Ś)hims (XX 99) Ein junger Mensch muß sich heut zu Tage durchaus nicht geniren. (50ethe 1817 ștak. Reije (XXXI 44) Bitte sich nicht zu geniren.

2. Michnelis 1776 Räjonnement IV 489 dent bie Bsejelfichajt] will ihm nur einen Gefallen thum, und ist dabey genirt. Echiller 1787 Brieje I 333 wemn es sie nämlich nicht geniert. 5eermes 1789 Fïr ËItern I 275 ohne daß das im mindsten Sie geniere. Sotzebue 1810 săual. Btwiț (XXIV 155) Daß man vernünft'ge Leute blos dadurch genirt. Dazu baz alimälylich zum :roj. getororbene Partizip

gentert 'gestuntgen, verfeger" Miiller 1789 (5mmerich VIII 218 in einer etwas genirten Stellung. Sint 1798 Intlyropologie 〔. 13
Das âjuerfen auj jich jefbit] macht entweder genirt (verlegen) oder affektirt (geschroben).

imgeniert 'tmgezmungen' Noüller 1792 5err Thomas IV 165 er gieng seine Bahn so ungenirt, so ruhig fort. Retwalo 1835 Iheater. rebute G. 232 die ungenirte Lustigkeit. Ghass brenner 1836 Birlder ang mist I 40 je ungenirter du bist, je fröhlicher, je mehr gefällst du. Tieấ 1838 Iijd)lermeijter II 46 inschenirt.

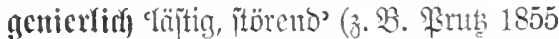
Maijifuntenturm I 200 Es ist dir wohl sehr genirlich) vieffach, a. B. in E(t) (eiien, Mnedten= burg, ber bolfstümliche Crjat fiur ge $n \mathfrak{a} \pi t$,

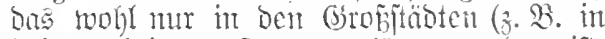

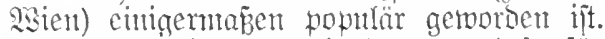

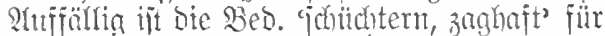

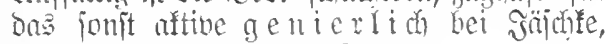
Echlej. Frembrob. ङ. 128.

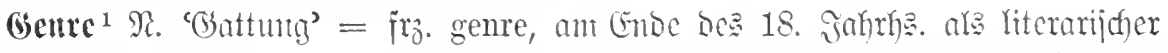

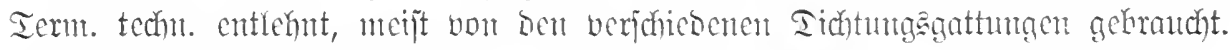

Belege: Miselano 1776 Bricje an Merd Sie ja an den Merkur - 1777 an facobi (I 268) ๔. 58 Wenn Thnen etwa bald wieder etwas wiewohl er [Gothe] im Grunde von dem, in diesem genre eingegeben würde, so denken was das wahres Wesen der Oper ist, nicht. 
mehr weib, als Du, und das ganze genre ein neues Genre getresen. (jocthe 1805 2um.

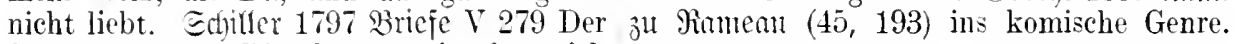
Gang nach dem Eisenhammer ist für mich

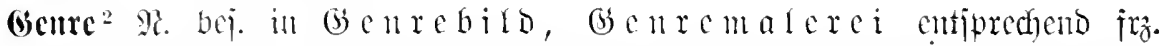
peinture de gemre. Sgl. Stahr 1847 (Fin Jahn in Ĵtalien I 353 Derjenige Kreis von Darstellungen, welchen man mit dem Ausdruck des Gemre zu bezeichnen gewohnt ist. Es ist dies das Gebiet des allgemein Menschlichen . . . in dem einfachen, gattungsmäßigen, gleichblejbenden Flusse des Lebens, als ein Allgemeines aufgefaßt und dargestellt.

Gentebild Gukfon 1836 Goetbe (VIII 307). Gíabremer 1836 Berlin II 6. Lemald 1837 Aquarelle IV 74.

(Benremaler ioj. v. Beroldingen 1780 Bricfe an Mierte $\Subset .244$ der Mensch ist als Kupferstecher und Genre-MIaler deplacirt in genrelañt Fontane 1891 Jenny Ireibel Paris. (Guromsify 1845 Tour Durch Be!gien

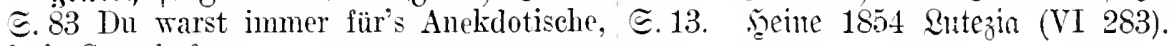
für's Genrehafte.

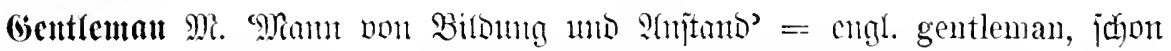
am Ende bes 18. Jahrhs. als charafterijtijcher englijeder Iitel befamit (1), aber crit

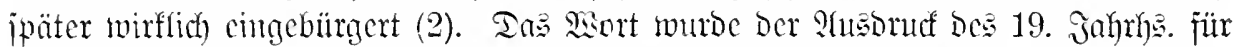
Das gejollidaftliche Mame sidocal, Das im 18. Jahrh. mit Weltmann, im 17. Jahrh. mit galanter Menja mb früher mit Savalier, im 16. Jahry. mit Biedermann bezeiduct wurbe.

Belege: 1. Boic 1777 an Bürger (II 117) ihn in a complete new suit gewickelt. Er ist kein Kind, hat die Welt gesehen und Eeworlo 1843 Dic Maphe હ. 165 daß ein ist vollkommen, was die Engländer nennen Gentleman bald diese ganze gute und beßte a gentleman. Techenlyol 1787 Engyano III 81 Gesellschaft sehr gering schätzen wird. Am häufigsten wird durch die Benemung, Frentag 1855 Eoll i. Sraben II 70 er war Gentleman ein Jann von feiner Lebensart ganz Gentleman und erwartete vornehmen verstanden. Sinigge 1788 llmgang @. 308 Besuch.

Wenn der Titel eines Gelehrten nicht hent zu Tage so gemein wiirde, als der eines gentleman in England. Mit Bezielyung aư Eng= lämber nod) bei sistt n. Iörritg 1830 Frng mente I 128. Pï̈fler 1831 Brieje I 186.

2. 9homanm 1833 Siterreich I 1 厄.46 "re hat den Tamen eines honnetten Menschen, eines österreichischen Gentleman rerloren. Rauke 1837 ieijenowellen V 426 ich stanne den Mnth an, wenn ich solch einen Gentleman des dreisten Stegereifs offen und ehrlich mit seiner Maitresse promeniren sehe. 1841 Entopa $176 \mathrm{der}$ Proletaire wird darum heute gcutrcmautifie $=$ engl. gentlemanlike Pov. (1). Jut Deutichen mirs bas Mort häufig auch als ?asieft. gebraucht (2). Belege: 1. Nont3 1783 Reijen cines Teutichen in Englans ङ. 76 aber er mache ihn zu Gentlemanlike, das ist zu selrr mit dem Air und Wesen eines Gentleman oder feinen llannes.

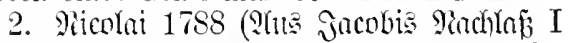
101) das niederträchtige ungentlemanlike Betragen. Sceine 1833 Franz. 3uitünto (V 69) in der Leidenschaft immer anstandsvoll, würdig, gentlemanlike - 1854 \&utej̧ia (VI 353) sein Vortrag ist so gentlemanlike. noch nicht zum Gentleman, weil Mlr. Gunkel

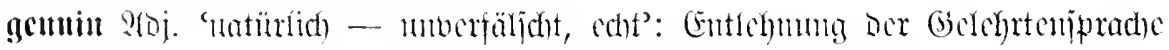
Des 18. Jahrbs. ans gleichbes. lat. genmimus (cigtl. 'angehoren').

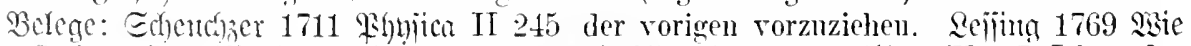
Alle Steine iibertrifft (\&0 er je genuin) an bie ?llten ben Ton gebirset (Xl 17) Ich wüßte seltamkeit und kostlichkeit der Drachen- im Geringsten nicht, was hier wider die

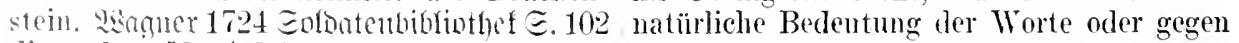
dir andere [sopie] ist gemniner, besser und die genuine Construction der Sprache wäre.

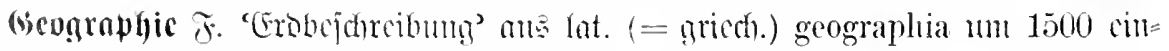

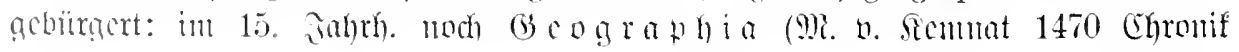




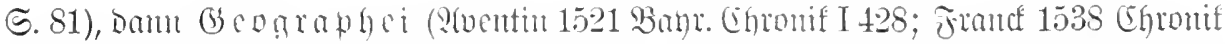

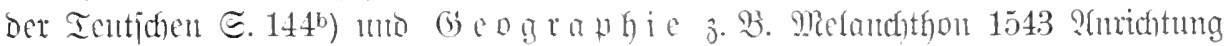
Dex Ratcinjulen $\Xi .6$ aller Historien, Geographi, Rechmmng der zeit. Mäniter $15 ّ 4$ Rosntoaranhic @. 10 die Ceography beschrybt die hauptstuck der gantzen erden.

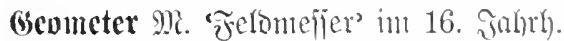
aus lut. (= ariech.) geometres eingedentiont. Bgl. Gebiz 1580 Felobm ๔.469 Tíewol die kunst deb Feldmessens viel mehr den Geometris oder ErdkreyBmessern zustehet. Sultio 1598 Enchinioion $23^{z}$ "bon Den Geometris". E(b) wenter 1618 Beometria II 136 "einem Geometrae". Belege fiir (is e o meter: nadh seigano* bei gutberns 1540 Dictionar. u u $2^{\prime}$ Erathostenes Cyrenaeus, einen gelerten Geometer. Dilidh 1598 siftor. Reidireibum Є.55 der erfahrensten Astronomen, der sinnreichen Geometren. Duad 1598 Endi= ribion $\Subset .108$ durch den künstreichen vnnd hogerfarenen Astronomm rnnd Geometren Gerhardum Mercatorem.

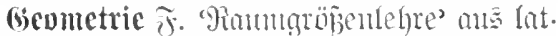

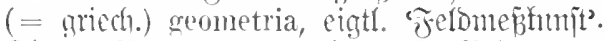
Die zu Gs e o m e ter jtimmende Bedeutning Deś lat. 结ortes ift in mho. gêometrîe, jêometrî nod betwant, tritt nuer jeit Den 15. Tuthrh. Fïr Ge duetrie bei ung bällig zurïf bor ber techniīh=mathemati= jonen Bermendung. Iie Embürgenth ber gelehrten Entlehnumg gejchah im 16. Sahrh. (5) o metria mad bei Etrtise 1556 sathrh.

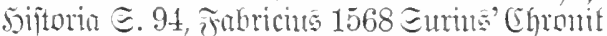
ङ. 235 ; wher (3) e metren iftou bei Siroma 1511 mirtica (6) 2a, Sübel 1516 Rechenbithlem $\Xi 24$ mo (b) e ometrie

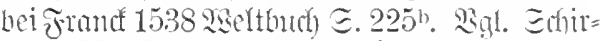
mer, mortich. D. Whathematit $\Xi .26$.

gerieren reflex. Btw. 'jich benefnuen' jeit Cume des 18. Jahrbs. bezengt. Das

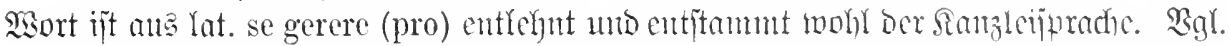

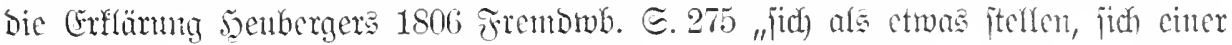

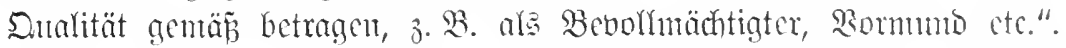

Belege: Sormes 1791 Siterar. Dërthrer Jäger sich geriren. Ievrient 1835 Gumint des I 274 er gerirt sich als wolle er ich weis nicht. Q⿹ngenblicks (I 206) da ich mieh nicht als ob die Entlassung mir verweigern, oder mir unverschämter Sansfacon geriren kann. $\Omega_{e}=$ Zulage zu geben. Govethe 1810 Sanempatete mald 1837 ?qunarelle (IV 186) auch er ist ein (II 200) Dem fiel es ein, er wollte doch als Pariser und gerirt sich so in der Frende.

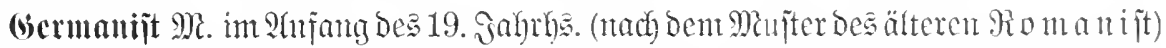

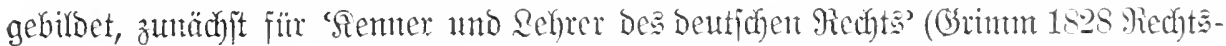

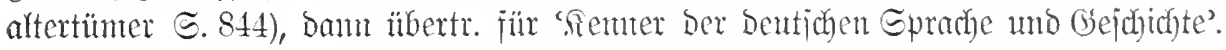

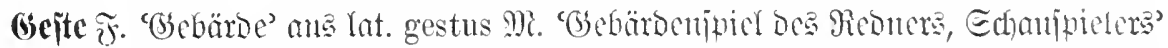

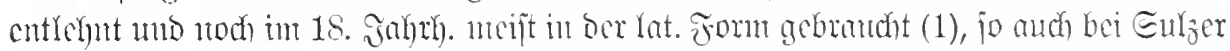

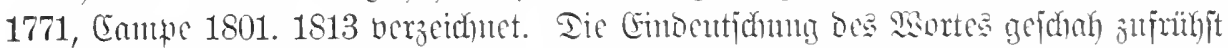

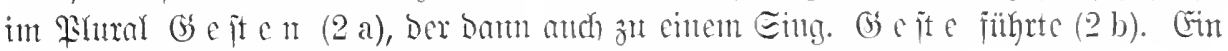

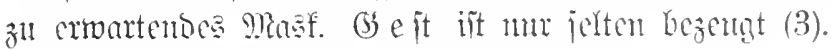

Belege: 1. Beioler 1700 Eieben böje den er mit dem Hute begleitet, zu schließen.

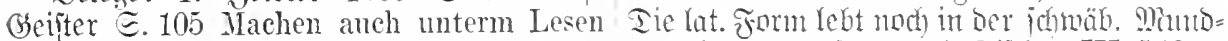
ein hauffen gestus und Gauckelpossen mit urt als geštes fort; ugl. Filicher III 556.

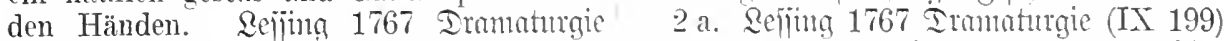
(IX 196) durch ihre Gestrs verderben sie diese Gradation ron bedeutenden zu mahle[Die Echaufpieler] vollends alles - (199) risehen Gesten - nnter den bedentenden Es sind dieses, mit einem Worte, die indi- Gesten. Govethe 1809 sishfuertombtichaften vidualisirenden Gestus - (200) in dem Tone, (XT 251) das, was sie vortrug, mit Gesten

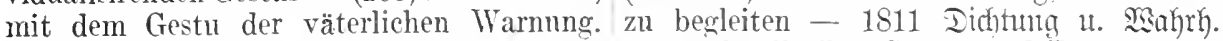
Schiller 1781 Räuber (IV 70) Er macht (26, 279) alle ilhre Gesten und Bewegungen.

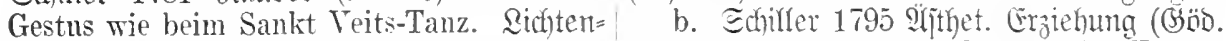
berg 1794 nognoth I 129 ein liederlicher X 380) Der gesetzlose Sprung der Freude Gestus - 1796 ebo. III 111 Aus dem Gestus, wird zum Tanz. die ungestalte Geste zu 
einer anmuthigen harmonisehen Gebärdensprache.

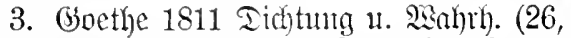
253) worauf er denn jenen Gest wiederholte.

geîtifulieren $3 \mathrm{tw}$. 'Gébürden madjen' \{d)on in 17. Gurhry. aus gleidjbed. lat. gesticulari abgeleifet (1). Cinte ipezielle Beziehutg

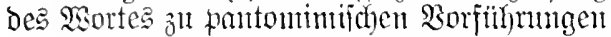
iff fitr bie ältere Beit nidht zu erweijen, erit im 18. Jalyrh. ift ac ftifulieren in Bereid) ber Sortragefumpt belegt. (2). $\mathfrak{B} e=$ lege: 1.1607 Ginmmajialordmung b. Joadym tal (Bontbaum II 74) soll ein Jeder mit fleiß zuhoren, darunter nicht lachen, gesticulirn oder Fantasey treiben. Eommer 1609 Seilpilajter $C 6^{a}$ der Son setzt die lincke hand in die seite und gesticulirte mit der rechten hand. Edrwenter 1636 Ielitiae phyj=math. E. 290 eine Person kan der andern also durch deuten und gesticuliren ohn einige stimm oder geschrey etwas zu verstehen geben.

2. Refing 1767/8 Dramaturgie (X 145) Gesticuliren sie [Die \{ituzen] wohl jemals, wie Besessene und Rasende? Echitfer 1783 frieato (III 17) Vor einem Spiegel gestikulirend [Bitfnenamweipung]. Boethe 1796

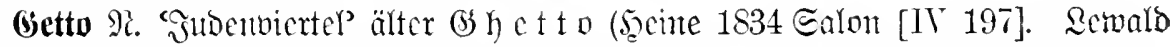

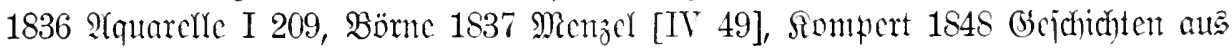
bem (Sh)etto) = ital. ghetto.

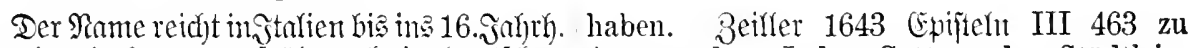
zurüaf uno begegnet frïl) aud in Dentichen Ancona der Juden Getto oder Städtlein.

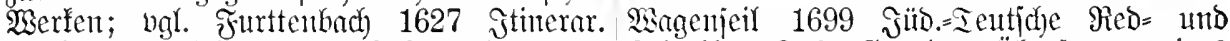

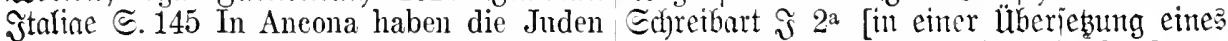
einen eygnen Getto oder eingemauerten Ort, ital. Briefes] des Ghetto (oder Wohnplatzes darinnen bey 1500 Seelen jhr Wohnung der Juden).

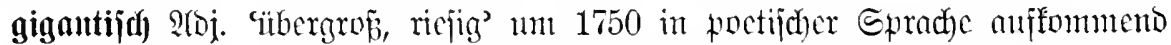
uno von 巨chönaich 1754 nod) als 9eologi 1638 Eolsatentenfel $\Im .137$ gigantische Himmelsstürmung, aljo mit birefter $\mathfrak{B e}=$

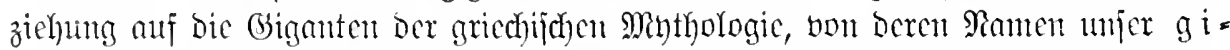

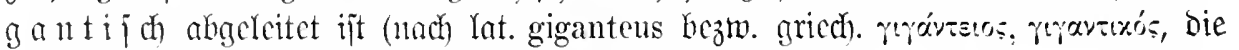
and jodon ilbertr. als 'ricjig' belegt jimb).

Bclege: Bobmer 1752 Noal) $\Subset .137$ Wo seinen g.-en Verstand bewundern. Sa Rodje er die Männer vom Riesengeschlechte ver- $1771 \mathfrak{F r l} v$ v. Etermheint $\subseteq .185 \mathrm{im}$ g.-en Ton lassen, Eine g.e Treppe zu bam. Inju der hohen Tugend. Edybart 1775 Dentiche

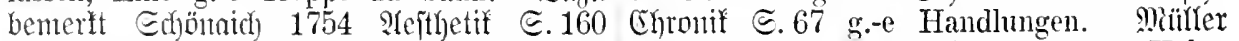
Giganten: so hat nummehr die Riesen der 1787 Gnmeridi II 271 mit dieser g.en Höhe. g.-e Dichter umgetaufet; sind nieht in seiner P(thenlyol 1787 Staltien II 15 Von den BruchZirbeldrüse g.-e Treppen? wo ein g.-er stüeken dieses g.-en Werks. Cufiller 1798 Gedank nach dem andern hinuntersteiget? Sïrgjờnt (II 35) Der Bäume g.e Sehatten. Wir wollen den g.-en Dichter verlassen und

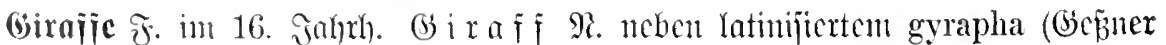
1551 Hist. animal. I 162): ani ital. giraffa berukenb. 2lber aud Dic jeit Dem 14. Jahrb. 


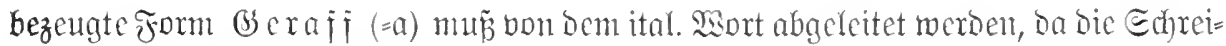

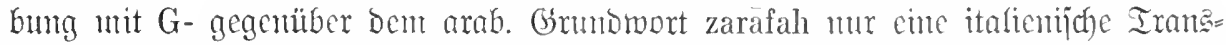

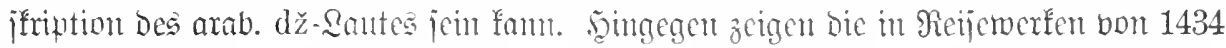

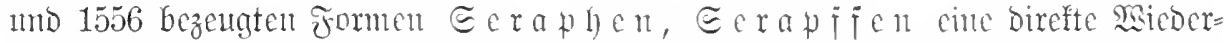
gabe Des arab. zarafah obne Bernittlumg oes Stalientichen. Iic Belege i. bei Burger, 3fo然. XI 304.

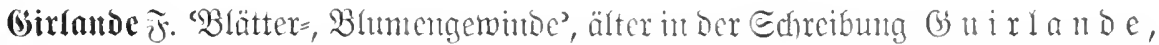

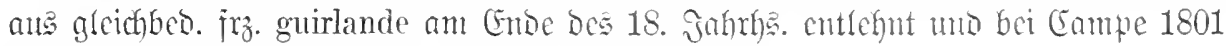
(muter Forberung franzöiticher P(usijurache) acbudt.

Belege: Edfiller 1784 Sabale u. Sicbe III 209 mit Guirlanden festonartig ge(III 476) worüber der Morgen seinen goldenen schmïckt. Biahrot 1790 Rindvigius II 111 Teppich breitet, und die Frühlinge ihre bunte eine Guirlande von Blumen hieng er dem Guirlanden streun. Afchentgols 1787 Englanto Vater über die Schulter wie ein Ordensband.

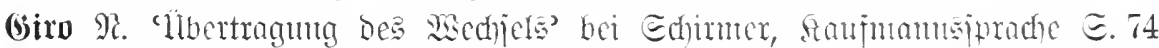

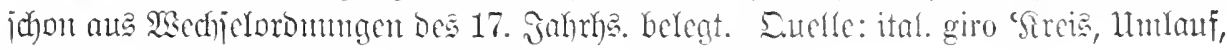
Ilmjabs. Dazu gleidhalt gixicren=ital. girare.

Gitarre $\tilde{F}$. Der Rame des crit jeit Ende bes 18. Jahrha bet un populär gex

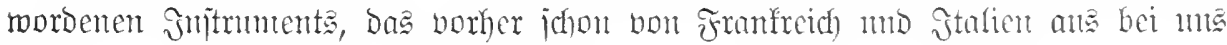
befannt war, cigtl. aber ans Epanien ftammt. Dnelle: inant. guitarra.

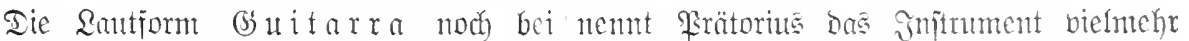
Melifius 1715 Flentre Є. 225. Inch ngl. Quinterna; bgh. II 53 Qrinterna oder Chiterna

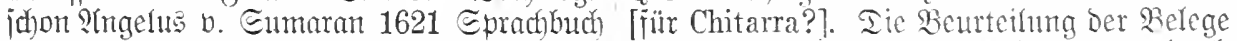

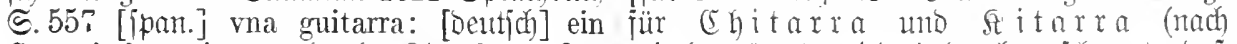

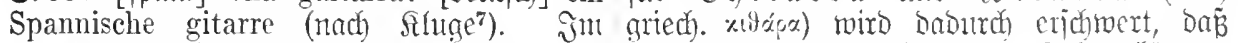

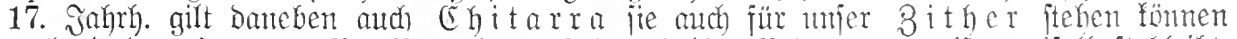

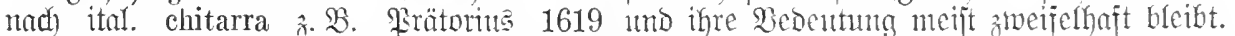

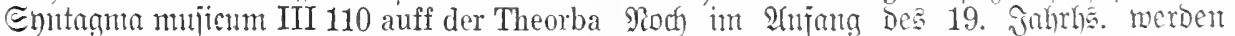
oder Chitarron - 146 auff der Lautten, s'u itale und Bither (und Laute) Harffen, Chitarron oder Theorba. Aher 1620 villig promiscue gebraucht.

in Iheatrum Juitumentoum BI. XVI 4

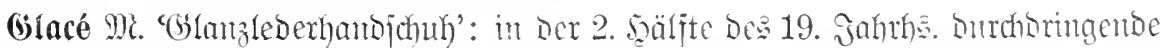

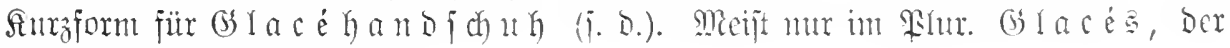
wicoer jranzöijich gebiloct ift.

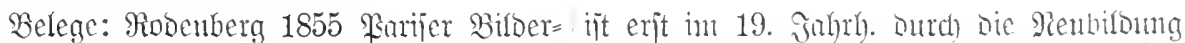

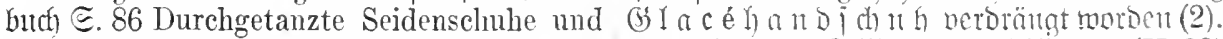

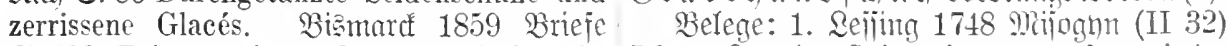
ङ. 429 Bringe mir noch Handschuh mit, Ich muB meine Spitzenkranse vorher wieder gelbe Glacé und braune rauhe. Evicthagen abbinden und die glaBirten Handschuh ein1860 Broblemut. Patıren VII 125 In Laek- steeken. Picolni 1779 Siertin $\Xi .402$ Sonderlich. stiefeln und tadellosen Glaces. Golth 1869 sind die Berliner glasirte Handschuhe beSEeltflugheit I 104 Sanskulotten in Glanz- rühmt, die besonders von den französischen stiefeln und Glacee. Rinbenbern 1883 Berlin Handschnhmachern rerfertigt werden. Mniull= 134 Herren mit den elegantesten Glacées. Ior 1792 Şerr Thomng IV 145 Seine schön

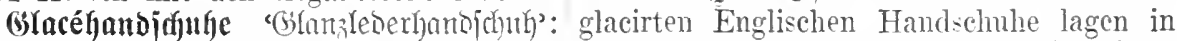

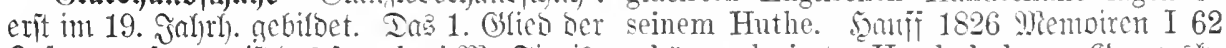

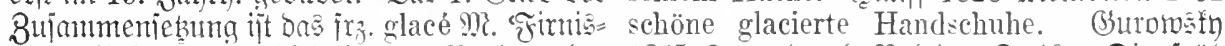

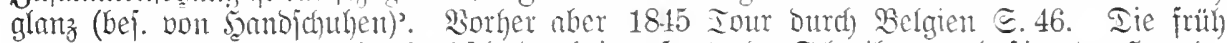

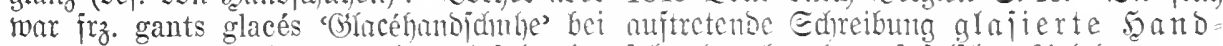

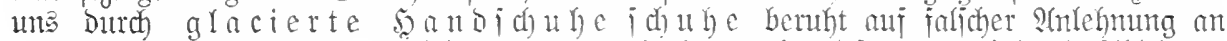

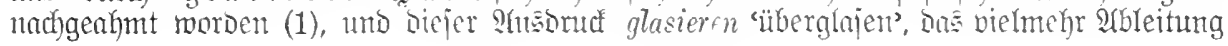




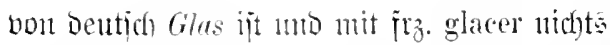
jul tum hot.

2. Sistt v. Iörring 1827 r tagmente II 427.

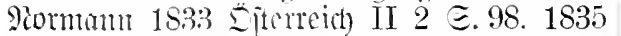
Europa I 246. Sieditein 1836 Reijetage I 10. 13. Rimuld 1836 P(quarelle II 198.

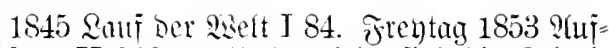
iäbc II 268. - lluberedhtigt jind bic Edyrei= butigen of a c e e $=$ (s)eme 1836 Romant. Edhule [V 279] - 1840 Bönte [VII 128]. (Bollis 1869 sieltflugheit I 135) ober gar Ievrient 1843 sier bin id (III 184). Chomniţ VI 115).

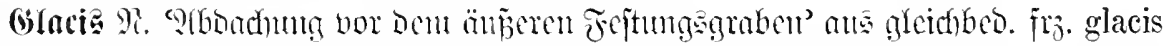

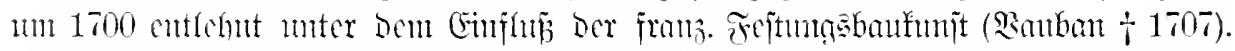

Bclege: 1702 Europ. Fanta $\Xi .539$ als I 24 auf dem Glacis vor der Stact. Gothe sich dieselben in die Festung Landau werffen 1822 Belug. v. Maintz $(33,299)-1829$ San= wolten, und bereits bil an das Glacis ge- berjahre $(25,40)$.

langet waren. 1757 Franffuter Miärelation

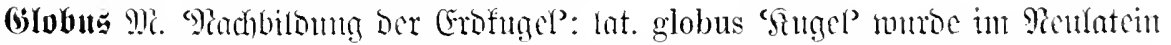

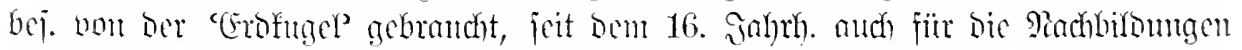

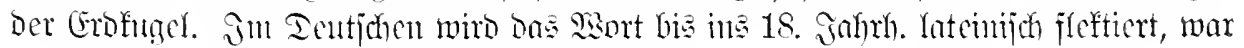
aber gemij (non ber Gedule ans) gut befmunt.

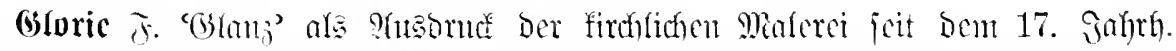
bejengt (bgl. Ricolat 1699 De Nimbis $\Xi .106$ ). Dod jofon um 1300 bei Iurambus,

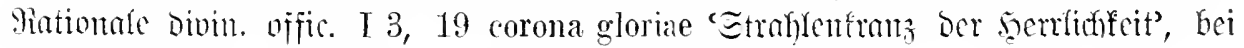
ben Minjtifen (I 98. 359) das licht der glôrjen.

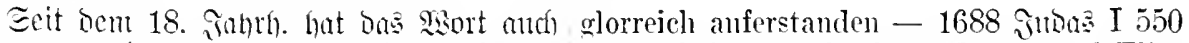

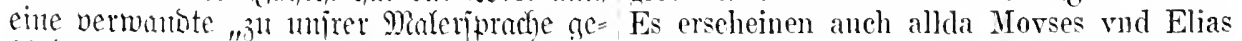
hörige Rebeutumg, in weldher es bas silo mit glorreichen Leibem - dise 2. glorreiche

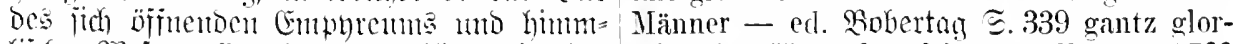

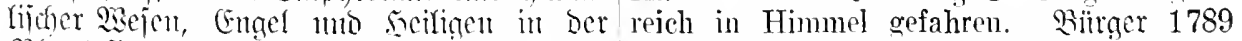

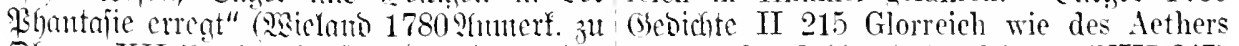

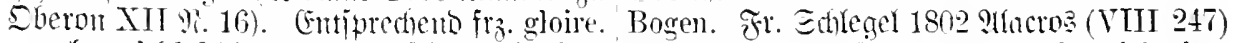

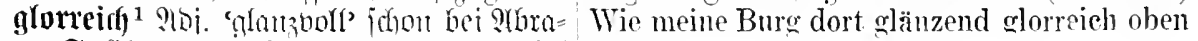

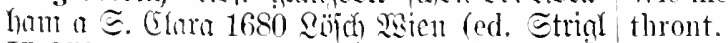

II 372) Wie der Herr Jesus von den Toten

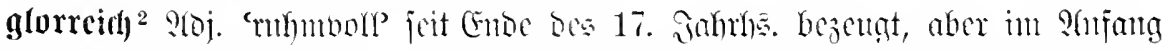

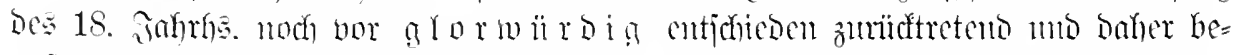

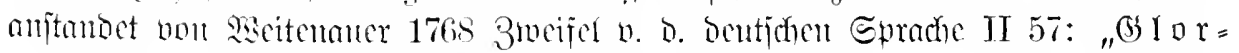

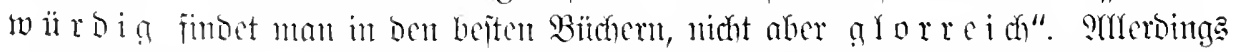

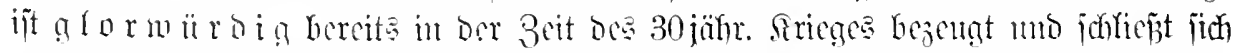

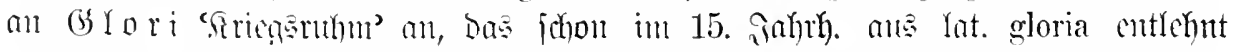

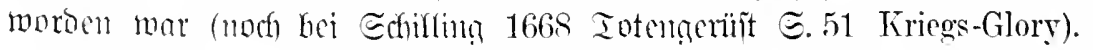

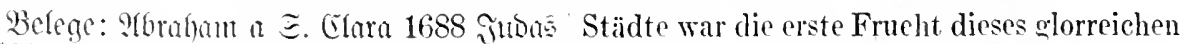
I 508 gar recht, dab sie zu ciner solehen, Sieges - 1792 23orrese (IX 396) durch die glorreichen Action nicht seynd gelangt glorreichen Thaten des Johanniter- und

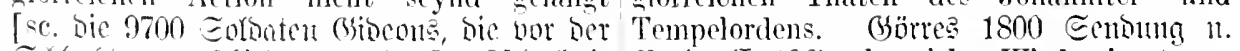
Ehlacht augaciffeben wurben]. Bichafwiz łaris (I 106) glorreiche Wiedereinsetzung 1723 forl VI. E. 163 Tud dieses war der der Priesterschaft in ihre entzogenen Rechte.

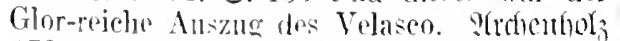
1787 Cunfouid T 2:37 Wilkes behauptete rinst im Parlament. daf. dieser Tag der glor-

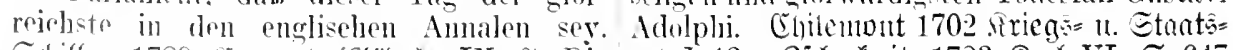

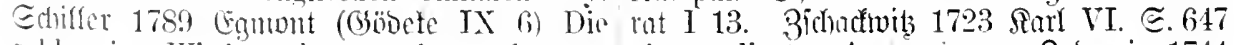

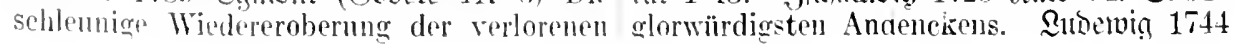


(5jel. Snzotgen II 171 zu glorwürdigstem 1785 Ion fartos (V 20) Fiaiser Karls glor-

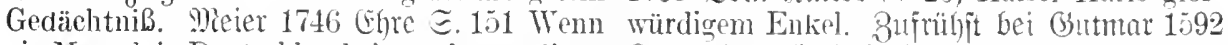

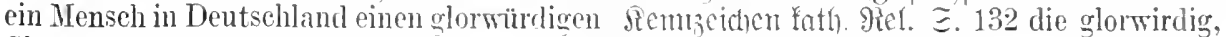
Sieg um den andern erfochten hat. Echilfer triumphierende Kirchen.

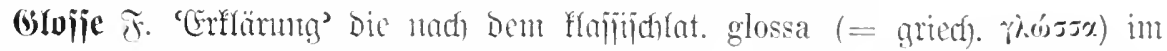

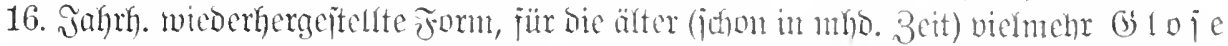

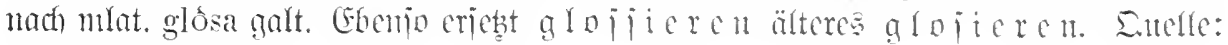
lat. glossare.

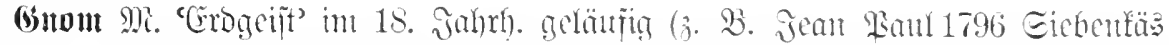

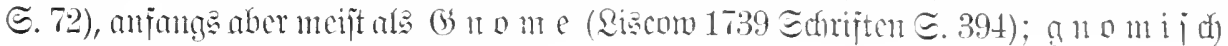
bei Zact)miä 1744 genommijt 3.83.

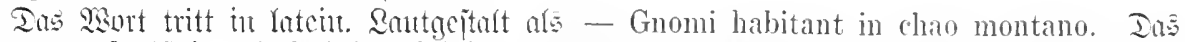

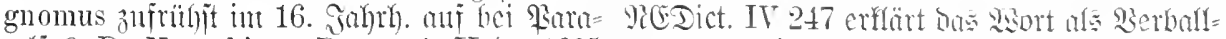

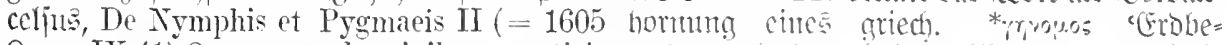

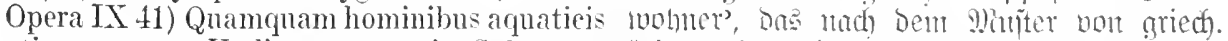

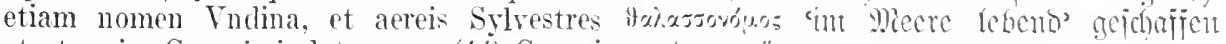
et terreis Gnomi indatur - ( 14$)$ Gnomi moroen toüre.

humiles sunt, duas eireiter spitham aequantes

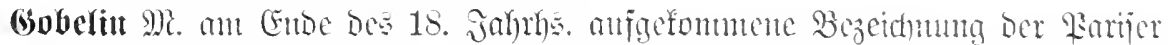

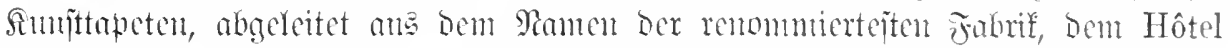
Ropal des Gobelins. Dic i. Э. 1667 gegrümbete Firma nante fich nad) einem be=

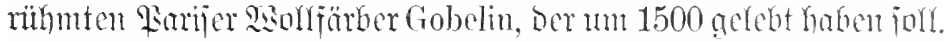

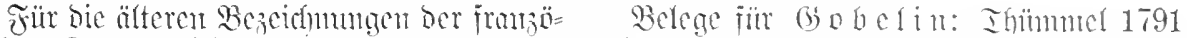

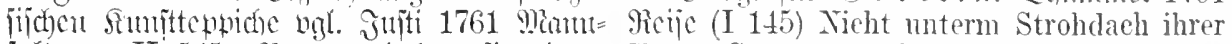
fafturen II 545 , \$son gemirăten figuriten Hütte Gern seine Gobelins rergißt. 1800

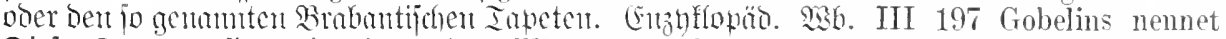
Dicje Tapeten jum cine ber alten Mam = man besonders sehöne Tapeten. S̆anj 1826

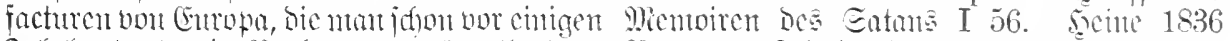

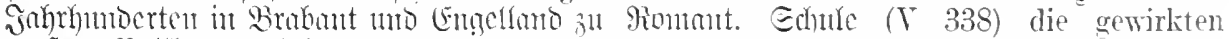
groferer Solffommenheit gebracht hut, ohn= Tapeten, die wir Gobelins nennen. Säin=

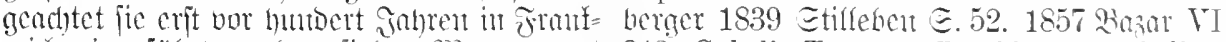

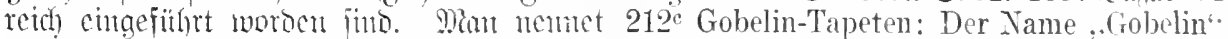
fic Dajelbit Eapeten von Santelijie mo ist uns Allen bekannt. Evielfagen 1873 Baijelifie [o. i. Fro. tapisserie de haute lice, llitimn E.132 Gobelin-Teppich.

de basse lice $]^{\prime \prime}$.

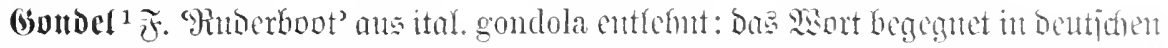

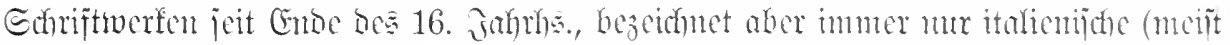

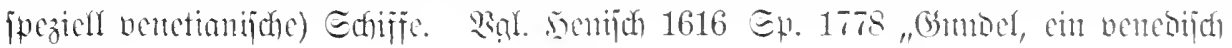
[(d)ifflin."

Belege: Entur 1598 (unthirioion E.299 1861 I 19) Bis zur innersten Hafenspitze vff die manier der Venedischen Gondalen. hineingondehn mag er allerdings. Bierbun Beiller 1643 Epijtefn III 461 anff eimem 1893 Entoentenbeichten I 168 'nen AmeriGundole oder Sehifflein. Gallentach 1715 kaner, der eigens herïber gegondelt ist uim. Duafi @. 39 ich hab die Gondolen zu Venedig 2. alfg. 'Fafrem', anch 'geben' erit etrwa $u$.

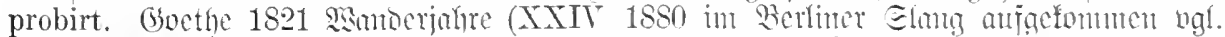

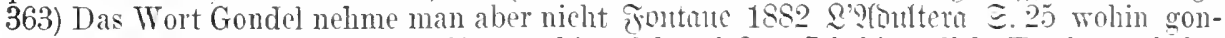
im traurigen renezianisehen Sinne: hier deln wir? - Ieh bitte dich. Etzel, nur keine

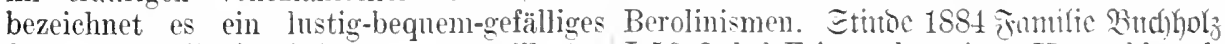
Schiff. Eo fälrt bie Cinthiugenutg des 然ortes I 52 Onkel Fritz nahm einen Hanssehlïssel, erit ins 19. Sathrh.

gondeln $3 \mathrm{tm}$. 1. 'in cinter Gimtoci fuhren' motive. und wir gondelten los.

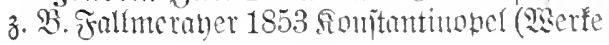




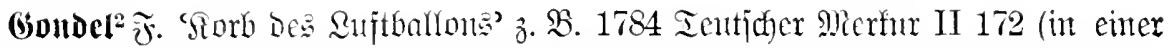

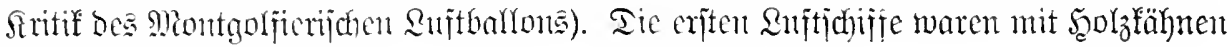
in Gound form perjegen.

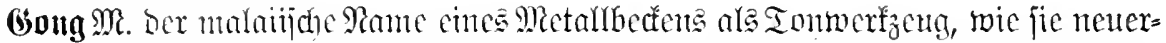
bings importiert und nachgeahnt werden, um die Mittagighlocte (and) Dic Theater=

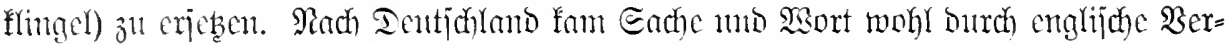

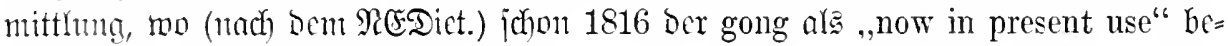

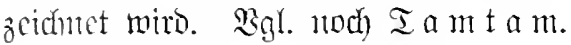

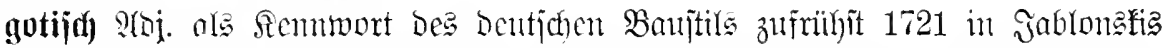

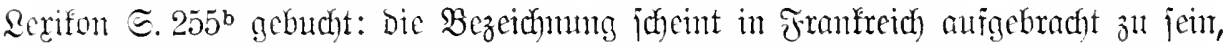

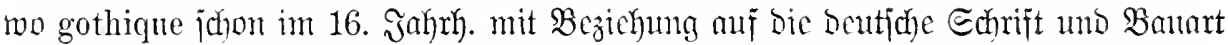
bes Mittelalters üblich war, oft freilich mit ber Rebenbedeutung barbarijch, roh,

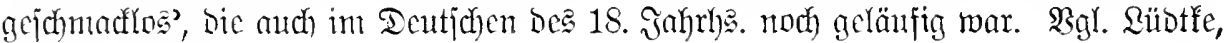
3和照. IV 133.

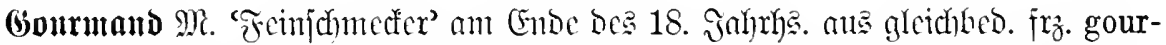

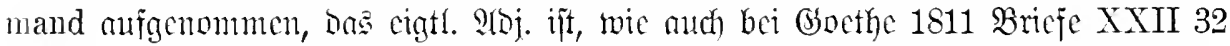
lieben Sie uns nicht weniger, wemn wir Ihnen etwas gournrand erscheinen sollten.

Belcae: 1765 litherietrung $\mathfrak{b}$. Eteme's von den Gourmands zu Athen für etwas sehr Irijtım Ehanon VII 40 Die Franzosen essen Leckerhaftes gehalten wurde. Richtenberg gern was gutes - sie sind insgesammt 1795 foggartf II 353 Der Tropf ist blos ein gourmands. Qejifing 1779 Bricfe (XVIII 248) wenig Gourmand. Şcine 1822 Berfintr Brieje Sie sind ja ein rechter Gourmand im Arbeiten. (VII 566) Welehe Gefühle erregt diese Sonne SAiclanb 1782 5eoraz' Briefe I 212 daß es in dem Magen eines gourmands.

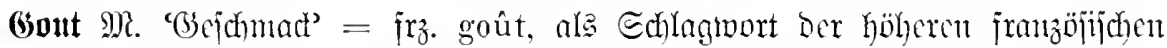

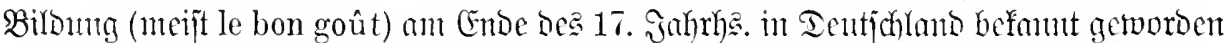
(1). Snt itreng=äjthetijchen Eime wurbe ce allerbings hald burch bas bentiche Geschmack

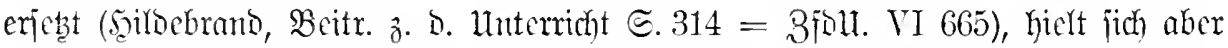

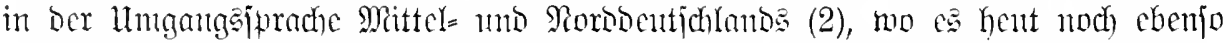

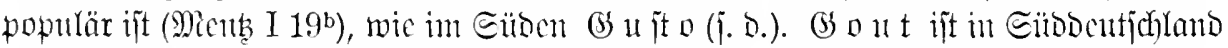

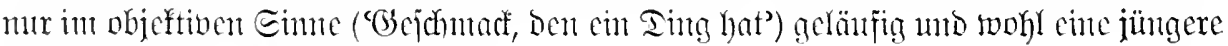
Entlehmmą (bgl. Firifher III 890).

Betege: 1. Thomajum 1687 Siachahmuma dienet, der so viel die Simnen betrifft, zum ber Frranzijen $\Subset$. 10 Le bon gout, gleichwie Exempel eine artige und geschickte Lieberey es eigentlich einen gnten und subtilen Ge- auszusuchen weib, oder der sich lieber an schmack bedeutet, und damnenhero von einer anmuthigen Laute oder wohlgestrichesolehen Leuten gebrancht wird, die nieht nen Violine als an den besten Brumejsen oder alleine das was gut sehmeekt von andern der zierlichsten Sackpfeiffen delectiret. Surr= gemeinen Speisen wol zu unterseheiden wissen, fürritin Eophic 1710 an Frriebridy I. (E. 204) sondern auch geseliwinde dureh ihren seharff- daß zu Saltzthal so viel verendert ist, kömit sinnigen Geselmack urtheilen können, woran vom Hertzog her, welcher einen solchen es cincm essen mangele: Also haben die guhten goust haben. Bonmer 1720 Brief

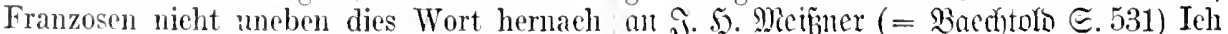
figürlicher Weise von allen denen zubrauchen möchte gern den Gout der Deutschen ver-

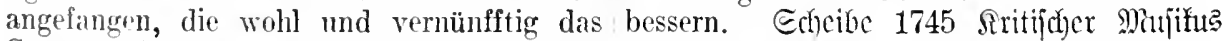
Gute von dem Bösen oder das artige von dem S. 121 Die Wörter: Methode, Gout oder unartigen unterseheiden, daßalso den Nahmen Gusto werden insgemein verwechselt, oder d'un homme de bon gonst der jenige ver- wohl gar zu einer Sache gebrauchet, worauf 
sie gar nicht zielen. Alle Wolt schreyet: practica II 134 b diesc erwählen, welche am Methode, Gusto und dergleichen. Wenn besten nach seinen Goût zu seyn scheint. man von einem fremden Musikanten redet, Mcifler 1777 an Rürger (II 214) Das ist so so fraget er alsobald: Hat er Methode? Hat etwas für Studenten, denen man auch Speisen er Gout? Bjlcich baralt: Der Giout oder eigentlich der Geschmack, wemn er gut ist, ist eine Sache, die allen Stücken eine wahre Schönheit zuwege bringt, wemn ihn der Componist selbst besitzt. Bucthariä 1754 Berwanolungen (I 181) Und sarre bleu! der Gout ist recht daran verschwendet.

2a. '(s)ejd)mad des eimzelnen': ?tun= ranthes 1715 Franenzinnerlerifon welche hernach ein jeder nach seinem goût zubereiten und essen kan. Prillo 1722 Rubm des Tabafs @.10 Im übrigen bin ich ein Eclecticus und raisonnire nach meinem Gout. Wagner 1724 Eoldatenbibliothef $\Xi .316$ Thre Officier aber sind besser gekleidet, ein jeder nach seinem gout und range. Fleifcher 1730 Seer $\mathfrak{v}$. 2yoto I $2^{\mathrm{b}}$ Derjenige mun, der es nicht nach seinem Gout findet, ist ja nicht gehalten es durchzulesen. Döbel 1746 Jäger=

nach ilhrem Gout vorsetzen muB.

b. 'शrlgemeine (bejdmadsridtung': BBer= trom 1728 Einteituma $\Xi .152$ es ist aber nach dem gout der Walt frey geschrieben. Echeihe 1745 frit. Munifus 厄.121 Man saget insgemein: dieses Stïck ist von einem besonderen oder fremden Gout, oder dieser Componist hat einen ganz neuen Gout.

goutieren Btw. 'Gejhmadé am etro. Finden,

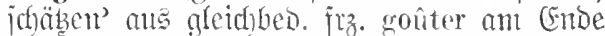
bes 18. Jahrhas. entlehnt. Belege: 2eijing 1778 Briefe (XVIII 265) Besonders freue ich mich, daß Du das haut-comique der Polemik zu goutiren anfängst. Miuller 1789 (Enmerich VIII 301 von einem Manne, dessen Character man nicht goutirt. Syente 1822 Berliner Briefe (VII 588) ieh kann seinen Humor nicht gontiren.

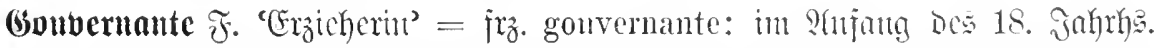

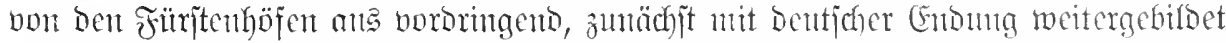

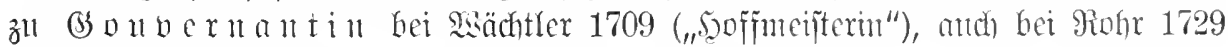

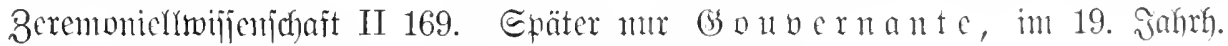

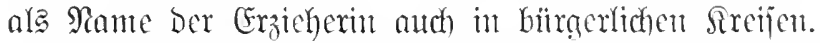

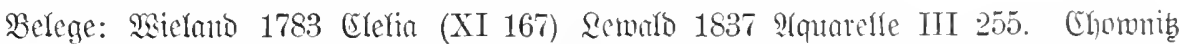

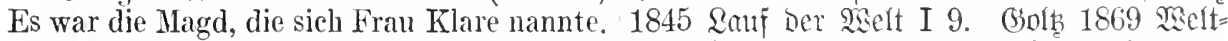
Die Amme erst hernach die Gonvernante. ffugljeit I 53 die unbemittelten, aber ge-

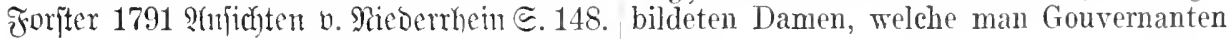
Rotebue 1806 srgane de? Gebirm (XX 98). I nennt.

(Goubernemx M. 'Gtatifalter' in 17. Jahrl). aus gleichbed. irz. gouverneur ent=

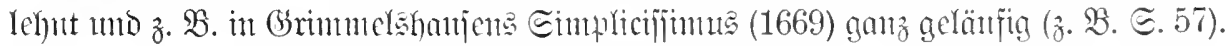
Bufrifyjt bei Enzuger 1590 Relatinnen I 139 Gramuen von Lalaing Bailly, Goumerneur oder Stathalter von Henegaw.

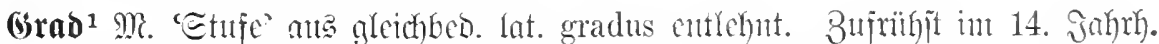
im afademifach Bereid) non Den Etujen Baffalar mo Rizentiat (j. B. 1379 2fften v. Erfurt I 2 baccalariatus ac licentiaturae gradus), nicht bom Toftor (bgl. I i t c l).

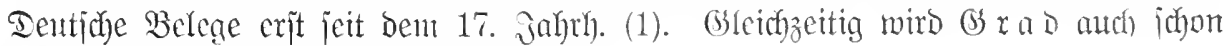

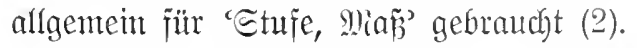

Belege: 1. Megfart 1636 ‥ D. Srodh= ressirenden zu communiciren auff Gewissen idhulen 巨. 27 sie wollen diesen oder jenen schuldig ist. Eedentorif 1665 füritenjtaat II EhrenGrad anf andern Universiteten sich 101 zwar ist ein Unterscheid und orad in annehmen. Stber bei Giturimutus 1610 Grend solchen inclinationen. Thomains 1691 Ber= 厄. 1310 den Doctorhehen Gradum.

2. Mengering 1642 Gerviffenšrüge 〔. 709 muntfefre II 221 der schon die Weibheit in einem hohen grad besitzt. 1699 Etant: darumb man solche trawrige Fälle vnd böse, finiegel I 61. Chyilemont 1705 frriegs= $\mathfrak{u}$. Zeitung nicht so schlecht vnd blob, sondern @taaterat II 13 neben diesem ist auch im durch gewisse grad, gantz vorsichtig den inte- höchsten grad impertinent, was mein Ge- 


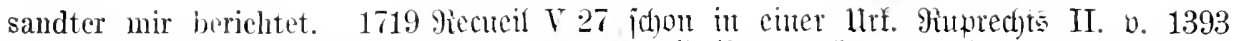
zu einem hohen Grad der gelahrtheit ge= (5eibelberg. Urfintoenfutch I 56) meister und

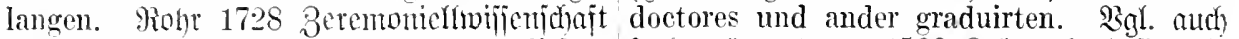
I 27 würde er einen gar ansserordentlichen Iabernämontonus 1588 fräuterbutch $\mathrm{I} 225^{\mathrm{b}}$ Grad dazı ronü̈then haben. graduirte Personen. Mleviant 1636 年. D. 5od $=$

grabuticren 3tw. mach mlat. gradnare iflulen @. 38 graduirte Gesellen.

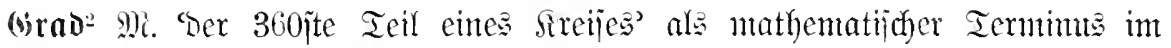

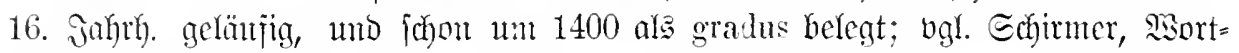

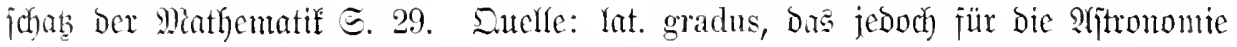
in Der Bed. 'Teil eines Birfels' bezcugt ijt (Mianilius, Astronomica I 581).

(iranumatif $\widetilde{J}$. 'Sprachlehre' aus gletchbed. lat. =gried). grammatica (cigtl.

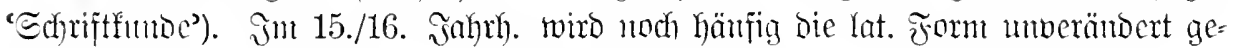

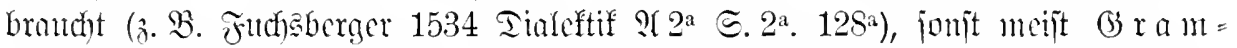

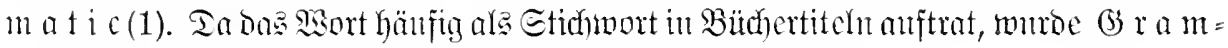
matif audh als 'grammatifiches Buch' gebrautht (2).

Belege: 1 . 2uther 1521 gegen Emier II 84

2. Eேmier 1524 immotat. $51^{\text {b }}$ hat er die Aber solchen buchstaben meynet $S$. Paulus grammatick nit recht angesehen $-\mathfrak{H}_{02}$ nit. Es gehört 5n die grammatick vnd kinder yhn wölcher grammatick er aber gelesen, schulenn. Emijer 1524 Shmotat. I $3^{\text {b }}$ wo der das iussus vnd hortatus ein feltgeschrey heyß, irrtlummb allein die grammatick vnd nit den ist mir verborgen - ebenị $\mathfrak{\AA} \mathfrak{1} 2^{\mathrm{b}}$. Becher glauben betrifft. Polnchoring 1536 Eneton, 1668 Miethodus bidactica D $2^{a}$ die Lexica, ङ. $36^{a}$ vil gelerter in der Grammatic. Tomenclaturen vond Grammaticken.

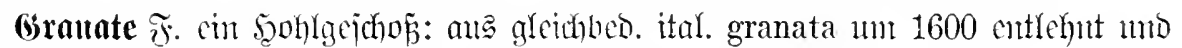

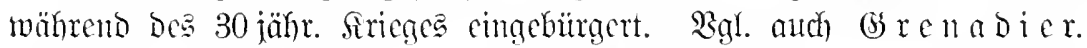

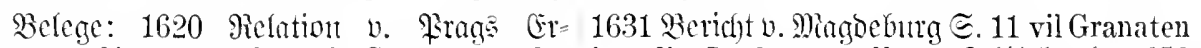
oberung $\mathfrak{A}^{b}$, Kugel vnd Granaten oder imn die Stadt geworffen. Echilofitecht 1652 eysene Sprengkugel. 1628 Beitutg $v$ v. D. Şamtonia II 64 Hand=Granaten. 1664

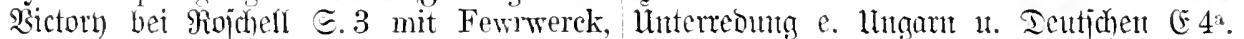
Granaten vmnd andern Kriegs-Instrumenten. Talhover 1689 Gartenbeetlcin II 815.

Grand M. Der Rantc eines Epiels im Efat, ans bem fro. 2loj. grand ‘grop̉ um Dic Mitte Des 19. Jahrhes. gebildet mo bet Secule 1873 gebucht. Beleg: Stinde $18 \$ 4$ Fan. Buchbols I 116 er sah so fidel ans, als hätte er einen Grand mit Vieren in der Hand.

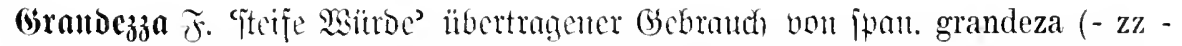

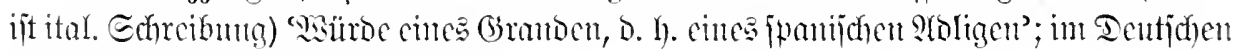
icit Dent 17. Tahrh. zh belcacu.

Bclege: 1668 siatio Etatı $\Xi .92 \mathrm{dz}$ die länder sind von solchem Temperament, dab gantze weite Welt sich sol daran spiegeln sie zwischen der Frantzosen Leichtsimnigkeit und kein Nensch sich mehr gelüsten lassen und der spanisehen Grandezza gleichsam das meine Grandetza und Altetza zu defendiren. Nittel treffen. ßob)r 1728 3erentoniefl=

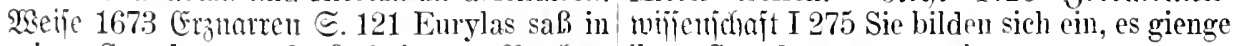
seiner Grandezze und ab Qvitten. Bercten= ilurer Grandezza etwas ab. mener 1712 ?ntiquarits $气 .164$ Die Engel-

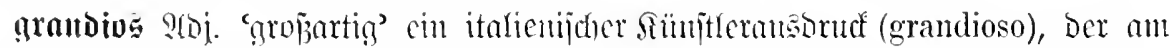

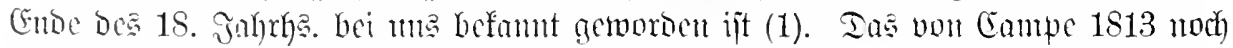

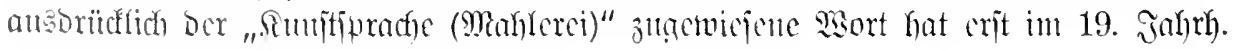
aflacmene bettumg exlangt (2). 
Belege: 1. 1781 Senticher Dierfur II 82 sie [Die Engländer] eine grandiose Art haben, Eine majestätischere, grandiosere Figur hat es [on (jitute] zu rerbreiten. Geine 1830

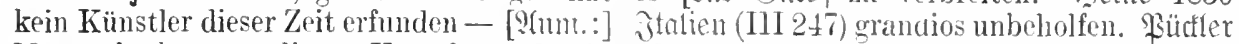
Man erlaube uns diesen Künstlerausdruck. 1831 Brtęe 116 grandioseren Effekt. Granon Er sagte viel, und besser als Grob (3Fons. 1836 Inquebuch (I 198) Ob ich so etwas GranII 69). (bocthe 1786 Sagebud) Der itnl. dioses nur habe ahnen kömnen. (Glag̈brentuer

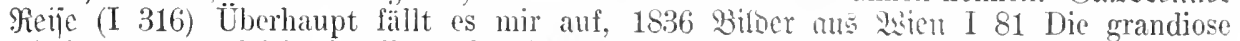
wie in Toseana gleich aie öffentlichen Wege, Dame. Sanbe 1837 gevientoellen V 275 eine Brücken für ein schönes grandioses Ansehen tadellos vornehme, grandiose Stadt. Paitrn= haben. Brum 1800 Echriften III 183 welehe berger 1839 Etillleben હ. 186 Nur das GranKonsequenz in jeder Falte des grandiosen diose, welches Ihre Traumvision andentet, Wurfes - IV 24 so grob (grandioso) ge- fehlt. Fitcfer 1810 Biberjanl I 346 mit zeichnet - 1809 Epijoben II 364 der ganze grandioser MIunifizenz - 193 in ihrer Pallast ist grandios und edel.

2. Gónethe 1816 stal. Reije $(27,87)$ Dab srandiosen Willheit.

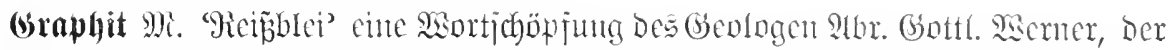

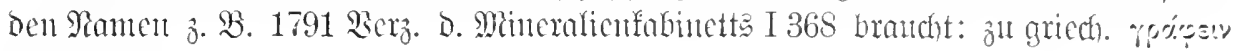
Gercifuen'.

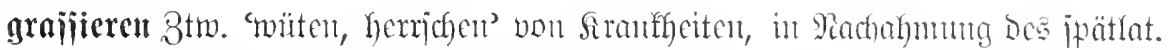
(Gebraudfs (Roman pestilentia grassabatur 4. Jahrh.), Der anch Durd bas beutiche

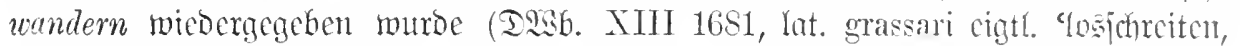
umbergehen'). Beleg: Rhone 1582 Reinteujel (Theatrum Diabolorum II 99a) da kein Pestis grassiret. Euhon geumet bei Rot 1571.

gratis 2(ov. 'unentgentlich' in 16. Jahrh. auz gleid)bed. Yat. gratis entront. Die

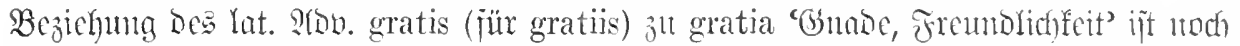

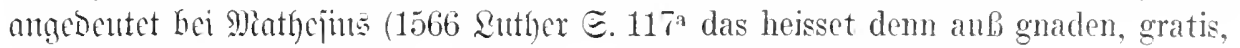
nicht aub vas selber) in ben Belegen aber nirgents metre lebendig.

Belege: 1558 Scibelherger Etntuten હ. 44 wie Abraham, zurechmet. 1588 jocibelberg. das num furtan in diser faculteten der theologi Etututen Є. 223 es were dann sein naher $\mathrm{zu}$ iedem halben iar ordinarie ein clisputation verwandter und guter bekanter fremn, den furgenomen und gratis, ohne beschwermng er gratis und freundschaft halber herberig und entgeltmus des respondenten gehalten gebe. Gunmonis 1610 Greud 〔. 831 gratis

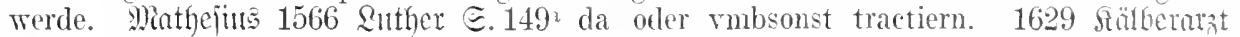
vns Gott seines Sones gehorsam vnd gerechtig- @.64 der Tenffel kans anch rnd lehret seine keyt, gratis vnd allein durch den glauben, Schüler gratis, vergebens rnd rmb sonst.

gratulieren 3tm. int 16. Jahth. ans Iat. gratulari cutlehnt mo bei E. Orot 1571

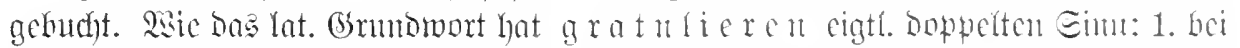

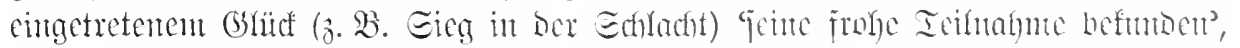

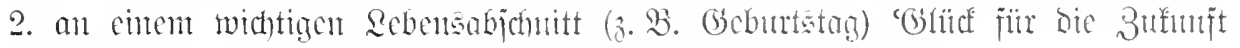

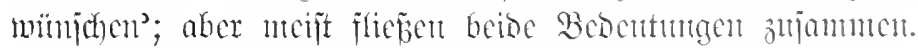

Belege: firchbof 1563 s.senoummnt I 51 gratulinten mit diesem Lied S. Dach und

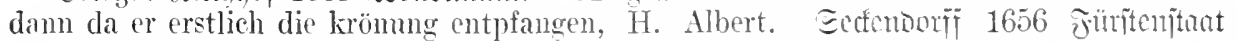
wolten ihm die Jüden allenthalben her ver- I 192 man gratuliret ihnen bey Freuden oder

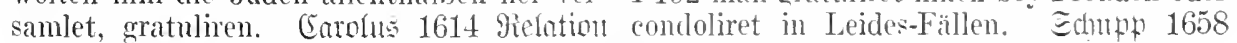

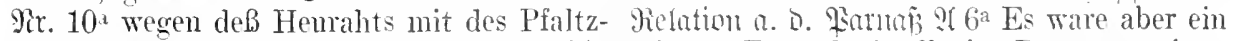
graffen Sehwester zu gratuliren. Qfibert 1650 schöner Tag, als Apollo im Parnasso seinen

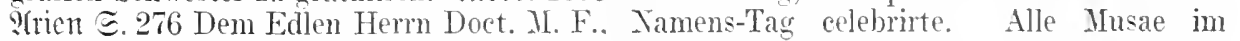
Als er dureh Gottes Gnade um 50. Jahr den Parmasso gratulirten jhm.

gradmm Doctoris hochrïhmlich geführet, iich gratulieren tvie lat. sibi gratnlari 
gernbezu 'jïh) freuen' (vgl. oben bie 1. $\mathfrak{B} e=$ Deutungangahe). Belege: soartmann 1678 Yuatomia $\Xi .69$ Der Geitzige und Wucherer segnet sich und gratulirt ihm selber und ist froh. firajit 1683 Beosenfen v. D. Mamu= fafturen ङ. 198 man hat sich vielmehr zu gratuliren, daß man vicl auszugeben habe. Thomajut 1688 Monatâgeipräche I 53 weil sie dannenhero mir hierimen beygepflichtet, so habe ich mir desto mehr zu gratuliren. জeije 1697 Bertr. Bejpräd)e $\subseteq .44$ auff die Maße müssen sich etliche Väter gratuliren, daß ihre Söhne zu dergleichen Ungelegenheiten nicht Anlaß geben.

Gratulation $\mathfrak{F}$. '(Glürfwumid)' nad) lat. gratulatio: bei $\Subset$. Rot 1571 gebudet, aber erjt im 17. Jahrlh. ljäufiger belegt z. $\mathfrak{B}$. Epangen= bera 1611 2hbmb=23rieje $\Re^{\text {b }} .1620$ Calvin. Mantwill $\mathbb{C} 2^{\mathrm{b}} \cdot \mathfrak{F} 2^{\mathrm{b}}$

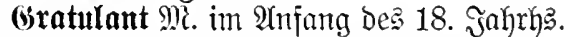
aut Dem lat. ßart. gratulans gebildoet $z . \mathfrak{B}$. PGilippi 1743 Reimijdmiebefunit S. 67 Gratulanten-Vers. Bachariä 1754 :Bermandlungen (I 160). Edyönaich) 1754 2ejthetif Є.177.

gravieren 3tw. 'einjanciocn' (bef. auf Metall) aus frz. graver entlehnt, z. B. Irahenlyolz 1787 (Englanto II 211 er machte Kupferplatten, gravirte solche, druckte die Banknoten.

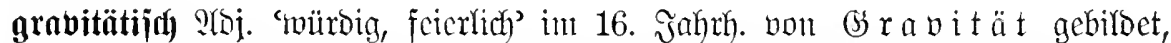

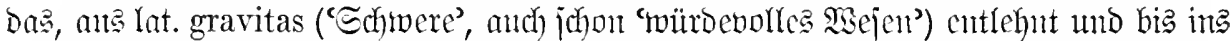

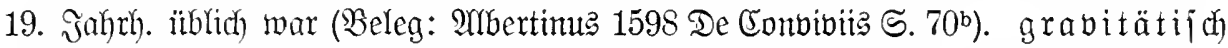

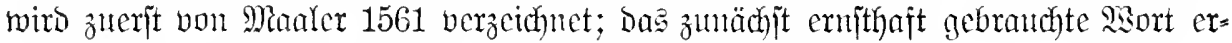
hält früh (†. z. B. Die Belege von 1608. 1673) ironijacn fllang.

Belege: Fij dhart 1577 Irojtbüthlcin $\subseteq .81$ Fürsich-gehen. Francişci 1672 siiftor. Raud = daß ich [Das \$oDagra] aines gefärtin bin vud faß̃ I 227 g.e Männer, allesamt mit langen jne gemachlich vnd g. daher gelaite. 1596 schneeweisen Bärten gezieret. Rebenwalst

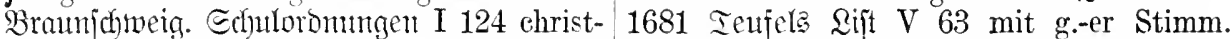
liche, g.-e stuck, welche zur andacht dienen. Bigler 1689 2rjiat. Bantije $\Subset .52$ er gieng

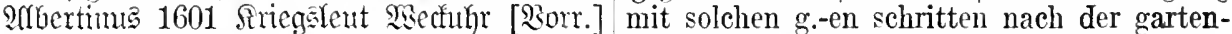
g.-e vnd ernstliche warnungen vnnd er- thüre zu, als ob er dem Actäon ein horn mahnungen. Eommer 1608 Ethogranfia I abgerannt hätte. Sulynau 1700 Duaffalber

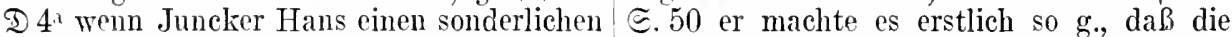

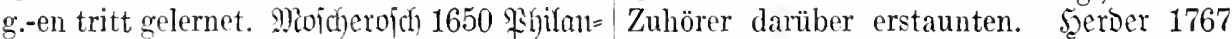
Der (ed. Bobertag ङ.92) Sie stelleten sich D. Literatur (1 432) das g.-e Kopfnicken des alle gar g., züchtio und still — 〔. 189. Grint= Präceptors schreckte mich. 巨đhubart 1774

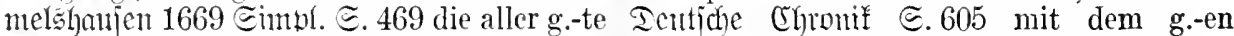
Männer - 1673 Ieutjdjer Midjel $\Subset .69$ als Schmeerbauche. Mällter 1778 Faufts ¿eben wolten sie andere ererst recht reden lernen, Є. 20 gehn meistens mit vollgestäubten wie jener alte Krebs seinen Jungen das g.-e Perücken g. einher wie Gänse.

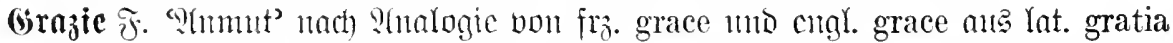

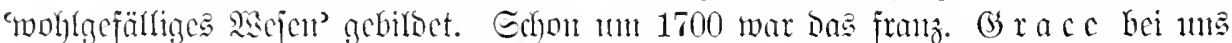

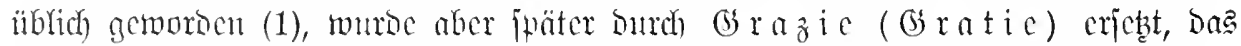

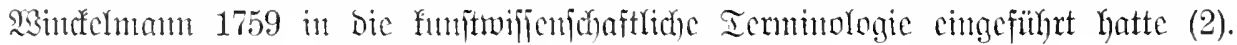

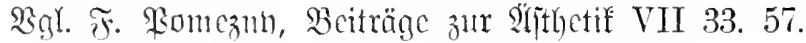

Belege: 1. Sulnum 1700 Dutufalber Є.47 grace und gewicht. Sermes 1778 Eophjens ich spielte anff meinen 3 Saiten die Sonata $\Re$ eije V 722 sie konnte auch mit ciner Art mit einer solehen Grace und Anmuth fort, von grace ilıren Geifer speien.

als wenu dic Geige noch vollkommen bezogen wäre - $\Xi .202$ srin Instrument mit schönster

2. Mindfelmanm 1759 Bon ber Bsrazic Grace anzugreiffen. Gumbling 1739 Eatir. ist das vernünftig Gefällige. Es ist ein Begriff Echriften $E_{.105}$ wie denn die Patiniana, von weitem Umfang, weil er sich auf alle so man vor liurtzem zusammen gesammlet, Handlungen erstreckt - in jeiner fiumit=

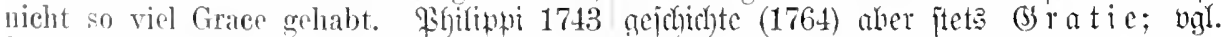

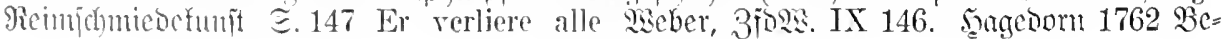


tradtumgen über die Minleret $\subseteq$.21 Von dem Zeit mit einem entbehrlichen fremden Worte Reitze oder Grazie insbesondere. Mendels= Grazie nennt (8fors. VI 108). Erfifler 1793 john 1760 Riteraturbriçe VII 43 Die Ähnlich- Inmut u. Si:übe (XVII 326) Grazie ist keit, der Geist, die Grazie, alles ist unter ihren immer nur die Schönheit der durch Freiheit Händen verschwunden. Б̃erber 1766 sierfe bewegten Gestalt.

I 53 Die dritte und höchste Stuffe der grajiö 2 doj. ans $\mathfrak{i r z}$. gracieux entlelynt Schönheit ist der geistige Reiz, die Anmuth 3. B. Sabater 1778 Bhtfitomom. Fragnente und Gratie, die alles vorige belebt. \&ejïntg IV 477 Ein graziöses Gesicht. گ́ftere Echrei= 1767 Dramaturgic (IX 198) Tanzmeister- bungen: grat io s bei Eperander 1727 umb

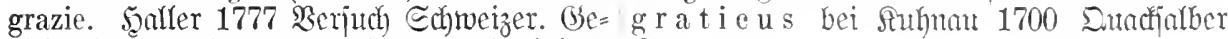
bidyte (Borr.) die Anmut, die man seit einiger |

Grenader M. ant Cube des 17. Jahrhes. aus frz. grenadier enttehnt, anfangs

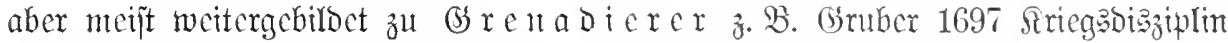

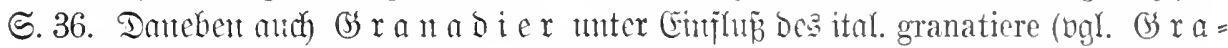

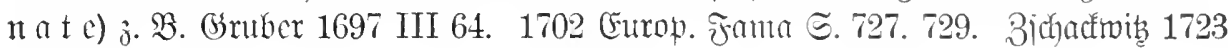
Rarl VI. ๔. 139 .

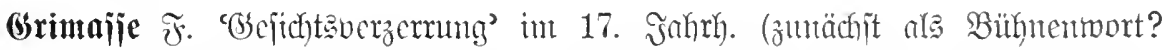

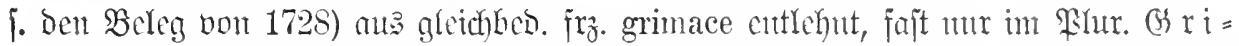

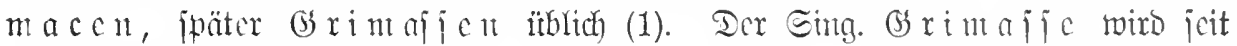

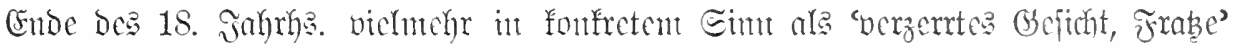
gebraudit (2).

Bclege: 1. Ihomajute 1688 Mronat: (XIII 45̆) Grimassen von Erstaunen und geipräche I 217 was der arme geplagte Herr Ekel. Goethe 1774 merther (XIX 34) die David hierbey allenthalben mit Maul und wunderbaren Grinassen, in die ich mehrere Nasen, Händen und Füssen für Abendtheuer- Franenzimmer ausbrechen sah.

liche grimacen machte - 537 in Beschreibung derer grimacen, die Aristoteles bey Eröffnung und Lesung dieses Brieffes machte. Ientiel 1689 Unterrebungen $\subseteq .581$ der eine blieb mit dem Fuß an der Erden hafften, darüber er eben so wunderliche Grimacen machte, als Aristoteles, da er mit dem Studier-Rocke hengen blieb. Mentife 1710 Sicbichte ङ. 181 wenn ein 'Lantz-MLister seinem Scholaren die Unarth, die er an ihm warnimmt durch allerhand grimacen recht natürlich vorstellen kan.

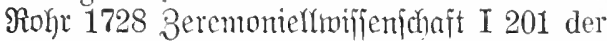
ihnen ihr affectirtes Comoediantenhafftes Wesen und übrigen Grimacen abgewöhnte. నscifjbad) 1732 fur $\Subset .500$ solche grimacen machen, als bey der fallenden Sucht sich ereignen. Fleipder 1734 Seerr t. Sybio III 198 weil $\mathrm{er}$ ] gegen das Fräulein Helena so viel Grimacen machte. GSellert 1747 Betidineiter (III 181) sie machte über diesen Verlust unerträgliche Grimassen. Ramler 1754 an Głleim II 162. Reffint 1772 Emilia (III 382) die Verziehung [Des Mantoes] muB nicht bis zur Grimasse gehen. Sisteland 1774 Mbocriten

2. Sabater 1776 Bhyintognom. Fragmente II 183 Bifl 2] Ist blob Grimasse. Syerme? 1790 F⿻̆丶 Ërtern V 220 es kamn sern, daß ich der Alten eine Grimasse cemacht habe. Mielano 1798 Micrfur 1267 Wilibald macht eine Grimasse. 5einte 1855 Miemniren (VII 497) Der Jupp schnitt eine säuerliche Grimasse.

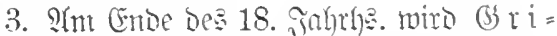

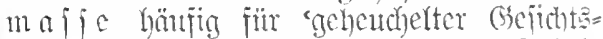

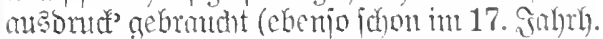
irs. grimace): vgl. Leijing 1767 Iramaturgie (IX 198) Reitz am unrechten Orte ist Affektation und Grimasse. Sa ßadhe 1771 Frel. ๖. Etcruthcim ङ.110 keine lächerliche Grimasse, dummer Junge, daß du mich über diesp Kileinigkeit froh siehst, da ich es sonst kaum über den ganzen Sieg war. Sisicland 1783 Clelia (XI 218) der Thor vermengte stets Gefühle mit Grimassen. Miülfer 1789 Cimmerich VI 186 ein frivoler Vorwand zum Kriege oder sonst eine Grimasse - 1789 cbo. VIII 373 Fy, ma soeur, wozu die Grimasse.

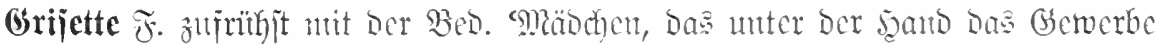

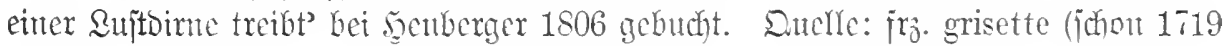




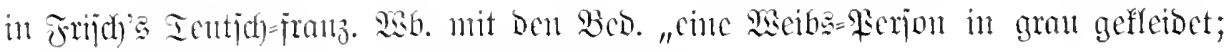

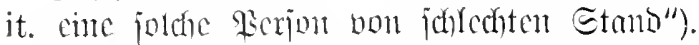

Bigl. Mercier 1788 (bemäloce v. Farie I 322 eine leichte Grisette) einen fidelen Tag zu Es ist mbegreiflieh, wo diese Waare [9!nnta= machen. 1835 CEuroma I 259 In der schönen nndhe] linksommt, die sieh in den nnzähligen Jahreszeit geht de Kock nach Romainville, Ta:chen der Grisetten verliert; dem jedes neben jenem von den Grisetten so geliebten

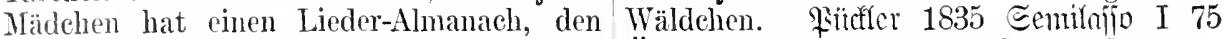
sie zum nenen Jahre bekommt. Erfmufe Ĺberdies giebt es in dieser Gegend [Eger -

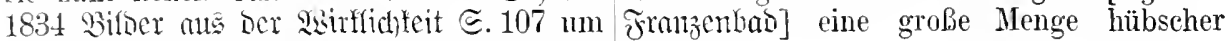
sich und scinem Schätzchen (wahrscheinlich Grisetten.

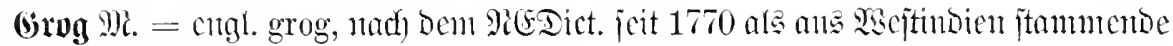

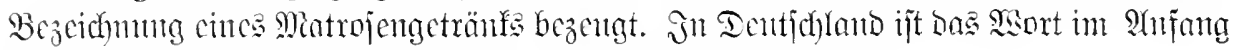

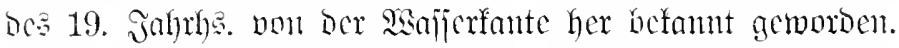

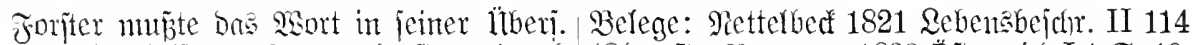

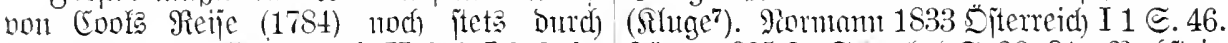

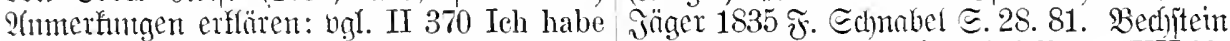

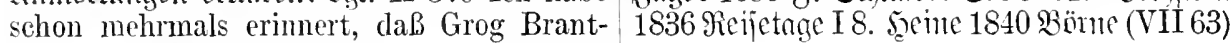
wein mit Wasser vermiseht ist. Ieutj(f)e

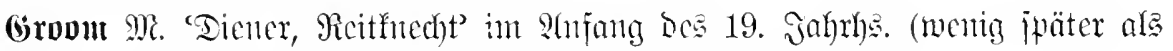

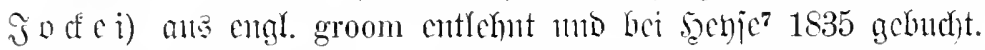

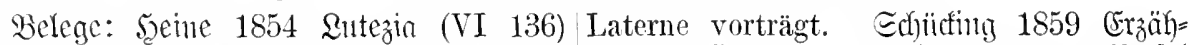
der fashionablste aller Sonderlinge, Diogenes hungen II $145-1865$ Frment u. Rätfel zn Pferde, dem ein eleganter Groom die II 52.

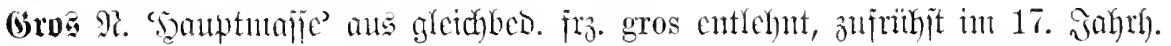
im militärijchen Bereich (1), allgemeiner im 18. Snlyrh. vertoentoet (2). Ilnabyängig

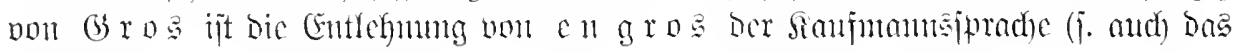
flg. 的ort).

Belege: 1. Etieler 1695 Beitungấluît Begriff: Gros der Tation. Mülter 1787

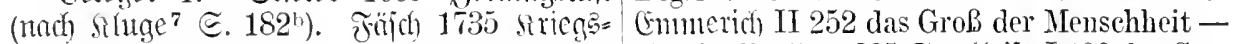
lexifun $气 .375^{\text {? }}$.

2. Bmzenbor 1747 Santurerte Refferionen der Gesellschaft - II 117 das Gros der S. 6 das Gros der Menschen. 1783 Edjüzers Menschen - 1840 Bifnerian II 118 mit Etnatsnuzeigen III 258 man bemerke den dem Gros der Effekten.

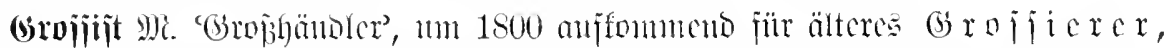

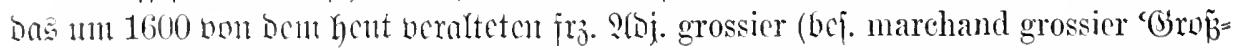

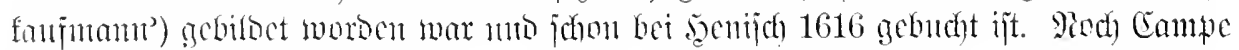

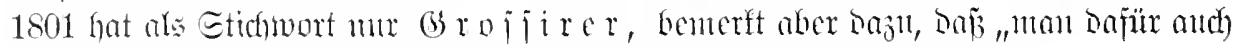

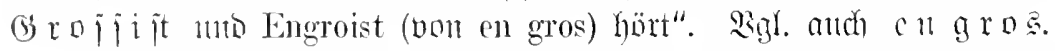

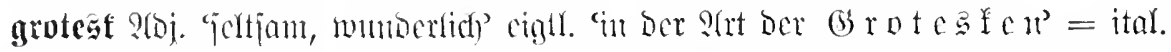

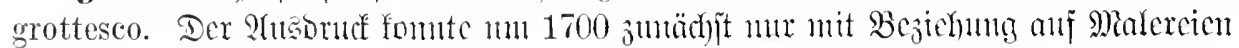

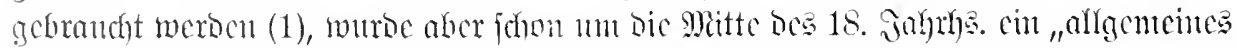

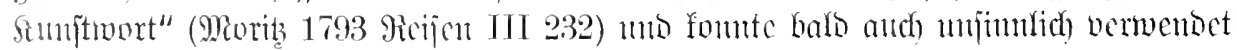
incriocu (2).

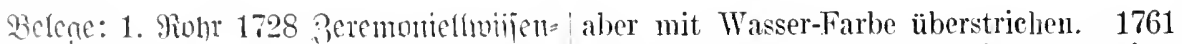
ichnft I 524 die Winde wurden nit Täfel- Qiteratnibrieje IX 36 mit einer grotesken

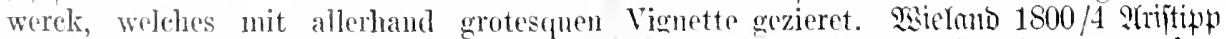
Züraen, theils mit Oehl-Farbe, meistentheil: (XXIII 114) Jupiter in einer grotesken 
Gestalt, woran nichts als der Kopf sein eigen, schreibt, indem die anfmerksamen Künstler alles übrige aus den versehiedenen Thieren in Rom in manchen unterirdischen Höhlen seltsam genug zusammengesetzt ist.

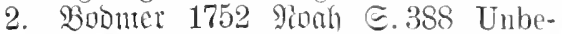
hauener Narmor erhob groteske Gestalten. Dicic Etelle wiro noch bemiftambet bout Edjönaich (1754 2ijthetif E. 167), Der bas

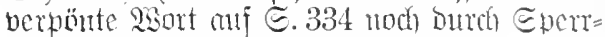
brute heroorlyebt: Doch locket uns das Ungeheure und die Seheußlichkeit der g r otesken Stüeke immer weiter. 13citer Belege: Badjatiä 1756 Sageszciton (II 140) ein nngewohntes groteskeres Ansehen giebt ihm [sent Torfe] der Mond. Serber 1767 Deutiche Sitcratur (I 490) Alle Gedanken, die ins Groteske fallen, allzuhäufige $\mathrm{O}$ mel Ach und Weh. Mitiller 1778 Fanfis Seben ๔.21 das groteskste Perspectiv, das je die Hölle von unten hinauf gesehen. פisenter 1787 Gebirgenten kegelförmige oder sonst grotesk ansgezackte Berge. 2hrchenhof 1787 Starlien I 164 wegen der Menke grotesker Larven - II 72 woraus ein groteskes Ganze entstehen wird. Morid 1790 2tuton Reifer Є. 429 seine ungehenren und grotesquen Vorstellungen.

Grotesfe $\widetilde{F}=$ ital. grottesca: "פ⿹er = zienutgen von feltiamen Einfällen meld)e au Raubwerf, Blumen, Früdten, Figuten,

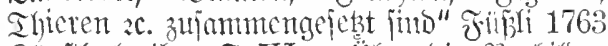
fitmitlerterifon $E$. XI ${ }^{\mathrm{a}}$. Ither die Borbilder bicjer Minlereien ugl. Boethes "2tbleitung bes

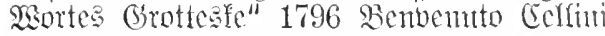
$(43,85)$ Solche Arbeiten werden von den Unkundigen Grottesken genannt; welche dergleichen Zierrathen fanden; weil diese Orte ehemals als Zimmer, Stuben, Studiensäle und sonst gebrancht wurden, min aber, da durch den Ruin so großer Gehäude jene Theile in die Tiefe gekommen sind, gleichsam Höhlen zn sein scheinen, welche in Rom Grotten genannt werlen; daher denn wie gesagt, der Name Grottesken sich ableitet. In Intichlono murbe bie Brotestemmaterei ber italientifder Fenaifiance erit am Ende bes 17. Juthrts. Gefomnt; bgt. Icdfer 1711 Fitritt. Sianneifter I $\mathfrak{B}=$ Der Auffrib ler einen Seite enthält in lanter Grotesqven das Leben des berïhmten Trojanischen Ilelden Eneae. Iart nod) (Grotestenmarer Edjön= (aich) 1754 ifithetif $\Xi .87$.

grote (sottided geriditeter Etreitjorift, roartefin oner Bertherbigung bes (Brotesfe=Somijhen" (1761), argefüh)t 3. 3. 1763 Qiferaturbricfe XII 331, ¿efint 1767 Imomaturgic (IX 258).

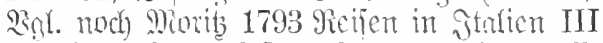
232 Grotesk wurde] nachher zn einem allgemeinen Kunstwort, das anch zu einer besonderen Unterscheidung des komischen dienen mubte, das man nun da, wo es ins Possirliche und Phantastische fällt, das Grotesk-IKomische nemt.

grote ment IV 338 Ich will hier mein Buch nicht mit Kunferstichen der Carcer ron allen Universitäten schmücken, es sollte sonst wol ein grotesque-schöner Anblick seyn.

Benemung sich von den Neneren her-

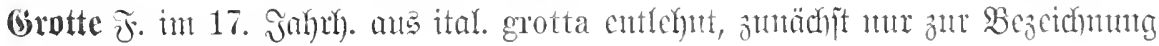
fituitlich angelegter sobhlen.

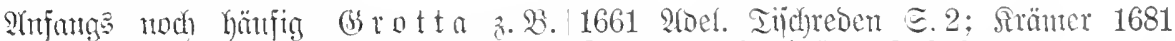

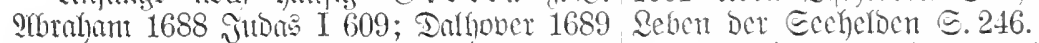

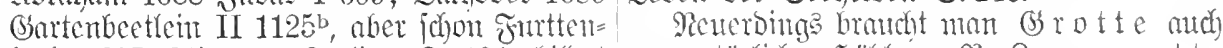

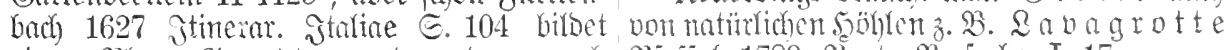

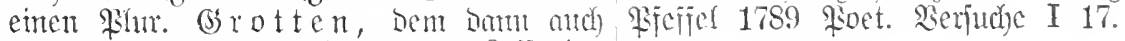
Der Eing. Bs to the folgt z. B. Sajicuints

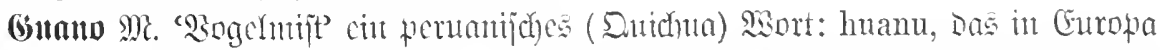

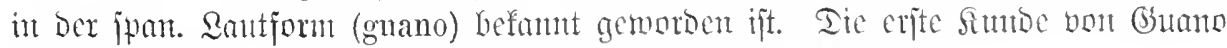
gab Garcilaso de la Tego 1604 in jenten Comentarios reales.

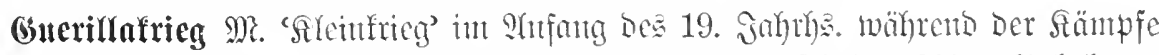

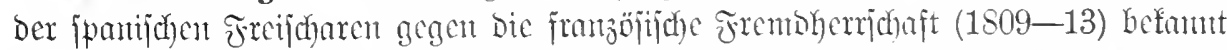
getworbcu (1), hätfig aud in ber Edretbung (3) uerillastieg (2). Tarin ijt (5) ueriylas= ber Plutal von ipan. guerila 'Fretjoüryer'.

Belege: 1. Börne 1823 Edfmollen D. VI xur. Seine 1840 Böme (VII 42). Rüufler Wciber (I 131). Ratbe 1837 Retjenoberlen 1841 3irierjant III 8.

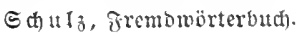




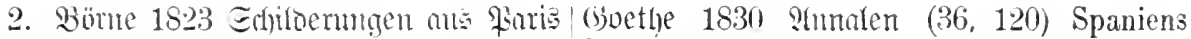
(II 98). テren 1814 Bilber E.301. Edherr für einen Feldherm so chicanoser, den 1862 silitidher I 84. Guerillas so günstiger Grund und Boden.

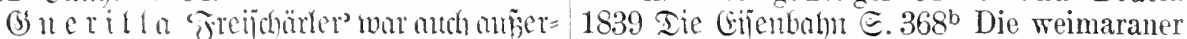
halb ber Bminmenjetum bei ms befomnt Literaturkräfte sind Guerillas. Die Brund=

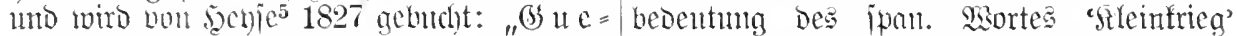

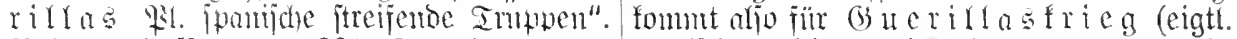

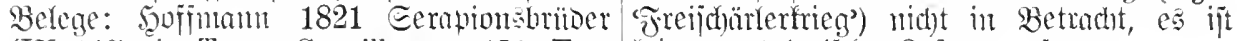
(IX 146) ein Trupp Guerillas - (150) Em- teine tautologijde Bujammenjetiung. pecinado, das berühmte Haupt der Guerillas.

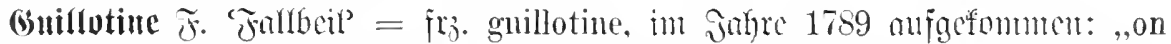
appelle le coupe-tête proposé par M. Guillotin 'guillotine's (iu cincu Renolutions=

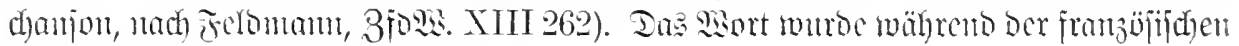
Revolution raid) hiberalf befinmt.

Belene: Qichtenberg 1792 Sqhorismen|(VI 167) Ich ward verhaftet, der G. durch IV 172 Die Maschine, womit man in Frank- ein Wunder entrissen.

reich jetzt die Köpfe abschlägt, heißt G. guillotinieren Btw. nady jrł. guillotiner

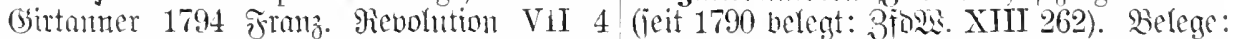
Einführung der G. in Frankreich. Goethe Brentuno 1800 Grijtan Kaja E. 83 Ach nein, 1795 lluterhaltungen (XVIII 108) er hoffe, er ward guillotinirt. Eemme 1803 Epazier= daß die $\mathrm{G}$. anch in Dentschland eine ge- gamiz (III 129) der General hatte ehemals segnete Ernte finden werde. Görres 1800 in Domingo kommandirt, wäre fast bei seiner Eenoung n. Forts (I 65) die G. mochte noch Rückkehr in Brest guillotinirt worden. so gefräBig aufräumen. Sïlond 1802 Crbteil

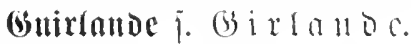

(buitaric $\bar{j}$. 0 it a r r

(bufajuf 2. '

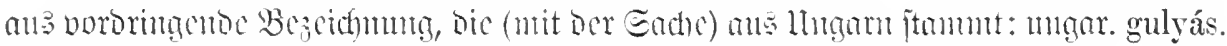

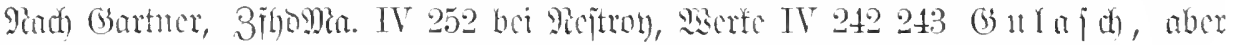

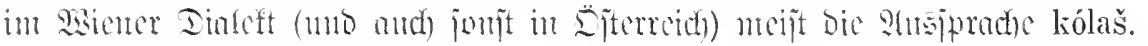

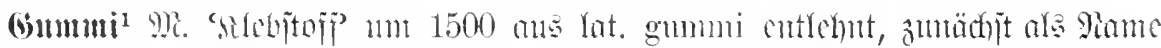

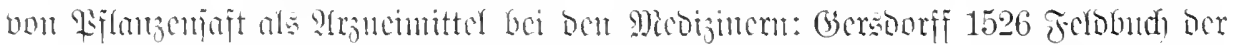

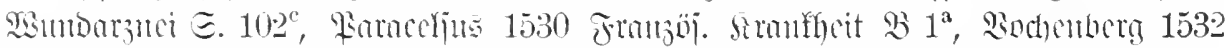

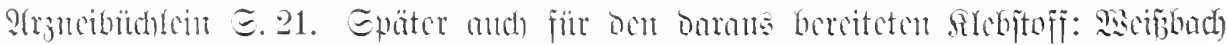
1732 stur $\Xi .360$ cinem lalb dürren leim oder gummi ähnlich. Cramer 1794 Gonice fitrcicle I 67 mit einer Art Gummi oder Leimwasser.

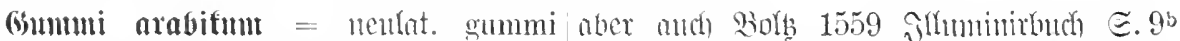
arabieum 'mabiicher (bumni', Bezeid)unng Gummi Arabicum ist ein frembdes Hartze.

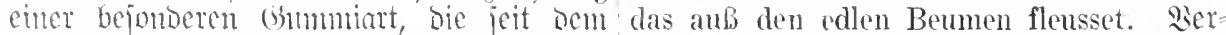

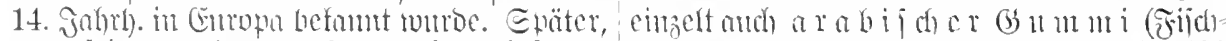

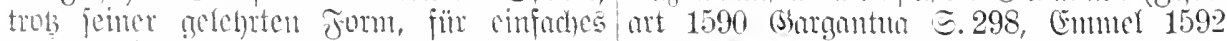

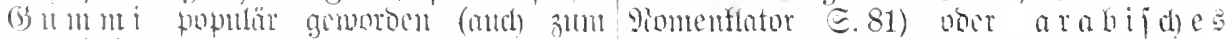

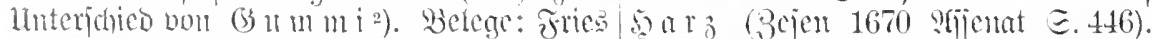

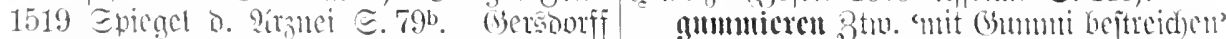

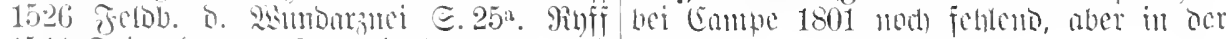

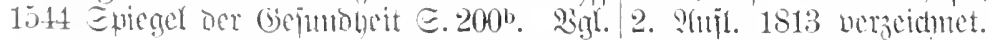

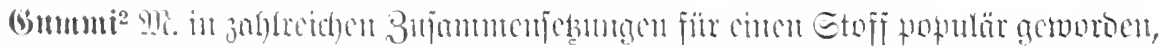

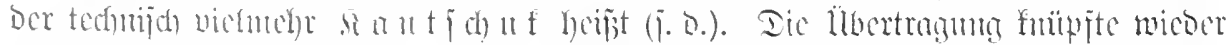

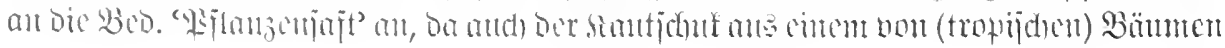




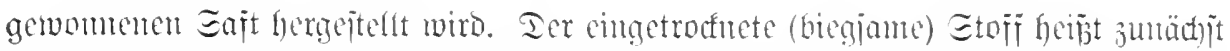

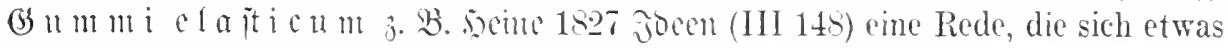
in die Länge zog, wie Gummi elastikum.

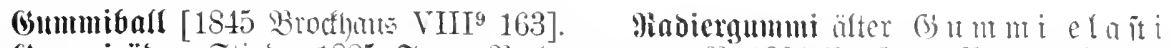

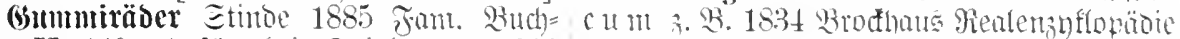
holz II 140: Dafür bei Epiehagen 1866 IV 1020 Des Gummi elasticum bedient man Reih u. Ǵlied II 128 gummiüberzogene Rüder. sich gewöhnlich zum Verwischen der Blei-

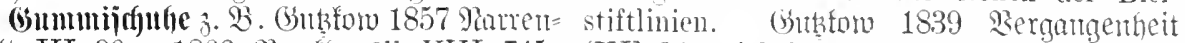
welt III 90. 1866 Brodfousil VIII 745: (XIl 94) mich brancht er als Gummi elasti1830 machte Thomas Hancock die ersten kmm, seine Flecken zu reinigen. Infür vieder

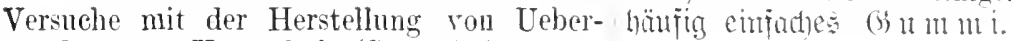

schuhen aus Kautschnk (Gummischuhe).

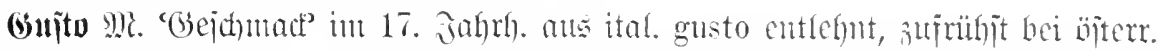

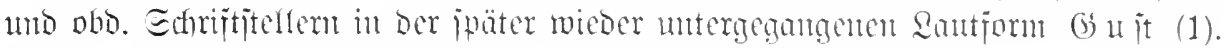

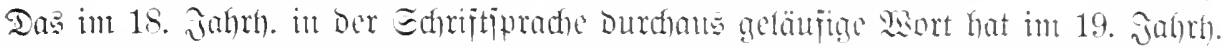

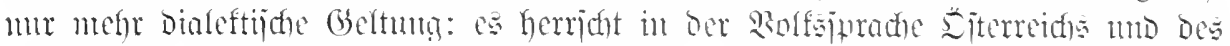

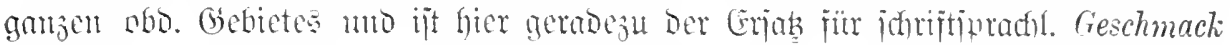

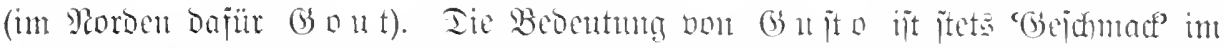

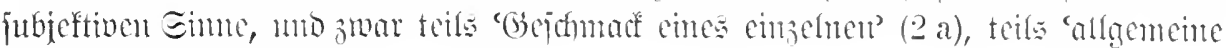
(3)

Belege: 1. Bej. in (b) un un $u$ o $2 u$ jt.

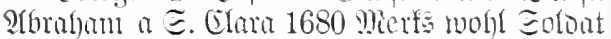
(Etrigl I 164) mit großem Lust und Gust, mit unbeweglicher Beständigkeit, mit höchsten Begierden wollte er leiden - 1686

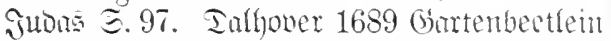
II $636^{a}$ cinige, so anch den Kirchen-Bann verachten, jhren Gust vund Lust nur an den schmotzigen Häfen rund stinckendem Knoblach irdischer Gelüsten suchen rnd

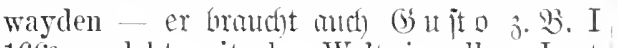
$166^{3}$ er lebt mit der Welt in allem Lust vind Gusto.

2a. Mforufan 1688 jubus I 512 im Nahmen Clristi dasselbige mit Gustu[!]
verzehrt. Callentod 1714 wimatia $\cong .67$ das wäre nach meinem gusto, es stehet auch besser - Ruer $\Xi .35$ daß ich geröstet weiß Brod in Chockolada einduncke, das ist mein gusto. Bohn 1728 Beremoniellmijentichait I 434 Man mub auch wegen des unterschiedenen Gousto der Lente bey einer Gasterey die Speisen in einer kleinen Anzahl aufsetzen.

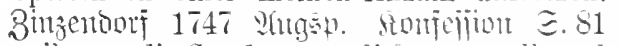
weil uns die Sünde gemiitlien, naturell und unserem Gusto gemäB. (joethe $1769^{*}$ Leips.

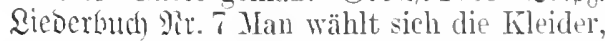
nach Gusto den Schneider. Ieuricut 1835 Gumit (I 198) das ist nicht mein Gusto.

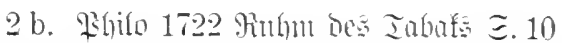
einer, der sich nach dem heutigen Gousto richtet. Rsiripni $17+3$ Reimichmedefumit ङ. 201 je mehr wird es nach dem allgemeinen gusto seyn - E.203 Demu solches ist dem gusto unsers itzigen seculi entgegen. Pantle: 1757 an Gítem (II 279) mach Italienischem Gusto. soener 1765 Ientide Ritterntur (I 305) auch nicht Virtuosen im Wielandischen hohen Gusto. Goctbe 1770 Bricje I 226 ich kriege 10 Zimmer alle schön und wohl meublirt mach Frankfurter Gusto. Firau Gat Goethe 1782 sirteje I 115 Durchaus nach dem neusten gousto gestickt.

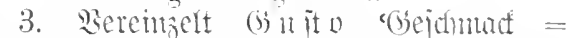

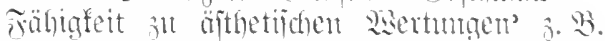
Eallentbad 1714 Edtiple $\Xi .37 \mathrm{Es}$ mub wohl ein verdorbener gusto seyn, der sich in solche Waar wiirde verlieben. Ectimabe 17to Iuntemiäb ङ.31 sintemaln sie ein jedem Leser, der für ein Heller Gusto habn thnet, besser gefallen werdn. Gocthe 1768 sirieje I 165 Das Halstuch ist mit dem größten Gusto fertin. Sit Diejent Eimte jomt nur

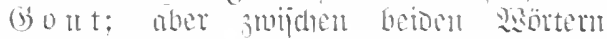

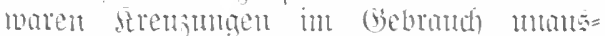

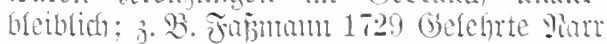
E. 47 Erfindungen und Auszierungen de bon gusto. Bigl. (jo 041.

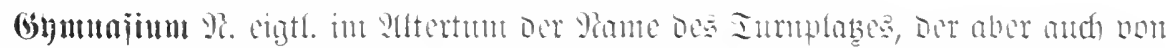

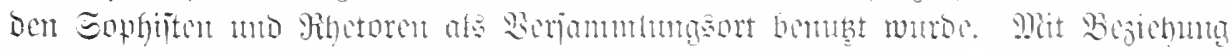

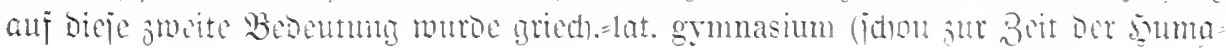


nij̣ten? vgl. If Ral. aud $\Omega$ n $j$ c $11 \mathrm{~m}$.

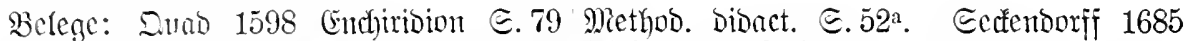
Vmb das Jahr Christi 1346 hat Pfaltzgraff Chriftenftant I 594.

Rupertns alda ein herlich Gymnasium auffgerichtet. Mienfiart 1636 Dou Den Scodifinulen ๕. 5 die crbarn Sitten auff hohen Schulen vnd Gymnasien. Moj(herojd 1644 \$ryilander II 128. Fleming 1646 (jedichtc I 80 . Prütorits 1666 intlyropodemus I 2S8. Becher 1668

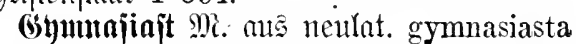

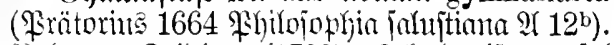
Belege: Bcibler $(1700)$ Edulmeijterteufel

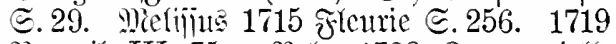
Recucil III 75. Rohi 1728 Berentoniell= wijicnijart I 384 .

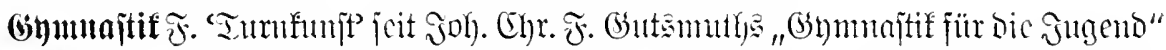

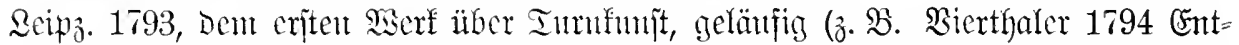

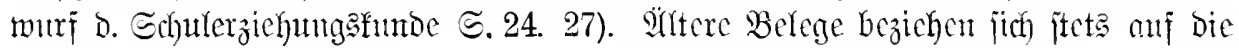

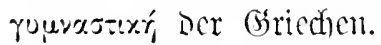

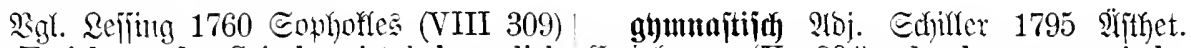
Die Erziehung der Griechen ist bekanntlich Ergiehung (X 294) durch gymmastische Grammatik, JIusik, Gymnastik. 5̧cinje 1794 Übungen bilden sich zwar athletische Körper

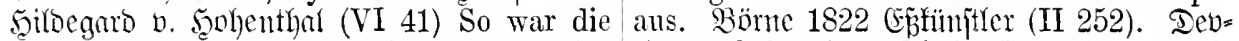
Erziehung der Griechen ein immerwährendes rient 1840 Ibeaterjdule (IV 352). Sisbs Gefühl der Harmonie: Gymnastik für den 1847 Budh Der Sinoheit @. 411.

Körper, Jusik für Herz und Geist.

$\mathfrak{5}$.

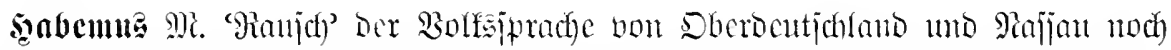

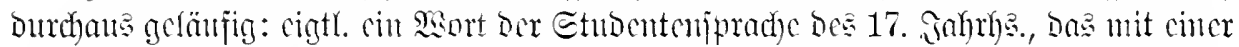

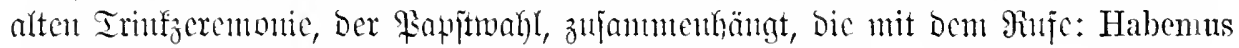

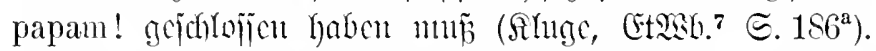

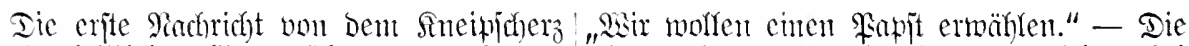

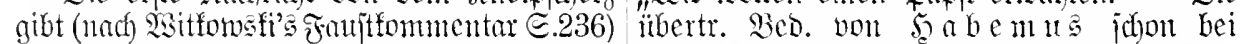

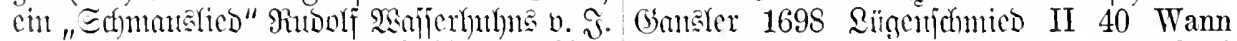
1644: "Es jiţen wir, an Bahl nun Bier, mir ein Pommerischer Trunck nit den Gaul

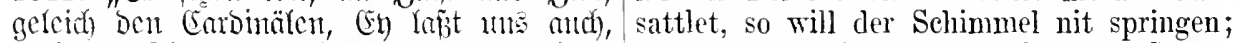
nad) Römidhem Brand zrum bayten cinen ein einziger Habemus thut alles; der Sporn,

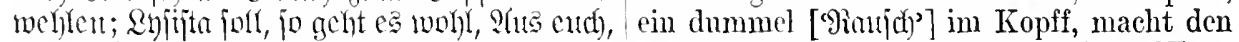
o Jungfern, jehen, sb Pibitentun gemutgian Rappen erst recht springen, mit einem Wort,

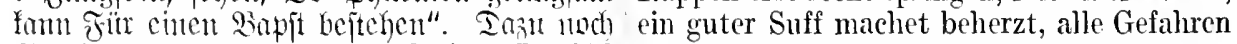
(bocthes Fanft (Stuerbad) Seffer) I 2098 zu veraelten.

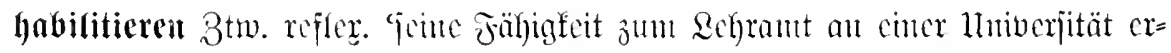

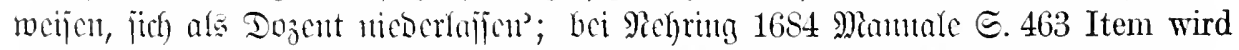
gesagt, wenn einer Licentiat oder Doctorand wird, er habilitire sich [Geibe 然üroen

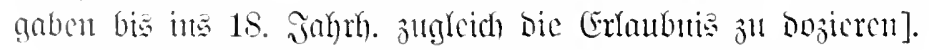

3clege: Thïnntel 1791 9icije (I 150) wie $\mid$ versität habilitirte sich vor Jahren ein ein Magister, der sich seit kurzem zum Weg- Privatdozent.

weiser der wahren Glückseligkeit, wie man Sinumblorge ift bus mIat. habilitare 'ges=

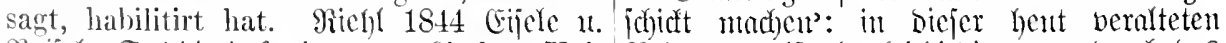

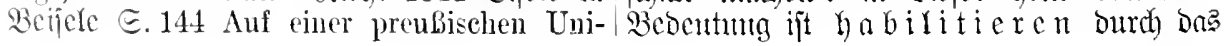




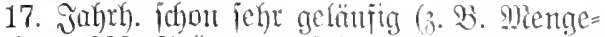
ring 1633 Coldatenteufel હ. 199; Grumbur 1663 5ouribilicr. E. 4; Pidfelfüring 1685 Sleiberaffe S. 44; Inumujus 1691 Bermuty =

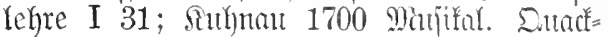

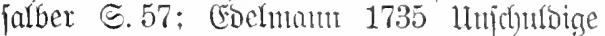
Wabrheiten III 190), nber jeit Dem Ende
Des 17. Jaljufis. erlangt bic ipeziellere afabe= mifhe Sertoentoung (eigtl. ciid) zum Sehramt gejchict nachen, zeigen') mehr unto mehr das libergewidht. Rigl. aud Roljr 1718 Etant马= fnugheit $\Subset .298$ sich zu dem Predigt-Amt habilitiren.

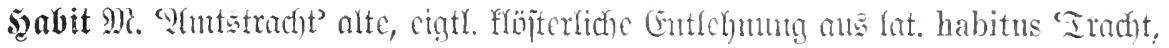

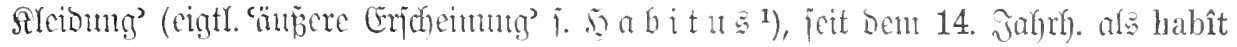
(1u1to abît) bezertgt.

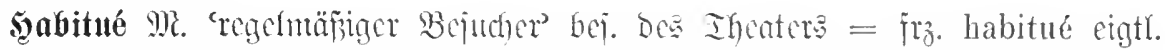
'getwohnter'. Beleg: Serwald 1835 Theatertente $ミ 126$ es hat kein Publikum von eigentlichen habitués, wie das Wiener Burgtheater.

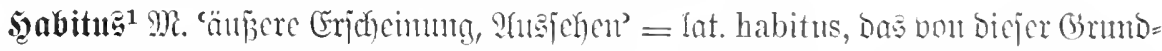

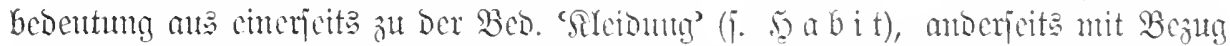

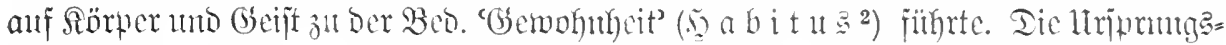

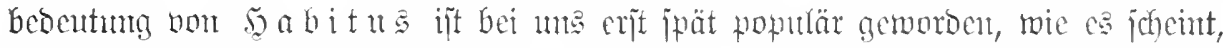
von ber medizutijchen Terminologic aus, fïrr bic jobn 1784 bie Snomatologia medica II 969 bucht, ,Habitus scilic. corporis 2 cibesbcichaffentheit".

Belege: Echilfer 1797 Brieje V 229 wie wie sie sagen, ein habitum darausz gemacht. ich ans seinem ganzen $\mathrm{H}$. schließe, mu er Bïtner 1574 Dinlectica $26^{2}$ Vnd mercke, recht in der wilden Einsamkeit und vielleicht solch exercitium oder vbunge ist nicht der in einer niedern Condition Ieben. Brum 1806 Habitus, sondern das jm der Mensch durch Epijoben I 211 deutsche Gelehrte, deren vbung, lenfftig, gemein vnd genge machet, ganzen H. er anch hat - II 144 der ganze, dasselbig bekömmet den Tamen Habitus $H$. des an uns vorüberziehenden Clerus. (D $6^{\text {b }}$ so bekömmet er einen Habitum, das

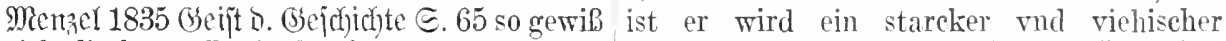
sich die bösen Begierden in den Mienen und Sänffer. Grefiffinger 1675 fromplimentier= im ganzen $H$. des Menschen ansdrücken. biuchlein $€ .9$ es beflejssigen sich anch etliche

sabitua2 $\mathfrak{M}$. '(Stetwohnheit' ein von 16. gar hieranf, bekommen darinn gleich einen

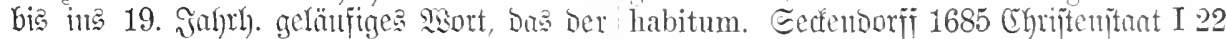
jdjolnjtiphen Terminologie entitammt (habitus in eine Gewohnheit oder habitum der Sünclen

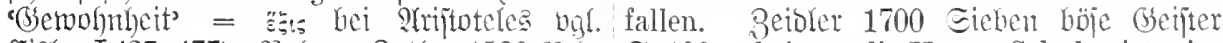
(Fialer I 437. 477). Belege: Rnther 1520 ‥ D. E. 100 so kriegen die Herren Schulmeister im guten sierfen (VI 206) Ja sie haben den Sauffen einen guten habitum.

glauben nit ein werck bleiben lassen, sundern

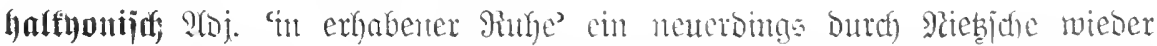

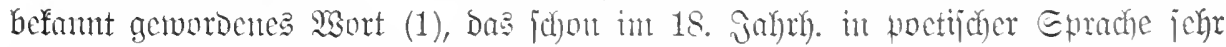

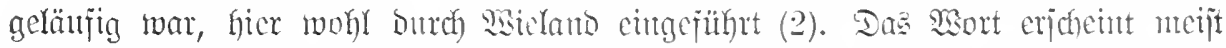

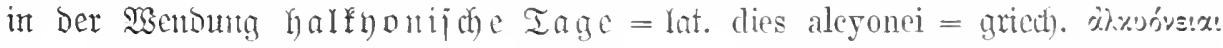

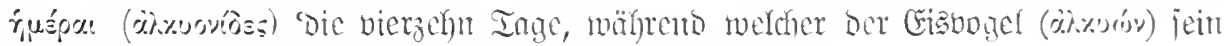
Nejt baut, eine Bcit, in ber Das Macer ohne Etürme ift'.

Belege: 1. Nitesidue 1886 jenjeit vou Biat u. Böfe こ. 168 hallikonische Selbstgenügsamkeit - $\Xi 292$ halkyonischer Meister - bgl. aud 18s8 Fall sisugiter ङ. 36 wir Halkyonier (Bfons. TII 46). Reute Belege nodh bei mener, Schlagmorte E. 64: Sorjt, 8fors. X 35.
2. ․․ichor 1759 (5nus $(26,315)$ wenn mit wehendem Fittig Friedsame Zephyrn das Meer in den haleronischen Tagen Sanft an den kräuselnden Wellen hin schwebend in schlummernder Stille Wiegen - 1791 Peregrime Rirotens (XVI 119) die halcronische Stille, welche in der ersten Hälfte 
des Tages mein Gemïth, wie ein heitrer ben Gelehrten idhn irtiber befoumt: Taf. wolkenloser Himmel die Erde unter ihm, Serrenjamio 1622 Coronologia jacra $\Subset .11$ umgeben hatte - 1796 Ignthooünnn (XVIII Gott gebe seinem betrübten evangelischen $322)$ die Haleyonisehen Tage - 1798 Ge- Kirchlein die erwünschte Halcyonia oder imräd) (32, 172) ein ganzes Jahrhundert Eyssvögelins Tag, bchüt vor Verfolgung

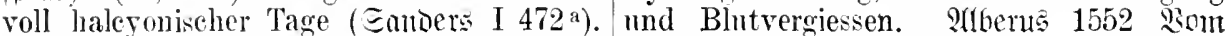

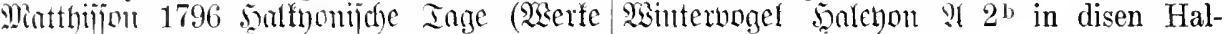
II 74). Deuted 1798 Geimmbrumen $\subseteq$. 27. cyoniis (denn also wirt diese zeit vom suebel 1798 Rroper (3foפs. II 70, VII 45). Aleyon genennet) - ? 3b Daher wird die

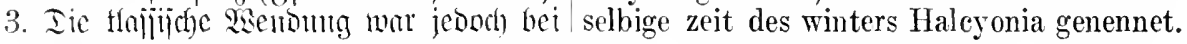

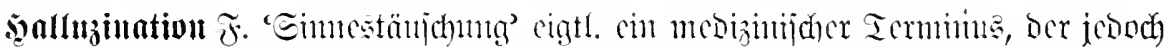

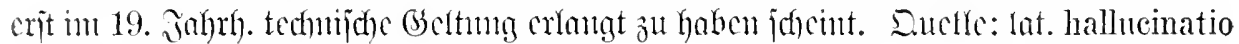
fïir alucinatio 'Fajelci, Iräumcrei'.

Belege: Görres 1842 Minftif IV 1410 Bis- in H.-en mancherlei Art. Crrfemmener 1854 weilen werfen diese Nachtkrankheiten sich Gehinntrophje @. 24 die H.-en des Gehörs. in die geistigen Gebiete und äußern sich dort

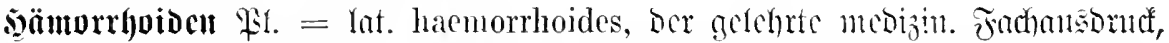
Der Dic volfstümlichen Pamen goldene Ader (Jijacr III 739), Zacken (bcj. nob.

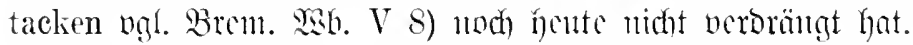

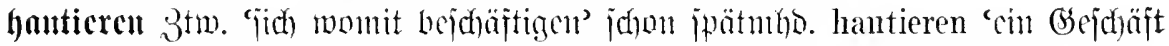

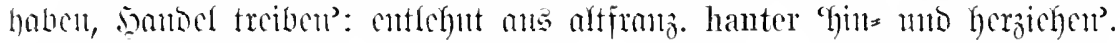

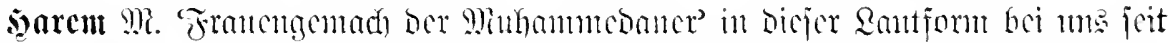

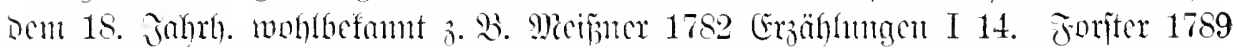

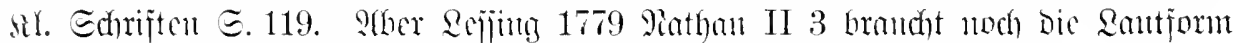

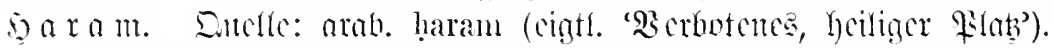

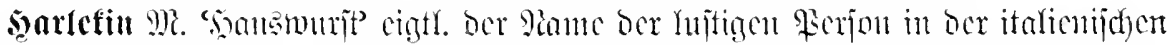

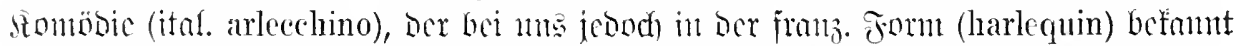

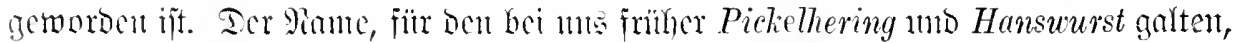

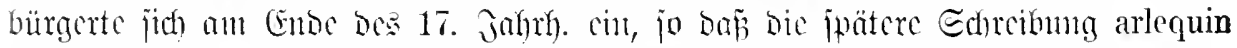

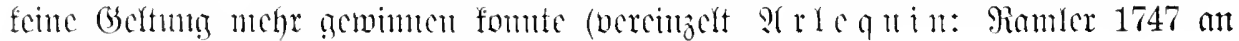

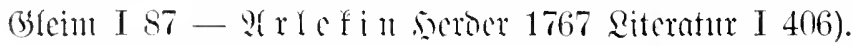

Belene: \$loidherojch 1642 \&hilamer I $320 \mid \Xi .292$ alle Harleqvins oder Pickelheringe in Ich dachte deßwegen, es möchte vielleieht Italien. Gottiched 1728 bei Reidhel I 536 Harlequin oder Hans Wurst seyn, oder einer Ich rede also hier von einem histigen Harlekin, dergleichen Gauckel-Narren, der einNummen- nicht aber voin cinem nnflätigen Hans Wurst.

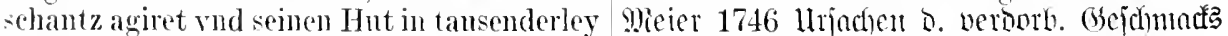

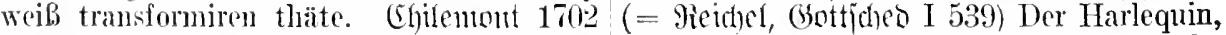
Striegintat I 143 also dab ein Frantzos in der Zotenreisser, der Possenreisser herrscht Gesellschafft eines autorisirten Spaniers in noch anf dem Theater. Mniojer 1761 sorfefin

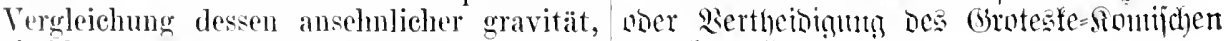
ein blosser Harlequin oder Conödiant zu seyn ( $(2 S e r f e$ VIII 70).

scheinet. Rerdemmerser 1712 9httiquatis

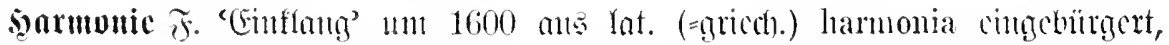

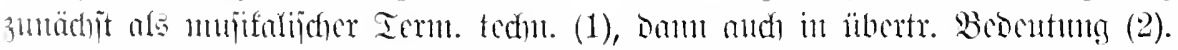

Beleae: 1. [Shumenijer 1583 Snunníticun die Harmony der Consonantiarmu. Nienge=

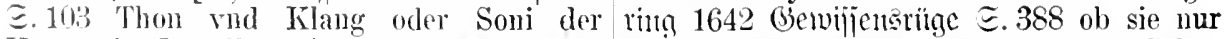
Harmoniae.] Frätmits 1619 Emutagnu anff den Tact, resonantz vul harmoni Gehör muijicum II 47 die Liehligkeit der Harmony - vnel Achtung gegeben. Prötorius 1665 


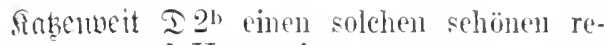
sonantz und Harmonie.

2. [Guminomitu 1610 Gretsel こ. 169 das Menschliche Gremüht müsse ein Harmoniam, gleichsamb ein reeht und lieblich zusammen stimmende Musicam inn sich haben.] Eectemontif 1665 Süritentitunt II 83 wenn gute Harmonie und gütliches Tractament erhalten wird - aber II 76 die harmonia des Reichs - 1685 Chriitemitant II 401 $\mathrm{Ob}$ er mit andern seinen Collegen in fremullicher harmonie stehe. inblonsfi 1699 m Qeibniz (II 128) die Harmonje der Gemüther.

harmonicren 3tw. 'iibereintimmen' in 17. Gabrh. grhiloet. Belege: Siohr 1729 3eremnuterfuijemidhoit II 261 Die äusserlichen Ehren Bezeichmungen solten mit dem Stande und der Tugend hamoniren. EDel= mami 1740 Moies I t5 - 1752 Eelbjt= biogranhie @. 210. harmuniidy 9(bi. mad lot. harmonicus

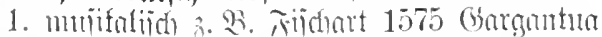
E.234 w hesal die grose Glocken desselben Thurns. rnd liesse sie car h. vund wolstimmig zusammen läuten.

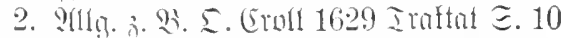
Ind wolte Gott, os kïme deb Carriehters als eins der Gewälds tberaub erfahmen Mannb lang wwïnschtes Buch von den Signatum der Dinge, in welchem er die Irrolische Sterne der Kräuter mit den Sternen des Firmanents wunderbaulich rnd Harmonischer Weise rercleicht, dermal eins an Tag. Reboumalot 1681 Ienfels 2i jt V 38 die harmonische Übereinstimmung.

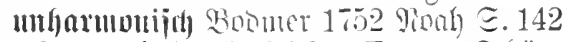
zu unharmonischen häßlichen Tönen. Echön= nich 1754 ?(eithetif $\Xi .224$ Kilingt das nicht unliarmonisch.

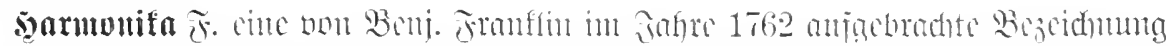

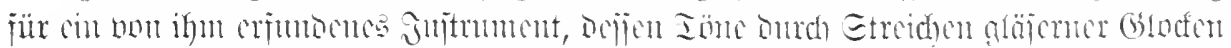

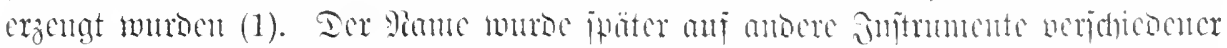

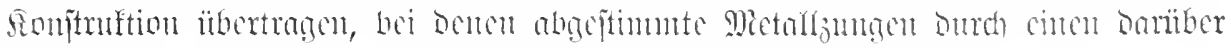

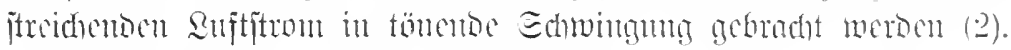

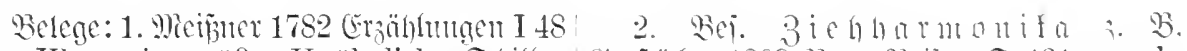

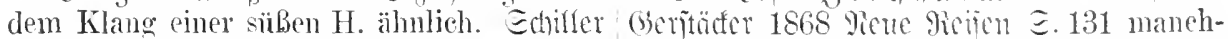
1785 Sirtefe I 264 auf der H., die Wirknng mal hat e'mer der schwarzen Fenerlente eine dieses Instruments kann in gewissen Situa- ,Ziehharmonika“, deren Klappen natürlich tionen mächtig werden. Bärflu 1790 seitr. in der fenchten Flußluft verrostet sind. ?(uch

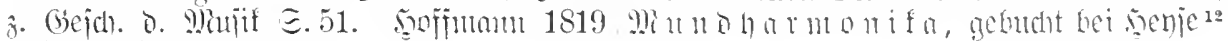
Brief Strister (XV 171). 1859 .

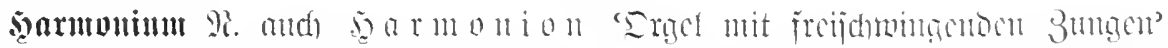

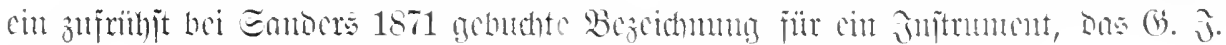
Grenté im Jahr 1802 erjumben, aber Orgne expressif gicnamut hatte.

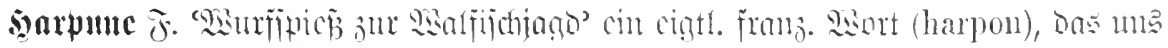

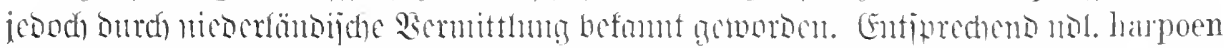

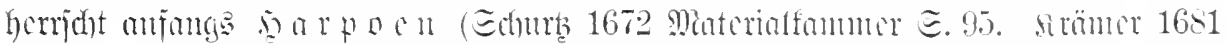

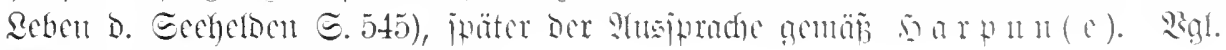

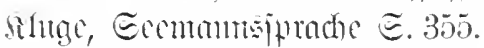

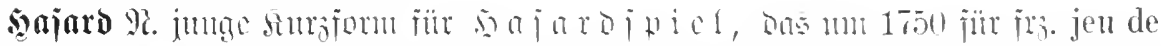

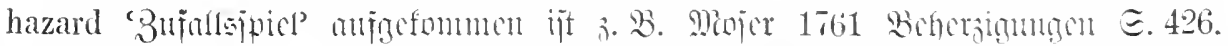

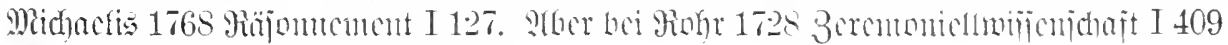
Man spiele keine jenx de hazard.

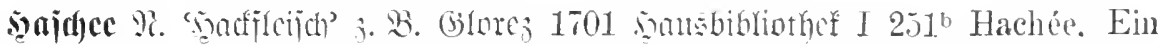
gehackte Füll von Fleisch ode: Fische (abor bri Edfellhommer 1692 södhin ङ. 310

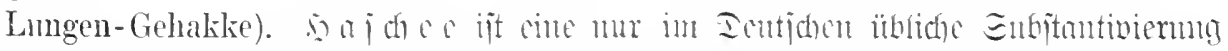

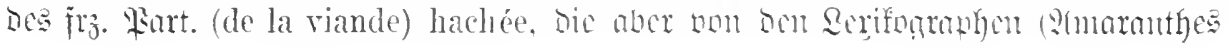


1715, Campe 1801, nenberger 1806 mij.) Burchweg nidyt jugegeben mb vielmehr

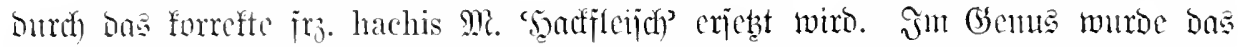

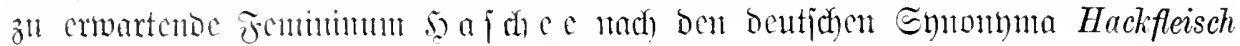
mo Gehacktes jum Reutrum gentadit.

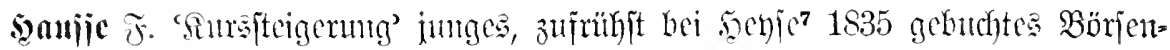

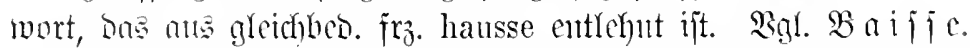

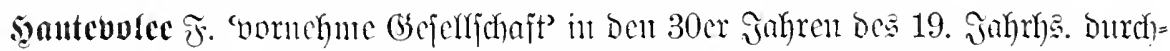

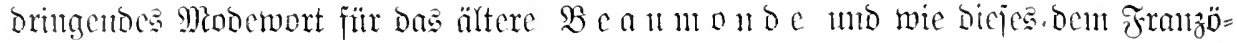

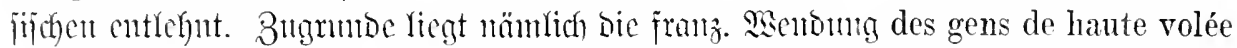

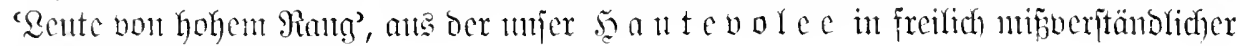
趾cije ijolicert worben ijt.

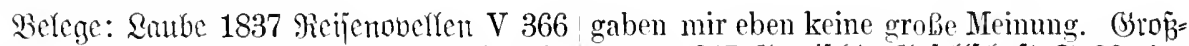

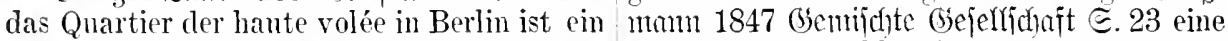
gar nieht großes Quadrat in der Friedrichs- glänzende Assemblee in einem der ersten stadt. 1841 Gurona I 41 b eine dichte Pha- Häuser der haute volée. Golţ 1847 Buh lanx von Damen der haute volée. Frey ber fimbheit $\Xi .361$ in eine große Gesellsehaft 1844 Bilder a. Wielt $u$. Beit $\Subset .78$ schlechte von lanter vornehmen Damen, und so zu Weiber waren als ,hante volée" einge- sagen in die hante volée der Provinz. B̉ig:

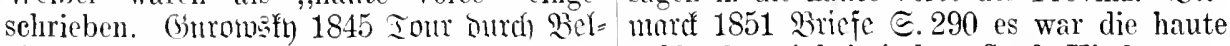
gien Є.43 Die Abschnitzel der Brüsseler volée der einheimischen Stadt-Kinder. haute volée, welche ich hier zu sehen bekam,

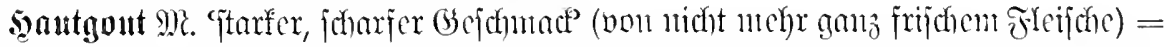
fro. haut goût, als Terminus ber franz. Sühenfunft fohon frith bei un befount (1), aber erit im 18. Jahnh. cingebürgert (2 a) und bam and hänfig übertr. gebrandht (2 b).

Belege: 1. 1684 Icutfichlanto ïber Frant= küche vereinbart, den kommenden entgegen

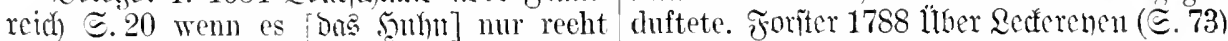
Frantzösisch gebraten ist und cinen haut Durch die Beymischung des süßen, sauren goust hat. Sfriiger 1750 Iiüt $\Xi .136$ einen oder würzhaften erhält sogar in manchen so starken Geruch und Geschmack, oder, Fällen das Widerliche cinen ganz erträglichen, wie es die Franzosen nemnen, einen haut gont. oft pikanten, und von leckern Zungen sehr

2 a. Moier 1761 Behersigutạen $\Xi 301$ gesnehten Reiz, für welehen die KunstDie Edellente anf dem Land verstehen sprache unserer Sardanapale die erborgten zwar meistentheils wenig oder niehts von Tahmen fumet und hant-gont geheiligt hat. dem hant gont, ron Moden, von Music, b. Mojer 1766 Reriquien @. 311 Dieser Opern, Iahlereyen. Poreclain, mnd andern hant gout stellt sieh so gar in blos philoWerekzengen der Eitelkeit. Mgunän 1781 sophischen und dichterisehen Wercken ein.

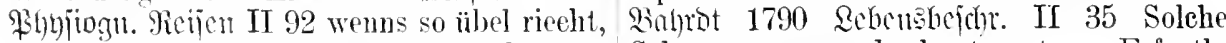
daß man die Nase zuhalten möehte, so Schmmren waren der hant gout von Erfurth. heiBts Fumet mul Hautgont - IV 43 ins Devricnt 1837 sermmgen (II 9) der kennt Speisegemach, aus welehem der Wiener den eigentlichen hant goût des Lebens gar Hantgout, mit der fränkischen Provinzia!- micht.

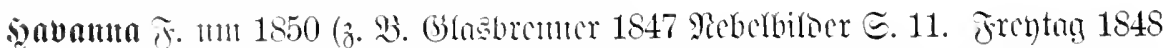

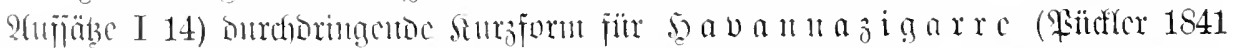

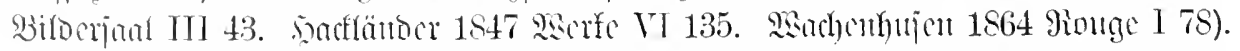

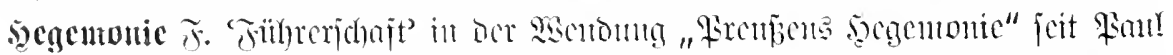

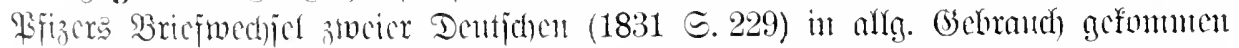

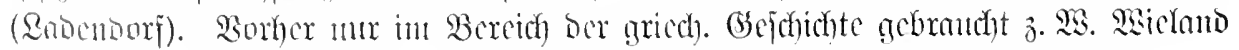

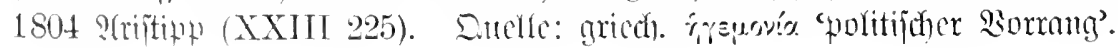




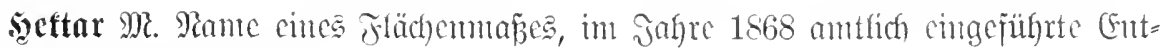
lehtung auz jrò. hectare.

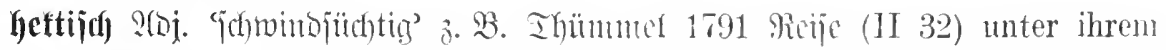

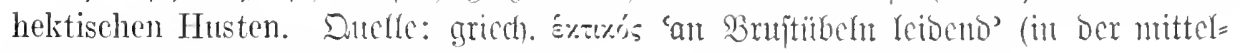

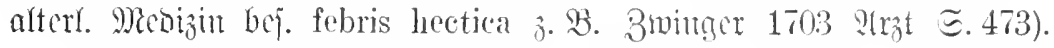

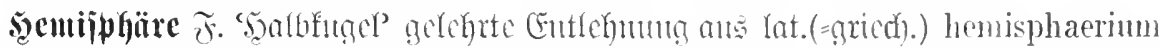
(im Gcum nach bem Brmbmort sphacra 'Sugel' gerichtet). Beleg: Edyintaich 1754 Ueptbetif $\Subset .174$ Er scheidet die Erde in zwoen Hälften und nennet cine Henispliäre Halbscheid.

semriquatre $\mathfrak{M}$. 'furzer Simbart' un 1800 anfäcfommente Brzcidnmmg (z. B. Sobebue 1804 Sultan Bumbanbum [XVI 286]), Dic cin j̆rz. barbe à la Henri quatre

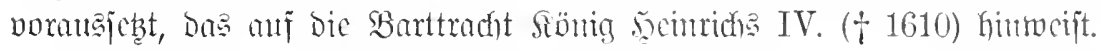

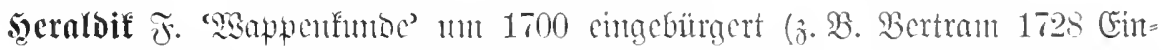

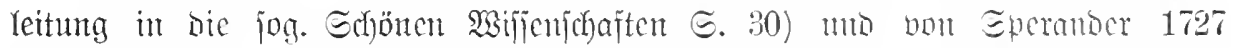
gebucht, fohon im 17. Juhrh. Iatinificert als (ars) heraldica geläujig. Suclle: Frz. (science)

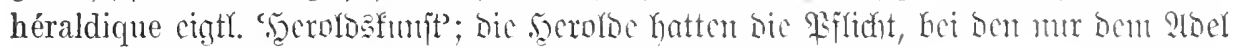
offenen Tumieren das satwen jedes fäntwers ju wrifen.

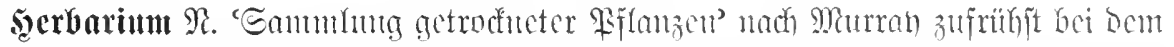
franzöfijchen Botantifer Ionnucfort 1700 Instit. rei Herb. I 671 Herbarimn sive Hortum siccum appellant collectionem plantarmm exsiccatarun quae in codicibus vel capsis asservantur. Iodh fonon in 16. Iahrh. Herbarimm 'Sränterbuch' = lat. 16. Iahrh., herbarimu.

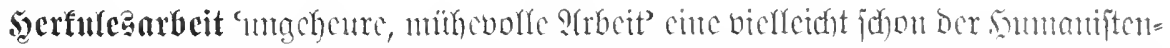

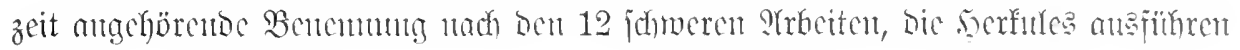
muspitc.

Belege: P(muruthes 1710 Proben bor (XXI 164) Auch war rie sogenannte HerPoefie ङ. $362 \mathrm{Ihr}$ laßt euchs, ists nicht wahr? kules-Stärlse, da eine Reihe Männer, auf den so saner hier auf Erden Bey dieser Plackerey Schultem einer ersten Reihe stehend, aberund Herculs-Arbeit werden. Eemter 1781 mals Franen und Jünglinge trägt, sn daß Sebensbejchr. I Borr. bey aller Einbildung zuletzt eine lebendige Pyramide entsteht. auf pädagogische Herkulsarbeit. Friebrich II. Bâl. Mojer 1766 Retiquien 巨. 95 gar zu 1760 an Den Marquis D’argens (XIX 215) starcke Geister der erst n beeden Arten [ïnto] Ce sont les travanx d'Hercule que je dnis e'ben so sulten, als die Riegen, welche die finir, wo 9frchenholy 1790 Eiebenjäht. fiticg so genannte Stärke des Hercules rorstellig

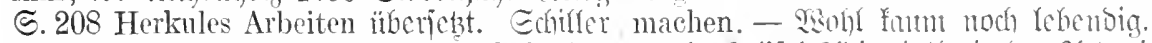

1781 Räuber (IV 170). Frentạ 1848 ?tu= ¡ätze I 56.

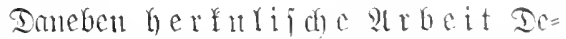
nis 1777 Cinlcitung I 83; Cramer 1794 Gentie=

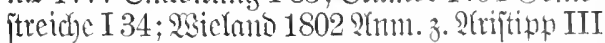
(XXIV 360); 巨eume 1803 Enażiergang (III

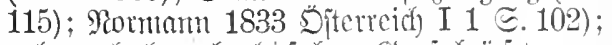

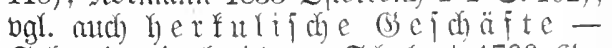
Sd wierigleiten Sdubart 1766 (5e= bidjte 5.46 - 1774 Deutiche Ehronif 5.623.

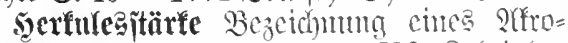
batenfunititüas bei (joethe 1796 Sehriabre

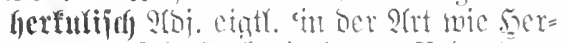

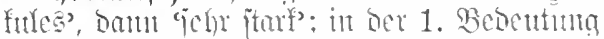
(mit jeter birefter sejefumg mif oen Eagen=

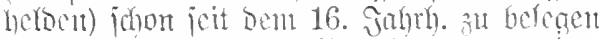
3. B. ङ. Brant 1509 Sarrese 311 Ientglers Sabenipieaget $\mathfrak{B} 1.1^{1}$ ron den Herculischen

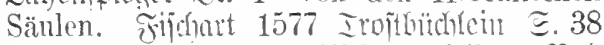
mit den Herculischen gifftigen pfeilen. $\mathfrak{B g h}$.

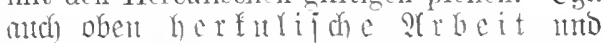
3adbariä 1744 Renommift ‥ 1291 Herkulschen Fleis. Crift im 18. Jahth. aber entiteht bet 


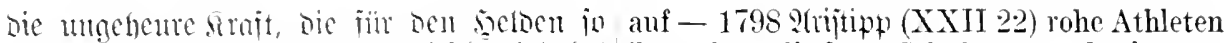

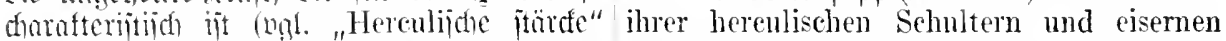

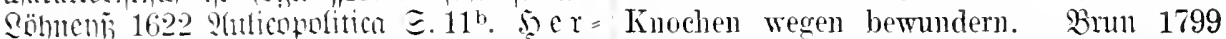

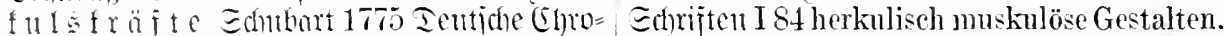

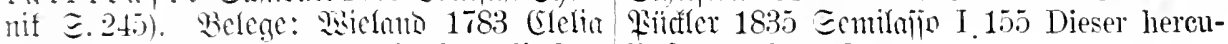
(XI 235) So fassen sie nit vier hereul'schen liseh gestaltete Manu.

Händen Andäehtiglich zwei Sänftenträger

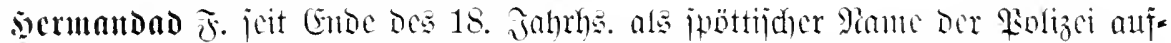
aefommen (1), meijt "heilige secrmanono" af sesebergabe vou fpan. Santa Hermandad

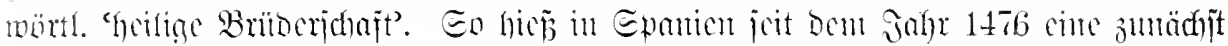

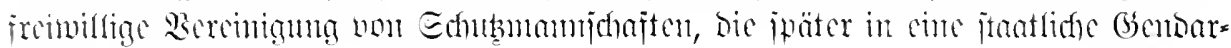
meric untgetwantolt murio (2).

Siclege: 1. Jean Fant 1793 lunindthare Roge (I 23) weil er [oer Eheriporitnerijter] das ganze Jahr nichts zu thun hatte, als einmal darin der Gast, die Santa Hermandad and der theure Dispensazionsbullen-Macher der Wildmeister zu sein. Böne 1833 Brieje a. Laris (VI 104) Im prenBischen Lande dir einen Burschen, der dich himbringen soll, Posen haben zwei Briider der heiligen Her- wo dich die hoilige Hermandad sellst nicht mandad Rottecks Weltgeschichte verbrannt. findet.

sermaphrodit 92. ' 3 witter' int 16. Jahrh. intlohnt ma lat. luermaphroditus

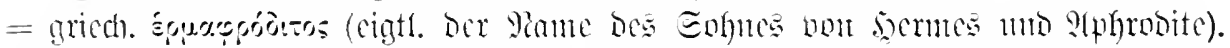
Beleg: Fincelin: 1567 semberzeidon III os sa ist ein Hermaphrodyt, an einer seiten mänlichs, an der andern weiblichs geschlechts gewesen.

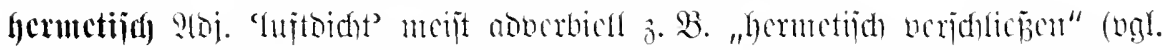

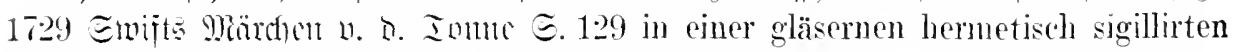

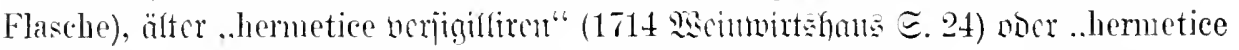

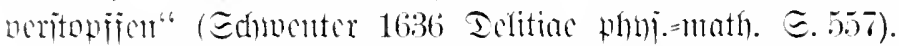

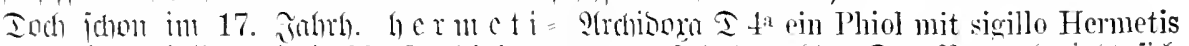

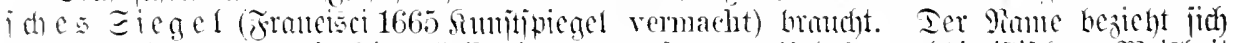

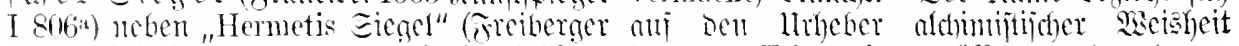

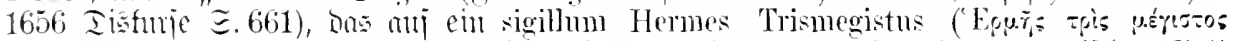

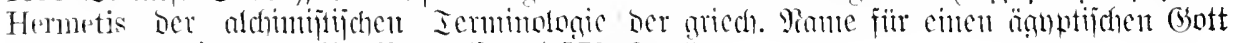

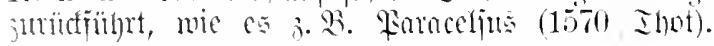

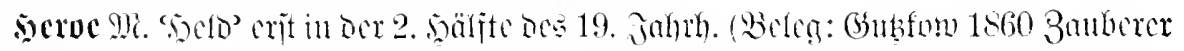

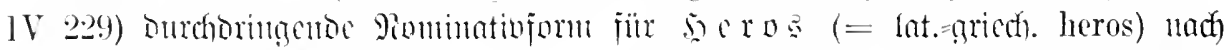

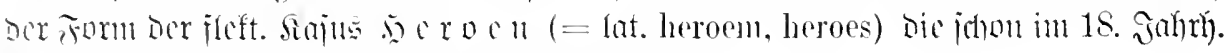

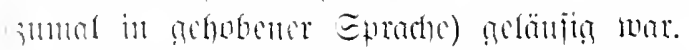

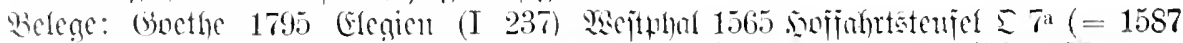
Deren rerwandelte List manchen Heroen Inoutr. Iinb. II $19^{\mathrm{h}}$ ) hertzhaffigen Mimmern betrog - (242) Hast du ihr einen Heroen vmnd Heroischen Gemiiten stehet solch herauf zu fïhren ucboten? Sceroer 1796 Lappenwerck warlich nieht zu, noch wol an.

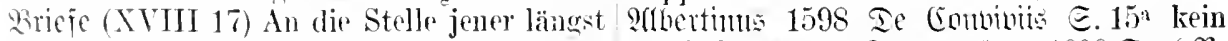
valloben Heroen und Nationalwohlthäter heroischer Mann. Equngenberg 1606 Enul $\mathfrak{B}$. traten jortat neue Heroen, elic Märtyrer. (incthe 1830 (ehrijttis $(49,91)$ Moses. Diesen Heroen kann ich mir freilich nicht anders als sitzind denlien. 1805 An dir zwar nichts Heroisch ist.

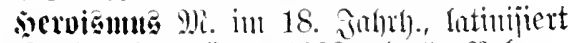
ans $\mathfrak{j r}_{j}$. héroisme (idhon 1668 belegt). Belege: 1765 qulg. ๖. Sibliothef $12 \Xi .27$. Reifing

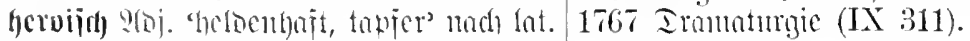

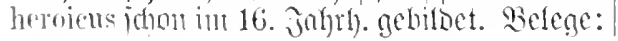




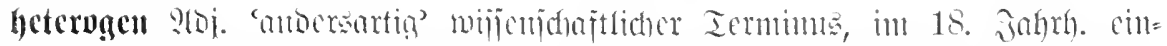

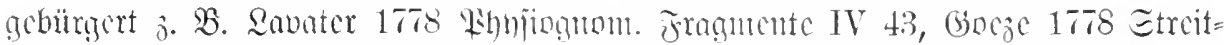

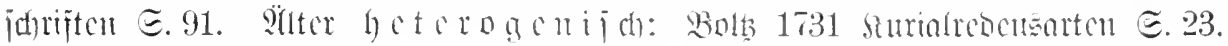

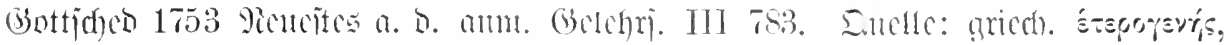
in joblaptijenen satcin heterogeneus.

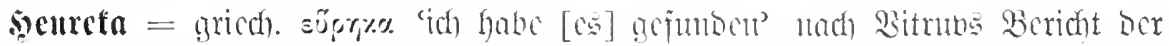

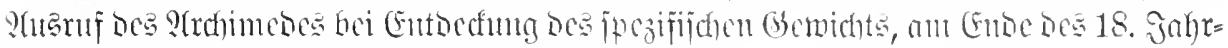

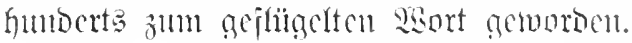

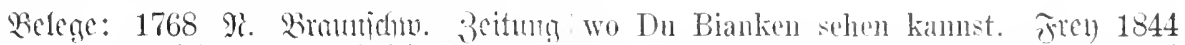

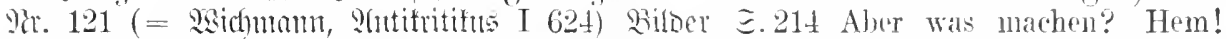
Der Nenerer mub nur bedachtsan zu Werke Hem! Hem! Heurekal Heureka! Ich schmiere

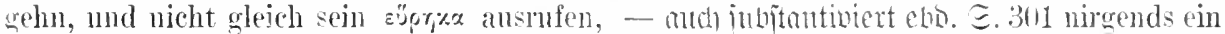
nicht gleich mit jeder Hirngeburt herror- Heureka, nirgends ein siegestuf unsterblicher rücken. Bedntein 1832 Tonelten I 117 er Wahrheiten.

jubclte: Henrälan! Gefunden! Ich weib

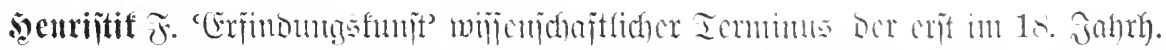

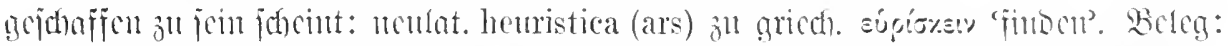
Sorber 1767 Deutide Riteratur (I 444) als Poetische Herristik wolleus wir die Mythologie der Alten studiren - mgl. aud $\Xi .447$ ron mejnem levristicchen Gebranch der Mythologie.

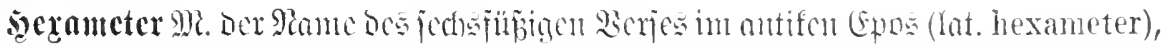

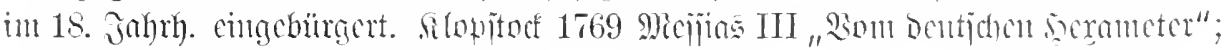

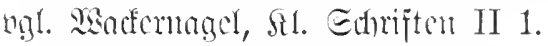

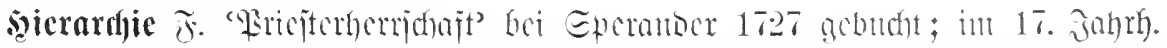
nod) in lat. Form j. B. Eccfemonrĩ 1685 Chriftenftant I 450 die Hierarchia oder das

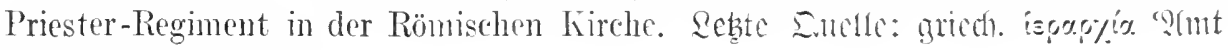
Bes Pricjterworitehers.

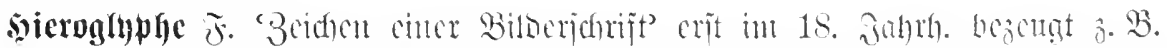

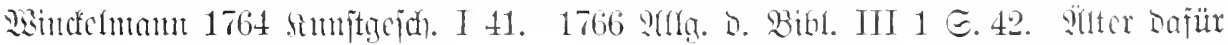

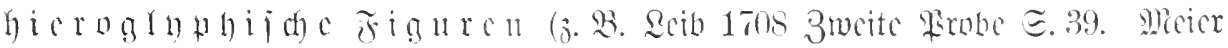

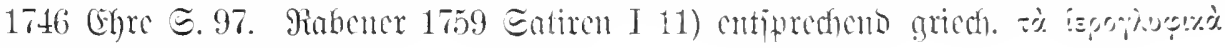
(iscuuse) 'Bitocrichrift'.

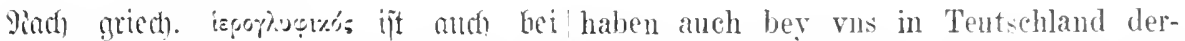

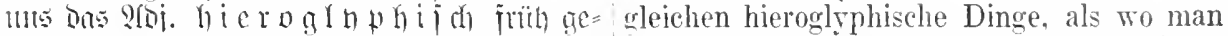

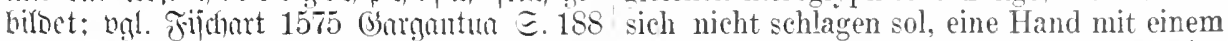
Die Weisen in Egypten habeu vorzeiten Berel. Ins junge Enbit. Sieroglnthe him= der sachen vil anders gethan, wann sie durch gegen jteht unter Cinflú Des Franz., mo jobn genälschrifften rnd Schilderbilder, welche an Enoe Des 16. Juhrt): hiéroglyphe gebilnet sie Hieroglypisch nanten, geschriben haben morten mor.

Bedher 1668 Miethodus bie Dact. $\Xi .5^{\text {h }}$ Wir

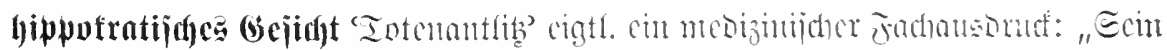

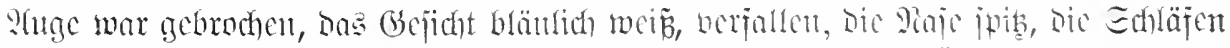

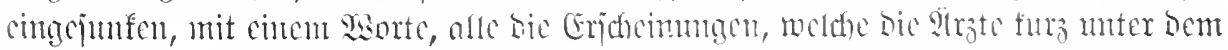

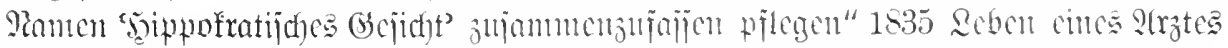

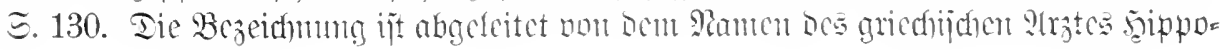


frates, ber in jeiner Schrift Prognosticon die Semzeid)en des nahemben Tobcs auf Dcm

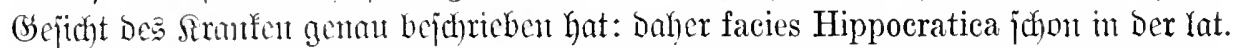

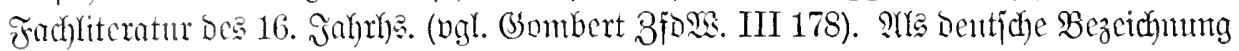

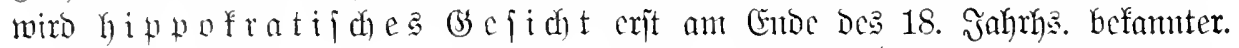

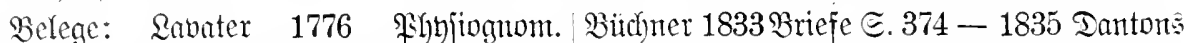
Frugntente II 48 hippokratisches Todten- ToD હ. 35. Fürffer 1835 Eemilajio I 235.

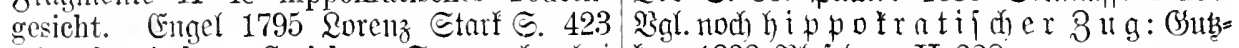
Hippokratisches Gesicht. Eo aud) bei fow 1838 Slajebow II 228.

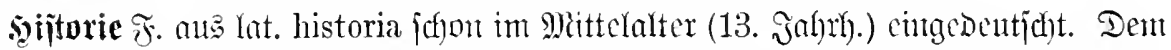

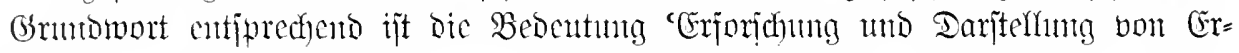

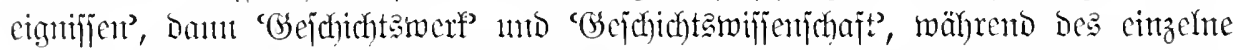

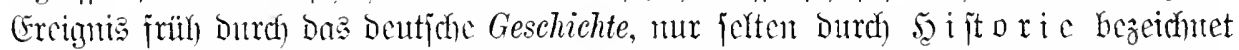

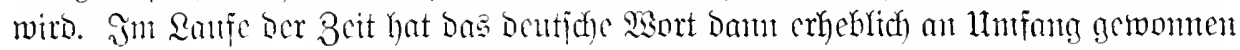

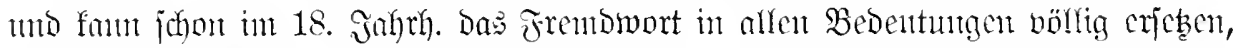

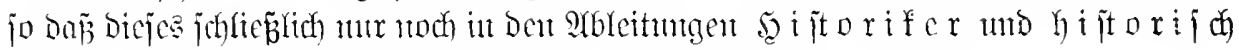

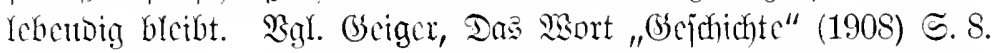

Syobve $\mathfrak{F}$. Der Rantc bce int 17. Jahrh. meijt französische Schalmei genamtent

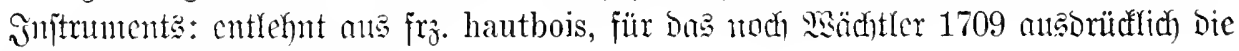
2utajuractic , "roboä" mugibt.

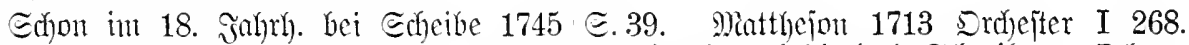

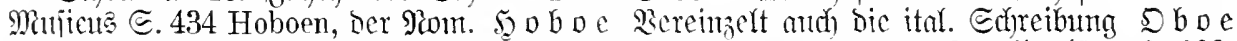

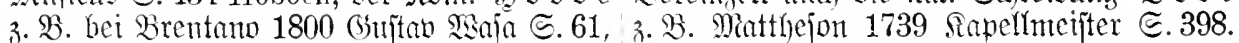

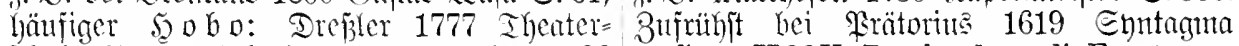

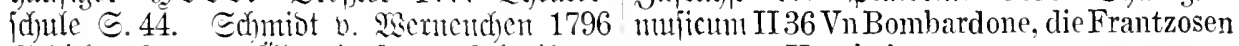

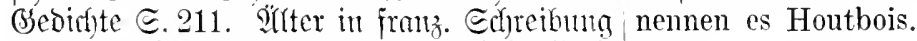

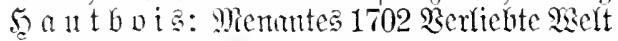

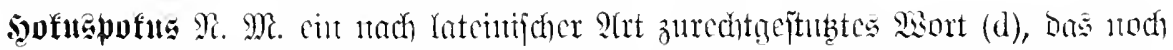

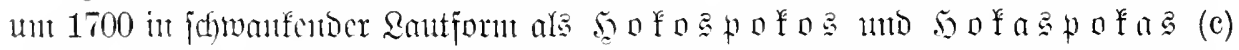

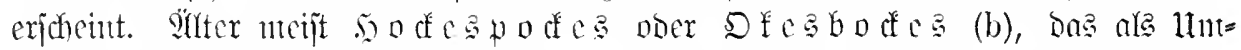

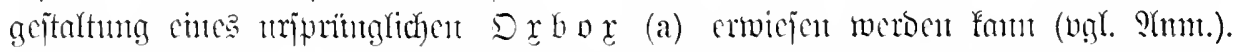

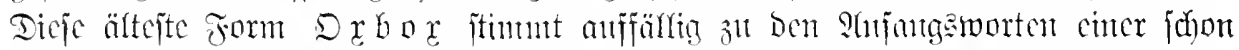
int 16. Jahrh. belegten Bantberforntel: , H a $\mathrm{x}$ p a max Deus adimax", mb bicje

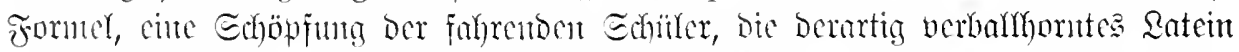

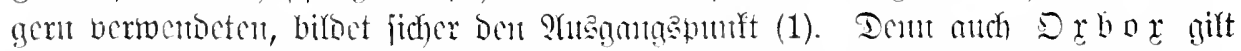

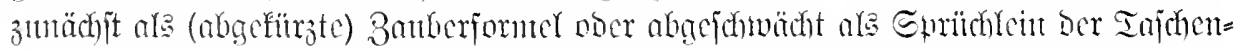

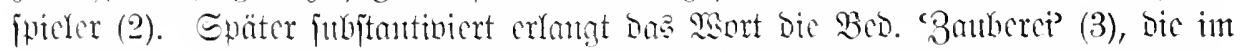

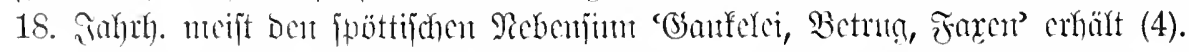

Belege: 1. Mgicus 1563 De Pracstigiis stück Apffels, darauff er etliche wort, Hax Daemonum ङ. 360 Non infimae sortis nobilem pax, max, Deus adimax, geschrieben zu essen cognovi, simili curationis ratione celebrem, geben. Dieje Formel wicoerlyolt $1696 \mathrm{Min}=$

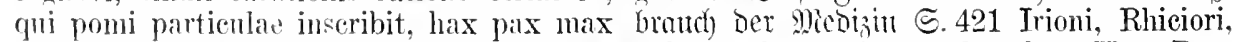
Dens adimax: atque edendam illam renenato Eslera, Rhader, ferre. oder aber: Hax, Pax, a cane rabido porrigit. Epantgentern 1594 max, Deus. Adlimax. Bgl. muth Coutin 1706 Mochifpiegel II 367 Vorgedachter D. Wierns 9atrrenvelt I 108 ber Etubcut] fieng an

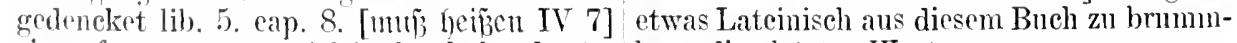
eines fürnemen von Adel, der habe denen, len, die letzte Wort waren, ogas pogas so von tollen Hunden gebissen worden, ein huperates Siedt es nicht so Brat es. 
2 a. Martin 1628 Colloques ๔. 117 Ox, Box[-] oder Täschenspieler, gauckler -

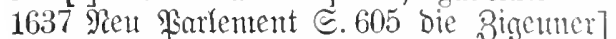
können ox pox spielen, vnnd machen daß der andern Leut Geldt in ihren seckel gegauckelt wird.

b. शGele 1654 Gerichtąänol હ.404 Heist das nicht Hogges und Pogges, geschwind wie der Wind, sehwartz und weib, und gerad mit ungerad spielen? Tazn Fachel 1664 Eatyren S.110 Das muB nicht okes boks, wie aus der Taschen gehn.

c. Noetius 1659 Difputationes thent. III 542 Vanam hane \& otiosam artem, Agyrtae vocant Okos Boeos, vocabulis a vero vel fieto nomine Itali cuiusdam hujus artis mystae \& mystagogi, ant aliunde desumptis. Est autem ars, quâ peculiari quadam agilitate, celeritate et occultatione miri aliquid facere videntur \& facere se jactant, cum re vera nihil tale faeiant. Daว̆ 1640 Echerzach. เ. Borfabentel (= 1721 Recneil XXIII 67) Possen die die Gaukler machen, Sind erfunden nur zu lachen. Ocos Bocos und die Dinge Sind, daB man die Zeit hinbringe. SImaranthe? 1710 Broben Der Poefie §.338 bie 3auberer, bie] Ihr Hocas Pocas anch darbey nicht fehlen liessen.

d. Reuter 1696 Edjelmutfefy E. 9 Hocus Pocus schwartz und weib Fahre stracks anf mein Geheiß Schuri muri aus dem Knaben. Ettner 1697 Chnmicus @. 49 die Chymie kommit mir vor, als wie der Scherwentzel in der Karte oder Hocus Pocus in dem Taschenspiele, ein jeder maeht die ilım zu nutze. Gangler 1700 \&ugenidmio III 9 Hocus pocus, g'schwind wie der Wind. 1790 Der Beobacter $\Subset .458$ Hokuspokus ein Sack voll Geld.

3a. WSeije 1705 förbetmacher Є.110 Wenn sie die Kanff-Brieffe schreiben, so steigt ihnen manch $\mathrm{Ox}$ pox in die Nase.

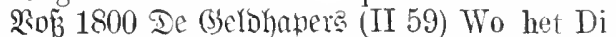
de spuddige Snieder besehummelt De Di so väl Hoxpox voermäkerde.

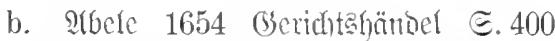
oder auf einen andern Schlag und Manier (das Hogges und Porges) dir verkehrte, umgekehrte oder vertrexlete Red - $\widetilde{5} .506$ Sophistische Possen und gleichsam von dem Hockes und Pockes zuzeiten wunderlich (geschwind wie der Wind) entlehnete Griff oder Rentk. Gambler 1697 Iugenichmio I 224 von Gigges Gagges und Hockes Bockes etlieh Stund nacheinander predigen.

c. Sebentualot 1682 Tenfels Rift VIII 136 es sehleichen vil vmnütze Gedancken vnd eytle Reden darbey cin, ja offt abergläubisehe Hokos Pokos vnd andere Possen.

d. Buerit in Rüchertiteln 1667 Hocus Pocus junior oder Taschen-Spielkunst [rug bem Englifchen madh Tsish. IV 1, 17.22]. 1668 Hocus Poeus, oder Taschen-Spieler [Qllemantia XVII 70.71]. 1677 Machia= vellifher 5rocuenocus [i. Sullenberz.]. Reuter 1696 હchelmufigłn હ. 9 Hocus Pocus Kreiß. Lefing 1759 Riteraturlriefe (VIII 10) Bergmann macht sein hocus pocus, und alle Gedanken alle Einfälle, die wirklich da waren, sind weg.

4. 1677 Madhianell. 5ocusnocus @.119 unter anderen Maehiavellischen Hocus pocus grifferchen. Merde 1716 Charlatumerie ङ. $3^{2}$ dergleiehen gern-groß-seyn-wollenden HocusPocns-ILachern. 1720 Secueil XXII 56 ein Hocus-Bocus-Spiel vor das gemeine Volck.

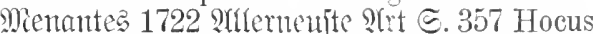
pocus Diener. ¿dhmist 1728 Eurienje Gritlen ๔. 82 mit hocus pocus Griffen, Lïgen ङ. 296 spielet er sein hocus pocus mit frembden Gütern. Gocthe 1796 Rehrjahre (XXIII 213) Alle diese wurden mit Iystificationen und anderm Hocus Poeus theils aufgehalten, theils bei Seite gebracht.

Q̂nu.: Bur Entîtchung ber Sefundör= nofíle bgl. rips rups all ripp's rappes bei

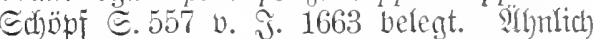
kribs hrahs neben hribbes hrables nuto gichs gacks neben gick's gacks.

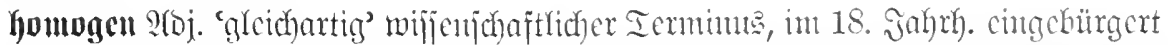
3. B. Ravater 1776 \$injiognom. Fragnente II 96. Goethe 1796 2ehrjabre (XXII 176).

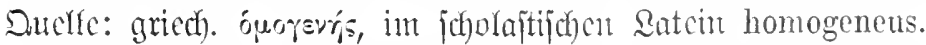

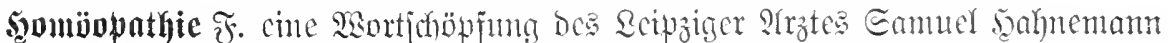

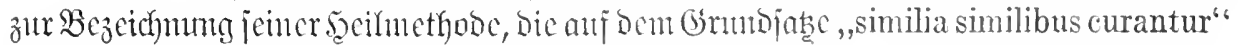

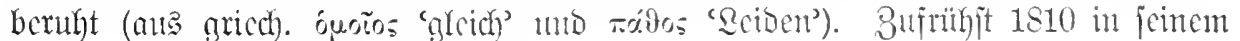
Drganou der rationellen Scilfunde.

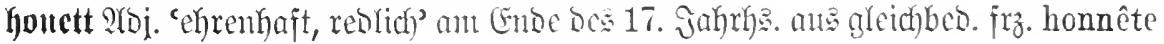




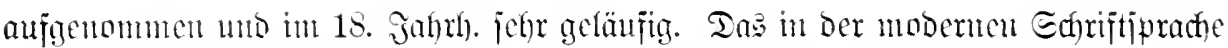

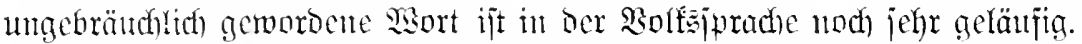

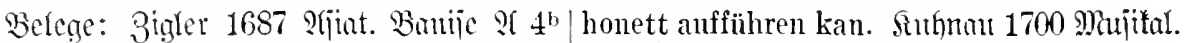
daß sich demnoch riel honette gemuither Eunafjarber ङ.149 unter die honnetten finden werden, dieses mein wolmeynendes Lente. Erfilemout 1702 Siriegas $\mathfrak{u}$. Etaat?at unterfangen meir loben als schelten. Siseije I 204 homett und bürgerlich leben. Rohr

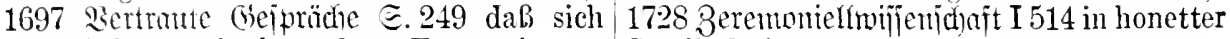
sein Sohn auch bey dem Franenzimmer Gesellschaft.

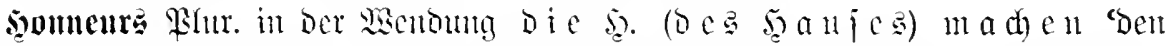

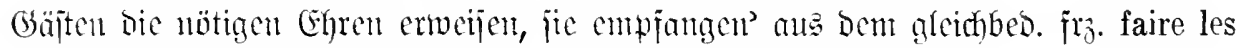
honneurs d'une maison (17. Jahrefh.) etwa um 1750 cutfehnt.

Belcge: Rabenter 1759 Eatiren III 22, moniofe II 1234 Nachricht ron denen wemn er einen Dncaten für jeden Rausch Honneurs, so man grossen Herren, oder bekömmt, den er sich trinkt, so oft er die denen commandirenden Generals bey einer homneurs vom Hause macht. Sgermes 1778 Armee zu erweisen pfleget.

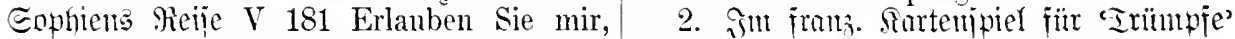

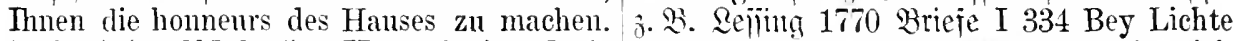
Archenfyor 1787 Ittulien II 70 Bebiente] die zwar nnd einer Partie Wisque möchte ich nichts thun, als die Honneurs machen. das Bild freslich nicht untersuchen lassen:

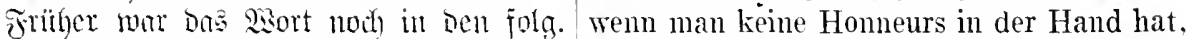
Bebeutungent iibfid): 1. 'miffitärifghe (Ëhren= ist einem in dem Augenblicke nichts recht.

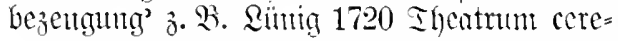

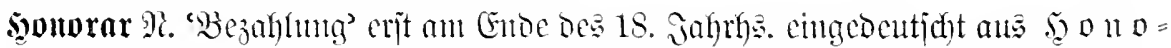

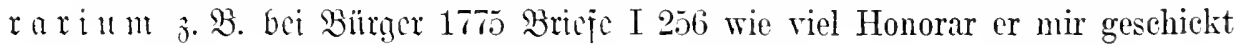
habe - neben: ein ehrliches Honorarium - mit dem Honorario. Dueffe: lat. hono-

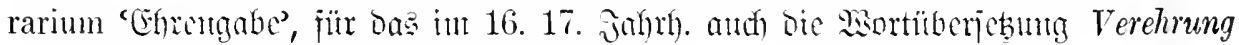

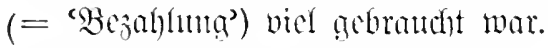

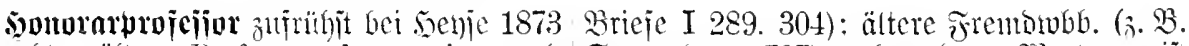
gebucht; äfter Professor honorarins vgl. Eperanoer 1727) gebent bem sisorte meiït

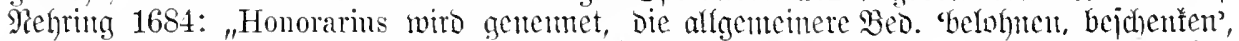

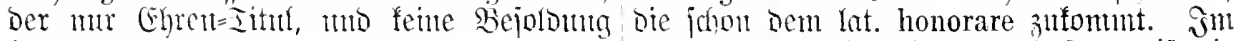
bat".

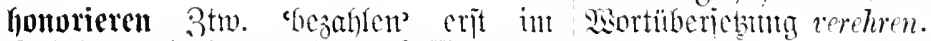

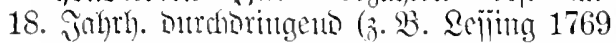

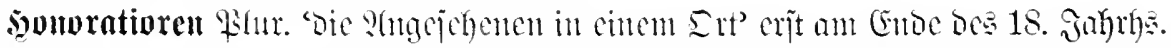

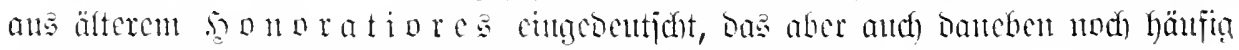

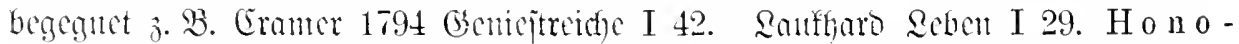

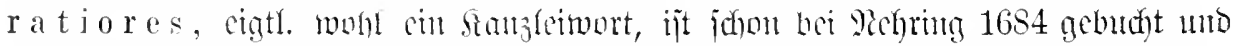
ijt (mit ber (Grmobeos. 'Die Geeheteren') Somweratio jull lat. honoratus.

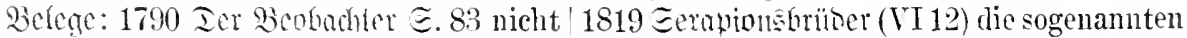
nur auf den niedrigsten l'öbel, sondern anch Honoratioren der Stadt.

anf Lente, welche sich unter die Honorazioren Ser Eing. ijt jehr ieften, hent fantm

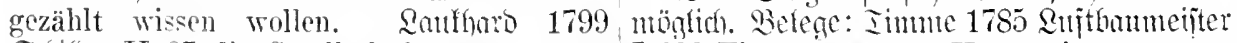
Edtifín II 87 die Gesellschaften fer Hono- I 693 Ein sogenamnter Honoratior trat zum

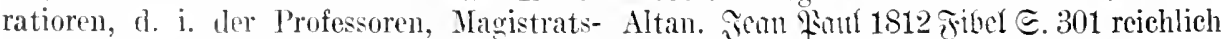
personen und der vornehmeren Fabrikanten, genoß ieh die Gesellsehaft jedes Honoraziors Kauflente, Hechaniker usw. 5ofifunu - $\Xi .302$ über den dritten Honorazior.

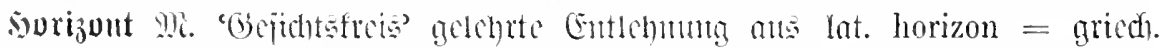

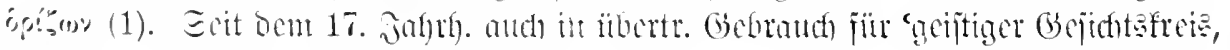

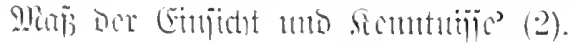




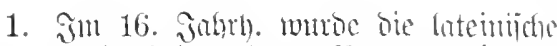
Form nod beibchalten: Pom. brison (Ditrer 1525 llutermeijutg D. Deintug o $5^{b}$ )

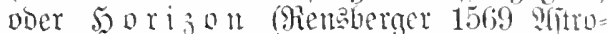
nomie $\widetilde{S} .193^{b}$. Siententerg 1586 in Thent. be Beneficis $\left.\Xi .310^{2}\right)$ - siff. ho rizonte m 3. 2. Shumenjier 1578 sijtoria v. Cero= gewäd) twrobe Dan ein Pom. Sorizont gebirbet

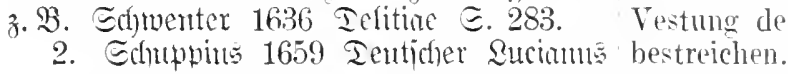

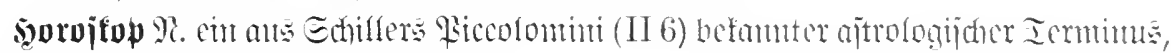

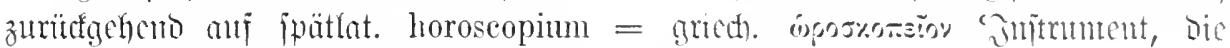

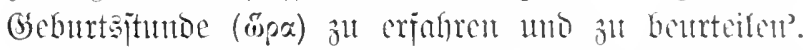

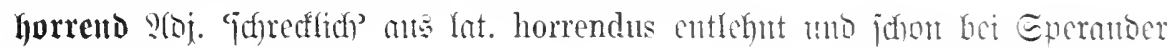
1727 gebudit.

Belege: Eenme 1803 Enariergang (II 69) halte, ziemblich horribel zugehet. . . will mit einer horrenden Volubilität. Sobebute ich lieber darvon still schweigen. Iipne!

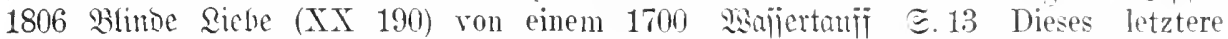
horrenden Verlust von 200 Dukaten. Etimbe schiene vielen horribel, das erste aber noch 1884 Fran. Buthhors I 81 er mache dort gefährlich.

horrende Geschäfte.

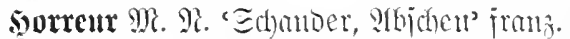

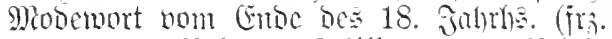
horreur). Belege: Edhitler 1799 Brieje VI 116 unser Freund hat die Damenwelt verführt, es in Horreur zu nehmen. Ghutifow

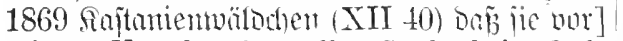
seinem Terschmällen aller Sauberkeit, Ordnung und Seife ein ,horreur" gehabt hätte.

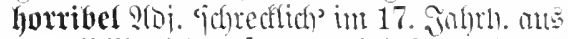
lat. horribilis (ooer fro. horrible?) entlehnt. der menschlichen Tatur vor - LaternenBeleg: Errirofnledi 1652 şammonia III 28 pfählen.

weil aber dises, was ich noch zuriicke he-

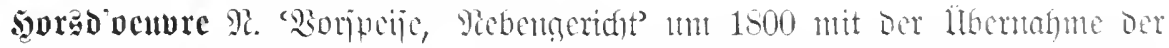

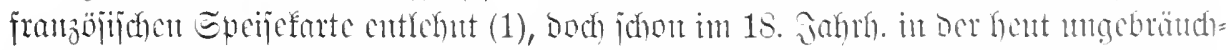

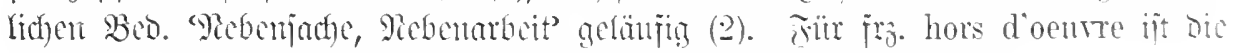

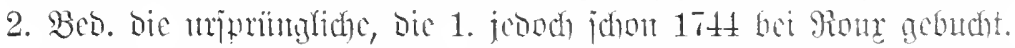

Belege: 1. Enfser 1774 Theorie II 1141b Hochaltar, mitten in all' dem L'nwesen einSelten haben auch die zwischen den Anf- geengt, ist zum Hors doenrre gewrorden. zügen der Oper rorgestellte Ballette würk- 2 Sütefer 1831 Sirtcis III 258 in einem Winkel liche Beziehung anf das Schauspiehl, und des Parks, gleich einem hors docurre. sind in der That nichts anders, als völlige verborgen. Sanbe 1836 geijenuncffen IV 41 hors d'oenrres, die die Eindrücke, die das daß Sie sich ans gefülligkeit ein hors d'oenvre Schanspieht gemacht hat, wieder auslöschen. aufgebürdet.

Forịter 1791 ?(rijichten v. Mieserthein $\Xi .437$ Die Blumen nul Trräiter zeugen ron der Sorgsamkeit des Künstlers, aneh in diesen hors d'oeuvres nichts was täuschen könnte zu vernachlässigen. Juinge 1792 ?eije madh Bromidheig 282 Die Totariatscene ist äusserst komisch; aber sie ist ein hors d'ceuvre. Bitun 1809 Enliponen II 142 Der
2. Doteme 1804 Erimemugen こ. 259 Der hors d'oeurres (kleine kalte Schüsseln) sind fünf und zwanzig. Somif 1825 miam in montoe (XII 180) Hors d'oenves [in Der Encinturte7. Semiro 1836 squmelle I 151 dab ich ror den Braten, Gélés, hors d'oenvres und entremets einen tiefen Bückling machte. 


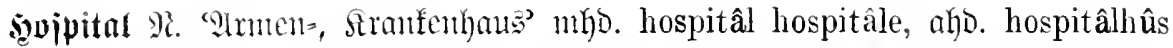
eigtt. Srojpitnlfunes. Dneffe: mlat. hospitale, Das aber in volfstümlicher Epradhe

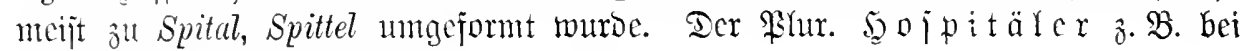

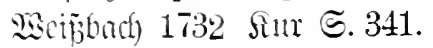

scoipitant Me. 'wer als Gajt cine Bonfejuntg hört' bei Campe 1813 gebucht. Bu älterent

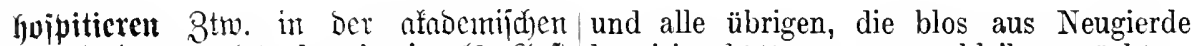
Termintologie aus lat. hospitari 'alg Gangt hospitirt hätten, unn wegbleiben möchten.

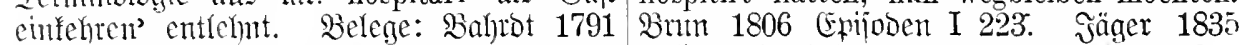

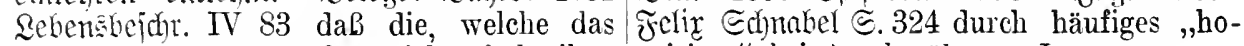
Kollegium forthören wolten, sich aufschreiben spitiren" bei den berühmten Lehrern.

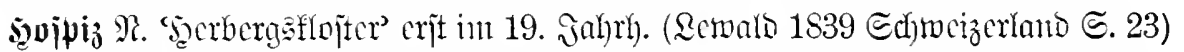

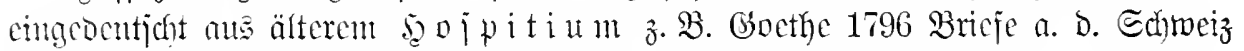
(XIX 293) Wir haben kein Hospitium, wie die Patres auf dem Gotthard. Brum 1809 Epijoden II 302. Dutelle: Yat. hospitium Sacrberge.

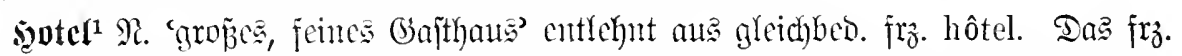

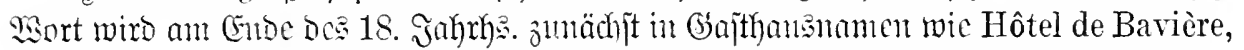

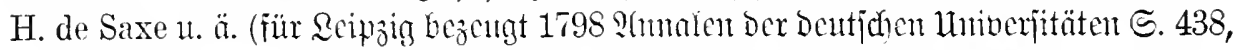

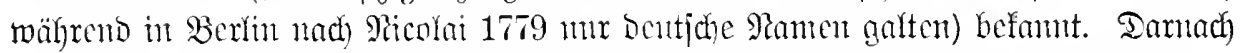
wiro Dant setel bie cinzige Benenmmg für femere Gajthäufer, bie jefon von

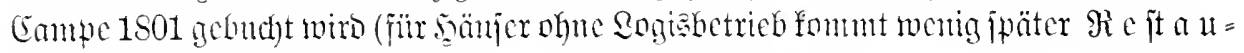

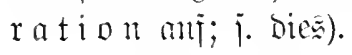

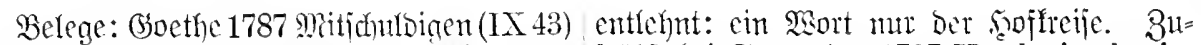
Es kennt die ganze Welt den Wirt zum frithyt bei Eperamber 1727 Hotel 'eine königschwarzen Bären. Jetzt wird mein Haus liche Wohnung, ein Fürstlicher Palast'. gemalt und dann heiß ichs Hotel (Eeifer, Epäter bej. 'Minifter=, (strafenmohnhaus's. B.

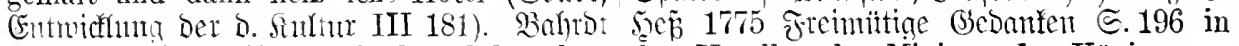
1789 Religion ist zu Berlin im Hôtel, die Stadt Paris Preussen. Sifland 1795 geife nad) Der @tabt genannt. Gerntes 1789 Tiitr Söchter II 109 (II 8) bin bei allen Schweizern, an allen das Hotel wo ich meiner Torheit Gedächtnis Hotels die Runde gegangen, habe mir oft gestiftet habe, ist eine Art Gasthof. Sanif vou den Excellenzen antworten lassen.

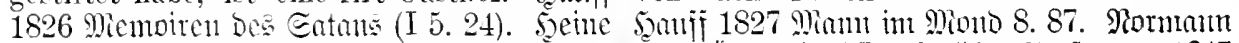
1830 âtalien (III 269). Rewarlo 1836 Pquarelle I 44. 247. (Sintidy) 1836 Tageh. (I 179).

sotcl ${ }^{2} \Re$. ‘niopes

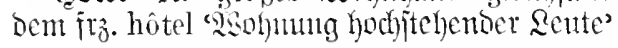

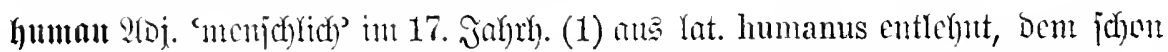

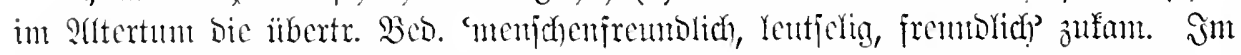

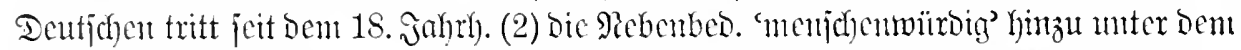

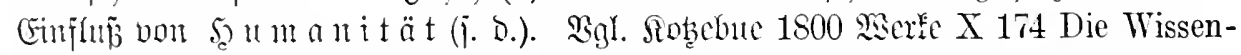
schaften veredeln den Menschen, machen ihn - wie nennen sie es doch gleich? h u m a n. Das ist ein nenes Modewort.

Bjelege: 1. Mflert 1627 Tagebuch) હ. 67 હ. 123 Der Churfürst bezeigte sich gegen Frtul (5).] hat so humane und freundlich, männigiich gar human.

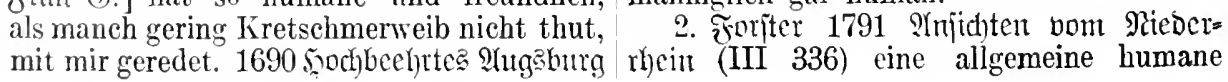


Theilnahme an allem, was unserer Gattung humanitet als in der ranitet studirt hab.

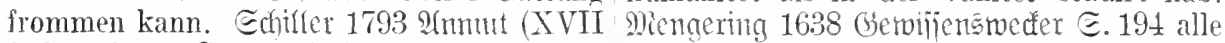
316) scinem [Des Griechen] humanem Ge- Christiche Liebe, hmmanitet, Mitleiden vnd fühle ist es gleich unmöglich, die hohe Tier- Handreichung. 1699 Etnats̃piegel II 11. heit und die Intelligenz zu rereinzeln. Narwerger 1711 Neelien I 171.

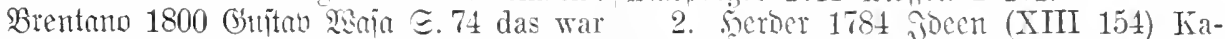
gar sehr human. Eenture 1803 Eraziergang pitel 6: Zur Humanität und Religion ist der (III 103) ob das eine lnumane Art wäre, einen Mencch gebildet - Ich wünschte, daß ich in ehrlichen Mann zu behandeln.

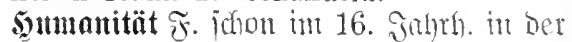
as ich bisher über des yenschen edle Bildung Bed. 'Nemjenjrembficheit, Rentjeligfeit, zur Vernuft und Freiheit, zu feinem Büte' ans lat. numanitas entlehnt (1). Ceinen Sinnen und 'Trieben, zur zartesten und neuen Jnhalt gob ferber bent Saort, als er, stärksten Gesundleit, zur Erfüllung und bej. in jeinen Briefen zu Betönerung oer Beherrsehung der Erde gesagt habe: denn

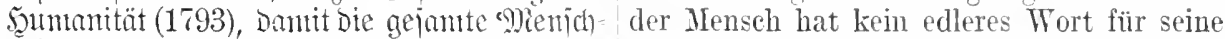

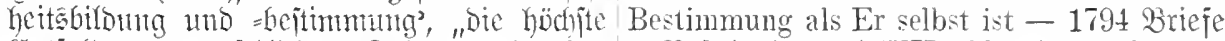

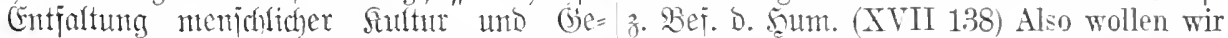
jittung ars "Gnoziel be Sanbelns" (eister), bei dem Wort Humanität bleiben, an welches bezeidnete (2). In biejem Einne erfongte unter Alten und Teuern die besten Schrift$\mathfrak{5}$ u manität an Crnde des 18. Sahrhs. steller so würdige Begriffe geknüpt haben. fajt Die beltung eines Edflagmorts, in Der Humanität ist der Charakter unsres Ge-

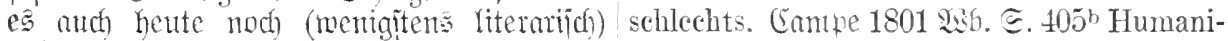
befount ijt. Belege: 1. Forer 1563 Gep̃ners tät. Dieses fremde Wort ist seit einigen Jijd) fund (Borr.) deß versich ich mich gegen Jahren, besonders durch Herder'n, der es eiiwerer humanitet rnnd freündtligkeit, zum Titel eines seiner Werke machte, in welche ich weib euweren edlen gemuittern lebhaften T'mlauf gekommen. Bahlreidje

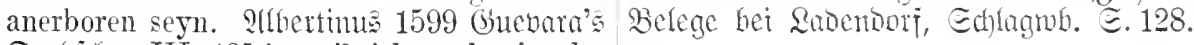
Eenbjdyr. III $135^{\mathrm{b}}$ weil ich mehr in der

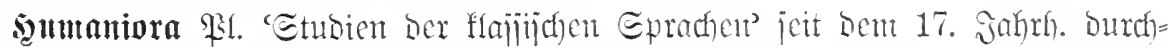
oringende fï̈rung (1) aus studia humaniora (2). Tieje tonfl jafou im 16. Jahrh. üblidye Bezeidnung jollte andeuten, baj jolche Etudien bejähigten "mehr sienjeh

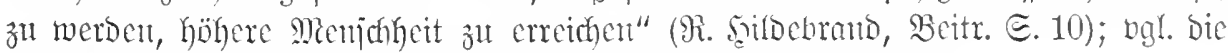

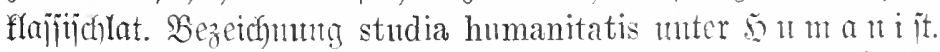

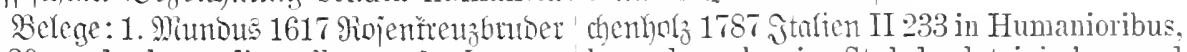
€. 20 vnd thäte dir selbsten hoch ron- besonders aber in Styl der lateinischen und nöten, du giengest noch ein weil bey den ITuttersprache. Nï̈lfer 1792 Seer Thomas Jesuitern inn die Schul, rnd liessest dich III 42 was die Lateiner sonst Humaniora in Humanioribus, besonders in der Dialectica, nennen.

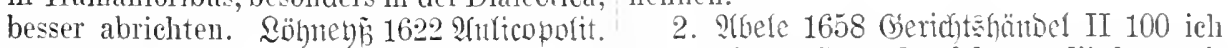
ङ. $17^{\mathrm{b}}$ nachdem sie in humanioribus den hab mich vou Jugend auf den studiis humaniGrund gelegt. Deibnis 1696 sierfe I 379 oribus ergeben. 1672 Etatnten D. Unito. $\mathrm{Zu}$ allem Gliick war ich in den sogenannten soetselgerg હ. 295 sambt denen artibus Humanioribus ziemlich fortgeschritten. $2(t=$ humanioribus (wie man sie insgemein nennet).

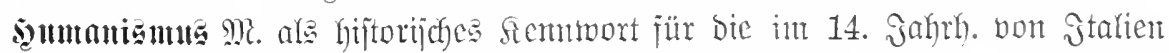

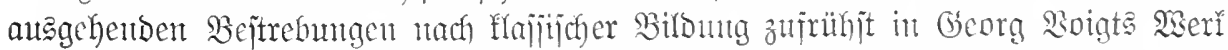

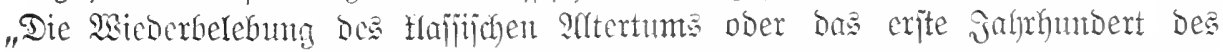

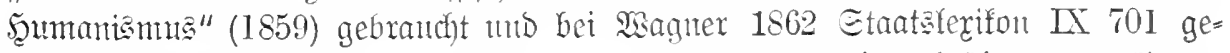

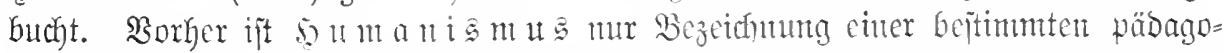
gijchen Richtung, die an Gnbe Des 18. Jahrhe. heftig bejehbet wurbe; vgl. Niet=

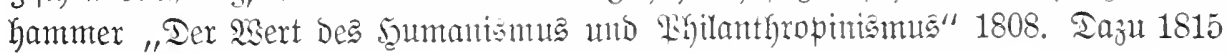
Brodfyat: IV 835 man nannte das pädagogische System, das alle Bildung auf die Erlernung der alten Sprachen baut, den Humanismus. 
Somtanifit \$le. eitt beut mus nod mit

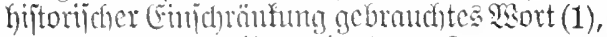
Das cigtl. gats allgement ben 'fenner und Richnaber Der flafitichen Eprachen'bezeichnete (2), mo fo nod in bem ?(oj. hum a nijtijd) fortlent. Ces ift einc neulat. Biloming Des 15. Galyrtje. mo icheint in Stalien aije= fonmen zu jein (ital. mmanista ctron ieit 1500 belegt); ine gehört zu lat. humanitas 'fubhere Biloung, gelchrte Senntuilje’, dos in ber

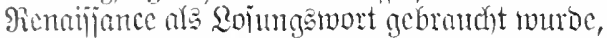
bej. in der aus cicero entlehnten sisenoming studia humanitatis, bie faron 1406 in Poggios Ëpijtulne I xin, mo 1459 in Guarino's De ordine docendi cricheint. 9igl. Sonotse, Revival of Learning $\Subset .128$ ( = Hist. of Class. Scholar= ship II 71); Boigt I² 214.

\section{soumanität $j$. untex h) 4 m a 11 .}

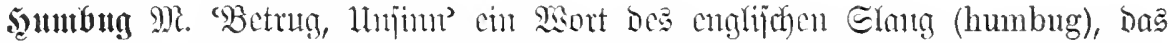

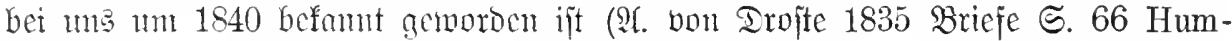

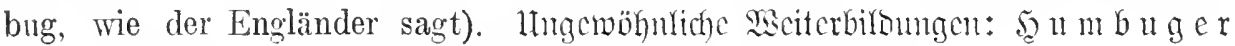

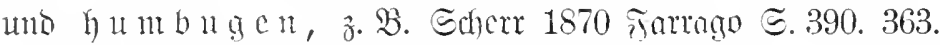

Belcge: 1841 Enropa I 189a [Somoner Fopperei. Die sogenamnte fashionable GeBeridit] John Bull macht eine ähnliche sellschaft bedient sich mit besonderer VorNotifikation, und erklärt seinerseits, er wolle liebe dieses Wortes bei jeder Gelegenheit

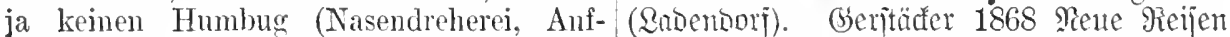

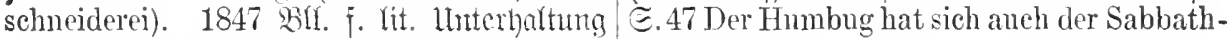
ङ. 1335 Amerikanischer Humbug - 1849 feier bemächtigt.

ebo. E. 1064 Humbug - Ein Spaß, eine

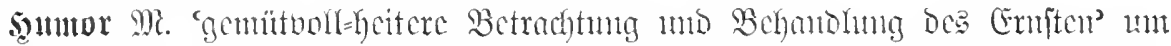

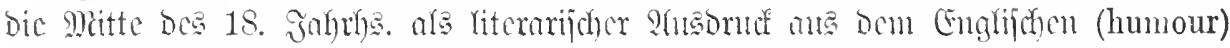

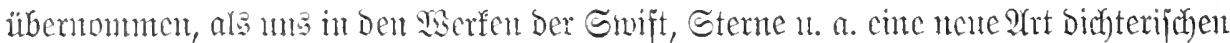

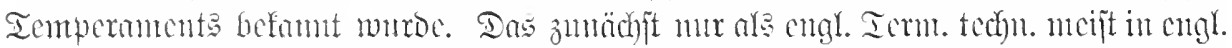

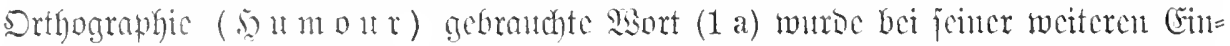

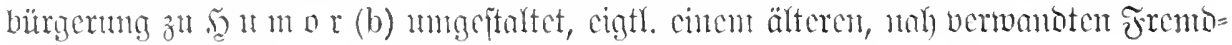
wort angeglichen, Das ' 2 ante, Etimmnng' bebentete (2).

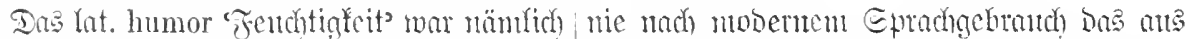

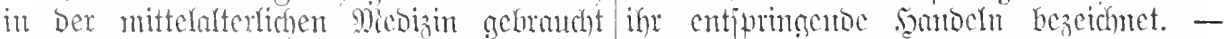

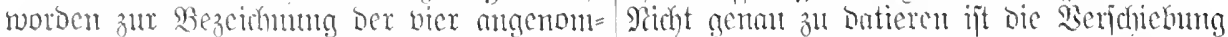

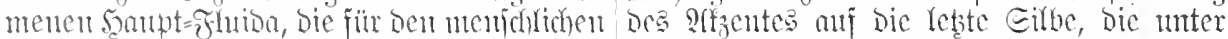

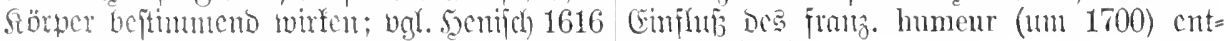
Ep. 611 Complexion, die naturliche vermi- jtanoen ijt (3).

schung und temperatur der vier humoren. Relene: 1 a. Reifing 1760 Sitcraturtricfe

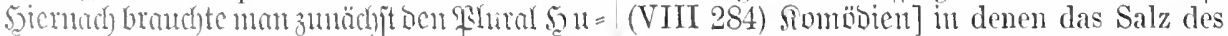
ur ore für 'Semperment, Charafter' (2a), Moliere, mit dem Humor der Engländer

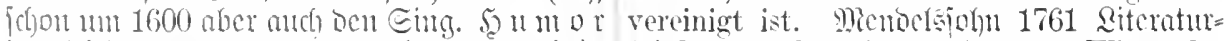
in glcidfor sebenumg (b), mitunter mud in briefe X 269 diejenige Art von Witz oder Der nakefiegenoen bico. "worïbergehenbe (G)= Scharfsiunigkeit, die von den Engländern

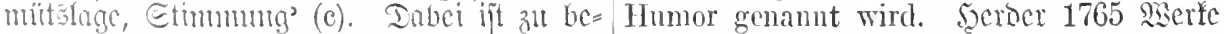
acten, Daj in gelegentlichen Berbinoungen I 109 Ein Engländer voll Spleen und Humor

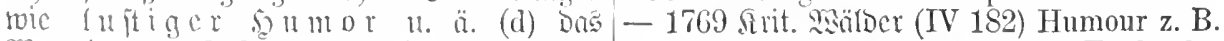

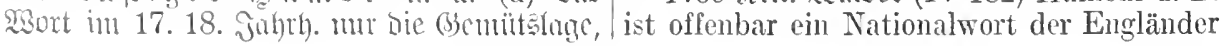


aus ihrem Charakter. Riedel 1767 Theorie ๔. 91 Die Worte Humour und Laune sind neu - S.92 die Engelländer, bei welehen der Humonr eigentlich zu Hauße ist. Qidjtenberg 1774 stphorimen II 193 Laune oder der sogenamte Humour der Engländer.

b. Reiing 1759 Riteraturbriefe I 77 Der herrschende Ton darimn ist Satyre und Humor. Boethe 1774 Cravigo (XI 80) spare deinen Humor auf meine Hochzeit. Alinger 1778 (Rieger I 417) Troz sey deinem Wiz und Humor von der Göttin Steifsimm und Wahrheit gebothen.

2 a. Breuning v. Budtenbach 1585 Re= Iation $\Subset .69$ weil aber monsieur Fontaine des graven von Essex humores bekant, hab ich mich bei ihme erkïndiget (DMg6.). 2 (riber= timus 1598 (suevara's Sentid)r. I 102a aber das spendiren rnd außthailen beschicht nach vieler Leuth will vnd humorn.

b. Sanintyofer 1610 Brieje ๔. 65 das sies nach mein humor machen. Prätorius 1619 Enntagma III 134 nach eines jeden Componisten humor vnd capriccio (Gehimn vnnd

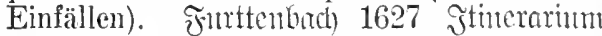
BL. $1^{\text {a }}$ Es ist, günstiger Leser, mit dem Menschlichen Ingenio oder, wie man jetzo zu reden pflegt, Geblüt vind Humor sehr vngleich bewant. Mengering 1638 (berwijen weder $\subseteq .225$ viser heutigen Welt Sim vnd humor. Riebe 1665 Reitbud ङ. 76 ein Pferd von bösen humor. Sorrtmann 1678 2tmatomia હ. 147 des jungen Herm humor. Eoclmann 1740 9gojes III 55 Ein Paar derselben sind sonderlich nach seinem Humeur. $\mathfrak{L e n z} 1774$ Cuntfiifinungen (II 99) alle Leute von Ihrem Humor.

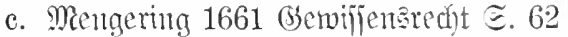
gleichen humor in Kirchen-Diensten benalten. Grimmetaraten 1669 હimpliz. ङ.413 an meinem melancholischen Humor. Bsothe 1774 Elnvigo (XI 92) kommst du in dem
Humor von deiner Braut? - YBerther (XIX 44) mehr Eigensinn und übler Humor.

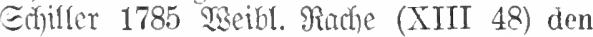
mutwilligen Humor. Frau ßath 1800 Brieje II 73. Goethe 1809 mahlberm. (XX 28). Eichendorfi III 108.

d. Srimmelshanjen 1669 Eimpliz. ङ. 159 der eines sehr frölichen Humors war. Ertinger 1697 Reifacidyr. E.39 Die einwohner sind eines lustigen Humors. Echiffer 1783 Fiesco (IV 205) jeh sei heitern Humors. Sunigge 1788 llmgana Є.261 den natürlichen guten Humor. Boethe 1811 Didftung $(26,41)$ wäre der qute Humor nicht manchmal unterbrochen worden.

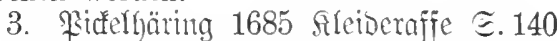
seinen hustigen humeur. Thomaius 1688 Monatsgejpr. I 2 von lustigem humeur. Suthuan 1700 Duafialker 厄. 200 eines lustigen Humeurs. Berfenmener 1712 2ntiquarite $\Subset .266$ die Höflichkeit und lustige Humeur der Frantzosen.

Sumnoreste $\widetilde{F}$. Dentidie Rilloung vom Mnfang Des 19. Jahrbs. nad bem sluiter Der ärteren Bur le Beleg: 1838 Die Crifonbahn E. 142b Man beschließt endlich, eine bekannte CaffechausGesellschaft in einer Humoreske durchzuhecheln.

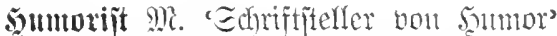
um 1750 ans engl.humorist entlehnt. Belege: Ricol 1767 Thenrie $\cong .93$ Lafontaine und Swift waren die grösten Humoristen.

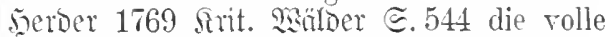
süße Gesellschaft aller lustigen Humoristen ๔. 545 Britanniens unzählige Humoristen.

humtoriatijaf Exmio 1775 Shronologie D. D. Ifycaters $\Xi .85$ ein treflicher komischer Schauspieler in humoristischen Alten. Serber 1796 Brieje (XVIII 124) Dic englifthe fonnöic] mit all ihren humoristisehen Lamen und Charakteren.

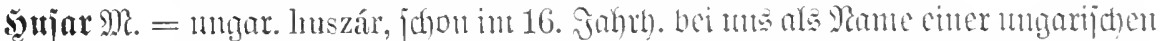

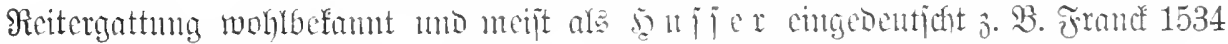

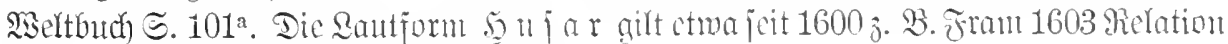
V 20. Carolue 1609 Rulation Pr. 6b.

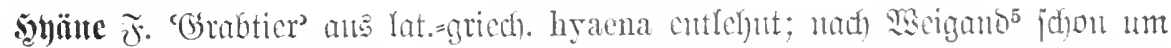

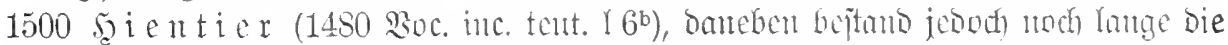

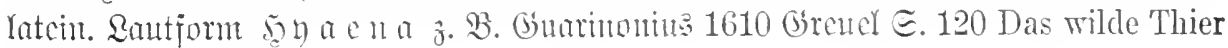
Hyaena.

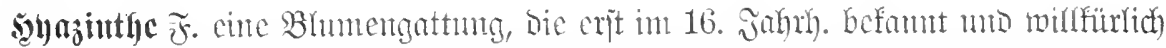
nach Den Yat. hyacinthus, befjen Beocntmug mujicher ift, benamt muros. Bufrifhit 


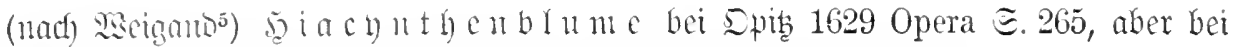

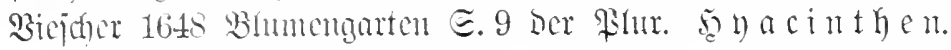

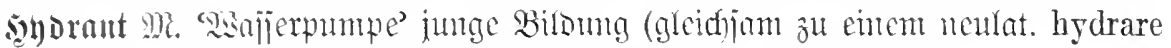

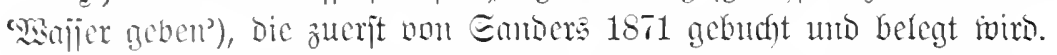

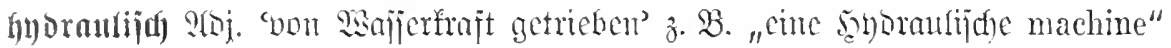

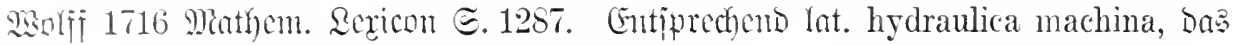

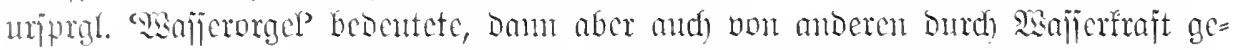

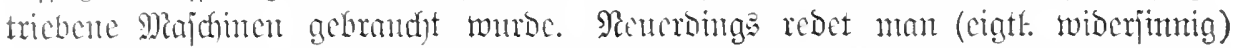
audf bon, ,

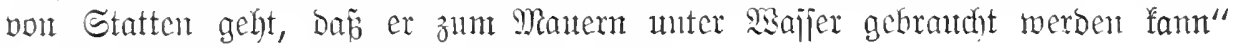

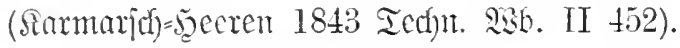

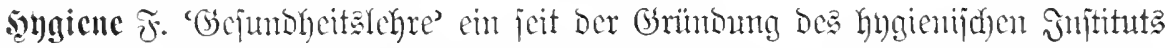

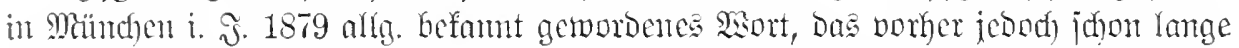
techuiliche Geltung hatte uns o. B. 1784 Dnomatologia med.=pract. II 1190 gebutht ift. Beleg (nact) Grombert, Beitr. E. 16): Mryling 1754 Echriften @. 131 ich habe zur Fahne der Hygiene geschworen. Edjon im 16. Jahrf. miro neulat. Hygiena (jdjon

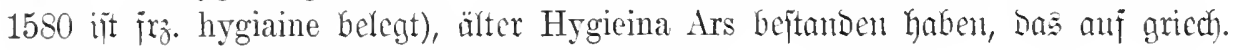

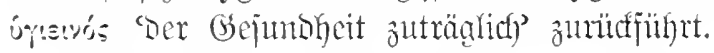

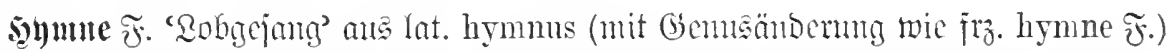

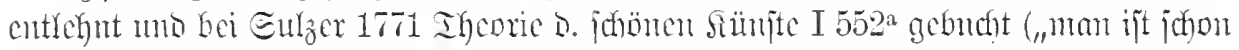

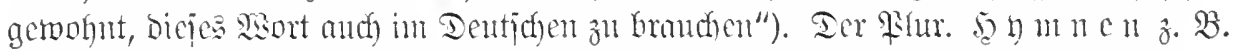
Zadfariä 1756 Iage

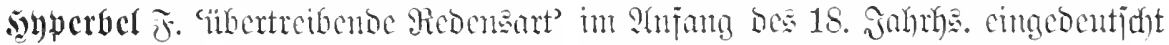

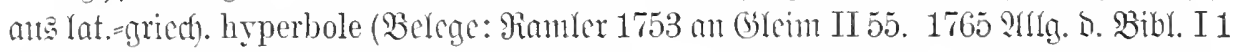

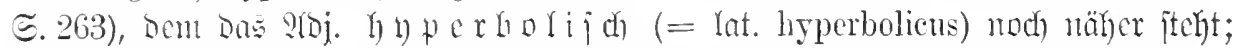
Beleg: Bajcono 1758 Praft. Philnjophic E. 193 hyperbolische Redensarten.

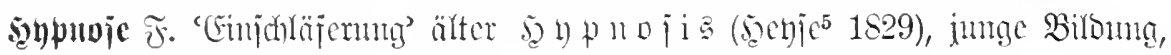

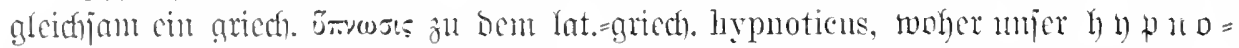
tija (1780 Mragazin $\tilde{j}$. Sapthefer II Ammerkungen über die Vorschrift des Hypnotischen Pulvers). Die särter suputisum und hyputipieren fino

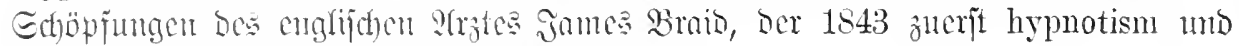
hypnotize anwemoete (ogl. Das Re

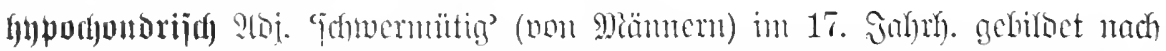

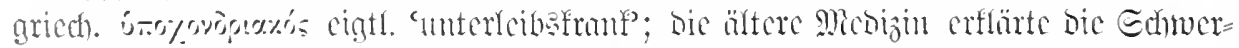

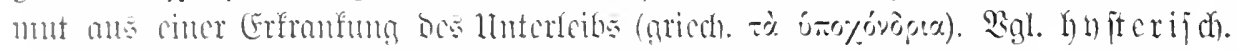

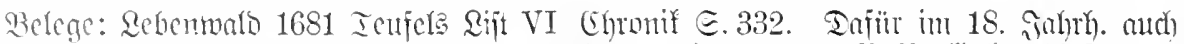

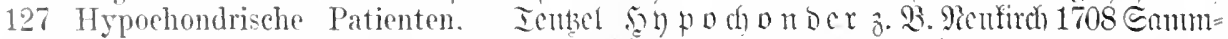
1689 linterteomgen $\Xi 633$ hypochondrische lumg IV 357 kommt einer mit dem Hypo-

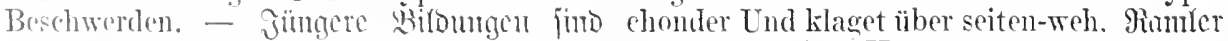

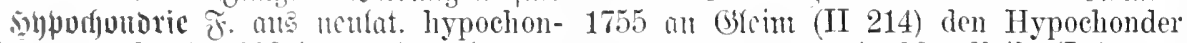
dria, das jufrithit 1668 in Englano bezeugt rerjagen. Shimmel 1791 Reife (I 3) Du 详 (9iesict.). Belege: Midfaclis 1773 widersetztest Dich der stolzen Uebermacht

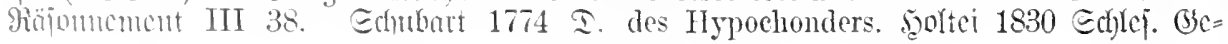




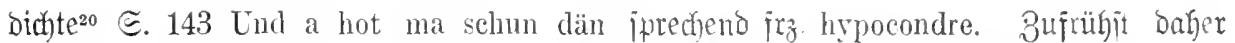
Gast im Haus, Dän de Dukter Hyppu- HuäDifatio (ohite 2(rtifel!) ber Goethe 1787 chunder nennen. (Geje)wijter (IX 129) daß er mir nicht $\mathrm{H}$.

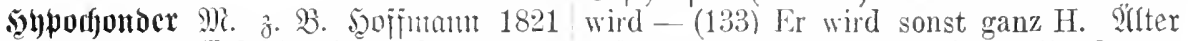

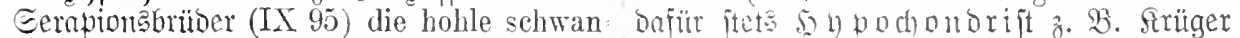
kende Stimme des abgelebten Hypochonders. 1750 Iiñt E. 255. Bürrger 1785 Brieje III

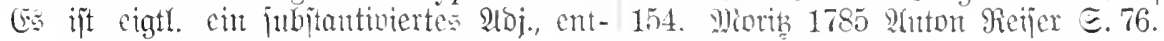

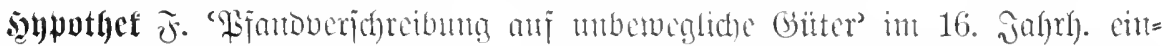

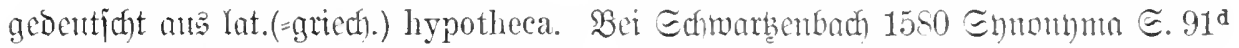
[Regifter] Pfand - Pignus, Hipothec - aber $\Xi .63^{a}$ Hypotheca. Tazu gleichacitig bas 3tw. ver hy othefieren z. B. Cyzinter 1591 Relationen II 143.

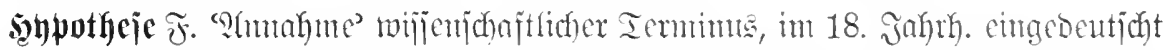
aus mlat. (=griech.) hypothesis (vielleidht nuter (Einfuñ von frz. hypothèse). Belege:

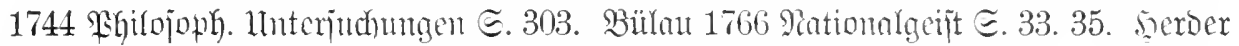

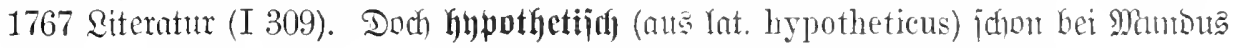

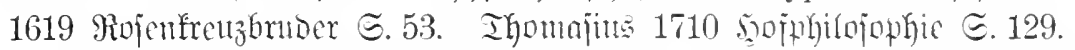

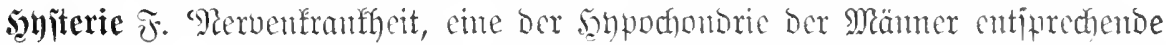
Frauenfrumfeit' eine junge Birbung Des medizit. Satcins (Hysteria) zu Den älteren hy it erijh. Beleg: Echiller 1780 sijfertation (XVII 141) das große Feld der Hysterie und Hypochondrie.

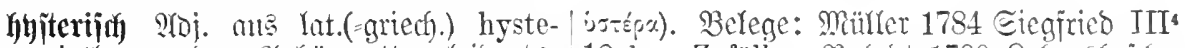

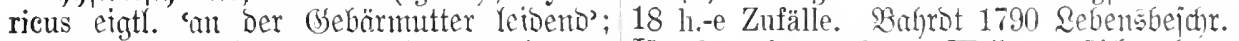

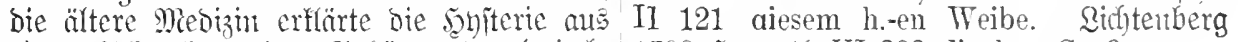
einer Crrfranfung ber Gebärmutter (griech. 1798 soggarth VI 289 die h. -e Gräfinı.

\section{ঔ.}

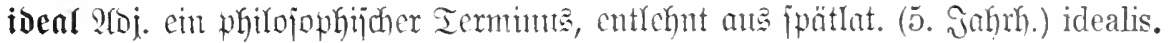

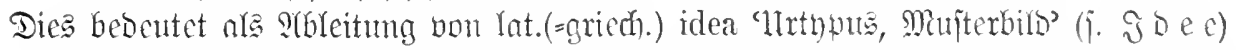
zunächit 'mujterhaft, vorbilolich) (,esse exemplariter" Cišler I 513), bam (zufrithjt

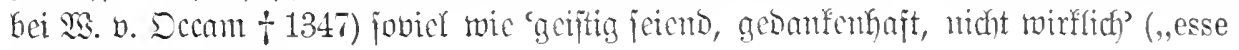
in intellectuc6 cbo.).

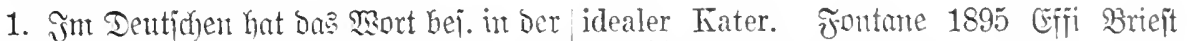
1. Bebeutung 'vorbirslich), muiterhait' allg. @. 455 so wäre es ideal.

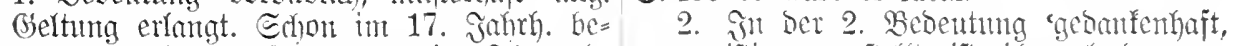
gegnen Bujammenjebuntaen wie so eal $=$ mu geifting borgeftellt ijt is a al bagegen

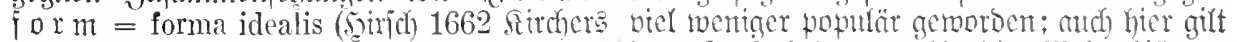

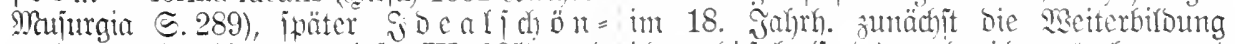
heit (1759 2iteraturbriefe IV 285) und ibealijef (i. D.), und ibeal begegnet

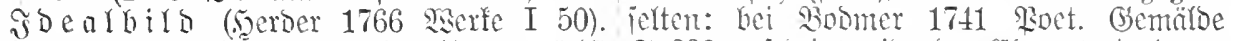

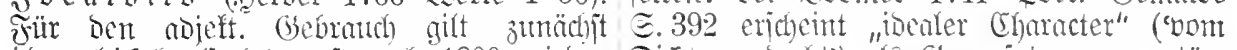

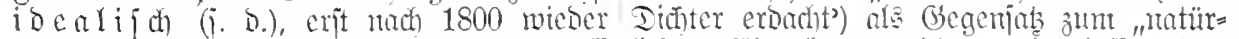

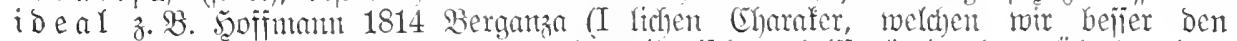
124) die ideale Bühne, welche nur im min- hijtorijhen heiffen" in Der lłberị. einez desten den gerechten Ansprïchen zusagt. Ed)reibens bun 2ntontio Conti (Cinteit. Zu

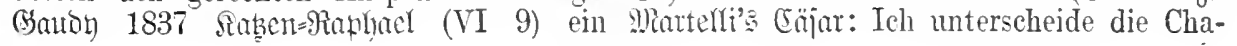


racter der Personen in ideale und natürliche), atjo moly sinchahmung italien. Evrach= gebranter. Enn̈ter 3. B. Iimme 1785 Rnft= banmeifiter I $27 \%$ diese Abstracta wieder in ein ideales Ganze zu rereinigen. Erit Echiller Graudht hüufiger bie Form i beal: 1796 Panine u. jent. Iichtung (XVII 508) indem hier wirklieh das Individum ideal sei und das Ideal in einem Individun erseheine die Aufgabe auch in der Dichtkunst, das Ideale $\mathrm{zu}$ individualisieren mond das Indiridnelle zu idealisieren - $(540)$ dazu ist er [Sé̈ner: sirte] ein zu ideales Wesen. Sm 19. Jahry. wird bicjes i de a l burch id e ell erjest.

3. Ias alte is eal aher leht mit einem unffaren Bebeutungsinthat jort, in bem jich bie beiben eben crörterten Bebeutungen gemijht haben. Im Bereich Der funjt bezeidnete mu

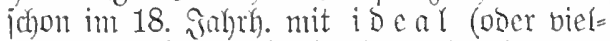
mehr mit ibealifal) bas uber bng ge= wöhnlide ㅃan erhabene Edhöne, nach dem ber fämitler ftreben forl (zu 1), bas aber in femer hödyjten Bolfommenheit umerreichbar bleint und nu im Beift borgejtelft weroen fom (zu 2). Beleg̣: Eomenfels 1768 Porträt= maler હ.34 wann der Künstler die individuelle Schönheit der Idealen am nächsten zu bringen weiB. Epäter geht Das sisort aus ben Bereid Der Sithetif nod in ben Bereid

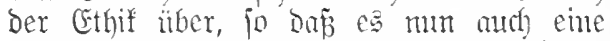

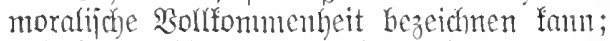
bgl. Jocalismus, Jocali jt.

Joeal $\gg$. 'QSolfommenheitshegrifj' Eub= ftantibienmg aus i Deal 1, nad) Sicland (1775 Merfur IV 62) "feit cumgen Jahren

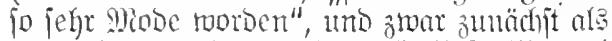
æaot ber "Echönen Sümite" (bej. Malerei

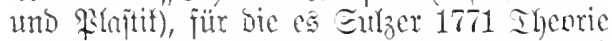
I 354 hudft. Belege: Miendelsform 1760 Riteraturbricfe V 124 So wol die Lebensart als die Empfindungen können entweder der Natur gemäß, gleichsam porträtirt, oder nach dem Ideal verschönt werden. 1761 cbD. IX 56 Homer vermeidet mit aller Sorgfalt das sittliche Ideal. Jerber 1766 sierfe I 50 ein Ideal der Schönheit. Rejing 1767 Irmmaturgic (IX 281) das poeticche Ideal von dem wahren Charakter. Edfiffer 1796 Didnturig (XVII 543) Alle Wirkliehkeit bleibt hinter dem Ideale zurück.

2trm. Das friblyte Beugnis für dos Eubit. Ideal glaubte Rejing (Collectanea BD. XV 288) mi itafienififem Soben nath=

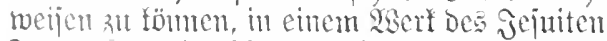
Franc. Sant ( $\doteqdot$ 1687). Dod ijt jiir Die Etelle aud) abjeft. (Geltung möglich: Io vorrei, che li pittori pigliassero le sue parti dal naturale, ne sò intendere, perchì debba esser più bella una figura dipinta a capriccio, che chiamano di maniera, ed io la direi ideale, di quella che è presa dal naturale (nach) Manthuer, 然. Der Rginojopjie I 532b).

idealiign 2(Dj. cine hent ungebräubliche meiterbiloung an ibeal, bie bei. im 18. Jnhry. mit ben gleichen Bedeutungen wie Diejes gntt. Belege: 1. "vorbilslich,

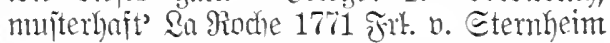
ङ. 197 meinen idealischen Plan. Bocthe 174 2iertfer (XIX 90) eine gewisse idealische Behaglichkeit - 1796 Rehrjahre (XXII 239) das ganze Verhältnis, das wirklieh eine Zeitlang beinahe idealiseh gehalten hatte.

2. 'qebanfenlaft, mur geirtig vorgeitellt' Neier 1755 Metanhyif I 272 Wenn man sagt, daß das Leiden einer Substanz zugleich ihre eigene Handlung [bejier: ßorjtellung] sey, so nennt man das Leiden ein idealisches

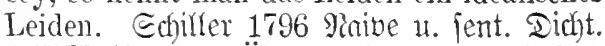
(XVII 504) Die Übereinstimmung zwischen seinem Empfinden und Denken, die in dem ersten Zustande wirklich stattfand, existiert jetzt bloß idealisch. Börme 1828 :3. D. Serbe (I 309) in einem solchen idealischen $\mathrm{Zu}$ stande.

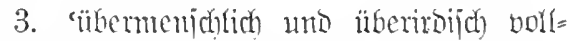

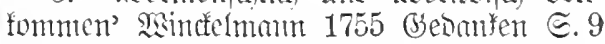
Die Kenner und Nachahmer der Griechischen Wercke finden in ihren Meister-Stücken nicht allein die schönste Natur, sondern noch mehr als die Tatur; das ist, gewisse Idealische Schönheiten derselben, die von Bildern blob im Verstande entworffen gemacht sind - $\Subset .15$ Die simnliche Schönheit gab dem Künstler die sehöne Natur; die Idealische Schönheit die erhabenen Züge: von jener nahm er das Menschliche, von dieser das Göttliche - 1764 (Bicjch. D. Sumit I 151 Die Bilsung ber Echönlfeit] ist eine Wahl schöner Theile aus vielen einzelnen und Verbindung in eins, welche wir Idealisch nemen. Ravater 1776 figniognom. Frag= mente Il 21 ein un- oder antiidealischer Christus. Echilfer 1787 Ion frarlng (V 81) in einem idealischen Geschmack, schön aber einfach gekleidet.

idealijieren Btm. 'Dem Borffommenheits. Gearifi näher bringen, berjebünern' in 18.

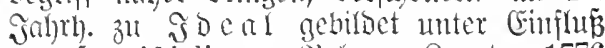
bon irz. idéaliser. Sielege: Sanater 1776 秥ningnom. Fragmente II 86 alles versehönert, idealisiert! (joethe 1795 Unter= galtumgen (XVIII 107) jumge Leute, die einen Gegenstand $z u$ idealisieren geneigt 
seien. Edriller 1796 Iidytumg (XVII 539) Die $\mathfrak{R}$ oejic] kann ein Tnendliches sein der Materie nach, wenn sie von ihrem Gegenstand alle Grenzen entfernt, wenn sie ihn idealisiert.

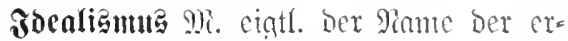
femtnistheoretiogen Qefre, ntad) Der Dic

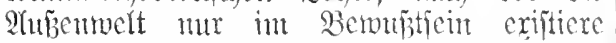
(Bclea: Menderafohn 1786 Niorgentumben

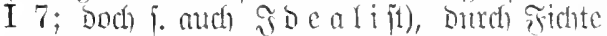

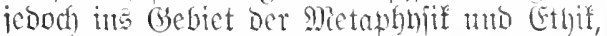
burdy Edriller nodh in das ber gifthetif gezogen.

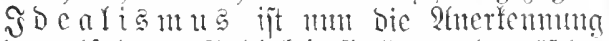
Der abjoluten Güftigfeit jittlicher ober äthe=

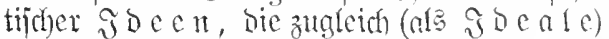
als Bicle Des menjlytiden Etreben auf= geitelft merben. Belea: Echiffer 1796 Raibe u. jent. Diditung (XVII 566) Nicht zwar, als ob der Idealism mit der Sittlichkeit je in Streit geraten könnte, welehes sich widerspricht; sondern weil die menschliehe Tatur eines konsequenten Illealism gar nicht fähig ist.

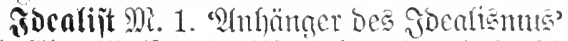

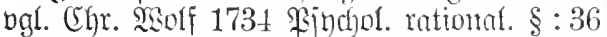
Idealistae dicuntur qui nonnisi idealem corporum in animis nostris existentiam concedunt adeoque realem mundi et corporum existentiam negant. Selege: 1745 Phifojopl).

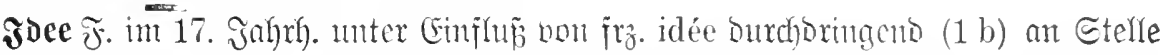

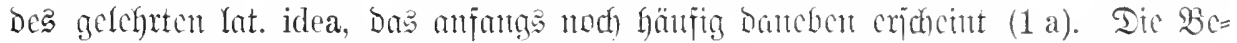

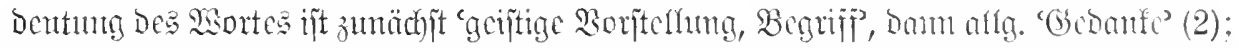

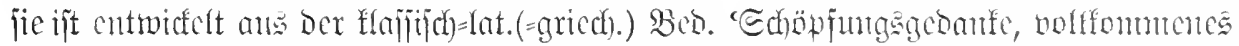

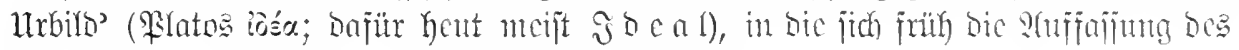

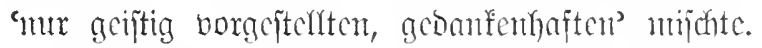

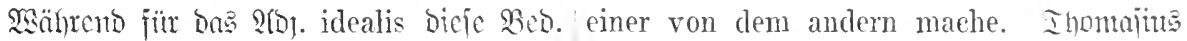

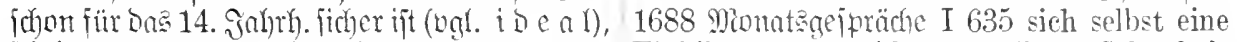
jocint ber neue bebraud vou i d e a crit Einbildung oder idee von ihrer Sehönheit

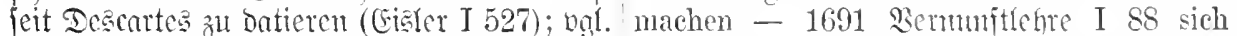
Deficn 1642 Resp. III 5 ostendo me nomen so gar wunderliche und falsche ideen von

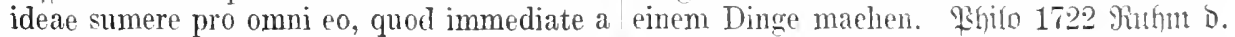
mente pereipitur, adeo cum volo et timeo, Iabaks $\Subset .19$ wenn ieh ihm ron bemeldten quia simul percipio me velle et timere, Sorten eine lileine Idée gebe. EDelmam ipsa volitio et timor inter a me munerentur. 1740 Mojes II 78 daß er behaupten will, daß

Bclege: 1 a. Eectenonrif 1685 Chriften= gantze Völcker keine Idée von Gott hätten. ftant I 67 ein concept und idcam von Gott - Bobmer 1741 Roetijehe Gemäloe Є. 39 II 65 Gedancken und Idea oder Einbildung, Der Seribent ist bemühet, die Phantasie was ein Gott sey. Beibler 1700 Böje Geifter der Leser mit Gedancken anzufüllen, das હ.140 eine Ideam von der Tugend. Mar = heißt in der Sprache des Hrn. Descartes, perger 1714 Srobieriftein $\Subset .50$ wann er ihm er will ilmen Bilder von Dingen in das Geeine Ideam davon machet.

b. Seibuiz 1670 Eecuritas publ. (I 201) hime mahlen .... Eine Sache, die auf diese Weise mit Worten abgebildet worden, heißt daß man sich zu Friedenszeiten kennen nun mit dem Kunst-Wort eine Id e e, lerne, und nicht so wilde abschenliche Ideen welches auf deutsch nichts anders heibt, 
als ein Bildnib und Gemählde - E.159 bei Edferling 1800 Enftem bes trongzeno. Thre blane Farbe führte ilm auf die Idee ioenfismus 〔. 76 Nun muß aber die Schranke vom Himmel.

2. Seroer 1767 lither bie Dentiche Riteratur (I 147) Worte und Ideen sind genau in der Weltweisheit verwandt. Bocthe 1774 sierther (XIX 56) Eure Idee will noch nicht die meinige werden - 1796 Rehrjahre (XXII 222) um unsere Leser nieht mit unzusammenhängeuden Ideen und bänglichen Empfindungen zu quäleu. sterher bie Buij. Sermimus (1660 Essay coneern human

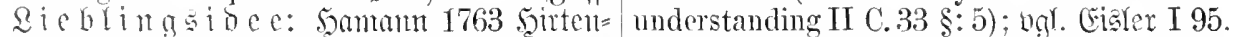
briefe (II 429). Goethe 1774 sierther (XIX 411). Pinteler 1831 Briefe III 15.

isecrir soj. "gedonfenthajt, mur aeiñtig bor= gejtellt' Im 1800 anftretente bentiche Pren= bilbumg fïr i Deal (2) wohl nad bem

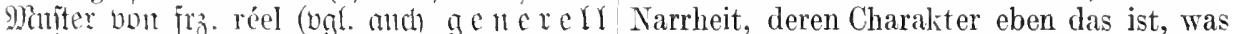

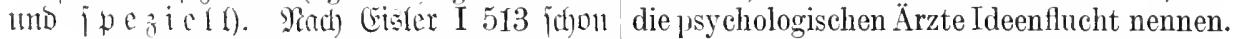

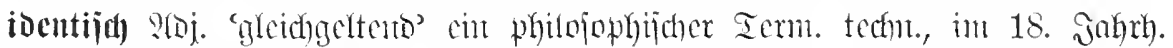
( ccijing 1767 Drontaturgic $\subseteq .265$ vollkommen identische Sätze) eingebürgert

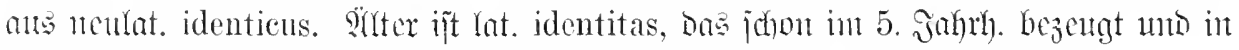

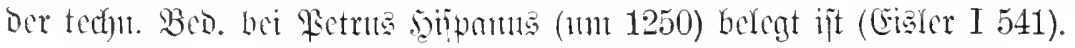

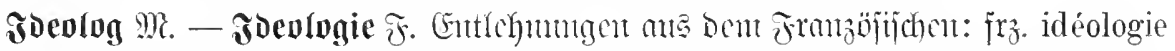

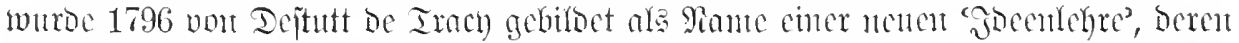

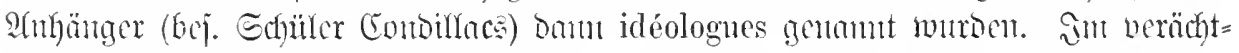

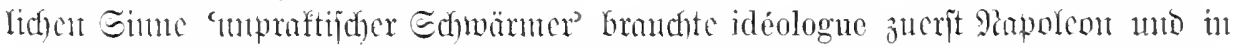

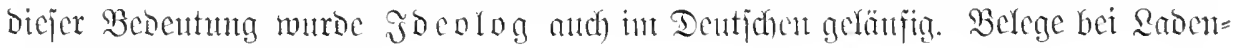

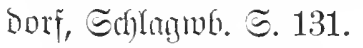

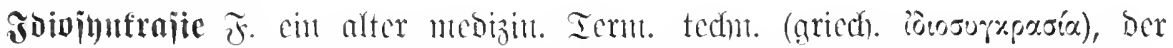

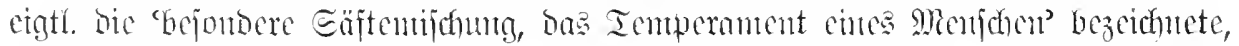

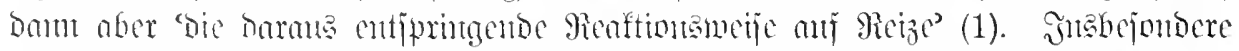

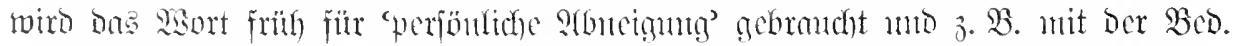
"unbezmongliefner Eefel" 1784 Dimmatologin med.=pract. II 1231 gebucht (2).

Selege: 1. Strüger 1750 Iï̈t E. 13 Diese Geruch ihnen so willkommen ist, als Nelkenbesondere Einrichtung, dadurch sich ein duft. Eeume 1806 Eommer (IV 91) es menschlicher Cörper von allen übrigen der- kommt mir vor, als habe ich etwas von der selben Art interscheidet, ist eben dasjeni@e Idiosynkrasie, daß ich nur die Nacht recht welches die Aerzte mit dem Tamen der 1. gut scnlafen kamn.

belegen. Edhitfer 1780 Differtation (XVII 2. 5roffmam 1819 Erixiere (II 51) er 141) wemn es mir erlaubt wäre von Tem- fand violmehr in meinem Abseheu gegen peramenten, I.-('u und Konsensus zu reden. Euphemien nur eine höchst merkwürdige I. Foriter 1788 Qeforeien (ङ.72) Ter sich an (52) daß Hermogen mit mir vielleicht die I. diese I.-en kehren wollte. 9lïlter 1791 teile. bente 1830 Stafien (III 411) während S)ert Ihoutns I 75 der ihmen diese - I. mögt ich sprach, wirkte ihre I. gegen diese Blume ich sagen, mitheilte, vermöge welcher kein, so stark.

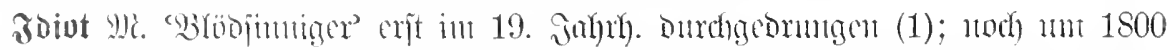

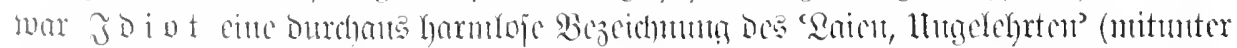

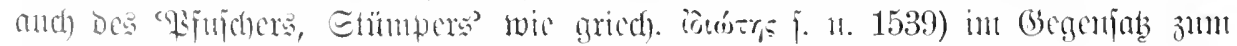

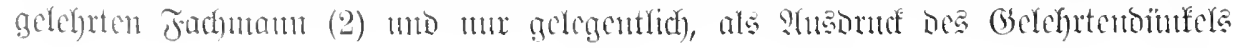




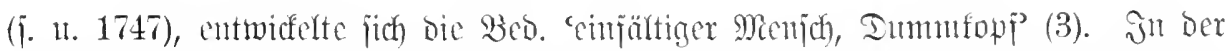

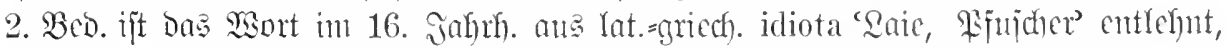

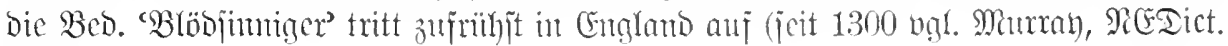
$\left.\mathrm{V} 22^{\mathrm{a}}\right)$.

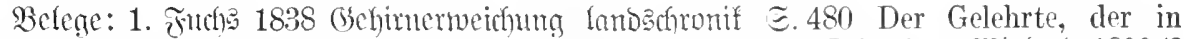
S. 147 aie Kranken sind im Begimne förmlieh diesem Fache oft Idiot ist. Micland $1800 / 2$ wahnsimnig und später Idioten. Shevie 1873 ?friftipp (XXIV 165) wir bekennen ms

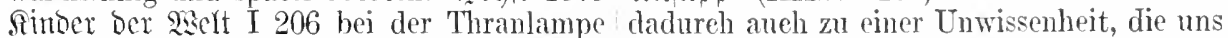
dieser biederen Halb-Idioten [sc. fimtifdye mit den ungelehrtesten Idioten in Eine Reihe

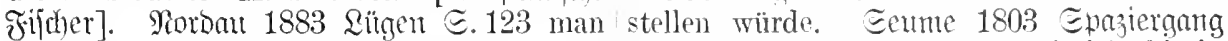
weiß, daß er ein Idiot ist.

2. Begarbi 1539 Index Sanitatis @. $27^{a}$ die hecken oder kälber ärtzet, oder die idioten, wie man sie pflegt zn nennen. 1564/7 3inmter. Chronif II 501 eben die, dorzu geschmeist, verordnete dieser Wahnso uf historias sich zum wenigisten versteen simnige dem Kranken 100 gran und curirte und sieh als idioten und ungelerten leut deren ihn feliciter zu Tode. Wann ieh aber weiB, zum wenigisten wissen zu gepranchen. daß ein solcher Mann ein Idiot ist, warum Frand 1576 Catalogus Haereticormm $€ .81$ branche ieh ihm. Grmoling 1738 Eatir.

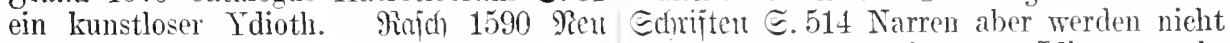
falember $\supseteq 2^{\text {b }}$ das ich aie wörtlein idiot, refutiret, sondern wie mser Idiot vor abvnglert, lay, gmain mann, pöfel vnd der- wesend gehalten. ¿elimg 1747 jg. Gelehrte gleichen, nit aus oder zu verachtung schreibe, (I 283) Der alte Idiote - (318) Was für sundern das mann diejenigen die nit studiret, ein Idiote! Ich rede ron der Republik der anderst nit nennen kan, wie die glerten Gelehrten. Robenter 1751 Entir. Echriften

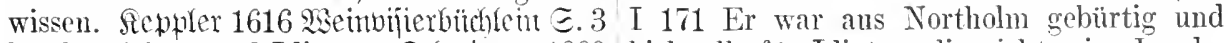
beydes glehrte vnd Idioten. Edrmieger 1660 hielt alle für Idioten, die nicht seine Lands-

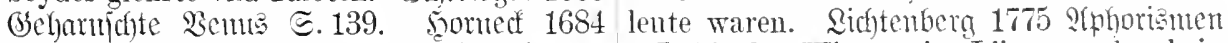

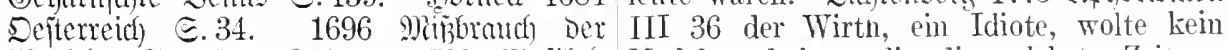

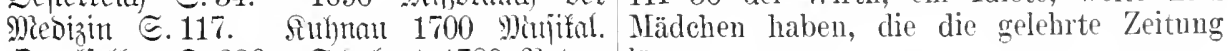

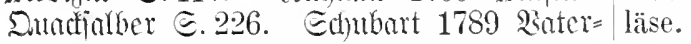

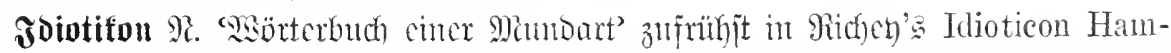

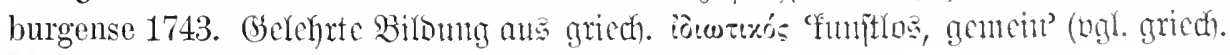

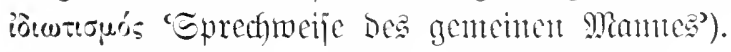

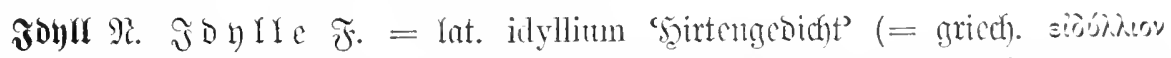

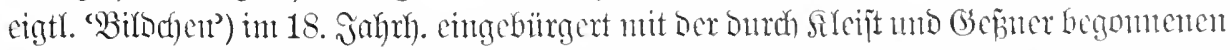

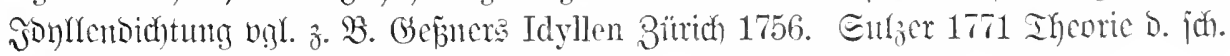

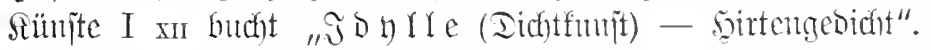

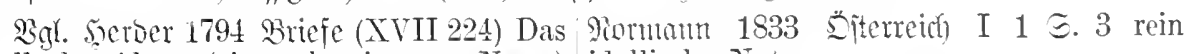
Idyll der Alten (ein unbestimmter Name) idyllisehe Tatur.

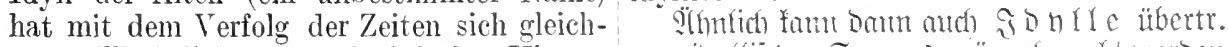

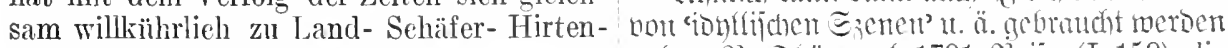
Fisehergedichten zurïckgezogen.

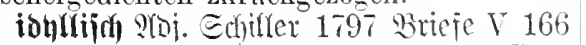
daß Ihr Gedieht idylliseh endigte. Sülifiger

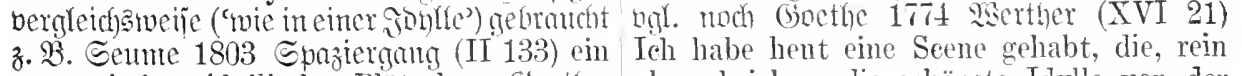
romantisehes, idyliisches Plätzchen. Gónethe, abgeschrieben, die schönste Idylle von der Faụ̂t $\mathfrak{B} .9587$ wie idyllischem Liebespare. Weit gäbe.

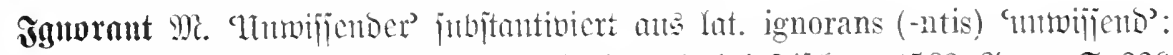

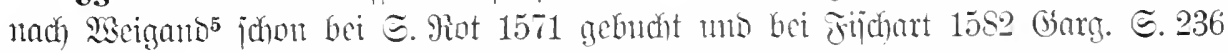

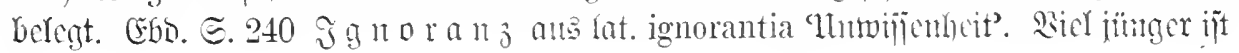


ignorieren 3tw. 'nicht fenuent wollen, Quittung geschehen kömne. Michaefis 1776

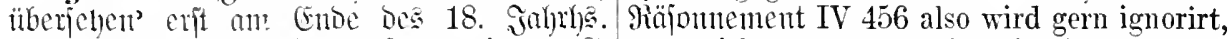
aus lat. ignorare (ooer frath. ignorer?) was nicht so gerade in die Augen fällt. entlehnt. Sielene: Qeifing 1770 Brticje (XVII Ectiffer 1789 Briefe II 304 so zerreissen und 327) Ew. Durehlameht Cammer Cassa aber ignorieren Sie diesen Brief. noeh ignoriret, dab solches numeln auf meine

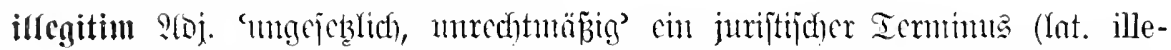

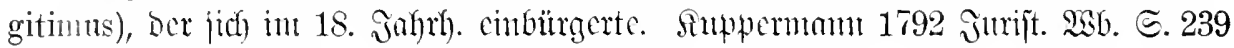
bucht ,Illegitimes berfahren" nebent Illegitime - illegitimus filius. Beleg: Echiller 1796 Bricịe V 16 Theresens illegitime und bürgerliche Abkunft. Bgl. l e g it im.

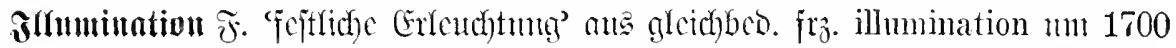

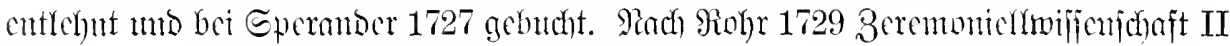
839 "hat unan in Tentichland nur ctwan vor 30 Jahren bic erifte illumimation gejehen".

Belege: Sïutig Friebrich I. 1706 Brieje ๔. 112 Heute ist regen wetter, weshalb die illumination bis anf ein andern Tag verschoben wirdt. Bichadfwith 1723 Sint VI. ๔. 687 So waren auch alle Häuser sowohl dieser als anderer Strassen mit den sehönsten Tlluminationen reziehret. Rioly 1728 Bere= feurhtet

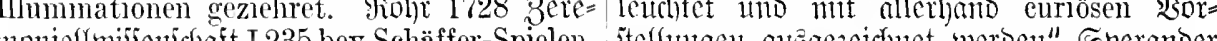

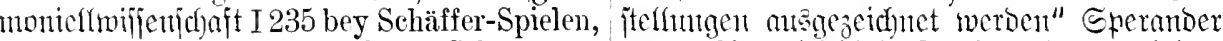
Illuminationen, Fenerwercken, Schneppen- 1727. ST1s gleichbes. Frz. illuminer entlehut.

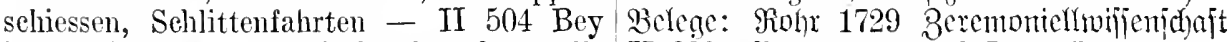
ihrem Einznge werden die Stücke gelöset, alle II 839 alle Häuser und Kran-Läden ansGlocken geläutet, des Abends lllnminationen zuzieren und zu illuminiren. F:lorin 1749 angezündet und Feuerwereke angebrandt. Scanšater II $71^{\mathrm{b}}$ die Häuser illuminiren.

illuminieren' 3 tro. 'mit Farben ausmalen, folorieren' cin alter 9usond ber Druterjpache (ans leat. illuminare 'crlendeten' cutlebut), Der crjt im 19. Jahrb. unge= bräuchlidf wurbe, als ber modeme Farbendruct bie alte scanbfolorieruntg verorängte. Beleg: Eberliu 1521 Pifafjentrojt (II 84) bïcher corrigieren, cinbinden, illuminieren etc.

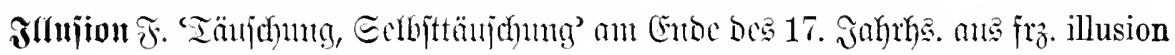

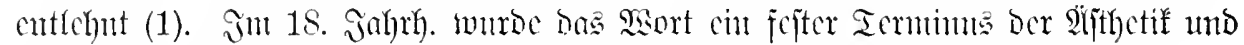
wird beị. in Der Debatte über Die Saturmahrheit Des Dramas viel gebraucht (2).

Befege: 1. 1699 Etantajpienel II 11 es 'was die I. hier nicht befördert störet die I. würde auch solehes aller natürlichen und (333) die 1. des Dramas. Scerber 1767 Riteratur gesunden Vernunfft $\mathrm{zn}$ wieder lauffen und (I 344) kurz bis zur I. und zum höehsten also nicht anders als ohne allen Effeet und Wohlgefallen erhebt sich der Zweek der Nachdruck ja einer puren I. unterworffen Idylle. Edfiffer 1780 Iiffert. (XVII 135) die

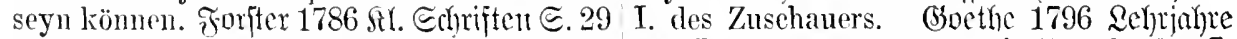
um die gewöhnlichste aller I.-en zu ver- (XXI 19) als Zusehaner die Freude der I. meiden. Laube 1836 Reijenobellen III 164 zu genießen - 1811 Sidgtung ı. 2iahrb. Die Jngend unserer Zeit verwirft die Pietät (XXVI 148) alles was man bei'm Theater und will keine I.-en gestatten. Sot)je 1873 I. nennt.

Stimoer D. Medt II 144 ich gehe olme I., als ob ieh irgend einen Einflub auf den Gemüthszustand der Fran Gräfin auszü̈ben vermöchte.

2. Seifing 1767 Iranuturgic (IX 226) und will lieber aller $I$. als dem Vorrechte entsagen, den Zayren und Meropen auf die Sehleppe treten zı können - (229) alles

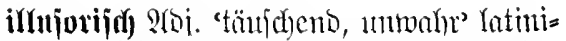
fiert aus greid)bed. Fro. illusoire (Iat. illusorius 'verjpottento). Belege: Rejiutg 1767 Dranta turgic (IX 185) in einer so illusorischen Stetigkeit. (3ïurrę 1819 Teutfa)lano S. 37 gar keine oder mur eine illusorische Verfassung. 


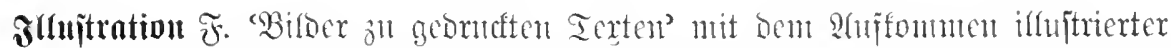

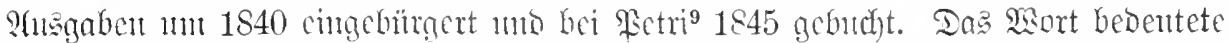

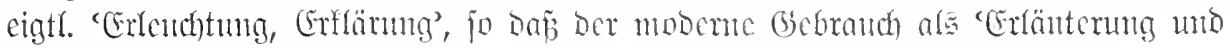

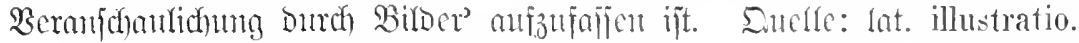

Fmofern aud jofjon in äterex Beit cinte II 39 dieweil die praecepta für sich selbs Beramiffanlicfung Durch Bifoer üblid) war bloß seind, und keinen nutz schaffen, wo

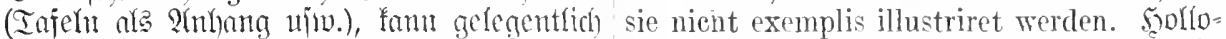

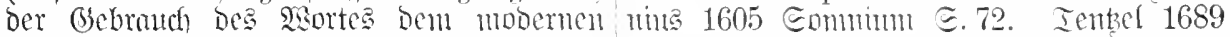

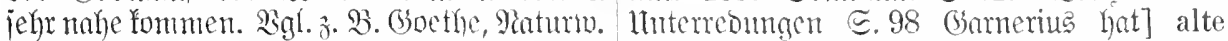
Schriften II 60 Man gehe die sogenannte Schrifften zum ersten in clen Druck geIllustration dieses Experiments und die bracht und den Liberatum, Theodoretum derselben gewidmeten Figuren und Beschrei- und dergleichen illustriret. bungen dureh. Dagegen Minur 1846 Intitich= Innd S. 3 manche Artikel [Des fremionentelis] sind sogar noch mit Illustrationen versehen.

illuitrieren Btro. 1. 'mit Bilnern werjehen (eigtl. crlöutemI) jeit Retri ${ }^{9} 1845$ gebucht. Beleg: 1839 Tic Eifenbahn E. $621^{\mathrm{b}}$ Bonaventura Genelli wird die bei Cotta erscheinende Prachtausgabe des vossischen Homer mit Umrissen illustriren. Tic "ŝlfuptrierte Beitung" in Reipzig erjcheint jeit 1843.

2 a. 'erlentuten, erffären' au lat. illustrare

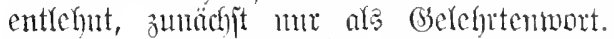
Belege: 1569 Braumjow. Eefulorbumigen

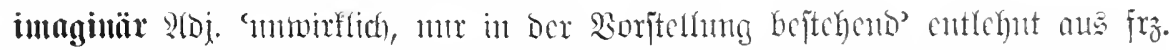

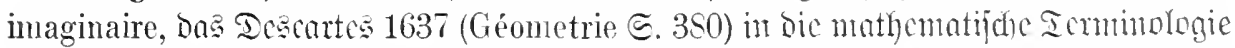

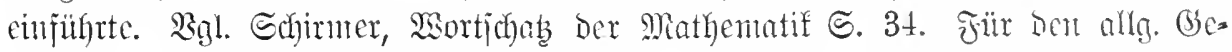
braud bgl. Gocthe 1814 Didht. 11. MEafrh. (28, 247) Auf diese Weise war er Zeitlebens ein Scheln in der Eimbildung, Seine Liebe wie sem Haß waren imaginär.

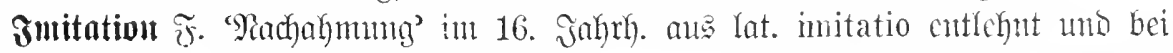

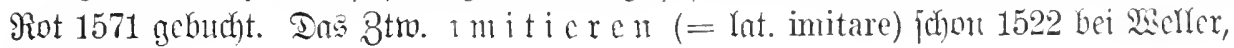
Beitungen S. 45 .

inmatrifulieren $8 \mathrm{tw}$. 'in Dic Natrifel einer Itniberjität emidgreiben' 1558 int

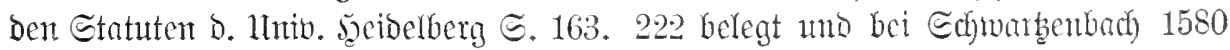
ङnnonynta $\Subset .28$ a gebucht.

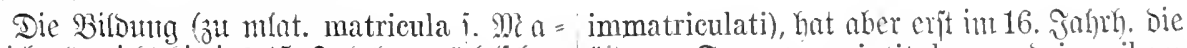

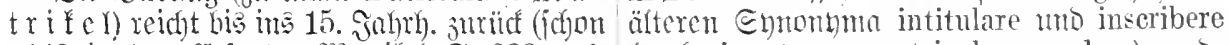

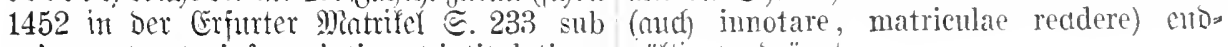
cuius rectoratu infrascripti sunt intitulati seu gïltig verorängt.

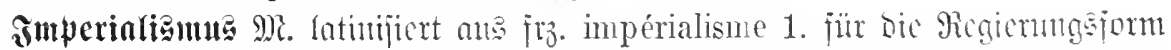

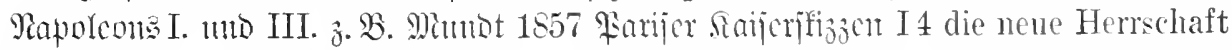

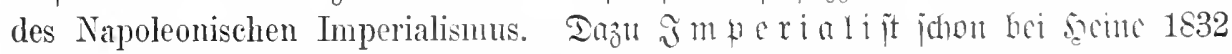

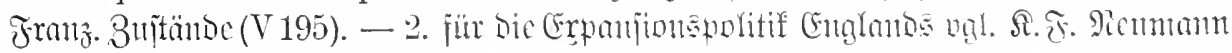
1857 (3) cjh. D. engl. Reichce II 65 den imperialistischen englischen Standpunkt.

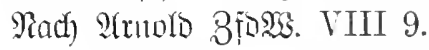

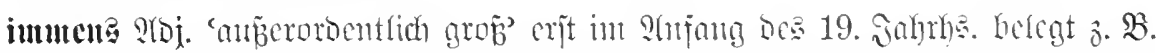
(5socthe, Stal. Rcijc III $(32,169)$ Die Rembaln gibt uns doch noch einen Begriff 
eines solchen immensen Raumes. Ganufi 1826 Mcunoiren II 169 seine Sprünge reichen

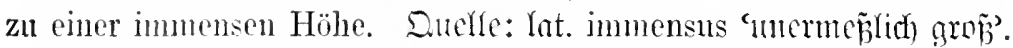

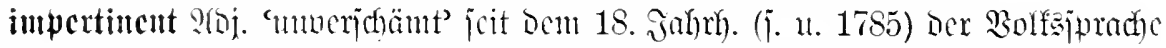

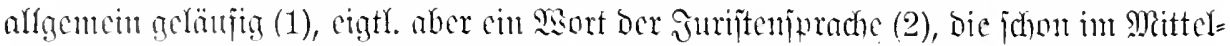

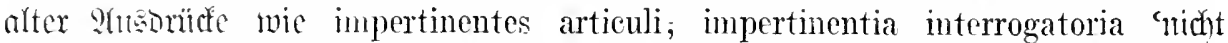
jur Sache gehörige, nicht jachoienliche Fragen’ fannte (Suclfe: ipätlat. impertinens, 5. Juhnef.). Der moderne (Gebrauch), Der etwa jeit 1700 bezengt ift, max wohl alfo

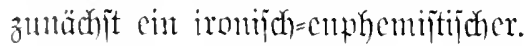

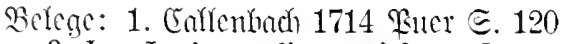
so $\mathrm{muB}$ der Jupiter selbst weichen, despotische Befelch, trutzige Minen, impertinente Zumuthungen. Evernder 1727 Sambleri= for $\Subset .301$ Impertinent, ungereimt, abgeschmackt. grob z. E. ein impertinenter Kerl. Bbleim 1753 an Pianter II 7 ein impertinenter Kerl. Cramter 1773 an Bïrger (I 80) Der Kerl ward so impertinent. Micolai 1785 Reije V 304 Die Frau rief der Magd zu: Oetz scherts eng no glei, oda $\mathrm{i}$ gieb eng ann auf d' Fotzn, öhs impertinents Mensch.

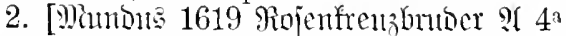
ist doch sein Sudlschrifft mnd Seartecken so rngeschickt, impertinens rnd rngereimbt.] Thomaitus 1691 Bemunftleyte II 248 in Gegentheil aber die Bücher gemeiner Leute als bürgerlichen Standes, Kanffleute, Handwerckslente, Bauren u. s. w., als ob sie voller impertinenten Thorheiten wären, zu rerachten. CGitemont 1705 Siriegerat II 13 Nebst diesem ist auch im löchsten grad impertinent, was mein Gesandter ron Regenspurg mir berichtet. (juthfon 1838 Blaiesow

II 234 Der Einwand ist irrelerant, oder wie wir Juristen sagen, impertinent.

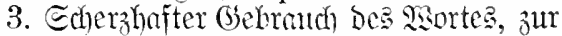
Glożen Serftärfung alggejdyächt (bgl. i n= fam), bej. impertiuentbyoub cröt= (icis) nady Bicdr. III 179 in emem Brief ber Rahel Barnhngen bei smbe, Eharnfteriftifen I 362 die sogenannte impertinent blonde

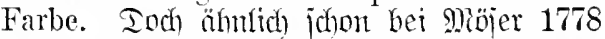
gihantafien III 19 wie impertinent boshaft.

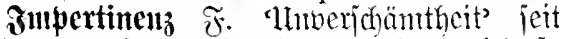
Empe bes 18. Jahntys. hezeugt, Dod nicht jo

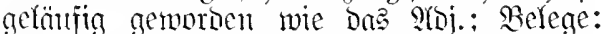
Midfaclis 1770 Räjomement II 314 haben diese Impertinenz genug, im Concilio einen lauten Ton anzunehmen. Siurger 1776 Brieje I 298 Wunderlichs Impertinenzen [297 Proben ans seinem paradoxen Buch].

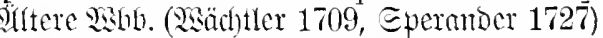
muchen "Inpertinentien, ungcreinte Iinge", D. h. cigtl. 'Tinge, bie nidht zur Eache ge= Gören' in ben bben bei impertinent beiprodienen juriftifden Eime.

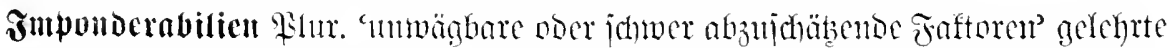

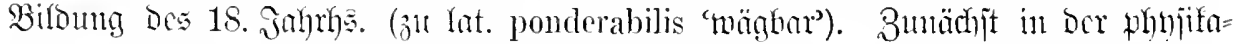

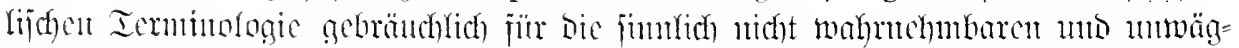

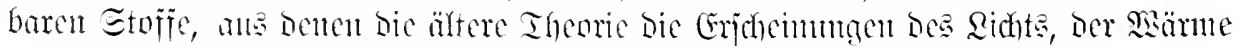

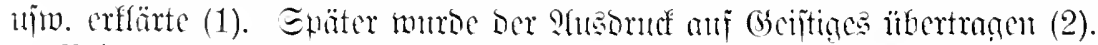

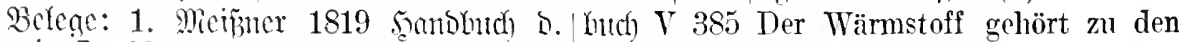
Ergmie I 193 Tach der einen Anordmung im p o nd e rabeln Stoffen.

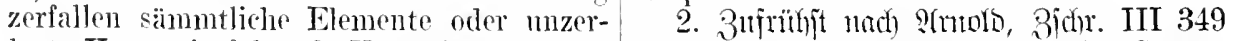

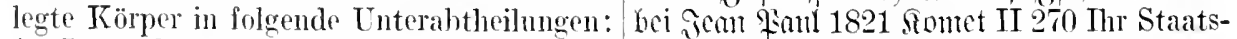
A. Imponderabilien. Incoercibilien (unwäg- nnd Geschäftsmänner, sehet doch die Philobare Stoffe, uneinschliebhare Stoffe). Dahin sophie und Poesie, welche kein kameragehören: das Lieht, die Wärme, die Electri- listisches Gewieht aufzeigen, darnım nieht eität, derGalvanismus und der Magnetismus. für unwichtig, sondern gerade für die geiB. Ponderablien (wägbare Stoffe). Binunner stigen I. an, welche den körperlichen gleichen, 1848 Firutzenjchtte I 127 Sie haben doch schon die, wie z. B. das unwägbare Fener, Licht, ron d'n unwïgbalren Stoffen, von den I. ge- Anziehen und Abstoßen, allein erst das Gehört. Fö̈r bie kiorgejchichte ber Shilbung \& $\mathrm{m}=$ wiehtige und Körperliche zusammensetzen

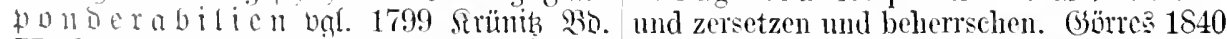

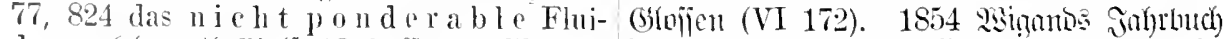

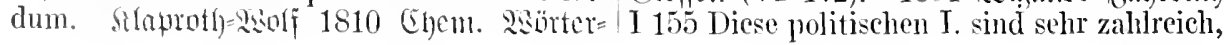


Bišnumat 1868 Reben IH 432 zu den I. in sind als die der Heere und der Gelder. Eeit= der Politik, deren Einflüsse oft mäehtiger, Den alfgenein getäuịig.

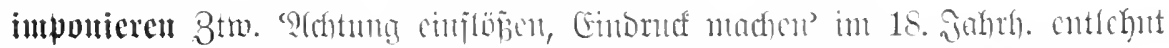

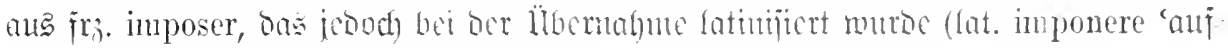

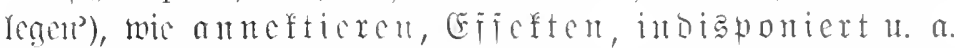

Belege: Bumzemonf 1749 secrenhnt in impoiant 2roj. ans fro. imposant (eigtí. Tumbre II 670 der allerschlechteste Hensch, Fontiz.), eme jumgere Entlehmug: Echilfer der viel mit Lenten umgangen, kann was 1788 Brieje II 1 ös Es ist kein imposanter gerades, was kühnes, herzhaftes und impo- Karakter. Setmes 1790 Fiur CEltern V 72 nirendes in der Mine führen. Reiïing 1767 Verschwiegene Entschlüsse und Eigenmacht Dramaturgic (IX 204) jene Ruhe, welche in der Ausführung haben auch etwas impodie alten Kunstwerke so imponirend macht, santes. Forjter 1791 2(mijuten (III 6) Die was 1769 in đlobens Bibfiothef III 59 als Hügel haben nicht jene stolze, imposante

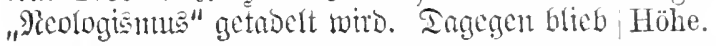

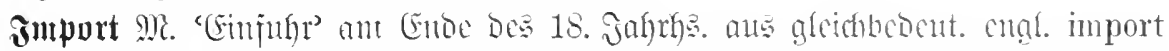

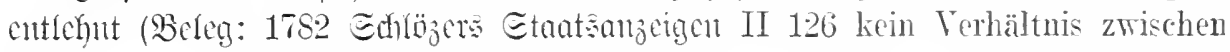
Importen und Exporten) un bei Cantie 1801 gebudht (hicr aud "Importen, Eim=

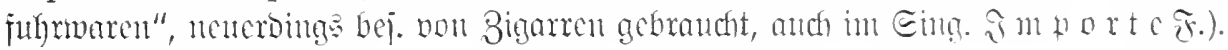
Bgl. Export. Q̈llter ît

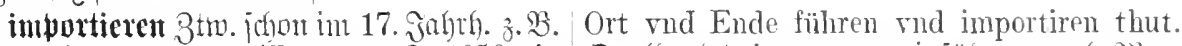

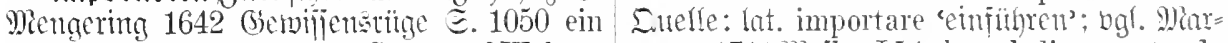
Kauff vnd Handelsmann, so Güter vind Wahren perger 1711 . Niefien I $5-1$ ob auch die exportanda in der Frembde einkanfft rnd in andere die importanda oder diese jene übertreffen.

impojant $j$. mater i nt p o n i e r c n.

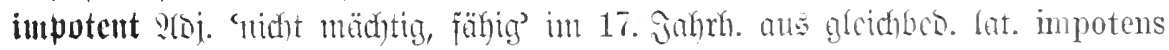

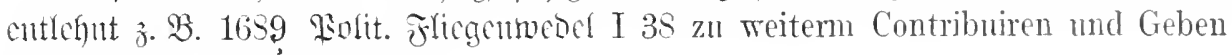
dermassen impotent gemacht.

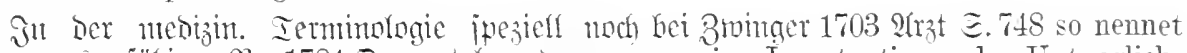

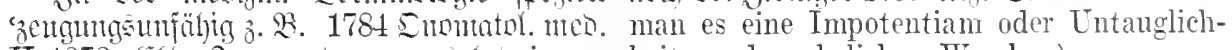

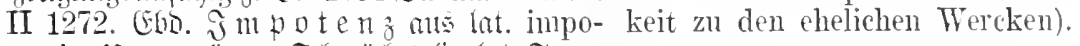

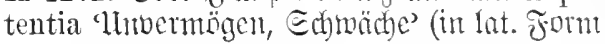

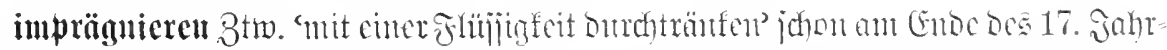

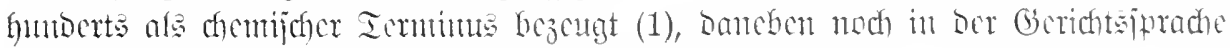

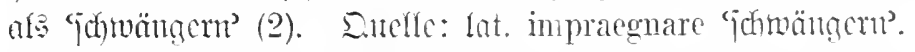

Belege: 1. Ettner 1697 Chtmuten $\Xi .510$

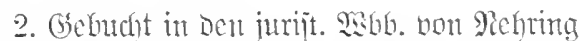

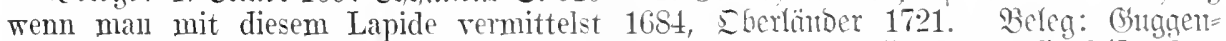
seimer Eintunckung einen Löffel voll Oel berger 1722 Prozejie @. 214 jie jei] schon impraegnire - 1715 ğebamule ミ. 114 der for 13. Jahren von einem gewissen ledigen impraegnirte Essig - 〔.139 impraegnirte. Dienstknecht impraegnirt und derentwegen Erde. von der Herrschafft abgestrafft worden.

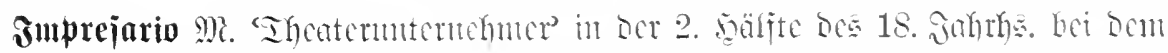

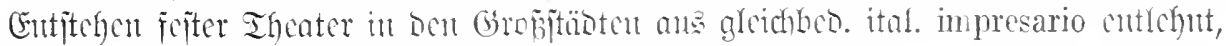

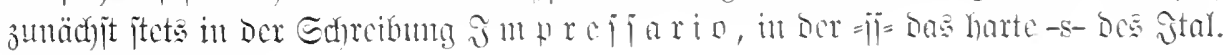
miedergeben folite.

Belege: Seiting 1771 Rriefe I 407 mit Herr oder Führer eines Trupps soll mehr dem Wiener Theater, welches unter einem wissen, als Geld einnehmen und Leute eigennützigen Impressario steht. ํㅣㄹer 1776 schlecht zu bezahlen. Impreijario Rhantajien II 398 die Impressarii. Iref̧let nod bei Remald 1837 ?quturelle IV 213

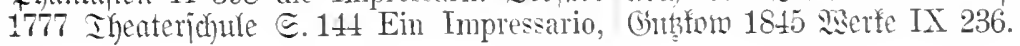




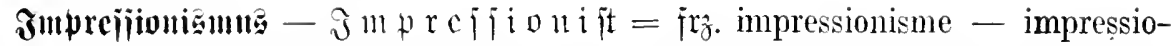
niste, nach 1870 aufgefonmene S(h)lagmorte für bic ucue Malted)nif bcs, „plein air".

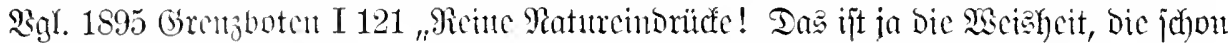

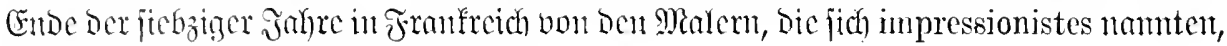

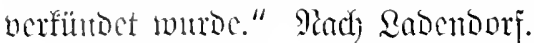

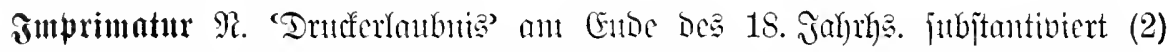

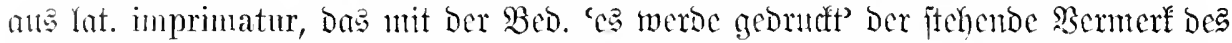

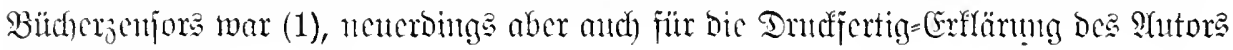
feitgchalten worben ift.

Belege: 1. Ricolai 1778 Nh bic Butdyer=/das Vorspiel bey 20 Thaler Strafe verCensores (GSeb. I 171) Und als er sie darum boten ist. Mitrffer 1798 (Emmerid) VIII 309 befragt, So haben sie kurzum versagt das Natürlich wars, daß ihm der Censor das Im= kleine Wörtlein: imprimatır. Das scheint mir wieder alle Natur.

2. (Suben 1768 Jntuitrie S. 175 Uebrigens ist es nicht so gar schwer, den verführenden Sehriften Einhalt zu thun, es darf ihnen nur kein Imprimatur verstattet werden. Sisich = mann 1769 2frtiffritifıs II 387 In der CensurFreyheit ist dieser Iann gewiß keiner Unbilligkeit $\mathrm{zu}$ beschuldigen. Konnte er wohl

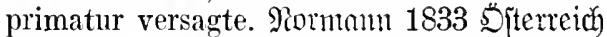
II 1 ङ. 108 Wenn ein Schriftsteller irgend ein Werk dem Druck übergeben will, ist er verpflichtet, zwei Abschriften davon im Revisionsamte abzuliefern, um das Imprimatur (ohne welches kein Drucker ermächtigt ist, auch nur eine Zeile setzen und drucken zu lassen) für die Schrift zu erhalten.

das Imprimatur an seinem Orte geben, wo

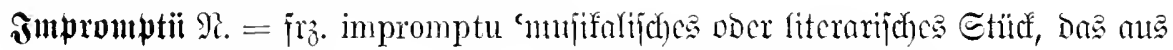

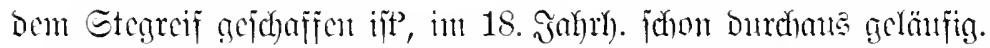

Belege: Matthejon 1739 Siapelfmeitter gesungen wurde. Sobater 1775 Frngmente ๔. 408 Der zweite hier einzurüeken wirdige I 232 ein Impromptüldiehter. Rejing 1776 Satz ist würklich ein so genanntes impromptu, Bricice (XVIII 203) damit er das völlige welches in einer gewissen Sommer-Gesell- Ansehen cines inpromptn hätte. Edfijtler schaft anfgegeben und stelenden Fußes nieht 1784 Sabule (IV 336) Ein herrliches Innur zu Papier gebraclit, sondern anch herum promptn des mensehlichen Witzes.

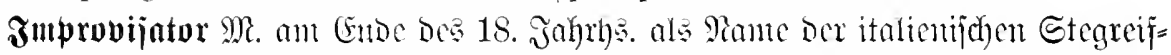

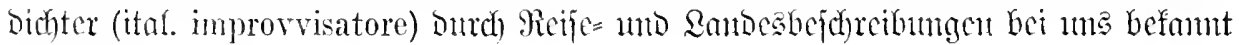
geworisent.

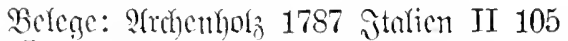
Dic Improvisatoren wählen gewölnhlich den Platz von Termini, um hier ihre Künste zu zeigen. Jieses versteht sich von den herumziehenden, dem es gicht andere, die nur in Gesellschaften und olne alle Belohmung improvisiren - 106 Dic alte römische Gesehichte ist gewöhnlieh ilır Steckempferd, weil mit derselben die Improvisatoren ziemlieh bekannt sind. Alle großen Begebenheiten des alten Italiens, als Hamibals Zng nach. Italien, die Ermordung Cäsars u. s. w. werden improvisirt, sobald man ilnen die Wahl des Süjets überliast. Ecunte 1803 Epuziergntrg (II 72) Drollig genug sind die gewölunlichen Improvisatoren und Jekkamatoren anf dem Markuplatze - welch ein Abstand von diesen Improvisatoren bis zu den römischen,

von dencu wir zuweilen in unsern deutschen Blättern lesen. (boethe 1809 sinhlyerwand= ichaften (XX 232) Sie bat wic ein Improvisator um einen Gegenstand - 1819 Noten $\hat{z}$ Dinar (VII 119) Höre man nun den moderuen Improvisator auf öffentlichem Markte.

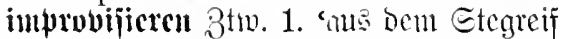
bichten' ane ital. improvvisare entfehnt, an=

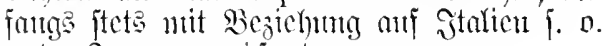
unter interovifator.

2. 9ึ(ก. ' norbercitet Darftelfen' 3. 93 . Gocthe 1830 : $n=$ Itelen (35, 102) Det Dnüfer=[3ottesoienit] dessen nach langer Erwartung für improvisirt gelten sollende Rhetorik kaum jemand das erstemal, gesehweige denn bei wiederholtem Besuch für inspirirt anerkenmen möchite. Siomm 1833 S̈fterteich II 2 
ङ. 98 oft improvisiren sie sogar Golegenheitsstïcke. Rewald 1836 Squarelle I 121 Niemand verstand es so gut wie er, Anckdoten zu improvisiren.

3. 'ofne \$orbereitung herítellen' z. 2 3. Marr 1846 Deutjolano ¿. 121 das Innere

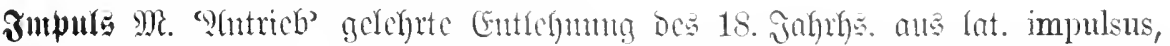
von Campe 1813 gebucht. Beleg: Görres 1800 Polit. Echriften I 80 die einen immer nur von äußeren Impulsen, die andern von inneren Ideen bestimnt.

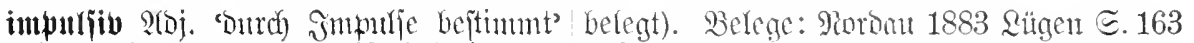
eit SUabud ber neteren Finchologic, Der daß der Mann ein Degenerirter im wissentwohl me bent Gngl. entlehnt ift (cngl. impul- schaftlichen Simne, eine schwache simnliche sive in gleidher Redeut. bei Marrat) jeit 1847 und impnlsive Natur ist.

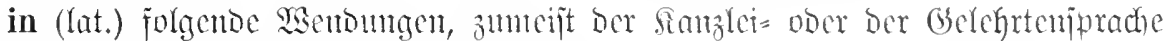
entftammeno, jumb allag. gelöuffig getworben:

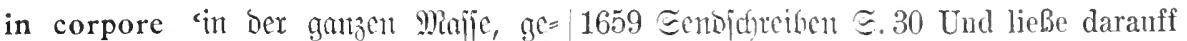
(d) lofien' wohl aus bem finnzleilatem itant = menb. Belege: Echmid 1775 Efronologie D. D. Theaters E. 36 der ganze Magistrat in corpore. Sffíno 1781 Shumeijen (VIII 303) der sämmtliche Magistrat in corpore bittet um Andienz. Mithlfer 1791 soer Thontog I 31 die familie in corpore.

in dulci jubilo mörtl. 'in jïf̧em Tukel'

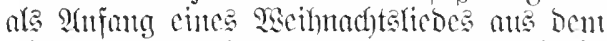
15. Jahrh. popultir geworsen uns häufig in Stubentenliebent auftretend, bort meift int

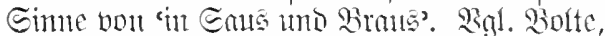
Feitgatie f. Siseintholo (1896) E. 124.

in effigie ante ber (beridhtapradie, hej. in effigie liängen sie Crefution an Bifonte Des sentrteilten worlsteben, weif ntan feiner Perjon micht hablyoft werben fomm?. Belea: ¿iscov 1739 Entir. Erfiriften હ.106 da ich diesen vortrefflichen Mann an den Ecken aller Buchläden in Effigie habe häıgen gesehen. artlgentemer bei (5octhe (mi 1780) Thent. Ecroutua S. 299 Wie kam es einem vernünftigen Mame schmeicheln, sich in Effigie aufgestellt zu sehen.

in flagranti 'auf frifcher Tat' ats ber (be= richtejprache (3. B. Solbele 1654 (Bericht Gänoel I 72 von einem Dieb, so in flagranti oder auf frischerThat ergriffen wird) abgefiurat aus in flagranti crimine (bsuber 1697 Siricg: Diszinfin II 25 anf frischerThat oder in flagranti erimine von dem Profosen ertappet). Edjon in Suftintion. Sosex: adlune flagrante crimine comprehensus 'anf frijcher Iat $\mathrm{cl}=$ griffen' Secmmant= Echel $\Xi .217^{\mathrm{b}}$.

in floribus ifletzhofte Eteigenung be ge= lehrten in flore 'in Der Bhlite, in bejtent

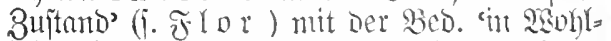
leken, in Ents un Braus? Belege: Edhup dieser kleinen improvisirten Republiken. Sinldan 1850 Mad D. Ratur I 8 Der letzte Schnee kam als improvisirter Wildbach. Siachentinen 1882 Etraje E. 272 ans einem improvisirten Traghette. die Trompete blasen, und alles in floribus gehen. Fidfelbering 1685 Alcibernffe $\subsetneq 50$ Also gehts in Floribus. Etoppe 1729 Ge= Didite II 108 da er sonst in floribus gelebt. Sflter "in floribus ianjen" (Fachel 1664 Eatir.

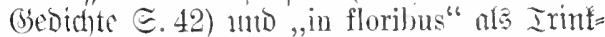

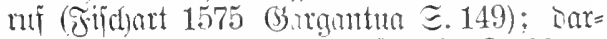
itber vgl. fituge, Etudententiputade હ. 38. in Folio $i$. Folio.

in infinitum 'tus llnenofidfe' idyon bei Prinus bezengt. Beleg: Fohr 1729 Bere= montelfrwifenjogat II 157 die Kinder mnd Kindes-Trinder in infinitum.

in medias res objute llutichneife zam

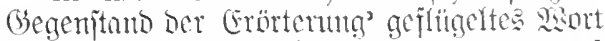

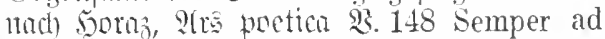
eventum festinat et in medias res Non secus ae notas anditorem rapit.

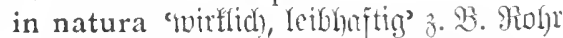
1718 Etanteffutoryeit ङ.466 entweder in natura oder in Niodellen. Bij. ale Gegemjats

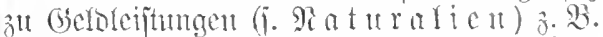
Gutuber 1697 strego welche num entweder in Natura oder am Gelde muB gelieffert werden.

in naturalibus (ruphemism fitr 'noute Itrteil des Sarta (X 35) So zeigt euch alle drei in Naturalibus. 然eitere Belrge Bfo in nuce 'in georängter Form' ïbertr.

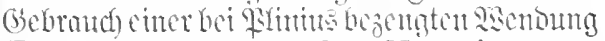
(In nuce inclusam Iliadem Homeri carmen in membrana scriptum Patutr. Litit. VII 21, 85), an Der (Belehrtemintade allg. üblich ge= moroest. Beleg: Bitrger 1777 Bricfe II 97 mein poetisches Glanbensbekänntnib, welches eine Poetik in nuce ist. joffimam 1814 frreisteriana (I 61).

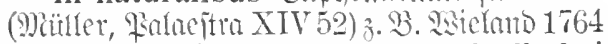


in petto bej., in petto haben" cim Einute

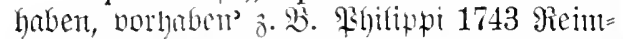
(a)micochunt $\Xi .141$ Dieser erhabene Dichter nun, den ich in petto habe. Tie sicnoung

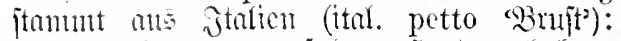
"Havere à petto, auj Dem Secrtzen Yjaben.

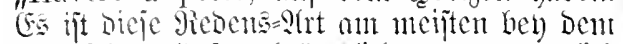

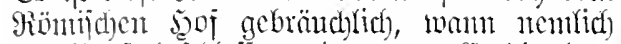
Der Pabjt bejolojien, cinen zun Carbinal zu machen, Denjelben aber öffentfid Dowor zul beclarien nod cinige Beit mafidiebet" Epe= rantoer 1727.

in puncto puncti cin zufrithyit bei Bürger 1789 Selliu (II 91) hezengter Euphentinus fiir in puncto sexti (j.2B. Etoppe 1729 (bie= Didhte II 73), ms Dem Sanzleilatein jtammens; urjprgl. mogl in puncto sexti mandati. Bigl.

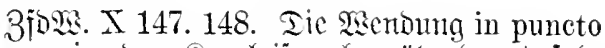
twar in Der ftanzleipradie überhanpt jehr

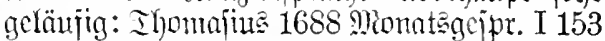
in puncto der Juweelen, Zobeln. Richter 1738 Srtuninalprozen $\Subset .167$ in puncto eines an seinem Dienst-Herrn rerübten Diebstahls. in spe in ber skenoung "in spe haber" entipredfend bent flajitichen (Cic.) in spe habere 'hoffen' bei (Eallenbady 1711 luti ante har @. 64 was wir anderswo haben in spe, kamn uns leichtlich veranstaltet werden. Reucroing (bej. jtubentija) aber nttrifutio 子. B. Banjufe 1834 Iijtelbiiten ङ. 62 Konsistorialrath in spe. Jäger $1835 \mathfrak{F}$. Edunabel ङ. 271 die Schwiegermutter in spe. Sramby 1837 jubiläum (VI 216) das Portefeuille in spe.

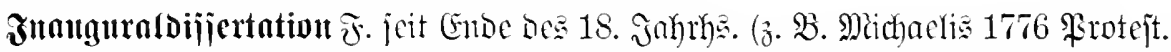
Univeritüten IV 715), ältex meijt in Iat. Fonn als dissertatio inauguralis. Taneben audf) disputatio und oratio inauguralis (bics 1632 Catologus Marpurg. XV 30).

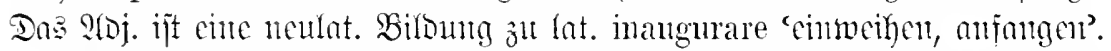

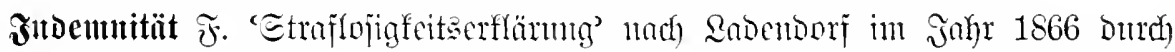

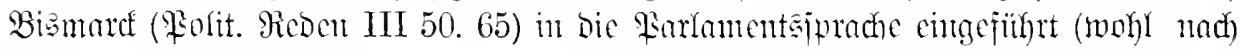
engl. indemuity 17. Jahth.). :agl. noch Jontane 1892 1Inwederbringlich $\subseteq .153$ Indenmität, auch solch Wort aus dem ewig Parlamentarischen.

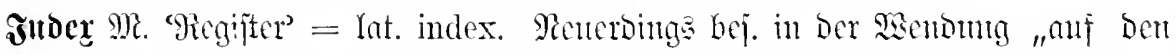

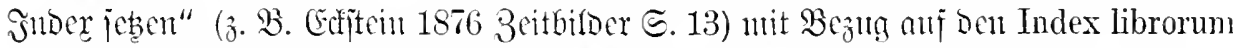
prohibitorum (et expurgandorum) Der fatholijhen Situde (16. Jahrh.).

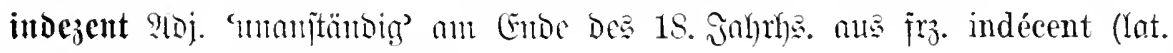
indecens) entrehut. Sigl. De $30 n t$.

Belege: Gocthe 1774 jahmmaftīicit (XVT indecent und nichts weniger als schön aus.

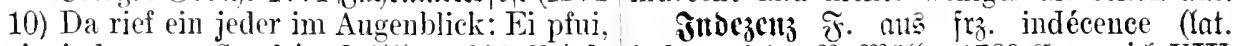
ein indecentes Stück! Echiller 1801 Briefe indecentia) s. P. Mïller 1789 Enmerid VIII (VI 272) Sie [Die Iänjer] sehen mnschicklich, 371. Forjter 1791 P(njichten (III 326).

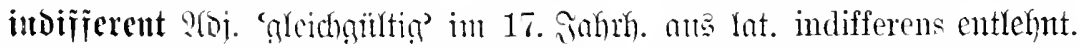

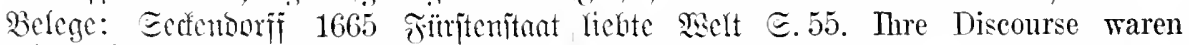
II 205 da die Leute nicht viel zu thun haben, im Anfang indifferent.

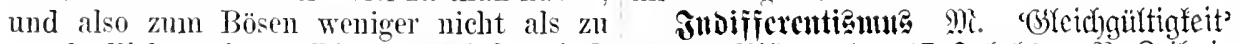
unschädlichen i.-en Dingen gefaßt sind. menlat. Bilsmg Des 17. Jahnty. o. B. Reibniz Thomajur 1688 Mionatigejur. I 543 mit 1670 sierfe I 154 der überhand genommene so ciner i.-en und kaltsimngen Ehrerbietung. I. cum in fidei, tum in moralibus et politicis

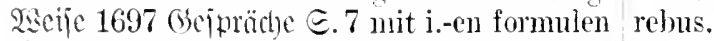

einander auffgehalten. Micnantes $1702 \mathrm{Ba}=$

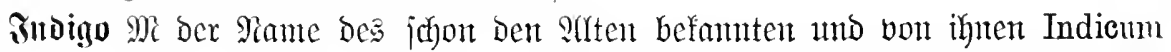

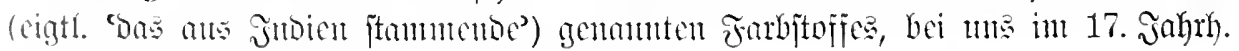
in Der ipanijonen Saution Durdhgedrungen.

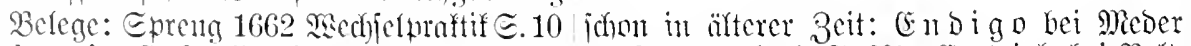

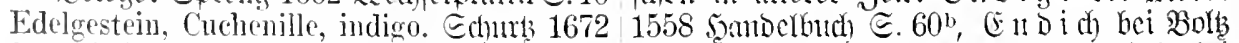

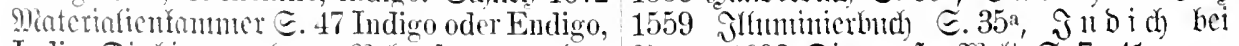

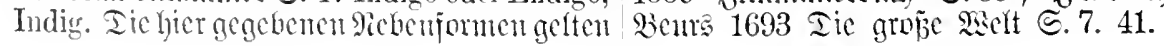




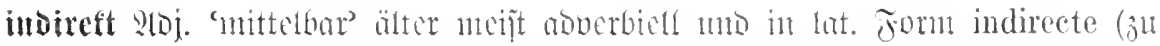

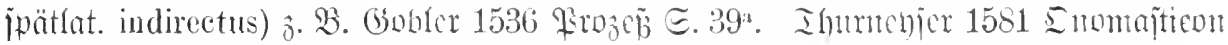
ऽ. 79 man möchte es branchen directe oder indirecte, gerad oder vingerad.

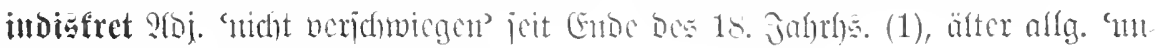

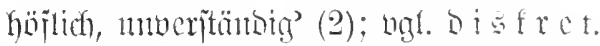

Belege: 1. Seijing 1771 Briefe I 425 meinem i.-en Schreiben molest. Iaffober Ich hoffe, dab er anch nur gegen Sie so i. 1687 Gurtenbeticin I $45^{b}$ dann der Esel hat wird gewesen seyn, sich von der Sache gar ein wrobe Stimm, rnd ist dabey gantz etwas merken zu lassen. Mitchaclis 1776 i. bobhafftig vod Muthwillig.

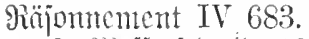

Judisfretion $\widetilde{\pi}$. Gonethe 1774 Clavigo

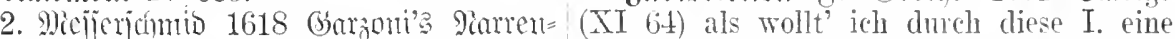
iptatal 厄. 140 welche gewißlieh durchans in eitle Nengierde befriedigen. Sliuller 1787 allem vnnd jedem dissoht vnd vnordentlich, Emmerid III 92 Verschweigen Sie sorgja i. vnd vnbescheiden ist. Ecfill 1644 fältig, was ich Ihnen sagen will, die kleinste

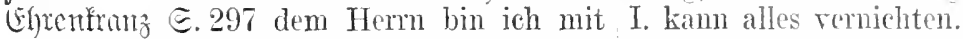

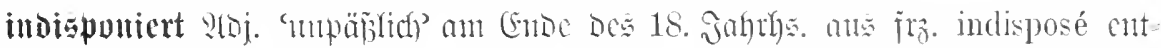

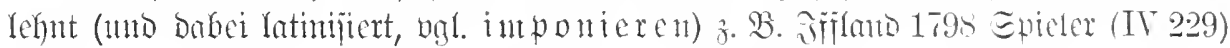
Die liebe Contesse ist indisponirt? Ich bedanre ron Herzen. Q̈Uter ift

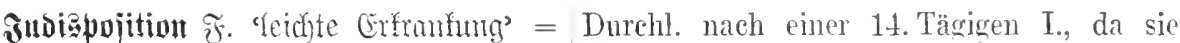
irz. indisposition. Beleg: 1699 Etantaipiegel von einem continuirliehen Fiber angegriffen, II 65 indem höchstgedachten Chur-Printzens den Geist anfgegeben.

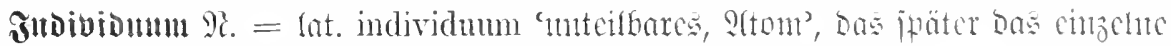

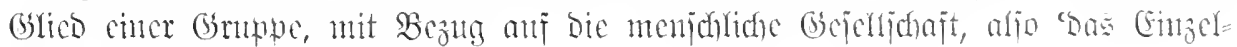
mejen, bic Rerion' bezcidutete.

Bgl. Rütner 1574 Iinfectica $C^{c} 3^{\text {b }}$ ron I 122 daher ist eben Individualisirung die einer besondern Person Tamen (den man wiehtigste Hauptregel beim Elementarunter-

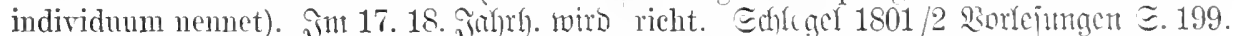
bas sert meift nod int lateinither fferion gebraudat z. 23. In d i r i d 110 Bittmmm 1668 Medicina forenji: E. 205 . Beinnors lange bueibt ber Prur. In diridu a

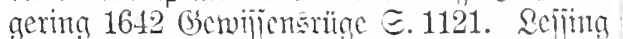
1768 Drmaturgie (X 153). Ju d i b i D 1 en sufrühit bei Sabatex 1777 oragmente III 83.

indivibutal Soj. aus mlat. inaivichalis nod) bei Edfilfer 1795 üter bie neithetijebe Eroiefung (XVIIl 65) An dem Menschen findet sie [bie \$sommit] einen schon rerdorbenen und widerstrebenden Stoff, der ihr gerade so viel von ihrer idealen Tollkommenheit ranbt, als er ron seiner individualen Beschaffenheit einmischt. Epüter wird individuar ourd indivisuefr

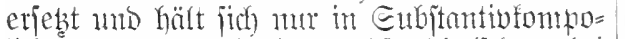

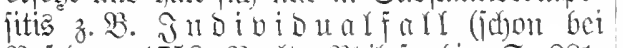
Bajeon 1758 Proft. Rhitojongic હ. 881. Serder 1767 T. Siteratıtr S. 462).

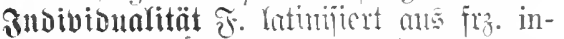
dividualité. Releg: Rnuater 1775 Trmantente I 84. 9us Rerbentichung miro 1766 iflg. D. Biblinthet II 1 e. 262 Besonitureitsgrund vorgejoffragen.

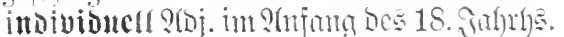
ats frz. individuel entlount uno im 19. Juthry. affein acbröntchlich an Etelle Des älteren i n b v ibual. Belege: Binsenorf 1748

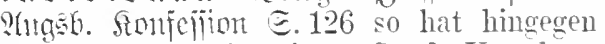
ein jedes über seine eigene Sünde Lrsach zu weinen, über sein personelles Elend, über seine individnelle Untreue. $176+$ (bejd). D. Sunturt I 151 die Bildung der Sehönheit ist entweder Individuel, das ist, auf das einzelne gerichtet. Eommenị 1768 Portrïtmaler $\widetilde{E} .38$ die individuelle Schönheit. Edhmis 1775 Egronologie $\Xi 295$ individuelle Ursachen. Savater 1778 Fragmente IV 60 ihrer eigensten, individuellsten Empfinindividualificten $3 \mathrm{tm}$. Mnd fro. individua- dungen.

liser. Belege: Gédicte 1789 Edurliduriftent

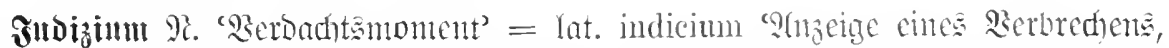

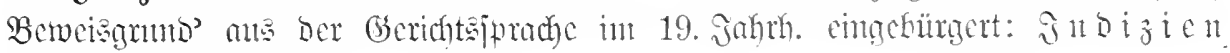




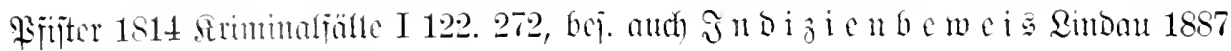
Qrme Mäd hon $\Xi .314$.

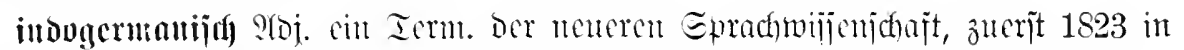

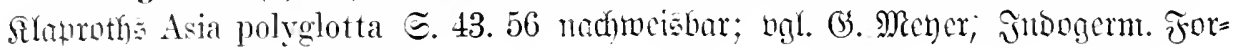
f(f)mọen II 125.

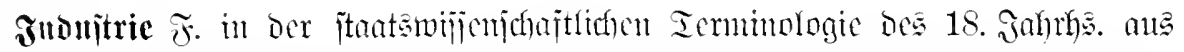

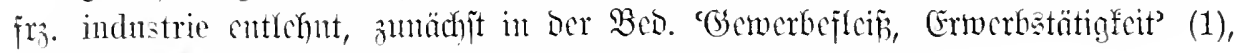

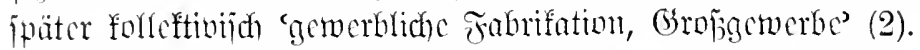

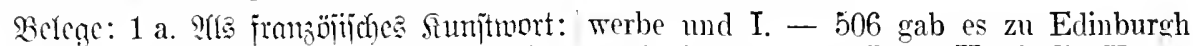

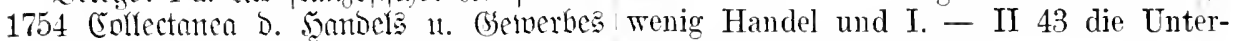
$\Subset .151$ die Verhinderning der $I$. (ieh meine, haltung einheimischer $I$.

die auf dem Fleiß der Menschen gesetzte Taxen). 1765 Rreismifgabe D. Gö̈ttinger Eojictät (= qüitter I 265) Die wirksamsten Mittel, die Einwolner eines Landes zum Fleiße oder zu dem, was man im Französischen Industrie nennt, zu bewegen. Tur: $=$ auf bejichen jith bic termumolngithen ?has=

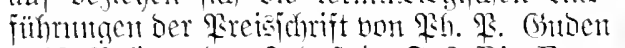
1768 qubizen ber Indutrtie E. 3 Die Franzosen nelmen zwar das Wort Industrie anch in einem weitläufigen Verstande, so wie wir Deutschen den Fleif, oder die Befleissigung. Jedoch die Industrie wird in den mehrsten Fällen und gewölnnlicher Weise von den besten französisehen Schriftstellern nur in einem engern Verstande genommen, da es den kïnstlichen Fleiß, oder den Fleiß in den Manufacturen und Fabriken, bedeutet. Der Herr ron Fortbonnois, der Verfasser der Interets de la France mal entendnes, und Herr X[elon, unterscheiden die Industrie dadureh sehr genau von dem Ackerban. Daher, weil die Könnigl. Großbrittanische Sneietät der Wissenschaften bey der Aufgabe den Fleiß durch die Industric erklïret so habe ieh vermuthet, dab sie dirses Wort nieht in einem so weitläufigen Verstande, als im Dentschen den Fleiß, nehme. Ich will also im nachfolgenden hauptsiaehlich ron dem Fleisse in den دranuficturen handeln, und beyläufig etwas von Ackerbau mit anführen.

b. Reiiintry 1766 Ronfon (IX 126) man

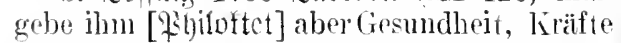
und $T_{\text {., }}$ und es ist ein Robinson Crusoe.

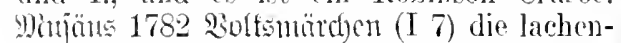
den Gefilde, welele die menschliehe I. ver-

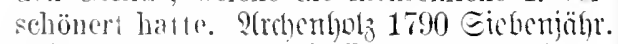
Stricg E. 199 durch die I. zallheicher Generationr'n.

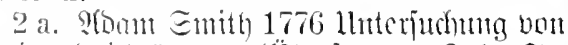
Siationtalreidntiuntert (liberi. bon Joh. Fr. Echitler) I 192 die in Stidten getriebene Ge-

b. Secrmes 1778 Eopryens Reije IV 306 $\mathrm{Es}$ wäre für Kunst und Indüstrie sehr zu wünschen, dab er in einer andern Pfarre stünde. Einntive 1781 fonfmumehefte ङ. 419 Es giebt keine I., keine Manufakturen [in Polen]. P(rothenthet 1787 Englond I 128 Selnr oft ist die englische I. durch dentschen Beystand belebt worden.

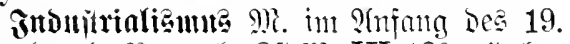

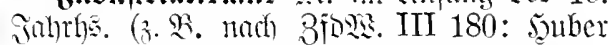

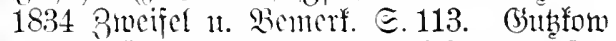

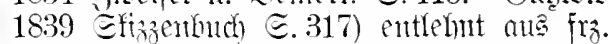
industrialisme, bas zufruilfift bei Enint= Simon 1823 Catéchisme des industriels meisbar ift (Endentonif). Evenio fint bie fold.

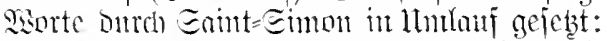

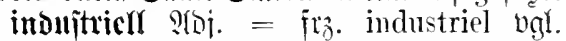
Enint= Cimnon: Du syst ème industriel (1821) mo in Catéchisme ฮ. 2 La classe indnstrielle. Dentidfer Boleg: Füuffer 1831 Biticfe I 21 das industrielle Jalnhundert des Gesehäftslebens.

induittriefle $M l=\tilde{f r}$. industriel, are

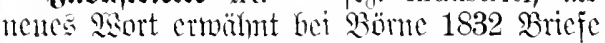

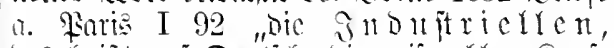

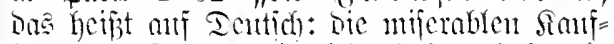
lente und Srömer, Die nidyt haben als Furcht

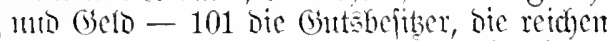
Banfiers, Dic Sin̈mer, bie fith mit cinem

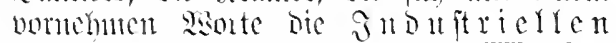

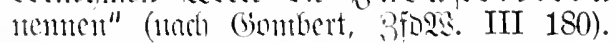

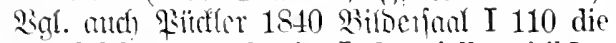
Handelsleute und die Industriellen bilden selbst die neue herrschende und aristokratisehe Klasse. Sgeme 1854 Rutejia (VI 181) Kapitalisten oder sonstige Industrielle.

Jndujtricritter 9\%. int ?fnjunt bes 19.

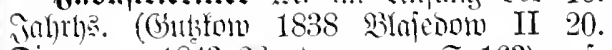
Diczman 1843 simtoenungen હ. 163) atf $=$ gefommen für $\mathrm{fr}_{\mathfrak{z}}$. chevalier d'industrie, oas

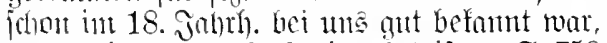
3. \$. $2 t 3 c 0 m 1739$ Entir. Esthriften $\subseteq .758$ 
einem unglückseligen Chevalier d'Tndustrie, die, Da jie kein cigenes Bermögen haben, fich) der auf einem Jahnmarkte über den Ge- voust Evielen nähren, oder Durch allerlen brauch seiner verbotenen Kunst crtappet. Sntriguen, betriegliche Sïmfte, Finefien und

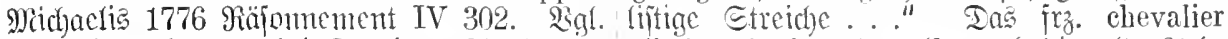

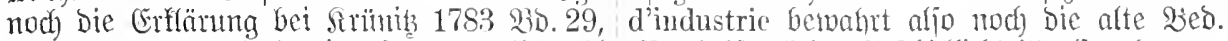

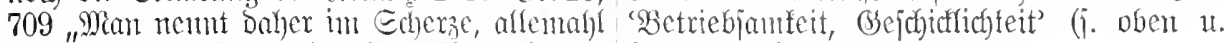

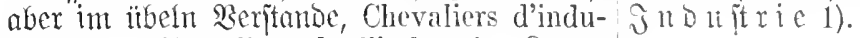

strie ober Chevaliers de l'industrie, Sente,

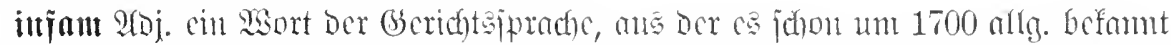

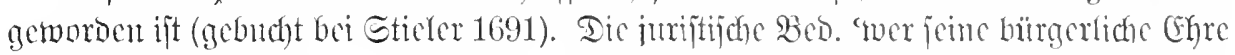

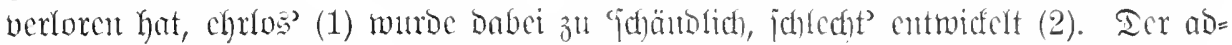

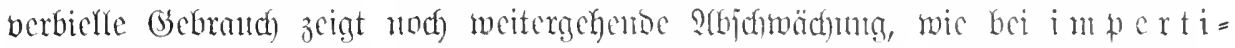
ueut, $\arg$ un häßlich ( $\mathfrak{j}$. B farbloje Berịtärfung jein fonm (3).

Belege: 1. Feino 1709 Ammerfungen dergleichen infamen Scartequen. Fohn 1718 ऽ. 12 Was heist aber, Ehrloß seyn? Heist es Etnatsflugheit $\Xi .495$ solche infane Häuser. nicht infam seyn, als ein Mensch, der mnter Gellert 1746 Fabeln Є. 62 Mein Tachbar, des Büttels Händen gewesen - S.17 Ehr- der infame Mam. Sejïn 1772 Brieje lose, ungerechte Beut-Richter, Infame, Meyn- (XVIII 43) wegen hundert lüderlichen und eidige und Pasquillanten. Bjofactwib 1723 infamen Streichen. B̈̈rtger 1778 Brieje II farl VI. 5.55 für infam und unehrlich de- 269 Es wäre der infamste Streich, der mir

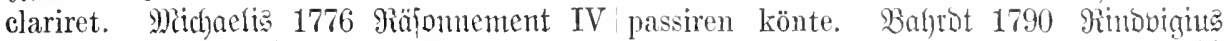
467 einen falschen Eid zu schwören ist in- I 239 der infamste Halunke. Gócthe 1793 fam. Gdjuffer 1781 Räuber (IV 131) aus Sufgeregte IV S ein erzinfamer Spitzbube. besonderer Gnade infam ans den Grenzen 3. Bürger 1776 Brieje I 322 Ein Refüs gejagt - 1783 Ficsco (IV 218) Ich habe sie bey einer speciellen Anfforderung würde mich verloren, infam ist mein Stamm.

2. Miendfe 1710 Unterredung $\subseteq .183 \mathrm{zu}$ infam verdrießen. Bismarcf 1851 Ririefe

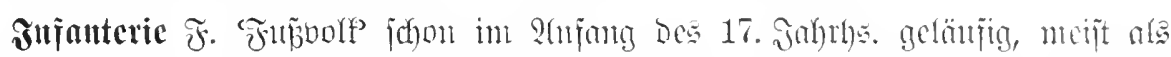

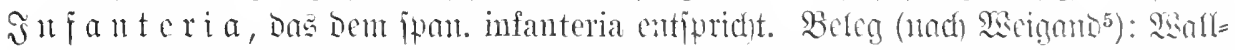
haujen 1616 Siricgnmomol હ. 139 Infanteria (neben Enfanteria) - Sisterfunt ङ. 82 Infanterey.

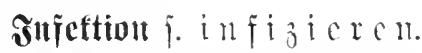

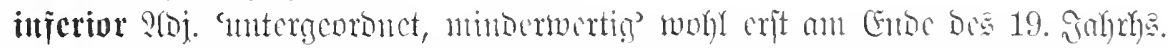

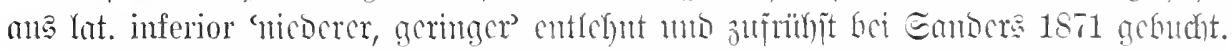

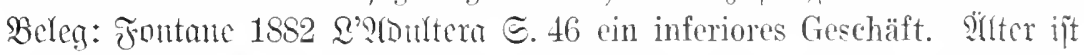

anjerivritöt $\widetilde{\mathcal{V}}$. wohl an Trz. inferiorité wird ihn immer in einer gewissen I. erhalten. (17. Jahrh.) entrehnt. Beleg: Edjiller 1796 . netber IX 196 (bei fehrein) I. anderer Briefe V 15 Lotharios vornehmes Wesen Nationen.

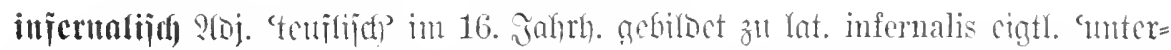

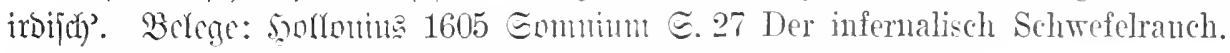
Ettncr 1698 Chimugus ๔. 923 die Infernalische Bestie [= Ienfel].

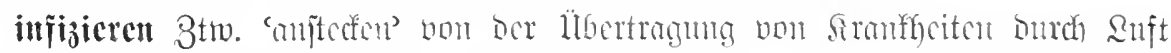

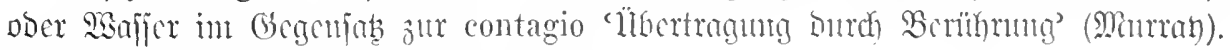
Duelle: Yat. inficere 'veroiften, anjecten'.

Belege: $\Re$ nff 1544 Eniegel o. Gejumbheit ron pestilentz rnd andern dergleichen schwe$\mathfrak{a} 4^{\mathrm{b}}$ wie vil menschen on vnderlaß von ren plagen getödtet werden. Iabernämon= faulem gifftigem lufft schedlieh inficiert, tamus 1588 firüuterbuck I $46^{\mathrm{b}}$ So bald einer 
mit diesel vergiffen Seuche inficirt wird - vor Pestilentzischer Vergifftung vnnd I. $107^{\text {a }}$ einem Goldschmict, so mit dieser $389^{a}$ ron der I. deB Sehelmens oder der PestiKranckheit ist infieirt. lentz. Meugering 1642 Gemificnšrüge ङ. 721

3njeftion $\mathfrak{F}$. ans ipätlat. infectio $2 \mathfrak{n}=$ Mittel der Artzney, Hutsamkeit etc. wider

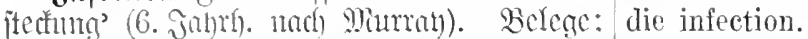

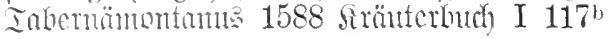

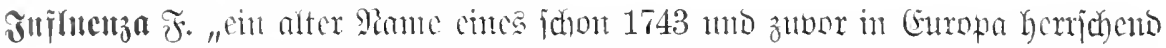

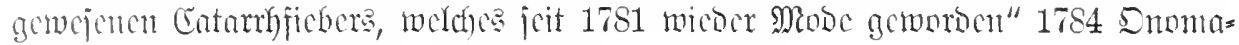
tologia mes.=pract. II 1376. Duefre: itol. influenza.

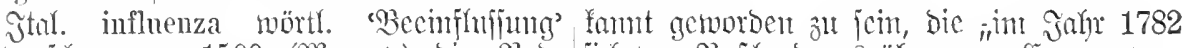

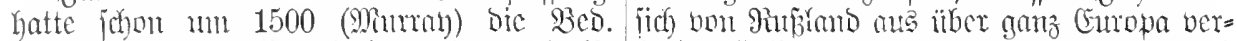

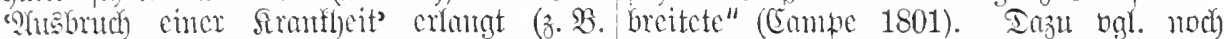

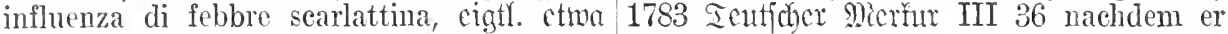

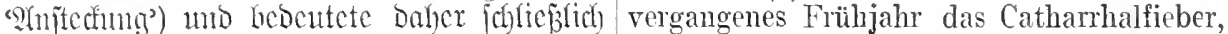
gerabezu 'Entionite'. Dic nencre CEn= so unter dem Tamen der Influenza allentjochrënfung auf bie aud Cirippe genamte halben herumging, ausgestanden. Morits

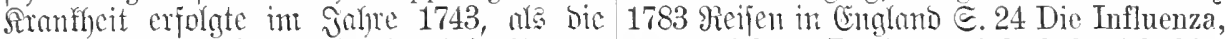

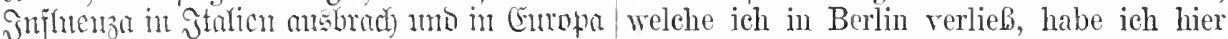

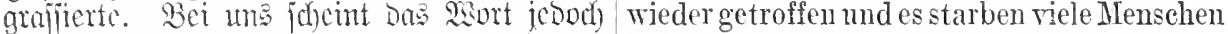
erjt mit bex zweiten Jnffuenzacpioentic $\mathfrak{b}=$ / daran.

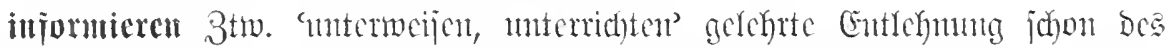

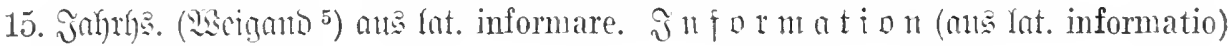
bei Sutfer (XTX 273).

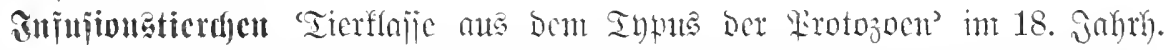

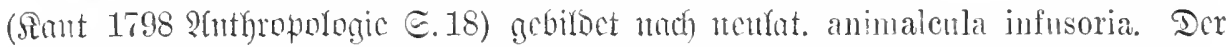

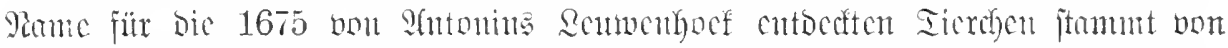

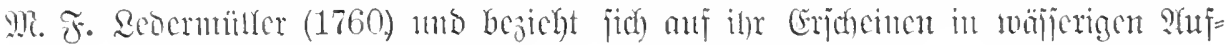

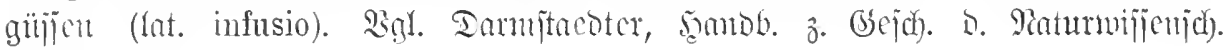
๘. 142.205.

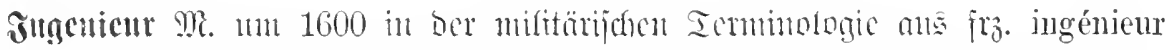
cutldfut 3. 2. Rord 1605 Relation હ. 12 den Predigem, Ingenienren, Edel-

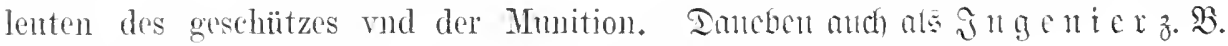

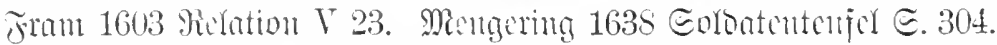

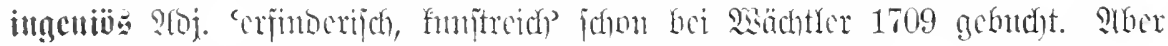

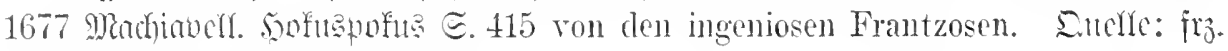
ingénienx mod Yat. ingeniosns.

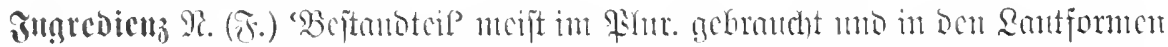

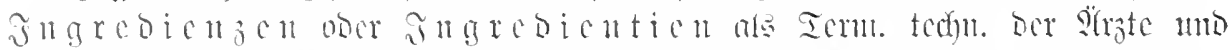

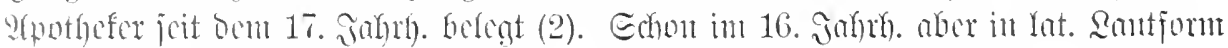

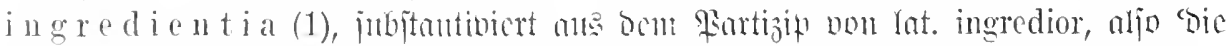

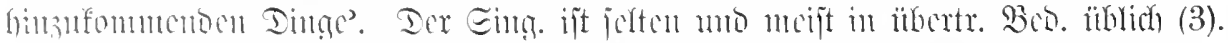

Relege: 1. Bobentein 1567 Rourebe zu

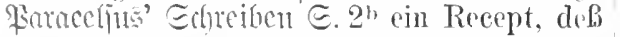
ingredientia warn, spiritus Vitrioli, liquor

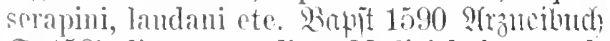
$\Xi .15 S^{1}$ die vorstendigen Mecliei haben auch vill Composita rnd von maneherley Speeiebus oder Ingredientibus zusammengesetzte Ricept.
2. Diongering 1642 Geswijentsinge ङ. 1518 swothefer fünotgen] wemn sie in die rerschriebene Recept nicht alle ingredientien nehmen. (B́rinmeryman 1669 Eimplis. ๔.312 nit Eichenlaub, Weydenblättern und dergleiehen herben ingredientien. Sonmed 1684 šftermeid @. 103 ich weib nicht von was für ingredienzen. 
3. Seijitug 1768 Irantattutic (X 110) ob Frivolität ist keine Ingredienz in dem eigentsie [Die Fittort] schon ein notwendiges In- lichen Clarakter der Deutsehen. Echifler gredienz des Mitleids ist: so gilt dieses doch 1793 ?(tuntt (XVII 366) das rührt von der nicht anch umgekehrt, und das Mitleid für Liebe her, die ein Ingrediens der Hochachtung andere ist kein Ingredienz der Fureht für ausmacht.

uns selbst. Misielmto 1791 S(1tzeige $(36,184)$

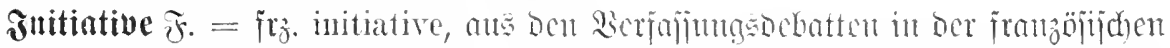

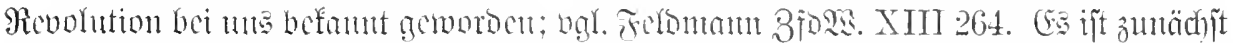

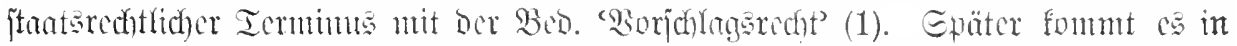

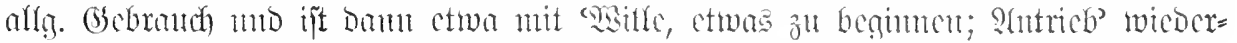

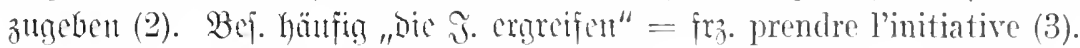

Belege: 1. Wielond 1799 Gejptäche (32, Bruder. Guthon 1836 (bothe (VIII 267) 242) Dite Fitritenfonmter] hat überhaupt die I. der Schillerschen Dichtung war das (jedoch nicht ausschließlich) die sogenannte Interesse. Bei. "nute cigenjter Jntitiotine" I. zu allgemeinen Reichsgesetzen. Sutdhyorz 3 . 1808 (jementbe II 21 daß er sich von der ge- (Rabenoorī).

setzgebenden und vollziehenden Macht nichts weiter ammaßte als die I. und die Promulgation der Gesetze (Bfos. III 181). Görres 1821 Gutopn ङ. 352 die Gültigkeit jedes in der I. von den Ministern eingebrachten Gesetzes.

2. 5xeme 1834 Gulon (IV 206) dem großen Frankreich gebührt anch hier der Ruhm der I. - 1836 Rontant. Echule (V 272) die I. seiner Gedanken gehört noch seinem

3. (5oethe 1821 sismberjatre (XXIV 178) In solchen Fällen . . . nehme ich nicht gern die I., ich suche mir eine Antorität, bey welcher ich mich beruhigen kam (fefrein). Gut3on 1835 chandtere (VIII 37) entweder beizustimmen oder die gleiche Verantwortlichkeit zu tragen oder gar die I. zu übernehmen. Bauby 1839 Paris (VI 127) Derjenige, welcher die $\mathrm{I}$. ergriffen.

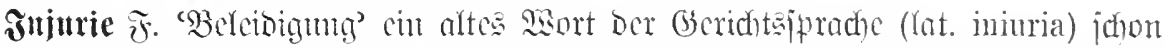
Im 1500 eingebcuticht. Belege: Emjer 1521 Etreitjontiften II 7 mit Inimrien rnd

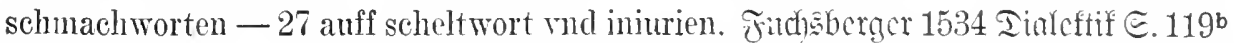
das haist iniuri oder schmach, wenn aindweder der leyb mit straichen, oder wir sonst mit schmachworten werden belaidigt.

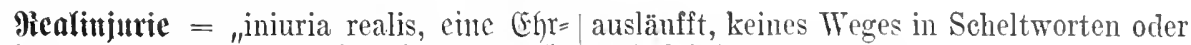

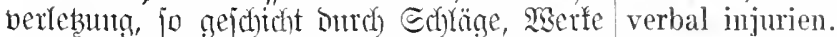
น. Dgl." Mehring 1684. Beleg: 1712 Eärfj. Dudflutonont (= 9iduter $\subseteq .47)$ wenn RealInjurien vorfallen, dreyssig Thaler.

Berbalinjurie = "iniuria verbalis, étie Wörthiche Ehrenwerlebuma ober Echmach = rede" Mehtutg 1684, Beleg: Mentgeting 1661 (Semifientired)t @. 616 eine solche Gegenwehr und revange, die auff Mord und Todtschlag

Die moberne Termintologie für bie john int römijonen Recht geltento: Echeibung bes gulurienbegriffes (aut le aut verbis) folleint erft tm 1600 Durchgebrungen zut jeint; Sie $\mathfrak{A}$ usoritofe iniuria realis - verbalis zufrühft bei sarpwrecht 1609 Tractatus eriminalis

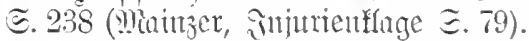

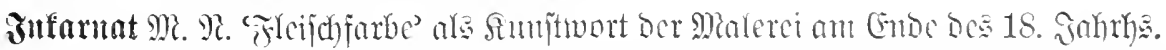

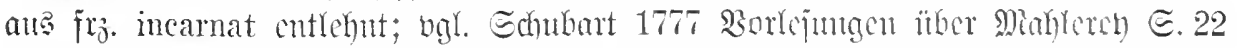

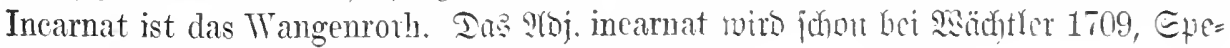
rander 1727 น. a. amfaciuthrt.

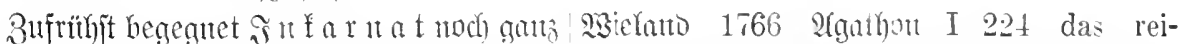
als jranjöitiches fintitwort bei Serber 1766 Werfe I 52 das blosse Teint, der Franzose mag es mit so viel Namen benennen, als er will, er neme es fraicheur, coloris, incarnat, vermeil u.s.f. Qher us cingebüruert bei der Gesundheit. Thiummer 1791 Reije (II 24) zende Incarnat dieser Wangen zu erhöhen. Erhuthart 1774 Ehronif @.181 Machts, wie die Landmädgen; die holen ans der Quelle sich ihren Inkarnat - S. 365 das Incarnat 


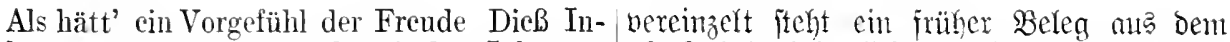

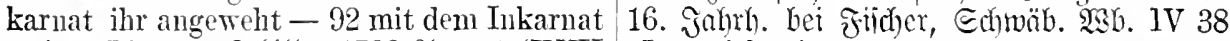
meiner Lippen. Erfiffer 1793 2lnnut (XVII ,Luess ich mir nachstend Klaid die Farb in= 344) der feine Inkarnat der Wange. - Gour | garnad genant machen".

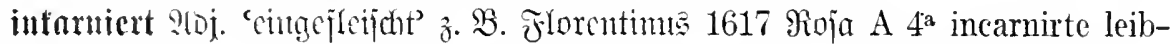
hafftige Teuffel - entiprechent Dem fircherlatcin. diabolus incarnatus.

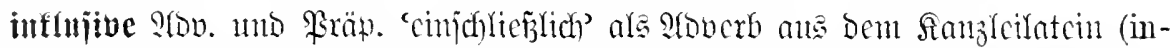

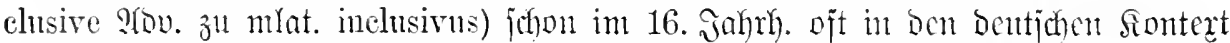

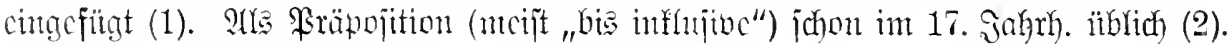

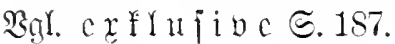

Belege: 1. 1558 5reiberbera. Etatuten ๔. 46 bis uff den montag nach Invocavit inclusive. E(t)weinichen 1579 Ienfrüurbig= feiten ๔.209 das angefangene erste Buch aber voll ist und mit dem 78. Jahr inclusive geschlossen. Ghutmur 1592 Siennzeiden fotr. Rer. ङ. 99 vom 17. Jar inclusive an biß zu seinem vnseligen Ableiben. Gruber 1697 friegsoisziplin III 22 alle commandirende Officiers biß zu dem Obristen inclusive.
2. Börfler 1665 ๔chola militaris હ. 74 ein Rittmeister [erfält] auff 6 Dienst-Pferd inclusive deß harten Ran-Futters und Stren, jedes 8. Reichsthl. Marperger 1717 Banfent 厄. 255 In denen Jägerey-Officianten biß inclusive den Forstmeister. Roht 1729 Beremonidfmifientaft II 56 vom kleinen Pfennig an biß inclusive eines gantzen Thalers. 5crmes 1789 Für EYtem II 256 gegen Alle bis inclusive die Secretairs.

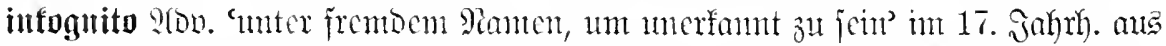
ital. incognito 'uncrfannt' entlchnt; Sancbent a l l' in c o g n i t o Birfen 1669 Utrnjiez E. 60, Dalfoncr 1687 Gartenbcetlein I 114, Gamaler 1697 Ingenjomico I 46.

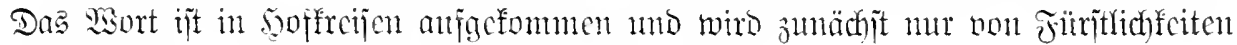
gebrandyt, die auf Rerjen unerfinmt bleiben mollon.

Belege: Birfen 1669 Brantonfurg. Diarium $\subseteq .120$ der Sultan selbsten incoglurnjes (Bujchrift ङ. $2^{3}$ ) Ein Fürst gelanget nito - 〔. 122. Mentantes 1702 Berlicbic durch Reisen, zu diesem Zwecke: sonderlich SElt $^{\subseteq} .51$ er hatte sich fest vorgenommen, wann er incognito oder unbekannt reiset. einen Ritt incognito dahin zu thun. Calfen=

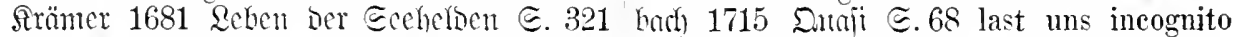
[oer fïnig] nahm seinen Weg incognito stehen, seine Critica zu vernehmen. ¿üntig dureh Franckreich und mit einer schlechten 1719 Theatmum ceremoniale I 843b Allhier Suite. 1690 God)beehrt. Shugabura $\Subset .107$ hielt sich Mr. Piementel beständig incognito ein Ball zu welchem sich auch noch höhere auf. Tefoe 1720 Rob. Cruine II 381 da er Personen ineognito einfanden - E.129 sich incognito in unserer Wohnung einfand.

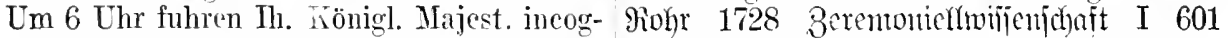
nito nach dem Werthachbrucker-Thor. $\Re u r=$ mit der er im Ehestande lebet, jedoch so fürịtin Eophtie 1706 an Friebrich I. (ङ. 101) riel als möglich incognito. Bachariä 1744

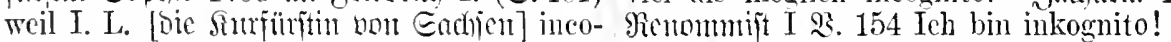
nito durchs Land reisten. Rotn 1729 Bere= monieryijienidhart JI 126 (Von den Reisen der Fürstl. Herrsehaft) wie es mehrentheils zu geschehen pflegt, incognito reisen.

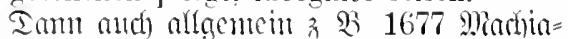

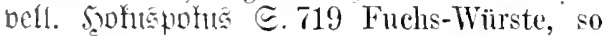
sich off incognito vinquartieren. Ihomoints 1688 Minntagejpräde I 490 er sondete einen Nahler incognito nach Mitylenen, der ihn abconterfeyen muste. Sienter 1696 Echel= mujfy $\Subset .38 .73$. sich incognito aufhalten. Siseije 1697 Rertr. (B́cipräche $\subseteq .26$ Auff der Post reisen wir incognito. Eimpert 1701

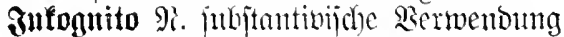

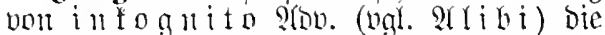
Im die Mitte des 18. Jahrhe. Kei. in ber

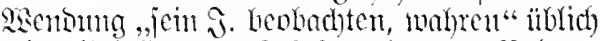
miro (hei campe 1813 Fremionh.). Selege: Qejing 1757 Sirice I 107 daß ich mein Incognito allmählich aufgeben müßte. Büllam 1766 Bum Dentjonen Shationdalgeift $\mathfrak{I} 1^{\mathrm{b}}$ mit dem angenommenen incognito. Edubart 1775 Ientide chronif $\Subset .181$ dieser singt in seiner Klause im strengsten Incognito. Midhaelis 1776 Rnijomlentent IV 43 weil das Incognito den Unhöflichen sicher stellt. 
Edfutler 1782 an Intherg (I 54) weil mein gnito heranszuziehen. Foriter 1791 Injïchten

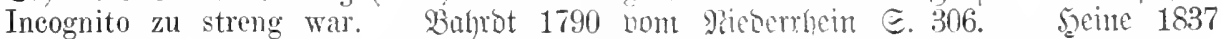
Rebenabejd). II 82 ihn aus seinem Inko- Eaton III 396 sein Inzognito bewahren.

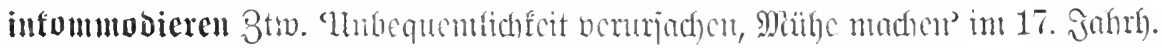

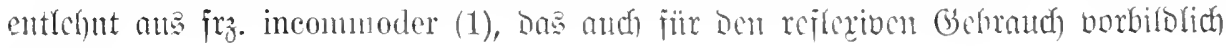
war (2).

Bekge: 1. Francišci 1672 Raudfän I 43 diert gewest. Seibniz 1700 Brieje (II 172) es damre ihn nicht so sehr sein Schiff, als Ich bin mit einem kalten, etwas beschwerdieses, daß man ilum einen solehen Ort an- lichen Flub auf dem Hals und Schulter ingewiesen hätte, đarimm er den Feind das commodiret gewesen.

Geringste nicht incommodiren kömnte. 1684 2. Callenbad) 1714 Liner $\Xi .51$ Bitte sich

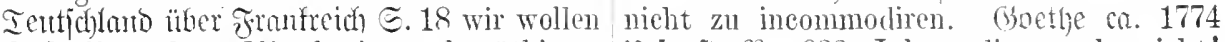
doch die rechten Nlittel, sie zu demïthigen, 14 farjt $\mathfrak{B} .933$ Inkomodirt euch nicht! weil sie uns ein wenig ineommodiren nicht Mintler 1787 Ennterich IY 296 Ich kanu das branchen. Ertinger 1697 Rejieteidn. E. 34 Geld schon einige Zeit entbehren, olme mich weil jeh allda wahr mit dem Fieber incomo- $\mid$ zn inkommodiren.

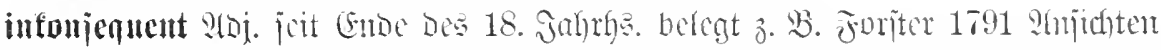

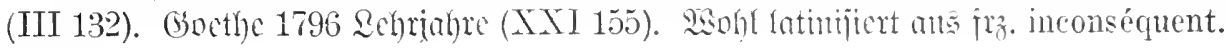
(5)ciljo

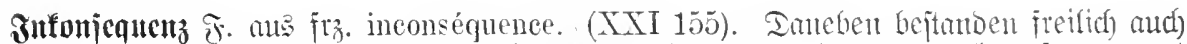
Belege: Edhiller 1787 sirefe I 374. Sungge die älteren Entlehmtigen fomjequent

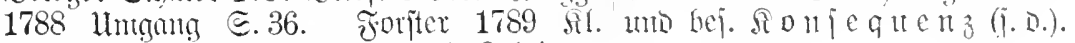

Ediriften E.124. Goethe 1796 aebrinure

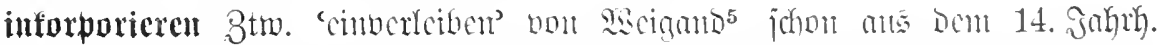

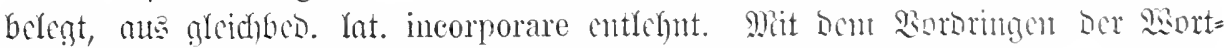

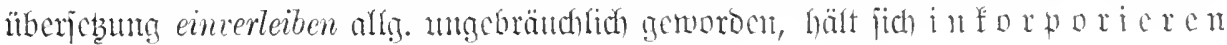

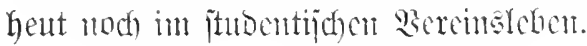

inquirieren 3tw. 'Hadforịchen, geridftlidh unterjuden, verhören' mm $1500 \mathrm{nts}$

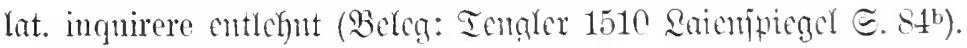

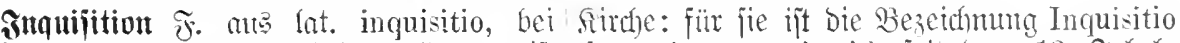

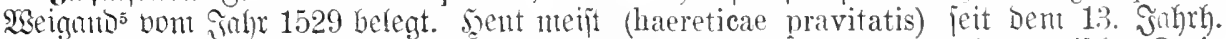

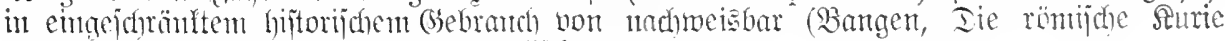

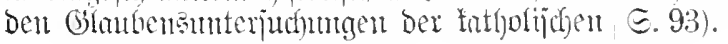

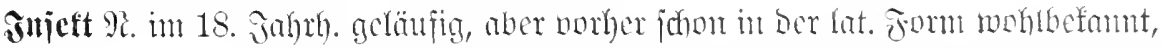

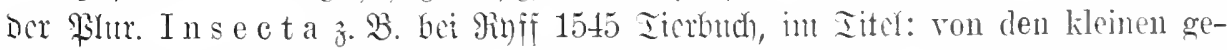

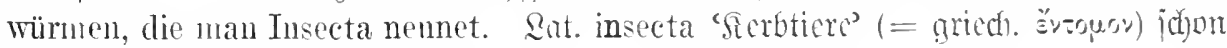

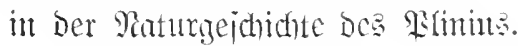

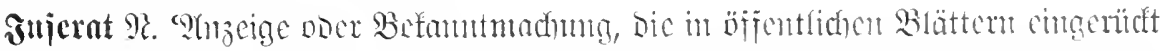

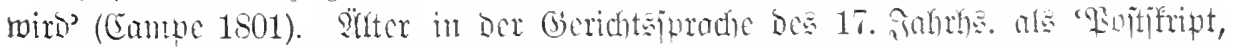

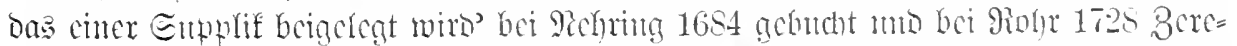

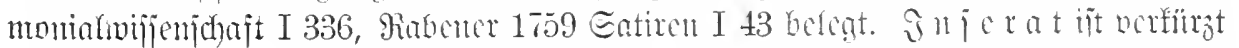

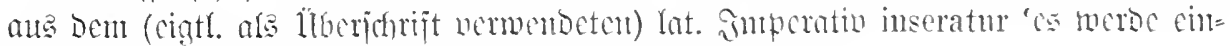
gefuitgts (ugl. Dumger, Bethefte D. Enrathucrems IT 117).

Die bolle gom noch bei mengering 1638 lautende. Wir ete. per totmm inseratur. 2(jo

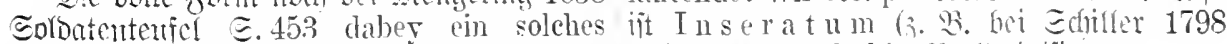

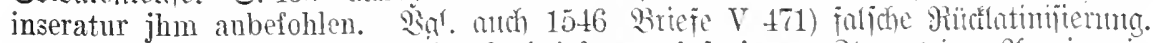

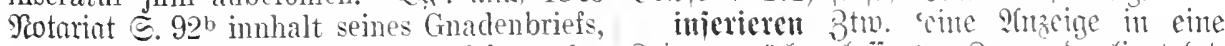

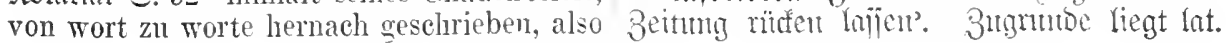




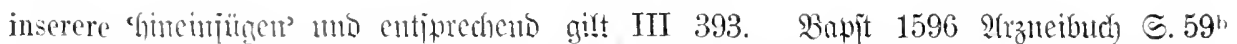
and in Fentiden bie allog. Bebentung cein = wil ich hie anch etliche stïcklein inseriren.

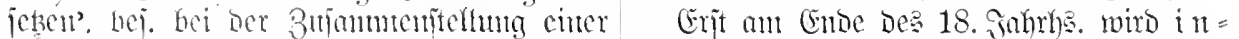

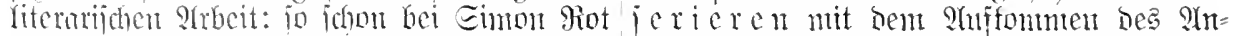

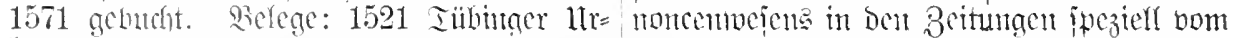

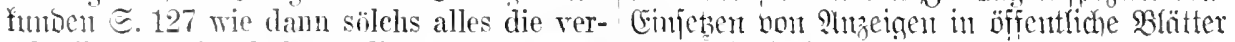
schreibungen imnthalten, die wir ron wort gebraudht (bei (Eampe 1801 gebud)t).

zu wort fur inseriert haben wellen. 1546 injertiun $\mathfrak{F}$. nug frz. insertion mu in

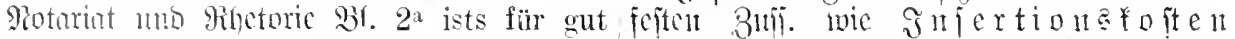

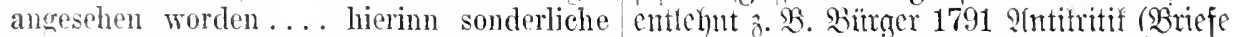
Formular (welche am besten vnd besten- II 112) den für mien ilicht. unerheblichen digsten) aller Contracten zu Inseriern. Verlust an Insertions- und Portokosten.

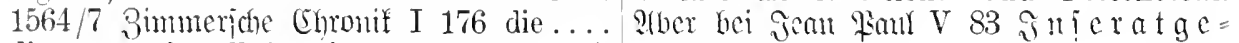
diesem werk soll inseriert werden - 205. G it hre n.

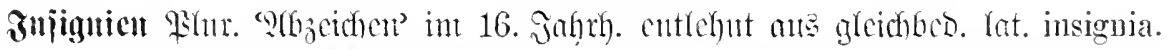

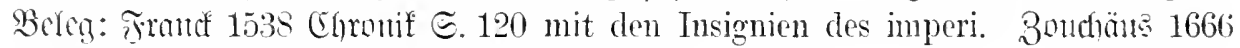
Bölferredft ๔. 2.2S die Wapen und Insignien.

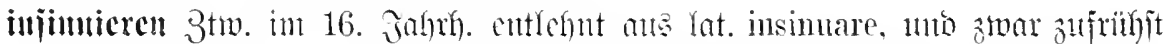

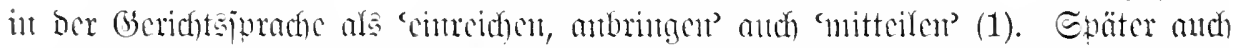
in reflerivem Gebranch entipuechend lat. se insinuare ëich herandoüngen, in Ginnt

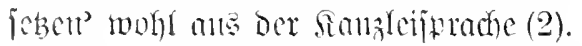

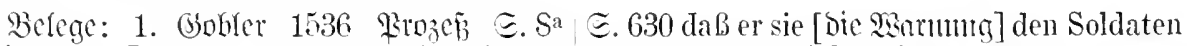
Insinuiren, Ist ein ding an vnd fürbringen, insimiren vnd einhändigen wolle.

Als so dem Richter ein sehriftlich Appel- 2. (PUbertime?) 1600 f̧ofleben $\Xi .302$ lation oder ein Inhibition fürbracht würd. die SchalkBnarren, Zutitler vnnd hohe

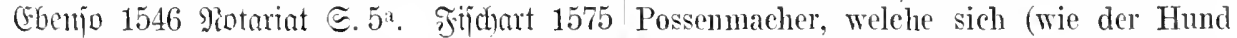
(Barg. $\subseteq .126$ Ich insinuir dir mein nomi- zum Aaß) allenthalben insinuieren rnd zunation inn dein Hertz, verstehst dib Dinten- schmücken. Mefferidmio 1615 Epeltn's dentsch? Edmartienthach 1580 Ennounma Sarmeit II 13 sie insinuiren sich bes hohen

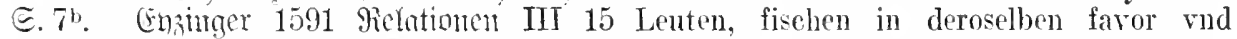
demselben die Tïyserl. Nlandata zu insi- Gunsten. Miengering 1642 Beswijiensitige nuiren. Mengering 1638 Enlontentenfel $\Xi .1170$ sieh insinuiren rnel einschleichen.

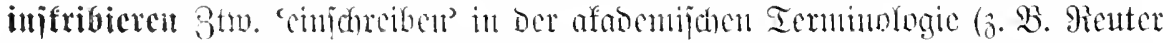

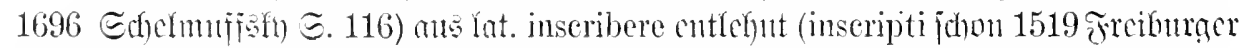
Matrife( I 240. 241). Jut Den riberberger Etatuten 1558 ङ.10 intitulieren und einschreiben.

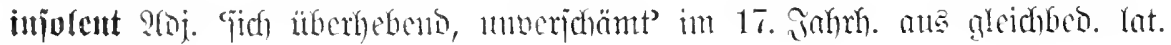
insolens cutlofint.

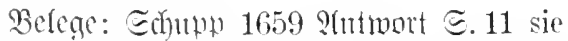
werden besser zeugen kömm, ob ich in- insolentia. Sielege: Ecthicle 1674 Ecfunto= (16) 1666 Edmutene E. 287 dir ron einem jeden Insolenzen. Grenel, Nord mud Unthaten. Höhern und insolenten! Gesellen kömnen Ertinger 1697 gicijefejchr. E.41 grobe Inunterdrückt werden. (Ealfenbad) $171111 \mathrm{ti}$ solentien verüben. Edirfer 1789 Einumont ante hoc こ. 31 Sehe der Herr was das rin (bib̈befe IX 9) die I. der spanischen Truppen. insolenter Ferl ist.

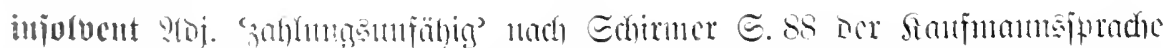

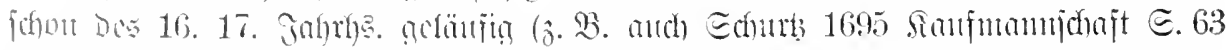
giobet er sich für fallit oder insolvent aus). Sontelfe: ital. insolvente. Sigl. jo l v cut. 


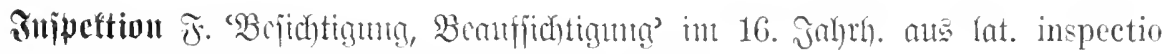
entlelynt, anfange bej. in firchen= mo E(fultucjen.

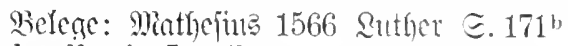
Es kaufft ein Landherr nur die Bauren, ir Zins vonnd fröne, die inspection der Kirchen, wird keinem im kauff eingereumbt. stenge= ring 1638 Bewijijentoneder @. 203 Gott liat jhnen [Den 7 farrem] befollen, daß sie auff die Schulen fleissige inspection anwenden. Soneius 1657 Bedenfert $\Subset .19$ ist auch Recht, daß die Pfar-Herrn auf den Dörffern die Inspection über die Schulen haben.

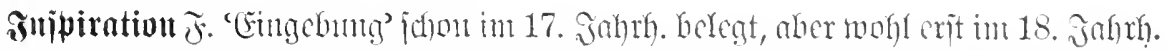

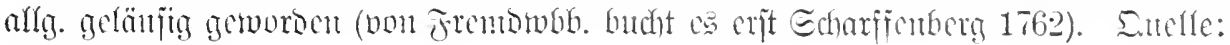
lat. inspiratio.

Belege: 1631 Beridft v. D. Belngenntg Magocburgs $\Subset .8$ zweyffels olune auß sonderbarer göttlicher inspiration. Rejiinta 1778 2Ynti=(Goneze (XIII 146) das ganze System von Inspiration, welches Sie amehmen, Herr Pastor. Bimmermam 1784 Einjamfeit I 201 Pachomius verstand durch Inspiration, oder wie man will, Griechisch und Latein. Bgethe 1796 Rehriabre (XXI 161) aus einem dinklen Gefühl herans, oder, wenn man will, aus Inspiration ausgesprochen.

infpirieren 8 tw. im 18. Johth. an lat. inspirare entfergnt, zuntächjt bou ïbernatïr= ridjen Eingebungen (1), Dam abgeichnächt zu ber Beb. 'zu ctw. antreiben, veranlajien' (2). Belege: 1 . Burzenour 1741 "Behemer Briej= wechiel mit benen Inspirierten" (Frantjutt). Sountant 1761 sidflfen (II 87) daß man diese Evangelisten folglich für die einzigen inspirirten Schriftsteller erkennen müsse. ‥

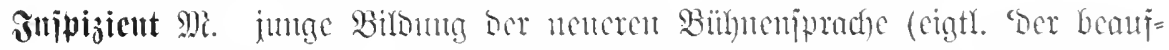

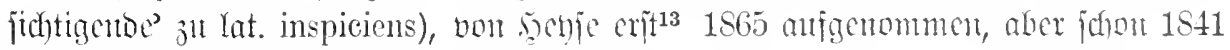
in Ditringers Iheaterlerifon 5.597 gebutht.

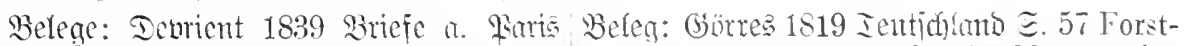
(IV 204) Theaterinspicient. 5adflüner 1841 beamten, insofern sie ibre Waldungen inErzäblumgen (VI 133) der Inspicient des spiziren. Bei. aud) militäriich) 3. B. Psüdfler Theaters.

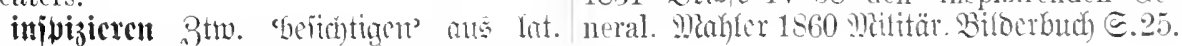
inspicere, zufirifyjt bei Eampe 1801 geburbt.

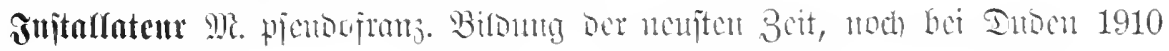
nid)t gebucht.

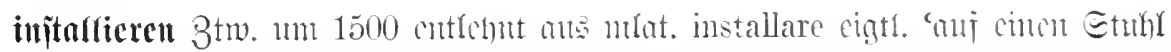

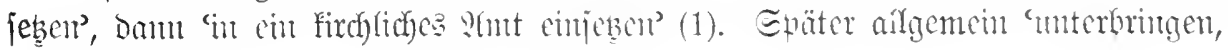
eiutrichten' (2).

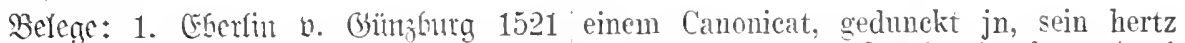
Bfaffenflnge (II 75) do er jnstalliert wurd zu wüschte rff als grob wie ein faust (nach) 
Malferbe E. 56). Finder 1835 Eemilaifo 2. Gaudy 1836 Tagebud (I 190) Ich hieß I 32 der bisherige Kïister war abgesetıt, also nun Romeo, war im Hanse installirt. und der neue noch nicht installint worden.

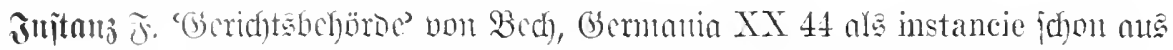

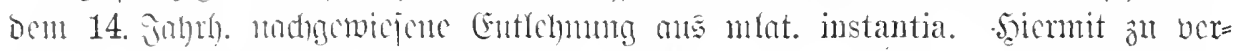

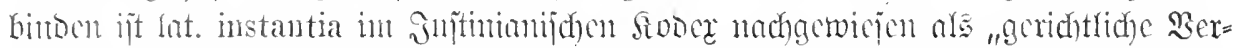

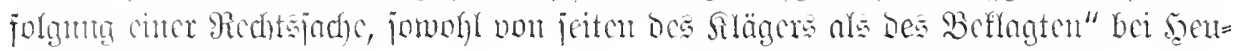

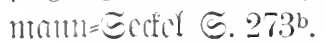

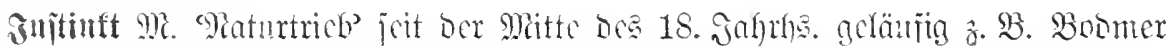
1752 Ponh Є. 256 zmm Schwein, das schwach an Instinkt in Schlamme herum-

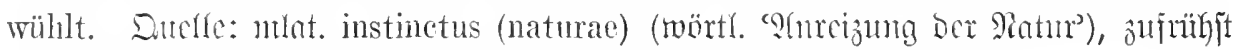

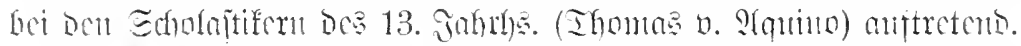

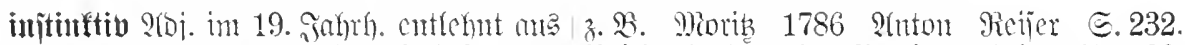

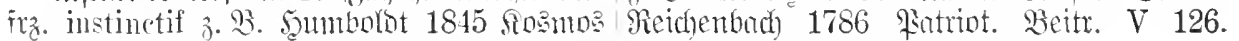
I 16 das Product instinctiver Empfänglich- Siant 1798 Sutfronologie @. 35.

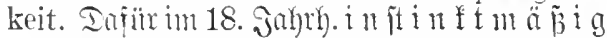

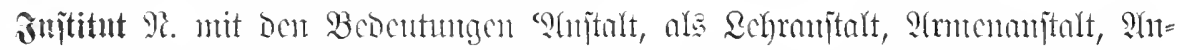

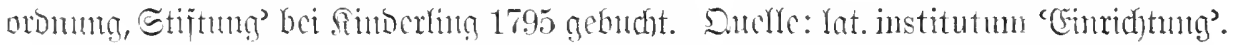

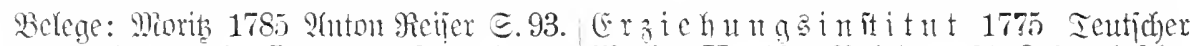
Nun war in H. ein I., in welchem junge Merfur II 136. Bahtot 1790 acbensbeichr. Lente zu kïnftigen Dorfschumeistern ge- II 288. Sigl. auch Serser 1795 Brteje (XVII

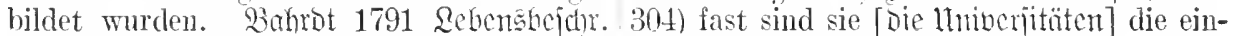
III 146 er strebte darnach in meinem I.-e zige Gattung Deutscler I.-e, die jedes die dirigirende Person zu werden. Inzn Ansland mit Recht ehret.

intrutieren 3tw. 'Anterweijen' im 16. Jahrl). nus grcidyed. Yat. instruere cut=

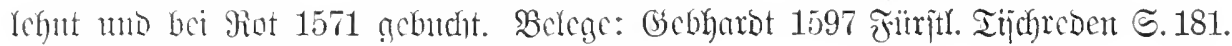

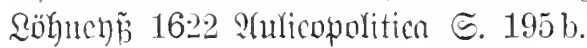

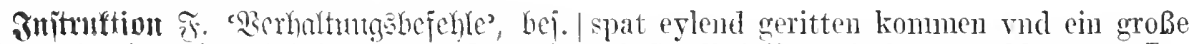

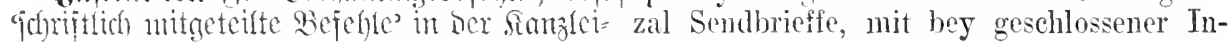

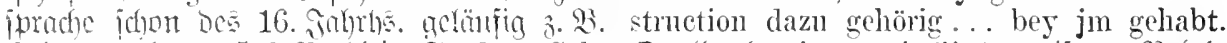

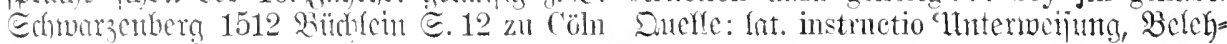
ist ein höllischer postbott . . . an einem abent ruug?.

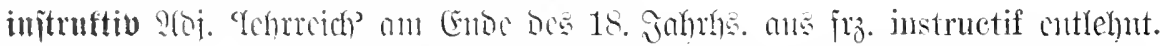

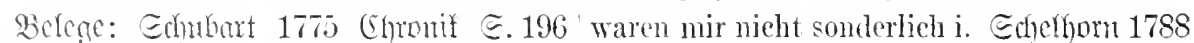
Die 2 atifitze] sind zu kurz gefaßt, $1 \mathrm{~m}$ so i. Puteit. f. Bibliothefore I 161 der reiche und

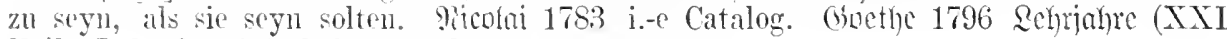
Reiic I 3 oft wiederholte Handhungsreisen 114).

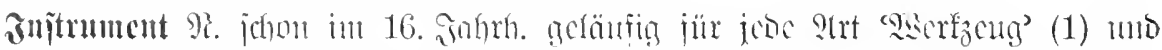

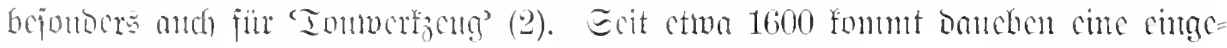

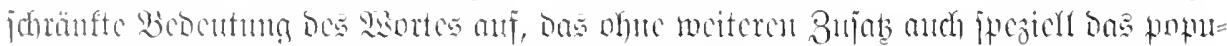

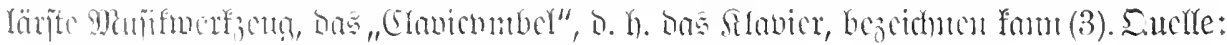
lat. instrumentum 'Gictüt, Merfjacug'.

Relege: 1. Trice 1519 Enteget D. Aranci so anb Sieilia ein new i. bracht wart, genant

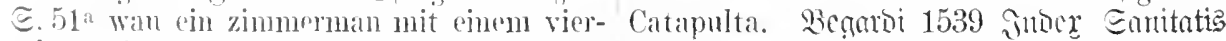
ecketen i. machet er nit, daz er mit einem $\Xi$. 34b eynen diener der natur vnd vn-

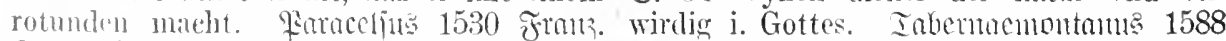

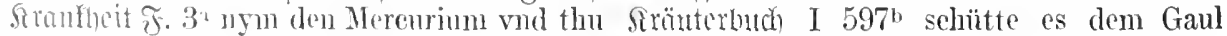

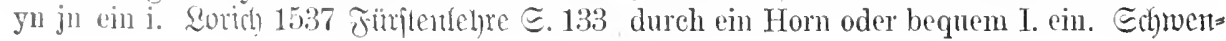


ter 1618 Geometrie I 57 Circel, Linial oder ander I.

2. Birbuna 1511 Minfica $21^{\text {a }}$ von der musica der instrument - Wie vil seind dann der selben instrument. Ett 1523 Ricberbuch [Sitel] lustig zu singen, vnd auff allerley Instrument dienstlien. Ronsherger 1569 arftrononic ๔.294 vnud wirlt sein freud haben mit Instrument der Musica.

3. Prätorius 1619 Enutama mujicum II 11 Wie dic Wörter Instrument und Instrumentist.. zu verstehen seyn - Allen Irrthumb, der aus vngleichem gebranch der Wörter, Instrumentist vnd Instrumenta, herrühren möchte, zuvermeiden, ist allhier erstlich zu wissen; DaB ob wol von dem gemeinen Nanne das Wort orler der Name Instrumenti, gar Specialiter fals nemlich, von eim Clavicymbel, Symphony Spinet, Virginal vnd dergleichen: so wol auch der Name Instrumentist, allein von einem, der auff eim solchen vorgedachtem Clavicimbel oder Symphony, schlagen, vnd wie es in den Niederlanden genennet wird, spielen kan) verstanden vnd auBgesprochen wird: So kan doch solches nicht passiren, vnd ist vnrechtII 5 Instrumentum specialiter sic dictum Virginale, Spinetta, Clavicymbalım, Clavicytherium, ein Instrument - II 62 Eine
Symphony (wie denn anch ein Clavicymbalum, Virginale Spinetta) wird in gemein von den meisten ohn vnterscheyd mit dem Wort Instrument (wiewol gar vnrecht) genemnet - IIJ 10.5 Vud ist derwegen besser, dab man sagt, auffm Claricymbel oder Symphony, all auffm Instrument schlagen oder spielen: denn das Wort Instrumentum mus allein auff die einfache Instrumenta (alb Zincken Geigen etc.) roferiret vnnd gezogen werden. (Ettner 1697 (Egnmicus 厄.749 Eckartl erzehlte tine Geschicht, von einem biinden, der ein guter Geiger gewesen, wie auch eines gleicher Art, der vortreflich auf dem Instrument oder clarier gespielt hïtte. En and nod bei sambe 1836 Edrampiclerin

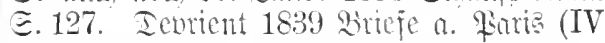
207).

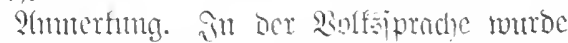

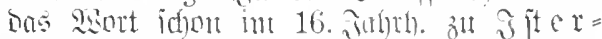
ment entitelft 3. B. Niangarete Romm= gnatiter 1591 Briefe $\Xi .133$. Bogl. ivetter

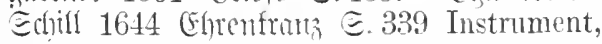
die Bauren nennen solches Nister me nt.

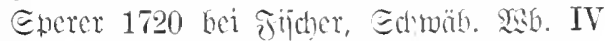
43 mit ihren Dustrementen. wie der grobe Baner sagt - cho. wirb bic Rantform

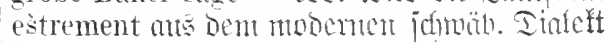
nadigetwicjen.

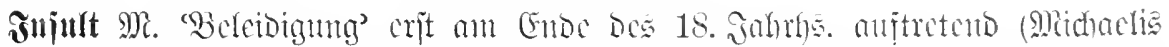
1773 Räjomement III 37\%. Gocthe 1819 Iinan [VI 217]), wohl gefolgert ans Dem älteren

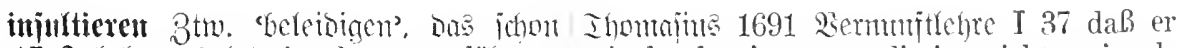
im 17. Jafth. aus lat. insultare 'veriöhnen' mir durch seine contradiction nicht zu insul-

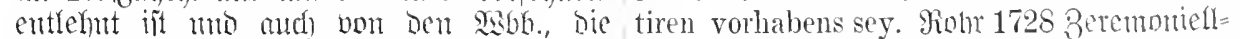

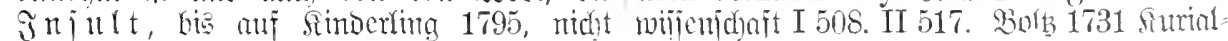
femen, regelntäpìg gebucht wiro. Relege: reberenaten Є. 13.

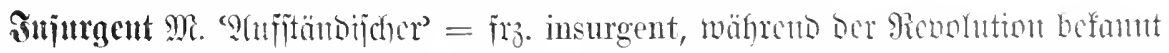

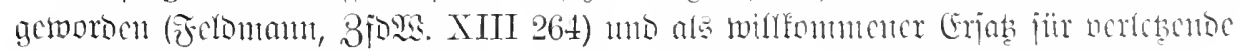

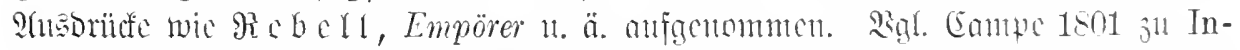

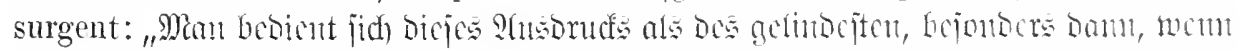

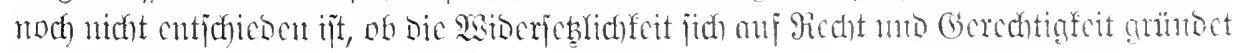
oder nitht."

Berege: Socmes 1791 Riterar. Miärtnrer I 284 welchergestalt die erbetne Dinission Thme nicht erteilt werden könne und möge, bevor er nicht obbesagte Insurgenten [巨chii= [er] wieder beruhigt haben wird. 1795 forit. Soutnal 5.601 die Insurgenten, die nun mur Rebellen hießen. Ecume 1803 Enaz̧ierganta (II 117) Links hinauf nach den Hïgeln des Albanerbergs hatten sich die Franzosen und Insurgenten hartnäckig geschlagen.

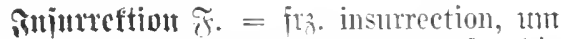
1790 ars renolutionäres Edhogmont für bie 'Sivffischebutg' anfactommen und (nach) Felomm, Pfors. XIIT 261) hafs aud bei

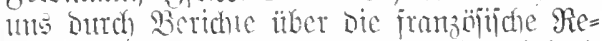
nohution befomt gemorben. 2igl. Siseland 1792 Ftaus. Repubfif $(31,193)$ wodurch die Quelle der Insurrectionen und Revolutionen verstopft würde und die neue Republik Consistenz gewinnen könnte. 1793 Politifj)e 
Toumal Є.596 alle ilne rerirte Unter- so hoeh gepriesene Maratische Recht der thanen, die sich bey den aufrührerischen heiligen Insurrection. Iam allg. z. B. Bjents

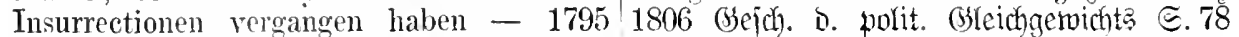
Beiträge alt Gejdichte ber franzöjifchen $\Re e=$ Volks-Aufwiegler, Insurrekzionsstiffter und volution I 543 Wenn die Insurrektion so Freiheitsschwärmer. Börne 1829 Dramatırg. unglücklich ausgefallen wäre, um Revolte $/$ Rlätter (II 335) Nun ist zwar die Insurrektion genannt zn werden - III 37 Man heißt der Tiroler eine Dampfmaschine gewesen. Insurrektion diejenige Bewegung, wodurch (Gubfow 1835 Eharaftere (VIII 21) in der ein ganzes Volk, oder auch ein Theil des- jüngsten italienischen Insurrektion. Şeine selben für das Ganze, sich wider die einge- 1837 厄alon (IV 503) Anderswo bringt es die setzte Gewalt erhebt, die ihren Eid brach Fran kaum zu einer kleinen Emeute, höehund ihre Gränzen überschritt. Wielelat 1799 stens zu einer Insurrektion.

(Sc)prëche $(32,70)$ das vor einigen Jahren

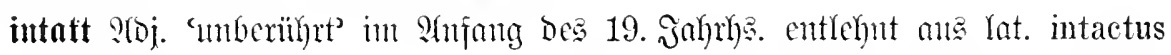
oder $\mathrm{jr}_{\mathfrak{z}}$. intact.

Belcge: Goethe, Deuticher Saturbidfter $/$ Briefe I 247 wo die Wand des Gemaehs ganz (9. ‥ 5. 45, 236) Bewunderung und Freude, intakt geblieben war - 1835 હemilajio III wie man sie an allem Ursprünglichen, Reinen $147-1840$ Billocijal I 32.

und Intacten zu haben pflegt. Büuffer 1831

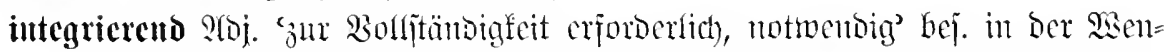

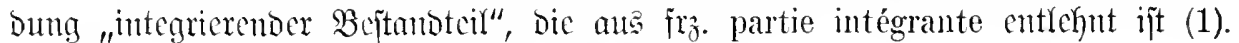

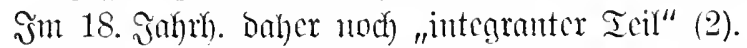

Belege: 1. Soffinann 1820 Rater Murr|grierender Bestandteil des eehten Dichters (X.38) daß die Liebe zur Kunst und Wissen- sein soll.

sehaft nur als ein integric render Teil des eigent- 2. Sisielanto 1774 IGbocriten (XIII 21) lichen Hoflebens anzusehen ist - 1821 der Magen, der Bauch und die übrigen inteEerapionthrïber (IX 11) die goldene mit granten Theile des sichtbaren Mensehen Spaniol gefïllte Dose, einen integrierenden Teil 1799 (Scfpräche $(32,84)$ Diese Frage wäre seines innern Selbst. (Socthe, Sitnl. Diteratur also: ob dem Deutsehen Reiche zngemuthet (2. 1. S. 38, 269) unser Orchester, welehes ein- werden könne, eimem so wichtigen intestimmt in das was auf derBülme geschieht, granten Theil seines Staatskörpers gutja in der Oper, im Ballet einen integriren- willig zu entsagen. Eallegel 1798 (bejej. den Teil macht. Gubifow 1840 Eharaftere D. Toejie Є. 228 ein integranter Theil des (VIII 146) daß der Verstand ein inte- ganzen Studiums.

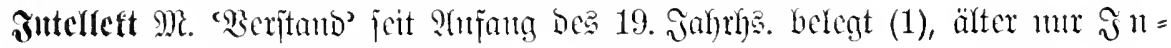

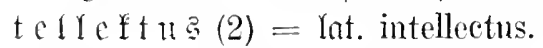

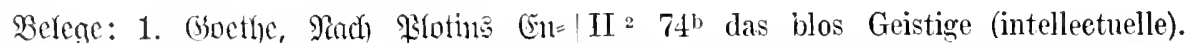
nenten (48, 196) Da wir überzeugt sind, serber 1797 Briefe (XVTî 288) der intelJaß derjenige, der die intellectuelle Welt leetuelste Europäer - intellectuelle Kräfte beschant und des wahrhaften Intellects - (290) die höehste Aeußerung intelleetueller Sehönheit gewahr wird, anch wol ihren Vater, Kraft. Ecfinter XVIII 423 (bei Ribrein) Daß der über allen Simn erhaben ist, bemerken or im Intellektuellen und Sittlichen auf könne. Gutbfow 1872 Sinabenzeit (X 180) einer Stufe mit ihm stehe. Dufür älter

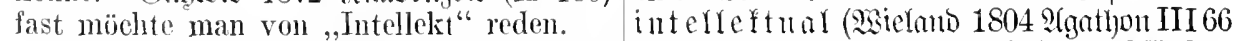

2. Serber 1797 Stricfe (XVIr 288) Der Daß die körperliche Schönheit ein Wiederreine Intellectus bedarf keines Lasthiers. sehein der intellektualen Schönheit des Geistes

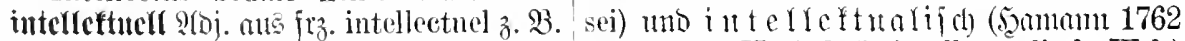

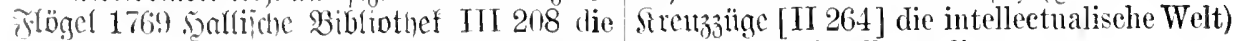
intellectuelle Sehönheit. Eulzer 1775 Iheoric ans [pötrat. intellectualis.

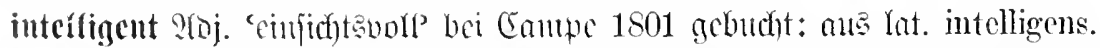

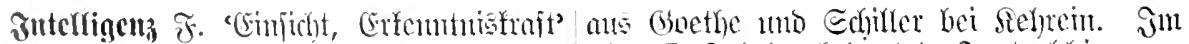

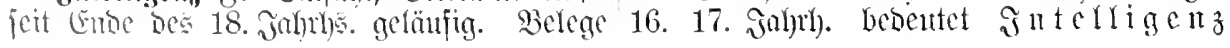




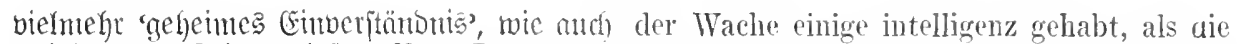

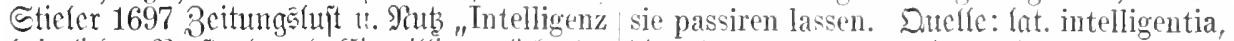

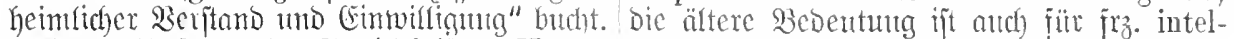
Belege: Emjer 1521 Etreitjchriftert II 210 ligence bezcunt.

Derhalben, als tzu vermuten, onch deyne Interfigenjblatt im 18. Infrh). übfich als

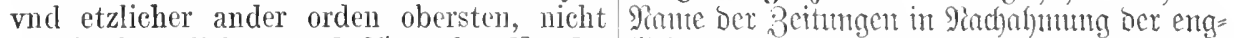

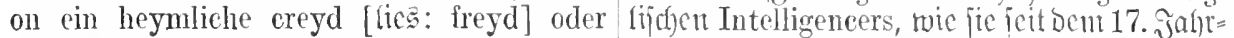
intelligentz, dem spil so lang zugesehen. Gumbert bejtanden (9iesict. V 371" an intelli-

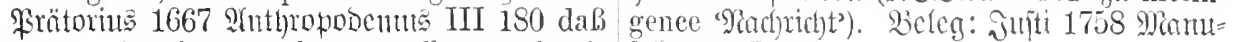
sie den König wegnehmen wollen, und mit fofturen I 115.

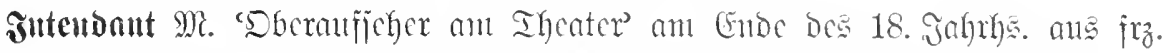
intendant entlehnt z. B. Echubart 1775 Egronif $\subseteq .213$. Sfffland 1798 Iheatral.

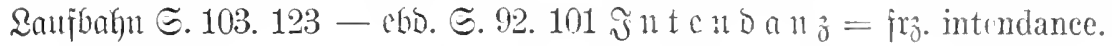

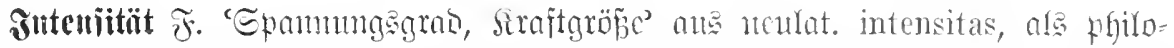
jophifdyer Texminus bei 恕lfif 1730 Intolog. \$ 759 intensitas sive intensio . quasi gradum multitudo. Beleg: Scrocr II 23 (bei fechrein) Die Kunsttriebe der Thiere nehmen an Intensität zu.

inteniib ?roj. aus neufat. intensivus (ober 131 ) Lieber einem einzigen Antriebe alle mögfra.intensif). Belege: Re fintug 1767 Dramaturaic liche intensive Traft geben! Ecfiller 1793 (IX 215) Der gänzliche Nangel intensiver 23om Erhabentu (XVII 389) Ans diesem Aecente verursacht Monotonie. 1770 Salfijche Grund ist das Kontemplativerhabene weder Bibliothe IV 658 die intensiven Accente, von so intensivstarker, noch von so ausgeden Nachdruck. Gerber 1793 Bricfe (XVII breiteter Wirkung als das Pathetischerhabene.

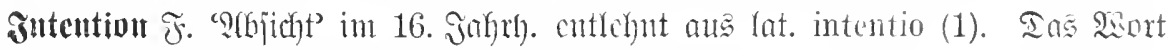
wurde int 18. Jahrh. cin Ierminne ber fumftjprad) (2) und lebt mit ber jo berengten

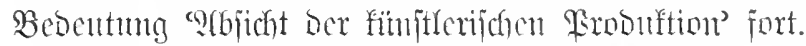

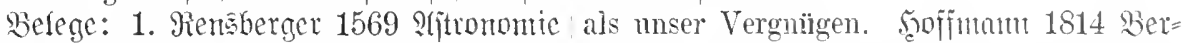
ङ. $69^{\mathrm{a}}$ er wisse dann zunor die intention gaıza (I 126) Auch der mittelmäBigere des fürnemens vnd der frag wohl. Francf Dichter hat seine Intentionen - (130) Ich 1576 Catalogn $\subseteq .347$ wurffe jhme dagegen hoffe, daß dn das Wort In t e n t i on für, mein fürhaben, Intention vnnd den nieht in dem höhern Sinn der KunstGlanben der kirehen. Cogzinger 1590 \&elatio= sprache nimmst, sondern mur den wenigstens nen I 30 der Stände mainung vnd intention. scheinbar moralischen Zweck der Schall-

2. Goethe 1796 Zehrialye $(22,176)$ Die spiele jenes Dichters darunter verstehst. Intention des Autors liegt uns nicht so nahe,

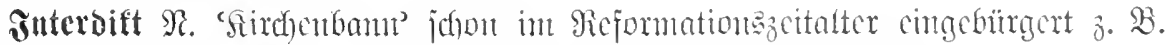

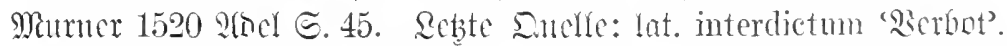

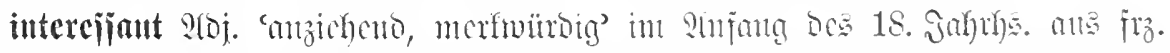

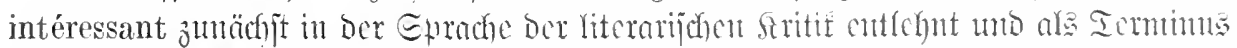

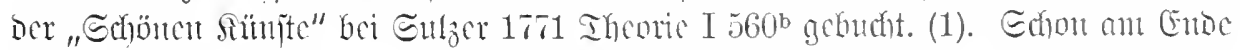

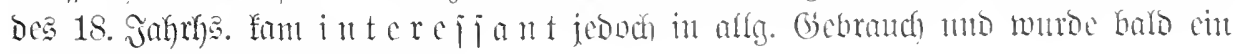

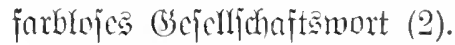

Belege: 1. Friedriff D. Grog̉e 1740 Rumb= (IX 267) daß sie nicht sehr komische, auch bcmerkumg (ङ. 103) Gazetten, wenn sie inter- wohl sehr i.-e Seenen veranlassen - (310) essant sein sollen, dürfen nicht genieret alle Kunst des Dichters kann sie uns nicht werden. Meicr 1744 Sumitrichter $\Subset .159$ i. machen.

wenn er Dinge beurtheilt, die ihm niehts an- 2. Goethe 1774 siertfer (XIX 29) dessen gehen, und darüber der interessentesten [!] Geschichte mir doch i. und herzlich wird, Sachen vergisset. ¿eifurn 1767 Drmmaturgic als mein eigen hänslich Leben. Bürger 
1776 Riricie I 272 die Sache ist gar zu i. und kitzlich. miöller 1778 Famits Seben ङ. 8 ieh wubt es nicht, damals noch nicht, da dis Ding zum Niederschreiben mir i. wurde. Ectiller 1780 Brieje I 16 der Verstorbene thenre und edle Jüngling war mir äuserst i. Gothe 1807 Briefe XIX 467 Ich bin renötigt, um mich hier der gewölnlichen Gescllschaftsworte zu bedienen, ihn i. und sogar liebenswiirdig zu finden.

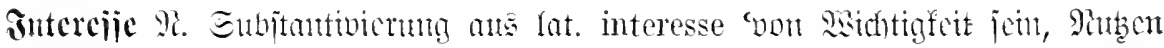

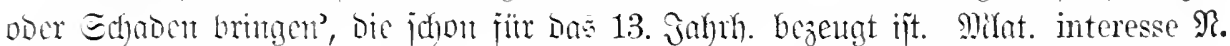

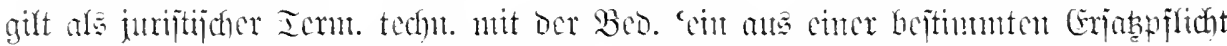

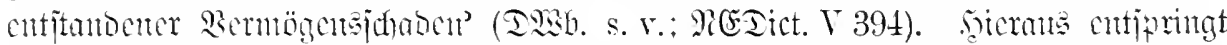

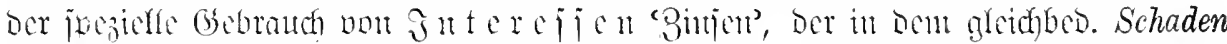

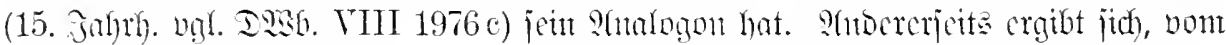

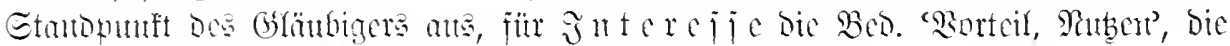

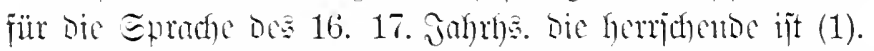

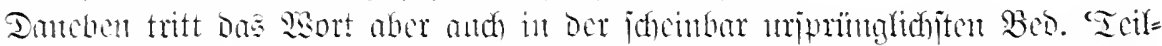

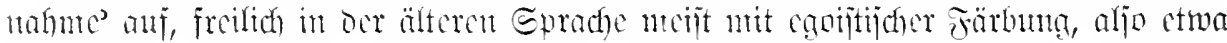

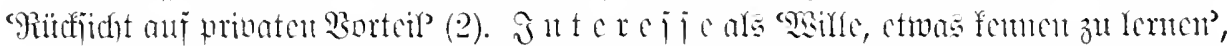

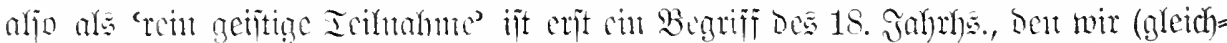
zeitig mit interejiant) aus Dem frang. intéret cutlebnt haben (3).

Belcac: 1. Frienentuerg 1597 Discur Priester, der ein i. darbey habe, daß solche BI. $2^{b}$ den Schein vnnd praetext der ge- Licentz werde eingeführt. sjorher nod)

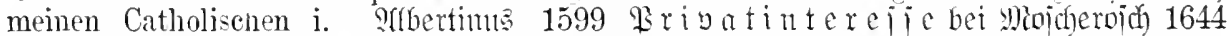
Guebarns Eenoidr. III $103^{b}$ welches Weib Rhilander II 504 daß bei den meisten Ständen nicht liebet, rmb geliebet zu werden, sonder des Reichs alle Verhinderung deß edelen von Gelts vnd I. wegen. Mejieriffmio Friedens einzig and allein von eines jeden 1615 Epelta's Parrbeit I $72 \mathrm{jhr}$ selbst i. Privat Interesse und Reputation herrülre. rnd wolstand. Bei. jein cigenes Gntereije 1689 Rolit. Fliegentweod I 100 . Bülou 1766

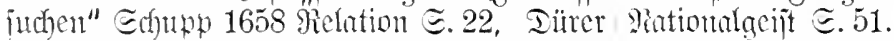

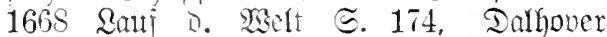
1689 Gortenbectlein II $12^{\mathrm{b}}$; "ohne cigents gnterelie arbeiten" Frande 1702 siaijenhau 162.

2. 2(thertim 1598 Gmevaras Eemojhr. I $129^{1}$ die freundschafften, so anff ein I. nnd gewinn fundirt seind, eben ron solches $\mathrm{I}$. wegen ein Endt zu nemen pflecen - 148 der Geitz wnd I. der Geistlichen - $1599 \mathrm{chs}$. III $84^{b}$ das jenjge allein kan man für gesehenckt halten, wann der jenig der es gibt, solches gibt, olme Respeet vnd I. (5rottnits 1647 Regimentont $\Xi .16$ von losen Leuten, Aerer I. nur auff ilure eigne Hoheit wind Auffnehmen riclt. Siej. "cin Interejie hoben

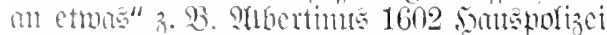
I 2032 J je Woiber, welehe dises lesen vnd wrehe ein i. darbey haben, werden mir villeicht einen schlechten Danck verjehem II $71^{\text {a }}$ wo findt man heutiges Tages cinen

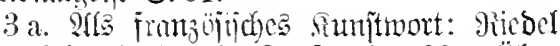
1767 Theorte D. joh. Sïmpte ङ. 328 („Ïber Dng Intercife") Diese Bewegungen zusammen genommen nennt man das Interesse. Ind Herz ron der Seite der Sympathie, der Neugierde, des moralischen Gefïhls und der Eigenliebe anzuøreifen un 1 zu rühren fähig itt - $\Xi .330$ Das allgemeine Interesse ist clas Interesse der Menschheit, wie es Batteux

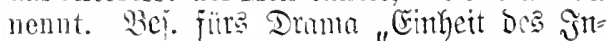
terefjes" val. Seffing 1750 Ploutus=? Tritif (r)empel XI 1, 126) "Dieje it Dic Einheit des interls, ober wie er [o: la Motte] iie it jenter Enrache ntemnt, l'unité de l'intérêt" - Dazn 17 万r Drmmaturgie (IX 255) Andere Foller möchten schwerer zu entschuldigen sin; der Mangel de Interesse, die kahle

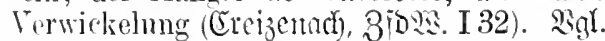
itod) 1770 sourtif:he Bibl. IV 656 Eigentlich interessant ist ein Gegenstand, der unser 
sollte man das Kunstwort Interes:e, welche: man insgemein ron aller dramatischen Theilnehmung braucht, nur für das Anzielsende des Trauerspiels sparell.

b. Flögel 1770 Serinth über o. Echönheit (NIot, Bibl. IV 5) Das Wort Interesse ist seit jeher manchen Weltweisen so anstöbie gewesen, daß sie immer ctwas böses oder unanständiges darunter verstanden haben (6) ich mub aufrichtig bekennen, daß ich die fürchterliche Gestalt gar nicht finden kann, unter welcher man uns das Interesse vorstellen will. Laßt uns die bisher verengerten Gränzen desselben erweitern, alsdenn werden wir es nutzen können, wie es die Tatur der Dinge zu erfodern scheint. Wer nöthigte uns denn, dasselbe blos auf Gegenstände der Habsucht, des Ehrgeitzes und der groben Wollust einzuschränken : ist nicht sein Gebiet riel weitläufiger? Es giebt tausend Arten eines edlen Interesses, dessen sich der tugendhafte Mann nicht schämen darf - (7) Denn wenn ist unsre Seele thätig? Nur alsdenn, wenn ein Reiz zur Thätigkeit vorhergeht, und dieser Reiz ist irgend eine Art des Interesses. SAont 1790 Urteisfrnft I \& 2 I. wird das Wohlgefallen genannt, was wir mit der Vorstellung der Existenz eines Gegenstandes rerbinden. Goethe 1796 Qche = jahre (XXII 213) das I. am Hamlet war erschöpft - 1809 sahlverwanotichaten (XX 47) da ich euch nicht zu weit von dem augenblicklichen I. wegführen will - (114) Das würde freilich das I. der Gesellschaft sehr vermehren.

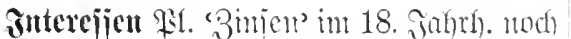

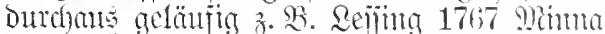

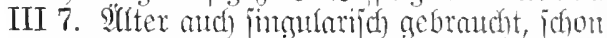
bei Suther 1520 Eermon o. D. SEudher (TI 50). Edron mlat. interesse (j. 0.$)$, bas im (5)gi. zu usuria Den firdjenteditid erlatbten Bin bezeidnete.

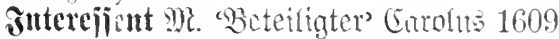
Relation $9 x .14^{\mathrm{a}}$ biß sich die Herm I.-en sich der Succebion halben werden vergleichen.

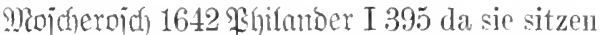
und ihrer noch übriglebenden Consorten und i.-en alle Taqu biß zum Ende der Welt mit rerlangen rrwarten. Edhup 1659 Stalender I $6^{b}$ ich wil licber zehen helffen bey Ehren erhalten, als alle die 1.-en zu schanden machen.

intereijieren Btw. 'jntereije erregen' 1. 3u interejie 2: Gur maftiöchen $2(n=$ teilnahme neronlajien' io bei. int Rart. in texejifert 3. 2 . Enginaer 1590 Rela= tionerr I 164 die genachbarten interessierte Fürsten. Coroln 1609 Relation Mr. 2 den jenigen, so darinn Interebirt sein - 9r. 12c die vbrige Gravamina, dabey die Catholiscnen nit wenig Interefiert. Iarer beoentete un $\mathrm{n}=$

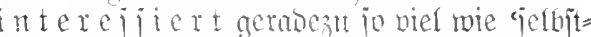

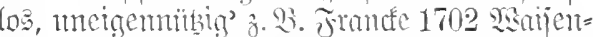
haus I 46 solche gewissenlafte und gantz uninterressirte Arbeiter. 将oris 1886 ?. Reijer I 6 eine röllig uninteressirte Liebe zu Gott.

2. 3n iो ne rejie 3: areintige Ieilnahme

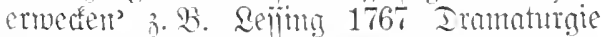
(IX 383) einen jungen Menschen, der Sie kurz zuvor so sehr interessirte. 1769 I. Bibl. (תIon) III 689 Julianens Eifersucht kränkt den Zuschauer mehr. als daß sie interebiren sollte. Eothubart $177 \pm$ I. Chro= nif $\Xi .515$ Die Beförtlerungen waren ausnehmend g]änzend. Wen sie intereßiren... Dermes 1789 Fitr Cefteru II 184 einen Mann, der das Glück zu haben scheint, Sie zu interessiren.

3. Bej. anch reflexib, moht mach jus. s'intéresser. Beleg: Ricdet 1767 Theorte こ. 32S Dic Römer intereBirten sich für ihre Gladiatoren, wie die Engelländer für ihre Hälne. 1769 I. Sibliothef (stob) III 455 Die Meinung, die auch Voltaire hat daß man sich mehr für den Turnus, als für den Aeneas intereßire. Gelegentlich and io

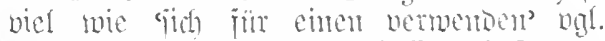
Chormith 1845 Sani 8 . 些elt I 30 indem er ihm rersprach, sich für ihn zu interessieren.

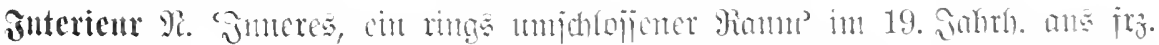

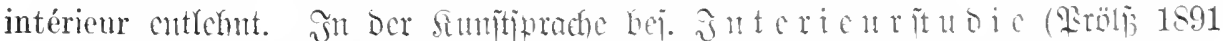

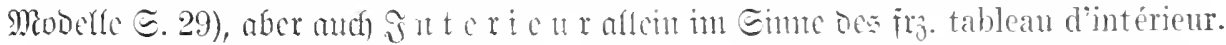

Betege: Mar.v. Mexifo 1851 Reben I 192 Interieur [3immer] noch behaglicher zu

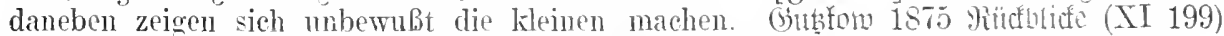
Intérieurs, Gärtchen und Terrassen. Edhüfing Das Arbeitszimmer, das cigentümlichste In1863 Sfftiengejerlidiajt III 1 Ein trantes terieur des Dichters.

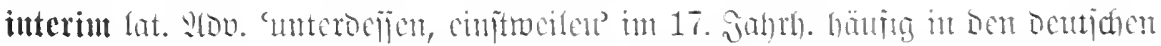

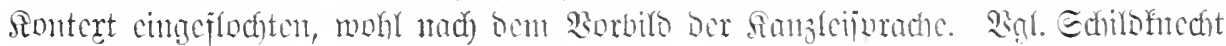




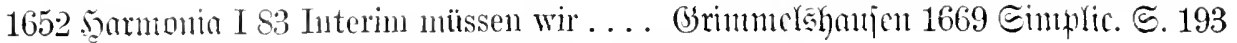
Interim schlng der Geistliche selbst ein Liecht an.

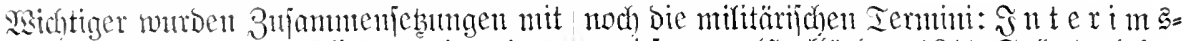
interim- als eritem Blied: "interims- un i f orm (jadflüntoer 1841 Eolontenleben

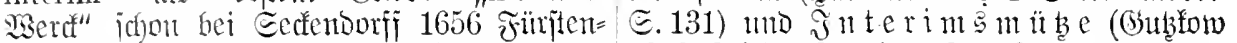
itunt I 75. "Interims-ভchein" Minperger 1869 Edhön. Etunden હ. 118). 1711 Bejdx. В. Meijen I 371. Bei atrden= hol 1787 Englano I 139 Interimsvortheil II 143 Interims-Gefängnis. Siuppermann 1792 Jurift. \$g: E. 290 bucht interimsDecret, Interims-Quittung [aud) bei Goethe, Briefe XXV 341], Interims-Verwaltung, Interims-Wechsel. Tazll bei (3obetfe 1796 Lehrjahte (XXII 23) Interimsdirector. Sistrf $=$ (ich) allg. geläufig finc hent wohl mur

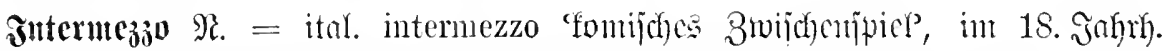

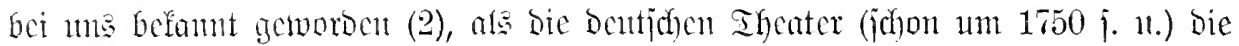
italieuijhe Sitte nadjutahmen begamen. Bald wurbe bas Sort aud in ber allg.

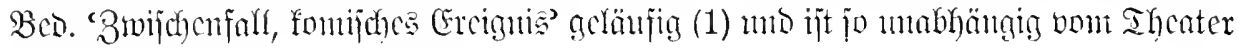
erbalten geblicben.

Belcae: 1. Santam 1761 niolfen (II 62) oder vielmehr proBirlichen, Opern, wo nur Laß er ihre Anzeigung des Buchs widerlegen, zwey oder drey Personen vorkommen; weil ohne sich bey einem Intermezzo vom Histör- dergleichen Stïcke ehemals in Italien chen aufzuhalten. 1767 QIlg. D. Siblinthef IV 1 zwischen den Akten oder Aufzügen der ङ. 159 Nun komunt ein I. von einer Mordge- großen Oper, zum lustigen Zeitvertreib, vorschichte. Sindleben1781 Florion $\subseteq .197$ es gab gestellet worden. Echmid 1775 Egronologie noch ein I., wo er anf eine Viertelstunde mit ihr D. D. Theaters $\subseteq .159$ Herr Koch ließ daher allein war. 1790 2(nctosoten I 18 Man lächelte damals in Deutschland über dieses $I$. Intermezzo (Schauspiel). Gegenwärtig giebt spiels - aufzuheitern suchte. man diesen Namen italiänischen comischen,

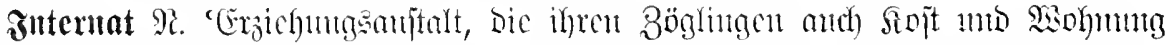

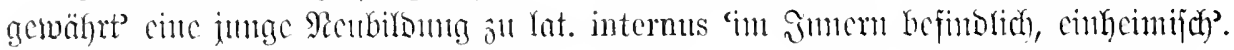
Gebutht bei scheje 1859.

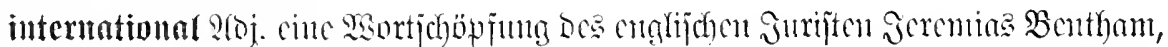

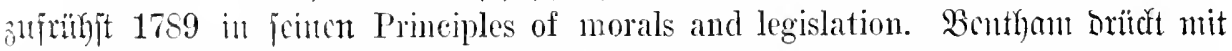
, interuational law" Den Begriff bes jus gentium aus, ber eigettlich als jus inter

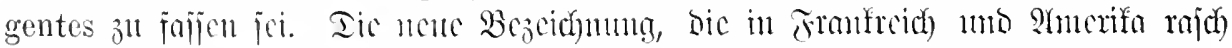

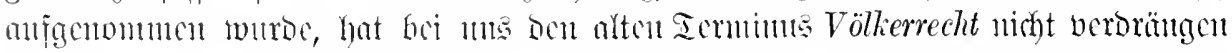

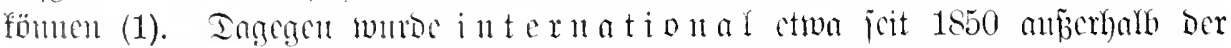

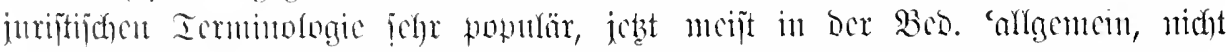

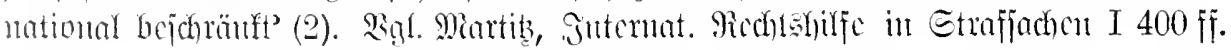

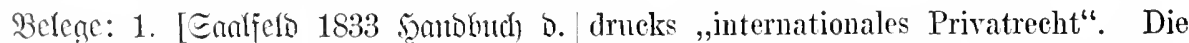
Söfferredhts E. 1 Das Völkerrecht - Droit Englische und Nordamerikanische Jurisprudes gens, law of nations, international law.] denz sagt schon lange: private international Echäfiner 1841 Entwidfung des internatin. law. Der dentschen Sprache gebrach es Fribatredits $\Xi .3$ Es bedarf wohl keiner bisher an einem entsprechenden Worte. weiteren Rechtfertigng des dentschen Aus- Feffter 1844 Gurop. Sölferrect)t (Borr.) Zu- 
vörderst nemne ich das Völkerrecht noch zureichend, als die Liraft seiner Regierungen. immer bei seinem alten Nanen, nicht, wie Mintib 1888 Jnternat. Medhtshilfe I 401 es manclse mit fremder Zunge zu nemnen Man spricht voll internationalen Ausstelangefangen haben: internationales Recht. lungen (sio haben wohl seit 1851 am meisten

2. Frentug 1848 2fuffïb I 45 er reprä- beigetragen, das Wort in Kurs zu bringen), sentirt den bequemen Verkelı der billigeren von internationalem Verkehr, Handel, Markt, Existenzen des Südens, ist aber für den Absatz usw.

großen internationalen Umsatz ebenso n11-

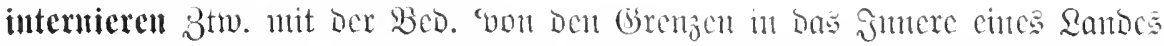

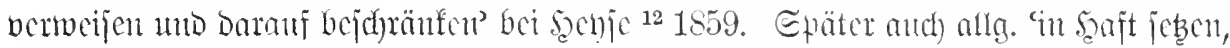

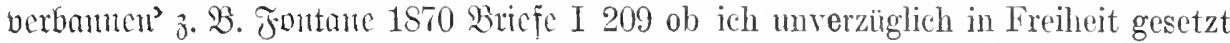
oder als prisonnier de guerre im fernen Westen interniert werden würde. Ducffe: $\tilde{f} \mathfrak{r}_{j}$. interner.

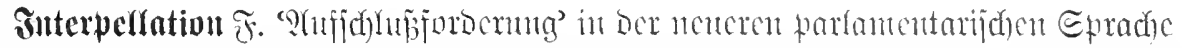
aus frz. interpellation entlehnt; vgl. Rauner 1849 Bricfe a. Franffurt I 372 durch unnütze Fragstellungen, zu deutsch Interpellationen. Iazu inter f e r y e r e u aus fro. interpeller.

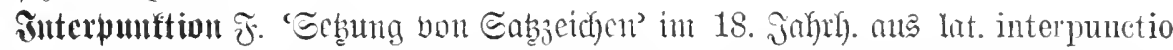
entlelynt z. B. Sefjing 1772 Dricfe (XVIII 40). Dafiur älter Diftinftion (5om:

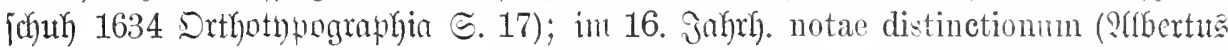

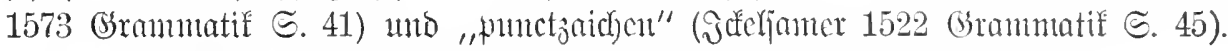

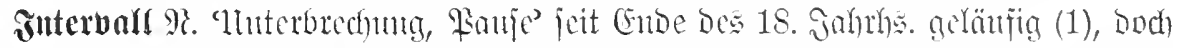

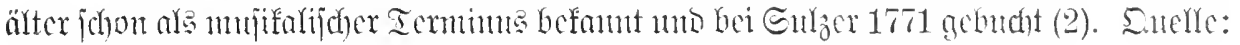

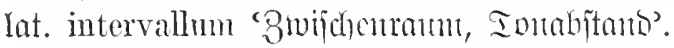

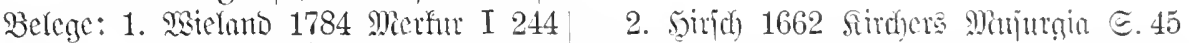
sie waren in zu langen I.-en von einander es steigt damit auf und nieder dureh die

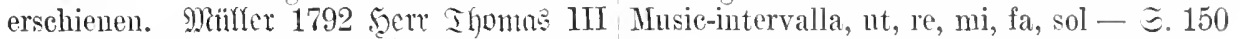
133 Er benutzte jegliches $\mathrm{I}$. das ilm sein aus der Natur aber dieser Intervallen entPodagra ließ. Brm 1806 Enijoben I 231 entspringet die Natur eines ieglichen toni.

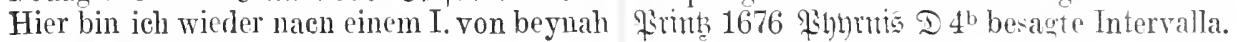
vier Jahren angelangt.

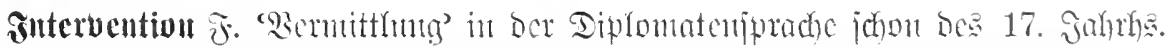

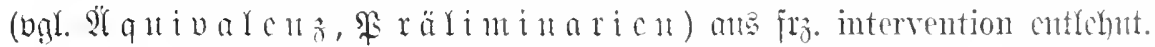

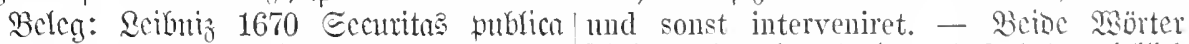
(I 172) so wird unsre I. mehr cine Zugabe jofjeinen jeboch crjt im 19. Jahurh. wirffich der Niederlage als ein Ansschlag der Defen- gefüufig gemorben zu jein; vgl. anch 1839

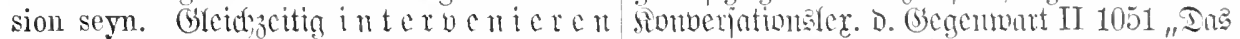

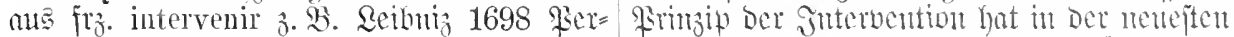

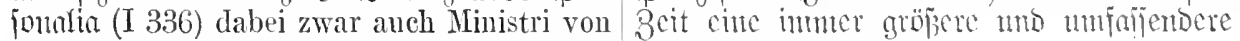
Frankreich und andern Potenzen mediando STustifioung crhalten".

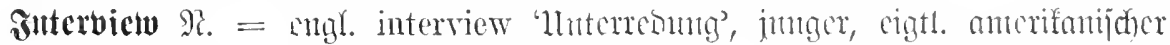

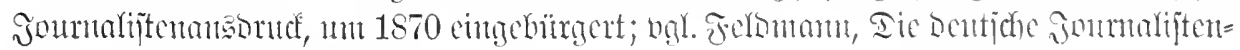
ipradic (8fors. XIIT 2SS).

interviewen 3tiv. nadi engl. interview

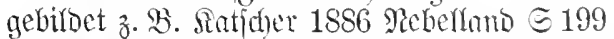
Alle an der Affaire beteiligten Personen wären äußerst genan, interviewt" worden. bin ieh gereist, wie man nenerdings darStumb 1886 Fonu. Budjhol III 70 Die stellte, nicht wie ein zudringlicher CorreKellner, welche ich interviewte, wollten nichts spondent des New York Herald. derartiges beobachtet haben. 


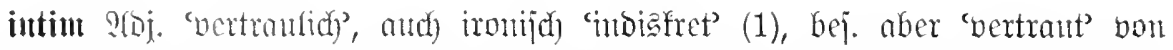

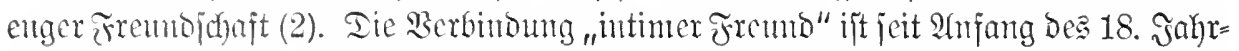

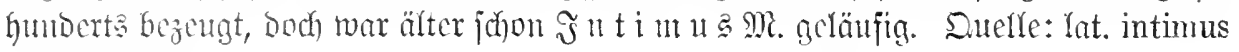
(aud) Eubit.).

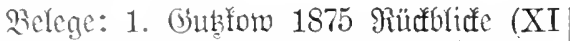
11) Diese vielleicht etwas zu, ,intim" ansgefallene Anekdote. Dazn os nt $\mathrm{im}$ it ät $\tilde{c}_{=}$ frz. intimité) Fontane 1897 Etedilin 巨.47.

2 Fleifher 1731 ger $y$. es cin Verwandter und ein intimer Freund und Bruder mit gleicher Fhr-Affection beton uns ware. Edfirler 1788 Briefe II 39 gegnen. Golmant 1752 Eeloitgiographie

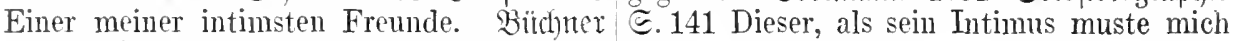
1835 Briefe @. 347 Böckel und Bam sind zu sprechen suchen. fortwährend meine intimsten Freunde.

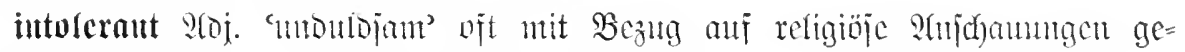

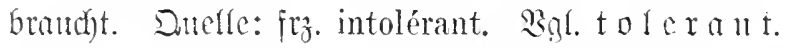

Belege: Sichman 1768 2ntifritifus I 75 weil man fand, daß die I. dieses Reich senr über den i.-en Ton mancher Theologen. entvölkerte. Savater 1776 \$injiogriom.

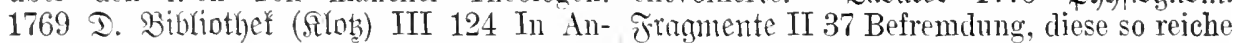
sehung des dictatorischen, i.-en, gebiethe- Quelle von I. Echlözer 1782 Etaratantzeigen rischen, groben und spöttischen Tones hat I 167 Toleranz und I. zeigt allgemein das es Hr. Herder bereits so weit gebracht. Betragen der herrschenden Religion gegen

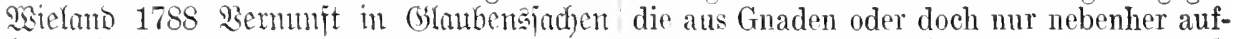
$(30,38)$ Tarren und böse Lelte sind von genommene, an. Nielano 1788 Bernumft Natur i. in GSlaubensiact)en $(30,7)$ die abschenlichen

Intoleranz $\mathfrak{F}$. an frz. intolérance. Se= Folgen der I. und des Fanatisnnus - (64) lege: ङdhubart 1775 chronif ङ. 145 Man eine Partei, bei welcher die I. sogar ein sagt, der König werde den Katholischen in Grundartikel ilırer Religion ist.

seinen Staaten Religionsfreyheit verstatten,

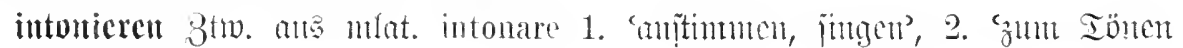
bringell'.

Belege: 1. Mengering 1642 Genijiens missen - 1689 ebo. II 433 diß so offt rüge $\widetilde{E} .794$ ein Bulen-Liedlein vber das intonirte Liedl.

andere, darin offtmals grob Gam gnug auff- 2. Prätoring 1619 Enntagma mu. II 2 geweiffet ist, intoniren vnd anstimmen. etliche [Jnftumente], die allein mit dem

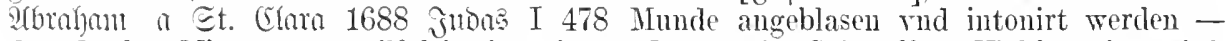
den Psalm Miserere so vilfältig intoniren 47 wemn eine Säite vff der Viol intoniret wird.

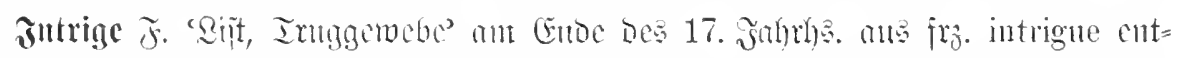

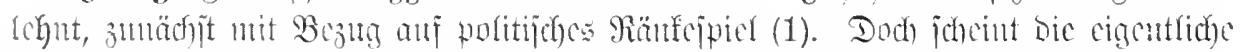

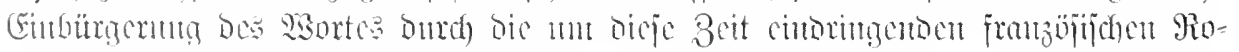

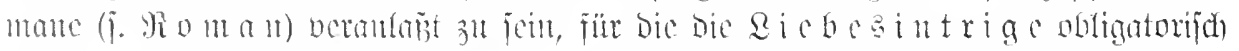

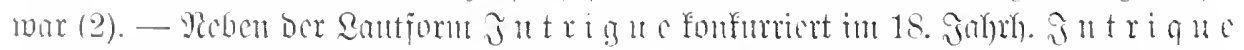

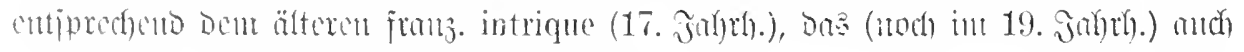

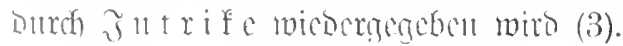

Belege: 1. Qeifuiz 1670 Eccuritas mublica Wolte man also die Holländer eines Theils (I 235) Dirse Conspiration aber muB durch durch Drohungen und dann anch durch InIntrigum rerhindert werden. Cettuer 1697 Egbutus $\Subset .307$ der Herr hat viol tausent lieinten und intriguen wieder soinen König

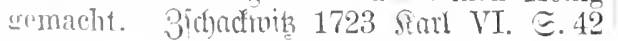
triguen gewimnen. Iazu@ $\subseteq$ a a gue bei 2(rchenlfor 1787 Euglano II 105. 2 a. Ihomainte 1688 mionatsigcipröche I 28 weitläufftige Umbstände, so gantz nichts zm 
Sache tun, oder intrigven, die von einer albern Erfindung herrühren und die geringste Wahrscheinlichkeit nicht haben. Menantes 1702 2loalie ๔. 188 dieses Fräulein ergetzete sich von Hertzen, daß ilnr der Anfang dieser Intrigve so wolnl gelungen. Bicander 1726 Edhanpiele હ.82 Die in-

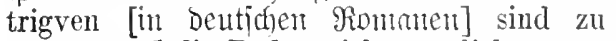
plump, und die Reden nicht zärtlich genug abgefaßt. Dazu $\mathbf{R}$ i e besintrigue jobn bei Ihomajius 1688 Monatigeipr. I 481 - 1696 Sittentehre E.319. Singner 1724 Soldatenbibliothet ๔. 63.

b. Darnuch aud von Edfalpiel; vgl. Edjlegel 1739 Irauerpiele Der 2vlten u. Reueren (ङ. 8) Insonderheit zeigt sich in den Charakteren der Helden, wie die Alten sie gesehildert, ein großer Abschen vor den Lügen und vor Intriguen - In unsern Stücken aber findet man oft nichts, als Intriguen wider einander angespomen; und das darum, weil wir glauben, daß es die Staatsklugheit großer Herren also erforderedas ist nicht genug, daß Unflätereyen daraus verbannt sind; Liebesverwirrungen, Intriguen der Helden, und die Sprüche der Opern-

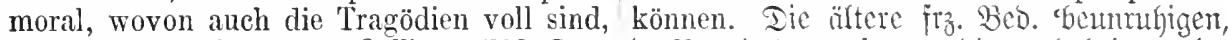

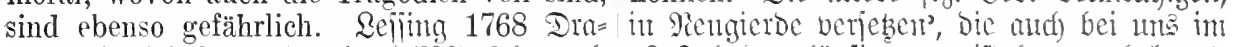
maturgie (X 84). Goethe (1780) Iheatral. 18. Jahrh. geläufig war, iqt heut unbefomnt.

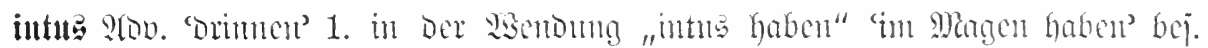

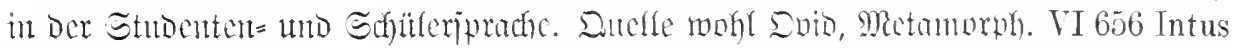
habes quod poscis. 2. ,intus et in cute" cintwendig und an Der saat", aber jejon bei Perjus 3,30 ego te intus et cute novi 'idf Fente Dich in= und auswendig'.

Belege: 1. Mantfner 1882 ahräber I $1 \mathcal{}$ wie vor gesagt intus et in cute mit der sone Seltcrflaschen zn zehn Mark intus z" Regiersucht angestecket. 5orber 1767 I. nehmen. Etindo 1884 Fam. Bud holz I 12 Riteratur (I 308) Auf welcher Classe muB Als wir das Eis ,intus" hatten, wie der dem der Dithyrambist sizzen, wenn er den Student Herr Weigelt zu sagen pflegt. Foll= Pindar intus et in cute kemen lernen, den tane 1895 Poggenpubla $\Subset .256$ Das Wasser ganzen Poeten in succum et sanguinem verhab ich intus.

2. Eommer 1608 Ethographia II 56 die.

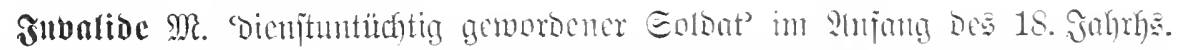

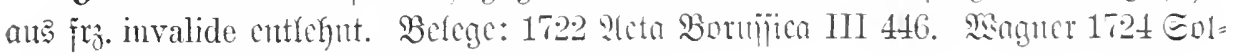
Datcubibfiothc $\approx .327$ Invalidenhäuser.

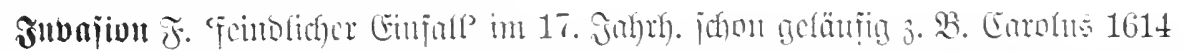

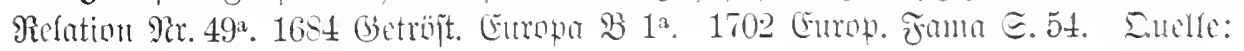
$\mathrm{fr}_{3}$. invasion.

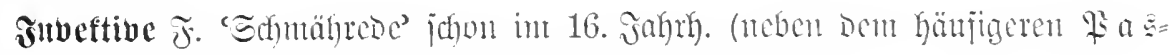

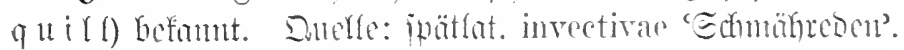

Belege: Mathejius 1562 Earepta $\Subset .170^{\text {b }}$ schmebücher nud der zenckischen PrediWie denn auff grosser Herren inuectiven vnd canten geschwinde schrifften gemeiniglich 
Kirieg, zenüttung der Firchen rnd rnter-pflegen zu folgen. 1619 bei Sonoon II 774 gang oder versetzung der Herrschafften harte Innectiven.

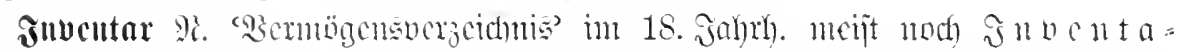

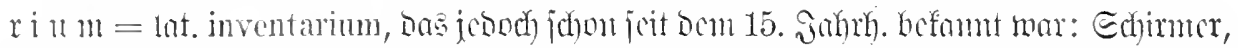

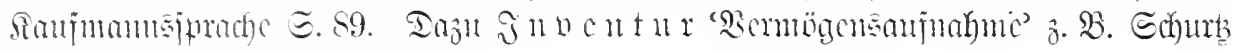

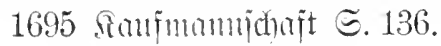

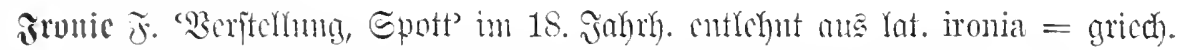
sipoveice. Ber quele 1654 Geridftänhol I 73 per Ironian und Schertzweiß.

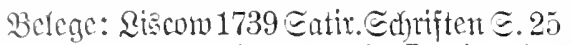

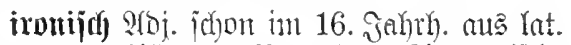
Tarum wagte er sich an die Ironie, eine ironiens gebiloct $3 . \mathbb{R}$. 1564 Binmerijate Figur, die ihm zu hoch war. Señing 1760 Chronif II 631 Es ward vil darab verspottet, Qiteraturbricfe (VIII 231) ein gnter, mit als es anch ain ironis [!] ostentatio ist.

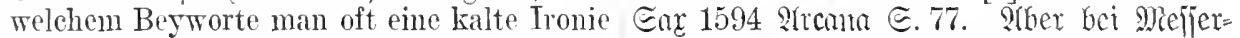

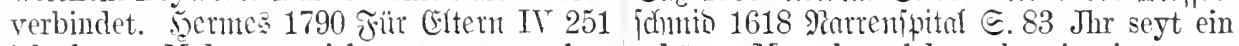
ich hatte Mïh, was ich antwortete, ohne schönes Mensch, solches aber ironice meyIronie zu sagen. Sigielans 1798 afriftiph nend.

(XXII 59) Diese Art ron spottender oder irunifieren Btw. ans jiz. ironiser z. $\mathfrak{B}$. auch bloß scherzhafter Verstellung ist es Guthón 1845 Reijecintoriofe (IX 231) Selbsteigentlich, was die Athener Ironie nennen. ironisienung.

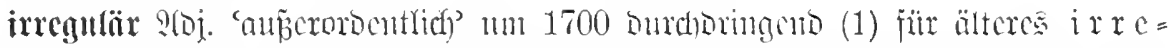

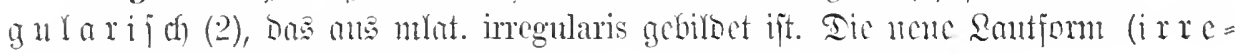

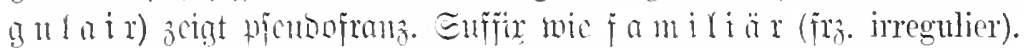

Belege: 1. Prmanthes 1715 Frouenjim= merlex. E. 1179 Es rühret solcher Appetit 2. Arthertims 1599 Ghebarn's Eendjort. III $27^{\mathrm{b}}$ das auß demselben leichtlich abzuvon dem irregnlæeren Einfluß und Circh- nemmen, daß ich ein jrregularischer, gelinung der Lebensgeister und des Geblüts. schwätziger, stolzer, vermeßner vnd muthRohr 1718 Etantäflugheit 厄. 123 die jenigen williger Münch seyn müsse. Inzu jujon in

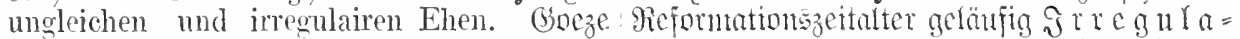

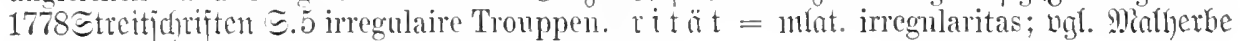

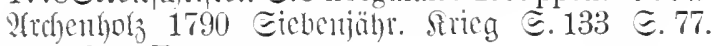
irreguläre Trmppen.

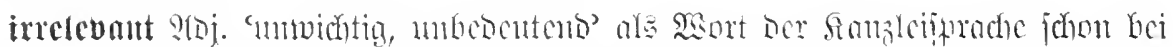

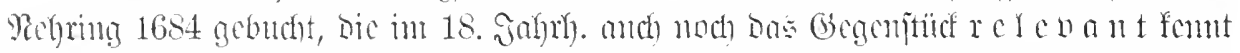

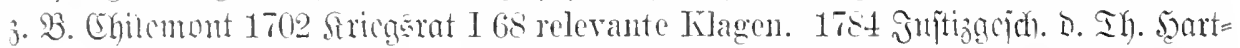

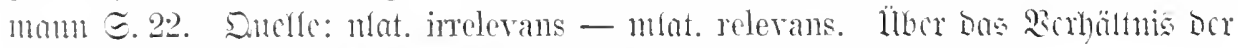

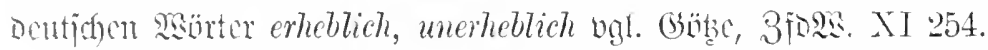

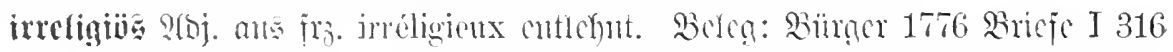
zum Beweise gegenwilrtiger irreligiöser und sittenloser Zeiten. Dazu arxeligi=

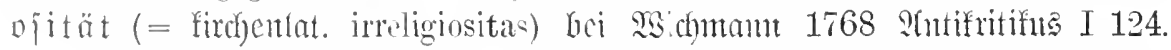

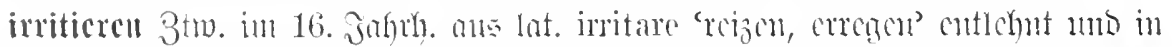

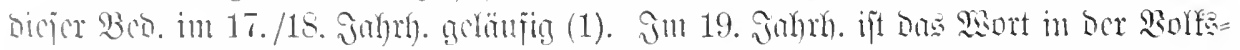

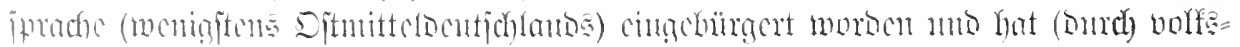

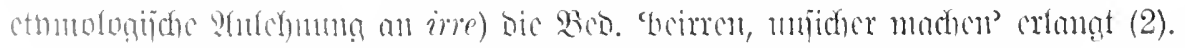

Belege: 1. Enzinuer 1591 Rofationen IV tiren rnd dermassen in Zorn zu bewegen, 89 jre fuind also meln wider sie jritieren. daf sie incandesciren rnd in Zorn end-

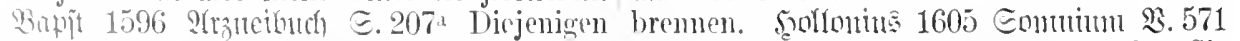
welche mit kalten kianckheiten opprimiret Wer sich an Thorn rnd Narren reibt, Sie rnd beladen sein, die pfleget man zu irri- irritirt rnd zerret viel, Nuß hören, was er 
nicht hören wil. Mengering $16: 38$ Eofonten= stramm auf den Andrea los. Tief 1836

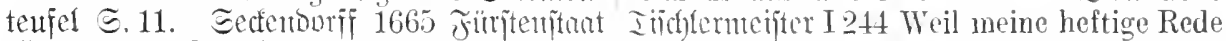
II 62. 181. Scibniz 1670 Eccurters (I 171). Sie ersenreckt, initiert und an meinem

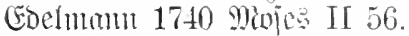

2. Gaubn) 1836 Iagchuch (I 194) ieh lief Ireue Siche (III 108) dab so etwas das mich aber keinesweg irritiren, sondern ging sicherste Pferd irritiren kann.

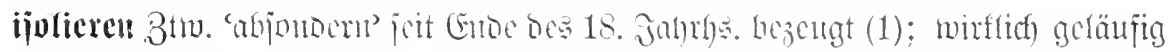

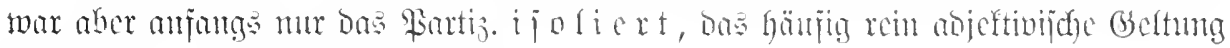
crlangte (2). Donelle: ịr. isoler - isolé.

Belege: 1. Mä̈ller 1789 Emmerich VI II 47 die Gebäude stehen ganz isolirt. 222 daß diese Stelle im Zusammenhange Edhfler 1787 Brteje I 357 Wirland ist hier nicht so kindisch ist, als sie jeder finden muB, ziemlieh isoliert. Geoide 1789 Echulichriften wenn man sie isoliret. Edhlegel 1797 Griedhen I 259 isolierte Begriffe. Ihümumel 1791 u. Rönter ङ. 130 Die ästhetisehe Beurtheilung Rerjen (I 10) von beiden Seiten meines nun isoliert die Bildung des Geschmacks und der ganz isolirten Stuhls. Gucthe 1796 Refriahre Kunst aus ihrem kosmischen Zusammen- (XXII 270) Auf diese Weise war ich morahange.

liseh und physiseh sehr isolirt. Saube 1836

2. Bürger 1776 Birteje I 339 ans diesem Reijenoveflen III 133 Je isolirter ein Jenseh isolirten Winkel. q(rdyenthol 1787 Jtolien lebt, desto weniger hat er Beziehungen.

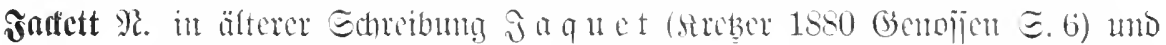

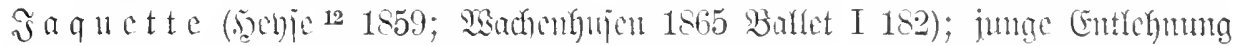

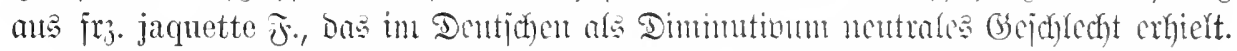

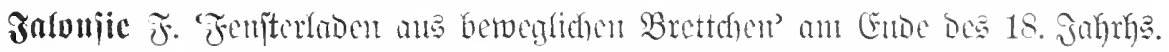

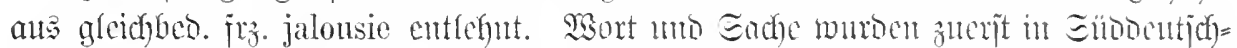

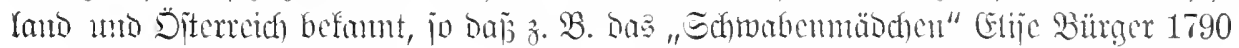

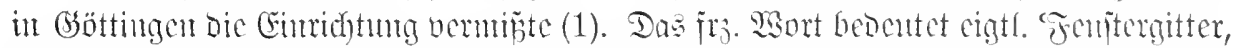

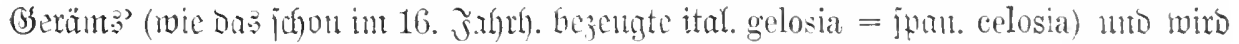

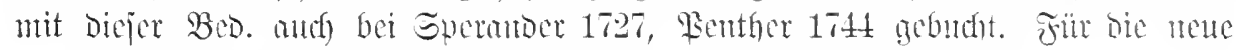

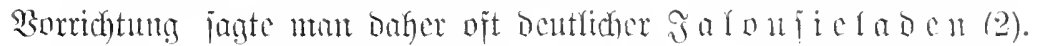

Belege: 1. Rabater 1767 Erhwizerlieder ebo. V 309 Schalonserl statt Jalonsien oder Ir. 2 Str. 3 Laßt doch hinter Chalousien bewegliche Bretter die Fenster zu deeken [1770: Jalonsien] Augen voller Wollust [af ójterr. gebucht]. E. Bürger 1790 Briefe glühen. Ricolai 1784 Reije [खæìcn] III IV 87 ich mache mun gegenwärtig neue 139 Die meisten Fenster, besonders nach Rouleaus vor die Fenster, weil man hier der Mittagsseite sind, um die Hitze abzu- keine Jalousien hat. Ectry 1797 Ientiche halten, durch alle Geschosse mit Fensterlä- Soiotismen [Phitnbera] den, welche aus schmalen beweglichen grïnen 2. ient \$aul 1793 Unijchtb. Soge (I 63) Bretterchen bestehen, oder mit sogenannten - 1797 jubelicnior (TI 49). Eer 1797 i. Jalousien versehen - [9.mm.] Der gemeine u. 1. Pifiter $181 \pm$ Crimtutulfälte I 149.

Mann in Wiell nemnt sie Schaluserl - 1785

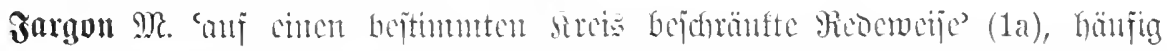

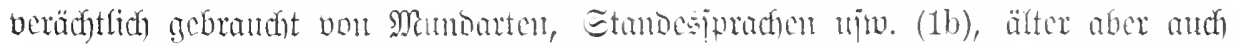

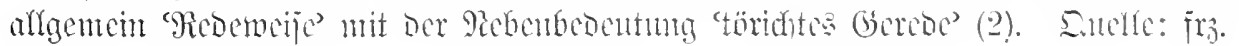
jargon.

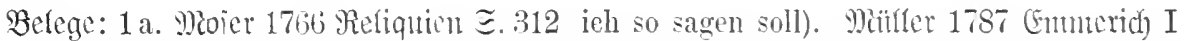
einen gewißen mystisch-pretiösen politischen $17 \pm$ den steifen und simnlosen Jargon der Jargon. Wieland 1767 Igathon II 223 der feingenamten Welt. Jeroer 1796 Briefe erhabene Jargon der Philosophie. Eonner = (XVIII 161) nur mit denen von gleichem

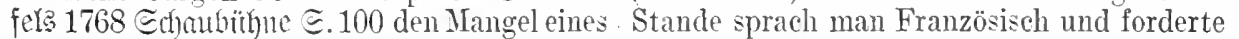
wearbeiteten gesellschaftlichen Jargons (wemn von ihnen diesen Jargon als ein Zeichen des 
Eintritts in die Gesellschaft von guter Erziehung.

b. Scrmes 1790 Firn Eltem Y 67 wie richtig unser Vater den Jargon der Gascogner gehascht hat. Eeume 1803 Ena= ziergang (TI 59) Das war num ein Jargon, Dentsch, Iralienisch und Krainisch. Seeine 1823 lither Polen (VII 194) Judenjargon. (3) abtremer 1836 Biroer I 66 der Wiener Jargon. Piüffler 1840 Birberjanl II 18 den

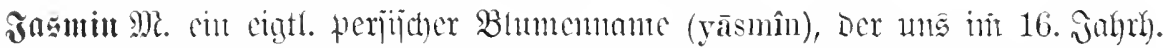

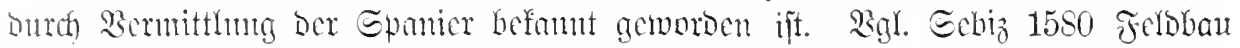

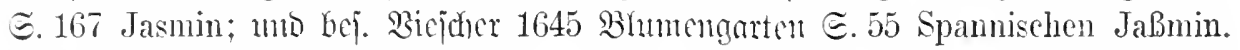

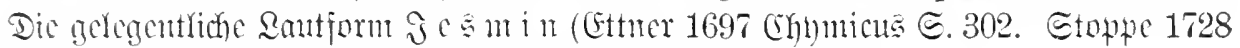

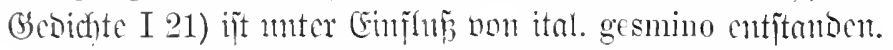

je ne sais quoi ( $\mathfrak{f r}_{z}$.) in 17. Jahry). jubjtantiviert mit ber $\mathfrak{B c o}$. 'etwas unbejtimm=

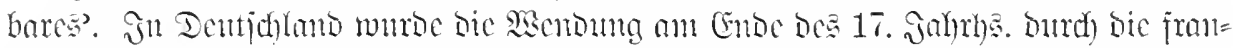

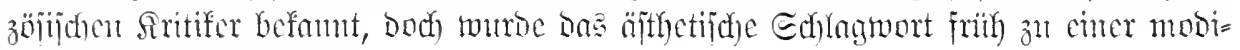

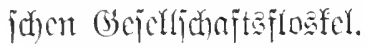

Belege: Thomajus 1687 Rad)ahmung Der tzösischen Kunstrichter beurtheilen. Es ist Franzoien $\Subset$. 11 bey welcher Beschaffenheit allen Weltweisen bekannt, dab wir unsere dann die Galanterie und das je ne scay qvoi dumckeln Begriffe nicht rortragen kömnen, wo von obgemelter Pere Bonhours ein gantzes und daß es viele verworrene Begriffe gebe, Gespräch verfertiget, einerley wären. Ich die eben diesem Schicksaale unterworffen sind, aber halte meines bedünckens davor, daß indem wir nicht eimmal ein Tort in unserer Mons. Vaugelas und Mons. Costar die Eigen-- Sprache haben, welches dieselben auszuschafft der Galanterie ein wenig genauer und drucken geschickt genug wäre. B̉izmatuf deutlicher beschrieben haben, daß es etwas 1847 Brieje $\Subset .51$ ihrem weltklugen Sinne gemischtes sey, so aus dem je ne scay qroy, [fehlt] jenes je ne sais quoi. Sfilgelgen 1870 aus der guten Art etwas zu thun, aus der Jugenoerinnenungen $\Subset .96$ ein gewisses süßmanier zu leben, so am Hoffe gebränchlich lich widerliches jenesaisquoi [(Gerudf]. Fron= ist. ans Terstand, Gelehrsamkeit, einem tone 1887 (Eecile ๔. 291 die sich einfach daguten judicio, Höfflichkeit und Freudigkeit durch jenes je ne sais quoi erworben haben, zusammengesetzet werde. Nieier 1744 fimit $=\mathrm{daB}$ sie Gebildeteren und selbst Fiügeren ridfter ङ.94 Aus dem rorhergehenden kan ïberlegen macht.

ich beyläuffig das: ie ne scai quoi? der fran-

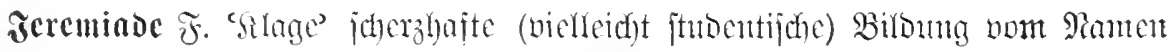

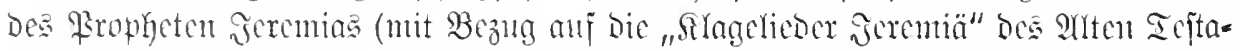

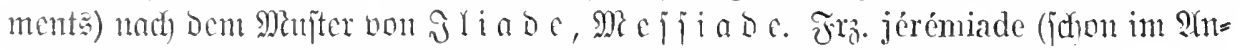
fang Des 18. Jahrbs. Gelegt) fteht wohl mu in mittelfarem Bujanmenfang.

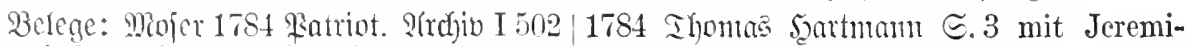
Jeremiaden gelingen bei Hofe; ewige Weh- aden über Unmenschlichkeit, Pfaffentrug klagen ermüden das Herz eines Regenten. I nnd Intoleranz.s

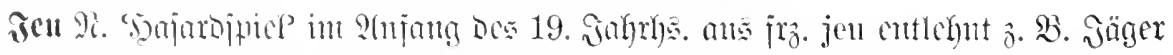
1835 Jelix $\Xi$ ¿nabel $\Xi .81$ ein Kaffeellaus, da giebt es guten Grog und ein Jeu. -

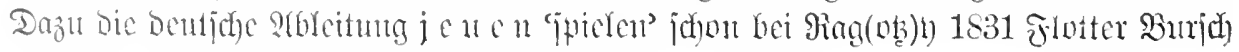
๔. 123 So haben wir bis jetzt gejeut.

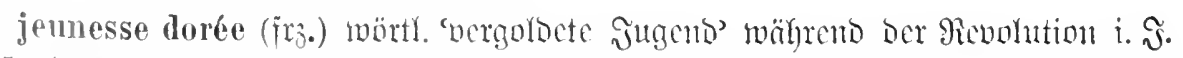

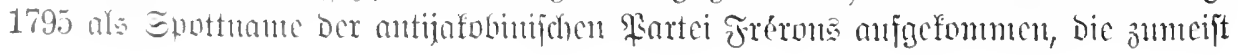




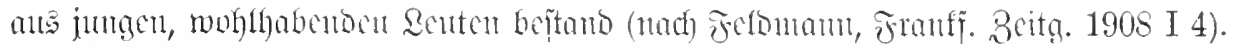

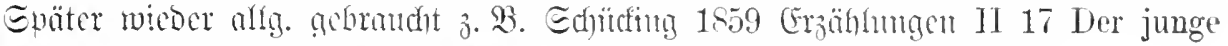
Mann war das hervorragendste Hitglied dex jemese dorée der Stadt.

gobber MR. 'Börictipefulant' = engl. jobber, an Emb Des 18. Jahrbs. bej. in

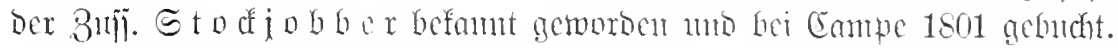

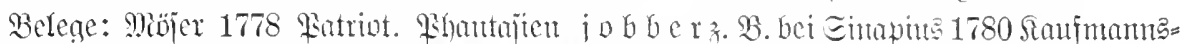
III 40 Die Stockjobberey ist eine Art von heite ङ. 244 (Echimmer). Seine 1830 Stalien Actienkrämerey, die vor zwey Jahren in (III 278) - 1810 Bibne (VII 130).

England aufs höchste gestiegen war. $\subseteq 10 \mathrm{D}=$

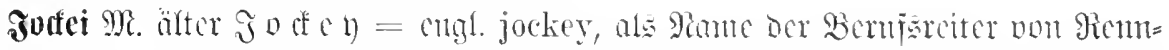

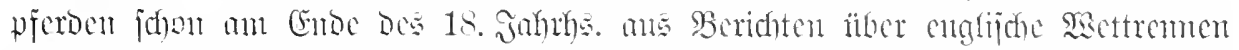

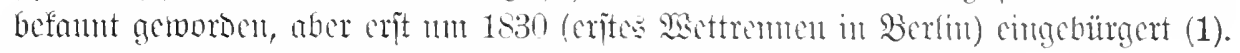

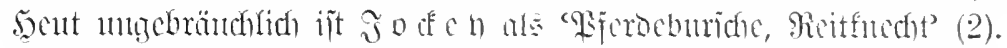

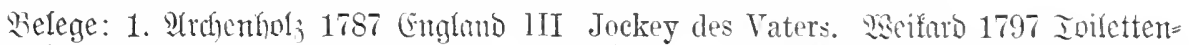
227 Die Bereiter der Rempferde sind leicht leftïte I 43 In Wien und Paris ritten junge und zierlich angekleidet - Dieses Wiegen Hanswürste mit krmmmen Rücken, nm für der Reiter, die man Jockeys nennt, wird Engländer angesehen zn werden, welches nach dem Wettlaufe wiederholt. Manl 1787 freylich gar nicht fehlen kam, wem sie soBagntelfen II 245 Soutte] die von den Jockeys gar Jocqueis mit sich reiten haben. Echlegel

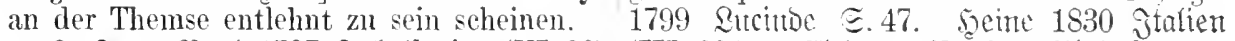

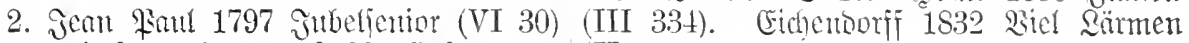
hinter mir kam ein alter kahler Lakay nnd (II 111).

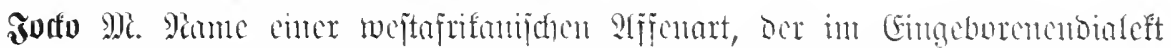

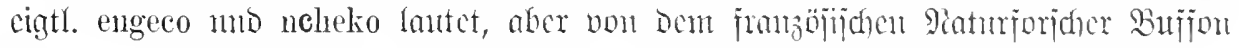
1766 zall jocko entiptell wutroc. Beleg: Rabater 1776 Fragumente IT 175 ein OurangOutang oder Jocko, der kleine Walduensch.

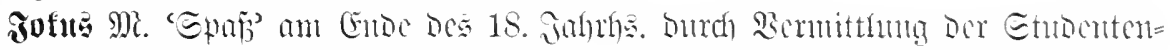

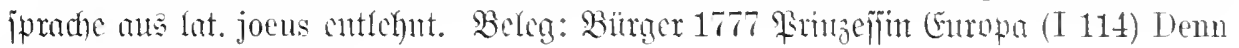
er verstand den Jocus.

Campe 1801 butdy "Jocus, oder wie es ¿.529 [aus einem Etubutentricf] Das war

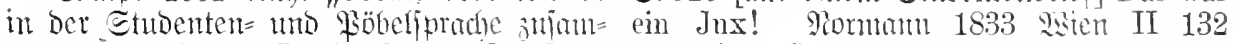
mengezogen lantet, Jnes". In oer Santĩorm Hanptjux: So nemnt der Wiener derlei Be-

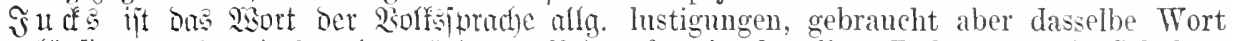
geläufig gemorben ( $\overrightarrow{3}$. I. mit veränberter Bed. öfter in derselben Bedentmng wie Schaber-

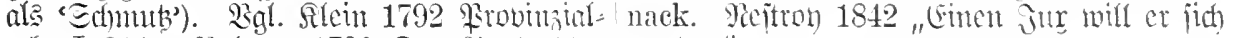
wb. I 214. Belege: 1790 Ter Beobachter machen".

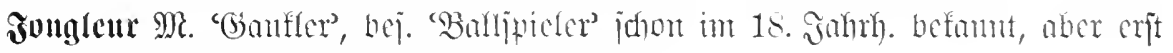
bei Cantpe 1813 getudft. Duelle: frö. jongleur.

Belege: 1766 Morgentüno. Erzählutitgen Alchymisten, Propheten, Zanberer, Jong. ऽ.36 Marktschreyer(Jongleur). Bimmermum lenrs und Schwärmer, Urimbeschaner und 1784 Cimfanteif II 64 Tenfelsbanner und Wunderthäter ron jeder Art.

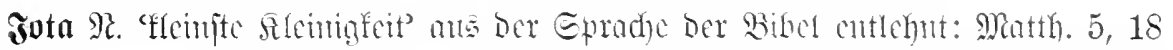

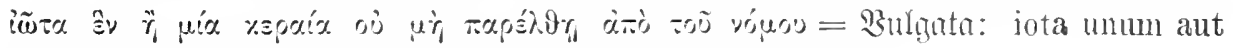

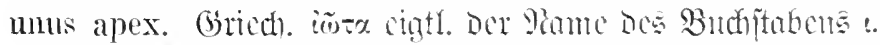

Belege: Ilgmajü 1688 Mnumategeipräche Hast du meinen Auftrag vollzogen? Auf ein I 366 die nicht leiden kömen, daß cin jota Jota, mein Gebieter. Goethe 1796 Sefrjahre von ihren compendiis observationibus usw. (XXII 91) ich kam anch hier nicht ein Jota umkomme. Echiller 1783 Fise (IV 227) nachgeben. 


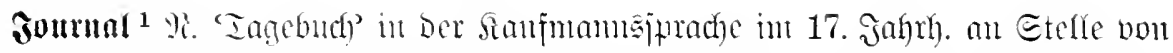

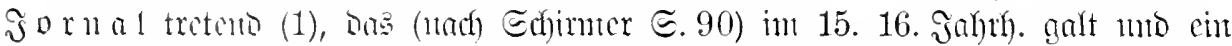

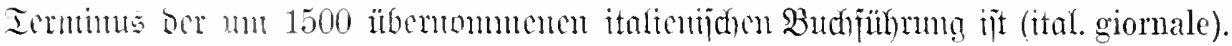
2uj̈erdem hat jo

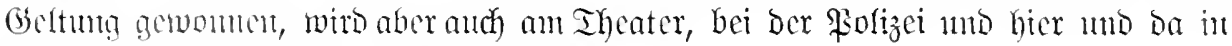

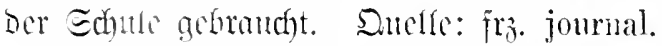

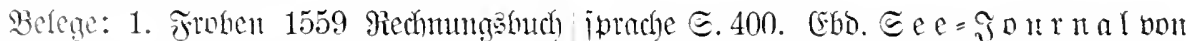

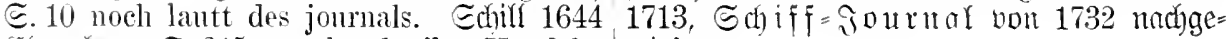
Ehrentran ङ. 315 man besehe jhre Handels- wiejen.

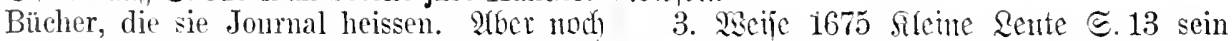
bei Exhmb 1662 Buthbulten $\Subset .8$ Diß Buch Jonrnal, welches er auf der Reise zusammen Jornal, so das ein Haupt-Buch und wol ein getragen. Ftrüner 1681 Sehen D. Eceheloen täglich Hand-Buch heissen mag, neunen die @ 513 diese Reise is $九$ in dem Joumal (TagFrantzosen Journal, von Jour, dem Tag: Register) so hierron gehalten. Inzu Re i

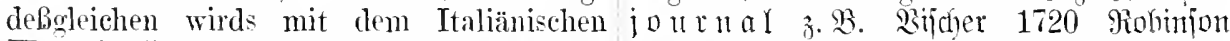

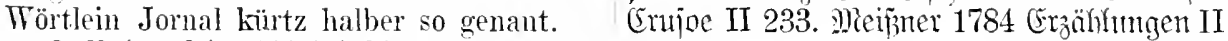

2. Belege jeit 1669 hei §luge, Ecentants= 63.

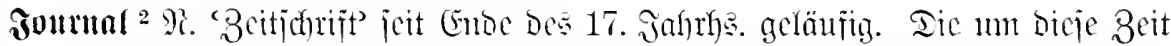

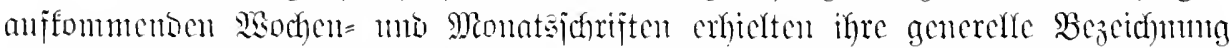

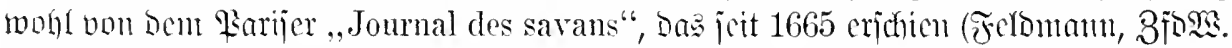

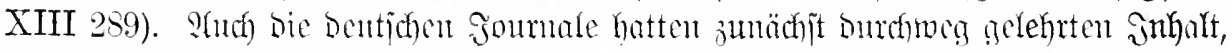

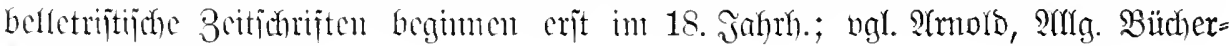
funde ङ. 143.

Belege: Ihomnitus 1688 Montatigeimräche

Fournalijt M. am Ende Des 17. Juffrys.

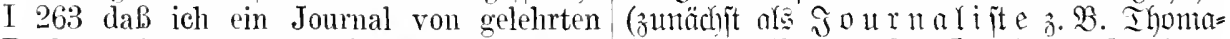
Büchern in teutscher Sprache schreiben fitt 1688 Mnonatsgeim. I 245) aus ju. jourwolle. Tentel 1689 Monnil. Itnterredungen naliste entlehnt, z. B. Whende 1716 (Char=

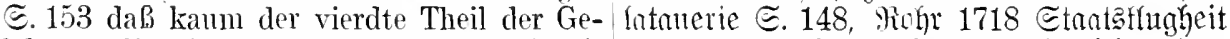

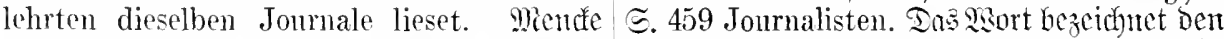

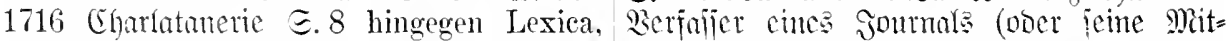
Journale, kleine Piecen, Bücher in Ana und arbeiter), afjo ciner gelefrten Zeitsehrift nady solche lieben Sachen mehr werden fleibig unjerem Eprachgebrauth; fitt ben Mitarbeiter

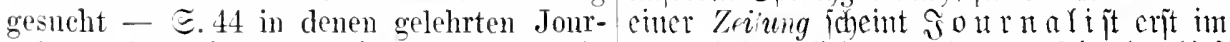

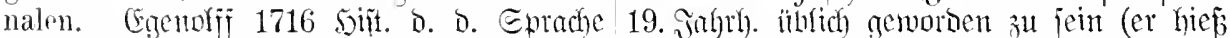
ङ. 266 was ich mich erinnere, in einem zn Annalist. aud Tovellist). Sagl. 5̧öm 1721 Jena gedruckten Tage-Buche oder so ge- Betmigjerifon I 88 die Herren J-en in ihren nannten Journal gelesen zu haben. Bertram Monatsschriften. Edelnam 1740 Moies I 59 1728 (Einl. in D. jh. Sivijenj(h. E. 258 Jour- unter den gelehrten Spürhunden, den soge= nale: Weil nun die letzte Art zu unsern nannten J.en. Meicr 1744 Simntrichter $\subseteq .34$ Zeiten sonderlich Mode geworden, so ist es In diesen Folhler failen auch einige J.-en und dor Mühe werth der Jugend einen hinläng- Verfasser der gelehrten Zeitungen. Jufti lichnn Begriff claron zu geben. Sajebow 1765 Echriften II 259 ein Gelehrter-Zeitungs1758 Finft. Philojontie @.428 einige ge- schreiber und wemn sie auch wollen, ein lelirte Zeitungen und Journale lesen.

J.-e der gelehrten Neuigkeiten.

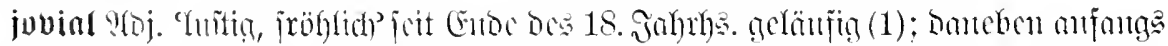

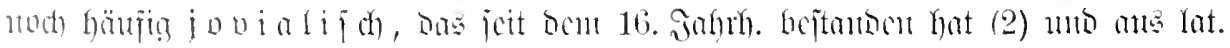

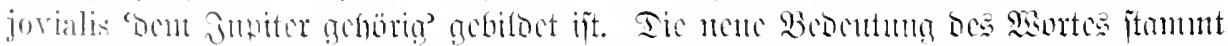

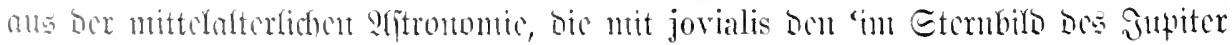

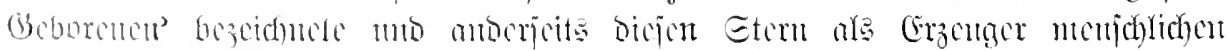
Frothinuts ariah. 


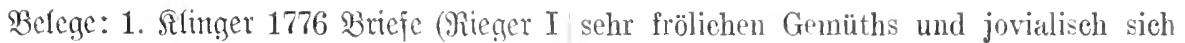
404) Der wahrste, jovialste, liebste alte Miann, erwiesen, dab jedermann an seinem Thun den du dir idealisirn kannst. Seir 1785 und Reden eine große Frende gehabt. Nie= Die Epieler હ.112 Ruhig und gegen alles lomb 1771 Stmoti. (XV 157) aus der Zahl im Hause jovial und freundschaftlich. Der jovialischen Iente, die gern zum Spaß’ Irdyentholy 1787 England III 231 auch habe euch schrauben. Savater 1778 Fragmente ich nichts Joviales wohl aber viel Gravitiat IV 350. Sisun 1800 Entioben II 306 . Eeume dabey wahrgenommen.

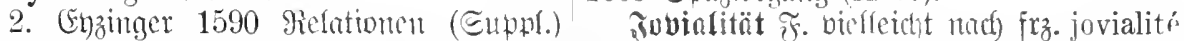
G.21 Die weil er anch vou natur höfflich gebildet. Belege: Buhrot 1790 Sebengbeichr. vnd Jouialiseher art allzeit frölich. Ientsel I 54.67. Eemme 1803 Ekrziergang (III 12). 1689 lluterredungen $\Xi .1040$ hat er doch

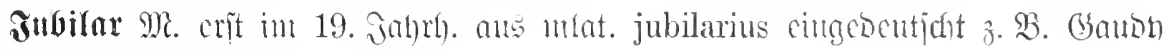
1839 Jubiläum (VI 207).

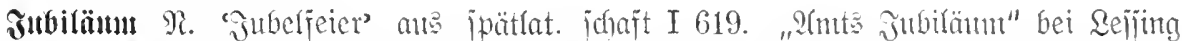

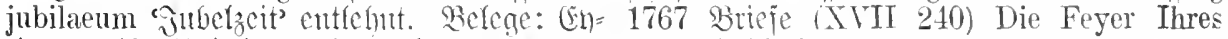
jutnger 1590 Relationen (巨ułnl.) こ. 44 vnnd Amts Jubiläi.

letzlich beschlossen worden ein gemein Jubeleum außgehen zu lassen. Gointipjer 1617

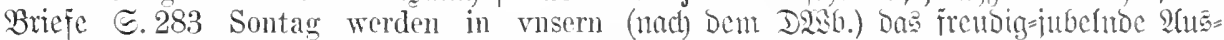
Euangelischen Kürchen auch das Jubilaeum fliugen des niftelalterlichen Sirchentgejangá

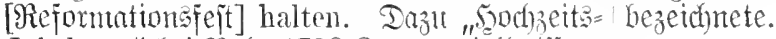

Jubeleum" bei Rohr 1728 Berentmieltwifen=

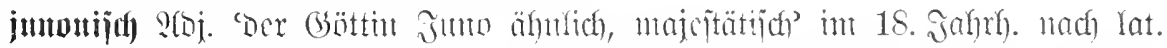

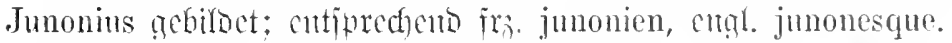

Belege: Brum 1800 Sdiriften III 90 nische Thurm-Madomna von Carlo Waratti. Der vollere Zuschnitt des Gesichts und die ñeine 1834 Ealon (IV 101) Eine kühne. gewaltige Brust [einer Bejtolin=〔tatue] sind junonische Gestalt. Findéler 1835 Eemi= ganz Junonisch - 236 Die gewaltige juno- laijo III 121 ein junonisehes Franenzimmer.

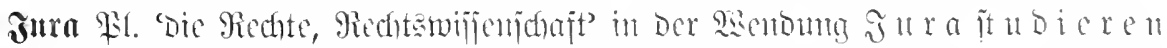

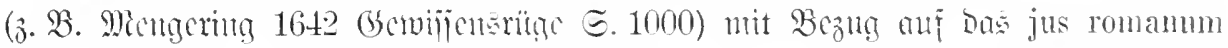
und Das jus canonicun (vgl. doctor utrinsque juris). Der Sintg. I us begectunct

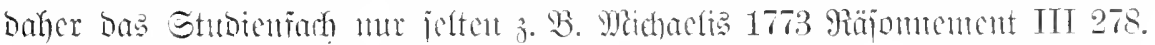

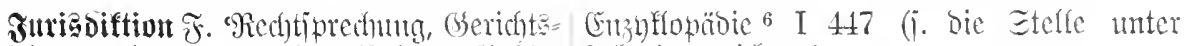

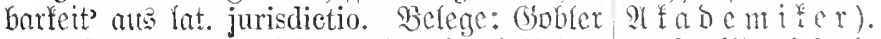

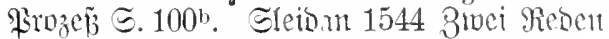
ङ. 193.1558 seibelb. Etatuten ङ. 15.

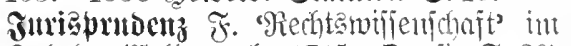
18. Jaf)rh. (Callenbach) 1715 Duait ङ.30) eingeocutijcht ans lat. jurisprudentia.

Jurijt 9 . 1. "Redhtogelehrter" jonou in Mittelnlter eingedentidht ans mlut. jurista und int Disb. jeit 1300 belegt.

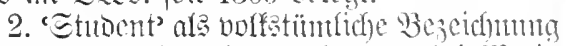
fiir Szantuber (Ssöttungen) bezengt bet indorts 1790 Mnton Reijer 5.350 so fragte er ihn sogleich, ob er ein Jurist sey, welches in diesen Gegenden [Duberiftond] die gewöhnliche Benennung für einen Studenten ist, weil die Theologen größtentheils in Klöstern stıdieren, und schon als Geistliche betrachtet werden. Qurf Der Göbttinger Profefior Şngo

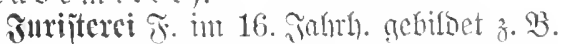
Fuchberger 1534 Iinleftif $\circlearrowright .2$ b landsordnungen, so auß lateinischer Juristrey (!) vmb gmains nutz fridlicher ainigkait willen. durch die glerten zusammgefast. Epüter meijt in berähtridyem ober ipöttifhem Eimne, bụl. Göponer 1777 an meref (II 111) dem in der lieben Juristerei und ihren Schriften siehts noch gar dunkel und confus aus.

oury $\widetilde{\mho} .=$ engl. jury 1. in Der beo.

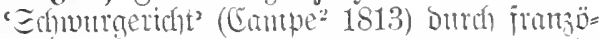
jiiche Bermitthung hefomut gemorben: Das in Englato ansgebirocte gedisinjtitut war in Frantecid jeit 1791 eingefuihnt mo galt jeit 1806 (nut Den jrang. Recht itberhaunt) in benfintertheinifhen Ieifen Preupens, Banerns,

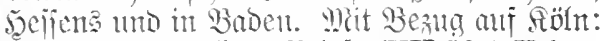

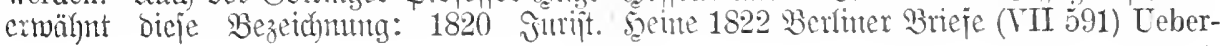


haupt, meint er, das dortige Gerichtsverfahren tauge nichts. Wozu diese Oeffentlichkeit? - Wozu diese Jury, diese Geratter Schneider und Handschmhmacher. Böme 1829 Irama= turg. Siln̈tter (II 362) Yit Schmerz denkt ein Liberaler daran, daß in Deutschland die Geschworenengerichte werden eingeführt werden dürfen. Telches Unheil würde daraus entstehen, wenn man einer in der neuen ästhetischen Schule gebildeten Jury die Strafgerechtigkeit in die Hände geben wollte?

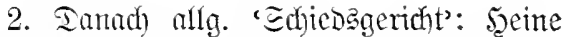
1827 ?norbice (III 113) diese Jury hat den Kaiser gerichtet und verurteilet: ewig zu leben, ewig bewundert, ewig bedauert. Iiejtermeg 1836 Rebenfingen @.76 Eine Jury, bestehend aus Professoren und Studenten, bildet das akademische Gericht. -

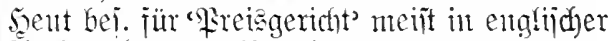

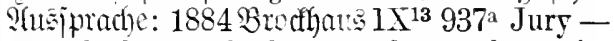
Ausschuß von Sachrerständigen als Preisrichter (bei Ausstellungen).

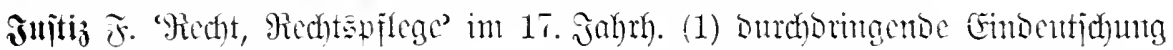
für lat. justitia. Da: 16. Jahrn. brandet meift mod) bie latcinijhe Form (2).

Beleae: 1. Nengering 1642 Gemijien riige 厄. 942 zu Erhaltung der Justiz. Echill $=$ hörig bestraft werde -1783 ebo. III 514 frecht 1652 5armonia II 49 Persohnen der des JustizMordes von Amberg. Inวu 厄(huh)=

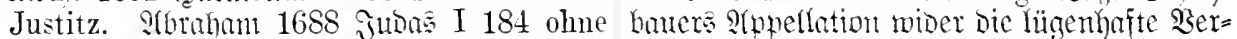

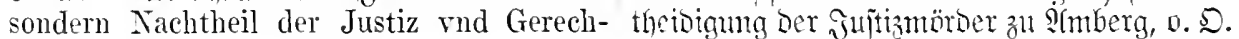
tigkeit.

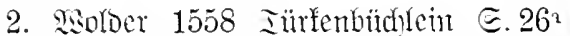
gleichmessige Justicia - 厄. $42^{a}$ sampt guter Justitia nnd Polizei. Friebenturnerg̣ 1597 Dišctris 厄.9: Justicia. Earolus 1609 Reln= Iation Mr. $10^{\mathrm{b}}$ der helt gleiche Justitia.

Jujtiamoro cine 柋ortichöpiung Des sijto= rifer $\Xi$ d)lözer: 1782 Etnatenzeigen II 271 Abermaliger Justiz\Iord in der Schweiz [2nm.] Ich verstehe unter diesem neuen Worte die Ermordung eines Unschuldigen, vorsetzlich und so gar mit allem Pompe der heil. Justiz, verübt von Leuten, die gesetzt sind, dab sie verhüten sollten, daß kein Mord

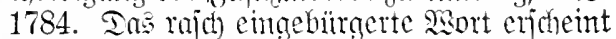
jhon 1784 als Sitel emer Provelfe bei :. (3).

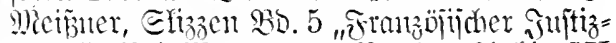
moto". Bei Mojer 1785" Patriot. Yrothin III 139 und פisieland 1785 I. Merfur II 45 Cabinets-Justiz-Nord. Da: Borbilo für dic Sartjdyopfung mar wobl ing. meurtre juridique (3. B. Soltaice 1760 Eurres XVII $3 \times 8)$.

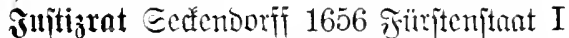
102 die man sonst würckliche RegierungsHof- und Justitien-Räthe nennet und zu der Regierung des Landes, in der Rathsstuben und Cantzles gebrauchet werden.

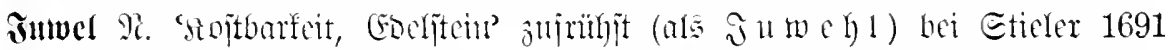

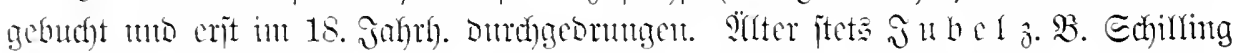
1668 Intengerüit $\Xi .128$ mit Geschmiick und Jubellen. Tic Sautjorm $\mathfrak{d} \mathfrak{w}$ el

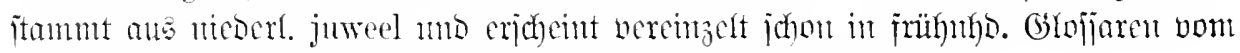

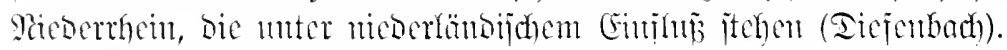

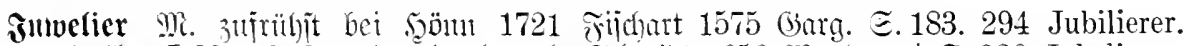

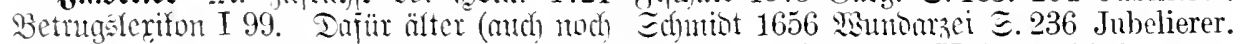

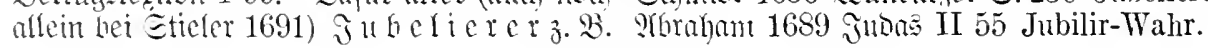

I.

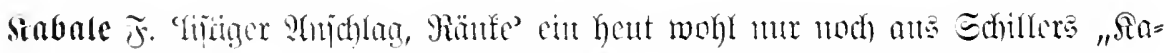

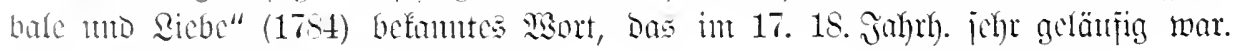
Diretfe: iri. mabale.

Bełege: 1630 Ronoorp, Icta publ. II bale wol gewust.... Prjilippi 1743 322: weil der Hertzog in Bayern vermög Reimijumieoefunt $\Subset$. 236 alle Finessen der heimlichen rnter sich habenden Ca- und Cabalen. Julji 1758 Etuatemuifijen= 


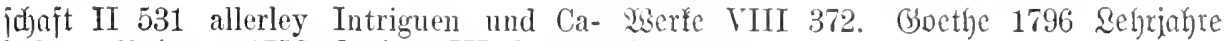
balen. Babener 1759 Eatiren III 80 die (XXI 90).

Cabale meines Gegners. 5ecroer 1778

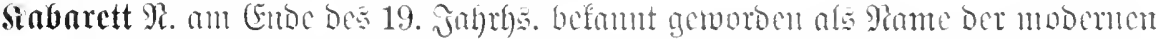
fümitlerijhen Bariétés, Die undh Dem Muiter ber Larijer cabarets artistiques entjtmben.

Bgl. 1903 Bühnte u. SBettl III 2 als Eruremberg 1652 Erherzgebichte હ. 11 ehemaliges Mitglied diverser Pariser Ka- Bi allen paticiers, in allen cabaretten, barets -3 in der That wurzeln die ,Elf Pasteiden werden backt. Brun 1809 Scharfrichter" im Münchener Boden ebenso Epifoben II 374 nun ists ein Cabaret, tief, wie die Kaberets in dem von Paris, wo wir ein schlechtes Mittagessen ein-

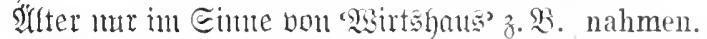

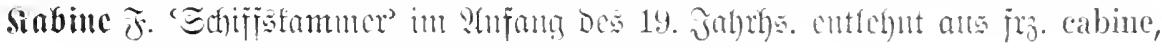

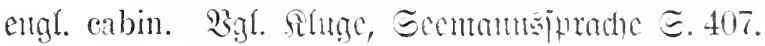

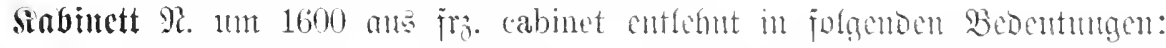

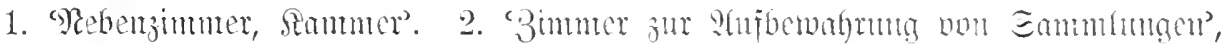

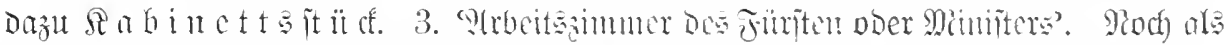
jremb bei Cyzinger 1588 sift. Relat. Appendix 5.29 ,in jeincm Cabinct (wie

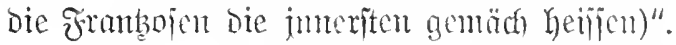

Belege: 1a. Enjinger 1591 Relationen IT 21 auB Ewren heimblichen Cabinet oder schlaffkämmerl. Smuremberg 1652 ๔uhers= gevidfte ङ. 38 gelyek einm Cabinet und Kamer, Darin men is loseert. Fritj 1667 De Augrito $\Subset .81$ ein kostbares Zelt und ein von gantzen Glaß aufferichtes Ca-

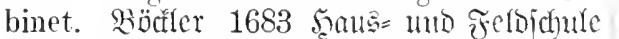
ङ. 40 das Neben-Stüblein oder Cabinet.

b. Rencroinge anch cuphemiftij fiur

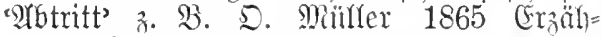
Inngen III 33 ein Stübchen, dessen Thüre die mysteriöse Aufschrift trug: Kabinett für Herren. Entipredjent jro. cabinet (d'ai-ances).

2a. Eulzer 1771 Theorie D. jđ. Süntte I $466^{\mathrm{b}}$ die Cabinetter oder Sammlungen geschnittener Steine zu sehen. Bej. ge=

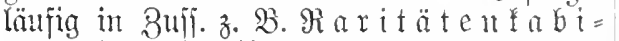
th e t $t$ (1677 Madjiabelr. 5ohuspofus ๔. 694), 隹atura Eatir. ๔anr. ङ. 174. Iujn 1764 Bricie I

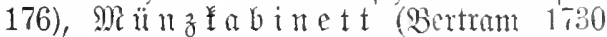
?nfangalebren S. 24. Rabener 1752 Eatiren III 72), 络a d) (G) asbremer 1836 Biloer a. Sien I 91).

b. Son etruas Atuerlejencm, wie ca für ein $\Re$ abinett pajjen tountroe (bgh. $\Re a=$

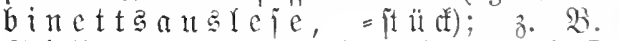
Epielfagen 1860 Problem. Jaturen VII
161 zwölf Flaschen Johannisberger Kabinctt.

c. 'Format bon Photographien' $\tilde{i} . \mathfrak{\pi} \mathfrak{a}=$ bi nettformat.

3 a. Freiberger 1656 \&olit. Tisfurje

๔. 25 Auff daß ein Potentat in seinem Cabinet nichts wider die Erbarkeit und Gottesforcht fümehme. Neier 1746 Chre ๔. 89 ein Mann, der nur im Felde gebrancht werden kann, niemals im Cabinette. Serber 1767 I. Riteratur (I 166) Der Scribent bequemt sich nach dem ordentlichen Wege, um ins Cabinett seines Fürsten zu gelangen. Edjifler 1787 Ion Carlos (V 61) Herzog ron Alba, sagt man, ist im Kabinett Bereits zum Gouverneur ermannt.

b. Taher bam die in Sabinett arbei= temben Rerionen, Minifterium, Reaicrustg": Echubart 1774 I. Chront $\Subset .194$ aber wer ist scharfsichtig genug in die Geheimniße der Kabineter zu dringen? Micolai 1778 Gebichte I $165 \mathrm{Als}$ ob der Regimenter Zahl, Der Kappen Form, der Farben Wahl die ganze Wissenschaft des Kabinettes wäre. Povoliz, Edrifien I 206 Auf dem Standpunkte der Kabinetter ist keine Vereinigung denkbar.

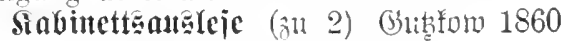
Bauberer v. Rom V 188.

Sabinttajefide (zu 3) Edubart 1774 Cfjronif ङ. 193 Der ganze lirieg hat sich nunmehr in eine $\mathrm{K}$. verwandelt. Tajür

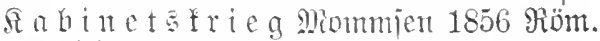
(Geididite III 63.

Sabinettrormat (3u 2) 1864 Siational= zeitung XX 441 Für [photographiidue] Porträts wird jetzt in Paris das sog. TiabinettsFormat beliebt (nad) Eanbere).

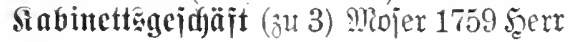


u. Iiener $\Xi .172$ zu den Cabinetsgeschäften berufen - 1766 Refiquiest ङ.227. Echubart 1774 Chronif $\Xi .597$ Seine Thaten sind Wunder, und seine Cabinetsgeschäfte Göttergeheimnisse [vou Fricorich D. Grr.].

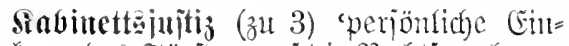
rvirfung bes Jilriten mi Die Rechtiprechung'

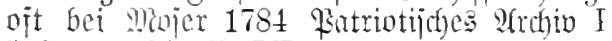
518 - 1785 ebo. III 1 zur Theorie und Geschichte der Kabinets-Justiz - 1796 Polit. sistrubeiter I 238.

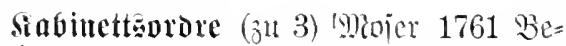
berzigungen ङ. 350 Wir haben keine seidene Stricke noch Janitscharen, wir haben aber Lettres de cachet, CabinetsOrdres, Befehle ex plenitudine potestatis.

Stabinettôpolitif (ju 3) beeren 1811 Dandonch $\subseteq$. 10 so bildete sich jene C. aus. welche das europäische Staatensystem be- sonders charakterisirt. Sajjalle 1850 खserfe II 403 Bubenstück machiavellistischer K.

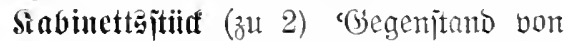

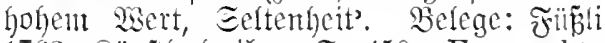
1763 füujterlexifon 厄..450a Er machte Portraite, anticke und moderne Cabinetstücke. Mojer 1766 Reliquien $\subseteq .165$ Steine. die C.-e abgeben könnten. $\mathfrak{M i e}=$ land 1771 9madis (XV 211) rerehrte die gute Dame mir Dieß seltene C. hier [sc. einten Färber]. Ifümmel 1791 Reije (II 115) was willst du mit diesem $\mathrm{K}$.-e [einer Reliquie] anfangen. Bum 1801 Echriften IV 168 Ein sehr seltenes K. [grauer ¿ava] zog besonders meine Anfmerksamkeit an - cbo. und ïbertrugen: III 336 Welche unschätzbare C.-e der Natur!

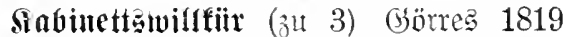

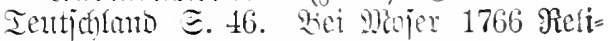
quien હ. 115 Cabinets-Despotismus.

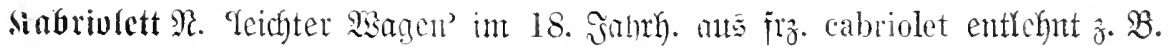

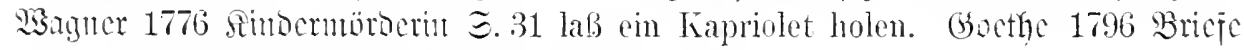
a. D. Schtocis (XIX 4t1) in einem leichten C.

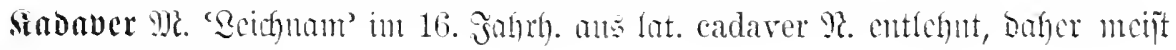

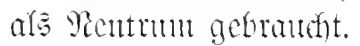

Belege: Carion 1532 Chrontica $\Xi .120^{b}$ von abschewlichen Cadauern. Mej̈er= Er hat den Formosum lassen ansgraben, jumid 1615 Epclta's Parrheit I 113 Was rnd das Cadaner degradirn rnd köpffen, ist ein Alter anderst, dann ein Lebendiges

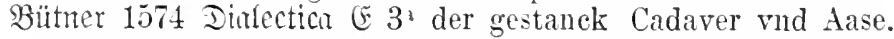

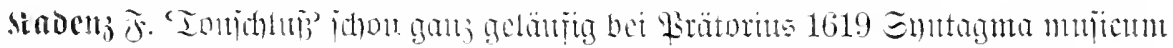
II 47 Cadentien - III 130 Cadentzen. Borfer bei Fijdart 1575 Gang. 5. 42 Musi-

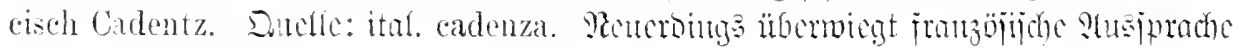
(math irj. cadence).

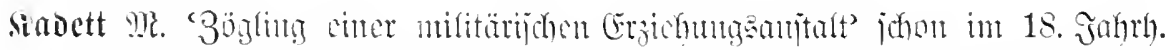

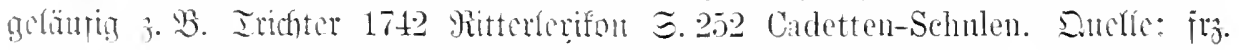

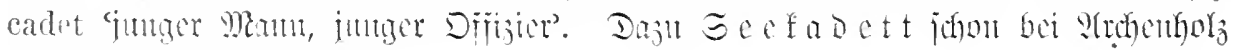

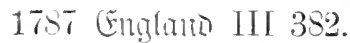

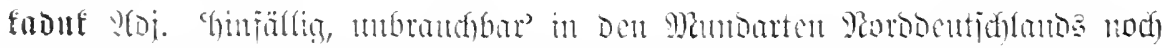

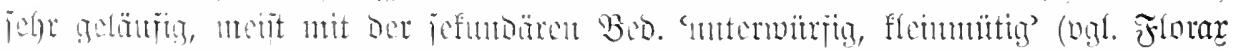

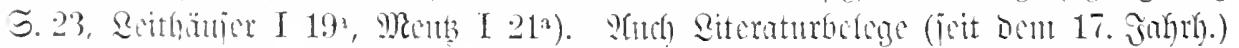

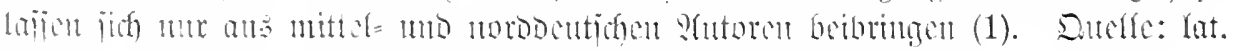

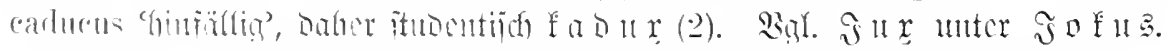

Relege: 1. Miengeting 1661 Gewij̈eng= Capitalia möchten eaduc werden. 1702

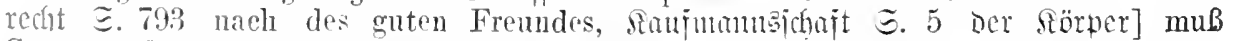
Fönners, Patronen Tode sihet man Wit- schwindsüchtig werden oder caduc gehen. wen und Waisen nicht über die Achsel an, Gortum 1799 Gobitube $\Re .233$.

solte man über sie stolpern und fallen: 2. ¿toppe 1728 Gedichte I 145 Mei die seyn Caduc, man ist ihnen nichts zu Roock, mei schwartzer Roock, ihs au

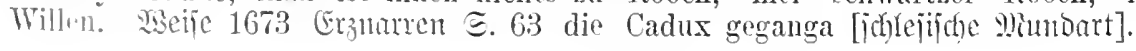




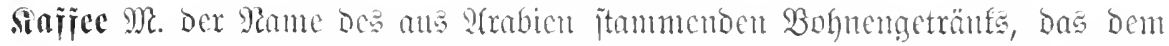

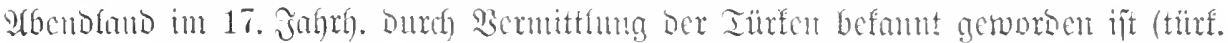

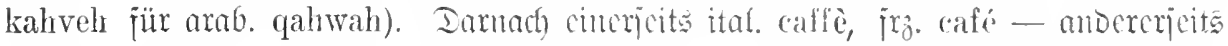
engl. coffee, nol. koffie. Baci ms geften bis juät ins 18. Jabrh. Die beidon Raut=

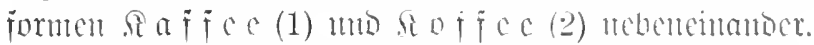

Belege: 1. Epon 1688 Ireh Mene Curieuje Iractätgen Bon Dem Irandéte Cafe, Emejificm The und Der Chocolata [überf. des Traetatus de Potu Caphe, Paris 1685.] Ehilemont 1705 frriegsint I] 179 Caffée. Pmaranthes 1710 Froben

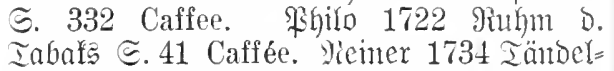
markt I 220 sogenannten Caffé. Bjellert 1745 Betjc)mefter (III 159) Caffee. Rabener 1759 caticen I 56 Caffee.

2. Thomajin 1688 Nonnatsejpräche I 37 coffée. Tentiel 1689 Innterrebungen ङ. 868 coffeé. B̧winger 1703 2rat હ. 13 Cofféc. Eallenbach 1714 Sammiland @. 42

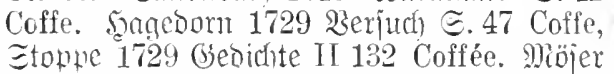
1778 PGantajien III 167 Coffeeplantagen.

3. Tie Einbürgernng des fremben Vaments erleichterten verdeutlichende $311=$

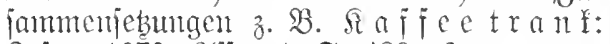
Bejen 1670 alfienat $\Subset .489$ den so genemnten Tioffeetrank. Cinxujadens 1751 Bren. 2rounturier $\Xi .347$ Speise und warmen Coffee-Tranck. - Si a ffee= jup $p$ : Ettrer 1697 Doftor 厄. 839 Chave-Suppe. - faffecrafier: 3winger 1703 2\{rzt ๔. 513 Coffee-wasser.

4. Dic frübjten Ermälnumgen des Saffees (vor peiner roirflidjen (Einführung un 1670) in Reijewerfen Des 16. 17. Jahnhas. zeigen jofrounfende Snutjormen; bgl. (nad)

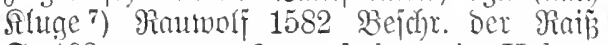
ङ. 102 unter anderm habens in Halcpo ein gut Getränk, welches sie hoch halten, $\mathrm{Ch}$ a $u$ b e genannt, das gar nahe wie Dinten so schwartz. Dlearius 1663 Reije ธ. 382 eine poreellanen Schale voll heib schwartz Wasser, so sie [Die Perjer] I a h a w e rennen - 厄. 598 Bey dem Tabacktrincken haben sie das heisse schwartze Wasser $\mathrm{C}$ a h w a e alsbald zur Hand. Froncisci 1665 AนEี Eitteripiegel 厄. $879^{\mathrm{b}}$ eine kleine Schale mit warmen C a v ve, aber ohne Zucker. Die Edyreibung (cha me aud nod bei

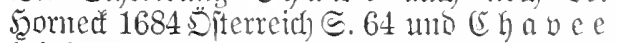
bei Ettrter 1697 Cynmicus ๔. 1033.

5. Tie moderne llumgangsipradje betont

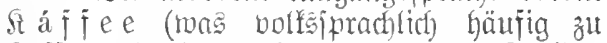
SÁfifo reduzicrt wird) und untericteidet Daber den Manten des Betrünfs von Ca jé 'Suffehars' (j. D.). Ingegen ijt in Diter= reich bie (Endbetomung rach frambojificher

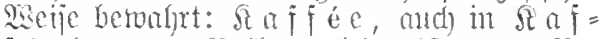
féelyau. Bolf́stimliche (Enott=) Ra= men des Saffecs jum (nach) Silbebrand,

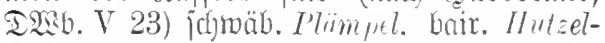
uns:er, jächi. Latsch, Luike, johlej. Kafjerplanech.

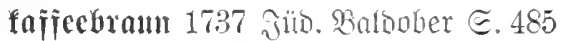
drei Stück Caffé-bram Görlitzer Tuch.

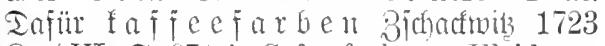
farl VI. Є. 671 in Cafee-farbeuer Kleidung.

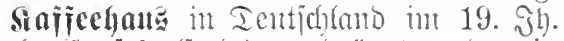

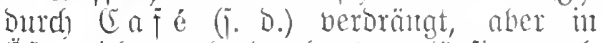
siterreid noch Durdaus gelänfig; ogl. Saube 1836 Reijenobellen III 5 was man liaffeehaus nennt, das ist in Wien zu Hause.

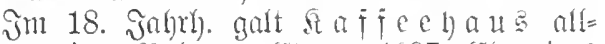
gemein; Selege: Ettuer 1697 Ehnnteus ङ. 1033 Charee-Hauß. (Callenbad) 1714 Piner ๔. 35 Caffe-Hauß. Gellert 1746 Sons (III 292). Sejing 1767 Iramatumgie (IX 232). \$iefiel 1789 serjuche I 70. Goethe 1796 Rehrjahre (21, 89) - (23, 104). Eeume 1803 Epasiergang (II 47). Secite 1822 Berl. Briefe (VII 568). Remalo 1836 íqumelle I 131. Edjücting 1859 Erzzälylumgen I 68.

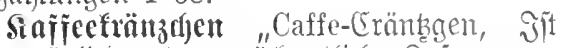
einte täglidje ober mödjentiche Bmiammen= funfit und Berjanlnurg cintiger bertrauter Franenzmmer, meldye nach ber Rieine herum gehet, worben jie jidy ntit Caffee trinden nto $10 \mathrm{mbre}=$ epicl divertiren unt ergibizen" Shumanthes 1715 Franenzimmer= texifon 厄. 286.

Siafijeciduluejter "Eafje= Edbuejtergen, Seifien einige bertrante und gute Freut=

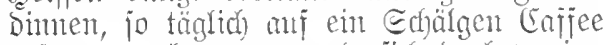

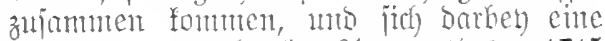
Ergönuntg madhen" Smaranthes 1715 Jranenimuterlerifon ङ. 286. Beleg: Sotzebue 1799 Eilb. 5ectbeit (TIII 150) líaffeeschwestern.

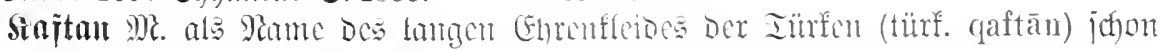

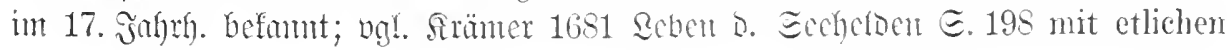




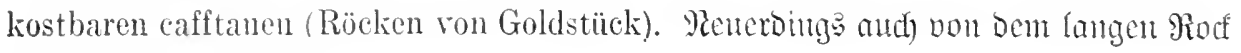
Der Juthen in \$olch.

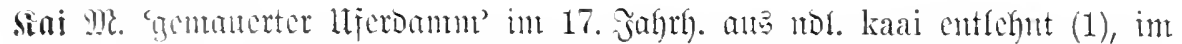

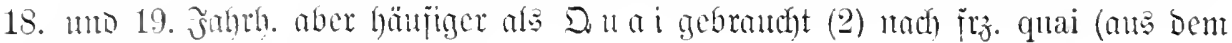
aud bas unl. wart entegnt iit).

Belege: 1. 3ejen 1664 24mjterban ein (ebo.). 1790 Der Beobnchter E. 329 ๔. 75 langst der Geldrischen Schifslage den Kay von Santarena in Lissabon.

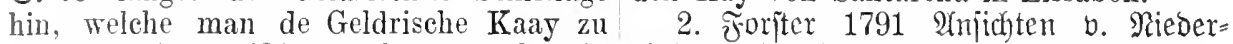

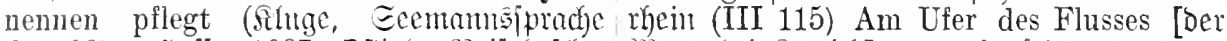

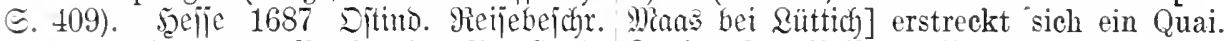
ङ. 349 giengen vollends in die Stadt ఇaube 1837 Reifenoberfen V 34 was noch Hamburg, und logirten uns auf der Cay, von Badegästen in Swinemünde war, kam in der Stadt Staade, bey Matthias Ellers an den Quai, Bolwerk hier genannt.

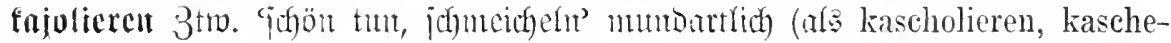

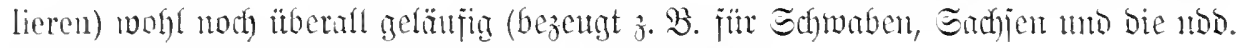

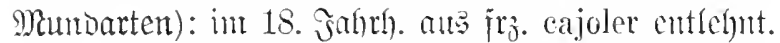

Belege: Rhilo 1722 Ruhn D. Iabafs mujte] den stolzen und beim Vorsteher S. 53 ihre Hauß-Ehre statt eines Cusses, sehr loch angeschriebenen St. Petri-Küster wie Mimus, der Brassendorffische Schul- kascholiren. ₹ontune 1878 Briefe I 256 Major, mit Fünff-Finger-Kraut cajolirt. ich habe Anspruch darauf, ,kajoliert" zu Babrot 1790 Sebensejejr. I 315 man werden.

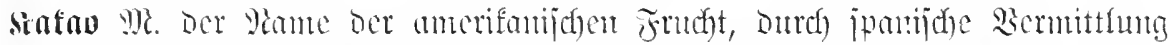

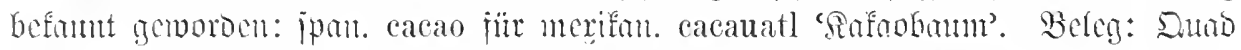
1593 Entfirión cosmogranr. 5. 273 Cacao (ein Frucht den Mandelkernen gleich. darans sie ein sehr licblichen Dranck machen).

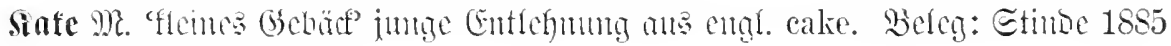
Fom. Buthof; II 82 Cakes.

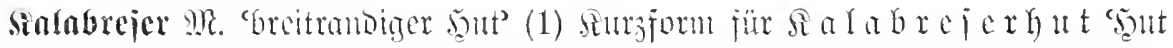

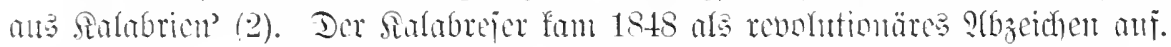

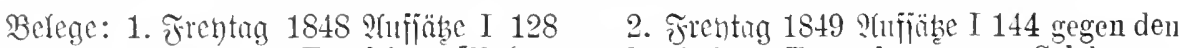
Scit der Unselige von Frankfurt [ $: 0$ hert studentischen Taumel unserer CalabreserBł[um] nach Wien kam, in der Aula lüte und gegen nichtdeutsche Zumuthungen. spraclı und den Calabreser in sein Antlitz $\Xi$ chüdding 1863 ifftiengejerffchajt I 67.

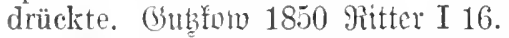

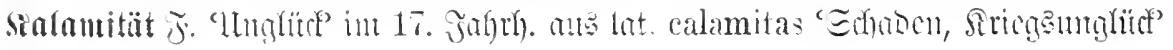
contlenit.

Belege: Borne 1641 Conjultatio $B 1^{\text {b }}$ sie als couragieúse Helden werden alle menschen, welche mitten in so vielen cala- solche calamiteten toleriren. Rebenwalot mitäten vuld miserien hatb in verzweif- 1680 Teufeds Rijt III 30. 1689 Polit.

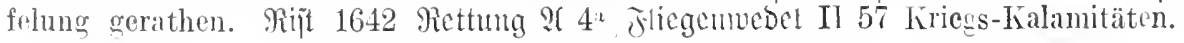

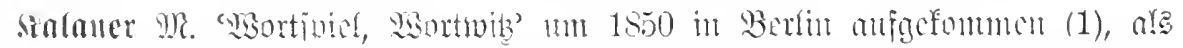

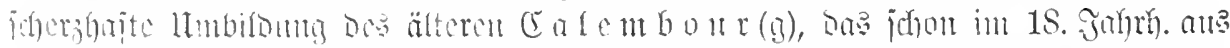

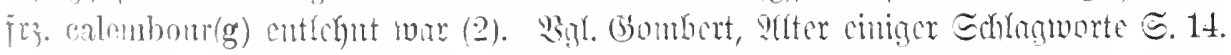

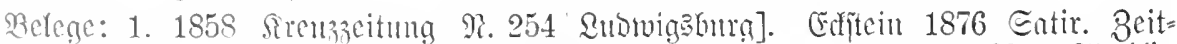

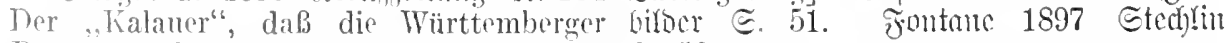
Remnen auf deu Hund gekommen sind ङ. 58 .

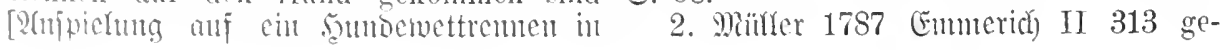


sunde Vernunft mit platten Einfällen und zösische Conversation mit allen ihren abgenutzten Calembours abzufertigen. Bonmots, Calembours. Rormann 1833 Goethe 1815 an Zelter I 408 Da wir die siterrein I 1 こ. 153 Calembourg. Saube Berliner zum Nachdenken und zum Calem- 1836 Reijenovellen IV 16. Devrient 1841 bour gebracht haben - (ogl. Belter こ. 404 Irene Riebe (III 103). Głubfow 1845 Einer hat das Stück [Cpimenides] I-wie- Reijeemorüde (IX 226) Ein kahlenberger menen-Sie-deb? genannt). 5̧ofintmu Spaß ist ein Calembourg, ein Wiener 1821 Serapionebrüber (IX 11) die fran- „Bär".

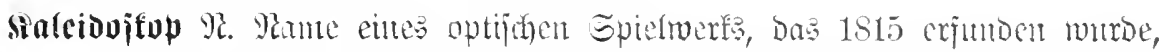

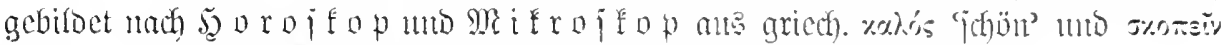

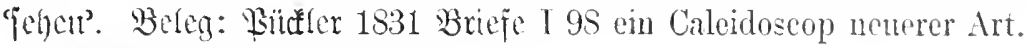

\section{Salembourg i. unter fia la li er.}

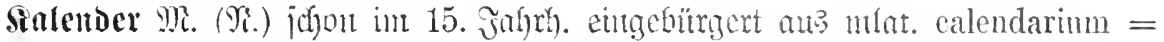
lat. calendarium 'Schutobuth' (Dic calendac touren Baflumgaterminc).

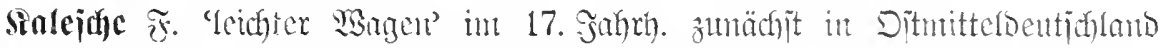
befamt gerooroen (1), anjung nod) mit Der Rebenform Ralcije (2). Der Name

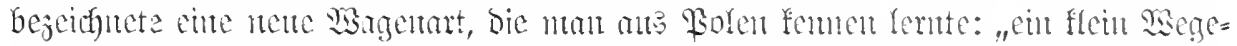

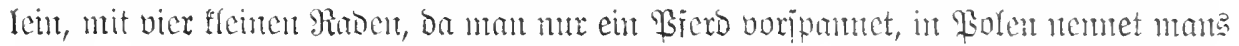

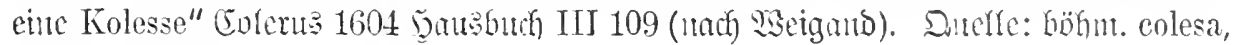
pulnt. Kolaska.

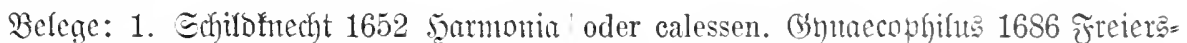

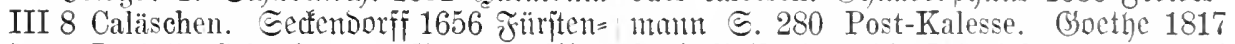
ftaat I 617 Caleschen. Grymacophilus Stal. Reije (31, 28) Wir fuhren auf zwei

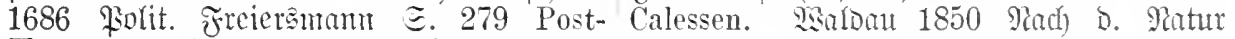
Kalesche. Eittner 1697 Doftor こ. 579 III 312 Aus dem hohen ,Kalessel“, dessen Calesche. $\quad$ sich der deutsche Bauer in Schlesien zu

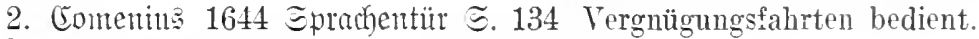

in kutschen, kutschkarren, vnd rollwagen

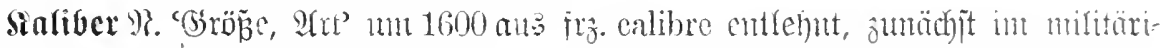

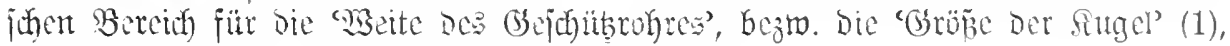
idout in 1S. Sahrf. aber and übertr. gebrandit (2).

Belege: 1. Malmaujen 1616 feriegs= 2. Fforin 1749 Sembuater II $48^{\mathrm{b}}$ mit manuel ङ. 90 ein leicht Stück Geschïtz, 6. Pferden von einerley Calibre und Farbe welches doch einen grossen Caliber hat - - $42^{2}$ von jenem Calibre sind zum ExemS. 157 nach dem Caliber der Röhren. De pel die Grafen und Barons. Gimion 1-36 Bry 1617 Bajta's Generalfelobberĩt S. 17 Iugebuch (I 185̃) Orden von allem möglichen einerley caliber. Kaliber.

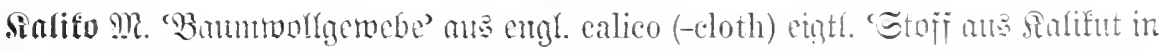

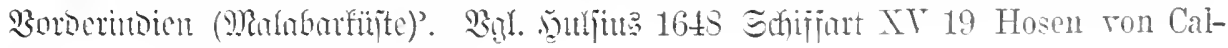
lico oder Indianischen Leinwath.

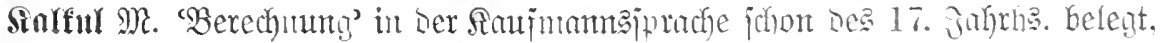

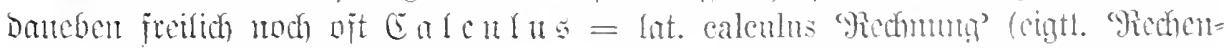

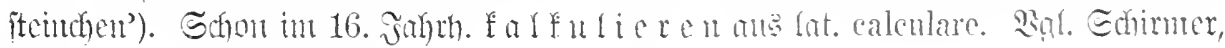

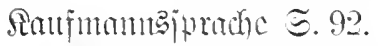

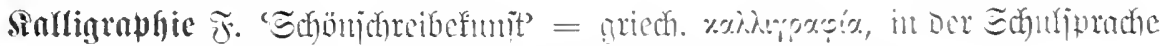

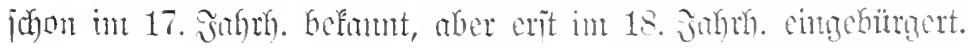




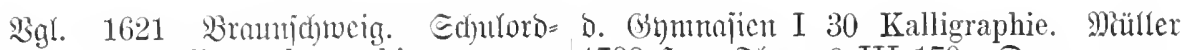

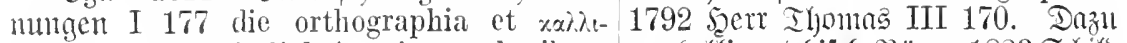

rpopix oder zierligkeit im schreiben. falligrnphifd Böme 1823 Sdjilderungen 5erzog Emit 1642 Edulmethodus $\Subset .29$ a. Faris (II 119) Ein k.-es Werk fand dieses gehört zur Calligraphia oder zum großen Beifall. Frentag 1855 soll und zierlichen schreiben. [IIfrid) 1780 (bejd). Haben I 8 ein k.-es Kunstwerk.

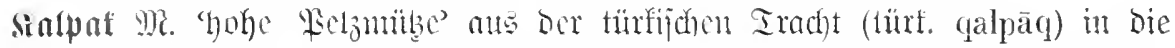

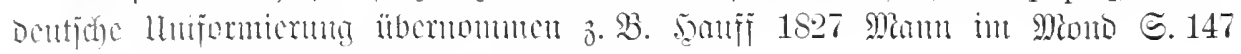
Uthanen-Kalpak. Grobbe 1831 Mapoled 1111.

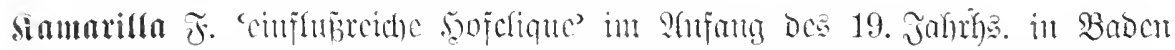

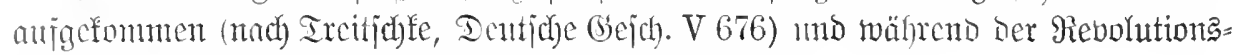

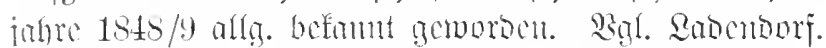

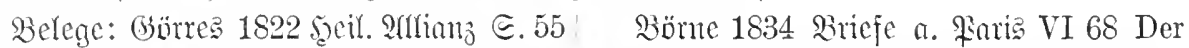
cine gewisse Menschenklasse, die an den Herzog Decazes machte ihmen den Hof Höfen neuerer Zeit nur allzusehr sich ver- im Namen der Camarilla. (Jutomiffy 1845 mehrt und allerwärts die eigentliche Ca- Iour D. Belgien $\Subset$. 281 Nichts verlautet merilla mit und ohne Livree ausmacht. von Tiamarilla, Hofintriguen. Frreytng

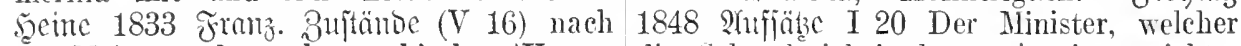
der Meinung der nckermärk'schen 'Kama- die Selamlosigkeit hat, mit einer nichtsrilla - (13) Dic Jïriten] schmachten in. würdigen Camarilla zu conspiriren — von den Ketten ihrer kleinen Kamarillen. den Einflüssen einer Camarilla.

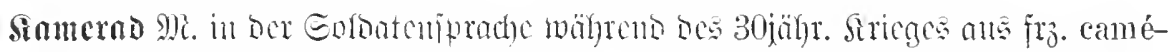

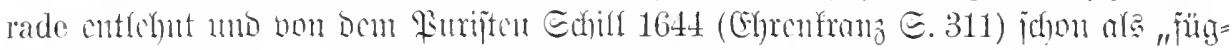

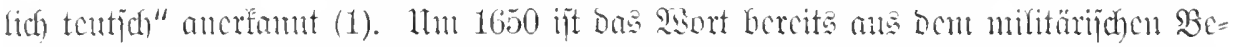

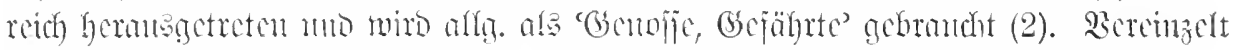

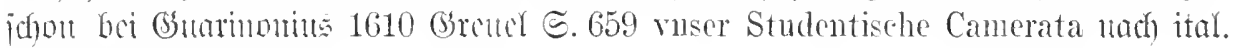
camerata 'Gicführte'.

Belege: 1. Binfgräf 1639 STpophtheg=, sein guter getrewer Freund vnd Camerade

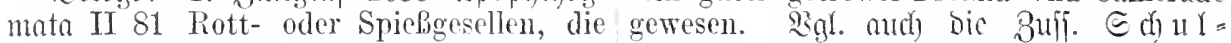
jetz auli new-tentsel Camaraden heissen fam ex a d (Ettner 1697 Ioftor @. 240),

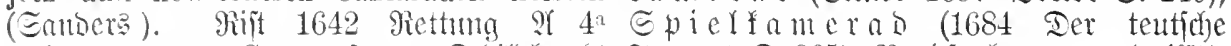

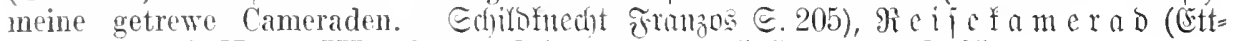
1652 sarmonia II 31-III 140.174. Eshup ner 1715 scehmme @.95).

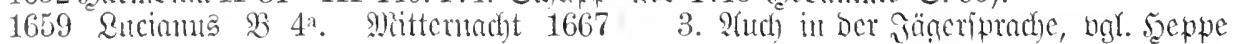
Rolitica 52 2

2. ¿auremberg 1652 Edherzgebichte gewöhnliche Ehrenwort, womit ein Wegsミ. $43 \mathrm{Im}$ Stalle kan man Complementen genosse, wenn er zum andern kommt, hören: ,Myn hochgeshrter Cammerade, donselben ans Fremulschaft begrüsset; Monsör Bören". Echorer 1663 Qfrz!tci D. eben wie as die Soldaten auch also unter Reifenoen €. 38 Er kenne einen alten sich halten.

Schlaffgäinger, welcher von Jugind anff

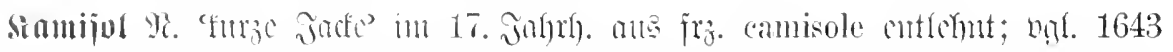
Entachoctorber 5.32 die Schneiler, die fangen sehon anch an solehe frembde Frantzösische Wïnter jhrer tentschen Sprach an zuflicken; da heisset es bey jhnen, joh kamn cin meretes alamodisclees Camisol machen.

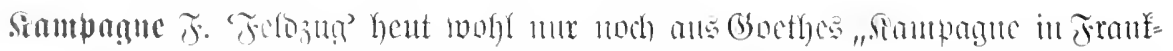

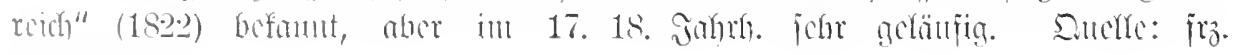
camprague. 


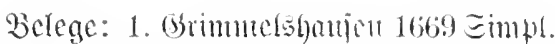

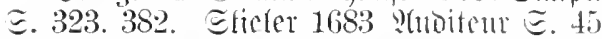
da wir anstatt der Kriegesheere Armeen. anstatt ler Feldziige Campagnen wehabt. windler 1696 Edetmann E.788. Qsibuti 1698 Perjonatia (I :343). S(robent)or 1790 Sicbenjähr. sirteg こ. 268 .

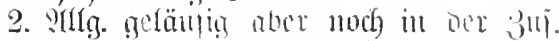

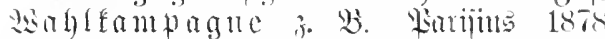
Furit. Partcien I 47 Die Wahldngblitter haben selten Jahreszahl mol 1)atum. so daßs man die einzehnen Wahllkampagnen nich!

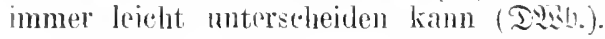

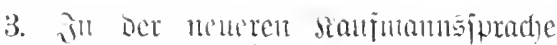

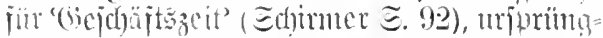

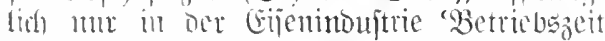
cutes 5odfofens: 1777 simtits X 582 Lieses sind die (in Verorle vehung mit den Krommmöfen ) : genannten Hohenojen. . . dir die:t manfhiolich im liange bleiben, so lanne ihr Gestelle chatert. Welche: armeinirlich 40 und höchstens follochen anshäl, welche Zeit

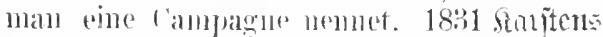

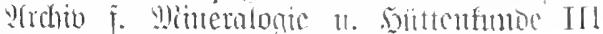
$209-1835$ (6). IJI $4: 3$.

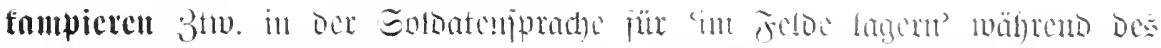

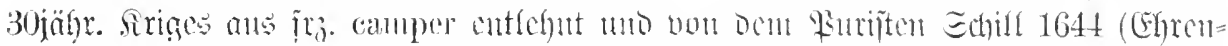

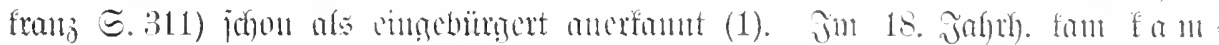

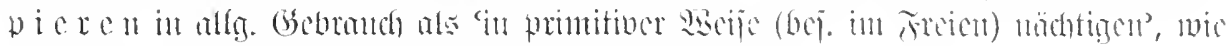

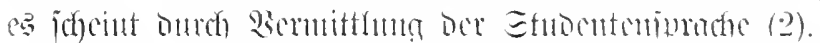

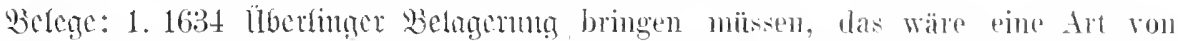

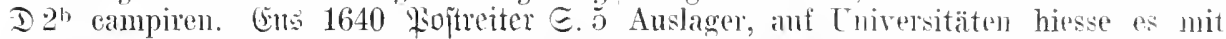
ein Lager formiren und campiren. Böfler dem Fumstwont Campiren. Eethirfer 1785 1665 ङ Lägern und dem Campieren.

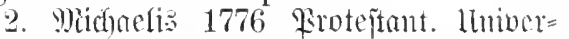
jitüten IV 171 Was man Campiren und zu Dorf $t$ steigen nennet. ist sonst jedem Bürger erlanbt - 220 er soll drey bis vier Wochen Familien den Sommer über anf den benachbarten Dörfern zu kampieren. und das Land zn genießen. 2trcherbols 1787 cing= fontio Ill 161 Tansendo ron gomennen Leuten auf dem Dorfe in einem Wirtshanse zı-

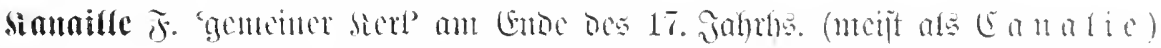

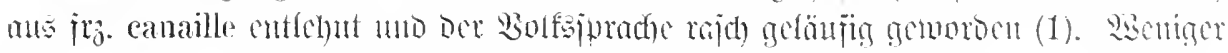

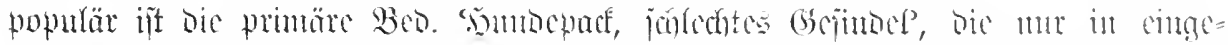

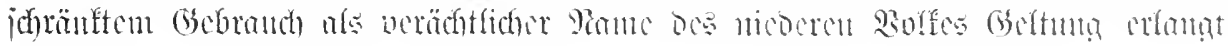
but (2).

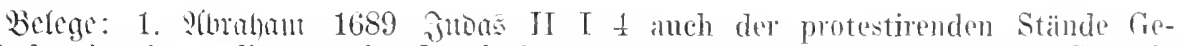
113 der in alweg die gemaine Leuth für sandte, wegen der schlimmen Canaille rerworffene Canalien gehalten. Döpler daselbst nicht gar sieher sern dürffte.

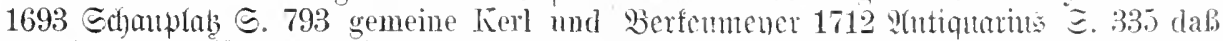
Canalien. Siseije 1697 Siertrante Gripr. man 4. Citadellen anlegen müssen, die 5.237 mit einer auswärtigen Canaille in Canaille in Zaum zn haltem. Robener Karten und Würffeln um Geld spielen. 1759 Eatiren III 389 Bïrgercanaille. Berber

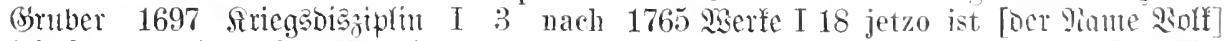
falscher gemeinen Canaillen-Art.

2. Chifemont 1702 stricgs: 1 . Etantsint

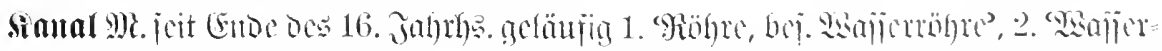

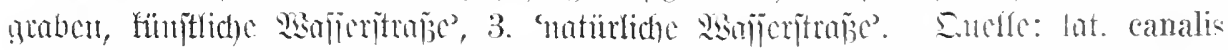

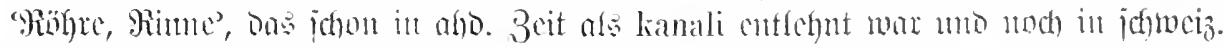

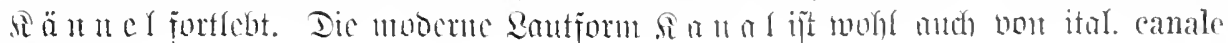
bccinflunt.

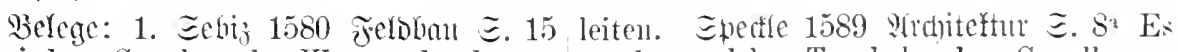
die jrdene Canal - das Wasser durch ron werden solehe Tenchel oder Canall ron laimen bebachene rör vnd Canäl hinein gantzem fornen holtz aubgebort. \&rä= 
torin: 1619 Enntagntu ntuj. II 106 das von dem Flub Scalde, oder Scelt, welcher man Canal oder Windtröhren gebrancht. strom, da er am tieffsten ist, die sehiffer

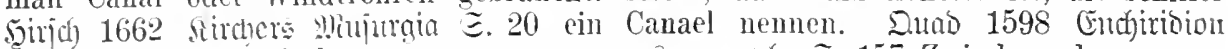
gläsern Canal oder Rohr.

2. Jurtenbad 1627 Stinerar. Staltac cosntograph. E. 157 Zwischen der grossen Jatra vind Sumatra ist ein Canal in dem hierzu gemachten Canal, der bes Nord-Heer ein großer Canal. Sei. i ift 12. Schritte braitt biß nach Liromo fahren. Sa nal jeit bem 15. Jabrh. Der game

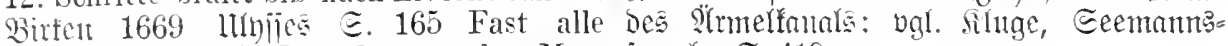
Straßen [in Renedig] werden von dem Meer iprache e. 419.

durchgossen (so sic Canalen nemnen). Samalijation $\tilde{\sigma}$. vgY. Birchotw, luber bie

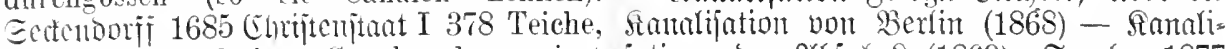
Däme, Durchschnitte, Canale oder wenigst fation ober $\mathfrak{A}$ bfuhr? (1869). Faucher 1877 Landstrassen zil machen.

3. 5orjot 1580 Qentum Gehcimijie Hie Canalisation!

๔. $747^{\circ}$ die Tnsel Scaldia hat den namen

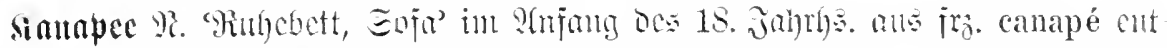

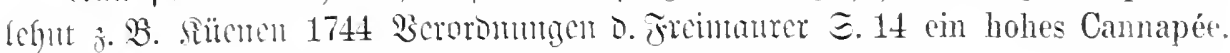

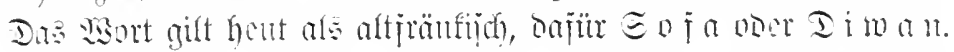

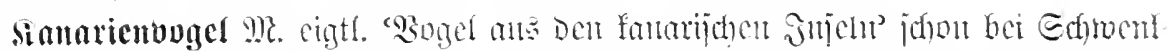
fin 1603 belegt (Canarien Togel, Zucker Vogel, Canarien Zeisle). Bufrübịt bei

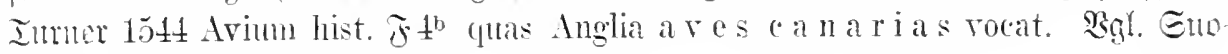

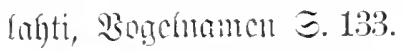

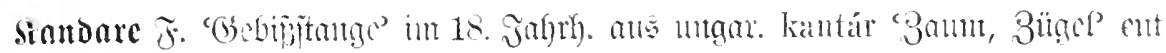
lefut uno be sonberger 1807 gebudt.

Bgl. Scrntcs 1778 Cophteng Reije V begegnete, die Candare lassen Sie nach! 150 Lassen Sie mir die Candare etwas nach, - Aber liebe Zeit, wer gewust hätte, daß rief mir ein hübscher Mann zu, der mir Candare ein Zügel, oder so was, heisst!

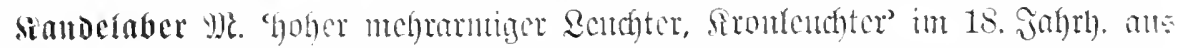

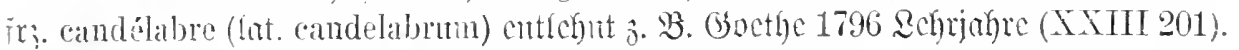

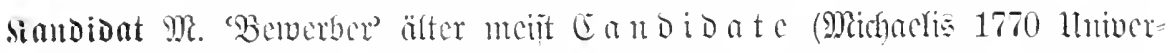

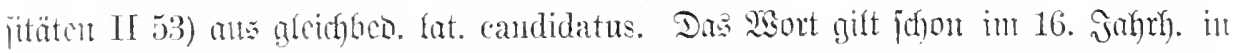

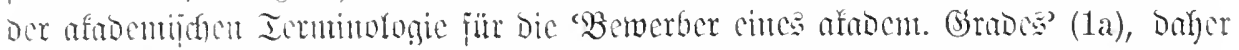

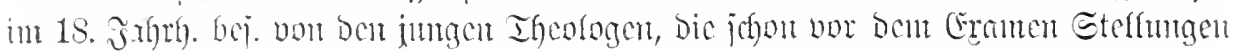

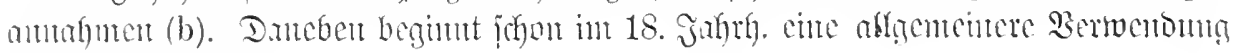
oce 1 sortes $(2)$.

Belege: 1a. 1580 Etatuten D. Ultib. betrat. Wingner 1776 Rintormörberit

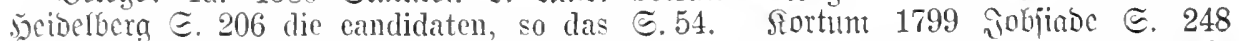
magisterium begerm. Menjart 1636 5ock $=$ ichulen $\widetilde{\sigma}$. 276 die Faculteten seyn zu rülımen, bey welehen die Candidaten müssen vorlegen die Jahre, in welehen sie studiert liaben. Miartin 1637 Parle ment ङ. 675 einen Candidaten. der in den Reehten den Gradum anmemmen wolte.

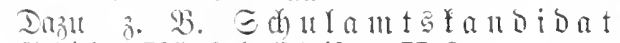
(Bedicfe 1795 Ectulfidnriften II 8.

b. Giflert 1746 rabeln E. 168 Ein seh\% gesehiekter Kandidat, Der lange sehon mit vielem Lobe Die Kanzeln in der Stalt

D. 54 . Sortum 1799 inelt er sich einen Kandidat als Kaplan.

2. Mieter $17 \pm 6$ Ehre $\subseteq .147$ Diese Candidaten der Elıre sind mehrentheils zu hitzig.

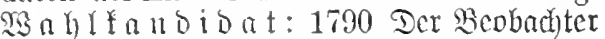

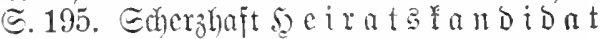
Edhefer 1847 Id htzeht Tödter E. 90.

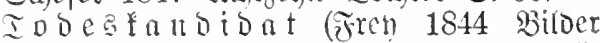
ङ. 344. (3rojutantu 1847 (s)ejerlichajt S. 225) idyeint aus Der Eprache ber Silrate zu fitam= illen val. Bürger 1794 şrtefe IV 243 Der zuletzt Herbeigerufene [îtzt] erklärte 
mich fast für niehts mehr als condamnatum, leg: Freltag 1863 2fufiäbc II 75 Die Canfür einen Candidatum mortis. Worker frel= didatur des Prinzen Leopold für den (ich fiton religiös bei Danntauer 1642 griechisehen Thron.

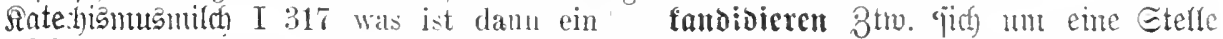
solcher auder' als ein ('undidatus mortis (ein Mianoat) betwerben' 3 . \$B. Epielfagent aeternae. 1866 jit ?heih u. Blied IV 66 für die

Sanbibatur $\mathfrak{F}$. 'Berverbung' in poli, näehsten Wahlen zu kandidieren. tijchem Eime, me $\mathrm{Fr}_{\mathrm{z}}$. candidature. $\mathfrak{B} \mathrm{e}=$

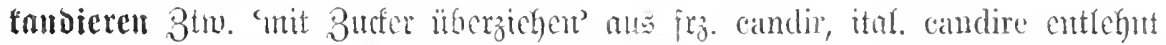

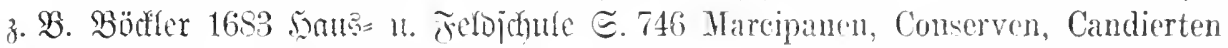

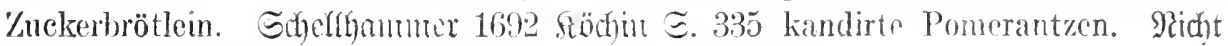

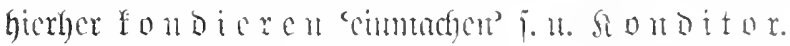

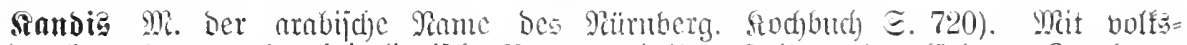

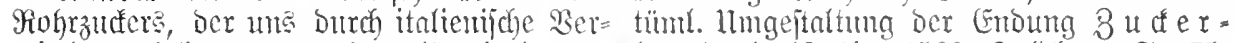

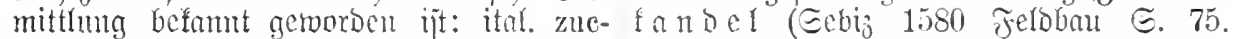
chero candito vocr eandi fïr arab. qand Tabernaemontantis 1588 siräuterbuch $\mathrm{I} 68^{\mathrm{b}}$ )

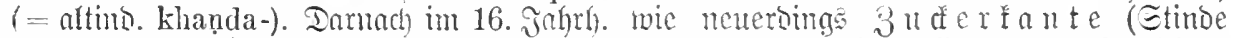

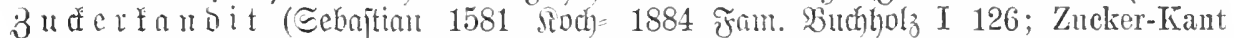

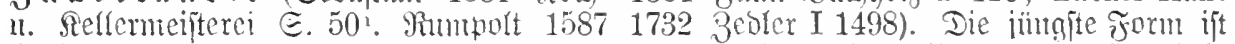

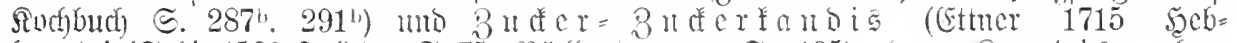

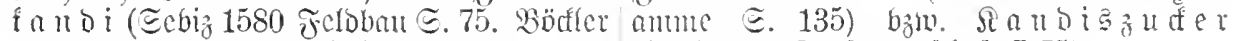

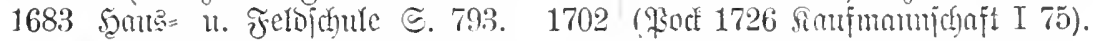

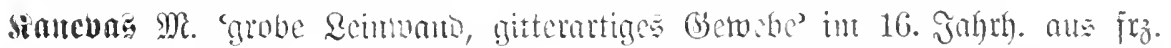

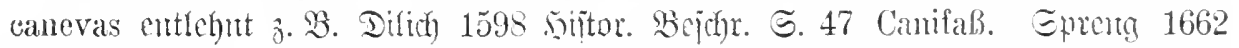

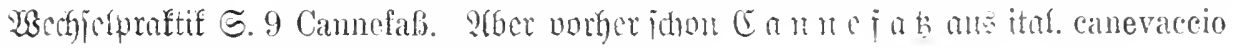
bei Mesor 1559 sambelbuch $5.16^{\mathrm{b}}$. $55^{\mathrm{b}}$.

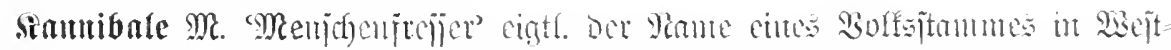

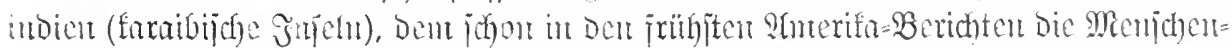

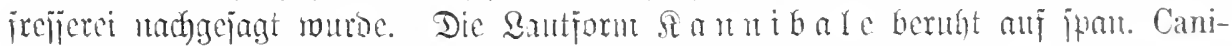

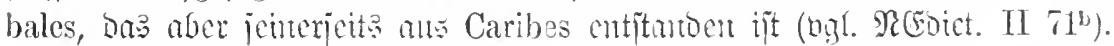

Belege: Serr 1534 Die ncue $\mathfrak{\text { Sclt }}$ ङ. 30 jrem Lande schiffeten in andere inseln Cannibali heissen dieselben, die mensehen vnnd fiengen die leut, sehlugen sie zu fleisch essen, die waren die unsern fur ge- todt, fressen sie. Diftid 1598 jijtor. Be=

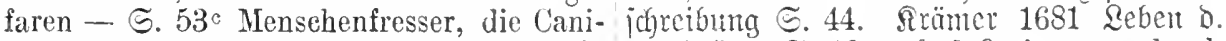
bali hießen. Mäniter 1544 Eommograbjia Seehelden 厄. 19 auf daß sie etwa durch $\Xi .638$ Die weil nun Columbus in diser inseln die Cariben, Canibaleu und dergleiehen was mit seinen mitgeferten, klagten jm Barbarische Menschen-Fresser elendiglich die ynwoner grosse not über etlich völeker, ermordet und zerrissen werden.

die sie Canibalen nenmen, wie die anß

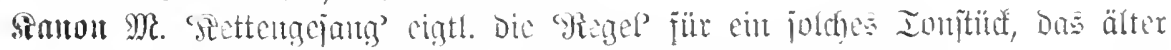
Fuga legata, in conseguenza hicí. Ditefr: lat. canou 'Regel.

Bgl. Cetfug Enlbipiuß 1630 Melopeia anderes anzeigen oder bedenten als eine Eap. XIX Fuga ligati est, quae dum Regel oder Riehtschnur, weil man nemlich omnia accidentia cantus, quo ad tempus einen Canonem mit solehen Regeln und et figuras, unico seripto Duce canitur. Anmerkungen anfsetzet, daB eine oder Inscribitur certo titulo, quem Canonem mehr Stimmen alle Figuren oder Noten, Musici vocant. Bononcini 1701 Mnificus so in der ersten Stimme befindlich, nach-

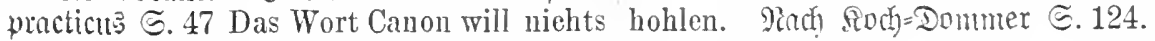

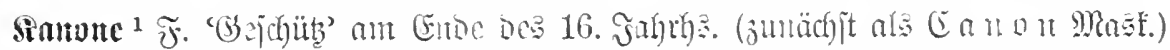

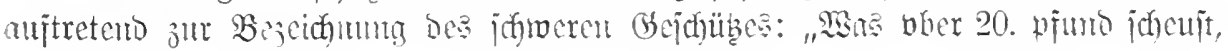




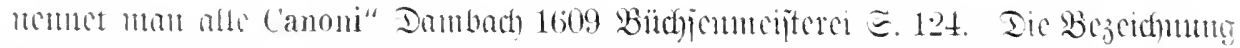

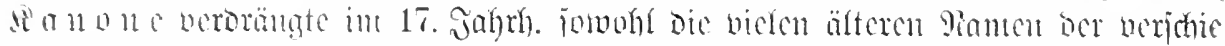

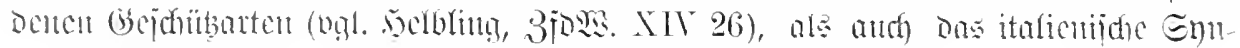

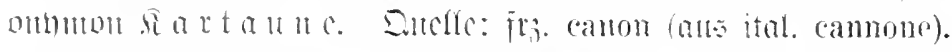

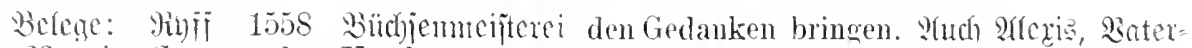

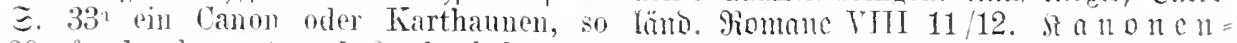

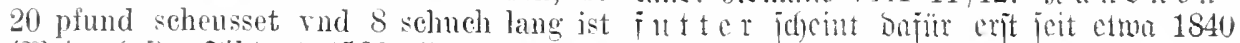

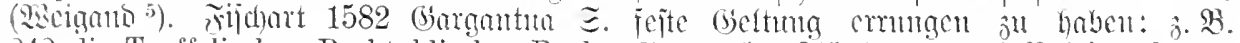

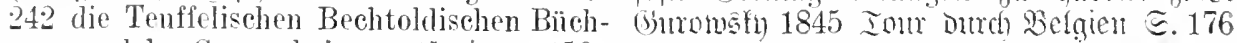
ssen. welche Canon heissen. Enjinger 1591 Erbärmlich war die Hilfe. da die Masse Relat. IV 76 dab dem Graffen von Mont- dieses Kanonenfutters zu klein war. 10 bazon die zwey beyn hinweckh geschossen militärisch einen Ausschlas gaben zu seindt worden mit einem Canon oder können.

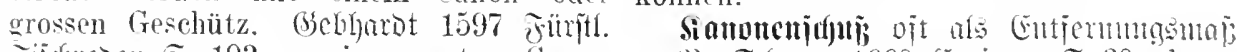

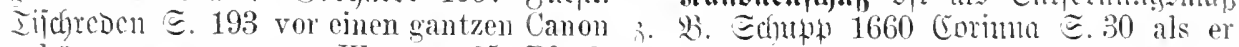
gehören, wanns gut Wetter, 25 Pferd. kaum einen Canonensehns ron der Stadt

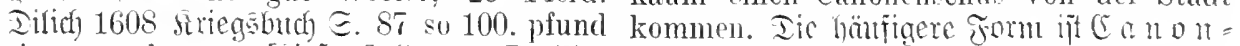

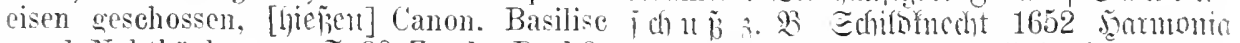

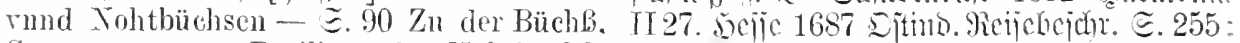
Canon genannt, Basilise oder NohtbüchB. Sirümer 1681 Seben D. Ecefelocn $\Xi$. 486:

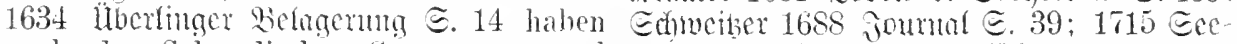

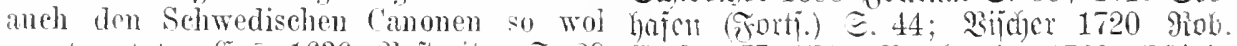

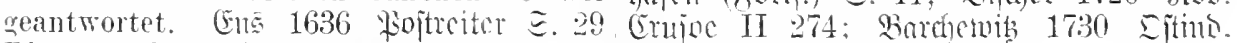
Die ron Schencken Schantz haben sich anch durch jhre Canonen tapffer hören lassen. Witriter 1643/7 Echtwed. Sirien ‡. 69 die schwedische canonen. Gruphin 1663 soorribifict. E. 38 mit allen spinesi Fenerspeyenden Granaten und Donnerschwangeren Canonen. Bicalex 1689

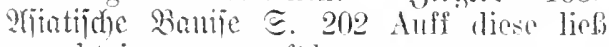
er achtzig canonen führen.

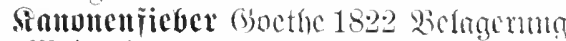
vout Matus $(33,72)$ The hatte soviel rom $\mathrm{K}$. gohört and wïnschte zu wiscesn. wie p's cigentlich damit beschaffen spi- (299) eim. Allwandlung jenes K.-..

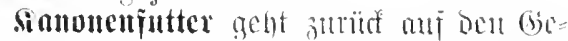
brauch bon engl. food for powder in Ehafe-

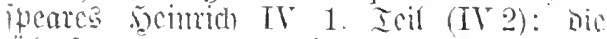

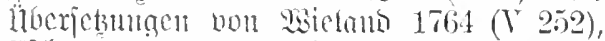
Eichenburn 1779 (XVT 149), Edhlegel= sicd

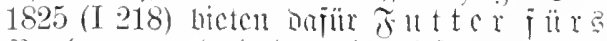

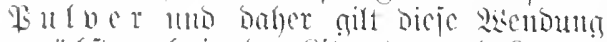
juntöbjt anch in ber Eiferatur, ugl. Ecmatio 1836 9toumelfe I 14:3 Das Fallstaff'sche "Futter für l'ulver" komente ich nieht aus

Ricijebcidt. $\Xi 639$.

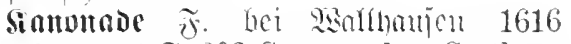
Stricginantur ङ. 203 Cammonades: Carthaunen Schul. Em 1631 Ier Rojtreiter

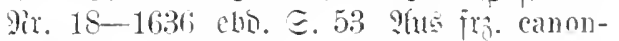
nade.

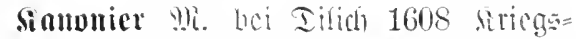
unch こ. 21: Zul ordinari Arckeley uff ein Regiment gehören 4 Canoniers oder

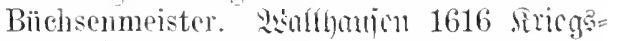
mannal こ. 203 Camonier: Ein Büchsenmeister - rbo. E. 99 dab du jhm [sc. Donl Frint] seine Stück abhebest. seine Canonirer erscheust. ?h $\mathrm{fr}_{\partial}$. canomier.

f́ntonicren 3 two bei 2 salfigmen 1616 Stricgumanun! ङ, 203 Canomiren: Ein Ort mit Carthaunen beschiesen. Gus 1631; Roptreiter $\Xi .29$ wegen Continuirlichen Canomirens. Büffer 1665 Schola militaris E. 4 sprengen rnd stürmen. eanoniren.

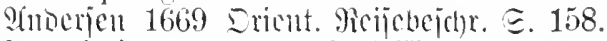
Francisci 1669 Irancrjan th 1033. 2he frô. eanonner.

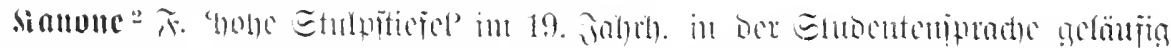

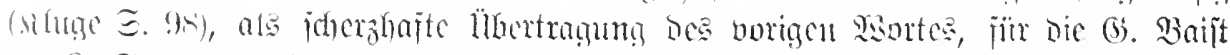
an 2. Etcruce Irittram Ehanon III siat. 22 (two mortar-pieces made of a pair uf jack-bootsi crimucrt.

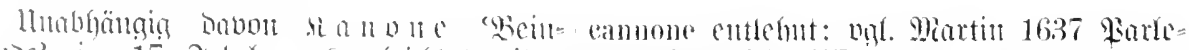

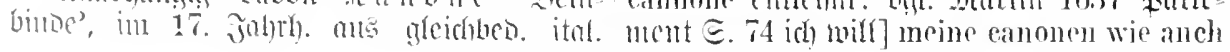


mir meine sporen anthun. Edbill $16 \pm 4$ Enten nonen, Stiffeh rud Sporen, in Summa reeht franz $\Xi .319$ Wie werden nur die Fïb be- berenhenteriseh. Qaurenberg 1652 Echerz. kleidet? Erstlich mit einen paar weissen gebichte Є. 33 Würden uth Halskragen Strümpffen, darnach mit Seidenen aller- Stevelsktagen grebahren, De nömden se van hand Gattung, hernach allererst Canonen, den Canonicis Canonen. Etieler 1691 Ep. vond dann endlichen grosse Flötzer-Stilfel. 928, ocrealia ista lintea, fuar and pompan

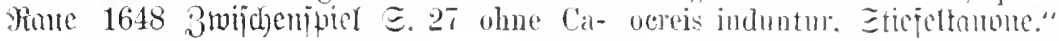

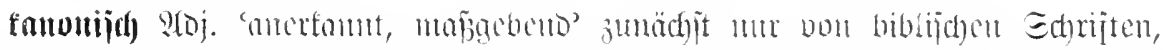

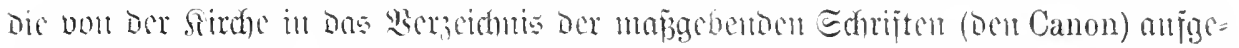

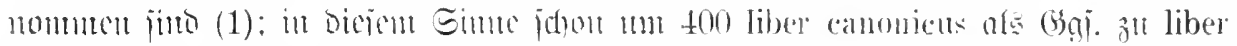

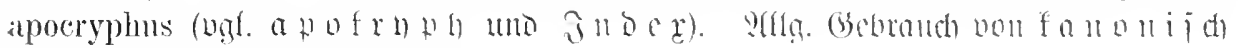
begiunt erit in 18 . inal)th. (2).

Belege: 1. Emjer 1525 9motaten ID S. Litteratur so l'anonisch geworden ist, als wölche clie kirchen ortermig bib auff den er uns in de! Bibel Apokryphisch dünkt. hewtigen tag für gewisse bewerte eanoni- (jocthe 1796 Lehrjahre (XXII 88) das sche schrifft gehalten hat.

2. 5erber 1767 I. Siteratur (I 134) (in germe geben möehten.

Beruf, der hell zu Tage im Reiche der

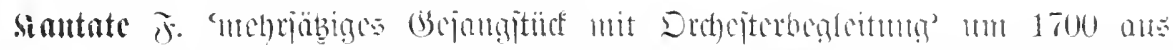

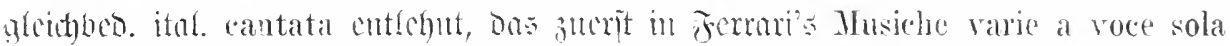

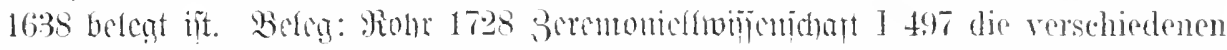
bey den Opern und derglejehen Poesien rorkommenten Kunst-Mörter. als Nrioso, Recitativ. Cantate, Cavate nsw. - II 3:21 Traner-Cantaten.

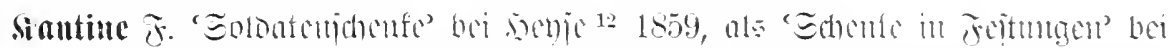

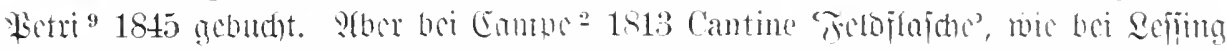

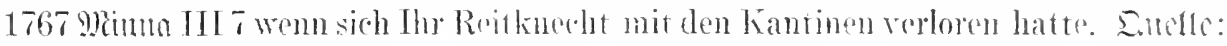
iri. cantinte.

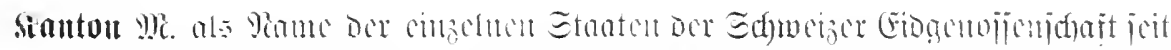

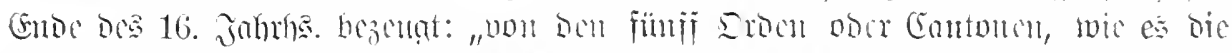

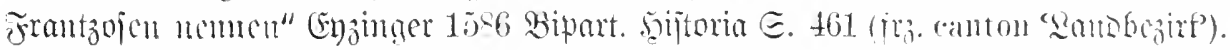

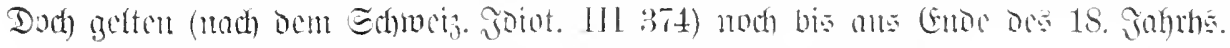

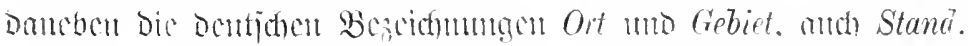

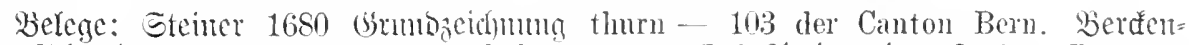

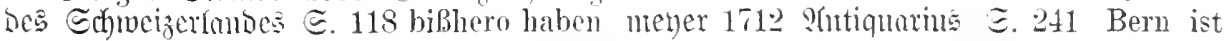
wir von den 13. Cantonen in Schwoitz die gröste und mächtigste unter den kürtzlichst gehandelt - 〔.121 Sonst sind Schweitzerischen Cantons. Edjeucher 1716 in einem jecten Canton etliche Commu- Maturhiftoric D. Edhweizerlandes ङ. 32 nitates oder Gemeinen. 1699 Etnatsipiegel einer jeden Provinz, Canton oder HerrII 102 die 4 mit Neufchatel Alliirte Canl- schafft des Schweitzerlandes.

tons als Bern. Lucern. Friburg mol Sole-

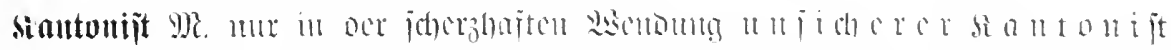

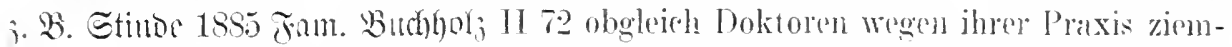

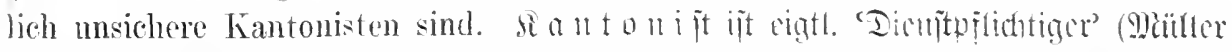

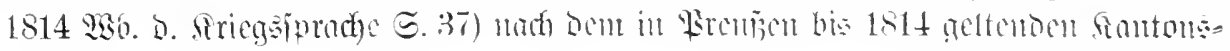
in)itent.

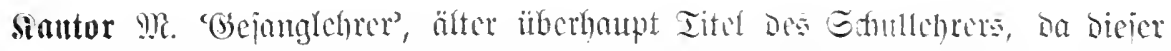

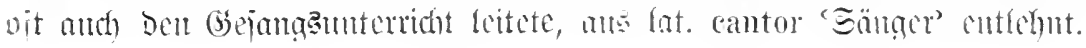


Bulege: Lin̈torins 1619 Enntagna nuj. tor oder schumeister. Epeer 1687 unterr. UI 32 Ob nun zwar ein jeder Cantor. anch v. D. mujifal. Funjt ङ. 5 seinem Herm Canein Knab in Her Sehulen wissen muß.... tori nder Sctulmeister.

Mengering 16t:- Gemijiensrïge S. 980 Can-

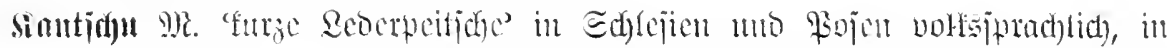

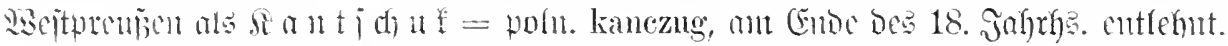

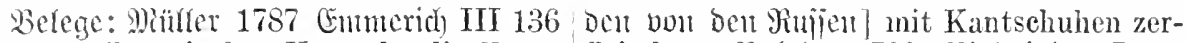
so wurde ihr mit dem Kantschu die Kunst fleiseht. Babrot 1790 Rinbviging I 40 beygebracht. Yrohenholz 1790 Eicbenjähr. indem ihn dieser den Kantschuh fühlen Srieg $\Xi .55$ Edellente und Prediger [mu= ließ.

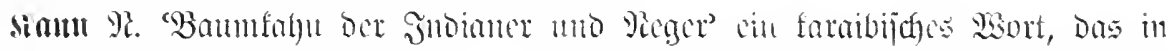

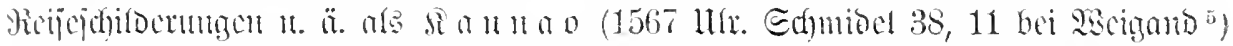
mo Ca

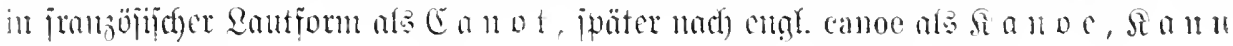
पุeläufị mirts.

Belege: Bobnter 1752 \$onh $\subsetneq 51$ cin Dieses aber ist gemein; jenes hingegen (3) [i] Ueber welchen zu setzen die kraft belehret uns, daß Rath Bodmer anf seinen des sehwimmenden I'ferdes, Oder der epischen Reisen auch Amerika besegelt stärkern Kanots niehts taugt. $\mathscr{D} \mathfrak{n} 31$ hat; denn die Kähne der Wilden pflegen

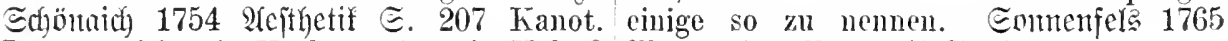
Ist das nicht ein Nachen oder ein Kahn? Mant ohne Worurteif ๔. 19.

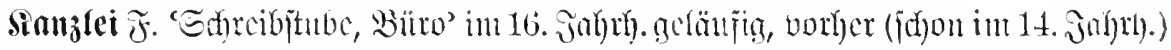

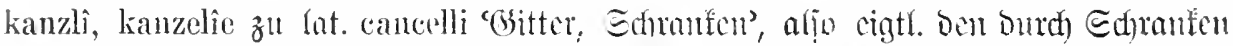

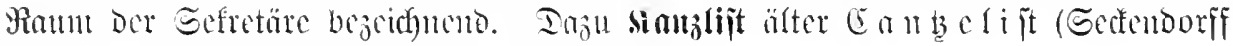
1656 F̈̈rjtemïtant 1 689) ans mlat. cancellista.

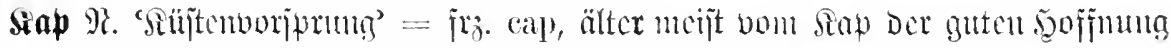

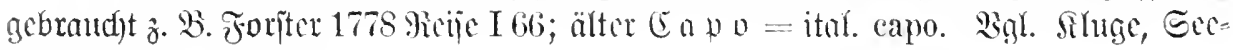
mammipradic 5.420 .

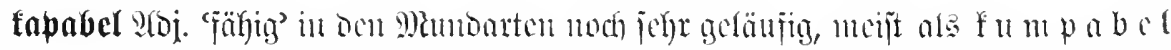

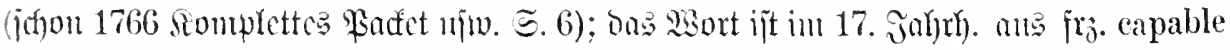

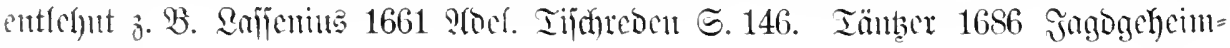

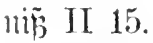

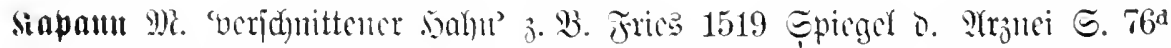
cappamen theisch; jofon mho. kappin. Dutfe: lat. caponem (zu capo = gried).

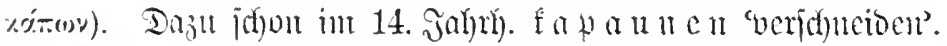

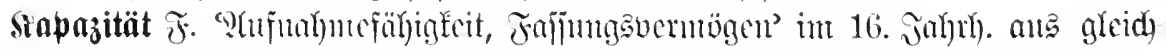

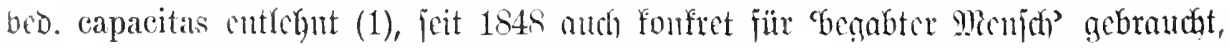

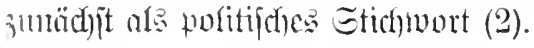

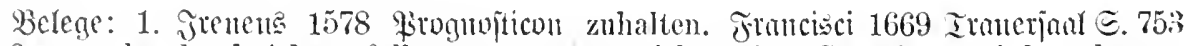
P. $2^{2}$ von der dureh Adams fall gantz ver- so viel meine Capacität wird zulassen. derbten Natur vnd Wesen des Menschen, Shomajus 1691 Bermurftehre II 57.

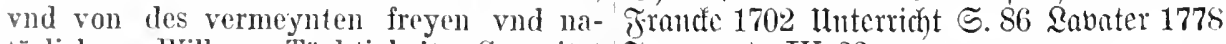
turlichen Willens: Trïchtigkejt, Capacitet Jatumente IV 23.

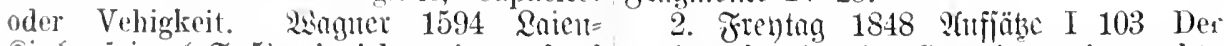
Airchenjpieger $\mathcal{S}^{5} 5^{\mathrm{b}}$ wie ich meiner schuel zweite aber ist eine Capacität, eine rechte Jugent wochentlich als ein vuwürdiger Stätze der Freiheit. 1848 (3tenzboten I Catechista auf den Enangelijs vnd Ca- 2, 290 (2nbentonti).

techismo nach jhrer eapacitet pflege für- 


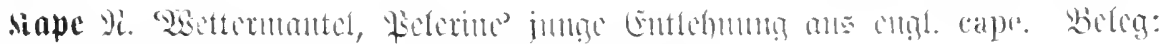
Fomtanc 1897 Etchlin $\approx .171$ das schottische C'ale.

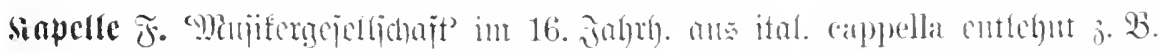

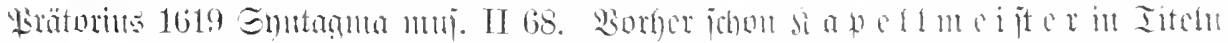

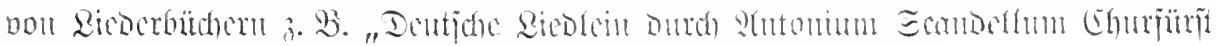

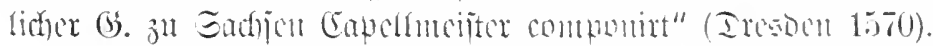

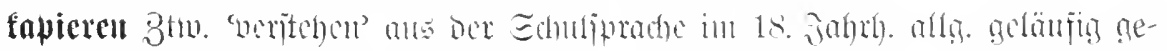

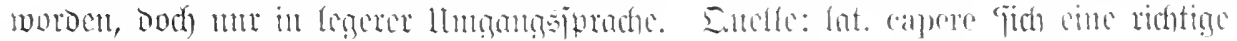
Roriterlmat machen, weriteban.

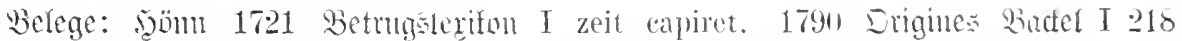
351 Wenn sie [Edyntehrer] bey ihrem Vor- Holwig konte die Ursache dieser nnertray mit Fleiß ubsenr seyn, damit man sie warteten Einladung nicht kapiren. Sif= nach ihrer aigenen gewöhnlichen Redens- land 1795 Edneimerbienit (TV 104) Capirt art: Quis capere potest, eapiat! nicht so er das? oder ist es die Figur der Ironias? gleich eapiren kömne - 125 Wenn sie - 1799 fiomet (TV 265) oh Sie das... [Dijputunten] sich anstellen, als ob sie das hinlänglich eapirt haben? Subchuc 1799 Argument nieht capiret hätten - 409 Eiln. nocheit (VIIT 251) Ich capire nieht dem Professori, welchen sie zium Anctore ganz.

angeben, dessen Mentem abur nicht alle-

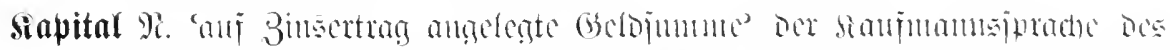

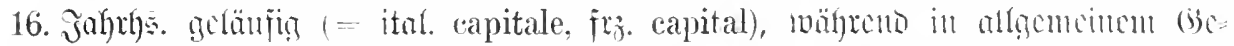

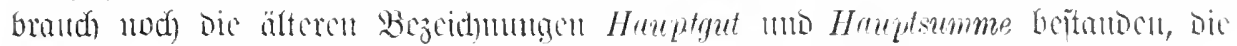

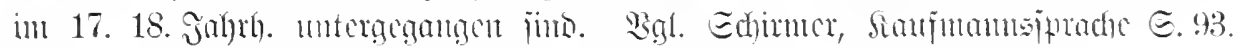

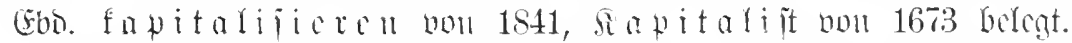

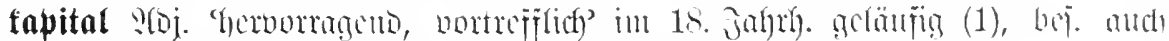

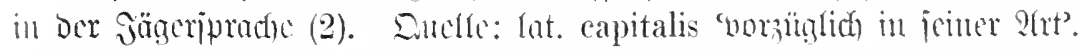

Belege: 1. Disiclamo 1770 Reij Des I 275 dab in der That der Untersehied Briejters abulfauntis $(29,247)$ Der sehr gering und zum wenigsten nicht capital sey. verehrliche Priester der Isis hat, vielleicht ohne es selbst zn wissen, einen kilpitalen Eiufall gehabt. (jovethe 1829 an Better V 195 ( nung ron Rembrandt. Fontanc 1855 sitie I 39 ein kapitaler lierl.

2. Döber 1746 jügerpracticn I $17^{\text {t }}$ so es ein alter Hirsch ist, [wird ar] ein recht guter, oder starcker Hirsch orler anch ein capitalguter Hirsch genemlet - $18^{b}$ ein

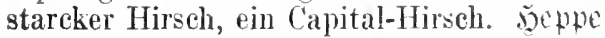
1751 Rehroring こ. 356 zu dem hiesse es auf gut weidmännisch: ein hallpt- oder capitalguter Hirseh, und nicht ein recht braver, grosser Hirsch. 1790 Eriginte Badfer II 233 So'n kapitalen Vierzehnender!

3. Geut beraltet cabital chöchit gerähr = lict), folgenjd)mer' $=$ lat. capitalis (inimicus, hostis). Belege: Reibuiz 1670 Eecuritus pubr. (I 228) nachdem aber jetzo die beiden nordischen Reiche in capitaler Feindschaft begriffen - 1671 Ectrifter

4. Fint bie jurift. Bed. 'todesumbig' i.

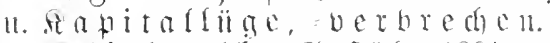

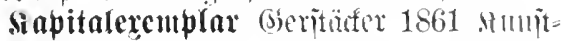
reiter 厄.208

siapitalliige bọl. lat. capitalis fraus (,propter quod capite puniendus est"). bugt. gatitaloerbreden. Beleg: Cods mam 1752 Eelbithioglanhie ङ.210.

Sapitalipañ ladi lat. joeus: eapitalis. Belege: 1790 Erigincs Baftel II 121. 170. Injl 1786 Sort situminberg I 97 Kapitalnärrin.

Sinpitalverbredjen nad lat. capitale

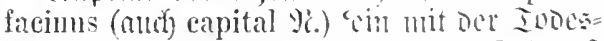

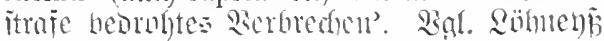

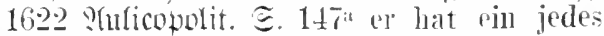
crimes fuir capital wehalten. Böcfler 1665 Ëfoĺa milit. こ. 325 Verbrechungen so nicht Capital seyen. Gonethe 1796 Qehrjahre (XX 70) auf einem capitalen Verbrechen

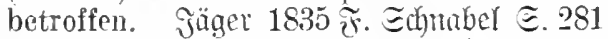

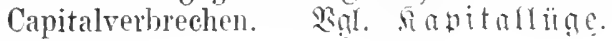




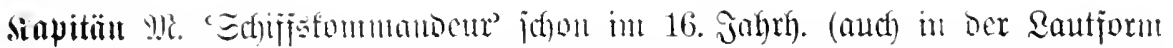

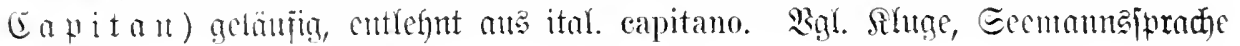
‡. 4.2.).

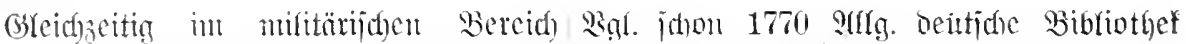

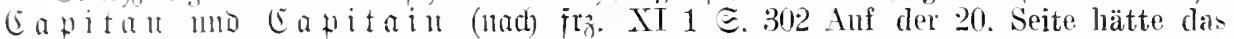

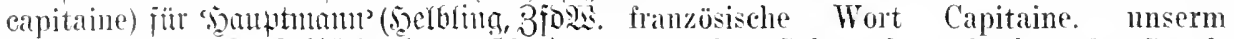

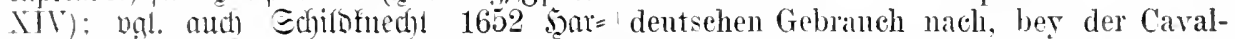
monia II 49 ein Capitain. so unter dem lerie durch Rittmeister, und bey der InRegiment eine Compagnie führet. Tameben fanterie dureh Hamptmam übersetzet idfon bänjig Hauptmam, baś in 19. כahrh. werden sollen.

Das jrembmort enbgintig berorängt hat.

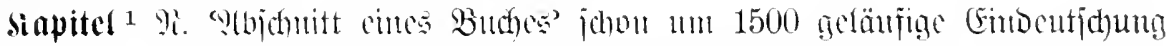

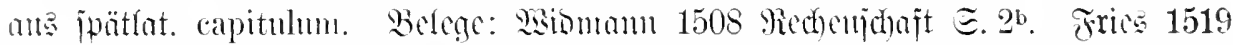

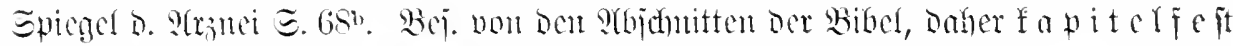

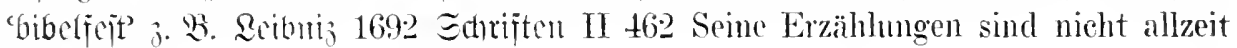
rapitelfeste.

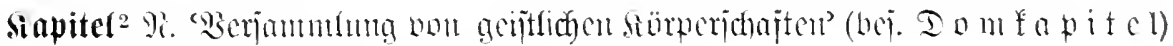
jofou mbo. capitel am mlat. capitulnu!.

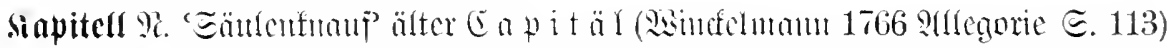

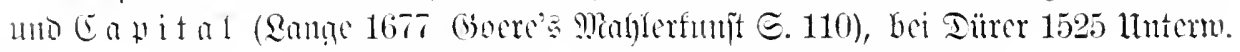

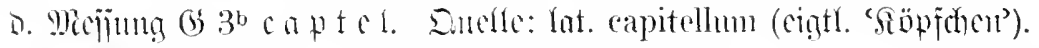

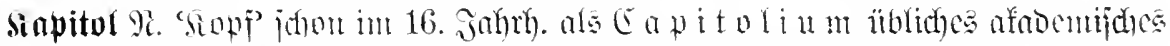

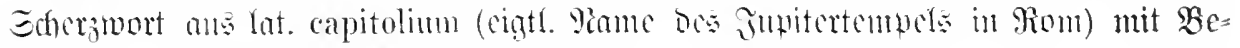
ziebung ani lat. caput 'suri'.

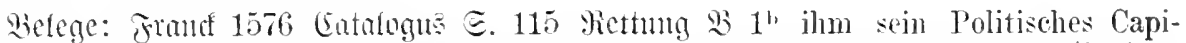
Fs bant ain jeder ain besumder Capell in tolium reehtsehaffen gesalbet. Y(brab)an sein wahnsinnigs Capitolimm oder Narren- a E. Clarm 1703 Tarrenteit E. 28 des

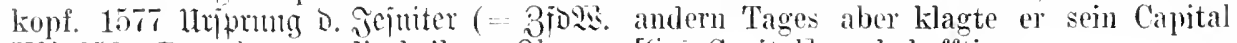
VIl 259) Drumb nem dis heilsam Oleum, [[ics Capitol] noch hefftiger.

Schmint ju rmbs Capitolinm. Sitjt 1642

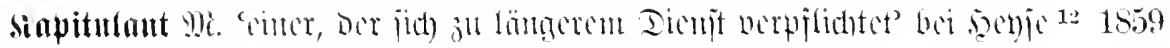

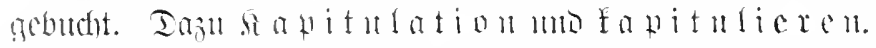

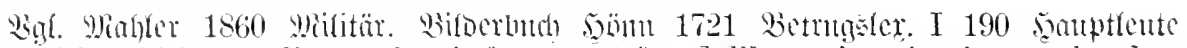
E. 90 ich erhielt von diesem len Aultrag, betrïgen] Wem sie mit einem oder dem mich anf die Kommantanter zu begeben. andem von ihrer Compagnie auf ein, zwey un dort zul ..kapitulieren". I'nter Kapi- oder drey Jahre capituliren, und da diese tnlation rersteht man aber in fricllichen verflossen, solchen mnter dem erdiehteten militärischen Leben die schriftliche Ver- Vorwand, es wäre ihnen das Lente-Abpflichtıng, rin Jihr freiwillig länger dienen ancken höherer Orten rerboten worden, zn wollen. als es das Gesetz eigentlich ver- entweder gar nicht. oder wenigstens nicht langt. St a itulicreu bedentet nber ehender. bis ein gutes Stüek Geld vor cig11. 'verhantolt, Sebingungen foftjctsen' dem Absehiel ihnen gegeben, dimittiren.

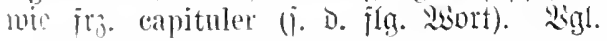

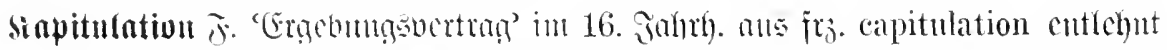

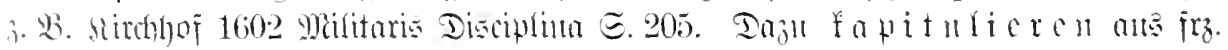

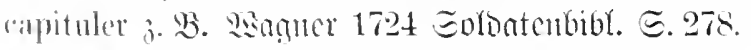

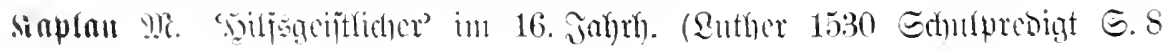




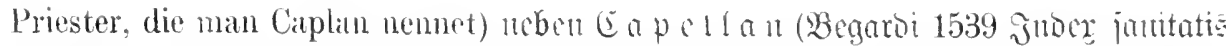

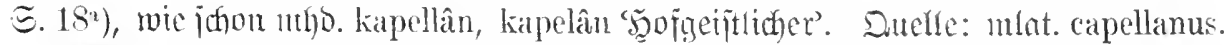

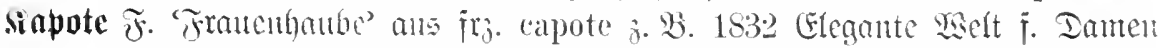

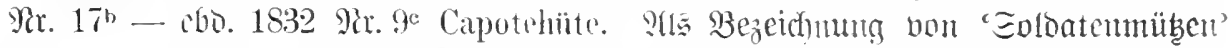

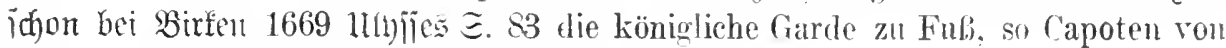
gelbem Tuch mit des Königs Wappen anhatten.

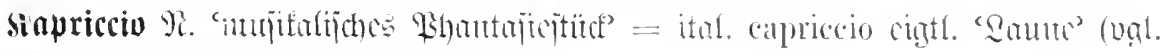
D. Fig. wast), gebucht bei Iridfter 1742 .

Edjon bei Prütorius 1619 Enntugma lang immoriret. sondern bald in rine andere mulicum III 21 Capriceio seu Phantasia fugan wie es jhme in Sinn kömpt, einfället subitanea: Wenn einer nach seinem eigenen - Tne kan diner in solehen Fantasien vnd plesier vad gefallen eine Fugam zutrae- Capriceien seint Kunst vnd artificiun tiren vor sich nimpt, darimen aber nicht eben so wol sehen lassen.

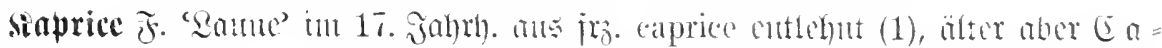

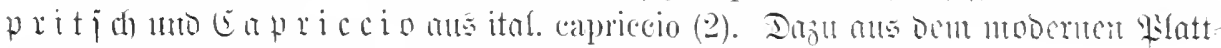

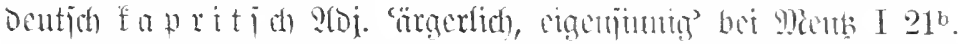

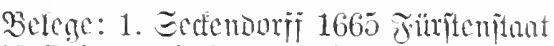
II 62 Drittens befördern das eaprice und den rigenen Sim der Herren aneh nicht wenig solche Diener. Reibnis 1670 secu= ritns mubl. (I 255) ob sie sich ihrer Caprice oder eingebildeten Interesse aufopfern wollen. Biegler 1689 Banije Sorr. a $6^{2}$ ein nützlicher buch nach seiner Caprice zu ergreiffen. Rucac 1711 belifon こ. 9 weib nieht anb was vor einer canrice ihrer Kinder. Edröber 1721 Fैiritl. Edhats. tulumer $\Xi .79$ welche caprice der bedienten die Fürsten often als theuer bezahlet haben.

2. Rrütoria 1619 Enntaunu III $13 t$ ob zwar solches ordentliche gewisse Regeln seyn, so mïssen sie doch gleichwol naeh eines jeden Componisten humor rnd Capriceio (Gehim vund Einfällen) allerley exceptiones leiden. Eelhomter 1699 Inbo I 610 womit er, seiner Capritschen naeh. bald dib, bald wieder ein anders Kleid selhst zuschneiden mas. faprizicren 3tw. 1. Geut meijt reflerio “eigenjumig ar etmas bejtehen' is. 边. 1790 Der Beobachter $\Xi .467$ Sie hat sich num eben auch darauf kaprizirt. Echüctinta 1859 Uränfumgen I 91 Er wirt damn sarade sich daranf eapricir'n.

2. 'ans Rrme füntfid surediturden,

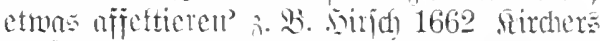
将üugia ङ.132 kommt hierzu das ungereinte caprizieren der Stimmen, da mehr. Gelächter als affectus bewogen werd(n. nach dem sprüchwort: Itali caprizant. Sigl anch Rebentuator 1680 Ienjels Qift IJ 38 ulab sieh offt gelehrte rnd geistliche Uänner in de: Phantasey incapricirt haben.

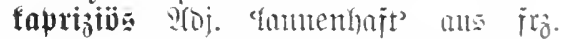
capricieux: Sieleac: Ihomajus 1688 9go= matsquprianche I 12 Dieweil auch instemein die halbgelehrten Leute caprieieux sind. Intbel 1689 lluterreoumgen $\Xi .1249$ capri-

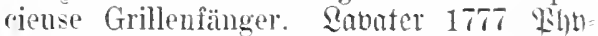
jiognum. Jragmente IIT 70 Ein sehr kapriziöser Hengst.

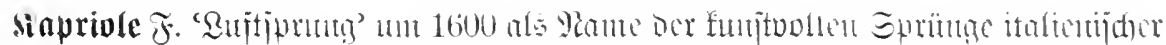

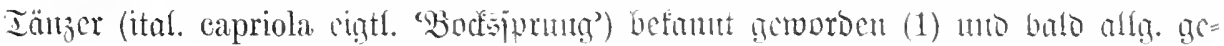

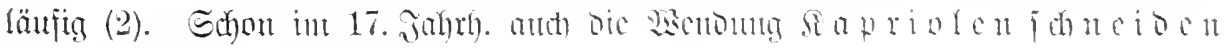
'Sprünge, Faren machen' (3).

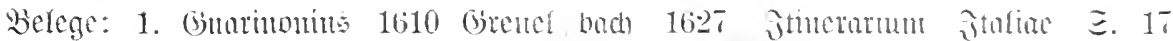
હ.1190 in weleher Vhung die Welschen sechzehn Mattacini. welche die beste Tantzer anBbündig. wie aneh in dem Dantzmeister waren. erzcigten sich mit andern, so man den Crentzsprung nennet, sehr schönem Dantz rnd vber dir massen allda man die FuB in Lüfften ein, zwey, zierliehe Ballerinisehe capriole.

drey mal rerweehslet. rnd die Gabriollen 2. Subertimn 1599 Gutuarn's Gents= bey jhnen genemet werden. Furtten= iffreiben III 39. wann ein Edelmann mit 
einer gramitet anfängt zucrzehten vind sich Füssen dergestalten, als wolt er vor Freuden zu rühmen, wie er so meisterlich die Vögel etliche nasse Capriol schneiden.

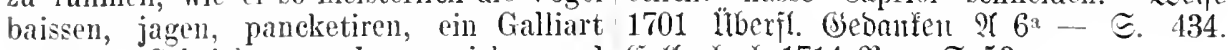
tantzen, Cabriolen machen, spielen vnd Ealfenthad) 1714 Puer Є. 53.

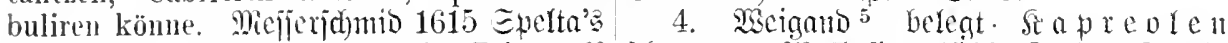

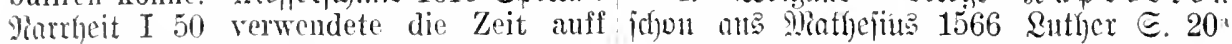
Springung de Capriolen. 2ugehts $\mathfrak{v}$. cin bletlein von Luther geschrieben, gebe Emmaran 1621 छntudhbuch こ. 455 er jhm meln bericht, als der gantze Thomas lantzt vond gangelt gar wol, vmel macht mit allen seinen Capreolen vnd Sophisten. gar hohen Capriol.

3. Edrilotitedit 165: Dommonia II 43

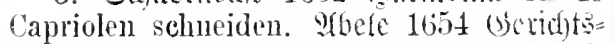
bälloel I 76 den Capriolschmeider'n, da doch jene den Galliart Winter und Sommer tantzen. Echuth 1659 Qncimm $2(3: 1670$ Edfanbühne 0 . engl. Combobinnten I 210. Srïmer 1681 Eeeheloen $\Xi .369$ etliche Capriolen an Galgen zu schneiten. $9(6 r a=$ ham 1688 Juba: I 15 hupffte vor seinen

fapriziercu, fapriziï i. unter si a r i c c.

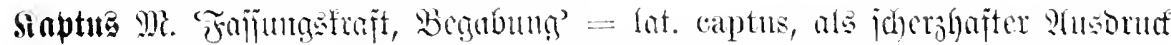

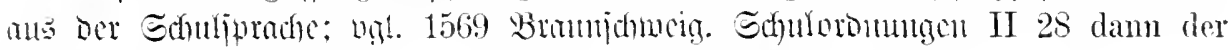
Knaben verstand, captus und erndition anch antisteigt. Sgl. fa d i c ren.

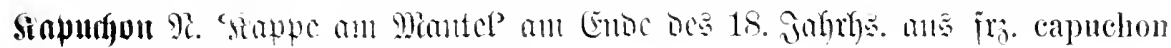
entlehnt nolo meipt kapsehon gejprockent.

Belege: Signter 1776 Simbermbotorin von Kappen, welche man Capuchons ङ. 56 Den Kapuchon hinauf. Øof 1787 nennt. Forjter 1791 Gnjid)ten (III 245)

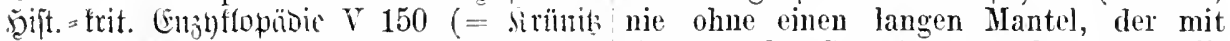
92, 508) Man verbesserte seit einiger Zeit einem großen Capüchon versehen ist. iguff=

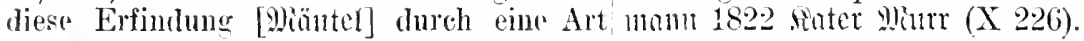

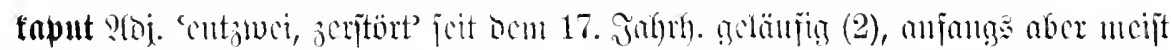

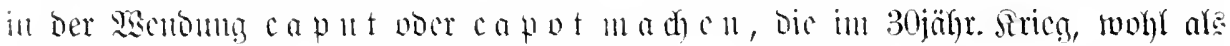

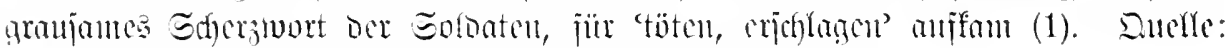
irz. faire capot 'eimen in Epich vorffänoị berlieren madhen'.

Beleye: 1. Chennids 1648 Echned. Strieg machte oder gefangen nahm - 1044 und I 462: Worüher eine compagnie Crabaten machte manchen Türcken caput. Sieuter von denselben attrapiret, vnd meist capot 1696 Edhelmuffift) $\Xi$. 35 welcher so viet gemachet worden (Eseigano ${ }^{5}$ ). Edfiro= Seclen caput gemacht häte.

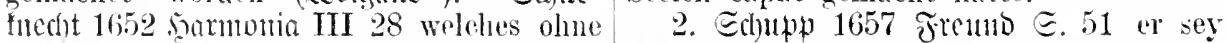
das alle's derm Feindr, wemn ich Caput ge- gantz capot gemacht, es sey mit ihm uni macht würle. in seine Klawon kame. Frei seines Viters Hauß gantz amb. 1666

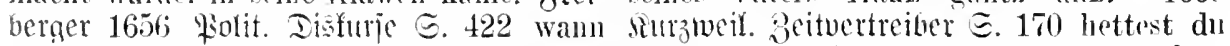
der Frind mich Capott gemacht oder ge- das Blech nicht in die Hosen genehet. fangen vol hoch rantzonieret hat. Wiitter so wäre ietzt mein Heriz capnt gegangen. nadit 1667 Foritica $58^{a}$ Die Bauren im nud burt gewesen. 1737 jüb. Sarbobes santzen Königreich haben rebelliret und 5.26 allein Ehr und Reputation veralle Antleute caput gemacht. Grimmels= loren ist alles caput. Siortum 1799 iob= hanifu 16f;: Eimnlic. E. 340 sonst möchte fiabe E. 49 Ingleichen sind meine Pandich dieser Unmencel erst caput machen. toffeh und Hut, Auch andere KleidungsFrancisci 1669 Irancriant II 510 daB man stücke kapnt.

sio schier allesimtlich entweder caput

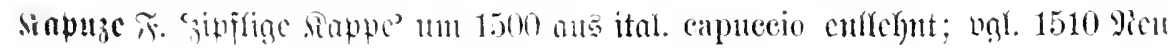




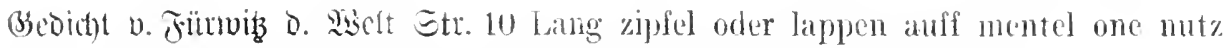
hangen an welschen kappen, Das nennen wir Kaputz (nach silnge ${ }^{7}$ ).

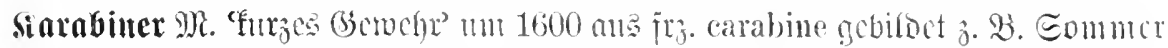

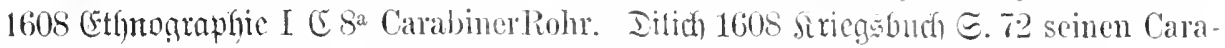

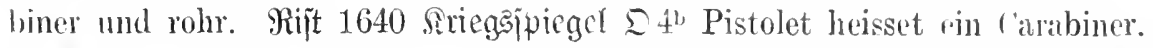

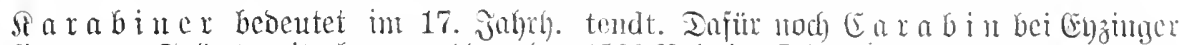

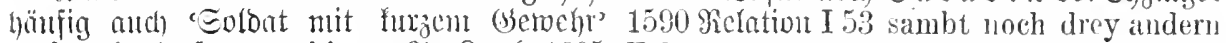

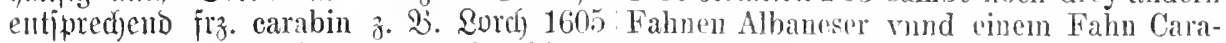

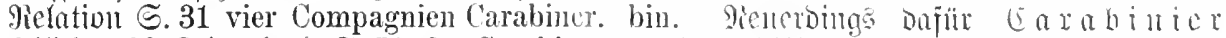

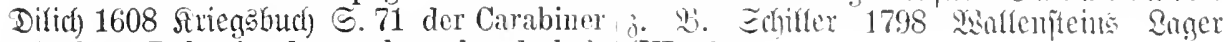
sein lang Rohr in der rechten handt hal- (VI 23).

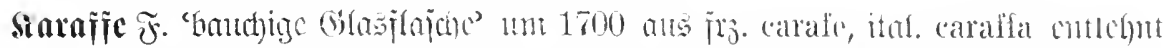

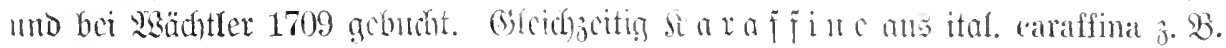

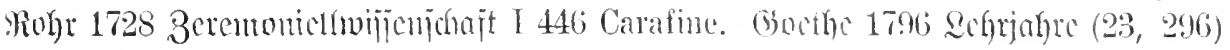
Caravine.

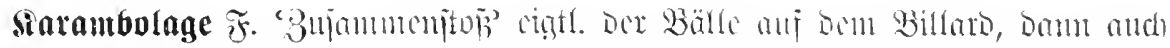

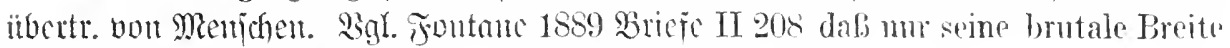
die Carambolage reranlaßt hat. Ducle: Fri. carambolage.

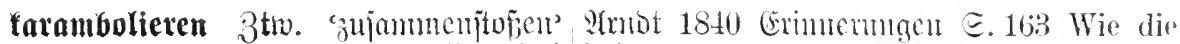
aus jrz. caramboler. Belege: Pïffler 1835 beiden lebendigsten Menschn'n sich mit Semilajpo I 100 der kleine Traineur, mit einander karambolierten - 1858 sism= dem ich unwillkürlich carambolirt hatte. Derungen $\Xi .58$.

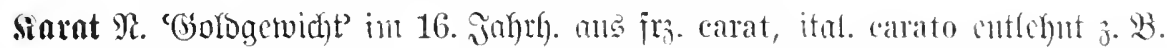

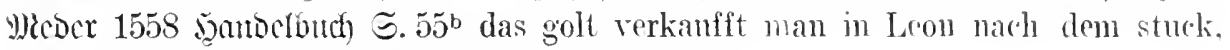
vnd ist die wehrschafft Karat $2: 31 / 2$, anf das fein.

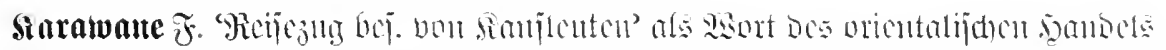

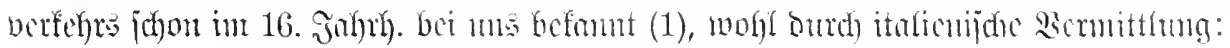

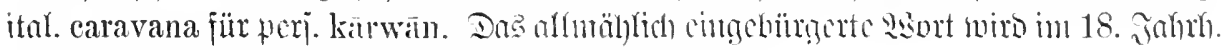

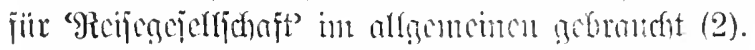

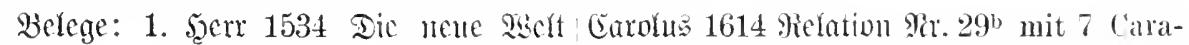
S. $6^{2}$ Er bestellet etlich der seinell, die vanen oder Hauffen Kriegsvolek [Des

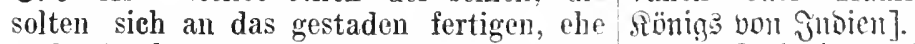

vnd die kemen, die die Carauan oder 2. 3achariä 1763 serchuia (I 409) Camel brechten. Meder 1558 Scandelbucl) seltene Getränke, welche die Caravanen ङ. $1^{\text {a }}$ da ist zu ernemen, ob die Carouany der Harzmädchen auf ihrem Rücken hergen Damascon, Baruti oder Alexandria anftragen. Gocofingf 1777 an Bïrger (If ankommen. Duas 1598 (Enduitioion cus: 102) Tn einer förmlichen Karavane ziehen nugraphy. S. 237 von hunderten, so etwan wir denn fürder. (3)oethe 1795 lliterfal= mit der Carouana dahin gefurt werden. tungen (XVIII 96) als Fühnerin ciner

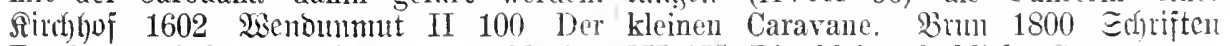
Türcken wahlfart gen Mecea und Hedina II 375 Die kleine fröhliche Caravane zn - welchs sie eine caravana nennen. Esel und zu Fub.

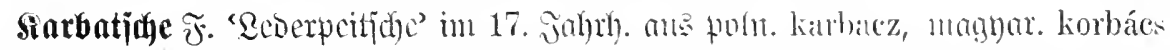

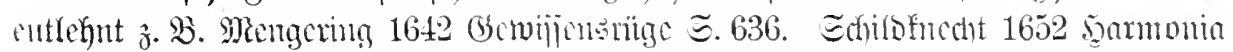

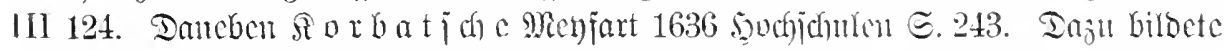

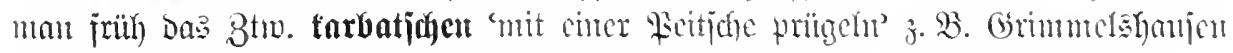

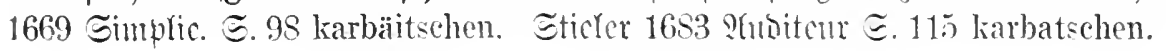




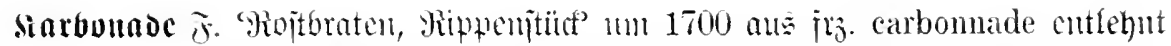

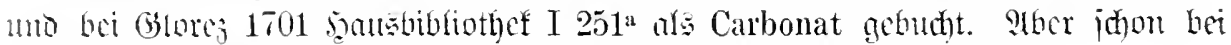

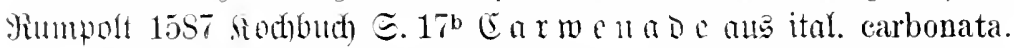

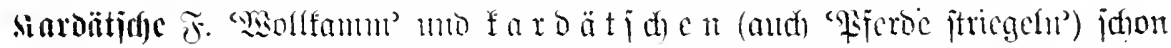

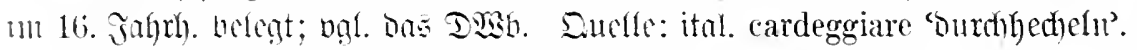

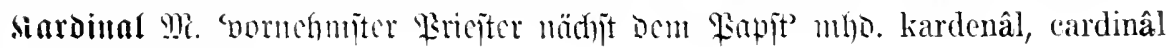
ans mlat. cardinalis.

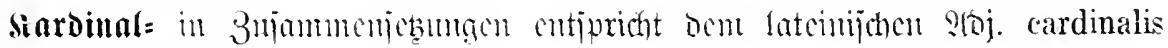

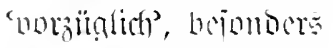

Siadimaljefler (bolts 1869 seltthg= Ieufels [IV 73]) aus lat. virtus cardinalis, heit I 50 . iduon bei bent firubenlebrer ambrojiue

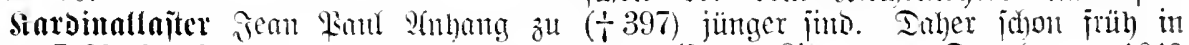
Iitan I $80,31,80$.

Siardinalucruen Echubart 1774 Ieutiche (Ehronif $\Xi .376$. theologijuch Siteratur: Dammanter 1642 der Forcht Gottes, als welche die dritte

Siavoinaloberit in 16. jonkb. anch boj Cardinal- und Haupttugend ist im ersten

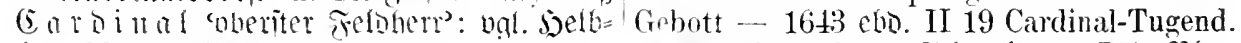
ling Bjog. XIV 36 .

Sardinaltugend (Näller 1787 Emme= jicn II 210. rich III 129. jean \$aul 1789 Propiere Des

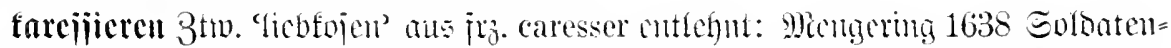

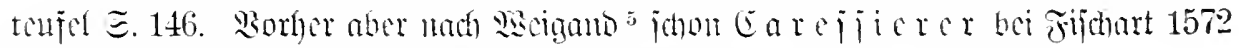
In ruftif ङ. 12 Spanische Caressierer, Liebthurnierer, Händleintrucker.

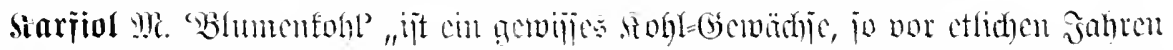

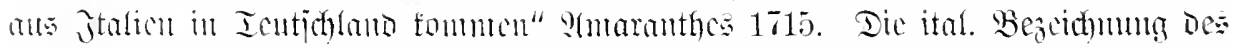

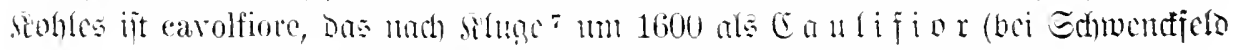

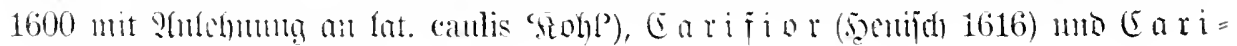
i i v l cimgeocutidht muroc.

Belege: Rannitgartner 1587 Brieje der kleine Pflantzelkhöl, so man den Cari-

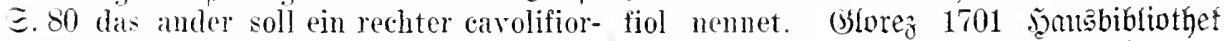
samen sein. Gutarinonius 1610 Grentel Cont. II 143: Blumenkohl oder Carfiol.

こ. 5661 der Köpffelköl. der Kresteckhöl,

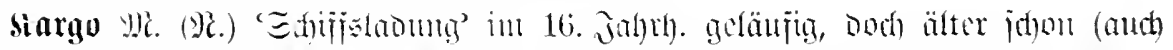

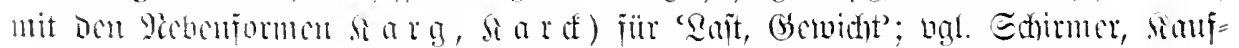

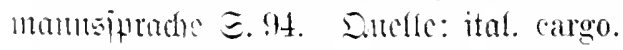

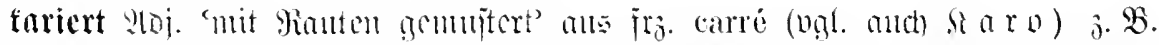

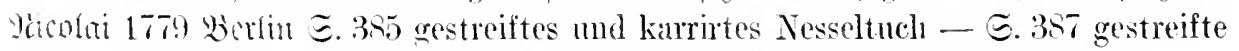

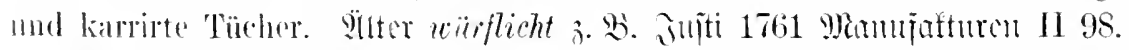

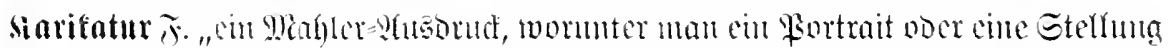

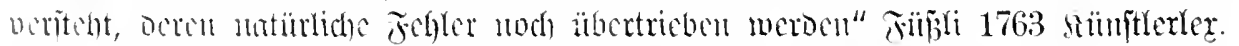

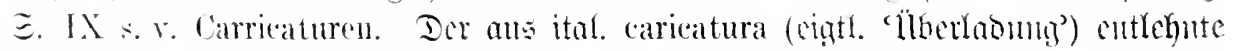

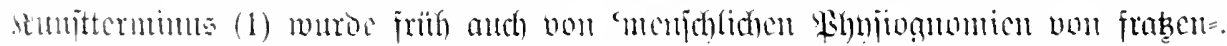

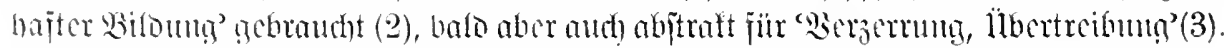

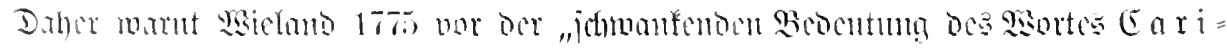
cot $u x "$. 
Belege: 1. Finjtit 17ti3s simiterler. E. $60^{\mathrm{b}}$ lächerliche Figuren, woldw" dis Italiäner Carricature nennen. 1768 . Dall. Bibfiothel I 1 5. 84 lustige Uebertreibung, in der Mahlerey Carricatur. Erhubart 1774 Bar: repungen über Materei ङ. 21 ('arrieaturen sind auf deutsch: Frazen oder Verzerxungen, die der Mahler übertrieben rolstellt. 5acroer 1778 gínitif (VIII 39) Seine [5ogurtho] Formen sind meistens häßliche Carrikatnr. Wrobenholz 1787 Eng= Iants III 298 Viele dieser Lärden sind blos politischen Kuplerstichen und Karrikaturen gewidmet.

2. Jerber 1766 merfe I 49 Das Kind. deBen Mine des Gesichts dureh ein langwieriges und bittres Schreien sich verzerrt und endlich diese Carikatur-Figu in seine

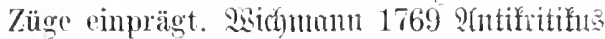
II 472 ein Carricatur-Gesieht. Eaboter 1775 Rigniognom. Frogmente I 69 rine traurige Menge häblieher verzogener Gesiciter - Carikaturen aller Arten treff ich an. Miillfer 1778 Fomits 2 eben $\Xi .22$ die tagtäglich so lustig Affenspiel mir besorgen und Caricaturen schneiden.

3. . Damant1 1762 stiensönge. (IT 165) nach Maßgebung eines namhaften Rleinmeisters [D. i. Fenitmaitre], der durch seine Carricatur von der schwarzen Kunst zu herrschen und der Heldengabe zu dienen den blödsimigen l'öbcl geäfft. Lejïing 1767 Dramaturgie (IX 275) auBer dab das erste [こtüç] olnugefähr die Limrikatur von dem andern ist $-1768 \mathrm{cbn}$. $\left(X_{1} 156\right)$ Wenn die Einbildungskraft sich keiner wirklichen fregenstände del Nachahmung mehr erimmen kinn, so kompunirt sie der'm selbst. whlches dem froylich meisten: Carricaturen werdan. Miojer 1775 Phanto jicu I 126 Seine Beschreibung roul ihrem Auszuge ist vollends eine auberondentliche Karikatur. Nisichmo 1775 5. Diertur IV 62 Hïten wir uns, von piner sehwankenden Bedentung des Wortes ririeatur nicht verführt zur werclens. Es pllegt diesem armen Wort pbenso zu troehen. wir dem Wort Jdeal, das spit rinigen Jahren so sehr Hode worden ist. Schimären werdens häufig mit Idealen und raricaturen verweehselt.

Sarifatmiit 将. m5 itnl. caricaturista

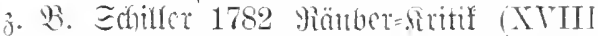
63) Die Inxurieremete Phantasie des Karrikaturisten.

farifieren 3tw. crịt in 19. Juhrih. als itnl, caricare entfehnt. Belege: Büne 1829 Iramaturg. Blïtter (II 336) wie einer, der sich über Schwärmer lustig macht, ey karikiert ihre Sprache. Devie 1837 Enton (TY 554) diese feiste karikierte Figur.

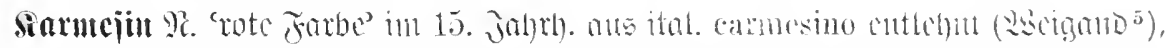

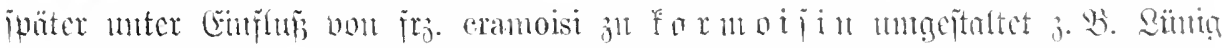

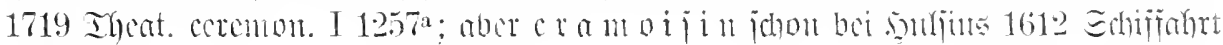
III 78 .

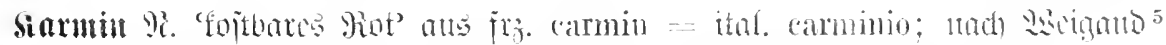

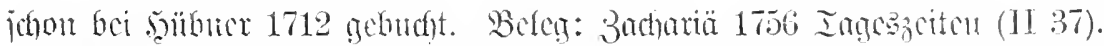

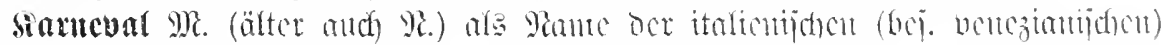

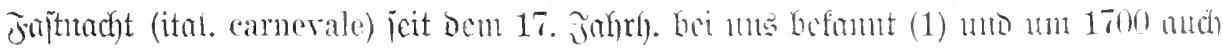

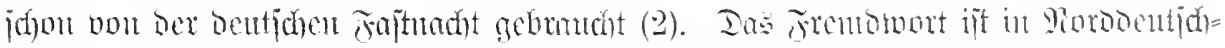

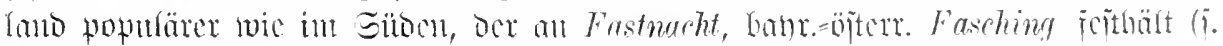
1L 1749).

Belege: 1. Sirfen 1669 Brandentura. urrijes 厄. 130 Weil man folgenden Tags [in Rom] Carneval oder Fastnacht zu halten anfienge - $~ ๔ .132$ alda Sie den BeschluB des Carnevale angesehen. Grim= melshaulen 1672 Simplic. (Fort). Neller I 272) wie damn alljährlieh auf die Carnewal oder Fastnacht, nach Venedig, ein Hauffen Volkes reiset. Gröben 1694 Reijefrefdrt. §. 396 in Willens auf den Carneval naeher Venedig zu gehen.

2. 1699 Etantajpicad II ss Siehet man also jetzo zu Warsehau lauter Vergnügung und Carnevals-Lustbarkeit. isreorid) I. 1703 Bricje E. 32 Nachdehm muln mehro dab carnouyal zum Ende. Cartenbach 1715 Enaji vero $\Xi .56$ pin christliches Täntzlein ist ellaubt, wam die Jungfem Carneral lalten. Rohr 1728 Beremonielimilienichait I. 509 Diese Arten der Lustbankeiten. welehe insgemein das Carmeral genennt werden. leiten ihren Ursprung aus Italien. 


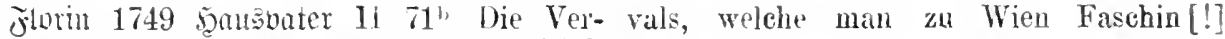
sammlung aller Masqueraden und Hof- nennt.

Plaisirs sind die Fabnachten und Carne-

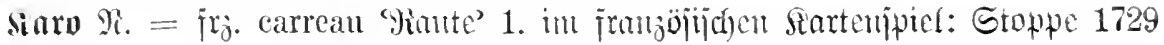
(3́cbidfte II 45 seh' ins Buch hinein, Wo 'Treffle, Caro, Piqu' und Cour die besten Blätter seyn. 2. in Stoffmujtern: 1831 Elç. Selt F. Seren Mr. 20 ein nener Mantelzeng, der arenturine carreaux auf hellblauem Grunde hat. Molll älter, vgl. fariext.

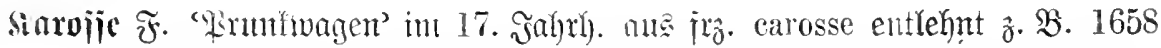

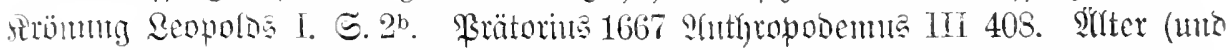

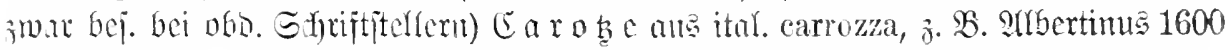

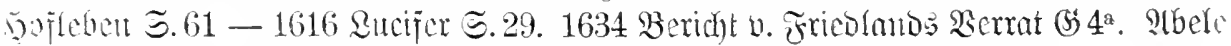

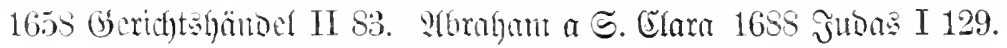

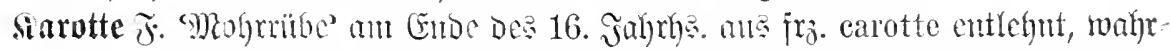

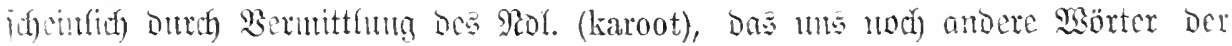

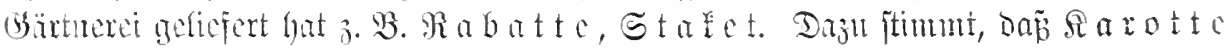

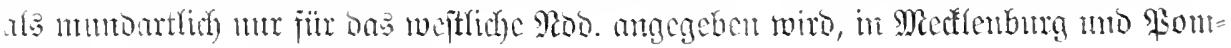
meru Dagegen unbefament ijt.

Belcge: Ecbiz 1580 Fersbnu E. 295 Rood peen and Caroten. Hochdeutsch die wilde vnd die Garten Pastenach, rote Rüben, rot Pasteneg vnd Caroten welche man sonst Carottes zu nemmen 239: die roten Möhren oder Caroten.

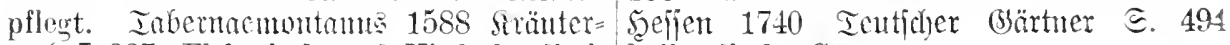
butch I 237. Flehmisch vnd Niederländisch holländische Carotten.

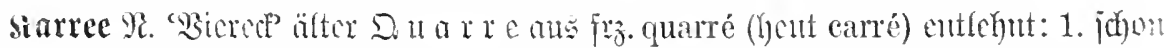

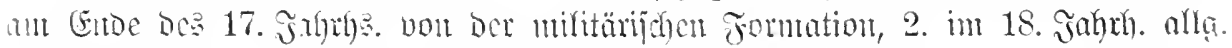

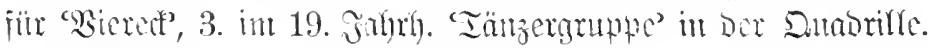

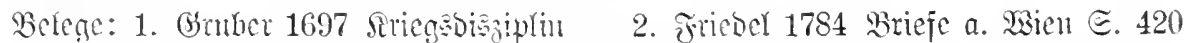
III 212 Wie eine Bataillon quarré eingeschlossen von einem Quarré von ohme Mannschafft an dem Boden zu for-Bäumen. Füufler 1831 Bricje IT 221 in miren. 1708 Seopold der Grof́ge I 54 ein einem Carré erbaut.

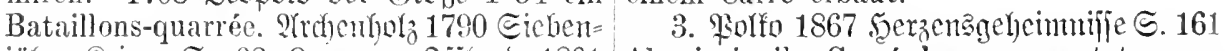
iäl). Srieg ङ. 92 Quarre. Sffloms 1801 Als sie in ihr Carré kamen, wartete man 5öhen (VII 121) ein Quarré von dreifacher bereits anf sie.

Iamnschaft.

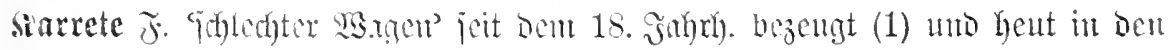

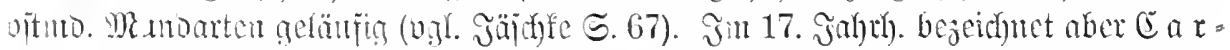

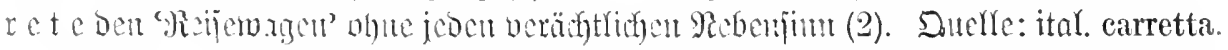

Belege: 1. Bahrot 1791 Lebengejchr. puocmus IIt 312 cine Car tte mit Pferden. III 371 Wenn man die deutschen Karreten sintefter 1696 Eoclmam ङ. 62 ein Kutseher besteigt, die auf den Poststationen den mit einer schönen saubern Karrete. Mohr Passagiren gegeben werden, da meint man 1728 Beremonieffuiffenjdjaft I 58 dab anf allen Schritten liegen zn bleiben. damahls gute Zeit in der Welt gewesen,

2. Friff 1667 De Shuguț $\subseteq$. 80 zwan- da die Gnädigen Herren Thro Gestrengten, zig mit 6 Pferdt bespanten zirlichsten die Careten Wägen, und die Maitressen

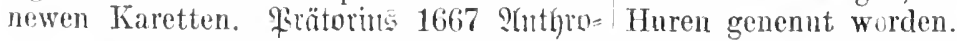

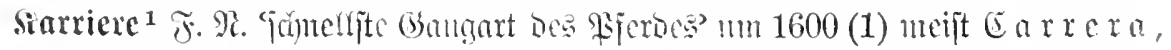

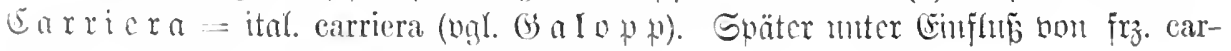

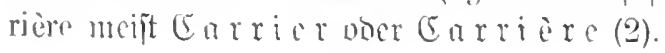




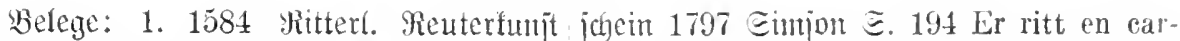
5. $35^{\text {b }}$ eine schnelle Carriera. Dilid) 1608 riere nach Jena. Znube 1837 Reijenobelten Siriegăbuch) ๔. 79 Im rennen, welenes anch VI 342 er flog im Karrière durch die Welt.

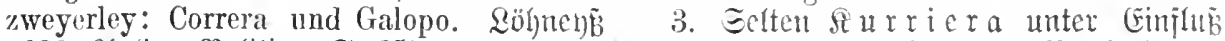

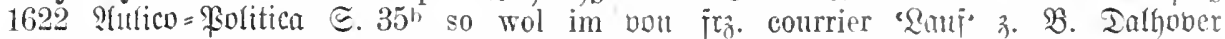
Gallopo als sonst in voller Carriera. Qiebe 1689 Gertenbectlein II 552b ein Pferdt

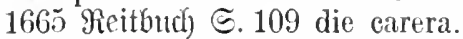

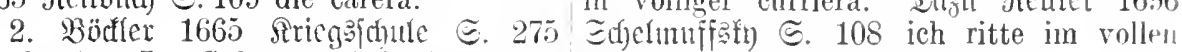
Im Carrier, Im Galopp. ITrchentholz 1790 C o $u$ r i er die Treppe hinunter. Siebenjî̆hr. Sirieg 厄.163 in Carriere. Bort=

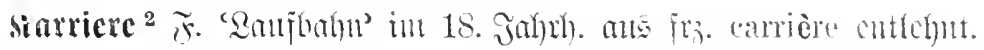

Belege: Sefing 1769 Siricje (XVII 309) Erhiller 1787 Brieje I 378 Der Ham der dab ich manchmal wünsche, die armselige Charłotte ist es, der die Carriere am Carriere der Alterthümer schon geendet Zweibrückischen Hofe machen wird. §ĩ i = zu haben - $1773 \mathrm{cbn}$. (XVIIT 79) ob Sie In 1784 Betbrechen (V 6) kannst eine

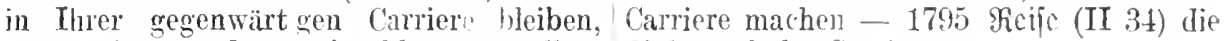
oder eine andere einsehlagen wollen. diplomatische Carriere.

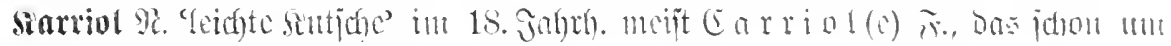
1700 ans jro. calriole suttehnt i it.

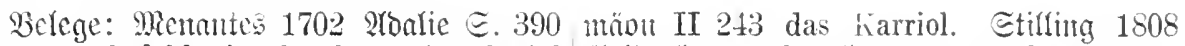
deswegen befahl sie also fort, eine Cariol, Beifterfunde $\subseteq .153$ ans der Cariole geanzuspannen. Şermes 1780 mantci) ,̆er= worfen.

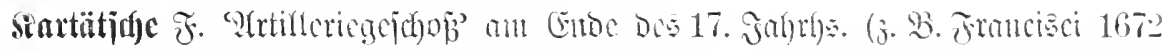

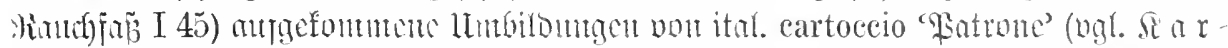

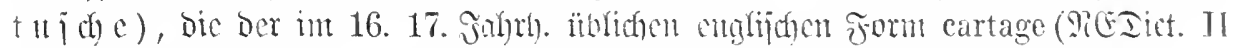

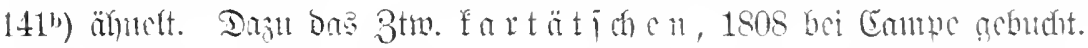

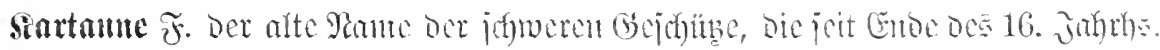

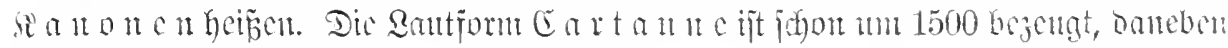

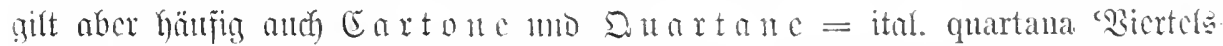

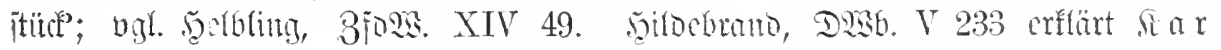

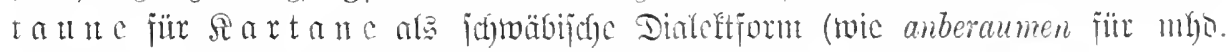

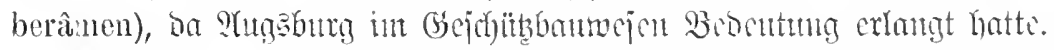

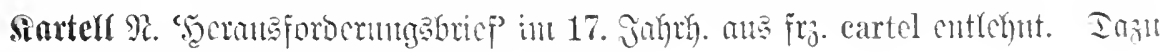

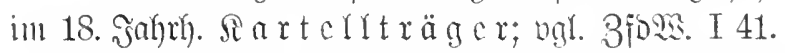

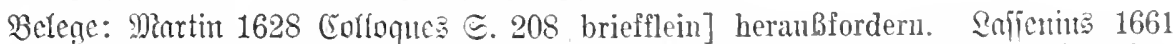
vn cartel de deffi: ein Carthel, ein AuB- Stocl. Iijgreben ๔. 125 Wann aber derforderungsbrieff. Mofderojch $16+2$ Gejichte gleichen Duelle geschehen, so pflegt ein I 488 sich als hirnwütende Leute einander Theil den andern mit Zuschickung eines mit Cartellen [1650: Cartels und Fehde-Cartels auszufordern.

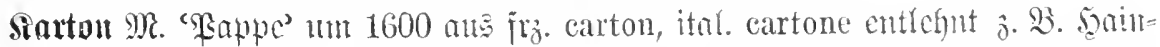
hofer 1610 Bricfe 5.20 perspectivische kuglen auß Cardon - S.22 ain außgeschnittne fruchtschüssel auf Cardon [genult] nit öhlfarben. Ecit bom 18. Jahrh. it jolgenoen bejouberen Bernenbutgen:

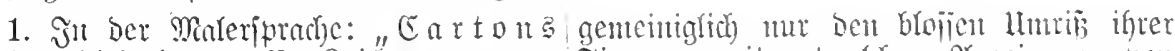

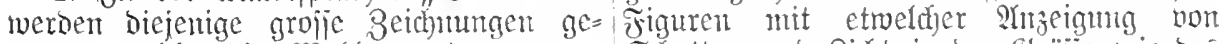

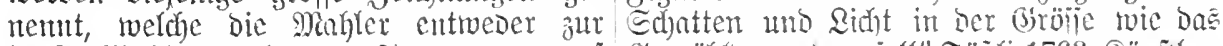

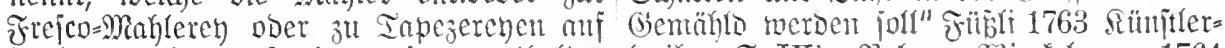

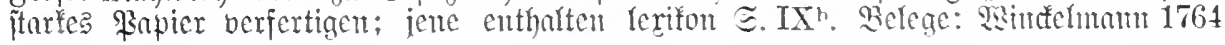




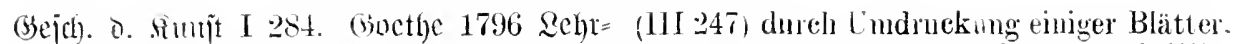

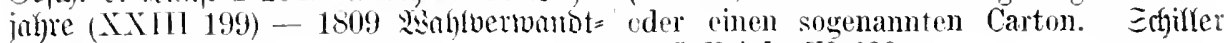
idhajteit $(X X 216)$.

2. 3it Der Druteriprache 'untgeducte Eeite, die ani den Reinoride gefleht miro'

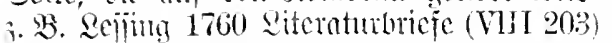
Einen Carton aber machen zu lassein, das wiirde ihn zil selir verrattien haben - 1772 , Brieje (XV11[ 21). Znugbein 1789 an Bitrger

1795 Briefe IV 329.

3. 'تdhachtel ans Bappe' o. B. Jijlano 1795 Reije (II 51) besteht nicht die ganze Aussteuer in Milchflor, Krepp und etlichen Kartons - 1796 ?(owotater (VIII 34).

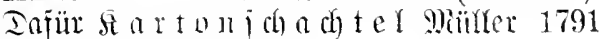

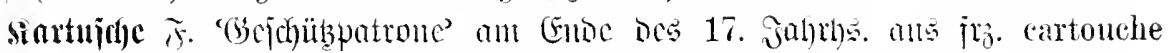

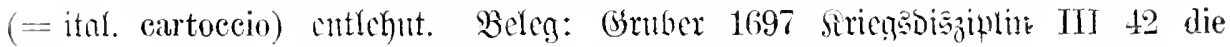
Patrone oder Cartonche (so man anch die Ladung nennen kan).

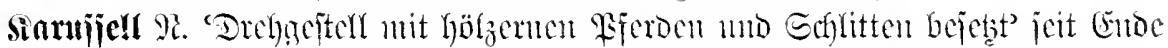
Des 18. Jahrhs. geläufị (1). Doof gelten Daneben viele volfatümliche Bencmuntgen (2),

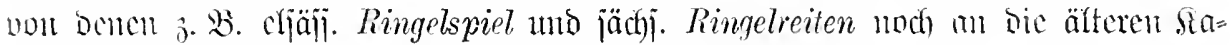

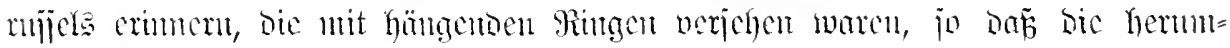

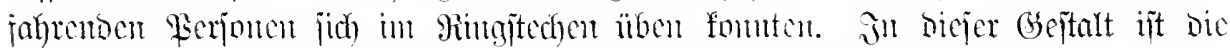

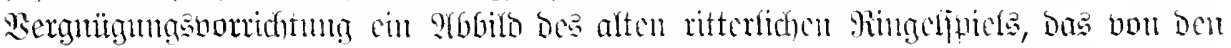

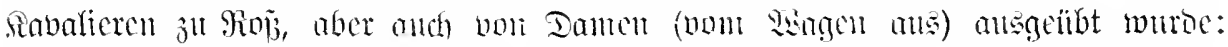

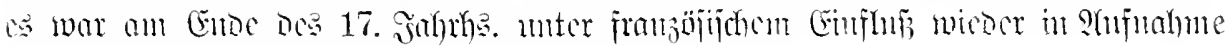

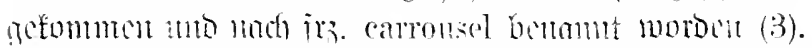

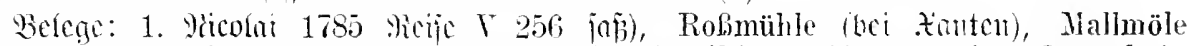

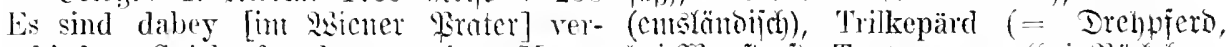
schiedene Spiele für don gemeinen Dam. bei SEmitori), Tanterwagen (bei Bücfeburg Unter andern sah jeh einmal ein bedecktes mo Minocin), Draimeulen (= Drehmïhle

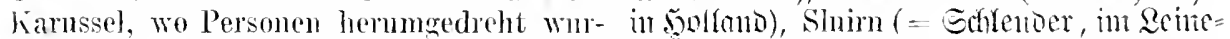

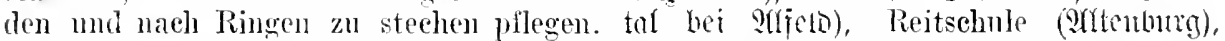
Hier wurden nicht. wie es sonst wohl ge- Ringelreiten (Brwicfoul), Drehbude (Ergge=

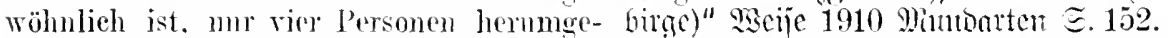

dreht, sondern wohl zwölf und mehrere. Aber die Hermmgedrehten liebten das Spiel mur als Bewegung, nicht als Karussel. nnd mütaten die Zeit viel besser; dem sie speiloten ihre gubachne Händel nul Kipfel im Herundrehen. sehr mubekümmert um Ringe und Stechen. Ecume 1813 Miein Qeben (I 56) Sehaukeln, Karousseldrohen und ähnliche gymnastische Uebungen sind die besten Vorbereitungen zu Scereisen. boine 1830 Stalicu (III 301) man läbt sich Karussell fahren oder olektrisieren. OSfas: brenner 1836 Serfin IV 29 Vergeb nieht die vergnichte stunden mit unser beiden Gelübden bejt Karobell. wo wir sehifften III sir uf de helzerne Ferde ritten in in den Rink staichen. Tieuerbing and Eisembahnkarnssels mo Marinekanssels

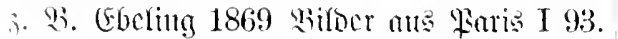

2. "Rösseritli (Elañ), Ringelspiel (EE

3. Ettuer 1697 (Sh)micus હ. 791 wio Imo Majest. . . e cin Carousel halten wolten. da demn sie beyde gemiß einen Ritt wïrden

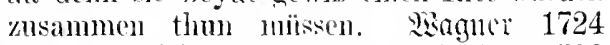
Eoroatcubirlioflyef 巨. 13. Roljr 1728 3 cremonicumijicuichnit I 235 Carrasellen - 1729 ch. II 769 Von Carousellen, RingRemmen und Rob-Balletten. Florin 1749 nomonoter II 68' Damm Carrousel hat ohmfehlbal seinen Namen ron Wagen, ob schon nicht bey einer jeden Carrousel Wagen gefïlnret werden und ist eine Terkleidung bey cincm Ring-Rennen genug ein Carrousel zol machen. 1769 Proteptent. Intuturittüten $\Xi .217$ Wenn man also freylich anf Tniversitaiten fechten und Caroussel reiten lemen kan. Mod bie Epricl= Yogen 1866 jul Yeil) mo (j́lied I 370 daß sie an Geburtstage des Kromprinzen cin Carussed im rostüme reiten wollen.

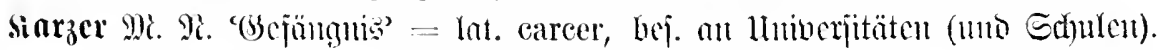

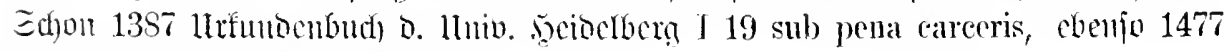
İ̈binger llrfimbenbud $\Xi .59$. 


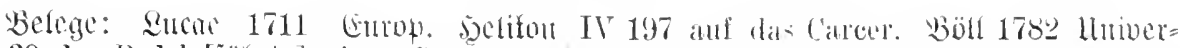
5. 39 der Pedel [fïhrte] cinen Studiosum jitätsugcien I 41 TTnter die Akademische ins Carcer. Stoppe 1728 Gebichte I 134 Stralen rechuetr man bisher dou Calrear.

Carcer-Loch. Wiefonetis 1776 Piajomement

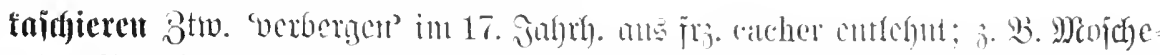
rojef $16 \pm 3$ Spradjoctocrfor $\Xi$. 32 und conjurire ihn, mir solches ja nicht zu cachiren.

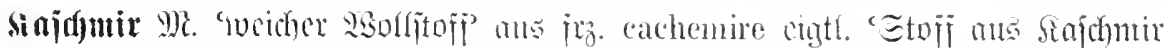

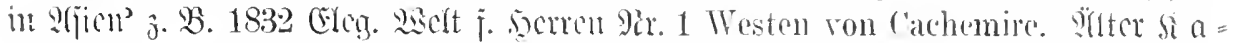

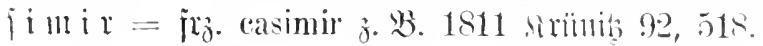

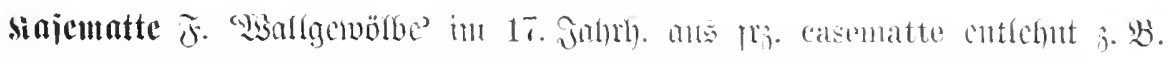
Jrentay 1631 ?ndjectum mifit. 5.2 Bollnerk ron mawern mit casematten.

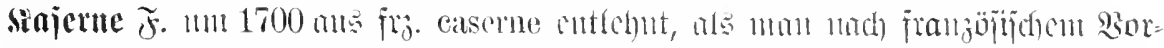

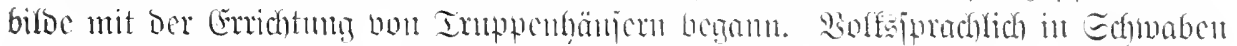

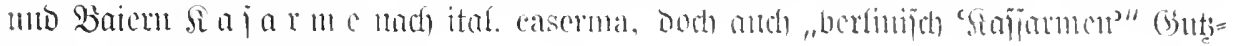
forw 1872 Sinabenjeit ( 123 ).

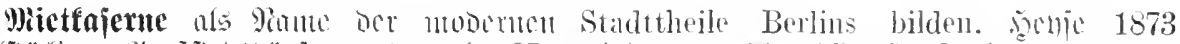

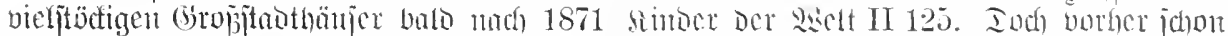

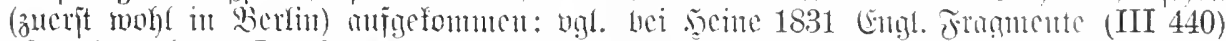
1872 Grenjboten I 1 E. 76 jene fürchter- zwei nuendlich lange kaserne llatige

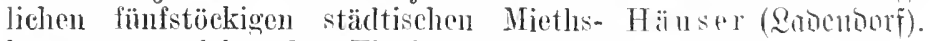

kasernen, welche den Fluch der neuen

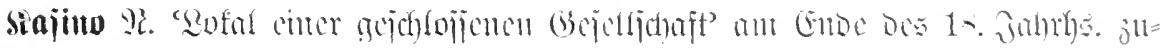

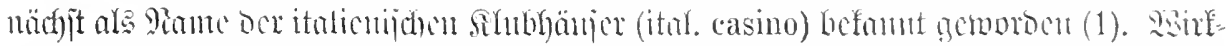

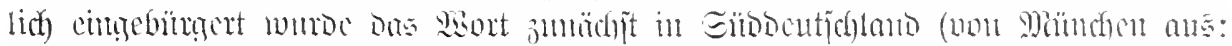

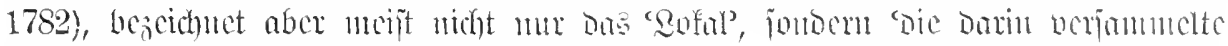

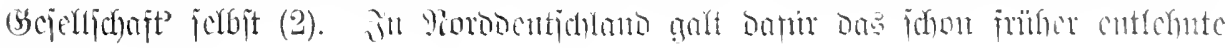
Si 111 b (i. i.).

Belege: 1. 1775 Ecuticher Micrfur II (welches ausländische Wort weit schöner

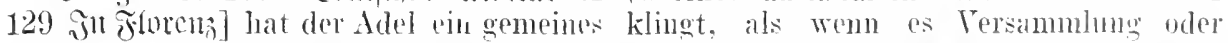
Spielhaus, welches Casino de Tobili ge- Gesellschaft hieb) anfängt, wiebt os aller

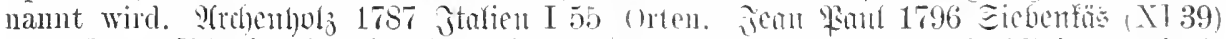

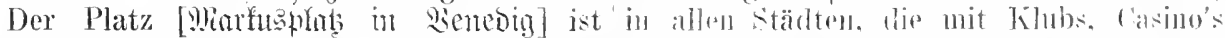
mit einem Portico umgeben, wo nichts als. Hamonien, Mnsen rerehen wänn. Burges=

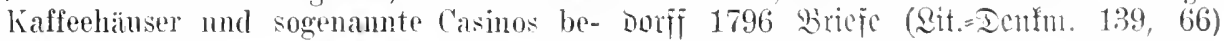
findlich sind.

nach mehrem Gesellschaften, anch nach

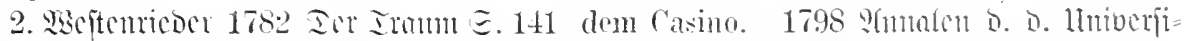
Solche Versammlungen, die man mun hier tüten E. 209 Casinos und Liebhaber-Konin Nünchen mnter dem Tamen Kassinn zerts. die im Winter gehalten werden.

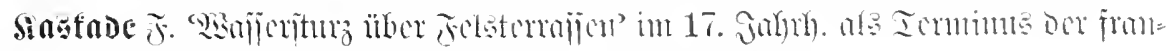

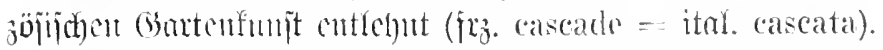

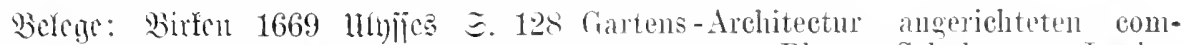
Dieser Garten ist sehr angenehn erbant, portamenten, Blmmen-Schulen . . . Lauber und hat unterschiedliche Caseaden oder Hütten, Grotten, Cascaden. Frienrific I.

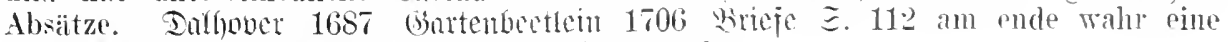
I b 3' Zier- und W'under-Gärten, mit cascafle.

jhres nach wol in Acht genommener

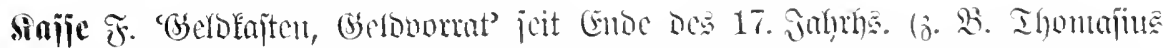

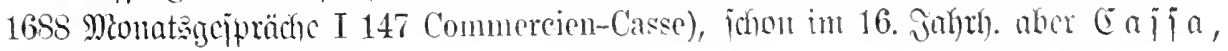




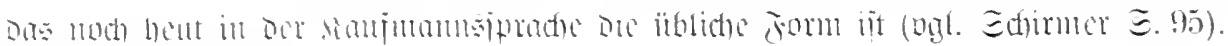
Endite: itat. cassal.

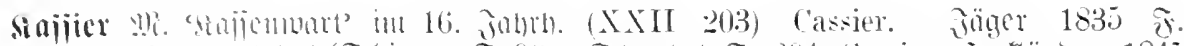

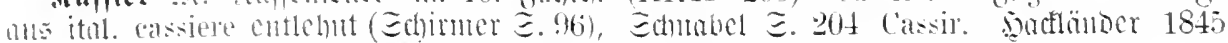

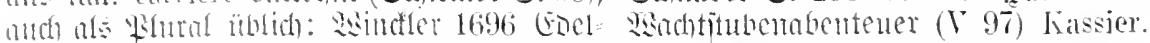

mun! $\Xi$. Sol die Buchbalter und Cassier. Eilbanter 1699 Inba I 350 Man nemnt diese Lent Cassirr. Iic hent n̈bliticre

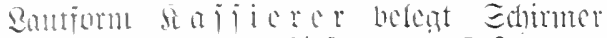

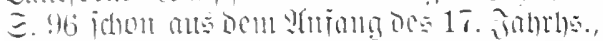

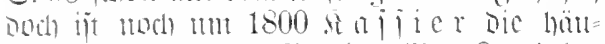

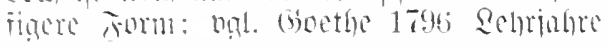

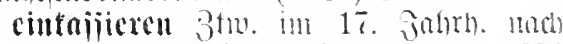
itul. incassire gebilnet: Belege vou 1624

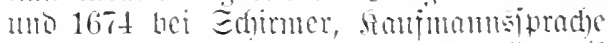
E. 51. vare bei Etcinbera 1541 Engronit ¿. 138 anff Trinitatis worl es, wiederumi incassiret. wardt angizeeget, das main solliclis gedelt wider den Turckens samlen wolde.

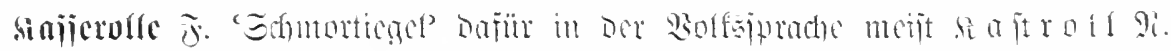

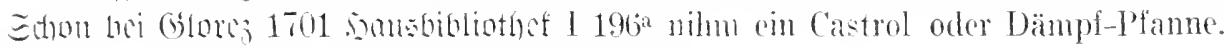
Enefre: fris. casserole, Damben bialeft. castrole.

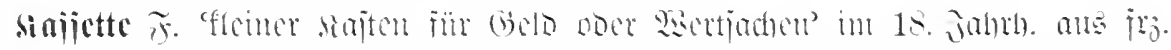

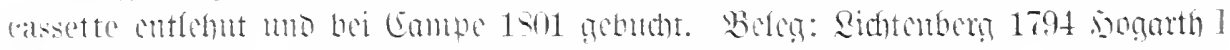
?r das Stroh. worin die Jurrelen in Nalter-Casettchen gepackt sind.

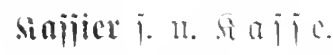

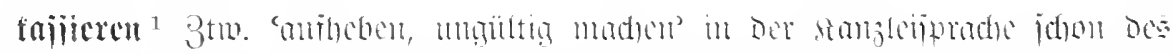

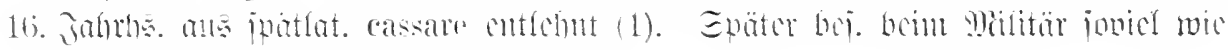
'an jeinem ?me entajien, aboanfen' (2)).

Weleac: 1. bober 1536 Lerozer $\Xi$. Cabirn: Ist rin ding abthnu ind zernichtigen. Als so einer. Was er gehandelt. nichts mehr sein wolt lassen, oder so er sein Testament and anders wider zerbricht rnd vernichtiget. 1538 sicue 3 eitumg b. Bertrag v. Sirian $\Xi$. 20 aller Krieg soll aub

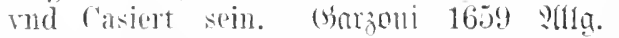
Echaunlas E. 45on. welches (iehott er aber hermach casiret.

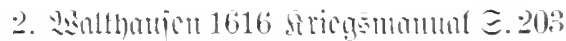

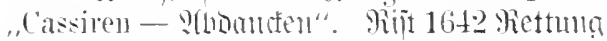
If $7^{\prime}$ dab die beste Reginenter ohme das sollen cassieret werden. Habener 175!1 Eatiren II 2006 ein Fänderich cassirter.

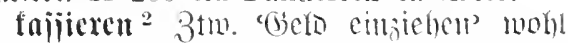

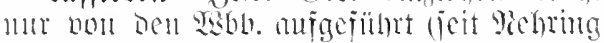
1694); Dos übriche mar cintajicen (i. D. meter fi a jio).

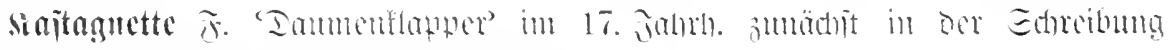

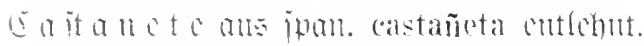

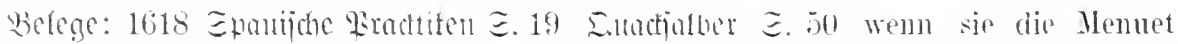
anf de spanische drt mit Castaneten an mit den Castanietten tantzen. ?ma=

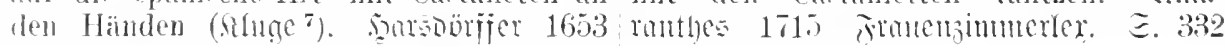
Exmucfitumon III 369 castanete oder Castignetle.

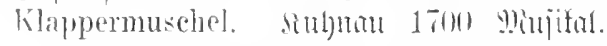

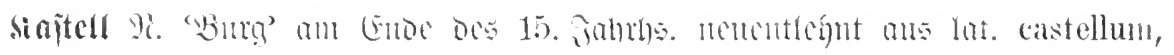

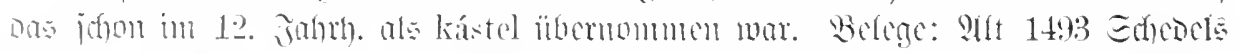

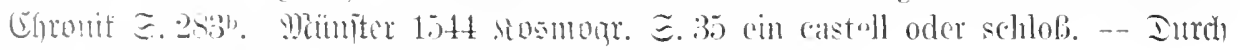

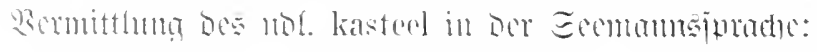

sintertajtell 1. 'Das hohe, bejeitighte binterteil des Echiffes mol. agted hastell, 1tod. (1582) hinder kasteres. Sit leqe: Comenim 1638 Eprachentiat 53, 463.

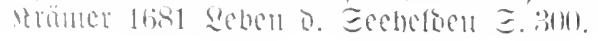

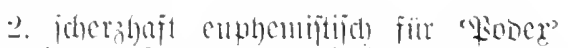
idnon im 17. jabrh. Francišsi 1663 Suptige Echmesibure I 1044 sie zichen num dem Lojb etwas inwerts: schlagen nud stampfen mit dem rechten Schienbein: setzen die 


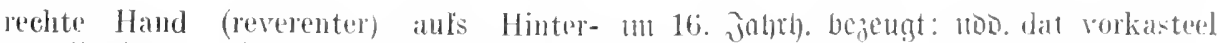

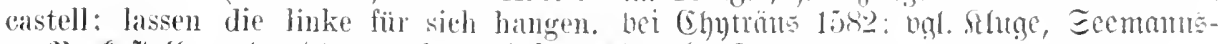

Borfajtell mach mol. voorkasteel ithon ipradhe E. 249.

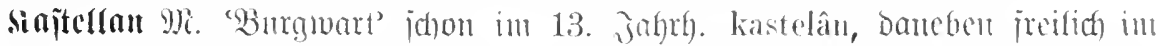

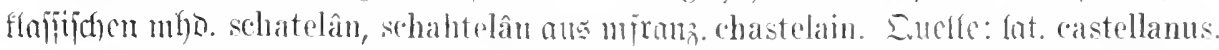

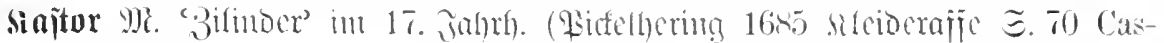

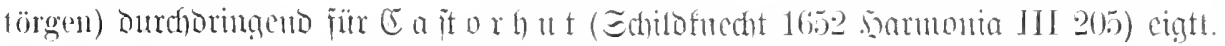

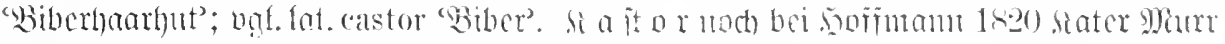

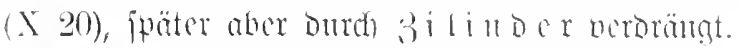

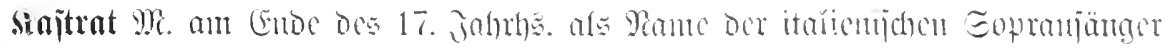

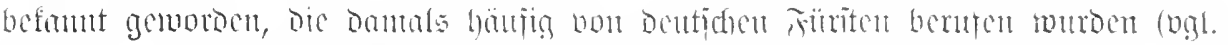

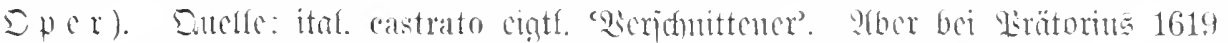

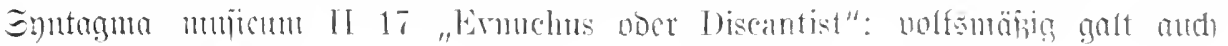

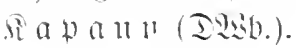

Belege: Sortmam 1678 vantontin werfen gehtantht (2). Belege: 1. Eilich 1598

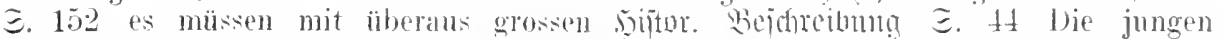
Unkosten in etlichen Höfen aus Welsch- Kuaben kastriren sie, rnd mesten dieselben. land castraten beruffen und alimentiret wie man bey uns den capaunen thut.

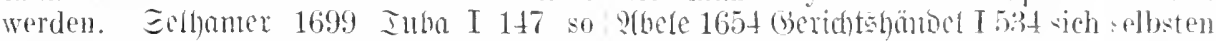
schlïgt man offt auf ein uocklhanisch castriern (oder 'Teutsch darvon zon reden) krälen, anf ein mannehmliches und un- seine Mannliche Samnen-Gefässe stimlen. natüliches Gigitzen eimes Castraten über Edhiel $167 t$ Edhandhonif E. 191. Q Sercfen

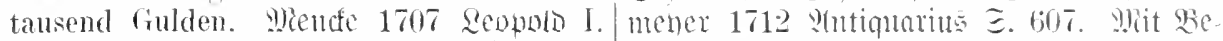

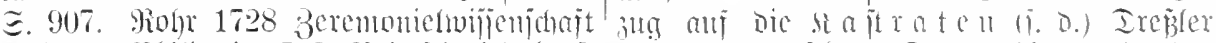

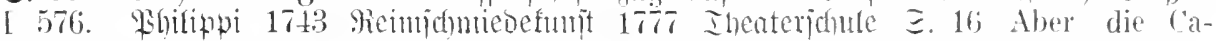

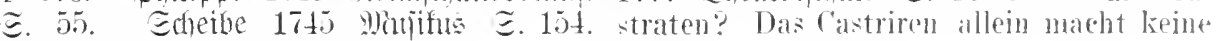

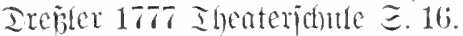

fajtrieren 3tw. 'verichneinen', ans lat.

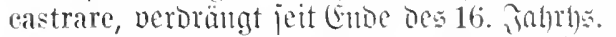
(1) Die ätteren mïnchen, mönchen (cig.,

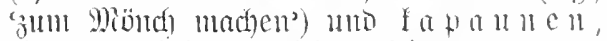
Die mu nod int Bereidh ber Sierantht gelten.

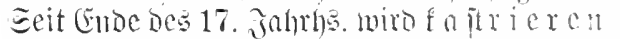

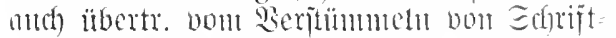
Sänger.

2. Inomaing 1688 mionatsucipräde I 255 Das 2 serf 1 nach seinem Tode daselbst auffrichtig und uneastriret herausgeben.

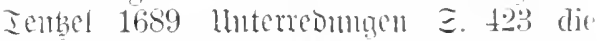
Gewibheit, dab die Dïrutzische Edition castriret worden - E. 64 i dab die Juden selbst ihre Bücher castriret.

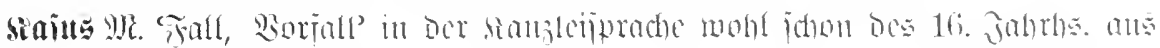
gleichbed. lot. casus cutlethtt.

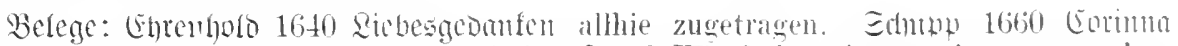
1) 2b Gott Jupiter gedacht, es müsten hohe こ. 13 Wir haben jüngst einon casm bey Sachen Vnd schwere Casus Sie. die Jumo der Cantzeles gehabt. Edhid 16 it Edhomi.

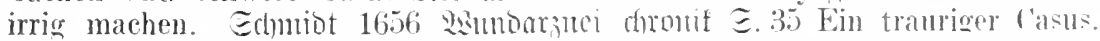

こ. 180 Anno 1655 hat sich ein feiner Casus

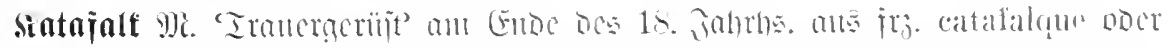

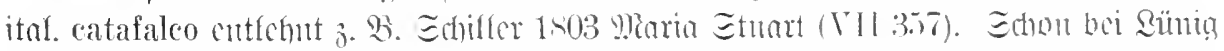

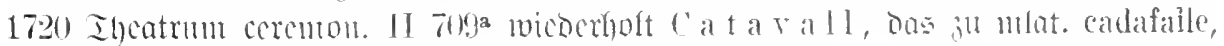

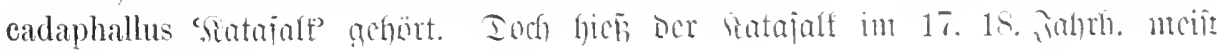
Castrum Doloris.

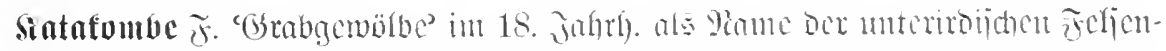
gräber in Stafien Eefumt geworden (ital. catacomba). Beleg: Bobmer 1752 ?oak 5. 207 in Todiengersiilhen l'nter den C'atacomben. 


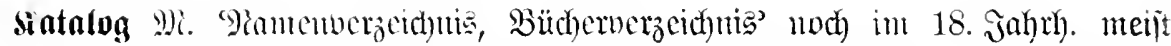

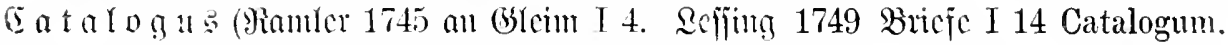
Sdiller 1788 Bricfe II 46 Meßkatalogus) = lot.(=gried).) catalogus.

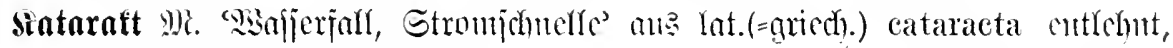

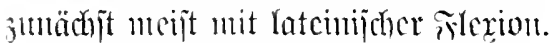

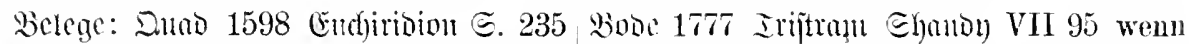
das sich eben dasselbe auch mit dem Nilo ich mit schwindehden Augen die Felsen, zutrage, da er seine Cataractas habe. Gebirge, Cataracte und all das Gewühl sehe. Birfon 1669 llftjie Є. 41 Sie besahen den Brun 1809 Epijodcit II 335 , neben den RheinFall oder die Cataractas Rheni. Katarakten des wilden Stromes hin.

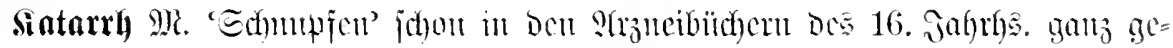

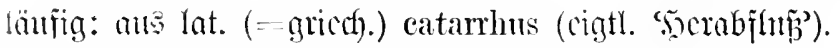

Belege: Fries 1519 Epiegel D. Uranei schmpffen vmnd Cataren geneygt. Inber= $5.117^{\mathrm{d}}$ von einem catarren des haupts. Macmontauts 1588 firüterbud) I $227^{1 .}$ Bogter 1531 Urzutcibüd)lcin E. 24 von Wamn dic Nase in dem Catharr gar vereinem Catarren. Riff 1544 Epicgel D. stopfft oder der Schmupen nicht auß der Gejumblycit $\mathcal{S}^{2} 2^{\text {" }}$ zu flüssen des hampts, Nasen wil.

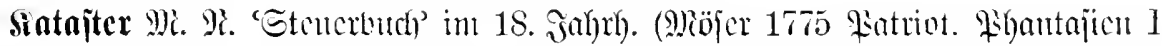
138) cingeocutfint ans neufat. catastrum (

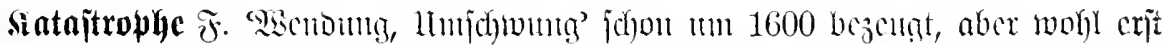

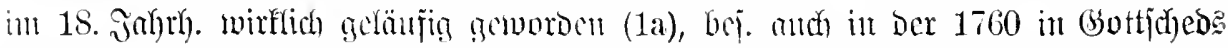

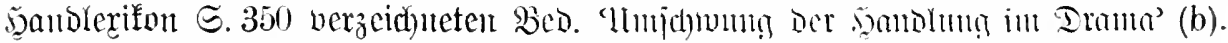

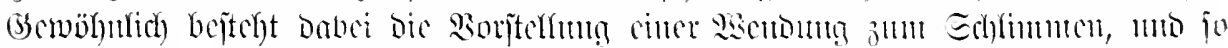

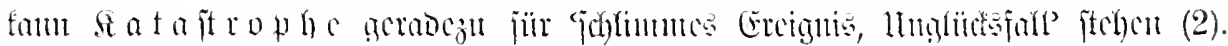

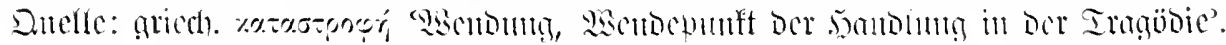

belege: 1a. Räslin 1605 Ittoicimn ober 177) Die K. ist ansgebrochen -1767 Dra=

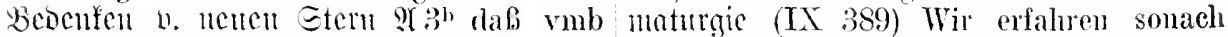
dise zeit ein C. sein werde aller Sachen, gleich Anfangs die Entwicklung und die die in der Christenheit sich vor vil Jalnen ganze K. 1770 Iflg. §. Bibriothef XI 1 her angezettelt. 1620 bei Zonoord II $\Xi .11 \mathrm{Es}$ ist ein gemeiner, phmper Begriff S33' rnd also zu befahren stehet, es dörffte von draunatischer Handlung, sie sich nicht in Polen leichtlich zn rinen Rakosch anders als in einer K. zn gedenken.

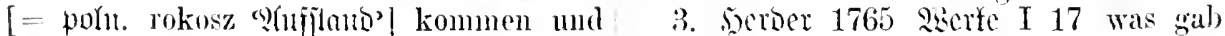
daselbsten inch eine C. vorgehen. Dann= es damals nicht für blutige nnd ungerechte

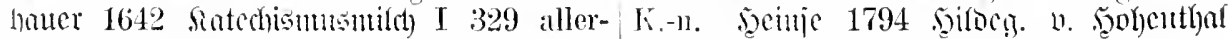
massen wie ron .Job geschrieben wird, er (VI 108) Doch, da sie ans london her an habe nach seiner C. Kinder und Kindeskinder Abentener und K.-en gewöhnt war, so

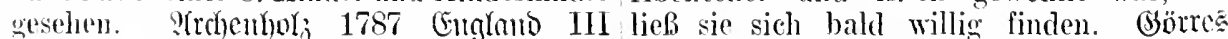
322 Der nëichste Krieg dürfte die fatale 1800 Forit. Ectrriften I 35 Die Hoffnungen, K. beschlemigen. Crmiter 1794 Genic= die die politische K. in Immern geweckt jitrciche I 51 Dats Mädehen war bereits ver- hatte. Nisitt w. Dörring 1827 Fragmente II dorben genng, $n$ m diese seltsame K. recht 209 Die K.-n von Rieti nud Novira verherzlich belachen zu können.

b. 2effing 1759 Siteraturbricje (V'1H

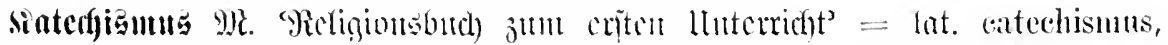

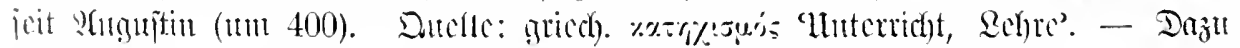

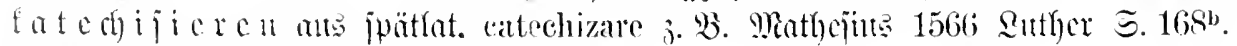

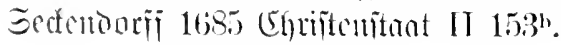




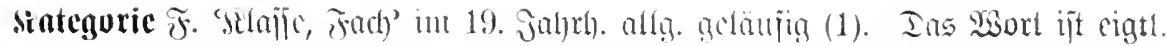

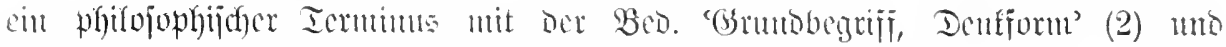

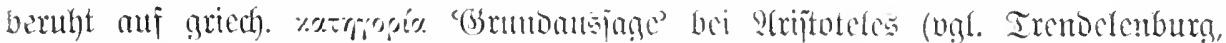

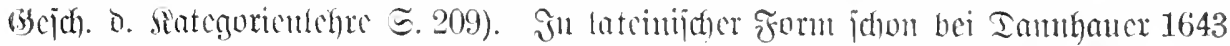
Ratedismumila II 405 in diese rategoriam werden gezehlet alle Mittel und Weissen eler Hoffart.

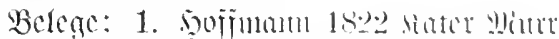
(X 214 ) ich häte in dio Kiltegrese jenere veriehtlichen lente geraten kïmmen. Secine

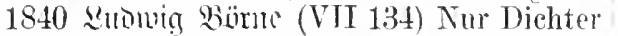
- wir werden msere Gegner nie so tadehn, dab wir sie in eine und dieselbe hategorie setzen mit Dinte. Hilton nim. (Gnromifn 1845 Sour duth Belạien $\Xi .190$ Jeme Betitelten gehören nicht einmal in die oben genannte geschichtliche Categorie.

2. Sant 1781 sititit o. reinen Sermunt (II (ib) Anl these Weje entspringen gerade so viel reine Verstandeshegriffe, welch a priori auf regenstainde der Anschauung überhaupt gehen, als es... logische Funktionen in allen nü̈glichen I'rteilen gab: demin der Vorstand ist dureh gedactite Functionen vällig orschöpft.... Wir wollen tiese Begriffe, nach dem Aristoteles, kategorien nennen.

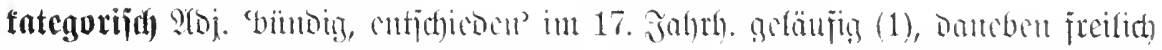

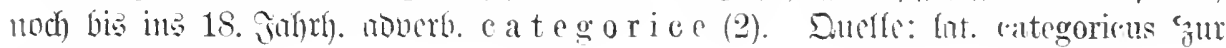
2)

Siclege: 1. 1619 bei Lomborp I 459 1

2. (E) Ihr Categorische Antwort auff die Com- Cathegorice rermeynen - 43 Cathegorice tenta - 1621 cbo. II 1110 eine catego- zn croffnen. 1601 Foutes rexum anjtriac. rische kmtze Erklämng ((jombert). Eeden= 60, 185 categorice zu begehren. Ed)urt Dorff 1665 Tinuitenftan II $181 \mathrm{jh}$ votum 1662 subhalten $\Xi .39$ categorice darauff categoriseh und ans dem Stegreiff zu cr- mit Ja erkläret. Eallenbach 1714 Eclipjes

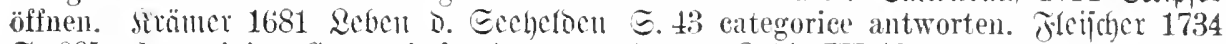
ङ. 665 ohme einige Categorische Antwort. bert v. Znowo III 58 so aber sagte ich ihm Etmer 1697 Doftor E. 107 seine Worte cathegorice, dab er dergleichen nimmerwären Categorisch. mehr vorbringen müsse.

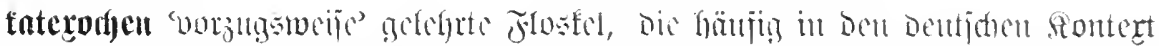

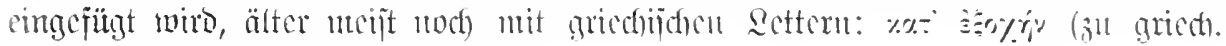

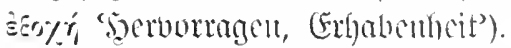

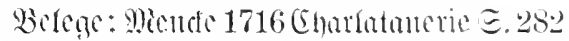
der Titul eines Juristen als ein ordentlicher Ehren-Xahm und wis tie Griechen sagen $\%$ : હ. 341 In Ober-Teutschland zwar pflegt man die Anssätzige xa' soorir-sieche zn

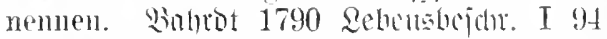

tlie zwölf ersten der Klasse \%s:

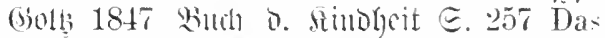
Nomale und Allbekannte ist nie ein poetisclies \% \% rago こ. 184 dic Köniqin kat" "xochen.

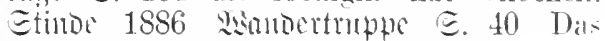
Prinzip des Fortschritts kat exoehen.

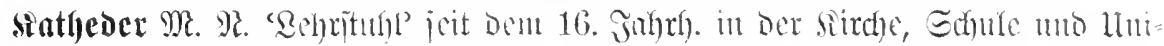

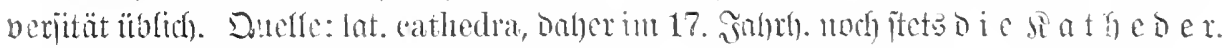

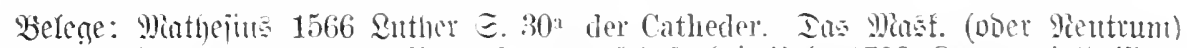

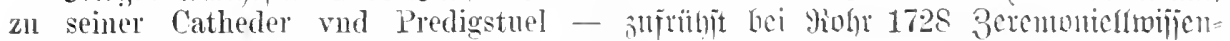

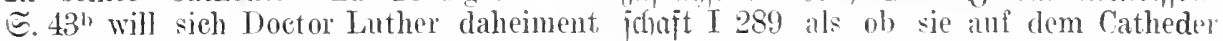
inm guter whe seines Predigstuls vind Cathedren trewlich annemen. Menfart 1636 B. D. Sodjichulen E. 382 in den Cathedren der Universiteten. こchupp 1657 Frento $\Xi .25$ Wann ich num einen alten Studenten sahe auf der Catheder stehen. Riscom 1739 Edhriftell E. 294 auf stïnden.

Siathederamiplud Cranter 1778 an Bitrace $\approx$. 172. sitheoriders 1768 Sillitide sibliothet II 236.

Sathedergefehter Ieutis 1778 exin=

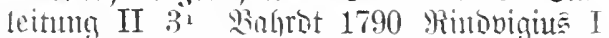

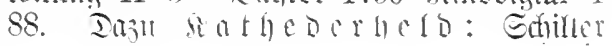




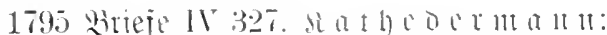
Jacobi 1812 (gachlaj II 100). Souff 1826

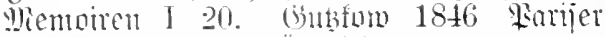

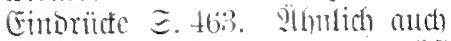

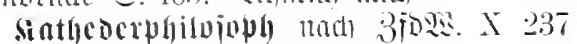
עech 1818 (Jacobis Viadraij II 137).

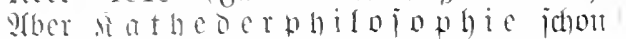
bei Nibillor 1792 nem Elyomas III 103. Echout lat. philosophi eathedrarii.

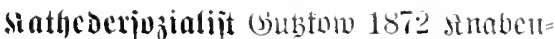
zeit (X 143) unser gegenwärtiges, ,soziales”. Chaos. aus welchem uns weder die österreichisch-deutschen Ministerialkonferenzen noch die ,Kathedersozialisten" retten werden. 3ujrishit Eppenfeim, "Mandhejter idnule mis satheneriozialiomm "1871 gratio=

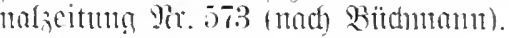

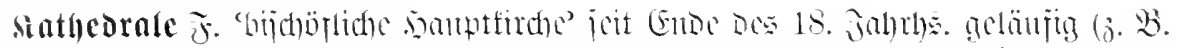

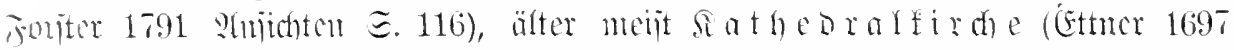

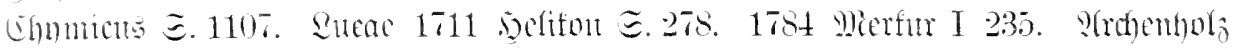

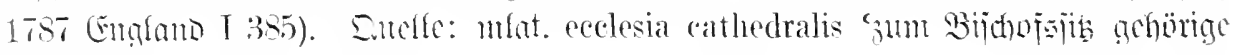
lindes.

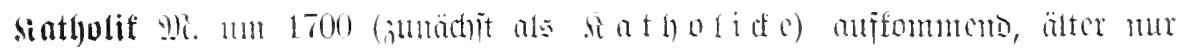

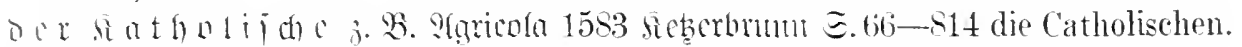

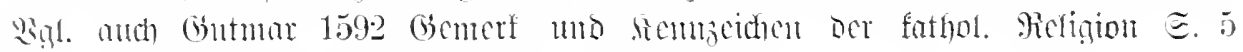
Ego smm Catholicus. das ist. ich bin Catholisch.

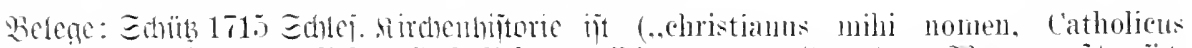

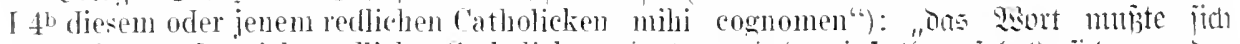

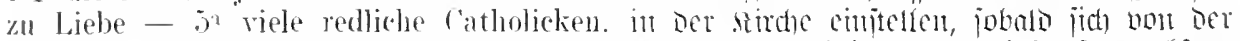

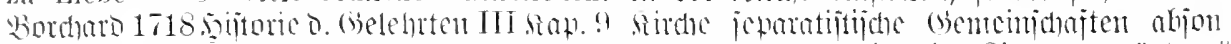

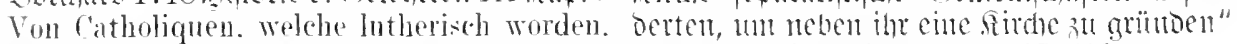

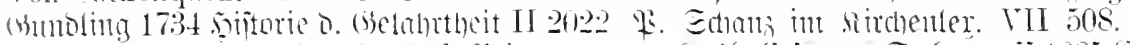

a mogte einer ein Hussite oder ('at tholicke seyn.

Sintholizi

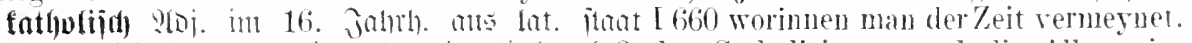

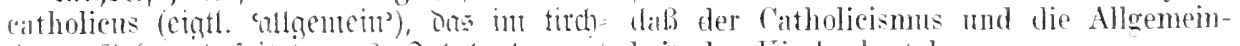

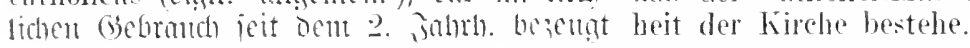

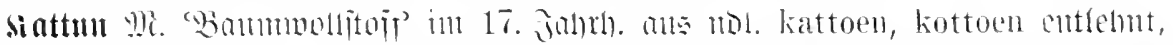

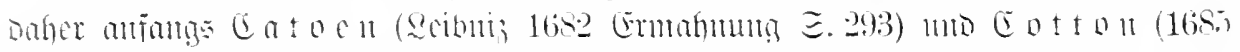

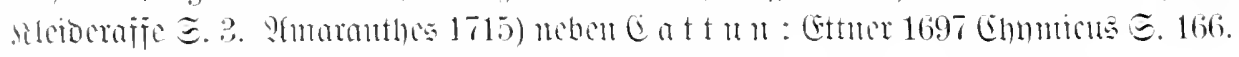

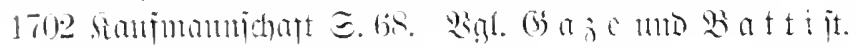

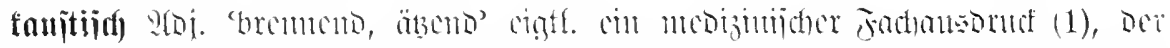

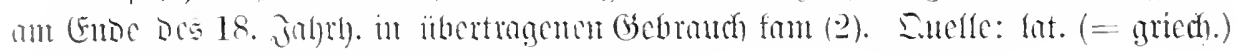

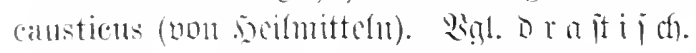

Beleac: 1. jermo 1791 Ziterar. Whär pulogic こ. 163 in Sachen des kaustischen

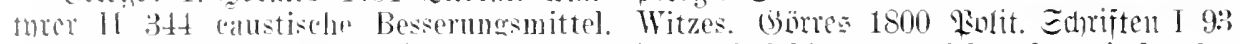

2. Wuïlfor 1787 Emmeridi II 258 der jenes Gefühl, dals nicht kanstisch das kaustische Hartial. Sant 1798 ynthes Schöne ergreift und in sich anflöst.

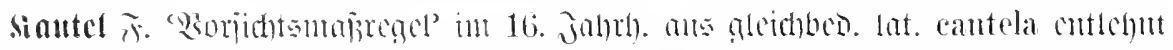

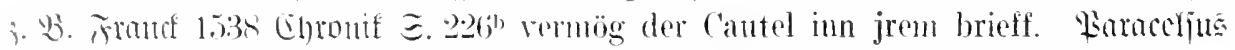

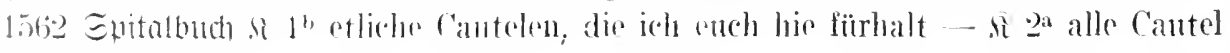
sorer rnd allost.

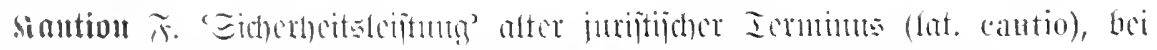

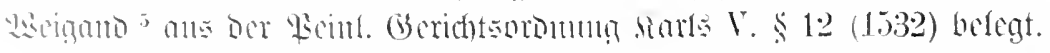

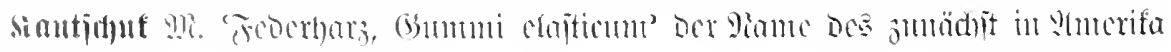




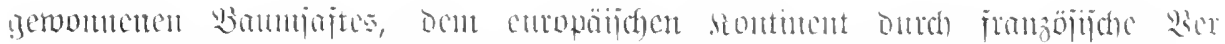

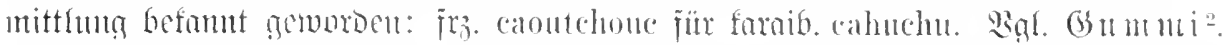

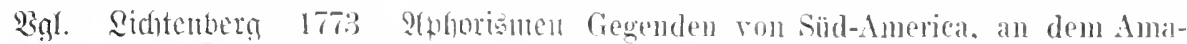
(II 34) Im 96. Stiick 177. and im 6ten zonenfluses. Wie autl in Cagenne häufig 1773 eben dieses [Somntiverighen] Magil- anzutreffen ist. Die Indianer nemnen zins finden sich Abhandlungen rom Feder- diess Hanz Cautschuck, und bereitcon harz, sonst auch Cahutchu genannt. Bej. daraus ein drt vou Wisserstiefeh, weil

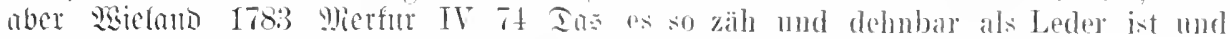

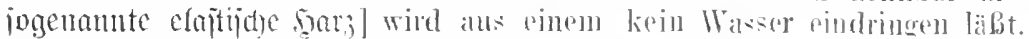

Baume gesogen, der in rersehiedenen

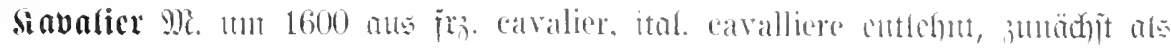

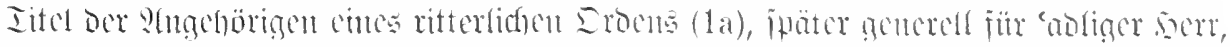

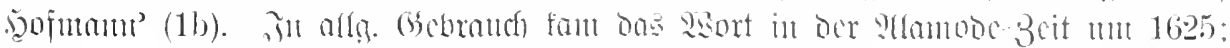

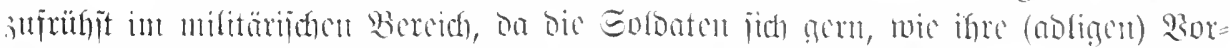

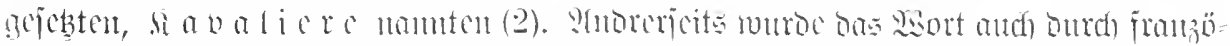

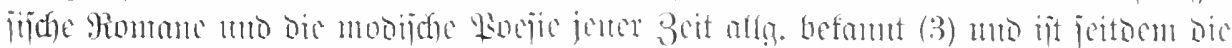

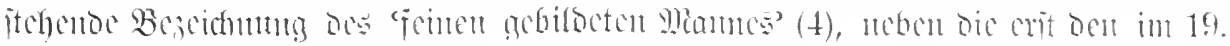

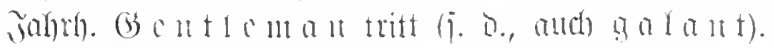

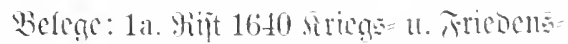
iniegel yi $1^{\mathrm{b}}$ Da hat der König jhn zmm Gavallier gemacht, Nicht der gemeinen Art; Er darff den Engel führen )): gleich wie im Königreich Spanien viel ritterliche Orden werden gefunden... also wird in Franckreich fürnehmlich aepriesen der Ritter-Orden Sanet Michael . . . anff welchen Orden diese. Wort ziehlen: kir darff den Engel führen. das ist: den Ritter-Orden S. Wichael.

b. Corolus 1614 thelation Mir. in dels Känigs Bruder mit vielen andern ('avallipren.

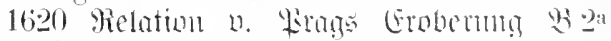
in beysein der kayserischen rnd anderes

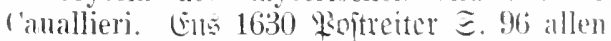
andern Hoffrähten rnnd rauallieren.

2a. Miengerint 1638 Evolnatentenipel Er hielt nicht dafiir, dab rin reehtschaffener Cavallier in Himmel kïme. Bei. Sijt 1640 Epieger $B 3^{a}$ den hochlöblichen Orden der (avalliere (mit wolchem voleutschen Nahmen alle tentsche Krieges Lente ins Gemein hent zil Tage getauffet werden).

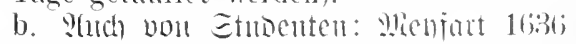
Dodhidulen $\Xi$. 140 Es ist geschelen auff der Universitet zu $X$. daselbst theten sich zusammen etliche junge Lappen rnd scholien jhre Gesellschafft die Cavallierel delas ist. Ritter) der Ehren.

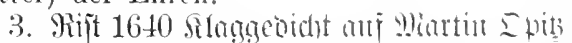
办 $3^{\text {b }}$ Dieses mnteutsche Wörtlein Carallies ist allhie nur schertzweise hinzugesetzet, dieweil es bey rns nämischen Teutsehen so gar gemein worden, dab anch die Bemhänter rnd Stallbuben winander' r'avallier

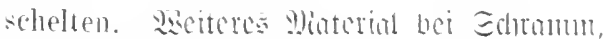
Ed) agmäter D. Qflontobescit.

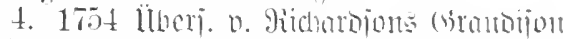
II 56 ihmen Cavallicr-satisfaction zu geben =

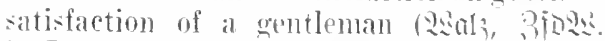

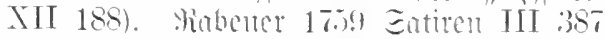
Geqen alle ('aralier" werde ich zärthorher thum als gegen Sie. Edviler 1781 gäuber (IT 86) du bist ein kavalier. Dn nubt den Schimpf nicht auf dir sitzen lassen. Eambe 1836 Reijenouellen III 181 Kavalier ist bekamntlich der technische Auselruck in Oesterrejeh.

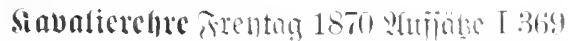
Wer das besondere Destillat in sich bewahnt. welches man favalierehre nennt.

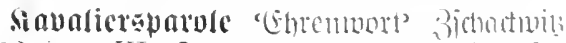
1723 fiorl VT. E. 94 anff C'avallier:-T'arole

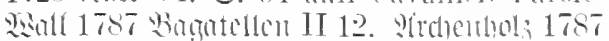

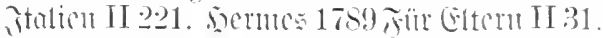
beine 1830 italion (III 313).

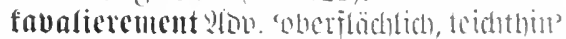
$=$ iri. cavalierement cil ber ?trt cutes

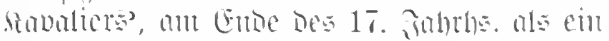

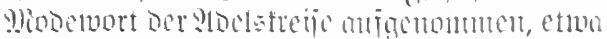
im serte Dos moserncu stand, sgemiiß (1).

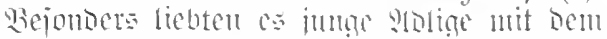
唯orte um jids in werfen, lum ihre mangel-

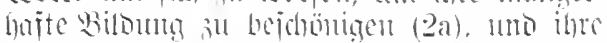

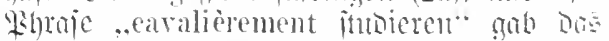
Wanter ab jür änntiche scembungen, Die sine

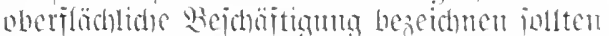
(b). Selege: 1. Eectemori 1685 Ehritten itout I 24 Dahero siehet man. wie offtmahl Hohe Standes-Personen olme Schen ho- 
kemmen, dal.j sir ron liott und dee Religion niehts halten, sondern ilner Meinung nach sich von solehem \%wang sehr weiblich und muthig. und, wiosio zorden pflegen, generose oder cavallirement, und ans galanterie frey gemacht und emancipiret. Igomojus 168 s yionatsgejpräde I 462 rin bunt Kleid mud ravalierenent einen Degen an der Seiten. б) man die angethane Beleidigung sehon, wie dir von Adel reden, Cavallierement mit dem begen oder Kungehwedsel revangiren. Riohr

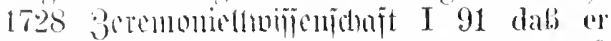
stinem Adelichen Stand mach sich gemäifo anffïhren und tavalierement lohen kann.

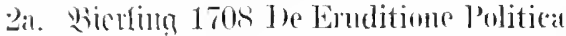
こ. 7 .. Tilit magis ineptum est, ynam si lommes nobiles, qui aliquot in Academis ammos non studendo, sed guibuseunque aliis ocenpationibus "xegerunt, so tamen pro doctis habeant, ae de materiis eruditis satis pro antoritate disputent, falsitatis vero vel erroris convicti respondeant: Eic befinn. uneten jid) un bic Ednu(fiü(d)jeren nidht, jie Łätten ravalierement studierel."

b. Sohr 1728 3erenumichmifienifont I 265 davor die Hinde in den Rock stecken, sich also eine besondere Air reben und entweder gar nicht, oder doch cavalierement beten. Reîina 1759 Siteraturbrieje (VIII 11) Wir wissen es freylich, dab Bolingbroke oft ziemlich caralierement von der Bibel spricht. Miïller 1787 [Enuterid II 371 ar giug] mit dem Ban seiner Vers sehr kavalierement $1 \mathrm{~m}$. Echilter 1795 Biricje IV 201 Ich lebe jetat wanz cavalierement. demn ich mache Gedichte fiir meinen Husenalmanach.

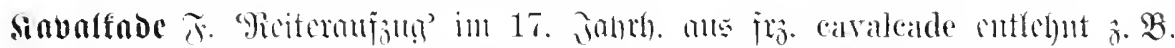

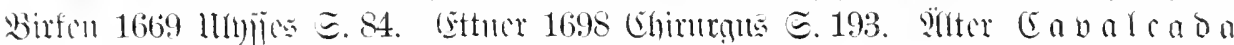

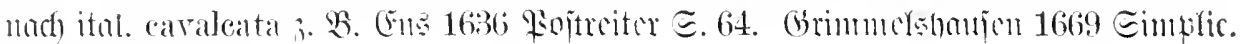
ธ. 179.223.

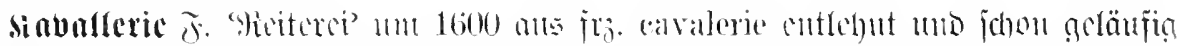

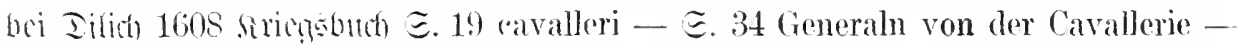

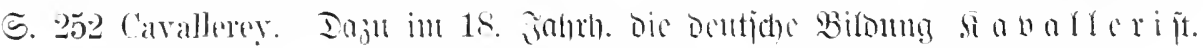

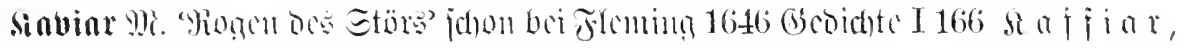

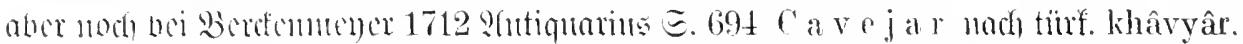

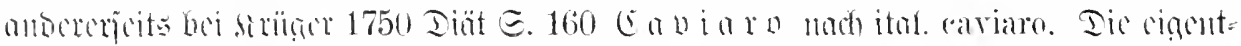

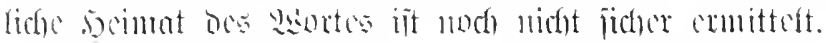

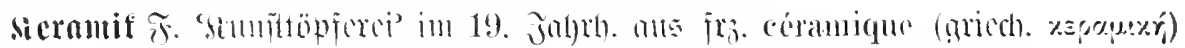

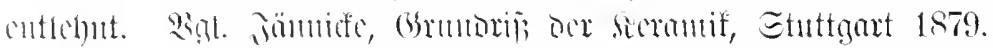

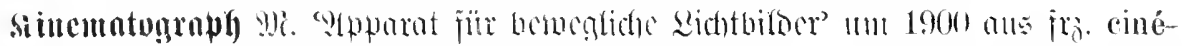

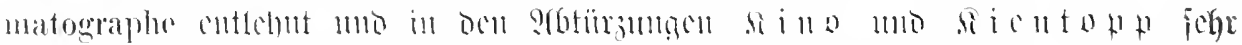

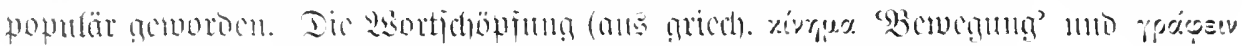

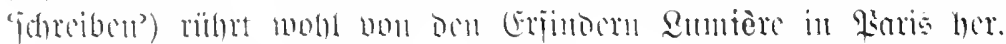

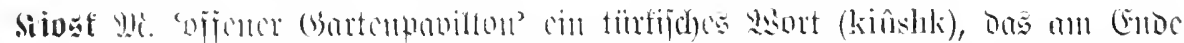

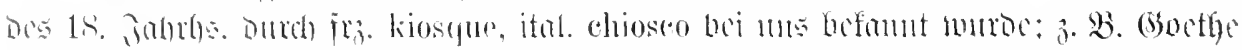

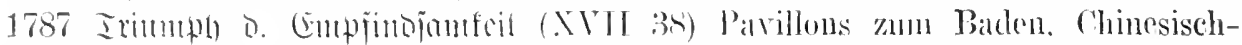

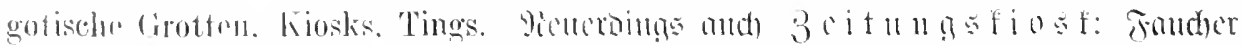

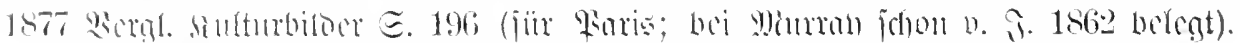

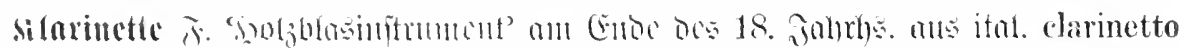

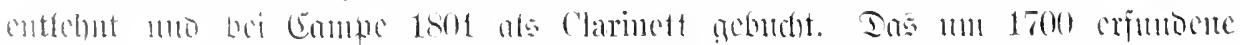

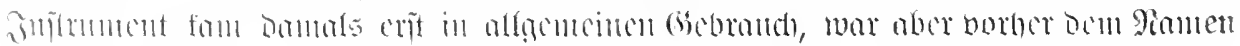

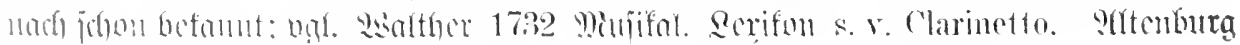
1795 Iroukctitumit E. 12. 


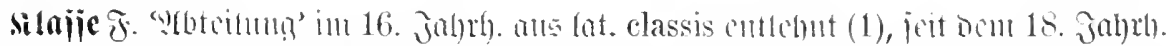

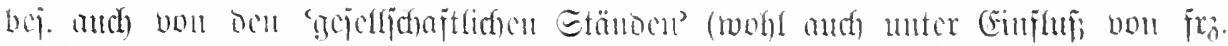

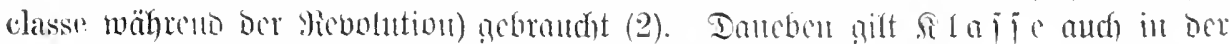

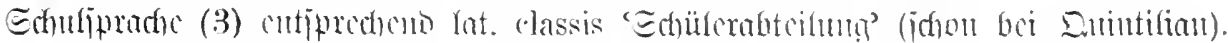

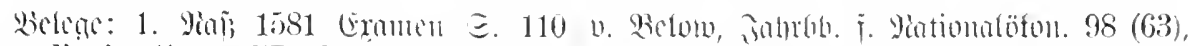

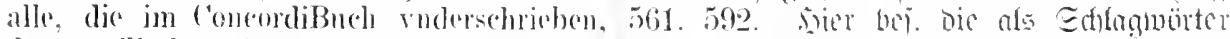

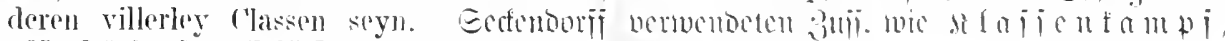

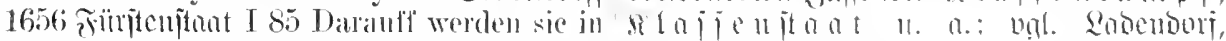
sondere Gemïldyer gerviesen, als in Fïrstenthiimern und Landen dir Praelaten in rines.

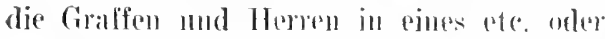
uach Gelegenherit blejbet as ber zwo oder

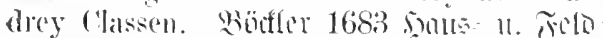

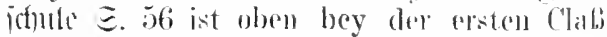
etwas Andeutmog geschehen. Ihomafus 16ss

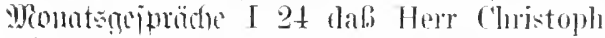
mit denen Epientern in wine (liase zu setzent sey. Hherer 1746 (E) E. E.87 Man kall alle mensehliche Vollkommenhwiten in ver= sehiedene Classem. Gattungern. Artun oder wie nlan "s memen will, abtheilen.

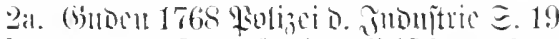
noch mehr aber [untergderioen jids] busondere Gattungen mel classen ron Einwolumern im

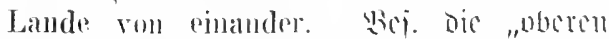

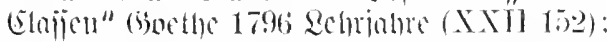
Dic "arbeitenocu (Elajpen" (burbusth 1845

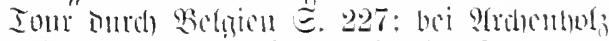
1790 Eicbentühts. sirieg E. 206 die arbeitenten Tolksklassen. Ginch Girtmunc 1791 Franl.

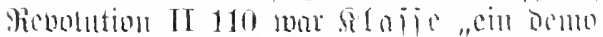

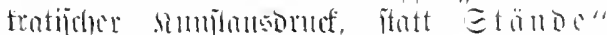

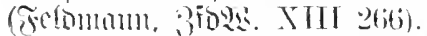

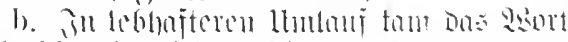

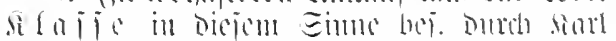

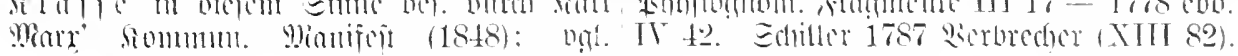

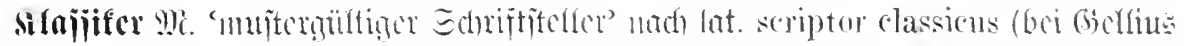

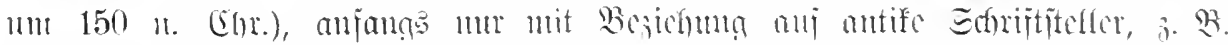

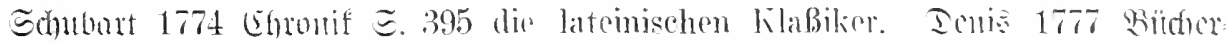
funoc I 157 Ansoaben der griechischen Classicer.

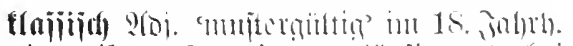

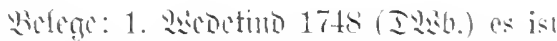

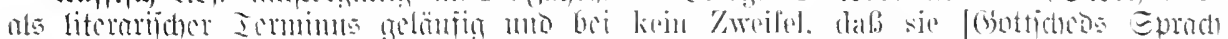

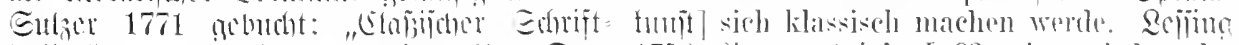

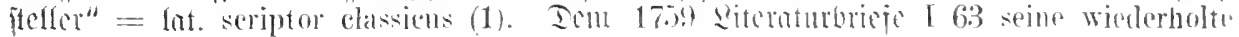

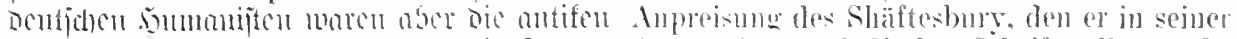

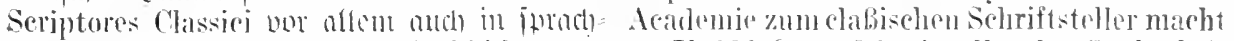

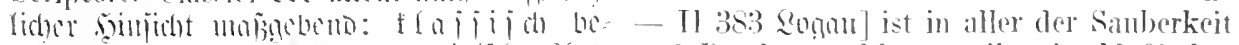

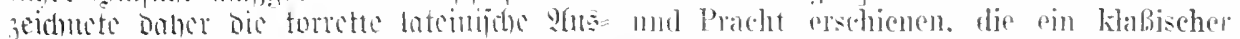

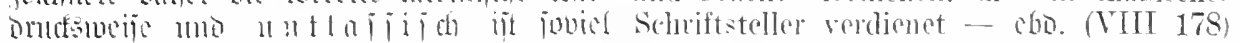

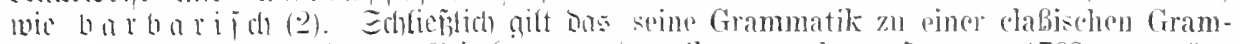

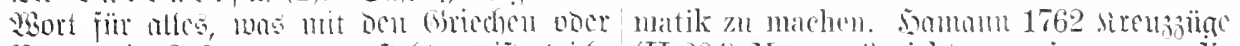

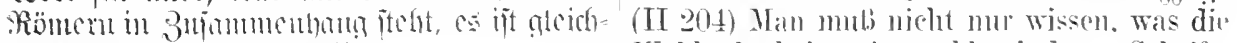
beocuteno mit ant it (3).

Wohluelenheit aines kissischen Schrift- 


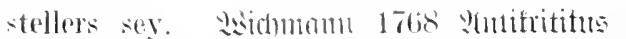
I 469 weil ar uns alst mit FleiB die clabischen stellen sammlet [= ueuht. locus classieus].

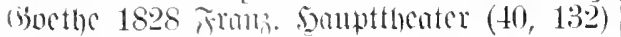
cin Ibenter] der sunz reinen, regelmäbigen, sogenamuten classischen Art.

2. Deroer 1767 Ieutide Siteraut (I 412) lud mun entschlob man sich, des Ausdrucks wegen in der spratehe der Alten zu schreiben: natïrlich wars, daß. da dieser der Hauptvortheil und der Hanptzwerk war, daß, man alles Unclassische vermied. um nicht von den Alten abznweichen: also entsagte man seiner Eigenheit, man opferte alles auf, das uns den Xamen lassisch streitig machen könnte: und ward ein rassischer Nachahmer! - O das rerwünschite Wort: Classiseh! Es hat uns den Cirero zmm rassischen Schulredner: Horaz und Virgil zu classischen Schulpoeten; ('acsar zum Pedauten und Livins zum Wortkrämer gemacht. Das Wort:

Classisch! is as gewesen, das den Ausdruck rom Gedanken, und den Gedanken ron der ihn erzengenden Gelegenheit gesondert. das uns gewöhnet hat, nach Horaz Exerzitien zu machen und ihn in seiner Sprache ïbertreffen zu wollen - 1778 serfe (VIII 406) dab man recht klassiseh schricb - 1796 Bricic (XVIII 16) die Schönheit eine: klabischen Ausdrueks.

3. Beroer 1794 Bricie (XVII 151) Wem in spätern \% \% pen bei irgend einem Schriftsteller. ar sej Geschäftsmann. Arzt, Theolog oder Rechtslehres. eine feinese, ieh möchte sagen, classische Bildung sich änberte, ist diese meistens auch anf rassischem Boden. in der Selmule der Griechen und Römer exworben - aud jebu 1793 Bricic (XVII 30) Man wandelt in ihmen [Trieoridh E(t)riften] wie anf klabischem Boden. (Gocthe 1795 (Elegien (I 239) Froh empfind ich mich mun auf klassischem Boden begeistert.

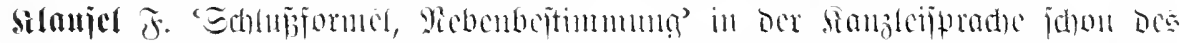

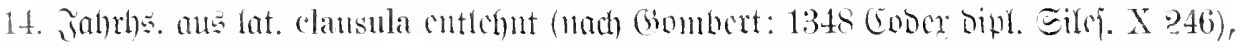

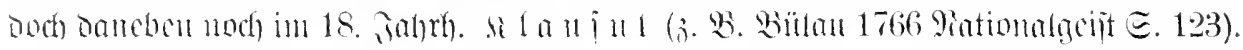

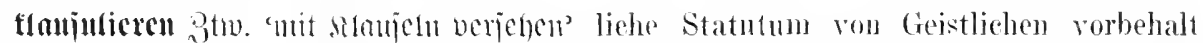

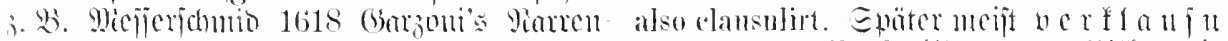

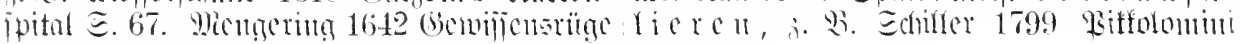
E. 9.5 daselbst wird das lieyser- rnd Känig- (VT 128).

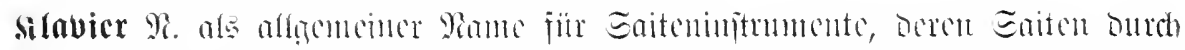

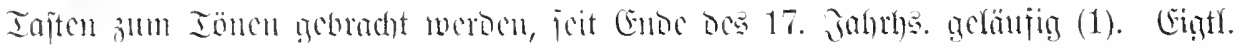

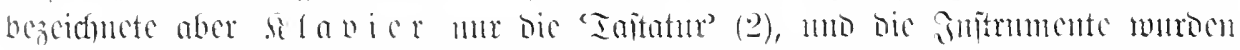
als E

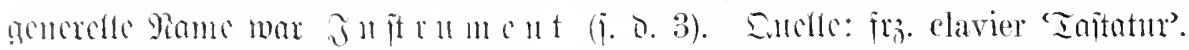

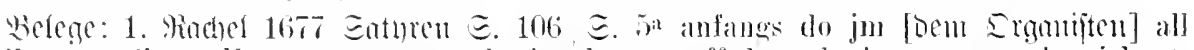
Woil er zu dieser Kimst so gal gereedst ist kunst auff dem clauir vor alugen bezeichnet.

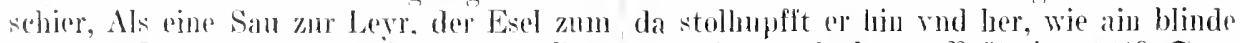

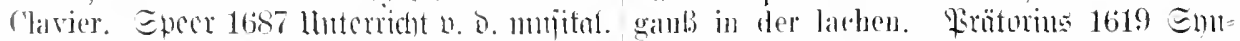
sumpt $\Xi$. 46 zur repetitions-Information deb toṇun unficum II 98 ron diesem rud derC'laviers - amf dem Clavier informieset. glejehen Oroblwereken, Manmal rnd Pedal

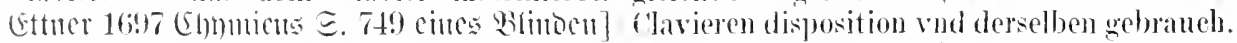

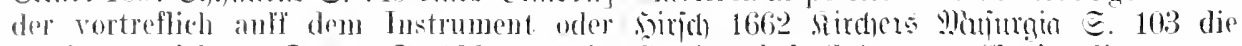
Mavier gespielt - Iottur $\Xi .133$ so er in Clavicymbel, Spinetten. C'aricordia, manu-

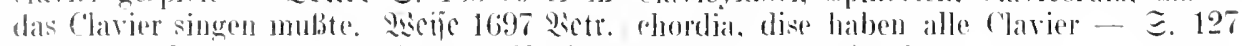
(Weipräde $\Xi$. 180 doch anfi dem C'laviere Tastatur oder Clavier.

habe ich mich etwas exereiret. Wicucte 1710

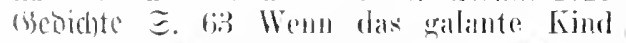
die mensten Molen trägt, Lud wie dor Mejster Fix anf dem claviere sehlïgt.

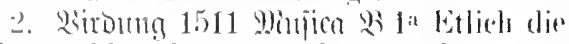
hathen schlirsed val nade denselloen mag man sy regulieren ... als zu gheicherweib dir instrumenten mit den clanimen seind

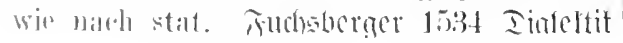

silabiatur $\pi$. 'Sajtatute bei commes 1801

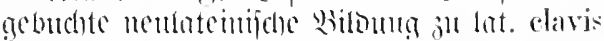

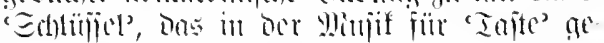

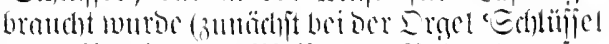

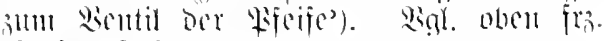
clavier 'Enftatur'.

sitavidfurd $y_{i}=$ mentat. elavielordimm

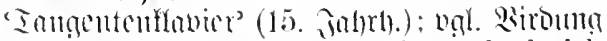
1511 Minjico es ga ranieordim glaub ied 
(l\% seyn, welchs Giwido aretanus monocordum lat wenemet - (5 $2^{\mathrm{b}}$ wer anch al instrument nach denselben s(chlüsseln also naluicordimm hab getauffet oder gonennet, waib ich nit. (buarinonims 1610 (brestel 三. 1028 bas ('Jauicordim rnd Instrmment habxu ein sehr ueringe Thung. Diätorim 1619 Enmtaqua

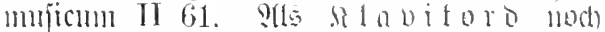

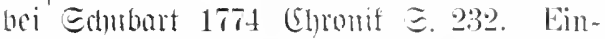
fältig ists, daB man so unbestimmt hinschreibt, if Sonaten fïrs Klavier. fiür welches? Für den Flügel? Fiir das Fortepiano? - Fïr das Klavikord?

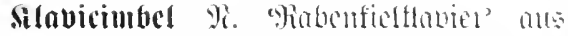

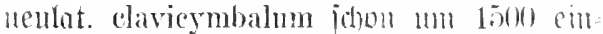

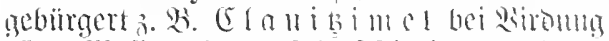

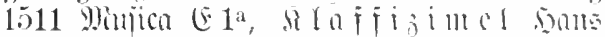

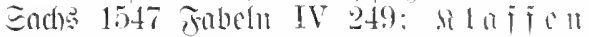

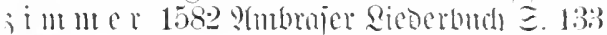

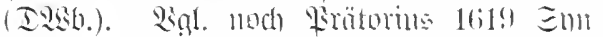
taguma II 61 rff den Clavicymbeln odej

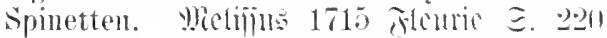

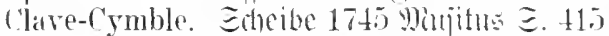
inf dem Flïgel oder Clarecymbel.

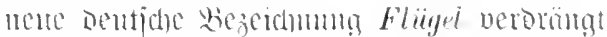
im 18. jahrh. Dio Frembunte, sod meroen jreilid mach Fräged als dil a biere be ieidnet. Rigl. much Ebiult.

flavierem 3tw. 1. "mit shoniatm berjelen"

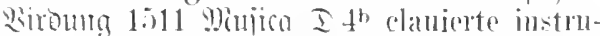

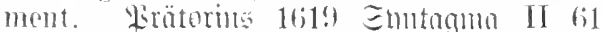
aller rlavirten lustrument.

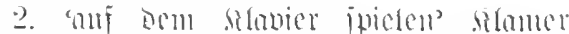
Edmutet: der aine klavierte, der anderes verigte (combe 1808).

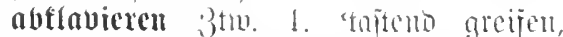

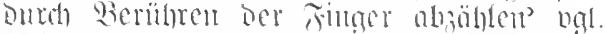
Sinenc XIX 40: Cont weib. in wessen pedantischen Amon Diosel sich div Metrik ablilaviert.

2. 'muiblotos herasbefommen' sourn 1860 ㄲipe III 493 Hab's so an meinen fünf Fingern

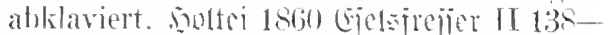

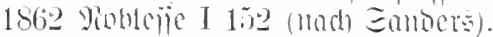

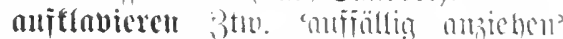
Wibller 1787 Emmerioh 111 106 wio das Weibsstück sich mit Einmal ntoeklavinet Iic hat in Kanten nnd Sieiden.

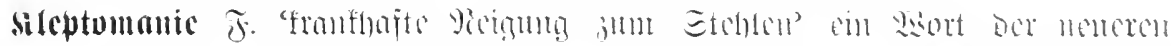

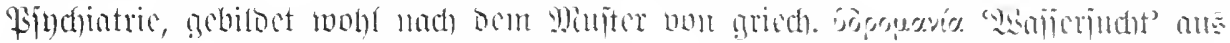

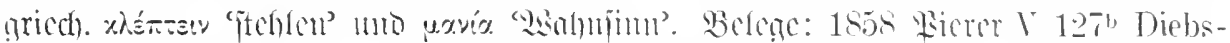

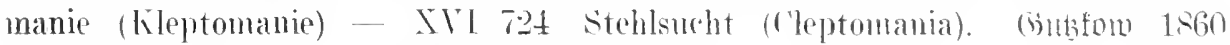
3auberex III $3 \pm 1$ In Folge angeborener $K$.

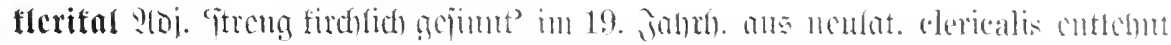

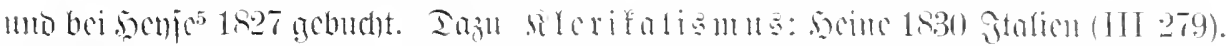

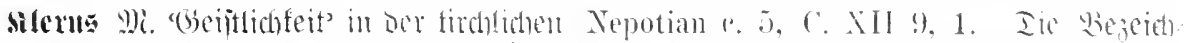

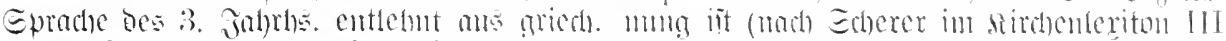

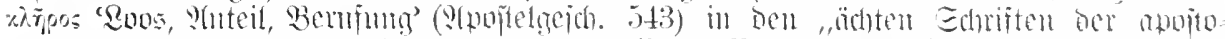

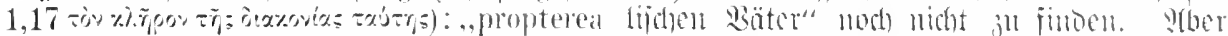

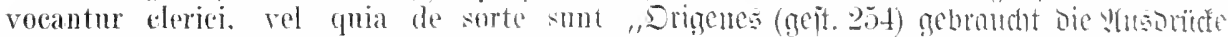

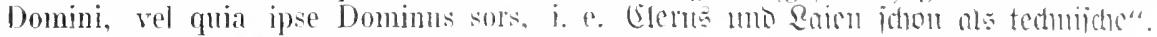
pars clericormm est" Gicroummus Epist. all

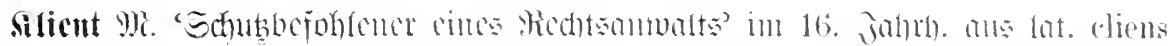

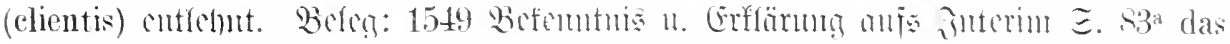
sie sich rnterschiedlich rnser rnd rmser sachen anmemen, als dir Aduoraten jrel clienten.

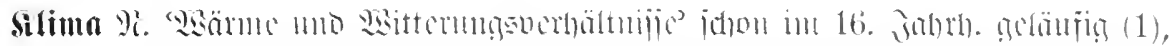

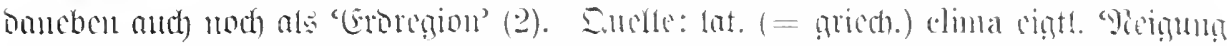

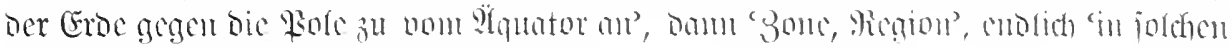

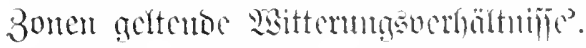

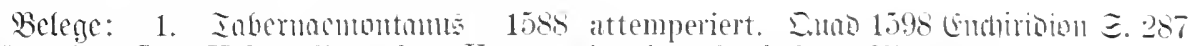
sinüuterbud I $3^{\text {b }}$ Haben die andern Krenter in ein sehr kalten Climate.

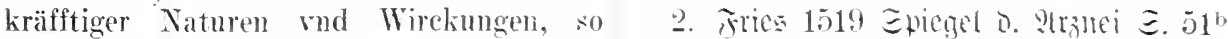
seind sie aber doch auff rnser ('lyma nit von wegen der natur sn d\% land hat seiner 
gelegenheit halb. nach fere vod nahe gegen ein solich breit spacium gerings rmb dat den vier winckend des himels, auch der siben ertrich das der tag von anfang deb elima reil der welt, Climat[a] genant. Miünter bih zu symem vhgang sich verwandlet vff 1544 sasmograthic $\mathbb{E}$. 19 vold begrifft clima cin lablbe stmod.

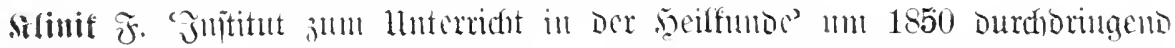

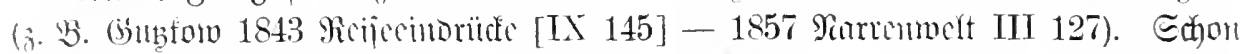

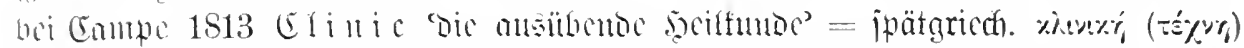

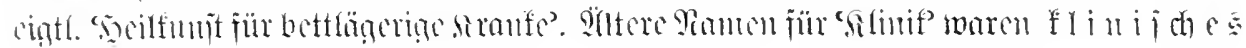

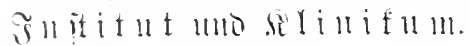

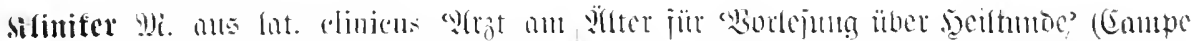

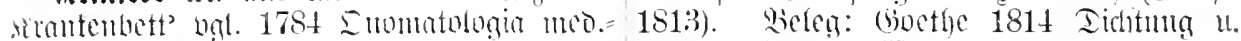

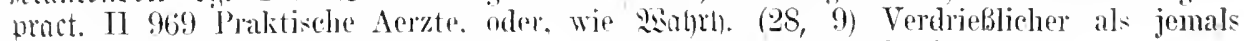
rinigr es lieher hören. Kiliniker.

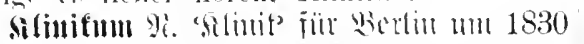

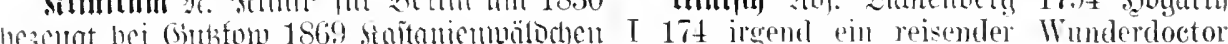
(XIL 50) Im Enele der Dorotheenstrabe lag habe hier seine elinische Sestion gebalten.

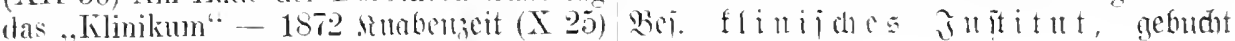

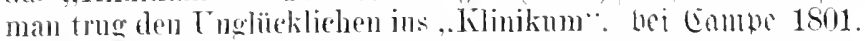

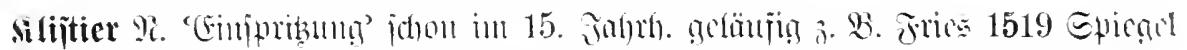

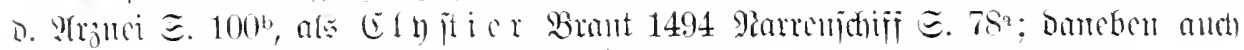

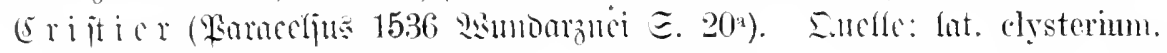

slonfe 穴. "Qf

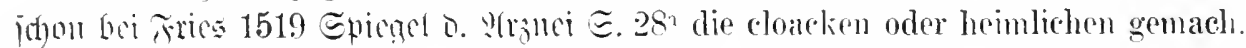
Euclle: lat. cloaca.

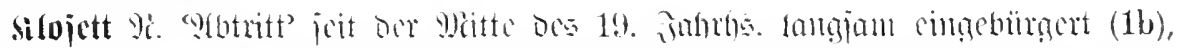

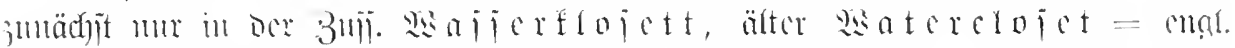

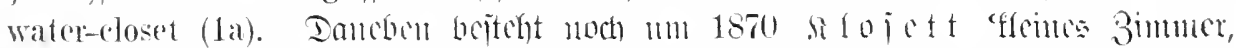

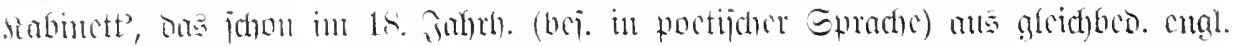

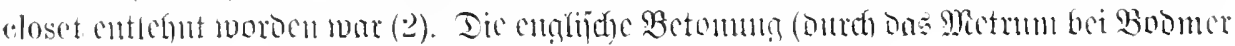

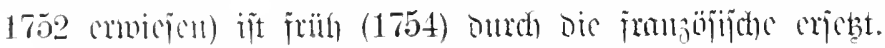

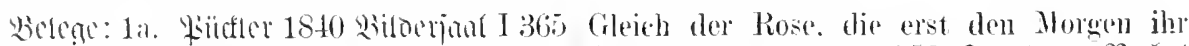
das wie bei den Waterelesets. allen Unrath Closet verlassen - 1752 fncob 1 . Fandhel sogleidh durch Wasser abfülnt. Fontune I 39 dic Bhuncul hyten noch des Closets -

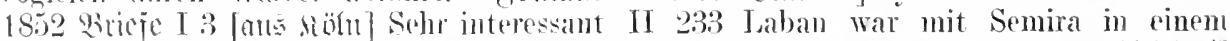

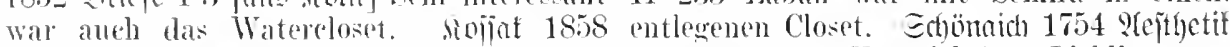

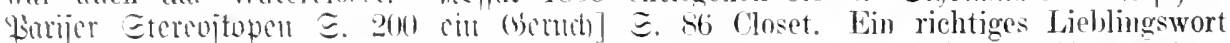

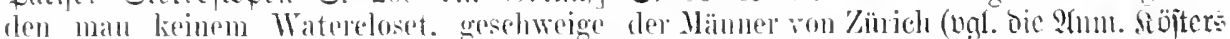

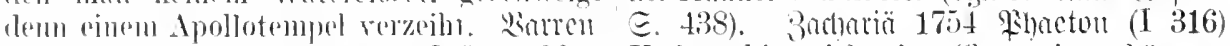

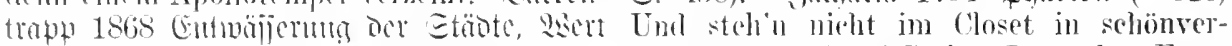

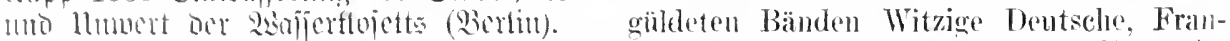

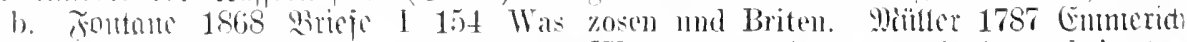
wïrden sie tun, damit os in der Kübebe III 115 auszuwittern, was in dem geheimsten ubcht rancht mol anf dem (loset nicht riecht. Closet vorgieng. Ifiummel 1791 Reijen

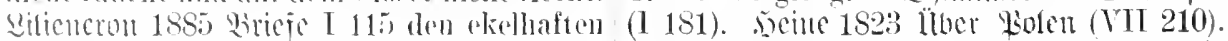
r'loserperrieht.

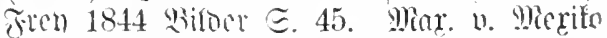

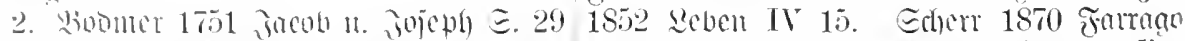

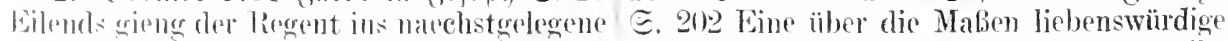
zimmer... E vouseh die vangen. Fam liran, gut. in heimlichen Klosett mit ihr

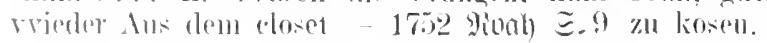




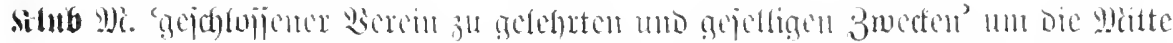

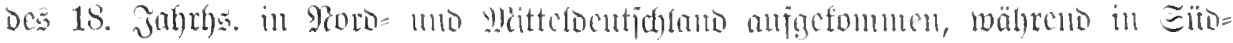

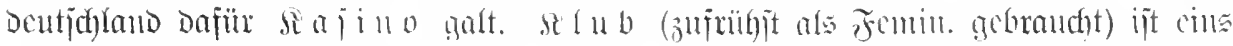

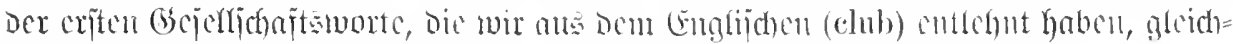

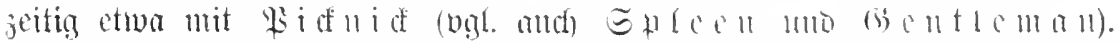

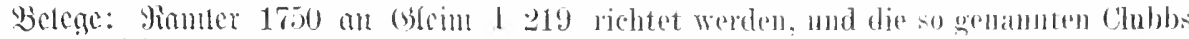

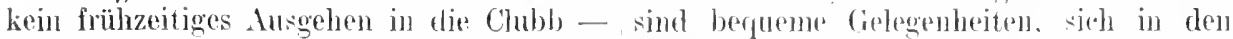

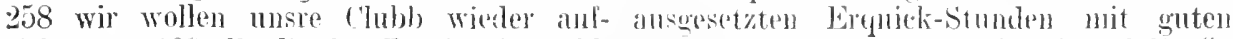

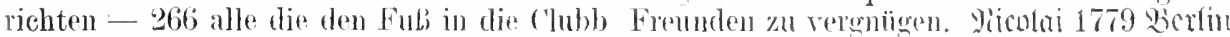
setzen diurfen - 316 Wir haben ilu soh E. T21 Sogenamute Ressouren und ('lubbs.

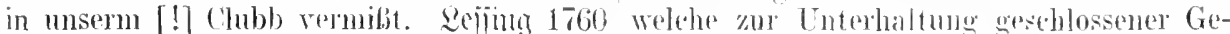

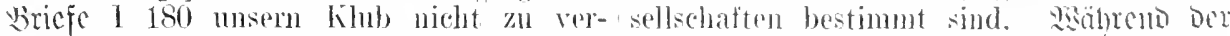

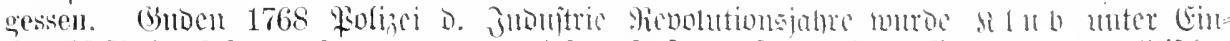

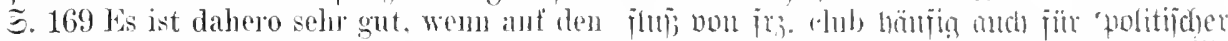

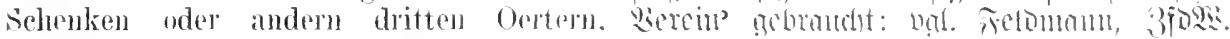

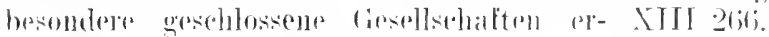

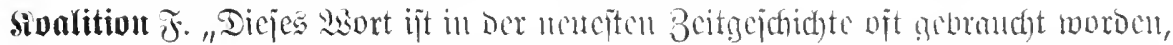

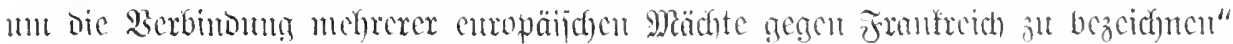

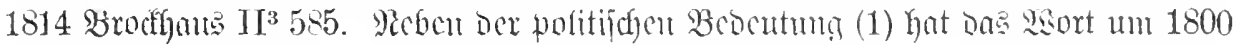

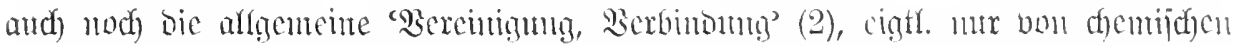

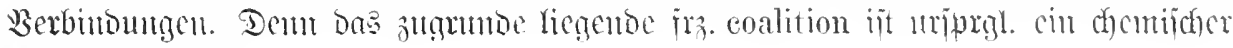
Ierm. tedfuicus.

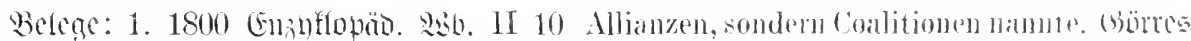
Coalition: Seit der franzosiselen Rerolution $181+$ \&olit. Eonriften I 255 Er sej noch immer wird diese's Wrort ofter's gebraucht eine Yer- reicher als die ganze Coalition, rïhmte sich bindung wider die Regierenden, oder iiber- Napoleon.

hampt zu einer politischen $\mathrm{Ab}$ siclit anzuzeigen. (3)octhe 1803 Serouemito Estlini $(44,336)$ alle Arten rou roalitionen nnt Teutratisationem, wodureh man die Herrsehaft zil erlangen und zu rinalten stucht. siscres

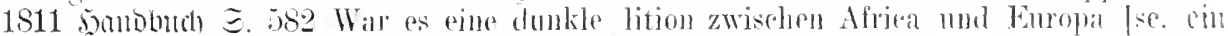
Almung daron. wemn se das Keitalter uicht sichespary.

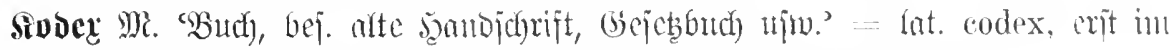

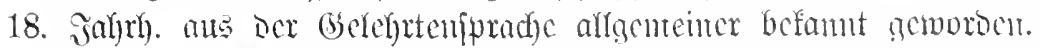

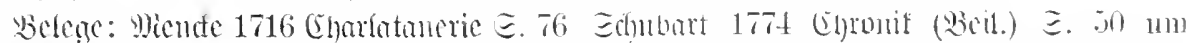
dab dieser so gar alte Codex mit einigem einen Codex ron Volkshedern drams zu

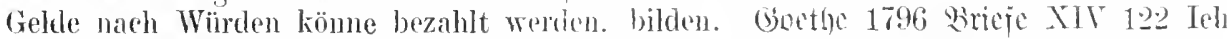

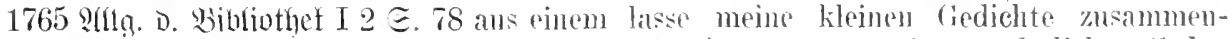
Kodex der Weimarischen Bibliothek. Bürger schreiben, worams rin wunderlicher Codex 1773 Bricje I 129 den elenden Regeln Codex. Pntstaluen wird.

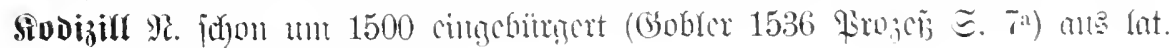

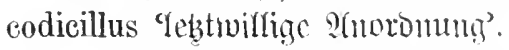

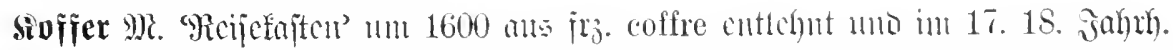

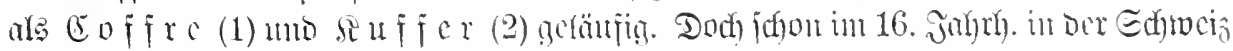

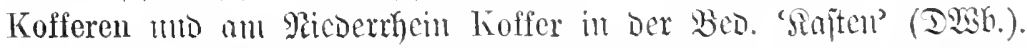

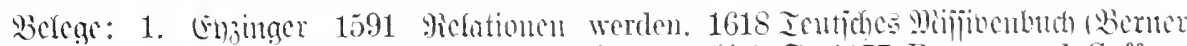

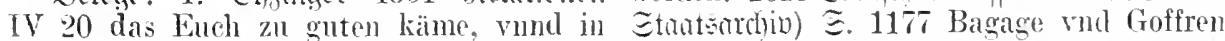
die Coffess oder Truhen golegt möhte [torrigiert in: Coffres]. Tuhman 1700 Eunat. 


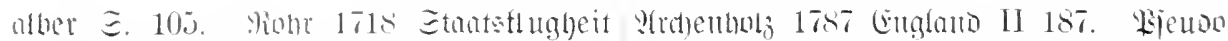

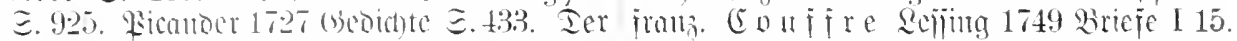

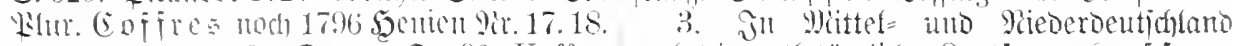

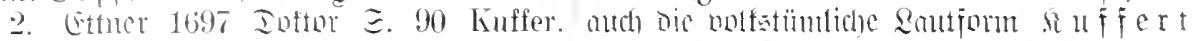

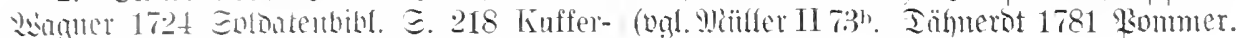

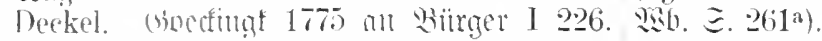

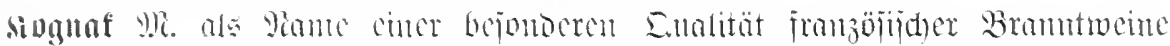

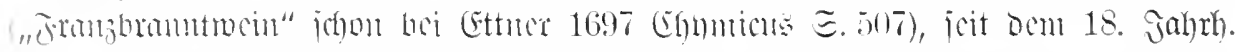

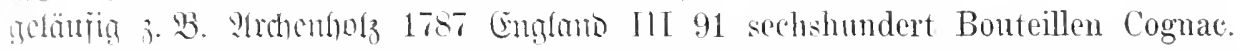

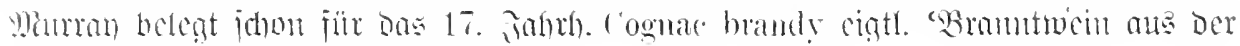
frambijithen Etadt Eogmae'.

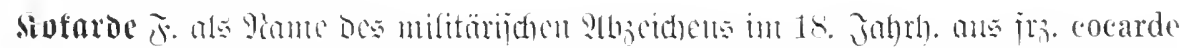

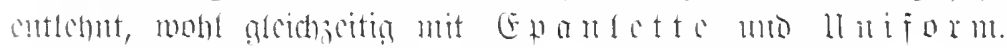

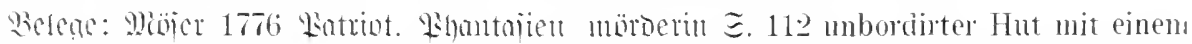
Il 6 i Der Landmann. der sein Hofgewehr weissen Knopf wie auf der C'niform. weisser'

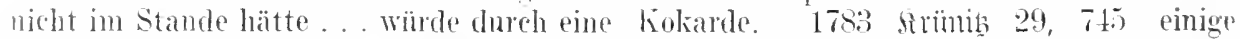
coearde am Hnte noch diirftiog geziichtiget [sumben] mit uniformen Kitteh. mit bunten

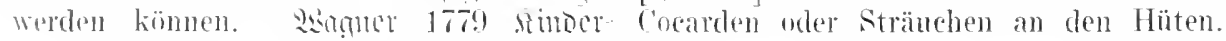

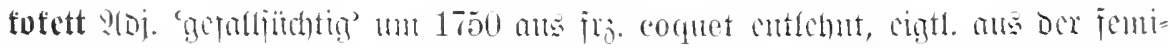

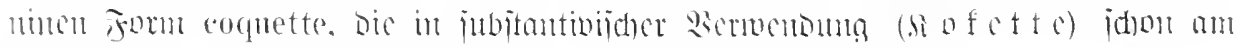

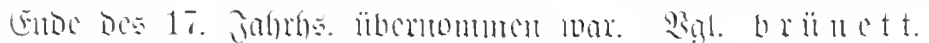

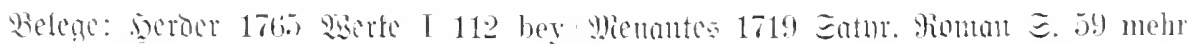

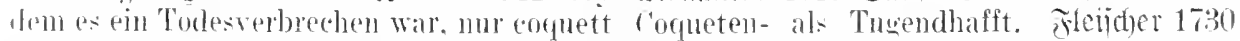

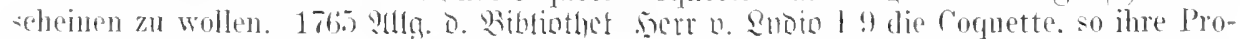
I 1, 1.28 es ist dab blobe trockne Gerippe fession ex fundamento rerstunde. Piniliphi

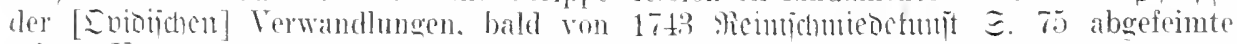

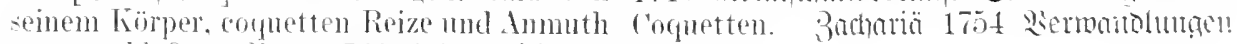
wanz entblöbet.

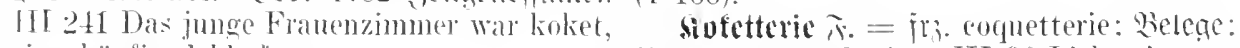
rigenkïpfig. lebhatt.

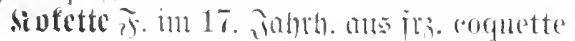

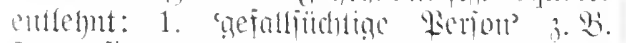

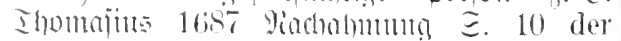
zum Exempel ein galantes und liebreitzendes framenzinmer für eine alberne und närrische roupuette sich zum licbsten wehlet - 1688 Wionatsgeinräche I s? thörichte Coquetten.

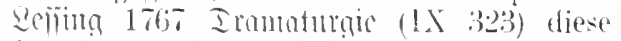
Roxelane ist bei dem llarmontw vine kleine märrischer l'urquette.

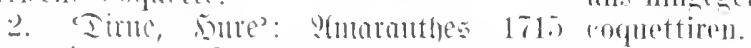

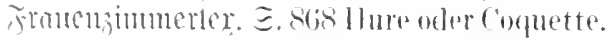

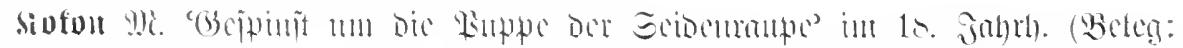

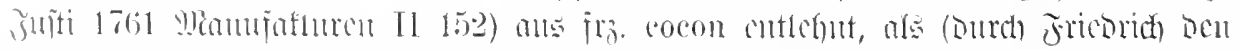

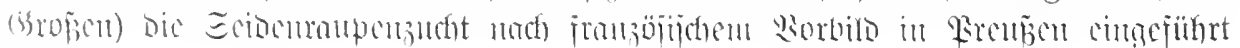
mutos.

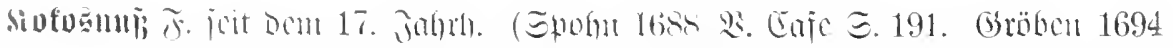

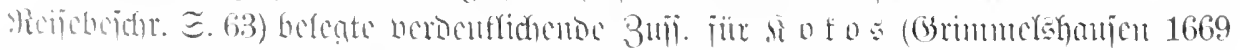

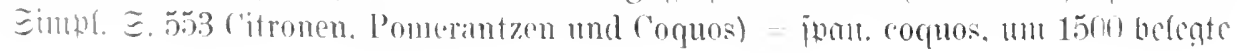




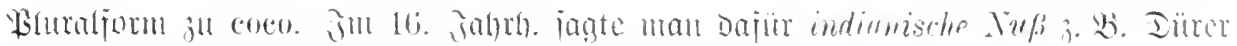

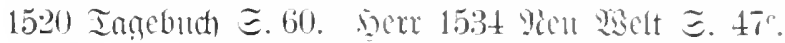

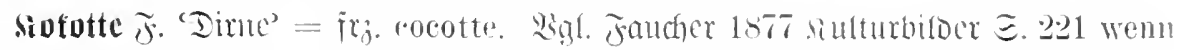
sie jetzt anch nicht mehr (irisetten, sondern mit etwas anrïchigerem Klang des Wortes, Corotten heiBen. Rimenberc 188.3 Bertin I 13.

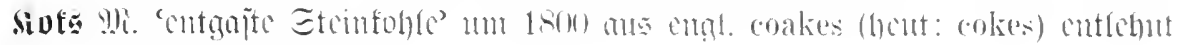
mo bei comtle 21813 gebudit.

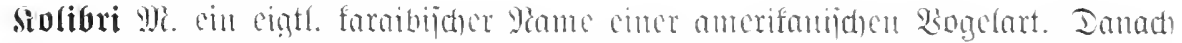

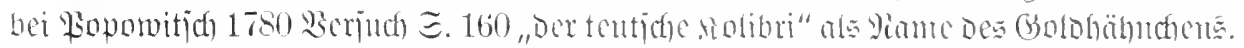

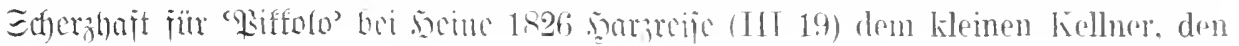
man Kolibri nemnt.

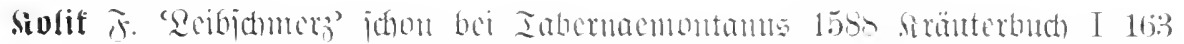

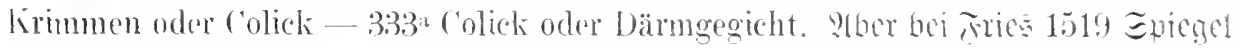

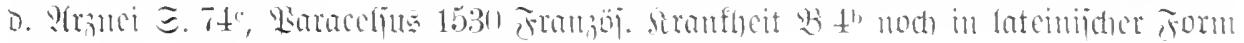

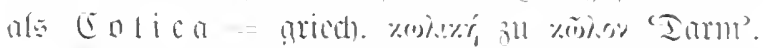

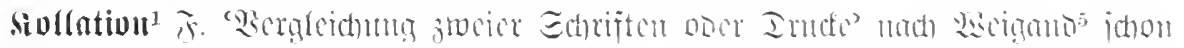

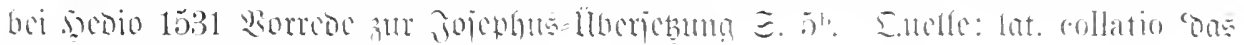

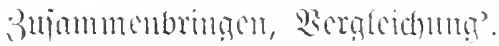

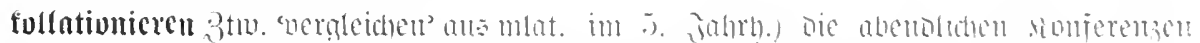

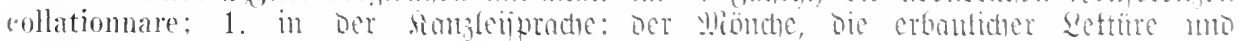
Fud

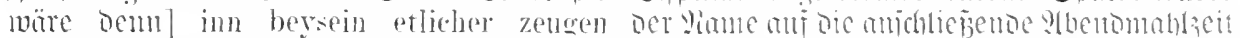

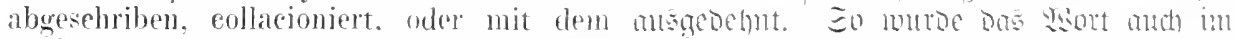

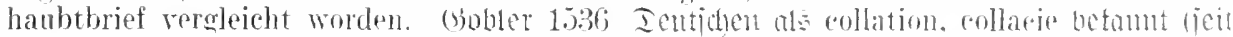

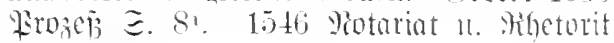
ङ. $6^{\mathrm{a}} .25^{\mathrm{l}}$.

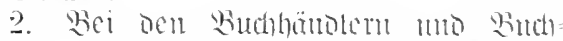

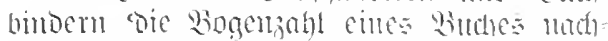

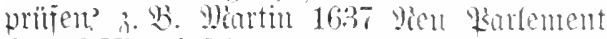
כ. 473 Xim, fal jenes rnd heffts, es jot gantz, ich habs collationirt: es hat gratt zwey alphabet.

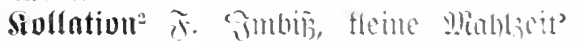

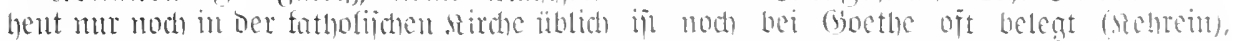

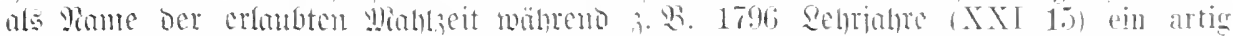

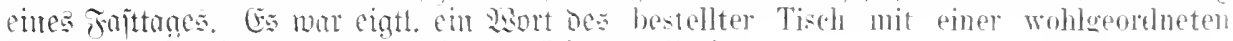
flöfterliden Suteins: collatio bejeidnete (ichon rollation.

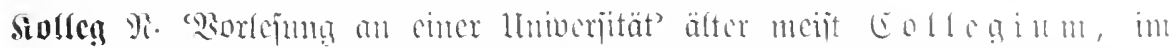

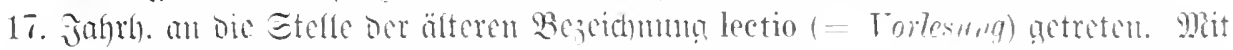

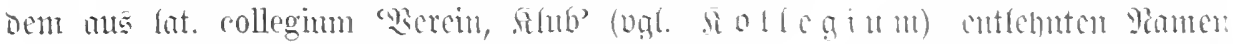

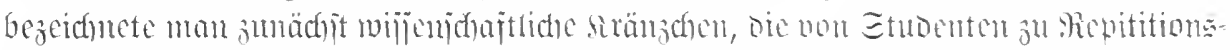

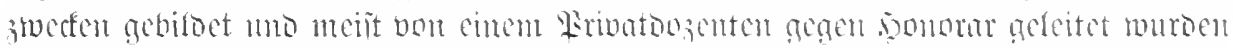

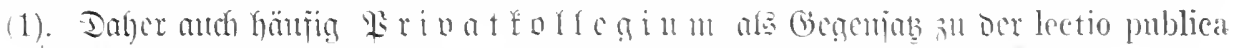

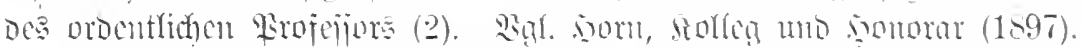

1. [stilin Berchtolo 1533 Eijputation quibus non pauci se jam exercent.] 1654

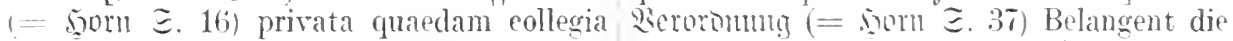
jpsorum ope et eonsilio instituta sunt, in privata exereitia. so man collegia nennt. 
jst vorkhomen das dio smolios mit dem honorariis sbernomen.

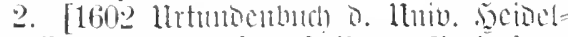
berg I 350 dan mehrertheils studiosi theologiate exterarum nationm haben neben den ordinariis mblicis lectionibus anch ihre privata collegia, logica physica und theological. daranfi sie die fürnembste zeit anznwenten pflegen.] Ercfendorif 1665 Tinjten= ituat II 128 dafo er etwa anff einer ['niversiait ein Jahr oder drer kümmerlich seine liost habe mud die langweilige lectiones publicas hören, oder etwan ein par privat-collegia (wie man sie nemnet) umb etliche Gïlden des Jahrs lialten kam. Sevije 1673 Grimmen E. S6 Lnb neun jot ein privat collegium iiber das Griechische. Echilfer 1789 Siticic II 193 Meln als ein Privatcollegimm gedenk jeh nicht \%u leselu.

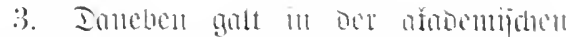

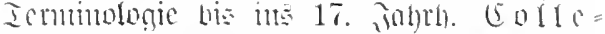

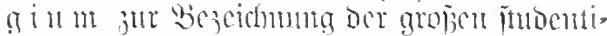

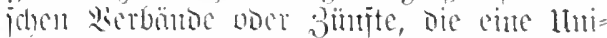
beritait bilieten (wit das ental. college, bgh. Mesict. II 6234). Iaher bej. anth bou den

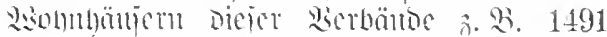

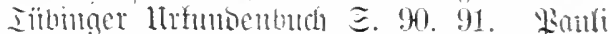

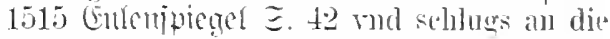
lirchthïren rnd an die Collegien. S(bentin 1521 Wanr. Chroutif (I H1) collegien and

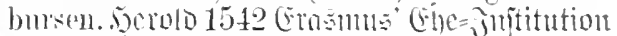
こ. 181" als da seind anff den sehnlen. die man etwa Collegia. etwa Burse nemnet.

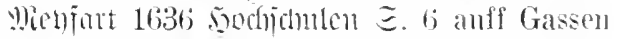
rnd Stritsen, vor den Tempehlu rnd Collegien.

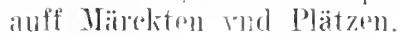

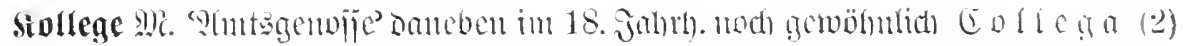

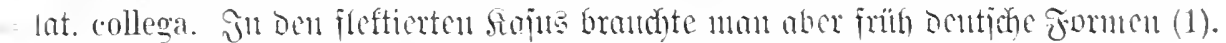

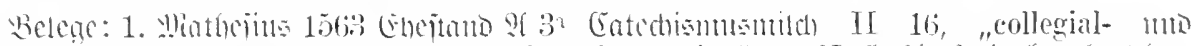

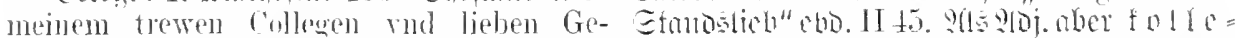

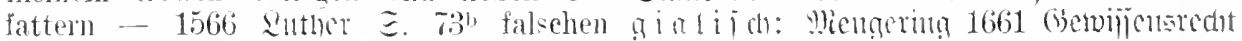
Predigem rnd Collegen. 将njart $1636^{\circ}$.

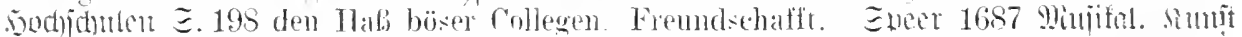

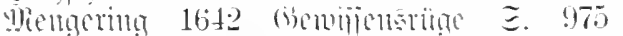
solcher Schul-Collegern Wolfartli.

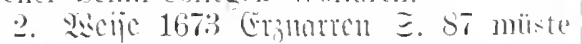
rin college die logieam alsu tractiren. -

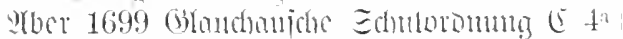

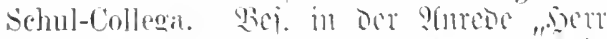

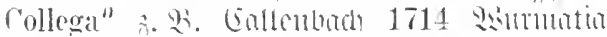

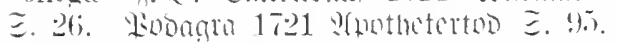

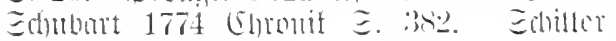
1801 Immond II 4 .

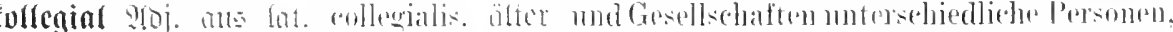

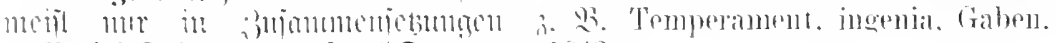

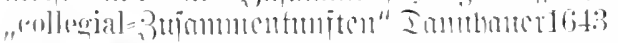

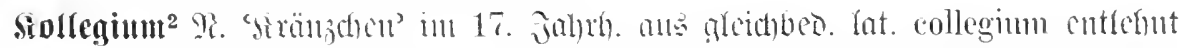

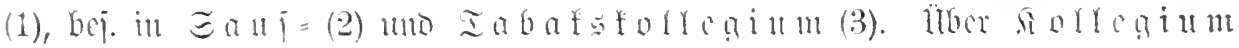

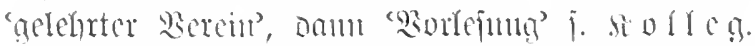

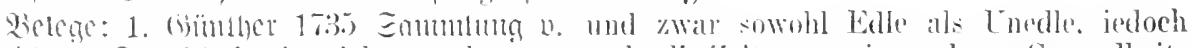

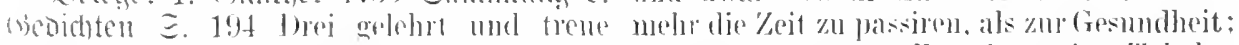

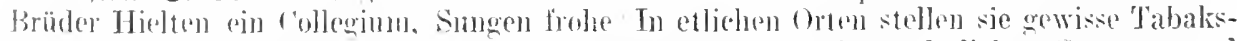

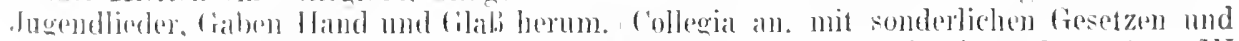

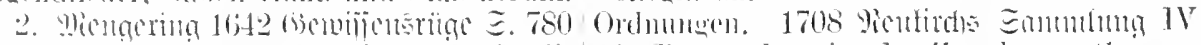

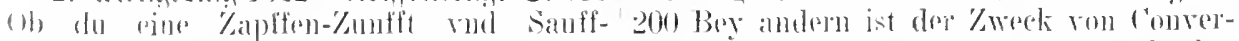

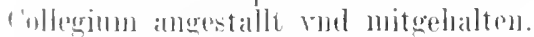

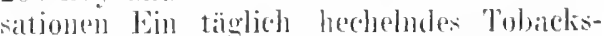

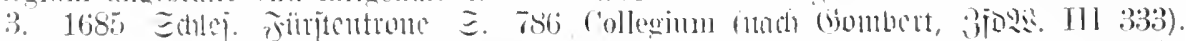

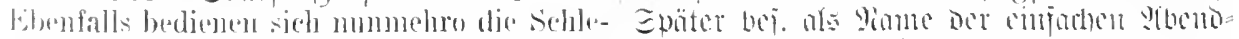

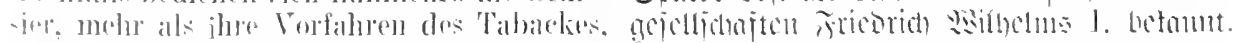

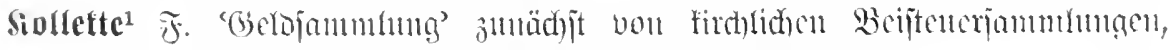

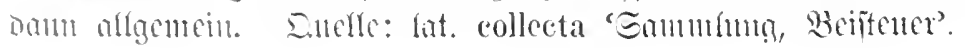




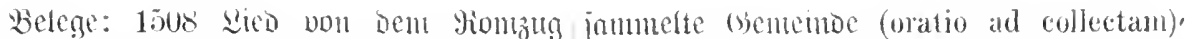

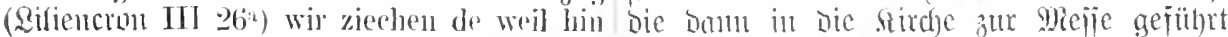

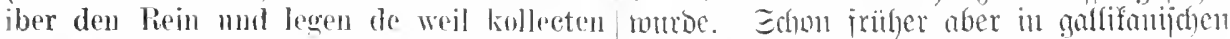

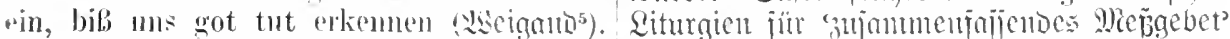

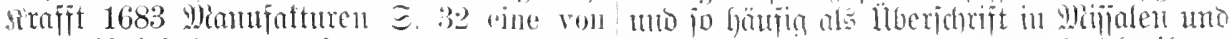
hoher Obrigkeit consentirte publique Collecte Breviarien. Belege: (llu 1450) Bejd)reibung

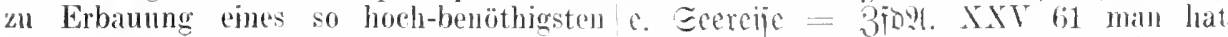

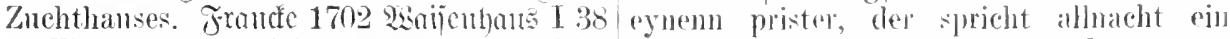

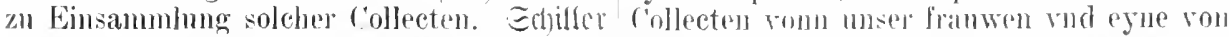

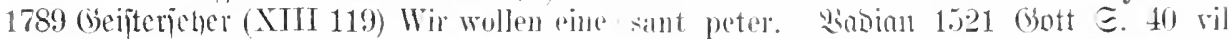
Kollecte machen.

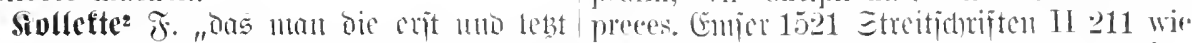

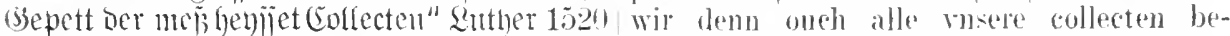

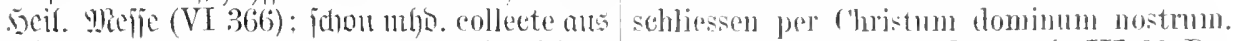
unlat. collecta cutlebnt. Collecta bezeidnut Each 1532 Jobehn u. Edhmänfe IIT 90 Der

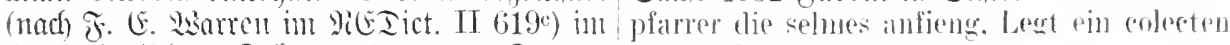

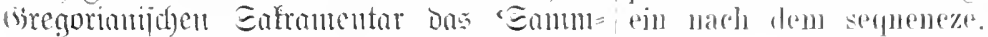

humgegebet, ל. h). Das Giebet an bie ner-

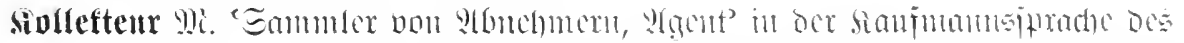

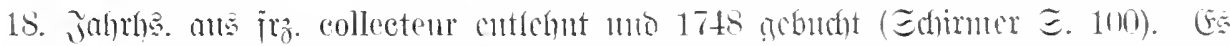

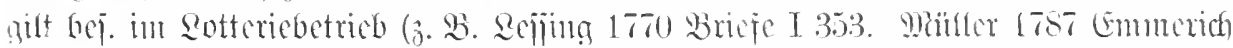

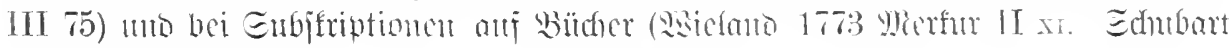
175 Chronif $\Xi .343)$.

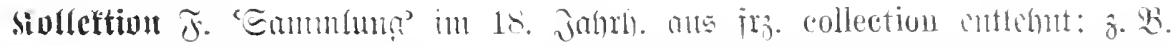

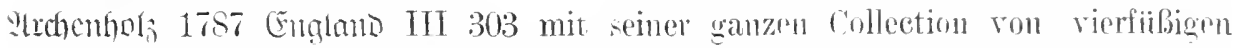
Theren - Capitain Cooks Privatcollection südländiseher Hausgerätle. Enäter

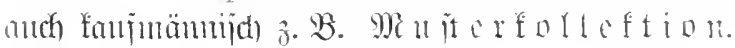

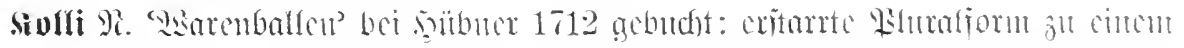

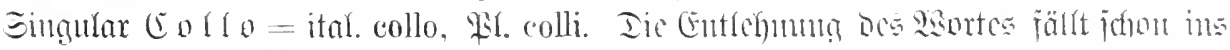

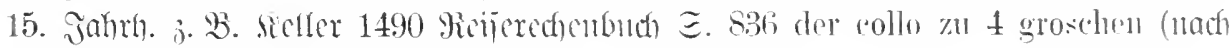

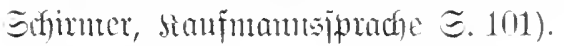

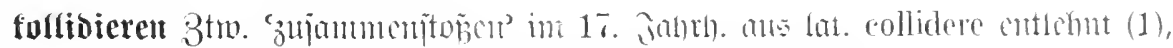

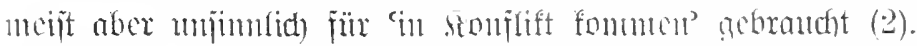

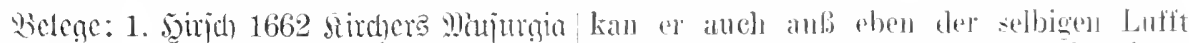
こ. 5 Nicht genug ist es zur production deb bewegung rmme c. aime Stimme formiren.

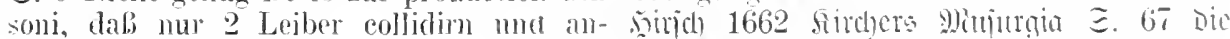
einander stossen.

2. Dorned 1684 Diterrein E. 175 Wamm dero wegen beyde collidiren, so ists billich. dab die Kauff-Lente zurnck stehen.

Winijit] hat gleich im Anfaug der Walt ihren [rsprung genommen aus mannigfaltiges $c$. der Leiber. anfïnglich ('. zul rejmeiden. ano

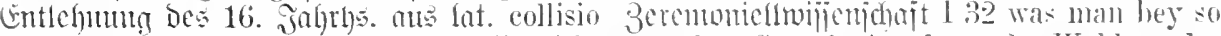
(1). Qdelg. geläufig ijt nu oer uminulidge manchen C.-en, in Ansehnng des Wohlstandes

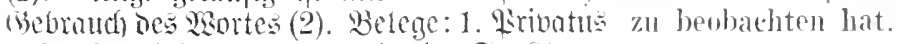

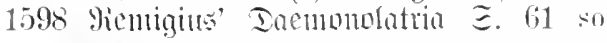

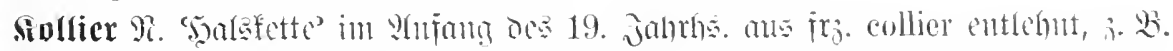

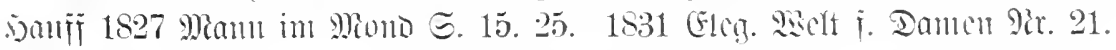

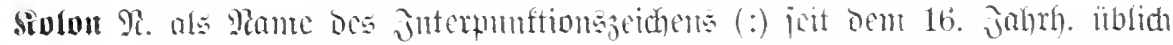

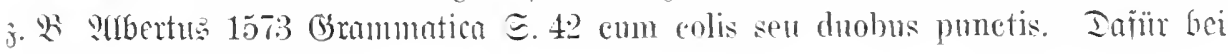




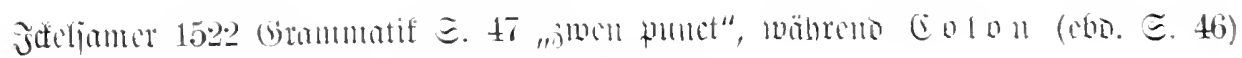

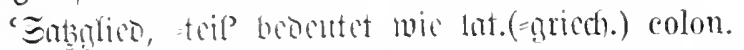

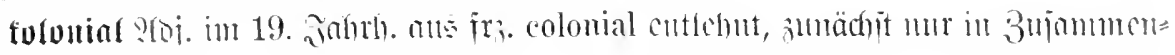
ienmitich.

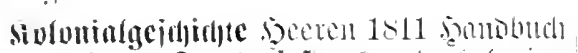

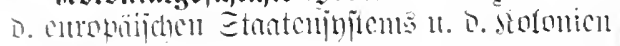
$\lesssim 608$ ?tum.

Sivlonialfantod becten 1811 inamobuth

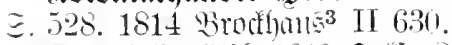

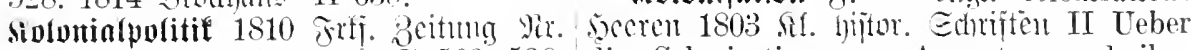
135. Decren 1811 smobuch ङ. 503. 526. die Colonisation von Aegypten und ihre

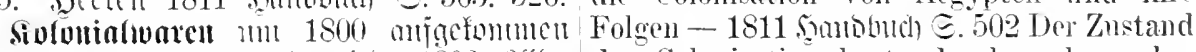

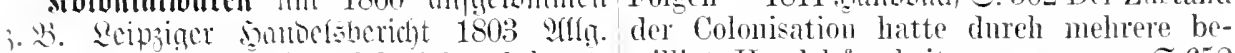
3 citumg 5.989 (nchen Kolunialprodukten), willigte Handelsfreyheiten gewonnen- -5.652

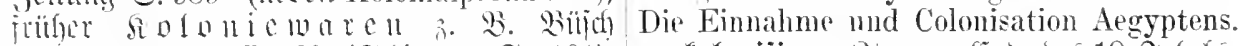

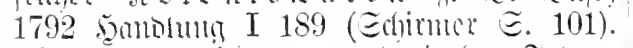

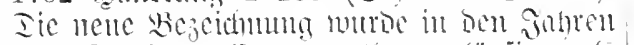

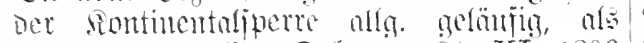
Viapolen Bertiner Iefret 1). 21. XI. 1806

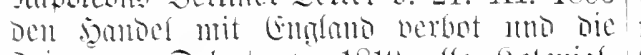

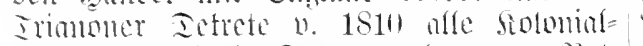
manen mit $50 \%$ Etcur belogten. Bgy. Senturiti 1810 an Ed)its (II 513) die mwliickliche Ifabregel wegen dor englischen Fibrikate mol Colonial-Waaren. Comme 1813 Für Colonialwalren. woron jetzt so oft die Rede ist.

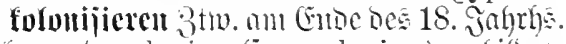
nad) ellẹt. colonize ( $\mathrm{fr}$. coloniser) gebilaet:

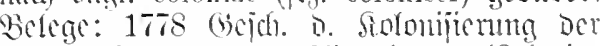

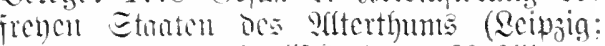

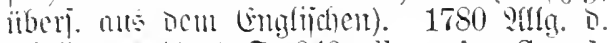
Wibliothet 41,1 E. 242 allgemeine Grundsätze der Verfissung der bürgerlichen Gesellschatt und der Kolonisirung. Weeibel 1836 Fotted 16 . Selofers Etmatsterifon III 532 die Mittel aler Kolonisimmg.

Sivluniit mi. me engl. colonist j. 岁.

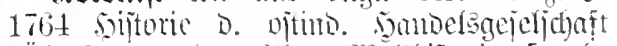

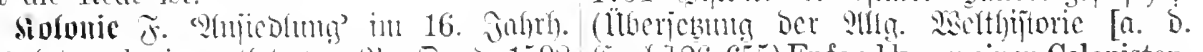
an fot. colonia cutfebut is. ㄴ. Ento 1598 (Engl.] 26, 655) Er fand kaum einen Colonisten, Enchiridion @. 290 Fünfl spanisehe Colonien Mannfacturier oder Soldaten. Echnbart 1774 and daselbsten: Salta, Steo, S. Yrichel, Chrout E. 179. Miojer 1775 Phantajien I 179.

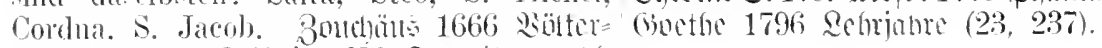
recht E.2.2. Scimir 1670 Eecuritas mut.

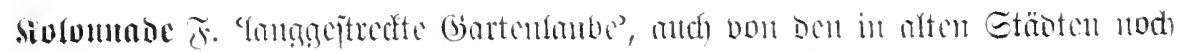

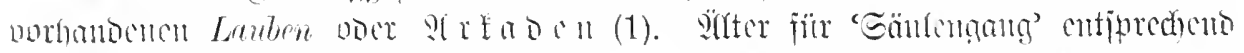

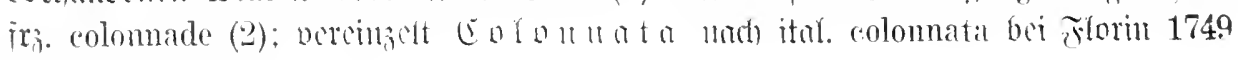
r)alsuter II $476^{\circ}$.

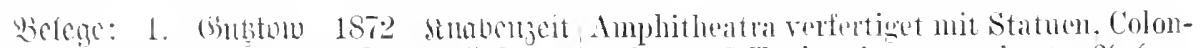

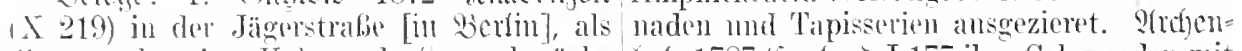

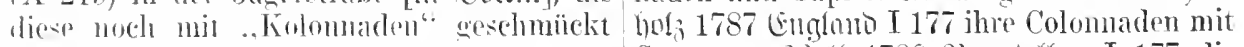
war.

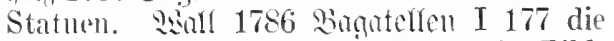

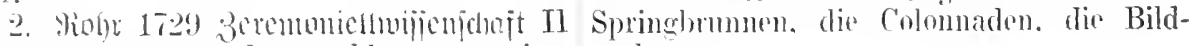
185 Bifwrilen werden wohl gall corwisse silulen.

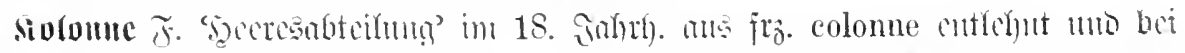

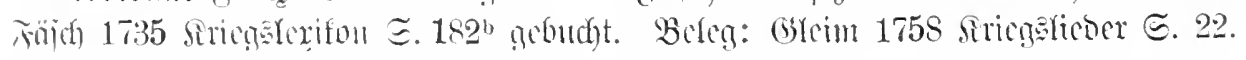

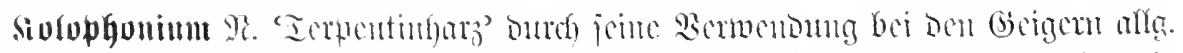

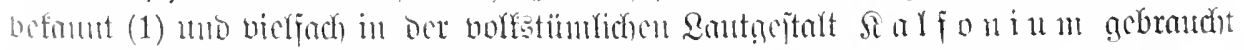

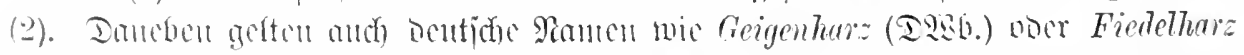

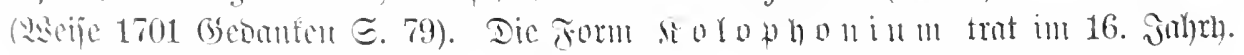

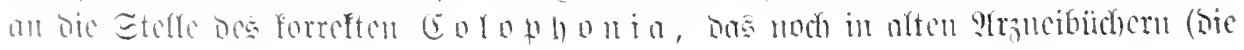




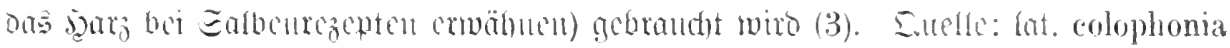

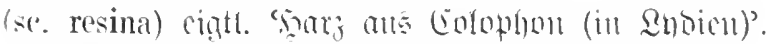

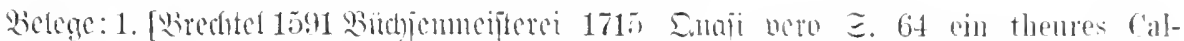

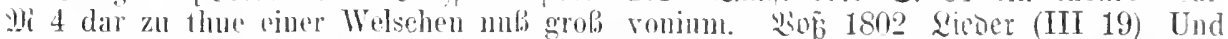
Colophonium, das ist. Ciriechisch pech.] bestrejcht den Bogen tüchtig mit Kalfonium.

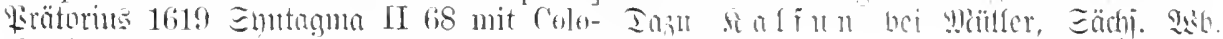

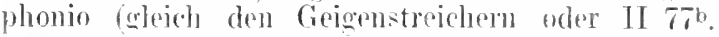

wie es sonsten in gemein genenuet wird den Fidelbogen) bestrichen. Martin 1628 (Eollo ques Є. 106 bald ein rollen ron Instrumentseitten. hernach Colophonien [i. 11. 3].

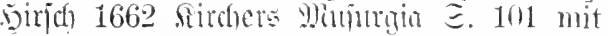
Hartz oder Colophonien [i. u. 3]. (ifrimmel:baupen 1673 Iettidger Midhel ङ. 61 man maç] das Colophonimm Geigenhartz nemen.

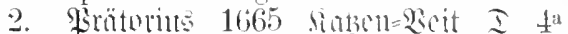
man mache rin halb Schock I'ferde Schwïntze in den Bogen. rnd verschmiere dran olrich rin Pfund Calefonien [i. 3. 3]. Callentuads

3. Vogter 15331 Y(rancibüd)tein こ. 13 mit Colofonien. Qudhenterg 1532 Qfrotei= bitctrein 三. 14 Colophonia. Faracelju 1536 然montioi $三 .30^{\prime}$ ein pfund wachs, colofonja, schusterhart\% - $こ . ~ 55^{a}$ mit den pflasterm. so mit rolofonla gemacht werden.

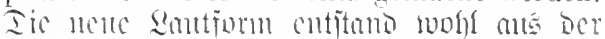
flettierten Fom (L)toll)

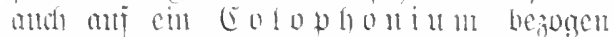

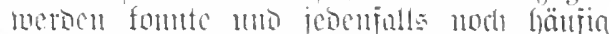
neben ben geutnm ericheint i. o. inter 1:

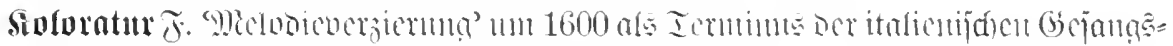
funit befount actomocu aus ital. coloratura.

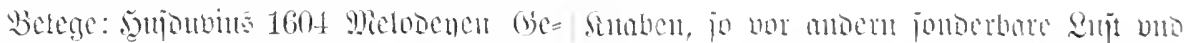

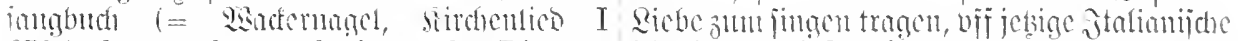

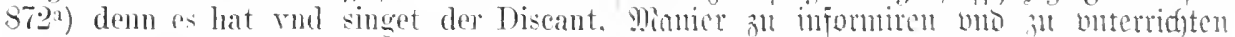
welcher stets ohen stehet. die gewöhnliehe icmu") 232 Fürs ander muls der Sänger rud sonderlich dieser örther bekandte Nelo- rechte Wissenschaft haben, die Diminntiones ley, welche dam auch gar nicht mit colo- (so sonsten in gemexin Coloraturen genemet raturen rnd weit rmbher fahrenden Kunst- werden) lieblich vnd Apposite zu formiren gengen schwär gemacht werden. Litütorite 229 die modnlos oder Coloraturen (so von den

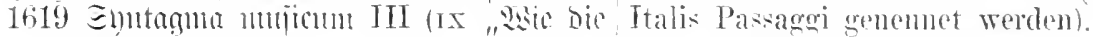

foloricuen 3tm. 'ansmtalen, färben' in 16. Jahrb. ms lat. colorare cutfen) 3. B. Mathejus 1562 Earenta E. TS wie atliche Alchimisten das Kupffer also Colo-

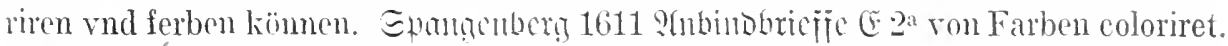

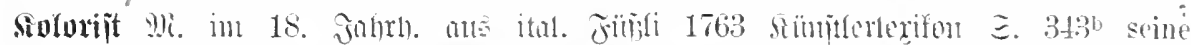

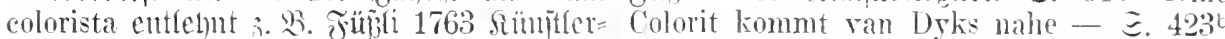

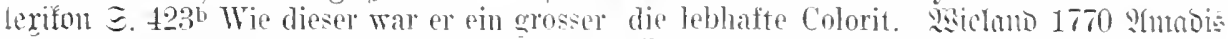
Colorist - こ. $481^{\prime \prime}$ der treflichste Colorist. If 132 Damen. rou jeder Colorit (8foss.

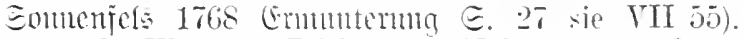

nur zu der Klasse der Zeichmer und Koloristen herabzusetzen.

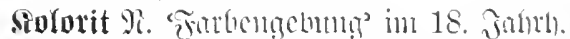

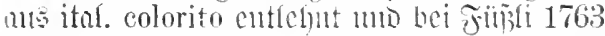

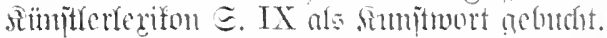
Buprithint gilt feminimes bejehledit (1), dos

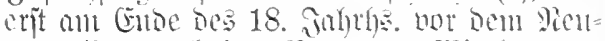
trum (2) zuninftritt. Belege: 1. SAindelmam 1755 Gedanfen こ. 37 Perspectir. Composition und Colorit spricht man ihnen ab こ. 3S In der Colorit. Seriing 1760 Diteratm= uricie (VIII 221) die Sprache ist die Colorite.

2. 1759 Q Qiculais Eammulunt II 167 die Manieren in de Mnsik. das Colorit in der Mahleres - $1760 \mathrm{cbs}$. IlI 75 Ein sehr guter Kenner der Mahleres nennt das Kolorit des Unterhändler seiner Schwester. der Zeichnme. Geroer 1764 然erfe I 5 das Colorit, den Glanz der Einfalt. Imjo 1765 Brieje II 16 durch das Colorit, was ihm die Hand eines Shakespear oder Dantes zu geben weiß. Sejïn 1767 Iromutumie (TX 233) das nationale Colorit [emes Trameis].

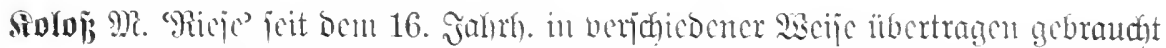

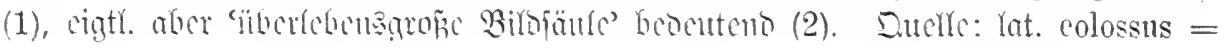




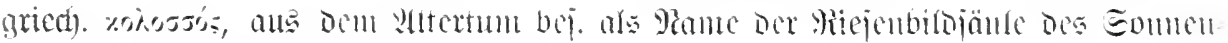
gottes auj ocr Jujel gihoods befarmt.

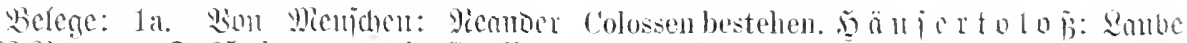

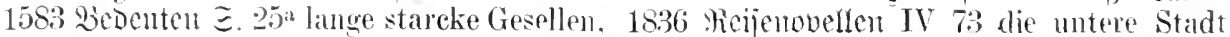
so da stoltz vol viel von sich halten, alleine unit ihren steinernen Häuserkolossen.

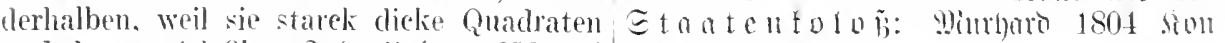
and lange f'olobi. inf. Wiafor 1653 bei itontinopel II 21.

Dorobortfer, Erquictumben III 196 Colos: grob, doch kräfften lof, du briistest dich mit

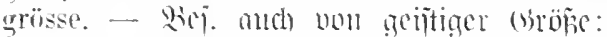

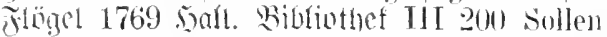
wir unste guten köpfe awig neben jenc Colossen stellen. Eihiller 1781 Büuber (IV 65) Dats Cresetz hat nodh keinen oroben Nann gebildet, aber die Freiheit brïtet Konlesse und Extremitiiten ans.

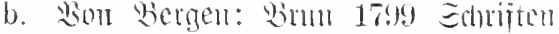
II 98 diese mäehtig aufrethiirmt (no Kolossen.

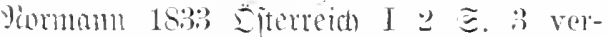
wittertes Gestein auf der Basp des Kolosses.

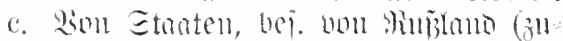

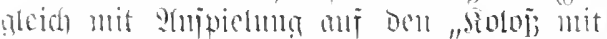
tönemen Fiijsen" oer Bibel, Imnel 2, 31)

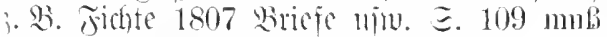
beiden Staaten daran gelexen sein, sich gegen den Colos in Norden anzustammen (D26.). Chamiijo 18:1 Sic Rerbonuten (IV 57) Lab cine Zeit noch laden Sehuld anf schuld. sich dehnen and antliäiften den Kolossen [Rughtomo], Umfassen eino halbe Welt. Saube 1833 gienc inhrmmert I 11 Xoeb ist's ein asiatischer Kolol. mit vielen anfepefropften Kulturleism wher Kinltur.

d. Won sounjern: i. 11. 3.

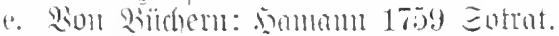
Enofmindiafeiten (II 14) Stamley mond

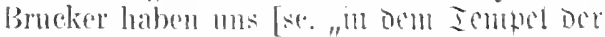
(belebrianteit"] Kolosien endiefert. dir eben so sonderbar und murollendet sind.

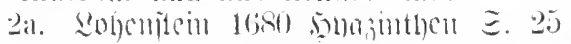

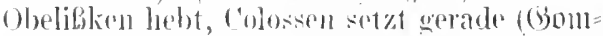

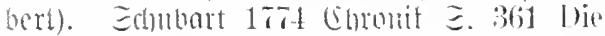
steinermen rolossen whichen. Suctor 1788

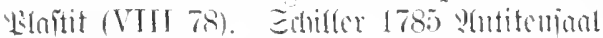
(. 1711181 ).

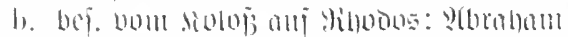

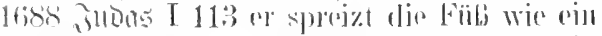
anderer Colositls za Rhodis. berter 1767 I. Silerotur (I 364) Ist dats wondersame Bild ain 'Tratum? - Es ist rin erober colossus.

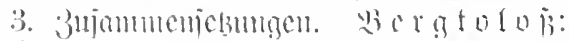

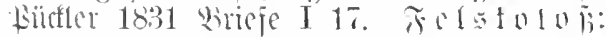

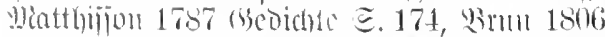

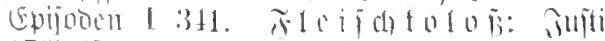

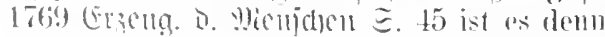

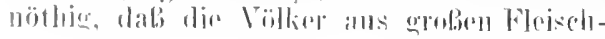

folvijal gioj. 'ricigg' im 18. Tabrl). (วu=

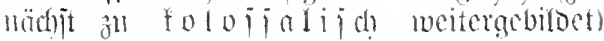

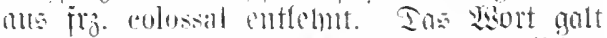

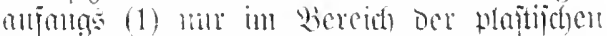
simit (bgt. selojial bï ite), wiro aber

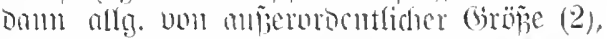
irïl) aud unimulich (3) acbrondht. Eo tomite

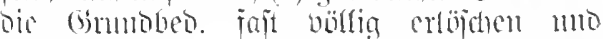
folojial in cimemi oit mingmanden Beritärfungsmort meroen. Bielegr: 1. Edhlegel 1801 Rorlemmen I 72 der k.-en Gestalt

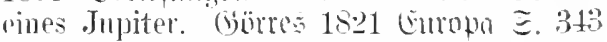
in den Haaren sejuer e.-en Bilder.

2. 2omm 1800 Ednriften III 17 die k.-en Massen - 1806 Epijonsu I 275 seme [oes Berges] e. ill:gerindeten Schichten. Gürres 1821 (Emron E. $346 \mathrm{Da}$ in diesem Streite alles in grobon k.en Massen sich bewegt. Geme 1830 italien (III 2022) k.-e Banwerke.

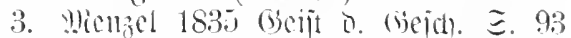
In (hina ist die sterblichkeit an rolossalsten. Liüfter 1835 Eemilajio I 31 i eine k.-

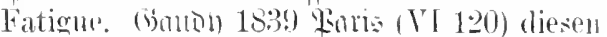

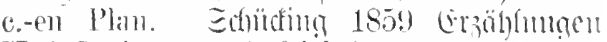
II 215 eime ध-1' Anfrichtigkeit.

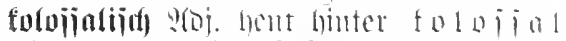

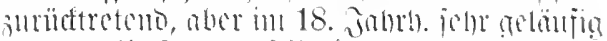

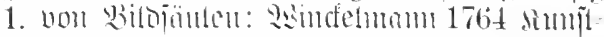

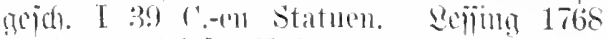

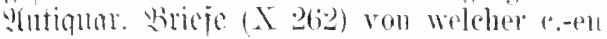
Cröbo die Fignren des Vordergrundes an-

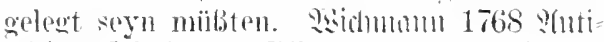

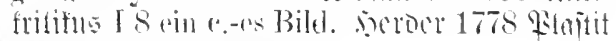
(VIIl 74) K.-f? Figmen.

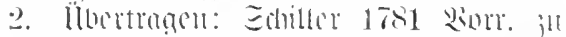

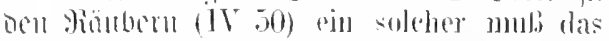
Laster in seiner natekten Abschenlichloeit enthiillen und in seiner ki-ent Gröbe vor das

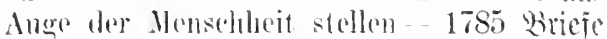

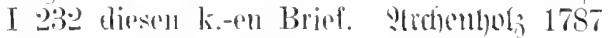

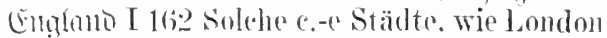

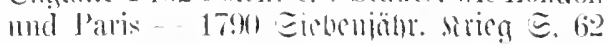

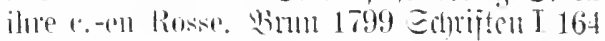

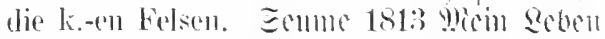

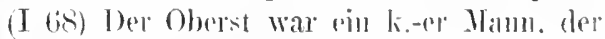
anflat wie ein Herkules.

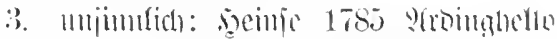
I 313 den külnsten kolossalisehen Fir-

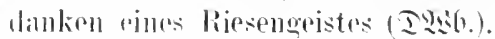




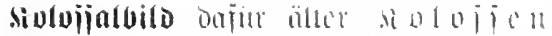

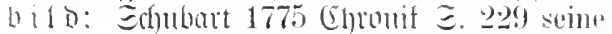
zwergengestalt am Kolosienhilde limanfmessent.

Sivloijalbiijte oft bei \&un 1800 Edntiften III 128. 141. 346 [bieje Etelle miro $\Xi$. 428

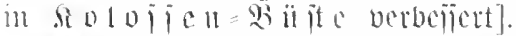

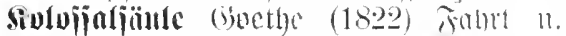

Hogras (2. 9!(n) IX 110) Ifr Imtut steht ils prächtige tuscanische Colossal-Säule ummerklich kegelförmig abmelmmend.

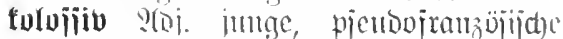

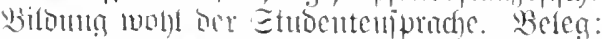
Etinoc 1886 siondertmone $\Xi .100$ was man jïhlich für Theaterzeitungen ausgeben mul; das geht ins Kolossive.

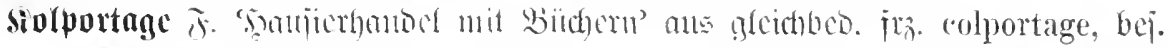

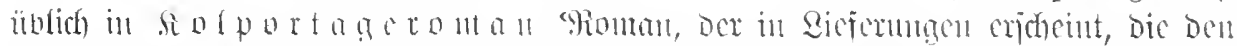

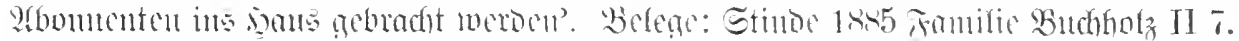

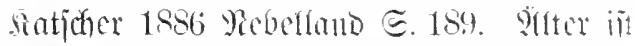

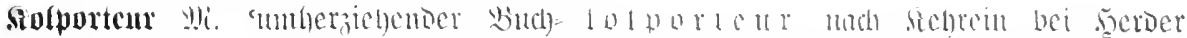

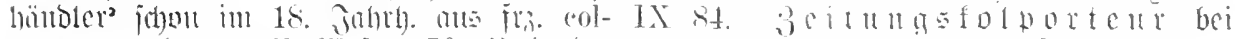

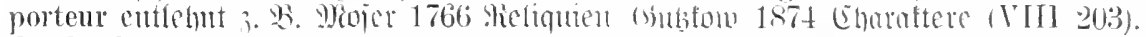

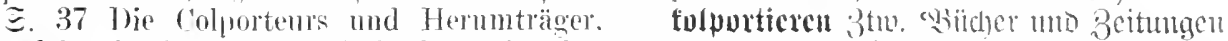

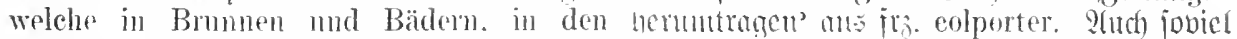
Hänsern unterm Mantel dergleichen ver- wis 'veruitteln, weitergeben' $3 . \mathscr{S}$. Siorban

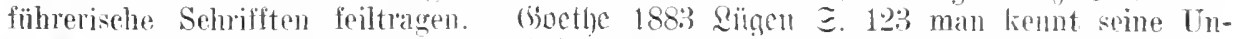
1774 Clavigo (XI 6it). Foriter 1791 :(njidhten wissenheis. man kolportirt seine mortho(III 209). Wabtot 1791 Ecbensucjor. TII 162 eraphischen Briple.

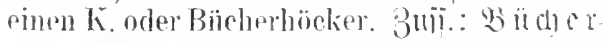

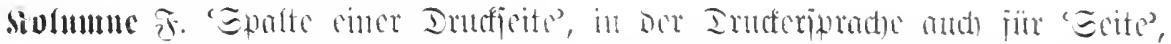

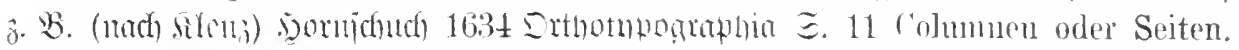

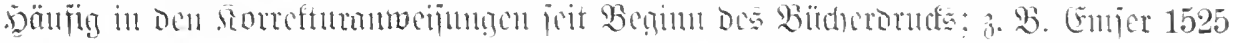

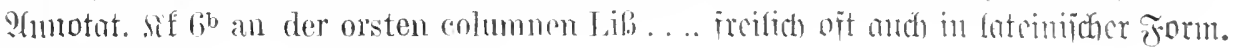
Eutelle: lat. columna 'sänle'.

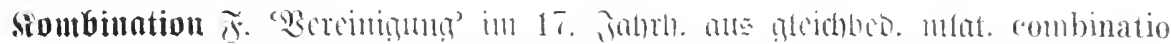

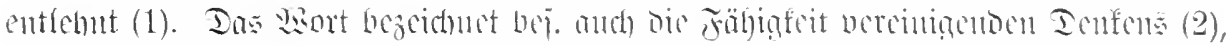

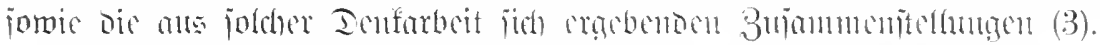

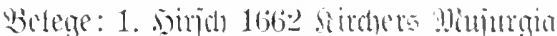
$\Xi .11$ Vullershiedliche speeies soni mitstehen ans derselben manigfaltigen $c$. und $\mathrm{Zn}$ -

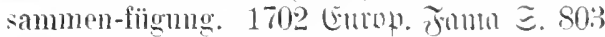
die C. der Frantzosischen und Spanischen Macht.

2. Ecifing 1768 Elomatmaic (X 117) naeh den rerschiedenen Combinationen der hier vorkommenden Begriffe. Edhiller 1795 Totucuo. (Himan (XVII 456) Der Verstand beobacktet in seinen $\mathrm{K}$-en strenge Notwendigkeit - (457) Durch Gesetzmäbigkeit

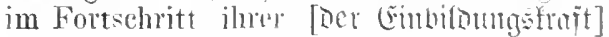
Willkür in K.-en schranken zl, setzen.

3. 1759 Vicolnis Emmutum II 162 ans dieser Vorbindung entspringen nome Verhältnisse. es werden nem C.-en möglich.

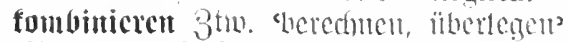
jeit Embe bes 18. Sulgrh) gelümitio (1), äfter in ber cigtl. Beo. "srjommentïgent, verentigen" (2). Ducle: jpätlat. combinare cigtl. 'je smei

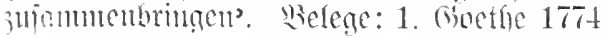

wirether (XIN 106) Wacht num dirrans was ihr wollt und rombinirt die möglichen Fälle. Echiller 1787 viricio I 3\% So sagte er. combinierte der l'rophet

2. Becter 1668 9lethonts Dibact. E. 94b dafs die Natur der Wörter and die Yatur jhrer Bedentmo combinirt werden. 1689

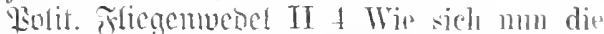
Verheisung des ewigen $\mathbf{H u m b}$ Gottes. mit vorvermehrten Zengmus. . werden rombiniren lassen, das ist mir zol begreiffen etwas zu hoeh. Savater $17 \% 5$ a romumento I 21 dieser innere Trieh kombinirt anch mehr oder weniger dis Erfahrungen die der Venich macht.

3. Bei. "tombinterte Flotte" = Flottc

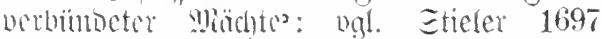
3 citulngant $\therefore$ v. Pombiniren. Zusammenfïigen. als die Combinirte Flotten so aus Engell- mud Holländischen Schiffen bestehen. Relege: 1702 Emop. Fonna $\Xi$. 119. Bidhat. wits 17.29 siur VT. こ.117. 


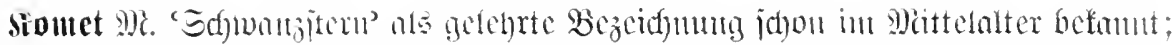
nyl. Fold 1482 Eprud v. D. Psit 3.42 und die cometen mit den swenezen, die man in teutschen schöpffsteln heißt. Eutclic: lat. cometa, cometes = griech. \%suris: rightl. 'Şarajterm'.

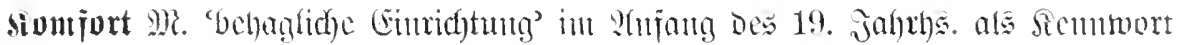

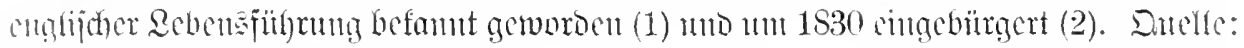
cual. comfort eigtl. 'Behag̣lichteit'.

Belege: 1. 18013 eitming T. D. eleg. sielt 9r. 46 ङn. 366 Der C. der Engländer läBt sich durch solche gleichgültige Dinge nicht stören (B⿰氵工贝 Buff (VII 2+1) sein eigner $K$., sein rigner, unmittelbarer, persönlicher $K$. ist der große fregenstand all seiner Wünsche - K. und Unabhängigkeit, unter dem einen rersteht er die Beflugnis, sich alles zu kaufen, was zu seiner bequemsten Behagliehkeit beitragen kann. Fïctler 1831 Bricje I 3 Ich gab mich dem Gefühl des C.-s recht con anore hin, das man nur in Englant vollkommen liemen Imont (Miener Pir. 34).

2. Revunio 1836 Sqquarefle I 261 Man vermißt dort nichts ron dem eleganten C., der die Gasthänser am Rhein auszeichnet. Sanbe 1837 reijenoverfen VI 130 diese größte Einfachheit, der Nangel alles moternen Komforts, der Mangel der (rardinen, eines Sophas.

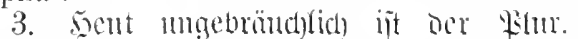

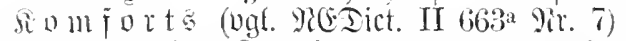

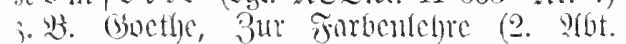
IV 142) weil alstam nach wiederhergestellter Communication der Reichthum und die C.-s der Englïnter dem... Franzosen gar wünsehenswerth in dis Angen leuchten miissen. Wenget 1836 I. Riterntum IV $323 \mathrm{Er}$ hat von seinem stande nur dic C.-s, umr den fein'n

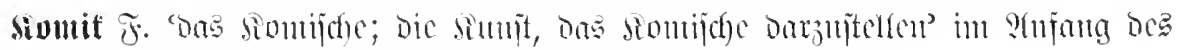

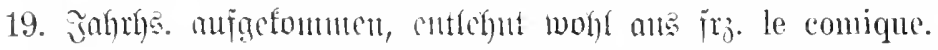

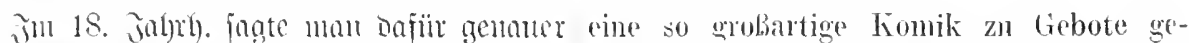

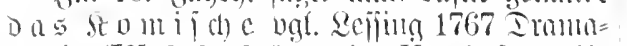
turgic (IX 212) dab' "r, im Komisehen, die Rolle des Falstaff $\%$ ihrel gröBten Follkommenheit g(brachit - (293) Mnster bines foinem, höhern Komischen - am wahren Komischen so geringhaltig. SEem ipöter Dö̈ür bas fem. Si o m if ïblich mumber, jo

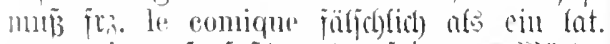

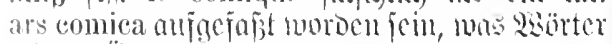

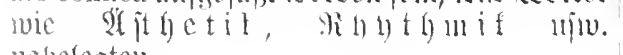
milecegter.

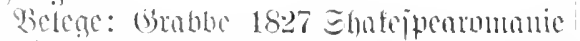
(I t59) Solten jodorts hat rincen birhter

Epikmräismus, die sehönen Sitten beibehalten.

fomportaber s(oj. 'behnglich), Bebaglichteit bicteno' = 'mal. comportable. 1. nod) als

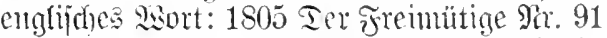
ङ. 362a Nitten im Walde glauben sie in dem Hotel garmi ciner großen Stadt zu sein und sie gestehen auch selbst, weml sie in England verwöhnt wären, daß es hier vollkommen comfortable sei (37s Miattrinion 1819 Edfripten II St Was die Engländer in ihrem comfortable zusammenfassen, war die von dem höflichen und zurorkommenden Wirte mir angewiesene in der vollen Bedentung dieses Wortes: traulich, anheimelnd und fremdlich.

2. Ecume 1803 Enaziergang (II 53) Du siehst, dab man für das letzte Zipfelchen unsers dentschen Vaterlandes hier ganz komfortabel lebt - (III 149) es ward nicht eher wieder komfortabel, bis die Straßen bei Chalons wieder zusammenfielen. Scine 1827 Porofec (III 104) Trümmer eines zerschlagenen Riesenpalastes, worin sich meine Srele vielleicht komfortabel befunden hätte - 1830 Jtalien (III 243) wo die Kirchen nicht so komfortabel gebaut sind. (3) bremer 1836 Birber a. Sision I 130 Die Kaffeehäuser sind alle zu ebener Erde, reinlich, elegant, comfortable.

stanten als dim Shakspeare. o. v. $2 \dot{0} \bar{b}$ 1817 (inntsherren (= Dönte II 274) dam ists alleh ein treflich Ding um eine auf Zeit, Örtlichkeit, Beduinfuis im Gemeinwesen achtende, moralische Komik, Scrualo 1835 Ihentertivuc $\Xi .133$ Später wollte man seine Konnik trocken nemmen.

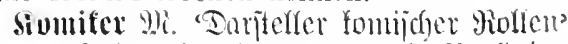

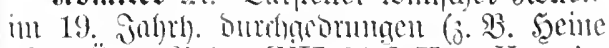
1823 ïbre + tulen [VII 211] Herr Vogt ist der K. Vionmm 1833 sfterteid) I 1 ङ. 44 cin beliebler K.) fïr äteres fiv $\mathrm{m}$ ifus (uad) bei Einchoorff 1834 Didnter 1t. ille 


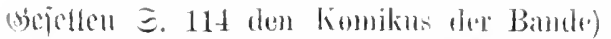

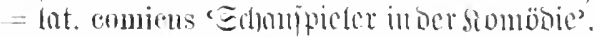

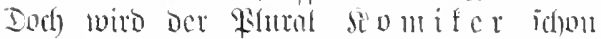
Im 18. Jabrh. gebranthe 3. S. Edhutio 1775

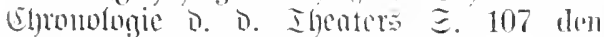
Originalwitz dentscher Komiker.

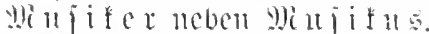

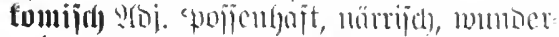

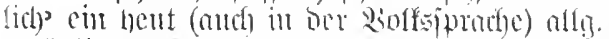

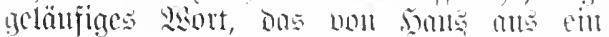

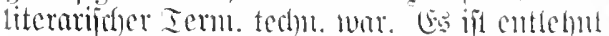
0113 lat.(sgried).) eomicols sult stombois

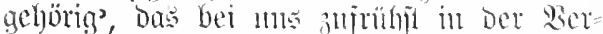
bindung comicus (poeta) siontiobicmbidnter

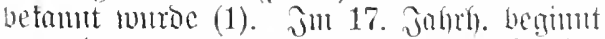

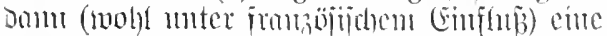

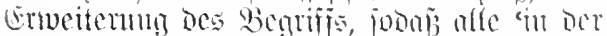

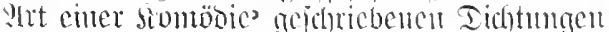

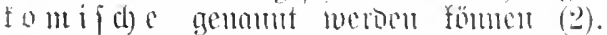

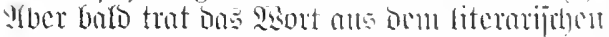

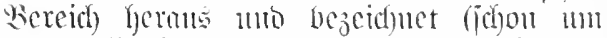
1740) alls ingenbruic Siomibimbafte, ift aljo

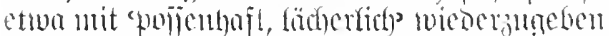

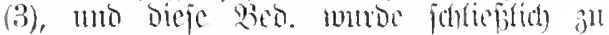

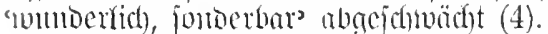

Belenc: 1a. 1499 liberf. ocs Teren E. 99" Wunderbarlich der Conisch poet rli des rinen worten zeigt, was der ander getm hat.

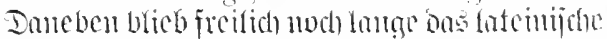
wort in bebrauch, andericits ïberipte man comiens poeta oit atud mit lustiger Pot;

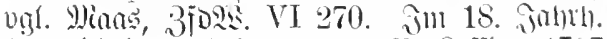

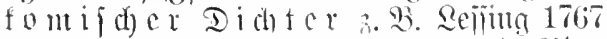
Dramtatmrgic (IX 233). 1769 sorthifhe sibbl. III 184.

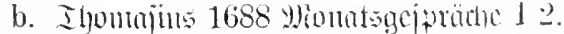
vion. ङ. 5a man wird durchgehends tie Sachen so darmmen enthalten sind, anf eime Comische Weise abgehandelt finders, in Comoedien aber trifft man mehrintheils alltägliche actiones. Edhegel 1740 Edhriften こ. 23 so ist es ein Fehler ron unsire ganzen deutschen Poesie nicht aber rou dor comisthen allein. Bobmer 1741 foet. Gemälor

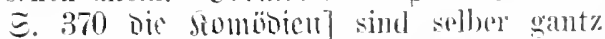
comisch. Dammun 1759 Eotrat. Ent wittsigfeiten (II 17) den komischem Schatten nines Thomas Diaforius.

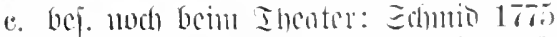

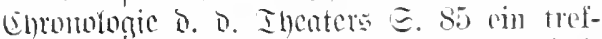
licher komischer Schauspieler in humoristisehen Alten. Etmoe 1886 sismocrtunte

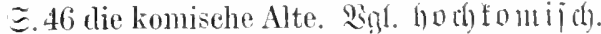

2a. Romtane: 1668 Sollfomment comifide

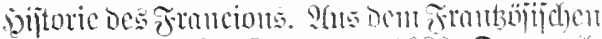
foes Du Pare]; Sentin. 1680 Ier muts-

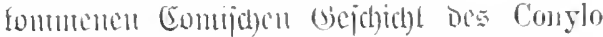
mocrer Iheil; o. 2 .

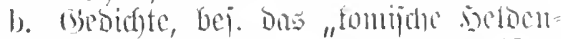

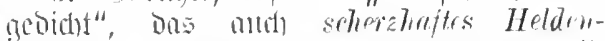

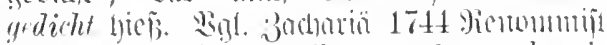
1 ㄴ. 18 and nie entweihet ward rom komi-

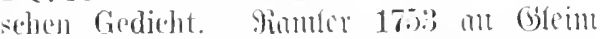
(II 76) in moinem comischen Hedlengedicht. Inid $176+$ Wiricje I 251 Von dem komischen Heldenerediedite. Eit and $f$ b m i i ch

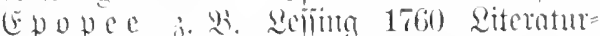
brefe (VIIT 281). Injd 1764 占ricic I 251. seroer 1760 ;

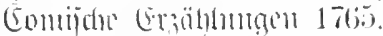

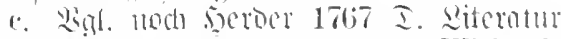
(I 4t1) Man möchte dies let\%te an Wielands komischen bathlumgens vermissen. allein die Art des Er\%:illung gibt ihm in alken Theilen Zweres mul Xembeit gemug. Wemn jm Ganzen ujeht gemus Hanptrweck und Haupton herrschen dörft: so sind sie

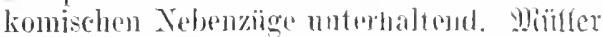

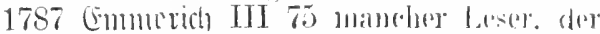
in rinem Buche, weldes das Wont Komiveh auf dem 'Titelblatte lat, durchiuls nur Stoff zu Lachen fodert.

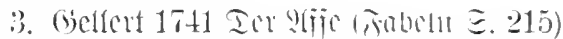
kanm hatte norh des. Shmoriders Hand Ein buntes komisches fiewamel Dim musterm Affen umgehangerl. 1759 gricoda's Enmun= huma II 28 alle Torstbläge. die wir vorlegen kömmen, pflesen rinem so vorejngesmmenen

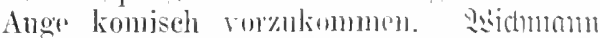
1768 9tutifritifus J 369) a bimbet komisch.

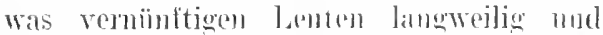

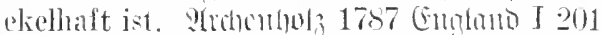
in altmodjschen Tnilomen, dir an komisches Ansehen habeus.

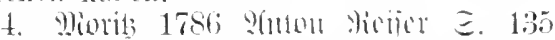

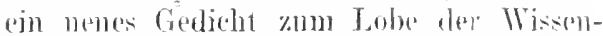
selatten. welches sich liomisch genug anhoh.

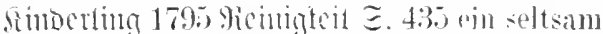
gebildetes mot shom an sich komisches Wort. Sonsebue 1810 3eriftente (XXIV 129) Erlauben sie. dats ist ein komisches schmupf-

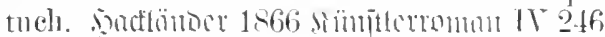
der magere, kemische Bildhamex.

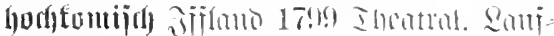
buhu こ. 39 tas Fach der hochlomichen Charakterrollen - E. fll das Fach ter hochkomischen Aten. Bigl. Enijer 1771

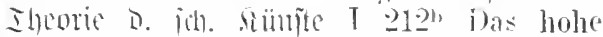
Comische ist der Tubalt mud Ton der Comödie. der ans Traurespiel gränzet. und wo schon starke und ensthafte Toddensehaften ins Spiel liommen. 


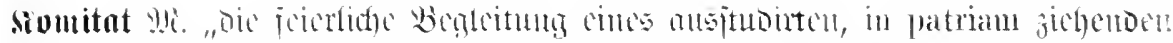

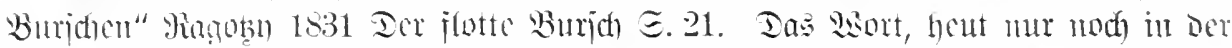

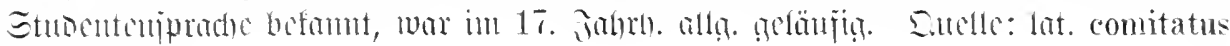

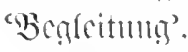

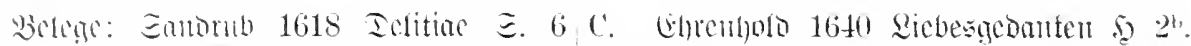

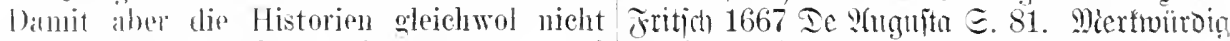

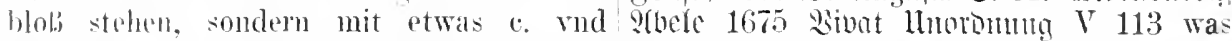
gefertschafft mïchten anbgeriustet nnd ab- [wirb] hierzn absonderlich der junge Hen wefertigt werden. Eus 1630 Roitreiter $\Xi .85$ Gral [jogen], dessen C. Idamit ich recht mit einem stattlichen C. 1633 sumitanzer und eigentlieh auf die Tugarische Manier

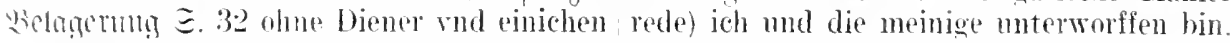

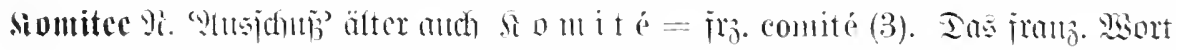

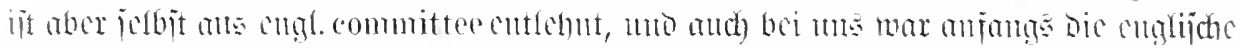

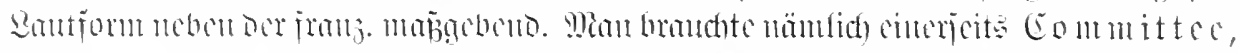

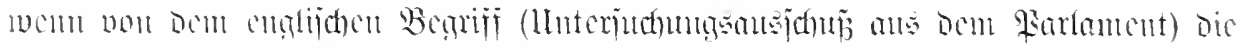

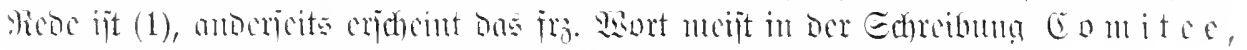

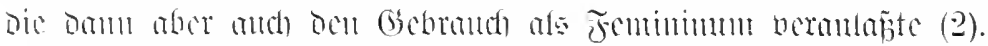

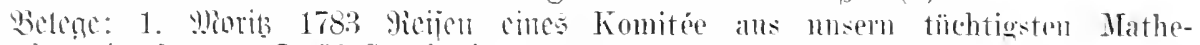
Eentidien in Ëmọtano $\Xi$. 50 So oft sich das Hall: in eine sogenamnte liommittere oder hlober Contersuchung rerwandelt (?)

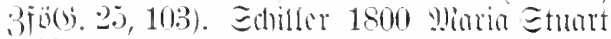
(VII 32) Wer in der Kommitee ist meinesgleichen? Nin Kïnige sint meine Prers.

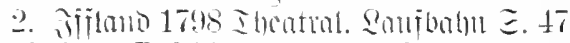
Anf höher'n Befehl wurke eine Comiter rom rhurfiirstlichen Räthen nirelergesetat — E.48 dess ïbrolasse ich der leberzengmg jener

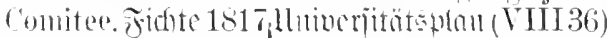
Aul allen Fall ist mein Vorschlag, elab eine matikern ernemnt wiïrde.

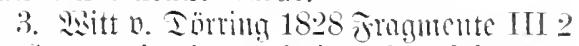
die Communication zwischen dem leitenden Comité in Paris und den Italiänern. immer= mam 1830 sambal $\Xi .150$ Ein festordnendes comité. Remalo 1835 Ibentermente こ. 285 deren gemeinsame Interessen rou einem Comité rertreten wrden. Gubtom 1843 Reijecinorinte (IX 183) ein Komitee errichtet sich.

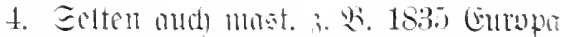
I t(1) Der Comite des... Kunstrereins.

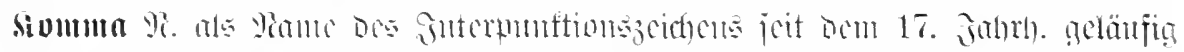

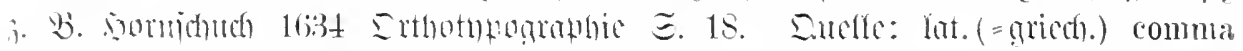

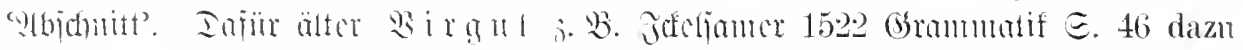

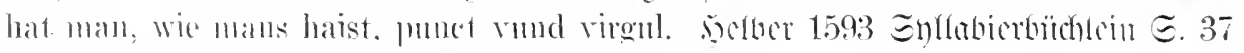
Dises heisis pin strichlein ader lirgul.

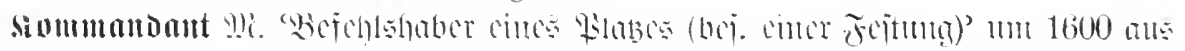

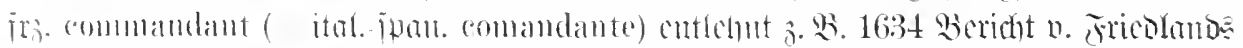

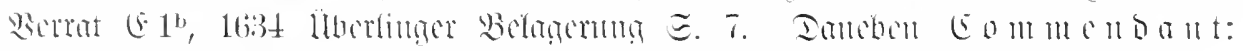

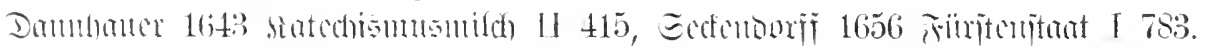

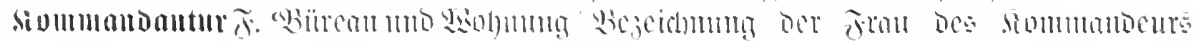

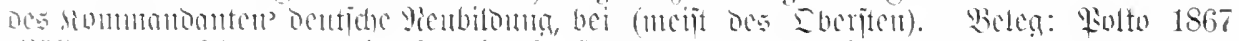

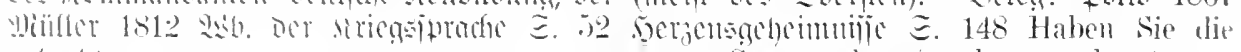
arbitht.

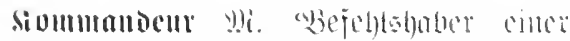

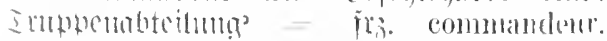

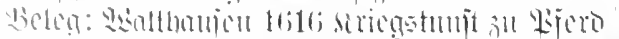

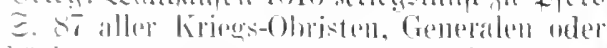

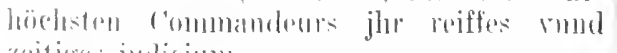
zeritigen indiciums. nent" ,commintensis" schon gesehen?"

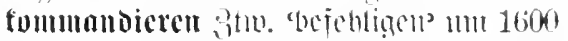

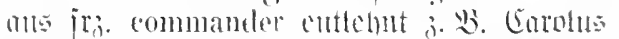

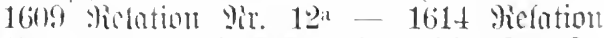

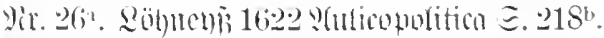

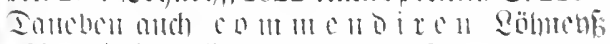

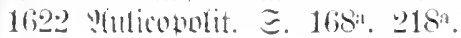

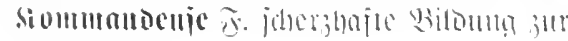




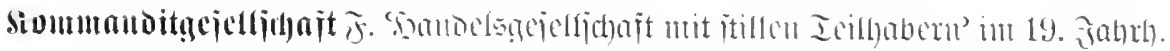

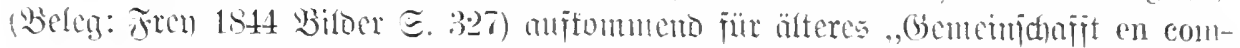
mandite: (こavorn) 1676 Parfait Negociant

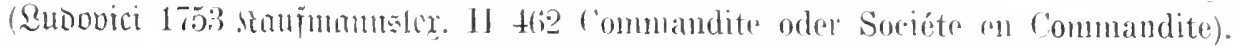

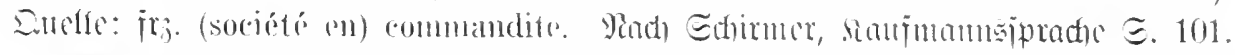

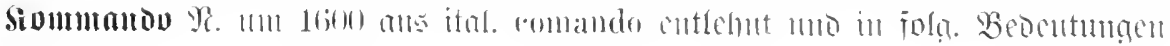
grobaudit.

1. "Bejehl' hei. "Bus si. Moben, jübtos",

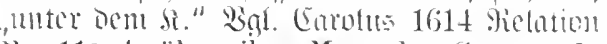
ver. 11" dariber ilher May. das Commande allein haben. Vicolai 1621 Veettrin. Sintrat E.17 der das ( $^{2}$. in Holland absolute an sieh

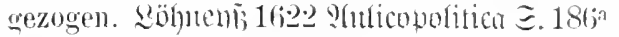
das r. rber jh gant\% hrieglowesen. 16:2:3

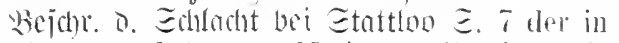
Abwesen elel.j rom Herberstorff rher dir Herberstorficche Reutterey tal: C. geführ.

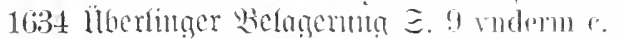
del Herren Obrist Wachtmaister:

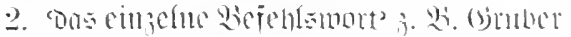
1697 striegsoijzintin III 36 Ciebet Fenter: So hald dises (: gegebon ist mim. Wionmer

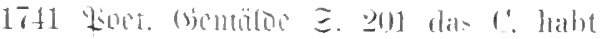
areht!

3. "sin abtommmoister Emppenteil'

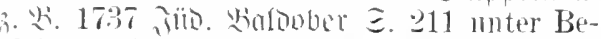
gleitung eines 1. vom Fïnff Hann. Edhubart 1764 Ehronif $三 .578$ den Prenbischen r.-. dir 1 m Remontpferde zin kaufen, nacls

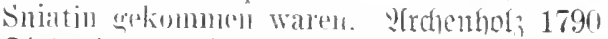

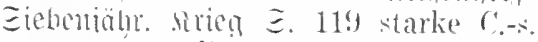

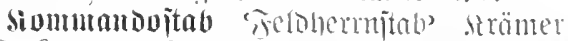
1681 Eehen ถ. Eechelom E. 481. Rohr 1728

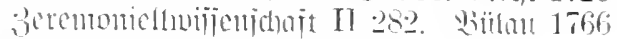
Yintionalaciät 三. 126i.

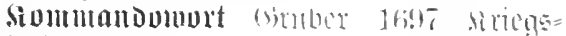
Dij,iblin III 2-i.

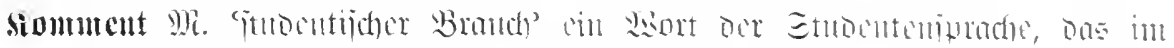

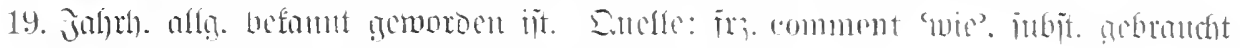
mit Dex Bed. '? rt mo 然eje etwas in tum?.

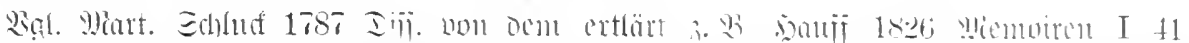

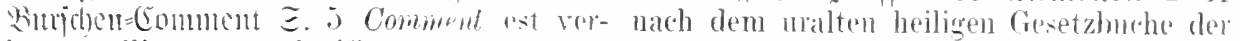
hum gallicum et significat quomodu - Burschen. das man Komment heibt. 1835

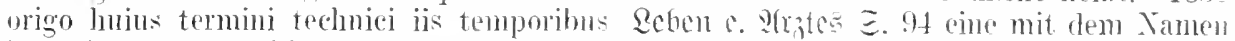
imestiganda est. whi landi ducehatur, flos:culos gallicos linguae rernaculae immiserere. Inde illud tritisimmm: Rirn, rien, so spricht rin dummer Jungr, der noch nicht Coinment

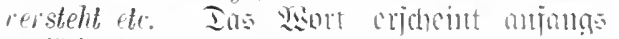

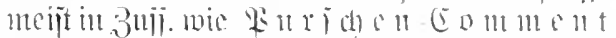

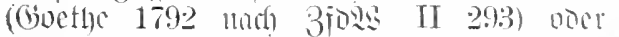
Etubeutenfoum unt Gallut 1810

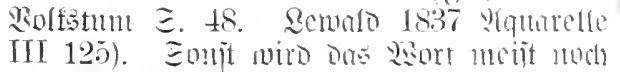
comment bezeichnete. muter den studenten pingelïhrte änbere Sitte. Sante 1837 Reijenobellen VT 2399 hekanntlich hat "s nuf den Tniversititen pinen ins:eehildetpll Kunltus. welcher lismment heilit.

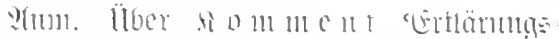

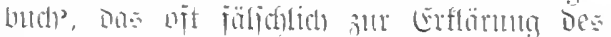

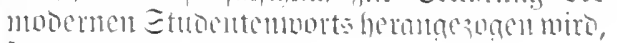

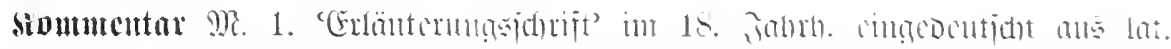

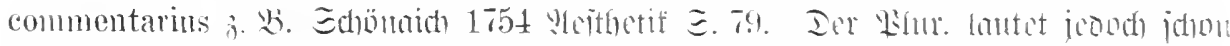

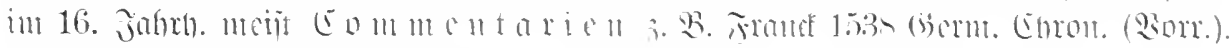

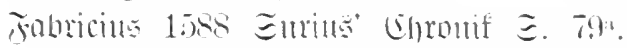

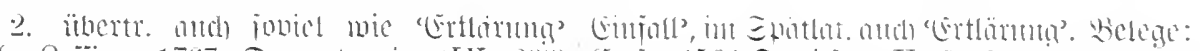

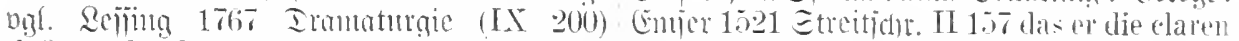
dab er dureh ilue stinme die dentichste schrifft Pauli ad Cralathas... . orst mit einer Erklärung. deri vollständigsten Commental nawen postill. comem rol glosen vortun-

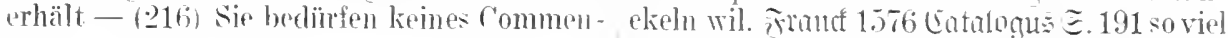
talls.

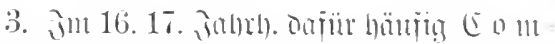
C'omment. Postillen vint Aublegungen. Mien germut 1633 Eicastronc E. 66 vinser Theologen

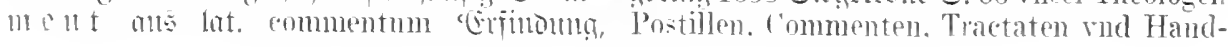




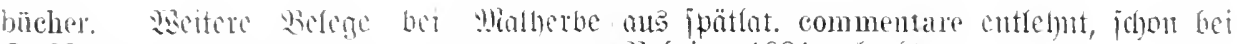
三. 68 .

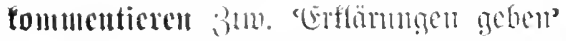

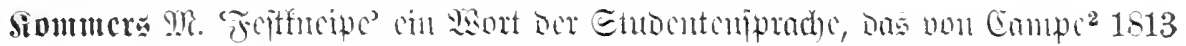

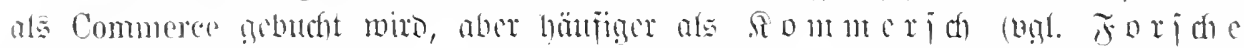

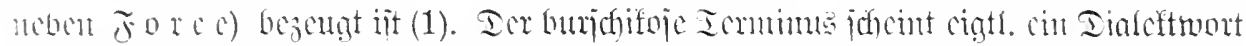

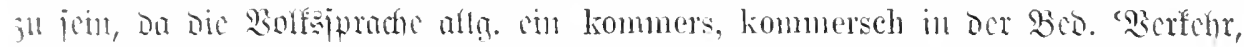

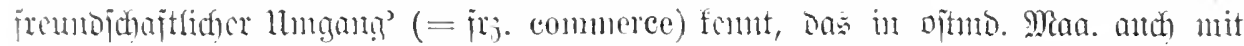

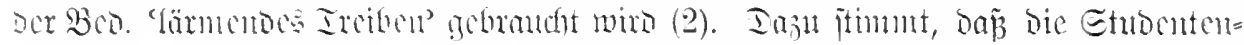

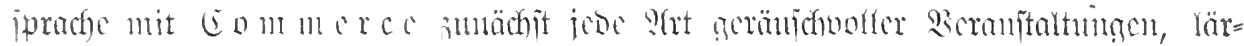

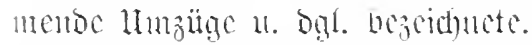

Eo int eimen Beridit ïler Dos weihntacht= lidle

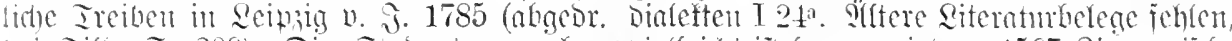

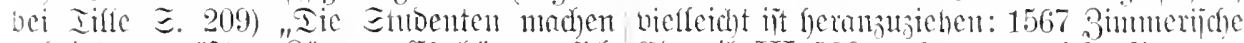

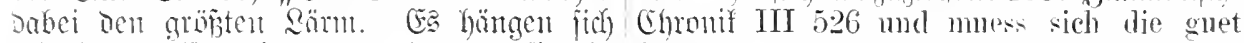
udft bis sublf nucinomor und ment jie ein fraw vil erleiden: den rorteil hat er, das er

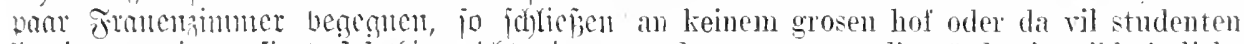

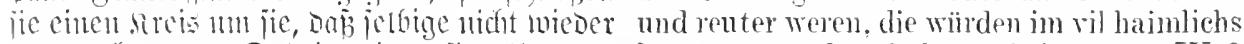
herans fönten. Dabei treiben jie nlferband kommers nud anfechtens bringen - IV 3

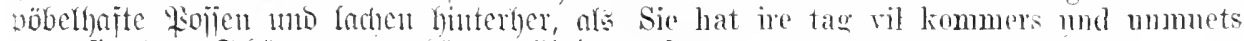
ment pie etroas Edjönes gethan bätten. Einige gehapt.

non ibuten jumo jo moerjoünts, buj jie jith

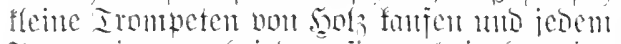

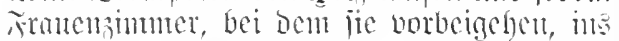
Elp brajen. Ins nemen jie ecommerre?".

Belege: 1a. 1776 sicicimedijel afobem. Fremino $三 .110$ ('in rorgeschlagenes Commerce, wie mans nemut. Qijt 1785 Geitr.

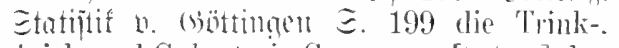
spiel- mnd Galanterie-Commerce [baben] den Rangrur den übrigen (Neier, Sall. Etnoenten.

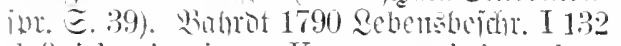
lab ich nie rinem fiommeres bejerewohnt.

b. simblchen 1781 Etmontenter. E. 124 Kommersch, pine Trinkgesellschaft der Stndenten. da sie den Landesvater und andere lustige Lieder absingen. 1786 sart Gobtuman

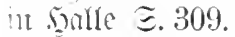

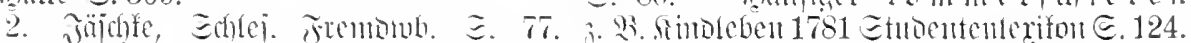

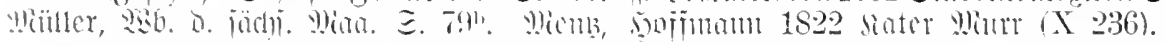

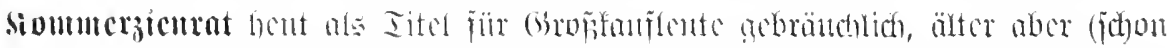

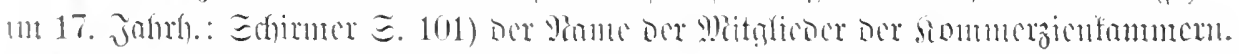

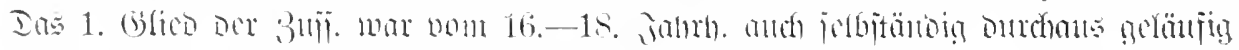

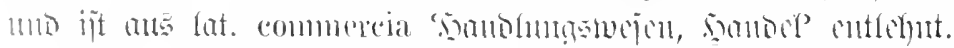

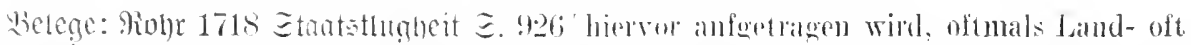

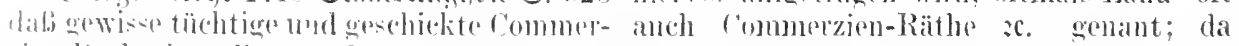
rien-Rähe bestelled werden. welche and die bekant jst: dab der Handel und die damit

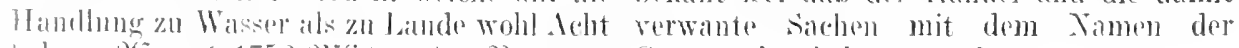

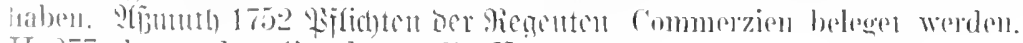

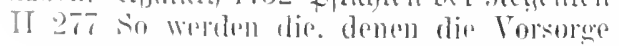

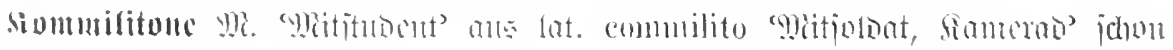




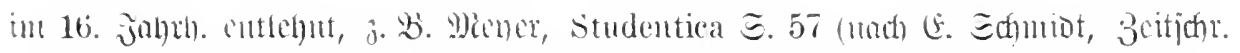

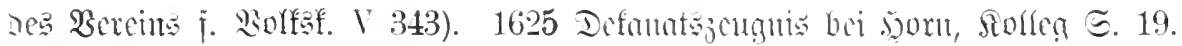

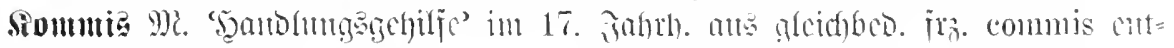
febut (1) mo getegentlid) zu C

Belege: 1. Eowarn 1676 Parfait Negociant seinen Prineipal oder r'omil. \%u bezahlen I 13 als ein Diener oder so genannte Commis richten lassen. dienen - 217 die Commis oder Bediente (nad) E(himer, stammanmiprad)e ङ. 102).

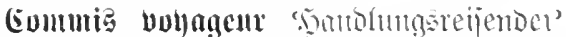

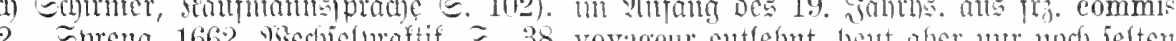
so der praesentans einen adiunctum oder (uncijt mit ipöttijenem lebenjum) gebraud)t. Commil setzet, so auff Special-Vollmacht Relege: Böne 1821 I. Rojtichnecte (I 51). die Zahlung vom acceptante erhebt - こ. 42 ssitt $v$. Dörring 1828 Fragmente III 11. des Presentanten oder Commib. Echunt Liidfer 1835 Eemilnijo I x. Bemalo $1836^{\circ}$

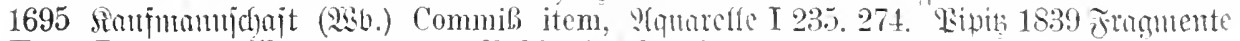
Unter-Beamter. Starperger 1711 Bejert. D. 三. 137.

Mefijen II 99 soll er den WechselBrief an

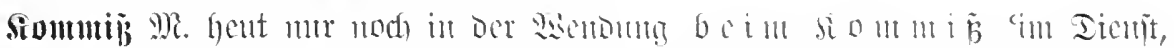

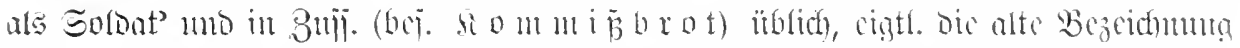

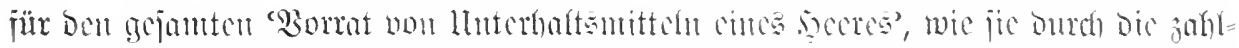

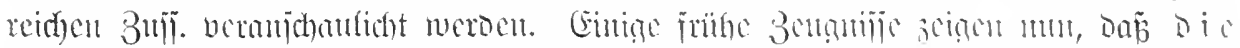

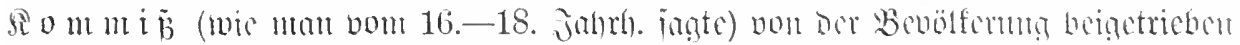

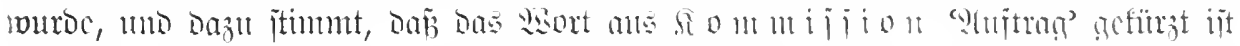

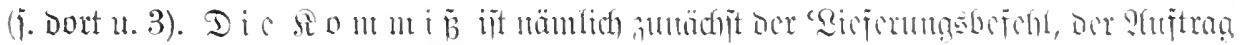

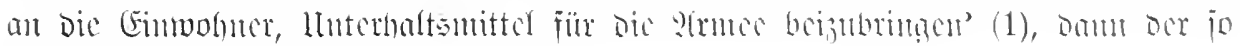

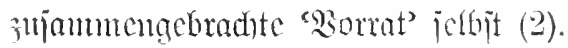

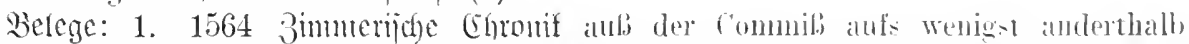
III 586 Hierauf macht er in einer sollichen Pfundt Brots rnd ein hall) Bomnisch Mal., unbesinten weis mit etlichem Kriegsvolk. Weins (3jogs. XIV j2: Diciclle Eterfe bei ein lauf, die kamen hanfecht zu im geen Eyjunce 1591 Relut. III t0). Encefl 1589 Cruckenwiss. Do warden sie uf die pauren $\mathfrak{T}$ (rdhiteftur $\Xi .62$ Hergegen soll ein Obrigkeit. gelegt, die muesten den krieg erhalten, wie aluch der Fürst, für die Kinecht jn die inmassen als so man ein commiss ufgericht Commib, wenn die Früchte rechtes kanffs het (Bfors. XIV 52). Fromperger 1571 sindt, die Speicher vud die Keller mro-

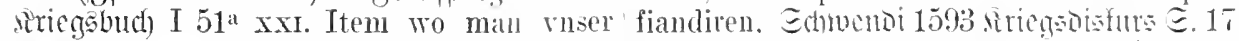
Saluaquart ansehlecht, da sollen die Reuter da pr in seinem Land oder in der Tähe krieget, allenthalben sieherheit halten, anch in der kan er jhm einen grosen Tun vnel Tortheil Freund Land nit plündern, rauben oder sehaffen, da er die Commib der Proniant nehmen, noch in die Commißs greiffen, bey [ocu siortat an Proviant] in s'inen Händen Leibstraff, sonder an beyden orten anch bellält vnnd solbs rerlegt [bonhlt] — こ. 31 alles dasjenig ehrbarlich bezalen, was jnen alle l'rouiant. so ins Läuger kompt oder ins auBder Commib gegeben wird - xxrn. Es liregshem Commib ist. Gebbarot 1597 sollen auch die lohen Befelchhaber rnd rürịt. Iijarcoen $\Xi$. 131 mit Rüstung. andere, sie seyen wie oder wer sie wöllen, Eroben vund kleinen Greschitt. Munition,

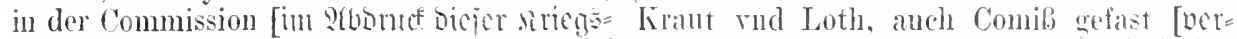

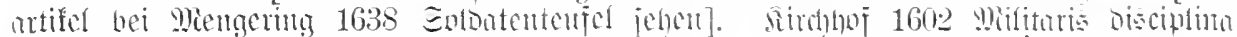

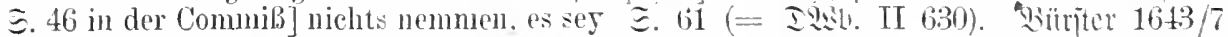
Wein, Fleisch, Käß, Fisch, läre Vab, Vihe, Échues. Sirieg E. 10 commib, fuoterasch. Häut, noch jeht anderß, sie bezalen ès denln, sondern sich mit jrer Besoldung genügen lassen.

2a. 1584 Relation v. D. Etad Bonn こ. 8 Nun lat ein jeglieher Kriegsmann täglich proviant. Echifofuecht 1652 samuntia II 55 So trehen wochentlich auf 5000 Mann solcher gestalt $7000 \mathrm{lb}$. Brodt in Commib auf.

b. bej. medh Bex Bomet an Brot, Dejien

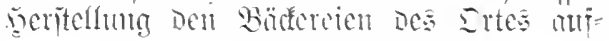


crlegt 1muro: Vlengermen 1661 (bemilienstedt §. 1053 wemt sie fül dir Amee l'reviant schaffen und Commib hatken sollen. Gjell

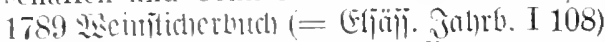
Ja so gar haben nusere müllen miessen Comis ror die gutnisout anlf Colmar miiessen mahlen.

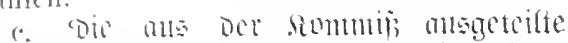

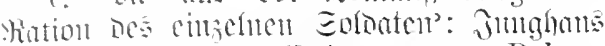
1589 stregsoromung (E) wann man Pulner, Zindtstricke. Commibs anbtheilet, so berufft man mu die Rottmeister - 是 $2^{2}$ abgezogen [st. oou Der Siblmung] 6 fl. für Rantzion, di er rom Feinde gefangen ward; $8 \mathrm{fl}$. fiir Commis rnd Proviandt. Eiftch 1608 intregangud $\Xi .51$ bei anbitheilumg der Comil under das fähnlein. Iannhaner 1642 satechis= muntide I 314 Soldaten, flip $\mathrm{mm}$ einen geringen Sold. Commilis, Bent mol stuck Geldes, Leib und Leben gewagt. Miojocheroju 1641 Prifanoer II 812 arme Soldaten, die bißwerlen ein gantz Jahr ohne Lehming ron ledigem commis: leben mïssen.

B̈ 111 i

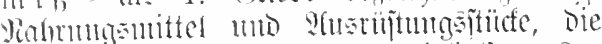
dem Eoroten, ,ans Der sommis" (j. 0. 2a:

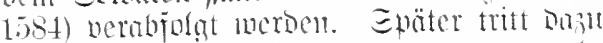

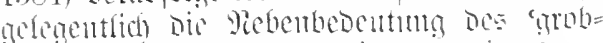
acarbiteten', anth bes 'mintorivertigen'.

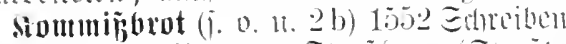

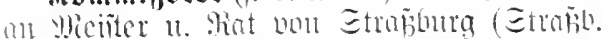
Etabtarcfiv 9ir. Ad 578) Am Montag nach - tubilate anno 155\% ist der Statt Strafburg redordneten zin Dachstein und molekheim weliffertt worden XII VI Comissbrott, so in des Künigs ron franckreich leger gefïertt

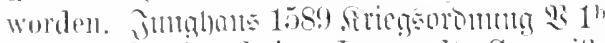
wo die hechte haben Lesongelt. CommibBrodt. Wrin, Bier, Flaisch .... ond derateichen bekommen. Enthofnedht 1652

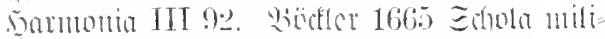
tatis כ. 73 .

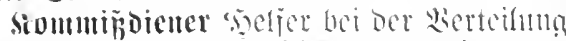

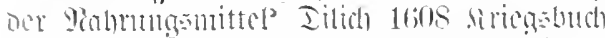

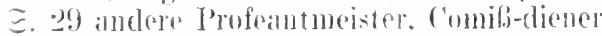
und dererloichen persohnem.

Siomutijenthuijo

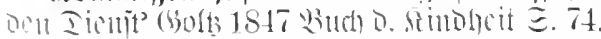

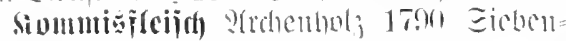

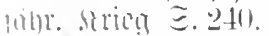

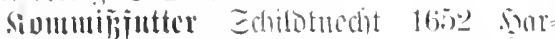

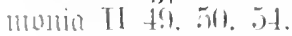

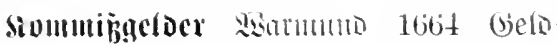
mangel in Ieutichlanid $\Xi .25$ Vorpflegungs oder Commibgelder.

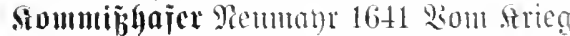
ङ. 134 (5) orit 巨. 26)

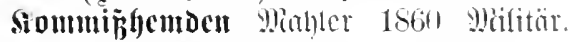
silorbuch $\Xi .27$.

\section{66 .}

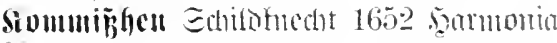

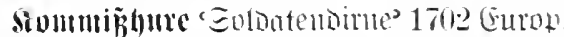

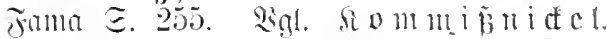

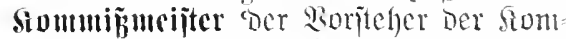
mijuerteinutg' gebud bei Edhöntener 1625 als cpraefectus annonae (I

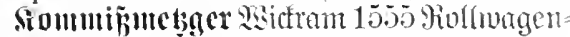

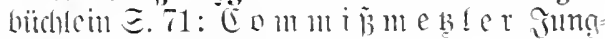
hatr 1589 sitiegsursmutg $\Sigma 3^{2}$.

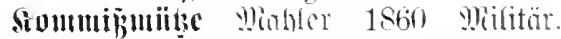
Biberbud $\Xi .74$.

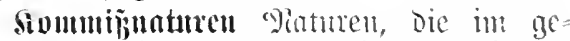

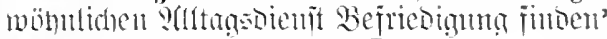
然adiculujen 1865 Ballet I 85.

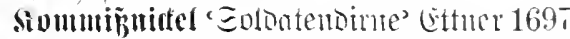
Ioftor E. 339. Gallenbach 1715 Euaji E. 48

Sivmmifordum 1564 Bejuthug uir. (Fenerabens) E. 5a Commib Ordmung. welcher gestalt ein anzal Kriegholeks in einer Besatzung mögr erhalten werden.

Sommibylat: "Flats im Sager, mi Dem

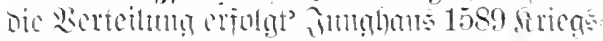
oromm I $33^{\circ}$

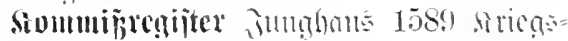

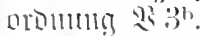

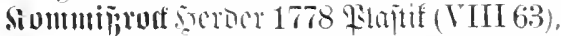

sivmmijian 'oer Ead Der EnlDaten,

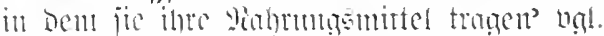

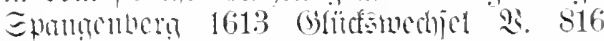
Wilt du sein ein reehter Landsknecht. So henck den rommibsack anch recht - 92. 424

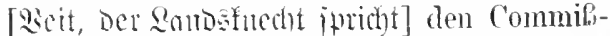
sack nimb ron mir. l̈tbertr. autf nom Sette!

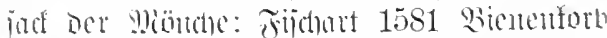
こ. 199 jren Commiss oder Bettelsack.

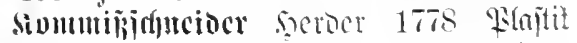
(VIII 19).

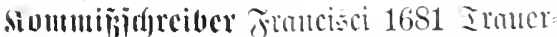
joul TV bith die Commin-Sehreiber der Selat?Meister

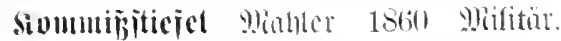
Siltorbuth E. 27.

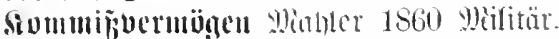

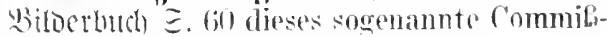
rermïgerll.

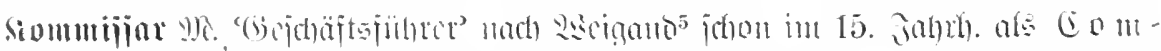

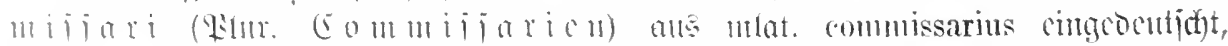

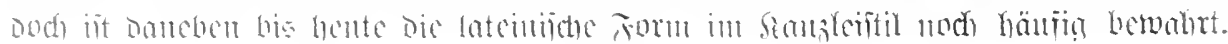




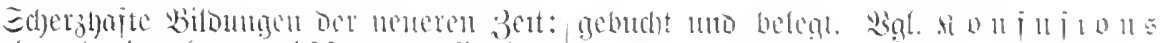

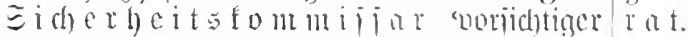

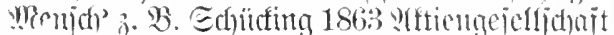
LII 17 Der geborene Sicherheitskommissar!

Sivmmiijariat ans neutat. commissuriatus:

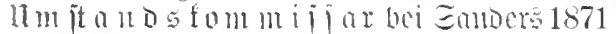
Eteinbera 1548 (onrunif $\Xi .163$. Edtme inthen

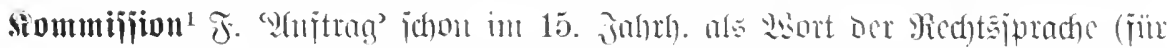

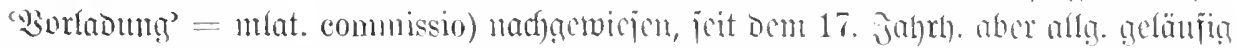

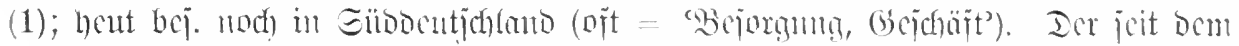

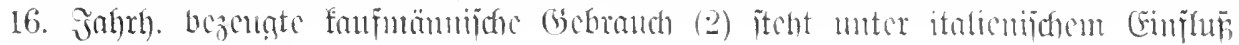
(ital. commissione).

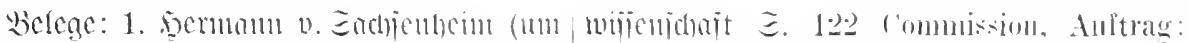

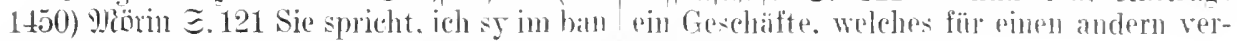
líerlin Und onch darzuo in aberauteht. War richtet wirk. Ia,iu hant die comysion mir braucht. Als sich webïrt zuo sölchem recht? (⿱ㅗㅇiganto5) - E.155 Und her gefueret ist mit gewalt On alle recht and commission. Man nö̈clit in wol geladet hom Zuo Swaben dort fïr mang gericht. Wividheroja 1650 Rhilanoer I bt1 ein fürnehmer Tentel, dem e. und $B$ afehl int-

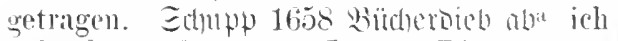
habe $C$, von fürnehmen Leuten, Dir zu sagen. Enlfoubad) 1715 Entuii G. 37 hab etliche C.en an benachbarte Höfe zu rerrichten. Goethe 1768 Briefe I 165 die übrigen $\mathrm{C}$-en sind alle nicht vergessen, wemn sie gleich nicht alle ausgerichtet sind. Echiller 1783 vicso (IV 214) Braucht mich zu allen K.-en, 类is=

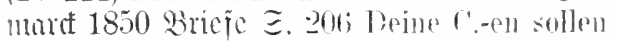
alle besorot werden.

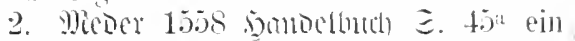
jeglicher Trutscher gibt seinem Wallen C., vmb so ril Carlini eimzukauffen, als vil jim gefelt. Bigl. Echirmer, stomijummsiprache

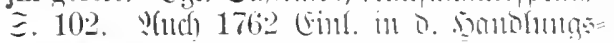

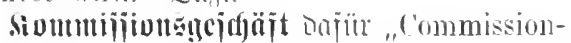

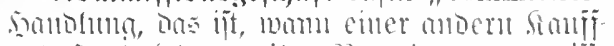

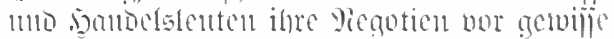

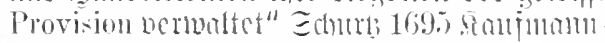
idhoit E.t.

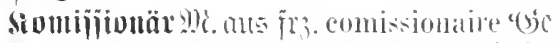

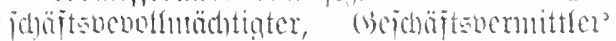

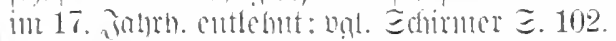

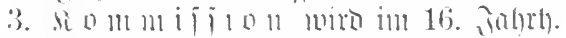

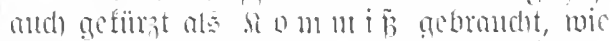

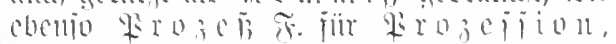

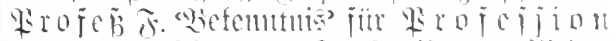

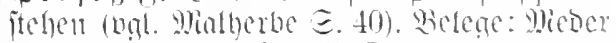
1508 innoflud $\Xi .19^{\text {h }}$ Item weyter mag einer mit stinem Walchen anff die Siffion märckt ziehen rud selbs rinkauffen oder seim Walchen (ommil, achen, inn solehem preys rimzukatufen. 1.564 immeripte Chronif IV 97 barmub so wardt dieser graf insonderheit zu einem Commissario genduet .. Aber grave Willohm Wernher schlug solche commiss mit bisten fupgen ab.

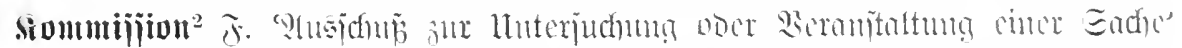

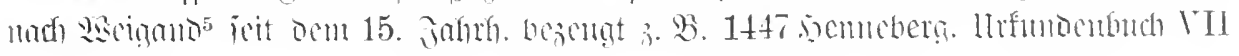
ir. 252.

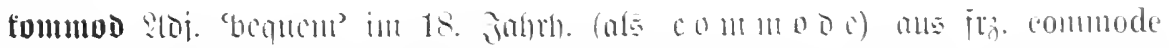

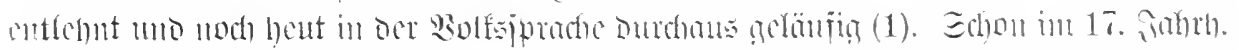

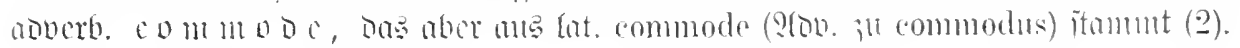

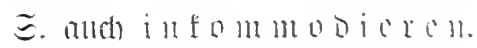

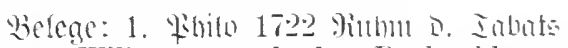

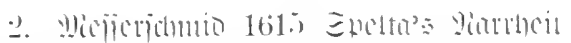
三. 113 Will man auch den Rock ablegen I 12s die tiferoc ziehen die Gutschen, mit uder sich sonsten commode im sitzen machen. denen wil Commodè vond bequemlichen durch

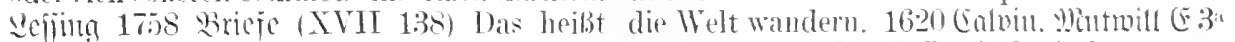
ohne Zweifel commode philosophiern! - Nun aber dise Leuth Thr Behmisches natïl1767 Ermuturgic (IX 300) Jïrge ist zu Fub liches Hirn (wie jhnen gal wol rnd commodè regangen, weil 's kommoder ist. Jubsebue dises zugemessen wirlt) ron sich hinweck 1804 Fingentreich (XVII 118) ohme zu geworffen val Thren anatomirten Streitkopff wissen. was ich that. machtr ieh mir's mit frembden Hirn angefiillet. rommode [in watt]. 


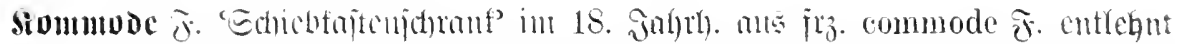

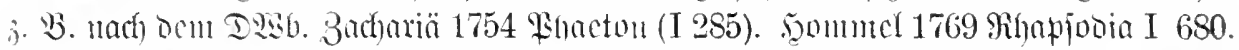

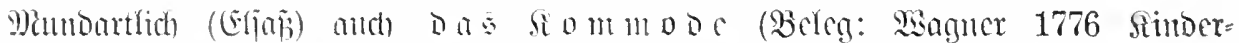

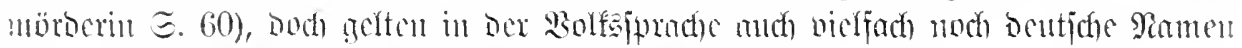

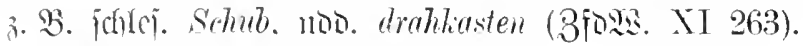

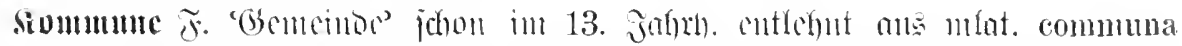

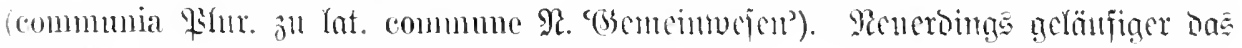
B(oj. fo m m 11 ! a 1 mo lat. commumalis.

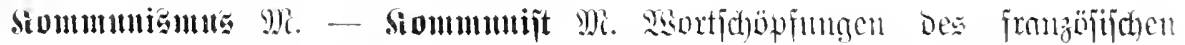

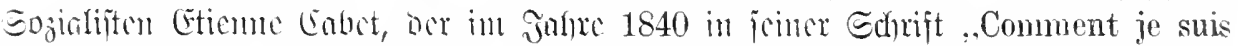

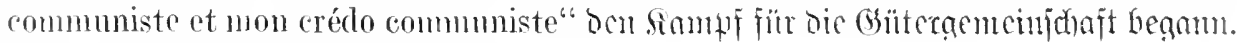
Bạl. Radomouri, Edhlagivlr. E. 175.

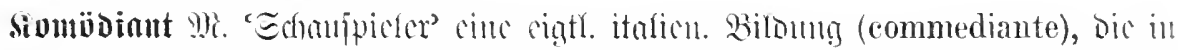

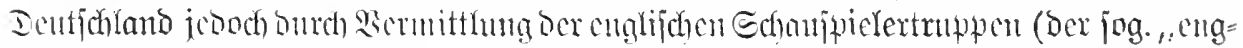

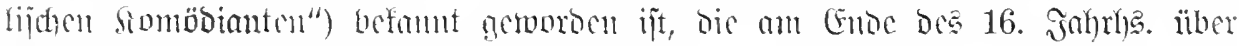

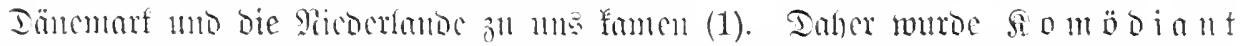

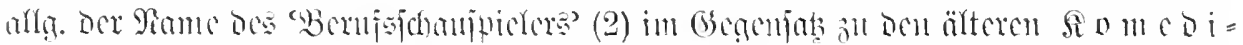

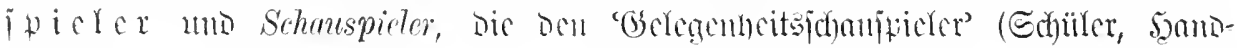

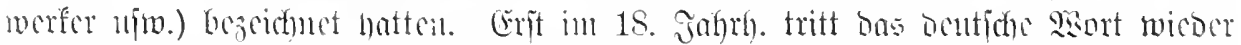

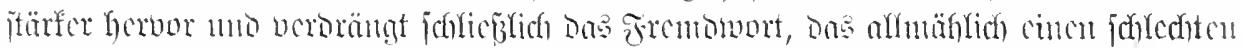

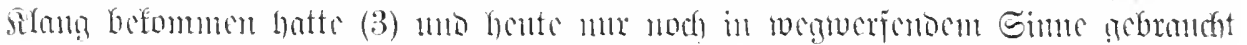

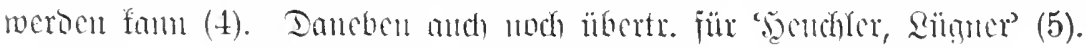

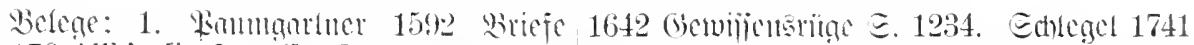
$\Xi .176$ Allhie [in Franffutt] seind malisehe Echriften હ. 29. Tutiti 1765 Ed)riften I 76

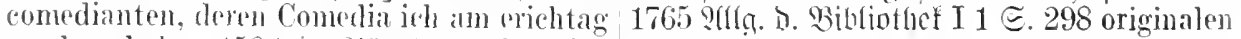
gesehen hab. 1596 in liumbora: fïrstlich hessisehe Diener und comortianten (nuch) (Ereizentad), Sint.=2itt. 23, E. V). Bigl. nod)

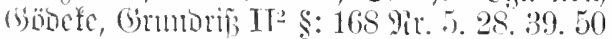

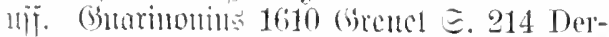
gleichen schaw- vind hörspiol seyn der Zurit in Tentschland zufinden vnd dern Comoedianten wie $i c h$ selbst gesehen aub

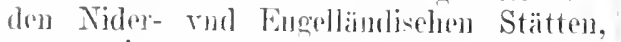
a) rou rim ort zum andern herumb zjehen.

2. Sectber 1593 Entlabierbüblem $\Xi 6$ comediant. U? Eemojdyt. III 9:3 rnter don Ferhtem. Comme-

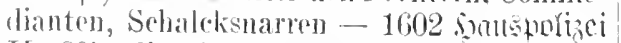
II sob die Comedianten, ganckiter rund

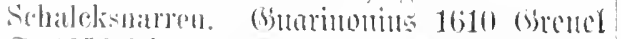
¿. 1256 Die dritten sayn dic Connordianten.

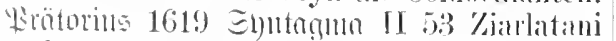
vend Salt'inbeureo, das sind bry vis fast wie dir Comoedianten vand Posschreisser"

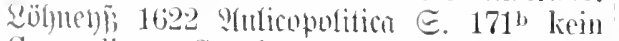
Comoediant, Gamckler, noch Schalcksnarr.

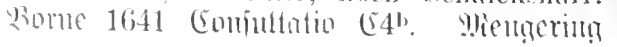
Unsimu bernmziehender Comödianten.

3. 1670 Edhatbithne ber sugl. mo fram.

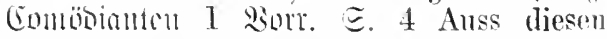
jetzt-erzehlim Ursachen mu, sind die Comödien und Comödianten hoch geschätzet. geehret und befördert worden: Alldieweil aber nichts bestimliges in seinen Würden anff dem gantzen Erderiits, Eben also ist es anch zorgangen mit dem Exereitio und der Ehrbarkejt cler Comödianten, da church etliche leichtsinnige: Gesellen theils wegen ihres mohlosen epicurischen Jobens, theils anch wegen Gold-Geitz und anderer Ungerechtigkeit, aler löbliehe Nahme der Co mödianten also viphasst worden, dasseswohl nach dem Sprïchwort heisset: Die Laster und Missbränehe der Menschen können das jenige böss machren, welches an ihm selber gut ist. Meinlfer 1789 (Emmericl) VII $83 \mathrm{Er}$ war ein Komödliant . . . sogar die grewöhnlichen Bonenmungen zeigten keine Achtung a11 ... das Wort Schauspicler hatte noch keinen Kours. sontei 1852 sagabunden 


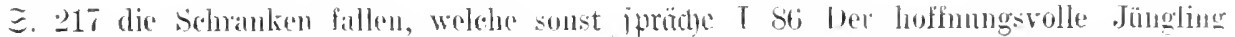
den ,Komödianten" vom Isben tremnen. hat sich in rinen fiomödianten verwantelt.

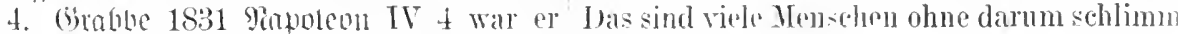
nicht Komödiant? - Komüdian!! Spi z.n sevn.

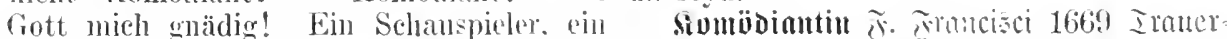
darstellender Künstler, ein Yime war cr, jot II 89 die schinc ('omediantin. 1702

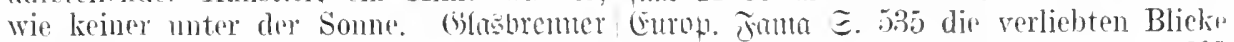
$18: 38$ Sicrliu VIIL $27 \mathrm{Er}$ war frïhlerkomödiant, einer wol exrecirten 'omödiantin. 1755 Schauspieler nennt man das.

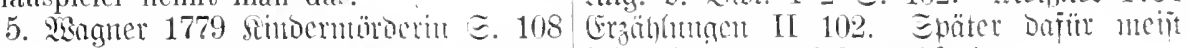
In unseren gleißnerischen Tagen, wo alles of $\mathrm{f} t \mathrm{r}$ ice mo Schanspirlerin. Kumödiant ist. Bentsel= Etermm 18050 (b)=

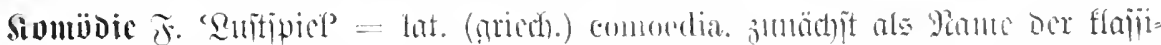

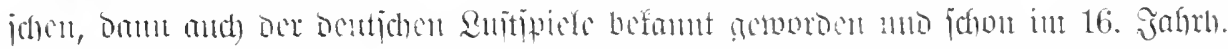

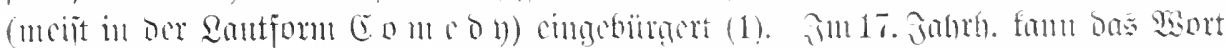

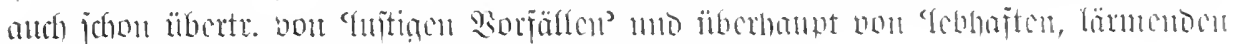

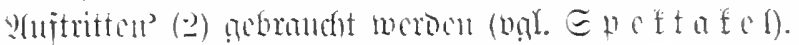

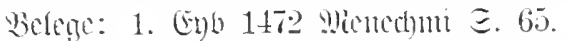

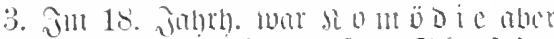

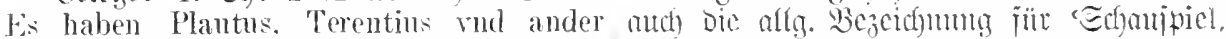

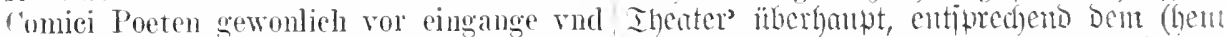

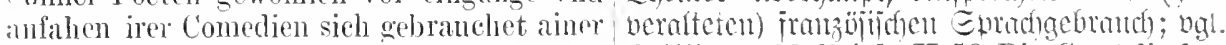
frïlichen schimpflichen vorrede - dlas arou- Ectiller 1788 Siricfo II 53 Die Comödie hat ment vnd matery diser Comedien - solhe uns verlassen. Ihïmmel 1791 recije (I 125 ) rnd andere nachuolgend. Comedien. Sim ols es nicht Zeit sey in die Komödie zul

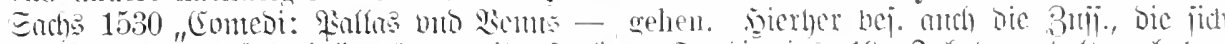

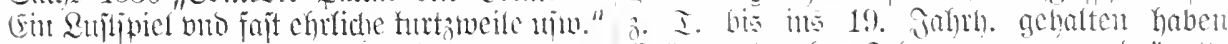

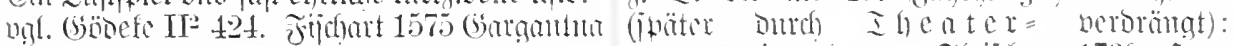

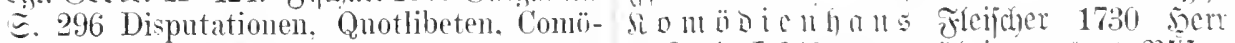

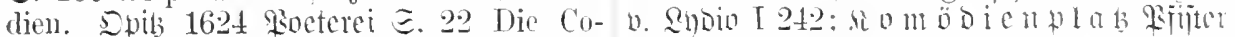

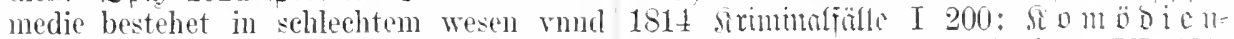

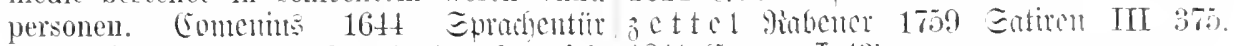
こ. 308 Eine comedy oder ein frewdenspiel. $18+1$ (Empra I $43^{\text {b }}$.

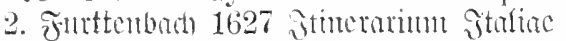
$\Xi$. It als mam [oic Bifificl] nach Livorno brachte, gienge erst die Comoedia recht an, also, clab sie manches mal so wild wor-

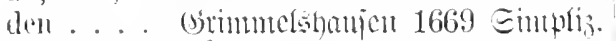
こ. 37 Ist eine selzame Comödia von 5 . Bauern. Gelfert 1746 200马 (III 316) Tin wird mir die Comödie zn lang. Kmz ich habe das Loos der Fran Orgon geschenkt.

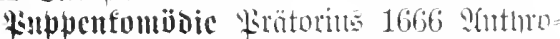
nobennt I 315 Närrischen Ganckelers Zelten. wo der alte Hildebrand und solche Possen mit Docken gespielet werden. PuppenComedien genannt. Iajür Do de cut̃

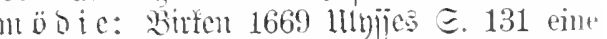
zwar elende und recht kindische DockenComedie [am shato: Pnppen-Comordie].

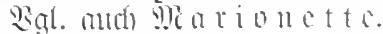

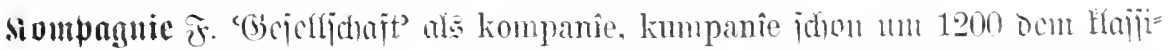

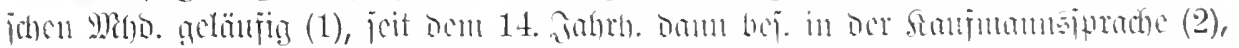

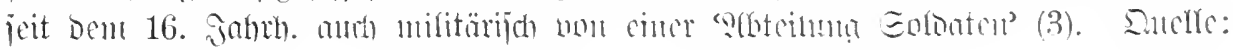
irs. compagnie.

Befeac: 1. Woljrum (1210) Faminal 147,18 dor knappe valsches vie, derbôt im kmmpanie. Gottjrico (1215) Irijtun 2. 4814 si unde ir cumpanie - \$. 9418 die schoenen alle dive, diu lichte cmmpanie. $\mathfrak{B g l}$. Screr, Mago. ․s.6. I 1671. すm 16. Jahrh. meijt

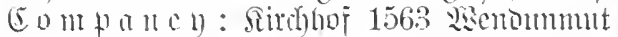

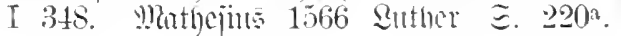

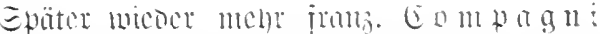

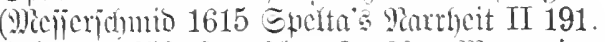
こ(hup 1659 Endoj(b). こ. 30. Miengerint

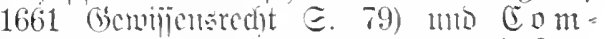
H a g n i : Prötorits 1665 Mntsenveit $\& 4^{\text {b }}$. Qeibutis 1673 Erfiriften (II 18).

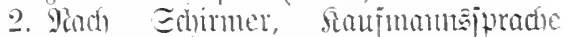
ङ. 102 ichou im 14. Jornrh. kumpenie. 


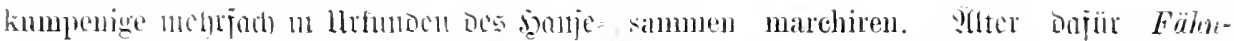

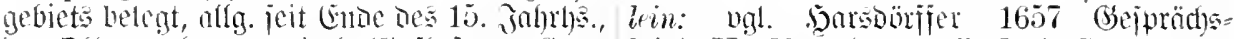

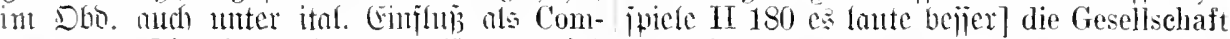
pagnia. Iic Forntel "nn Eompognie" oder Genobschaft, als Compagnie, oder in jehou 1527 juggerinuentur ङ. 63 Barto andern Verstand ein Fahneı oder FähuWellser u. Compagnic (cho. こ. 102). ojer= lein Soldaten.

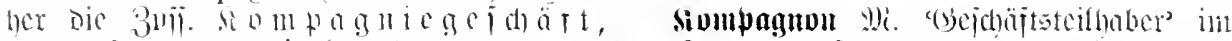

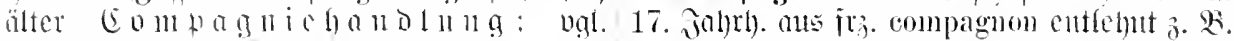

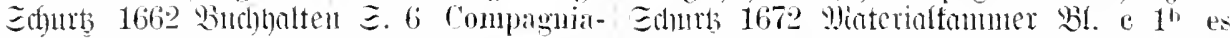
Handlung, als ihr 2. 3. oder mehr anf sey dam daf. es in einer Compagni-Handgleichen gewinn und Verlust oder pro rata lung wäre. so ist ein Compagnion dem andern eines jedern Einlegen, negotieren und handeh. schuldig wegens seiner Verwaltmng Rechnung

3. Enjuger 1590 sielationen I 119 mit mu thun (nad) Edhimer $\Xi .103$ ). Eateben!

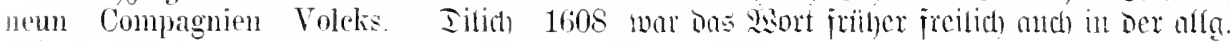

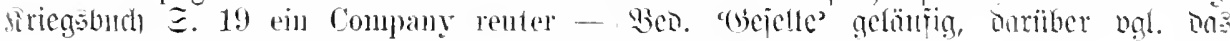

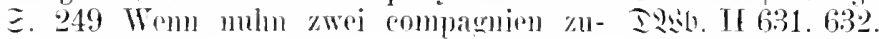

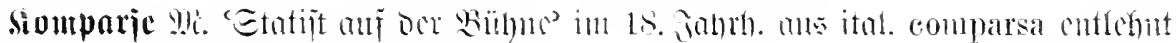

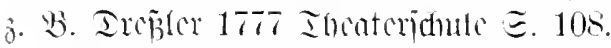

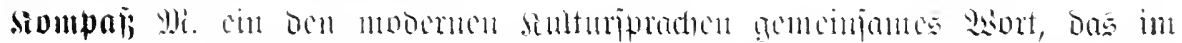

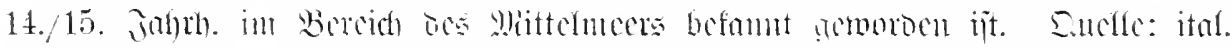

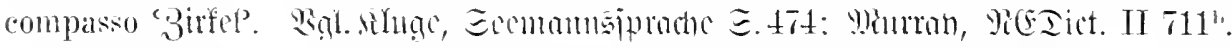

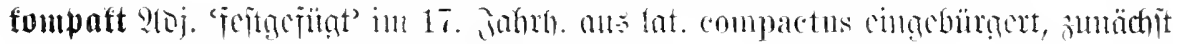

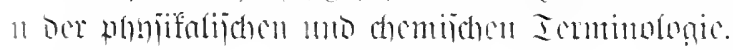

Belege: Littner 1697 Ioftor $こ .147$ ein Ein Gewächse ist kiein und nicht ein soleh nummeliru arstorbenes und compactes Ye- compakter und erober Khumpen. ecoho

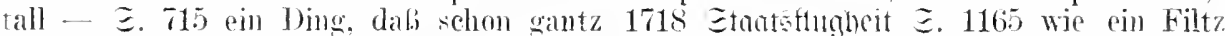

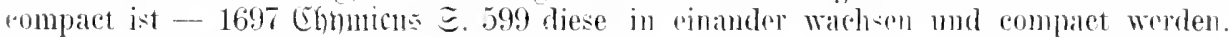
compacte Materie - 1715 sctamme $三 .457$

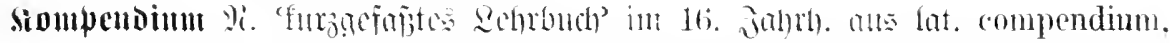

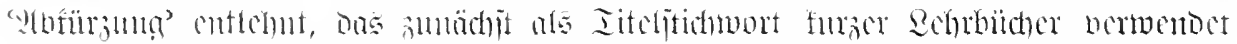

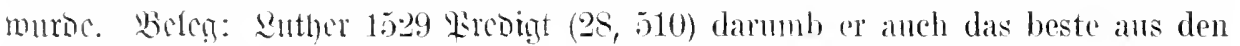

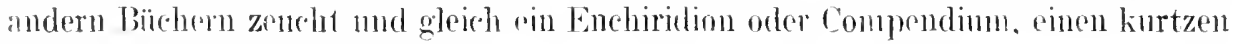
ansmg umel smmmarien machet.

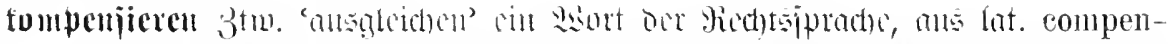

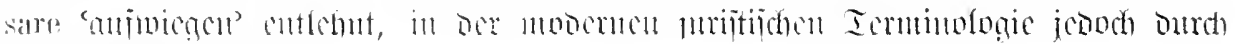
"mijerhne" aichtst.

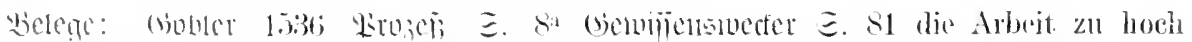

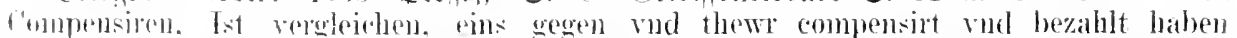

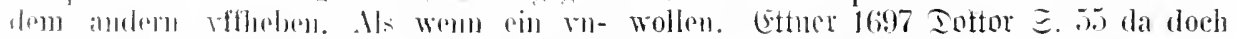

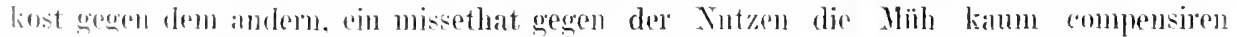

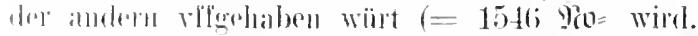

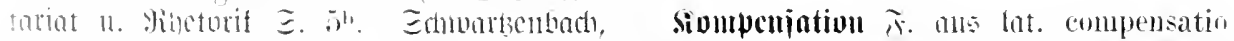

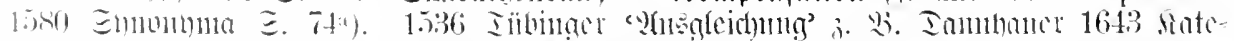

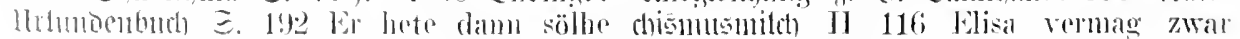

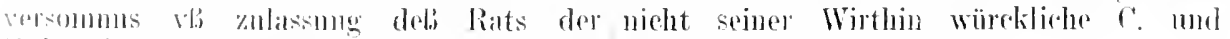

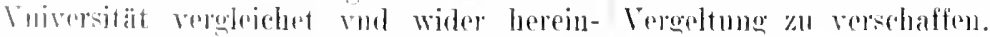

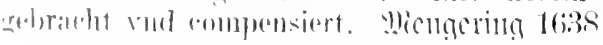

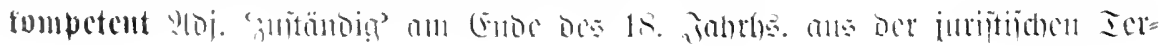




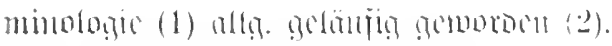

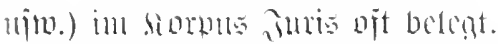

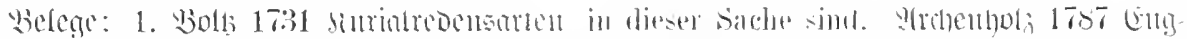

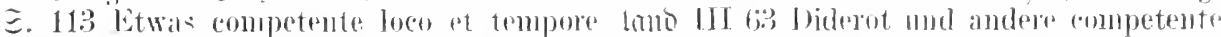

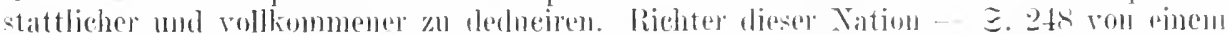

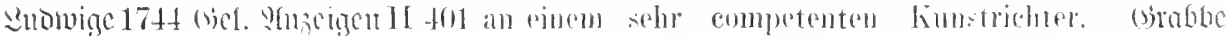
indice compretente.

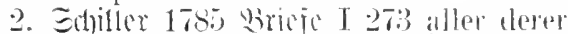

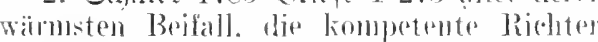

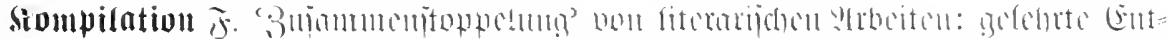

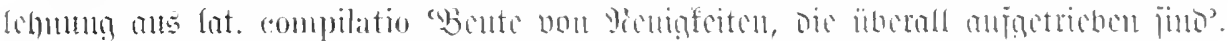

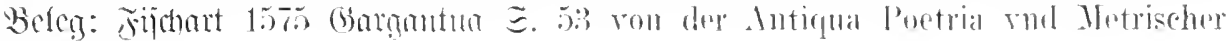
rompilatious.

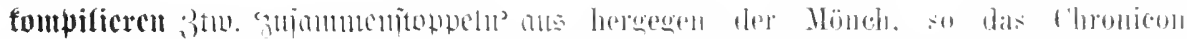

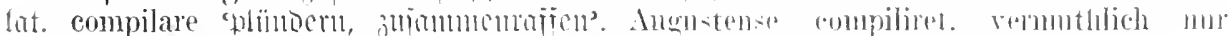

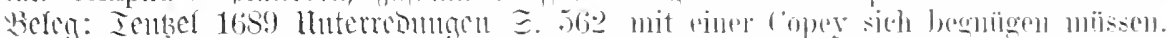

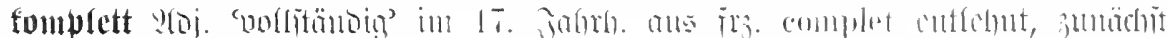

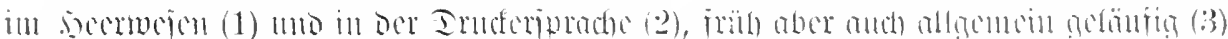

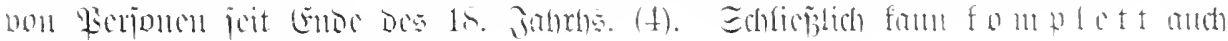
mosrbicle getorated merocu (5).

Welege: 1. Jiengering 1638 Eoloatentrufel $હ$. 591 vleichwol geben sie jhr. Rusimenter rnd Compagnien vor roll rud complet als - 1642 (3́culijensmeder こ. 1511 machen ihre Compannien rut Fehmlein liein mal Complet. Tummouer 1643 siontedis musnilch T[ 327 haben aber ihr Regiment nicht complet. Seibui 1670 Eecrutas mbl. (I 196) ein wolhoerichtetes tompletes Regiment. Etieler 16839 mbitem こ. 29? sone Kompanie romplet halter.

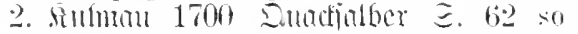
habe ich die überschickten Parthien [Yoten]

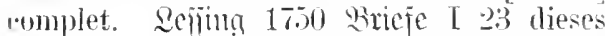

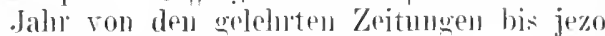
("o)mplet.

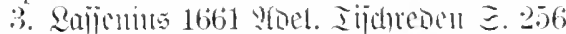
wann Hurerey dazu kommet, welche docl qempiniglich bey der Vullerey ist, so wird

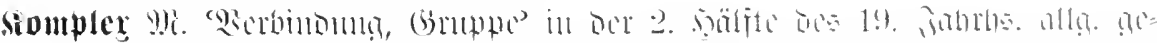

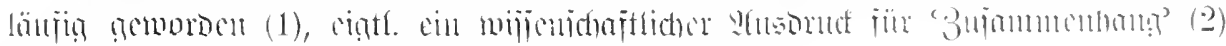

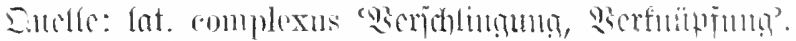

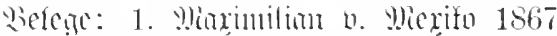
Echen II 105 Häiser-Complex - Ir 2.2 Häuseromplexe. Enichnagen 1879 Rhatt "anb I 284 ein Complex ron Banlichlieiten.

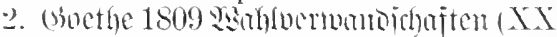
347) wo nicht rou dieser oder jener Bodingumg des lebens. wo vom ganzen Complex des lebens die Rede ist - 1821 ismoner fohre (XXIV 177) dem es jst auch hior rom

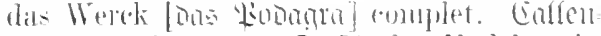

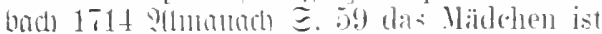

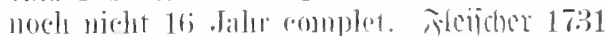

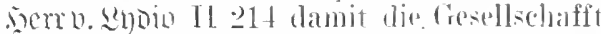
complet werden möchte. Sirloms 179.5

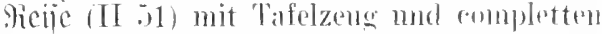
Fleidern. sotsebue 1810 Eorgen $(26 \%, 188)$ die rompletteste Lurorshämtheit.

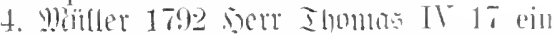
kompletel cieck. Cramer 1794 benejtediche 1 gs er durfte mu den Rock anziehell. so wall der komplette Bamerjumge dis.

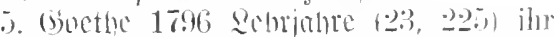
babt sie so complet celiobt, als man es mor

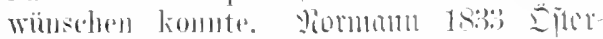

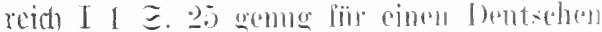

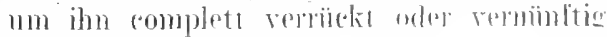
zil milehen.

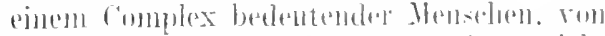

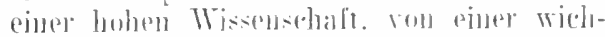

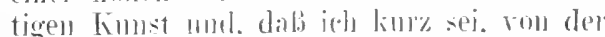
Mathemalik dia Redo - 18\%8 3almo tenien VI (III :3(is) Sind mun dip Element nicht An: tem complex zu tremmen. Wa ist demm an dent ganzen Wieht original zu Hent1) 


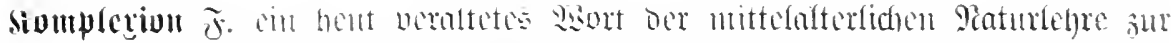

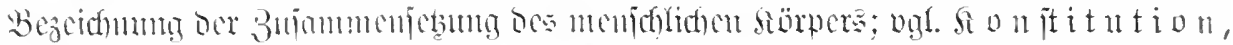

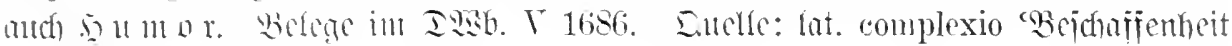

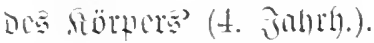

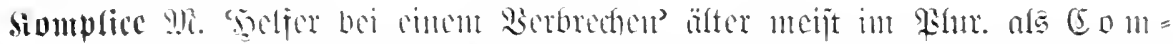

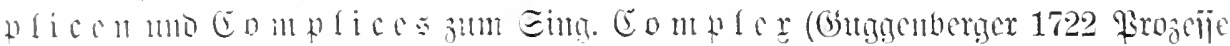

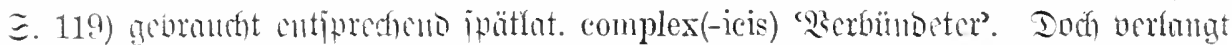
idnon .

Belege: 1600 Fontes rer. antrinc. LX 85 ethehen seiner Mithelfer ma complicen. wnessenen berelch: Dich burgorafen und Ettuer 1697 Chmicus 巨. 270 damit wir Euch verordneten in specie und alle com- in Tachforschmo ihre complices hätten tr-

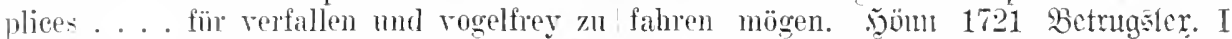

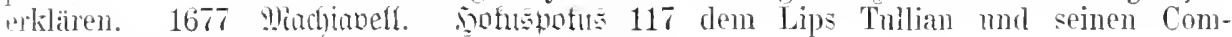
こ. $27 \%$ seine besden Herren complices. plicen.

trimer 1681 Reben Der Eecheloen E. S8

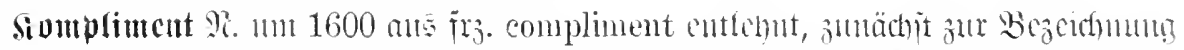

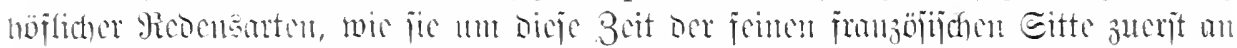

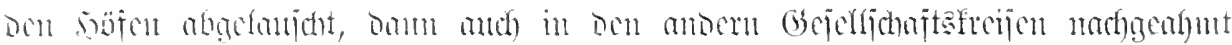

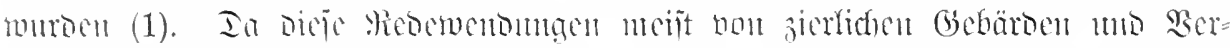

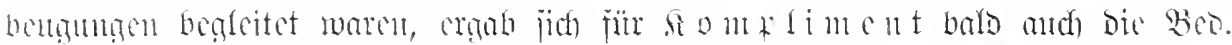

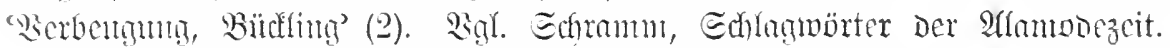

Belege: 1 a. Sainhojer 1617 Rejietage=/anch seine Krafft in Teutschland einge(nnc) XXII: $1610 \mathrm{im}$ April hat der gelehrte führet worden. Denn Complementen ist sn gottsel. Herr Hr. Philippus Ir. Herzog zu viel als Gepräing (gnt tentsch Auffschneideres. Stettin durch Dr. Hieronymm Bechler, Betrug, Heucheley). Gref̣linger 1646 from-

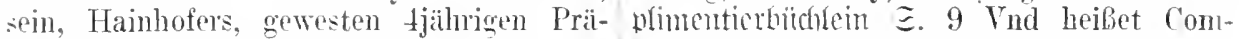
ceptorem et inspectorem in peregrinationi- plementum oder complementiren höfliche bus ihm ein Compliment- oder GruBschreiben zierliche Geberden. Reden rnd Thaten ber und die Fïrstl. Bildnul., zustellen lassen. Lenten fünren, mit geschickten Sachen anEtettler 1627 Edmeiser. Chronif II 497 / gefüllet, sich rud anderm damit zu niit\%en dit sie tann den Crlïckwunsch zu tlem Fürst- rnd zu behstigen.

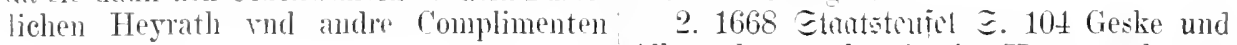
verrichteten.

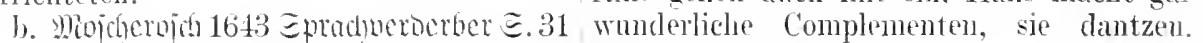

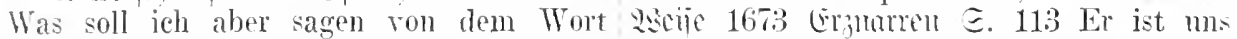
Complementen, welches seln gemein ge- noch ein Complimente schuldig. ror die worken. Ich sage mit diesm Wort sey Bicklinge die wir genacht haben.

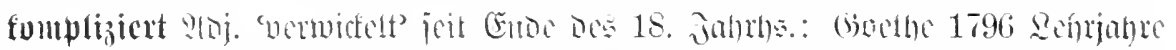

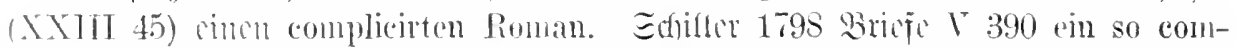
plicirtes, weitliufiges und undankbares Geschät. Entelle: lat. complicitus ‘zu= fammentiejaltet' (3) romplicare).

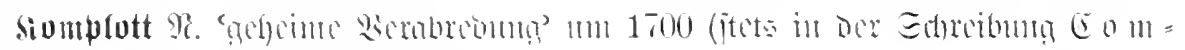

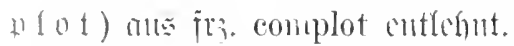

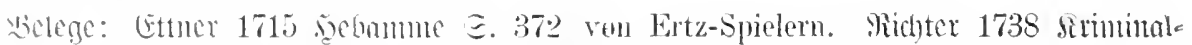
wrhen nach Hanse, machen ein Complot trosej E. 251 Diebs-Complot. Bobmer

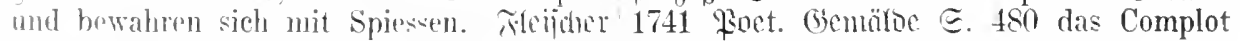

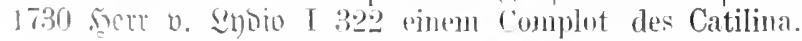

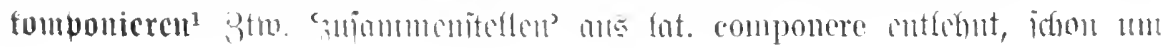




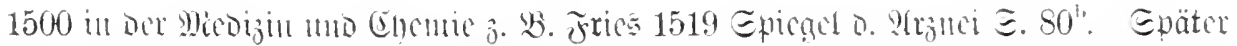

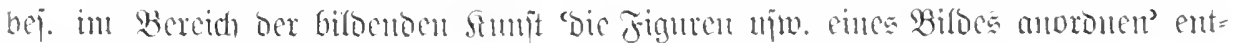
julectentio iri. composer.

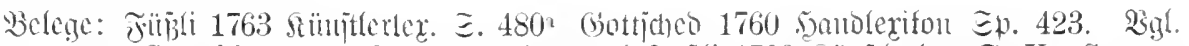

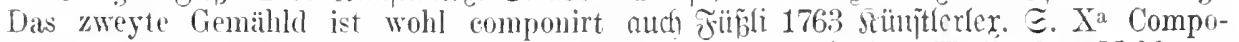
und besteht atls: mehreren Figuren, die sition ist derjenige Theil der Mahlerey. gleichwol den Ramm genugsim anfüllen welcher das anständigste ausufinden, und - E. 481" eine unglanbliche Geachwindig- die Gegenstände. welche der Künstler zu keit im Componiten nnd Nahlen.

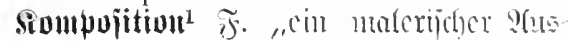

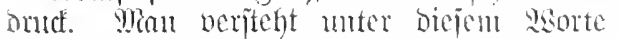

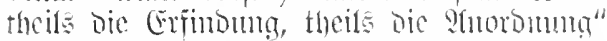

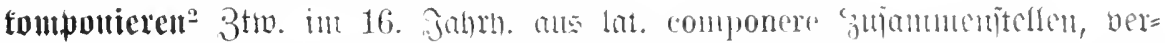

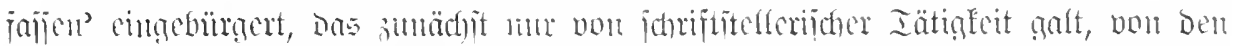

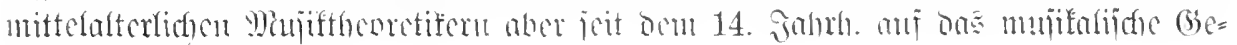
bict libertugen wurbe.

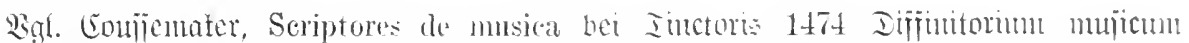
medii aevi III 93b (Ars Discantus see. Joh. (Comjiennter JV 180) compositor est alide Muris) De compositione carminmm. cuins novi cantus editor: vgl. paütlat. conAd sciendum componere cammina... - positor melodice (un 500 bezeugt). (Ent= 289 (Guilelmi Monachi De Preeeptis artis Ipredeno ital. compositore. Fra. composimusicae libellus) Regula ad componendum teur. Wortibergeheno bafjer anch bei uts

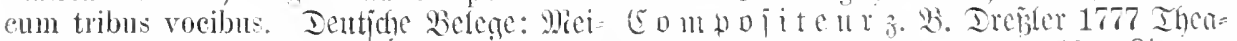

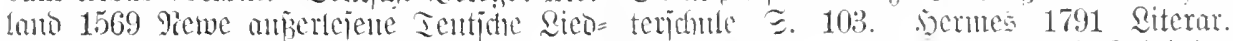

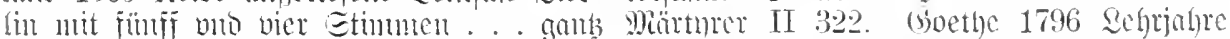

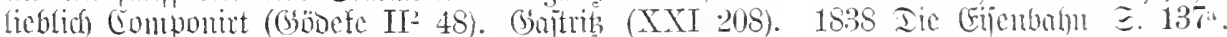
1571 Rerve Emmbola. . Eontpoumt (cho. $\left.\mathrm{II}^{2} 49\right)$.

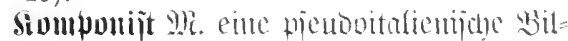
Dutg, Dic nach Iies johou in einem sirief

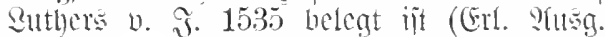
30. 55, 83. $84=$ Ie siette IV 586). Dafiir

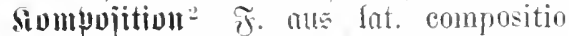

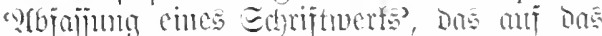

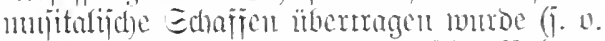
u fompouicreul. Deutiche Belege:

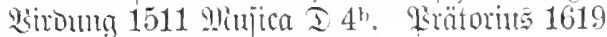
Eิmutagna mujicum II 14.

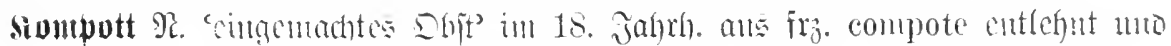

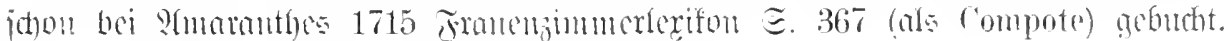

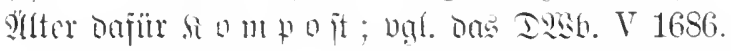

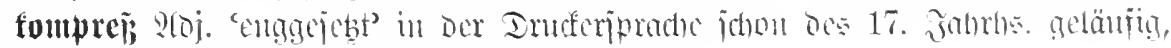
entichut aus lot. compressus '̧̧eoriünt, enạ'.

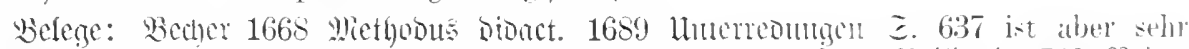
三. $34^{\mathrm{a}}$ nebst seinen andem Schrifften, compress gedruckt. Whifipui 1743 Reiu=

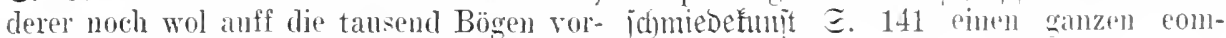
handen seynd, vil Compresser, als wam pressen Bogen.

sie gedruckt wïren, qeschriben. Ientel

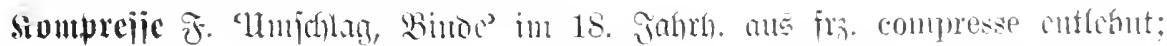

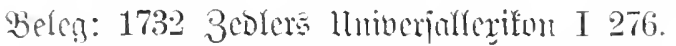

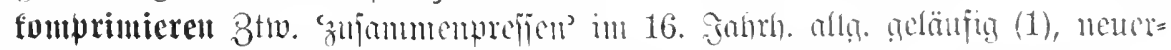

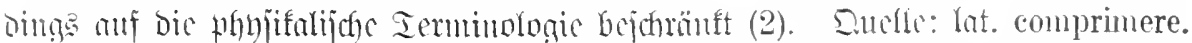

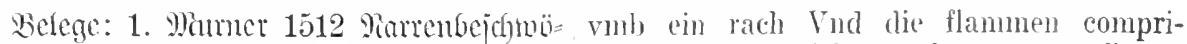
rung ङ. 257 Tie inngen solten von den mieren. Die warlich manchen man rerfieren. alten. Den das blut schon ist erkalten, Baracelints 1567 Echreiben ${ }^{E} 1^{\text {b }}$ das die Leren, das sy nit so gaeh Wiiten, tohen sehlaff aderen mögen dureh jhr drucken 


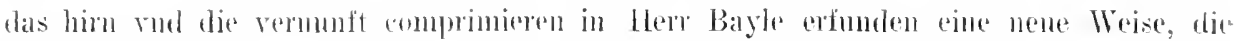
der pia matre.

Luft in pine kleine Enge zu treiben oder

2. Edhendzer 1711 米hujitn I 193 lat gewaltig zu comprimiren.

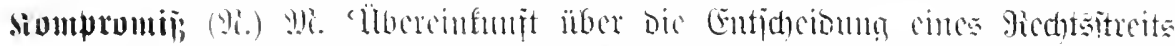

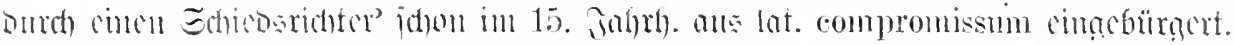

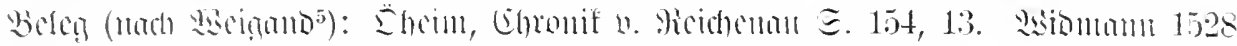

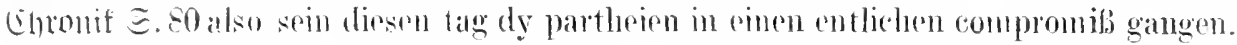

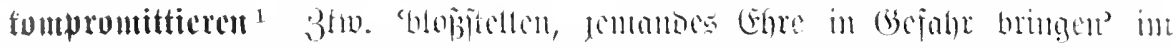

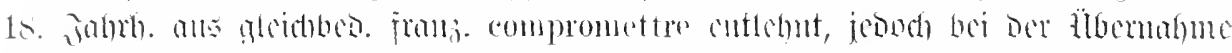

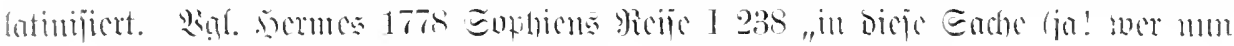

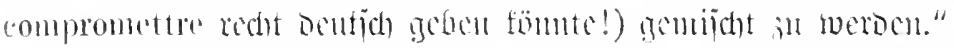

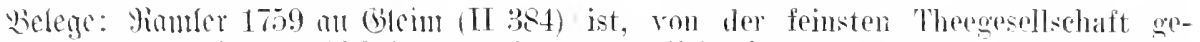

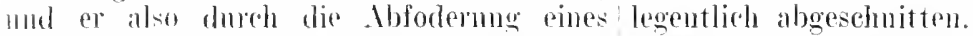

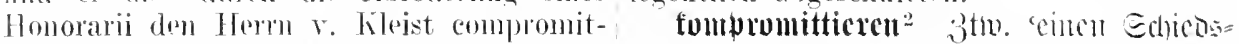

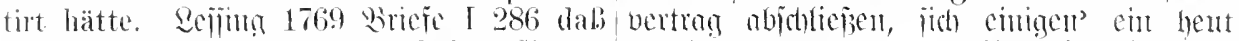

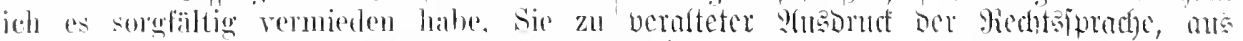

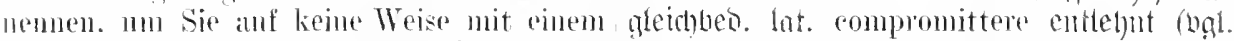

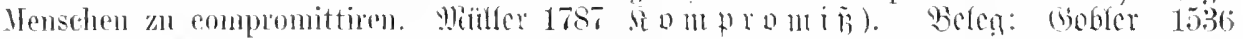

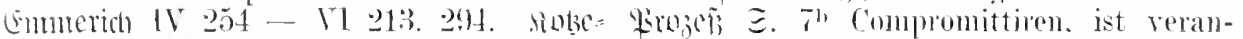

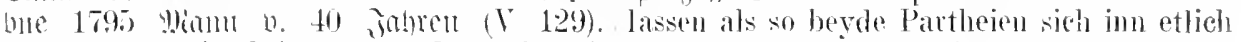

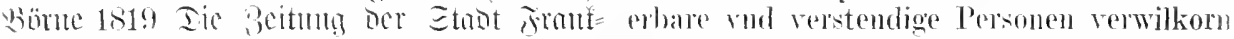
inut (I S4) Jir obersten Behörlen dïrfen was die solbigen zwisehen jnen sprechen durch Tadel nieht ..kompromittiert" wroden. rnd rrkemen es dabei bleiben zn lassen

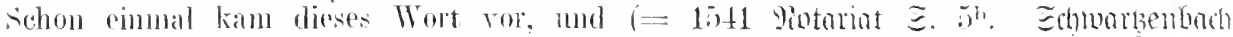

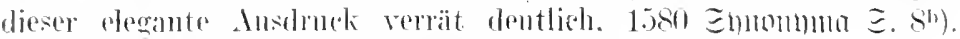

dilli der. Aufsatz rin limsersationsstïck

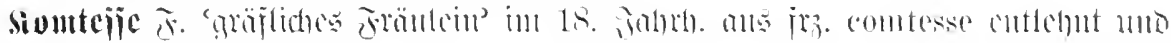
bei Eperamer 1727 geturcht.

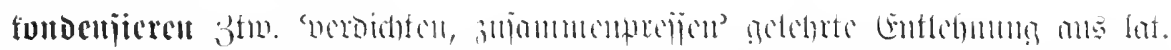

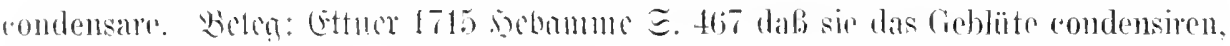
rerdicken.

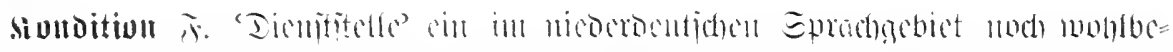

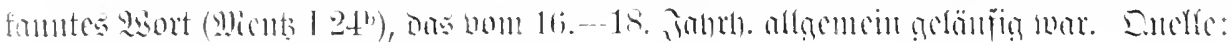

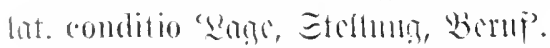

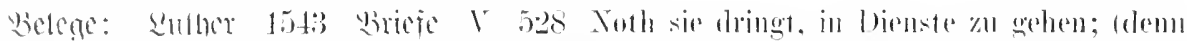

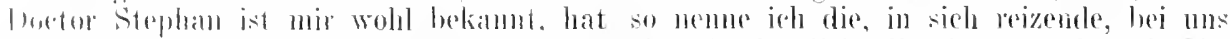

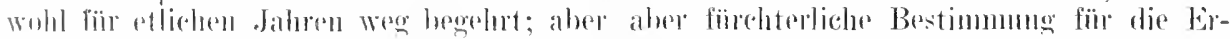

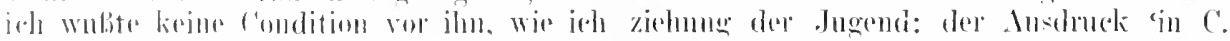

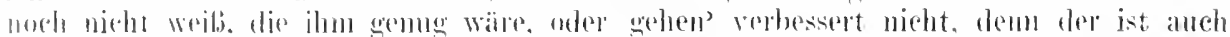

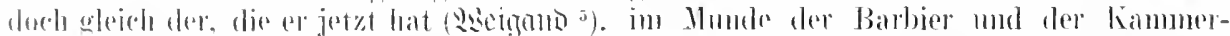

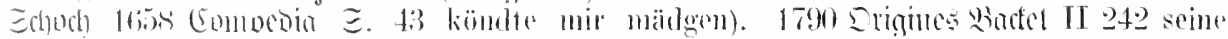

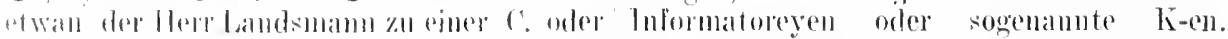

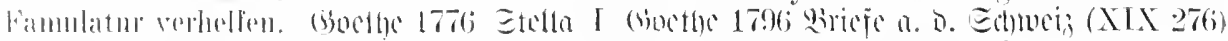

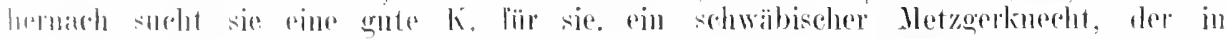

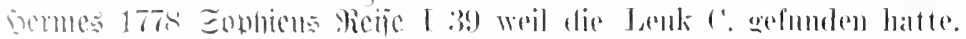

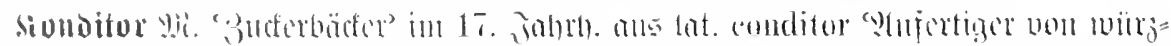

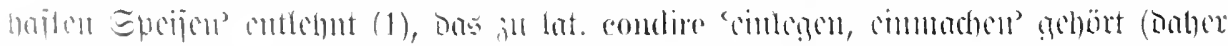

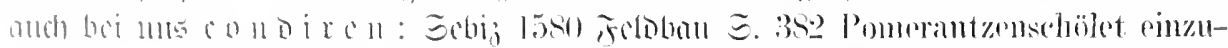

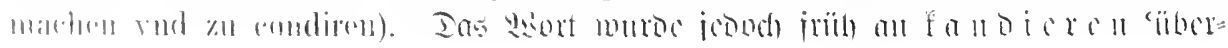




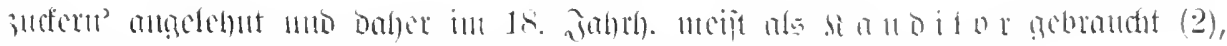

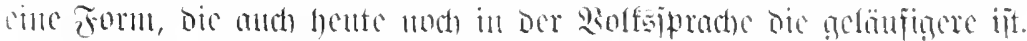

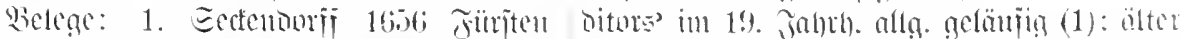

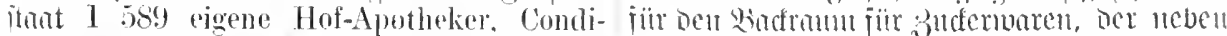

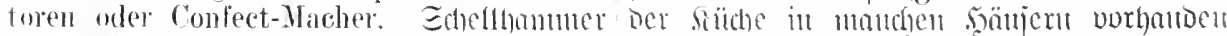

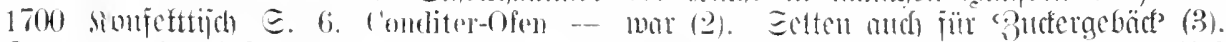
こ. 10 ('onditer-Srhiïssel.

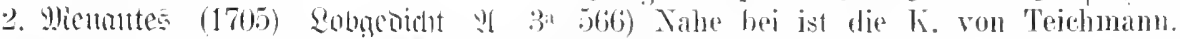

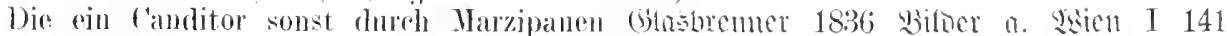
macht. Juiti 1761 Minnụ̣aftuten II 5.52 weil man allenthalben durch erinen Zuckerbecker einen Canditor verstehet. Connte

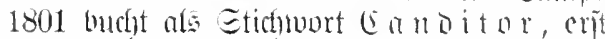

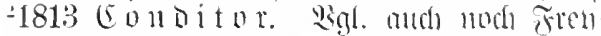

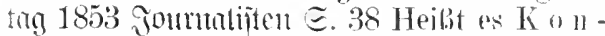
ditor oder Kanditor? De] neme horrektor hat korrigiere $h$ a $n$ diterl.

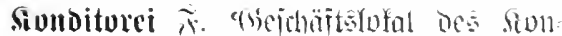
Wenig (t)-en sind in Wien.

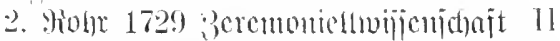
71 In der untern Etaro sind geneiniglich die Dienst-Gienächer. al: die Silber-Cammer. (lie Kürcle und ('.

3. Eemme 181: !lum Leben (I 65) Die Lieblingsneigung trines jungen Mannes, welcher Butlar hieb, zur li. machte besonder: unseri losecerte sehr rejoh.

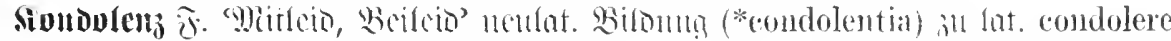

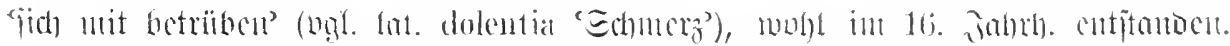

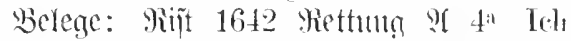

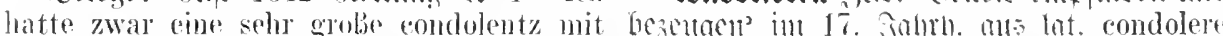

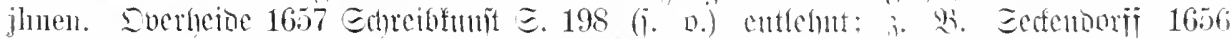
zweiffel nicht. der Herr Vetter werde Fintenitant I 192 man eratuliret ibnen bey hierimnen anch mir, als einer mmmehr hoch- Frenden oder condoliret in Leides-Fällen. betribten Witwe seime Cluristliche Comdo- Ettner 1697 Inttor E. 437 Eckarth condo-

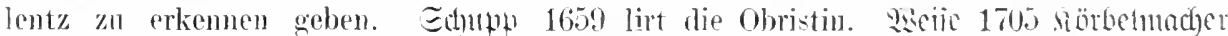

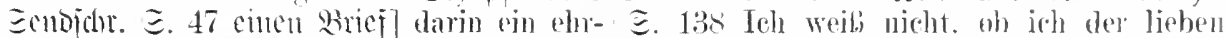

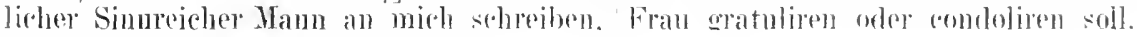
mil' seine Comdolentz contestiret.

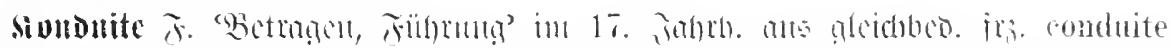

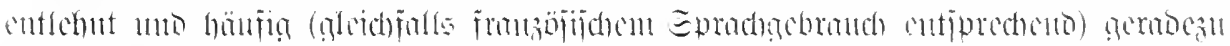

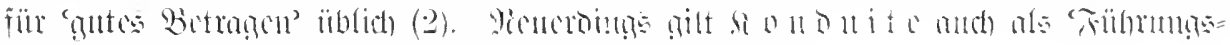

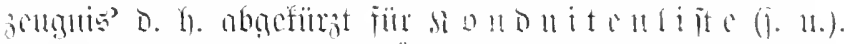

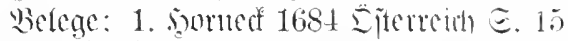

2. Midhatis 1768 shijumentent I 7 !

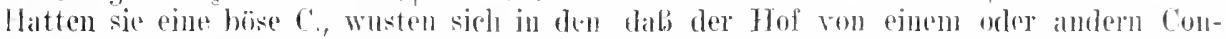
Hol nicht zukchicken? Iention 1689 ) Lluter = lluitenlisten hekomme oder über die fon-

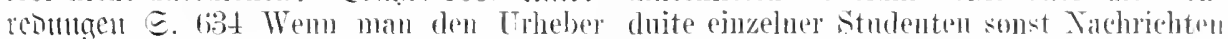
kinnet und ron dessen guter e. versichert einziehe. Jijtant 1785 gäger (I 123) Solche

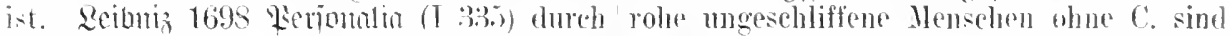

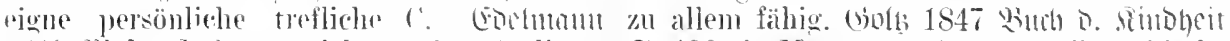

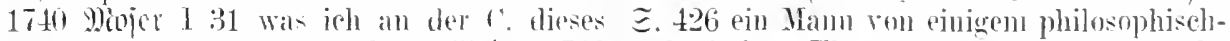
guten Herm answetzen solte. Whior 1746 ästhetischem Ehr- und Zartgefühl und nichu

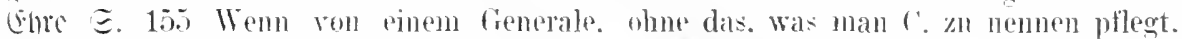

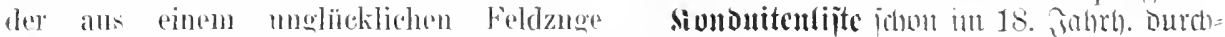

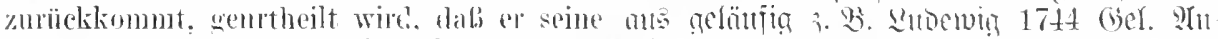

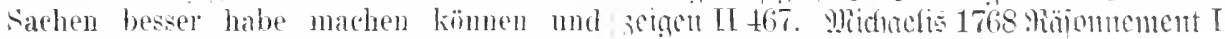

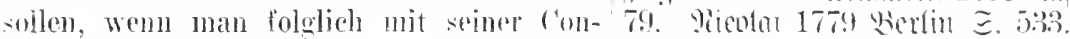
duite iihel zufrieden ist.

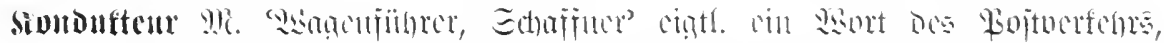

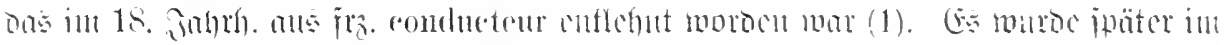

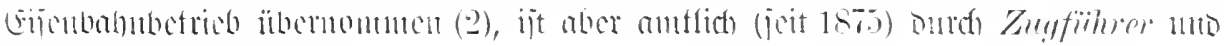
simaffuer crictist. 


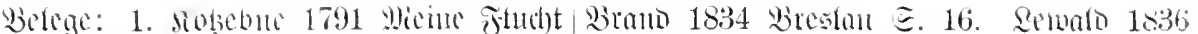
11. Horis E. 84 Nan sitzt in einem Gefängnib, 9(quorefle II 98.

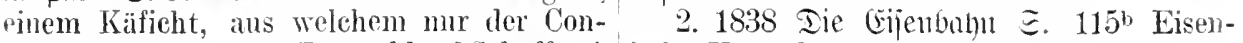
ducteur (soviel als in Dentschland Schaffner) bahn-Konduktenr. buaffünder 1847 Reije befreyt. (3octhe 1796 Bennemuto Celfini in. Faris (VI 230) der Zug länft von selbst $(43,218)$ den Condneteur der ordinären hinab, sorgfältig überwaclit von den MaPost von Venedig. Siemer 1811 Jieijejdyatten schinisten und Condneteuren. Dismard

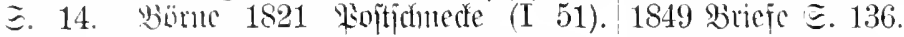

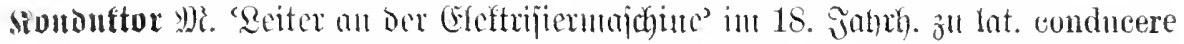

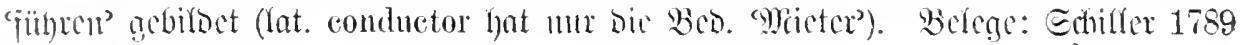

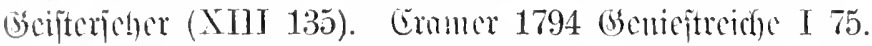

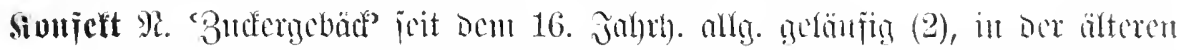

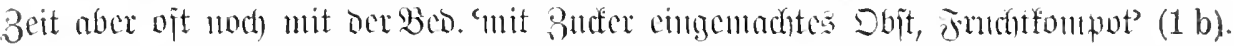

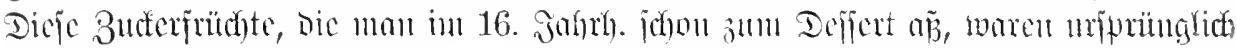

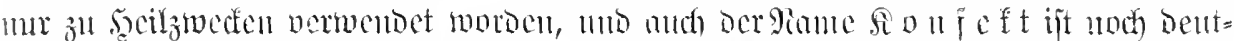

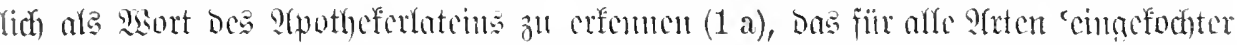

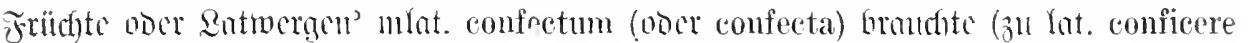

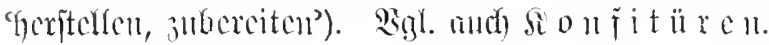

Befege: 1 a. [Son Der Erbncten 1477 im eonfieiren vnd einlegen gantz rnd vnSeuthoniifta: confect of gesult van crnide zerstosen pleiben. Conservazncker aber. of van snicker (D2SG.).] Fries 1519 Enicgel wamn solehe ding nicht gantz sondern zer-

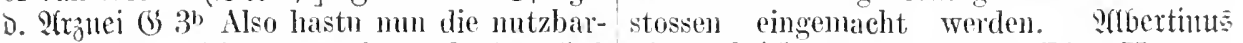
keit der apoteckischen tonfect. Qnther 15301603 Beitfiurzer 厄. $159^{\mathrm{b}}$ Die Hennen, Ed)ulprebigt $\Subset .34$ hie mit kan der Artzt Kapamen, Pasteten, Latwergen vnd Conallerley schmertzen lindern, wnd viel susser feet rerenderstu in ein bitterkeit rud guter confect machen rnd salben zor richten. nagende Würm.

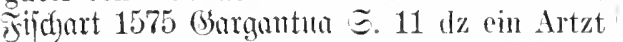
nit allein mit lirentern, salben, träncken vnd confecten gerïst sein sol - こ. 19 gleich wie solche Hanfgebntzte Apoteckergeschirr vnd Weinbüichsen von ansen hälislich vind greblich oberaub scheinen, vmud doch zu jmierst mit herrichem schleck vind Confect seind geschicket vmud gespicket - $\Xi .105$ sie bereit Confect fïr den Schmuffen, Hnsten.

b. Eevi 1580 Jeloban $\Xi .253$ Unter-

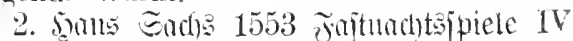
$138 \mathrm{Al}$ is denn solt dn aufftragen thon [ajien] Den gesten ein Colation Von zucker nnd gutem Confeck Vnd ander seltzamen geschleck - 1558 Fabehn II 12 Was man anf lneb vons herren disch Auch confect, rosin, mandl vald feigen. Miathejins 1563 Erhe=

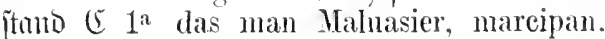
confect vnd kuchen aufftregt. Buthler 1605 Inejaur. Ennunum. of S $^{\mathrm{b}}$ nachtiseh. alles was man uach der malzeit auffträgt. scheyd zwischen Confect vnd Conserf. Die als obs, kith, knchen, confect vind derConfect heyl.; ich, wann nit alleyn die gleichen.

Wurtzeh. sondern anch ander ding mehr

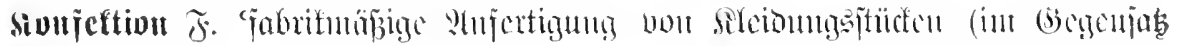

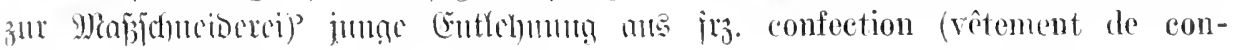
fection ctc.)

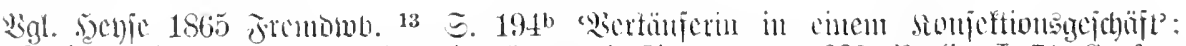

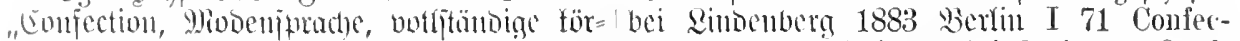

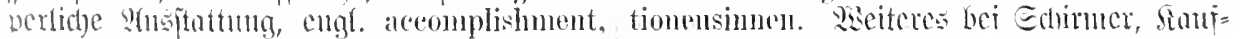

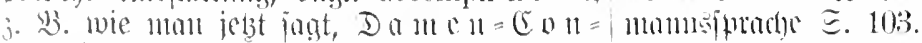

Fection". Danll sunfettioncufe

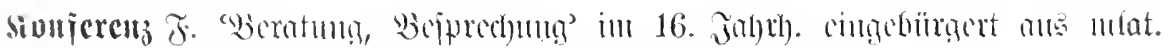

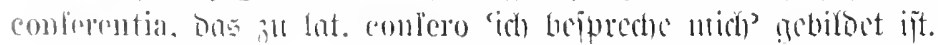




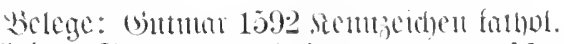
Feligion $\Subset$. 101 vond ist erst rermeldte Conferens mit vnd zwischen verstorbnem Schmidlin vind Osiander. gehalten worden. Eecfentorif 1656 Jïritentant I 86 durch mïndliche Conferentz des LandesHerm Räthen und allen oder etlichen von den Land-Ständen. (Strumuelshamien 1669

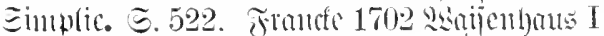
34 Abend-Conferentz. 1754 Wranmichmeig. Ednnforduntugen I 281 nit den informatoribus hält er wöchentlich bine eonfer'onz. (i)e = Dide 1795 Sofhtif(hriften II 12. in the halbjährigen großen Konferenz.

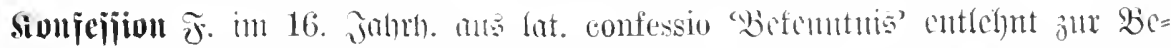

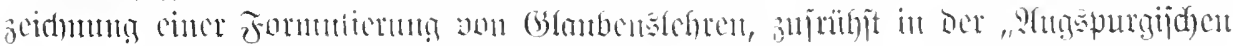

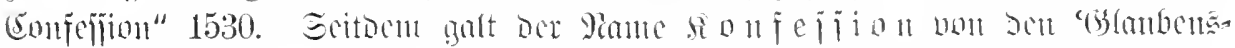

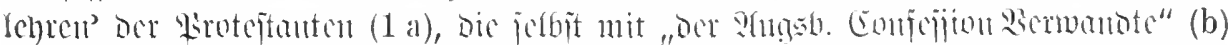

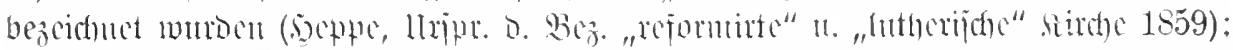

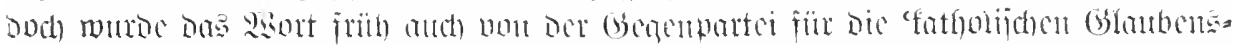

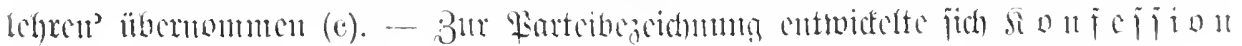

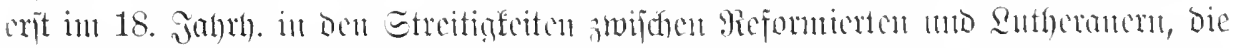

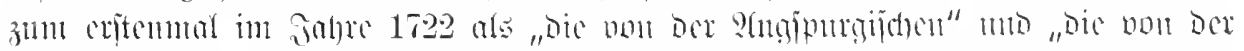

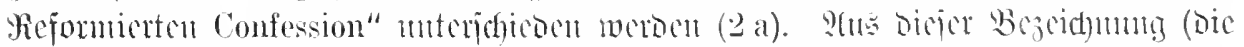

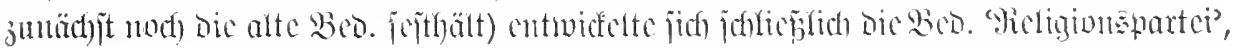

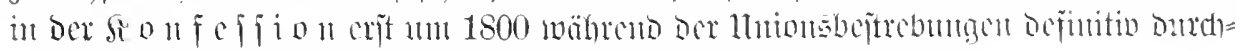

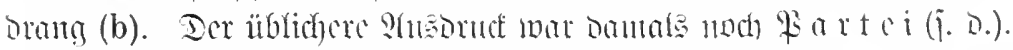

Befege: 1 a. Elcionnns 1557 Ghronica Confession verwandten Kirchen approbirt. $\Xi .371^{\mathrm{b}}$ Darzwischen ließ der Hertzog von Wirtenberg die Confession vnd bekantnub Co seins glaubens, ciie seine gesandten auff den Concilio ïbergeben latten, in truck

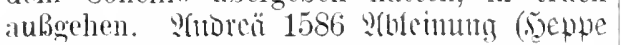
こ. 29) ron der christlichen Confession, so man den Lutherischen glauben nemnt. Eleidum: was sie deb Bäpstischen Concilij halben zn handhabung rnd erhaltung inrer Confession znthum oedr zulassen gesinnt. Mierdel 1606 Preoigt (5ephe 三.47) Standhaftigkeit

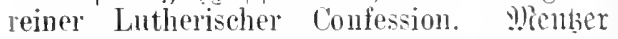
1607 (efrijtl. Pathbericht $\Xi .23$ wemm aber in den Kirchen Angsb. Conf. die Zwinglische Dentelei des Brotbrehens rerworfen wird. Qenderter $1607 \mathrm{Hp}$ ssorum Fides christ. ङ. 273 dab in Hassia the rorige alte reme Lutherische Confession und Lehre bis noch behalten wird.

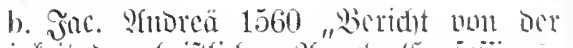

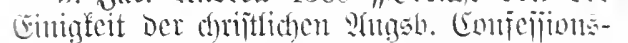
vertumbten Iheologen". 1580 sionforbien= formet (Gepue 5. 22) ron allen der Angsb.

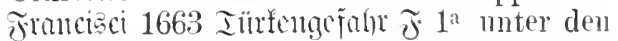
Catholischen und Aıgspurgischen Confe:sions=Verwandten. 9(nd) nod bei Ielfer 1780 Fremuit. Sctradntungen $\Xi .22$ die augsburgischen Confeßionsverwandten. Dabon abgeleitet fino Enottnament mie

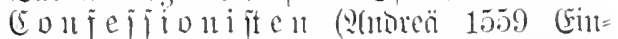
helligfeit $\mathcal{B} 4^{\mathrm{b}}$. Sian 1581 Exunten $\approx .195$,

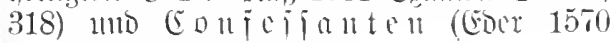
Evang. Inquiiition I $6^{\mathrm{b}}$ ).

c. Yain 1581 Cxumen E. 33 Aber S. Paulus sagt jnen von neyn, das rorhin nach Christi Verkïndigung . . jedermann dem Catholischen Glauben, der Römer Confeßion vnterthänig werden [mitiste] Gleich wie man die Römischen KinchenConfeBion nent Algemein, das ist Catholisch, dann solche Römische Confeßion vnd Glanben ist aller Welt gemein, nicht nur einem Landt bekandt. . . von solcher weitlenffigkeit rund ron def ersten fünemlichen keyserlichen Reichs Orts willen, wirdt der Römischen Kirchen Confeßion rnnd Glanben Catholisch Allgemeyn genaudt - 
E. bj sindtemal sie nich rinerley Confebion scheid machen, so sage man: die ron det rnd Kiprhen Ordmung halten. Oder aber, Angspurgischen oder die von dor Refordal. sie so mancherley confesion. Apolugien. mierten Confession.

rnd Lianckische Lehner haben.

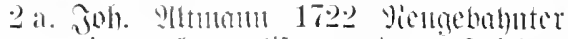

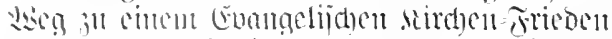

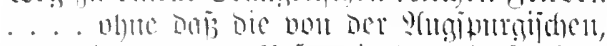

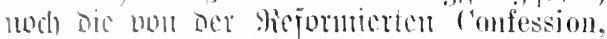

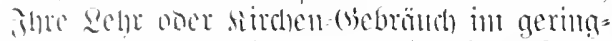

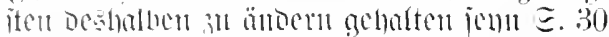
Es mag anch ein jeder Thejl seinen Nahmen behalten, and die einen sich zon der Angsmurgischen. dis andern zu der Reformierten roufebion bekemnen. jedoch sollen die alten verhabten Xihmen ibgethan werden und sollen die ron der Ansspmoischen Confebion die Reformierten nicht mehr Calvinisten oder 'Gwingliane", die Reformierten

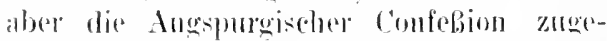
thanes nicht mehr latheraner schelteu. sondern matn soll sich modereinamler Evangensobe mennen, will man aber rinen Ttuder-

๖. 1790 9(tha. D. Bibliotlet 92, 1 こ. 67 Wenn der Verfiasel [Joh. Sijid 1788 Lid)t in fintiten 3eiten] ङ. 104 einen Blick auf dir Stifter der protestantischen Confession?

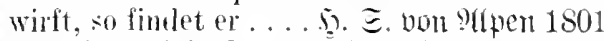

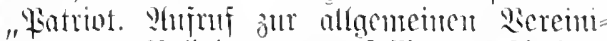
gunt oer sieligionen, sonfeifionen, Sirnen,

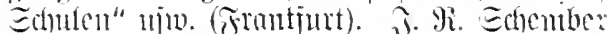
1803 "lleber bereinigung Der beboen prote

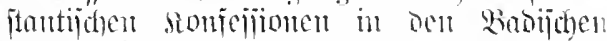

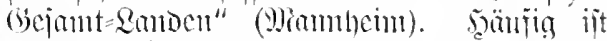
Das Lisort in mooemen Eim bei Echleier= madher 1804 (Butadhen in Endhen Des proteit. sirenembejers (V 48. 49. 52. 59), and ae= brandlt in oer llnionserflämma Friedrict

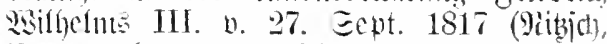

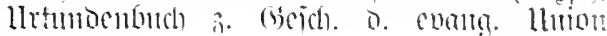
ङ. 125$)$

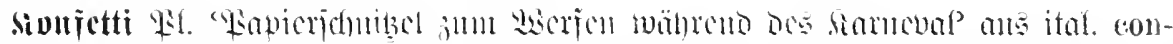

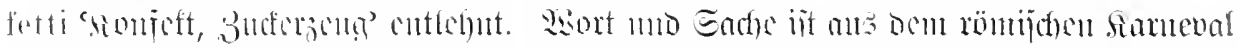

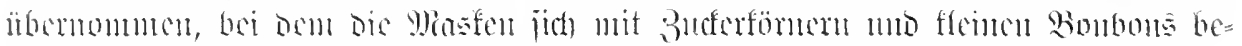

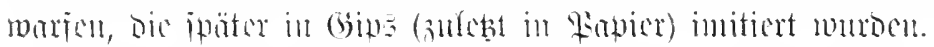

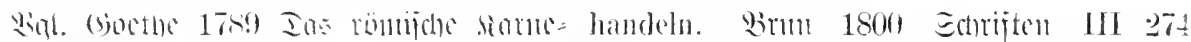

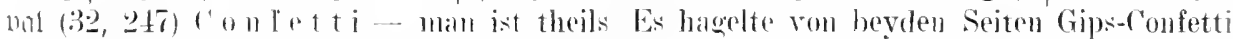

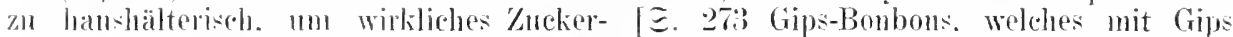
werk zи versehwendem. theils hat der Mili- äberzogene Bimssteine sind]. Gindon 1839

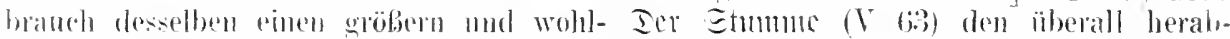

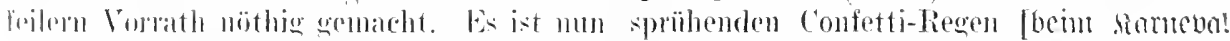

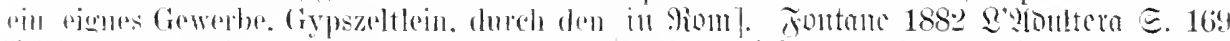
Triehter semalde die den Schein sun liuben wift ans seiner dunklen Ecke Con-

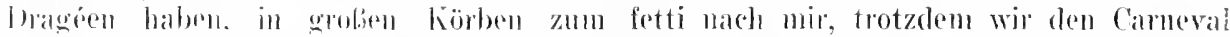

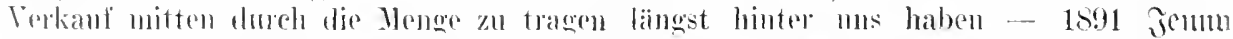

(2) 49$)$ mit rime lland ron confetti - die Iteibet こ. 144 wo man sich. wie bein römi-

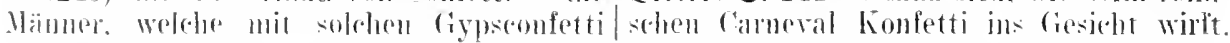

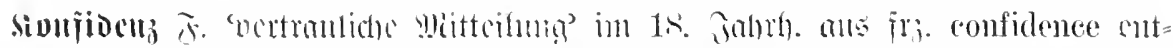

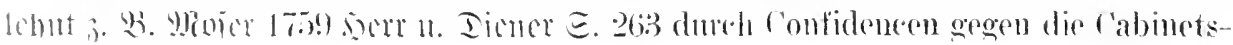
sulialternem.

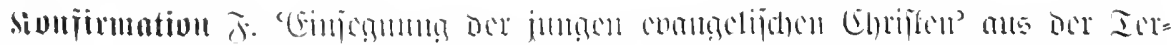

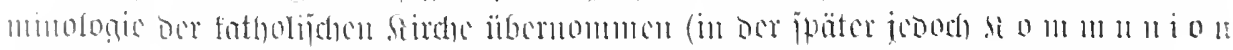

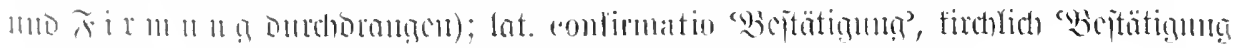

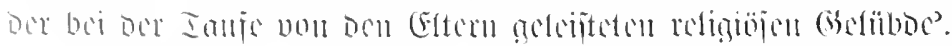

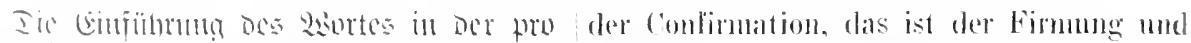

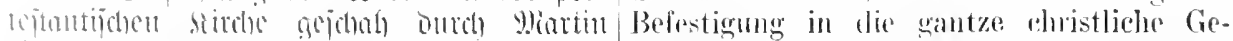

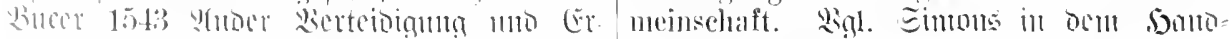

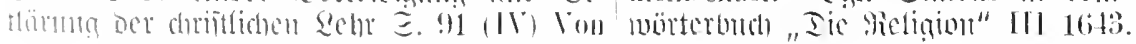

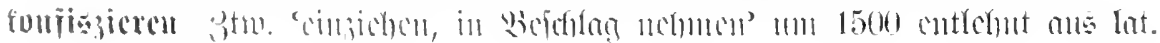




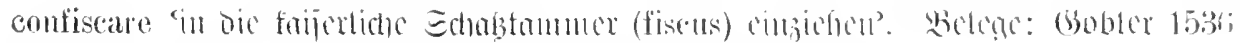

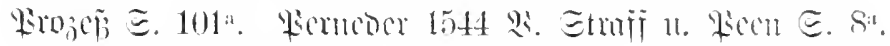

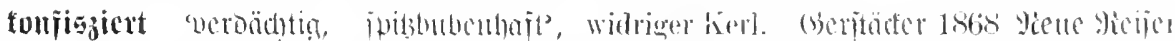

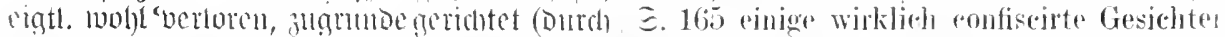

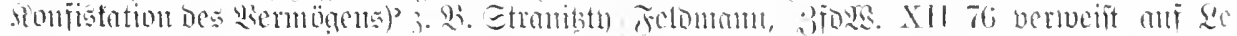

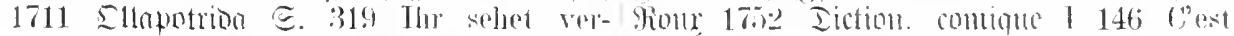

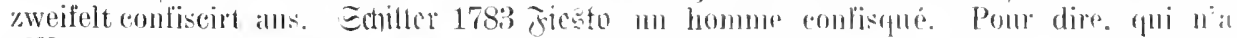

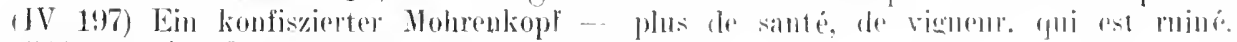

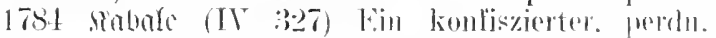

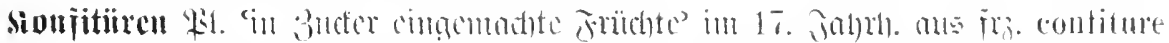

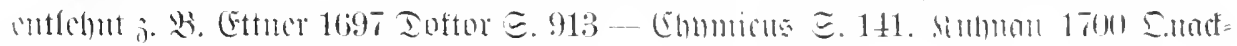

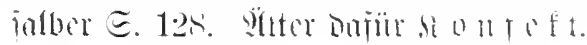

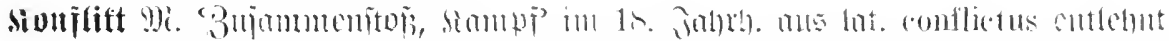

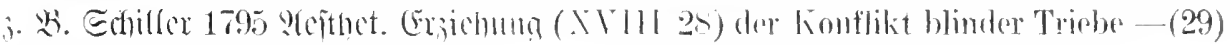
der Konflikt blinder Kräfte.

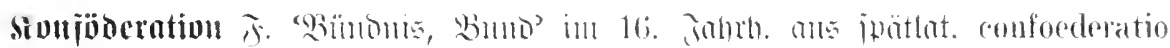
c!ntlenit.

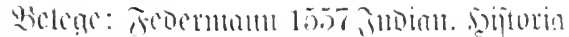
5. 25 lieinen Xideharas unther jhnen gedulden noch imn der confederation orler rerbüudtuïs der andern Pueblos ilner Nation - 三. 72 dern flecken so in diser ("onfederation mud bindtnus seiud. 1565 3ims= merijde chmonit $\mathrm{I} 30 \mathrm{~s}$. Eilbomm 1596 Weridt v. E. Watori I 20 Er aher als antchlosscoll, die getroffene confoederation rond Bündtmul. mit dem Römischen Kilyser bestendig zu hatten. 16:1 Epeculum (inermanios $\Xi .7$ mit der Hungerischen Böhmisehen vol Oesterreichisclen Erblanden fonfüderation (wie sie jhren bimelt vond sich Conförlerinten nemnen.।

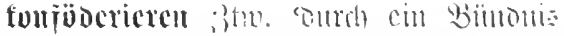
nercingen im 16. 3ahre). ans ipätat. con-

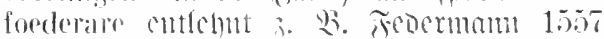
imoian. ivitorio $\Xi .23$ so sie bekriegt wurden. so wurden sifr sich one zweiffel \%u sammen rotten, comferlerieren und rerbinden - E.71.

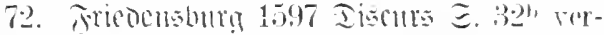

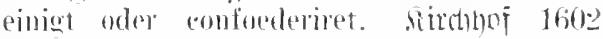
Militaris bisciblina $三 .89$ Dirru dich mit deine: gleichen Vurïhimen confoederirt vud

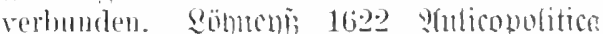

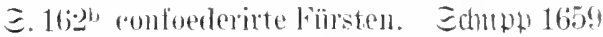

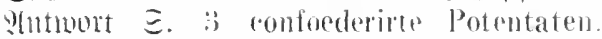

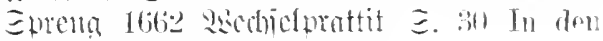
confoederirten Provintzintu.

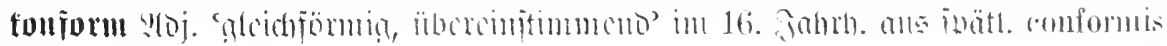
(ntfel)utt.

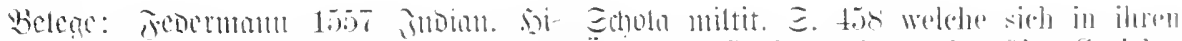

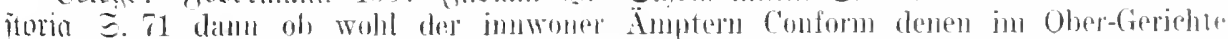

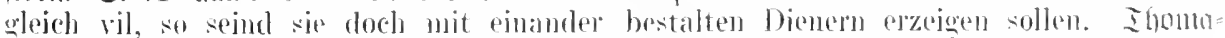

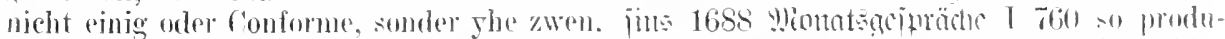

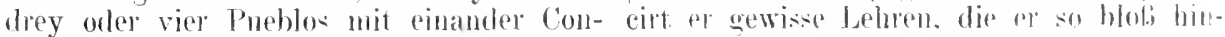

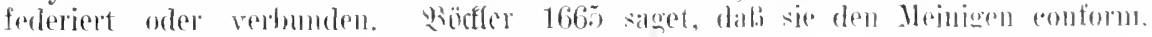

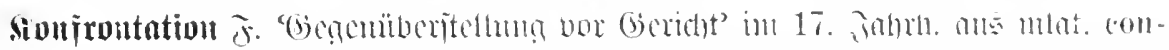

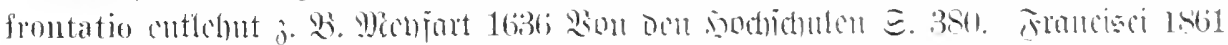

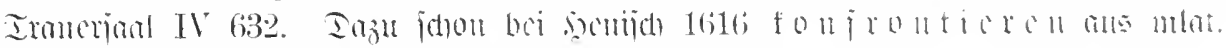

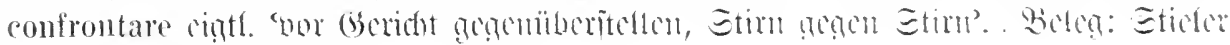
$168:$ ? 110 item $\approx$. 2.) 1.

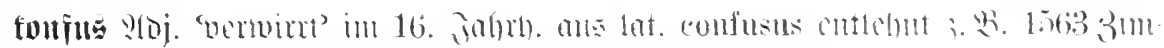

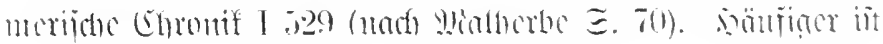


Sonunion 尔. ans lat. confusio, vereingelt der Posteritet ein Confusion erwachsen.

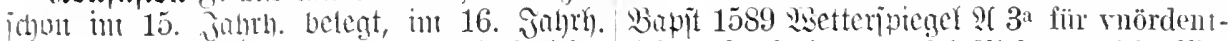

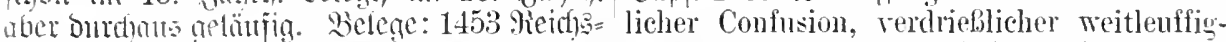

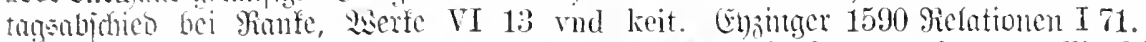

werdent andere nacion vnsere Tacion mit

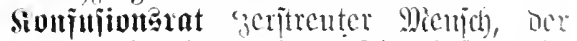

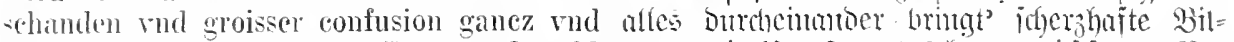
wal: rerdilgen. Paj 1581 Examen

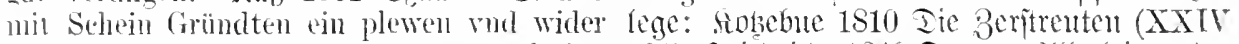

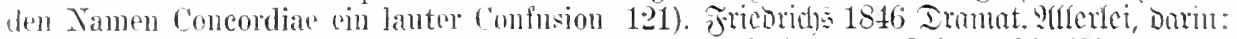
zurichten. Enbentaentutmuls 1588 strüuter = Der Konfusionsrat. Echerr 1862 Sliüher I 26 buch I 102b sintemal sie dureh jhe Con- Oberkonfusionsath. Pad Eeits, 3foge. XIII fusion romd rerwirung jhnen selbst ror 315 sonjujousat fitt rommissionsat

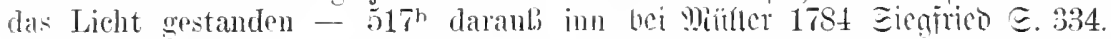

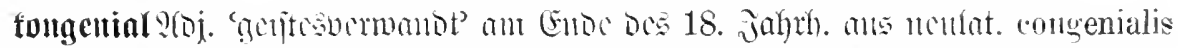

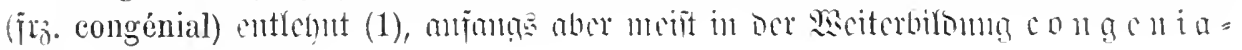
$1 \mathrm{i} j$ 占 gebratht $(2)$.

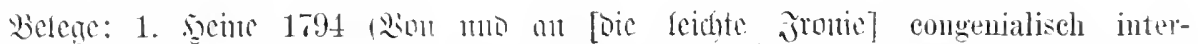
niroer II 224) So wie Sie es behandelt pretiert. Wisclano 1798 qrijtipp (XXII 163) haben, ist os so congenial mit dem Nenschen. weil dn mein Freund, ein mir rerwandes

2. Soctor 27, 86 (bei giebrein) In Horaz' congenialisches Wesen hist. Sommonen und Briofen hat Wieland sie

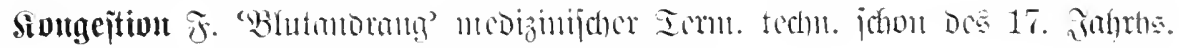

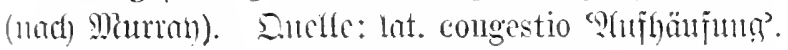

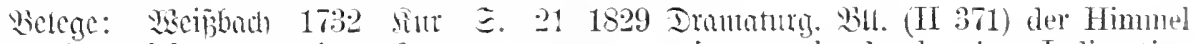
wem eine solche congestion oder pressung mag wissen, ob durch eine Indigestion deß gebliits gegen das Haupt vorgenommen oder eine Kongestion weich gemacht. Fon= wird. Strüger 1750 Diüt $\Xi$. So eime Con- tane 1897 Etchlin $\Xi .43$ wie alle an Kongestion des Bluts nach dem Kopte. Büruc gestionen Leidende.

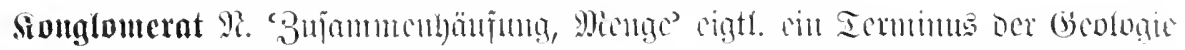

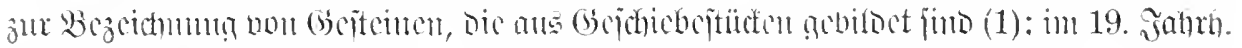

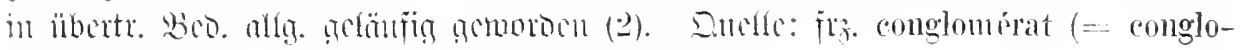
meratuin ju lat. conglonerare 'jujanm

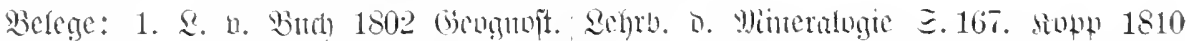

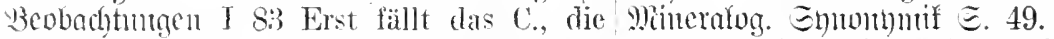

groben Geschiebe - 104 aine gröbere An- 2. Devrient 1840 Ibeaterjchulc (IV 339) häufung des C.-s - 105 unter dem eckigen ans diesem C. der verschiedenartigsten

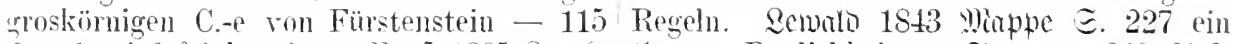

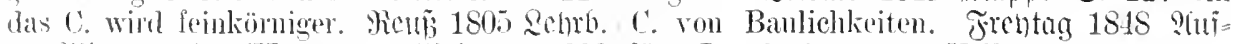

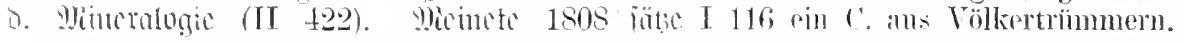

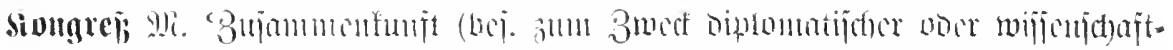

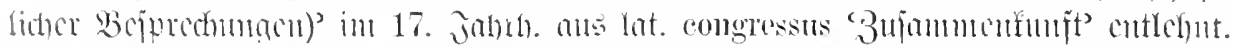

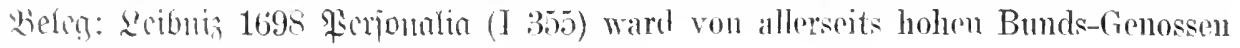
bei den Congresse inn Tlaag gut befunden.

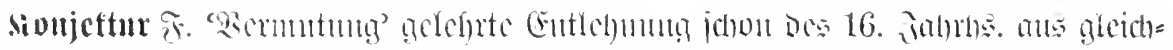

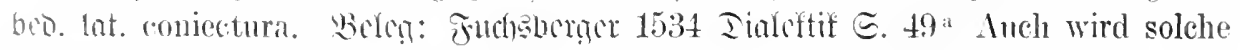

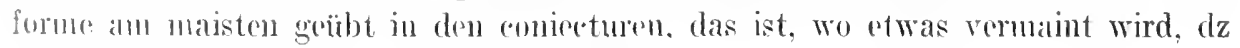
weiter bezelgons and furbringens durfftio.

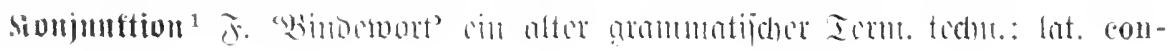


iunctio. Beleg: Entter 1610 \&hrajeolongic 三. 16 das daß, wam es ein Conjunction ist.

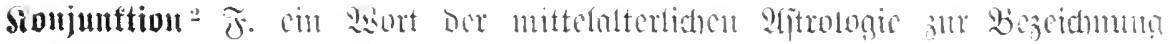

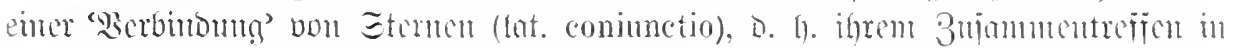

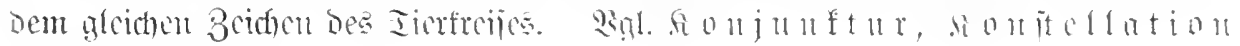

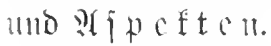

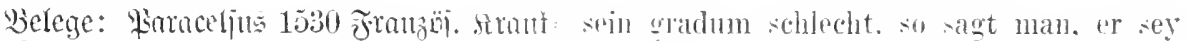

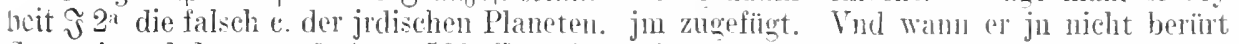

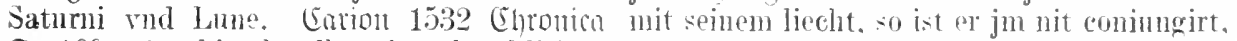
כ. $169^{\mathrm{a}}$ der himel selb mit schrecklichen sondem wehet zn der coninnction. Vnd zeichen, Finstemus rnd C. Fincelins 1567 die coniunction branchen die wersager

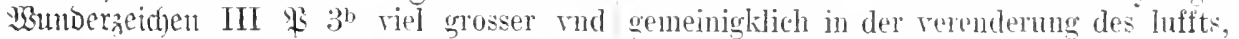
schrecklicher C. oder Congressus Planr- ind andere accidentia. dir sich im Jar zutarum vnnd stellanm - sonderlich die C. tragen. Aber ron dem ersten weg der Solis, Martis etc. Rerröberger 1569 Qlitrono=: conimetion rerlen sie, die auß der Natinitet mie $\subseteq$. $14^{\mathrm{b}}$ wann ein Planet den andern des monschen znkïnfftige ding sagen. anzieht, vnd wam ar mit seinem liecht

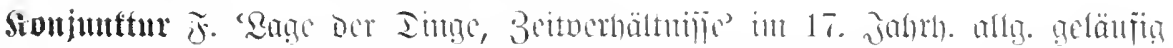

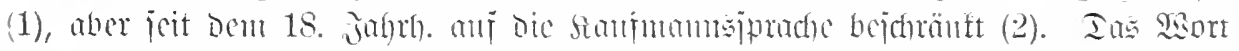

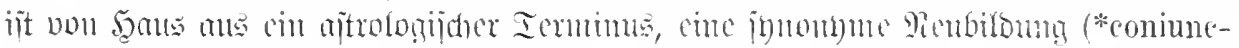

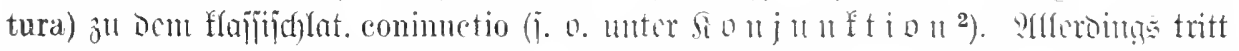

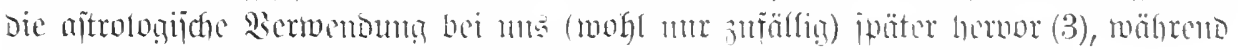

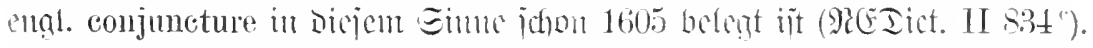

Belege: 1. Sondork 1618 :Ictar publ. I こ. 123 C.. der Zeitlauf, der Lmstand. der 383 vnverhoffte fäll, welche imn solchen für gewisse Waaren schädlich oder nützlich c.-en sich wol ohne einigen füsatz zutragen ist. 1783 Echtözer Etnotsm. III 399 - 1619 ens. II 570 bey jetziger gefähr- Die rorhandene Yenge der Waren maeht licher c. 1631 Beridht ט. Mngoeburg $\Xi .4$ anf die Preibe selten wichtigen Einflul.. bey solcher ohne Zweifel erwünschter c. sondern, in inrer Sprache zu reden, blos C.

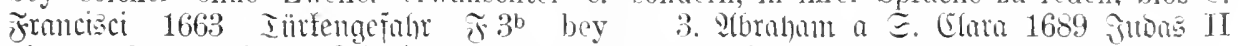
diesen schweren C.-en. Reibuiz 1670 Eccuri= 413 dibfalls aber werden die jenige nit tos publ. (I 162) gegenwärtiger glïcklieher beschimpfft welehe auß sonderer WiscnC. - 1698 Perjoutuliu (I 347) die C.-en in sehafft wegen Lauff der Planeten, Beder Nachbarschaft. Fricorict 1. 1711 Brieje schaffenheit der Sterm, Conjunetur der

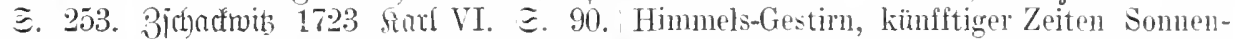
Bejiutg 1768 Brieje I 260. Bürger 1777 schein, Finstermus, Hitz, Kälten, FeuchtigBrieje II 69 die fatalste C. Echiller 1781 keiten, Suchten rnd andere deroleichen iönber (IV 50) Unglückliche K.-en. natïliche Ding rorkïnden.

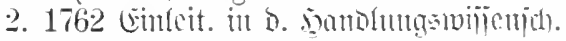

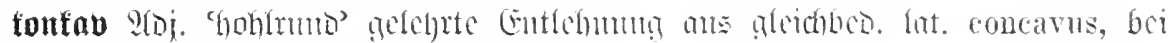

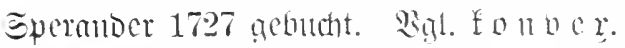

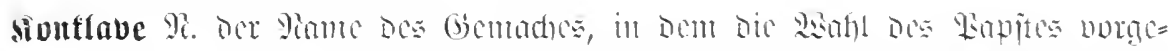

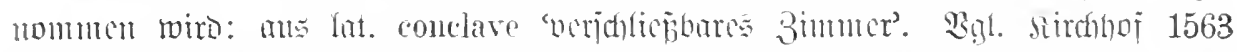
semommut I 142 Zu Ron ist ein schöner pallast auff dem Taticaner berg, in sanct Peterskirchen, in welchem pallast die bäpst wohnen mud die cardinäl zu raht gehen, wo es die notturfft erfordert. In disum pallast sein under andern fünff herricher sil und ein spatziergang und zwo eappellen: diese gentach alle werden das conclave. oder das beschlossen genennet. 


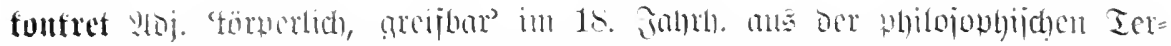

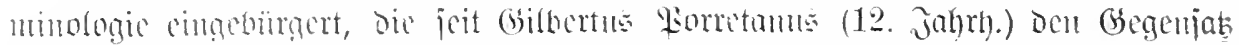

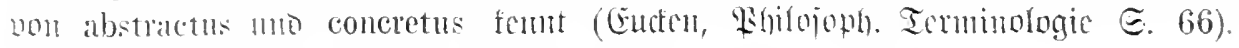
Detite Eutele: lat. concretus 'werbärtet, itar'.

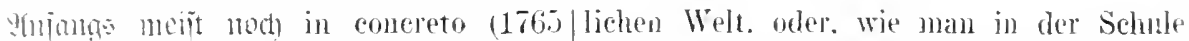
?

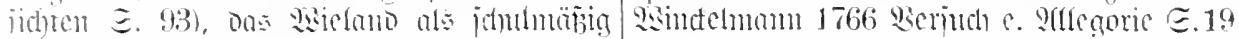

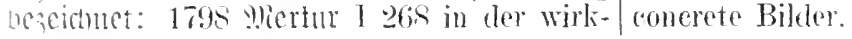

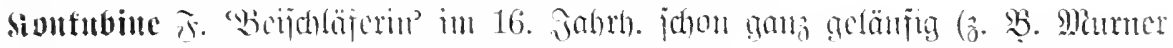

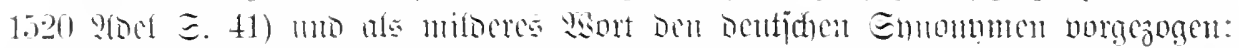

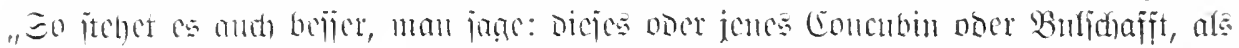

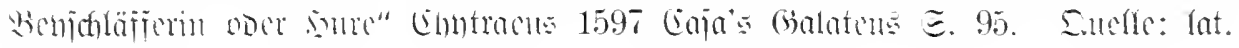
roucubina.

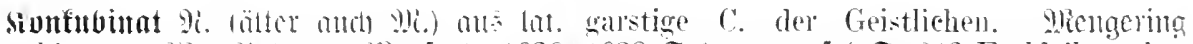

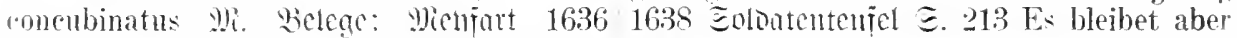

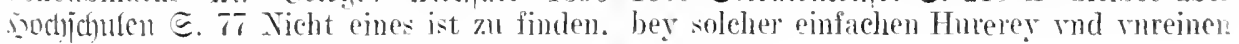
las ansser dem r. gebohren - E. 84 der C. nicht.

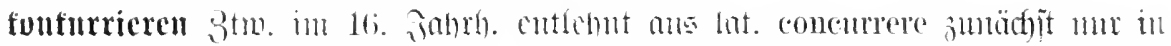

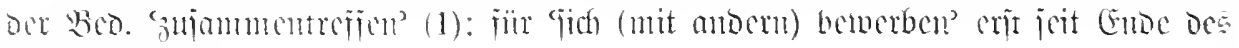
1- Juhth: (2).

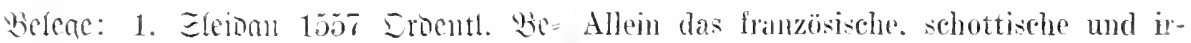
idureinum (2. Sorreos) Nm haben in be- ländische linnen wird ameh äberall mit dem

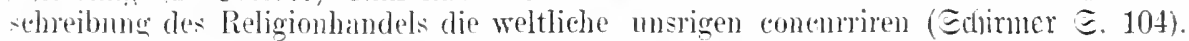

Händel nicht mö̈ren vinbgangen werden. dam wie obgemeldt treffen sie jmmerdar znsanmen . D Dab ste aher zusammentreffen vmol concurrieren. ist dise in der sehrifft gegrimelete rrsach. Vicuman 1620

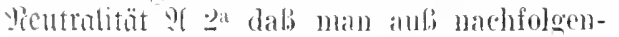
den Trachen $\%$ Tentralitet, wiewol derer

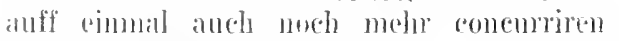

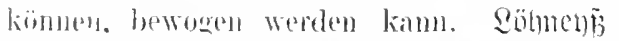

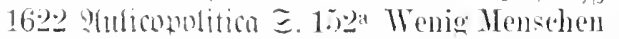
sind in dentu alle Laster wnd Vntugenden mit pinander concomiren.

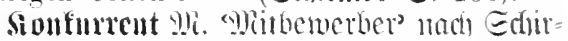
mer E. 10 bei Einonius 1783 Sciebuch $\Xi .32$ mit ihren fremden Conenrenten zil wetteiferm. Goetle 1796 Qehrjabre (XXII 2881 Die Stelle ward durch einen viel geringen Concomenten besetzt.

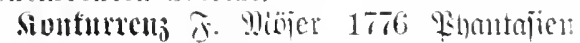
II 218 io muj] allen Gläubigern die Concurrenz zugestanden. nicht aber einem geholfen und den übrigen durch Bestätigune des Stillestandes ihre Concurrenz abgeshuitten werden. Brombes 1776 an Bürger

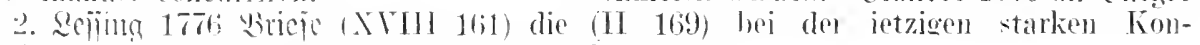

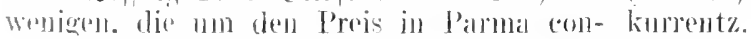

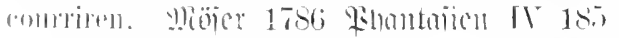

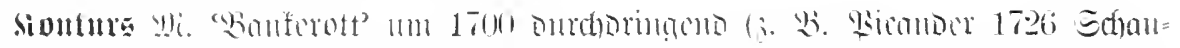

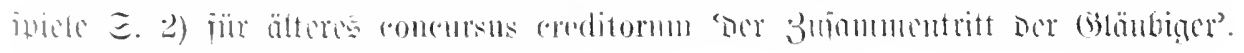

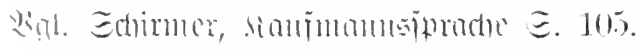

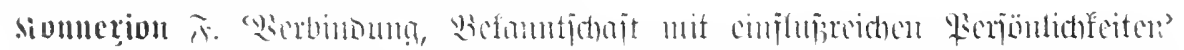

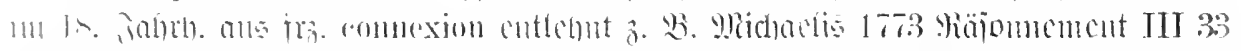

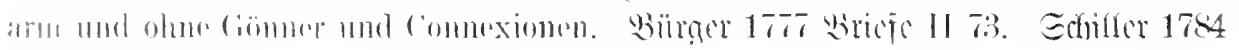
vition | 165 .

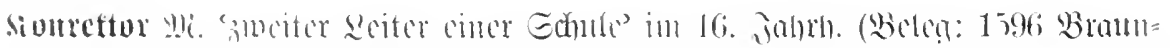

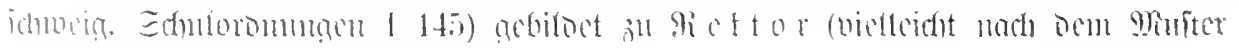

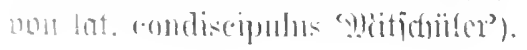




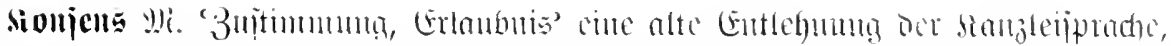

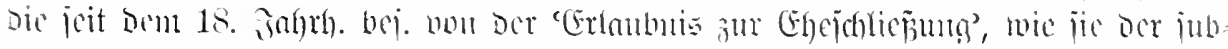

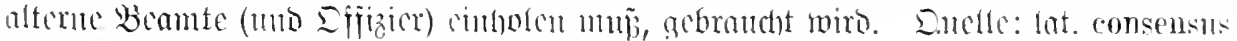
'L̈lbercintimumung?.

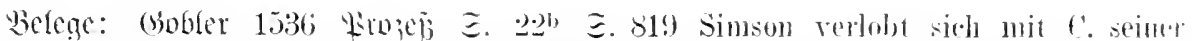

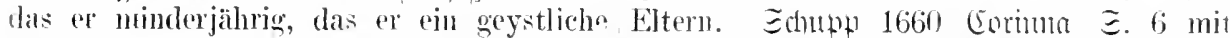

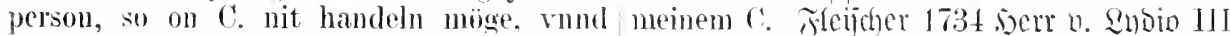

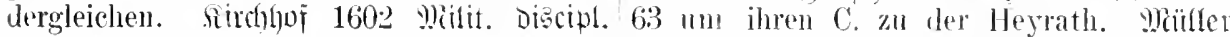
5. 124 mit e. vnd Bestätigung def. Feldt- 1792 .jorr Shoutas IV 195 weil ein Fähnhrurn - こ. 221 mit dessen $C$. vnnd Be- rich den K. seines Chefs zur Vermählung

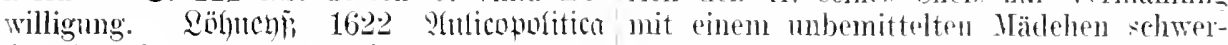
5. 242 ohne c. vnd vorwissen des Landes- lich erwarten darf.

fïrsten. Mengering 164 - bentijenstïge

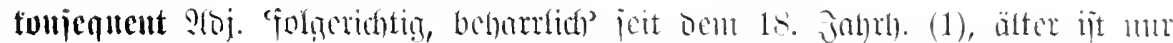

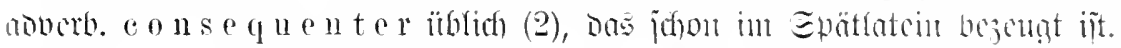

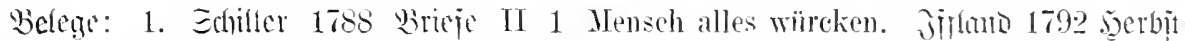
Wieland ist sich nicht gleich. nicht c, nicht tog (II 19t) Consequenter tarf ich mein selbst fest genug. Möiffer 1789 Enmeridn Mündel dem nicht geben.

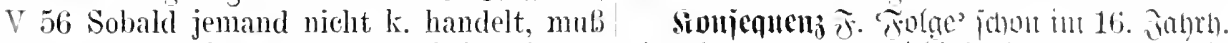
ar Dir von rechtswegen verdichtig sein. cingebingert ans gleifincs. lat. consequentia

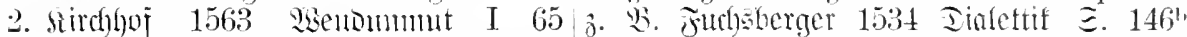
Gleichwol ist nicht hieraub consequenter zu Aub welcher rngereinten probe rud resach schließen . . Gutmar 1592 sumzeichen kain noturfftio consequent\% oder volge mas

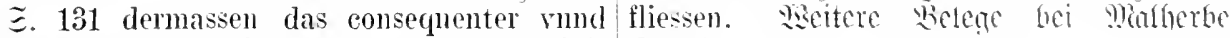
zwanglich... Sebermalnt 1680 Ienjelg 巨. 45.

siit I 69 consequenter kan ein soleher

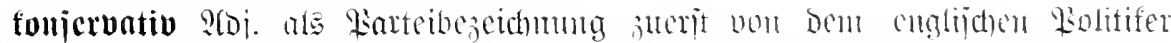

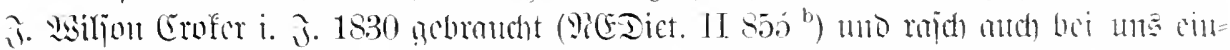

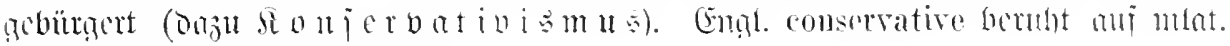
conservativus cigtl. 'crhaltend).

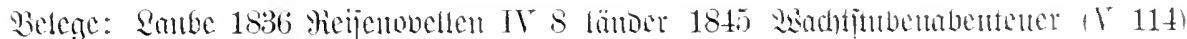
wo er [Genb] ein Hauptrepräsentant des Er, einer der loyalsten Unterthanen. consergesetzten, geordneten Conservatismus wurde. vativ bis zmm Exzels. Ninr 1846 ìmges

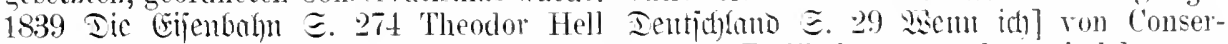
war rielleicht manchmal etwas zu conser- rativen, Radikalen usw. rede. so sind dannter vativ in seinem IVirken als Leiter der Abend- die Fïhrer der genannten Parteien rer.

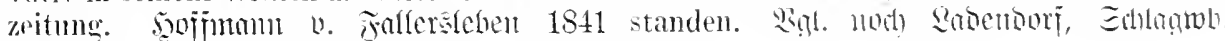
llupulit. Qicder II 5.j Du möchtest Allen こ. 176. Alles sein. Conservativ und liberal. Sinf

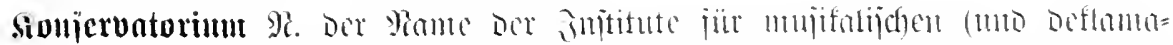

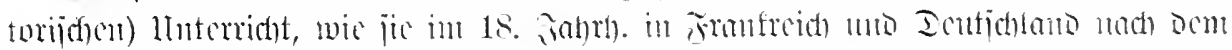

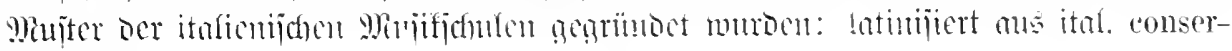
vatorio.

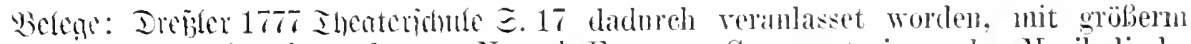
in den Conservatorien, besonders zn Teapel Fortgang Conservatorien, oder Mnsikalische

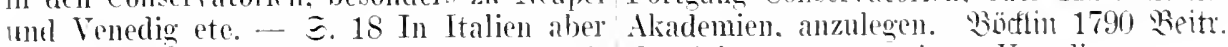
ist es allgemeiner. weil eine reinere Luft $\Xi .20 \mathrm{im}$ conservatorio zu Venedig.

die Sprachröhren reiner erhält, und man

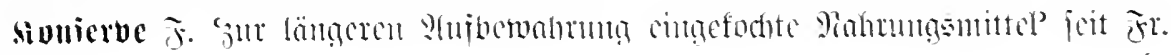




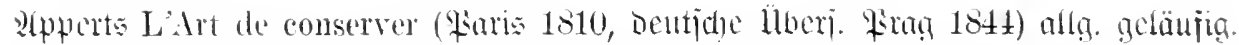

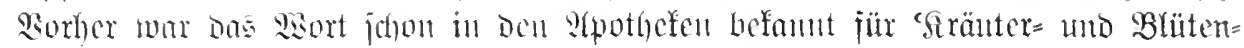

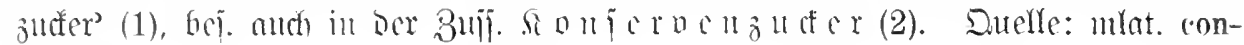
serva.

Belege: 1. Eebij 1580 Jchbun こ.70,383 rin Büchsen mit Conserven ..., als sie Item ist wider den Schlag oder Popelsie davon af, sagtesie. wie sanerist dieserZucker. auch sehr mutz, das man eyn Conserff ron 2. Echiz 1580 Felobau こ. 253 ConservaLavanderblumen mit Zucker brauche. $\Xi e=$ zucker, wann solche ding nicht ganz, son-

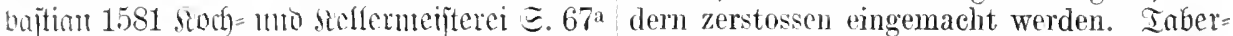
Von Confect, Conseruen vnd Einbeytzmngen memuntam 1588 Sirüuterbud ' I $18^{\mathrm{b}}$ Man - $\Xi .70^{b}$ Zucker Rosat, oder Consernen von macht auch aub dem Wermuth ein Edlen Rosen zu machen. Siscioner 1644 ?(pophth. III KonseruenZucker.

tonjervicren 3tm. 'crbalten, anfocmahren' in 16. Tahth). aus lat. conservare

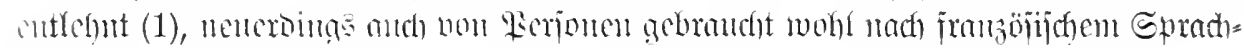
actorauch (2).

Belege: 1. Hurnceljus 1570 Qtrthiouxu Landes Vermögen zu conserviren sey. 1712

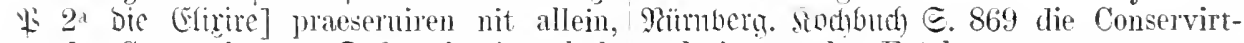
sunder Conseruiren - I $2^{a}$ wie ein gebal- mul eingemachte Früchte.

:amierter Cörper on leben erhalten wurdt, 2. Sintebue 1801 fingăberg (XII 257) also ein lebendiger noch vil mehr Conseruirt Tch habe mich wirklich zum Erstaunen

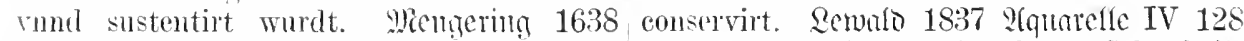
Eoldutentenfel S. 208 wie sie jhren Feld- Eine andere, chemals beriihmte Schönheit, Herrn sein Armo'e conserviren. Sorne 1641 die sich jedoch nicht so conserviert hatte.

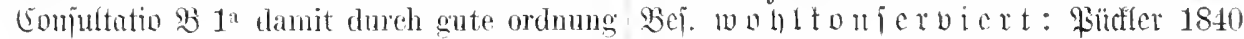
rud disciplin die menschliche Societet er- Bilocrjat I 459. Frentan 1855 Earl mis

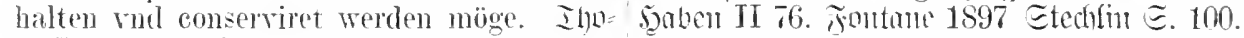

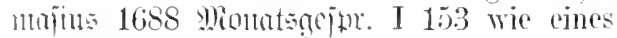

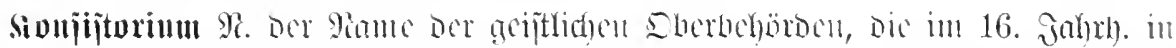

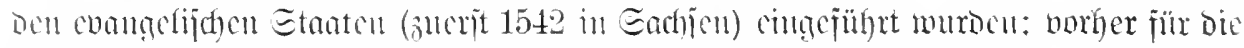

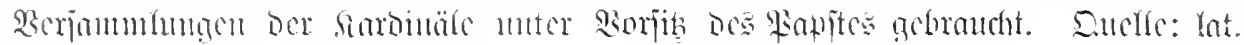

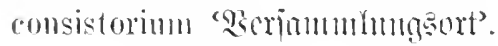

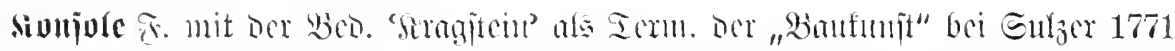

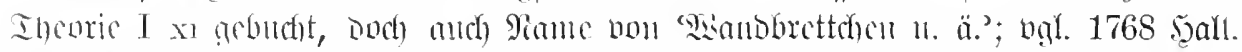
Bibl. IJ 413 Statnen anf gerundeten Consolen. Yicofui 1779 Borfin $\subseteq .656$ Konsolen mit Kanmen. Tasm. Sultelle: frò. console.

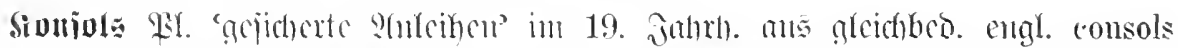

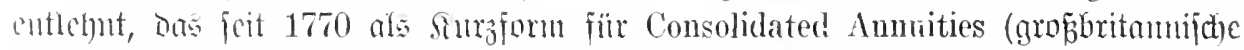

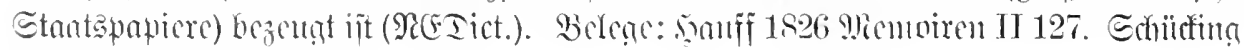
1859 Erzä̆funtacn II 67.

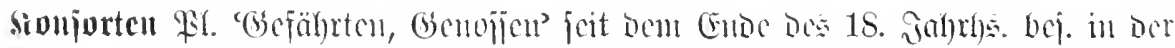

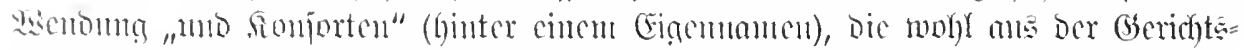

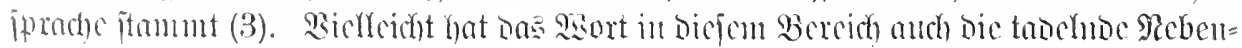

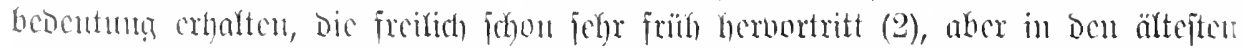

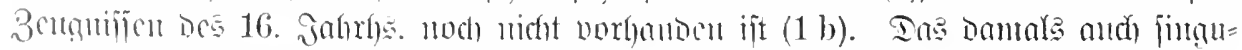

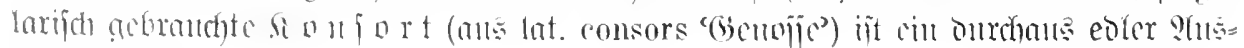
Dind (1 a). 


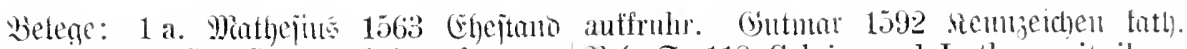
Eq $2^{a}$ Den der Son Gottes wird anch rnser giel. C. 112 Caluin vnd Luther mit jhren aesell, gemeiner rnd Consort genenut - anhangenden C. 2öbuenji 1622 i(ulicu-

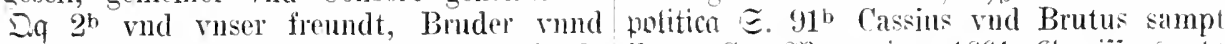
Consort für vand für bleyben wird - Da $3^{3}$ jhren C. Mengeting 1661 Gemijensted)t die spons vond gesellin Jest Christi jres $气$. 251 und bekennens ihre eigene C. und lieben Brentiganns consort vund gesellin Spiefogesellen, dab sic [oie fatbiniften] daist.

b. Mathejuts 1563 Cinejtano E⿺ 3 drumb sir auch S. Peter $c$. vind theylnemer der gnade Gottes nemei - 1566 Quther $\Xi .91$ die Geistlichen vund jre C. Etör 1602 Gécitł.

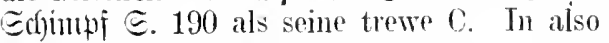
habn getröst mit Worten.

2. Mathejus 1566 Quther $\Xi .126^{2}$ fïr mit mercklich fehlen.

3. Eochnam 1740 Wojes I 25 den Herm II. Stockfinster und scine C. 巨chubart 1775 D. Chronif $\Subset .148$ Voh, Clandins und C. Goveje 1778 Etreitichriften $\Subset .63$ die Verfasser der allgemeinen deutsehen Bibliothek und C. Frouter 1789 . Sil. Echriften dor Widertanffer vnd aller jrer C. lïgen vnd Feije $\Xi .216$ de Hankknecht mu $\mathrm{K}$.

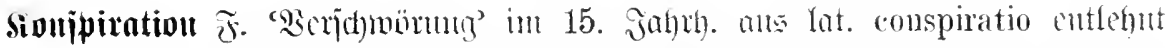

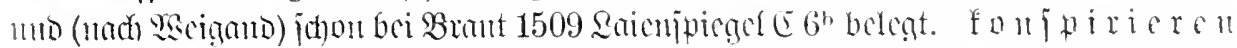

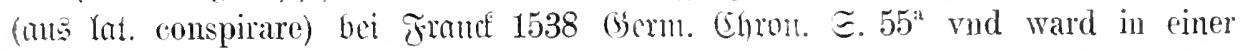
auffrur von Conspirierten erwïgt.

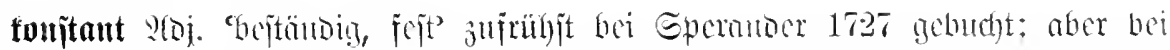

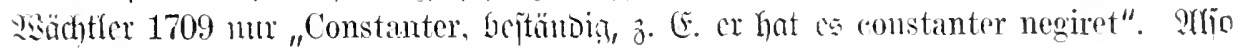

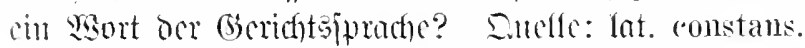

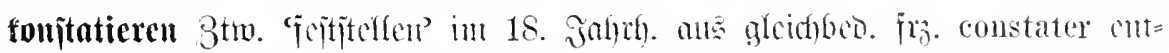

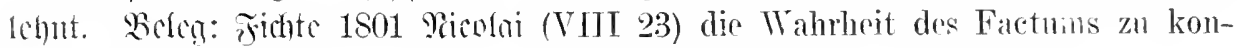
statiren.

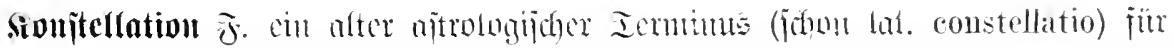

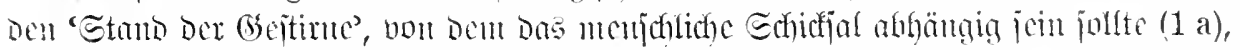

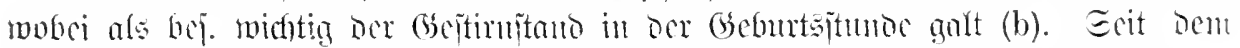

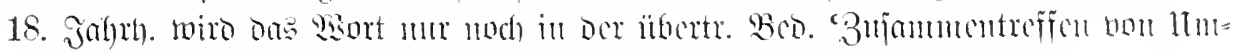

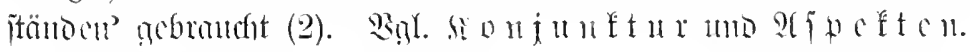

Belege: 1 a. Faracelin 1530 Franjö. deb Himmels nemen. Sebenwalst 1681

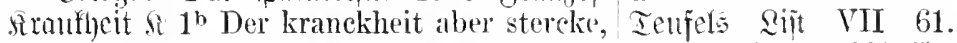

böse grimmigkeit viel oder wenig nimbt sich b. Echupp 1660 Corimna モ. 61 Corinna nit aus der Venıs, sunder aub der arth der miiste nuter einer bösen C. gebohren seyn. andem inhangenden planeten, auff solichs Qnjenit: 1661 ?foct. Iijd)renen $\Xi$. 53 wie wissend, das die selbig $c$. an dem orth ein ar zmm stelen geboren. dieweil dicses oder impression genent wirdt $-\AA_{2} 2:$ Dir selbigen jenes Planeten $C$. bey seiner Geburt sich

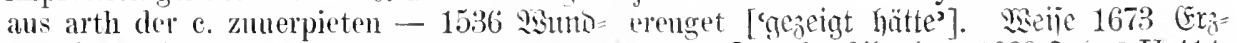

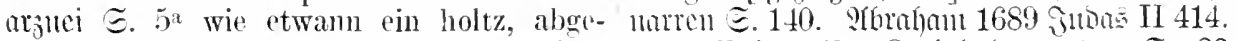

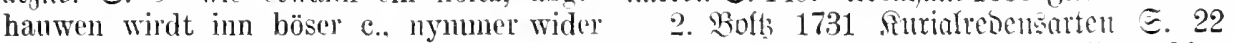

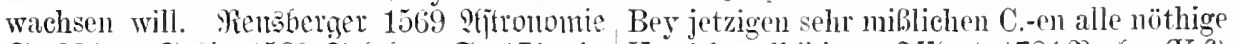

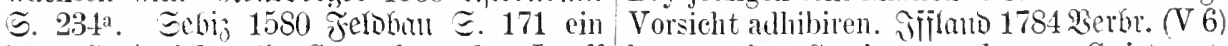
böse C. (welehe die Gartenlent den Lanff kannst eine Carriere machen - $C$. ist gut.

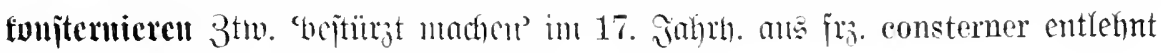

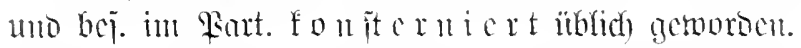

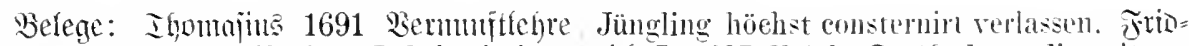
II 7 wïrden wir gewib einen Lehrbegierigen rich I. 1697 Sicic $\Xi .10$ damn die zeitung 


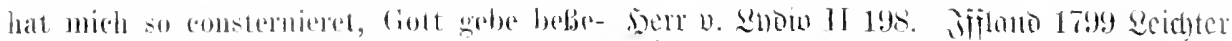

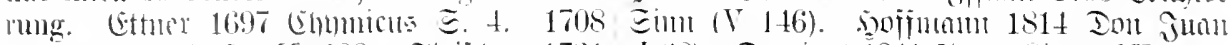

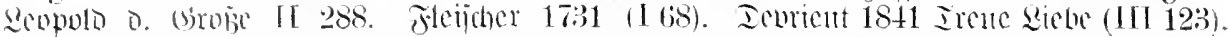

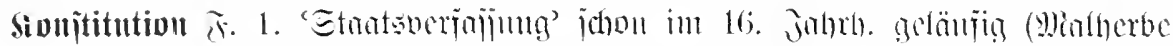

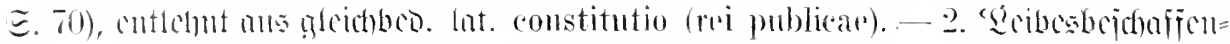

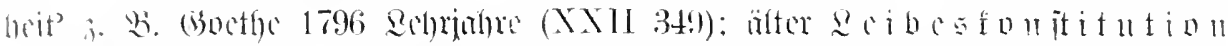

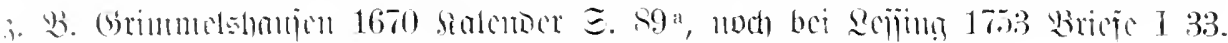

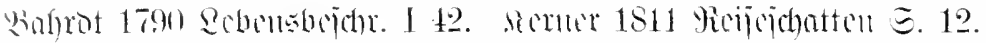

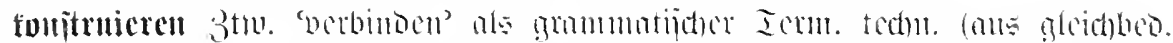

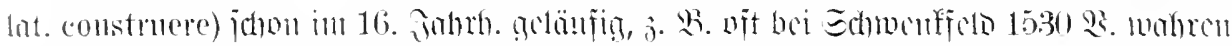

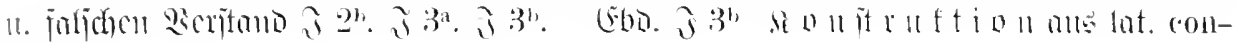
structio.

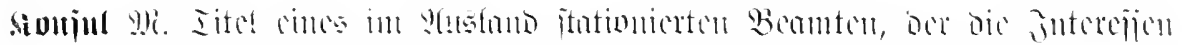

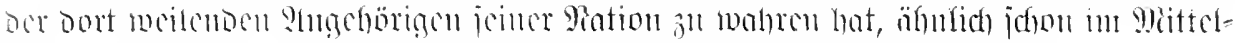

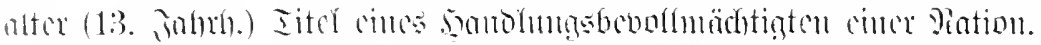

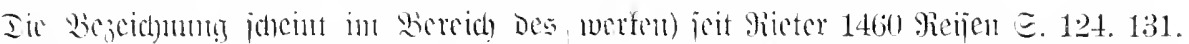

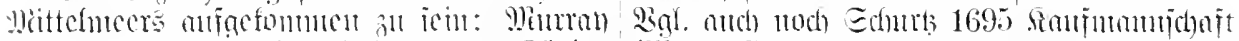

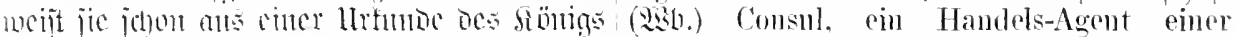

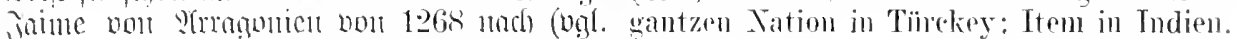

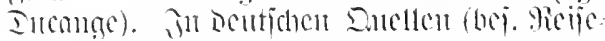

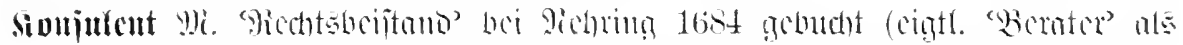

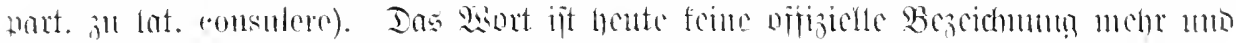

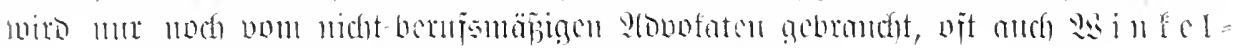

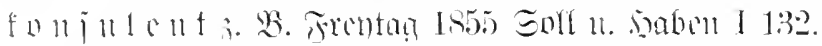

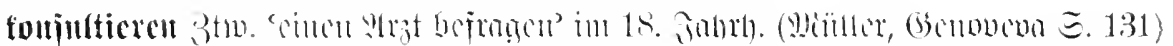

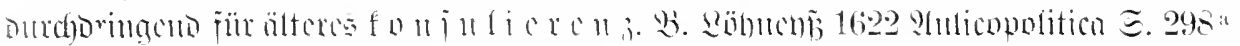

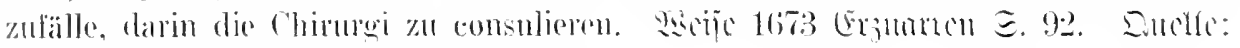

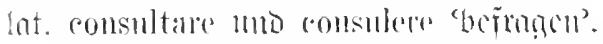

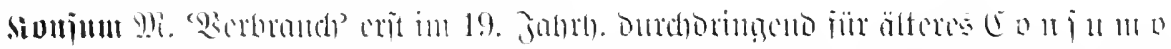

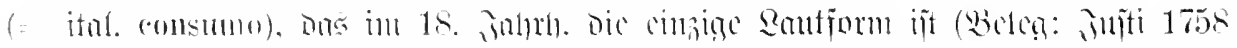

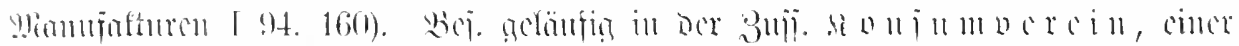

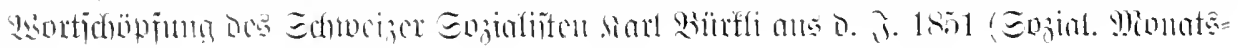
note Y $97 \%$ ).

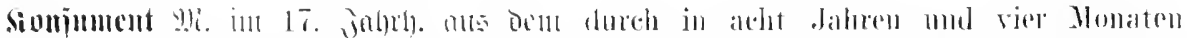

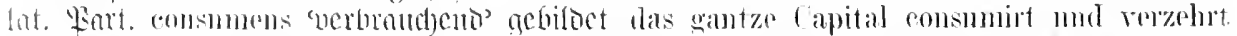

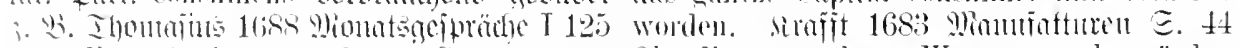

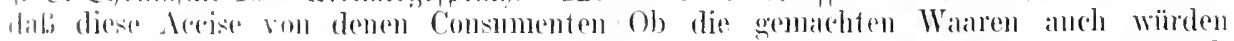

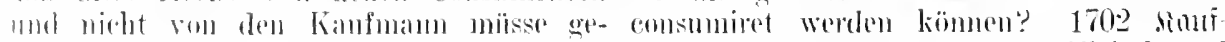
anhen werdents.

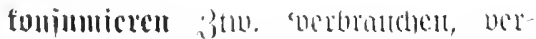

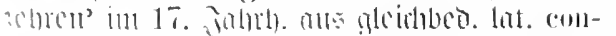

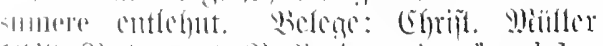

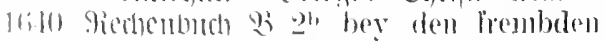

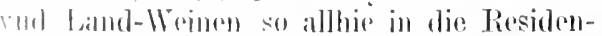

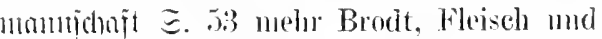
Bier wirde consmmiret. Scib 1708 3meito

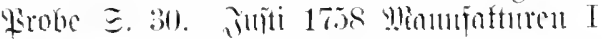
173.

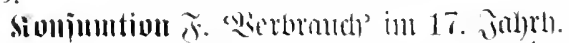

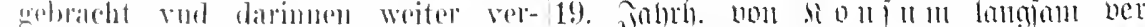

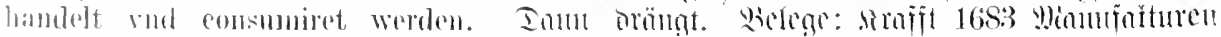

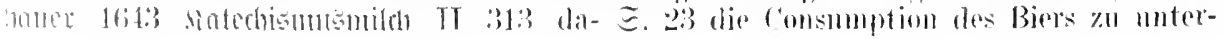




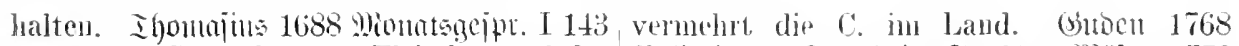

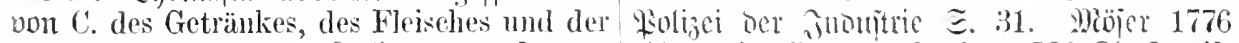

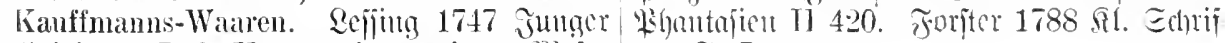
Belebrter I 6 Konsumtionsaccise. Diojer tert こ.71.

1761 Bebergigutgen $\Xi .60 \mathrm{We}$ viel trinkt,

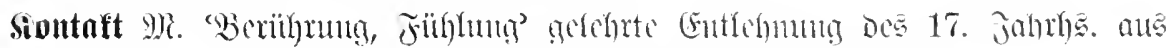
lat. contactus (1), neuerbiugs aber mu noch mijumlich gebraudht (2).

Beleac: 1. Debcumalot 1681 Ientels siñt VI 103 Die Diffienltet ist allein per Contact mit der Simnenwelt - 71 durch ynod medium diser Contact geschehe. Rid)ten= allgemeineren und ummittelbaren Contact berg 1794 .5ogarth I \& so sind sie [Die Bettel] mit der Natur. (jolb 1869 Meltffugheit II doch mit den so eben genannten Meubehn, 196 National-Bewnlitsein mit Tationalstol\% Kleidem und Victualien in ummittelbarem im tiefsten Contact.

contact.

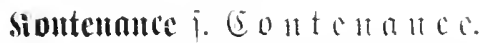

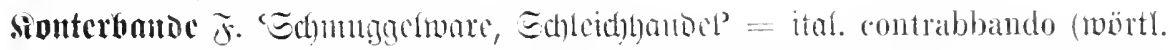

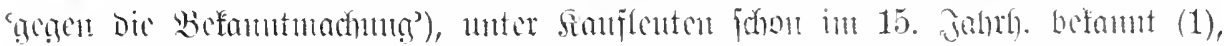

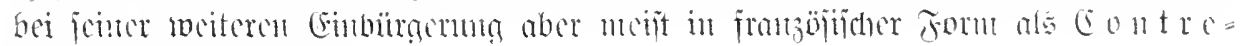
ba 11 o c gebramt $(2)$.

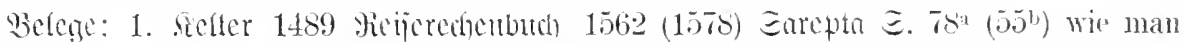
(こ. 838) me dem fackin [S rüger] gebn, der auch etlich liederne müntz. . haben mitt mir des nachts rffstnnd rud mir half maehen lassen. Joch dib gehört vor die den eontrabando machen (ङ્dhimer હ. 106). Wardein, damit kein Contrabant gebraucht

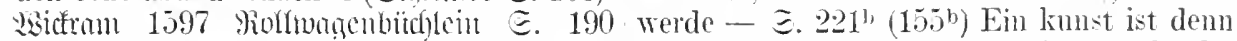
da wehr ein wahr in den Kasten, die wer ein rechte kumst, wemn sie ein grund oder Kontrebando. Mabcrtim 1599 Guebaras gute vrsachen hat, vind in der prob vind Eenojobr. III $78^{\mathrm{a}}$ wucherliche contracten, erfarmmg augenscheinlich, rnd one falsch contrabanden vnd partiten. Donthofer 1611 , rnd contrabant ins werek empfindlich vond

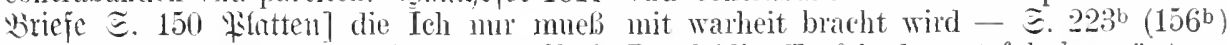
sechen contrabanda fortzubringen. Pou Der leidige Teufel, der ertzfalsche müntzer. , contrabande wasaren" bei Berdenumener brancht sein eontrabant für rnd für rond

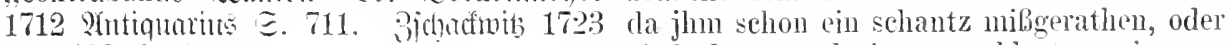
sint VI. 2.276.

2. 1702 sianfutumichajt ङ. 59 durch Untersehleiff und Contreband der Kaunfleute. 1702 Cirop. Fomta $\Xi .827$ als Contrebande Waaren zu rechnen. Ritbener 1759 Eativen II 14 contreband machen. ssid)= manu 1768 Qnutifritifus l 148 als Contrehand weggenommen.

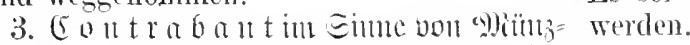

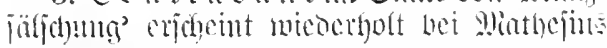

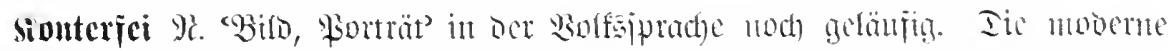

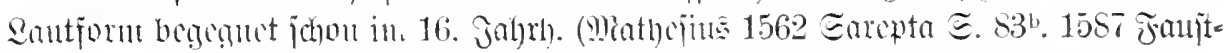

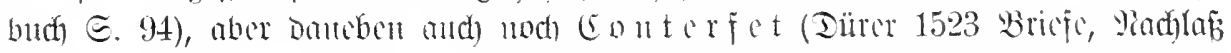

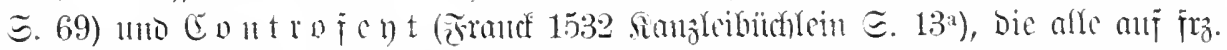

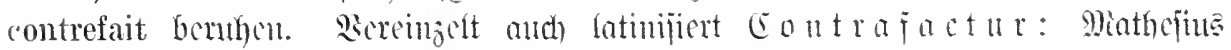

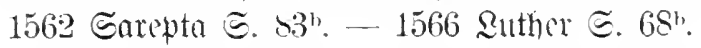

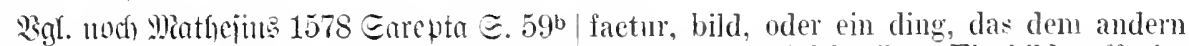
Ebenbild oder Character heißt ein Contra- elnulich oder gleich sihet, Ein bild anff eim

$\Xi$ d) 
Schawgroschen sihet offt einem menschen kohln conterfeit. Ich hab den Erasmum ehnlich, aber da sind zwey wesen. Conter- Roterodam, noch einmahl conterfet fer, wie oben redacht, das ist ein schön 1506 Brieje, Sachlaj $\Xi .37$ Wan ich hab messig oder veronlt rnnd colorirt kupffer, etlich zul kunterfetten. den ichs zugeseit das sihet wol wie gold - - . $101^{\text {a }}$ sonst habe. Edheibt 1551 Grobiants $\Xi 580$ braucht man es [⿰纟: isnut] zu Meilendischer natürlich abcontrafeit rnd mit so groben, arbeit, welche man conterfey nennet.

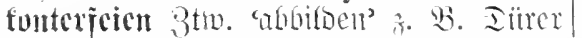

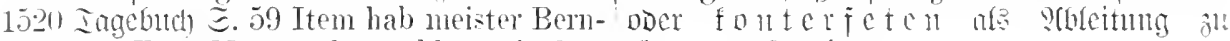
hart, der Frau Margaretha mahler, mit dem E E ut e r je ( i ) r.

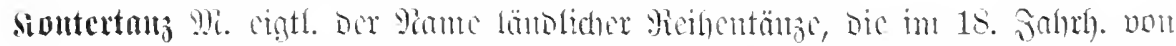

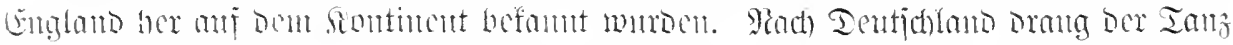

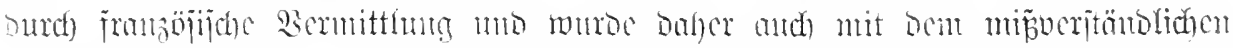

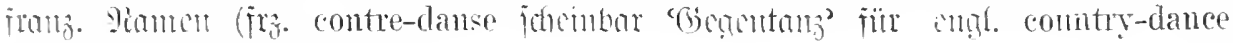

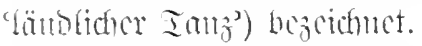

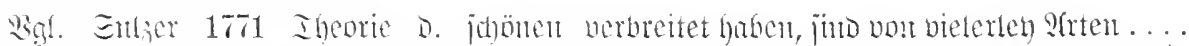

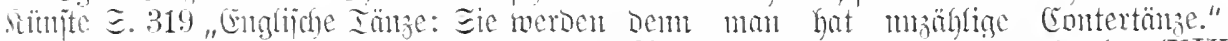

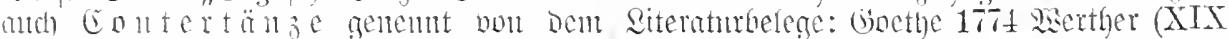

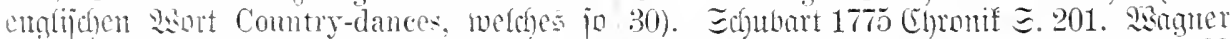

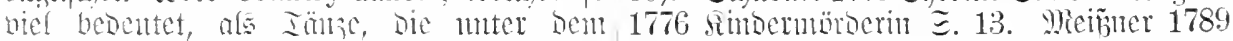

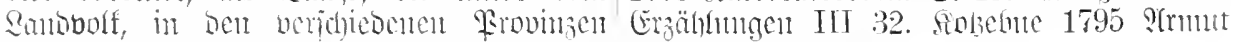

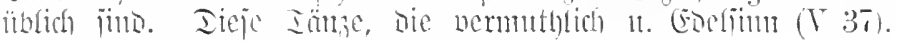

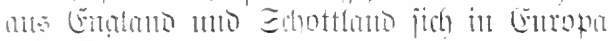

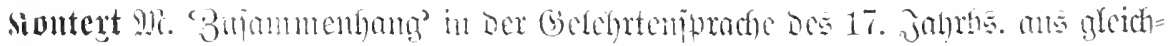

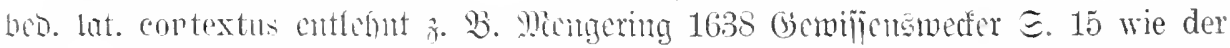
gantze context besaget - 1661 (bomijicnsedft こ.6 von den context also abgerisen.

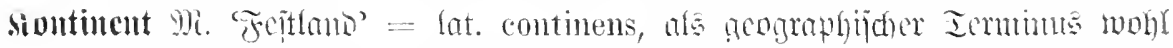

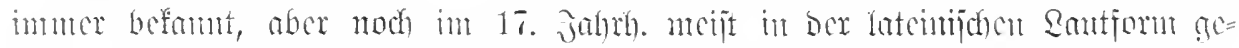

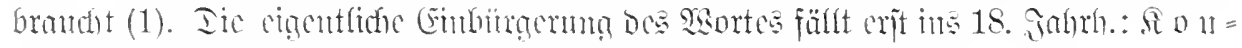

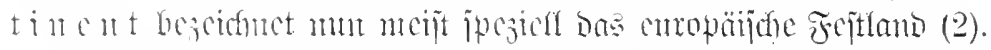

Belege: 1 a. Duno 1598 Cintiribion cos Groenland ein Continent (ein eintzigs festes mograph. $\Xi .30 j$ Continens noer Contimum Land) wäre.

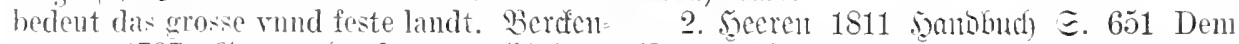
mener 1737 Gengraph. Fragen (Shthang K. stand England gegenüber. Görres 1821

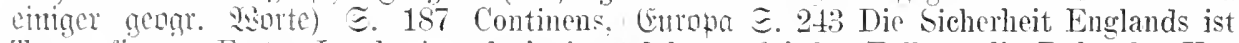
Terra firma, Festes Land, ist dasjenige, daher auf jerlen Fall an die Ruhe des K.-s welches keine Insul ist.

gekniipft. Remald 1836 : iauarelle II $1 \mathrm{im}$

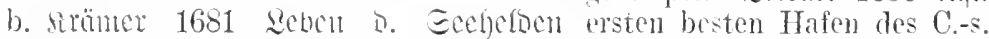
こ. 534 daßs dieses mit Mleta Ineognita oder

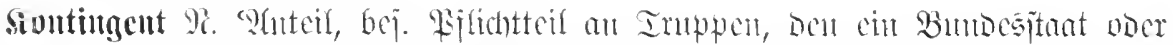

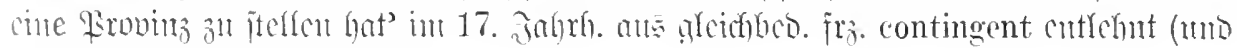
in Der Saspiprade laturijicrt).

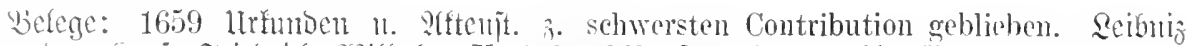
Sheg. Des stur. Friedrid) Sgifhelut X 340.1670 Eecuritas publ. (I 155) dab jeder us seind die Einwohner dieser Lande ... Stand mit seinen C. entweder an Volk oder nacle wir ror in dem Contingent der aller- Gelel richtig inhalte.

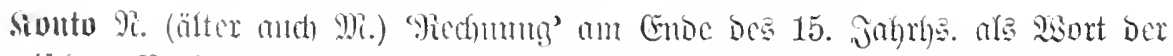

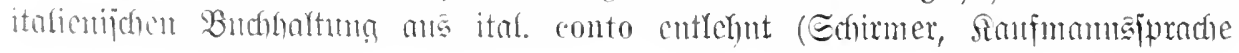




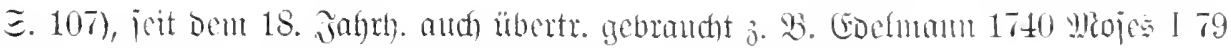
Ich werde ihm fort mehr nicht viel auf sein Conto glauben.

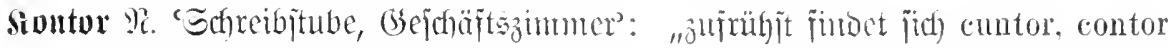

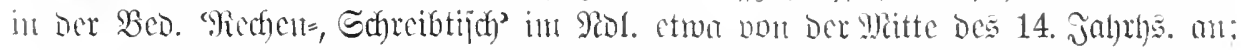

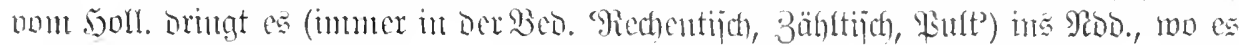

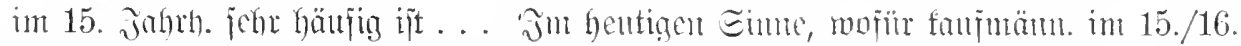

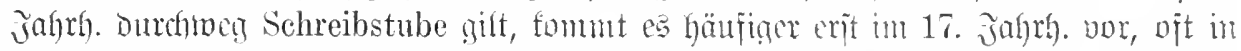

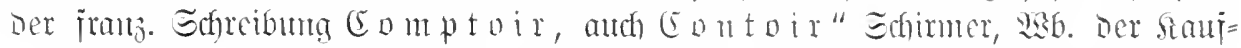

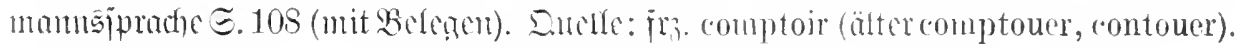

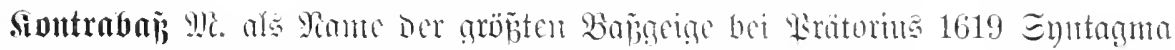

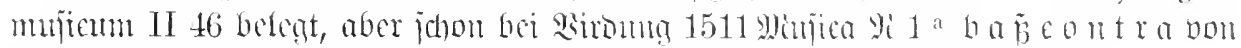

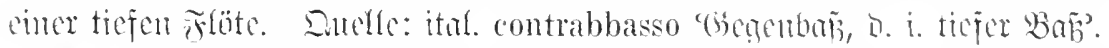

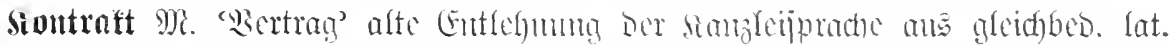

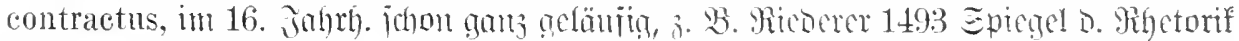

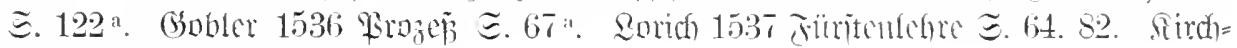
hơ 1563 然mbutmut 厄. 352 .

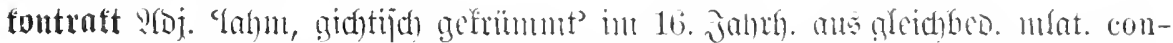

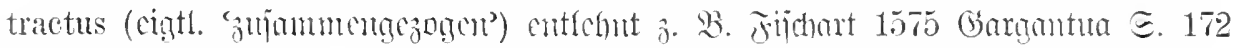
der Hofleute rngrubbare contracte hend. Banfinus 1599 simberbab 3u Boll $\Xi .14$ an Hand rnd Fïssen Contract.

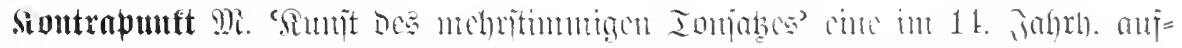

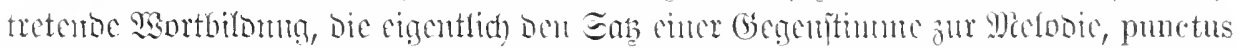

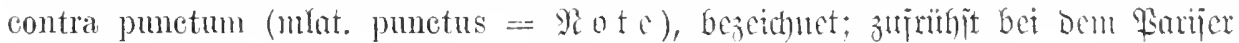

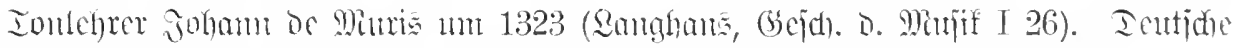

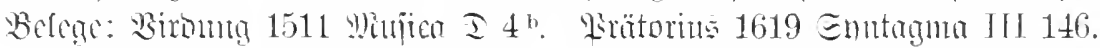

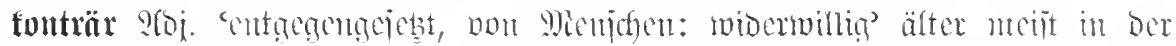

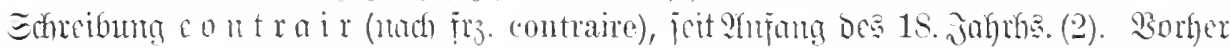

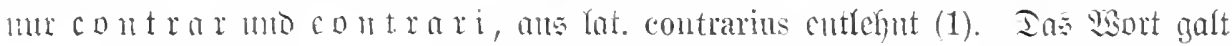

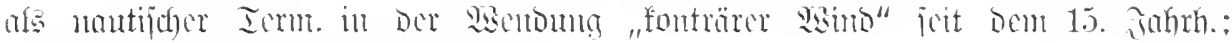
unl. Siltge, Ecomanmipradge ๔. 479.

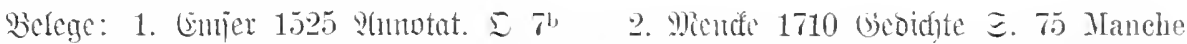
Wie könd aber Paulns so vergessen sein, läufft wohl für ein Kïßgen und stellt sich dats er im selb in eym capitel so oflt con- so sehr contrair. Codehmum 1740 Mlojes II

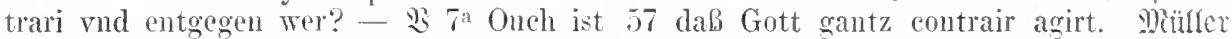
5m Lnther in difer glob selbs contrari. Nicije 1789 Emuterich VII 55 Steht aber der 1673 Exnarreu $\Xi$. 178 Einer rerordnete Wetterhahn Thnen nach wie vor kontrair. Galenische Tränke, der andere hatte kleine Ievricut $18+1$ Itene Siebe (III S) geht chymische Pulver, und gewiß es lieff contrar hent Alles conträr.

dureh einander.

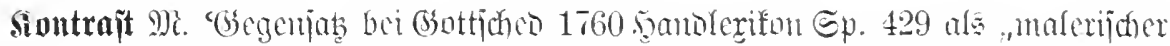

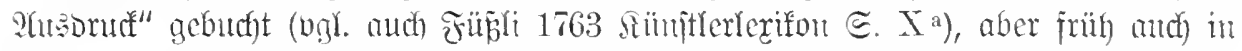

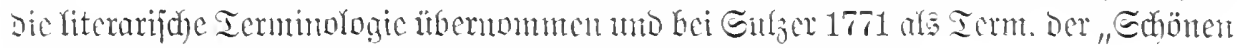

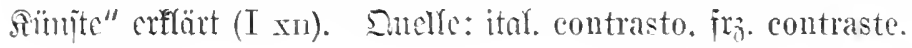


Belege: Wiver 1761 Beherzigungen $\bigodot .15$ I 158 Der Difhter] schliebt dab die Gluckder sonderbarste C. von Religion, Wahrheit seligkeit des Menschen so wohl mit dem und Tugend einer Seits mit Irreligion, Be- moralischen, als physischen Uebel bestehen trug und Heucheley anderer Seits. Duja) könne: wie schön sind nicht beyde con1764 Briefe I 115 Sie sind sehön, wemn trastiret! - 2. 'in Gegenjati jiehen, $a b=$ man sie einzeln betrachtet; allein in dem jitchen' serber 1766 rserfe I 116 dab es Contrast, worin Virgil sie gesetzt, wird ihre mit der Poetischen Fiktion oft kontrastire. šchönheit noch gröber. 1765 Iflg. D. Siebl. Edubart 1775 Chronif ङ. 359 es contrastirt

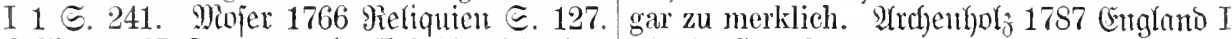
Seijiutg 1767 Drantaturgic (IX 302. X 150). 20 ein Grundsatz der sehr seltsam mit den :a Hoche 1771 Frl. v. Sterthem $\Xi$. 69. Maximen derjenigen Tribunäle contrastirt. Widjaelis 1773 Räjomtement III 199.

(boethe 1796 Lehrjafre (XXI 43) Die Reden

fontrajticren 8 tiv. aus $\tilde{i}$ rz. contraster beider Personen contrastiren gehörig.

1. 'int Gegenjats jtelten' Dujd) 1764 Brieje

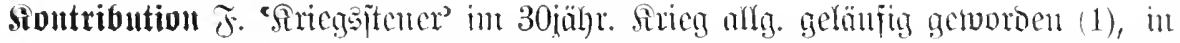

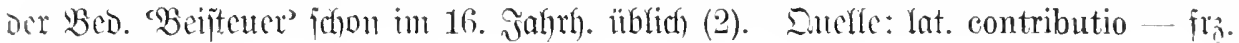
contribution.

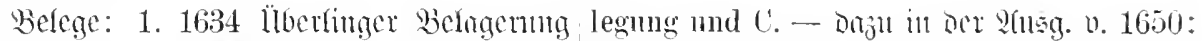
$\Xi .6$ welche bib dahero zn Hanß geblieben Gott erbarme, dab uns clende Tentschen rnd mit C.-en jhre sicherheit vermaintlicb dieses Wort nun so gemein und gar Tentsch erkaufft. Miit 1642 Rettunt ${ }^{5} 7 \mathrm{~b}$ theils durch ihre rom Teufel erfundene C.-s-Mittel (wie sie solche ihre Rauberey nemnen).

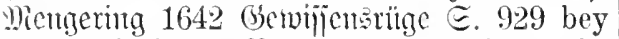
diesen Kriegslïufften, da zur C. grobe berg 1597 Dišcurs $\subseteq$ ङ. $14^{\text {a }}$ seine C.-en ron Sorten vnd gantze species gefallen müssen. Jahren zu Jahren gesteigert. Whicheroid) 1642 Phillander I 993 in Kriegs-

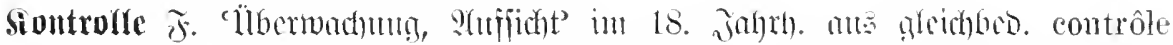

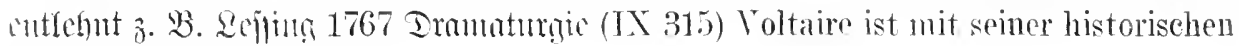
Controlle ganz muleidlich.

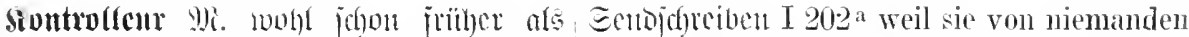
Beontentitel an jor. contrôleur cntlehnt: visitirt oder controlirt wurden, thate rnd

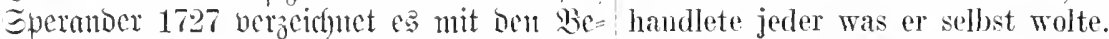

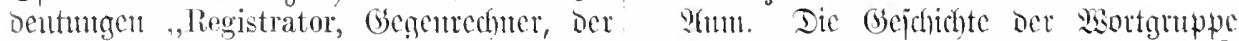

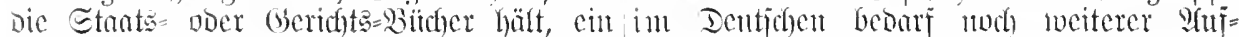

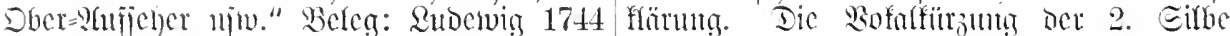

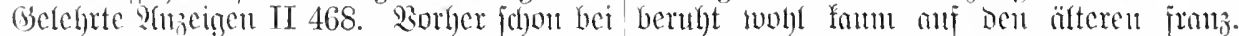

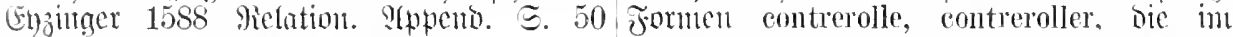
der Contrerrolleur Nicola Crafft.

16. Jahth. jolyou anfgegeben waren, als viel=

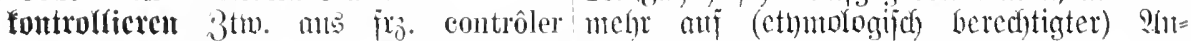

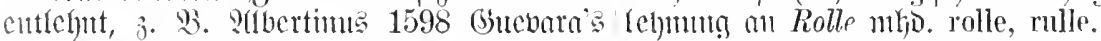

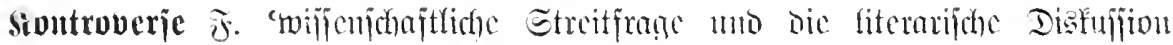

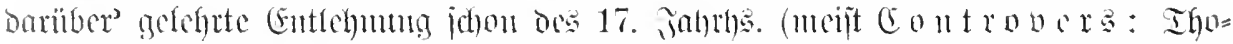

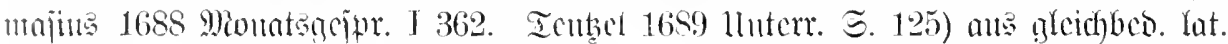
controversia; Dor Bifu. Daber jutäd)

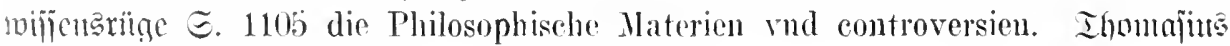
1691 Эermuitlefre II 135.

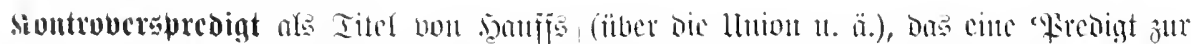

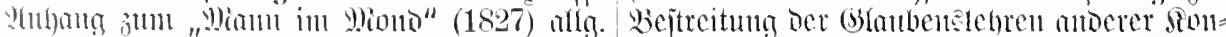

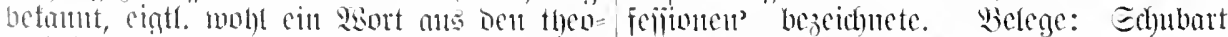

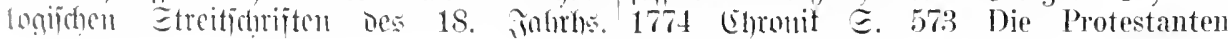


halten's wirklich für lächerlich, Controvers- merich IV $38: 3$. 96r(henl)ol; 1787 ittafien I predigten zu schreiben. Müller 1787 (5m- 205.

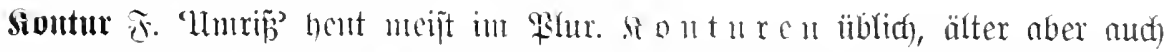

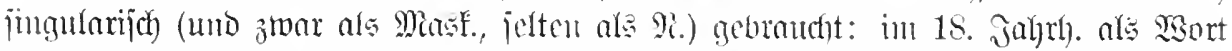

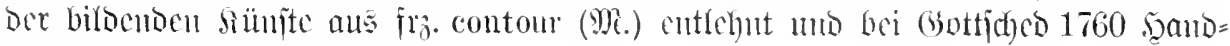
lexifon ङ. 429 verzeciofunet.

Belege: Winfelmam 1755 brebanfen Shyjiognonn. Fragmente I 217 mit dem ङ. 10 Dic Cörper erhielten durch diese Contour des Untertheyls desCesichtes-1777 Uebungen den grossen und männlichen cbo. III 16 in reinen Schattenlosen Contonrs. Contour, welchen die Griechischen Meister Mäjer 1776 \$hantajien II 77 Nie habe ich ihren Bildsäulen geben. Reijing 1760 Riter $=$ ein feineres Contour gesehen. Marimitian turbrieje (VIII 221; Charalitere und Situa-'v. Mierifo 1857 Reben I 81 Die Contouren tionen sind die Contours des Gemähldes, [Des Gebirge: wurden klarer.

die Sprache ist die Colorite. Rnvater 1775

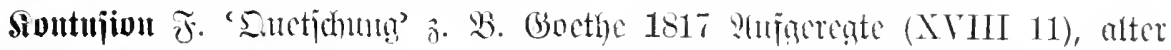

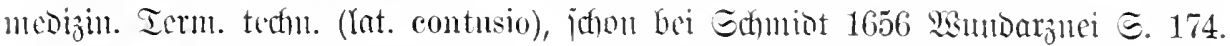

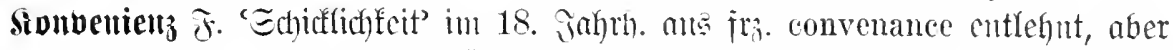

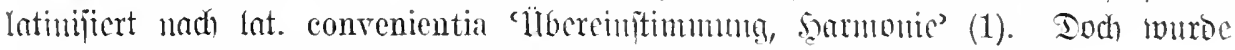

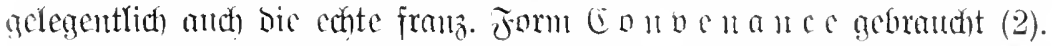

Belege: 1. Refing 1768 Dimuatugie 2. (joethe 1805 QHmerf. Ju Raments (A 50) uncehte C. muß keinen echten Affekt $\mathfrak{R e f i e}(45,175)$ Der Franzose scheut sich besiegen. Edhiffer 1782 Ihenter (XVII 151) auch keineswegs, bei Urtheilen über ProTyramisiert etwa die K. die Natur darum ducte des Geistes von Convenancen zu weniger? - 1784 fabole (IV 353) je tiefer sprechen. ein Wort, das eigentlich nur für die Natur mit K.-en zerfallen ist. Sianf 1786 die Schicklichkeiten der Societät gelten Bagatelfen I 65 nach der C. deines Hanses. kann.

ritrigge 1788 llumgang ङ. 24. 131.

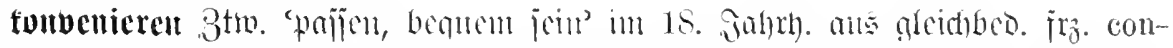

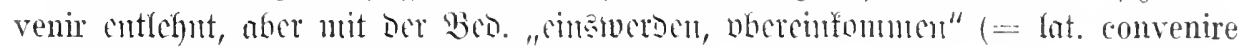
johou bei gint 1571 gebutht.

Befege: Dermes 1789 Fin Iödter I 60 wechselseitig zn - zu konveniren. Bi: Darf ich Ew. H. Gnaden noch einen Vor- mark 1849 Sriễe $三 .144$ es kömnte mir unter schlag machen, falls ich sonst Ihnen con- Umständen besser conveniren - 1851 ebo. venire. Benzel=Etentan 1806 Geippräct)e II $こ .287$ Die nicht so sind, conveniren mir 41 Dagobert und Elfride scheinen sich noch weniger.

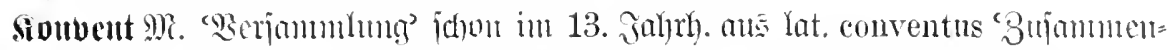

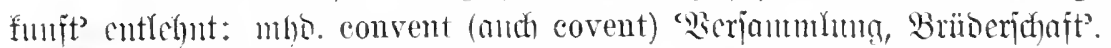

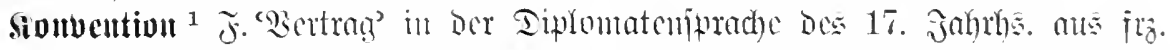

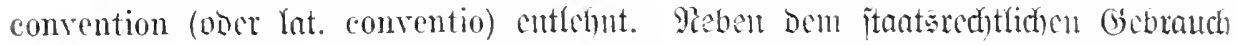

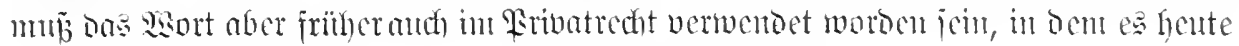

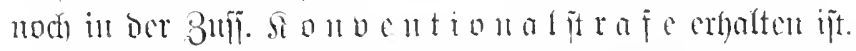

Beleg: Ronn 1718 Etnatsflugheit $€$. It wächst die Begierde eine solche convention Da bibweilen von einigen Fürsten opponiret anfzuriehten - $こ .75$ so würden viel Friewird, daf einige allgemeine und öffentliche dens=Schlüße und conventiones über den Contracte und Vergleiche aus Zwange ge- Haufen fallen.

schlossen werden, so fragt sichs, ob eine Die folgenben 3 mammenjetntgen fomen

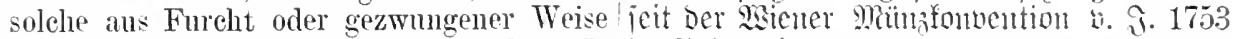
geschlossene Conrention gïltig sey? - Je in (Gebrandín:

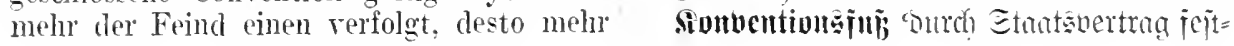




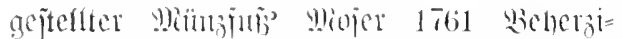
quntgen こ. 157 es wäre wohl \% wiinschen, dab wir anch einen Conrentionsfub lätten, wie viel l'atrioten anf die Marek fein zil rechmen syyen.

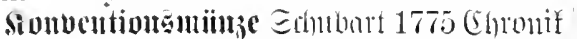

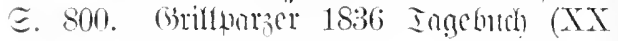
$102)$.

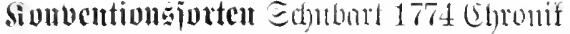
¿. 591 Gulden, Thaler, in lanter olänzenden conrentionssorten.

Sivnuention

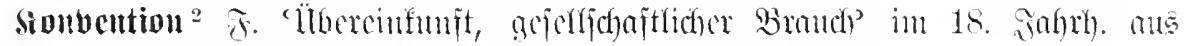

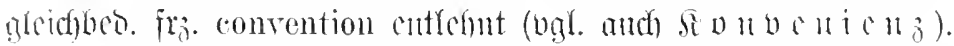

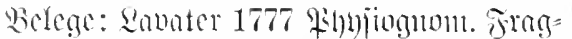
unsute III 206 mangetastet vom Hauche. Ton, Schimmer - irgend einer Ilode, ('onvention, kiüntlichen Manier. Mï̈llex 1778 Truits Qeben E. 8 gegen Schicksal und Welt, die uns niederträngt mud unser odles selbständiges Wesen, unsern handelnden Willen durch Conventionen niederbengt. Edhiller 1781 Brieje I 42 dem Unverstand derGallerie oder sonst leidigen Convenzionen anf-

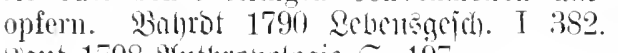
thant 1798 Wuthropologic E. 197.

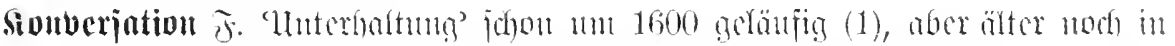

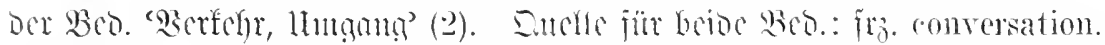

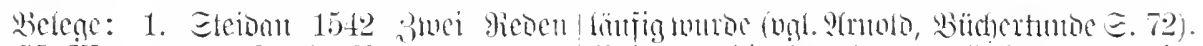

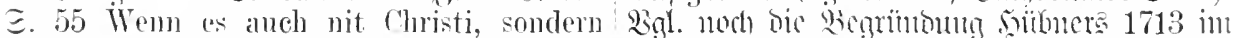
S. Petri seins Vorfaren. wie er spricht, eusserlich leben und conversation will ansehten. 1565 Ecript. 2er. jilci. IV 225 damm th meine hertzliebste Hertzogimn roud fiemahl sewislich nicht allein solcher lentte 'onnersation vmud Wamdel gohessigk (Gombert, ?(Fon. IV 160). Enjouger 1590 sirlationen 1139 linhlich in dere commersation mit den Imiten.

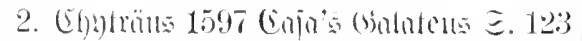
es begilst sich aben so wol in der commersation, rnterredung rand wandel defi ge-

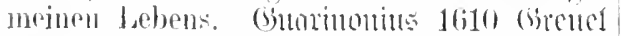
こ. 1173 in lustiger rnd lieblicher" Ausperach, Commersation ender ] lisputation. Sicher 1668

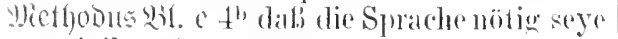
zall civilen (onversation.

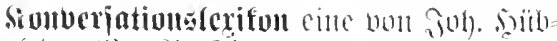

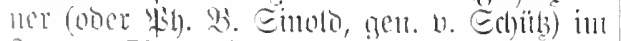

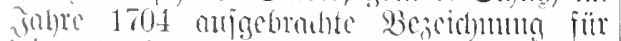

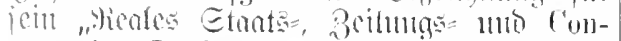
remations-Lexicon", bie Dam nom dent

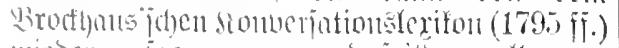

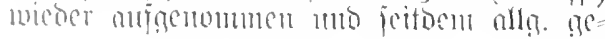

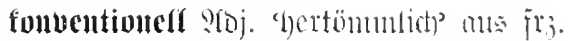

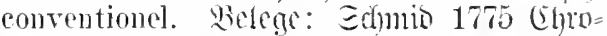
nologie D. D. Theater E. 63 die k.-e Mechanik. nach der sie [aniolimo. Sicrfe] zusammentgesetzt sind. Sorber 1778 serfe VII 340 nieht durch willkïrliche, hinangeflickte. k.-e. sondern durch Taturkräfte. Sistelano 1784 Mierfux I 240 ein so richtiges Gefühl dessen was im Menselen natürlich nnd was c. ist. Edhiller 1796 yinine n. jent. Iidntung (XVII 49:3) Tnkmude dieser k.-en Cresetze.

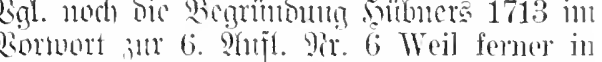
diesem Buche lieine Cathedralische Emdition, sondern nur allerhand zom täglichen Politischen Unganger mit geschenten Lenten. menthehliche Stiicke der galanten Geledrsamkeit enthalten sinel: so kam mans wohl mit allem Rechte, ein Staats-. Zeitmossund comversations-texicon nemuen.

Sonveriationsition ,man fiflegt cilce

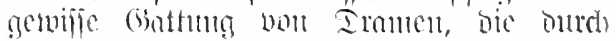

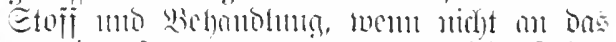

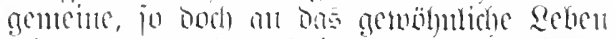

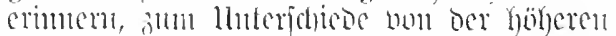
Gattuma, Bic jich Butrd eoleren Etofi atmo

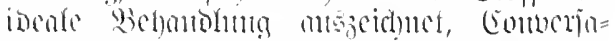

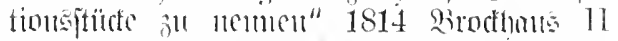
701. Rounte 1819 Seserte I 90. Innchen in

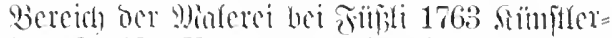
lex. E. 27 Er mahlte IIstorien, Portraite und Comsersatjonstiicke, in welchen or die Kleider-Trachtens sejuen" "zeit rorstellte ङ. $39^{\mathrm{b}} \cdot 247^{\mathrm{a}}$.

Sidnveriationston somigge 1788 1lungan E. 26 grol, Mamigfaltigkeit des conver- 
sationstons. Bun 1800 Edhriften 111306 schul mit den stulenten conuersient vad

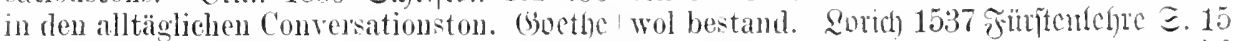
1802 gisint. 5ojthentex $(40,74)$ ein falsch welchem er zu latein gebeichtet, jm viel verstandener Conversationston [oor Edhm= fremultschafft, seiner leer haben erziget, ipieler].

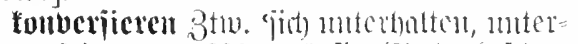
nit ym connersirt, yn allein hervorgezogen.

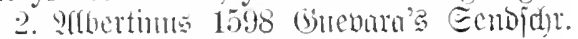

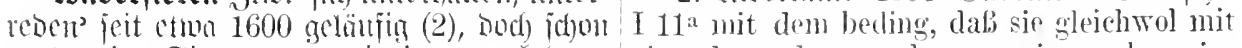
borber int Eimme boit 'mit jent. berfehren' einander reden vnnd comuersiren, aber ein-

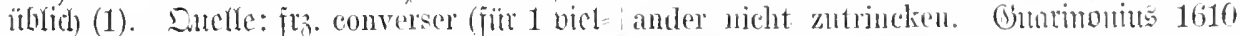

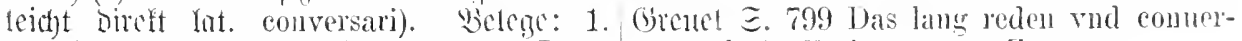

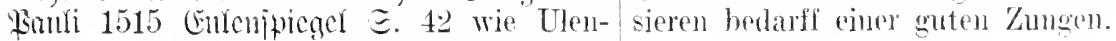
spiegel zu Prag in Behemen vff der hohen

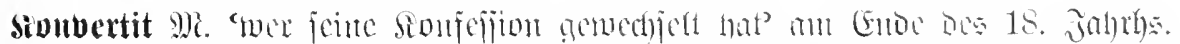

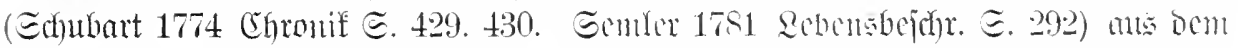

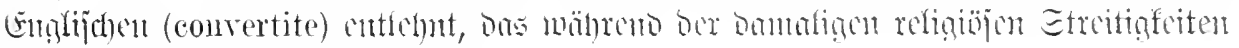
audh Dos ㄴ.surt dissenters ficfortc.

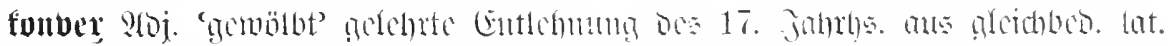

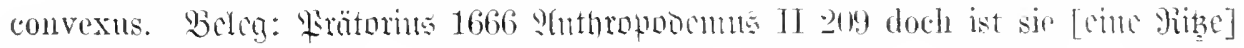
conves oder gebogen.

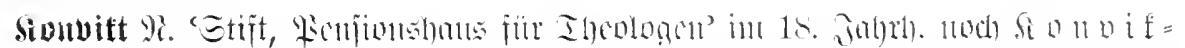

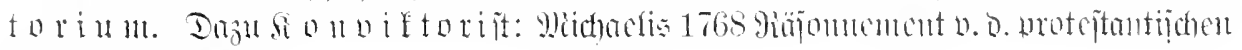
Ilineritiötest 14.

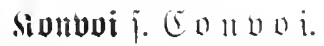

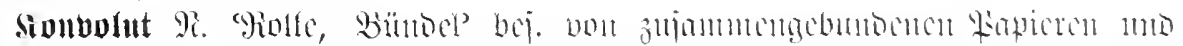

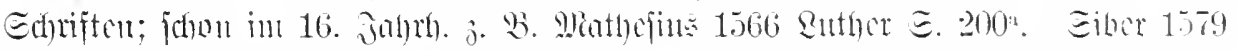

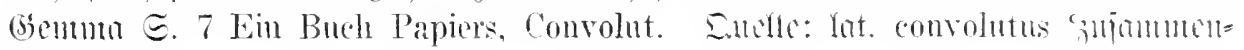
gerwitelt's

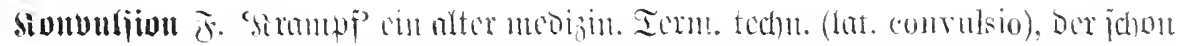

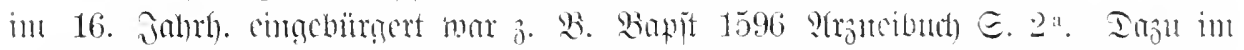

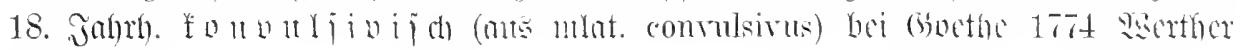
(XIX 190).

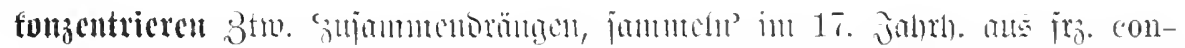

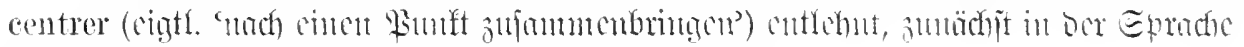

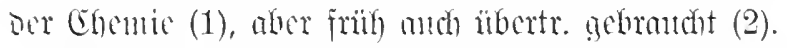

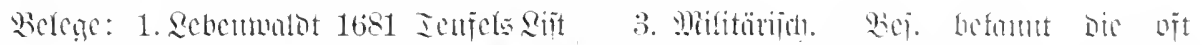

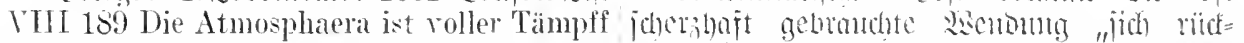

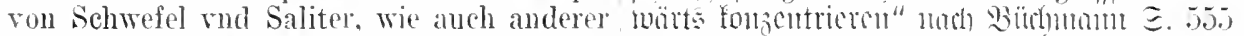
Mineralischer Raueh ete. was ron der- ichon in énem siricje bes Eberjen nom

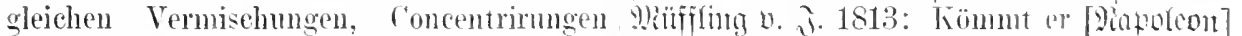
etc. für Wirckungen entsteken, sieht man endlich aus seinen lock - schmell rückdurch die Kunst vnd Tatur.

wïrts konzentriert. Bigl. its. mourement

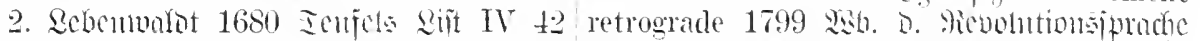

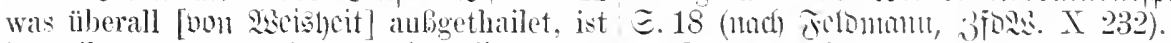

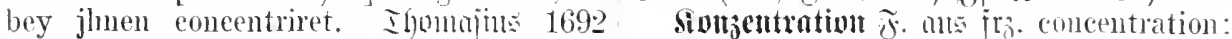

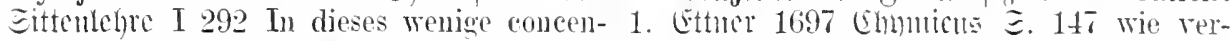
triret sich alles das, was Seneca so weit- mittelst der C. der Teine und des Biers ein läufftig und nicht allzu ordentlich. . . . ron, dergleichen angefïlltes Fals 16 und mehr in ieneu Gutthaten rorgetragen.

der Wiederauffkochung geben kömue. 


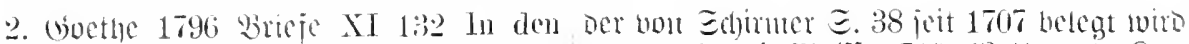

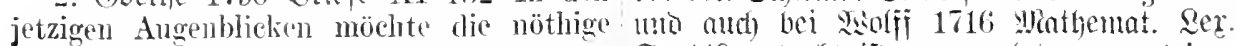
Sammmng und C. Kamm möglich seyn - E. 449 gebudft ift: ans mint. concentricus

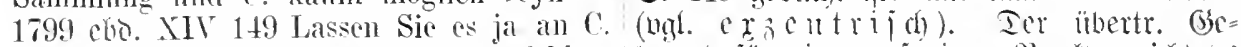

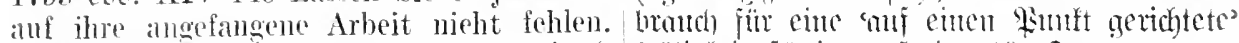

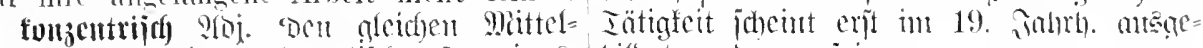

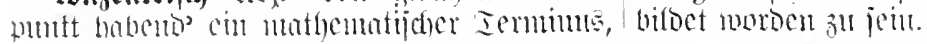

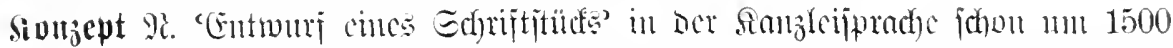

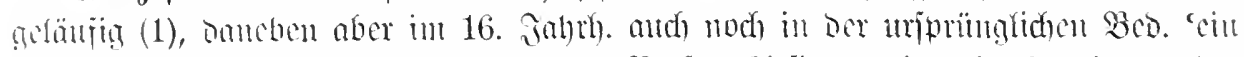

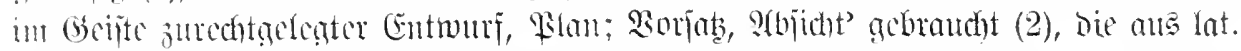

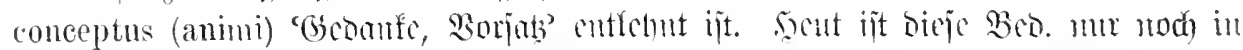

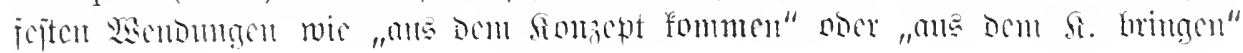
befount. (3).

Belcge: 1. Wivfoer 1558 Iürfenbühlciu er ans dem Concept gekommen, sich durch yf 2b dilj Bïchlein, von wellichem Ewer eine natïrliche Beredsamkeit wieder zul keyserliche Maiestat vor zweien Jaren das helffen wisse. Rejïng 1748 刃lijoghn (II 29) Concept zul Augsurg geseheu.

2. Llı1 1530 Büricher Bibel $\Gamma^{2} 266^{\mathrm{a}}$ Als ar aber ron scinem fräfenen Concept rnd fürnemmen nit wolt abston. Fudjuberger $153+$ Iinleftif $\Subset .70$ Dermassen dam die rerkïndiger Göttlichs worts im anfang jrer predig otliche kurtze wort oder ain behende summa jis concepts fïllegen. Fiätorins 1619 Enutagna III $\sigma^{\prime}$ do dieses Concept rnd werek list zim Ende gebracht. Leben= walot 1680 Iellifels 2ijt III 21 dab ein Memsel dem andern anff ril 100. Meyl Weges sein Concept vond Willen eröffnen möge.

3 a. Stroctien 1669 Errit. Seijebejdr. E. 10 und kompt dariber gar ans seinem Concept und wird confindiret. Jiohr 1728

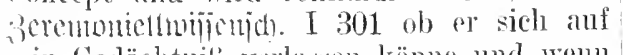
Ich wollte licher, das Sie mir cine Ohrfeige gegeben hätten, als dab sie mich ans dem Koncept gebracht haben.

b. Seut jelten, "bas sionjent verrincten"

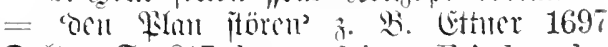
Ioftor $\Xi .817$ hastu deinen Feinden das Concept rerrïckt. Siogel 1716 Ditmb. Beije= bejdyr. E. 524 Alleine unser Concept wurde uns gant\% verrickt. Seisto 1764 Temn= jthenes I 21 was dem Pll. am meisten das Concept verrïket. sioje 1873 simber $D$. Siselt I 100 wirklich war sie von so seltner Schönheit, dafs sie auch cinem rerwöhnten Franenkemer das (oncept rerrïcken komte. e. Edriller 1781 Vhünber (TV 113) du verdirbst ihm ja das Komzept - er hat seine Predigt so bras auswendig gelernt [i. o. 2 แ. 1.534$]$.

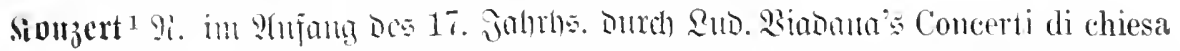

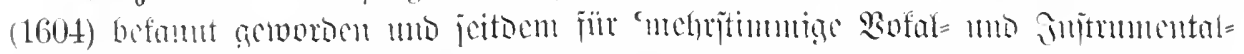

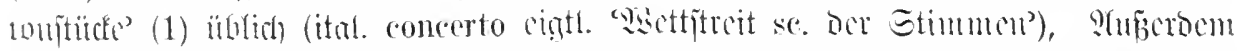

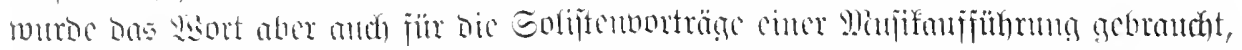

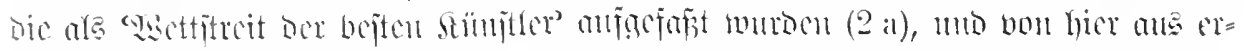

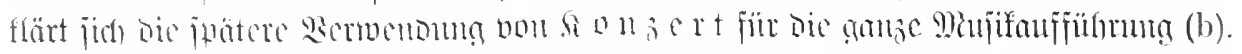

Belege: 1. Frätorim 1619 Enutagna \&ublifationen: 1621 Geift. Concert-Gejüng

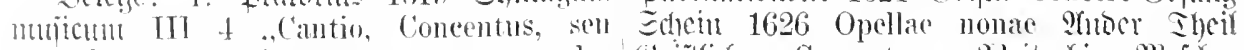

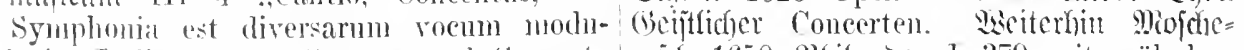
litio. Italis vocatur ('onectlo vel Conferto rojd) 1650 Rigilamber 1379 mit wälschen

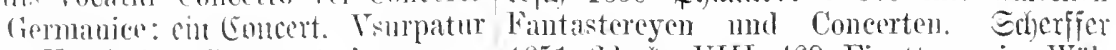

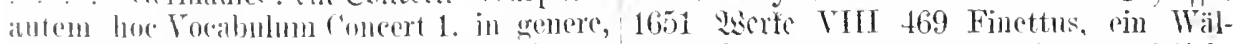

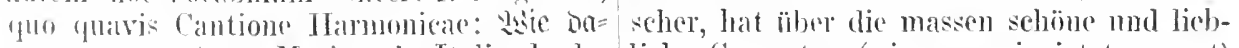
bon cun nonebner Mnsiens in Ttalia, Ludo- liche Concerten (wie man sie jetzt nemet) vicus Viallana foinc Cantiones. uif dic in Drukk gegeben.

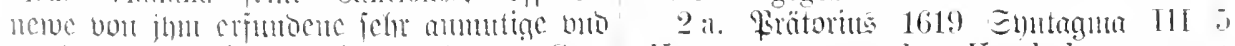

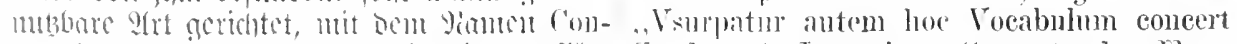

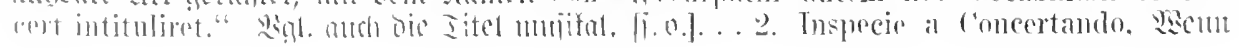




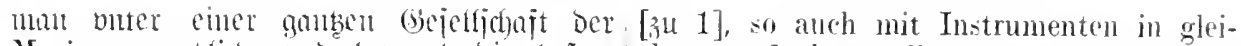
Wnsicorum ebliche bub bevornb bie bejten chem modo kan vollzogen werden, so hent

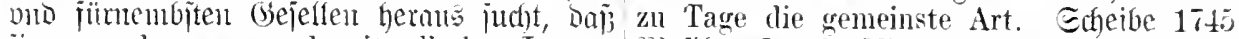
iic voce humana rnd mit allerley Instru- Mujifus $\Xi .182$ Kircheneoncerte - $~ こ .630$.

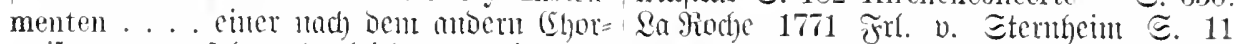
meije bubuedjedn bno gleich gegen cumber Zuweilen wurden anch kleine Concerte itreitten, aljo, Daj es jumer ciner Dem an= gehalten. Enlzer 1771 Theorie I 223a.

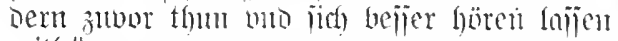
will."

b. Seibuiz 1682 Ermalmung $\Xi .299$ jo wentig] als rin taubgebohrener von einem herrlichen concert zu urtheilen vermag. Epeer 1687 Ilnterridgt $\Xi 75$ Ist eine roncerten Art, da rine Stimm mit der andern war annehmlich nach wenig Pausen certiret

fouberticren 3 tru. aus itnl. concertare.

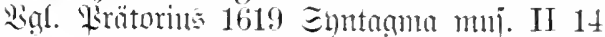
das concertiren rnd mit allerhand Instrinmenten zugleich in einander zn musiciren.

Sionzertmeijter Echeibe 1745 stritijcher פiuifus 厄. 58.

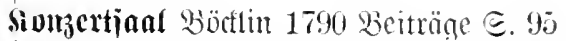

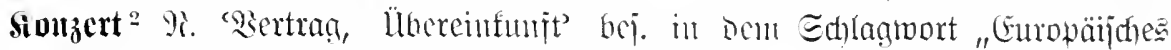

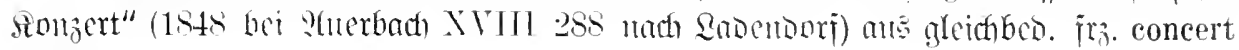
entfehut.

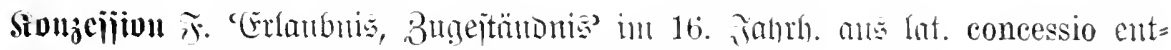

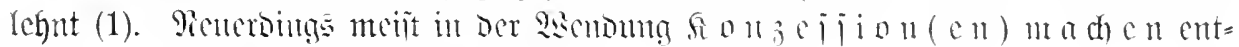
ipredicno firs. faire des concessions (2).

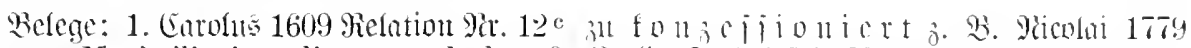
Kayser Maximiliani seeligster gedächtnub Kerlin こ. 349 Die Koncessionirten sind dieConcessionen anff die Angspurgisehe Con- jenigen, welehe eine Koncession haben.

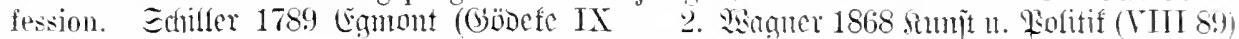
11) weil er den Protestanten einige geringe anch machte man hie und cla etwas Kon-

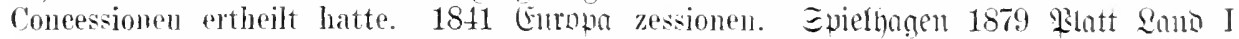
I $286^{\text {a }}$ der bekannte Sehriftsteller sei mu 312 nicht einen Finger breit vor einer "Koncession" zur Heransgabe einer poli- Drohung zuridckweiehen oder die mindeste tischen Wochenschift eingekommen. sier= Concession maehen.

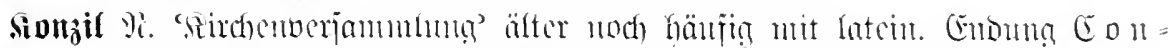

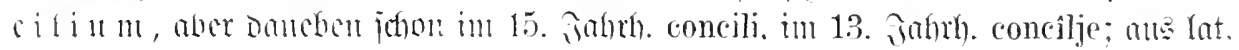
concilimm 'sicriommlumạ’.

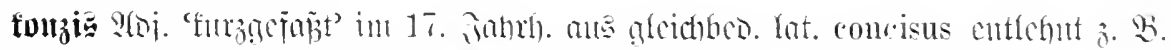
Ientel 1689 Lntumentugen $\Subset$. 564 eine concise. aber wolgesetzte und in etwas nach den Französischen schmeckende Schreib-Art.

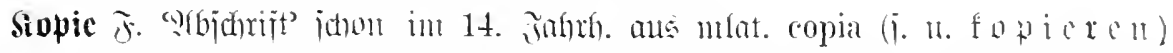

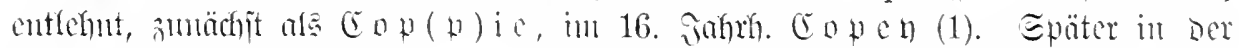

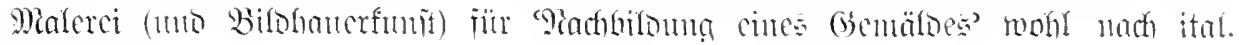
copia (2)).

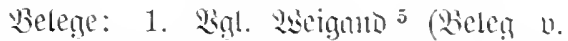

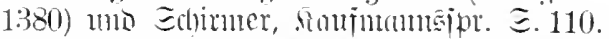
Inzu nod givoerer 1493 Epiegel D. Rhetorif E. $67^{\mathrm{b}}$ coppien - $3.68^{\mathrm{b}}$ ein coppye. Tilltis

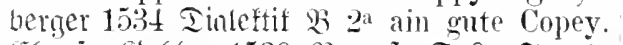

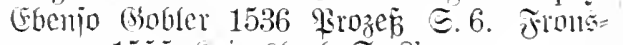

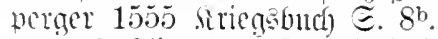

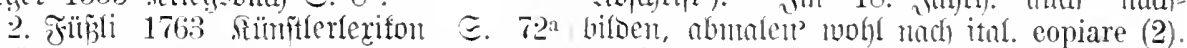

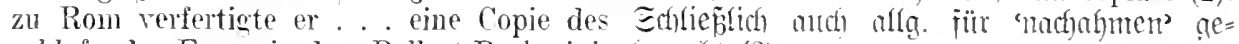
schlafenden Fauns in dem Pallast Barberini. Granditt (3). 


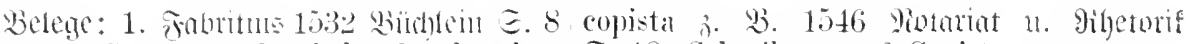
so mann Coppiert oder behend schreyben wil - wan sie solten ander brieff anl.; Coppieren romm worth zu worth.

2. Tilijli 1763 silujtertexifnn $\Xi .25^{\mathrm{a}}$ vibellmo] copirte viele Gemuilulde scimer Terhmejster - E. $40^{\mathrm{b}} .45^{\mathrm{l}} .54^{\mathrm{a}}$ atc.

3. Iuj(h 1765 sucic II 109 Allem dieses [poetijone] Gemälde hat kejnen ron liesen lebendigen Zügen, welche so tief eindringen. Es ist, wenn ichs so reden darf, mr mit lehlosen Farben geschildert: es copiret mu eine todte Schöpfung. Scoinje 1794 sildegaro v. Sebhenthol ( $\mathrm{V} 175)$.

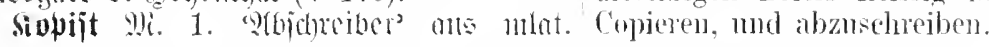

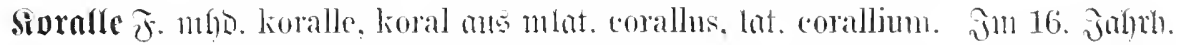

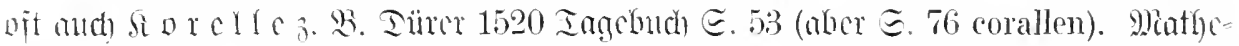

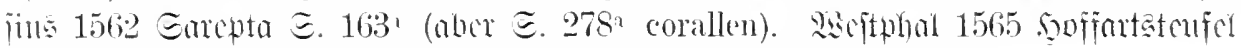

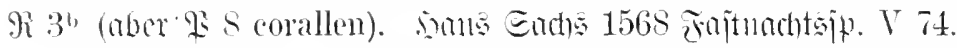

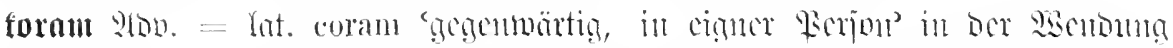

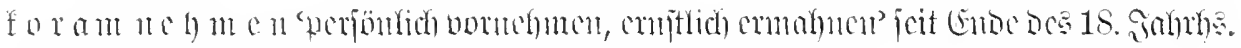

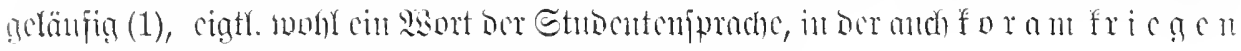

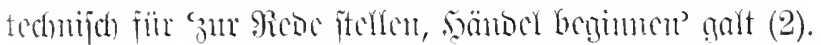

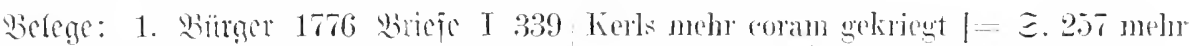
Tarch diesen beyden will ich den Osialn und Hämdel gemacht].

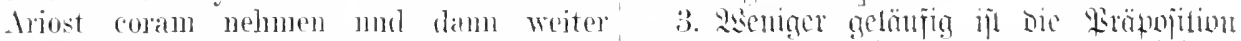

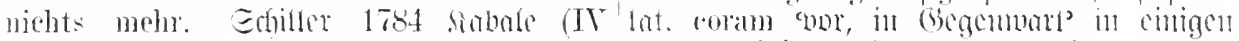

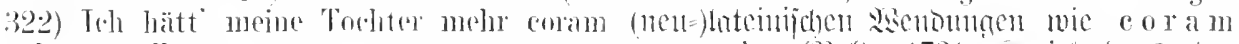
ndemens sollen.

2 a. nimbleben 1781 Etubentenlexiton| E. 16 Sirh coram exteris zum Spott dar-

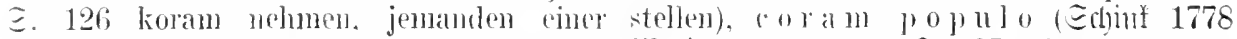
Siache halber zur Rede stellen.

Mharimetsuthenter $\Xi$. 27. 37 ), cot a m

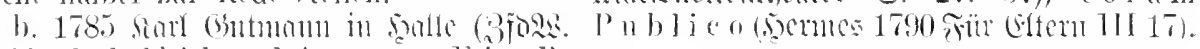
I 2.5i) da hali ich und Amtmamus Fritz die

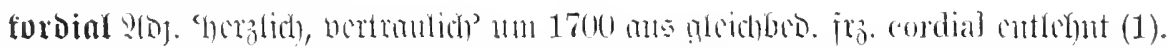

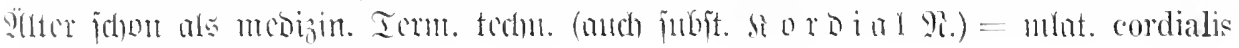

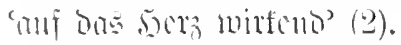

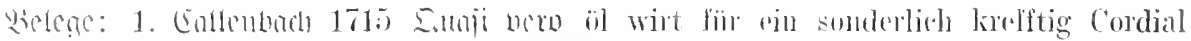

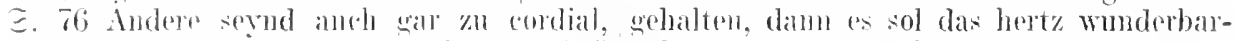

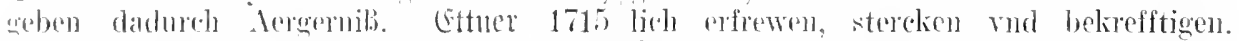

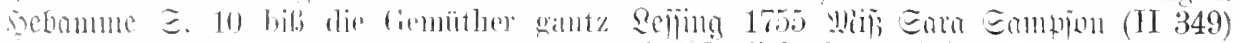
(nrdial wurdent.

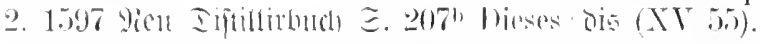

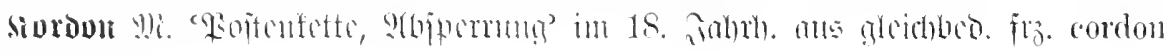
(cightl. 'こdtulur').

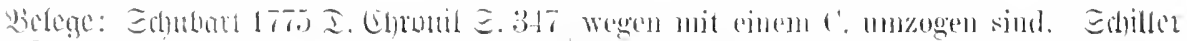

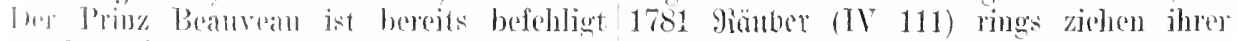

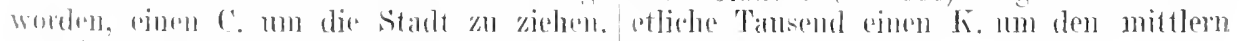

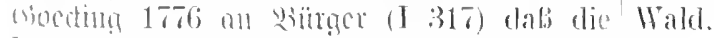

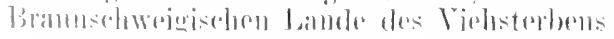




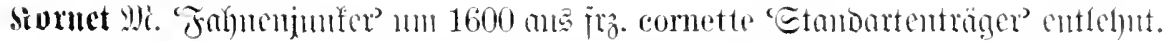

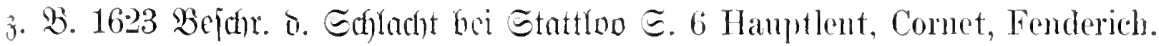

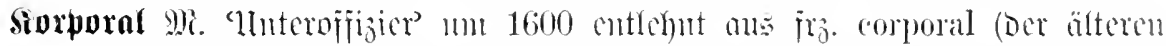
latinifierten Ricbenform zn caporal ans ital. caporale). Beleg: Dilich 1608 seriegs= bud) S. 249 ron einem Corporalen oder dem Lentenant - ebo. E. 20 st o r w o r a l $=$ itha it.

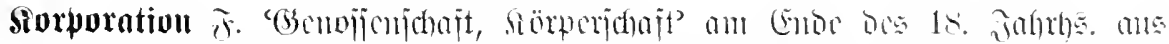

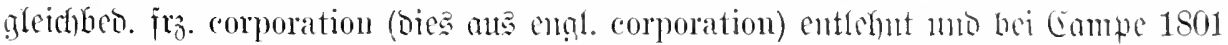

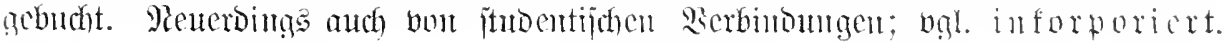

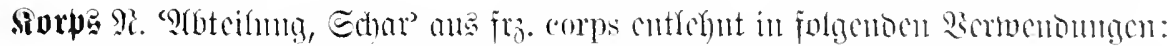

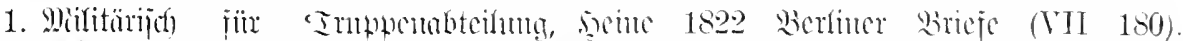

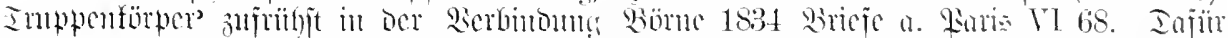

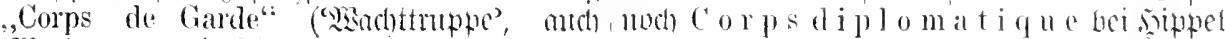

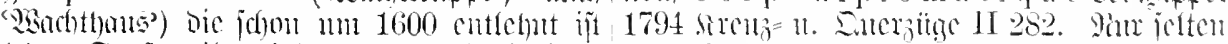

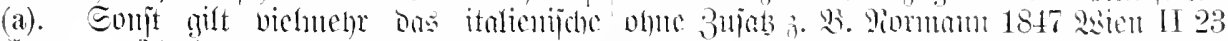

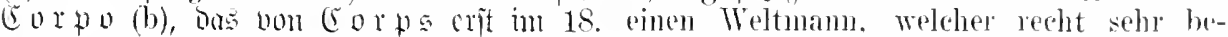

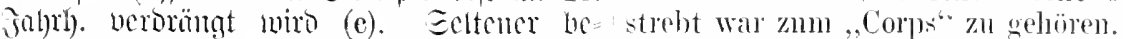

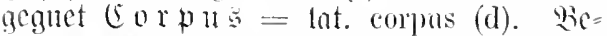

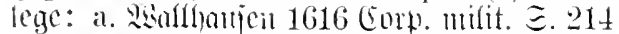
Er selbsten sol besichtigen die ('orps de garde oder Wachstat. Grimmelshonticul 1669 Simplic. $\Xi .51$ die mich anpackten mel in ihr Corps de Guarde fülnten. Niscig 1673 Eryoluren $\Xi .67$ wann ele einen in die Corps de Garde schicken wolte und sagte, er solte in die Wacht-Versammlung gehen, wer wiurde ihn mit den neu rebalckenen Wörter'l verstehen?

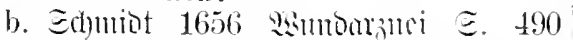
bey solehem stattliehen anselmlichen Corjo. Brimuclshmijen 1669 Eimblic. こ. 230 Derowegen ruckte muser Graf mit dem gantzen Corpo ror besagten Ort - E. 503 conjungirte sich mit dessen Corpo. Bijder 1720 Siob. Emioe II 120 Jetles Corpo bestund aus Acht Persohmen.

e. 1757 Frauff. Mejurelation II 42 Dieser Vortheil diente zur Begünstigung cler Retraite eines grossen Corps Infanterie. Wict=

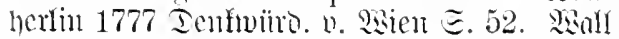
1786 Bagntellen I 84. Eamule 1803 Erra jiergantg (II 20). scente 1827 grombice (III 108).

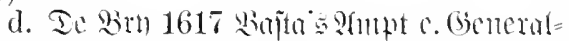
jerouberiten $\Xi$. 20. Wann man ein jedes grof Corpus in dem marchiren in sein membres theilen sol. SUncrion 1669 Erieut. Reijebejort. E. 19 ein schlecht Corpus zusammenbringen - 厄. 156 ihr Corpus bestunde aus 300000 Mamm.

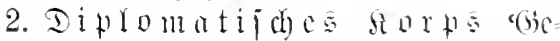

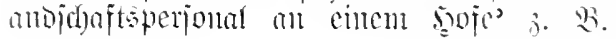

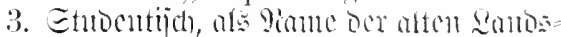

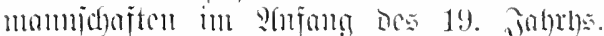

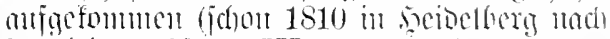

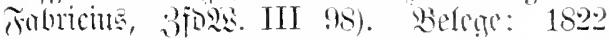

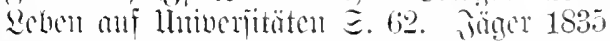
Fetir Edhubel E.23 kleinere Haufen, welche sofort eigene Terbindungen oder Landsmannschaften stifteten. Der urspringliche Zweck dieser letztgenannten Verbindnugen. die anch Corps hieben, war... Inat

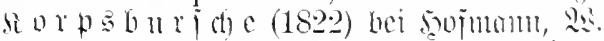
.

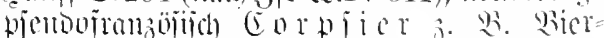
burm 1897 Entre E. 2.2.

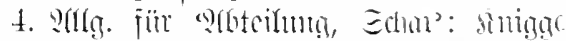
17881 mingung $\Xi 2.26$ das Corps der Hoflente. s!iuller 1792 sorr Ehomus IV 72 the ich nicht selbst zamm Corps der Hausväter gelü̈re. Sichtenberg 1798 seogarth IV 72 die Parole dieses reistlichen Corps. Eaber

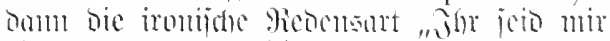
cin joüntes surts!"

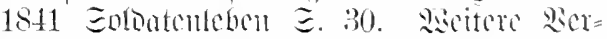

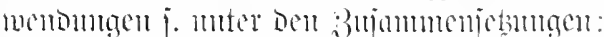

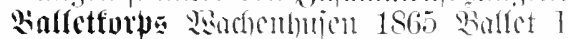
8. Infür älter mo mod jetst bänfiog in

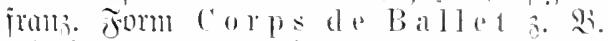

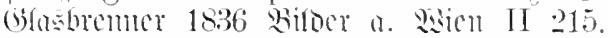
Ievricut 1839 siricic a. Limis (IV 40).

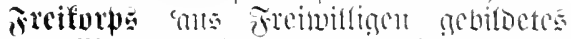

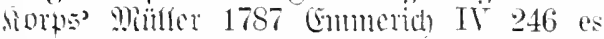
war keins von jenen schnellen Genies. das sich im Kriege als Chef eines Freykorps herrorgethan haben würde.

sinocttenforps sosebute 1797 Faliche 
Edhau (VI 2.58) Ich bin unglïcklicherweise im Kadetten-Corps erzogen.

Manjifforpe Gierjtäcter 1861 sumptreiter ङ. 6 den Marseh. den das gemietete Musikkorps blies.

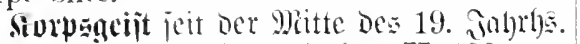
(Fientag 1855 Eoll 11. Saben II 193) ge= länig, norber mur in Der franjijijchen Formi Esprit de Corps: :mäjer 1766 qatriot.

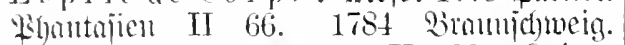
Edmlordmugen I 432- II 488. Smigge 1788 llmgang $\Xi$. 362. sermes 1790 Sir (Eltern Y 293 so wills der Esprit-de-corps [Qfum. Standsgejst]. Geroer 1794 Brieje (XVII 2.28) Andre [Cimbilomgen] haften an Stänten, Aemtern, Lebensarten, Zünften und bekommen den Ehremamen esprit de corps, Gefülıl seines Staudes, Familienehre. Sfflano 1798 Theatrat. Raufbahn ङ. 93. खistt v. Dörring 1830 Jragmente I 53. Bünfter 1831 Briefe I 101. Raube

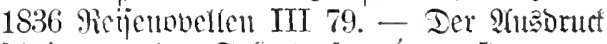
jocint ans ber Eolontempradbe jul jtammen: bal. Mojer 1767 Brieje $\Xi$. 44 Nennt sich diese Modification und Subordination der Gesimmungen, ihr richtig passentes Verhältnis zumGanzen bey einem ganzen Heer oder Regiment Esprit du Corps ... I I nod Semals 1835 Ineaterrevui $\Xi$. 143 Ieh will hier nicht untersuchen, ob das, was man im Militär esprit de corps nennt, bei Kunstvereinen überhanpt seiner vollen Bedentung nach wiunschenswerth wïre.

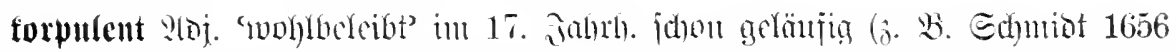

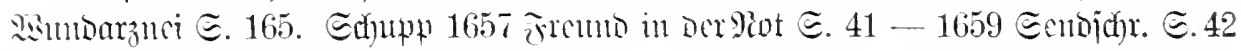

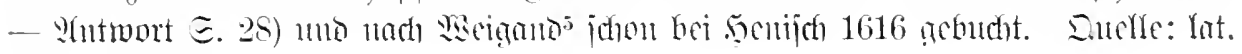
corpulentus.

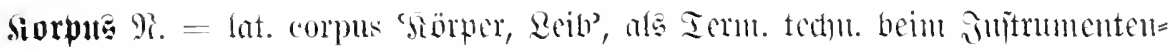

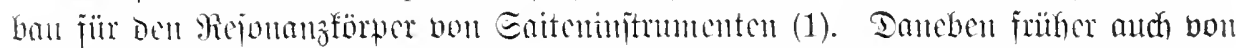

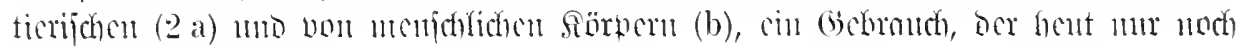

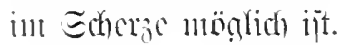

Belege: 1. Lrätorins 1619 Enntognn weilen des Hern gantzes Corpns mit Hit\% mujicum II j1 Ob anch wol ein jedes Thej angestefkt. 1790 Ier Bicobadnter @. 372 an der Lanten ron dem einen also, rom sein Verdienst bestand rermuthlich in andern anders genennet rud aub gesprochen, seinem stattliehen Korpus; denn dies ist wirt, So lab ich mir doch dieses zum besten anch ein Verdienst.

gefallen: Dab remlich Die vinterste runde oder der Banch genemut wird das Corpus. Mnrtin 1627 Colloques $\Xi .104 \mathrm{Es}$ is ein Lant ans Padua mit breiten Spänn: das ged Corpus ist alt. es ist aber nit lang. Enerr 1687 Lntertidet $\Xi .91$ Viola Picenla hat ein kleiner Corpus als ein Violin.

2 a. Emeiot 1551 Grobinus E. 102

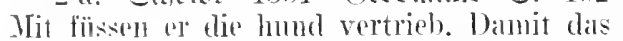
Corpus [ons gebratene subur] liegen b]ieb.

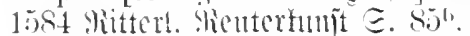

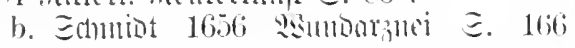

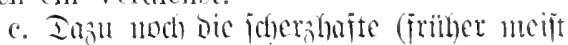

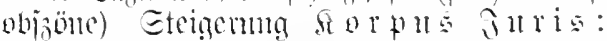
Prïtorius 1666 9futhropobems I 3 Nicht gedenckende, dab er sieh anff ein ander lebendig Corpns jurjs privatum fleischlich geleget und den Alp in Kammern und Unziichten geagiret habe. Nivije 1701 l̈lbcrfi. (jobonteri e. 160 Rosilis: Monsieur, es ist mir leid, ar stolpert im processe. Coridon: Wolan. so mub sie mir ihr Corpus Juris leihı.

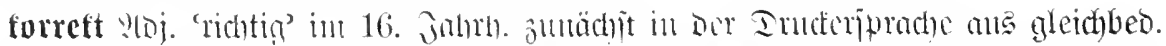

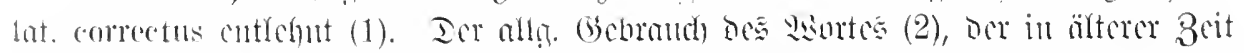

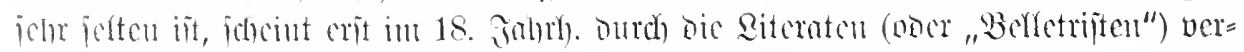

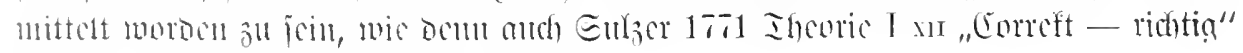

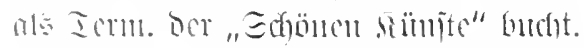

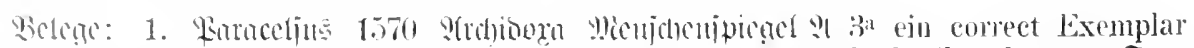

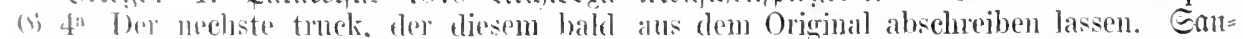

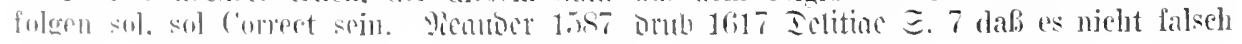


vnnd incorrect solte gedruckt werden.' Ientigel 1689 Interreoungen $\Xi$. 220 von denen correcten Codicibus.

2. Dund 1598 Enctuiridion હ. 17 das alle freie studia, die Hebreische, Griechische und Latinische Sprach so lauter und correct in Teutschland geleret vnd geubet wird.

- Reijing 1759 Riteraturbricfe (VIII 145) die nur an einem correcten Racinen Geschmack finden - 1767 Iramaturgie (IX 390) die resetzmäßigsten Geburten eurer correkten Racinen. 1765 ?Ilg. D. Biblio= thef I $1 \Xi$. 77 Das Griechische ist wohl nicht ganz correkt und die Uebersetzung hin und wieder etwas hart. Biitrger 1776 Wrieje I 274 Es wird mir selten mehr saner, so ziemlich genau und korrekt zu sein. Forjter 1791 201jichten (III 291) Die Zeichnung ist korreliter, als Rubens gewöhnlich zu zeichneu pflegte.

Sorreftheit $\mathfrak{F}$. Edhtege 1801 \&ortcimngen I 25 das sind besonders diejenigen [s rititer] die vorzugsweise oder gar ansschliebend auf die sogenannte Correktheit gehen. Man kam diesem Worte zwar einen gültigeren Sinn unterlegen; sie meynen aber damit eine Vollkommenheit der einzelnen Theile eines Kunstwerks, nnd zwar bis in die kleinsten hinein, die ohne Beziehumg auf das Ganze Statt finden soll. Shut 1809 Expljoben II 345 mit einer landkartenälnlichen Correktheit und Klarheit.

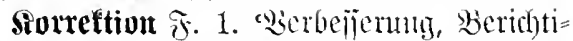
gumg’ iut 15. Jahrh. aus gleidfbed. Int correctio entrehnt $j$. W. Senter 1510 Qnienpiegel Ut $5^{\mathrm{a}} \mathrm{Tr}$ wöllen mit guttem fleib vnd Correction in Jeblich vind rerstendig buchstaben zusetzen in Eüwer druckerey verordnen.

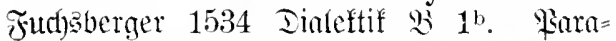
celjus 1536 2simbaranei $911^{\mathrm{b}}$. Suhnau 1700 Dundjalher હ. 234 . Shäter Ditrch fier ofefturerjebt.

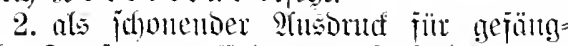
fiche Etrafen an Enoc Des 18. Jahrbs. aus

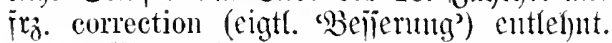
ว. B. Sffflan 1801 รูöhen (VII 107) Da sehe ich schon eine zuchthäusliche Correktion angewiesen.

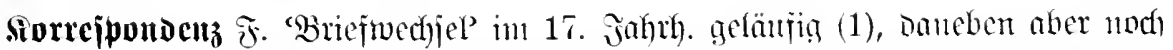

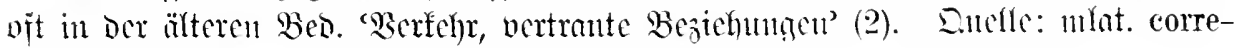
spondentia - $\tilde{i} \dot{j}$. correspondance.

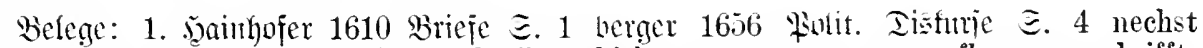
ihm ein Compliment- oher Grueßschreiben hiebevor vnter vns gepflogener schrifftund die Fürstl. Bildnüß zustellen und $11 \mathrm{~m}$ |licher Correspondentz.

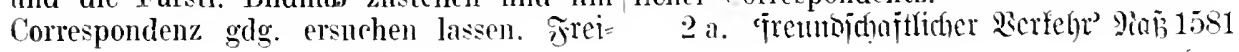

Siorreftionshans mad) irg. maison de V 409 Jene alten Schulen waren Erziehungsschulen für Zöglinge, die neuern müßten Correctionshäuser für Züchtlinge seyn. (Gür res 1821 Entron $\Xi$. 30 . Witt v. Tärring 1827 Fragmente II 118. Sgl. sion te f t i ou 2.

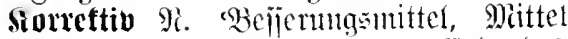
jur Bejeitigung von Fehtern' an Ende des 17. jobrbs. aus $j \mathrm{jr}_{\mathfrak{j}}$. correctif entlehnt $\mathfrak{\gamma}$. $B$ Epudn 1668 2ion ben (5aje ङ. 90 so ordnete er sie [oie Whitch] mit Kalch-Wasser, welches die Milch alleine und ohne solches Correctiv (linderndes) oder andre dergleichen Mittel nicht thäte. Ibimmmet 1791 æeije (IN 25) dab ich dem Rücken dieser Heiligen den Stempel ihres Lebens zum Correktiv ihres verfïhrerisehen Anblicks aufdrïcke.

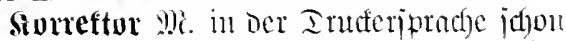
Des 16. Jubrlyums. aus lat. corrector' ' $\mathfrak{B C}$ '. lieber Correktor!

Sorreftux $\tilde{J}$. in oer Iructeriprache jeit Deut 16. Jabrb). in jolg. Bedentumgen ge= läufig: 1. 'Tunffehlervergeidnus", eight. Die

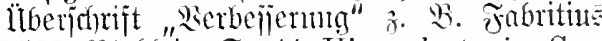
1532 Büchlén $\Xi$. 44 Hie rolget ein Correctur, yn welcher angezeygt wurth die vbersenen wörther. Miengering 1642 (be= wijientriige $\Xi .1526$ dab offt die Correctur hernach eben lang ist, wenn ein opus publiciret wordell.

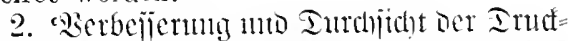

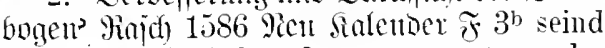
vormals auff jeder dessen correctur oder besserung alzeit gnte änderung erfolget. Epedfle 1589 Q(rofitcftux $\Xi 113^{\mathrm{a}}$ Correctur der Errata. Miengering 1642 (Gemiijensrüge ङ. $403 \mathrm{Ob}$ sie in Aufflegung vnd Verfertigung eines Bibel-Drucks die Auffsicht rnd Correctur mit Fleib bestellt.

3. 'fiorrefturbogen' Edicibe 17t5 sirit. Mariftis 3orr. (c $\left.4^{b}\right)$ Da ich zu weit ron Leipzig entfernet bin, so ist es mir nicht möglich gewesen, dic Correctur selbst nachzusehen.

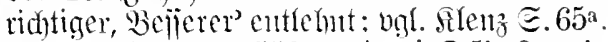
Beleg: Rinnener 1558 siabipuri $I 5^{\mathrm{b}}$ O mein 
Exrmen E. 378 wolan so sollen sie gute $C$. finden, wie sie mich grïssen, also soll jhmen gedanckt werden. Errtin 1592 Reidgen= probig̣t $\Xi .20$ Nit den benachbarten anch Protestirenden Fiirsten haben sie stets gute C. wehalten. Mannolo 1596 Miarfichifi

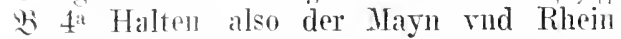
C. Ind antrerein. Memuna 1620 Sientra=

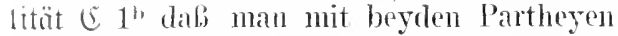
allzeit wute Freundsehafft vind $\mathrm{C}$. gehalten.

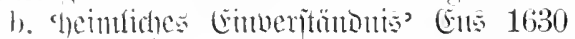
Woitreiter $\circlearrowright .51$ hat es in der Stadt Mantna an Rebellion vund ' '. mit dem Feindt nicht gefehlt. Rajientits 1661 ?(toel. Iijhresen E. 355 [ Ex hat] mit seinem Gegenpart heimliche $C$. gehalten. Mittertudht 1667 Politica is $7^{2}$ mit anderer Potentaten Abgesandten oder Bedienten nichts communiciren oder heimliche e. pflegen.

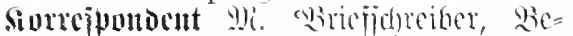
riditerịtatter 1634 sericht b. Frteolanos
Pierrat (s) $1^{\text {a }}$ Als er auch vmb dieselbe Zeit. von Lintz aulis ron seinen Correspondenten avisirt worden. Grimutelignujen 1669 Eimulic. ङ. 290 bey unsers Kost-Herm Correspondenten. Bej. aud in ber fialifntamsgapradic

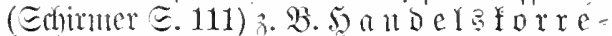
if o u b e ut Goethe 1796 Qehrianre (XXII 83): ncuerding andh $3 \mathrm{c}$ it 11 us

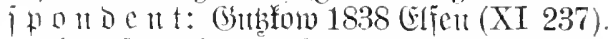

forrejpunderen 3tw. ane $\tilde{i r}$. correspondre, mtat. correspondere 1. SBriefe wedhefm' 1634 sericht v. Frieblanios Berrat If $4^{\text {b }}$ derethalben alsbalt mit dem proseribirten alten Heinrich Matthesen, der sich Graff von Thurn genennet, mündt- vad schrifftich nacher Berlin correspondirt.

2. '3ujanmentreffen, 3ujammenhängen' Eebir 1580 Trelobut E. 472 mit acht Liechtfenstern oder durchsehen. welche eben mit den acht Linien zutreffen rnd correspondiren. Enjounger 1590 Relutionen I 50.

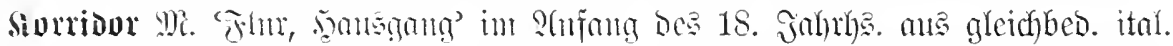

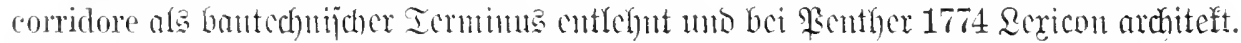

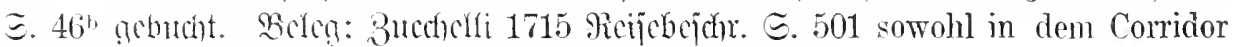
aIs in der coporta - E. 502 den Schlïssel des Corridors.

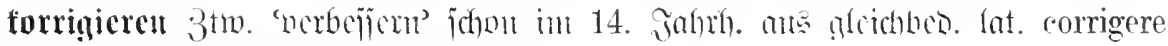

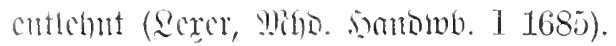

victeg̣e: Bishem 1343 Enomgetientuth bêren tohmetschêren sint ubele wz gigebin ¿. 1 daz ich icht turve in den alden bucheren — E. 2 daz mur die wort gecorrigiret worden, zı legin odir wandelin olir corrigîren - die man merkite. daz si wandelten den sin. eorrigrien die dine dip entweder von lastir-

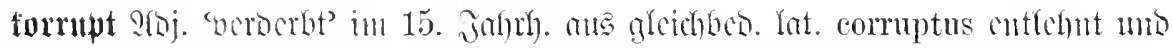

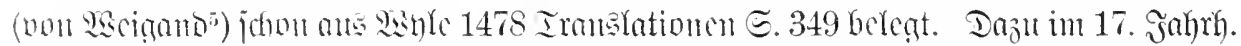

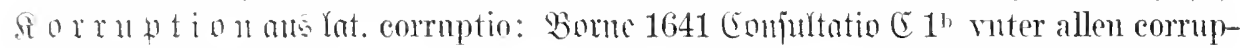
tionen rnsers seculi.

Siorjar 9). 'Eceräuber" - ital. corsare (eorsaro), als Pame Dex Piraten be?

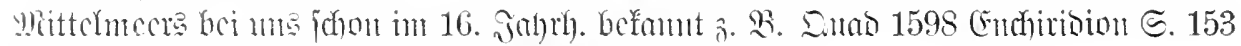
das gantze Land ist vol Renber. das Meer vol Corsaren.

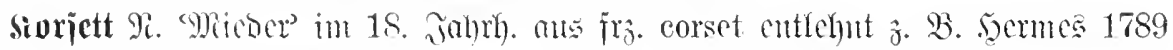

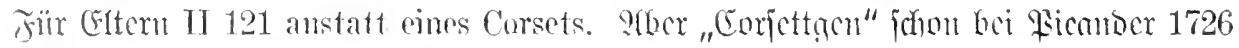
ङhampiche. 22.

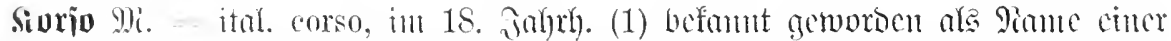

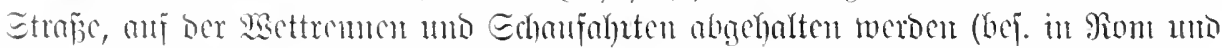

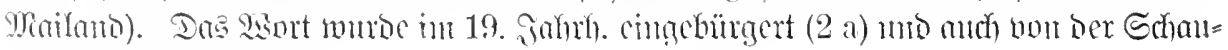
jahrt jolbĩt gebraucht (b).

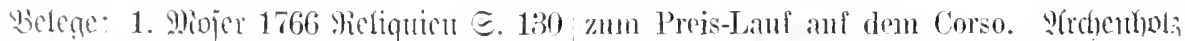
das Englische J'ferd, bostimmt zum Wett- 1786 Stolien I 79 Thr Hauptgeschaft ist, Romnen in Towmarket, der Neipolitanep ilure Herrschaften nach dem Corso zu he- 
gleiten; pin Spazierplatz, woselbst sich der man glaubt sich anfi dem Bonlevard uder Adel täglich bey gutem Wetter gegen Abend Cor*o irgend riner groben Stadt - 18t?

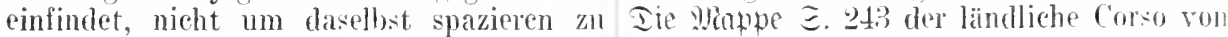
wehen, sondern in Kintschen auf und nieder Baden.

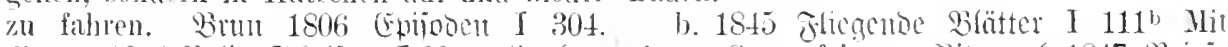

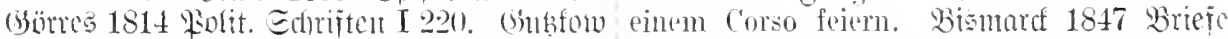
184:3 Reijeembritte (TX 151).

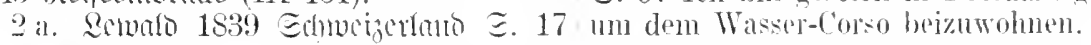

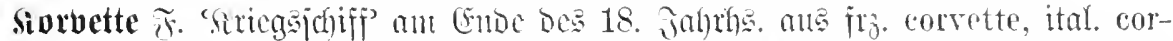

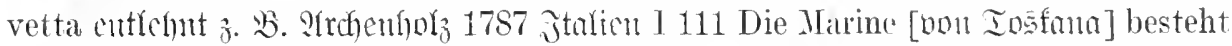
nur aus ein paar Corvetten und drey Galleeren. Gobthe, Jtal. Retie (31, 75). $33 g h$.

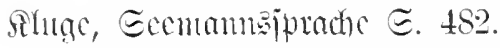

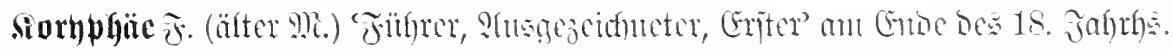

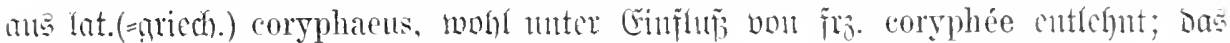

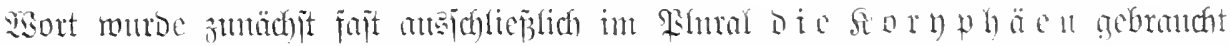

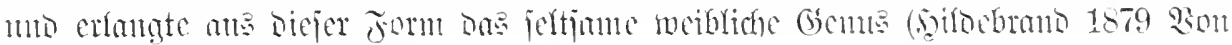
Den Frenomörtem ङ. 142).

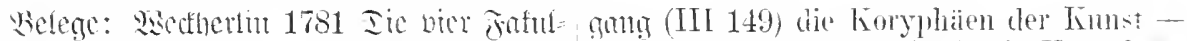

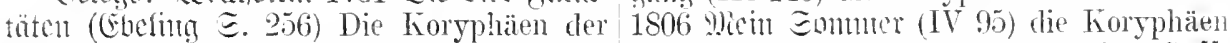
Hedicin sehen nicht mehr einem Unkepunz der schönen griechischen Gralanterie. Snofi= ̈̈hnlich, sie sind Elegants. Sungge 1788 mann 1814 Bergnnan (I 130) Er war einer Unmgang $\Xi .293$ daß jungere, oft sehr un- der Koryphäen jener langweiligen... Sekte. hedentende Lente jetzt die Koryphäen Grabbe 1835 Ihenter (IY 12) Yan scheint sind. Görre 1800 \&olit. Eduriften I 76 hier noch nicht gewöhnt Einen Korgphäen weil er der Talente der Coryphäen der ehr- spielen, die Mitspieler lifuschen zu lassen. losen Zunft bedarf. Eeunte 1803 Enotior.

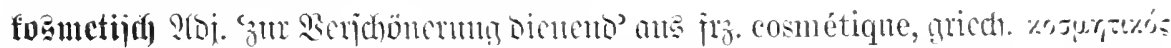

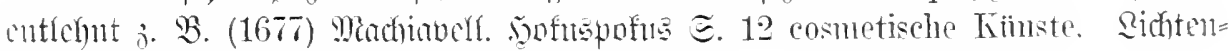
berg 1795 sogarth II 133 kosmetischer Apparat.

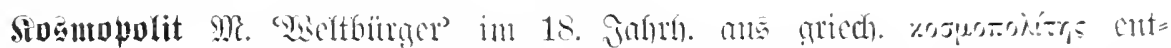

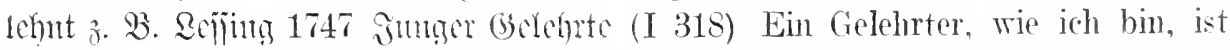

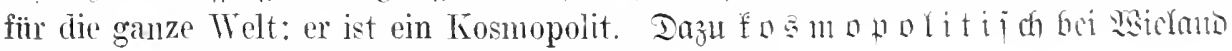
1775 Merfur IT 117. Bal. Feloutam, 370然. VI 345.

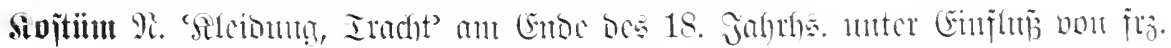

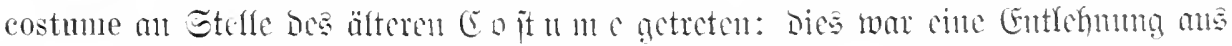

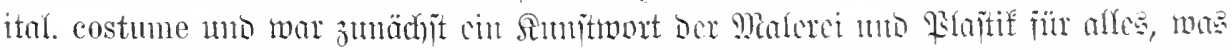

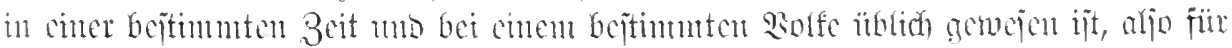

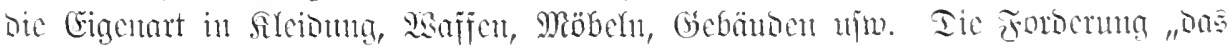

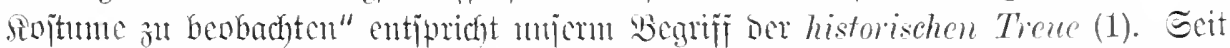

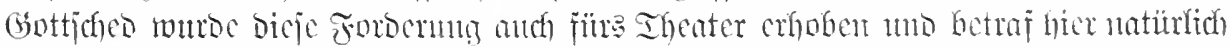

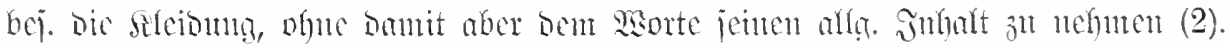

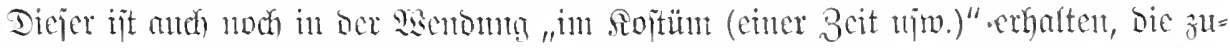

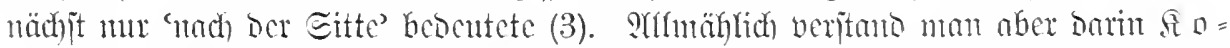

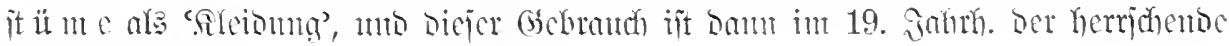
gemorben (4). 
Betege: 1 a. Incoretije Icjinitionn: gekleidet werden soll, damit wir nicht gegen Gottjd)e 1760 ionticritun $\Xi$. 448 Costume. Ein malerischer Ansdruek, wodurch man dasjenige rersteht, was der Zeit, der Denkungsart, den Sitten, Gesetzen. dem Geschmacke, dem Reichthume, dem Charakter und den Gewohnheiten eines Landes yemein ist. dahin man die Scene eines Bildes

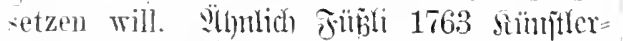

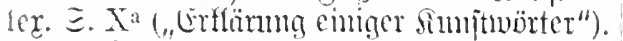
Eomtenfel 1768 Ermunterumg zur Reftu E. 11 Kostume, wie es die Italiäner nemmen. las ist: die in der Kleidung, in der Lebensart, in Sitten, Gebänden, Geräthen, selbst in Tieren, genau beobachtete Gewohnheit. Tatm, Beschaffenheit der Länder, der Zeit, der Umstände, in welche die Handhng des Gemäldes versetzet.

b. 5eanam 1759 Eofrnt. Ipuffüirdia = feiten (II 23) und seine [oes Eotrates] Gratien widersprachen dem Costume des damaligen Göttersystems. 1771 sonllijate Sibriothef VI 1.56 ein wahrer "Vorzug" dieser Bücher, dab das Costume in ihnen nicht beobachtet ist. Q(robenfor 1787 italien II 97 daher seine historischen Cremälde volier Fehler gegen das Costume sind.

2. Seijing 1767 Etomatmaic (IX 181) Der sorgsante Schanspieler hat in seiner Tracht das Costume vom Seheitel bis zur Zehe genan zu beobachten gesucht. Echnio

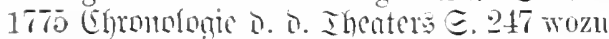
Herr Kioch lanter nene Kleider in genanesten Kostüme [!] hatte machen lassen. Govefing 1776 an bürger (I 300) das Costime. das auf unsrer Bühne noch ibherall so selu rernachlibiget wird. (jonethe (17-9) Eneatral. Ecmonn ङ. 30t rorbrreiten, wie die Göttin

das Costume rerstolien.

3. Woethe 1796 Refriabre (XXI 87) die Ärmel seines Sehlafrocks nach orientalisehem Costïme liurz stutzen lassen. Shnu 1806 Enifosen I 396 durchans in edeln Costum der Antike rom Scheitel bis zur Zehe gekleidet. Goethe 1817 vifuro. an e. mos. Bifonnuter $(49,2 \Subset .55)$ wemn das christliche Militiir ju Costïm des sjebzchnten Jahrhmolerts anftritt. ivofimam 1822 Sinter Maur (X 300) Und doch stellten die alten, vorzüglich die dentschen Maler alle biblisehen und heiligen Geschichten in dem Kostïm ihres Zeitalter's dar.

4. Siflomo 1798 Ihentrul. Sanflum ङ. 12 Ein seidnes Tuch flatterte als der Mantel des Antiochus hinter mir leer . . und manchmal, ohne das iibrige fiostume zu ändern. vollendete ein Reifrock meiner Grobmutter die Kleopatra. Gocthe 1817 Iie Infge= regten (XVIII 30) Familienbilder in den mannigfaltigen reistlichen und weltlichen Costiimen fin ber sombidnutit: in rersehiedenem Lostum!].

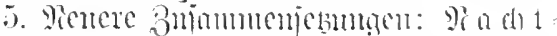

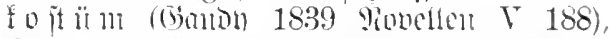

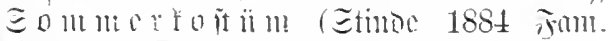

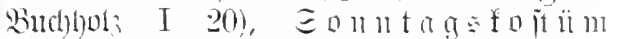

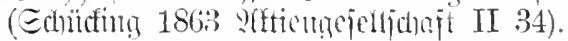

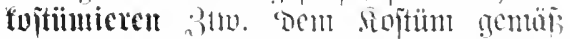
fleideli', Dom überbant 'in eine sracht

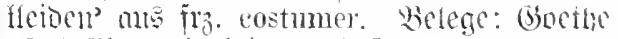
1814 sens mix brimgen (XIII 110) Sie sint antik als Genien costümirt - 1817 ? an c. mos. Bifohaner $(49,2 \Xi 57)$ beide fast gleich rostiminte Tationen. Miener 1817 આt. Edrriften こ. 114 m'm] die Figuren wunderlich costumirt sind.

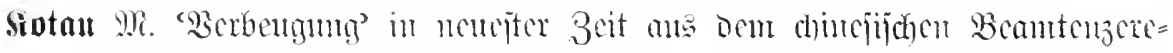

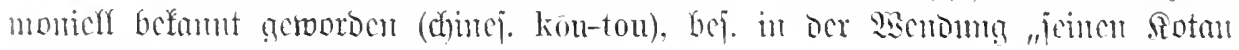

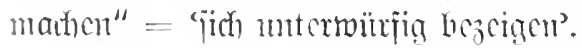

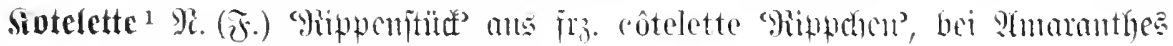

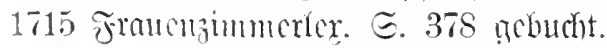

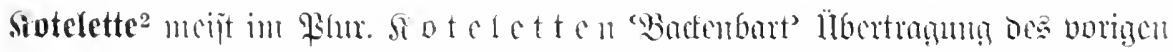

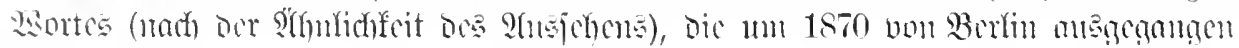
jul jein jocheint.

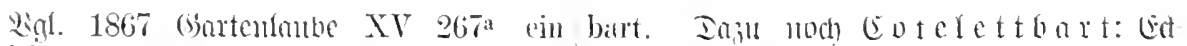

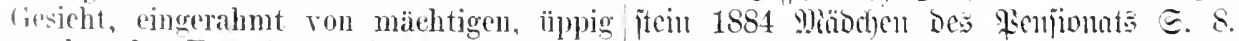
whehernden Favoris, welche man in Berlin Sicleg fïr siofelette: Fontme 188:3 .Haarkoteletten" zu memen pflegt. Miüller Siriefr II 73 Je älter jeh werde, je meh"

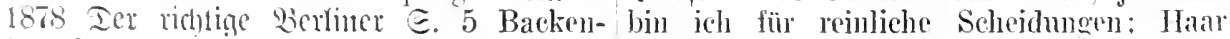
kutteliften. anch Bartknteletten, Backen- apart und Kotelett apart. 


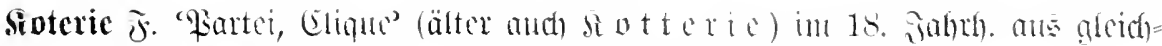

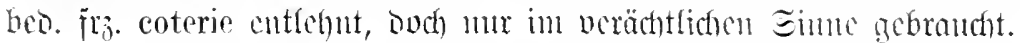

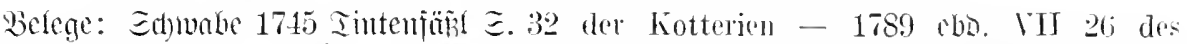
Donnerstags-Coterie - $\Xi$. 34 Vahlem- giftigen Bedincrus der klatschenden Kot-

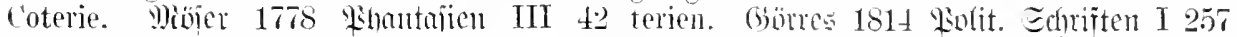

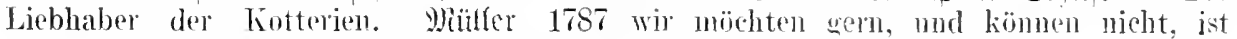
Emmerid) II 312 den kriechenden Jargon dits Stichwort aller Cotterien.

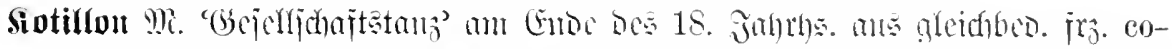
tillon cutfelunt $j$. SW. Forjter 1791 S(ujichten (1II 493) mit dem sogenannten langen Menuet, dem Cotilion. Sotzebuc 1795 2rmut (T 10s) einen Cotillon zu tanzen.

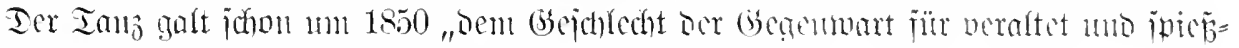

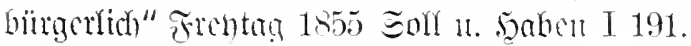

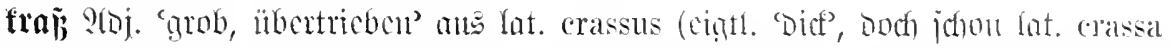

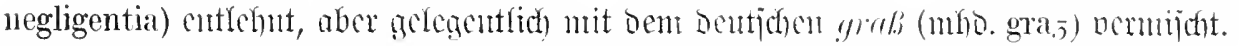

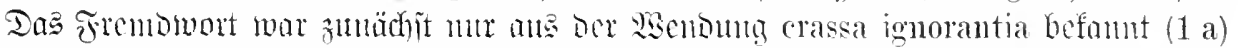

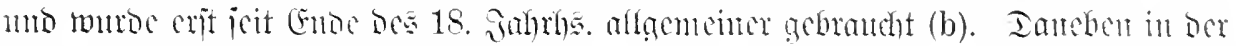

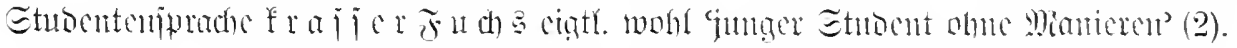

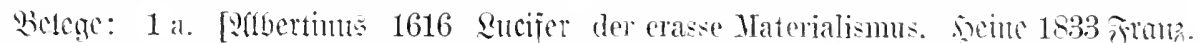
こ. 99 Dise rnwissenheit wirdt genannt Znjtünoe ( $\mathrm{V} 200$ ) ron krasem Obskmantis-

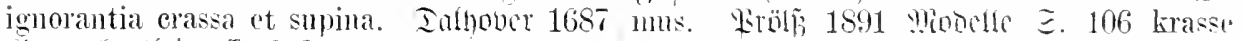
(Gatenbetfein I $213^{\text {b }}$ erasa, die vrobe Effekte.

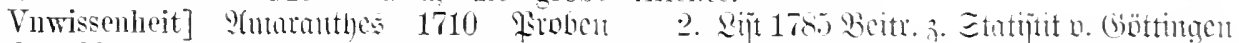
こ. 338 Anf einen grassen [!] Tgnoranten. E. 130 crab heibt in weitläntigem Ver-

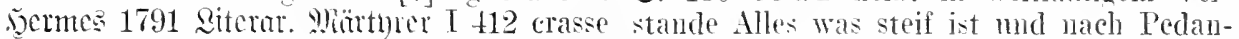
Ignoranz. J. 3. 2. \$lener 1797 Fragnente terie schmeckt. Ein draser und ein petit a. Soris I 255 kasse Ignoranten. (jobrre maitre beobachten zwey Extreme und sind 1880 Polit. Echriften I 34 crasse Lnwissen- einem studioso honorico gleich nnverdanheit. Ebeno Remalo 1835 Inenterente lich. Simbleben 1781 Etmoententeder $\Xi 20$

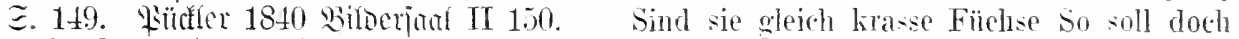

b. Enhlegel $1801 / 2$ Sorlejungen I bt ihre Büchse Lns Allen dienlich spin. Qtach

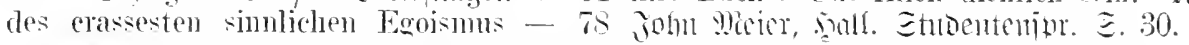

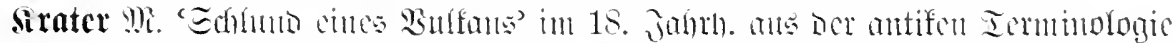

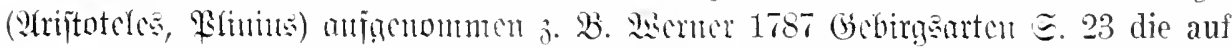
ihnen [urfmen] rorhandenen trichterförmigen Schlünde (Kraters). Etatt bcs

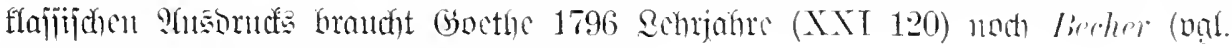

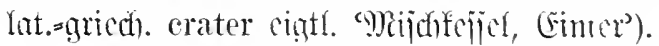

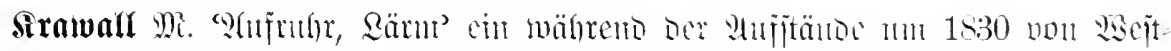

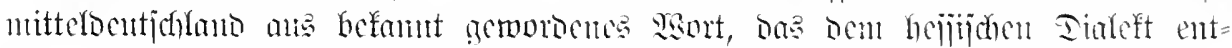

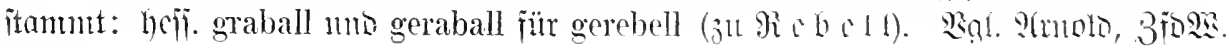
LI 157 .

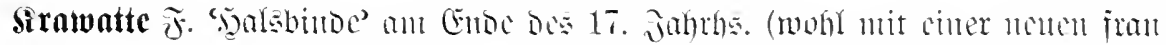

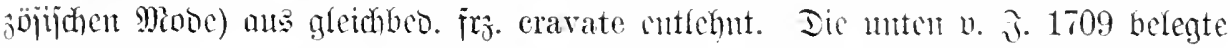

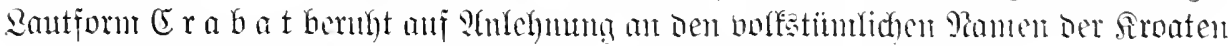

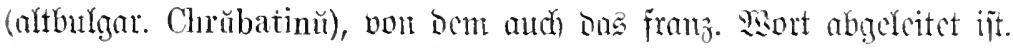

Belege: Menejtrier 1694 berorn= ober wurden, so die junge Leute am Hals trugen, sisuppenfunjt E. 48 waren vor zeiten Bänder. mie man jetzund die Cravattes und Halswie anch dergleichen mit Stefften getragen tïcher pflegt zu tragen. 1709 Marum 
Evim ङ. 298 Der Kragen oder Hals-Theh junge Herren, habt ihr nichts zu schacheren, [beif̈t] nicht mehr Kragen, sondern Crabat. Mäntel, Cannisole, Bücher, Cravatte?

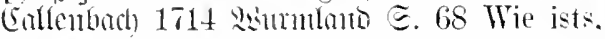

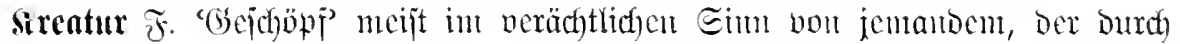

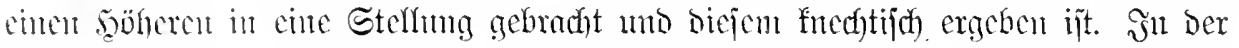

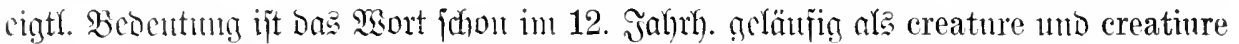

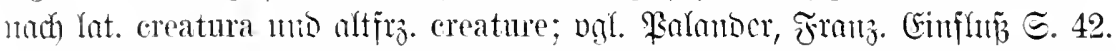

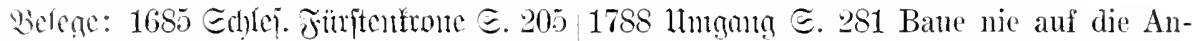
trieb Cantzler und Räthe herans und be- hänglichkeit Deiner sogenannten Creaturen. stellte die Ämpter mit seinen Creaturen. das heißt, solcher Menschen, die dir ihr Entenis 1784 Sallo $\Xi .66$ sie hatten noch Gliick zn verdanken haben.

immer ihre Kreaturen am Hofe. Sinigge

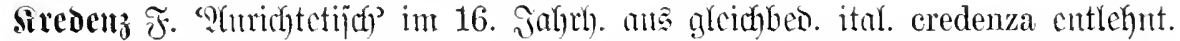

Belege: Fincelnu 1566 SSumberzeichen

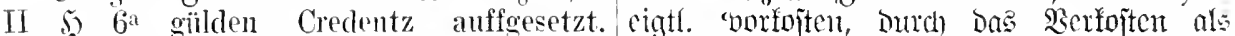

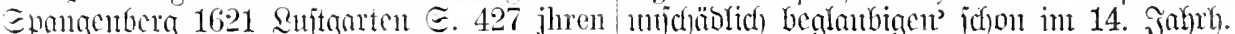

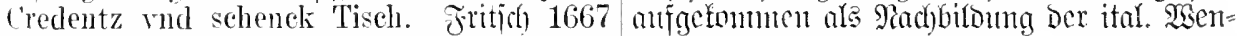

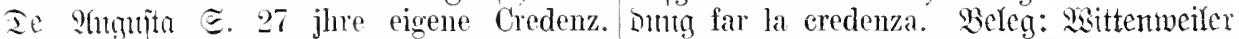

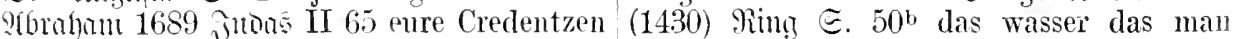
uberschwemmt. Iafiur berbentfidsend nuth trinken sol, sol man vor credentzen wol,

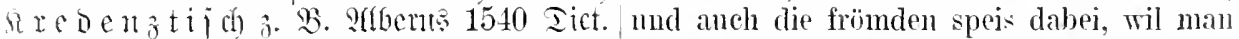

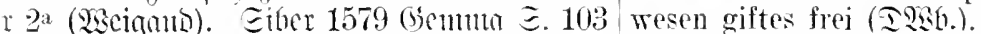

credentztisch, Amrichttaffel.

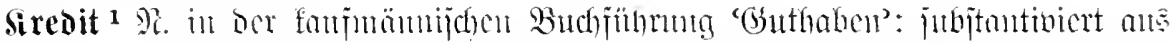

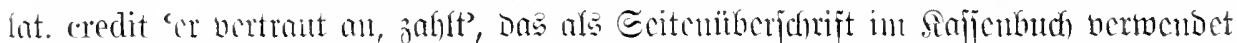
munc: Ioffoner 1687 Gortenbectlein I 227b in welchem man credit rnd debit führet. S̈lter aber in e re d i t o : Rom 1552 Iagebud ङ. S1 alle und jede Schulden

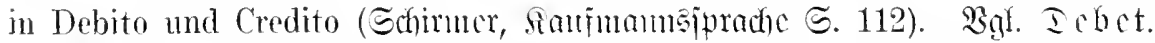

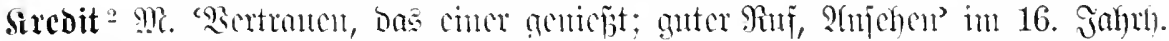

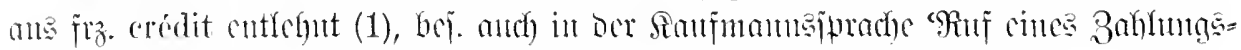

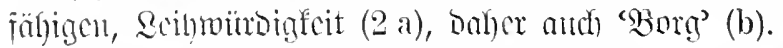

Belege: 1. Edtumintidgen 1566 Ient= her, kein Mangel hetts, wemm Gelt da wär.

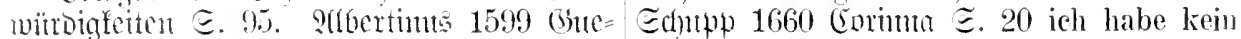
vore's Eonoidheiben III 62 wann nieht Geld vnd keinen eredit.

der credit vol gnter Tam des Matachiar das best gethan hette. 1634 Sericit b. Fricolande der Fridtländer bey der Kays. May. wäre. befiel 1666 Ethmieoc ङ. 29 wer sich einmahl in guten Crediht gesetzt, der wird nicht leichte hemacher in ïbehn Ruff konmen - E. 53 wird er delihaben in Verachtung und ïbeln Credit bey männighichen yerahten.

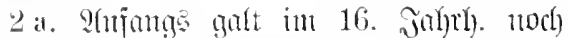
die ital. Form Eredo ito: Echimer, samf =

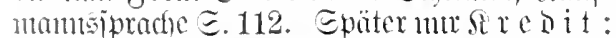
Mantgolo 1597 Marfichifis Machen \& $^{\text {b }}$ Dal, sie den Credit oder Zill Nicht halten kömuen rnd damit Ihren Glauben verlieren

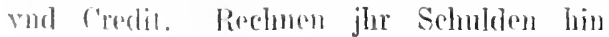

b. Edhoch 1658 (Conwedin $\Xi .74 \mathrm{Im}$ Fall jo aber das Geld nicht zureichen möchte. so kanstu nur credit machen. Eecfentonif 1665 Fituitemitant II 107 dab er jhme ron seinen Einkiünfften (ohne Borg und credit) Renter und Wagen geschaffet.

Miigftredit "oiejes 9 sort ijt in Jahr 1709 in ber seantulung eingefithret worben, ben Dantaligen folled)ten Wert ber indoijchen STctien anzubenten" 1762 Einleitung in bic

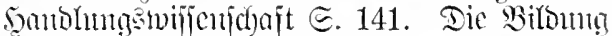

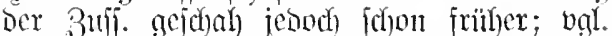

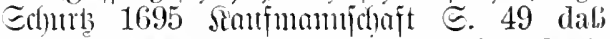
ihm ron denenselben die schnldige Capitalia anfgekündet und folglich er in MibCredit gesetzet werde. Micht fomtmämnifoch bei hom $1718 \cong$ tontsflugheit $\Subset .48$ weil sie 
besurgen mïssen, dalj der Landes-Fürst alles was sie vornahmen, wieder erfahren und sie sich also in Mils-('redit bey ihme sutzen möehten.

frediticrert 3tw. 'burgen' im 17. Jahrt). mêे gleichbes. froz. créditer entlehnt: val. Echirmer, simminamispprache E. 112.

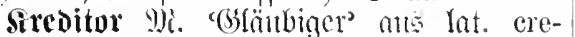

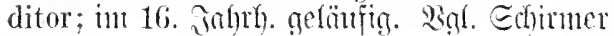
ก. ก. D.

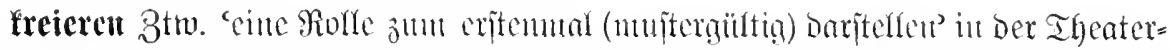

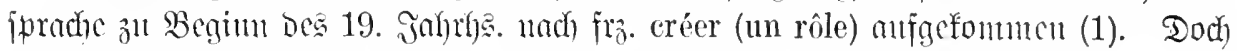

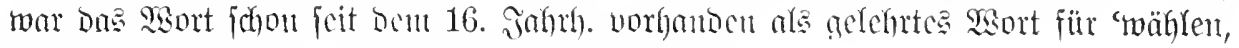

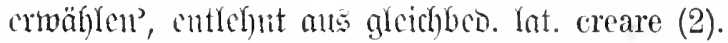

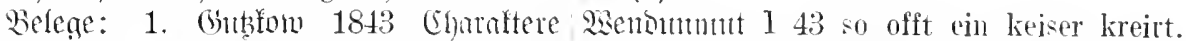

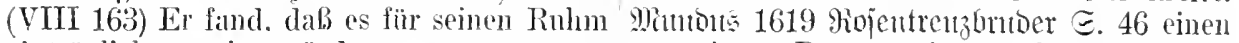
cinträglicher sein wïrde, wemn al neve rermeinten Bapst creiret. 1629 ä̈lbernrat Rollen krejerte, als wenn or alte neu, હ.9 dabich bald hernach in cin anfibündigen

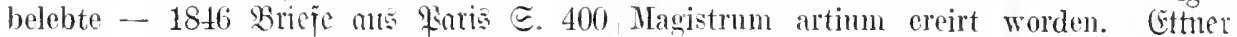
nachdem vor 21 Jahren die Grorges anf 1719 jebanme $\Xi$. 353 Es werden anjetzo dem Odeon die Jeanne d'Are, ,creirt" latte, cine grobe Menge Doctores creiret. Fobe=

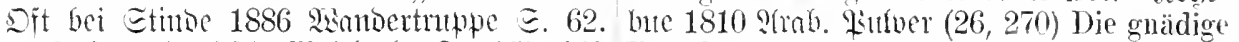

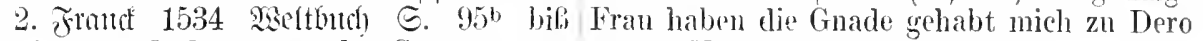
Congiusta aul der ansag der Götter erster ersten Kammerfran zn creiren.

kïnig ron ynen creiert warkl. Sird)hoif 1563

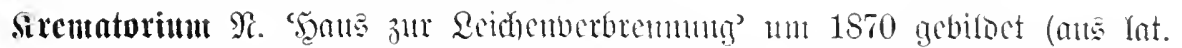

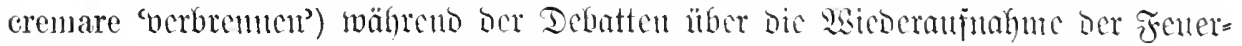
bejtattung (bas crîte firematorium wurbe 1878 in (jotha worlendet).

frepieren 3tm. 'itcrben' als Eolbatomont im 30jôln. Siricge mis ital. crepare

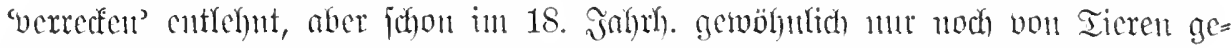

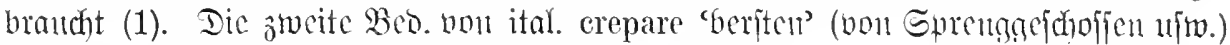
forlecint crit um 1700 ïbernommen zu fein (2).

Belege: 1 a. Eordatif : Grimmels= b. Eternheim Є. 303 mit dem Ausdruck, daf hantien 1669 Eimpric. $\Subset .44$ biß sie endlich ich da crepiren möchte.

mach und nach in Sehlachten, Belägerungen,

Stiimmen, Feldzïgen und in den Quartieren selbsten umkamen, starben, verdarben und crepirten. Ettner 1697 Ehnmicus ๔. 339 bedient sich ilurer wie der willigen Wann dergleicher Cavallier erepiren miissen, Pferd, die man anspannet, bis sie ron sich wïrde andern die Lust in Kriege zu dienen selbst erepiren. Döbel 1746 gägerurnatien I bald vergehen. Sejing 1763 Miuna v. $135^{\text {a }}$ muß mancher junger Fasan daran

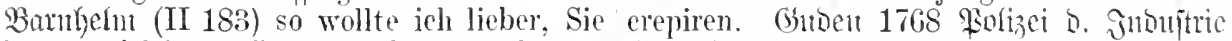
hätten mich in dem Lazarethe krepieren lassen. $\Xi 465 \mathrm{im}$ Fall ihr Vieh erepirte.

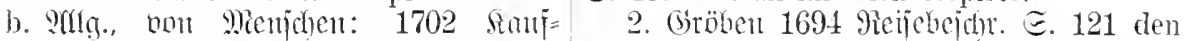
mummonit ङ. 110 wenn das Getreyde in 27. warffen die Florentiner 6 Careassen in diesem Lande nicht wohl geräth . . . und die Vestmng, aber zwey erreichten nur ihren viel Innwohner dariber crepiren mïsten. Effect, die andern 4 crepirten in der Lufft.

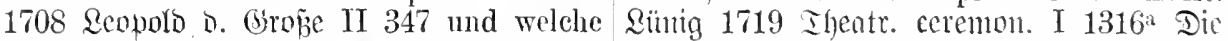
nicht für dem Feind umkamen, durch diese $\Re$ nfete] crepirte nachlıero mit großem Ge-

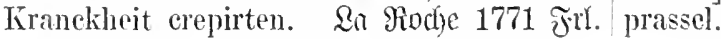

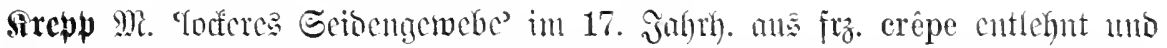

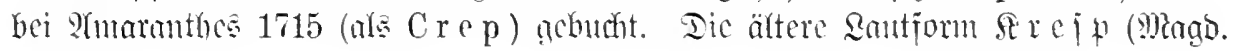


Baumbartuct 1594 Brieje S. 227 ron schbarzen krespen) entitantmt Dent nor. crespe (neten kerspe); vgl. Batijt und baje.

Strethi und

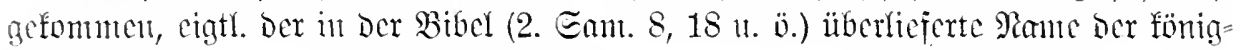

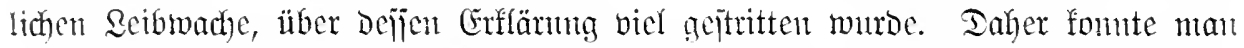

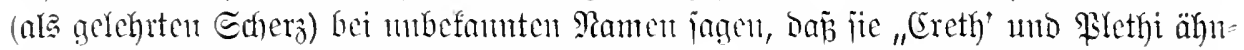

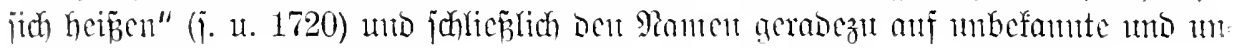
jithere Gejeflen ïbertragen.

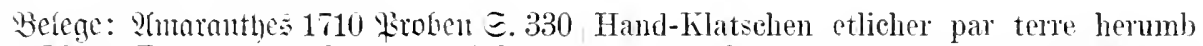
Der Mnsen-Berg ist reeht von Tichtern irrenden Crethi und Plethi, vor das Muster iiberhäufft, weil aller Henker drauff, ja einer viel bedentenden Haupt-Person, auf cret- und Plethi läufft - 1720 Reijere dem Schan-Platze der gelehrten Welt an-

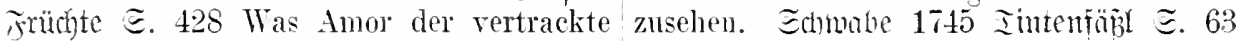
Creist, Vor Völkehen da zusammen stoppelt, Itze will ieh halt dem Gelerten Lesser Das Cret und Plethi ähnlich [!] heibt. Kreti und Pleti wieß der Seuhirt anßtreyben Mlendfe 1716 Charlatanerie $厄 .3^{\mathrm{b}}$ wie man thuet, fürsetzen. Das wird ein schöner gar nicht Lrsache habe iedweden halb ehr- Mischling werden.

baren Peter Sqrentz so bald anf das erste

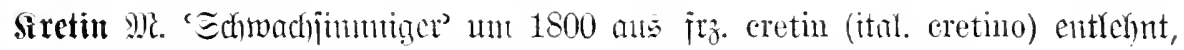

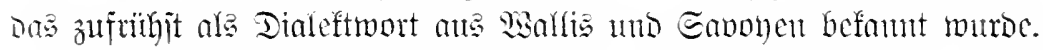

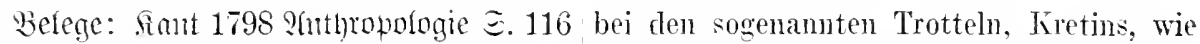
Die gänzliche Gemiithsschwäche, die pnt- sie sich in jedem Gebirgslande, namentlich weder selbst nieht zum thierischen Ge- im Schweizer-Thale Engadin häufig vorfinden.

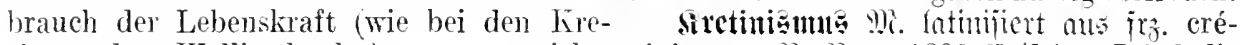

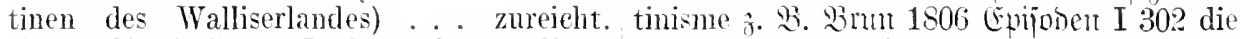
Brm 1806 Epijoben I 304 in Sitten, dieser guten Walliser geben sich mit dergleichen Cretins-Stadt - 310 denn der Name Cretins Geschäftigkeit nicht ab, zumal an diesem kümmt ron Chretiens her: da man sie für Orte, wo der Cretinismus so recht seiner:

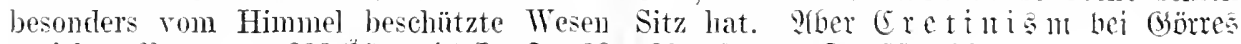

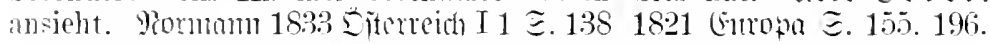

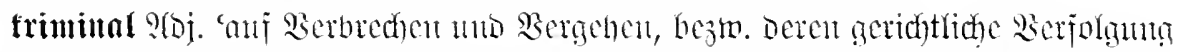

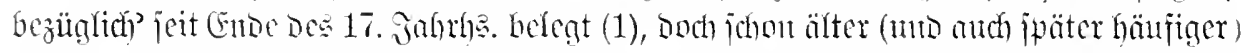

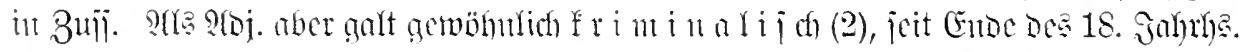

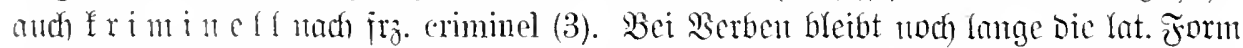

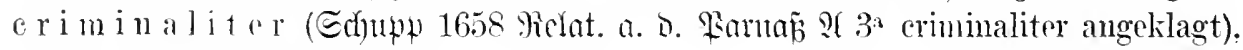
mic lat. criminaliter appeti.

Befene: 1. Scibniz 1699 sirieje (II 126) eriminellen Inkulpationen hüten. Echjiler wobey die 1)issimulation ganz unverant- 1796 givieje IV 459 Ieh bin anch sehr dafür, lich und eriminal sein wïrde.

2. Qffuertims 1603 Beiffinger $三 .85$ a begehen riel criminalisehe, präindicirliche vinnd bolihafftige ding. Etettler $162 \mathrm{~T}$ Ecthweizer= dnconif I $215^{1,}$, vil bioser rond eriminalischer stucken - II 584 a dafie sie criminaliseh wider denselbigen procedirten. Asagner 1776 simber= nürderin $气 .85$ ihnen nebst ihrer ganzen kriminaliselen l'nfühlbarkeit zum Trotz.

3. (Goethe 1796 S Sriefe XI 85 ber Ge= Domfe] dals wir bey aller Bitterkeit uns vor daR. wir niehts Criminelles berühren.

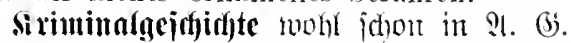

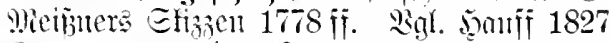
soutroberspresigt $\Xi .191$ wemn ihr ron Meißner etwas anderes gelesen als einige Kriminalgeschichten.

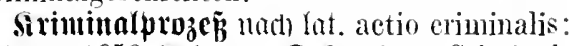
Edinup 1659 salender 22 a eimen Criminalprocess anzustellen.

Siriminalinafic noct fat, eansa criminalis: Dutad 1598 Entdinioum $\Xi .51$ weder in 
Bürgerlichen noch in Criminalstehen. Beiller Des 17. Jahrhs., gebutht bei Sädhtler 1709

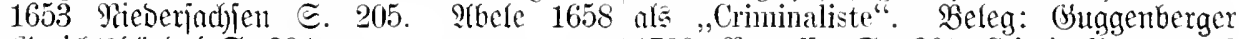
(Beridytšnändel 厄. 294. 1722 Prozeije ङ. 361 Criminalisten und

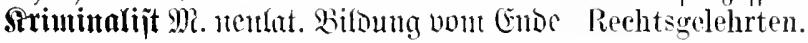

Srintine $\mathfrak{F}$. 'Reifrod in Fahre 1856 aug $\mathfrak{j} z$. crinoline entlehnt, mit Der Damals in Baris alfgefommeneu un bou $u$ ü übernommenen Mode.

Belege: 1856 Slluptrierte 3eitutg $\Subset .367^{\mathrm{c}}$ Themata: Sein und Scheinen, Tugend und Soll die Crinoline verbannt oder der Tanz GemuB, Lady Rotschilds Hochzeit, Lenaus aufgehoben werden? - ङ. 368 bie Crino- Gedichte, Krinoline, Unsterblichkeit u. dgl.

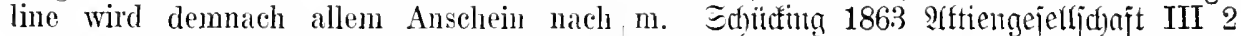
sich lïnger noch als Herrscherin behaupten. des heutigen leichtsimnigen Geschlechts der Fontane 1857 Briefe I 88 die ïblichen Crinolinen.

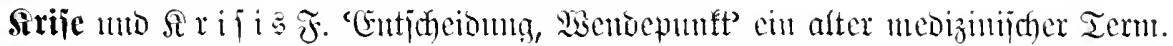

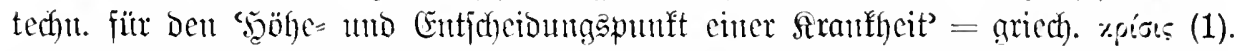

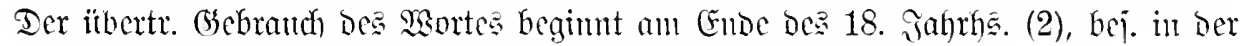

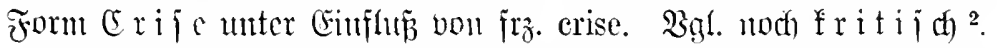

Beleage: 1 a. Frries 1519 Eniegel ber desorganisirt, nicht en Grise, nicht Claire2(rznei હ. 169d Von dem vrteilenden tag, voyante, nicht en Rapport: sie war bloh Crisis genant. Dieweil Du nun ghört hast im hitzigen Fieber.

von den febern Soltu wissen das etlich tag 2 a. 1782 Edhlöjers Etratsanjeigen I seind an welchen der artzt vrteilen mag 462 über diese Crise, in welche die innern $\mathrm{dz}$ heil oder mheil der Kranckheit. Vnd Zerrütungen diesen Stat versetzt haben. heißt das selbig vrteil Crisis. Sorid)t 1580 Görres 1800 Polit. Ed)riften I 81 er ver-

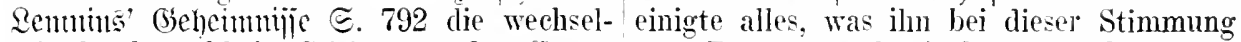
zeit der kranckheit, Crisis genandt. Ettner zum Retter aus der bedrängten Krise qua1715 jebamme 5.523 die Crises oder Aende- lificiren konnte.

rungs-Tage.

b. Eeltener Sitiis: Edhiller 1786

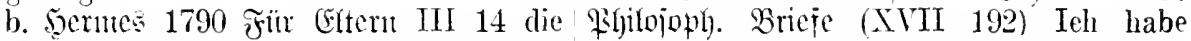
Crise der Krankheit des Bauinspectors. nichts gethan als eine Krisis beschleunigt, Sdjiller 1797 Siricfe V 197 da ich in der die solchen Seelen wie die Deinige früher Crise bin.

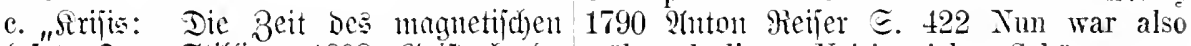

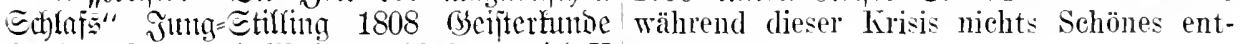
હ. 51. Daju vgl. Mäller 1789 (Entuterid) $Y$ :tanden.

164 Klärchen war nieht manipulirt, nicht

Sirijtall $\mathfrak{M}$. Frühe gelehrte (Entlehmutg ans lat. crystallus, bie jedoch itets die undentiche Bctonumg berwahrt hat; aho. krystálla, mbo. kristálle kristál. Dażu Die jüngeren $\mathfrak{A b l c i t u n g e n : ~}$

Striptallifation $\mathfrak{\mathfrak { Y }} .=\mathfrak{f r}_{\hat{\lambda}}$. cristallisation; Das im Wasser aufgelöbte . . Salz crr-

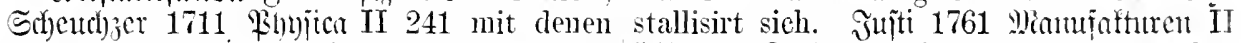
künstlichen erystallisationen oder anschie- 553 ber $3 u d f e r ~ m u \tilde{B}]$ auf die vorgedachtu Bungen der Salzen. Baaber 1786 şärmejtofi Art chrystallisiret werden.

$\widetilde{\Xi}$ כ4 bey der Krystallisation dieser unge-

2. litbertr. 'iich aus fleinten Ieilen żu= heuren Granitfelsen.

intumenicken beroer 1795 siefe (XVII

trijtarlijieren rejl. 3tı. $=\tilde{j} r_{\tilde{j}}$. cristal- 324) Karl V. machte in Italien Ordnung; es

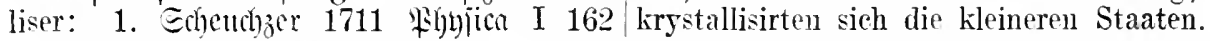

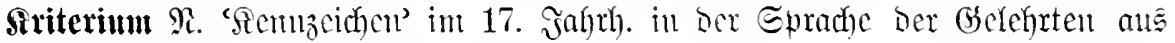
gleid)bes. gried). xperipos entlehnt uno latimijiert.

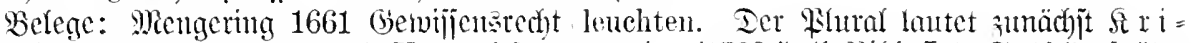

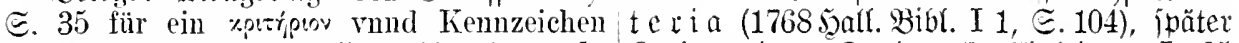

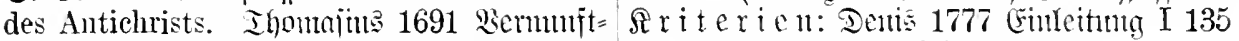
legre I 135 Aber wir müssen num auch das im Abgange andrer Kriterien.

andere criterium der Walrscheinlichkeit be- 


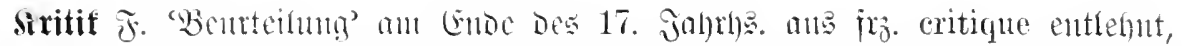

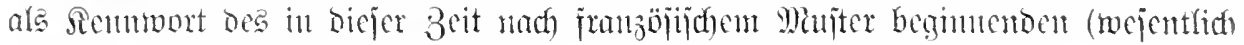

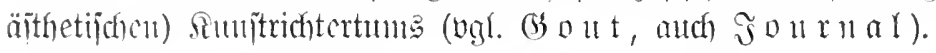

Befege: 1 a. Siscnific 1704 Gebidite Fehler zu verbessern, das was eine frente Sorr. こ. $\mathfrak{b} 3^{\text {b }}$ Man ist gäntzlich der Mei- Hand hinzugethan, von dem zu unterscheinung, dals was die Frantzïsche Schreib-Art den, was der Urheber selbst geschrieben, die zn der hentigen Vollkommenheit gebracht Lücken zu entdecken und anszufüllen, und hat, meistentheils daher rïhre, daß sobald unzälige andere philologische und grammanicht ein gutes Buch ans Licht kommt, daß tikalische Verbesserungen rorzmmehmen.

nicht denselben eine sogenannte Critique gleich auf den Ful, nachfolgen solte, worimen man die vom Verfasser begangene Fehler sittsamlich und mit aller Höflichkeit und Ehrerbietung anmerket (Silde= brand, Beitt. 3. D. Unterricht $\Xi$. 268).

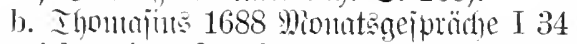
zwar ich meines Orts bin mit dieser Critique einig - 1701 si. tentidhe Edfriften $\Xi .61$ weil ich Ihn, olne Ihn zu kennen, ans dieser b]ossen Critique würdig achte - モ.63 Die andere Critiqve... hat mich recht erfeuet. J゙eino 1709 Qnnerfungen $\Xi .2$ unterwirfft sich der Critique aller Welt. Micuntes 1710 Entir. Roman $\Xi 1^{b}$ daß, ich nur gewisse Laster, nicht aber gewisse Personen mit meiner Critiqve anmoreiffen intendire. Wiente 1716 Eharlatancrie $\approx .6^{\text {b }}$ Tch lobe vielmehr selbst eine verminfftige Critiqve.

c. Rofr 1718 Etuntsfugheif $\odot .6^{\text {b }}$ keine Gelegenheit zu einiger Critic. Phifippi 1743 Rcimijhnicdefunit ङ. 217 Eine aufrichtige Critic. Meier 1746 efme $\Xi .23$ Sie wird das Gespräche und der Vormurf ['Begenen[tanto'] der Critick aller Modegesellschaften. Rejining 1760 Ritcraturbrieje (VIII 201) Bey ihm ist alle Critik umsonst.

d. bej. "Inter alfer Stritif", eigntl. cinte bielgebrande jombrijtenthraje; ngl. 1769 Joallipche Sibliothet III 162 Solche Piecen ist es erlaubt mit einem: Fs ist nuter aller Kritik wegmwerfen. Bömpiger "muter ber stritif" (VIII 14) dergleichen schlechte Uebersetzer sind unter der Critik. nocrocr 1765 sgerfe I 93 Ohe jam satis - alles muter der Kritik. 1768 stíg. D. Wibliotbet VII $1 \Xi .307$ dem sie ist winklich unter der Critik.

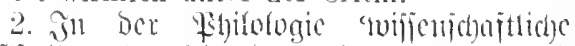

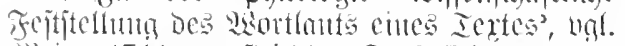
Wicior 1744 smuftridter e. 6 Hier war es also gantz natiorlich, dab nain durch die Critik nichts anders, als rine Wissenschaft, verstund, cine Schrift hlol. in Absicht auf die Worte, Redensarten, und den gantzen Tortrag zu beurtheilen, die ringuschlichenen

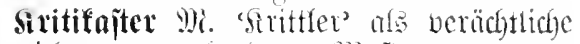
Bezeichunuty nach bent minjter bou tat. philosophaster 'Echeimprilojoply' gebirset (ogl.

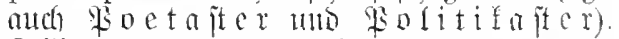
Seiïnn 1767 Iramatumie (X 182) Nur dab sich nicht jeder kleine Kritikaster für das Publikum halte. Sistomanu 1769 9htti= fritifus II 43 . Edjubart 1775 Egrmil ङ. 62. Eshinf 1778 Dinrionettentheater ङ. 194 .

Stritifer 97. Dafiur bis ins 19. Jathth.

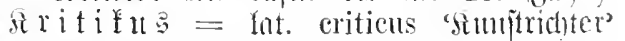
3. 2. Tentiel 1689 Lntemenugen 巨. 223. Rabenter 1759 Eatiren II 129. Qejiung 1760 Qitcritubrieje (VIII 201). Doeroer 1767 D. Riteratur (I 248). Grable 1827 Ehafe= inenromnute (I 437) Theater-Kritikus. 9ld

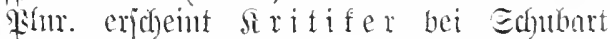
1774 (E)routit $\Xi .229$ die Zerfereyen der Kritikes:

fritija $)^{1}$ Q $(0 j$. 'mit stritif bermftaltet, $a b=$

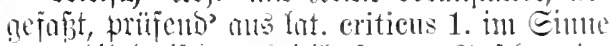

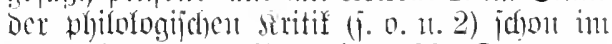
17. Jafnh. 3. \$. Frätorins 1662 Inemonto= Iogia I 83 Rübezahl achtet licine philologische Quackeley oder Critische Ausflïchte, da man einem garstigen Namen eine gute Etymologian auffbüuden will - 103 dals solche Critische Urtheilung keinen Grund habe. Edyottel 1663 semutiprache હ. 141 nach Anweisung solches Critischen Traumwesens.

2. jul 18. Johthl. befiebt zut siemzeid)=

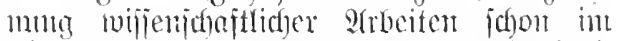

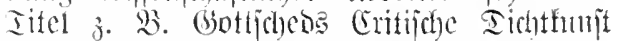
(1730), Soomers 5ijtorijhe and Eritijche

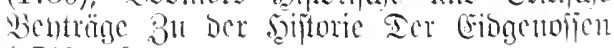
(1739) 1110.

3. Reijitit 1759 Riteriturbricje (VIII 32) nit eritischen Augen. Wlojer $1761 \mathrm{Beher}$ i= guntgen $\Subset .117$ in critischen Wortklaubereyen. Siciste 1764 Iennothen I $4^{\prime \prime}$ mit einem critischen Auge.

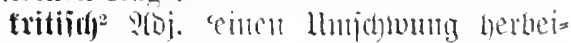

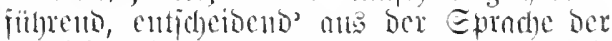

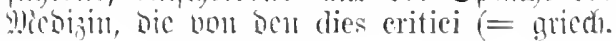




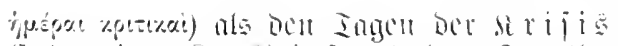

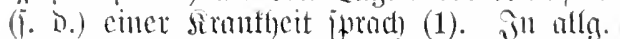

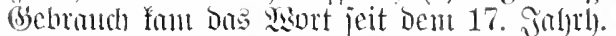
junächit mur bou cinent entîcheidenden' zeit= abjdnitt voer Beithumft (2a), Dam aber

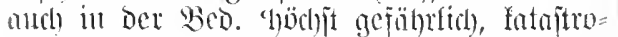
plol' (b). Siclege: 1. Jutes 1519 Enicget D. $9\left(r_{z} n e i=60^{2}\right.$ wie wol etlich tag seind (dies eretici [!] genant) als der fierd vold der sibend die hinein weissasen heil oder schaden. Riegnot 1539 snocx juntuti: こ. 7 die täg, an welchen das votheyl über die krancklıeyt fillen wirt (dies eretici [!] genant). Seriphach 1732 sur $\Xi .54$ circa dies eriticos, oder un die Zeit, da sich die Krankheit brechen sollte.

2 a. Ediffung 1668 stathol. Eotengeriait こ. 31 Weilen vnser vnstrafflicher Statthalter nur anff 54. gelanget, ist sein letztes Jahr jhm nicht Crittisch gewesen. Reisfe 1764 Demoitbenes I 109 zu einer solchen eritischen Zeit. Wiojer 1766 Peliquien E. 48 just in dem eritischen Augenblick. Gocthe 1774 sierther (XIX 182) in dem kritischen Momente.

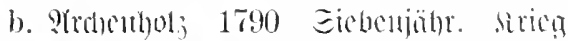

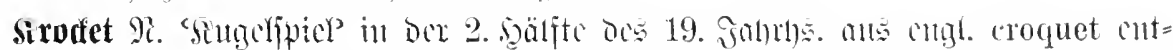

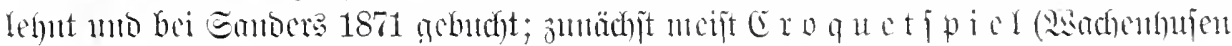

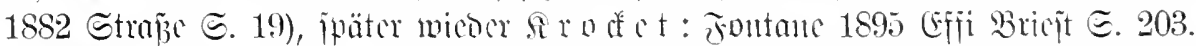

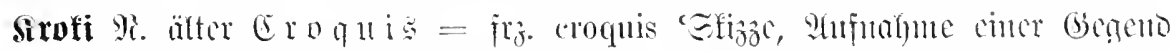

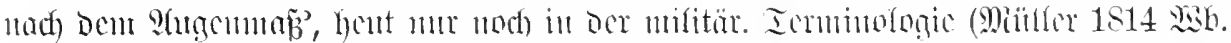

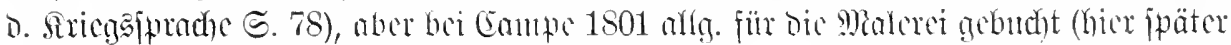

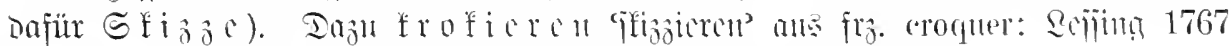
Dramatumẹic (IX 267) einige allzu küln croquirte Pinselstriche.

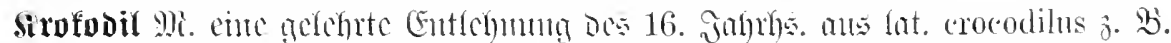

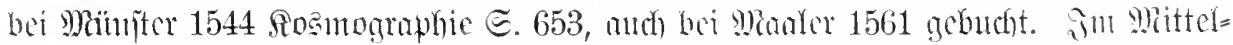

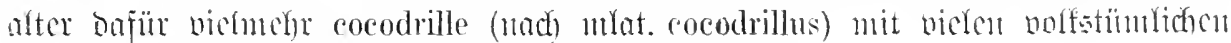

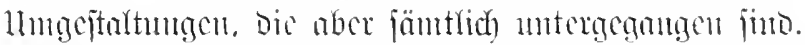

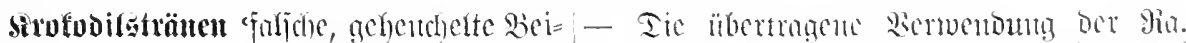

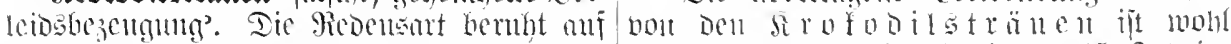

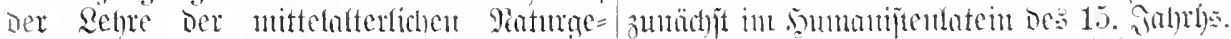

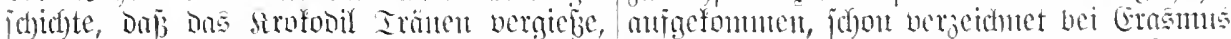

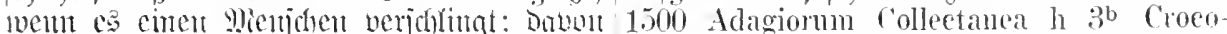

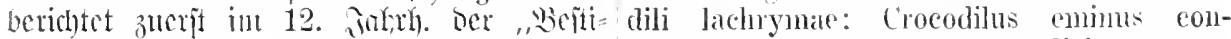

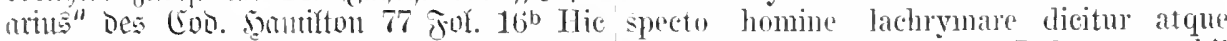
aum invenit honinem si poterit emu rineere, enden mox derorat. Inde proverbii comedit. post et semper plorat enm; Domu Crocodili lachryme: in eos qui se graviter

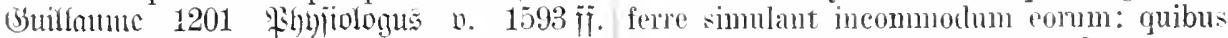

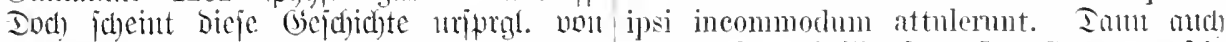
Ben sarphen ju gelten

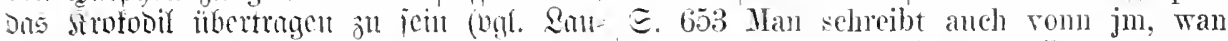

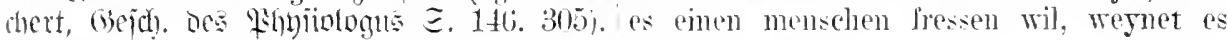


rorhin, das jn die trähern auls den angen krokodilsträhnen genemnet. Scenijd 1616

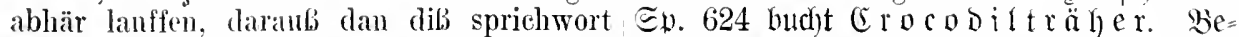

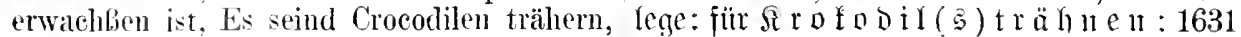

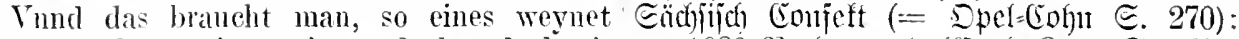
oder sich tranrig erzeigt rnd ghat doch nit ea. 1680 Bntbermorb (Engl. fom. S. 170):

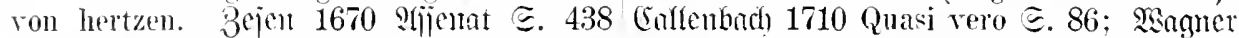
so pfleget er [oer firofobil] zu reinen, wie 1776 Sintormörberin $\Xi .34$. Benzel=હternau, ein Hensch, die menschen, wie man sagt, Ier fleine Bantherer (füridner હ. 470). anzulokken. damit er sie fressen möge. Da-

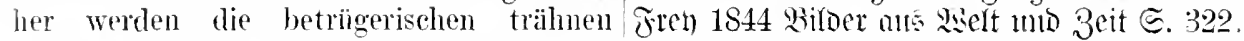

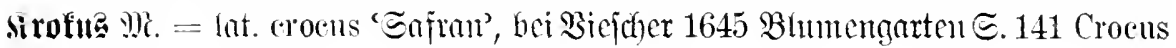
autummalis.

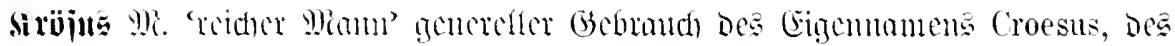

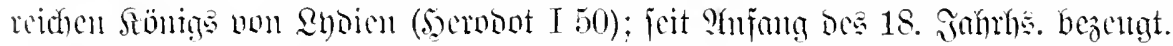

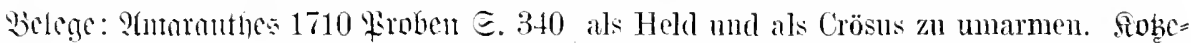

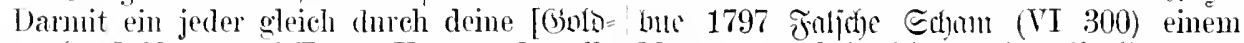
macher $=$ ] Kunst auf Erden Lnd sonder alle Mamme, der Kein Krösus ist. Hëtuffer 1831 Müh ein Croesus könnte werden. 9 trefen= Brieje III 123 wie sehr die englischen hod 178 G Englum TII 134 die Freude. ihn Crösusse sie verdorben haben.

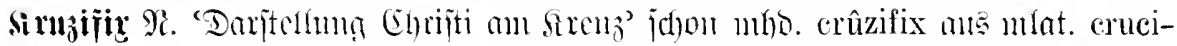

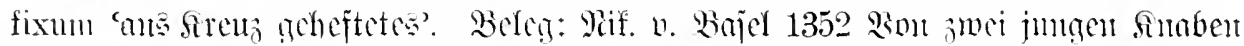
モ. 93 wie das crncifix sich herabe neigende was ( excr).

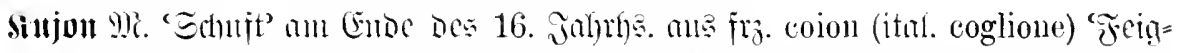

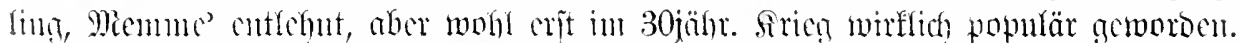

belege: 1567 3immer. Chronif II $531-$ III 526 sehad ist, dats ein sollicher eiferender, ungesehickter cojon ein solehs adentichs

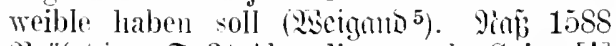
Rrö́thtoium @. 31 Aber dieser grobe Cuian [!] reracht ommem honam et necessariam distinctionem, spot dels Glanbens (ieignto ${ }^{4}$ ).

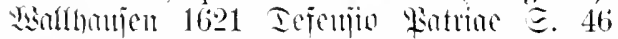
welches dam ein lo:er, verzagter schhimmer Grijon sein mub. Edfill 1644 Qünrenfrom こ. 114 wie jone. Jungfraw gethan, die gesagt, der Herr ist rin braffer Cuirom, vermeinet, darmit gar wolgeredt zul haben.

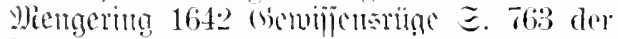
hält seine Bawren vand Zuhörer fïr lanter Cujonen vith Ilmudes-Buben. Sommenberg

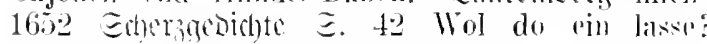

Schlingel wals, de is mu rin Cojom.

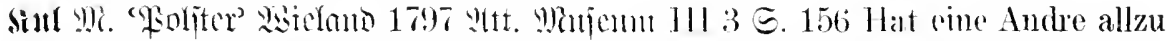
schmale Jlïften. wer füttert sie mit einem Cul. sänfigex Cul de Par is (ju fro.

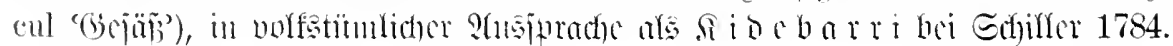

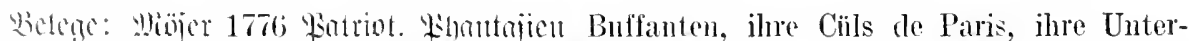

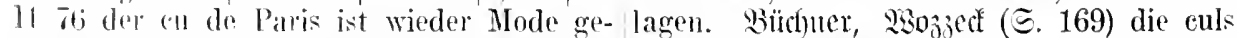
worden. Edhitter 1784 Sinbule (TV 413) de Paris der Maidchenpension. Edherr 1870

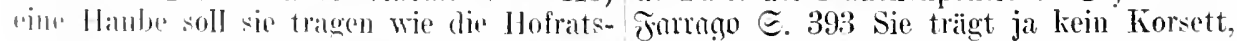
töchter. mo cinn Kidebarri, wie sies kinen Cnl de Paris, keinen Chignon.

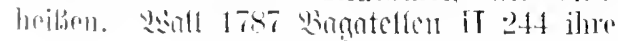




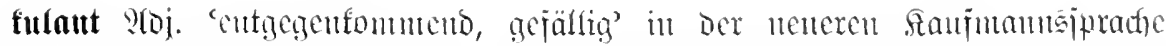

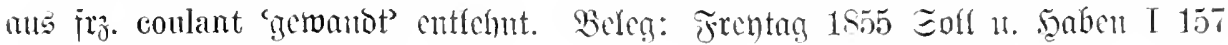
sein Benehmen ist coulant.

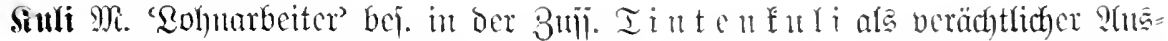

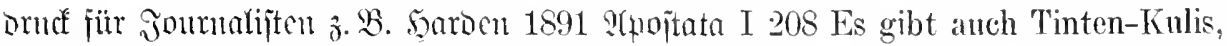
und jeder Kuli ist seines Erlasses werth (Eabenondì). Dutelle: ino. kîli, ruūli

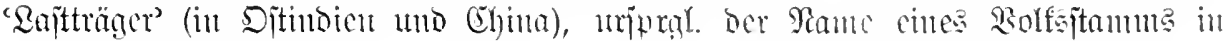
(Giulojdrat ((SHuzcrat).

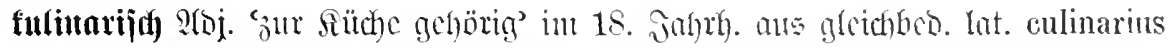

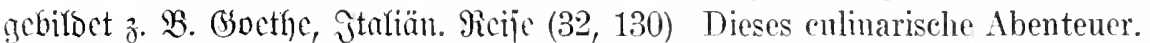

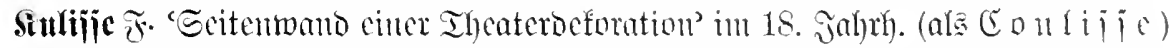

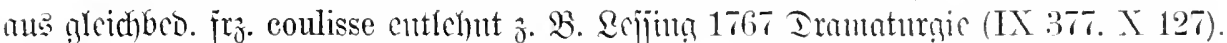
Dref̈ler 1777 Iheateridule ๔. 123. 150.

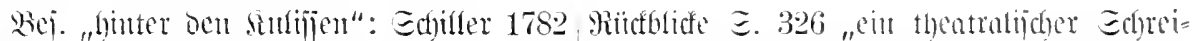
Incater (XVII 151) wem nicht] eurer bidfans, ber bic fullijen und Sampen mit tragischen Kunst aus dem Stegreif hinter fortreibt"). Sifter nou outrierten Roulen. den Kunlissen ein demütigentes Opfer ge- Backe: 1. Sönter 1813 Bricje (气. 666) bracht wird. 5offmam 1814 Bergang Drauben thrfte ich nur Conlissenreiber (I 123). - Soünfia auch ïbcrtr. o. $\mathfrak{B}$. Ihüm= schreiben, in der Stadt liegt das komische mel 1791 Reije (II 3) den Blick, den hinter und tragische Feld in gleither Freilheit ror die Coulisse the Lüsternheit mich werfen mir. Semoro 1837 ?qquarelte III 327 Pioflen] lieb. Mary 1846 Junces Deutidntano $\Xi .6$ woran ihr so gut die Starle Eurer Lungen nachdem ich einen Blick hinter die Con- erproben könntet, als an Enern beliebtesten lissen ter Litteratur gethan habe.

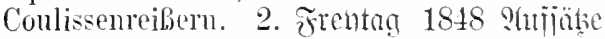

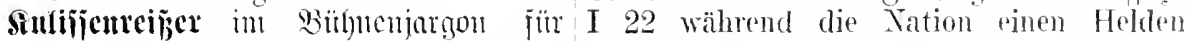
einen in Icflantation mo Géfifulation über = nnd CoulissenreiBer wïnsehte.

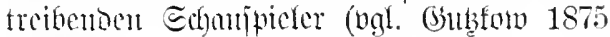

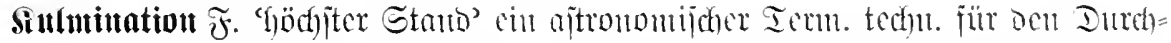

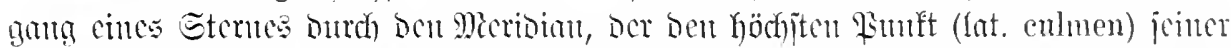

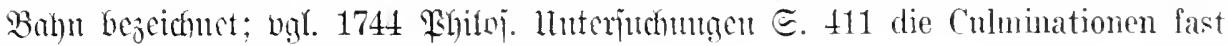
aller Sterne. Zuefle: irz. enlmination.

Stuluinationşunt bäıĭg übertr. ge=

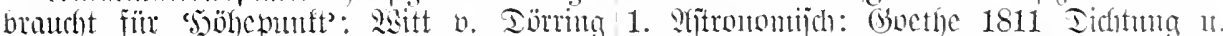

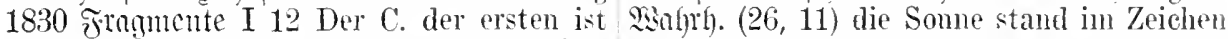
die Wartburgsfeier. Qiuffer 1831 Brieje der Jungfrau und endninirte für den Tag. IV 212 der C. der Abtes. Glasbremter 1836 2. llbertr.: Serocr 1793 Briefe (XVIT Silber a. Ssion I 65 wann seine Zudring- 113) der einzelne Nensch wäehst, culminirt lichkeit den C. erreicht. und geht rückwärts.

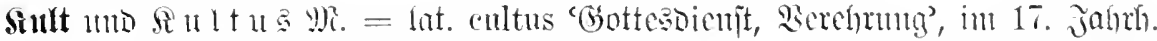

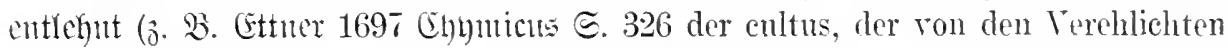

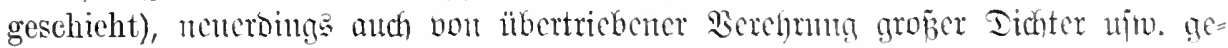

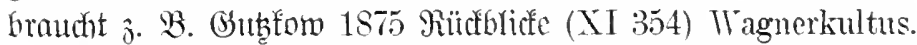

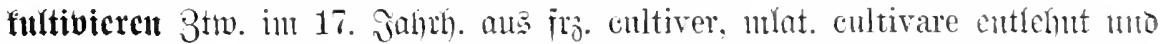

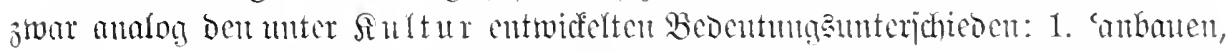

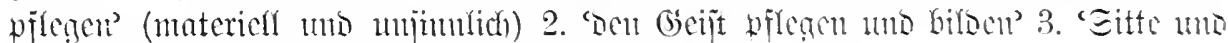

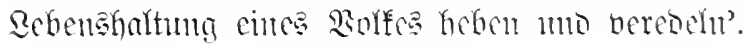


Butege: 1 a. 1689 Folit, Fltegrumenel I 38 Da nicht der hundertste vermag, ihme mur . . . . ein Hüttlein aufzurichten, geschweige dann zu Cultivirung der Gründe mnd Landes, Pferde, Züge, Viehe, Geschirr nud Besammug . . . zil verschaffen. Sufti 1758 Wiantfaftumen I 17 zu Cultivinm des Bollens - 1769 Ergeng. o. \$lenjdent હ. 144 rine Nonarchie, welche einen wohl cultivirten Boden hat. Buun 1799 Ed(hriften I 296 reich kultivirte Hügel.

b. Jablousfi 1699 an Reibui, (II 99) die neu angelegte Correspondenz bestens zu cultiviren und zu unterhalten. Borth

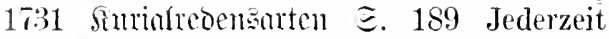
vertrauliche Correspondentz und gute Harmonie beständig zu cultiviren. 1765 ?(llg. В. Sibliothef I 1 Ð. 21 jede Sprache, die cultivirt ist, fällt anders in das Gehör. Wiertforter 1794 Gntwumi ङ. 14 Gegrenstände [Des Wijiens], die man einst so sehr schätzte und cultivirte. Fiudfler 1835 Eemilaijo II 11 seine lehrreiche und ehrenvolle Bekanntschaft in Zukunft reichlicher zu cultiviren.

2. Reijing 1768 Briefe (XVII 269) Studiere fleiBig Noral, lerne Dich gnt und richtig ansdrïcken und kultivire Deinen Charakter. Savoter 1776 Fragutente II 130 überans cultivirt, erlenchtet, roll ächter Wissenschaft. Echiller 1792 sierfe (Göbofe) IX 401 bis unser I'ublikum kultivirt genug sein wird.

3. Widgaelis 1768 räpmmentent I 89 unter den cultivirtesten Völkern. Flögel 1769 sarlijache sibl. III 211 in den wilden veler wenig cultivierten Nationen.

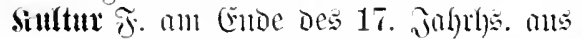
lat. cultura "Weboumig, Dejtethung, \$iflegi" entletnt (1) und zwar jowoh! (a) in materi= ellen Eimne (lambinitifinatlicher Shbou), als and) (b) unimutid) (bej. Fiflege Der Eprodbc,

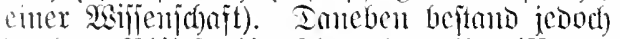

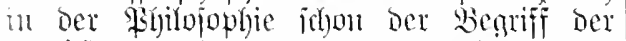

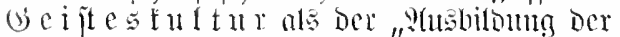
miterleftuellen mo mornlij(ben Fäljigfeiten

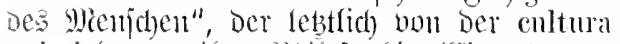
animi ber antifen 壮hilojophic (Cicero) ans=

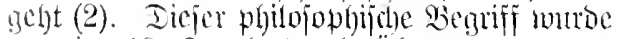
mun im 18. Jabrily. Dutch llbertragmen von

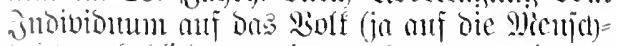
keit) erfyeblich erweitert (3) mo crfongte

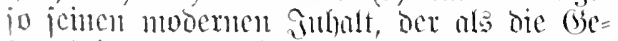
jantheit ber "jozialen sebensformen mo - prozefle, atrbeitsmittel mo =rejultate, geijti= gen wic materiellen" Defmiert wiro (sern=

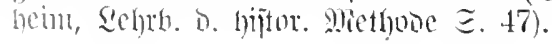

Belege: 1 a. Seib 1708 Enite tirobe s. 40 warumb man sich in Teutschland so wenig umb die Cultur der Seide bekümmert. ¿n アludye 1771 Frl. v. Etemheim 厄. 97 für die Anpflanzung und Cultur guter Frïchte. Möjer 1776 Patriot. Pyastajien II 281 den Bau verschiedener Futterkräuter, die Cultur der Maulbeerbäume. Frentag 1855 Zoll u. 5oben I 341 Rïbenkultur.

b. Sievie 1692 Ged, v. ฉ. Berjen II 24 so waren sie doch um die cultur der Sprache weng bekümmert. Jablonsfi $1700^{\circ}$ Brieje m Reibuiz (II 151) daß man auch anf die Cultur der dentschen Sprache bey dieser Fundation gedencken möchte. Bertrnn 1728 Cinteitung $\Xi$. 74 bey hentiger Cultur der Gelehrsamkeit - E. 179 die cultur der schönen Wissenschaften.

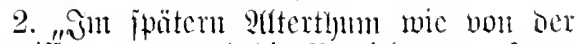
Benaifjance an mard bie bezeidunung cultura amimi of́t veriband, mobei bis ist? vorige Jahrbumbert Das Sildhiche weit lebhafter empfinden surde als in der Gegentiont; eine Einfïgung $D C$ s Begriffes in ein philn= joprifiches Enftem veriuchte aber erjt Baco [13. Jahrh.]" Endfen, Gmanbegriffe D. Segenwart E. 184; Deij. Bejh. D. philoj. Ierminologie હ. S4. \$igl. Eulzer 1775 Iheorie II $13^{a}$ für die allgemeine Cultur

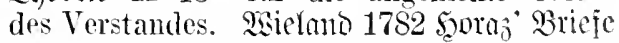
II 16 alie Schönheit und feine Cultur seines Geistes. berder 1791 joeen IV 317 Cultur der Vermunt - 1787 joeen III 82 (INيb.) - 1793 Briefe (XVII 26) Geistescultur.

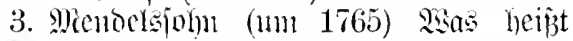
aufflären (II 246) Die Worte Aufläärung, Cultur, Bildung sind in unserer Sprache noch nene Ankömmlinge. Sie gehören vor der Hand blob zur Büchersprache. Der gemeine Haufe rersteht sie kaum - Indessen hat der Sprachgebranch, der zwischen diesen gleichbedeutenden Wörtern einen Untersehied angeben zu wollen seheint, noch nicht Zeit gehabt, die Grenzen derselben festzusetzen. Bildung, Cultur nud Aufkliarung sind Modificationen des geselligen Lebens, Wirkungen des Fleißes und der Bentïhmugen der Menschen, ihren geselligen Zustand zu verbessern - (247) Cultur im Aeuberlichen heibt P'olitur - Aufkïïrung verhiilt sich zur Cultur, wie überhalupt Theorie zur Praxis - Man kam sagen: die Nürnberger laben melvr Cultur, die Berliner mehr Aufklärung - die Griechen latten beides, Cultur und Auflsairung (vgl. Goloptein, Feptidnift $\tilde{f}$ Eshate $\Xi$. 61). 
Berder 1784 goeen I 20ur. E. VI Welches Volk der Erde ists, das nicht einige Cultur habe? und wie sehr käme der Plan der Vorsehmng zu kurz, wemm zu dem, was Wir Cultur nennen, und oft nur verfeinte Schwachheit nemmen sollten, jedes Individum des Menschengeschlechts geschaffen wäre 1787 ebo. III 221 Die Cultur eines Volks ist die Blüthe seines Daseyus, mit weleher es sich zwar angenehm, aber hinfällig offenbaret.

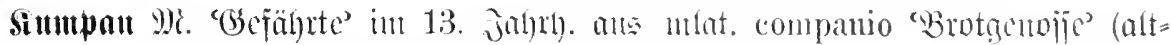

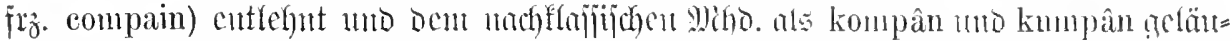

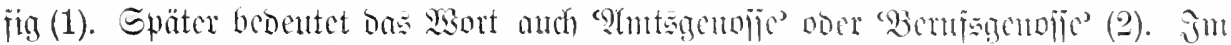

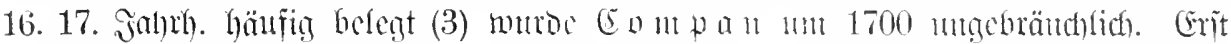

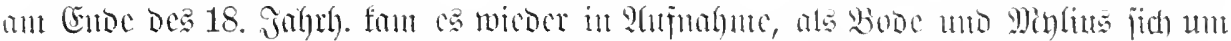

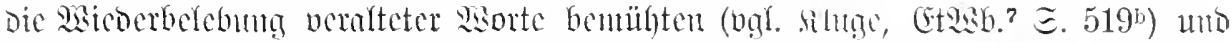

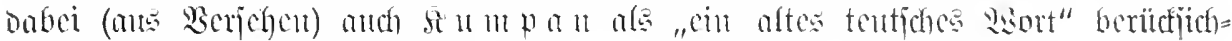
tig̣ten (4).

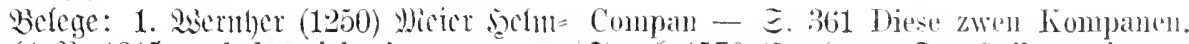

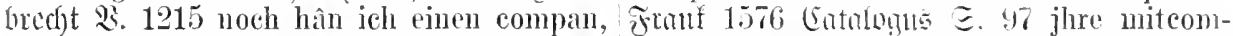
daz nie knappe gewan einen namen also panen. ircucus 1578 irognofiticon $1^{\mathrm{b}}$

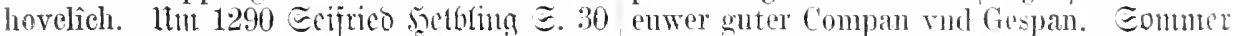

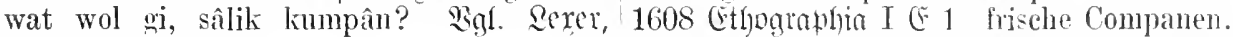
Medo. …‥ I 1671.

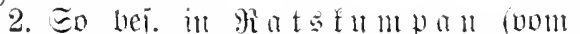

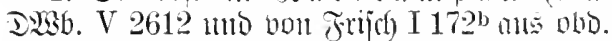
und mos. Dutelfen belegt), bas jojledythin riix 'gintswerjon' iteht, eintl. wohl aber 'Mat弓follege' bedentet. Merfmüroin braudst Die sambuerferjpradie unjer Wort in ber

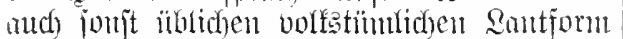

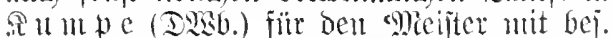

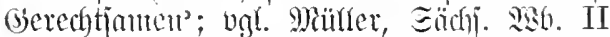
80b. Dazu Beier 1685 Der Mieinter $\Xi .116$ Nim. differunt Magisterium et sodalitium, sic, ut per Illud ad Hoc fit ingressus: Nemo in Collegium adsumitur, quin Magister fiat; aliud est, esse Magistrum aliud contribulem, ein sompe - E. 124 quoniam aliud est, esse Magistrum, alind sodalem, Wieijter mo Comte. Illud ad personae statum et qualitatem, hoc ad jura realia pertinet.

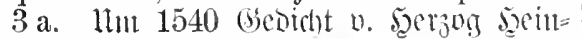
ridy (Eunde, Eatiren I 48) Wie auch fleibig haben gethan Im Kammergericht seine compan. Sindener 1558 Sukituri If $^{\mathrm{b}}$ Es war ein leyden guter Compan. Fijomt 1575 Gargnutun $\underset{E}{E} .132$ Dieselben gnten

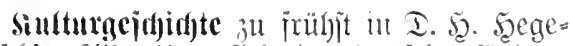

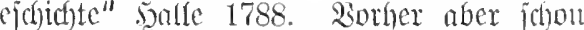

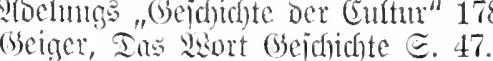

sulturfampi politijhes Echlugwort jür

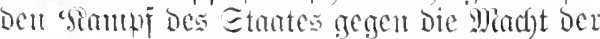
fatholijchen sirche”, Das un 1873 (Gej. Durch (uad) Bübthum 3citichr. Firr Iheulogie IV 176.

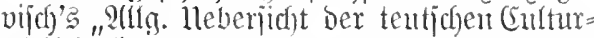
Sirchotw) allg. geläntia muroe. Bufrühit Rollenhagen 1614 Qmuntes $2\left(2^{\mathrm{b}}\right.$ en Bawrcompan. Wicngoring 1642 betwijicusrïge モ. 497 der beste Compan - こ. 897 seinem Gefremulen rind quten Companem. (orm= Whits 1663 somribil. $\Xi .65$ Ach Jusuph du lieber Mam, bist mein Compan. Wrätorin 1666 Onthroposcuns I 332 solehe Renter oder Compans. 1677 Minchinuell. sonfis: polus ๔. 133 Companen.

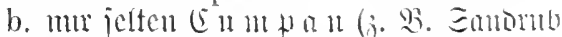
1618 Idlitioc $\bigodot .84$ ein seltsamer Cumpan). Das cigtl. bie mod. Santrorm gewejen all jein jeheint: val. Die Selege Des I 2 sb. II 631; 1498 Reinfe De 203 ㄱ. 61.3124 . 4205. 6663.

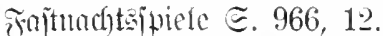

4. Bone 1772 somming simfer I 108 mein alter Seekumpan - 1786 Iom gonts II 115 für'n vel wackeren Kunıan $1 t$. 0 .

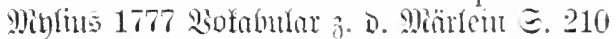
Kumpan, Gefährte. Ein altes teutsches Wort, worans die Franzosen ihr Compagnon gemacht haben. Hr. Bode bedient sich dessen. Bgh. Whert Miaicr, Ins (bifoifar Des 政lius (1909) I 294 ĩ.

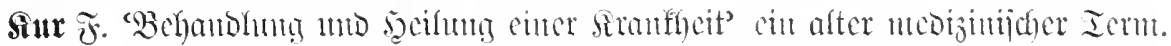

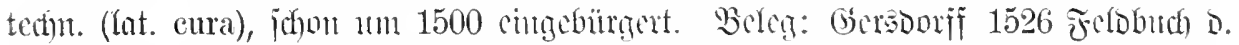
Wambarzmei $\Xi .61^{a}$ wie man den haissen prand erkennen soll. vund dargegen sein

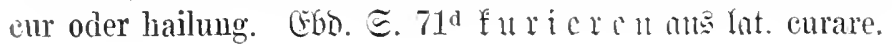




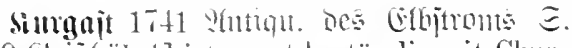
239 Gerishitbel] ist sonst beständig mit Churgästen angefüllet.

Simurt "Shbent' Echiicting 1868 : Qtrien= gejellighaft II 5 .

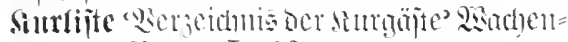
minen 1864 gotnge I 103.

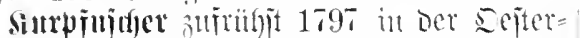
reidiijonen Seroromm Bas Einhalten be:

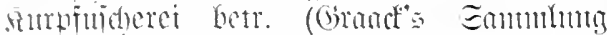
E.112) dabs sie in imem Burgfrieden einen K. geduldet haben - bey Entdeckmng eines Kurpfuschers oder Hansierers mit Arzneyen.

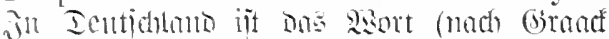

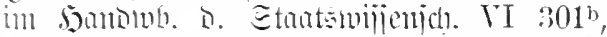

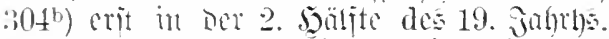
befunt gemorocu, Bufiti meipt cinfaches Piuscher (sit bei boifmam 1782 Som

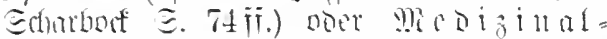

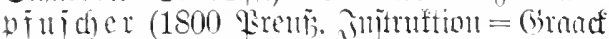
こ.69), Mesifajtar u.

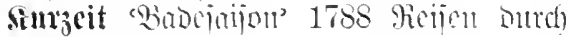
Ientidilano E. 194.

Babefur Etoppe 1735 Lamuj E. 151.

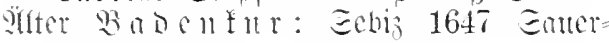

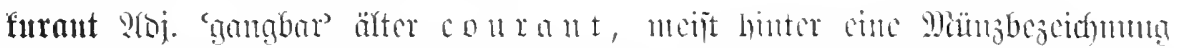

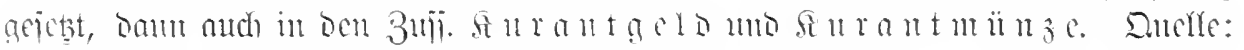

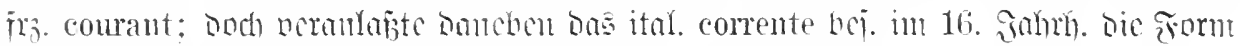

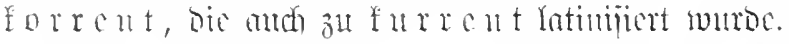

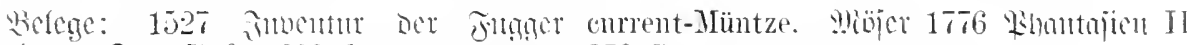
(Ed)imer @. 115) fur 600 cluc. corrente - 378 Currentmïnze.

duc. 610 eurrenti. Dieber 1558 . sambelbuch こ. 50: rmb Dueaten oder fl. current. Francte 1702 sistipultions II 10 nebst zehen Thalern currant. Fiferijter 1730 sere b. 2nBiu I 9 einen Bentel mit 50. Rthl. conrant.

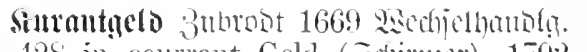
E. 428 in courrant Geld (Edituter). 1702 Exurop. Fomn E. 1028 r'ourant Geld. Iafiur Cotreutacto Echurs 1672 Minterialien

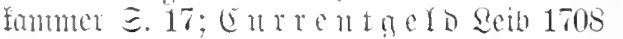

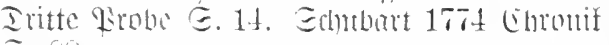
ङ. 88 .

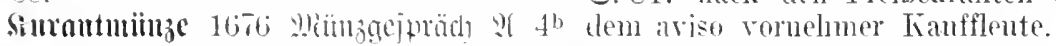

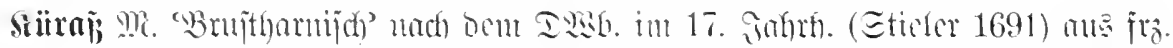

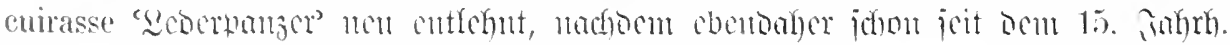

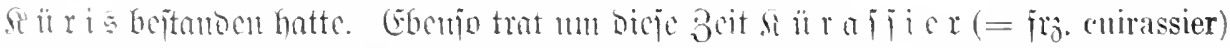
an Dic Etclle oce

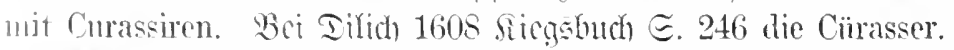

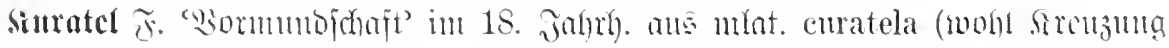

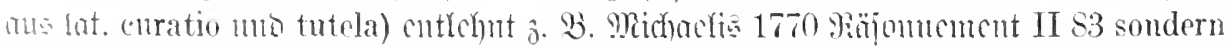
es [Bos Sollegitum] mïßte unter riner umbittelbaren Infsicht der Curatel stehen. 


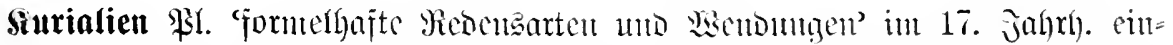

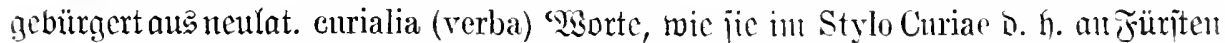

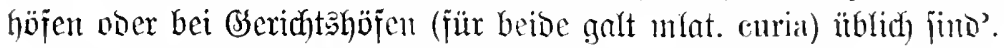

Belege: Ettner 1697 (E)hnnicus こ. כ̆41 Glïekwünschung. benebenst den gewöhneinen des Hoffs und andern curialien er- lichen Curialien geschehen. Wigl. aud Bofts

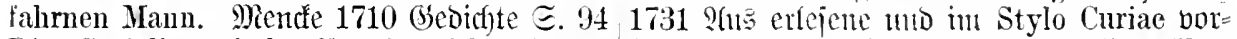

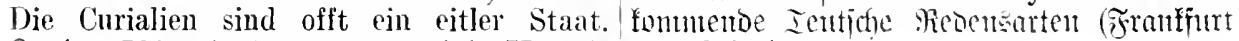

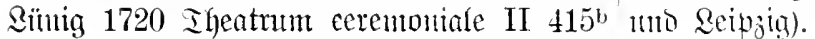

Als nun die beyderseits Empfängnib und

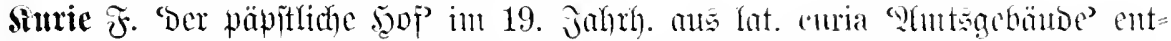

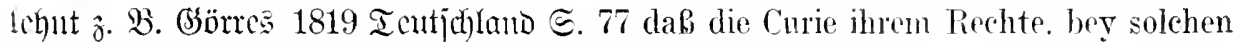
Gerichten einen Delegirten zn haben, nicht vergeben werde.

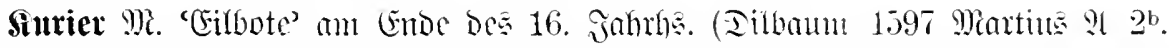

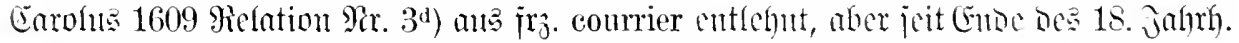

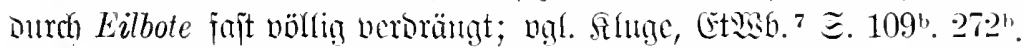

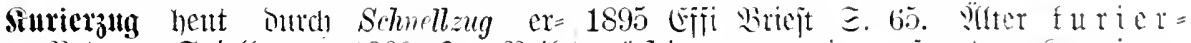

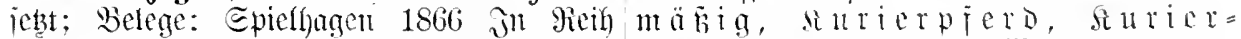

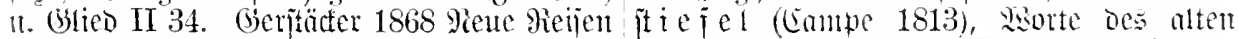

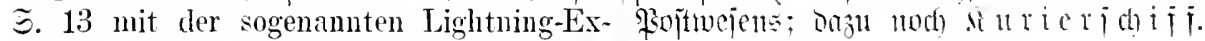
press - dem Blitz-Courierzug. Fontane

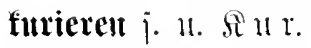

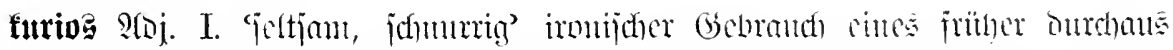

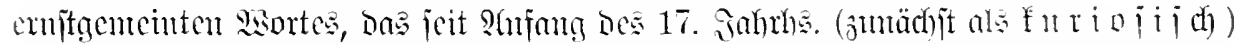

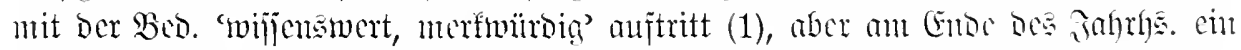

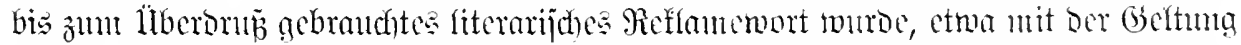

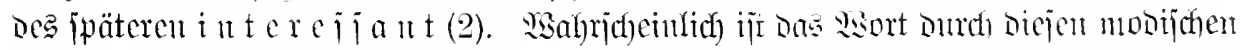

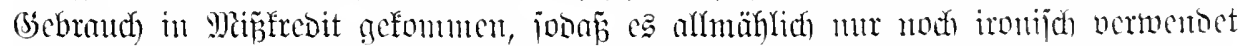

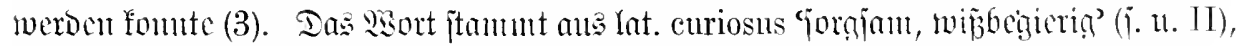

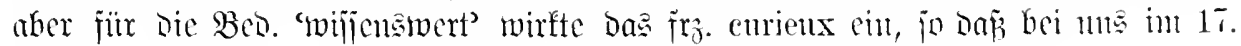

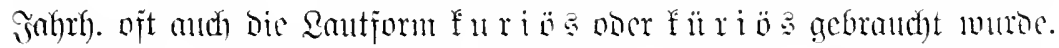

Belege: 1 a. Furttenbach 1627 jtine= Weißheit abgehandelt wird: Lnd wemn rarinu ปtufiae $\Xi .86$ mancherley Curiosische eine Disputation nebst dem Lateinischen Sachen - E. 189 sehr Curiosische vnd alte anch einen Teutschen Titel hat, gehet sie Rüstungell.

b. Eecfentiorif 1665 Fiirjtemitant II 12 Die Beschreibung eines Fürstenthumbs .... ist Ber o... Wort curios sonsten darimen enthalten curios, als nothwendig. Birfen 166911 11nijes eler lob werden. als wenn dieses Wort

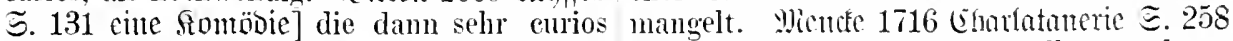
und ammutig zu sehen ware. Rebenmalst Du erinuerst Dich, noch selbst, wehrter 1680 Ienjels Qift III 26 Von welchen Schau- Mnsen-Freund, der Zeit, in weleher alle spilen ... . ist Curios die Ursachen zu er- Büeher Curieuse heissen musten. Bahlreidhe

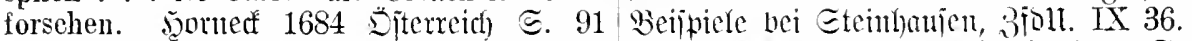

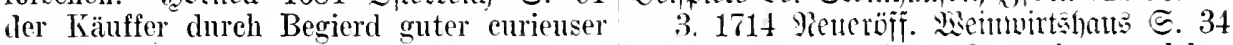
Waaren.

2. Thomaịus 1691 Bermuitlehre II 243 fallet mir ein curioser Casus bey, welcher sich unlängst zugetragen. Sobebtie 1810 Ein Politischer Maul-Affe oder ein Politischer 3erītrente (24, 118) Hm! hin! Curios! Fenermänerkehrer wird viel höher geachtet Seinte 1830 atolien (III 298) Eine kuriose

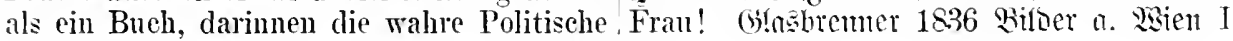


60 Der superlativ alles Interessanten heilit brim Wiener": .Curios".

II. Iic Sien. 'nenugierig' int 19. Jannfh.

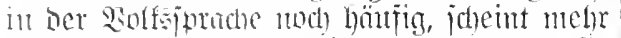

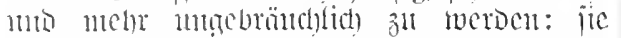
Fliefst mis ber Gmmobed. bon lat. curiosus

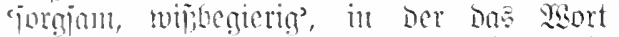

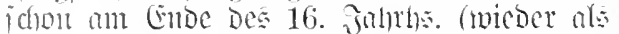

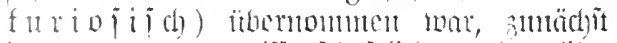

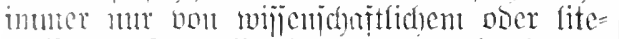
mrijd)en snterejie (1), was Durdh Die an

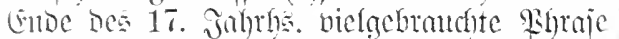
nom furinjen acjer hejtütiat wotr.

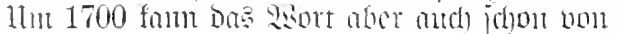
Der nicberen sifibegierse, Der Nentaier ge= brantht werben (2).

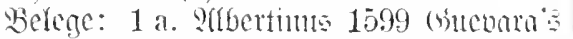
Eenojdreiben III 203b Til curiosische rund sorgfeltige Lent, welehe die l'assion lesen - 1601 beij. Gerijt. Epregel こ. 353 bil. dato hab ich lieinen emriosisclsen rnd sorgfältigen Münch gesehen. daraub nicht hernacher were worden ein proprietarins.

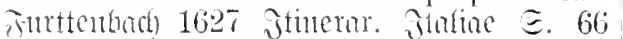
sonderbare Antiquiteten, so der Curiosische mit belieben anschanen wird.

b. Bome $16+1$ Cominttatio \& $3^{\text {b Die }}$ heidnischen Philosophi seind in dieser materia dermassen curieux gewesen. Iomm=

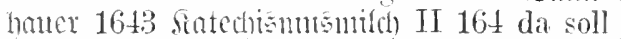
man auch nicht allzu curios forschen und

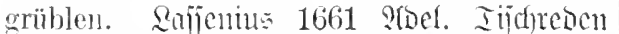
こ. 167 Dic Holländer sind hierinn mächtig curios. Riätorits 1667 ?hithropudemen III 79 curiosen Cremüthern. Sirten 1669 lumijes こ. 135 ein curioses Ang. Reibuiz 1670 Eecuritas mbl. (I 227) pinen curiensen Rej-endesl.

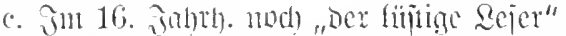

(órimmelshmuen 1669 Eimplic. E. $29 \mathrm{dem}$ curiosen Leser, der auch offt das geringste wissen will - 1670 Senjuger Jojeph [Iitel]. Friberici 1684 (Eryptographia $\stackrel{\subseteq}{\subseteq}$. $3^{b}$ Du aber. curieuser Leser. 9geitere? bei Etembanjen,

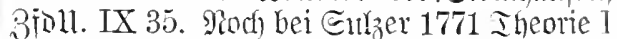
VII fiir den curiosen Liebhaber oder Dilettante.

2. 1685 fleidorajie €. 220 Ich war curieus, solches mit anzuschauen. 经近e 1697

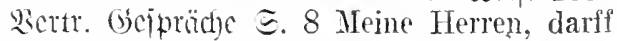
ich so curieus seyn, und fragen ... Ettner 1697 Conmicus 巳. 321 Wann ich nicht eine faute beginge und mirs rerarget würde. möchte ich wohl curiens sern. zu fragen ... Mande 1710 Huterredung E. 280 So sind wir curiös, so offt das Posthorn klingt. 9nitilfer 1784 Eiegfrico હ. 64 Bin doch liurjo: zu wissen, was da so gröhlet. Jiffout 1799 somet (IV 254) Thas bin ich doch kurios zul wissent.

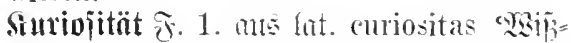

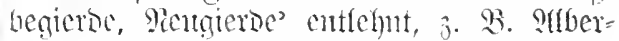
time 1599 Ginenara's sendidneiben III $169^{\mathrm{b}}$ Die curiositet rnd rnmessige Begird. frembde Ding zusehen rnd zuwissen - 1603 Iefi. Beiffiurzer હ. 99: ein wolersparte curiositet. fürwitzirkejt rnd rubescheidenheit.

2. "Eeltianteit; jeltome, interejomte Endéc aus fro. curiosité: Frmucisci 1663 Iürfengefahr (a) $3^{2}$ der Ergetzmngen, als Jagens, Ballenspiels, der Balleten oder anderer Tirzweil und Kuriositäten. Sieife 1673 Erammen $\Xi .167$ daf mich keine curiositit so seln afficirt, als wenn ich solche Thiere zahm und gewohnet sehe. Thounius 1691 semuntflehre II 243 wenn nur der Titel [eines Sinchen] von Curiositäten gedencket.

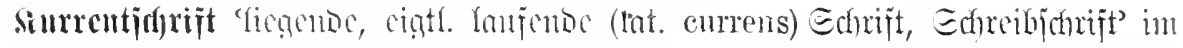

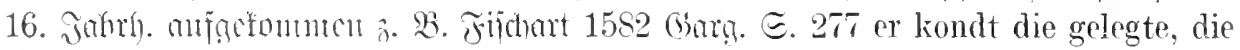

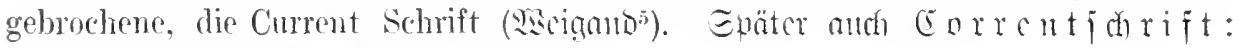
Etople 1735 Parnai; ङ. 141.

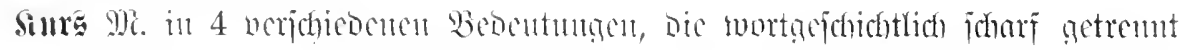
merben mijijen.

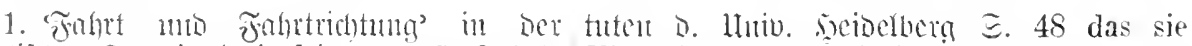

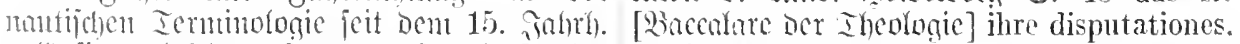

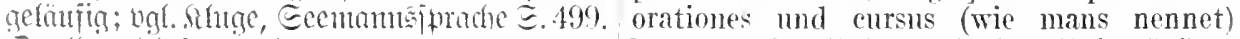
Ditelle: minl koers, lat. cursus.

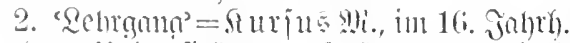

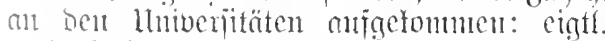

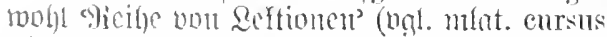

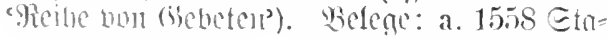
halten. 1600 llrfumoculuch D. lluiv. Secidel= berọ I 342 dab der gantze cursus imnerhalb vier iahren zu end gebracht werden kan.

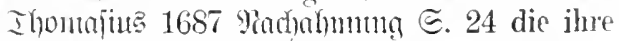
cursus auff denen Academien absolviret. 
b. 1786 joibelb. Etatuten E. 328 Von den Lehr-('ursen. Benzel=@teman 1805 Gejpräche I 53 der Kurs war schon angefangen - 1806 cbs. II 78 den ganzen statistischen Kurs. Ban 1806 Eviljoben I 194 Pictet giebt den Genfer Franen rincen Cours der Experimentalphysik.

3. "Siertitand, Iagespreis it ber Santí= mantsjprache bes 17. Jahrh. als ital. corso,

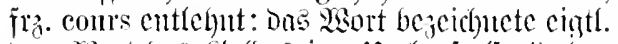

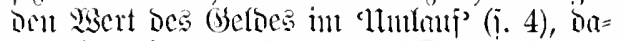
her bej. in Taljed = ober Miedjelverfehr. Sial. Epreng 1662 wechielpraftif ङ. 60 dab er ulas verleyhende Geld mach den corso jenes oder jenes Orths schliessen val bezahlen wolle. E(butts 1662 Sitdhalten $\Xi .41$ Wam aber an einem oder anderen Ort der Cours üher den pari, als gibt man in Wechselis etwas drüber. Eitner 1697 Iottor $\Xi .881$ wie der Curs hier oder da steige und falle. Whuarmithes 1710 Proben $\Xi$. 354 was ist der Cours jetzt von Dncaten. In Lised jelturs: Murperger 1711 Mieljen I 402. Subewiạ 1744 Q(11;. II 308. Sutjti 1758 刃onufaftuten I 195.

4. 'llutlonf' (in fejten stombutugen wic

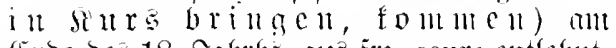

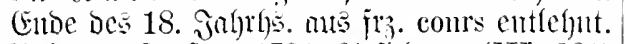
Belege: Forjter 1791 9(nifichten (III 381) dafs anch im gemeinen Leben manche nene Wörter in Cours gekommen sind. Eifhifler
1794 Watthijpon Geoichte (XIX 272) eine Erklärung, die sich neben den vielen, dir über diesen Gegenstand im Kurs sind, auch noch wohl wird erlatten können.

5. Paur jelten in Der Bed. 'Gang' von wijjenj(b)afttichen it. a. Erörterungen $\hat{\jmath}$. 2 . Rabater 1777 Traamente III 162 So hätteı wir also einen kleinen Cnrs durch eine Reihe von jugendlichen Gesichtern gemacht.

furjicren Btw. 'in Muthlouf fein' aus lat. cursare 'untherremen' gebilbet, in ben ver=

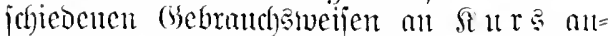
geịc)lojīen.

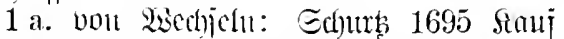
mamichajt ङ. 95 die Wechsel corsiren [jalich italieniijicrt!] von Nümberg per Amsterdam à Grot 65 per Kr. 65.

b. von Mïmsen: Imiti 1761 Manujat= tureu II 225 die coursirenden Mü̈zen. l̈bertr. bei Gocefing 1775 an Bürger (I 226) denn unter diesem Stempel [Mitfeio] coursirt die mehrste falsche Niintze.

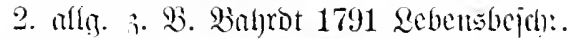
IV 135 Jetzt hiefs es, das Manmscript kursine bei der Faknltät. Sinticbute 1810 Ejels Ecfattel $(24,190)$ Jetzt cursiren die Nameu schon unter allen Strabenbuben. Seinc 182.2 Berl. Brieje (VII 585) deshalb kursirt jeder gute Einfall gleich unter dem Namen des Kronprinzen.

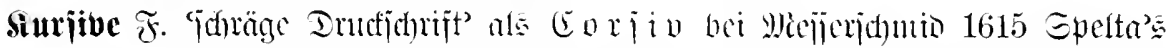

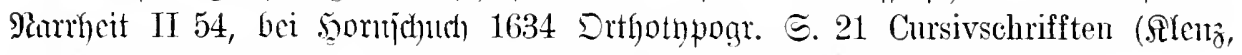

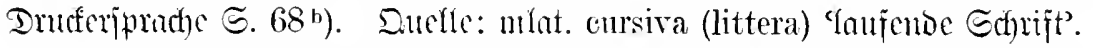

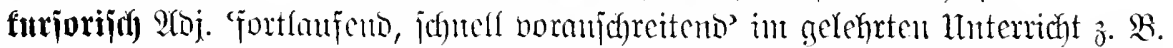

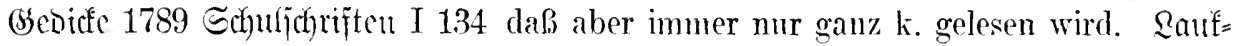
hard 1799 9umalen III 263.

Siurjü ¡. Rul:2.

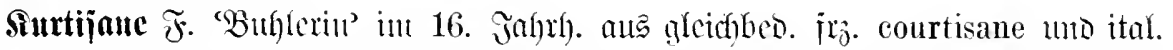

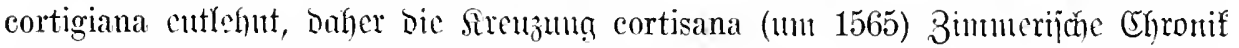
III 63. Beleg: Mathejü 1566 ฉuther $\subseteq .6^{\text {a }}$ ruchiose Curtisanen vnnd Hofgesinde.

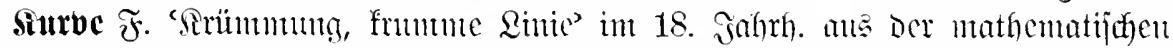

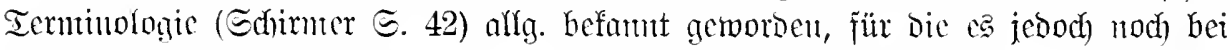

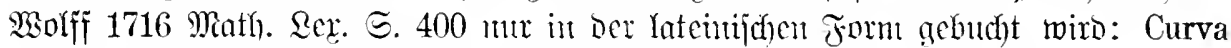

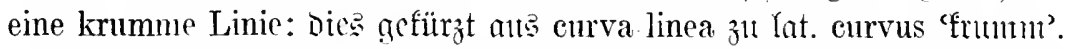

Belege: Savater 1776 Fragunente II 99 pumkte ihrer Curve gelangt. Mürnberger wenn ein mathematisches Genie - diese 1839 Etilleben $\Xi$. 121 stellt sich die Bahn betreten und seine Kraft an den Bahn eines jeden Planeten als regelrechte

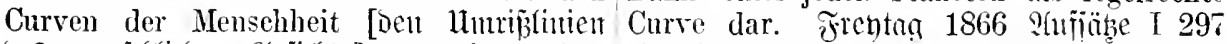
bes menjchlidgen befid)t: versnchen wird. eine Curve von 140 Meilen Länge militärisch Görres 1819 Teutichlant $\Xi$. 124 nachdem zn behampten.

sie zum Ziele des Wurfs und zimm Scheitel- 


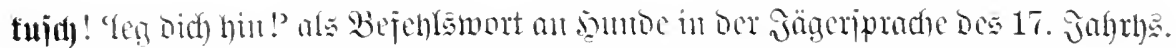

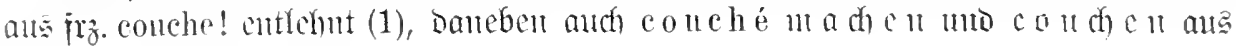
fro

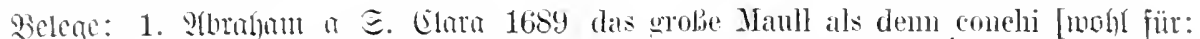
juon If 434 Bey dem Hunde deß Tobiae conché] machen lernet. ¿äbcl 1746 Jäger= lat es doch bißweilen geheisen: gusch! punftifo I $105^{\mathrm{b}}$ darneben muß man ihn anch Callenbad 1714 Gentertogic $\Xi .79$ sa, sa lemen, dab er sich auf die Erde niederlege: gusch - - anx genous - dance - spring . . sprechende: Conché! Halt! Conche! über den Stecken.

106 wam er dem anch dieses thut, so

2. Ihounaïus 1688 Mronatggeint. I 851 lasse ich ihn Couché machen - 107 kriege ¿o wird man seine Lust sehen, was für ich hin, wo sie gelegen, Lasse iln daselbst Complimenten da gefallen werden und wie conchen und straffe ihn.

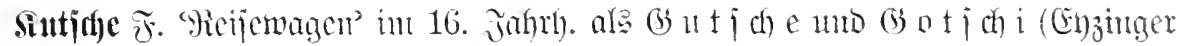

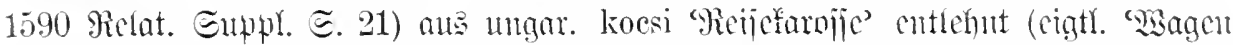

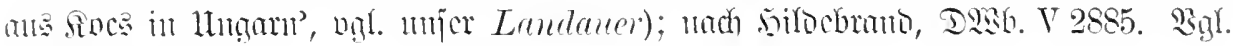

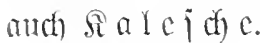

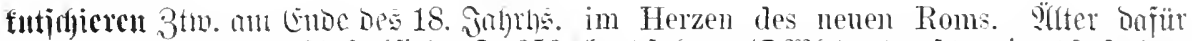

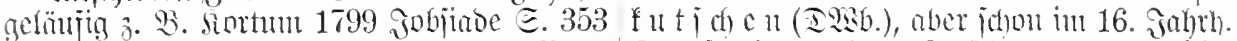

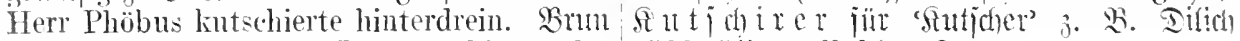

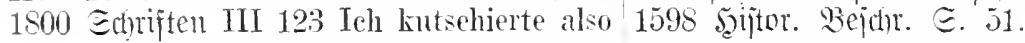

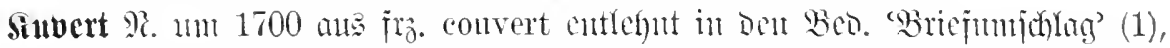

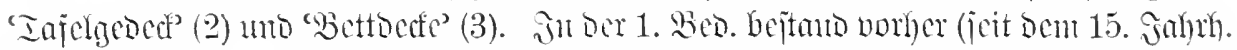

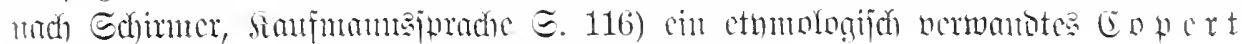

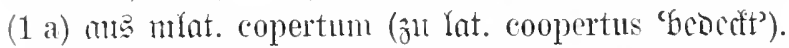

Berege: 1 a. 11 m 1466 Etüntedirnuten $\mathrm{T}$

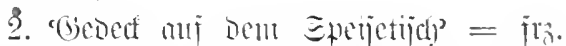

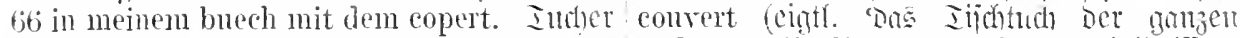

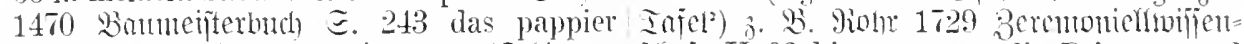
und copert. 1527 Fuggermuentur (Échimer fohat II 93 hingegen vor die Printzen und ミ.116) papier und copert. Grimutefhoujen Princeßinnen ein blober Teller mit einem

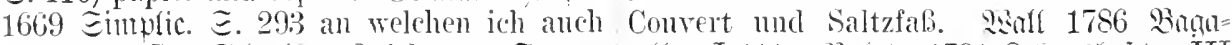

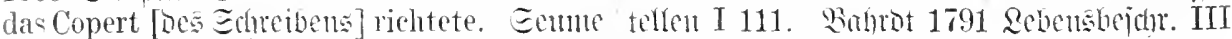

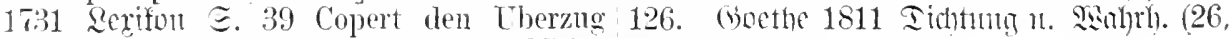
und Briefes-Umichlag neme (6rönc, 3fogs. 328).

XII 299).

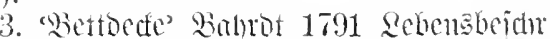

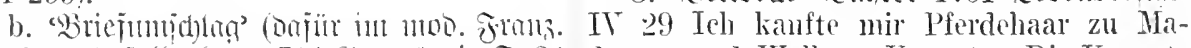

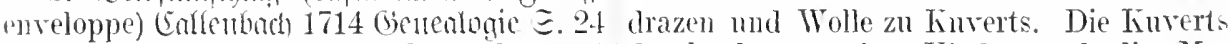
man kamn die Couverts nicht mehr grols durchnähten meine Kinder und die Magenug machen, der Titnl ist manchmal drazen verfertigte ich selbst.

weitläuffinger, als der stylisirte Brief. Gohn

fincrtieren $3 \mathrm{tm}$. 'mit cinem llmijalan

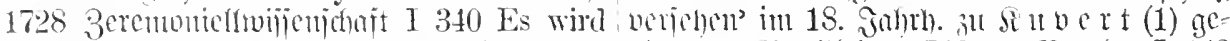
dem Gebrauch nach vor manirlicher ge- Liloet 3 . 23 . (j)feim 1748 an Ramler I 143 achet, wenn man converte um die Bricfe Sie haben vielleicht meinen Brief, den ich Jer ronehnen Jante schlägt. und hernach an den Hoffiseal Meyer courertirt, erhalten. den Titul auf die courerte inicht. 


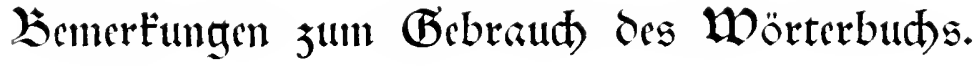

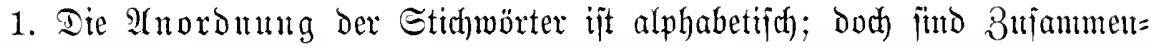

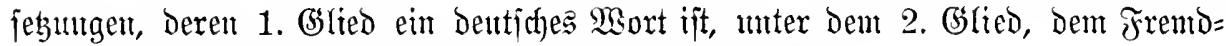
wort, untergeoronet (3. 3. Hausapotheke inter Apothele).

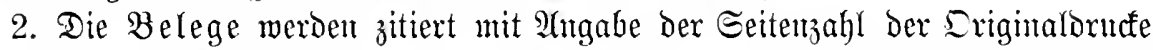

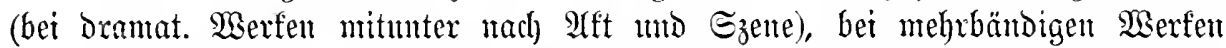

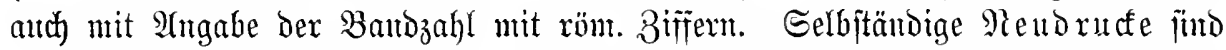

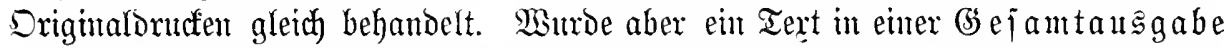

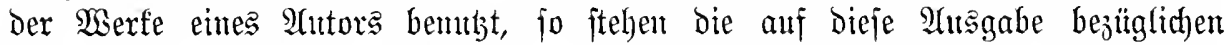
Bamb= und Seitenzahlen in Silammern. Exponentzahlen bezeidyen bie Aluflage éne? Berfes.

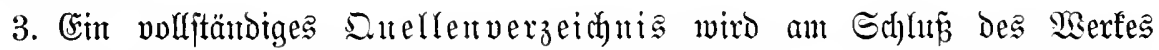
gegeben merben; hier folgen mur bie Titel ber mituter mutr mit bem Pament ber Berfajfer jutterten Sörterbürder:

2l belun g, Grammatijd =fritijdes Mörter: buth Der hodbentidjen Matudart.

Brodf $\mathfrak{a n} \mathfrak{S}$, Ronverjationslerifon.

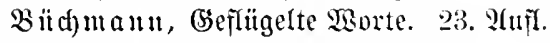

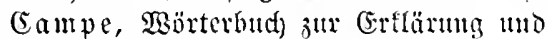
Berbentid)ung Der fremben 2 (4tsorïfte.

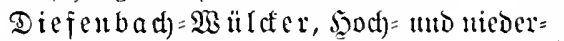
beutiches $\mathfrak{B}$ örterbuct).

(Sizler, Mörterbutd) ber phifofophijhen historical principles. Begriffe. 3. Tlufl.

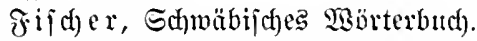

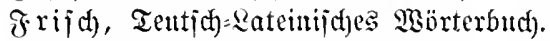

Grimu, Dentījez SBörterbutd.

Dabjeld = Darmejteter, Dictionnaire général de la langue française.

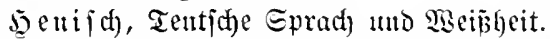

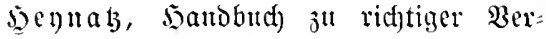
fertigung ber Brieje.

Şenje, Frembioirterbuct).

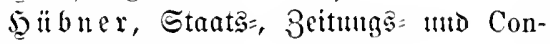
versations-Lexicon.

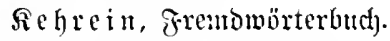

Sinderling, Beinigfeit ber bentiden Bud. Epracte.
Siluge, (Etımologijd)es Sïrterbud) Der Dentichen Epradhe. 7. 2tuifl.

zadendorf, Edylagmörterbud).

Martin= Zienhart, Wörterbuth ber elfäjijichen Mumbarten.

Müller = Fraueuth, Sisouterbuct) ber oberjüd)jifden Mutbarten.

Murar), New English Dictionary on Rebring, Manuale juridico-politicum.

Bot, (Ein teutict)er Dictionarius.

Sander: Frembuörterbutd).

Sd)ottel, 2lusiüfrl. 2labeit von Der

Teutidjen SautbtSpradie.

@(f) weijerifde S Soidtifon.

Sperander, A la mode Eprad der Ientijent.

Stieler, Der bentid)en Spradie Etamm= baum tuto fortmacts.

Stieler, Beitungas:

Bold v. Sertheim, Brieijteller.

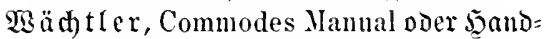

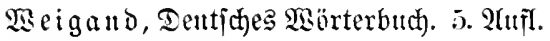
herausg. von $\mathfrak{\mathfrak { S }}$. פ̧irt. 


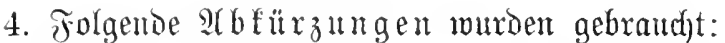

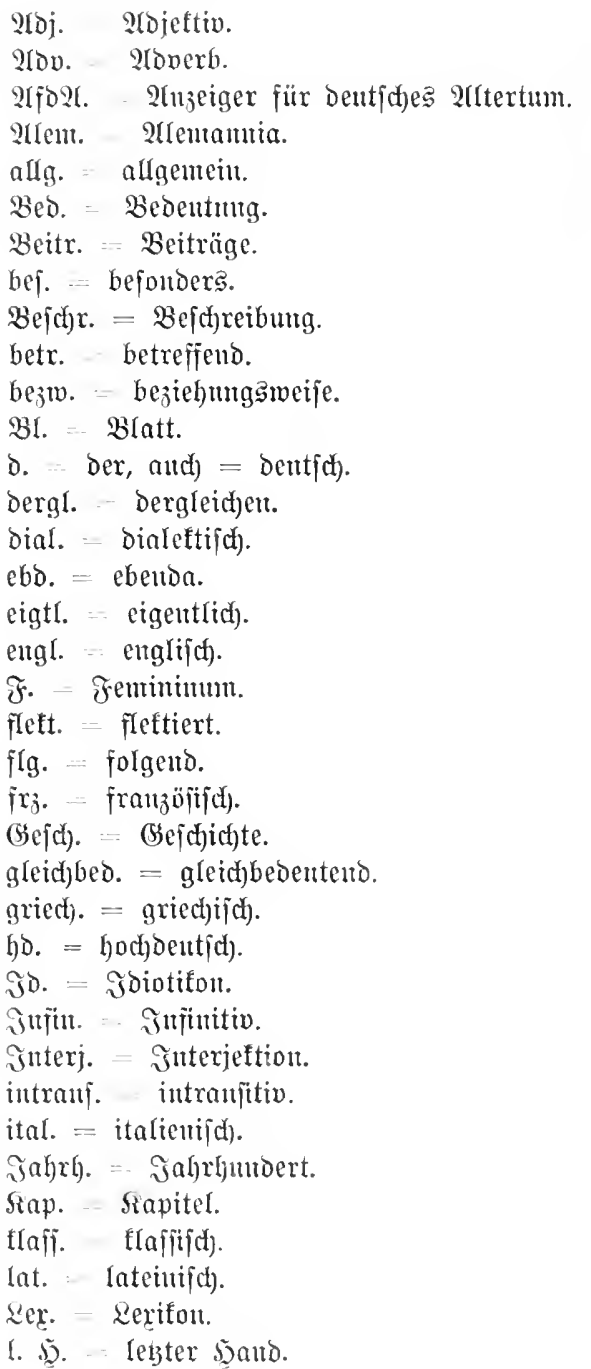

$\mathfrak{M} .=$ Magfultutum.

$\mathfrak{M a}_{\mathrm{a}}=\mathfrak{M}_{\text {undart. }}$

mo. = mitteldeutich).

mbo. = mittelfoctonentid).

mumbartl. $=$ mutuortlict).

$\mathfrak{R} .=$ Mentrum.

nod. = niederdentidy.

nol. = niederlündifd).

nhd. = ueutyod)deutid).

REDict. = New English Dictionary.

Rom. = Momiuatio.

obd. = oberdentid).

BI (ur). = Plural.

reff. $=$ refflerio.

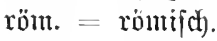

rufî. $=$ ruijitifd).

f. $\grave{b} .=$ jiehe diefes.

Sing. = Singular.

Subjt. = Subitantio.

jubjt. = jubitantivifdj.

Superl. = Euperlativ.

Ierm. ted)n. = Terminus ted)

$\mathfrak{u} .=\mathfrak{m b}$, auct $)=$ intert.

ïbertr. = ̈̈bertragen.

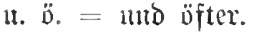

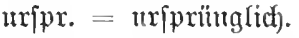

njw. $=$ mo jo weiter.

$\mathfrak{B} .=$ Ber?.

vgl. $=$ vergleid)e.

WBb. = $\mathfrak{\text { Bärterbuch). }}$.

ว. $\mathfrak{B}$. = zแแ Beippiel.

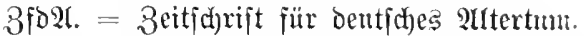

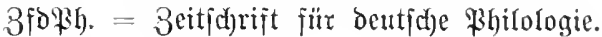

3fors. = 3eitjarift für deutidje $\mathfrak{3 o r t =}$

forfd)ung.

$3 i .=3$ eitjorift.

3tw. = 3eitwort. 




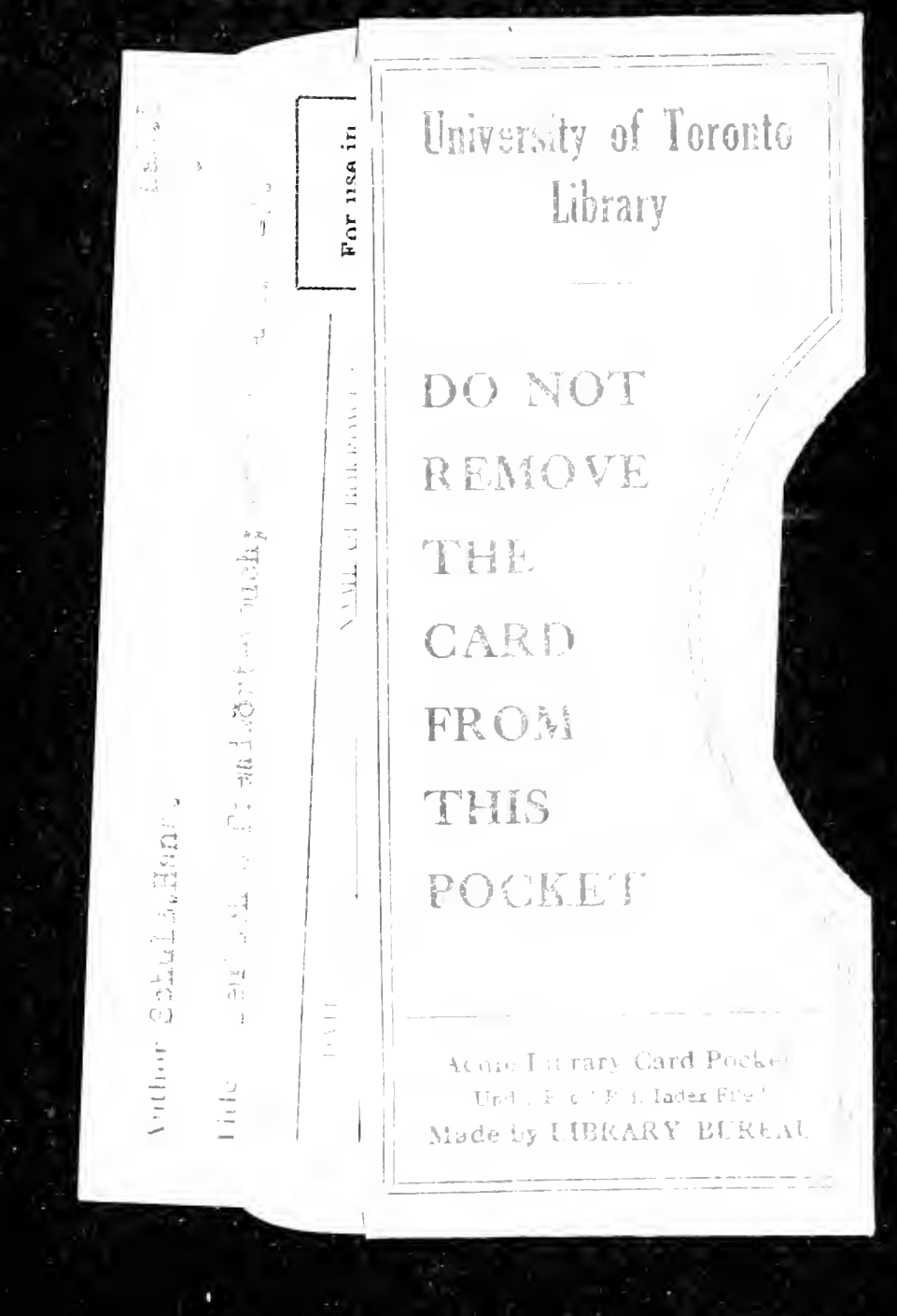


